\title{
Religionsgeschichtliche Beziehungen zwischen Kleinasien, Nordsyrien und dem Alten Testament: Internationales Symposion Hamburg 17.-21. März 1990
}

\author{
Edited by: Janowski, Bernd ; Koch, Klaus ; Wilhelm, Gernot
}

\begin{abstract}
Der Band thematisiert die vielfältigen religiösen Beziehungen zwischen Anatolien, Nordsyrien und Palästina/Israel vom 3. bis zum 1. Jt. v. Chr. Am Beispiel der Götterwelt, der Mythenbildung, der Ritualistik, des Kults und des Rechts wird in den 18 Beiträgen von Alttestamentlern, Assyriologen, Hethitologen, Gräzisten und Archäologen der Frage des Religionskontaktes in diesem Kulturraum erstmals umfassend nachgegangen. Einen besonderen Schwerpunkt bilden die gemeinsamen/verwandten mythisch-epischen und kultisch-rituellen Überlieferungen.
\end{abstract}

Posted at the Zurich Open Repository and Archive, University of Zurich

ZORA URL: https://doi.org/10.5167/uzh-151649

Edited Scientific Work

Published Version

Originally published at:

Religionsgeschichtliche Beziehungen zwischen Kleinasien, Nordsyrien und dem Alten Testament: Internationales Symposion Hamburg 17.-21. März 1990. Edited by: Janowski, Bernd; Koch, Klaus; Wilhelm, Gernot (1993). Freiburg, Switzerland / Göttingen, Germany: Universitätsverlag / Vandenhoeck Ruprecht. 
Janowski

Koch

Wilhelm
Religionsgeschichtliche Beziehungen zwischen Kleinasien, Nordsyrien und dem Alten Testament 


\section{ORBIS BIBLICUS ET ORIENTALIS}

Im Auftrag des Biblischen Instituts

der Universität Freiburg Schweiz,

des Seminars für Biblische Zeitgeschichte

der Universität Münster i. W.

und der Schweizerischen Gesellschaft

für orientalische Altertumswissenschaft

herausgegeben von

Othmar Keel

unter Mitarbeit von Erich Zenger und Albert de Pury

Die Herausgeber

Prof. Dr. Bernd Janowski lehrt Altes Testament an der Universität Heidelberg, Prof. Dr. Klaus Koch ist emeritierter Professor für Altes Testament und altorientalische Religionsgeschichte an der Universität Hamburg, Prof. Dr. Gernot Wilhelm lehrt Orientalische Philologie an der Universität Würzburg. 


\section{Orbis Biblicus et Orientalis 129}

Bernd Janowski / Klaus Koch / Gernot Wilhelm (Hg.)

\section{Religionsgeschichtliche Beziehungen}

zwischen Kleinasien,

Nordsyrien

und dem Alten Testament

Internationales Symposion Hamburg

17.-21. März 1990

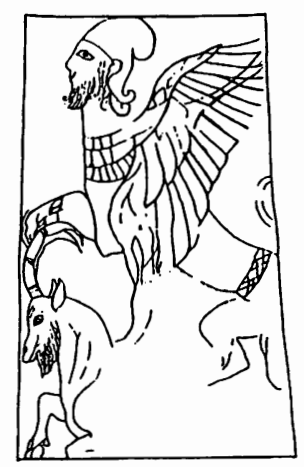

Universitätsverlag Freiburg Schweiz Vandenhoeck \& Ruprecht Göttingen 
Die Deutsche Bibliothek - CIP-Einheitsaufnahme

Religionsgeschichtliche Beziehungen zwischen Kleinasien, Nordsyrien und dem Alten Testament: Internationales Symposion Hamburg, 17. - 21. März 1990 / Bernd Janowski; Klaus Koch; Gernot Wilhelm. - Freiburg, Schweiz: Univ.-Verl.; Göttingen: Vandenhoeck und Ruprecht, 1993

(Orbis biblicus et orientalis: 129)

ISBN 3-525-53764-6 (Vandenhoeck und Ruprecht)

ISBN 3-7278-0878-0 (Univ.-Verl.)

NE: Janowski, Bernd; Koch, Klaus; Wilhelm, Gernot; GT

Die Druckvorlagen wurden vom Herausgeber als reprofertige Dokumente zur Verfügung gestellt

(C) 1993 by Universitätsverlag Freiburg Schweiz Vandenhoeck \& Ruprecht Göttingen

Paulusdruckerei Freiburg Schweiz

ISBN 3-7278-0878-0 (Universitätsverlag)

ISBN 3-525-53764-6 (Vandenhoeck \& Ruprecht)

Digitalisat erstellt durch Florian Lippke, Departement für Biblische Studien, Universität Freiburg Schweiz 
Inhaltsverzeichnis

Vorwort

I. Beiträge

Alfonso Archi

How a Pantheon forms

The Cases of Hattian-hittite Anatolia and Ebla of the

3rd Millenium B.C.

Walter Burkert

Lescha-Liškah

Sakrale Gastlichkeit zwischen Palästina und Griechenland

Peter Frei

Die Bellerophontessage und das Alte Testament

Volkert Haas

Ein hurritischer Blutritus und die Deponierung der Ritualrückstände nach hethitischen Quellen

Manfred Hutter

Kultstelen und Baityloi

Die Ausstrahlung eines syrischen religiösen Phänomens

nach Kleinasien und Israel

Bernd Janowski / Gernot Wilhelm

Der Bock, der die Sünden hinausträgt

Zur Religionsgeschichte des Azazel-Ritus Lev 16,10.21f

Klaus Koch

Hazzi-Ṣafôn-Kasion

Die Geschichte eines Berges und seiner Gottheiten

Cord Kühne

Zum Vor-Opfer im alten Anatolien

Oswald Loretz

Nekromantie und Totenevokation in Mesopotamien,

Ugarit und Israel 
Jan-Waalke Meyer

Tempel- und Palastbauten im eisenzeitlichen Palästina und ihre bronzezeitlichen Vorbilder

Erich $\mathrm{Neu}$

Knechtschaft und Freiheit

Betrachtungen über ein hurritisch-hethitisches Textensemble aus Hattuša

Edward Noort

Seevölker, materielle Kultur und Pantheon

Bemerkungen zur Benutzung archäologischer Daten -

ein kritischer Bericht

Eckart Otto

Körperverletzung im hethitischen und israelitischen Recht

Rechts- und religionshistorische Aspekte

Thomas Podella

Notzeit-Mythologem und Nichtigkeitsfluch

Moshe Weinfeld

Traces of Hittite Cult in Shiloh, Bethel and in Jerusalem

David P. Wright

Analogy in Biblical and Hittite Ritual

II. Diskussion zum Thema "Opfer- und Eingeweideschau"

Oswald Loretz

Opfer- und Leberschau in Israel

Philologische und historische Aspekte

Jan-Waalke Meyer

Die Eingeweideschau im vor- und nachexilischen Israel, in Nordsyrien und Anatolien

Hinweise zu den Autoren 
Vom 17.-21. März 1990 fand in Hamburg das Internationale Symposion "Religionsgeschichtliche Beziehungen zwischen Nordsyrien, Kleinasien und dem Alten Testament im 2. und 1. Jahrtausend" statt. Das Symposion, dessen Akten hiermit vorgelegt werden, hatte etwa zu gleichen Teilen Alttestamentler und Altorientalisten zusammengeführt, die sich mit der Erforschung religionsgeschichtlicher Erscheinungen in bestimmten Kulturen des Alten Orients beschäftigen. Der Anstoß zur interdisziplinären Fragestellung ist der gegenwärtigen Lage der alttestamentlichen Wissenschaft entsprungen. Die deutschsprachige Bibelwissenschaft hat sich nach dem 1 . Weltkrieg weithin von religionsgeschichtlichen Vergleichen abgewandt, und zwar unter der Voraussetzung, daß sich die monotheistische Religion Israels und nachfolgend des Christentums als einzige göttliche Offenbarung grundsätzlich von jeder anderen menschlichen Religion unterscheide. Eine Übernahme mannigfaltiger mythologischer und kultischer Motive aus der altorientalischen Umwelt blieb zwar unbestritten, sie wurde aber als jeweilige ornamentale Randerscheinung abgetan. In den beiden letzten Jahrzehnten hat sich jedoch eine Tendenzwende angebahnt. Insbesondere die Diskussion um eine relativ späte Entstehung des Monotheismus im alten Israel läßt mehr und mehr unübersehbar werden, daß sich die Jahwereligion erst allmählich aus einem nordwestsemitischen Kontext herausentwickelt hat und den Umweltreligionen grundsätzliche Anstöße verdankt, die sich ebenso im Kontakt wie im Kontrast ausgewirkt haben. Beispielhaft für die neue Einsicht sind zahlreiche Bände, die in den inzwischen begründeten Reihen AOAT (seit 1969) oder OBO (seit 1973) erschienen sind.

Wo gegenwärtig eine Verflechtung der israelitisch-alttestamentlichen Religion mit denen des Alten Orients untersucht wird, stehen die Religionen des Zweistromlands und des Mittelmeerraums naturgemäß im Vordergrund des Interesses. Das ergibt schon ein Blick in repräsentative Textsammlungen wie ANET oder TUAT oder auch in ikonographische Zusammenstellungen wie ANEP, wo jeweils das ägyptische oder mesopotamische Material überwiegt. Doch besteht Übereinstimmung darüber, daß die Einflüsse, zumindest was das Zweistromland betrifft, weitgehend über Syrien-Kanaan vermittelt worden sind, wenn auch aus diesem Bereich entsprechende Belege weithin fehlen. So wird die israelitische Religion mehr und mehr zu den Kulturen des Fruchtbaren Halbmonds insgesamt in Beziehung gesetzt.

Kleinasien spielt bei solchen Untersuchungen, wenn überhaupt, eine nebensächliche Rolle. Wirtschaftlich und politisch war aber Anatolien zumindest im 2. Jt. v. Chr. eng mit Syrien verbunden. Ikonographische Denkmäler beweisen einen regen Austausch. Gerade auch auf religiösem Gebiet gibt es eine Reihe von Erscheinungen, die auf enge Verbindungen zwischen der anatolischen und der syrisch-kanaanäischen Welt hinweisen. So sind Eliminationsriten, wie sie durch das biblische Motiv des Sündenbocks, ob nun zu Recht oder nicht, sprichwörtlich geworden sind, in hethitisch-hurritischen Ritualen in einer Weise 
dargestellt, die den Vorschriften des Buches Leviticus mehr ähnelt als alle anderen verfügbaren Parallelen. Dazu tritt eine herausragende Stellung der Nekromantie, die in manchen Zügen etwa an die Erzählung über die Totenbeschwörerin von Endor (1 Sam 28) erinnert. Die Verbreitung einer intensiven Verehrung von Berggöttern und von Steinkulten lassen die Bindung Jahwes an den Berg Zion, aber auch die umkämpfte Rolle der Mazzeben im Alten Testament in besonderem Licht erscheinen. Solchen Beziehungen sind einige Beiträge des Symposions genauer nachgegangen. Die Wege, die die hinter solchen Parallelen stehenden Kultureinflüsse genommen haben, bedürfen genauerer Untersuchung, wobei zu fragen ist, ob die Völker Anatoliens - vornehmlich die im anatolischen Hochland ansässigen Hethiter und Luwier, aber auch die in großen Teilen des nördlichen Vorderasien lebenden Hurriter - bei solchen Kontakten nur die nehmende oder bisweilen auch die gebende Seite waren.

Eigenartigerweise reichen die Ähnlichkeiten teilweise über das mittlere Anatolien hinaus bis weit nach Westen, wo sie im alten Griechenland Parallelen finden. Das gilt für das "Sündenbock-Ritual" ebenso wie für die Nekromantie, oder für die Bindung großer Gottheiten an ihren Sitz auf einem Berg, darüber hinaus aber auch für eine Reihe von Einzelmotiven bis hin z.B. zur Bellerophontes-Sage.

Die Ergebnisse des Symposions wecken die Frage, ob es auf kulturellem und religiösem Gebiet im Altertum neben den Gemeinsamkeiten des Fruchtbaren Halbmonds nicht auch, in mancher Hinsicht gegenläufig dazu, eine Art levantinischen Halbkreises um das östliche und nördliche Mittelmeer gegeben hat, von Palästina bis nach Hellas reichend, der seine eigenen mythologischen Ideen und kultischen Praktiken ausgebildet hat.

Solche Übereinstimmungen dürften mit den klimatischen Verhältnissen und ihrer Bedeutung für die äußeren Lebensbedingungen zusammenhängen. Der erwähnte Nordost-Bogen betrifft Länder, in denen Regenzeitkulturen vorherrschen. Deren Daseinsbedingungen sind grundsätzlich anders als im Niltal oder Zweistromland. Da aber jede Religion die numinosen Mächte nicht nur im spirituellen Bereich verortet, sondern sie als hintergründige Garanten und Urheber bei elementaren Lebensbedürfnissen erfährt, treten Götter des Regens, des Wetters überhaupt, neben Berge und Quellen wie von selbst in den Vordergrund und rufen entsprechende Kultformen und mythische Muster hervor.

Darüber hinaus haben die Völker Kleinasiens, Syriens und Palästinas oft auch politisch ein ähnliches Schicksal erfahren, was dann den entsprechenden Niederschlag in religiösen Deutungen gefunden hat. Das ließe sich nicht nur bei großen Umbrüchen wie dem Siegeszug Alexanders des Großen aufweisen, oder ein Jahrtausend früher bei dem Übergang von der Spätbronze- zur Eisenzeit, der traditionell mit dem Einbruch der Seevölker verbunden, aber damit gewiß nicht hinlänglich erklärt wird. Abgesehen von den wenigen Jahrhunder- 
ten des hethitischen Großreichs war der gesamte Raum vor dem Einbruch der Assyrer durch eine Vielzahl von kleinen Terrritorialstaaten geprägt, und das hat in den Kultüberlieferungen entsprechende Spuren hinterlassen.

Ein viertägiges Symposion vermag nicht alle anstehenden Probleme in Angriff zu nehmen. Innerhalb des beschränkten Rahmens war es z.B. nicht möglich, Entstehung und Entwicklung der Idee von Wettergottheiten, zu denen auch der alttestamentliche Jahwe mindestens partiell zählt, zu verfolgen. Auch das in den 50er Jahren heftig diskutierte Thema eines alten Bündnisformulars, aus einem Vergleich gewisser alttestamentlicher Bundeszeremonien wie Jos 24 mit den hethitischen Staatsverträgen erschlossen, konnte nicht aufgegriffen werden. Erst recht ließen sich die vielfältigen Beziehungen griechischer Götter zu Kleinasien nicht thematisieren. So beanspruchen die Beiträge des Bandes keineswegs, die in Frage stehenden religionsgeschichtlichen Beziehungen erschöpfend zu behandeln. Sie bieten aber, wie Herausgeber und Teilnehmer hoffen, eindrückliche Beispiele dafür, wie erfolgversprechend vergleichende Religionsforschung in Zukunft werden kann, auch und gerade für die genauere Erfassung der biblischen Gottesanschauung.

$\mathrm{Da} \beta$ das Symposion stattfinden konnte, verdanken wir der finanziellen Unterstützung der Fritz-Thyssen-Stiftung. Auch die Drucklegung des vorliegenden Bandes wäre ohne ihren namhaften Zuschuß nicht zustandegekommen. Das betrifft ebenfalls den großen Einsatz an Geduld und Arbeitskraft, mit dem Frau M. Bauks-Vogt, Heidelberg, und Herr Dr. Th. Podella, die durchgängig schwierigen Manuskripte in einen reprofertigen Zustand gebracht haben. Ihnen und Herrn Kollegen O. Keel, der den Band in die Reihe "Orbis Biblicus et Orientalis" aufgenommen hat, gilt unser besonderer Dank.

Die in diesem Band verwendeten Abkürzungen richten sich nach dem Verzeichnis von S. Schwertner, Theologische Realenzyklopädie (TRE). Abkürzungsverzeichnis, Berlin / New York 1976, für die ägyptologische Literatur s. LÄ, für die assyriologische Literatur AHw und Borger, HKL I-II, für die hethitologische Literatur $\mathrm{HW}^{2}$. 
It is comparison which allows us to understand and evaluate better certain aspects of a religion which are not evident at first reading of the data. Through the analysis of how a phenomenon developed in certain environments, elements can be identified which help to devise a model according to which working hypotheses related to other religious experiences can then be verified.

The two investigations presented here demonstrate the repercussions that occurred in a religious system when peoples of different cultural traditions came into contact and merged. In the first place, they have phenomenological value. But in the second case - that of Ebla - not only the environment was similar to that in which the Old Testament traditions were formed. Both the Eblaite and Israelite languages belonged to the Semitic group. Moreover, some of the populations involved in those processes could have presented socioeconomic forms analogous to Palestinian ones between the 2nd and the 1st millennium B.C.

\section{Hattian-Hittite Anatolia}

A prelude to the formation of the Hittite state in the central Anatolian plateau delimited by the wide bend of the river Kizil Irmak (classical Halys) is the conquest of the town of Kanes (= Nesa) by a ruler from the town of Kussara (18th cen.). Kanes, which lies to the south of the Halys, not far from Kayseri (Caesarea Mazaca), was in the 19th cen. one of the most important city-states, chosen for that reason by the Assyrian traders as the main centre for their activity. It is uncertain where Kussara has to be placed; in any case the trend of the military operations by Anitta, son of that Pithana who was the conqueror of Kanes, is towards the central plateau. The cities defeated by Anitta are Salatiwara and Ullamma, in the "Lower Land", south of the Salt Lake (as well as Purushanda, whose ruler recognized Anitta's supremacy), and Salampa, the Land of Hattum (/ Hatti) together with Zalpuwa, on the plateau. These were manifestly the political opponents of the dynasty of Kussara. ${ }^{1}$

These deeds are recorded in the Proclamation of Anitta, a text in Old Hittite, which has to be considered the first written document of Hittite cul-

1 For the historical references concerning the Old Hittite kingdom, see Gurney, Anatolia. For the Hittite pantheon, see the well-balanced synthesis given by Gurney, Aspects, 4-24. The Proclamation of Anitta is edited by Neu, Anitta. All these works give abundant literature. For an attempt to define the Hittite and the Hattian ethno-cultural area, see Singer, Hittites and Hattians. 
ture. Three gods are mentioned there: the Hittite Weather-god Tarhunna (written DIM-unnas) "Victorious, Hero" (derived from tarh- "to win"), the patron of Anitta; the Hattian deified throne Halmasuit; Siusmi, Siusummi, an epithet meaning "My, Our god". Hittite and Hattian elements stay side by side. Even the kingship is influenced by the Hattians: "My god", Siusmi, delivers Hattusa to the Throne-goddess Halmasuit, meaning: into Anitta's hands.

Some similar ideological aspects are found in an Old Hittite ritual for the erection of a new palace. Here "father" of the king is the Weathergod ( $a$ s), undetermined by a geographic name as well as in the Anitta text: "mother" is the Sun-deity ('UTU-us); and the Throne-goddess Halmasuit brings to the king the emblems of power:

"To me, the king, have the gods - Sun-deity and Weather-god - entrusted my land and the house ... To me, the king has the Throne-goddess brought from the sea the (insignia of) power and the chariot. They have opened the land of my mother and called me, the king, Labarna. From then on I extol my father, the Weather-god". ${ }^{2}$

Both texts are linking by the same number of gods, and the same roles for the Weather-god and the Throne-goddess. Therefore it has been suggested that "Our god", Siusummi, should be identified with the Sundeity. The noun sius goes back etymologically to Indo-European *diēus, as Latin deus, Greek Zeus. Also cognate with *dieus (with the suffix -att-) is Tijaz, Tiwaz, the Sun-god in Palaic and in Luwian, respectively; and sius should have been the name of the Sun-god by the Hittites. The noun originally meaning "sky", as the source of light, might have developed semantically into "Sun(-god)" in the Indo-European Anatolian languages. When the Hittites took over the (feminine) Hattian Sun-deity, then sius lost its original connotation and became the appellative for "god". ${ }^{3}$ Brilliant though this theory may be, it is not easily acceptable, ${ }^{4}$ although it is a fact that Luwians and Palaites preserved an Indo-European word for the god of day-light.

There is no continuity between the dynasty of Anitta and that of Hattusili, which also originated from Kussara. In this new phase, Kanes is destroyed, and Hattusa (which was cursed by Anitta) is chosen as capital. It is impossible to detect the events of that dark period, but two facts are clear. The Hittites

2 KUB XXIX 1 I 17-26. See the translation of the whole text by Goetze, in: ANET, 357-358; and for an evaluation of this passage, see Neu, Anitta, 125-126. Neu, Anitta, 116-131; Bin-Nun, Tawananna, 147-152.

4 There is no divine name with the pers. pron. suffix. In I. 11, ${ }^{d}$ UTU-az could be the writing for the "Sun-deity" (without pers. pron. suffix!) if we understand the passage as following: "whatever land rose up from the Sun-deity", see Carruba, Chronologie, 232. Further, the change in meaning of sius should be dated between Anitta and Hattusili I, and the former noun for "god" disappeared subsequently. Cf. Starke, Halmašuit, 47-65; his identification of "Our god" with Halmasuit, however, is unacceptable. 
called their language nesili / ( $k a)$ nesumnili "that of (Ka)nes", which certainly means that Kanes was the major citystate in the area where their language was used. But the political centre then shifted directly to the Land of Hattum, where the new dynasty is active from the middle of the 17 th cen. ${ }^{5}$

What caused friction between the dynasties of Kussara and their antagonists was surely not an ethnic contrast. Because of the two changes of capital, there was also something different from a simple rivalry between city-states. We can only state that a group bound by the same language seized rapidly an area substantially allophone. People of different languages: Hittites, Hurrians, Hattians and perhaps other Asiatic languages, had coexisted in central Anatolia already for a longer time, as it is shown by the Old Assyrian tablets from Kanes. Further, a few geographic names show that the Hittite-Luwian speaking population had settled there for some time. ${ }^{6}$ Perhaps "the Land of Hattum" was linguistically more uniform. Hattian was still a spoken language there, as it is proved by whole rituals (not simple invocations) recorded by the Hittites surely from native speakers and not just copied from ancient tablets. Judging from the events concerning Zalpa, the important town at the Black Sea, whose Elders asked the Hittite king for one of his sons as ruler, ${ }^{7}$ the formation of the Hittite kingdom must have been achieved by a small group of people.

These political events are reflected in the pantheon, which developed through assimilation. Privileges are acknowledged for great centres of the Hattian cult, like the towns of Arinna, Nerik and Zippalanda (Laws $\$ \S 50-51$ ). The main gods of the lustration ritual for the royal couple are the Weather-god and the Sun-deity (the latter in the double hypostasis of the sky and of the earth) ${ }^{8}$ The fact that in this ritual also Arinna is involved, shows that the Sun-deity was already related with the Hattian goddess of Arinna. Hattusili I declares himself "beloved of the Sun-goddess of Arinna" in his annals; 9 and there are good reasons to think that ${ }^{D}$ UTU in the Old Hittite texts, also when undetermined, has to be mostly identified with the Sun-goddess of Arinna. The other gods mentioned in the lustration ritual are the Hittite Hantasepa "the First one", and the Hattian Inar. In the ritual "When the Weather-god thunders", celebrated obvious in a crucial period of the seasonal cults, the Weather-god is associated with Wasezzili and the Sun-goddes with Mezzulla, both Hattian; and the other gods are the Hattian Inar and Tuhasail. ${ }^{10}$ The associa-

\footnotetext{
The grandfather of Hattusili I appointed his heir in Sanahuitta.

Bilgiç, Ortsnamen, 8-10.

KBo III 38; see Otten, Zalpa, 8-11.

8 The ritual is published by Otten / Souček, Ritual.

9 Cf. Gurney, Aspects, 11-12. On the Sun-goddess of Arinna in the Old Hittite kingdom, see Archi, Anrufung, 7-15.
}

10 The ritual is published by $\mathrm{Neu}$, Gewitterritual; see also Neu, Ritualtexte, 62-69, no. 25. 
tions of the Weather-god with Wasezzili and of the Sun-goddess with Mezzulla are rather frequent in Old Hittite religious texts, ${ }^{11}$ and go back to the Hattians.

Some connections between gods of different cultural origin are quite clearly understandable as in the case of a celebration for the dead, where the Hattian Parcae Isdustaja and Papaja are grouped together with Lelwani, the Hittite queen of the Underworld, and her circle. ${ }^{12}$ But further the Hittites took over esoteric practices, like conjurations to gods, who are addressed also with an "heavenly title":

"When the (crown) prince conjures, [the singer says:] 'For mankind Wasezzili, but [among] the gods a Lion-king (art) thou, and [thou holdest] Heaven and Earth'. And so is decided in the Weather-god's prayer". ${ }^{13}$

Cult is determined by social and institutional relations, especially in those ancient cultures. This is manifest in the Old Hittite KI.LAM festival, "(of) the Market", which presents two main aspects. The first one is concerned clearly with the magic reintegration of hunted wild animals. In a ceremonial procession opened by the royal pair, the following groups passed: 1) a "holy" priest and a priest of ${ }^{\mathrm{D}} \mathrm{KAL}$, the tutelary god of the wild animals, whose symbol is the stag, accompanied by a psalmodist; 2 ) several spears and 10 or 20 copper shields, the hunters' weapons, carried by attendants; 3 ) the figures of some "animals of the gods" in silver, gold or lapis lazuli: a panther, a wolf, a lion, two boars and a bear; 4) some hunters; 5) four figures of the stag in precious materials; 6) perhaps some birds in ivory. The figures of animals were rather large because they were pulled or dragged by some officials, so that the connection between animals and hunters had to be quite realistic. The following section is rather fragmentary, but it is clear that the ritual action had to appease the tutelary god of the wild animals in order to assure their reintegration, an idea which has to go back to an archaic age, when hunting played an important role for the maintenance of a social group.

The second aspect concerns instead the need for supply of victuals in an urban society. The administrators at the head of the storehouses, ${ }^{\text {LU.MES AGRIG }}$ $\dot{\mathrm{E}}^{\mathrm{NA} 4} \mathrm{KISYIB}$, of several towns were aligned before "the gate of the house" which they represented (because the festival took place at Hattusa, it is probable that the houses were just symbolized in some way). In front of the gates were placed food, drinks, small livestock. When the king passed before an admini-

11 See the index in: Neu, Glossar, 344 and 349-350.

12 KBo XVII 15 obv.! 8-18; see Haas / Wäfler, Bemerkungen, 84-87, cf. Neu, Ritualtexte, 72.

13

KUB VIII 41 II 4-6 and VBoT 124 rev. 6-9 (Hittite) = KUB XXVIII 75 III 11-14 (Hattian), see Laroche, Hattic Deities, 187-192. On the double name of the gods, see Friedrich, Gottersprache. 
strator, the herald called him by the name of the town he belonged to and he bowed down to the king. Some of the towns belonged to the Hattian area (as Ankuwa and Harharna); others were to the south of the Halys (as Hupisna, Nenassa, Tuwanuwa, Zallara), and belonged to the Hittite kingdom from Hattusili I's time. The geography of this festival may be that of the Old Hittite kingdom: the towns are listed (with several others) in Telepinu's edict as seat of "storehouses" ${ }^{14}$ But in the case of some administrators, instead of using a genitive of relation, the name of the town is enlarged with the Hattic suffix -il, which characterizes the masculine ethnics: $(H)$ anikkuil, Hupisnail "the (man) from Ankuwa, from Hupisna". Clearly this festival - where also the temple of Halki "the Grain" plays a central role - institutionalized in cult the supply system of the Palace administration. Now on this celebration which concerns so crucial an aspect of the Hittite state, the Hattian influence is such that the gods worshipped are, with only few exceptions (as Halki and Ulza), Hattians: $:^{15}$

\begin{tabular}{|c|c|c|}
\hline 1 Tauri(t) & 13 [Zizzasu] & 24 Hasamili \\
\hline 2 IM, Wasezzili & 14 Zulija & 25 Hattu Teteshapi \\
\hline 3 UTU, Mezzulla & 15 Susumittu & 26 Puskuruna, Tapalhuna \\
\hline 4 IM, Wasezzili & 16 NIN.É.GAL & 27 IM $^{\text {URU Ziplanda, Katahhi }}$ \\
\hline 5 Inar, Habandali & 17 Hanikku & 28 Ulza, Uliwasu, Katarzasu \\
\hline 6 EN.ZU, Kuzanisu & K[atahhi] & 29 Susumahi, Simmisu \\
\hline 7 Hulla & 18 Zilipuru & 30 Haratsi \\
\hline $\begin{array}{l}8 \text { Telepinu } \\
9 \text { ZABABA }\end{array}$ & $\begin{array}{l}19 \text { Katimu } \\
20 \text { Halki }\end{array}$ & $\begin{array}{l}31 \text { [Sita]rzuna,Tahampiwu, } \\
\text { Wahzasu, Takkihau }\end{array}$ \\
\hline $10\left[\mathrm{UD}^{A M}\right]$ & 21 Zilipuru & 32 [..]natasu, Kuzanisu, \\
\hline 1 GAL.ZU & 22 Wahisi & Tahpillanu \\
\hline 12 Tuhasail & $23[\ldots]$ & 33 IM, Wasezzili \\
\hline
\end{tabular}

The Palaic documentation, which concerns a culture formed under conditions similar to the Hittite ones in a borderland (Paphlagonia) of the Hittite area, offers a suitable verification of the Hattian influence in the process of pantheon formation. The ritual KUB XXXV 165 gives in rev. 11-18 the following list of gods, where the priority in the offerings is according to rank:

Zaparwa, Katahziwuri, Tijaz, Ilalijantikes (pl.), Hasamili, Kamama, Saushalla, Hilanzipa, Gulzannikes (pl.), Ulilijantikes (pl.)

14 See $\S \S 4$ and 37-38, in Hoffmann, Telepinus, 14-15.40-45.

15 The gods are listed in the following table in the order they appear in the text, so that some of them are repeated. The list is given and commented by Singer, KI.LAM I, 101-103. For the interpretation of the festival given here, see Archi, Société, 29-31. 
That Zaparwa was the first god of the Palaites is apparent also from other texts, some of which are written in old ductus. In any case, all the Palaic documentation must go back to the Old Hittite kingdom. It is rather uncertain if Zaparwa as well as Saushalla have to be considered Hattian gods, but surely Hattian are Katahziwuri, Hasamili and Kamama. Tijaz is the Sun-god whose name is an enlargement of an Indo-European base: *diēus-att-s. The other four gods are genii whose names are formed with "Anatolian" bases (that is common to Hittite, Luwian and Palaic, the Indo-European Anatolian languages): ilalija- "to desire", zipa- "genius", guls- "to mark", ulili- "the green". ${ }^{16}$

The Palaic pantheon therefore, as well as the Hittite one, was formed through assimilation.

A change of language needs newcomers, but not necessarily a large number of people. The assimilation of gods, the registration of cultic rituals in Hattian, the continuity in the material culture as well, could mean that it was a process of infiltration. That is in agreement with the fact that the personal names of the population settled already before the conquest of Kanes by Anitta are Asianic, Hurrian and Hittite-Luwian. But the new political structures created by the Pithana dynasty at Kanes and later on by Hattusili at Hattusa were the result of a conquest.

The Hittites brought to Hattusa some few gods, who are said to be those of Kanes, and therefore were "sung" in ( $k a)$ nesili - the name the Hittites gave to their own language - but who are not frequently quoted in the texts. They are: Pirwa, Ilali, Tarawa, Assijat. ${ }^{17}$ The Hittites had also several genii, whose names are composed with the element -sipa, -zipa: Asgasepa "the daemon of the door", Hilazepa "the daemon of the court", Ispanzasepa "the daemon of the night", Kamrusepa the patroness of healing, Mijatanzipa "the daemon of prosperity", Daganzipa "the daemon of the earth".

The only god whose name goes back to an Indo-European root is that of the Sun-deity of the Palaites and of the Luwians: Tijaz, Tiwaz. This is a general feature of the panthea of Indo-European peoples, and it has to be explained by the fact that the Indo-European speaking populations developed societies very different from that stage when they shared some common beliefs. More evidence of a common heritage can be found in some cultic practices, like that concerning the hearth (Hitt. hassa-, Lat. ära, Osc. aasaí, Skt. āsa). ${ }^{18}$

The Hittites constitute a case where a population sharing an urban culture overlapped another urbanized and evidently more sophisticated population, taking over its pantheon. That pantheon came then to reflect that political

16 The text is studied by Kaminenhuber, Das Palaische, 8 and 31-36 (see also the commentary in the "Wortschatz", 70ff); and by Carruba, Das Palaische, 19 and $48 \mathrm{ff}$.

17 See Goetze, Theophorous Elements; Laroche, Noms, 288-289.

18 On the cult of the hearth by the Hittites, see Archi, Focolare. 
change, when the whole country was unified in one kingdom. All the local gods, mostly naturalistic in character, were included, organized hierarchically under a couple at their head, formed by the Sun-goddess of Arinna, the deity of a celebrated sanctuary, and the Weather-god of Hatti, who takes his appellative from the core of the kingdom.

\section{Ebla $^{19}$}

The archives of the royal palace of Ebla are to be dated to the 24th cen. B.C., and concern every sector of Palace administration. The main body of the texts comes from the central archive, which covers a period of about 50 years. Minor archives deal with special administrative sections for the years immediately preceding the destruction of the Palace.

The documentation pertaining the pantheon can be classified as follows: 1) bilingual lexical lists; 2) some few hymns and rituals; 3 ) very few juridical documents provided with an invocation to the gods; 4) documents concerning sheep deliveries with sections of offerings to the gods; 5) administrative documents which register gifts to the gods or to the officials devoted to their cult; 6) personal names.

\section{Lexical lists ${ }^{20}$}

The bilingual (Sumerian-Eblaite) word lists are arranged by the initial sign. In the section based on the sign $\mathrm{AN}$, which, besides expressing phonetic values, may stand for the divine determinative, about fifteen gods are listed. The selection includes some deities having a correspondence in the Eblaite cult. ${ }^{d} U T U$, the Sun-god(dess) and probably ${ }^{\mathrm{d}} \mathrm{TU}$ (a short form for ${ }^{\mathrm{d}} \mathrm{Nin}-\mathrm{tu}$ ), the Mother-goddess, are without Eblaite renderings perhaps because those names were considered to be self-evident (which deprives us of knowing them). The correspondence ${ }^{\mathrm{d}}$ Inanna $=\left({ }^{\mathrm{d}}\right) E \widetilde{S}_{4}$-dar was surely established in Mesopotamia, while the following have to be ascribed to a Syrian milieu (Ebla or Mari): ${ }^{\mathrm{d} N e ̀-u ́ r u g a l ~(N e r g a l) ~}=\left({ }^{\mathrm{d}}\right)$ Ra-sa-ap (Rešep); ${ }^{\mathrm{d}}$ Izi (not ${ }^{\mathrm{d}} \mathrm{Gibil}$, the Sumerian Fire-god $)=\left({ }^{\mathrm{d}}\right) \grave{I}$-sa-du; ${ }^{\mathrm{d}} \mathrm{G} \dot{A} \mathbf{x S I G}{ }_{7}-r a=\left({ }^{\mathrm{d}}\right) I Y s$-ha-ra.

A second group is made up of Sumerian gods who appear in Sumerian hymns and rituals, or, if in Semitic, of Mesopotamian origin, like ${ }^{\mathrm{d}} \mathrm{En}-\mathrm{lil}$ = ( $\left.{ }^{\mathrm{d}}\right) I-l i-l u ;{ }^{\mathrm{d}} \mathrm{En}-\mathrm{ki}=\left({ }^{\mathrm{d}}\right){ }^{\prime} \dot{A}-u_{9} ;{ }^{\mathrm{d}} \mathrm{Nisaba}$. To this group ${ }^{\mathrm{d}} \mathrm{En}-\mathrm{zi}=\left({ }^{\mathrm{d}}\right) Z u-i-n u$, the

19 An expanded version of this section will appear in Or.

20 For the section AN in the Ebla word lists, see Lambert, The Section AN. On Enki in the offering lists, see Pettinato, Culto ufficiale, 104. The priest Aku-Enki is quoted in ARET I 3 (65). 
Moon-god, can be added, who is attested, besides these lists, only in personal names of people from the Mari - Kish region, that is from central Mesopotamia.

Only for Enki can there be a case of assimilation to the Eblaite cult. The process was facilitated by the fact that this god was already assimilated by the Semites settled in Mesopotamia to one of their deities: ${ }^{d}$ É-a. As the Eblaite writing shows, the name /hayyu $(m) /$ must go back to the root $H Y Y / W$ "to live", and Hayyu must be a god of fresh water springs. In Sumerian writing, Enki appears, although seldom, in the Eblaite offering lists, and to him an "anointed" priest, $\mathrm{pa}_{4}$-šeš, is devoted, whose tie with the god is made clear also by his name: $A-k u-{ }^{\mathrm{d}} \mathrm{En}-\mathrm{ki}$.

\section{Rituals ${ }^{21}$}

Nine rituals are in Sumerian, and two others are just translations from Sumerian originals. All of them mention the Sumerian goddess of incantations Ningirim, and in some cases also Enlil, Enki and Ninki. Another one (in three different versions) is a re-elaboration in Semitic of Sumerian themes. In the mythological section Enlil, "the father of the gods", his vizier Kabkabu, the Star, and the Sun-goddess Utu (here, differently from Mesopotamia, feminine, as it is proved by a verbal form with the prefix $t i-$ ) are quoted; in the ritual action the Weather-god Adda appears instead. This re-elaboration, and the fact that the other rituals are in syllabic Sumerian, show that those documents had in some way a practical use, and were not seen just as library texts. The prestige of Sumerian culture, to which was owed the cuneiform writing system, must have been enormous. But that did not have any influence on the cult and only a minimal effect on magic.

In another ritual, clearly composed in Ebla, the acting gods are the Semitic Adda, the deified Syrian river Balikh (known in the Sargonic period also in middle Mesopotamia) and two local deities like Adarwan and Amarig, a deified mountain south of the Amanus.

\section{Juridical texts ${ }^{22}$}

In a verdict confirming the awarding of an inheritance to the sons of the vizier Ibrium (TM.75.G.1444), the king pronounces his sentence invoking the following three gods: ${ }^{\mathrm{d}} \mathrm{Ku}-\mathrm{ra}$, ${ }^{\mathrm{d}} \mathrm{Utu},{ }^{\mathrm{d}}{ }^{\mathrm{P}} \mathrm{A}-\mathrm{da}$. Utu and Adda, but not Kura, are

21 For the rituals, see Krebernik, Beschworrungen. The ritual in Semitic, in three versions, is ARET V 1-3; see Fronzaroli, Scongiuri eblaiti.

22 The verdict TM.75.G.1444 is published by Edzard, Text TM.75.G.1444. The Ebla - Abarsal treaty is edited by Sollberger, Treaty, 129-155. 
also mentioned in the curse which closes the treaty between Ebla and Abarsal (a city-state to the east of the Khabur river): "(who) will do all that for evil, Utu, Adda, all the gods...". The reason why Kura is not mentioned in this international treaty is probably that his cult was known only in the Ebla region. But at Ebla oaths were taken, also by people representing other city-states, in the temple of Kura.

At the head of the Ebla pantheon was therefore a triad: Kura, the Sun-goddess, and the Weather-god, and among them Kura was the city god.

\section{Offering lists 23}

Approximately twenty tablets record deliveries of sheep to the Palace. These are monthly documents, and the totals of animals delivered range from 500 to 1,000 head. The texts present three sections listing sheep for: 1) offerings to the gods; 2) alimentation for the court; 3 ) alimentation for officials not residing in the Palace.

These lists are rather stereotyped. They register more or less the same gods and the same acting people. The number of the listed deities slightly exceeds forty. One can group the most frequently attested of them according to the diffusion of their cult, and in some cases with the support of an etymology, as follows:

\section{a) Semitic gods}

d' $A$-da: The relevance of his cult (see above no. 3) together with the Sargonic documentation, proves that he was the most important Semitic Weather-god in the northern and eastern areas.

dUtu: Although the Semitic rendering of this ideogram is not given, this deity must obviously to be taken as Semitic. The verbal form ti-a-ba-an "you make bricks", with the feminine prefix in the ritual ARET V 3 I 2, shows that the deified Sun was considered in Ebla to be a goddess, as later in Ugarit, Canaan and among the Arabs.

${ }^{\mathrm{d} D a-g a n:}$ To this god one has to refer the epithet: lugal Du-du-lu ${ }^{\mathrm{ki}}$ "Lord of Tuttul", whose variant ${ }^{\mathrm{B}} \mathrm{BE} D u-d u-l u^{\mathrm{ki}}(\mathrm{BE}=b \bar{e}(l u m))$ is well attested also in other economic texts. ${ }^{\mathrm{B}} \mathrm{BE}$ Ga-na-na could be also an hypostasis of Dagan, because Ganana was a region in middle Mesopotamia. There is no direct evidence that " $\mathrm{BE}$ ma-tum / kalam-tim "Lord of the country" refers to this god, as well as lugal mätim attested in Mari of the sakkanakku age. Dagan, whose major cult place was Tuttul on the Balikh, was one of the most important gods of the northern Semites.

${ }^{\mathrm{d}} \mathrm{Ga}$-mi-is: During the 1st millennium Kamos was the tutelary god of Moab.

Four of these documents have been studied by Pettinato, Culto ufficiale. 
${ }^{\mathrm{d}} \mathrm{Ga}$-aš-ru: This god is known also from the Imar tablets (second half of the 2nd millennium), and must not be identified with Ugaritic Ktr.

${ }^{\mathrm{d} I}$-sa-du "the Fire-god": He is seldom attested.

${ }^{\mathrm{d}}$ Ra-sa-ap: Rašap is the god of pestilence according to the West Semitic tradition (Ugarit, Arameans, Phoenicians).

${ }^{\mathrm{d}} \mathrm{BE}$ dingir-dingir-dingir "Lord of the gods": It is unknown to what kind of a god this rare epithet could refer, and the relevance for the Eblaite religion of an idea like that of lordship over the gods remains obscure.

dingir a-mu, dingir en "God of the father; God of the king": These gods are discussed below.

b) Gods received from the substratum

${ }^{\mathrm{d}} \mathrm{Ku}-\mathrm{ra}: \mathrm{He}$ is the most frequently attested god together with ${ }^{\mathrm{d}} \mathrm{NI}-d a-\mathrm{KUL} / \mathrm{BAL}$. His feminine counterpart is $\mathrm{d} B$-ra-ma.

${ }^{\mathrm{N} I}$-da-KUL/BAL: He is mostly qualified by four place-names: 'Amadu (Hamath), Atanni, (L)arugadu and Luban, but a NIdaBAL/KUL of the Palace $\left(\mathrm{SA}_{\mathrm{ZA}} \mathrm{k}_{\mathrm{k}}^{\mathrm{k}}\right)$ is also attested. His female counterpart is known only by the epithet "BE-mí (bälatum) "lady", who also receives offerings. The writing with NI which can be read: $n i, i,{ }^{\prime} a_{x}, b u_{x}$, and the alternation of BAL with KUL (the latter a simplified form of the first sign) makes the analysis of the name difficult.

d $A$-dam-ma: She is the female counterpart of Rašap. In the 2 nd millennium she belongs to the West Hurrians' pantheon.

'Am-ma-ri-gú: According to the Hurrian documentation from Hattusa, he is a deified mountain.

dAs-da-bíl: In the 2nd millennium he is the Warrior-god of the West Hurrians. 'Ba-li-ha: The river Balikh deified. The name is in the dual, and "the two Balikh" are attested in the rituals ARET V 4, 5. This god is known also from Sargonic personal names and from the Imar texts. Although the name is treated as a Semitic one, it has perhaps to be considered as belonging to the substratum because of the general archaism of river names. The dual form may reflect the fact that it is formed by two watercourses.

${ }^{\mathrm{d}} \mathrm{G}$ ÁxSIG ${ }_{7}-\mathrm{ra}$ : The reading of this name in the Lexical Lists is: $\left({ }^{\mathrm{d}}\right) I S-h a-r a$. This goddess appears as theophoric element in Sargonic personal names. She was included in the pantheon of the Hurrians settled in Syria, and is attested also in the documents from Imar. She has to be considered as belonging to the Syrian substratum.

${ }^{\mathrm{d}} \mathrm{TU}$ : Short form for ${ }^{\mathrm{d}} \mathrm{Nin}$-tu, the Sumerian Mother-goddess. It seems probable that the Sumerian name hides a local goddess with similar functions; in fact such deities are well known in the Syrian and Anatolian regions. 
c) Sumerian-Akkadian gods

${ }^{d}$ En-ki and his female counterpart ${ }^{\mathrm{d}}$ Nin-ki: They are rarely attested. For Enki see no. 1: Lexical lists.

'Nin-kar(-DU): This deity should be Ninkarrak, a goddess attested in Old Akkadian texts.

d $\breve{S} a-m a-g a n: H e$ is the Akkadian Sakkan (Sumerian Sumukan), the god of the wild and herding animals. Therefore he opens the offering lists. His cult was probably introduced under Mesopotamian influence. He is attested in Mari in the name of the king Iku(n)-Šamagan.

\section{Administrative documents}

A way to ascertain the relevance of a god in the cult is to compare the number of quotations refering to him in the economic documents registering the deliveries of goods. In the volumes ARET I-IV, VII-VIII, concerning every sector of the administration, the gods most frequently mentioned whether for gifts dedicated to them or for deliveries to their personnel, are the following:
(1) NIdaBAL: 105 (references);
(2) Kura: 82;
(3) Rašap: 40;
(4) Adda: 29;
(5) Gamiš: 23;
(6) GÁxSIG -ra (Išḩara): 19;
(7) Ašdabil: 16;
(8) Utu: 12

The first two gods: NIdaBAL and Kura, have more than twice as many quotations as the third one: Rašap. That NIdaBAL preceeds Kura is explained by the fact that he is represented by several hypostases. But Kura's pre-eminence over the other deities is confirmed by the annual accounts (about twenty in number) of silver and gold expended by the Palace. They invariably begin with the recording of "one mina silver (470 grs.) for the head (of the statue) of Kura". This donation is likely to refer to a rite of yearly renewal (well known for many cultures) of the main god's statue in the city.

Both Kura and NIdaBAL, as well as Išhara and Ašdabil, belong to the substratum. Rašap, Gamiš and the feminine Sun-deity are diffused in later times in the cultures of the West-Semitic area. The Semitic Weather-god Adda has a rather high number of quotations, although it seems probable that some of his functions must have been similar to those of either Kura or NIdaBAL: the main male god in the religions of the Ancient Near East has usually the feature of a being controlling meteorological phenomena. Dagan appears rarely, and always as "the Lord of Tuttul". 


\section{Personal names}

A quite different picture emerges from the scrutiny of the theophoric elements in the personal names. The most frequently attested are listed here below according to the number of names where they appear.

Malik, Damu, Il

Lim, Išar

Da'ar, Zikir, Kura, Eštar, Naim, Adda, Daban, Rašap, Ba'al / BE Utu, Gamiš, Dagan, NIdaBAL, Enki

The names are all Semitic with the exception of Kura, the main god of the city, in the third group (where the frequency is one name in ten with respect to the first group), and NIdaBAL in the fourth. And it is also significant that gods like Adda, Dagan and Rašap, among the most important of the official pantheon, are to be found no earlier than in the third group or even in the fourth.

Most of the elements are appellatives: Malik "King, Ruler", the most frequent of all; and then Išar "the Righteous one"; Da'ar "the Durable, Overlasting one"; $\mathrm{Na}$ ' im "the Favourable one". Besides, there are deified elements which recall a pre-urban social organization: Damu, the bond of blood, "the Stock" (damu "blood"); Lim "the Clan" (lim "multitude, people"; Akk. "thousand"); Zikir "the Name" (zikrum) or "the male" (zikanum).

These names are not the expression of a popular religiousness. In fact, out of eleven names of kings of Ebla, two are composed with Lim and seven with Damu. ${ }^{24}$ They reflect instead an archaic tradition: that of the Semitic populations before their urbanization.

As W. Robertson Smith saw one hundred years ago: "the system of an antique religion was part of the social order under which its adherents lived", and "the first steps of a social and religious development took place in small communities, which at the dawn of history had a political system based on the principle of kinship". ${ }^{25}$

Some names, like those compounded with Kura and NIdaBAL, attest contact with the population of the northern Syrian substratum. Others, like those with the Semitic gods Adda, Eštar and Rašap, testify an already rather articulated gods' world. But by far the most frequently attested elements are some deified social structures and appellatives. Those appellatives reflect a

24 The lists of the kings of Ebla are published by Archi, Konige; id., Prosopography, 212-214. One has to notice also that 21 of 38 names of "king's sons" are composed with Damu, see Archi, ibd., 225-230.

25 Robertson Sinith, Lectures, 28 and 32. 
phase of the social development, when, above all, the gods of the group or of the place where the tribe had settled down were venerated, that is the same stage which had "the clan" and "the bond of blood" deified. They can only go back to a period when there was not yet a pantheon organized in several major gods, otherwise it would be unclear to what gods they would refer.

The case of II is meaningful in this respect. It is the most frequent theophoric element after Damu and the appellative Malik. While -ilum, written -NI(i)-lum/lu/la/li is the appellative meaning "god", -il has the function of the subject in a verbal sentence in several names, as in Old Akkadian, and "thus should be in the status rectus, not the absolute or predicate state. Therefore it cannot be merely the general word 'god'". ${ }^{26}$

Now, Il does appear neither in the official pantheon of the offering lists, nor among the gods attested in the other administrative documents. This is exactly the situation for Old Akkadian. Il is a very productive element in forming personal names, but he does not succeed in becoming part of the official pantheon. This also applies to the sources from Mari: Il appears very frequently in Amorite personal names, ${ }^{27}$ but he is excluded from the official pantheon of Mari. ${ }^{28}$ Three different cases and one and the same pattern!

The formation of an urban society gives rise to specialization among the gods who are sometimes taken over in part from the population already settled in the region. In the three cases mentioned above, Il does not find any place in this process. This is probably because the identity of Il was not sufficiently characterized by any particular aspect, in contrast to Indo-European *dièus, which is linked to the notion of "light".

Il was the divine which manifests itself in particular situations and places. Significantly, his name is morphologically the absolute state of Common Semitic ilum "god". For this reason II remains still very productive in the tradition of name-giving.

It is probable that Il had originally those characteristics proper to a "supreme being". But even if one would ascribe an "Urmonotheismus" to the ancient Semites, it could be only similar to that of other "primitive societies". It is always doubtful to define a god through verbs and appellatives attested in the theophorous personal names, because in most cases they apply to several deities; and it is incorrect to give to words (e.g. to "bny "to build, beget"; *qny "to acquire, create") values determined by later theological evaluations. ${ }^{29}$

\footnotetext{
26 Roberts, Pantheon, 31-33 and 121-144.

27 See Huffinon, Amorite Names, 162-165; Rouault, ARM XVI/1, 260-261.

28 See Edzard, Pantheon in Mari.

29 See MAD 3, 98: d'́E-a-ba-ni, ${ }^{d}$ EN.ZU-ba-ni, Ib-ni-d EN.ZU/dM/LUGAL; cf. Huffmon, Amorite Names, 176-177, sub BN², $\mathrm{BN}^{3}$; cf. Gröndahl, Personennamen, 176.
} 
The documentation of Ebla gives a different perspective to the Ugaritic one, considered to be the expression of the Canaanite culture in its archetypal stage.

According to Ugaritic texts Il is the lord of the gods, he receives the epithet of "father", $a b$, and several gods refer to him as their "father". According to some myths he procreated in fact several gods. Il is also "father of mankind", $a b$ $a d m$, and perhaps he is described in a text as modelling mortals from clay. ${ }^{30}$ $\mathrm{He}$ is at the head of the pantheon and opens the offering lists. In order to show that the Ugaritic Il was "creator of the cosmos" like El Elyon, venerated by Melchizedek as "creator of heaven and earth" (Gen 14: 22), from one side one has tried to identify his attributes with those of El of the Old Testament, and from the other side one has produced parallelism from contemporary cultures as the Hurrian myth of "Kingship in Heaven" in order to elucidate the conflict between Il and Baal, as well as the Babylonian Enuma Elish. The conclusion was: "It would seem that there is reason enough to assume that like the Sumerian god Enlil, the Babylonian god Marduk and YHWH the God of Israel, $\mathrm{El}$, the supreme god of the Canaanites, was thought to be the creator of both the cosmos and man".

The only precise datum which could be produced for Il as creator of the earth is the name Elkunirsa in the Hittite translation of a Canaanite myth, in which (according to most scholars) the title attributed to Il also in the Karatepe inscription (8th cen.) is preserved: el qn 'rs " $\mathrm{El}$ creator of the earth". ${ }^{32}$ But this Ugaritic Il, so characterized in functions and personality, is the result of the influence of some of those cultures quoted in order to elucidate him by similarities. The new evidence from Ebla, together with a careful evaluation of Old Akkadian and Amorite evidence, compels us to accept this conclusion.

To have already organized the gods in lists (which we call "pantheon") is a typical Mesopotamian feature, as it is to provide the gods with ancestors. And it is typically Hurrian to mention in those lists also unnamed "gods of the father", enna attanni-bi-na, for several gods like Tešup, Hepat, Şauška and Simegi (and for the man to whom the sacrifice is celebrated), as well as the two parts of the cosmos "earth and heaven" eše hawurni, followed by "mountains and rivers". In the Anatolian-Hurrian lists "the gods of the father" and "earth and heaven" are preceded by the major gods. In the Ugaritic-Hurrian ones, however, a "god the father" (eni attanni), here in the singular and without the genitive (-bi), stays at the beginning because one has to match the Babylonian theological order. The influence is mutual. Only in one case (II d) there is a plural: enna-šta attanna-[sta-]ma "to the gods the fathers", which reflects the

\footnotetext{
30 See Pope, El, 47-54; de Moor, El.

31 So de Moor, El, 186.

32 Cf. Pope, El, 49-54, who is very cautious about this matter: "All the Ugaritic allusions to El's creativity are in terms of generation and paternity".
} 
Hurrian idea of plurality for those gods. They are always preceded by a mysterious "god šalanni" (eni šalanni; in II d, in the plural: enna-šta salanna-šta-ma) who is attested also in the Anatolian-Hurrian lists. ${ }^{33}$ In the Ugaritic lists "Il the father" (ilib / DINGIR $a-b i$ ) is preceded in one case (I b) by an otherwise unknown Il Safon (il spn) created only in order to make this list as complete as possible. Further, there are: Il, Dagan, Baal (Safon), in this sequence because one has to respect the Hurrian order according to generations: El (who stands for Anu), Kumarpi, Tešup. One offering list has the sequence: Ilib, earth and heaven (arș wa smm), Kotarot, Dagan, Baal Safon, where also the order: "earth and heaven" shows Hurrian influence". ${ }^{34}$

a

\section{Ugaritica V 18}

gods lists

il șpn

DINGIR a-bi il[i]b

DINGIR-Ium i[l]

dDagan

dIM be-el

Hur.sag.Hazi

\section{Ugaritic lists}

a

KTU 1.110

gods lists

in $\underline{\ln (d)}$

in $\operatorname{atn}(d)$

il(d)

$\underline{t t} b(d)$ b

KTU 1.47

gods list

dgn

b'[l s]pn

b'lm
KTU 1.118

gods list

ilib

il

dgn

b'l șpn

b'lm d

KTU 1.148 offering list

ilib ilib arș w smm il ktrrt dgn dgn b'l șpn b'l sppn b'lm

$\begin{array}{ll}\text { il } & \text { arṣ w smm } \\ & \text { il } \\ \text { dgtrnt } & \text { dgn } \\ \text { b'l șpn } & \text { b'l șpn } \\ \text { b'lm } & \end{array}$

II Hurrian lists from Ugarit

CTA 166

ritual ritual

in(t en(tht) $\operatorname{atn}[\underline{t} \mathrm{t}] \mathrm{m}$ il(d) $\underline{t t} b(d)$

in atn

il

kmrb tte hlbg

KTU 1.116

d

\footnotetext{
33 Laroche, Giossaire, 212.
}

34 Part of the data are aiready tabulated by Nougayrol and Laroche, Ugaritica V, 44 and 519-520. 
The introduction of Ilib, the gods' ancestor, in these lists was facilitated by the relevance of the cult of the ancestors in human society. It was prescribed to a son to honor "his ancestral god", ilibh (Aqhat poem, KTU 1.17 I 27, 45, IV 16), a cult well attested in Syria already in the Ebla age. The dead kings were considered tutelary beings in Ugarit as well as in Ebla, receiving the qualification of "god", il and Sumerian dingir in Ugarit and in Ebla, respectively. The Eblaite offering lists include a "god of the father", dingir a-mu, for the king, the queen and the princes, who could be the deceased father. It is also probable that "the god / gods of the king / queen", dingir(-dingir) en / maliktum have to be considered deified ancestors. 35

It is certainly correct to evaluate the God of Israel in the light of the Ugaritic evidence. Israel was formed in Canaanite milieu! In fact, Yahwe who was equated to El became the God of an urban society, and the redactors of the Old Testament (in large part a rather late source) were surely well acquainted with the theology about II which had developed in the Canaanite centres.

But the El of the Patriarchs' age was something different. As far as he is concerned, it is more proper to refer to the Eblaite evidence, which reveals to us Il as a deity of a pre-urban society. That holds good both for the revised Alt's theory, which maintained that Israel emerged from pastoral tribes settled at the periphery of the city-state, and for the theory according to which Israel formed in the rural settlements of those city-states. Their El was a tutelary god of the group, whose epiphanies were linked to rather primary needs: procreation for continuity of the group, and protection. Yahwe was assimilated first with this $\mathrm{El}$, and then with the $\mathrm{El}$ of the cities. The long process towards monotheism began at a later stage.

35 Archi, Cult of the Ancestors. 


\section{Bibliography}

Archi, $A$., "Il culto del focolare presso gli Ittiti", SMEA 16 (1975) 77-87

- $\quad$ "Die ersten zehn Könige von Ebla", ZA 76 (1986) 213-217

- "Eine Anrufung der Sonnengottin von Arinna", in: E. Neu / C. Rulster (Hg.), Documentum Asiae Minoris Antiquae (FS H. Otten), Wiesbaden 1988, 5-31

- "Cult of the Ancestors and Tutelary God at Ebla", in: Y.L. Arbeitman (ed.), FUCUS. A Semitic / Afrasian Gathering in Remembrance of A. Ehrman, Amsterdam/Philadelphia 1988, 103-112

- "Sociêté des hommes et société des animaux", in: Studi di storia e di filologia anatolica dedicati a G. Pugliese Carratelli, a cura di F. Imparati, Firenze 1988, 25-37

- "Studies in Eblaite Prosopography", in: A. Archi (ed.), Eblaite Personal Names and Semitic Name-Giving, Rome 1988, 205-284

Bilgiç, E., "Die Ortsnamen der 'kappadokischen' Urkunden im Rahmen der alten Sprachen Anatoliens", AfO 15 (1945-1951) 1-37

Bin-Nun, S.R., The Tawananna in the Hittite Kingdom (TH 5), Heidelberg 1975

Carruba, $O$., "Die Chronologie der hethitischen Texte und die hethitische Geschichte der Großreichszeit", ZDMG Suppl. I,1 (1969) 226-249

- Das Palaische. Texte, Grammatik, Lexikon (StBoT 10), Wiesbaden 1970

de Moor, J.C., "El, the Creator", in: G. Rendsburg (ed.), The Bible World. Essays in Honor of C.H. Gordon, New York 1980, 171-187

Edzard, D.O., "Pantheon und Kult in Mari", in: J.R. Kupper (ed.), La Civilisation de Mari. XVe Rencontre assyriologique internationale, Liège 1967, 51-71

- "Der Text TM.75.G.1444 aus Ebla", SEb 4 (1981) 35-59

Friedrich J., "Gottersprache und Menschensprache im hethitischen Schriftum", in: A. Francke (Hg.), Sprachgeschichte und Wortbedeutung (FS A. Debrunner), Bern 1954, 135-139

Fronzaroli, P., "Tre scongiuri eblaiti (ARET 5, 1-3)", Vicino Oriente 7 (1988) 11-23

Goetze, A., "The Theophorous Elements of the Anatolian Proper Names from Cappadocia", Language 29 (1953) 263-277

- "Hittite Rituals, Incantations, and Festivals", in: J.B. Pritchard (ed.), Ancient Near Eastern Texts related to the Old Testament (= ANET), Princeton 1955, 346-361

Gröndahl, F., Die Personennamen der Texte aus Ugarit, Rom 1967

Gurney, O.R., "Anatolia c. 1750-1600 B.C.", in: CAH ${ }^{3}$ II,1, Cambridge 1973, 228-257

- Some Aspects of Hittite Religion, Oxford 1977

Haas, V. / Wafler, M., "Bemerkungen zu Ệšti/ä (1. Teil)", UF 8 (1976) 65-99

Hoffmann, I., Der Erlaß Telepinus (TH 11), Heidelberg 1984

Huffmom, H.B., Amorite Personal Names in the Mari Texts, Baltimore 1965

Kammenhuber, A., "Das Palaische: Texte und Wortschatz", RHA XVII 64 (1959) 1-92

Krebernik, M., Die Beschwơrungen aus Fara und Ebla, Hildesheim 1984 
Lambert, W.G., "The Section AN", in: L. Cagni (ed.), Il bilinguismo a Ebla, Napoli 1984, 393-401 Laroche, E., "Hattic Deities and Their Epithets", JCS 1 (1947) 187-216

- Les noms des Hittites, Paris 1966

- "Documents en langue hourrite provenant de Ras Shamra", Ugaritica V (1968) 447-544

- Glossaire de la langue hourrite, RHA 34-35 (1976-1977)

Neu, E., Ein althethitisches Gewitterritual (StBoT 12), Wiesbaden 1970

- Der Anitta-Text (StBoT 18), Wiesbaden 1974

- Althethitische Ritualtexte in Umschrift (StBoT 25), Wiesbaden 1980

- Glossar zu den althethitischen Ritualtexten (StBoT 26), Wiesbaden 1983

Nougayrol, J., "Les archives 'de Rap'anu', Ugaritica V (1968) 447-544

Otten, H., Eine althethitische Erzâhlung um die Stadt Zalpa (StBoT 17), Wiesbaden 1973

- / SouCek, V., Ein althethitisches Ritual für das Königspaar (StBoT 8), Wiesbaden 1969

Pettinato, G., "Culto ufficiale ad Ebla durante il regno di Ibbi-sipis", OA 18 (1979) 85-215 Pope, M.H., El in the Ugaritic Texts, Leiden 1955

Roberts, J.J.M., The Earliest Semitic Pantheon, Baltimore 1972

Robertson Smith, J.W., Lectures on the Religion of the Semites, London 1894

Rouault, O., "Noms divins", in: Archives Royales de Mari XVI/1, Paris 1979, 251-268

Singer, I., "Hittites and Hattians in Anatolia at the Beginning of the Second Millennium B.C.", JIES 9 (1981) 119-134

- The Hittite KI.LAM Festival I-II (StBoT 27/28), Wiesbaden 1983-1984

Sollberger, Ed., "The So-Called Treaty Between Ebla and 'Ashur', SEb 3 (1980) 129-155

Soucek, $V$. $\rightarrow$ Otten, $H$.

Starke, F., "Halmasuit im Anitta-Text und die hethitische Ideologie vom Königtum", ZA 69 (1979) 47-120

Wafler, $M . \rightarrow$ Haas, $V$. 


\section{Walter Burkert}

\section{Lescha-Liškah}

Sakrale Gastlichkeit zwischen Palästina und Griechenland

Ähnlichkeiten, ja Gemeinsamkeiten in Anlage und Funktion der Heiligtümer von Palästina, Syrien, Kleinasien und Griechenland sind seit langem bekannt und teilweise diskutiert: der Tempel als 'Haus' des Gottes, realiter des Kultbildes, das Opfermahl im Heiligtum, das Verbrennen bestimmter Teile des Opfertieres auf Brandopferaltären, kostspielige Weihgaben, besonders Bronzekessel; den Hintergrund bietet eine im einzelnen variable Stadtkultur mit einem in der Regel polytheistischen Göttersystem. Die Befunde in Griechenland sind allerdings markiert durch die Zäsur der 'Dunklen Jahrhunderte'; Stadt- und Tempelkultur ist vor dem 8. Jh.v.Chr. kaum nachweisbar. In dieser Epoche jedoch, im 8./7. Jh. vor allem, gibt es einen markanten Kulturtransfer von Ost nach West, am deutlichsten in der Übernahme des Alphabets; doch kam er offenbar auch im Bereich der Religion zur Wirkung. ${ }^{1}$ Merkwürdig ist freilich, $\mathrm{da} B$ im sprachlichen Bereich so wenig von Entlehnung aus dem Orient faßbar ist, und das wenige Greifbare bleibt meist problematisch: Gibt es eine Bezie-

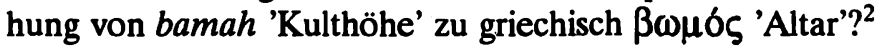

Einer anderen Wortgleichung sei hier nachgegangen, auf die seinerzeit schon Robertson Smith in seinen Lectures on the Religion of the Semites aufmerksam gemacht hat. Im Zusammenhang seiner bahnbrechenden Untersuchungen über die Opfergemeinschaft notiert Robertson Smith: "Eine Festhalle für das gemeinsame Opfer wird bereits 1 Sam 9,22 erwähnt, ihre Bezeichnung liška scheint mit dem griechischen $\lambda \varepsilon \sigma \chi \eta$ identisch zu sein." ${ }^{13}$ Liškah ist ein Nebengebäude fürs Opfermahl in palästinischen Tempelbezirken; die $\lambda \varepsilon \sigma \chi \eta$ der Knidier steht, offenbar zu ähnlichem Zweck, am Rand von Apollons Heiligtum in Delphi. Bautyp, Funktion und Benennung scheinen zusammenzutreffen. Ist dies zu sichern, daß ein wichtiger Typ von Bauten im Heiligtum im Hebräischen und im Griechischen mit dem gleichen Wort bezeichnet wird, und wie ist dies möglich?

Dabei ist vorab festzuhalten, daß liškah bislang nur im Alten Testament belegt ist - es gibt einen ganz unsicheren Beleg in einer phönizischen Inschrift, sie ist gebrochen, Kontext fehlt. ${ }^{4}$ Es gibt keine semitische Etymologie für liškah. $\mathrm{Da} B$ bei Nehemia dreimal in offenbar gleicher Bedeutung ein Wort

Dazu Burkert, Epoche.

2 Bajuós als semitisches Lehnwort bezeichnet u.a. von Lewy, Fremdwơrter, 32; Albright, Archaeology and Religion, 202; dagegen Wahrmann, Literaturbericht, 244; Yavis, Altars, 54,1; aus dem Griechischen nach Brown, Sacr. Cult, 1-7, vgl. Chantraine, Dict.ét., 203f; "urverwandt" Gese, Altsyrien, 173.

3 Sinith, Rel. Sem. 254,6 = dt. Ausg. Anm.406. Cf. Lewy, Fremdwörter, 94; Brown, Vine.

4 HAL s.v.; Jean / Hoftijzer, Dictionnaire, 138. 
niškah gebraucht wird, macht die Sache nicht einfacher. ${ }^{5} \Lambda \varepsilon \sigma \chi \alpha$ dagegen hat eine offenbar allgemein anerkannte, tadellose griechische Etymologie, zum Stamm $\lambda \varepsilon \chi$-, deutsch 'liegen', parallel zu $\lambda \varepsilon \chi$ OS $^{\text {'Bett'. }}{ }^{6}$ Das Wort liskah ist übrigens neuhebräisch revitalisiert worden, liškat-modi' im ist ein Auskunftsbüro, liskkat-'abodah das Arbeitsamt. Auch $\lambda \varepsilon \sigma \chi \eta$ lebt neugriechisch weiter, in der Bedeutung 'Club' und 'Büro'.

Die griechische Etymologie spricht nun allerdings von vornherein gegen die gelegentlich vertretene These einer semitischen Entlehnung im Griechischen, ${ }^{7}$ aber auch gegen die etwa von Eduard Meyer geäußerte Vermutung einer gemeinsamen Entlehnung aus einer unbekannten, vielleicht anatolischen Sprache. ${ }^{8}$ Die Möglichkeit einer Entlehnung aus dem Griechischen wird routinemäßig in den Hebräischen Lexika vermerkt. ${ }^{9}$ Wann und wie ist so etwas denkbar?

Um ein anschauliches Bild zu gewinnen, muß man die Belege genauer betrachten, was freilich, wie zu erwarten, die Sachlage kompliziert. Zunächst also liškah im Alten Testament: Am Anfang stehe ein relativ spätes Beispiel, Jeremia 35. ${ }^{10}$ Auf Geheiß Jahwes geht Jeremia zu den 'Söhnen des Rechab', der 'Genossenschaft der Rehabiter', und lädt sie ein zum Tempel Jahwes, "in eine der lešakoth"; Jeremia tut, wie ihm geheißen, er führt sie in die "liškah Chanans, ...die neben der liskah der Oberen, oberhalb der liskah Maasejahus ... gelegen" ist. Er setzt ihnen Becher vor und fordert sie auf, Wein zu trinken. Die Rehabiter weigern sich energisch, "denn Jonadab ... der Sohn Rechabs ..., unser Ahnherr, ... hat uns folgendes befohlen: Nimmermehr sollt ihr oder eure Kinder Wein trinken." Jeremias bzw. Jahwes Intention ist es, das fromme Festhalten der Rehabiter am Familienbrauch mit dem Abfall Israels vom rechten Gesetz zu kontrastieren; dies mag hier ebenso beiseite bleiben wie Erklärung und Kontext des merkwürdigen Familientabus selbst. Es gibt auch bei den Griechen eigentümliche Familientabus; die Ioxiden z.B., wie wir durch

5 Neh 3,$30 ; 12,44 ; 13,7$; vgl. HAL 689; Brown, Vine 151, der aus vagen Parallelen auf kyprische Herkunft schließt.

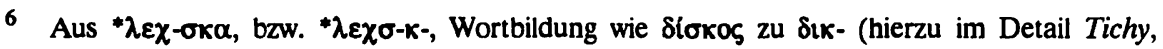
Studien, 225 Anm.44); vgl. schon Crain, Bedeutung, 580f; Curtius, Verbum, 278; Pott, Lautunterschiede, 188; Meister, Dialekte II, 50 Anm.; Wackernagel, Miszellen, 39f = Kleine Schriften I, $718 \mathrm{f}$ (der die direkte Verbindung mit $\lambda \varepsilon \chi \propto \sigma_{5}$ ablehnt, die mit dem Stamm $\lambda \varepsilon \chi$ aber akzeptiert); Schwyzer, Grammatik I, 541; Frisk, Wörterbuch, s.v.; Chantraine, Dict. ét. s.v.

7 So Schrader, Forschungen, 30; ders., Sprachvergleichung und Urgeschichte, 497; danach von Müller, Privataltertümer, 262,5.

8 Meyer, GdA I 2, 705 vermutete kleinasiatische Herkunft des Wortes. Vgl. auch Brown, Vine, 151-153.

9 "Unknown etymology" bei Klein, Et. Dict. s.v.

10 Übersetzungen im folgenden nach Kautzsch. 
Plutarch erfahren, reißen keine Disteln aus (Plut.Thes.8,6). Man bedenke lediglich, daß solche Tabus, die eine geschlossene Gruppe charakterisieren, dies durch den Kontrast zum normalen Verhalten leisten. Normale Menschen reißen Disteln aus. Normale Menschen in Jerusalem lassen sich in eine liškah im Tempel einladen und trinken dort Wein. Dafür sind diese Hallen gebaut, von privaten Stiftern, die wohl auch eine gewisse Kontrolle über die Benutzung ausüben. Drei offenbar bekannte Bauten dieser Art sind im Jeremia-Text erwähnt, offenbar nach ihren Stiftern benannt. Die Weinbecher, die Jeremiah dort benützt, sind wohl in der liškah dauerhaft aufbewahrt.

Eine weitere liškah im Tempel wird Jer 36,10 erwähnt; dort liest Baruch vor. Auch in den Königsbüchern wird eine liskah im Tempel, 'beim Eingang', erwähnt (2 Kön 23,11). Jer 36,12.20 heißt aber auch ein Raum im Palast ebenso, 'die liskah des Schreibers' - danach die neuhebräische Verwendung in der Bedeutung 'Amtsstube', 'Büro'.

Die lešakoth spielen ferner eine große Rolle in den Visionen Hesekiels. Er sieht 30 um den Tempel Jahwes $(40,17)$. Sie sind den Priestern zugewiesen, die dort essen. ${ }^{11}$ Nach der Rückkehr aus dem Exil ist weiter von den lešakoth die Rede. Nehemia hat eine Auseinandersetzung mit einem gewissen Tobija, 'für den' eine liškah eingerichtet war, aus der ihn Nehemia ausweist (Neh.13,4-9). Esra zieht sich bei Gelegenheit demonstrativ 'in die liskah Johanans' zurück $(10,6)$; allgemein aber werden in Esras Ordnung die lešakoth offenbar 'den Priestern' überhaupt zur Verfügung gestellt, die dort Gold, Getreide und sonstige Abgaben, heilige Gefäße aufbewahren (Esra 8,29; 10,38; 10,40); auch 'Torwächter und Sänger' halten sich dort auf. ${ }^{12}$

Nun sind im Buch Samuel - nach üblicher Ansicht also in recht alten Textschichten - solche Hallen, lesakoth, bereits vorausgesetzt, längst ehe es den salomonischen Tempel in Jerusalem gab; Robertson Smiths Bemerkung ging davon aus. Zunächst, noch vor der Geburt des Samuel, wird das Heiligtum von Silo eingeführt, wo ein 'Haus Jahwes' besteht, von Priestern verwaltet. Elkana zieht mit seinen Frauen und Kindern jährlich zu diesem Heiligtum, um dort im Rahmen eines Opfers zu essen und zu trinken, und zwar in einer liškah; als Channa, die bislang unfruchtbare Frau, vor Jahwe leidenschaftlich betet, meint Eli, der Priester, sie sei betrunken - Weintrinken gehört also dort auf jeden

11 Ez 42,13; cf. 40,44-46; 41,10; 42,1.4-13; 44,19; 46,19f; zum Tempelentwurf Hesekiels Galling bei Fohrer, Ezechiel, 220-241; Busink, Tempel, 701-775. Haran, Temples, 24, Anm. 20; 193 vertritt die These, die lešakoth seien in Jersualem sekundar.

12 Ferner sind lešakoth erwăhnt 1 Chron 9,26.33; 23,28; 28,12 (Plan des Salomonischen Tempels); 2 Chron 31,11. Vgl. Busink, Tempel; Haran, Temples. 
Fall zum Opfermahl. ${ }^{13}$ Später im Buch Samuel wird vom ersten Treffen von Samuel und Saul erzählt (1 Sam 9,22): In der - nicht mit Namen genannten Stadt trifft Saul auf Samuel, der lädt ihn ein, "Ihr müßt heute mit mir essen", und zwar am Abend beim Opfer auf der Kulthöhe; Samuel "nahm Saul und seinen Knecht, führte sie in die liškah und wies ihnen an der Spitze der Gäste Plätze an; derer waren ungefähr 30 Mann. Und Samuel sagte zum Koch: Gib das Stück her, das ich dir übergab", und er gibt Keule und Fettschwanz an Saul. $\mathrm{Ob}$ auf dieser Opferhöhe ein Tempel anzunehmen ist, ist umstritten; möglicherweise stand die liškah für sich, als einziges Gebäude im Heiligtum. ${ }^{14}$ Dies erinnert dann am ehesten an ein kretisches Höhenheiligtum wie das auf dem Juktas bei Knossos: Im Zentrum des Kultes steht ein Brandopfer-Altar neben der Felsspalte, in der die Opfer-Rückstände dann versenkt werden; auf einer etwas tiefer gelegenen Terrasse aber standen ein Gebäude mit fünf Räumen, wobei Tierknochenfunde auf Mahlzeiten am Ort hinweisen. ${ }^{15}$ In Samuels Welt jedenfalls ist die liškah der Ort des Opfermahls; dabei wird mit der Verteilung des Fleisches der Rang zugewiesen - das griechische Wort in diesem Kontext, für Fleischstück und Rang zugleich, ist $\gamma \varepsilon \hat{\varepsilon} \alpha \varsigma$. So designiert Samuel den König. Beiläufig sei bemerkt, daß nach griechischer Tradition, nach der altepischen Thebais Oidipus seine Söhne verfluchte, als sie ihm das falsche Stück vom Opferfleisch zuwiesen.

Das Interesse der Exegeten und Archäologen hat sich meist auf die 'Tempel' konzentriert; über die Typologie der Tempelbezirke gibt es weniger Studien. Dabei gehören die Nebengebäude immer zum Tempel, sie sind für die Funktionen des Heiligtums keineswegs Nebensache: Abstellräume, Sakristeien, Schatzhäuser, vor allem aber eben die Banketthallen, in Jerusalem so gut wie bei den griechischen Tempeln. Nebengebäude in Tempelbezirken sind archäologisch wohl faßbar, und zwar schon seit der mittleren Bronzezeit. Vor allem $\mathbf{M}$. Ottoson hat bemerkenswerte Beispiele zusammengestellt für "a lateral chamber or building built into or near the wall surrounding the courtyard", und er spricht dabei von liškah; Tierknochenfunde, Geschirr, Feuerstellen weisen oft direkt auf das Opfermahl hin. Ottoson nennt Teleilat Ghassul, Ein Gedi, Megiddo XIX und Hazor H 2 (um 1500 v.Chr.) für die Bronzezeit und Arad (900/600) fürs $1 . \mathrm{Jt}^{16}$ Hinzuweisen ist wohl auch auf die komplizierte Tempelanlage von

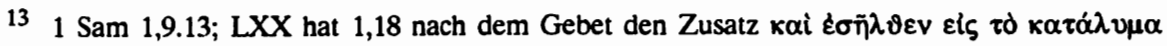

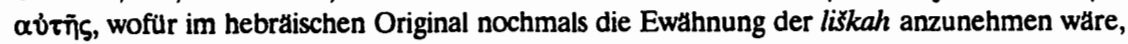
Brown, Vine, 152,1; Haran, Temples, 24, Anm. 20; 311, Anm. 36; vgl. 27f.

14 Kein Tempel: Haran, Temples, 24; Stolz, Samuel, 67f, anders Welten, in: Galling, Biblisches Reallexikon, 194f.

15 Karetsou, Mt. Juktas; Rutkowski, Cult Places, 75-79.

16 Ottoson, Sacrifice, 133f; genauere Dokumentation über syrisch-palastinische Tempel in Busink, Tempel; Ottoson, Temples; Starcky, Salles hat nur spătes Material. 
Kamid el-Loz. ${ }^{17}$ Wir können uns damit die lešakoth von Samuel bis Jeremia sehr konkret vorstellen; allerdings ist durch kein direktes Zeugnis gesichert, wie diese Gebäude außerhalb von Jerusalem tatsächlich benannt wurden.

In Griechenland sind, wie erwähnt, Tempelbezirke seit dem 8. Jh. faßbar. ${ }^{18}$ Neben Hallen für Weihgeschenke sind Banketthallen fürs Opfermahl fast allenthalben zumindest seit dem 6. Jh. bezeugt; bemerkenswert z.B., daß Kleobis und Biton mit ihrer Mutter im Hera-Heiligtum nicht nur schmausen

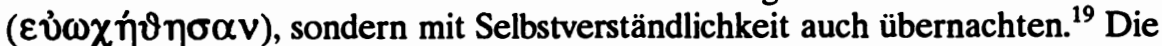
Bezeichnung der entsprechenden Nebenräumlichkeiten freilich variiert, man findet meist die allgemeine Benennung 'Haus', olkol, oikń $\mu \alpha \tau \alpha$, aber auch 'Speiseraum', $\varepsilon \sigma \tau \iota \alpha \tau \delta ́ p l \alpha .^{20}$ Im Temenos der Athena Chalkioikos in Sparta war, offenbar zunächst dem Eingang, ein Nebengebäude, wo Pausanias, der Sieger von Plataiai und Hochverräter, Zuflucht suchte und zugrunde ging; es heißt bei Thukydides einfach oǐk $\eta \mu \alpha$ ov̉ $\mu \varepsilon \hat{\gamma} \alpha(1,134,1)$. Berühmt dagegen ist die 'Lesche der Knidier' in Delphi; auch Robertson Smith hat gewiß diesen Namen im Ohr gehabt. Pausanias $(10,25,1-31,12)$ beschreibt detailliert die berühmten Wandgemälde des Polygnot, die dort die Wände schmückten. Plutarch (Def.or. 412c) verlegt in diese Lesche seinen Dialog über den Niedergang der Orakel. Die archäologische Identifizierung steht fest, die Lesche liegt am nördlichen Rand des Heiligtums, oberhalb des Heroons von Neoptolemos/ Pyrrhos, ein schlichter Rechteckbau mit Eingang in der Mitte der südlichen Längswand. Als Datum der Erbauung gilt, nach archäologischem Befund und entsprechend der akzeptierten Chronologie für Polygnot, 468/465 v.Chr. ${ }^{21}$ Knidos, Zentrum der kleinasiatischen Dorier, hat mit diesem Bau offenbar seine Umorientierung von Kleinasien zum Mutterland zum Ausdruck gebracht, galt doch der Gott von Delphi als der eigentliche Sieger der Perserkriege.

Der Bau der Knidier ist die einzige berühmte Lesche in Griechenland. Doch fehlt es nicht an weiteren literarischen und epigraphischen Bezeugungen für $\lambda \varepsilon \sigma \chi \alpha$ l. Prominent war der Begriff offenbar in Sparta, wie Plutarch erkennen läßt (Lyk. 24,5; 25,2/3). $\lambda \varepsilon \delta \chi \alpha \iota$ sind ein Ort der Männergesellschaften, der 'Älteren' vor allem, die dort sich die Zeit vertreiben und auch zu essen pflegen.

17 Vgl. zum spatbronzezeitlichen Tempel mit seinen vielerlei Gebauden Metzger bei Hachmann, Kamid el-Loz 1971-1974, 17-30.

Dazu Dragoumis, Пєрi $\lambda \varepsilon \sigma \chi \omega \bar{v}$; Dümmler, Delphika, 23-26; guter Artikel zu Lesche von Bourguet auch in Daremberg-Saglio, Dictionnaire III 2, 1103-1107; siehe auch Oehler, RE XII 2133f.

Hdt.1,31; bemerkt schon von Crain, Philologus 10 (1855) 581,11; Banketthaus des 6.Jh.: Gruben, Tempel, 99.102.

20 Bergquist, Heracles, 41-45 und dies., OpRom 9 (1973) 21-34; Börker, Festbankett.

21 Bourguet 1105-7; Schober RE Suppl.V 140; Wilamowitz, Pindaros, 73,1; erwăhnt auch Luk. Imag.7; Plin.n.h.35,59. 
Auf dic spartanischen $\lambda \varepsilon \sigma \chi \alpha \iota$ wird auch in der altischen Komödic angespiclt, besonders auf dic dort stattfindenden Mahlzeiten; angeblich hängen dic Würste nur so an der Wand (Kratinos 175 Austin-Kasscl = Ath.138c). Plutarch sagt insbesondere, in cincr Lesche seicn dic neugeborenen Kinder auf ihr Lebensrecht geprüft worden: dort saßen dic 'ältesten' der 'Phylengenossen' beisammen und trafen ihre Entscheidung (Lyk.16,1). Damit gewinnen dic $\lambda \hat{\varepsilon} \sigma \chi \alpha$ l cine Funktion in der Organisation der Gemcinde nach Familiengruppen. Pausanias nennt zwei $\lambda \varepsilon \sigma \chi \alpha \iota$ in Sparta, die der Krotanoi und dic poikile; beide liegen interessantcrwcise im Bercich von Gräbern, dic poikile bei den Heroa der Aigeiden $(3,15,8),{ }^{22}$ dic der Krolanoi bei den Königsgräbern der Agiaden $(3,14,2)$. Eine $\lambda \hat{\varepsilon} \sigma \chi \propto$ ist offenbar von cincr cinzelnen Familic errichtet und wohl auch untcrhalten. Dic spartanischen $\lambda \varepsilon \delta \chi \alpha \iota$ liegen nicht in Tempelbezirken, sic scheinen cher mil dem Tolen- bzw. Heroenkult verbunden - was zu ihrer Rolle in der Familienplanung durchaus paßt. Man hat längst darauf hingewiesen, daß auch dic Lesche der Knidicr in Delphi cben beherrschend über dem Pyrrhos-Heroon licgl; ${ }^{23}$ vicllcicht, daß man übcr dic Triopas-Tradition von Knidos Bezichungen zu Thessalien, zu den Myrmidonen, zu Achilleus betonen wolltc.

In dorischen Bercich führt auch dic Stiftung des Diomedon aus Kos, um 300 v.Chr.:24 Für Herakles und für dic cigenen Nachkommen wird ein Temenos

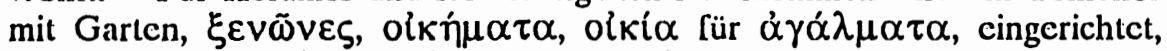

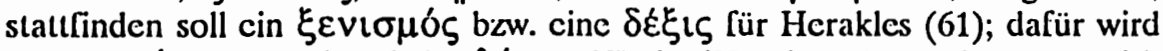
cinc $\sigma \tau \rho \omega \mu \nu \eta$ bereitcl (95; $\kappa \lambda i v \eta 127)$, im 'Haus'; vcrbolen ist, im Bczirk Ackcrbau zu trciben, in den $\xi \varepsilon v \tilde{\omega} v \varepsilon \varsigma$ auf Daucr zu wohnen, $\mu \eta \delta \varepsilon$

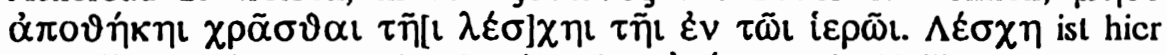
also offenbar cin Ncbengcbäudc, cincs der olkń $\mu \alpha \tau \alpha$ im Heiligtum, das man nicht als Schuppen verwenden soll; sic ist nicht identisch mit dem 'Haus', wo dem Herakles das Lager bercitet wird.

Wohl das älteste dorische Zcugnis ist cine archaische Inschrift aus Kamiros, Rhodos: EY TOYФY $\Lambda I \Delta A$, 'ich bin dic Lescha des Euthytidas, Sohn des Praxiodos, Sohn des Euphagos, Sohn des Euphylidas'. ${ }^{25}$ Bemerkenswert scheint das Insisticren auf der Gencalogic über vicr Gencrationen. Was dicsc $\lambda \varepsilon \sigma \chi \alpha$ ist, blcibt

s Jeffery, Local Scripts, 356 nr.15 cf. 349; problematische Ncubchandlung (A $A \rho \alpha \xi$ fov $\delta \omega$ ? metrisch?) durch Gallavotti, Helikon 15/16, 76ீ (SEG 26,867), der sich gegen dic Übcrsctzung 'Grab' ausspricht. 
freilich unklar. Die Steinplatte - $55 \times 27 \mathrm{~cm}$ - fand sich, bei unkontrollierten Ausgrabungen, im Kontext eines Grabes; der Erstherausgeber meinte, das Grab spreche selbst; dann vertrat Dümmler die These, es sei die Grabplatte selbst als Bahre oder Liege gemeint. ${ }^{26}$ In Analogie zu den anderen Fällen ist wohl eher an ein Opfermahlhaus der Familie im Bereich des Friedhofs zu denken.

Es gibt $\lambda \varepsilon \sigma \chi \alpha l$ auch im ionisch-attischen Bereich: Plutarch erwähnt eine

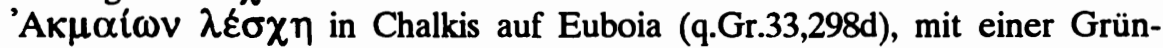
dungslegende: Dort hätten die 'in Blüte stehenden Jünglinge' Nauplios bewacht, dessen Auslieferung andere forderten. $\Lambda \varepsilon \sigma \chi \eta$ ist hier also ein Ort der Männergesellschaft, solidarisch, froh ihrer Kraft, nach außen aggressiv, mit einem problematischen Gast in ihrer Mitte.

Es gab $\lambda \varepsilon \sigma \chi \alpha \ell$ auch in Athen. Eine relativ alte Inschrift vom Piräus lautet $\Lambda E \Sigma X E O N \triangle E M O \Sigma I O N H O P O \Sigma$ (IG I ${ }^{2} 888$ ). Auffallend ist die ionische, nicht attische Kasusform. Zwei Grenzsteine aus dem 4.Jh. mit der Inschrift HOPO $\Lambda E \Sigma X H \Sigma$ zeugen für eine Lesche zwischen Pnyx und Areopag, die auch archäologisch faßbar ist. ${ }^{27}$ Bezeugt ist ferner eine Lesche im Demos Aixone, wo im Jahr 346/5 eine Pachturkunde aufgestellt wird: von zwei Stelen

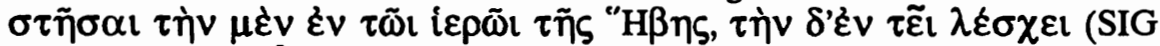
966,22 = IG II/III ${ }^{2} 2492$ ); die Lesche ist hier also ein öffentliches Gebäude der Gemeinde, gleichrangig mit einem Heiligtum aber nicht notwendigerweise mit einem solchen verbunden. Merkwürdig ist die Angabe in den Scholien zu Hesiods Erga (491, p.302 Gaisford), es gebe 360 Leschai in Athen; dies gehört offenbar zu der Überlieferung von den $360 \gamma \hat{\varepsilon} v \eta$ in Athen, die immerhin in der Athenaion Politeia des Aristoteles vorkam: ${ }^{28}$ Jedem Genos seine Lesche.

Speziell auf Böotien verweisen die Lexikographen: $\lambda \varepsilon \sigma \chi \alpha l$ seien dort

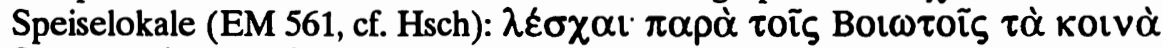
$\delta \varepsilon \iota \pi v \eta \tau \eta ́ p ı \alpha . \Lambda \varepsilon \sigma \chi \alpha \iota$ seien eine Art Exedrai, heißt es bei Kleanthes - eine baugeschichtlich offenbar irreführende Angabe. ${ }^{29}$

$\Lambda \varepsilon \sigma \chi \alpha \iota$ als Ort der Männergesellschaft, wo die Männer zusammenkommen und vor allem reden, kommt auch sonst in der Literatur vor. Die Homervita läßt den fahrenden Sänger in den $\lambda \hat{\varepsilon} \sigma \chi \alpha \iota$ der Alten in Kyme und Phokaia

26 'sepulcrum igitur de se ipso dicit' Selivanov, MDAI, 110; Dümmler, Delphika, 24f: der Stein

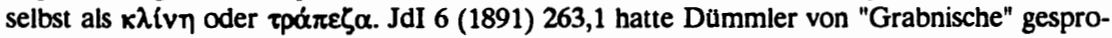
chen; nach Dümmler (1894) Oehler RE XII $2133 \mathrm{f}$.

27 Dragoumis, Пepi $\lambda \varepsilon \sigma \chi \omega \bar{v}$; IG II/III ${ }^{2}$ 2620, offenbar 5./4.Jh.; Judeich, Topographie, 299.

28 Arist.A.P. fr. 3 Kaibel-Wilamowitz =fr. 5 Oppermann = Schol.Patm. zu Demosthenes, BCH 1

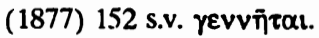

29 Die Angabe d̛ơ úpwrov (Schol.BQ Od.18,329; Eust.1849,2) hăngt mit Schol.Hes.Erga 493a zu-

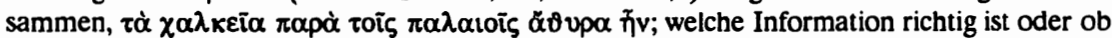
das ganze nur aus Homer/Hesiod erschlossen ist, steht dahin. Die Lesche der Knidier in Delphi hatte eine Tür. 

um zu schlafen, in eine Schmiede oder wohl auch in eine $\lambda \varepsilon \sigma \chi \eta$ gehen, sondern schwätzt hier viel einher..." Merkwürdig ähnlich in der Zusammenstellung von 'Schmiede' und $\lambda \varepsilon \sigma \chi \eta$ ist Hesiod in den Erga: Er empfiehlt, auch im Winter an der Schmiede und der warmen $\lambda \varepsilon \sigma \chi \eta$ vorbeizugehen (493) - wo offenbar die anderen müßig sitzen und schwatzen; der Bedürftige darf nicht 'in der Lesche sitzen' und sich auf die Hoffnung verlassen (501), sondern soll ans Werk gehen. Eine $\lambda \varepsilon \sigma \chi \eta$ ist also anscheinend ein allgemein zugängliches Gebäude; bei Hesiod scheint bereits der Übergang zur Semantik des 'Gesprächs' im Gang; in der Odyssee dagegen geht es nur ums Übernachten. Die antiken Erklärer haben längst die Odyssee- und die Hesiodstellen verbunden und dazu allerlei vorgebracht, ohne offenbar weitere unabhängige Informationen zu besitzen. ${ }^{35}$

Von dem Opfermahlhaus im Heiligtum werden wir damit scheinbar weit abgeführt. $\mathrm{Da} B$ es unter frühen, 'primitiven' Verhältnissen so etwas wie ein öffentliches Herbergswesen geben soll, scheint obendrein verwunderlich. Überraschende Illustration liefert allerdings eine Fern-Parallele: Türkische Dörfer in Anatolien haben ein "Dorfzimmer" (köy odas1), wo man Fremde übernachten läßt. ${ }^{36}$ Auf eben dergleichen führt für Kreta der Bericht des frühhellenistischen Lokalhistorikers Dosiadas: Im Zusammenhang mit den Syssitien der Männergesellschaft gebe es "überall in Kreta", d. h. in jeder Polis,

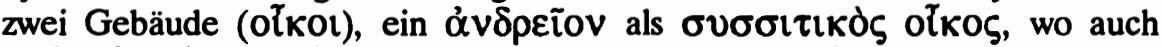

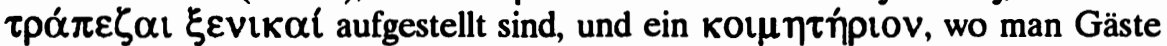
übernachten läßt (FGrHist 458 F $2=$ Ath.143 a-d). Dies wäre also das köy odas1, alias $\lambda \varepsilon \sigma \chi \alpha$. Das kulturhistorische Thema der Syssitien ist in der Zeit des Autors wohl schon ideologisch eingefärbt, doch die Information vom Übernachtungshaus der Polis in Kreta braucht nicht bezweifelt zu werden. $\Lambda \varepsilon \sigma \chi \alpha$ in dem in der Odyssee vorausgesetzten und zugleich im etymologi-

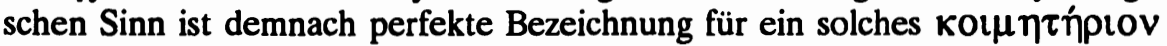
oder köy odasi.

Es läßt sich vom Griechischen her noch etwas weiter kommen: $\Lambda \hat{\varepsilon} \sigma \chi \alpha$ im griechischen Kontext muß etwas recht Altes sein, nicht nur wegen des Vorkommens in der Odyssee. Da ist zunächst eine Reihe von Eigennamen, die mit dem Element $\lambda \varepsilon \sigma \chi \eta$ gebildet sind. Lesches, der Dichter der 'Kleinen Ilias', ist

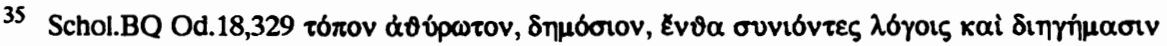

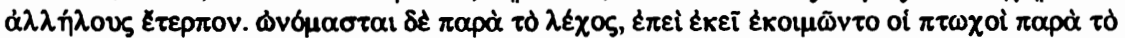

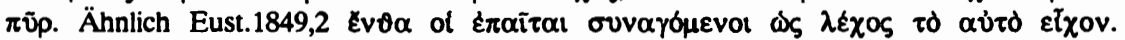
Schol.Hes. siehe Anm.29/30. Dabei bezieht sich d̊ov́pwrov wohl eher auf die Schmiede (so Schol.Hes.), das 'Feuer' stammt aus Hesiod 493.

36 Hinweis von Susanna Frei-Korsunsky und Peter Frei aus eigener Erfahrung. 
wohl der prominenteste, ${ }^{37}$ wenn auch historisch problematischste Vertreter; er wäre, nach dem Aristotelesschüler Phanias 'vor Terpander', d.h. im frühen 7.Jh., anzusetzen. ${ }^{38} \mathrm{Im}$ 4./3.Jh. gibt es einen Lescheus in Eretria, Leschos und Leschinas in Thessalien, einen Lesschon in Thespiai, in hellenistischer Zeit einen Dichter Leschides (Suda), im 1.Jh. einen Leschis in der Kyrenaika. ${ }^{39}$

Die Eigennamen hängen zweifellos damit zusammen, daß die $\lambda \varepsilon \sigma \chi \eta$ in bestimmter Weise im Apollonkult eine Rolle spielt: Es gibt einen Kult des Apollon Leschanorios/Leschenorios. Kleanthes (SVF I 123,33) ging darauf ein: "Die $\lambda \varepsilon \sigma \chi \alpha \iota$ gehören dem Apollon, sie seien eine Art $\varepsilon^{\xi} \xi \hat{\varepsilon} \delta \rho \alpha \iota " ; ~ P l u t a r c h$ erklärt den Apollon Leschenorios als Patron philosophischer Gespräche (De E 385c),

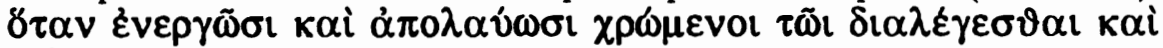

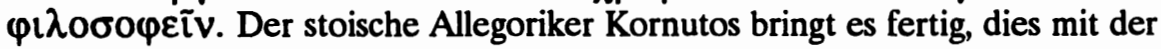
Gleichung Apollon-Sonnengott zusammenzubringen: Apollon heiße Leschenorios, "weil die Tage mit den $\lambda \varepsilon \delta \chi \chi \iota$ und dem gegenseitigem Verkehr die Menschen zusammenhalten" (32, p.69,14 Lang) - $\lambda \varepsilon \sigma \chi \alpha \iota$ ist hier also im Sinn des kommunikativen Geredes genommen. Die Wortdeutungen sind offenbar sekundäre, die Bezeichnung des Gottes ist ein vorgegebenes Faktum. Daß es auch in diesem Fall um so etwas wie einen Männerclub geht, paßt nicht übel zur Physiognomie des Apollon. ${ }^{40}$ Was der 'Mann der Lescha' im Kompositum Leschanor im genaueren bedeutet, bleibt aber unerklärt.

Auf Realitäten des Kultus führt jedenfalls die Tatsache, da $B$ es an mehreren Orten Leschanorios als Monatsname gibt, so in Thessalien, in Achaia Phthiotis, aber auch in Gortyn auf Kreta. ${ }^{41}$ Dies setzt wohl ein Fest Leschanoria voraus. Besonders interessant ist nun aber, da $B$ in Arkadien, in Tegea, in einer relativ alten Inschrift, vom Anfang des 4.Jh., ein Monatsname Leschanasios auftaucht. ${ }^{42}$ Dieser Name läßt sich kaum anders analysieren als ${ }^{*} \Lambda \varepsilon \sigma \chi \alpha$ -

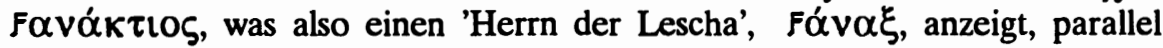
zum 'Mann der Lescha' in Leschanorios. Eine solche Bezeichnung aber kann eigentlich nur mykenisch sein; mykenisch ist der wanax, mykenisch und arka-

37 Bethe RE s.v.; Testimonia und Fragmente jetzt bei Davies, Epicorum Graecorum Fragmenta, 50 T 2-4; 52. Phainias Fr.33 (Wehrli).

Vgl. Fraser, Greek Personal Names; dieser nennt auch Leschaios Rhodos 4.Jh., Leschanoridas Tenedos 4./3.Jh.

39 Eretria: IG XII 9, 191 B 29; Thessalien: IG IX 2, 517,57; IG II/III ${ }^{2}$ 1956; Thespiai IG VII, 1888f 5; Kyrenaika: ZPE 20 (1976) 93; Bechtel, Personennnamen, 277f, der *Leschagoras als Ausgangsform der Kurznamen erschließt.

40 Vgl. Graf, Delphinios.

41 Samuel, Chronology, 81.83.86.135; vgl. Bischoff, RE XII 1568-1602.

42 IG V 2,3 = Schwyzer, nr.654 = LSCG 67,29f; "obscur" Chantraine, Dict. ét. Anlautendes F

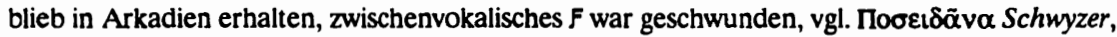
nr.657 gegen mykenisch po-se-da-wo. 
disch ist der vorausgesetzte Lautwandel kti >si. Es gibt einen anderen berühmten Fall, in dem ein mykenisch bezeugter Monatsname gerade in Arkadien weiterlebt, Lapatos. ${ }^{43}$ Wir werden also darauf geführt, mit einem Fest LeschaWanaktia in der griechischen Bronzezeit zugleich einen bronzezeitlichen Hintergrund für die Funktion der $\lambda \varepsilon \sigma \chi \alpha$ zu postulieren. Der Name Apollon selbst allerdings scheint eher nachmykenisch zu sein. ${ }^{44}$

Die Frage, worum es sich bei $\lambda \varepsilon \sigma \chi \alpha$ samt 'Mann' oder 'König' genauer handeln kann, wird so zur Projektion in eine sehr entfernte Epoche und damit, scheint es, zum Spiel der Phantasie. Immerhin ist wenn nicht $\lambda \varepsilon \sigma \chi \alpha$ so doch $\lambda \varepsilon \chi \chi O \varsigma$ das 'Bett' im Zusammenhang mit einem Fest im bronzezeitlichen Pylos direkt bezeugt. Es handelt sich um ein Fest 'Lechestroterion" (re-ke-to-ro-te-rijo), das 'Richten des Bettes'. 45

Dieses Wort ist nahezu identisch mit lateinisch lectisternium, einer Form der Götterbewirtung, die wir in Rom seit 399 v.Chr. finden. ${ }^{46}$ Es handelt sich aber bei den Wörtern doch wohl nicht um direkte Identität, was einen komplizierten Weg der Vermittlung postulieren heißt, sondern eher um Parallelbildungen nach gleichen Regeln von den gleichen Stämmen. Immerhin kann sich die Interpretation davon anregen lassen, muß freilich auch gleich die Unterschiede beachten: Die lecti in Rom sind Klinen, die für die Götter aufgestellt sind, mit Speisen ausgelegt; so lädt man die Götter zum Mahl. In der alten Zeit, der Bronzezeit zumal muß dagegen, wie gesagt, $\lambda \hat{\varepsilon} \chi 0 \varsigma$ ein Bett zum Liegen, zum Schlafen, zum Übernachten bezeichnen. Auf die Übernachtung eines fremden Gastes wies Etymologie und Verwendung in der Odyssee gerade für $\lambda \varepsilon \sigma \chi \eta$.

Natürlich ist mit dem mykenischen 'Bett' die Idee eines sogenannten HierosGamos-Rituals sofort aufgetaucht. Gösta Säflund hat in diesem Zusammenhang auch auf das Bett im 'Raum mit dem Lilienfresko' auf Thera, Xeste 1, verwiesen, gewiß ein suggestives Ambiente für ein Frühlings-Hochzeitsfest. Nach dem archäologischen Befund jedoch gehört das Bett nicht zum Kontext der Ausstattung dieses Raumes, ist sekundär über eine schon bestehende Aschen-

43 KN Fp 13, Docs. ${ }^{2}$ 305; zu mykenischen Monatsnamen Trümpy, Zeitangaben, 217-234.

44 Burkert, Griech.Rel., 225-233.

45 PY Fr 343 + 1217; Docs.579; Burkert, Griech.Rel., 84; Gérard-Rousseau, Mentions, 201-203; Trumpy, Zeitangaben, 214f.

46 Piso Fr.25 [in: Historicorum Romanorum Reliquiae ed. H. Peter I, Leipzig ${ }^{2} 1914$ 131] = Dion.Hal.ant.12,9 (der lectisternia mit $\sigma \tau p \omega \mu v \alpha$ übersetzt), danach Liv.5,13,6, vgl. 22,10,9; Latte, Religionsgeschichte, 242-244; Ogilvie, Comm. 655; Milani, Lectisternium, möchte eine direkte Übernahme des Wortes von Mykene via Cumae nach Italien annehmen. Darstellung eines lectisternium auf einer etruskischen Wandmalerei: Messerschmidt, Untersuchungen. -

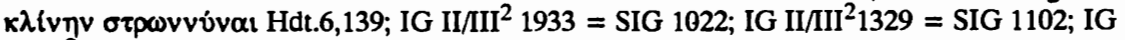
II/III' 676,14; 1934. 
schicht geraten oder gestellt worden. ${ }^{47}$ Es gibt aber anderwärts im minoischen Kreta einige Räume, die man als Übernachtungsräume, mit einem Bett, verstehen kann, so in Haghia Triada ${ }^{48}$ und in Tylissos ${ }^{49}$; Säflund hat auch auf sie schon hingewiesen. Damit wäre man freilich im minoischen Bereich, jenseits der griechischen Sprache, der $\lambda \varepsilon \sigma \chi \alpha$ doch angehört. Und doch - die griechische Tradition spricht von den Koı $\mu \eta \tau \eta ́ p l \alpha$ gerade auf Kreta.

Vom römischen lectisternium her wird man zunächst einmal auf Rituale der 'Götterbewirtung' geführt. Nun ist gerade die 'Einkehr von Göttern', die sich gastlich aufnehmen lassen, ein Motiv, das Palästina, Kleinasien und Griechenland besonders eng verknüpft. In der Keilschriftliteratur finden sich bisher offenbar keine genauen Parallelen - dort kehren die Götter eher beieinander ein und lassen sich großartig bewirten. "Wenn ihr vom Apsu zur Götterversammmlung geht, werdet ihr in Esharra über Nacht bleiben", stellt Marduk im Enuma eliš fest, indem er die Kultanordnungen trifft (V 125-128, cf. VI 52f); der Name Babylon, 'Tor der Götter', wird so gedeutet. Dem gegenüber steht das Motiv von der Wanderung der Götter incognito, die so die Menschen prüfen. ${ }^{50}$ Die homerische Odyssee spricht davon $(17,485 f):$ "Götter, Fremden gleichend, in mannigfacher Gestalt kommen in die Städte, der Menschen Übermut oder Rechtlichkeit überwachend." Aufnahme, Bewirtung, Übernachtung gehören üblicherweise zusammen. ${ }^{51}$ Modellhaft unter den ausführlichen Erzählungen des Typs ist die Geschichte von Philemon und Baucis bei Ovid; sie ist in Kleinasien lokalisiert; Philemon ist offenbar griechisch als der 'Bewirter' gemeint. ${ }^{52}$ Die bekannteste alttestamentliche Entsprechung ist der Besuch der geheimnisvollen Drei bei Abraham im Hain Mamre (Gen 18); dieser Besuch

47 Saflund, Beds, 44-46, siehe aber Marinatos, Excavations IV, 24 (cf. 41 f): "The legs of the bed were about $10 \mathrm{cms}$ above the floor of the room" (diesen Hinweis verdanke ich Nanno Marinatos). - Für orientalische Hieros-Gamos-Rituale vgl. Reallexikon der Assyriologie s.v. Ein ganz neuer Text über die Einsetzung einer Priesterin des Wettergottes, die in den Tempel zum "Bett' des Gottes gefurt wird, aus Emar: Arnaud, Textes, 326-337, nr. 369. Die altere Dissertation von Klinz, Hieros Gamos ist nur noch bedingt brauchbar.

Villa A, Spătminoisch I, Watrous, Ayia Triada, 125: Raum mit Bănken, Reste von Mahlzeiten und Geschirr, Nische mit Podium für Bett; vgl. Pernier / Banti, Festos II, 169; Graham, Palaces, 92.213; Marinatos / Hägg, Polythyron, 69f.

Säflund, Beds, 48, fig..9, nach Graham, Palaces, fig.20: Ein monumentales Gebăude, spătminoisch I, ein Raum mit einem erhöhten Podium, offenbar für ein Bett.

50 Dazu Flückiger-Guggenheim, Göttliche Gaste; Fontenrose, Philemon, zieht die Parallelen, insistiert aber zu sehr auf dem Zusammenhang mit der Sintflut. - Es gibt freilich auch eine Parallele aus Peru, Flückiger-Guggenheim, Göttliche Găste, 159,1.

51 Vgl. etwa Aischylos Cho.668-71.

52 Ov. Met. 8,618-724. Das 'Heiligtum am See', das übrigbleibt, könnte das hethitische Heiligtum von Eflatum Pinar bei Beyșehir sein, Flückiger-Guggenheim, Gơttliche Gäste, 174, Anm. 10; Akargal / Hirmer, Hethiter, T. XXI. 
führt zur Geburt des Sohns und Erben. In der Fortsetzung sind es zwei 'Engel', die bei Lot in Sodom 'übernachten' (Gen.19), die Gerechten von den Verdammten scheiden. ${ }^{53}$ Besonders eigentümlich unter den griechischen Varianten ist die Einkehr der drei Götter bei Hyrieus, die auf unappetitliche Weise Orion erschaffen - man hat das seit langem besonders mit der Abraham-Geschichte zusammengestellt. ${ }^{54}$

Die Erzählungen von der Göttereinkehr haben ihr Gegenstück ganz offenbar in Ritualen sakraler Gastlichkeit. Am auffälligsten ist dabei, was Paulus und Barnabas in dem gar nicht so weit von Philemon und Baucis abgelegenen Ort Lystra geschah: Paulus wurde samt Barnabas als Gott empfangen, als Hermes und Zeus (Apg.14,8ff). ${ }^{55}$ Die eigentliche Erklärung für solches Verhalten gibt der Bericht von Piso-Livius über das erste lectisternium in Rom: "Wer von Fremden gerade anwesend war, den nahmen sie (ins Haus zum Gastmahl) auf"; "offen standen die Häuser Tag und nacht, und ungehindert trat in sie ein, wer wollte". ${ }^{56}$ Man pflegt also in der Tat an solch einem Tag irgend einen Fremden, der vorbeikommt, ins Haus zu Tisch zu laden: Ist er vielleicht ein Gott?

Sofern eine Stadt ein Übernachtungszimmer hat - und sofern man griechisch spricht -, erwächst aus solchem Zusammenhang eine sehr präzise Rolle für einen 'Mann in der $\lambda \varepsilon \sigma \chi \alpha$ ', ja einen 'Herrscher der $\lambda \varepsilon \sigma \chi \alpha$ ' für diesen Tag. Für die Feste oder jedenfalls Monatsnamen Leschanorios, Leschanasios ergibt sich damit ein plausibler, ja ein überzeugender Sinn, der auch den Gesetzen der griechischen Wortbildung entspricht. ${ }^{57} \mathrm{Zu}$ erwähnen ist in diesem Zusammenhang immerhin, daß es einige weitere Zeugnisse gibt für Veranstaltungen mykenischer 'Gastlichkeit': Auf einer Tafel aus Pylos wird etwas

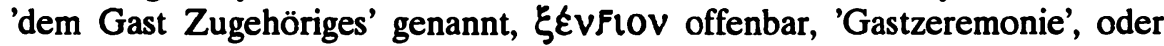
'Gastgeschenk', es ist offenbar für 'Potnia und die Dipsioi' bestimmt, po-ti-ni-ja

53 In der vorliegenden Fassung gehen die gottlichen Gasste noch am gleichen Tag von Abraham nach Sodom; sie übernachten erst dort und darum nicht bei Abraham.

54 Euphorion Fr.101 Powell bei Schol. Il.18,486 u.a.m., Übersicht bei Flückiger-Guggenheim, Gơttliche Gäste, 210.

55 In gewissem Maß vergleichbar ist, wie der Ich-Erzăhler bei Apuleius in ein Risus-Fest einbezogen wird, Met.2,31-3,11.

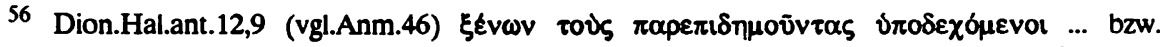
Liv.5,13,6 tota urbe patentibus ianuis promiscuoque usu rerum omnium in propatulo posito notos ignotosque passim advenas in hospitium ductos.

57 Es handelt sich am ehesten um ein 'Ableitungskompositum', vgl. dazu Risch, Komposita, 23,

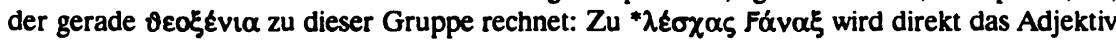
* $\lambda \varepsilon \sigma \chi \alpha$ favódoros gebildet, entsprechend $\lambda \varepsilon \sigma \chi \alpha v o ́ p l o s$. Setzt man dagegen * $\lambda \varepsilon \sigma \chi \alpha \dot{v} \omega \omega$ als primăr an, wăre an ein Possessivkompositum zu denken: 'wer Manner (oder einen besonderen Mann) in der $\lambda \varepsilon \sigma \chi \alpha$ hat'; entsprechende Bedeutung und Ableitung ergäbe sich für * $\lambda \varepsilon \sigma \chi \alpha$ Favóorog. Für Beratung zum Wortbildungsproblem habe ich Michael Meier-Brügger und Cathérine Trümpy zu danken. 
di-pi-si-jo-i ke-se-ni-wi-jo (PY Fr 1231.l); damit steht eine Form der Götterbewirtung fürs mykenische Pylos fest. In Knossos ist das wohl gleiche Wort mit 'Gewändern' (pa-we-a) verbunden. Es gibt dazu allerdings vielerlei einander widerstreitende Interpretationen. ${ }^{58}$

Man kann von hier aus auch auf den 'Hieros Gamos' zurückkommen: Zur rechten Gastfreundschaft gehört weitum ja auch die Bereitstellung einer Bei-

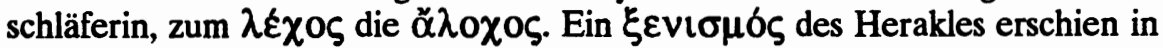
der Stiftung aus Kos; in Rom gibt es die Geschichte von Acca Larentia, die bei solcher Gelegenheit dem Hercules als scortum zugeführt wurde (RML I 2294f). Im süditalischen Temesa pflegte man einem 'Heros' alljährlich in seinem 'Tempel' (naos) eine Jungfrau zu überlassen, bis der Boxer Euthymos dem Brauch ein Ende machte (Paus.6,6,7-11; nach 462 v.Chr.). In Griechenland erzählt man, daß Dionysos, als er bei Ikarios einkehrte, mit Ikarios' Tochter Erigone schlief (Ov.met.6,125). Zu erinnern ist vielleicht nochmals an Paulus in Lystra: Wenn Zeus mit Hermes auf Wanderschaft geht, ist er dann nicht auf ein Abenteuer à la Alkmene aus? Wichtiger ist eine Geschichte über die Einkehr der Dioskuren im 'Haus des Tyndareos' aus Sparta, über ein 'Haus' im Heiligtum von Hilaeira und Phoibe: Als dort Phormion wohnte, kamen die Dioskuren in Gestalt fremder Gäste und forderten Aufnahme als in ihr eigenes ursprüngliches Haus; Phormion stellte ihnen das Haus zur Verfügung, mit Ausnahme eines Raums, wo seine jungfräuliche Tochter hauste; am Morgen waren Gäste und Mädchen verschwunden, Silphionstengel lagen auf einem Tisch, Emblem der Dioskuren-Theoxenia (Paus. 3,16,2f; vgl. RE XX 536f). Wir finden also in Sparta theoxenia und lechestroteria in Verbindung mit einer Art von gamos, und zwar in dem eher vordorischen Bereich des Dioskurenkultes. 59

Dies ist alles kein Beweis für das, was in der Bronzezeit Brauch war, aber immerhin Umriß einer Möglichkeit, in der die $\lambda \varepsilon ́ \sigma \chi \alpha$ als öffentliche Einrichtung eine besondere Funktion haben konnte und leschanorios/leschanasios seinen Sinn erhält.

Um zusammenzufassen: Sicher ist, daß $\lambda \hat{\varepsilon} \sigma \chi \alpha$ etwas sehr Altes ist, überaus wahrscheinlich ist, $\mathrm{da} \beta$ es sich um eine schon bronzezeitliche Institution und Bezeichnung handelt, insofern $\lambda \varepsilon \sigma \chi \alpha$ mit einem Wanax zu tun hat. Sofern man die Ableitung vom Stamm $\lambda \varepsilon \chi$ - 'liegen' nicht bestreitet, wird dies am

58 Gérard-Rousseau, Mentions, 61-64, 129-131; Aura Jorro / Adrados, Diccionario Micénico, I $353 f$.

59 Man hat auch darauf hingewiesen, wie merkwürdig rasch homerische Könige bereit sind, ihre Tochter einem Fremden zu vermăhlen, Il.6,190ff, Od.7,313ff; Vernant, Société, 75f (nach Gernet). 
ehesten mit einem Ritual der Göttereinkehr, vielleicht mit einem HierosGamos-Ritual zu tun haben im Rahmen eines $\lambda \varepsilon \chi \varepsilon \sigma \tau \rho \omega \tau \eta ́ p$

Der Zusammenhang mit hebräisch liskah ist damit nicht einfacher geworden, im Gegenteil. Die Überlegungen mit Leschanorios/Leschanasios haben eher weggeführt von der "lateral chamber or building built into or near the wall surrounding the courtyard" (Ottoson) im Heiligtum. Was damit direkt zu korrespondieren schien, die Lesche der Knidier in Delphi, ist in dieser Form eher ein Einzelfall. Die praktische Identität des Wortes hebräisch wie griechisch und immerhin eine gewisse Berührung in der Semantik bleiben trotzdem suggestiv. Die Chance eines zufälligen Kling-Klang-Gleichklangs ist nicht ganz auszuschließen, aber als die simpelste Lösung alles andere als befriedigend.

Falls ein Zusammenhang vorliegt, kann es sich jedenfalls nicht - was man sonst gern akzeptieren würde - um eine Entlehnung vom Semitischen ins Griechische aus der 'orientalisierenden Epoche' handeln, in der doch im übrigen mit vielem anderen aus den syrisch-anatolischen Bereichen auch der Tempelbau, die Idee des Tempels als des 'Hauses' des Kultbildes nach Griechenland gekommen ist. Die Opfermahlhäuser und Übernachtungshäuser sind davon unabhängig und offenbar viel älter.

Man kann statt dessen an einen Kontakt in der mykenischen Epoche denken, wobei zunächst der Gedanke an Ugarit naheliegt; dort gibt es ja viele eindrucksvolle mykenische Fundgegenstände, die enge Handelsbeziehungen zur Gewißheit machen. Dabei ist Ugarit kein Einzelfall. Es gibt mykenische Keramik, ja eine mykenische Statuette auch im spätbronzezeitlichen Tempel von Kamid el-Loz, ${ }^{60}$ es gibt Mykenisches auch in Beth-Shan.

Ernsthaft zu überlegen ist vielleicht eine dritte Möglicheit, Kontakte gerade in der 'dunklen' Epoche der Wanderungen, und zwar über die Philister. Die Philister sind ja, nach der schriftlichen Tradition wie nach dem archäologischen Befund, eines der 'Seevölker', sie haben ganz offenbar einen Ableger ägäischer Kultur im 12. Jh. nach Palästina gebracht. ${ }^{61}$ Nun tauchen die lešakoth gerade im Bereich von Samuel und Saul auf, und kultische Gemeinsamkeiten mit den Philistern - die Dagan verehren und die Bundeslade aufstellen möchten bestehen durchaus, auch wenn unsere Texte auf dem Kontrast zwischen Jahwe und den Philistern insistieren. Ein 'männerbündischer' Hintergrund, der den griechischen $\lambda \varepsilon \sigma \chi \alpha$ l zugeordnet schien, würde sich in die Philisterwelt recht wohl einfügen.

In diesem Zusammenhang sei noch an eine merkwürdige Geschichte aus dem Philisterbereich erinnert, an Simsons erste Hochzeit mit dem Philistermädchen von Timnat. Die Art der Feier war für den Erzähler selbst fremdartigaltertümlicher Art (Richter 14): Simson feiert sieben Tage lang im Ort der Phi-

Hachmann, Kamid el-Loz 1968-1970, 88f, T.26/27.

61

Vgl. Dothan, Philistines. 
lister, indem er dort tagsüber beim Gelage sitzt, beim 'Trinken', mit 30 'Freunden' (mere ‘im) der Philistergemeinde, denen er sein Rätsel vom Löwen und vom Honig aufgibt; in der Nacht schläft er offenbar mit seiner jungen Frau, die ihm dabei schließlich mit viel Tränen die Lösung des Rätsels entlockt. Welches ist der Ort der Intimität? Das Haus des Brautvaters - die Dorfgenossen drohen das Mädchen samt Vater zu verbrennen $(14,15)$ - oder doch ein separates Brautgemach? Die Zechgenossen sagen ihm schließlich die Lösung des Rätsels, 'ehe er in die Kammer ging' $(14,18)$ - dieser Text ist konjiziert, hachadrah statt unverständlichem hacharsah. ${ }^{62}$ Ich werde dafür nicht halliškah vorschlagen. Doch ein lechestroterion für den fremden Bräutigam in der Philisterstadt ist auf jeden Fall vorausgesetzt. Die Erzählung braucht genau die Organisation, die

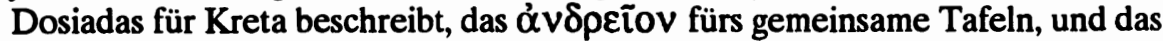
Koı $\mu \eta \tau \eta ́ p ı v$. Ist es Zufall, daß - jedenfalls nach der einen Tradition - die Philister aus Kreta gekommen sein sollen (Ri 16,25; Jer 47,4; Am 9,7; Ze 2,5)? $\mathrm{Da}$ sie griechisch sprachen, möchte ich aber auf keinen Fall behaupten. Aber vielleicht sollte man doch das $\beta \omega \mu$ ós-Problem unter dem gleichen Gesichtspunkt mit einbeziehen: Hängt beides sogar zusammen, geht es letzlich um den Typ des kretischen Höhenheiligtums mit seinem Nebengebäude?

Das Fragezeichen wird bestehen bleiben. $\mathrm{DaB}$ die Philister griechische Kulttermini aus Kreta ans Alte Testament vermittelt haben, bleibt immerhin eine Möglichkeit - die den einen einleuchten, anderen als abenteuerlich erscheinen wird. Das Spiel des Kling-Klang ist, wie gesagt, nicht auszuschließen. Im Grunde ist es wohl wichtiger, daß die etwas verschlungenen Wege entlang den Weisungen der Etymologie und der Belege vielerlei Ausblicke auf lebendige, farbige Details des religiösen Lebens aufgezeigt haben und dabei immer wieder vergleichbare Strukturen in den Blick rücken, auch wenn wir den Punkt des eigentlichen, auch sprachlichen Kontakts nicht definitiv festlegen können.

62 HAL 281 und 341. - Für wichtige Hinweise danke ich Peter Frei und Fritz Stolz. 


\section{Bibliographie}

Akurgal, E. / Hirmer, M., Die Kunst der Hethiter, München 1972

Albright, W.F., Archaeology and the Religion of Ancient Israel, Baltimore 1946

Amadasi Guzzo, M.G., Sacrifici e banchetti: Bibbia ebraica e iscrizioni puniche, in: C. Grottanelli

/ N.F. Parise, Sacrificio e società nel mondo antico, Rom 1988, 97-122

Amaud, D., Emar. Recherches aux pays d' Aštata VI 4: Textes sumériens et accadiens, Paris 1987 Aura Jorro, F. / Adrados, F.R., Diccionario Micénico, Madrid 1985

Banti, $L . \rightarrow$ Pernier, $L$.

Baumgartner, $W . \rightarrow$ Koehler, $L$.

Bechtel, F., Die historischen Personennamen des Griechischen bis zur Kaiserzeit, Halle 1917

Bergquist, B., The Archaic Greek Temenos. A Study of Structure and Function, Lund 1967

- Heracles on Thasos, Uppsala 1973

- Was there a dining-room, sacred or civic, on the acropolis of Acquarossa?, OpRom 9 (1973) 21-34

Bischoff, $H$., RE XII 1568-1602

Börker, Ch., Festbankett und griechische Architektur, Konstanz 1983

Bourguet, E., Lesche $\rightarrow$ Daremberg / Saglio, Dictionnaire III 2, 1103-1107

Brown, J.P., The Mediterranean Vocabulary of the Vine, VT 19 (1969) 146-170

- The Sacrificial Cult and its Critique in Greek and Hebrew (II), JSSt 25 (1980) 1-21

Burkert, W., Griechische Religion der archaischen und klassischen Epoche, Stuttgart 1977

- Structure and History in Greek Mythology and Ritual, Berkeley 1979

- Die orientalisierende Epoche in der griechischen Religion und Literatur, Sitzungsberichte der Heidelberger Akademie der Wissenschaften, Phil.-hist.Kl. 1984,1

Busink, ThA., Der Tempel von Jerusalem. Von Salomo bis Herodes I/II, Leiden 1970/80

Chadwick, J. / Killen, J.T. / Olivier, J.P., The Knossos Tablets, Cambridge ${ }^{3} 1971$

Chantraine, $P$., Dictionnaire etymologique de la langue grecque, Paris 1968-1980

Crain M., Uber die Bedeutung und Entstehung des Namens $\Pi \varepsilon \lambda \alpha \sigma \gamma o f$, Philologus 10 (1855) $577-590$

Curtius, G., Das Verbum in der griechischen Sprache I, Leipzig ${ }^{2} 1877$

Daremberg, Ch. / Saglio, E., Dictionnaire des antiquités grecques et romaines, Paris 1877-1917

Davies, M., Epicorum Graecorum Fragmenta, Gơttingen 1988

Deneken, $F$., De Theoxeniis, Berlin 1881

Dentzer, J.M., Le motif du banquet couché dans le Proche Orient et le monde grec du VIIe au

IVe siecle avant J.-C., Rom 1982

Dothan, T., The Philistines and their material culture. New Haven / London 1982

$-\rightarrow$ Gitin $S$.

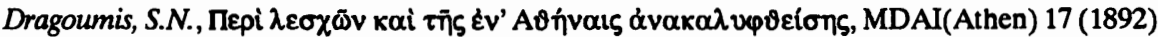
147-155

Drerup, H., Griechische Baukunst in geometrischer Zeit (Archaeologia Homerica II O), Gottingen 1969

Dümmler, F., Delphika, Basel 1894 = ders., Kleine Schriften II, Leipzig 1901, 125-154

Fehr, B., Orientalische und griechische Gelage, Bonn 1971 
Fluckiger-Guggenheim, D., Gottliche Gäste. Die Einkehr von Gottern und Heroen in der griechischen Mythologie, Bern 1984

Fontenrose, J., Philemon, Lot and Lycaon, University of California Publications in Classical Philology 13 (1945) 93-119

Fohrer, G., Ezechiel (HAT I/13), Tübingen 1955

Fraser, P.M. (ed.), A Lexicon of Greek Personal Names I, Oxford 1987

Frisk, H., Griechisches Etymologisches Wörterbuch, Heidelberg 1954-1970

Gallavotti, C. / Sacconi, A., Inscriptiones Pyliae ad Mycenaeam aetatem pertinentes, Rom 1961

- Scrittura arcaiche della Sicilia e di Rodi, Helikon 15/16 (1975/6) 76f

Galling, $K$, Biblisches Reallexikon (BRL ${ }^{2}$ ), Tübingen 1977

Gérard-Rousseau, M., Les mentions religieuses dans les tablettes mycéniennes, Rom 1968

Gese, H. / Höfner, M. / Rudolph, K, Die Religionen Altsyriens, Altarabiens und der Mandăer, Stuttgart 1970

Gitin, S. / Dothan, T., The Rise and Fall of Ekron of the Philistines, BA 50 (1987) 197-222

Graf, F., Apollon Delphinios, Museum Helveticum 36 (1979) 2-22

Graham, J.W., The Palaces of Crete, Princeton 1962

Gruben, G., Die Tempel der Griechen, München ${ }^{3} 1984$

Hachmann, $R$. Bericht über die Ergebnisse der Ausgrabungen in Kamid el-Loz in den Jahren 1968-1970 (Saarbrücker Beiträge zur Altertumskunde 22), Bonn 1980

- Bericht uber die Ergebnisse der Ausgrabungen in Kamid el-Loz in den Jahren 1971-1974 (Saarbrücker Beiträge zur Altertumskunde 32), Saarbrucken 1982

Hägg, $R \rightarrow \rightarrow$ Marinatos, $N$.

Haran, M., Temples and Temple-Service in Ancient Israel, Oxford 1978

Herzog, R. Heilige Gesetze von Kos, Berlin ${ }^{6} 1928$

Höfner, $M$. $\rightarrow$ Gese, $H$.

Hoftijzer, J., Religio Aramaica, Leiden 1968

$-\rightarrow$ Jean, C.F.

Horovitz, Th, Vom Logos zur Analogie, Zürich 1978

Jean, C.F. / Hoftijzer, J., Dictionnaire des inscriptions sémitiques de l'ouest, Leiden 1965

Jeffery, L.H., The Local Scripts of Archaic Greece, Oxford 1961, ${ }^{2} 1990$

Judeich, W., Topographie von Athen, München ${ }^{2} 1931$

Karetsou, A., The Peak Sanctuary of Mt. Juktas, in: R. Hägg, N. Marinatos, Sanctuaries and Cults in the Aegean Bronze Age, Stockholm 1981, 137-153

Kautzsch, E., Die Apokryphen und Pseudepigraphen des Alten Testaments I/II, Tübingen 1900

- Die Heilige Schrift des Alten Testaments übersetzt, Tubingen ${ }^{4} 1922 / 23$

Kern, O., Inscriptiones Graecae, Berlin 1913

Klein, E., A Comprehensive Etymological Dictionary of the Hebrew Language, Jerusalem 1987

Klinz, A., 'Iepós róuos, Diss. Halle 1933

Koehler, L. / Baumgartner, W., Hebräisches und aramaisches Worterbuch zum Aiten Testament, 3. Auflage: fasc.I-III, Leiden 1967, 1974, 1983 (HAL)

Krummen, E., Pyrsos Hymnon, Festliche Gegenwart und mythisch-rituelle Tradition als Voraussetzung einer Pindarinterpretation, Berlin 1990

Latte, $K$, Römische Religionsgeschichte, München 1960

Laum, B., Stiftungen in der griechischen und römischen Antike, Leipzig 1914 
Lewy, H., Die semitischen Fremdwörter im Griechischen, Berlin 1895

- Griechische Etymologien, ZVS 55 (1928) 24-32

Marinatos, N. / Hadgg, R., On the ceremonial Function of the Minoan Polythyron, Op.Ath. 16,6 (1986) 69f

Marinatos, S., Excavations at Thera IV, Alhen 1971

Meissner, B., Babylonien und Assyrien I/II, Heidelberg 1920/5

Meister, $R$., Die griechischen Dialekte II, Gottingen 1889

Messersclumidt, F., Untersuchungen zur tomba del letto funebre in Tarquinia, Stud.Etr. 3 (1929) 519-524

Meuli, K, Gesammelte Schriften, Basel 1975

Meyer, E., Geschichte des Altertums I 2, Stuttgart ${ }^{2} 1913$

Milani, C., Osservazioni su lat. lectisternium, Rend.Ist.Lomb. 110 (1976) 231-242

de Moor, J.C., An Anthology of Religious Texts from Ugarit, Leiden 1987

von Milller, I., Dic griechischen Privataltertüner. Handbuch der klassischen Alterthumswissenschaft IV 1,2 (2. Auti.), Nördlingen 1893

Ogilvie, R.M., A Commentary on Livy, Books I-V, Oxford 1965

Ottoson, M., Temples and Cult Places in Palestine, Uppsala 1980

- Sacrifice and Sacred Meals in Ancient Isracl, in: Gifts to the Gods ed. T. Linders / G. Nordquist, Uppsala 1987, 133-136

Pernier, L. I Banti, L., Il pälazzo minoico di licstos II, Rom 1951

Pott, A.F., Latein und Gricchisch in einigen ihrer wichtigsten Lautunterschiede, ZVS 26 (1883) 113-142

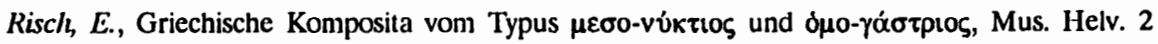
(1945) $15-27$ = ders., Kleine Schriften, Berlin 1981, 112-124

Rudolph, $K \rightarrow$ Gese, $I$.

Rutkowski, B., The Cult Places of the Aegean, New Haven 1986

Safflund, G., Sacrificial Banquets in the 'Palace of Nestor', Opuscula Atheniensia 13,6 (1980) 237-246

- Beds of the Nymplee, Opuscula Romana 13,3 (1981) 41-56

Sacconi, $A$. $\rightarrow$ Gallavotti, $C$.

Saglio, E. $\rightarrow$ Daremberg, $C h$.

Sainuel, A.E., Greek and Roman Chronology, München 1972

Schober, F., Delphoi, in: RE Suppl.V 140

Schrader, $O$., Linguistisch-historische Forschungen zur Handelsgeschichte und Warenkunde, Jena 1886

- Sprachvergleichung und Urgeschichte, Jena ${ }^{2} 1890$

Schwyzer, E., Dialectorum Graecarum exempla epigraphica potiora, Leipzig 1923

- Griechische Granmuatik I, München 1939

Selivanov, S., Inscriptiones Rhodiae ineditac, MDAI (Athen) 16 (1891) 107-126

Simith, W.R., Lectures on the Religion of the Semites, Edinburgh $1889 /{ }^{2} 1894$

Sokolowski, F., Lois sacrées des cités grecques, Paris 1969

Soggin, J.A., Judges. A Commentary, London 1981

Siarcky, J., Salles de banquets ritucls dans les sanctuaires orientaux, Syria 26 (1949) 62-67

Stolz, F., Das erste und zwcitc Buch Samucl, Zürich 1981 
Streck, M., Assurbanipal und die letzten assyrischen Könige bis zum Untergange Niniveh's, Leipzig 1916

Tichy, E., Semantische Studien zu idg. 1 *deik "zeigen" und dejîk "werfen", Münchner Studien zur Sprachwissenschaft 38 (1979) 171-228

Trumpy, C., Nochmals zu den mykenischen Fr-Tafelchen. Die Zeitangaben innerhalb der Pylischen Oelrationenserie, SMEA 27 (1989) 217-234

Vernant, J.P., Mythe et société en Grèce ancienne, Paris 1974

Wackernagel, J., Miszellen zur griechischen grammatik, ZVS 33 (1895) 1-62 = ders., Kleine Schriften I, Gottingen 1953, 680-741

Wahrmann, P., Literaturbericht für das Jahr 1926, Glotta 17 (1929) 191-271

Watrous, L.V., Ayia Triada. A new Perspective at the Minoan Villa, AJA 88 (1984) 123-134

von Wilamowitz-Moellendorff, U., Pindaros, Berlin 1922

Yavis, C.G., Greek Altars. Origins and Typology including the Minoan-Mycenaean Offertory Apparatus, St.Louis 1949 


\section{Die Bellerophontessage und das Alte Testament}

Zwischen dem westlichen Kleinasien der ersten Hälfte des 1. Jahrtausends v.Chr. und dem Alten Testament sind die Verbindungen offensichtlich eher locker, ja beinahe oder völlig sagenhaft. Meist sind es nicht mehr als wenig aussagekräftige Namensnennungen, die - nicht zufällig - mit dem Lyderreich, der einzigen wirklichen regionalen Grossmacht vor dem 5. Jahrhundert, zusammenhängen. So werden die Lyder selber als Lüdìm, bzw. Lüd an verschiedenen Stellen des Alten Testaments erwähnt, und ihre Hauptstadt Sardes begegnet als Sephārd bei Obadja ${ }^{1}$. Nur ihr König Gyges tritt als handelnde Gestalt auf, als Gōg bei Ezechiel, allerdings in einer massiven Verzerrung, die mehrere Zwischenstationen der Überlieferung voraussetzt.

Es existiert, soweit ich sehe, nur ein einziges erzählendes Dokument, das die hier interessierende Thematik berührt, die aus der griechischen Überlieferung bekannte und von dieser teilweise ins südwestkleinasiatische Lykien verlegte Bellerophontessage. Sie enthält gleich zwei Motive, die auch das Alte Testament kennt, nämlich die - vom Alten Testament aus gesprochen - Potiphargeschichte (Gen 39) und die Geschichte vom Uriabrief (2 Sam 11). Die Verdichtung der Gemeinsamkeiten in Story und Plot dieser Texte ist schon immer aufgefallen, aber ihren gegenseitigen Beziehungen ist, wie es scheint, noch nie jemand im einzelnen nachgegangen ${ }^{2}$.

Im folgenden soll der Versuch unternommen werden, die Natur dieser Beziehungen so genau wie möglich zu umschreiben und festzulegen. Das kann natürlich nicht ohne Hypothesenbildung geschehen, aber Hypothesenbildung ist immer nützlich; sie liefert oft die Voraussetzungen, welche es erlauben, durch ein antithetisches Verfahren komplexe Tatbestände zu erfassen. Zudem stellen sich methodische Probleme, die ein allgemeineres Interesse für sich in Anspruch nehmen können.

Zunächst haben wir uns um die Quellenkritik zu bemühen. Für beide Fälle ist dies recht schwierig, denn bei der einen wie der andern Erzählung sind die literaturgeschichtlichen Voraussetzungen im ganzen wie im einzelnen ebenso verwickelt wie dunkel. Der Bearbeiter muss seinen Standpunkt oft fast im Sinne eines Glaubensbekenntnisses umreissen. Dennoch bleibt kein Weg, der

1 Vgl. dazu von asianistischer Seite die Ausführungen von Asheri, Ellenismo, 35, der mit einer jüdischen Emigration aus Jerusalem nach Lydien rechnet.

2 Einen Gesamtüberblick über die motivischen Gemeinsamkeiten der griechischen Überlieferung und des Alten Testaments bietet Baumgartner, Sagenbeziehungen. Über die Uria-Geschichte bes. $18 \mathrm{f}=164 \mathrm{f}$. Baumgartner rechnet die Uria-Geschichte zu den Sagen und Sagenmotiven, die an verschiedenen Orten aus gleichen Voraussetzungen heraus entstanden sein können, ohne dass sich ein historischer Zusammenhang ganz ausschliessen liesse, vgl. aaO $21 \mathrm{f}=167 \mathrm{f}$, $28=174$. 
daran vorbeiführt, wenn das Verhältnis der Geschichten überhaupt fruchtbar betrachtet werden soll.

Ich beginne mit der Bellerophontessage, von der wir auszugehen haben, da sie die im Alten Testament getrennten Motive vereinigt. Ich durchgehe zunächst den Inhalt und zwar nach der ältesten und wichtigsten Quelle, die wir besitzen, der Ilias Homers ${ }^{3}$.

Vorausgeschickt sei, dass die in Südwestkleinasien wohnenden Lykier unter den Verbündeten der Trojaner an erster Stelle stehen. Ihr Führer Sarpedon gehört zu den glanzvollsten Kämpfern der trojanischen Seite.

Die Geschichte selbst wird im 6. Buch in den Versen 152-210 erzählt und dort Glaukos, dem Vetter Sarpedons, in den Mund gelegt. Glaukos und der Grieche Diomedes sind einander im Kampf begegnet. Nach einer auch sonst bezeugten Sitte geben sie sich zunächst gegenseitig Auskunft über ihre Herkunft und ihre Abstammung. Dabei entdecken sie Verbindungen, die zwischen ihren Vorfahren bestanden, und daraufhin trennen sie sich in Frieden unter Austausch von Geschenken. Die Szene ist als solche wahrscheinlich vom Dichter der Ilias frei erfunden und gestaltet. Der Bericht des Glaukos über seinen Ahnen Bellerophontes hat also zweifellos eine unmittelbare Funktion innerhalb des 6. Buches, darüber hinaus aber ist er unentbehrlich im Rahmen der Gesamtilias: er orientiert den Hörer zugleich über die Genealogie Sarpedons, der kurz vorher durch seinen Sieg über Tlepolemos ${ }^{4}$ eine erste Aristie erlebt hat.

Wir erfahren, dass Bellerophontes, auf den sich die vor Troja kämpfenden lykischen Führer zurückführen, aus dem im innersten Winkel der Argolis gelegenen Ephyra stammte und der Nachkomme des Sisyphos, des klügsten aller Menschen, war. Auf eine nicht erzählte Weise gelangte er an den Hof und unter die Herrschaft des offenbar irgendwo in jener Gegend regierenden Königs Proitos. Darauf lernen wir als erstes Agens der Entwicklung das Potipharmotiv kennen: Anteia, die Gattin des Proitos, verliebte sich in den jungen Mann. Sie konnte ihn allerdings nicht verführen, verleumdete ihn aber bei ihrem Gatten. Dieser geriet in Zorn, wagte es zwar nicht, Bellerophontes zu töten, doch schickte er ihn zum König von Lykien, seinem Schwiegervater. Es folgt das Uriamotiv: Proitos gab Bellerophontes 'schlimme Zeichen' mit, indem er auf ein gefaltetes Täfelchen viel Verderbliches schrieb. Der Vertriebene gelangte nach Lykien und wurde dort vom König gut aufgenommen. Nach neuntägiger Bewirtung wollte dieser schliesslich die 'Zeichen' sehen, die ihm Proitos mitgegeben habe. Als er 'das schlimme Zeichen' seines Schwiegersoh-

3 Eine ausführliche Interpretation des Ganzen findet sich bei Heubeck, Schrift, 128ff. In den Hauptzügen geht die im folgenden vertretene Auffassung in die gleiche Richtung. Auf Ubereinstimmungen und Abweichungen im einzelnen ist nicht besonders hingewiesen.

$4 \quad 5(\mathrm{E}), 628-669$. 
nes erhalten hatte, gab der König seinem Gast zunächst den gefährlichen Auftrag, die Chimaira, das feuerschnaubende Wesen, das vorne Löwe, hinten Schlange und in der Mitte Ziege war, umzubringen. Bellerophontes löste die Aufgabe im Vertrauen auf die Wunderzeichen der Götter. Dann kämpfte er gegen die Solymer, die östlichen Nachbarn der Lykier, und tötete die Amazonen. Als er überall siegreich geblieben war, legte der König ihm einen Hinterhalt, aber auch dabei kam Bellerophontes davon. Aus all dem erkannte der Herrscher schliesslich die göttliche Abstammung des jungen Helden. Er behielt ihn bei sich und gab ihm seine Tochter zur Frau. Bellerophontes wurde Mitregent und wohl auch Nachfolger, zog sich dann aber den Zorn der Götter zu und starb in der Einsamkeit. Sein Sohn Isandros blieb offenbar ohne Nachkommen, die Tochter Laodameia wurde von Zeus die Mutter des Sarpedon, der dritte Nachkomme, Hippolochos, ist der Vater des Glaukos. Isandros und Laodameia kamen um, Hippolochos ist offenbar noch am Leben.

Die literarische Analyse scheint für die Bellerophontes-Erzählung folgendes zu ergeben. Man wird nicht daran zweifeln, dass der Dichter der Ilias eine Geschichte reproduzierte, deren Inhalt und Verlauf als solche bereits feststanden. Das heisst in jener Zeit, dass sie ihrerseits Thema eines Epos gewesen waren, dessen Kenntnis der Dichter bei seinen Hörern voraussetzte 5 .

Ich kann den Beweis dafür nicht in extenso antreten ${ }^{6}$. Ich beschränke mich auf die wichtigsten Punkte. Es ist schon immer aufgefallen, dass Homer an manchen Stellen mehr andeutet als erzählt. Wo Proitos regierte, wird nicht gesagt - es muss in Argos oder in Tiryns gewesen sein. Die Beziehungen zwischen Bellerophontes und Proitos bleiben ungeklärt, ja werden durch die Formulierungen eher verwirrt: 'Proitos vertrieb den Bellerophontes aus der Gemeinde, weil er der Stärkere war" der König ist, dann ist die Feststellung eine Banalität, ist es Bellerophontes, etwa weil er der grössere Held ist, dann kann man die Bedeutung des Faktums höchstens erschliessen. Gerade in diesem Punkt zeigt sich also, dass ein Sachverhalt extrem verkürzt dargestellt wurde ${ }^{8}$. Wie der König der Lykier hiess, bleibt verborgen. Das Wunderpferd Pegasos, dem Bellerophontes, wie wir aus Hesiod und aus Pindar wissen, seinen Sieg über die Chimaira und wahrscheinlich überhaupt sein Davonkommen verdankte, tritt nicht auf, wahrscheinlich weil der Iliasdichter phantastische Züge nach Möglichkeit meidet. Wie sich

5 Das ist in der Forschung oft betont worden. Am ausführlichsten hat in neuerer Zeit Peppermüller, Glaukos-Diomedes-Szene, darüber gehandelt.

6 Vgl. zum folgenden Frei, Lykier.

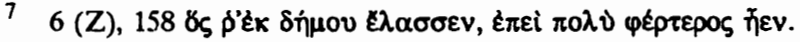

8 Vgl. dazu Heubeck, Schrift, 133f, der allerdings weniger mit Verkürzungen als mit gestalterischen Eingriffen des Dichters der Ilias rechnet. 
Bellerophontes und sein Geschlecht gegen die Götter verschuldeten, wird nicht berichtet, sondern als Faktum vorausgesetzt.

Als Hinweise auf eine vorhomerische Ausgestaltung der Geschichte sind aber auch solche Angaben zu betrachten, die ihren Sinn nicht innerhalb der Erzählung des 6. Buches selbst haben, sondern offenbar für andere, in der Ilias ebenfalls erzählte Zusammenhänge erfunden worden sind, dort aber vom Dichter nicht ausgeführt werden, weil sie nicht passen würden. Ich denke dabei vor allem an die Herkunft aus Ephyra. Sie verbindet Sarpedon mit dem Rhodier Tlepolemos, dem er, wie eben gesagt, im 5. Buch gegenübertritt ${ }^{9}$. An jener Stelle ist aber nur die gemeinsame Abstammung der beiden Helden von Zeus von Belang, und deshalb wird nur diese hervorgehoben.

Dieses von Homer vorausgesetzte Epos - ich möchte es das Lykierepos nennen - ist im späten 8. oder im frühen 7. Jahrhundert anzusetzen. Es hatte als Hauptthema wahrscheinlich die Auseinandersetzung zwischen den Rhodiern und den Lykiern um den Besitz der lykischen Küste. Offenbar bezog es auch die sagenhafte Vorgeschichte ein, wobei es darum ging, eine Verbindung zwischen den Lykiern und den Griechen herzustellen. Weil die Vorfahren der Rhodier nach der Tradition aus der Nordostecke der Peloponnes stammten, wurden auch die Vorfahren der dominierenden lykischen Herrscherfamilie in dieser Gegend angesiedelt. Daher wurde das realiter an der Westküste Griechenlands liegende Ephyra in dichterischer Freiheit nach der Argolis verlegt, was hier nicht genauer begründet werden $\mathbf{k a n n}^{10}$, und so gelangte Bellerophontes von dort über den Hof des Proitos nach Kleinasien. In welchem historischen Zusammenhang dieses vorhomerische Epos entstanden ist, kann hier offen bleiben. Es ist wahrscheinlich, dass der Verfasser ein Grieche war, der in Lykien als Sänger an einem Fürstenhof, vermutlich demjenigen von Xanthos, wirkte. Im 5. Jahrhundert ist die Anwesenheit griechischer Spezialisten in Lykien gut bezeugt, die gerade in Xanthos als Hofdichter tätig waren. Es ist keine zu kühne Annahme, dass diese ihre Vorgänger in einer viel früheren Zeit hatten. Dass die griechischen Beziehungen zu Lykien zur Zeit Homers schon bestanden, ergibt sich unter anderem daraus, dass der Hauptfluss Westlykiens, der lykisch Sibris o.a.. hiess, auch den griechischen Namen Xanthos führte.

Wir betrachten nunmehr die beiden mit dem Alten Testament gemeinsamen Motive.

Dass das Potipharmotiv, die Versuchung und Verleumdung des Bellerophontes durch Anteia, einen nahen Verwandten innerhalb des griechischen Erzählguts hat, ist längst aufgefallen, und zwar ist es die Geschichte von Hippolytos und Phaidra. Diese Motivbeziehung lässt sich vielleicht ein wenig klären

\footnotetext{
9 Vgl. oben Anm. 4.

10 Vgl. Frei, Lykier, bes. $821 \mathrm{ff}$.
} 
durch die Interpretation von Namensbeziehungen, die oft im Gewirr erzählerischer Erfindung einen rettenden Faden bieten können. Wenn die epischen Dichter Personen, die in der Erzählung auftraten, mit Namen versehen mussten, gingen sie oft assoziativ vor, d.h. sie benutzten oder variierten Namen, die in den vorausliegenden, inhaltlich verwandten Erzählstoffen vorhanden waren. In der Tradition, wie wir sie am frühesten bei Asklepiades von Tragilos ${ }^{11}$, einem Gelehrten des 4. Jh. v. Chr., greifen, wird nun behauptet, Bellerophontes habe einst den Namen Hipponoos getragen und habe erst nach der Tötung des Belleros seinen bekannteren Namen erhalten. Letzteres ist sicher ein belangloser Versuch, den unverständlichen Namen etymologisch zu erklären. Mehr entnehmen wir dem angeblich ursprünglichen Namen. Die alten Komposita auf -voos sind weitgehend von der aktiven Wurzel *nes- 'heil zurückführen' abzuleiten ${ }^{12}$. Im Zusammenhang mit Bellerophontes wäre 'I $\pi \pi$ óvoos sinnvoll als 'der durch das Pferd, bzw. mit Hilfe des Pferdes heil zurückkommt', zu verstehen, d.h. -vooৎ wäre auf mediales véo $\mu \alpha \iota$ zu beziehen. Eine Parallele, bei der die mediale Auffassung des Kompositums gesichert ist, liefert eine andere Sagengestalt dieses Namens: Hipponoos heisst auch ein Sohn des Adrastos ${ }^{13}$, und dies ist gut verständlich, wenn man weiss, dass Adrastos bei der Katastrophe der Sieben vor Theben als einziger davonkam, und zwar mit Hilfe des Götterpferdes Areion. Nun ist es in der Onomastik des Epos gut bezeugt, dass Söhne nach einer Eigenschaft oder auch nach einem bedeutungsvollen Geschehen im Leben des Vaters oder nach einer kennzeichnenden Eigenschaft benannt werden, man vergleiche die bekannten Parallelfälle: $\mathrm{T} \eta \lambda \hat{\varepsilon} \mu \alpha \chi \circ \varsigma$, 'der

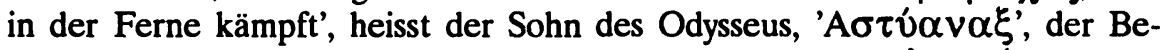

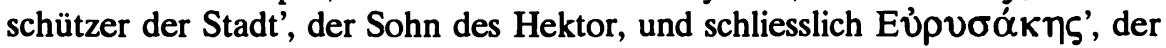
mit dem breiten Schild', der Sohn des Aias. 'I $\pi \pi$ óvooৎ wäre dann also für den Sohn des Adrastos und für Bellerophontes ein sprechender Name, und da die Komposita mit -voos, soweit wir sehen, in historischer Zeit nicht auf die Wurzel *nes- bezogen wurden, kann es sich dabei nicht um junge Erfindungen handeln, sondern es muss hier eine gute alte Überlieferung vorliegen.

Wie hat man aber das Verhältnis der beiden Namen zueinander aufzufassen? Die Tatsache, dass ausserhalb der Bellerophontes-Geschichte ein Hipponoos in der Deszendenz des in Argos residierenden Proitos (als Enkel oder

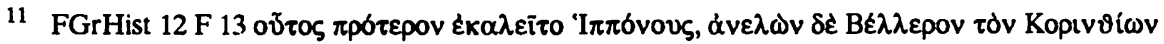

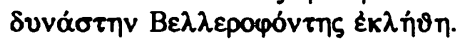

12 Vgl. darüber grundlegend Mühlestein, Neleiden, $157 \mathrm{ff}$.

13 Hygin. fab. 242, 5 Adrastus et Hipponous eius filius ipsi se in ignem iecerunt ex responso Apollinis. 
Urenkel) auftritt ${ }^{14}$, kann einen Weg weisen. Wir begeben uns damit allerdings auf das Gebiet der luftigen Hypothesen, aber man stösst dabei auf eine Reihe von Indizien, die in ihrer Gesamtheit vielleicht doch nicht übersehen werden sollten. Klar ist auf jeden Fall soviel, dass der Name Hipponoos im Umkreis von Proitos existierte. Wenn der Name sinnvoll sein soll, müsste eigentlich dieser Hipponoos, der Enkel oder gar - was nicht überliefert ist - der Sohn des Proitos, ein ähnliches Schicksal erlitten haben wie Bellerophontes, indem auch er in eine schwierige Lage geriet und auf die gleiche Weise, nämlich durch ein Wunderpferd, daraus gerettet wurde. Ist es eine zu kühne Annahme, dass er auch auf die gleiche Weise wie Bellerophontes in diese Schwierigkeiten geriet, nämlich von der Gattin des Proitos begehrt und verleumdet wurde? Proitos hätte dann zwei Frauen gehabt, eine ältere, die Grossmutter (oder die Mutter?) des Hipponoos, und eine jüngere, die sich in den jungen Mann verliebte. Hängt es damit zusammen, dass in der Überlieferung für die Frau des Proitos zwei Namen auftreten, Anteia und Stheneboia? Da ist vielleicht zu beachten, dass ein zweiter Hipponoos, dessen Beziehungen zu Argos nicht so eindeutig sind - er war König von Olenos in Achaia -, eine Tochter des Namens Periboia hatte, durch welche er der Grossvater des Diomedes wurde ${ }^{15}$. Waren Пعрi$\beta o \iota \alpha$ und $\Sigma \vartheta \varepsilon v \varepsilon$ - $\beta o t \alpha$ onomastische Variationen im oben umschriebenen Sinne, d.h. war der Name Hipponoos mit einem Namen auf - $\beta$ ot $\alpha$ verassoziiert, wobei wir nicht sagen können, wo die Verbindung ursprünglich fest war? Das andere Namensglied ( $\sigma \vartheta \varepsilon v \varepsilon-)$ erscheint vielleicht im Namen des Enkels

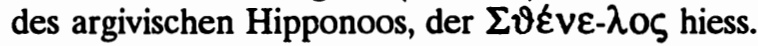

Wenn das richtig sein sollte, liesse sich eine Erzählung rekonstruieren, in welcher Proitos seinen von seiner zweiten Frau verleumdeten Nachkommen Hipponoos einem tödlichen Abenteuer ausgesetzt hätte, aus dem dieser mit Hilfe eines Wunderpferdes heil zurückkehrte. An die Stelle des Potipharmotivs träte das Phaidramotiv. Akzeptiert man das, so haben wir genau den Plot der Hippolytos-Sage vor uns, die ja ebenfalls in der Nordostecke der Peloponnes spielt. Wiederum gibt es stützende Namensbeziehungen. 'I $\pi \pi 0 ́-\lambda v \tau o \zeta$, derjenige, der nicht davonkommt, sondern 'durch die Pferde vernichtet' wird ${ }^{16}$, wäre dann eine Art Kontrastfigur zu Hipponoos. Ist es da wieder nur Zufall, dass als leibliche Mutter des Hippolytos ausser der sekundär aussehenden Hippolyte auch Antiope genannt wird? Trägt die homerische Anteia, deren Name nicht erklärt ist, ein singuläres Hypokoristikon dazu, war dies also der ursprüngliche Name der leiblichen Mutter des Hipponoos? Die bei Hippolytos greifbare

14 Als Enkel des Proitos wird er bezeugt durch Schol. Pind. Nem. 9, 30 (Прoí

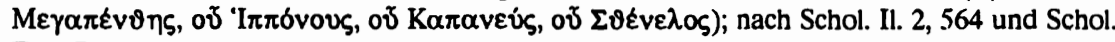
Eur. Phoin. 180 wăre er der Urenkel gewesen.

Am ausführlichsten sind die Belege zusammengestellt bei Roscher, Hipponoos 2689, $53 \mathrm{ff}$.

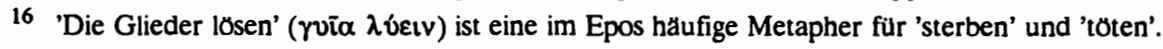


Verbindung mit Poseidon könnte darauf hinweisen, dass die Verbindung des Bellerophontes mit diesem Gott ${ }^{17}$ von seinem literarischen Vorbild Hipponoos übernommen ist, der sie seinerseits von Hippolytos bezogen hatte. Liegt in der Notiz, Bellerophontes habe einst um Aithra, die Mutter des Theseus, geworben $^{18}$, der Rest einer ursprünglichen Verbindung der beiden Sagenkreise vor (Hippolytos der Enkel des Hipponoos)? Nun spricht allerdings einiges dafür, dass die oben postulierte Auffassung des Namens 'I $\pi \pi \delta \delta \nu v \tau 0 \zeta$ nicht die ursprüngliche ist ${ }^{19}$, doch sei auch das jetzt nur gerade angedeutet. Man hätte wohl anzunehmen, dass der sicher nicht mehr eigentlich verstandene Name umgedeutet wurde, - schliesslich kam ja Hippolytos durch Pferde um - und man dann sekundär Hipponoos dazu erfand. In einem weiteren Schritt, den wahrscheinlich der Verfasser des Lykierepos tat, wurde die Erzählstruktur der Hipponoossage in vereinfachter Form auf Bellerophontes übertragen.

Vielleicht stossen wir also tatsächlich auf einen durch das Hinzutreten des Bellerophontes aufgesplitterten und nur noch in Bruchstücken fassbaren Sagenkomplex aus der nordöstlichen Peloponnes. So könnte sich auch erklären, weshalb die Gestalt des Bellerophontes in Korinth so leicht Eingang fand: eine verwandte Geschichte war eben in der Gegend bereits im Umlauf ${ }^{20}$.

Wenn dem so ist, heisst das, dass das Potipharmotiv in der Bellerophontessage griechischer Herkunft ist, gleichgültig ob das Motiv seinerseits selber vorher aus dem Orient nach Griechenland gekommen war. Ein direkter Bezug zur Josephs-Geschichte des Alten Testaments ist also sicher keine notwendige Annahme, ja vielleicht sogar eher unwahrscheinlich.

Umso gewichtiger wird für uns das sog. Uriamotiv - ich nenne es im folgenden das Todesbriefmotiv. Es steht im homerischen Epos, wie man immer gesehen hat, dadurch völlig vereinzelt da, dass nur in diesem Erzählzusammenhang die Schrift auftaucht ${ }^{21}$. Sonst ist in der Welt Homers das Schreiben ungebräuchlich, so wie er auch in den erzählenden Partien das Eisen nicht kennt oder keine Griechen in Kleinasien wohnen lässt. Das waren für die Zeit Homers lauter Fiktionen, und dies wiederum bedeutet, dass Homer ein bewusst ausgestaltetes Geschichtsbild vor sich hatte: so stellte man sich die politischen und kulturellen Verhältnissen der Vergangenheit vor, in welcher die Helden gelebt hatten. Nun ist das Todesbriefmotiv in der Bellerophontessage für die Erzählung konstitutiv und in den Verlauf der Ereignisse fest eingebaut. Man

17 Pind. Ol. 13, 68. Vgl. auch Hes. frg. 7b, $6 \mathrm{Rz}=43 \mathrm{a}, 82 \mathrm{MW}$.

18 Paus. 2, 31, 9.

19 Vgl. Burkert, Structure and history, $111 \mathrm{ff}$.

$20 \mathrm{Vgl}$. im übrigen zum Zusammenhang zwischen Bellerophontes- und Hippolytos-Sage - im Rahmen ganz anderer Gesamtanschauungen - auch Radermacher, Mythos, 102.

21 Ausführliche Interpretation bei Heubeck, Schrift. Zum ganzen Komplex vgl. zuletzt Burkert, Oriental myth, $51 \mathrm{ff}$. 
wird also nicht um die Annahme herumkommen, dass das Schreiben mit der Bellerophontes-Geschichte schon vor Homer verbunden war und dass Homer es mit dieser zusammen übernommen hat ${ }^{2}$.

Dabei ist es völlig unnötig, darüber zu rätseln, in welcher Schrift und in welcher Sprache der Brief geschrieben war. Er wurde offensichtlich vom Empfänger verstanden, mehr war nicht nötig, und weder Homer noch der Dichter des Lykierepos brauchten sich irgendwelche historisch präzisen Vorstellungen zu machen. Von Belang ist nur, dass demjenigen, der die Bellerophontesgeschichte in ihrer uns erhaltenen Form ursprünglich erzählt hatte, die Möglichkeit schriftlicher Kommunikation bekannt war; was für eine Schrift er dabei vor den Augen hatte, war durch sein kulturelles Umfeld gegeben. Die Unbestimmheit der Formulierungen bei Homer geht, wie man auch schon immer gesehen hat, darauf zurück, dass eben bei ihm nicht geschrieben werden sollte. Dem scheint zunächst die merkwürdig genaue Angabe, dass die Zeichen $\varepsilon \mathcal{\varepsilon} \nu \pi \hat{\imath} v \alpha \kappa \iota \pi \tau v \kappa \tau \omega \tilde{\iota}$, offensichtlich auf einem faltbaren Doppeltäfelchen, eingetragen waren, zu widersprechen, zumal sie bei Homer beziehungslos ist. Sie wird verständlich, wenn man beachtet, dass dieser Schriftträger die Geheimhaltung des Inhalts des Briefes gegenüber dem Überbringer gewährleisten sollte, da ein solches Täfelchen verschlossen werden konnte. Das war für eine sinnvolle Gestaltung des Zusammenhanges recht wesentlich. Die Verkürzung der Erzählung durch Homer und das Bemühen, alles, was die Schriftlichkeit betrifft, ins Undeutliche aufzulösen, haben zu einer Pseudopräzision geführt, die in der Folge immer wieder zu Spekulationen Anlass gegeben hat. Sicher bleibt, dass der ursprüngliche Erzähler der Bellerophontessage einen derartigen Schriftträger kannte und über seine Verwendungsmöglichkeiten im Bild war. Wegen der Funktionalität der Aussage wird man auch anzunehmen haben, dass die Einführung des Todesbriefmotivs in die Bellerophontesgeschichte und die Einführung des Täfelchens als Schriftträger gleich alt sind. Eine absolute Datierung der Geschichte ins 1.Jahrtausend, wie man sie bisher aufgrund des realen Auftretens der Doppeltäfelchen erschloss, ist heute allerdings nicht mehr möglich, da seit ein paar Jahren die Existenz von faltbaren Schreibtäfelchen für die zweite Hälfte des 2 . Jahrtausends nachgewiesen zu sein scheint ${ }^{23}$. Was die

Heubeck, Schrift, 134.138 ist der Meinung, das Motiv sei in der Bellerophontessage nicht alt und von Homer selbst eingearbeitet worden. Es ist aber nicht recht einzusehen, weshalb gerade der das Schreiben meidende Dichter der Ilias in diesem einen Falle auf diese Kulturtechnik zurückgegriffen haben sollte. Bellerophontes liess sich durch andere Kombinationen nach Lykien und in Gefahr bringen.

Im bronzezeitlichen Schiffswrak am Kap Ulu Burun an der Küste Lykiens wurde 1986 ein elfenbeinernes Tafelchen aus geretteten Resten zusammengestellt, das durchaus dem Typus des aus dem 1. Jahrtausend bezeugten Schreibmaterials entspricht, vgl. Bass / Pulak, Bronze age shipwreck, bes. $10 \mathrm{f}$ (mit Abbildung). Dass deswegen die Erwăhnung eines solchen Trăgers in unserem Zusammenhang nicht anachronistisch war, wie die Autoren meinen (ebd., 11) d.h. 
lokale Herkunft angeht, kann man nicht ausschliessen, dass ein Grieche das Motiv hätte erfinden und für die Bellerophontessage fruchtbar machen können. Ebenso gut aber ist es denkbar, dass das ganze Motiv mitsamt der Erwähnung des Schreibmaterials aus dem östlichen Mittelmeergebiet stammt. Über das alles wird erst die Gesamtbetrachtung entscheiden.

Ein weiterer wesentlicher Zug der Sage ist die Bekämpfung der Chimaira. Deren Name scheint griechisch zu sein: $\chi i ́ \mu \alpha \iota \rho \alpha$ heisst 'Ziege'. Man wird aber wohl zugeben, dass eine solche Bezeichnung für ein feuerschnaubendes Untier recht ungeeignet ist. Liegt deshalb eine volksetymologische Umgestaltung eines fremden, etwa kleinasiatischen Wortes vor? Bekanntlich wird das Ungeheuer so geschildert, dass es vorne Löwe, hinten Schlange und in der Mitte eine Ziege ist. Die bildlichen Darstellungen lösen das in der Regel in der Weise, dass der Körper derjenige eines Löwen ist, der Schwanz als Schlange gestaltet wird, während aus dem Rumpf ein Ziegenkopf aufsteigt ${ }^{24}$. Dies führt, wie man immer gesehen hat, in den Osten, und zwar in den späthethitischen Bereich ${ }^{25}$, wo in Zincirli ${ }^{26}$ und in Karkemišs ${ }^{27}$ ein derartiges Ungeheuer direkt dargestellt ist: Es handelt sich um einen geflügelten Löwen, dessen Schwanz in einen Vogelkopf endet, während unmittelbar hinter dem Kopf ein Götterkopf mit Hörnerhelm aus dem Rücken des Löwen aufsteigt. Die Annahme drängt sich geradezu auf, dass der griechische Ziegenkopf dem im hethitischen Relief dargestellten Götterkopf mit dem Hörnerhelm direkt entspricht. Ist das eine bewusst travestierende Umdeutung der Hörner? Derjenige, der zuerst von der Chimaira erzählte, wird eine entsprechende späthethitische Darstellung gekannt haben. Xí $\mu \alpha \imath \rho \alpha$ wird das Untier heissen, weil eben der 'Ziegenkopf' sein seltsamster Bestandteil war. Bei Homer ist sie ein schreckliches und gefähr-

dass die Geschichte nun ohne weiteres in der Bronzezeit spielen könne, ist natürlich ein vorschneller Schluss (etwas vorsichtiger in der Formulierung Bryce, Mitteilungen, 177). Über die Verwendung von Holztafeln (von denen nicht gesagt ist, dass sie doppelt waren) bei den Hethitern, in Ugarit und in Emar vgl. Hagenbucher, Korrespondenz der Hethiter, $7 \mathrm{f}$ mit Anm. 7. Über das Problem der Umschlage und der Siegelungen vgl. aaO 32ff. Festzuhalten ist auf jeden Fall, dass nach dem Ausweis der hethitischen Texte die Verwendung von Holztafeln deutlich seltener war als diejenige von Lehmtafeln.

24 Vgl. zum Ganzen aus neuerer Zeit vor allem Jacquemin, Chimaira.

25 Vgl. z.B. Akurgal, Orient und Okzident, 187f. Die Zweifel von Jacquemin, Chimaira, 256f sind unberechtigt. Dass Lowen- wie Götterkopf der späthethitischen Ungeheuer einen weiblichen Typus wiederzugeben scheinen, ist im vorliegenden Zusammenhang, wo es um die Umsetzung eines durch globale visuelle Eindrücke vermittelten Inhalts geht, nicht von so grossem Belang. Abgesehen davon war die Chimaira schliesslich ein weibliches Wesen.

26 Eine Abbildung z.B. bei Malten, Bellerophontes, 133. Malten bietet dort überhaupt reiches ikonographisches Material für allfăllige orientalische Beziehungen.

27 Eine Abbildung z.B. bei Akurgal / Hirmer, Kunst der Hethiter, Taf. 110 oder Bittel, Hethiter, $251 \mathrm{Abb} .284$. 
liches Wesen. Sicherlich war das Monstrum ein Gebilde mit komplexer Vorgeschichte, in dem sich verschiedene Einflüsse kreuzten. Ob es je in Griechenland wirklich angesiedelt war, muss offen bleiben. Der Verfasser des Lykierepos jedenfalls verlegte es zum vorneherein nach Lykien. Zu beachten ist, doch sei dem wiederum nicht nachgegangen, dass die Chimaira auch mit Karien fest verbunden gewesen $\mathrm{zu}$ sein scheint ${ }^{28}$.

Ähnlich steht es wohl mit dem bei Homer nicht genannten Pferd, dem Pegasos. Man wird nicht daran zweifeln, dass es ein genuiner Bestandteil der ganzen Sage ist. Das Motiv des mit Flügeln ausgestatteten Pferdes ist aus dem Orient, wo die ältesten Belege m.W. auf assyrischen Rollsiegeln auftreten ${ }^{29}$, schon früh nach Griechenland gelangt ${ }^{30}$, und der Pegasos kann also dort das Reittier des Bellerophontes geworden sein. Sonst sind allerdings die Wunderrosse, von denen man in Griechenland erzählte, chthonischer Natur ${ }^{31}$. Der Pegasos hingegen wird bei Hesiod ${ }^{32}$ in den Palast des Zeus versetzt und er trägt dessen Blitz. Diese himmlische Funktion gibt die Möglichkeit, den Namen aus kleinasiatischem Sprachgut herzuleiten. Er kann das luwische Element pihas- enthalten ${ }^{33}$, dessen Bedeutung 'Blitz, Glanz' heute gut begründet ist ${ }^{34}$. Das von dieser Wurzel abgeleitetete luwische Wort pihassassis ist Beiname des

$28 \mathrm{Vgl}$. Homer II. 16 (П), 328f, wo von einem Amisodaros, dem Träger eines typisch karischen Namens also, gesagt wird, er habe die Chimaira aufgezogen ( $\diamond \varepsilon \varepsilon \varepsilon \varepsilon v)$.

29 Vgl. Moortgat, Glyptik des 13. Jh., bes. $63 \mathrm{f} \mathrm{Abb.} \mathrm{25,} \mathrm{ders.,} \mathrm{Glyptik} \mathrm{des} \mathrm{12.} \mathrm{Jh.,} 32$ Abb. 22. Vgl. auch Malten, Bellerophontes, 138ff; Schachermeyr, Poseidon, 174 Anm. 2. 179ff; Dunbabin, Bellerophon, 1171 und jetzt auch Yalouris, Pegasus, passim, bes. 15f.

30 Nach Malten, Bellerophontes, 143ff und Dunbabin, Bellerophon, 1171, seit dem 8. Jahrhundert v.Chr., vgl. auch Yalouris, Pegasus, ebd.

31 Vgl. Schachermeyr, Poseidon, 180ff.

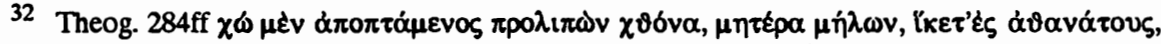

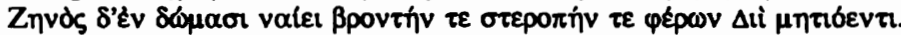

33 Diese Verbindung wurde zuerst von Bossert, Bilinguen, 333f vorgeschlagen.

34 Vgl. darüber jetzt ausführlich Starke, Stammbildung, 103ff $\$ 58$ (die auf S.104 erwahnnte Bronzetafel Bo 86/299 ist unterdessen veroffentlicht worden, vgl. Otten, Bronzetafel, bes. 47). Natürlich stellt sich dabei die Frage, wie man sich das Ableitungsverhältnis zwischen einem aus

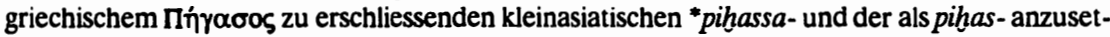
zenden Wurzel vorzustellen hat. Die Antwort kann nur spekulativ sein. Nimmt man an, dass die Bedeutung 'der mit dem Blitz' war, liegt am ehesten eine Ableitung mit dem Suffix -assa/ivor. $\mathrm{Zu}$ erwarten wăre dann pihassassa/i-, wie es im gleich zu erwahnenden Beinamen des Wettergottes bezeugt ist. *pihassa-würde in diesem Fall auf einer Haplologie beruhen. Man kann aber auch von einer nach den a-Stämmen umgestalteten Wurzel *piha- ausgehen. Dann wäre * pihassa- die erwartete Form. Vgl. auch die folgende Anmerkung. Für den Hinweis auf die Darlegungen von Starke danke ich Erich Neu. 
hethitischen Wettergottes ( ${ }^{\mathrm{d} U}$ pihassassis) ${ }^{35}$. So gehört also der Name des Pferdes und damit wohl auch dieses selbst wahrscheinlich zum kleinasiatischen Bestand der Sage.

Sehr wertvoll wäre es natürlich, den Namen Bellerophontes verstehen zu können. Das ist bis heute nicht gelungen. Auch wenn die bisher schwer zu erklärenden Namen auf - $\varphi \delta$ v́ $\eta \varsigma$ durch das Mykenische als griechische Bildungen plausibler geworden sind, ohne dass die genaue semantische Bestimmung des Hintergliedes gesichert wäre, so lässt sich auf jeden Fall das Element Bellero- nicht deuten, weder aus dem Griechischen noch aus einer anderen Sprache ${ }^{36}$. Dementsprechend ist es nicht zu entscheiden, in welcher ethnischen und kulturellen Umgebung der Held ursprünglich seine Heimat hatte, ob in Griechenland oder in Kleinasien, und welches seine ursprüngliche Funktion war, ob Gott oder Mensch.

Die griechischen Namen der Kinder des Bellerophontes sind wenig von Belang. Sie dienen vor allem der Verknüpfung des Erzählers Glaukos mit dem Stammvater, sind also wohl Erfindung des Dichters der Ilias und verfallen deshalb am Ende der Erzählung dem Tode. Das Schicksal der Familie erhält dadurch eine schicksalhafte Tragik, die dem Ethos des ganzen 6. Buches der Ilias durchaus entspricht.

Zusammenfassend wird man sagen, dass die Bellerophontesgeschichte offenbar Elemente griechischer Tradition enthält (Potiphar- bzw. PhaidraMotiv), einzelne Züge, die nach Osten, nach Vorderasien weisen (Chimaira, Flügelpferd, vielleicht der Todesbrief), während anderes wieder kleinasiatisch, vielleicht kleinasiatisch-luwisch sein dürfte (Chimaira, Pegasos). Können diese letzteren Elemente sogar lykisch sein?

Damit wenden wir uns dem Alten Testament zu. Da das Potipharmotiv der Bellerophontesgeschichte, wie wir gesehen haben, als solches wahrscheinlich aus einer griechischen Tradition stammt, wollen wir uns damit jetzt nicht weiter befassen. Was die entsprechende Geschichte des Alten Testaments betrifft, so ist, wenn ich recht sehe, ihre Herkunft einigermassen geklärt. Die Verbindungen führen nach Ägypten ${ }^{37}$. Jedenfalls haben wir das in der Uriageschichte -

35 Bossert, Bilinguen, ebd. hat sogar vorgeschlagen, ${ }^{d} \mathrm{U}$ pihassassis als 'der mit dem Pegasos (offenbar = pih̆assa-)' zu verstehen. Das bleibt natürlich vorlaufig reine Vermutung, ist aber

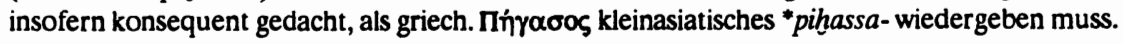

36 Vgl. zuletzt Watkins, Dragon, bes. 279f. Eine Wurzel g'hen- 'üppig sein o.a.' will Heubeck, Argeiphontes (über Bellerophontes bes. 25ff), zugrundelegen. - Völlig quer liegen die Versuche einer semitischen Etymologie als ba'al räpön (o.ă.) durch Leny, Fremdwörter, 190ff, die von Astour. Hellenosemitica, 226ff wieder aufgenommen worden ist. Sie würde aus Bellerophontes einen Heilgott machen, was trotz Astour, aaO $250 \mathrm{ff}$ wenig plausibel ist.

37 Vgl. z.B. Westermann, Genesis, 61 . 
so möchte ich sie im folgenden nennen - verwendete Motiv des Todesbriefs in den Vordergrund zu stellen.

Die berühmte Geschichte findet sich in den Kapiteln 11 und 12 des 2 . Samuelbuches. Ihr Ablauf sei hier kurz resümiert. Ein Affront von Seiten des Ammoniterkönigs gegenüber Gesandten Davids führte zum Krieg zwischen den Nachbarvölkern, die sich ohnehin in einer evidenten gegenseitigen Konkurrenzsituation befanden. Wir brauchen den Ablauf der Kämpfe hier nicht vollständig wiederzugeben. Im für uns entscheidenden Jahr beauftragte David seinen General Joab mit dem Feldzug gegen die Hauptstadt der Ammoniter und blieb selbst in Jerusalem. Hier erblickte er eines Abends vom Dach seines Hauses aus eine schöne Frau beim Bade. Auf seine Erkundigungen hin erfuhr er, dass es Bathseba sei, eine Frau aus angesehener Familie ${ }^{38}$, die Gattin des Hethiters Uria, eines seiner Elitekrieger. Er liess sie zu sich holen und schwängerte sie. Als sie David von ihrer Schwangerschaft berichtete, rief dieser den vor der Ammoniterhauptstadt kämpfenden Uria herbei unter dem Vorwand, er wolle sich von ihm über die Kriegslage orientieren lassen. Uria begab sich nach der Audienz nicht nach Hause, sondern schlief im königlichen Palast bei den Knechten des Königs. Damit hatte er auch keine Gelegenheit, mit seiner Frau zu verkehren, wie David offensichtlich gehofft hatte, damit das zu erwartende Kind als dasjenige des legalen Ehegatten ausgegeben werden könnte. Auch am andern Tag vermochte ihn David nicht dazu zu bewegen, in seinem Haus zu übernachten. Darauf schrieb der König einen Brief an seinen Feldherrn, er solle Uria im Krieg an einen gefährlichen Posten stellen und sodann im Stich lassen, so dass er getötet werde. Uria selber überbrachte den Brief Joab, und dieser sorgte dafür, dass Uria im Kampf fiel. Durch einen Boten erstattete er dem König Meldung von diesem Geschehen. Bathseba hielt die übliche Trauerzeit ein und wurde dann die Gattin Davids. Für sein Verhalten wurde David vom Propheten Nathan hart getadelt. Die Verheissung des Königtums an seine Familie wurde von Jahweh zwar nicht zurückgenommen, wohl aber mit Unheilsdrohungen verbunden. Der Sohn, den Bathseba gebar, starb bald nach der Geburt, eine Strafe Jahwehs. Der zweite Sohn aus der Verbindung mit David war Salomo, der schliesslich der Nachfolger seines Vaters auf dem Königsthron wurde.

Die literarkritischen Probleme der Geschichte sind recht schwierig. Sie können hier nur angedeutet werden ${ }^{39}$, und die an sich wünschbare ausführ-

38 Dass die Erwăhnung der văterlichen Herkunft bei einer Frau aussergewöhnlich sei, betont McCarter jr., II Samuel, 285 z.St. Es liegt nahe, mit Wesselius, Joab's death, 349ff die alte Vermutung aufzunehmen, dass Bathseba aus der angesehenen Familie von Davids Ratgeber Ahithophel stammte.

Eine ausführliche Darstellung der Forschungslage findet sich bei Gunn, King David, $19 \mathrm{ff}$. 
liche Diskussion muss natürlich unterbleiben ${ }^{40}$. Im folgenden soll nur auf solche Punkte eingegangen werden, die für unsere Zwecke von Belang sind, d.h. die für die Frage der Historizität und des Alters der Geschichte aussagekräftig sein können. Diese Fragen aber sind für uns wesentlich, da es ja darum geht, das Verhältnis der Uria- zu der sicher fiktiven Bellerophontesgeschichte zu klären.

Den übergreifenden Rahmen bildet das sog. Deuteronomistische Geschichtswerk. Enger ist die Einbindung in einen Erzählkomplex, der von Ereignissen am Hof des zum König arrivierten David handelt. Dabei bildet der Usurpationsversuch seines Sohnes Absalom einen zentralen Teil, und die Inthronisation Salomos bildet den Abschluss. Daher gibt man ihm meist den Titel 'Nachfolgegeschichten ${ }^{\text {,41 }}$ oder - m.E. passender - 'Hofgeschichten'. Er erstreckt sich mit ungewissem Anfang von einem der ersten Kapitel des 2. Samuelbuches bis zum Ende des 2. Kapitels des 1. Königsbuches; die genaue Abgrenzung ist für unsere Zwecke nicht erheblich. Die Einheitlichkeit des ganzen Komplexes kann man nicht bezweifeln. Es liegt ein geschlossenes Werk eines nicht greifbaren Autors vor. Die Uriaerzählung im besonderen ist mit einer Darstellung des Ammoniterkrieges verbunden ${ }^{42}$. Sie fällt dadurch aus den andern heraus, dass nirgends wie in ihr Davids Person ausgesprochen negativ gezeichnet ist: er handelt durchwegs moralisch verwerflich, und zwar aus klar eigennützigen Motiven heraus. $\mathrm{Zu}$ Recht werden gerade bei ihr Komposition und Stil besonders gerühmt ${ }^{43}$. Sie scheint im ganzen wirklich aus einem Guss zu sein. Dies sind - etwas vergröbert - die Voraussetzungen, auf denen die Kritik aufzubauen hat. Alle Einzelheiten sind aber offen.

Was den Einbau in das Deuteronomistische Geschichtswerk betrifft, ist vor allem nicht leicht zu sehen, wie sich die eher kritischen Darstellungen der 'Hofgeschichten' zur davidfreundlichen Sicht des Deuteronomistischen Werkes verhalten. Das hat u.a. zu der Annahme geführt, sie seien als jung zu betrachten, jünger als das Deuteronomistische Geschichtswerk, und dementsprechend sei ihr Inhalt weitgehend fiktiv ${ }^{44}$. Es läge dann eine Art historischer Roman

40 Insbesondere ist eine Auseinandersetzung mit der recht umfangreichen Sekundärliteratur ausgeschlossen. Ich habe im allgemeinen nur Arbeiten aus der neuesten Zeit berücksichtigt.

41 Gegen diese Bezeichnung wendet sich in neuerer Zeit zu Recht Conrad, Gegenstand und Intention, bes. $166 \mathrm{f}$.

$42 \mathrm{Vgl}$. darüber unten Anm. 56.

43 Vgl. z.B. Fischer, David und Batseba, bes. 50 .

44 Diese Meinung vertritt in neuerer Zeit vor allem van Seters, In search of history, 277ff. Er ist der Ansicht, die 'Hofgeschichten' seien erst im 6.Jahrhundert als konigsfeindliche Ergänzungen zum davidsfreundlichen Deuteronomistischen Geschichtswerk verfasst worden. Dieses letztere sei auch die einzige benützte Quelle gewesen, und es gebe keinen Grund anzunehmen, dass der Verfasser andere Grundlagen gehabt habe bei der Ausarbeitung der Szenen und Episoden. 'They may all be contrived'(290f). 
vor, vergleichbar etwa mit dem Estherbuch. Eine solche creatio ex nihilo aber ist bei einer komplexen Erzählung, die in realistischer Weise von historischen Angehörigen der eigenen politischen Elite handelt ${ }^{45}$, zum vorne herein wenig wahrscheinlich. Antike, auch altorientalische historische Romane sehen anders aus. Sie sind einsträngig und haben eine klare Tendenz. Wie immer man die Diskrepanzen in der Einstellung zu David erklären will, eine Argumentation hinsichtlich der Historizität ist daraus nicht zu gewinnen.

Die für uns wichtigsten Fragen, diejenige nach der Entstehung, nach dem Alter ${ }^{46}$ und nach den quellenmässigen Voraussetzungen der 'Hofgeschichten', wie auch diejenige nach den politischen und literarischen Anliegen des Verfassers sind schwer zu beantworten ${ }^{47}$. Die Meinungen der Forscher divergieren beträchtlich. Ich möchte neueren Auffassungen darin zustimmen, dass die Uriageschichte innerhalb der 'Hofgeschichten' eine Kernfunktion hat: Davids Fehltritt führt zu den Schwierigkeiten, mit denen er sich in der Folge ausein-

Gunn, King David, 48f. Keine der von ihm S. 49 angeführten Geschichten aus dem Alten Testament oder aus dem Alten Orient handelt von unzweifelhaft historischen Herrschern, auch die Esther-Geschichte nicht. Ebensowenig kann die Sargon-Epik als Stutze ins Feld geführt werden, denn gerade sie hat zweifellos einen historischen Kern.

Eine Zusammenstellung der textimmanenten möglichen Datierungshinweise bei Gunn, King David, 30ff; Kaiser, Beobachtungen, $18 \mathrm{f}$ glaubt, gerade aus dem Zusammenhang der Uriaerzăhlung einen terminus post quem gewinnen zu kőnnen. Der einleitende Satz 2 Sam 11,1 'und es geschah zur Wende des Jahres, zur Zeit, in der die Konige ausziehen' setze die Einführung des babylonischen Fruhjahrskalenders voraus, da der Terminus 'die Wende des

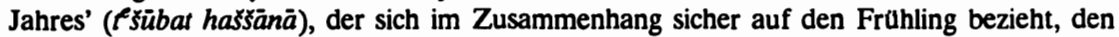
Jahresanfang meine. Das ist nicht so eindeutig. Die Fügung taucht abgesehen von unserer Stelle noch 1 Kön 20,22.26, 1 Chron 20,1 (sicher von 2 Sam 11,1 abhängig) und 2 Chron 36,10 auf, immer als Bezeichnung für den Zeitpunkt eines Feldzugsbeginns. Ein direkter Bezug auf den Beginn eines Kalenderjahres ist aber nirgends zwingend gegeben, und von der Semantik des Wortes $\ell$ süubat her sind mehrere Möglichkeiten des Verständnisses offen. McCarter, II Samuel, $284 \mathrm{f}$ z.St. bezieht die Aussage über den Auszug der Könige auf den Beginn der Aktivităten der antiisraelitischen Koalition von 2 Sam 10,6, nimmt also an, dass einfach der Ablauf eines Jahres bezeichnet werde. Fokkelmann, King David, 50f möchte sich für die Beibehaltung des $\mathrm{Q}^{\mathrm{e}} \mathrm{re} \mathrm{m}$ 'kjm 'Boten' entscheiden und stellt dann eine Verbindung zu 10,1-5, der Erzahlung von der Aussendung der Gesandten, deren Verletzung zum Krieg Anlass gab, her. Auch er denkt somit an den Ablauf einer Jahresfrist. Mir scheint das unwahrscheinlich, doch kann die Frage hier nicht diskutiert werden. Der Verfasser von 1 Chron 20,1 (s.o.) hat jedenfalls 'Könige' verstanden. Sowieso lăsst sich das Argument für eine chronologische Fixierung der 'Hofgeschichten' nicht benutzen. Für unser Anliegen ist zu bemerken, dass dieser einleitende Satz ohnehin lediglich redaktionellen Charakter hat.

47 Fokkelman geht in seinem eben erwähnten Werk bewusst von der erhaltenen Textgestalt aus und ist bemüht, diese nach rein strukturell-literarischen Kriterien zu verstehen. Man wird den Versuch ernst nehmen müssen, doch ist zu beachten, dass sich keineswegs alle Schwierigkeiten ohne weiteres beheben lassen. Im Grunde kann die strukturalistische Methode nur zeigen, wie der Text mit allen seinen Problemen verstanden werden könnte, nicht wie er am einfachsten zu verstehen ist. 
anderzusetzen hat ${ }^{48}$. Das würde bedeuten, dass sie in irgend einer Form immer ein Teil der Gesamtkomposition war ${ }^{49}$.

In der Geschichte selber sind an mindestens zwei Stellen Unstimmigkeiten im Ablauf der Erzählung zu erkennen, die für die Überlieferungsgeschichte relevant sind oder relevant sein können. Ich meine die Widersprüchlichkeiten innerhalb der Erzählung von Urias Aufenthalt in Jerusalem (6-13: Einteilung der Tage; Verhalten Urias [warum enthält er sich des sexuellen Verkehrs, lässt sich aber betrunken machen?]; Unklarheiten in der Darstellung der militärischen Lage) und die Inkonzinnitäten bei der Berichterstattung Joabs an David (18-25). Sie alle betreffen aber lediglich die vorliegende Gestaltung der Erzählung. Über das Alter und die Historizität des Ganzen wird dadurch nichts ausgesagt. Deshalb brauchen wir hier auf die möglichen Lösungsversuche nicht näher einzutreten ${ }^{50}$.

Der wesentliche Punkt ist wie in allen vergleichbaren Fällen der, dass nicht zu entscheiden ist, wie weit jüngere Bearbeiter altes Quellenmaterial vorgefunden und zur Darstellung ihrer eigenen erzählerischen oder ideologischen Anliegen verwendet haben, und wie weit durch fiktive, allenfalls ideologisch motivierte Erfindung nicht nur die erzählerische Ausgestaltung der Einzelzüge, sondern auch die Story selbst geschaffen bzw. umgeformt worden ist. Alle Urteile darüber sind Ermessensentscheide, was sich an der Literatur deutlich ablesen lässt. Besonders die Frage, ob ein bestimmter Zug der Erzählung als historisch betrachtet werden darf, ist meist mit den Mitteln der literarischen Analyse nicht zu lösen, sondern wird aufgrund allgemeiner historischer Argumentationen beantwortet ${ }^{51}$.

48 Vgl. z.B. Gunn, King David, 88f, vgl. auch Conrad, Gegenstand und Intention, 171f; Wesselius, Joab's death, 341.345ff.

49 Das ist zu beachten, wenn man den ganzen Komplex wegen der konigskritischen Tendenz und der aktiven Rolle, die Nathan in ihr spielt, einer prophetischen Quelle zuschreiben will, wie dies nach alteren Autoren z.B. McCarter, II Samuel, $290 \mathrm{f}$ tut.

Zum Problem der Tageseinteilung vgl. McCarter, II Samuel, 287 z.St., zum Problem der Motivation Urias und der militărischen Lage Fischer, David und Batseba, 54. Die Unstimmigkeiten bei der Berichterstattung betrachtet McCarter, II Samuel, 283 als Problem der Textuberlieferung, vielleicht zu Recht. Anders Stoebe, David, 391f (vgl. auch unten Anm. 56).

51 Ein gutes Beispiel dafür liefert die Behandlung der Frage durch Fischer, David und Batseba. Er erschliesst eine sehr wirkungsvolle Strukturierung der Geschichte und stellt dann die eben erwahnten Divergenzen in der Verteilung der Tage, in der Motivation des Verhaltens Urias wahrend seines Aufenthalts in Jerusalem und in der Darlegung der militarischen Lage fest. Daraus ergibt sich für inn erstens eine bewusste, d.h. literarische Gestaltung der ganzen Geschichte und zugleich die Tatsache, dass diese Gestaltung sekundar gestort worden sei. 'Die Beantwortung der Frage nach der historischen Zuverlässigkeit des Erzăhlten' aber wird S. 56ff rein nach der historischen Plausibilităt unter Berücksichtigung der Verbreitung der wichtigsten Motive (Todesbrief, Verhalten orientalischer Herrscher gegenüber Frauen der Untertanen, die Schone im Bade) vorgenommen. 
Vielleicht ist es deshalb lohnend, den umgekehrten Weg einzuschlagen und zunächst zu untersuchen, wie es um die Historizität der in der Uria-Geschichte berichteten Ereignisse bestellt ist. Sinnvollerweise kann man nur die Frage stellen, welche Züge überhaupt erfunden werden konnten. Dabei geht man wohl besser von der negativen Seite an die Sache heran und überprüft, welche Fakten nicht zu erfinden waren. Ich würde folgendermassen argumentieren, wobei ich mich, soweit ich sehe, in Übereinstimmung mit der Mehrzahl der Forscher befinde ${ }^{52}$ :

Dass Bathseba die Mutter Salomos und deshalb eine der Frauen Davids war, scheint mir völlig evident und kann nicht Fiktion sein. Dass der Geburt Salomos der Tod eines Angehörigen vorausging, wird dadurch zur Evidenz erhoben, dass der Name Salomo ('seine Unversehrtheit', vielleicht aber geradezu 'sein Ersatz') als sog. Ersatzname zu betrachten ist ${ }^{53}$. Dabei ist es für uns von geringerer Bedeutung, ob der Tote, an dessen Stelle der Neugeborene tritt, der Vater (d.h. Uria) ${ }^{54}$ oder ein vorher verstorbener Bruder (das von David im Ehebruch gezeugte Kind) ${ }^{55}$ war. Auf jeden Fall gibt dieses indirekte Zeugnis der Onomastik allen involvierten Sachverhalten zum vorneherein höhere Authentizität. Dass Bathseba einmal in erster Ehe verheiratet war, ist auch nicht so leicht als blosse Erfindung abzutun, und dass ihr erster Mann wirklich Uria hiess und im Ammoniterkrieg fiel ${ }^{56}$, scheint dann gleichfalls eine realistische Annahme. Welche Rolle bei diesen Ereignissen David auch spielte: dass es nach der Eheschliessung Davids mit Bathseba für die Zeitgenossen nahe lag, hinter Urias Tod eine Machination des Königs zu vermuten, liegt auf der Hand.

$52 \mathrm{Vgl}$. in ahnlichem Sinne in neuerer Zeit vor allem McCarter, II Samuel, 291, Stoebe, David, $388 \mathrm{ff}$, bes. $389 \mathrm{f}$.

53 Diese Auffassung ist in sehr plausibler Weise von Stamm, Name, begründet worden. Vgl. McCarter, II Samuel, 303 zu 2 Sam 12,24 mit der alteren Literatur.

54 Dies ist die Meinung von Veijola, Salomo. Eine Auseinandersetzung mit ihm ist in unserem Zusammenhang nicht nötig, da seine Anschauungen die historische Authentizităt der Vorgănge um Bathseba zur unbedingten Voraussetzung haben.

55 Dies ist die hâufiger vertretene Auffassung, vgl. die Belege bei McCarter, II Samuel, und ferner Stolz, Samuel, 242.

56 Damit ist die Verknüpfung der Uriageschichte mit dem Bericht über den Ammoniterkrieg selbstverstăndlich gegeben, auch wenn man annehmen will, dass dieser einst als selbstăndiges Überlieferungsstück existierte, vgl. Stoebe, David, 389f. Stoebe rechnet damit (390ff), dass die Einzelheiten des dargestellten militärischen Geschehens als historisch leidlich gesicherte Überlieferung betrachtet werden müssten. Wenn ich ihn recht verstehe (vgl. auch Stoebe, Überlegungen, 307f), wăren sogar die Umstănde des Todes von Uria bei der Belagerung sozusagen authentisch. Der Vorwurf gegen David habe zunächst eine menschenverachtende Kriegführung betroffen; er sei erst spatter durch den Einbezug in die Bathseba-Geschichte umakzentuiert worden. So seien auch die Ungereimtheiten um den Botenbericht (16-25) zu verstehen. Das kann hier nicht diskutiert werden. Im allgemeinen wird man festhalten müssen, dass gerade die Details von Schlachtschilderungen in literarischer Überlieferung oft topisch oder fiktiv sind. 
Gerne wüsste man, was es bedeutet, dass Uria als Hethiter bezeichnet wird; dass diese Benennung in der Tradition von Anfang an fest mit seinem Namen verbunden war, wird man annehmen dürfen ${ }^{57}$.

Wie der Ablauf der Ereignisse im einzelnen wirklich war, wird sich natürlich nie mehr erkennen lassen, sieht man vom völlig unwahrscheinlichen Fall des Auftretens neuen Materials ab. Die eben konstituierten Fakten aber (Tod des Uria im Feld, Übergang der Bathseba in das Haus Davids, Vermutungen über Intrigen des letzteren) bildeten den Kern der Story. Diese wurde dann ausgeformt zu einer Erzählung mit Einzelheiten der verschiedensten Art, die zum vorneherein keinen Anspruch auf Authentizität erheben können und zum Teil auch gar nicht sollen, wie dies z. B. für die Reden der Akteure ganz selbstverständlich gilt. Eine geschickte Erfindung dürfte ferner der Versuch Davids sein, Uria zum Koitus mit seiner Frau zu veranlassen. In welches Stadium der Erzählungsbildung der durch das Auftreten Nathans eingeleitete moralische Ausgleich (Davids Reue und Jahwehs Verzeihung) gehört, kann in unserem Zusammenhang dahingestellt bleiben.

Mehr Bedeutung hat die Frage, ob und auf welcher Stufe novellistische oder märchenhafte Züge einbezogen wurden ${ }^{58}$, da deren Vorhandensein bisweilen als Argument für die Ablehnung des historischen Charakters der Erzählung als ganzer benutzt werden. Als solche Motive werden genannt:

1. Die 'todbringende' Frau, welche Veranlassung zu tödlich verlaufenden Auseinandersetzungen gibt $^{59}$.

2. Das Verfügungsrecht des orientalischen Herrschers über die Frauen seiner Untertanen ${ }^{60}$.

3. Die schöne Frau im Bade, welche die Begehrlichkeit der sie beobachtenden Männer weckt ${ }^{61}$.

57 Die allgemeine Auffasung ist die, dass er ein Angehöriger der vorisraelitischen Oberschicht Jerusalems gewesen sei. Nach Wesselius, Joab's death, 344.346f wäre er im Gegenteil ein Auslănder (gèr) gewesen, der in eine einflussreiche israelitische Familie eingeheiratet hătte. Nicht zu bezweifeln ist, dass er einen jahwistischen Namen tragt. Daraus aber lässt sich kaum etwas ableiten, da zur Erklärung dieses Faktums zahlreiche Möglichkeiten bestehen. Die Annahme einer Umgestaltung eines hurritischen Namens (vgl. v.a. Mazar, Early biblical period, 136f) ist nur eine der denkbaren Hypothesen.

58 Eine Sammlung solcher Motive bei Gunn, King David, 38ff. Vgl. auch die Zusammenstellung bei Fischer, David und Batseba, 56ff.

59 Vgl. Gunn, King David, 43, auch Wesselius, Joab's death, $342 \mathrm{f}$.

60 Darauf legt v.a. Kegler, Politisches Geschehen, $162 \mathrm{ff}$ grossen Wert. Fischer, David und Batseba, 57 redet zunăchst von gefahrdeten 'fremden' Untertanen (im Hinblick auf das kaum unmittelbar zu vergleichende Motiv von der Gefahrdung der Ahnfrau Gen 12 und 20), gleich darauf von Untertanen generell.

61 Vgl. Fischer, David und Batseba, 57f. 


\section{Der Todesbrief.}

Nur das erstgenannte taucht in den 'Hofgeschichten' wiederholt auf ${ }^{62}$. Dennoch braucht es nicht von aussen eingeführt worden zu sein. Es ist schlicht biotisch. Konflikte um Beziehungen mit Frauen, die zu Mord und Totschlag führen, sind zu allen Zeiten in allen Schichten jeder Ethnie vorgekommen, und sie sind heute noch endemisch in Gesellschaften, in denen die Familie die tragende soziale Gemeinschaft ist. Was die anderen Fälle in den 'Hofgeschichten' betrifft, ist ferner zu beachten, dass die Verbindung mit Frauen der königlichen Familie in einem Staat mit Haremssystem stets ein Politikum ist. Das Auftreten des Motivs kann daher nicht a priori ein Argument dafür sein, dass der betreffende Erzählzusammenhang auf einer Fiktion beruhe.

Gar nicht von Relevanz ist das Motiv der sog. Verfügungsgewalt des orientalischen Königs über die Frauen der Untertanen. Die Uria-Geschichte, ob historisch oder nicht, lebt davon, dass David nicht ein Recht ausgeübt, sondern einen Fehltritt begangen hat und diesen nun so gut wie möglich verdecken muss. Zu einer zu postulierenden historischen Situation passt dies vorzüglich: die Legitimität des vom Bandenführer zum König aufgestiegenen Herrschers war immer noch prekär - das zeigen die folgenden Ereignisse deutlich. Er konnte sich einen offenen Übergriff gegenüber einem angesehenen Elitekrieger nicht leisten ${ }^{63}$, und wenn Bathseba wirklich aus einer angesehenen Familie stammte, so hatte er ebensosehr auf diese Rücksicht zu nehmen.

Am ehesten wird man die Bekanntschaft über das Bad als in die Erzählung eingeführtes Motiv werten, doch ist dies ein reines Wahrscheinlichkeitsurteil. Jedenfalls ist das als rituelle Reinigung interpretierte Bad sehr gekonnt in die Geschichte eingefügt worden als Hinweis auf die physiologischen Bedingungen der Schwängerung ${ }^{64}$.

Auch dass die Geschichte vom Todesbrief historisch ist, kann man im strengen Sinne nicht von vorne herein ausschliessen ${ }^{65}$. Allerdings wäre es für

62 Über die 'accumulation' bestimmter Motive und ihre Bedeutung im Hinblick auf die Beurteilung einer Erzahltradition vgl. Gunn, King David, 47.

63 Dass es bei der Uria-Geschichte um die 'Beseitigung potentiell gefahrlicher Opponenten' gehe, wie Kegler, Politisches Geschehen, will, wird durch nichts nahegelegt.

64 Vgl. McCarter, II Samuel, 286 z.St. mit der alteren Literatur.

65 In historischem Zusammenhang wird die Geschichte vom Todesbrief aus dem Griechenland des 5. Jahrhunderts v. Chr., aus dem vorislamischen Arabien und in Bezug auf Ahmad ben Țülün (868-883), den Begünder der Tulunidendynastie Ägyptens, berichtet. Während nun in der letzteren Geschichte, deren Belege bei Schick, Glückskind, 2, 291ff zusammengestellt sind, sich alle Kennzeichen der traditionellen literarischen Ausgestaltung vereinigt finden (sexuelle Untreue, die zu Unrecht dem Bedrohten zugeschoben wird, als Ausgangspunkt - Auftrag an einen nicht besonders spezifizierten Untergebenen des Machthabers, den Überbringer des Briefes umzubringen - Scheitern des Planes), zeichnen sich die griechische und die vorislami- 
David ein riskantes Unternehmen gewesen, zumal die Kommunikation zwischen dem König und dem im Feld stehenden Kommandanten sonst mündlich durch Boten geschah. Man wird doch eher annehmen wollen, der historische Tatbestand sei durch das Motiv ausgeschmückt worden, von dem wir ja heute wissen, dass es seit dem Anfang des 2. Jahrtausends in Vorderasien erzählt wurde und zwar angewendet auf die Beziehungen zwischen einem Herrscher und seinem hohen Beamten, den er beseitigen will.

Mit all dem ist nichts darüber gesagt, in welchen Stufen die Erzählung in ihrer jetzigen Gestalt entstanden ist und wie diese Stufen absolut-chronologisch anzusetzen sind. Der Kern als solcher ist alt, und wenn die eben angestellten Überlegungen richtig sein sollten, dann ist er zur Zeit Davids selbst zusammengewachsen, weil die begründeten oder unbegründeten Vermutungen über Davids Mitwirken am Tod Urias nur in unmittelbarem Zusammenhang mit den Ereignissen selbst ihren Sinn hatten. Das bedeutet, dass die Story schon im 10.Jahrhundert erzählt wurde, aber in welcher Form dies geschah und welche Motive damals bereits dazugehörten, welche später dazukamen, ist eine Sache reiner Hypothesenbildung, auf die jetzt verzichtet werden soll. Wir werden noch darauf zurückzukommen haben ${ }^{66}$.

Soviel zum Versuch, für jede der beiden Erzählungen die Vorstufen und die Ursprünge der Erzählmotive zu erfassen. Fragen wir nun, wie die beiden Erzählungen, die griechische und die hebräische, zu einander stehen. Da das

sche arabische Geschichte durch eine ereignismässige Konstellation aus, welche die Beseitigung des Opfers durch einen Todesbrief als an sich sinnvoll erscheinen lassen. - Die griechische Tradition überliefert kein Geringerer als Thukydides 1, 132, 5. Der Sklave, welchen der Spartanerkönig Pausanias mit einem Brief zum persischen Satrapen Artabazos schickte, wurde misstrauisch, weil keiner der früheren Boten zurückgekommen war. Er wagte es, den ihm ubergebenen Brief zu offnen, und fand seinen Verdacht bestatigt: der Brief enthielt die Aufforderung an den Empfănger, den Boten aus Sicherheitsgründen zu tơten. Das bewog den Bedrohten, den Brief den Ephoren zu ubergeben, wodurch der Verrat des Pausanias offenkundig wurde. - Thukydides leitet den ganzen Bericht uber die Entdeckung des Briefes mit einem $\omega_{\zeta} \lambda \varepsilon \gamma \varepsilon \tau \alpha \imath$ ein, bringt also damit eine gewisse Skepsis zum Ausdruck. Keinen selbstăndigen Quellenwert hat die entsprechende Darstellung bei Diodor 11, 45, 1f. - Eine Beurteilung ist wiederum nicht leicht, und die Problematik, die einen wichtigen und unendlich diskutierten Punkt der Thukydides-Kritik betrifft, kann hier nur gestreift werden. Der Verfasser des Artikels Pausanias in der Realencyclopádie, Schaefer, erwăhnt den Brief als schlüssigen Beweis für die Verhandlungen mit Artabazos, ohne auf den Anlass zu dessen Entdeckung einzugehen (2575, 63ff), âhnlich auch Vogt, Pausanias, bes. 301; Hooker, Spartans, $177 \mathrm{f}$. Skeptische Autoren sind zusammengestelit bei Clauss, Sparta, 193f. Zu ihnen zu zăhlen ist wohl auch Bengtson, Griechische Staatsmänner, 90ff, bes.91f, sowie deutlicher Schumacher, Themistokles, 230 ('fabulose Geschichte'). Die ausführlichste neuere Diskussion, die ich kenne, ist die - ebenfalls kritische - von Westlake, Thucydides, bes. 103f ('the story about the Argilian has an almost fairytale atmosphere'). Sicher ist das Motiv sehr eng mit der Sachlage verbunden und wirkt nicht aufgepfropft. - Zur vorislamischen arabischen Tradition vgl. unten Anm. 74. 
Potipharmotiv aus griechischer Tradition deutbar ist, hat sich als das tragende gemeinsame Motiv dasjenige des Todesbriefs erwiesen. Bekanntlich ist dieses in Eurasien weit verbreitet, wobei es für uns dahingestellt bleiben kann, wie weit zwischen den einzelnen Versionen ein genetischer Zusammenhang besteht $^{67}$.

Nach unseren heutigen Kenntnissen scheint es, worauf eben hingewiesen worden ist, zum ersten Mal in Mesopotamien, zeitlich wohl um Wende vom 3. zum 2. Jahrtausend aufgetreten zu sein. Wie nämlich H.L.J. Vanstiphout ${ }^{68}$, Bendt Alster ${ }^{69}$ und Veronika K. Afanas'eva ${ }^{70}$ fast gleichzeitig und unabhängig voneinander gesehen haben, wird der Todesbrief in der sumerischen SargonLegende verwendet, die Jerrold S. Cooper und Wolfgang Heimpel $1983^{71}$ veröffentlicht haben. Jedenfalls ist der Schluss des auf der Vorderseite der betreffenden Tafel erhaltenen Textes (Z.53ff) am ehesten in diesem Sinne zu verstehen. Der Inhalt, soweit er sich erkennen lässt, ist etwa folgender: Sargon, der Mundschenk des Königs Urzababa von Kisch, hatte einen Traum, der darauf hinwies, dass Urzababa umkommen und er selbst dessen Stelle einnehmen werde. Als er seinem Herrn davon erzählte, versuchte dieser zunächst, den gefährlich gewordenen Diener durch einen Schmied zu beseitigen. Als das nicht gelang, schickte er ihn mit einer in einen Lehmumschlag gesteckten Tontafel zu Lugalzaggesi von Umma und forderte diesen auf, den Überbringer zu töten. Der Umschlag für Tontafeln soll damals zum ersten Mal verwendet worden $\operatorname{sein}^{72}$. Irgendwie gelang es Sargon, den Inhalt des Briefes zu ändern, und so

67 Vgl. Thompson, Motif-index, 4, 303 K 511. 359 K 978. 369 K 1087; Schenda, Brief, 784ff, bes. 786f, auch Gaster, Myth, $478 \mathrm{nr}$. 140 mit den Anm. 4-6. Eine grosse Zahl von Versionen ist im jeweiligen Urtext und einer Übersetzung greifbar bei Schick, Glückskind, 1. und 2. Band. Vanstiphout, Remarks, 224 mit Anm. 65 (232f). Vgl. Alster, Uriah letter.

Russisch: Akkadskie praviteli. Deutsch und englisch: Sargon-Epos.

Sumerian Sargon legend. Sprachliche Besonderheiten legen 'a later Old Babylonian origin' nahe (68). Nach der Meinung der Herausgeber besagen die Verse Vs 53ff, dass es die Absicht Urzababas war, Lugalzaggesi gegen Sargon aufzubringen, damit er inn irgendwie beiseite schaffe (aaO 82).

72

So die sehr plausible Interpretation durch Alster, Uriah letter, 172f. Es ist beachtlich, dass die Geschichte auch bereits das mit dem Todesbrief verwandte Motiv des 'Ganges zum Eisenhammer' kennt (vgl. über dieses Shojaei Kawan, Gang zum Eisenhammer; die beiden Motive können auch spăter miteinander innerhalb ein und derselben Geschichte vorkommen, vgl. aaO 663f). Darf man das so deuten, dass damals relativ neue, 'moderne' Kulturpraktiken, Metallbearbeitung und Schrift, bei der Planung eines rănkevollen Anschlags eingesetzt wurden? Die attiologische Wendung hinsichtlich des Lehmumschlages scheint in diese Richtung zu weisen. Wenn dem so sein sollte, würde dadurch ein monogenetischer Ursprung des ganzen Motivkomplexes im Mesopotamien des spăten 3. oder des beginnenden 2. Jahrtausends nahegelegt. Es lohnte sich, diesen Gesichtspunkt weiter zu verfolgen. 
entging er dem ihm zugedachten Schicksal. Dies ganz kurz der Inhalt der ältesten Version des Motivs, welche zugleich nach dem heutigen Wissensstand die einzige ist, welche unseren beiden Geschichten vorausgeht. Der betreffende Text wurde wohl in der Schule verwendet - er ist akkadisch glossiert -, was ja für die Sargon-Legende überhaupt gilt. Die Geschichte kann daher über die Schule bekannt geworden sein. Es ist aber durchaus auch vorstellbar, dass sie sich durch volkstümliche Erzählung verbreitete.

Es war nötig, sie hier kurz zu resümieren. Beachtenswert ist nämlich, dass Uria- und Bellerophontes-Geschichte zweifellos gemeinsame Züge haben, die sie gerade von der Sargon-Version unterscheiden. Dazu gehört bei beiden die Verknüpfung mit einem Ehebruch, auch wenn die Beziehung jeweils verschieden ausgestaltet ist. Diese Verknüpfung ist sonst nur später bezeugt ${ }^{73}$, und zwar in der Ausgestaltung, wie sie der Bellerophontes-Version eigentümlich ist. Wichtiger noch ist etwas anderes. In sämtlichen Versionen (auch in der SargonVersion) ausser gerade in unseren beiden kommt der Träger des Todesbriefes davon, weil der Brief vor der Übergabe geändert wird (was vermutlich schon im Falle von Sargon geschah), weil er nach der Übergabe falsch interpretiert wird oder weil der Empfänger die Aufforderung zur Tötung nicht befolgt ${ }^{74}$. Nur im

73 Eine arabische Version bei Schick, Glückskind 2, 291ff, eine irische ebd., 341ff und eine indische ebd., $371 \mathrm{ff}$.

74

Das Motiv verbindet sich mit demjenigen des Glückskindes, daher der Titel des Werkes von Schick. - Eine gewisse Ausnahme bietet nur die Erzahlung vom vorislamischen Dichter al-Mutalammis und seinem Neffen Tarafa. Die beiden hatten sich am Hof des Lahmidenherrschers 'Amr ibn Hind (554-570) durch ihre Verse verhasst gemacht. Der Fürst veranlasste sie deshalb, in ihre Heimat zurückzukehren, und gab jedem einen Brief an den Statthalter des Gebietes mit, der angeblich die Aufforderung enthielt, ihnen Gunst und Gaben zukommen zu lassen, in Wirklichkeit den Befehl gab, beide grausam umzubringen. al-Mutallammis wurde misstrauisch und liess sich den Brief bei der Stadt al-Hira durch einen Knaben vorlesen. Nachdem er die Wahrheit erfahren hatte, flüchtete er und rettete sich so. Tarafa, obschon dadurch gewarnt, weigerte sich, den Inhalt seines Briefs zur Kenntnis zu nehmen, und wurde denn auch vom Statthalter umgebracht (so nach der bei Schick, Glückskind, 269ff gebotenen Version). Die Geschichte spielt also in einem historischen Rahmen. Ob sie als historisch betrachtet werden darf, wird im wesentlichen davon abhängen, ob die im Divan des Mutalammis erhaltenen Verse, die auf ein verhăngnisvolles Schriftstück recht deutlich Bezug nehmen (Vollers, Gedichte), als authentisch zu betrachten sind (vgl. Vollers, ebd., 154ff mit einer Zusammenstellung der einschlagigen Gedichte und Fragmente). Vgl. zum Problem zuletzt Sezgin, Geschichte, 116.173f. Wiederum wird man sagen können, dass der Todesbrief als Instrument der Bestrafung organisch in die Geschichte hineinpasst. Im übrigen wird diese auch bei der Frage nach der Verbreitung der Schrift im vorislamischen Arabien berücksichtigt (vgl. Endress, Schrift, 169 Anm. 30 [170]). Ein Argument gegen die Sonderstellung der Uria-Erzăhlung hinsichtlich des Opfers bietet sie deshalb nicht, weil das übliche Motiv der Rettung durchaus eingebaut ist: al-Mutalammis, der Vorsichtige, kommt davon, Tarafa hat seinen Tod sich selbst zuzuschreiben, was denn auch als sprichwörtlich gewordene Quintessenz in der bei Schick, aaO wiedergegebenen Version in einer arabischen Sprichwor- 
Fall von Bellerophontes und im Fall von Uria führt der Empfänger des Briefs die Aufforderung des Absenders in dessen Sinne aus, und zwar in beiden Geschichten so, dass er das Opfer der Gefahr aussetzt, im Kampf und Krieg getötet zu werden. Bellerophontes besteht die Gefahr dank überirdischer Hilfe. Uria kommt wirklich um; er ist weltweit der einzige, den die ganze Schwere der Bedrohung trifft ${ }^{75}$.

Diese Übereinstimmungen zwischen der Uria- und der Bellerophontes-Geschichte sind um so bemerkenswerter, als beide sich zeitlich nahestehen. Man könnte sie in diesem Sinne als die eisenzeitlichen Versionen bezeichnen. Sie unterscheiden sich durch diese gemeinsamen Züge von sämtlichen übrigen bekannten Ausgestaltungen, auch der älteren mesopotamischen. Es ist wenig wahrscheinlich, dass das nur auf Zufall beruht, sondern es wird dadurch nahegelegt, dass die griechische Geschichte wirklich aus dem Orient entlehnt worden ist. Die engen Beziehungen zwischen den beiden sind vielleicht am einfachsten so zu verstehen, dass die Geschichte vom Todesbrief an der Ostküste des Mittelmeers in der Einbettung in eine Ehebruchsgeschichte und mit echter Gefährdung des Opfers im Umlauf war und sowohl in Israel wie im griechischen Raum in dieser Ausprägung aufgenommen wurde ${ }^{76}$.

Dagegen ist freilich gleich einzuwenden, dass die Uriaversion in sich überaus konsistent ist. Der Tod des Uria im Kampf war ja vermutlich von den Fakten her, sozusagen biotisch vorgegeben, und die Ehebruchsgeschichte ist ebenfalls in der konkreten Situation verwurzelt, gleichgültig, ob sie real war, d.h. ob David sich wirklich dieses Vergehens schuldig gemacht hatte, oder ob sie einem naheliegenden Verdacht der Zeitgenossen entsprang. Das Todesbriefmotiv bildete ein geeignetes Mittel, eine Verbindung zwischen den Ereignissen herzustellen, d.h. den Davids - echten oder vermeintlichen - Intentionen im Wege stehenden Uria umkommen zu lassen: er bot einem Potentaten die Möglichkeit, einen hohen Gefolgsmann ohne Aufheben zu beseitigen. Das passte vorzüglich zur Situation, und zugleich stellte es David als heimtückisch handelnden Tyrannen hin, was den Tendenzen derjenigen, welche an die Ehebruchsgeschichte glaubten, durchaus entgegenkam. Es ist so leicht vorstell-

tersammlung des 12. Jahrhunderts betont wird (die Stelle bei Schick, aaO 280). Für Literaturhinweise habe ich Andreas Kaplony zu danken.

75 Aus diesem und auch aus anderen Gründen trennt Schick, Glückskind, 227f die Uria-Geschichte völlig von der 'Wandersage' und lehnt es ab, vom 'Uriasbrief' zu sprechen. Die Erzăhlung aus dem Alten Testament habe mit den übrigen Todesbrieferzahlungen nichts zu tun. Diese seien unabhăngig davon entstanden, unter sich allerdings verwandt. Dasselbe nimmt er mutatis mutandis für die Bellerophontes-Geschichte an (aaO 233ff).

76

Nach Gunn, King David, 46 wăre es 'unlikely that the story of Uriah was the first or only time this motif was employed by Israelite narrators'. Das ist aber eine petitio principii wie manche andere der mit den 'Nachfolgegeschichten' verbundene Auffassungen, die von Gunn bekämpft werden. 
bar, dass das Motiv des Todesbriefes aus einer sargonähnlichen Erzählung in den Ereigniskomplex von David, Bathseba und Uria einbezogen wurde. Von der alttestamentlichen Geschichte aus ist es demnach unnötig oder sogar unwahrscheinlich, dass es eine ältere umfassende Version im oben umschriebenen Sinne gegeben hat, die alle Einzelzüge, welche die Besonderheiten beider Versionen ausmachen (Ehebruch, Befolgung der Aufforderung durch den Empfänger des Briefes, Beseitigung des Opfers durch Gefährdung im Kampf) schon enthielt. Sie alle scheinen in der Uriageschichte genuin, d.h. durch die inneren Strukturen und Gegebenheiten von Story und Plot bedingt zu sein.

Das verleitet zu der abenteuerlichen Vermutung, dass die BellerophontesGeschichte von der Uriageschichte abgeleitet sein könnte. Dass diese letztere sich verbreiten konnte, ist durchaus zu verstehen. Sie handelte schliesslich von David, dem Begründer der temporären regionalen Grossmacht Israel, und die Geburt seines äusserlich glanzvolleren Nachfolgers war mit ihr unmittelbar verbunden. Es ist leicht vorstellbar, dass man sie auch im Reich des Verbündeten Hiram von Tyros erzählte. Bekanntlich stellte dieser Arbeiter für den Tempelbau in Jerusalem zur Verfügung ${ }^{77}$. Auch wenn man nicht annehmen will, dass gerade diese Arbeiter die Geschichte in Jerusalem hörten und sie weiter verbreiteten, so waren doch die Verbindungen offensichtlich eng und ein Austausch von Erzählgut ohne weiteres möglich. Wurde die Erzählung dann in Tyros und von Tyros aus weiter tradiert und dabei allmählich von ihren historischen Bezügen entkleidet? Dies müsste natürlich heissen, dass die Uriageschichte recht alt war, mindestens in der Zeit Salomos in allen ihren wesentlichen Zügen schon existierte. In Syrien - dieser geographische Begriff in einem sehr weiten Sinne verwendet - wurde sie dort anwesenden Griechen erzählt und von diesen rezipiert. Vielleicht handelte es sich dabei um einen kollektiven Vorgang, vielleicht aber war es ein einzelner, möglicherweise sogar ein epischer Dichter selber, der sie erzählen hörte und sie weitertrug.

Wie immer man die Zusammenhänge im einzelnen beurteilt, die griechische Geschichte von Bellerophontes bietet Gewähr dafür, dass spätestens im frühen 7. Jahrhundert an der Ostküste des Mittelmeeres eine Geschichte erzählt wurde, in welcher das Todesbrief-Motiv nach der Art der Uriageschichte die substantielle Grundlage des Plots ausmachte. Wie eben gezeigt, bestehen Argumente dafür, dass die Uriageschichte nicht aus ihr herzuleiten wäre, sondern selber ihr Ausgangpunkt gewesen sein könnte. Auch wenn man den letzteren Schluss ablehnt, wird man die frühe Existenz dieser Geschichte bei der quellen- und traditionskritischen Interpretation der 'Thronfolgeerzählungen' in Rechnung zu stellen haben. Dabei wird man beachten müssen, das sei nochmals sehr betont, dass die aktuelle Ausgestaltung der Erzählung nicht gleich alt sein muss wie ihr motivischer Kern. Jene mag viel jünger sein als

77 Vgl. 1 Kön 5,15ff. 
dieser. Und die Geschichte kann durchaus auch ihre ideologischen Tendenzen wechseln. Eine gewisse Davidfeindlichkeit haftete an ihr wohl von Anfang an. Offen bleibt, wann sie im israelischen Bereich schriftlich fixiert wurde, was ja die Voraussetzung dafür ist, dass sie in die alttestamentliche Überlieferung einging. Über alle diese Dinge ist schwer zu urteilen, da uns nur die literarische Schlussform direkt zugänglich ist.

Zweifellos ist die Verbindung zwischen Anatolien und dem Alten Testament auch in dem Bereich, den wir hier untersucht haben, eher locker. Jedenfalls führt der Weg von Osten nach Westen, und er führt klar über das Griechentum. Erst der griechische Dichter des postulierten Lykierepos hat das aus dem Orient bezogene Motiv mit Kleinasien verbunden. Das ist aber vielleicht für die Situation des westlichen Kleinasien ganz charakteristisch. Es gilt bekanntermassen generell für eine der wichtigsten kulturellen Leistungen der frühen Eisenzeit, die Alphabetschrift, welche die Griechen in Syrien kennenlernten, ihrer Sprache adaptierten und als neue Errungenschaft sodann an die westkleinasiatischen Völker weitergaben. Gerade die Lykier haben sich seit dem 7. Jahrhundert zusehends hellenisiert, aber sie haben es mehr als andere Völker verstanden, die kulturelle Identität trotzdem zu bewahren. Die BellerophontesTradition ist auch im späteren Lykien in der bildenden Kunst, im Kult und in der Namengebung zu belegen. Es wäre in diesem Sinne doch sehr interessant, wenn wirklich israelitische Erzähltraditionen ihren Beitrag dazu geleistet haben sollten. 
Bibliographie

Afanas'eva, V.K, Das sumerische Sargon-Epos. Versuch einer Interpretation, Altorientalische Forschungen 14 (1987) 237-246

- Akkadskie praviteli v sumerskom èpose. Sargon drevnij, Vestnik Drevnej Istorii 189 (2/1989) 3-16

Akurgal, E., Orient und Okzident, Baden-Baden 1966

- / Hirmer, M., Die Kunst der Hethiter, München 1961

Alster, B., A note on the Uriah letter in the Sumerian Sargon legend, ZA 77 (1987) 169-173

$A s h e r i, D$., Fra ellenismo e iranismo (Ideologia e Memoria. 3), Bologna 1983

Astour, M.C., Hellenosemitica, Leiden 1965 (die 2. Auflage des Werkes, Leiden 1967, stand mir nicht zur Verfügung)

Bass, G.F./ Pulak, C. (et al.), The Bronze age shipwreck at Ulu Burun: 1986 campaign, AJA 93 (1989) 1-29

Baumgartner, W., Israelitisch-griechische Sagenbeziehungen (1944), in: ders., Zum Alten Testament und seiner Umwelt. Ausgewăhlte Aufsătze, Leiden 1959, 147-178

Bengtson, H., Griechische Staatsmånner des 5. und 4. Jahrhunderts v. Chr., München 1983

Bittel, $K$, Die Hethiter, München 1976

Bossert, H.Th. Die phönizisch-hethitischen Bilinguen von Karatepe, JKAF 2(3) (1953) 293-339

Bryce, W.C., Epigraphische Mitteilungen, Kadmos 28 (1989) $176 \mathrm{f}$

Burkert, W., Structure and history in Greek mythology and ritual (Sather Classical Lectures. 47), Berkeley 1979

- Oriental myth and literature in the Iliad, in: $R$. Hägg (ed.), The Greek renaissance of the eighth century B.C. Tradition and innovation (Skrifter utgivna av Svenska Institutet i Athen 40, 30), Stockholm 1983, 51-56

Clauss, M., Sparta. Eine Einführung in Geschichte und Zivilisation, München 1983

Conrad, J., Der Gegenstand und die Intention der Geschichte von der Thronfolge Davids, ThLZ 108 (1983) 161-176

Cooper, J.S. / Heimpel, W., The Sumerian Sargon legend, JAOS 103 (1983) 67-82

Dunbabin, J.J., Bellerophon, Herakles and Chimaera, in: G.M. Mylonas (ed.), Studies presented to David Moore Robinson, Saint Louis/MO 1953, II, 1164-1184

Endress, G., Die arabische Schrift, in: W. Fischer (Hg.), Grundriss der arabischen Philologie I: Sprachwissenschaft, Wiesbaden 1982, 165-197

Fischer, A., David und Batseba. Ein literarkritischer und motivgeschichtlicher Beitrag zu II Sam 11, ZAW 101 (1989) 50-59

Fokkelmann, J.P., Narrative art and poetry in the Books of Samuel, I. King David (II Sam.9 - 20 \& I Kings 1 - 2) (SSN 20), Assen 1981

Frei, P., Die Lykier bei Homer, in: Proceedings of the Xth International Congress of Classical Archaeology, Ankara 1978, 819-827

Gaster, T.H., Myth, legend and custom in the Old Testament, London / New York 1969

Gunn, D.M., The story of King David (JSOT.S 6), Sheffield 1978 
Hagenbuchner, A., Die Korrespondenz der Hethiter, 1.Teil (THeth.15), Heidelberg 1989

Heimpel, $W . \rightarrow$ Cooper, J.S.

Heubeck, A., Argeiphontes und Verwandtes, BN 5 (1954) 19-31

- Die Schrift. In: F. Matz / H.-G. Buchholz, Archaeologia Homerica. III X, Gơttingen 1979

Hirmer, M. $\rightarrow$ Akurgal, $E$.

Hooker, J.T., The Ancient Spartans, London 1980

Jacquemin, A., Art. Chimaira (Lexicon Iconographicum Mythologiae Classicae III. 1), Zürich / München 1986, 249-259 (Abbildungen in III 2, Taf. 197-209)

Kaiser, O., Beobachtungen zur sogenannten Thronnachfolgeerzahlung Davids, EThL 64 (1988) 5-20

Kegler, J., Politisches Geschehen und theologisches Verstehen (CThM 8), Stuttgart 1977

Lewy, H., Die semitischen Fremdwörter im Griechischen, Berlin 1895

Malten, $L$, Bellerophontes, JdI 40 (1925) 121-160

Mazar, B., The early biblical period. Historical studies, Jerusalem 1986

McCarter jr., K.P., II Samuel (AB 9), Garden City/NY 1984

Moortgat, A., Assyrische Glyptik des 13. Jahrhunderts, ZA 47 (1942) 50-88

- Assyrische Glyptik des 12. Jahrhunderts, ZA 48 (1944) 23-44

Muhlestein, $H$., Namen von Neleiden auf den Pylostafelchen, MH 22 (1965) 155-165

Otten, H., Die Bronzetafel aus Bogazköy (StBoT Beiheft 1), Wiesbaden 1988

Peppermiller, $R$, Die Glaukos-Diomedes-Szene der Ilias, WSt 75 (1962) 5-21

Pulak, C. $\rightarrow$ Bass, G.F.

Radermacher, L., Mythos und Sage bei den Griechen, Brünn ${ }^{2} 1938$

Roscher, W.H., Art. Hipponoos, in: Ausführliches Lexikon der griechischen und römischen Mythologie I 2, 1886-1890, 2689,38-2690,8

Schachermeyr, $F$., Poseidon und die Entstehung des griechischen Göterglaubens, Bern 1950

Schaefer, H., Pausanias, PW XVIII (1949) 2563,51-2584,23

Schenda, $R$. Brief, in: $K$ Ranke u.a. (Hg.), Enzyklopadie des Mărchens, Bd. 2, Berlin / New York 1979, 784-789

Schick, J., Das Glückskind mit dem Todesbrief (Corpus Hamleticum. 1. Abteilung. Bănde 1 und 2). 1. Bd. Orientalische Fassungen, Berlin 1912; 2. Bd. Europaische Sagen des Mittelalters und ihr Verhältnis zum Orient, Leipzig 1932

Schumacher, L., Themistokles und Pausanias. Die Katastrophe der Sieger, Gymnasium 94 (1987) 218-246

Sezgin, $F$., Geschichte des arabischen Schrifttums. Bd. II, Leiden 1975

Shojaei Kawan, Chr., Gang zum Eisenhammer. In: $K$ Ranke u.a. (Hg.), Enzyklopádie des Mărchens, Bd. 5, Berlin / New York 1987, 662-671

Stamm, J.J., Der Name des Königs Salomo, ThZ 16 (1960) 285-297

Starke, F., Untersuchungen zur Stammbildung des keilschrift-luwischen Nomens (StBoT 31), Wiesbaden 1989

Stoebe, H.J., David und Uria. Überlegungen zur Überlieferung von 2 Sam. 11, Bib. 67 (1986) 388-396 
- Überlegungen zur Exegese historischer Texte - dargestellt an den Samuelisbüchern, ThZ 45 (1989) 290-314

Stolz, F., Das erste und zweite Buch Samuel (ZBK.AT 9), Zürich 1981

Thompson, S., Motif-index of folk-literature, Bd. 4, Copenhagen 1957

van Seters, J., In search of history, New Haven/London 1983

Vanstiphout, H.L.J., Some remarks on cuneiform écritures, in: H.L.J. Vanstiphout et al. (ed.), Scripta signa vocis. Studies ... presented to J.H. Hospers, Groningen 1986, 217-233

Veijola, T., Salomo - der Erstgeborene Bathsebas, in: J. A. Emerton (ed.), Studies in the Historical Books of the Old Testament (VT.S 30), Leiden 1979, 230-250

Vogt, J., Zu Pausanias und Caracalla, Historia 18 (1969) 299-308

Vollers, $K$, Die Gedichte des Mutalammis. Beitrăge zur Assyriologie und semitischen Sprachwissenschaft 5 (1906[1903]) 149-232

Watkins, $C$., How to kill a dragon in Indo-European. In: $C$. Watkins (ed.), Studies in memory of Warren Cowgill (Untersuchungen zur Indogermanischen Sprach- und Kulturwissenschaft. NS. 3), Berlin / New York 1987, 270-299

Wesselius, J.W., Joab's death and the central theme of the succession narrative (2 Samuel IX-1 Kings II), VT 40 (1990) 336-351

Westermann, C., Genesis. 3. Teilband Genesis 37 - 50 (BK I/3), Neukirchen-Vluyn 1982

Westlake, H.D., Thukydides on Pausanias and Themistocles - a written source, CQ 71 (NS 27) (1977) 95-110

Yalouris, N., Pegasus. Ein Mythos in der Kunst, Mainz 1987 

Ein hurritischer Blutritus und die Deponierung der Ritualrückstände nach hethitischen Quellen

Dem Wunsch der Veranstalter, über magische Praktiken im Alten Testament in ihrer Beziehung zu kleinasiatischen und syrischen Riten des 2. Jahrtausends zu sprechen, versuche ich mit zwei Themen aus hethitischen Ritualen gerecht zu werden: nämlich mit den hethitisch-hurritischen Traditionen der kathartischen Priestervorschriften im 3. Buch Mose, Leviticus $14^{1}$ sowie mit der Bewahrung hethitischer magischer Praktiken in der siebten Traumvision des Propheten Sacharja. ${ }^{2}$ Das erste Thema führt uns in das seit etwa 1500 v. Chr. hurritisch geprägte Südostanatolien bzw. in das alte Kizzuwatna; ${ }^{3}$ das zweite zu Überlieferungen Zentralanatoliens aus althethitischer Zeit.

\section{Der Blutritus}

Im Alten Testament ist das Besprengen mit dem Blut eines geschlachteten Tieres zur Entsühnung und Reinigung (haț̣a ${ }^{\prime} t,{ }^{\prime a} s ̌ a m$ ) im Tempelkult mehrfach belegt: ${ }^{4}$

"Der Priester soll seinen Finger in das Blut tauchen und damit siebenmal sprengen vor dem Herrn, vor dem Vorhang im Heiligen, und soll von dem Blut tun auf die Horner des Raucheraltars, der vor Gott in der Hütte des Stifts steht, und alles übrige Blut gießen an die Horner des Brandopferaltars. ${ }^{5}$

Am Versöhnungstag brachte der Hohepriester das Blut eines Bockes hinter den Vorhang und besprengte damit die heilige Lade, er "soll also versöhnen das Heiligtum von der Unreinheit der Kinder Israel und von ihrer Übertretung in allen ihren Sünden."

1 Vgl. die ausführliche Darstellung von Wright, Disposal of Impurity, 76ff.

2 Auf den Zusammenhang einiger der im folgenden zitierten hethitischen Quellen und der siebten Traumvision des Sacharja hat Delcor, La vision de la femme, aufmerksam gemacht. Zur Abhăngigkeit des Pandora-Motivs von den hethitischen Quellen siehe Popko, La boîte de Pandora, 381-383 (in polnischer Sprache) und Fauth, Schlund des Orkus, 105ff.

3 Zuletzt Kümmel, Kizzuwatna.

4 Vgl. Heiler, Erscheinungsformen, $210 \mathrm{f}$ und Wright, Disposal of Impurity, $75 \mathrm{ff}$.

5 Lev $4,6 \mathrm{f}$.

6 Lev $16,15 f$. 
Als Erkennungszeichen der hebräischen Gemeinschaft dient das Bestreichen von Türpfosten und Türschwellen mit dem Blut von Lämmern oder Ziegen beim Passah-Schlachtfest:

"Da berief Mose alle ÄItesten Israels und sprach zu ihnen: Geht und verschafft euch Kleinvieh familienweise und schlachtet das Passah. Und nehmt ein Büschel Ysop, taucht es in das Blut im Becken und bringt etwas von dem Blut im Becken an die Oberschwelle und die beiden Türpfosten".?

Kathartische Blutriten, die der Stillung des göttlichen Zorns, der Genugtuung und der Versöhnung dienen, ${ }^{8}$ sind verschiedentlich überliefert. So wird z.B. von den Nordgermanen berichtet, daß der Priester in das in den Opferkessel rinnende Blut des geschlachteten Tieres einen Wedel tauchte, um mit diesem das Volk zu besprengen sowie Altäre, Götterbilder und Tempelwände mit Blut zu bestreichen. ${ }^{9}$ Auch Heraklit kennt einen Blutritus zur Mordsühne: "Reinigung von Blutschuld suchen sie vergeblich, indem sie sich mit Blut besudeln, wie wenn einer, der in Kot getreten, sich mit Kot abwaschen wollte."10

Plinius berichtet, daß man, um ein Haus zu reinigen, die Wände mit dem Blut eines Hundes besprengt. ${ }^{11} \mathrm{Da}$ nach allgemeiner Ansicht im Blut die Lebenskraft ruht, liegt der Gedanke entsühnender oder regenerierender Blutriten nahe. Sie können mithin ubiquitär entstanden sein. Deshalb erfordert das Postulat einer gegenseitigen Abhängigkeit Übereinstimmungen nicht nur in der rituellen Idee, sondern auch in den rituellen Details, die schwerlich unabhängig voneinander entwickelt worden sein können. Für einen solchen Vergleich eignen sich verschiedene hethitische Ritualanweisungen und die Vorschriften von Leviticus 14 betreffs der Reinigung Aussätziger (V.1-32) und des Aussatzes (șära'at) an Häusern (V.33-57):

"Sodann soll der Priester Befehl geben, daß man den einen Vogel schlachte, in ein irdenes Gefaß uber lebendigem Wasser. Den lebenden Vogel aber, Zedernholz, Karmesinfaden und Ysop soll er nehmen und das [alles] samt dem lebenden Vogel in das Blut des über dem lebendigen Wasser geschlachteten Vogels eintauchen. Sodann soll er den, der sich vom Aussatz reinigen laßt, siebenmal besprengen und ihn so reinigen. Den lebenden Vogel aber lasse er ins freie Feld fliegen. Und der, welcher sich reinigen läßt, muß seine Kleider waschen, alle seine Haare abscheren und sich baden, so wird er rein werden" (1-8).

Der nahezu gleiche Ritus wird auch zur Entsühnung des Hauses vollzogen:

7 Ex 12, 21-22.

8 Heiler, Erscheinungsformen, 210f.

9 de Vries, Altgermanische Religionsgeschichte, Bd. 2, 127.

10 Diels, Fragmente der Vorsokratiker, 78 Nr. 5. Vgl. Rïsche, Blut, 105.

11 Plinius, Naturkunde, XXX, XXIV 82. 
"Wenn aber der Priester hineinkommt und bei der Besichtigung (des Hauses) finden sollte, daß der Aussatz nicht weiter am Hause um sich gegriffen hat, nachdem das Haus [neu] beworfen war, so soll der Priester das Haus für rein erklären, denn der Schade ist geheilt. So soll er dann, um das Haus zu entsuhnen, zwei Vogel, Zedernholz, Karmesinfaden und Ysop nehmen. Den einen Vogel schlachte er in ein irdenes Gefaß über lebendigem Wasser, das Zedernholz aber, den Ysop, die Karmesinfaden und den lebenden Vogel soll er nehmen und das [alles] in das Blut des geschlachteten Vogels und in das lebendige Wasser tauchen und das Haus siebenmal besprengen, und soll so das Haus mit dem Blut des Vogels und mit dem lebendigen Wasser, sowie mit dem lebenden Vogel, dem Zedernholz, dem Ysop und den Karmesinfaden entsühnen. Den lebenden Vogel aber lasse er hinaus vor die Stadt ins freie Feld fliegen und schaffe so dem Hause Suhne: so ist es rein" (48-53).

Der Sinn der Prozedur ist relativ leicht zu ersehen: Im Mittelpunkt der Ritualhandlungen steht der Ritus mit den beiden Vögeln. Der eine wird über dem mit frischem Wasser gefüllten Gefäß getötet und das Vogelblut in diesem Gefä $\beta$ aufgefangen. Nun wird der lebende Vogel zusammen mit der übrigen materia magica hineingetaucht und mit dem so verdünnten Blut in Kontakt gebracht, so daß sich die kathartischen Eigenschaften des Wassers und des Blutes auf die materia magica übertragen und deren Wirkung steigern. Die Reinigung besteht aus zwei Komponenten: Zum einen aus der reinigenden Kraft des auf den Aussätzigen bzw. auf das Haus gesprengten Wassers und Blutes, das auf den lebenden Vogel transferiert wurde, und zum anderen aus einem Kontakt- oder Übertragungsritus, der durch den Gestus des Besprengens eine Verbindung zwischen dem Aussätzigen und dem lebenden Vogel und der übrigen materia magica herstellt. Der nun mit den Unheilsstoffen behaftete "Sündenvogel" entfliegt und führt die Unheilsstoffe mit sich fort, damit sie der Gemeinschaft keinen neuerlichen Schaden zufügen können. ${ }^{12}$

Die Gepflogenheit, Vögel als Unheilsträger zu verwenden, ist - abgesehen von den mesopotamischen Namburbi-Ritualen ${ }^{13}$ - vor allem in hethitischen und hurritisch-hethitischen Ritualen südostanatolischer Provenienz wiederzufinden, in denen sowohl die in Lev 14 zur Reinigung verwendeten Materien Vögel, Zedernholz ${ }^{14}$, rote Fäden und bestimmte Kräuter - als auch die magischen Prozeduren mit den Vögeln, insbesondere das Bestreichen mit Vogelblut ${ }^{15}$, begegnen.

12 Vgl. Wright, Disposal of Impurity, 78ff.

13 Bearbeitet von Caplice, Namburbi Texts, 34-38, 273-278.

14 Zu der hăufigen Verwendung der kathartischen Materie Zedernholz ( ${ }^{\mathrm{GIS}} \mathrm{E}$ ERIN) vgl. z.B. ChS $\mathrm{I} / 2$.

15 Im babylonischen Schrifttum ist mir Vogelblut als materia magica nur aus AMT 73 2:5 - ÚŠ MUŠEN hurri - bekannt. 
Im Ritual des Ritualisten Muwalanni ${ }^{16}$ "bestreicht man" zum Zweck einer Reinigung (ähnlich wie in dem hebräischen Ritual) "vier rote Bänder, vier $k u$ rešsar-Tücher, vier Leinenstoffe, vier kišri-Wollobjekte ${ }^{17}$ und vier Vögel alles zusammen mit Blut."18

Der hurritische Ritus des Blutes (s.u.) zur Reinigung oder Entsühnung eines Hauses, nie aber eines Menschen, besteht aus drei Elementen: der Schlachtung von Vögeln, dem Bestreichen der zu reinigenden Gegenstände mit dem Blut der Vögel und dem anschließenden Verbrennen derselben. Dieser Ritus mit dem kennzeichnenden hethitischen Formular ešharnumae- / warnu- "mit Blut bestreichen / verbrennen" begegnet in mehreren Ritualtafeln, die aus verschiedenen Fragmenten wenigstens teilweise zu rekonstruieren sind. ${ }^{19}$ Das Ritual dient der Reinigung und Entsühnung des Sakralhauses oder eines Sakralraumes šinapši- ${ }^{20}$ - hier als "der Berg (ist) šinapši-" (papani=ni sinapši) ${ }^{21}$ bezeichnet. Wegen seiner Funktionen - der vorübergehenden Aufbewahrung des Toten ${ }^{22}$ oder der Purgation des Königspaares vor den Ritualhandlungen ${ }^{23}$ - ist das sinapši Verunreinigungen ausgesetzt und bedarf entsprechender Riten. So werden bei der Reinigung und Entsühnung die Bauteile (tali-, dulpuri-) ${ }^{24}$ und

16 CTH 703.

17 Nach Beckman, Hittite Birth Rituals, 174 "Handschuh".

18 KBo XI 5 Rs. VI:

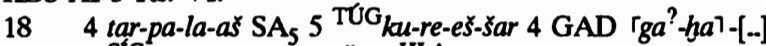

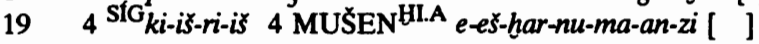

19 A KUB XXXII $52\left(t^{?}\right)$ KBo XXXIII 63.

B KBo XXXIII 169+1302/c+1228/c(+? $)$ KBo XXXIII 161 $\left(+^{?}\right)$ IBoT IV 257.

C 24/w (vgl. Haas / Wegner, Rezension, 83, 294). Parallel: 1556/c, 1273/v(?), 2/u .

20

Haas / Wilhelm, Hurritische und luwische Riten, 36-38; Gentili Pieri, L'edificio "sinapsi", 1-4;

Beckman, Hittite Birth Rituals, 113.

$21\left(^{+}\right.$) KBo XXXIII 161+ (siehe Anm. 19) rechte Kol.:

5. [1 MUŠEN-ma pa-a-p(a-an-ni)] si-na-ap-si w[a-ar-nu-an-zi]

6' [nu pa-a-pa-an-(n)i] si-na-ap-si iš-har- $[n u 1-m[a-a n-z i]$

7) [1 MUŠEN-ma ta-li du-u]l-pu-ri si-na-ap-š-aš w[a-ar-nu-an-zi]

8' [nu ta-li du-u]l-pu-ri Si-na-ap-se-ni-we[ ${ }_{e}$-na iš-har-nu-ma-an-zi]

Zum Zusammenhang Berg und sinapši vgl. auch KBo XI 1 Vs. 32: ma-a-an-ma HUR.SAG-ma ku-iš-ki na-aš-ma ši-nap-ši šu-up-pa $A \check{S}$-RU ku-it-ki HUL-ah-ha-an "wenn jemand einen Berg oder ein šinapši - irgendeinen heiligen Ort - böse gemacht hat ...", des weiteren 1273/v 2', I]-NA HUR.SAG si-na-ap-[si.

KUB XXX 28, bearbeitet von Otten, Hethitische Totenrituale, 94-97, Rs. 1-20.

23

KUB XXX 31 (Dupl. KUB XXXII 114), bearbeitet von Lebrun, Textes religieux, 93-116 Vs. 1-6 "Am 16. Tag, solange die Sonne noch nicht aufgegangen ist, entleeren sich der König und die Konigin in Hattuša - sie sitzen (dabei) getrennt. Sobald aber die Sonne aufgegangen ist, entleeren sie sich dort in Kizzuwatna im Tempel des Wettergottes (und) im šinapši-Haus."

Siehe Anm. 21 und Haas, Preis auf das Wasser, 269 mit Anm. 40. 
das gesamte Hausgerät, Möbel (kešhi- "Thron", tabri- "Stuhl", tuni "Fußschemel", das Möbel adani-), Räuchergefäßständer und Räucherschale (huprušhiahrušhi-) sowie der Opfertisch (nirambi-šalanni) ${ }^{25}$ diesem Ritual unterzogen:

7 Einen Vogel aber [verbrennt man] für nirambi-šalanni;

8 und man bestreicht den [Tis]ch mit Blut.

9 Einen Vogel aber [verbrennt man] für papanni-šinaps [i];

10 und man [bestreicht] pa[pa]nni-šinapši mit Bl[ut]

usw. $^{26}$

Ähnlich verfährt man in dem Geburtshilferitual des (einen hurritischen Namen tragenden) Ritualfachmanns Papanekri ${ }^{27}$ von Kummanni ${ }^{28}$, um die Geburtsutensilien zu reinigen, bzw. zu entsühnen:

25 Aus KBo XXXIII 169+ rechte Kol. 7'-8' (siehe Anm. 26) ergibt sich die Gleichung nirambi salanni $={ }^{\text {GIŠ }}$ BANŠUR, wobei šalanni wohl lediglich eine Spezifizierung bedeutet (vgl. auch ú-i-ma-aš-ši saa-la-an-ni KBo XXIII 42 IV 19, KUB XIVII 37 3', KUB XXVII 1 III 32). Zu vergleichen ist KUB XLIV 58 (= Beckman, Hittite Birth Rituals, 216) Vs. II:

2' tu-u-ni [tab-ri ki-iš-hii a-da-ni]

3) ni-ra-am-bi [sa-la-an-ni ${ }^{\left.D_{u}-u p-p i-n a\right]}$

4' 3 NINDA SIG ${ }^{\text {MES }}$ pár-ši-ia.

26 KBo XXXIII 169 + rechte Kol:

7) 1 MUŠEN-ma $\lceil n i\urcorner-r a-a m-\ulcorner b i\urcorner-i a$ ša-l[a-an-ni]-ia wa-ar-[nu-an-zi]

8' $n u{ }^{\mathrm{GISS}} \mathrm{B}[\mathrm{ANŠU}] \mathrm{R}$ is-har-<nu>-ma-a-an-zi [

9' 1 MUŠEN-ma pa-a-pa-an-ni ši-na-「ap?-s[i w]a-ar-nu-an-zi

10' nu pa-a-[pa]-[an'-ni క̌i-na-ap-si 「isT-[har-nu-m]a-an-zi

11' nam-ma $[A]-[N] A \mathrm{D}_{\text {um-pu }} \mathrm{D}_{\text {ta-aS-mi-i[s- ] }}$

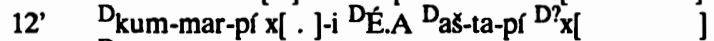

13' $D_{\text {nu-pa-ti-ik e-se ba-wu }}$-ur-ni pa-a-[pa-an-ni si-e-na]

14' D ${ }^{\prime}$ e-eš-su-up-pa-pí hu-u-pí-ti ${ }_{\text {Šar-r[u-ma ] }}$

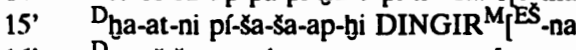

16' D te-es-su-up-pí

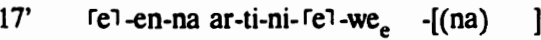

18' [t]a-li du-ul-pu-ri si-na[(-ap-si-ni-wi $\left.{ }_{\mathrm{i}}\right)$

19' re 7 -ri i-ia-a-ri ap-se s[(e-e-ri sa-a-ri)

20' [ku-u]n-ti es-ga-ri za-g[(a-p)u si-na-ap-si-ni-wi $\left.i_{i}-n a\right]$

21' [e-e]n-na bुé-e-a-ru-[un-na

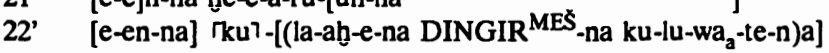

(Bruch)

27 Der Name bedeutet: "der Berg (papa-) (ist) der Riegel (nekri-)".

28

CTH 476; bearbeitet von Sommer / Ehelolf, Das hethitische Ritual. 
25 Ferner bestreicht er mit zwei Voggeln Gebărgestell und Pflocke, jedwedes

26 gesondert mit Blut; vor dem Gebărgestell

27 bringt er zweimal mit zwei Schafen und vier Vogeln ein Blutopfer dar. ${ }^{29}$

Im weiteren Verlauf des Rituals geschieht dasselbe auch mit einer Wasserschüssel. ${ }^{30}$ Ausführlicher beschreibt diesen Vorgang ein anderes Geburtshilferitual ${ }^{31}$ so:

12' Und den Stuhl, den Tisch, das Bett,

13' den Gefaßstănder, das Gebărgestell der Frau, und auch die Frau selbst, umschwenkt der patili-Priester

14' mit einer Brandgans.

15' Sodann bringt die Frau im Innenraum (des Hauses) für (ihr) zurki

16' (die Brandgans) als Blutopfer dar und wäscht sich ihre Hande.

17' Sodann bringt man sie vor das Gebărgestell hinein.

18' Sodann bringt sie eine Ente für (ihren) Weg(?) als Blutopfer dar; eine (andere) Ente aber

19' bringt sie für (ihr) habi, für (ihre) itkalzi-Reinigung (und) für (ihr) kulamu(r)š

20' als Blutopfer dar. Sodann bestreicht man das Gebărgestell und die Pflocke

21' mit (dem) Bl[ut] (der Enten).

22' Sodann sind Zeder(nholz), Tamariske(nholz und) Olive(nholz) mit roter Wolle

23. umbunden; und dies nimmt der patili-Priester

24' und legt sie für die / zu der Frau in die Binden(?) hinein;

25, und Feinol schüttet er ihr

26' auf ihren Kopf, und an ihre Hand

27' bindet er ihr rote Wolle an. ${ }^{32}$

29 KBo V 1 Vs. I:

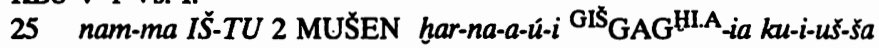

26 ar-ha-ia-an iš-har-nu-ma-iz-zi u-uz-zi-ia-ia har-na-a-ú

27 pi-ra-an 2-ŠU IŠ-TU 2 UDU 4 MUŠEN-ia si-pa-an-ti

30 KBo V 1 Rs. III:

$41 n u$ DUG ÁBxA ti-an-zi na-an IŠ-TU MUŠEN ǐ̌-har-nu-ma-an-zi

31 KUB IX 22 (mit Duplikaten), bearbeitet von Beckman, Hittite Birth Rituals, 86-115.

32 KUB LX 22 Vs. II:

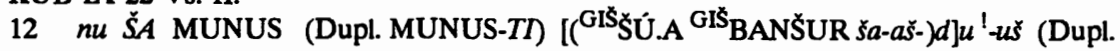
sa-aš-ta-an)

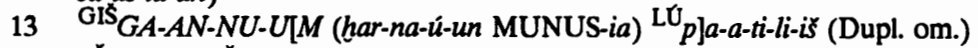

14 IŠ-TU MUŠEN [(HUR-RI wa-ah-nu)-uz-zi] (Dupl. wa-ah-nu-[(wa-)an-zi])

$15 n u-z a-k a ́ n$ [(MUNUS rÉ].)Š(À an-da zu)]-ür-ki-ia

$16 \check{s i}$-pa-an-t[(i nu-za)-kán(ŠUU$\left.\left.{ }^{M E S ́ s ̆ U}\right)\right] a-a r-r i$ 
Der mit esharnumae- bezeichnete zentrale Ritus des mit Blut Bestreichens ist in einem weiteren Geburtshilferitual ${ }^{33}$ mit der luwischen Verbalbildung ${ }^{34}$ zurkitae- ${ }^{35}$ "den Ritus des zurki- vollziehen", bezeichnet:

31 [ ] Dann geht die Frau in jene Raume hinein; am Gebărgestell aber

32 [ und in je]nen Raumen vollzieht sie den zurki-Ritus. Ferner

33 [ ]x wirft sie hinein; Zeder(n-Holz), Olive(n-Holz),

34 [Tamariske(n-Holz) ...] nimmt sie nicht. ${ }^{36}$

Dem Verbum zurkitae- liegt das hurritische Nomen zurki- zugrunde, das E. Laroche überzeugend mit hethitisch ešhar "Blut" geglichen hat. ${ }^{37}$ Mithin ist zurkitae- (Nomen zurki-) eine zu ešharnumae- (Nomen eshar) analoge denominale Verbalbildung.

Für das kathartische Zeremoniell des zurki, SÍSKUR zurkiyaš "Ritus/Ritual des Blutes", kann auch das Blut anderer Tiere - Schafe, Ziegenbock, Ziegen ${ }^{38}$

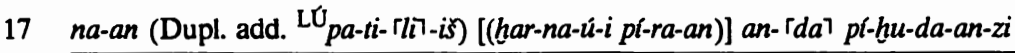

$18 n u 1$ MUŠEN.[(GAL ḩa-a-「ri-ia] ši-pa-an-t)]i 1 MUŠEN.GAL-ma

19 ha-a-pi-[(ia it-kal-zi-ia k)]u-la-mu-si-ia (Dupl. rkal-la-mur-ši-)

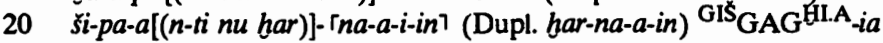

21 is-h[ar-nu-ma-a]n-zi

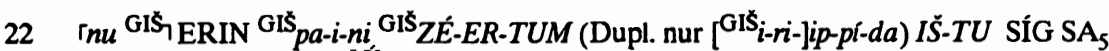

23 an-da iš-hi-ia-an na-at LÚpa- 「tiT-li-is

24 da-a-i (Dupl. om.) na-at-kán A-NA MUNUS (Dupl. MUNUS-TI) i-pu-ul-li-ia-aš

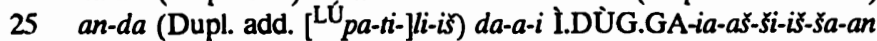

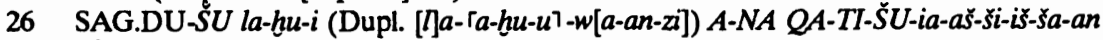

27 SÍG SA 5 ha-ma-an-ki

KBo XVII 65 + ABoT 21, bearbeitet von Beckman, Hittite Birth Rituals, 132-175.

Hinweis Erich Neu.

Vgl. Otten, Materialien, 13.

31 n]a-aš-ta rMUNUS1-זza a-pé] e-da-aš pár-na-aš 「an?-da pa-iz-zi har-nu-u-i-x[ ]x-wa-aš[ ]

32 a-pé]- $\left.e_{e}\right]-d a-a s ̌$ pár-na-aš $a[n-d] a$ zu-ür-ki-rta]-a-iz-zi nam-ma-aš-ša-a[n

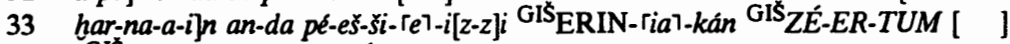

34 [ [IIS pa-a-i-ni a]n-da U.UL da-a-[i].

Laroche, Études, $95-98$ (mit Anm. 37); ders., Glossaire, 309. 
- verwendet werden. Bevorzugt ist Blut junger Tiere wie das von Lämmern und Zicklein, da sich in ihnen die Lebenskraft noch unverbraucht konzentriert. Singulär ist die Erwähnung eines Hasen (arnabu $)^{39}$. In den dem luwischen Milieu angehörenden Ritualen sind die Schafe und der Ziegenbock als Substitute (nakkušsi-/nakkušsahiti) bezeichnet. ${ }^{40}$ In dem Bau- oder Deponierungsritual CTH 415 werden die unter den Fundamenten zu deponierenden Gegenstände - vier Götterstatuetten, eine Stierfigur aus Bronze sowie ein ayakki-Kultgegenstand - mit dem Blut eines Schafes, dessen Fleisch dem Gott Ea geopfert wird, beschmiert. ${ }^{41}$

In dem Ritual des Ritualfachmannes Ulippi ${ }^{42}$, das anläßlich der Umsiedelung des Götterbildes in einem neu erbauten Tempel vollzogen wird, werden für den Ritus des Blutes die folgenden Ritualien benötigt:

3 Ein weißes kurešsar-Tuch, ein tarpala- aus blauer Wolle, ein tarpala- aus roter Wolle, ein kišri-Wollgegenstand,

4 eine Garnitur Vorhange, viermal dicke (Stoffe), zwei Sekel Silber, davon 1 Sekel Silber

5 für die Opfergrube, ein Sekel Silber aber für die gangatatt-Entsühnung, zehn flache Brote,

$\begin{array}{ll}\text { 4' } & 1 \text { UDU ik-ku-na-at-ta-aš } 1 \text { UDU[ } \\ 5 & \text { iš-har-nu-ma-an-zi } 1 \text { MÁŚ.GAL-ma } A-N[A \\ \text { 6' } & \text { na-ak-ka-uš-si-i-x[ } \\ \text { 7' } & 1 \text { ŠAH.TUR 1 UR.[ } \\ \text { 8' } & \text { MUŠENHI.A ǐ̌-[har-nu-ma-an-zi } \\ \text { 9' } & 1 \text { NINDA a-a-an[ }\end{array}$

KBo XXIX 3.Vs. I:

5 Š̀.B]A 2 UDU ${ }^{\mathrm{HI} . \mathrm{A}}$ a-ni-u-ra-aš BABBAR GE $\mathrm{B}_{6}-i a$

6 1] UDU sar-la-at-ta-aš 1 UDU."SÍG+MUNUS" ti-i-ta-an-ta-[as']

7 GIR] ${ }^{\mathrm{MES}}$ Š $U-N U$ ku-e-ez iš-har-nu-ma-an-zi

$8 k e-e l]$-di-ia-as $A-N A$ SISKUR da-an-zi

9 k]at-ta-an na-ak-ka-uš-sa-hi-ti da-an-zi

39 KUB LVIII 57 Vs. I?:

11' nu rSÍSKUR zu-ür-ki-an-za PA-NI x[

12' [nam?-ma [EN.SÍSKUR' AR-NA-B[I

13' [ ] ]x EN.SÍSKUR IT-TI x[

14' $\mathrm{j} x$-an-zi $n u$ SISKUR zu-ú[r-

$40 \mathrm{KBo} \operatorname{XXIX} 3(+)=$ Starke, Die keilschrift-luwischen Texte, $98-100$ und Bo 4388, s. Anm. 38, $2^{\prime}-8$ '.

41 KBo XIII 114 Kol. III 2-8.

42 KUB XXIX 4, bearbeitet von Kronasser, Umsiedelung der schwarzen Gottheit. 
6 zwei mulati-Brote eines halben Liters, ein kleiner Käse, ein wenig Feinöl,

7 ein halber Liter Olivenol, ein halber Liter Honig, eineinhalb Liter Butter, ein waksur-Maß Wein,

8 ein Lamm oder ein Zicklein - dies nehmen sie für das Ritual des Blutes. ${ }^{43}$

Vom Vollzug des Rituals des Blutes berichtet der folgende Absatz:

28 Wenn aber an jenem Tage zur Nachtzeit

29 ein(e) Stern(schnuppe) springt, geht der Ritualherr

30 in den alten Tempel; er verneigt sich nicht vor der Gottheit

31 und tritt hinter das Ritual des Blutes;

32 und andere vollziehen mit einem Vogel das Ritual des Blutes.

33 Hinterher aber bringen sie die kleine Ziege oder das Lamm als Blutopfer dar. ${ }^{44}$

Am Ende des Rituals wird der Blutritus nochmals vollzogen; genauso wie in dem rekonstruierten Ritual zur Entsühnung des šnapši-Sakralhauses und ähnlich wie in dem hebräischen Ritual werden die Götterstatuette und das Tempelgerät mit Blut gereinigt:

34 ... und sie graben fur die Gottheit vor dem Tisch eine Grube.

35 [Sodan]n bringen sie ein Schaf der Gottheit für (ihr) enumašše ${ }^{45}$,

36 und sie schlachten es in die Grube hinab.

37 [Das Ziehen] aber von der Wand ${ }^{46}$ findet nicht statt. Einen Tisch, der gemacht (worden ist),

38 [ ] $\mathrm{x}$ und sie bestreichen das Gơtterbild (aus) Gold, die Wand, die Utensilien der G[ottheit] (und) alles neue (Gerát) mit Blut.

43 KUB XXIX 4 Vs. II:

31 TÚG $k u$-re-eš-šar BABBAR 1 tar-pa-la-aš SÍG ZA.GÌN 1 tar-pa-la-aš SÍG SA 1 sig $_{k i-i s-r e-e s}$

4 1-NU-TIM KUŠ NÍG.BÀR 4.TA.ÀM ŠA-PU-Ú 2 GÍN KÙ.BABBAR Š̀̀.BA 1 GÍN KÙ.BABBAR

5 a-a-pi-ti-i 1 GÍN KÙ.BABBAR-ma ga-an-ga-ta-at-ti 10 NINDA SIG ${ }^{\text {MES }}$

62 NWNDA $_{\text {mu-u-la-ti-ǐ } \breve{S} A} 1 / 2$ UP-NI 1 GA.KIN.AG TUR İ.DÜG.GA te-pu

7 1/2 UP-NI İ.GIŠ 1/2 UP-NI LÀL 1 1/2 UP-NI İ.NUN 1 wa-ak-šur GEŠTIN

$81 \mathrm{SILA}_{4}$ na-aš-ma MÁS̆.TUR ki-i $A-N A$ SÍSKUR zu-ur-ki-ia-aš da-an-zi

44 KUB XXIX 4 Vs. II:

28 ma-ah-ha-an- 「ma] a-pi-e-da-ni UD-ti ne-ku-uz me-hur

29 MUL-aš wa-at-ku-uz-zi nu EN SÍSKUR ka-ru-ú-i-li

30 I-NA É DINGIR-LIM ú- rizา-zi na-aš A-NA DINGIR-LIM Ú-UL UŠ-KI-EN

31 na-aš EGIR SÍSKUR zu-ür-ki-ia-aš $\lceil t i\urcorner-i a-a z-z i$

32 โnu SÍSKURา zu-ür-ki-ia-aš IŠ-TU rMUŠENา ši-pa-an-da-an-zi

33 EGIR-šU-ma MÁŠ.TUR na-aš-ma SILA 4 ši-pa-an-da-an-zi

Vgl. noch Rs. III 56-57.

$45 \mathrm{Zu}$ enumašše vgl. Haas / Wilhelm, Hurritische und luwische Riten, 75-77.

46 Ein noch unklarer Ritus. 
40 Und (so) wird die [neu]e Gottheit und (ihr) Tempel rein. Vor

41 dem Tisch aber wird (das Schaf) verbrannt; niemand ißt davon. ${ }^{47}$

Die kathartische Ritualhandlung des Bestreichens eines zu entsühnenden Gegenstandes mit dem Blut eines geschlachteten Tieres hat die Bezeichnung SÍSKUR zurkiyaš "Ritual des Blutes". ${ }^{48}$ Mithin stehen die Ritualabschnitte aus Leviticus 14 in der Tradition des hurritischen oder des altsyrischen "Rituals des Blutes" SíSKUR zurkiyaš.

Das Besprengen mit dem Vogel in Leviticus 14 ist ein in hethitischen Ritualen häufig vollzogener kathartischer Ritus, der den Kontakt zwischen der zu reinigenden Person oder Sache und dem Vogel herstellen soll. Dies geschieht auf zweierlei Weise. Entweder wird der Vogel, gelegentlich aber auch nur Flügel oder Feder, um den (zu reinigenden) Ritualherrn herumgeschwenkt, ${ }^{49}$ oder man besprengt, wie in Leviticus 14 , die betreffenden Gegenstände oder Personen: In dem folgenden Abschnitt eines kathartischen Zeremoniells des großen südostanatolischen Landfestes, dem (h)išuwa- Festritual ${ }^{50}$, kommen beide Verfahrensweisen zur Anwendung: Abwechselnd besprengt der Priester die Götterbilder und den König, zuerst mit einer Fackel, die mit roten Bändern ( ${ }^{\mathrm{SIG}}$ ali, SÍG $\mathrm{SA}_{5}$ ) umwickelt ist ${ }^{51}$ und sodann mit einem Adlerflügel bzw. einer Adlerfeder:

47 KUB XXIX 4 Rs. IV:

$34 \quad \ldots n u$ A-NA DINGIR-LIM PA-NI GIŠ BANŠUR a-a-pi pid-da-an-zi

35 [na-aš-t]a 1 UDU A-NA DINGIR-LIM e-nu-ma-aš-si-ia si-pa-an-da-an-zi

36 [na-a]n-kán ha-at-te-es-ni kat-ta-an-da ha-ad-da-an-zi

37 [SUD-ar-]ma ku-ut-ta-az Ú-UL e-es-zi GIS BANŠUR i-ia-ran-ta]-an

38 [ne-a]n?-ta nu DINGIR-LUM GUŠKIN ku-ut-ta-an Ú-NU-TE ${ }^{\mathrm{MES}}$

$39 S$ SA DINGIR-LI]M GIBIL hu-u-ma-an e-es-har-nu-ma-an-zi

$40 n u$ DINGIR [GIBI]L É DINGIR-LIM-ia šu-up-pi-eš-zi $\ulcorner P A 7-N I-m a$

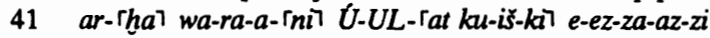

Zum Bestreichen von Orakelgruben mit Blut vgl.: KBo XIII 101 I 27'-30', vgl. Haas / Wilhelm, Hurritische und luwische Riten, KUB XXXII 67 Vs. I 2'-6', KBo XXIV 45 Rs. 11-12, KBo XXVII 202 8'-10'.

Der Terminus technicus hierfür ist šer arha wahnu- "darüber hinweg schwenken". In dem Ritual KBo XVII 1 (bearbeitet von Otten / Soucek, Ein althethitisches Ritual) wird über dem Konigspaar ein Adler geschwenkt, der dann als Bote zum Sonnen- und Wettergott fliegen soll (vgl. auch Keel, Vögel als Boten). Weitere Belege in Auswahl: ChS I/2 Nr. 25 Rs. 9-14; ChS I/5 Nr. 78 Vs. II 14, KBo V 2 Rs. IV 49. - Eine schlagende Parallele zu diesem Ritus bietet ein Substitutionsritus aus Palästina, in dem man mit einem Huhn um die von Damonen bedrängte Person bzw. Örtlichkeit schwingende Bewegungen ausführt, Scheftelowitz, Alt-Palăstinensischer Bauernglaube, 46. CTH 628; zuletzt Dinçol, Ein hurro-hethitisches Festritual.

51 KBo XXIII 28+KUB XXXII 65+61+KBo XXVII 198 Vs. I 54'-60'. 
7) Ferner umschwenkt er auch mit eben jener Fackel

8' den König und er spricht eben jene

9' Worte. ${ }^{52}$ Sobald er aber den Konig zu umschwenken

10 ' beendet hat, sprengt er

11' mit der Adlerfeder dem König gegenüber

12' Wasser; dabei 'klatscht'(?) er einmal. ${ }^{53}$

Am Ende solcher Ritualhandlungen läßt sich der hethitische Priester, ebenso wie sein babylonischer ${ }^{54}$ oder hebräischer Kollege, den Sünden- und Substitutionsvogel, wenn er ihn nicht verbrennt, ${ }^{55}$ entfliegen. ${ }^{56}$

\section{Die Traumvision des Sacharja}

Das Fortschaffen der Lymata - Unheilsstoffe und Ritualrückstände - wenn auch nicht direkt von einem Vogel, so aber doch von zwei Weibern mit Storchenflügeln, behandelt mein zweites Thema: Die siebte Traumvision des Propheten Sacharja.

Das Buch des Sacharja besteht aus zwei Teilen, die von verschiedenen Verfassern und aus verschiedener Zeit stammen.

Der hier interessierende erste Teil (Kapitel 1-8) geht unmittelbar auf den Propheten, nämlich auf seine Tätigkeit in Jerusalem vom November 520 bis zum Dezember 518 v. Chr. zurück. Er enthält die Verkündigungen des Propheten in der literarischen Form der Visionsbeschreibungen und Sprüche. Auf eine einleitende Mahnung zur Umkehr zu Jahwe folgen acht Träume, von denen wir uns die siebte Traumvision vom Weib in der 'êphä betrachten wollen:

"Da ging der Engel, der mit mir sprach, los. Er sagte zu mir: Hebe deine Augen auf und sieh das Epha-GefaßB, das dort loszieht. Ich sagte: Was ist das? Er sagte: Dies ist ihre Schuld im ganzen Land. Und siehe, da hob sich eine Bleiplatte $a b$, und nun saß ein einzelnes weibliches Wesen inmitten des Epha-Gefaßes. Er sagte: Dies ist die Bosheit, und warf sie in das Epha-Gefăß zurück und warf den Bleistein auf dessen Öffnung. Und ich erhob meine Augen und sah, siehe, da zogen zwei weibliche Wesen los, Wind war in ihren Flügeln, sie hatten Flügel wie ein Storchenflügel, und sie hoben das Epha-Gefäß auf zwischen Erde und Himmel. Ich sagte zu dem Engel, der mit mir sprach: Wohin bringen

52 Es handelt sich um den (rekonstruierten) hurritischen Spruch: [dariš ti]ariš uminnašinnae [upp]alurzǐ tiariš ininiš tiariš pašeneš tiariš panaqqa [ammaia marušenne] bittenni ašinnanti (KBo XXIII 28+ Vs. I 61-64).

KBo XXIII 28+ Vs. II. 
sie die Epha? Er sagte zu mir: Um ihr einen Tempel zu bauen im Lande Sinear, sie stellen sie dort auf inr (Götter-)Podest." ${ }^{\text {"57 }}$

Wie in der vorangegangen Traumvision, so geht es auch hier um eine Reinigung, um eine Entsühnung der Gemeinschaft. ${ }^{58}$

Das Epha-Gefäß ist ein großes Getreidemaß in Gestalt eines Pithos mit einem Fassungsvermögen zwischen 25 und über 40 Litern..$^{59}$ In diesem Trog ist die menschliche Bosheit - wiedergegeben mit der unüblichen femininen Form ris ${ }^{\prime} \bar{a}^{60}$ - gesammelt und mit einem Bleideckel verschlossen. Die Bosheit

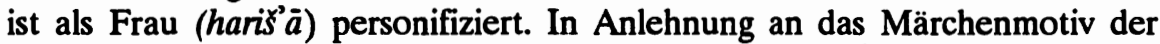
Luftreise tragen zwei andere Frauen mit Storchenflügeln ${ }^{61}$ die in dem Gefäß verschlossene Frau Bosheit durch die Lüfte weit fort nach Sinear, damit sie dort, in Babylonien, der Heimat alles Bösen, ${ }^{62}$ polemisch als die Hure Babylon bezeichnet, zur Anbetung in einem Tempel verbleibe. ${ }^{63}$

Motivgeschichtlich erinnert die Vision an den antiken Erzählstoff von dem Pithos, in späterer Überlieferung der Büchse der Pandora, dessen älteste Bezeugungen in der Theogonia und in den Erga des Hesiod, ${ }^{64}$ also etwa um 700 v. Chr., vorliegen. In den Erga erzählt Hesiod: Zu der Zeit, als die Menschheit noch ohne die den Tod verursachenden Übel, Mühen und Krankheiten lebte, befahl Zeus dem Hephaistos, die schöne Pandora aus Erde zu schaffen, um den Feuerdiebstahl des Prometheus zu rächen. Der Geleiter Hermes bringt die schön geschmückte Pandora zu den Menschen, wo sie Epimetheus, der Bruder des Prometheus, zum Weibe nimmt. Pandora öffnet den Deckel eines Pithos, in dem alle Übel und Leiden der Menschheit eingeschlossen waren und die nun bis auf Elpis, die Hoffnung, entweichen und sich unter den Menschen verbreiten. Von Pandora, so führt der frauenfeindliche Dichter in der Version der Theogonia aus, stammt das Geschlecht der Frauen, das ja seit jeher die Männer geplagt hat.

57 VI. 5,5-11. Nach der Übersetzung von Gese, Vom Sinai zum Zion, 212.

$58 \mathrm{Zu}$ dem von der Katharsis betroffenen Personenkreis vgl. Galling, Studien, 119.

$59 \mathrm{Vgl}$. Gese, Vom Sinai zum Zion, 212.

$60 \mathrm{Vgl}$. Gese, aaO, $212 \mathrm{f}$.

61 Storchenflügel wohl deshalb, weil der Storch ein Zugvogel ist, der weitere Entfernungen zurücklegt, vgl. Gese, aaO, 213.

62 Gen 11.2 ff.

63 Für die Annahme von Galling, Studien, 120, daß die Frau Bosheit letztlich die Ištar von Babylon sei, gibt es keinerlei Grund, vgl. auch Gese, aaO, 213, Anm. 51.

64 Hesiod, Theog. 571-584; Erga 70-82. Zur Frage der Interpolationen vgl. Lendle, 'Pandorasage' und die Rezension von Kilhn, Gnomon 31, 114-123. 
Wie in der Vision des Sacharja, so begegnet auch in dieser, etwa zweihundert Jahre älteren Erzählung ein Pithos, in dem alles Unheil deponiert ist und der mit einer Frau in engem Zusammenhang steht.

Konkret, zu magischen Zwecken verwendet, ist ein solches Gefäß in einem Brief an den assyrischen König Asarhaddon ${ }^{65}$ (680-669 v. Chr.) erwähnt. Darin wird in Anbetracht eines ungünstigen Omens empfohlen, die abgeschnittenen Fingernägel des Königs in ein Gefäß - [ina $\left.{ }^{\mathrm{D}}\right]^{\mathrm{UG}} l a-h \mathfrak{a}$-ni - zu versiegeln, und dieses an der Landesgrenze zu deponieren. ${ }^{66}$ Diese drei aus dem 1. Jahrtausend stammenden Belege stimmen darin überein, daß in Gefäßen verschlossene Unheilsstoffe bzw. Unheil verursachende Materien gebannt und unschädlich gemacht sind.

Das Deponieren und Verschließen solcher Unheilsstoffe in Gefäße ist eine magische Handlung, die in den hethitischen Ritualen verschiedentlich anzutreffen ist. In dem folgenden Absatz eines althethitischen Rituals ${ }^{67}$ (15. Jahrhundert) entledigen sich König und Königin ihrer Unheilsstoffe, die sich offenbar im Speichel konzentrieren, durch Ausspucken:

31 Ich (die Beschworrerin) halte einen Becher aus Ton, und in den Becher hinein spucken der König und die Konigin dreimal.

32 Und sein Deckel (ist) aus Blei,

33 und ich verschließe (ihn). ${ }^{68}$

Am Ende eines in das 14. Jahrhundert datierenden Rituals ${ }^{69}$ wird das Wasser, mit dem die beiden Ritualherren gereinigt worden waren, in Gefäßen versiegelt und der Unterwelt übergeben. Die Deponierung ist hier mit einem eschatologischen Gedanken verknüpft:

21 Dann reicht die Beschwơrerin aus einem Becher oder einer Schale Wasser

22 den beiden Ritualherren hin. Und Natron(?)

23 ist hineingeschüttet. Sodann gießen sich die beiden Ritualherren

24 das Wasser auf ihre Kopfe; und auch ihre Hände

25 und Augen waschen sie.

65 ABL 4; bearbeitet von Parpola, Letters from Assyrian Scholars I, Nr. 137; vgl. dazu auch Maul, 'Herzberuhigungsklagen', 31.

66 Vgl. dazu Parpola, Letters from Assyrian Scholars II, 123-125.

67 KBo XVII 1 (siehe Anm. 49).

68 KBo XVII 3 Rs. IV (Dupl.: KBo XVII 1 Rs. IV 35-37):

31 ha-li-i-na-aš zi-e-ri (Dupl. GAL-ri) har-mi ta-an an-da 3-iš LUGAL-uš MU.

NUS.LUGAL-ša (Dupl. -aš-ša)

32 zi-e-ri-ia (Dupl. GA[L-i]a) al-la-pa-ah-ha-an-zi (Dupl. al-la-ap-pa-ah-[ )

iš-tap-pu-ul-li-še-ta šu-li-i-aš

$33[(t)] a$ riš-ta-a-ap- Thé $7 \ldots$

69 CTH 404, bearbeitet von Rost, Ein hethitisches Ritual, 345-379. 
26 Ferner gießen sie Wasser in ein Stierhorn.

27 Die beiden Ritualherren versiegeln es, und die Beschwörerin

28 spricht so: "Wenn die fruheren

29 Konige zuruckkommen und das Land und die Sitten (Satzung)

30 prufen, erst dann soll dieses Siegel ebendort

31 gebrochen werden! ${ }^{70}$

In dem zum Teil althethitisch überlieferten Mythenkomplex vom Vegetationsgott Telipinu ${ }^{71}$ begegnen bei den Schilderungen der Katharsis des Gottes erneut jene Unheilsgefäße - hier ${ }^{D U G}$ palhi-genannt, die ebenfalls die Größe eines Kornbehälters erreichen können. ${ }^{72}$ Der Mythos berichtet: ${ }^{73}$

8 Gehen soll des Telipinu Zorn, Wut, Befleckung,

9 Groll. Das Haus soll es loslassen, den Mittelpfeiler

10 soll es loslassen, das Fenster soll es loslassen, die Türangel des Mittel-

11 hofes soll es loslassen, das Haupttor soll es loslassen, den Vorhof soll es loslassen,

12 die Königsstraße soll es loslassen - auf das bebaute Feld, auf Gărten (und) Baumplantagen, soll es nicht gehen - gehen soll es den Weg der Sonnengottin der Erde (Unterwelt).

14 Der Pfortner (der Unterwelt) offnete die sieben Türen; er zog zurück die sieben Riegel.

15 Unten in der Unterwelt steht ein palhi-Gefăß; sein Deckel

70 KUB XXXIV 84+ Rs. IV (Dupl. KBo II 3 Rs. IV 1-13):

$21 n u$ MUNUŠ̌U.GI wa-a-tar GAL-az (Dupl. IŠ-TU GAL) na-aš-ma hu-u-up-pa-ra-az (Dupl. hu-u-up-pa-ra-za da-a-i na-at)

$22 A-N A$ II $B E-E L$ SÍSKUR (Dupl. EN SISKUR) pa-ra-a e-ep-zi ${ }^{\text {NA4 }}$ ni-it-ri-ia-kán

23 an-da šu-uh-ha-an n[(u-)]za-kán II BE-EL SÍSKUR (Dupl. EN SISKUR) wa-a-tar I-NA

24 SAG.DU- $\breve{S} U-N U$ (Dupl. SAG.DU ${ }^{\mathrm{MES}}-\check{S} U-N U$ ) $\breve{s} a-r a-a$ la-a-hu-wa-an-zi (Dupl. la-hu-wa-an-zi) ŠU HI.A_ia-za-kán (Dupl. QA-TI-TE ${ }^{\mathrm{MES}}$-šU-NU-ia-za-kán)

25 IIGI ${ }^{\mathrm{HI}} . \mathrm{A}$ (Dupl. IGI ${ }^{\mathrm{HI}}{ }^{\mathrm{A}}$ _ŠU-NU) ar-ra-an-zi

26 nam-ma-kán wa-a-tar (Dupl. wa-a-tar caret) $\ulcorner A-N A\urcorner \mathrm{SI} \mathrm{GU}_{4}$ an-da la-a-hu-wa-an-zi (Dupl. la-hulwa-an-zi)

27 na-at II $B E-E L$ SÍSKUR (EN SISKUR) še-er ši-ia-an-zi nu MUNUŠ̌U.GI

$28 k i$-iš-ša-an me-ma-îi ku-wa-pi-wa ka-ru-ú-i-le-e-eš (Dupl. ka-ru-ú-le-e-eś)

29 LUGAL ${ }^{M E S}$ EGIR-pa ú-wa-an-zi nu-wa-az KURe 「̌̌al-ak- $\lceil l i-i n-n a$ (Dupl. nu-wa-za KUR-ia-aš ša-ak-la-a-in)

30 EGIR-an kap-pu-u-wa-an-zi (Dupl. kap-pu-wa-an-zi) ki-i-i[(a-w)]a NA4 KIŠIB $a-p i-i a-a k-\lceil k a\rceil$

31 ni-ni-ik-ta-[r]u (Dupl. ki-nu-ut-ta-ru)

71 Zusammengestellt von Otten, Die Überlieferungen des Telipinu-Mythus.

72 In dem Ritual ChS I/5 Nr. 56 kriecht ein Mensch durch ein palhi-Gefäß mit offenbar ausgeschlagenem Boden.

73 KUB XVII 10. 
16 (ist) aus Blei, sein Sperriegel (ist) aus Eisen. Was darin hineingeht, das

17 kommt ferner nicht mehr heraus, es geht darin zugrunde.

18 Und so mögen auch des Telipinu Zorn, Wut,

19 Befleckung, Groll hineingehen und nicht mehr zurückkommen. ${ }^{74}$

Der gleiche Absatz findet sich in einem auf die Totengöttin Lelwani bezogenes Ritual. ${ }^{75}$ Hier ist die Unterweltsgöttin selbst mit Unheilsstoffen behaftet, die nun in das palhi-Gefäß transponiert und verschlossen werden sollen:

$2 \quad$... [Unten in der Unterwelt steht]

3 ein palhi-Gefäß [aus Eisen; sein Deckel]

4 (ist) aus Blei, [was] darin hinein[geht, das]

5 kommt ferner nicht mehr [heraus, es geht darin zugrunde].

6 [So mogen auch] der Lelwan[i böser Zorn, Wut]

7 Befleckung, Gro[ll ebenso darin hineingehen],

8 dort [möge es drinnen ebenso zugrunde gehen]. ${ }^{76}$

74 KUB XVII 10 Rs. IV (Duplikate: KUB XXXIII 3 und 1216/v(+)XXXIII 29+30; vgl. Otten / Rüster, Textanschlüsse, 87):

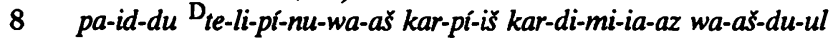

9 ša-a-u-ar pár-na-an-za-at tar-na-ú iš-tar-ni-ia-ša-at an-na-ăs-na-an-za

10 tar-na-ú Gišlu-ut-ta-an-za-at tar-na-ú wa-wa-ar-ki-ma iš-tar-ni-ia-ša-at

11 hi-la-ẳ tar-na-ú KÁ.GAL-at tar-na-ú hi-lam-na-an-za-at tar-na-ú

12 KASKAL.LUGAL-at tar-na-ú mi-ia-an-ti-li A.ŠÀ-ni ${ }^{\text {GIŠs } \text { KIRI }_{6}-n i}{ }^{\text {GIŠ̀TIR-ni }}$

13 le-e pa-iz-zi ták-na-ša-at ${ }^{\mathrm{D} U T U}$-aš KASKAL-an (Dupl. KASKAL-sa-an) pa-id-du

14 ha-a-aš-ta LÚ NI.DUH 7 GIŠ̀ IG a-ap-pa hu-it-ti-ia-at 7 GIŠsa-at-ta-lu

15 kat-ta-an da-an-ku-i (Dupl. -wa-i) ták-ni-i ZABAR pal-hni (Dupl. ZABAR) ar-ta ǐs-tap-pu-ul-li-ǐ̌-me-et (Dupl. -pu-li-)

16 A.BÁR-aš za-ak-ki-ǐ̌-me-ǐ̌ AN.BAR-aš ku-it an-da-an pa-iz-zi na-aš-ta

17 nam-ma ša-ra-a Ú-UL ú-iz-zi an-da->da<-an har-ak-zi

$18 \quad \grave{U} \check{S}_{A} \mathrm{D}_{\text {te-li-pi-nu kar-pí-in kar-di-mi-ia-at-ta-an }}$

19 wa-aš-du-ul sa-a-u-ar (Dupl. -u-wa-ar) an-da e-ep-du na-at a-ap-pa (Dupl. EGIR-pa) le-e $u-i z-z i$

Bo 7615 (2-8 verwertet von Otten, Lelvani, 130f).

Nach der Transkription von Otten, aaO (Anm. 75):

$2 \quad \ldots \ldots . . . . . . . k a t-t a-a n d a-a n-k u-i$ ták-ni-i AN.BAR-as]

3 DUG pal-hi-iš [ki-an-da iš-tap-pu-ul-li-iš-me-et]

$4 \quad$ A.BÁR-aš an-da-ká[n ku-it pa-iz-zi na-ǎ̌-ta nam-ına]

5 ša-ra-a Ú-UL [ú-iz-zi an-da-at-kán ḩar-ak-zi]

$6 \quad \check{S}_{A}$ Dle-el-wa-n[i-kán i-da-lu-uš kar-pi-iš kar-dim-ıni-az]

7 wa-aš-tril ša-a-u-w[a-ar an-da $Q A-T A M-M A$ pa-id-du]

8 a-pi-ia-a[t(?)-kán an-da QA-TAM-MA har-ak-du]. 
Die enge Beziehung des palhi-Gefäßes zur Unterwelt und zur Unterweltsgöttin tritt in einer Variante des nunmehr auf den Wettergott der Stadt Lihzina bezogenen Mythos zutage. ${ }^{n}$ Nach diesem Text befinden sich palhi-Gefäße mit bleiernen Deckeln in einem noch unterhalb des Totenreiches gelegenen Meer, wohin die Unterweltsgöttin die Unheilsstoffe bringen soll:

3' Das Handgelenk [gab] sie (die Unheilsstoffe) den Fingern,

4' die Finger [gaben] sie den Fingernägeln,

5 die Fingernágel gaben sie der

6. Unterwelt.

7. Die Unterwelt brachte sie der Sonnengottin der Erde,

8' die Sonnengottin brachte sie dem Meer.

9' Im Meer aber sind palhi-Gefaße aus Kupfer hingestellt, 10' ihre Deckel sind aus Blei. ${ }^{78}$

In hethitischer Überlieferung befindet sich das Unheilsgefäß im Gewahrsam der mit der Unterweltsherrin Allani identifizierten "Sonnengöttin der Erde". Die hethitische Version, nach der das Gefäß der Unterweltsgöttin übergeben und in der Unterwelt deponiert ist, klingt noch in der erst spät, von Apuleius in seinen Metamorphosen erzählten Episode an: Aphrodite überreicht der schönen Psyche eine Büchse, in der sich statt der erwarteten Kosmetika der Todesschlaf befindet. ${ }^{79}$ Schließlich ist auch Pandora, "die alles Gebende, die Gabenreiche", ein Epitheton der Erde, aus der sie ja erschaffen wurde. Auf einer bildlichen Darstellung führt Pandora das Epitheton Anesidōra, "die

\footnotetext{
77 CTH 331.1.

78 KUB XXXIII 66 Vs. II (=RHA 77, 1965, 130):

3 har-ga-na-u-i-sa-at ka-lu-l[u-pa-aš pi-i-e-er]

4 ka-lu-lu-pi-ša-at కa-an-ku-wa-ia-a[š pi-e-er]

5 ša-an-ku-wa-i-sa-at da-an-ku-wa-i t [a-ga-an-zi-pi]

6 pl-i-e-

er [ ]

$7 \longdiv { \text { da-an-ku-i-sa-at ta-ga-an-zi-pa-aš DUT-i [pé-e-da-as] } }$

8 DUTU-ša-at a-ru-ni pé-e-da- . [as]

9 a-rrt-ni-ma URUDU-aš pal-ha-eš ki-an-da[-ri]

10 iš-tap-pu-ul-li-iš-mi-it A.BÁR-aš . . .

Vgl. auch Wegner, Zauberpraktik, 114.

79 Apuleius, Metamorphosen 4:18-20.
} 
Geschenke Emporsendende", das sonst Beiname der Demeter und der Ge ist. ${ }^{80}$

Nun liegt die Annahme nahe, da $B$ die Pandora-Legende das Resultat einer vielfachen Umgestaltung eines einst zugrunde gegangenen Mythenstoffes ist. Für die Rekonstruktion desselben könnten die hethitischen Belege von Bedeutung sein.

Wenn auch die Traumvision des Sacharja von ihrer kleinasiatisch-hethitischen Ausgangsbasis weiter entfernt ist als die Pandora-Legende, so hat sie eindrucksvollerweise doch den bleiernen Deckel des Gefäßes bewahrt. ${ }^{81}$ Offen bleibt die Frage nach der Art der Überlieferung und Motivwanderung in diesem kulturell nahezu in sich geschlossenen geographischen Raum. Nach der Beschaffenheit der Quellen kann wohl angenommen werden, daß die Heimat des Motivs das hethitische Kleinasien ist, wo solche Gefäße ja einen realen Platz im Ritual innehatten. Was nun die Verbreitung des Motivs sowohl in der griechischen Literatur als auch im Alten Testament betrifft, so scheint es geraten, von einer Mehrzahl nebeneinander bestehender Überlieferungswege, die im einzelnen nicht mehr rekonstruierbar sind, auszugehen.

Die später erfolgte Rezeption des Motivs vom Unheilsgefäß, die zu dem bekannten literarischen Thema vom Geist im Glase führt, wird erstmals im Testamentum Salomonis faßbar, das vermutlich im 1. Jahrtausend $\mathrm{n}$. Chr. entstanden ist: Salomo zwingt den Dämon Ornias, ihm beim Tempelbau zu helfen, um ihn danach in ein Gefäß zu bannen. Der in der jüdisch-orientalischen und islamischen Welt beliebte Erzählstoff gelangte, wohl über Byzanz, spätestens im 12. Jahrhundert nach Europa, ${ }^{82}$ wo er seine vielleicht schönste Gestaltung in Friedrich Baron de la Motte-Fouqué's "Das Galgenmännlein" gefunden hat.

[Nachtrag zu S. 77, letzter Absatz von I:

Als Šuppiluliuma den für die Thronfolge bestimmten Tuthaliya ermordete, entsühnte er mit dem "Ritus des Blutes" den Palast, nicht aber die Stadt Hattusa, die daraufhin von einer Seuche erfaßt wurde. Erst Muršili II. entsühnte dann auch die Stadt und die Tempel mit dem "Ritus des Blutes" (KUB XIX 2 Rs. 10-12).]

Vgl. Kerényi, Die Mythologie der Griechen I, 214.

81 Dem Blei, dem kulturgeschichtlich altesten Metall der Menschheit, werden offenbar bannende Krafte zugeschrieben, vgl. auch Schmidt, Blei, 441f. Eine Variante bietet CTH 732 "Rituel de Hutusi, dit 'de la campagne", worin es heißt "Eisen der Ewigkeit ist sein Deckel": KBo XIII 106 Vs. I:

$22[u] k-t u-u-r i-i a-a s ̌-s a-a n$ AN.BAR [

23 [i] ${ }^{3}$-tap-pu-ul-li-iš-se-it $x[$

Vgl. Horálek, Geist im Glas, 922-928. 


\section{Bibliographie}

Beckman, G.M., Hittite Birth Rituals (StBoT 29), Wiesbaden 1983

Caplice, R., "Namburbi Texts in the British Museum II", OrNS 36 (1967) 34-38

Delcor, M., La vision de la femme dans l'épha de Zach., 5, 5-11 à la lumière de la littérature hittite, RHR 187 (1975) 137-145

de Vries, J., Altgermanische Religionsgeschichte, 2 Bde, Leiden 1935-1937

Diels, $H$., Fragmente der Vorsokratiker I, Berlin ${ }^{4} 1904$

Dinçol, A.M., Ein hurro-hethitisches Festritual: (H)isuwaš, Belleten 53 (1989) 1-50

Ehelolf, H. $\rightarrow$ Sommer, $F$.

Fauth, W., Der Schlund des Orkus, Numen 21 (1974) 105ff

Galling, K, Studien zu der Geschichte Israels im persischen Zeitalter, Tübingen 1964

Gentili Pieri, F., L'edificio "sinapsi" nei rituali ittiti, Atti AccTosc. 47 (1982) 1-37

Gese, $H$., Vom Sinai zum Zion, München 1984

Haas, V., Ein Preis auf das Wasser in hurritischer Sprache, ZA 79 (1989) 261-271

- Magie und Zauberei. B. Bei den Hethitern, RIA 7 (1987-1990) 234-255

- /Wegner, I., Rez. zu: H. Otten / Ch. Rüster, KBo 33, Berlin 1987, OLZ 83 (1988) 291-294

- / Wilhelm, G., Hurritische und luwische Riten aus Kizzuwatna (AOATS 3), Kevelaer / Neukirchen-Vluyn 1974

Heiler, $F$., Erscheinungsformen und Wesen der Religion, Stuttgart 1961

Horálek, $K$, Geist im Glas, EdM 5, 1987, 922-928

Keel, O., Vơgel als Boten, Gottingen 1977

Kerényi, K, Die Mythologie der Griechen, Bd. I: Die Göttergeschichten, Zürich ${ }^{3} 1964$

Kühn, J.H., Rezension zu O. Lendle, Die 'Pandorasage' bei Hesiod, Würzburg 1957, Gnomon 31 (1959) 114-123

Kümmel, H.M., Kizzuwatna, R1A 5 (1976-1980) 627-631

Kronasser, H., Die Umsiedelung der schwarzen Gottheit. Das hethitische Ritual KUB XXIX 4 (des Ulippi), Wien 1963

Laroche, E., Glossaire de la langue hourrite, Paris 1980

- Études de linguistique anatolienne, RHA 31 (1971) 84-99

Lebrum, $R$, Textes religieux hittites de la fin de l'empire, Hethitica II (1977) 93-153

Lendle, $O$., Die 'Pandorasage' bei Hesiod. Textkritische und motivgeschichtliche Untersuchungen, Würzburg 1957

Maul, S.M., 'Herzberuhigungsklagen'. Die sumerisch-akkadischen Ersahunga-Gebete, Wiesbaden 1988

Otten, H., Die Überlieferungen des Telipinu-Mythus (MVAeG 46,1), Leipzig 1942

- Die Gottheit Lelvani der Bogazkoy-Texte, JCS 4 (1950) 119-136

- Hethitische Totenrituale, Berlin 1958 
- Materialien zum hethitischen Lexikon (StBoT 15), Wiesbaden 1971

- / Rüster, Chr., Textanschlüsse von Bogazkoy-Tafeln (21-30), ZA 63 (1973) 83-91

- / Soǔek, V., Ein althethitisches Ritual für das Konnigspaar (StBoT 8), Wiesbaden 1969

Parpola, S., Letters from Assyrian Scholars to the Kings Esarhaddon and Assurbanipal, Part I: Texts (AOAT 5/1), Kevelaer / Neukirchen-Vluyn 1970, Part II: Commentary and Appendices (AOAT 5/2), ebda. 1983

Popko, M., La boite de Pandora, Meander 27 (1972) 381-383 (in polnischer Sprache)

Rost, $L$, Ein hethitisches Ritual gegen Familienzwist, MIO 1 (1953) 345-379

Riusche, F., Blut, Leben und Seele, Paderborn 1930

Rulster, Chr. $\rightarrow$ Otten, $H$.

Scheftelowitz, J., Alt-Palästinensischer Bauernglaube in religionsvergleichender Beleuchtung, Hannover 1925

Schmidt, L., Blei, in: EdM 2 (1979) $441 \mathrm{f}$

Sommer, F. / Ehelolf, H., Das hethitische Ritual des Pāpanikri von Komana (KBo V 1 = Bo 2001) (BoSt 10), Leipzig 1924

Soucek, $V . \rightarrow$ Otten, $H$.

Starke, F., Die keilschrift-luwischen Texte in Umschrift (StBoT 30), Wiesbaden 1985

Wegner, I., Eine hethitische Zauberpraktik, MDOG 113 (1981) 111-117

- $\rightarrow$ Haas, $V$.

Wilhelm, G. $\rightarrow$ Haas, $V$.

Wright, D.P., The Disposal of Impurity. Elimination Rites in the Bible and in Hittite and Mesopotamian Literature (SBLDS 101), Atlanta/GA 1987 



\section{Kultstelen und Baityloi}

Die Ausstrahlung eines syrischen religiösen Phänomens nach Kleinasien und Israel

Es ist eine weitverbreitete Erscheinung in den Religionen, daß Felsen oder Steine numinose Ausstrahlung zeigen. Daher ist es nicht ungewöhnlich, daß der vorderasiatische Raum Anteil an diesem Phänomen hat. Das dafür in Frage kommende archäologische Material wurde schon mehrfach gesichtet und funktionell zu klassifizieren versucht, wobei im Anschluß an eine Untersuchung von C.F. Graesser ${ }^{1}$ Stelen im syrisch-palästinischen Raum häufig nach folgenden vier Funktionen klassifiziert werden: Grenz- bzw. Vertragsstein, Grab- bzw. Gedenkstein, Sieges- bzw. Erinnerungszeichen und Kultstele. Obwohl eine Stele durchaus mehrere Funktionen gleichzeitig erfüllen kann, ist meistens leicht ein Schwerpunkt zu erkennen. - Der archäologische Befund gibt auch über die Form dieser Stelen Aufschluß, indem es sich dabei um aufrechtstehende Steine handelt ${ }^{2}$, die in verschiedenem Ausmaße behandelt sein können ${ }^{3}$.

Bezieht man nun terminologische Überlegungen und auch das anatolische Material, das bislang in Untersuchungen über Stelen weitgehend unberücksichtigt geblieben ist ${ }^{4}$, in die Untersuchung mit ein, so ergibt sich m.E. ein neues modifiziertes - Bild: Es läßt sich ganz klar die kultische Bedeutung einer Stele als Baitylos/Repräsentant einer Gottheit von der Aufrichtung eines Steines zu Kommemorativzwecken unterscheiden, wobei allerdings aufgrund der formalen Gleichheit des Monuments sekundär gegenseitige Beeinflussungen vorkommen. Ursprünglich sind jedoch Kultstelen von Gedenksteinen zu unterscheiden,

1 Graesser, Stones, 34-62, bes. 37. - weiters Jaros, Stellung, 152-168 und Schroer, Bilder, 359-367. De Pury, Promesse, 409-422, stellt sehr viel religionsgeschichtliches Material zu heiligen Steinen zusammen; er ordnet es nach folgenden Gesichtspunkten: Steine als Sitz einer Gottheit, als Sitz der Seele und Repräsentant eines Verstorbenen, sowie als Altar.

2 Ein eindrucksvolles Beispiel ist etwa die Darstellung einer solchen Stele auf der MacrinusMünze aus Byblos (3. Jh. n. Chr.), vgl. die Abbildung in $\mathrm{BRL}^{2}$, 209; weiteres Bildmaterial bei Jaroš, Stellung, 174-178 sowie die Typologie bei Graesser, Stones, 45. Ebenfalls zu erwăhnen sind zwei Beispiele aus dem urartäischen Raum: die Grabstelen aus Altintepe (Özgǚ̧, Altintepe, $73 f$ und Tf. 26f) sowie eine bildliche Darstellung auf einem Gewicht aus dem 8. Jh. (Bossert, Wort, 503 und Tf. CXXV, Abb.17); für anatolische Beispiele siehe unten II.1.

3 Die z.T. vorgenommene Unterscheidung (vgl. Graesser, Stones, 35 oder Welten, BRL ${ }^{2}$, 321-325, bes. 322) zwischen Masseben (= unbearbeitete Stelen) und Stelen (mit Inschriften oder Reliefs) ist kaum gerechtfertigt, vgl. Schroer, Bilder, $357.366 \mathrm{f}$ und Börker-Klähn, Bildstelen, 77.

4 Graesser, Stones, übergeht das hethitische Material vollkommen; daß die anatolischen Stelen in diesen Traditionsstrang gehören, haben Voos, Studien, 360 und Gurney, Aspects, 36 klar ausgesprochen. 
wobei die Errichtung von Kultstelen von Syrien aus ihren Ausgang nach Kleinasien und Israel genommen hat ${ }^{5}$.

\section{Syrische Kultstelen (sikkanum)}

Die bislang älteste inschriftliche Bezeugung einer Kultstele in Syrien stammt aus Ebla, wo der Gen.Pl. zi-ga-na-tim bezeugt ist ${ }^{7}$; dieser epigraphische Beleg ist etwa zeitgleich mit der bekannten Kultstele aus dem Hof $12 \mathrm{im}$ Tempel der Ninni-Zaza in Mari ${ }^{8}$. Diese somit ab der Mitte des 3. Jt. v. Chr. greifbare religiöse Tradition setzt sich in Mari weiter fort, indem in den abab. Briefen mehrfach davon die Rede ist, daß solche Stelen bereitgestellt werden sollen. So lesen wir im Brief A.652, der von Bannum, dem Gouverneur von Saggaratum, stammt, gleich zu Beginn folgendes':
"Wegen des Opfers fur Istar hat mein Herr geschrieben: 'Jenes Opfer ist nahe, und eine Kultstele (st-ik-ka-nu-um) ist nicht vorhanden. 100 Arbeiter und einen zuverlässigen Mann, der eine Kultstele zu bearbeiten versteht, schicke schnell."”

Insgesamt sollen dabei in Lasqum ${ }^{10}$ vier solche Stelen hergestellt werden, ähnlich wie nach A.7014 je eine Kultstele für Dagan und Adad aufgestellt werden soll. Die direkte Verwendung solcher Stelen im Opferkult zeigt ARM XXIII 284: Am 6. Tag des Monats Kiskimu werden in Mari im birikku des Dagan insgesamt sieben Schafe geopfert, davon eines dem Dagan und eines der Kultstele: 1 udu a-na [s]i-ka-nim 1 udu.níta $a-n a{ }^{d} d a-g a n$. - Weiteres Material liefern verschiedene Ritualtexte aus Emar: In der Beschreibung der Zeremonien bei der Inthronisation einer entu-Priesterin wird im Verlauf des 2. Tages die Kultstele beopfert und gesalbt (EMAR VI/3, Nr.369,34f):

"Man opfert im Tempel des Gad 1 Schaf dem Wettergott und 1 Schaf der Kultstele der Hebat ( ${ }^{\text {na4}}$ si-ka-ni sa ${ }^{\text {d }}$ hé-bat), und die entu-Priesterin gießt Feinol über das Oberteil der Kultstele der Hebat (a-na sag.du "a4 si-ka-ni sa hé-bat i-tab-ba-ak)."

5 Die weitere Verbreitung nach Arabien muß hier beiseite gelassen werden, vgl. dazu Jaroš, Stellung, 150f und de Pury, Promesse, 411-414.

6 Der Beitrag Dietrich / Loretz / Mayer, Sikkanum, wurde mir erst nach Abschluß des Manuskripts zugănglich. Teilweise decken sich die darin erzielten Ergebnisse mit der vorliegenden Darstellung.

7 MEE 4,166a; vgl. dazu Durand, Nom, 5.

8 Vgl. die Abbildung bei Durand, Culte, 80.

9 Vgl. Durand, Culte, 81f.

10 Lasqum spielt auch in ARM XIV 26 im Zusammenhang mit der Bereitstellung von Kultstelen eine Rolle, vgl. Durand, Culte, 79-81. 
Ähnliches geschieht am 2. Tag der Inthronisation einer maš'artu-Priesterin (EMAR VI/3, Nr.370,41-43):

"Am 2.Tag der Inthronisation errichtet man eine Kultstele auf dem Dach des Tempels des [ ] ( ${ }^{\text {aa4} s i-k a-n a ~ i-n a ~ u ́-r i ~ s a ~ e ~[~] ~ i '-s a k-k a ́ n-n u), ~ i n ~ d e r ~ N a c h t ~ s t e h t ~ m a n ~ a u f ~}$ und opfert 1 Zicklein, 1 zadu (mit) Zedernol [ ] der Kultstele."

Auch das Ritual des zukru-Festes zeigt, daß während dieses Festes zahlreiche kultische Akte bei solchen Stelen ausgeführt wurden: Man bestreicht sie mehrfach mit Öl und Blut (EMAR VI/3, Nr. 373,32.55f). Wenn am 7. Tag des Festes alle Götter von Emar mit Opfern versehen werden, empfängt die vergöttlichte Stele ('si-ka-ni) Hebats dieselben Opfer wie die anderen Götter (EMAR VI/3, Nr.373,166). Erwähnenswert ist auch eine mehrfach wiederholte Handlung, bei der die Götter zu den Stelen hinausgebracht werden und Dagan auf seinem Wagen zwischen den Stelen hindurchfährt (EMAR VI/3, Nr. 373,185-189) ${ }^{11}$ :

"Dagan, den Herrn der Rinder, und alle Gơtter laßt man zu den Kultstelen hinausgehen.

Sein Gesicht ist, wenn er hinausgeht und zurückkehrt, verhüllt. ... Der Wagen (Dagans)

zieht zwischen den Kultstelen hindurch, und er geht zu Ninurta."

Schließlich dürfen hier noch zwei bekannte Belege aus Ugarit angeführt werden. Im Aqhat-Epos werden die Pflichten eines guten Sohnes aufgezählt; derjenige erfüllt diese Pflichten, "der aufrichtet eine Kultstele für seinen vergöttlichten Vater (und) im Heiligtum eine Kultstandarte ${ }^{12}$ für seine Ahnen" (KTU 1.17 I 26f: nșb skn ilibh bqdš ztr " $m h$ ). Das zweite ugaritische Beispiel ist eine steinerne Stele, die folgende Inschrift trägt (KTU 6.13): "Stele, die Tarelli aufgestellt hat für Dagan. pgr-Opfer: [ein Schaf] und ein Ochse für den Verzehr."13

Aus diesen Belegen ergibt sich für die Bedeutung von sikkanum in Syrien folgendes: Die Opfer und kultischen Handlungen, die der Stele dargebracht werden, zeigen, daß diese Stelen gleich wie Götterstatuen behandelt werden, d.h. man kann in ihnen Repräsentationen von Göttern sehen. Dies wird auch

11 Vgl. auch Z.27f.42-45.178-181.191-197.207-209; schon zu Beginn des Festes findet eine solche Zeremonie statt, wie die fragmentarische Festbeschreibung EMAR VI/3, Nr. 375,6-16 zeigt. Weitere fragmentarische Belege, die aber ahnliche Zeremonien beschreiben, sind EMAR VI/3, Nr.376,11; 397,1; 401,3; 403,9; 422,4; 424,4; 428,2; 431,6. - Auch der Kultkalender EMAR VI/3, Nr. 448,3.24.26 nennt mehrfach Kultstelen.

12 Aufgrund der parallelen Verwendung mit skn ist auch ztr als Kultobjekt aufzufassen; wahrscheinlich handelt es sich dabei um ein LW aus hethitisch sittar "Sonnenscheibe". Für die Bedeutung dieses Kultobjektes in der hethitischen Religion siehe Popko, Kultobjekte, 121-123.

13 Die Übersetzung folgt TUAT II/4,505; dort ist auch weitere Literatur zu dieser nicht ganz unumstrittenen Inschrift - v.a. wegen des Terminus pgr (eine Art Schlachtopfer) - und dem ăhnlichen Text KTU 6.14 genannt. 
durch die Etymologie für sikkanum bestätigt, da sikkanum nicht von der Wurzel ŠKN "setzen, aufrichten", sondern von SKN abgeleitet ist, dessen Bedeutung "wohnen, leben" ist ${ }^{14}$. Somit kann man sikkanum wohl als Objekt betrachten, in dem eine Gottheit wohnt bzw. das von der Gottheit belebt wird. Semantisch ist sikkanum daher identisch mit dem Begriff bêt 'aelohîm. Für diesen westsemitischen Ausdruck hat A. de Pury gezeigt, daß die Bezeichung bêt 'ae lohîm (ohne Artikel) in Gen 28,17.22 und Ri 17,5 sowie in der Form bty 'Ihy' im Vertrag zwischen Bar-Ga'ja und Mati'-il aus Sfire ${ }^{15}$ der terminus technicus für solche von einer Gottheit "belebten" Steine ist ${ }^{16}$, eine Interpre-

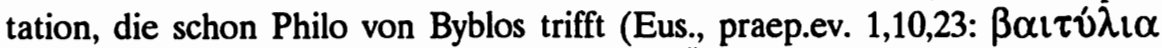
$\lambda$ í terminus technicus noch in hellenistischer Zeit fort, wobei die sachliche Identität mit sikkanum grundsätzlich erhalten bleibt ${ }^{17}$. - Der Aspekt der Anwesenheit Gottes in der Kultstele, wodurch diese selbst Göttlichkeit erhält ${ }^{18}$, führt dazu, daß eine solche Stele auch bei einem Vertragsschluß (bzw. als Grenzstein) aufgerichtet wird: Die Gottheit selbst ist in der Gestalt der Kultstele als Zeuge anwesend, falls die Vertragsbedingungen nicht eingehalten werden. Dies zeigt sowohl die Inschrift aus Sfire als auch eine Stele aus Ugarit, auf der ein Vertragsschluß dargestellt ist ${ }^{19}$. Aber auch aus Emar erhalten wir eine willkommene Bestätigung dieser Vorstellung: EMAR VI/3, Nr.125 ist ein Kaufvertrag für ein Haus zwischen Ilia und Itti-Da; nach der Beschreibung des Hauses und der Kaufhandlung werden die Zeugen angeführt, ehe die Urkunde mit folgender Fluchformel schließt (Z. 35-41):

"Wer diese Worte andert - Dagan, Ninurta und Ishara sollen seine Nachkommen und seinen Namen vernichten (und) eine Kultstele soll man statt seines Hauses errichten" ( ${ }^{\mathrm{na} 4}$ si-kd-na a-na é-šu li-iz-qú-up).

Die gegebenenfalls zu errichtende Stele repräsentiert den Gott als Zeugen des Vertragsbruchs und zeigt gleichzeitig die Verwirklichung des Fluches von seiten der Götter. - Die offensichtliche Anwesenheit der Gottheit im sikkanum,

14 Durand, Culte, 82 Anm. 10.

15 Sfire II C 2f.7; KAI 223 C 2f.7; TUAT I/2,186.

16 De Pury, Promesse, 426-430; die beiden weiteren Stellen für bêt 'aelohîm in Ps 42,5 und 2 Chr 34,9 beziehen sich auf den Jerusalemer Tempel und sind hiervon zu trennen, da sie eventuell

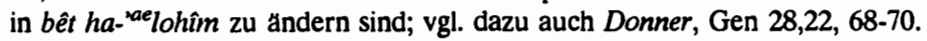

$17 \mathrm{Da}$ der Begriff Baitylos ein breiteres Bedeutungsspektrum aufweist, soll nicht bestritten werden, vgl. dazu Fauth, Baitylia, 806-808; Gese, Religionen, 191f; den Aspekt der "Götterwohnung" betont in diesem Zusammenhang auch Jaroš, Stellung, 167f.

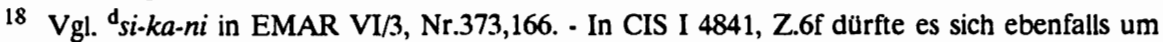
eine personifizierte Stele handeln, wenn ein 'bd bt skn genannt wird.

19

Caquot / Sznycer, Religion, Tf. XXIIIb. 
sei es als Empfänger kultischer Handlungen, sei es als Zeuge bei Verträgen, gibt solchen Kultstelen numinosen Wert. Ihre Bedeutung in der Religion AltSyriens ist dabei so gro $B^{20}$, daß sie sowohl in die Religion Kleinasiens als auch Israels wirken konnte.

\section{Die anatolischen und israelitischen Pendants zu sikkanum}

\section{Anatolien}

a) ${ }^{\text {na }}{ }^{2}$ ZI.KIN $={ }^{\text {na4 }}$ huwasi in hethitischen Texten

Die Übernahme der syrischen Vorstellungen, $\mathrm{da} B$ in Kultstelen die Gottheit lebt, ist im Hethitischen sprachlich faßbar: Denn das Pseudo-Sumerogramm

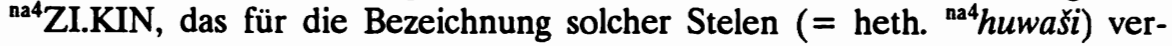
wendet wird, ist die hethitische Umsetzung des semitischen Wortes sikkanum wobei ein Stück Volksetymologie anklingen könnte: Die beiden bekannten Logogramme ZI "Leben" und KIN "Werk" haben durch ihre Zusammenstellung eine Bedeutung "l'oeuvre où vit (le dieu)" ${ }^{\text {"21 }}$ suggeriert, die dem semitischen Begriff nicht allzu fern liegt. Daß nicht nur ein zufälliger Anklang ZI.KIN / sikkanum vorliegt, zeigt m.E. die Tatsache, daß einmal ${ }^{22}$ - in fragmentarischem Kontext - sikkanum als Akkadogramm $S I ́-K \dot{A}-N U^{23}$ belegt ist. In Bo 3826 iii 4 steht $S I ́-K \grave{A}-N U$ parallel zu ALAM, wobei der Parallelismus Kultbild / Kultstele deutlich ist. Die Vorstellung der Anwesenheit der Gottheit im sikkanum führt im hethitischen Denken dabei sogar so weit, daß sich eine eigene unbedeutende - Stelengottheit entwickeln kann, wie der Terminus zikkanzi$p a^{24}$ zeigt. In KUB LVIII 33 iii 20f heißt es:

"Wenn sie (die Kơnigin) bei der Stele des Zikkanzipa (zi-ik-kán-zi-pa-aš $\left.\left[{ }^{\mathrm{n}}\right]^{\mathrm{a}} h u-u-w a-s ̌ i\right)$ anlangt, verneigt sie sich und opfert."

Gleich wie ZI.KIN ist auch huwaši ein Lehnwort aus dem syrischen Bereich. J.M. Durand weist darauf hin, daß die Texte aus Mari den Terminus humâ/-

20 Vgl. ferner die ON dha-bu-rí-tum si-ga-an ${ }^{\mathbf{k i}}$ und Sikkanni (Durand, Nom, 5) und den PN Warad-Sikkanni (Charpin, Bétyle, 44).

21 Durand, Nom, 6. - Die Volksetymologie würde auch den Vokalismus mit /i/statt /a/ in ZI.KIN erklăren.

22 Nach freundlicher Auskunft von Prof. E. Neu sind sowohl si-kà-nu als auch zikkanzipa in den Bogazköytexten Hapax.

23 Zur Graphie vgl. EMAR VI/3, Nr. 125,40.

24 Eventuell ist durch die Rasur vor zikkanzipa auf der Tafel sogar das Gottesdeterminativ entfernt worden. 
asum "pierre levée divine" bezeugen, womit ein großer Stein gemeint ist, der eine kleine Stele tragen $k^{2 a n n}{ }^{25}$. Es liegt nahe, daß dieses semitische Wort in Nordsyrien / Südostanatolien ins Hethitische übernommen wurde, wobei vergleichbar mit analogen Fällen - die Überleitung in die i-Stämme geschehen ist $^{26}$.

Die sprachliche Herkunft der in der hethitischen Überlieferung für Stelen verwendeten Ausdrücke bestätigt treffend den mehrfach in der Forschung angesprochenen sachlichen Vergleich zwischen huwaši und Stelen aus dem syrischen Raum. Auf diese Vergleichsmöglichkeit hat m.W. als erster A. Goetze hingewiesen ${ }^{27}$, und $\mathrm{H}$. Bossert ${ }^{28}$ hat schließlich in seiner Untersuchung des hluw. Wortes waniza auch nordsyrische und kleinasiatische Texte des 1. Jt. für einen solchen Vergleich in die Diskussion eingebracht. Obwohl dabei für den Vergleich meist nur die biblischen Masseben herangezogen wurden, kann man mit O.R. Gurney die bisherige geleistete Arbeit wie folgt zusammenfassen ${ }^{29}$ :

"The similarity of the mașșêba and the huwaši stone is striking. Both are cult objects set up both in temples and in rural shrines, where they are associated with trees."

Wenden wir uns nun im Detail den hethitischen Belegen zu: Die gute Aufarbeitung des Materials durch H.G. Güterbock, M. Darga, F. Imparati, M. Popko und I. Singer liefert eine solide $\mathrm{Basis}^{30}$, wobei als sicher gelten $\mathbf{k a n n}^{31}$, daß es sich dabei um Stelen von verschiedenem Aussehen handelt, auch wenn dies vielleicht nicht ausschließlich der Fall ist ${ }^{32}$. Das Material solcher Stelen ist meist Stein, doch kommt vereinzelt Metall oder Holz dafür in Frage $^{33}$. Obwohl das Aussehen der Stelen nicht ausdrücklich beschrieben ist, kann man folgendes erkennen: Es gab teilweise recht kleine Stelen, die auf

25 Durand, Nom, 6; dieser etymologische Anschluß von huwaši scheint lautlich und sachlich besser zu sein als die von Eichner, Anatolisch, 25), 205 erwogene Verknüpfung mit (unsicherem) hluw. hui $/$ hu(i)zi/a "einmeißeln".

26 Vgl. zu dieser bekannten Erscheinung im Hethitischen etwa Kronasser, Ethymologie, 242-244.

27 Goetze, Kleinasien, 158.

28 Bossert, Wort, 495-545.

29 Gurney, Aspects, 36.

30 Güterbock, Rezension Brandenstein, 489-496; Darga, Wesen, 11-20; Imparati, Concessione, 118-137; Popko, Kultobjekte, 123-127; Güterbock, Götterbilder, 215-217; Singer, huwaši, 245-253.

Vgl. Güterbock, Götterbilder, 215; Imparati, Concessione, 125.

Vgl. Singer, huwaši, 247f für die Möglichkeit, daß ein huwaši auch betretbar ist; er schlăgt dabei vor, daß Kammer $A$ in Yazilikaya als ${ }^{\text {na4 }}$ huwaši des Wettergottes von Hatti angesehen werden kann. Als begehbares $h$. betrachten Börker-Klähn / Meitner / Peckeruhn, Neues, 176-179 das Monument von Iflatun Pinar.

33

Detailbelege bei Darga, Wesen, 11 Anm. 6. 
einen Altar gestellt werden konnten ${ }^{34}$, oder deren Größe mit eineinhalb Spannen angegeben wird (KBo II 1 ii 22). Weiters ist zu bemerken, daß diese Stelen nicht ausschließlich bildlos waren, sondern zum Teil reliefiert sein konnten, so etwa KBo II 1 ii 21-2355:

"Wettergott von Wattarwa: 1 Stele: 1 Mann (als?) Bild, mit Zinn überzogen, von 1 1/2 Spannen, gepanzert; in der Rechten hălt er eine Keule, in der Linken ein kupfernes henzu: von altersher."

Ebenfalls zu nennen ist jene Stele, die mit (dem Relief von) einer Mutter und einem Säugling versehen ist, die durch die Reform Tudhaliyas IV. durch eine Sitzfigur einer Frau mit einem Säugling ersetzt wird ${ }^{36}$.

Die Funktion der huwaši-Steine läßt sich nun folgendermaßen charakterisieren. Es handelt sich dabei um Kultobjekte, die aber auch als anikonische Darstellung der Gottheit angesehen werden können; KUB VII 24 Vs. 1-5 drückt dies so aus ${ }^{37}$ :

"Berg Malimaliya: Von altersher gab es kein Götterbild. Seine Majestăt Tudhaliya (machte) die Statue eines Mannes aus Eisen von 1 1/2 Spannen, die Augen aus Gold; sie steht auf einem Lowen aus Eisen. In den Tempel des Berg(gott)es Kukumusa bringt man sie; als Stele stellt man (ihn) in Tuhniwara auf einen Felsblock."

$\mathrm{Da} B$ die Abgrenzung zwischen Kultobjekt und Darstellung der Gottheit nicht immer präzis geschieht, sieht man daran, daß mehrfach davon die Rede ist, $\mathrm{da} B$ früher (annallan) die Gottheit eine Stele (bzw. ein anderes Symbol, häufig ein wakšur) hatte, jetzt aber - aufgrund der Reform Tudhaliyas IV. - die Gottheit in Tier- oder Menschengestalt dargestellt werde. Hierin ist ein Nebeneinander von verschiedenen Darstellungsweisen mit dem konservativen Festhalten an alten Ausdrucksformen und keine einlinige religionsgeschichtliche Entwicklung zu sehen ${ }^{38}$. Aufgrund der Tatsache, da $B$ die Stelen die Gottheit repräsentieren, ist es naheliegend, daß sie auch im Mittelpunkt verschiedener kultischer Handlungen stehen ${ }^{39}$, d.h. sie konnten gewaschen und gesalbt werden, man brachte (vor) ihnen Brot und Gußopfer dar, brachte andere Götter zu ihnen und versammelte sich bei ihnen zum Opfermahl. Gerade letzteres zeigt, daß die Übergänge vom Kultobjekt (als Götterbild) zum Ort, an dem

34 KUB XXXV 133 i 15'1f: Man macht einen Altar und auf den Altar stellt man die Stele des Wettergottes.

35 Güterbock, Götterbilder, $215 \mathrm{f}$.

KBo II 1 i 33.39f; vgl. Güterbock, Götterbilder, 217.

$37 \mathrm{Vgl}$. Archi, Fêtes, $22 \mathrm{f}$.

Vgl. Güterbock, Rezension Brandenstein, 489.

Vgl. zahlreiche Einzelnachweise dafür bei Darga, Wesen, 13-15. 
man eine Gottheit verehrt, fließend sind. Daraus ergibt sich m.E. die Möglichkeit, daß ein größerer Komplex wie Yazilikaya ${ }^{40}$ oder ein ganzes Freilichtheiligtum, dessen Zentrum eine huwasiz-Stele markierte, als huwaši angesprochen werden konnte ${ }^{41}$. Doch glaube ich, da $B$ man darin eine sekundäre Bedeutungserweiterung sehen soll; huwasi im eigentlichen Sinn ist nur eine Kultstele.

Die kultische Bedeutung der Stelen wird nun wohl darin sichtbar, daß sie häufig auch als Objekte genannt werden, deren (Wieder-)Errichtung besonders hervorgehoben wird. Die Stelenliste KUB XXXVIII 15 nennt - wenn auch fragmentarisch - 2 Personen, die - offensichtlich als religiös verdienstvolles Werk - einen $h$.-Stein gemacht haben ${ }^{42}$ :

"Irus: eine Stele $\left({ }^{\mathrm{na}} \mathrm{ZI} . \mathrm{KIN}\right), \mathrm{Ta}[\quad$ hat sie gemacht. Ein Schaf, ein Gefaß mit Bier <und> Brot [gibt man] vo[n der Stadt (?)]. Der neue Gott ist eine Stele. Ta[ hat sie gemacht]. ... Milkus: eine Stele, Palla[క hat sie gemacht]."

In diesem Sinn dürfte es auch zu verstehen sein, wenn im Gelübdetext KUB XV 1 ii 1-4 die Königin gelobt, ein huwaši und einen Altar in Edelmetall zu fassen ${ }^{43}$, oder wenn ein Opfermandant der Göttin Uliliyašši verspricht, sie im Fall der Beseitigung seiner Impotenz als huwaši aufzustellen ${ }^{44}$. Genauso zeigt sich die Bedeutung dieses Kultobjekts, wenn Hattušili in seiner Apologie $\mathrm{sagt}^{45}$, daß Šaušga wieder in jedem Ort beopfert und hinter dem huwaši aufgestellt werden soll. Offensichtlich ist unter Arma-Datta die Sorge um die huwaši-Steine (und die Göttin) vernachlässigt worden, was Hattušili nun wieder gut machen will. Ebenfalls für die religiöse Sorge um die Pflege solcher Stelen spricht Muwatallis Gebet an Tešub von Kummahi ${ }^{46}$, worin er dem Wettergott verspricht, alles wieder gut $\mathrm{zu}$ machen, sei es, daß jemand den Thron des Wettergottes oder seine Stele umgeworfen hat, oder da $B$ jemand eine Quelle verstopft hat. In ähnlicher Weise ist weiters eine Vorschrift aus den bel madgal$t i$ Texten zu nennen ${ }^{47}$ :

40 Singer, huwasi, 249.

41 So verstehe ich jene Stellen, die vom Hineingehen ins bzw. vom Herauskommen aus dem huwaši sprechen; KUB II 3 ii 32f; X 1, 22'ff; X 61 Rs. 3f; XX 99 ii $25 f$.

42 Jakob-Rost, Bildbeschreibungen, $205 \mathrm{f}$.

43 De Roos, Geloften, $185 f$ und die Ergănzung von Z. 1 ebd. 194.

44 KUB VII 5 iv 11-18; zuletzt bearbeitet von Hoffner, Ritual, 276.

45 Otten, Apologie, 28 iv 72; TUAT I/5, 491.

46 KBo XI 1 Vs. 40; Lebrun, Hymnes, 297.

47 KUB XIII 2 iii 1-3, erg. nach KUB XXXI 88 iii 1; von Schuler, Dienstanweisungen, 46. 
"Oder eine alte Stele. .... Aber sie ist nicht nachgepruft (?). Prüft sie jetzt nach (?). Man soll sie wieder aufrichten. Dann soll man itr das Opfer darbringen, das ihr früher (zukam)."

Aus diesen Belegen geht deutlich hervor, daß die (Wieder-)Errichtung einer Stele von großer religiöser Bedeutung war, da man in der Stele eine Darstellungsform der Gottheit sah, die durch Opfer verehrt werden sollte.

Eine andere, davon abgeleitete Funktion dieser Stelen ${ }^{48}$ besteht darin, daß sie als Grenzsteine verwendet werden. Damit ist nur scheinbar ein Gegensatz zur vorherigen Situation gegeben, da der Grenzstein den Gott als Zeugen für die Beachtung und Nichtverletzung der Grenze repräsentieren soll, wodurch auch diese Verwendung die huwaši-Steine in den sakralen Bereich rückt. Deutlich kommt diese Funktion in Landschenkungsurkunden zum Ausdruck ${ }^{49}$, aber auch im Ulmi-Tešub Vertrag (KBo IV 10 Vs. 21) oder in der Grenzbeschreibung in KUB XL 2 Vs.37, wo es heißt ${ }^{50}$ : "Der Richter(gott) ${ }^{51}$ ist die Grenze, eine Stele ist aufgestellt." - Aufgrund des sakralen "Zeugencharakters" der Grenzsteine wird es auch möglich, daß huwaši-Steine in Entsühnungsritualen für Analogiehandlungen verwendet werden. Im bekannten Ritual der Maštigga werden 7 huwaši aufgestellt, und die Opfermandanten schreiten zwischen ihnen durch, wobei offensichtlich die Gottheiten als Zeugen in diesem Rechtsproze $B$, der im Ritual zum Ausdruck kommt, fungieren. Wenn danach die Stelen als Analogiezauber umgestoßen werden, sollen das Böse und der Streit, der die Opfermandanten entzweit hat, genauso "umgestoßen" und vernichtet $\operatorname{sein}^{52}$. Obwohl eine Beseitigung der Grenzstelen in Verträgen einen Frevel darstellt, da dadurch ein bestehendes Rechtsgefüge empfindlich gestört wird, ist das Umstoßen der Stele im Ritual durchaus gerechtfertigt, da dadurch das Unrechtsgefüge in gleicher Weise zerstört wird.

Diese Funktion betont zurecht Imparati, Concessione, 135.

49 KBo V 7 Vs. 45; 275/f Vs. 9; 2064/g Vs. 15-20; 165/n Vs. 5; die Deutung als Grenzstein durch Imparati, Concessione, 126ff ist derjenigen von Riemschneider, Landschenkungsurkunden, 363 Anm. 152 vorzuziehen, der die $h$.-Steine der Landschenkungsurkunden als kultisch-religiose Wirtschaftseinheit betrachtet, vgl. auch KUB XXVI 43 Rs.27 bei Imparati, Concessione, $36 \mathrm{f}$.

Goetze, Kizzuwatna, 62, vgl. auch die Errichtung von drei Stelen für Muwanu, Muwatalli und den Feuergott, ebd. 60, Z. 15f. - Auch für $\$ 128$ der Heth. Gesetze scheint es mir am verstăndlichsten zu sein, wenn man den $h$. Stein als Grenzstein auffaßt, dessen Diebstahl geahndet wird.

Zu Madanu vgl. AHw 571f.

52 KUB XXXIV 84 iii 54ff; Rost, Ritual, 362-365. Eine ahnliche magische Handlung wird auch im Ritual gegen die Dămonin DìM.NUN.ME (KUB XIIII 55 iv 7'f; Haas, OA 27 [1988] 90) ausgeführt. - Eventuell darf dieser Aspekt von huwaši auch für das Gerichtsprotokoll KBo XVI 59 Vs. 8-12 (Werner, Gerichtsprotokolle, 54) angenommen werden. 
b) waniza als Kultstele in hieroglyphen-luwischen Texten

Es ist das Verdienst von $\mathrm{H}$. Bossert, erkannt zu haben, daß heth. huwaši in hluw. waniza ${ }^{53}$ seine sachliche Entsprechung hat ${ }^{54}$. Durch die Tatsache, daß die Stele zugleich der Inschriftenträger ist, sind wir über die Form dieser Stelen aus dem 1. Jt. besser informiert als dies bei huwaši im 2. Jt. der Fall ist; es sind (meist) aufrechtstehende Steine, wobei ein sehr schönes Beispiel die in Karahöyük-Elbistan gefundene Stele ist ${ }^{55}$. Auch diese Stelen können mit Reliefs versehen sein, wie etwa die Beispiele aus Darende, Cekke sowie die ursprünglich aus Aleppo stammende Babylonstele zeigen ${ }^{56}$. Im Unterschied zu den hethitischen Texten weist die geographische Streuung der hluw. Texte hauptsächlich auf Südostanatolien und Nordsyrien ${ }^{57}$, was erneut die Verbindung dieser anatolischen Tradition mit Syrien belegt.

Funktionell lassen sich diese Stelen durchaus mit den heth. Pendants vergleichen: Noch aus der heth. Großreichszeit stammen die beiden Stelensockel aus Boğazköy, auf die wohl eine (Holz-)Stele gestellt war. Die Inschrift nennt jeweils den Stifter der Stele ${ }^{58}$. Der kultische Charakter ist durch den archäologischen Befund für die Stele von Karahöyük gesichert, vor der ein Opfertrog zur Aufnahme von Libationen - angebracht war. Der Beginn der Inschrift, die kurz nach dem Ende der heth. Großreichszeit datiert werden kann $^{59}$, nennt die Weihung derselben an den Wettergott des POCULUM. PES. *67-Landes durch einen gewissen Arma-nani während der Herrschaft Ir(i)-Tešubs ${ }^{60}$. Eben-

53 So die modifizierte Lesung nach den von Hawkins / Morpurgo-Davies / Neumann, Hieroglyphs, ermittelten Lautwerten anstelle von Bosserts ${ }^{+}$wa-na-i.

54 Bossert, Wort, 512; vgl. dazu Gurney, Aspects, 38. Die etymologische Verknüpfung beider Worter, wie sie Bossert vorgenommen hat, ist jedoch unhaltbar, ohne da $\beta$ bislang eine Etymologie für waniza gefunden worden wäre. Zu dieser Wortsippe ist hluw. wanni- "Stein"

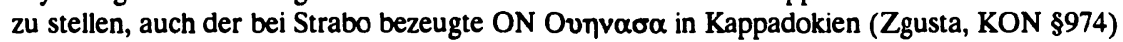
scheint davon abgeleitet zu sein. Eventuell ist auch lyd. vāna "Grabkammer, Hơhle" hier anzuschließen.

Abb. bei Darga, Wesen, 20f, Tf. I und II.

Abb. bei Orthmann, Untersuchungen, Tf. 6a, 5d, 5b; vgl. auch Bossert, Wort, 524-527.

Bossert, Wort, $498 \mathrm{f}$

59 Zum Alter siehe zuletzt Hawkins, Kuzi-Tesub, 105f; weiter Masson, Stèle, 225-241. Auch die aus der Zeit Tudhaliyas IV. stammenden Altăre aus Emirgazi bezeugen die kultische Funktion von Stelen, vgl. Masson, Inscriptions, 3-52. Anm. 36.38. 
falls klar ist der kultische Bezug der Errichtung der Stele für eine Gottheit in den parallelen Inschriften aus Restan und Apamea ${ }^{61}$ :

\begin{abstract}
EGO-mi U+ra/i-hi-li-na I para/i-tá-sa (INFANS) ni-mu-wa/i-za-sa I-ma-tú-wa-ni
(REGIO) REX à-wa za-na URBS+MI-ni-i-na EGO AEDIFICARE+MI-ha za-pa-wa/i (STELA) wa/i-ni-za (DEA) pa-ha-la-ti-ia CRUS-nu-ha. - "Ich bin Urhilina, der Sohn des Paritas, der Konig von Hamat. Diese Stadt erbaute ich, und ich errichtete ${ }^{62}$ diese Stele für Pahalatis / Ba'alat."
\end{abstract}

Die Stele aus Darende ist mit einem Relief von Hebat und Šarruma geschmückt, vor denen der König in Adorationshaltung steht; der kultische Charakter kommt auch im Text auf der Rückseite der Stele zum Ausdruck ${ }^{63}$ :

\begin{abstract}
AVIS $_{2}$ AVIS $_{2}$-wa/i-tá-sa 5 REX NEPOS-mi-sa PUGNUS-mi-li (INFANS) ni-mu-wa/i-za VITELLUS-li-zi (URBS) REGIO.DOMINUS-sa ${ }_{5}$ à-wa-tu 284-ma-ni-i-na (URBS) 485-lina SOLIUM-nu-wa/i-ha za-pa-wa/i STELA DEA-ni PONERE-wa/i-ha. " - (Ich bin) Arnuwantis ${ }^{64}$, der Enkel des Konigs Arnuwantis, der Sohn des Sulumili, des Landesherrn von Melid ${ }^{65}$. Und ich besiedelte inm ${ }^{66}$ die Stadt 284 -mani als 485 -li. Diese Stele aber setzte ich der Gottin ${ }^{67}$."
\end{abstract}

Als weiteres Beispiel darf noch die sogenannte Babylonstele angeführt werden, die wohl ursprünglich aus Aleppo stammt. Die Inschrift ist eine Weihung an den Wettergott von Aleppo, der auch auf der Vs. der Stele abgebildet ist. Der Fluch am Ende der Inschrift ist gegen denjenigen gerichtet, der die Stele beschädigt ${ }^{68}$. - Den bisher genannten Beispielen ist gemeinsam, daß die Stele als Kultgegenstand gelten kann, die zu Ehren einer Gottheit errichtet worden ist, so daß ihre Zerstörung die Strafe der Gottheit nach sich zieht. Da diese Stelen z.T. mit dem Relief der verehrten Gottheit geschmückt sind, liegt es nahe, darin gleichzeitig eine Repräsentation der Gottheit zu sehen.

Die Bedeutung von waniza als "Grenzstein" bezeugt die Inschrift Erkilet ${ }^{69}$. Da sich der Errichter der Stele, Huhha-Šarruma, als Diener Marduks

\footnotetext{
61 Vgl. Meriggi, Manuale II/1, $14 f$.

62 CRUS-nu- /taranu-/ entspricht heth. tittanu-, Hawkins, Negatives, 140.

63 Meriggi, Manuale II $/ 2^{\mathrm{a}}-3^{\mathrm{a}}, 34-36$.

64 Lesung mit Hawkins, Assyrians, 76f; zur Genealogie vgl. auch Ispekçür (Meriggi, Manuale II $\left./ 2^{a}-3^{a}, 44\right)$.

Darf für das Zeichen Laroche $109=$ VITELLUS ein phonetischer Wert $/ \mathrm{mi}_{\mathrm{x}} /$ vermutet werden? Zur Schreibung des ON mit /2/vgl. die aram. Wiedergabe mit $m l z$ in KAI 202, Z.7.

66 D.h. Sulumili.

67 Entsprechend der Darstellung auf der Vs. ist an Hebat zu denken.

68 za-pa-wa/i-ta (STELA)wa/i-ni-za LOCUS-ta 5 -za-' $\left(\mathrm{SA}_{4}\right)$ sá-ní-ti-i; vgl. Meriggi, Manuale II/1 ${ }^{\mathrm{a}}$, 41 und Hawkins, Negatives, 146.

69

Meriggi, Manuale II/1, $12 \mathrm{f}$.
} 
bezeichnet, kann man daran denken, daß implizit ausgedrückt werden soll, daß diese Stele Marduk geweiht ist, der auch als Zeuge für die Grenze fungieren soll:

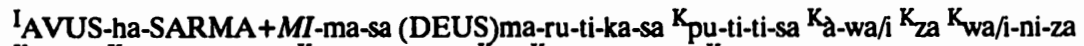

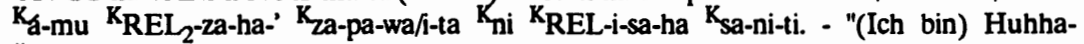
Šarruma, der Verehrer (?) Marduks. Diese Stele meißelte ich; niemand aber darf diese beschådigen."

Die Verbindung von kultischer und sakral-rechtlicher Funktion als Grenzstein wird durch die Stele von Cekke (1.H.8.Jh.) hergestellt ${ }^{70}$. Diese Inschrift handelt von Landverkäufen im Zusammenhang mit der Ansiedlung von 15 Familien in der Stadt Kamana durch Kaminis von Karkemiš ${ }^{71}$, wobei auch die Gebietsgrenzen umschrieben werden. Die im weitesten Sinn vertraglichen Vereinbarungen, die dabei getroffen werden, sind auf der Stele festgehalten, so daß die Stele selbst als Zeuge fungiert. Auf der Vs. lesen wir ${ }^{72}$ :

EGO-mi DOMINUS.SOL-wa/itra/i-sá wa/i-sa-mi-sa mi-ta DOMINUS.SOL-wa/i + ra/i-sá sa-sa-tù +ra/i-ia DOMINUS-ni á-pa-sa-na PONERE-tá $\mathrm{K}$ za-

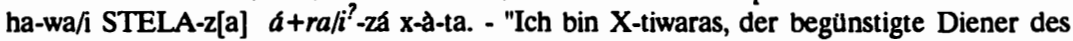
Sasturas. Und dieses (hölzerne) $x$-pamanza stellte X-tiwaras für seinen Herrn Sasturas auf. Und diese Stele $x$-te er als aranza $a^{73}$."

Dementsprechend lesen wir nach der Beschreibung der einzelnen Kaufhandlungen in der Fluchformel ${ }^{74}$ :

za-ti-pa-ti URBS+MI-ni REL-sa MALUS-hi-tà-ri+i VERSUS (PES 2$) i+r a / i$ ní-pa-wa/i FINES-hi-zi $A R H A$ MANUS+218(-)la/i-ha-i ní-pa-wa/i-sa za-ti STELA-ra/i+i (SCALPRUM) tara/i + pi CRUS-ia ${ }^{75}$ wa/i-ta za-ia pátra/i-ta $A R H A$ MALLEUS-i a-pa-ti-pa-wa/i (CAELUM.DEUS) TONITRUS ... (CRUX) wa/i-la PES-wa/i-tu. - "Wer sich dieser Stadt mit Bosheit năhert oder die Grenzen verletzt oder auf dieser Stele herumtrampelt und diese Worte auslösht, gegen diesen soll der himmlische Wettergott ... mit Leid kommen."

Der Parallelismus zwischen der Grenzverletzung, der Zerstörung der Stele und dem Auslöschen der (Vertrags-)Worte verdeutlicht nochmals, daß waniza in diesem Kontext eine klare sakral-rechtliche Funktion hat. Gleichzeitig wird die religiöse Sphäre noch durch die Opferaufschrift bestätigt, die auf der Vs.

$70 \mathrm{Vgl}$. Bossert, Wort, 527f.

71 Vgl. Hawkins / Morpurgo-Davies, Buying, 93.96-98.

72 A 1-4, vgl. Morpurgo-Davies, Analogy, 125; Meriggi, Manuale II/1 ${ }^{\mathrm{a}}, 108$.

73 Ist eine Verbindung mit heth. ara. "Recht, Angemessenheit" möglich?

74 Rs. 10-11, vgl. Hawkins, Negatives, 146f; ders., Kubaba, 163f; weiters Meriggi, Manuale II/1 ${ }^{\text {a }}$, 111.

$75 \mathrm{Vgl}$. die ăhnliche Formulierung in Ekinveren (Tilsevet) bei Meriggi, Manuale II/2 $2^{\mathrm{a}}-3^{\mathrm{a}}, 107$. 
der Stele angebracht ist. Man darf dabei wohl daran denken, daß die hier genannten Opfer dem auf der Stele beschriebenen rechtlichen Vorgang besonderes Gewicht verleihen sollen. Der kurze Abschnitt lautet ${ }^{76}$ :

za-ti-pa (CAELUM.DEUS) TONITRUS VITELLUS (ANIMAL) [A]RHA [FLAMMAE] ki-[nu]-wa/i-ti POST+ra/i-ta-pa-wa/i BOS (ANIMAL) OVIS (ANIMAL) (LIBARE) sa +ra/i-la-ti. - "Hier verbrennt man dem himmlischen Wettergott ein Kalb; in Zukunft aber bringt man (ihm) ein Rind und ein Schaf dar."

Gegenüber den heth. huwaši-Steinen ist im 1. Jt. eine Neuerung und Erweiterung der Funktion der Stelen zu erkennen: Die Beispiele aus Karkemiš ${ }^{77}$ bringen nun in verstärktem $\mathrm{Maße}$ auch die kommemorative Funktion dieser Stelen zum Ausdruck. Kark A 4b (Ende 2. Jt.) zeigt die Erinnerung an ein historisches Ereignis: Ura-Tarhunzas ist aufgrund des Beistandes des Wettergottes und Kubabas fähig, eine kriegerische Auseinandersetzung erfolgreich zu beenden. Deshalb setzt er sich selbst (und den Göttern) die Stele als Denk$\mathrm{mal}^{78}$. Genauso ist Kark A $18 \mathrm{~h}$ hier anzuführen ${ }^{79}$, welche Stele eine ähnliche Funktion hat. Daß die Erinnerung an historische Ereignisse auf Stelen festgehalten wurde, könnte dabei ein Einfluß aus dem mesopotamischen Raum sein, der ursprünglich mit den anatolischen Stelen wenig zu tun hatte ${ }^{80}$.

\section{Masseben im Alten Testament}

Terminologisch bringt das Wort mașsebāh nicht den Aspekt des Wohnens zum Ausdruck, sondern ist eine Nominalbildung zur Wurzel NȘB "aufstellen, errichten ${ }^{n 1}$. Diese mehr technische Terminologie ist allerdings insofern nicht völlig vom syrischen und kleinasiatischen Sprachgebrauch getrennt, als auch bei sikkanum und huwaši regelmäßig vom "Aufrichten" dieser Stelen die Rede ist $^{82}$. Aber auch das Aufrichten einer Stele (vgl. Gen 35,14: wyṣb mṣbh) hat den Zweck, diese als Kultobjekt zu charakterisieren, wie jene Stellen im AT zeigen, die einen kultischen Schwerpunkt erkennen lassen. Außerhalb der

\footnotetext{
76 Vgl. Meriggi, Manuale II $/ 2^{\mathrm{a}} \cdot 3^{\mathrm{a}}, 112$.

77 Hawkins, Inscriptions, 87-114.

78 Vgl. Meriggi, Manuale II/ $/ 2^{\mathrm{a}}-3^{\mathrm{a}}, 325-327$.

79 Vergleichbar damit scheint mir auch Ekinveren (Tilsevet) bei Meriggi, Manuale II $2^{\mathrm{a}}-3^{\mathrm{a}}$, 105-107; ferner 2 Sam 18,18.

80 Börker-Klähn, Bildstelen, 77.

81 Vgl. dazu Gamberoni, mașsebāh, $1065 \mathrm{f}$.

82 Vgl. ${ }^{\text {na4} s i k k a n a ~ i s ̌ a k k a n u ̄: ~ E M A R ~ V I / 3, ~ N r .370,41 f ; ~ n s ̦ b ~ s k n: ~ K T U ~} 1.17$ I 26; zu ${ }^{\text {na4}}$ huwaši šara tittanu- vgl. Darga, Wesen, 15.
} 
Jakobsüberlieferung sind es besonders die negativen prophetischen Stellen, die Masseben in Parallele mit Altar (Jes 19,19; Hos 10,1f), mit Opfer (Hos 3,4), mit dem Tempel (Jer 43,13) oder mit Götterbildern (Mi 5,12) nennen. Dieser kultische Tenor ist auch den deuteronomischen und deuteronomistischen Texten eigen ${ }^{83}$, wobei besonders 2 Kön 3,2 und 10,26f hervorzuheben sind, die Masseben mit Ba al in Verbindung bringen. Alle diese negativen Stellungnahmen bezüglich dieses Kultsymbols zeigen indirekt die Beliebtheit und Bedeutung des Objekts, das kaum grundlos in diesen Textschichten des AT abgelehnt worden is ${ }^{84}$. Die zuletzt genannten Belege, die die Masseben direkt mit Gottheiten verbinden, zeigen dabei, daß auch im AT mașsebäh als Repräsentant einer Gottheit aufgefaßt werden konnte ${ }^{85}$. Die sakralrechtliche Sphäre wird in Ex 24,4 angesprochen ${ }^{86}$, wenn Mose 12 Masseben entsprechend den 12 Stämmen Israels aufrichtet. Diese Masseben sind Zeugen, gleich wie Jakob und Laban als Zeugen ihres Vertrags eine Stele errichten (Gen 31,44-54). Die literarkritischen Probleme des Textes sind nicht einfach, wobei aber eine Scheidung des Textes in einen elohistischen Vertragsschluß, in dem die Massebe im Mittelpunkt steht, und in einen jahwistischen Teil, in dem ein Steinhaufen aufgeschichtet wird, nicht völlig befriedigt ${ }^{87}$. Sicher scheint die Funktion der Massebe zu $\operatorname{sein}^{88}$ : sie ist göttlicher Zeuge dafür, daß die Vertragsbedingungen, d.h. im konkreten Fall die Grenze, die durch die Massebe als Grenzstein markiert ist, von beiden Seiten akzeptiert werden.

In der Jakobserzählung spielen Masseben überhaupt eine wichtige Rolle, wobei die Erzählung in Gen 28,11-22 die umfangreichste Stelle im AT ist, an der ausführlich über die Errichtung einer Massebe (Gen 28,18.22) berichtet wird. Die zentrale Bedeutung ${ }^{89}$ dieser Stelle für den ganzen Jakobszyklus ist dabei daran zu sehen, daß noch mehrfach auf dieses Ereignis Bezug genommen

83 Ex 23,24; Ex 34,13; Dtn 7,5; 12,3; 16,22; 1 Kon 14,23; 2 Kön 17,19; 28,4; 23,14; weiters auch noch Lev 26,1 sowie das chronistische Geschichtswerk 2 Chr 14,2; 31,1.

84 Vgl. Jaroš, Stellung, 167 und Schroer, Bilder, 366. Für die theologische Wertung und Ablehnung im AT siehe auch Gamberoni, mașsebäh, 1068-1074.

85 Dies bestátigt auch KAI 214,1.14f, wenn nșb als Bezeichnung für eine anthropomorphe Darstellung des Wettergottes Hadad verwendet wird. Vgl. auch Jos 4,3ff; 24,26ff: 'bn.

87 Vgl. etwa de Pury, Promesse, 406f: E 31,44.45.49.50.53b.54; J 46.47.48.51.52.53a oder die Analyse von Westermann, Genesis, 607-610, der den Text in eine ursprüngliche Privatabmachung und einen spatter eingefügten stämmepolitischen Pakt scheidet; zu den Unterschieden zwischen MT und LXX siehe zuletzt Seebass, LXX, 30-38.

88 Vgl. dazu auch de Pury, Promesse, 408.423 und Westermann, Genesis, 609; m.E. soll man dabei Grenzstein und Zeugnisfunktion sachlich nicht voneinander unterscheiden.

89 Vgl. auch Marböck, Orte, 216 sowie ebd. 213, wo ausdrücklich betont wird, daß Masseben im Abrahamszyklus im Unterschied zur Jakobsubberlieferung keine Rolle spielen. 
wird (Gen 31,13; 35,14). Die Frage, um die es primär geht, ist, ob die Massebe $^{90}$ ein Repräsentant des Gottes, der Jakob im Traum erschienen ist, oder lediglich ein Erinnerungsmal ${ }^{91}$ dafür sein soll. Obwohl nirgends in der Erzählung die Identifizierung des Steines als "bêt 'aelohîm" ausdrücklich gesagt wird, ist dies intendiert. Denn die Benennung des Ortes als bêt 'aelohîm (V. 17) und die Errichtung der Massebe sind so eng miteinanderverbunden, da $\beta$ diese Gleichsetzung bewußt angestrebt wird. Der Gott, der im Traum gesehen wird, ist - auch für die Nachwelt sichtbar - in der Massebe präsent, wobei diese numinose Qualifikation des Steines durch das Aufrichten besonders deutlich wird $^{92}$. Der Ort ${ }^{93}$ strahlt aufgrund der Stele seine Heiligkeit aus, so daß Jakobs Begegnung mit dem Gott, der die Stele "bewohnt", die entsprechende Verehrung in V. 18 verlangt. Die Salbung bringt nämlich nicht die Dauerhaftigkeit oder eine (magische) Kraftzufuhr zum Ausdruck ${ }^{94}$, sondern es handelt sich dabei um eine religiöse Handlung ${ }^{95}$, was noch durch das Ausgießen einer Libation verstärkt wird (Gen 35,14). Die kultische Funktion, die die Massebe damit gewinnt, ist dabei weitgehend dem anatolischen und nordsyrischen Material vergleichbar. Neben den im vorigen Abschnitt genannten Texten scheint mir ein Abschnitt aus der Apologie Hattušilis III. von Interesse zu sein, wo es heißt ${ }^{96}$ :

"Das Haus des Arma-datta, welches ich ihr gab, und die Ortschaften, welche auch immer, des Arma-datta, da wird man sie Istar / Šaušga jeweils an jedem einzelnen (Ort) hinter der Massebe aufstellen und man wird den Pithos füllen.Ǐtar / Šausga, sie (ist) meine Gottheit, und sie werden sie für sich (als) erhabene Istar / Šaušga beopfern."

90 Die Große der Massebe spielt keine Rolle, so daß es kaum gerechtfertigt ist, in der Aufrichtung des Steines eine Reminiszenz an neolithische Megalithkulturen und an die Riesen als Vorbevolkerung Israels (vgl. etwa Num 13,28.32; Dtn 3,11) zu sehen; gegen Maag, Hieros Logos, 32 und Jaroš, Stellung, 190.

91 Westermann, Genesis, 557 sieht den Sinn von V. 18 nur darin, den heiligen Ort kenntlich zu machen.

92 Maag, Hieros Logos, 33. Ähnlich - und z.T. im Anschluß an Maag - Jaroš, Stellung, 190, der den Stein als Medium sieht, durch den eine vielleicht chthonische Gottheit oder ein Totengeist im Traum Weisungen gab, vgl. zu solchen "Orakelsteinen" etwa KTU 1.1 iii 13; 1.3 ii 23. iv $15 ; 1.82,42$.

93 Zu maqôm vgl. Marböck, Orte, 215.217f und de Pury, Promesse, 594-596; Bet-El (V.19) als ON ist erst aufgrund des Wortspiels mit bêt raelohim in den Text gekommen, vgl. de Pury, Promesse, 429.

94 Anders Westermann, Genesis, 558.

95 Vgl. de Pury, Promesse, 417f, der Salben bzw. Besprengen einer Stele überhaupt als Reste eines Speiseopfers an die in der Stele anwesende Gottheit betrachtet.

Otten, Apologie, 28 iv 71-75; TUAT 1/5,491. 
Dieser Text bringt die ideelle Verbindung zwischen Gottheit und Stele deutlich zum Ausdruck, da man sich des Eindrucks nicht erwehren kann, daß obwohl die Göttin und die Stele nicht identisch sind - beide in einem Kontext beopfert werden, womit indirekt auch die Stele als Repräsentantin Ištars (Šaušgas) erscheint. Das Nebeneinander von Göttin und Stele ist dabei wohl als ähnliche "Kultreform" oder Restauration zu werten, wie wir es eine Generation später unter Tudhaliya sehen: Neben die "alte" Stele tritt das Bild der Göttin. Für uns ist dabei bedeutend, daß die funktionelle Gleichwertigkeit zwischen Bild und Kultstele der Gottheit gegeben ist.

Die Massebe Jakobs ist aber gleichzeitig der göttliche Zeuge ${ }^{97}$ des nächtlichen Erlebnisses (V.16f) und des Gelübdes (V. 20-22). Obwohl das Gelübde als Erzählung in sich geschlossen ist, darf man es nicht vom Traum und der Errichtung der Stele trennen, da V.22a klar auf V.18 zurückgreift ${ }^{98}$. Denn Jakobs Versprechen für den Fall seiner glücklichen Rückkehr, die als Erfüllung der göttlichen Verheißung angesehen werden kann, setzt die augenblickliche Notsituation voraus: Dann soll der Gott, der ihm erschienen ist, Jakobs Gott werden ${ }^{99}$. Als Zeuge für dieses Gelübde fungiert dabei die aufgerichtete Massebe ${ }^{100}$, die gleichzeitig den Gott, an den das Versprechen gerichtet ist, repräsentiert ${ }^{101}$. - Dieses Ziel, auf das die Erzählung hinausläuft, führt uns nochmals zur hethitischen Literatur zurück. Im Beschwörungsritual der Paškuwatti an die Göttin Uliliyašši (KUB VII 5+) finden wir mehrere mit unserem Text vergleichbare Elemente: der Traum, in dem sich die Gottheit dem in Not befindlichen Menschen zeigt, die Errichtung einer Stele als Erscheinungsbild der Gottheit, das Gelübde, die Gottheit als persönliche Gottheit zu verehren. Paškuwatti spricht im Ritual stellvertretend für den Opfermandan$\operatorname{ten}^{102}$ :

"Er soll deine Macht sehen; er wird dich dann zu seiner persölichen Göttin machen und dir ein Gelübde machen.... Der Opfermandant legt sich nieder (und wartet), ob er die

97 Westermann, Genesis, 557 betont zwar den Zeugenaspekt, trennt ihn aber zu Unrecht von der Göttlichkeit und auch vom Gelübde.

98 Vgl. de Pury, Promesse, 434-446, der sich nachdrücklich für die Zusammengehörigkeit von Traum, Gelübde und Errichtung der Massebe ausspricht. - Westermann, Genesis, $558 \mathrm{f}$ trennt das Gelübde ab, weil es eine Spannung zur Verheißung bildet und Gelübde angeblich ein festes Heiligtum voraussetzen, das es in der Văterzeit nicht gegeben hatte.

99 Vgl. auch die Entfernung der fremden Götter in Gen 35,1-7.

$100 \mathrm{Vgl}$. besonders auch $\mu \mathrm{o}$ in LXX: "Der Stein ... soll mir gegenüber Zeuge [bêt 'aelohîm] sein", vgl. de Pury. Promesse, 424.

101 Anders ist die sogenannte Melqart-Stele (KAI 201, TUAT I/6,625) zu interpretieren: Die Errichtung der Stele $(n s ̦ b)$ durch Birhadad geschieht wohl als Erfüllung eines Gelübdes ( $n z r)$.

102 Hoffner, Ritual, 276 iii 11-14. iv 1-3.11-16. 
Gottin im Traum sieht. ... Dann kommt er und verehrt die Gottin. Wenn ihr ferner ein Pithos gut (scheint), stellt er sie als Pithos auf. Wenn aber nicht, stellt er sie als Kultstele $\left({ }^{\text {na4}}\right.$ hu-u-wa-si $)$ auf oder er macht sie als Statue."

Die Stelle ist auch im Zusammenhang mit dem Gelübde ${ }^{103}$ in der Jakobserzählung von Interesse, da J. de Roos in seiner Untersuchung der hethitischen Gelübdetexte gezeigt hat, daß die Gattung Gelübde im heth. Schrifttum speziell im 13. Jh. - große Verbreitung fand, im Vorderen Orient aber vergleichsweise wenige Gelübdetexte erhalten sind. Für die wenigen Beispiele aus Ugarit und dem AT könnte man daher mit aller Vorsicht, die aufgrund des geringen Materials geboten ist, daran denken, daß ein kleinasiatischer Einfluß vorhanden sein könnte ${ }^{104}$.

Gen 28 steht somit nicht nur allgemein in einer syrischen Stelentradition, sondern ist aufgrund des Gelübdes zugleich ein Beispiel dafür, daß diese syrischen Traditionen auch einen engen Konnex mit Kleinasien aufweisen. Für die frühisraelitische Religionsgeschichte - und der Themenkreis Masseben ist hierin zweifellos sehr zentral - ist somit ein Ausblick nach Syrien und darüber hinaus nach Kleinasien unabdingbar.

\section{Der Unterschied zwischen Kultstelen/Baityloi und Gedächtnissteinen}

Aus dem bisher unter vorwiegend terminologischen Gesichtspunkten disku-

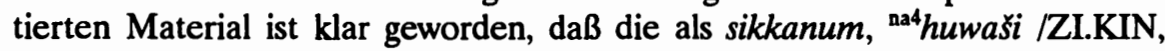
waniza bzw. mașsebäh bezeichneten Stelen primär eine Gottheit repräsentieren, die entweder für eine kultische Handlung oder als Zeuge in der Stele anwesend ist, so da $\beta$ man die von Graesser ${ }^{105}$ als Vertrags- bzw. Kultstelen getrenntbehandelten Monumente unter diesem Gesichtspunkt zusammenfassen kann. Davon abzutrennen sind allerdings die beiden weiteren bei Graesser genannten Funktionen von Stelen als Erinnerungszeichen bzw. als Grabstein ${ }^{106}$. Wenn man zunächst nach den Bezeichnungen für Grabsteine fragt, so fällt auf, daß

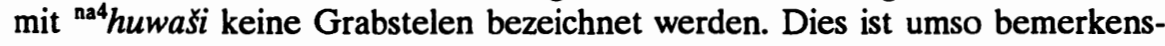

\footnotetext{
${ }^{103} \mathrm{Vgl}$. auch KUB XV 1 ii 1-4: "Die Königin gelobte im Traum [.... ??] Zababa von Urikina folgendes: Wenn du, mein Herr, mich am Leben laßt, dann werde ich dir eine Stele und einen Altar in Metall fassen"; vgl. die Ergănzungsvorschläge von de Roos, Geloften, 186.194 Anm. $14 f$.

104 de Roos, Geloften, 90-94.

105 Graesser, Stones, 37-39.44-48.

106 Ders., aaO, 39-44.
} 
werter, als humâ/ûsum gelegentlich auch ein Grabmonument bezeichnen $\mathbf{k a n n}^{107}$, doch wurde diese Bedeutung des Wortes nicht ins Hethitische entlehnt, wohl unter dem Einfluß von ${ }^{\text {nad }}$ sikkanum/ZI.KIN. Auch im AT bezeichnen Masseben nur selten Grabstelen, sicher ist nur Gen 35,20; allerdings kann auch jene Massebe, die Absalom für sich errichtet (2 Sam 18,18), funktionell mit einem Grabstein verglichen werden. Denn dieser Stein hat die Aufgabe, das Andenken an Absalom zu bewahren. Viel häufiger wird aber bei einer solchen Bedeutung eine andere Terminologie verwendet; so findet sich etwa in nordwestsemitischen Inschriften die Bezeichnung $n p s^{108}$. Dazu kommt weiters, da $B$ die beiden typischen Grabstelen aus Nerab (KAI 225,3.6.12; 226,2) weder von $(m) n s ̧ b(t)$ noch von $n p \check{s}$, sondern von șlm (Bild, Statue) sprechen. Gerade diese beiden Inschriften stehen aber von der Text- und Bildkomposition her in enger Verbindung mit einigen hluw. Inschriften ${ }^{109}$, die ihrerseits jedoch nicht als waniza "Kultstele", sondern als tasa "Denkmal"110 bezeichnet werden. Der naheliegende Schluß ist daher, daß Grabstelen als eigenständige Kategorie betrachtet werden sollen: die Sitte, mit Hilfe eines Steines ein Grab zu markieren, ist weit verbreitet, wobei man dafür verschiedene Ausdrücke wie $n p \check{s}, s \operatorname{lm}$, $y d^{111}$ oder tasa wählte, deren Bedeutung z.T. auf das "Bild", "Wesen" oder die "Person" des Verstorbenen Bezug nimmt, was treffender ist. Diese Grabstelen repräsentieren den Toten und dienen vielleicht auch als Sitz der Seele des Verstorbenen, wobei sie zugleich als Lokalisationspunkt für den Totenkult gelten können ${ }^{112}$. Aufgrund dieser klar umrissenen Funktion sind Grabstelen als eigene Gattung anzusehen, wobei m.E. "Massebe" als Funktionsbezeichnung erst sekundär auf den "Grabstein" übertragen worden ist ${ }^{113}$, wofür besonders die späten punischen Inschriften vielfache Belege ${ }^{114}$ bieten. Als Beispiel für

\section{Durand, Nom, 6.}

108 KAI 128,3; 136; 230,1 und Jean / Hoftijzer, Dictionnaire, 184f s.v.

109 Vgl. Hawkins, Monuments, 213-225; vgl. zum Komplex der syr.-anat. Grabstelen auch Voos, Studien, 347-362 und Börker-KJähn, Bildstelen, 79-82.

${ }^{110} \mathrm{Vgl}$. dazu Hawkins, Monuments, 222f und Eichner, Beiträge, 59-62, der damit auch lyk. $\diamond \diamond \varepsilon$, was allerdings eher die Bedeutung "Altar, Kultmal" hat, verbindet. Etymologisch ist tasa auf das Verbum ta- "setzen, (auf)stellen" zurückzuführen.

111 yd "Hand" als pars pro toto für die Person; zur Verwendung als Totengedenkstein siehe Schroer, Bilder, 369 f und zuletzt Loretz, Stelen. - Auch sywn (2 Kơn 23,17; Ez 39,15) kann ein Grabmal bezeichnen.

112 Voos, Studien, 349, vgl. auch de Pury, Promesse, 413f, der aber zugleich betont, daß eine direkte Verbindung zwischen solchen Stelen und den Totenriten wenig wahrscheinlich ist.

113 Etwas anders Voos, Studien, 360, wenn er die im Totenkult verwendeten Stelen als Hơhepunkt bodenstandiger Entwicklungen ansieht, die fest in der Massebentradition verwurzelt sind. Ich rechne mit zwei parallelen Traditionen, deren Funktionen sich sekundär beeinflußt haben.

114 KAI 34,1;53,1;100,1;149,1; 163,2; 165,2 . 
diese Bedeutung sei KAI 35 (TUAT II/4,600f) aus dem 3. Jh. genannt, das auch insofern interessant ist, als der Text eine Parallele zu 2 Sam 18,18 darstellt, wonach man seine Grabstele bereits :zu Lebzeiten errichten konnte:

"Ich, Abdosir, Sohn des Abd-SSM, des Sohnes Ḥors, habe eine Stele (mșbt) noch zu meinen Lebzeiten aufgerichtet über meiner ewigen Ruhestătte - auch für meine Frau Amot-Aštart, die Tochter TMs, des Sohnes Abd(i)-Milks."

Der Erinnerungscharakter, der in der Errichtung eines Steins über dem Grab zum Ausdruck kommt, verbindet diese Steine auch mit dem Gedenken an ein besonderes Ereignis. Auch hier zeigt sich, daß diese Funktion verschieden stark ausgeprägt ist. Die Termini ${ }^{\text {na4 }}$ huwaši bzw. mașșebäh für kommemorative Stelen kommen im heth. und atl. Schrifttum nicht vor $^{115}$. Lediglich in hluw. und aram. Texten finden wir die Termini für Stele in dieser Bedeutung. Es ist daher durchaus denkbar, da $\beta$ die Übertragung dieser Funktion auf Stelen in Nordsyrien auf den Einfluß Mesopotamiens zurückgeht, wo kommemorative Stelen (mit Inschriften) wesentlich größere Verbreitung haben ${ }^{116}$. Da der Übergang von der Weihung der Stele an die Gottheit, die den Sieg verliehen hat, zur Stele als Erinnerungszeichen des eigenen Sieges schmal ist, können jedoch die verschiedenen Funktionen ineinanderfließen. Dies zeigt etwa die Zakkur-Inschrift (KAI 202A 1; B 14): Zakkur errichtet für Ilu-Wer eine Stele, die aber gleichzeitig dazu dient, die Taten Zakkurs zu verkünden. Ähnlich fließende Übergänge lassen auch die schon genannten hluw. Texte aus Elbistan oder Karkemiš A 4b erkennen.

Gerade dieser Übergang, aber auch jene Stelen, die ursprünglich nur das Gedächtnis des Verstorbenen bewahren helfen sollten, aber zum Ausgangspunkt des Totenkults und der göttlichen Verehrung von verstorbenen Ahnen wurden, tragen dazu bei, daß Stelen, deren Form funktionsspezifisch nicht unterschieden wird, sekundär mehrere Aspekte bekommen können. Terminologisch ließ sich in der vorliegenden Untersuchung jedoch zeigen, daß jene Stelen, die als Wohnsitz einer Gottheit angesehen wurden, eine eigene Gruppe darstellen, die man als "Kultstelen" bzw. Baityloi bezeichnen könnte. Die Vorstellung, da $B$ die Gottheit in der Stele anwesend ist, hat dabei offensichtlich in Syrien ihren Ausgangspunkt gehabt, von wo aus dieses religiöse Phänomen sich sowohl nach Anatolien als auch nach Israel ausgebreitet hat, so daß es

115 Hattusili III. errichtet im Gedenken an den Sieg über seine Feinde in Hahha ein Siegesmal (ŠU.AN: Otten, Apologie, 10 ii 25); auch in den "Taten Šuppiluliumas" ist im unklaren Kontext einmal dieser Ausdruck erwăhnt, KUB XIX 14, Z.18: ] ŠU.AN-na ka-in an-da x [ . - Im AT finden wir auch $y d$ in der Bedeutung für (Sieges-)Mal, vgl. Schroer, Bilder, 368f.

116 Schroer, Bilder, 367. - Vgl. auch Durand, hamâsum, 45 für die Yahdun-Lim-Inschrift. 
beinahe gerechtfertigt ist, in diesem Zusammenhang von einer religiösen Koine zu sprechen.

Bibliographie

Archi, A., Fêtes de printemps et d'automne et réintégration rituelle d'images de culte dans l'Anatolien hittite, UF 5 (1973) 7-27

Börker-Klähn, J., Altvorderasiatische Bildstelen und vergleichbare Felsreliefs, Mainz 1982

- / Meitner, L. / Peckeruhn, K, Neues zu Iflatun Pinar, ArOr 55 (1987) 176-179

Bossert, H.Th, Das H-H Wort für "Malstein", Belleten XVI/64 (1952) 495-545

Caquot, A. / Sznycer, M., Ugaritic Religion (IR XV,8), Leiden 1980

Charpin, D., Le betyle au pays de Sumer, NABU 1987, Nr.77,41

Darga, M., Über das Wesen des huwaši-Steines nach hethitischen Kultinventartexten, RHA 27 (1969) 5-24

Dietrich, M. / Loretz, O. / Mayer, W., Sikkanum "Betyle", UF 21 (1989[1990]) 133-139

Durand, J.-M., "hamașum = "faire du carnage, piller, couper des arbres", NABU 1987, Nr.85,45

- Le culte des bétyles en Syrie, in: J.M. Durand / J.R. Kupper (ed.), Miscellana Babylonica. Mélanges offerts à Maurice Birot, Paris 1985, 79-84

- Le nom des bétyles à Ebla et en Anatolie, NABU 1988, Nr.8,5-6

Donner, H., Zu Gen 28,22, ZAW 72 (1962) 68-70

Eichner, P., Anatolisch, Sprache 25 (1979) 196-207

- Etymologische Beiträge zum Lykischen der Trilingue vom Letoon bei Xanthos, Or. 52 (1983) 48-66

Fauth, W., Baitylia, KP 1 (1975) 806-808

Gamberoni, J., mașsebāh, ThWAT IV (1982-84) 1064-1074

Gese, $H$., Die Religionen Altsyriens, in: $H$. Gese / M. Höfner / $K$ Rudolph, Die Religionen Altsyriens, Altarabiens und der Mandăer (RM 10,2), Stuttgart 1970, 1-232

Goetze, A., Kizzuwatna and the Problem of Hittite Geography, New Haven 1940

- Kleinasien, München 1933

Graesser, C.F., Standing Stones in Ancient Palestine, BA 35 (1972) 34-63

Güterbock, H.G., Rezension zu C.-G. von Brandenstein: Hethitische Götter nach Bildbeschreibungen in Keilschrifttexten, Or. 15 (1946) 482-496

- Hethitische Gotterbilder und Kultobjekte, in: R.M. Boehmer / H. Hauptmann (Hg.), Beiträge zur Altertumskunde Kleinasiens (FS K. Bittel), Mainz 1983, 203-217

Gumey, O.R., Some Aspects of Hittite Religion, Oxford 1977

Hauptmann, H. $\rightarrow$ Boehmer, R.M.

Hawkins, J.D., Building Inscriptions of Carchemish. The Long Wall of Sculpture and Great Staircase, AnSt 22 (1972) 87-114 
- Assyrians and Hittites, Iraq 36 (1974) 67-83

- The Negatives in Hieroglyphic Luwian, AnSt 25 (1975) 119-156

- Late Hittite Funerary Monuments, in: B. Alster (ed.): Death in Mesopotamia Papers Read at the XXVI Rencontre Assyriologique Internationale (Mesopotamia 8), Copenhagen 1980, 213-225

- Kubaba at Karkamis and Elsewhere, AnSt 31 (1981) 147-176

- Kuzi-Tesub and the "Great Kings" of Karkemiš, AnSt 38 (1988) 99-108

- / Morpurgo-Davies, A. / Neumann, G., Hittite Hieroglyphs and Luwian: New Evidence for the Connection, Gottingen 1973

- / Morpurgo-Davies, A., Buying and Selling in Hieroglyphic Luwian, in: J. Tischler (Hg.), Serta Indogermanica (FS G. Neumann; IBS 40), Innsbruck 1982, 91-105

Hoffner, HA. Jr, Paskuwattis Ritual against Sexual Impotence (CTH 406), Aula Orientalis 5 (1987) 271-287

Hoftijzer, J. $\rightarrow$ Jeam, Ch.F.

Imparati, $F$., Una concessione di terre da parte di Tudhaliya IV., RHA 32 (1974) 1-211

Jakob-Rost, L., Zu den hethitischen Bildbeschreibungen. I. Teil, MIO 8 (1961) 161-217

Jaroš, $K$, Die Stellung des Elohisten zur kanaanäischen Religion (OBO 4), Freiburg (Schweiz) / Göttingen 1974

Jean, Ch.F. / Hoftijzer, J., Dictionnaire des Inscriptions Sémitiques de l'Ouest, Leiden 1965

Kronasser, H., Etymologie der hethitischen Sprache. Bd. 1, Wiesbaden 1966

Lebrun, $R$, Hymnes et prières Hittites (HR 4), Louvain-la-Neuve 1980

Loretz, O., Stelen und Sohnespflicht im Totenkult Kanaans und Israels: skn (KTU 1.17 I 26) und jd (Jes 56,6), UF 21 (1989) 241-246

- $\rightarrow$ Dietrich, $M$.

Maag, V., Zum Hieros Logos von Beth-El, in: ders., Kultur, Kulturkontakt und Religion. Gesammelte Studien zur allgemeinen und alttestamentlichen Religionsgeschichte, Göttingen / Zürich 1980, 29-37

Marböck, J., Heilige Orte im Jakobszyklus. Einige Beobachtungen und Aspekte, in: M. Görg (Hg.), Die Vater Israels. Beiträge zur Theologie der Patriarchenüberlieferung im Alten Testament (FS J. Scharbert), Stuttgart 1989, 211-224

Masson, E., Les inscriptions louvites hiéroglyphiques d'Emirgazi, JS 1979, 3-53

- La stèle de Karahöyük-Elbistan: nouvel examen, in: Florilegium anatolicum. Mélanges offerts à $E$. Laroche, Paris 1979, 225-241

Mayer, $W$. $\rightarrow$ Dietrich, $M$.

Meitner, L. $\rightarrow$ Börker-Klähn, $J$.

Meriggi, $P$., Manuale di eteo geroglifico. Parte II. Testi, $1^{\text {a }}$ Serie, Roma $1967 ; 2^{\mathrm{a}}-3^{\mathrm{a}}$ Serie, Roma 1975

Morpurgo-Davies, A., Analogy and the -AN Datives of Hieroglyphic Luwian, AnSt 30 (1980) 123 137

- $\rightarrow$ Hawkins, J.D.

Neumann, G. $\rightarrow$ Hawkins, J.D.

Nowicki, H., Bemerkungen zur hier.-luw. Inschrift von Karahöyük-Elbistan, ZVSF 95 (1981) 251-273 
Özgüç, T., Altintepe II. Tombs, Storehouse and Ivories (TTKY V/27), Ankara 1969

Orthmann, $W$., Untersuchungen zur spathethitischen Kunst, Bonn 1971

Otten, H., Die Apologie Hattusilis III. Das Bild der Überlieferung (StBoT 24), Wiesbaden 1981

Peckeruhn, $K \rightarrow$ Börker-Klähn, J.

Popko, M., Kultobjekte in der hethitischen Religion (nach keilschriftlichen Quellen), Warszawa 1978

Pury, A. de, Promesse divine et légende cultuelle dans le cycle de Jacob, 2 Bde, Paris 1975

Riemschneider, KK, Die hethitischen Landschenkungsurkunden, MIO 6 (1958) 321-381

Roos, J. de, Hettitische Geloften. Een teksteditie von Hettitische geloften met inleiding, vertaling en critische noten, phil.Diss., Amsterdam 1984

Rost, $L$. Ein hethitisches Ritual gegen Familienzwist, MIO 1 (1953) 345-379

Schroer, S., In Israel gab es Bilder. Nachrichten von darstellender Kunst im Alten Testament (OBO 74), Freiburg (Schweiz) / Gottingen 1986

Schuler, E. von, Hethitische Dienstanweisungen für höhere Hof- und Staatsbedienstete. Ein Beitrag zum antiken Recht Kleinasiens (AfO B 10), Graz 1957

Seebass, H., LXX und MT in Gen 31,44-53, BN 34 (1986) 30-38

Singer, I., The huwaši of the Storm-God in Hattusa, in: IX. Türk Tarih Kongresi. Kongreye Sunulan Bildiriler. I. Cilt (TTKY IX/9), Ankara 1986, 245-253

Sznycer, $M . \rightarrow$ Caquot, $A$.

Voos, J., Studien zur Rolle von Statuen und Reliefs im syrohethitischen Totenkult wăhrend der frühen Eisenzeit (etwa 10.-7.Jh.v.u.Z.), EAZ 29 (1988) 347-362

Werner, $R$., Hethitische Gerichtsprotokolle (StBoT 4), Wiesbaden 1967

Westermann, C., Genesis 13-36 (BKAT I/2), Neukirchen-Vluyn 1981 


\title{
Der Bock, der die Sünden hinausträgt
}

Zur Religionsgeschichte des Azazel-Ritus Lev 16,10.21f ${ }^{1}$

\begin{abstract}
"Sprichwörtlich ist der 'Sündenbock' des Alten Testaments (Lev 16,21), viel diskutiert sind die 'Pharmakos'-Rituale in Kleinasien und Griechenland. Solche Rituale konnen regelmäßig institutionalisiert sein, sie kommen aber auch in außerordentlichen Notsituationen vor, Krieg, Hunger, Pest. Hier dürfte ein vormenschlicher Seelenmechanismus im Spiel sein, der in der Angstsituation atavistisch aufbricht: die Situation des von Raubtieren umkreisten Rudels - der von Wolfen verfolgte Schlitten beschaftigt Literatur und Phantasie bis in neueste Zeit. Es gibt nur ein Mittel, der Gefahr zu entkommen: sobald ein Mitglied der Gruppe - in der Regel ein junges oder aber ein altes, krankes von den Raubtieren gepackt ist, sind die anderen für diesmal gerettet. Die moralische Fragwürdigkeit des Vorgangs läßt eine doppelte Kompensation zu: man stilisiert das Opfer als abominablen 'Auswurf', oder aber man fuhlt sich ihm zu tiefstem Dank und höhster Ehrerbietung verpflichtet ${ }^{2}$.
\end{abstract}

\section{Einführung: Azazel und der "Sündenbock"}

Es gibt nur wenige religiöse Vorgänge, bei denen der Umfang der Überlieferung und die von ihr gezeitigte Wirkung so sehr auseinanderklaffen, wie im Fall des biblischen Azazel-Ritus: 4mal wird im Alten Testament der Name

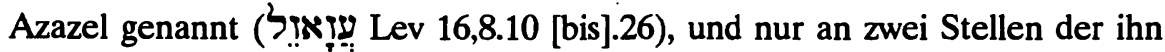
betreffende Ritus mit dem "Sündenbock" dargestellt (Lev 16,5-10.20-22). Wie kulturell prägend bis hinein ins Sprichwörtliche ${ }^{3}$ ist demgegenüber die mit dem "Sündenbock" verbundene Wirkungsgeschichte! Die Erinnerung an ihn hat sich im kollektiven Gedächtnis festgesetzt und öfter als uns lieb sein kann das soziale Handeln gelenkt - bisweilen ohne Rücksicht auf den Sinn des in Lev 16 beschriebenen Ritus. Auch wenn es unmittelbar evident ist, daß der "Sündenbockmechanismus" (R. Girard) ${ }^{4}$ oder religionshistorisch gesprochen: der

1 Die Teile I-II und IVb stammen von B. Janowski, die Teile III und IVa von G. Wilhelm. Bis auf wenige Ausnahmen wird die Literatur abgekürzt zitiert, vgl. die Bibliographie am Ende des Beitrags.

2 Burkert, Opfertypen, 173.

3 S. etwa L. Röhrich, Lexikon der sprichwörtlichen Redensarten, Bd. 4, Freiburg / Basel / Wien 1973, 1048-1050.

4 S. dazu v.a.: La violence et le sacré, Paris 1972 (dt.: Das Heilige und die Gewalt, Zürich 1972); Des choses cachées depuis la fondation du monde, Paris 1978 (dt. Teilübers.: Das Ende der Gewalt. Analyse des Menschheitsverhängnisses, Freiburg / Basel / Wien 1983) und Le bouc émissaire, Paris 1982 (dt.: Der Sündenbock, Zürich'1988). Eine gute (inzwischen aber ergănzungsbedürftige) Rezeption der Theorie Girards bietet Lohfink (Hg.), Gewalt und 
Azazel-Ritus Ausdruck eines kollektiven Bewältigungswillens (eines Willens zur Bewältigung sozialer und religiöser Desintegration bzw. von "Unreinheit") ${ }^{5}$ ist, will es kaum gelingen, zu dessen Wurzeln vorzudringen. Vielleicht hängt das eine: die zeitlose Evidenz des Vorgangs, mit dem anderen: dem Dunkel seines historischen Ursprungs untrennbar zusammen. Der "Sündenbockmechanismus" ist kein Oberflächenphänomen, sondern er reicht in die Tiefenschichten der menschlichen Seele hinab.

\section{Terminologische Vorbemerkung}

Was der historischen Rückfrage zunächst im Weg steht, ist der eingefleischte Sprachgebrauch. Wir reden vom "Sündenbock" und meinen den Bock "für Azazel" (Lev 16,8.10). Der Ausdruck "Sündenbock" ist in übertragener Bedeutung ('zu Unrecht Beschuldigter', 'unschuldiger Prügelknabe') zwar seit dem 17. Jahrhundert ein Wort unserer Sprache ${ }^{6}$, er fehlt aber in der hebräischen Bibel. Auch die ersten Bibelübersetzungen kannten das Wort noch nicht, sondern sprachen, wie etwa die Lutherbibel, vom "ausgesandten Bock". Das entspricht der Bezeichnung dieser Gestalt in der Septuaginta als $\alpha \pi 0 \pi 0 \mu \pi \alpha$ io der Vulgata als (caper) emissarius (fälschlich für Azazel) und lebt im engl. scapegoat wie im franz. bouc émissaire fort.

Der Hinweis auf den Sprachgebrauch klärt aber noch nicht das Verständnis des sogenannten Azazel-Ritus, denn der besagte Bock wird "für Azazel" ausgelost (Lev 16,8.10a), um ihn "für Azazel" in die Wüste laufen zu lassen (Lev 16,10b, vgl. V. 21 bß.22b). Der "Sündenbock" ist also irgendwie mit der Azazel-

Gewaltlosigkeit, 245ff, ferner North, Violence and the Bible, 1-27 u.a., zum Verstandnis s. etwa Schwager, Sündenbock; Lohfink, "Gewalt", 41ff; ders., Der gewalttatige Gott, 113ff (dort 114 Anm. $16 \mathrm{zu}$ Girards Gebrauch des Ausdrucks "Sündenbock"); Burkert, Anthropologie des religiosen Opfers, 207ff; Rüterswörden, Das Ende der Gewalt? Zu R. Girards Buch, JBTh 2 (1987) 247-256; M. Herzog, Religionstheorie und Theologie Rene Girards, KuD 38 (1992) 105-137 und die Beitrage in: Dramatische Erlosungslehre. Ein Symposion, hg. von $J$. Niewiadomski und W. Palaver (ITS 38), Innsbruck / Wien 1992

Vgl. K.E. Müller, Das magische Universum der Identităt, Frankfurt a.M. / New York 1987, 332ff, ferner Leach, Kultur, 101ff, bes. $115 \mathrm{ff}$ und Davies, Sacrifice, 394ff; zu den theoretischen Implikationen bei Leach und Davies s. besonders Rogerson, Sacrifice,45ff und Lang, Spione im gelobten Land, 169ff. Der geistige Vater all jener Versuche, den Azazel-Ritus Lev 16 mit den Augen des Ethnologen zu lesen, ist bekanntlich J.G. Frazer, The Golden Bough. A Study in Comparative Religion, Vol. 6: The Scapegoat, London ${ }^{3} 1913$, bes. $108 \mathrm{ff}$, vgl. die gekürzte dt. Ausgabe: Der goldene Zweig, 817ff und erganzend $M$. Douglas (ed.), The Illustrated Golden Bough, Garden City / NY 1978, $165 \mathrm{ff}$.

6 S. J. und $W$. Grimın, Deutsches Wörterbuch, Bd. X/4, Leipzig 1942, 1143f, ferner $F$. Kluge, Etymologisches Worterbuch der deutschen Sprache, Berlin 201967,$764 ; H$. Paul, Deutsches Worterbuch, Tübingen ${ }^{6} 1966,655$ und Ritter, Sündenbock, $110 \mathrm{f} .114 \mathrm{f}$. 
Gestalt verbunden. Und diese Verbindung ist das spezifische Problem von Lev 16,5-10.20-22.

\section{2. Überlieferungsgeschichtliche Vorbemerkung}

Den "Sündenbock" und sein Geschick hat sich wohl jeder schon einmal vorgestellt - vielleicht gerade so, wie ihn der britische Maler Holman Hunt (1827-1910) ins Bild gebannt hat:

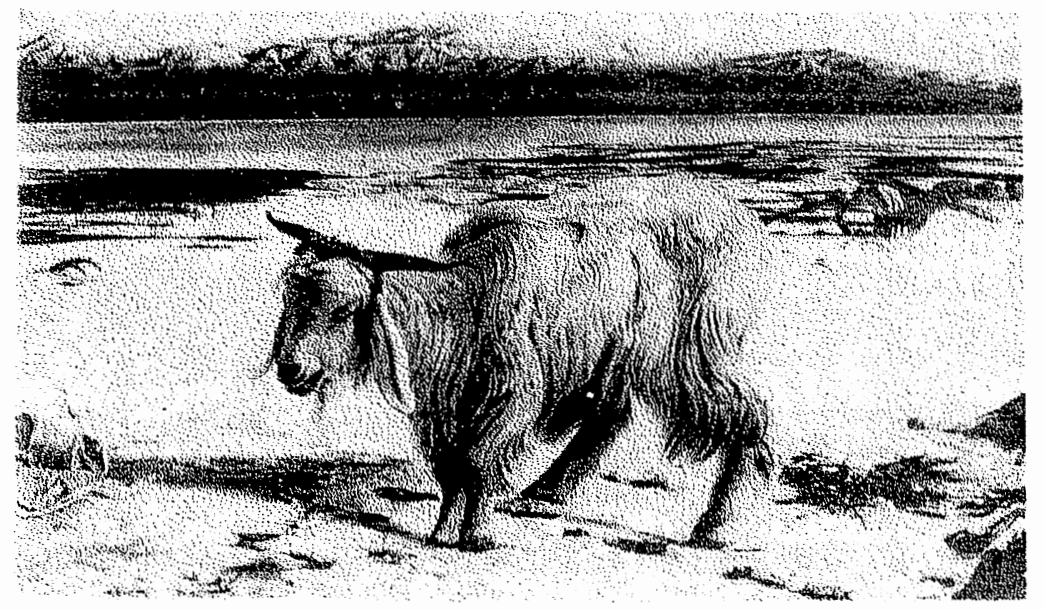

Abb. 1: H. Hunt, The Scapegoat (1854), Lever Art Gallery, Port Sunlight. Über den Maler und sein Werk schreibt C.M. Jones: "He ist said to have spent two years in Palestine making sketches for his religious pictures, and to have encamped for some time on the shores of the Dead Sea to capture the sense of loneliness and tragedy he wished to convey in this picture. The reproduction here cannot bring out the gorgeous colouring of the sunset, which is a distinctive feature of the original work ${ }^{17}$.

Der Mischnatraktat Joma ("Der Tag") ${ }^{8}$ hat die Ereignisse dieses Tages im Detail ausgemalt und ins Dramatische gesteigert. In der hebräischen Bibel wird

7 Jones, Old Testament Illustrations, Cambridge 1971, 172. $\mathrm{Zu}$ einer farbigen Wiedergabe s. unten Quellennachweis zu den Abbildungen; dort sieht man auch den karmesinroten Streifen, der an den Hörnern des Bocks festgebunden wurde (vgl. mYom VI 6a; 8d).

8 Edition: Meinhold, Joma. Zur Analyse s. jetzt Strobel, Sündenbock-Ritual, zu den literaturwissenschaftlichen und auslegungsgeschichtlichen Aspekten die Beiträge von Sh. Safrai, J. Magonet, J.J. Petuchowski und M.A. Signer bei Heinz / Kienzler / Petuchowski (Hg.), Versöhnung, 32ff.133ff.184ff.197ff. 
der Ritus knapp, aber dennoch eindrücklich dargestellt: Nach Lev 16,10.20-22 bringt der Hohepriester Aaron den "lebendigen Bock" - den Bock, "auf den das Los für Azazel gefallen ist" (V.10) - dar, stemmt seine Hände auf den Kopf des Tieres, bekennt über ihm die Verschuldungen Israels und läßt den Bock unter Begleitung eines dafür ausgesuchten Mannes in die Wüste laufen. Resümierend heißt es dann: "Der Bock trägt auf sich alle ihre Verschuldungen fort in eine abgelegene Gegend; so läßt er den Bock in die Wüste laufen" (V.22):

"(5) Und von seiten der Gemeinde der Israeliten nimmt er zwei Ziegenböcke zum Sündopfer und einen Widder zum Brandopfer. (6) Dann bringt Aaron seinen eigenen Sündopferfarren dar und schafft Sühne für sich und sein Haus. (7) Und er nimmt die beiden Bocke und stellt sie vor Jahwe an den Eingang des Begegnungszeltes. (8) Aaron wirft über die beiden Böke die Lose, ein Los für Jahwe und ein Los für Asasel. (9) Und Aaron bringt den Bock dar, auf den das Los für Jahwe gefallen ist, und besorgt inn als Sündopfer. (10) Der Bock aber, auf den das Los für Asasel gefallen ist, wird lebendig vor Jahwe gestellt' ', ihn für Asasel in die Wüste laufen zu lassen.

(20) Ist er fertig mit der Entsühnung des Heiligtums, des Begegnungszeltes und des Altars, bringt er den lebendigen Bock dar. (21) Aaron stemmt seine beiden Hănde auf den Kopf des lebendigen Bockes, bekennt über ihm alle Verschuldungen und alle Übertretungen der Israeliten, durch die sie sich irgend verfehlt haben, tut sie auf den Kopf des Bockes und laß ihn mit Hilfe eines dafür Bereitstehenden in die Wüste laufen. (22) Der Bock trăgt auf sich alle ihre Verschuldungen fort in eine abgelegene Gegend; so laß er den Bock in die Wüste laufen" (Lev 16,5-10.20-22).

"Über den Sinn dieser Zeremonie im Gesetz, so wie es uns jetzt vorliegt, kann kein Zweifel sein"9 konstatierte 1924 S. Landersdorfer und sah ihn in der "Fortschaffung der Sünde durch Abführung des Bockes"10. Gleichwohl läßt die Überlieferung wichtige Fragen unbeantwortet: Wer ist dieser Azazel, und wie ist sein Name (עִ עִ עִ Lev 16,8.10 [bis].26) ${ }^{11}$ zu deuten? Die Erklärungen des Azazel-Namens sind in der Regel hypothetisch, und zwar nicht nur deshalb, weil die entsprechende Überlieferung so änigmatisch ist; sie "sind auch meistens ... im Anschluß an eine bestimmte Theorie über das Wesen des Azazel aufgestellt und stehen und fallen darum mit derselben"12. Seit je neigt man dazu, in ihm einen "Kakodämon" der Wüste (H. Duhm) ${ }^{13}$ zu sehen, dessen Zorn durch Entsendung eines Ziegenbocks besänftigt wird. Ist das der Sinn der Zeremonie oder jene von S. Landersdorfer so genannte "Fortschaffung der Sünden durch

9 Landersdorfer, Versöhnungstag, 14.

10 Ebd.

11 Zur Lit. s. Janowski, Sühne als Heilsgeschehen, 268 Anm. 447 und Loretz, Leberschau, 50 Anm. 3, nachzutragen sind Görg, Azazel-Ritus; ders., Asasel; Wilhelm, Hurriter, 104; Strobel, Sündenbock-Ritual, 161ff.165ff; Wright, Disposal of Impurity, 15ff; Kiuchi, Purification Offering, 77ff.143ff; Deiana, Azazel; Gorman, Ideology of Ritual, 61ff und Janowski, Azazel.

12 Landersdorfer, aaO 14 Anm. 3.

13 S. unten Anm. 16. 
Abführung des Bockes"? Wie aber erklären sich dann Name und Gestalt des Azazel?

\section{Neuere Thesen zum Verständnis des Azazel-Ritus}

Wie die Deutungen des Azazel-Ritus von H. Duhm (1904) und S. Landersdorfer (1914) beispielhaft zeigen, kommt keine Theorie über Azazel und seinen Namen daran vorbei, das Verhältnis zwischen dem "Sündenbock"Ritus ${ }^{14}$ Lev 16,10.21f und der Azazel-Gestalt Lev 16,8.10 zu präzisieren. Dabei ist zwischen der text- und der ritualgeschichtlichen Problematik von Lev 16,5-10.20-22 zu unterscheiden. Im folgenden stehen zunächst die ritualgeschichtlichen Aspekte im Vordergrund ${ }^{15}$. Wenn man die neueren Thesen zum Verständnis des Azazel-Ritus einmal zusammenstellt und nach lokalen und strukturellen Gesichtspunkten ordnet, so lassen sich drei Grundtypen unterscheiden (die jeweils wiederum Varianten enthalten):

1. Der nomadische Ritualtyp,

2. Der ägyptische Ritualtyp,

3. Der südanatolisch-nordsyrische Ritualtyp.

\section{Die These eines nomadischen Ritualtyps}

a) Azazel - ein "Kakodämon" der Wüste

Die ältere Forschung ging mehrheitlich von einer engen Beziehung der beiden Größen "Azazel" und "Sündenbock" zueinander aus, dergestalt, daß der "Sündenbock" nicht nur "für Azazel" ausgelost (V.8.10), sondern auch zu ihm in die Wüste geschickt werde (V.10.21f). Das Resultat dieser Kombination war die These vom "Wüstendämon" Azazel, also die Annahme, daß Azazel "in der Wüste beheimatet und mindestens im Zeitalter des nachexilischen Monotheismus gewiß nichts anderes als ein Dämon (war)"16. Anlaß dazu schien die

14 Besser: Eliminationsritus. Zur Problematik des Ausdrucks "Sündenbock" s. etwa Küınmel, Ersatzkönig, 312, vgl. ders., Ersatzrituale, 192.

15

$\mathrm{Zu}$ den textgeschichtlichen Fragen s. unten Abschn. IV.

16

Elliger, Leviticus, 212 - der damit dem vorliegenden Textzusammenhang Rechnung zu tragen sucht, überlieferungsgeschichtlich dann aber differenziert, s. im folgenden. Zur opinio communis der alteren Forschung s. etwa Duhm, Geister, 56 ("Man versteht ... heute allgemein

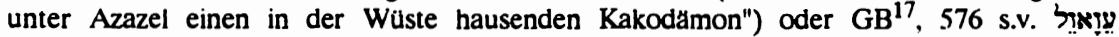
("Wahrsch. bezeichnet er [sc. der Ausdruck 'y] einen in der Wüste hausenden bösen Geist") 
Ritualüberlieferung Lev 16 selber zu geben, wenn sie vorschreibt, den lebendi-

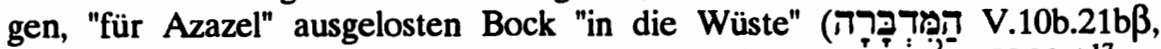

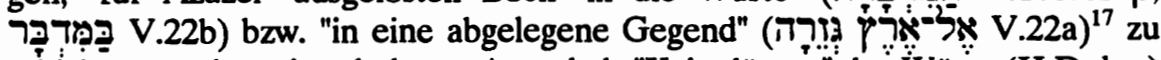
schicken - und somit nahelegte, Azazel als "Kakodämon" der Wüste (H.Duhm)

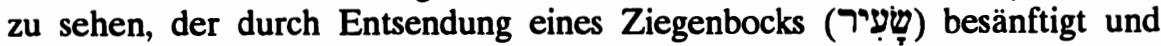
damit unschädlich gemacht werden sollte. Doch hatte bereits $\mathrm{H}$. Kaupel darauf hingewiesen, daß in Lev 16 nur das Forttreiben des lebendigen Bocks in die Wüste, nicht aber die Wüste als Aufenthaltsort Azazels erwähnt werde. Denn

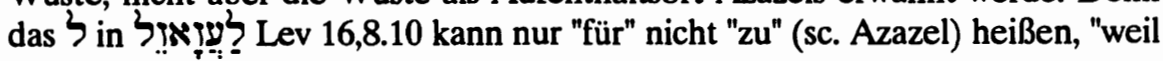

mit den entsprechenden Lit.-Nachweisen, vgl. HAL, 762 s.v.; Wanke, Dåmonen, 276, u.a. Typisch für die 'Dámonen-Hypothese' ist etwa die Argumentation von de Vawx, Lebensordnungen II, 370: "Der Name 'Sündenbock' ist eine Auslegung der Septuaginta und der Vulgata. Im Hebräischen ist der Bock 'für 'aza'zel' bestimmt. Neuerdings hat ein Gelehrter, wie die griechische und lateinische Übersetzung, hierin einen Gattungsnamen gesucht: er würde 'der Abgrund' bedeuten und wäre der Name des Ortes, an den der Bock geführt wurde. Welches auch der philologische Wert dieser Hypothese sein mag, sie paßt schlecht zum Text: der Hohepriester wirft das Los über die beiden Böcke, einen 'für Jahwe', den anderen 'für 'aza'zel'. Der Parallelismus scheint nicht zu genügen, wenn man übersetzt 'für den Abgrund', sondern fordert, daß der zweite Name gleichfalls ein Personenname ist. Es bleibt also wahrscheinlicher, daß es der Name eines übernatürlichen Wesens, eines Dämons, ist; so haben ihn die syrische Ubersetzung und der Targum und bereits das Henochbuch verstanden, das aus Azazel den in die Wüste verbannten Fürsten der Dämonen macht. Man beachte die israelitischen Vorstellungen über den Aufenthalt der Dämonen an verlassenen Orten, Is 13,21; 34,1114, vgl. Tob 8,3 und Mt 12,43".

17 Die verschiedenen Sinnaspekte von מרְּרָר "Wüste, Steppe" lassen sich nach Sh. Talmon auf folgende Grundbedeutungen zurückführen: "midbär bezeichnet trockene und halbtrockene Gebiete, die wegen ihrer Wasserarmut für Landwirtschaft und băuerliche Ansiedlungen ungeeignet sind. Diese Einode befindet sich im Zustand des Urchaos (Deut 32,10) oder wurde als gottliche Strafe für menschliches Vergehen wieder zum Chaos reduziert (Jes 64,9; Jer 22,6; Hos 2,5; Zeph 2,13; Mal 1,3). Sie erweckt Furcht und Abscheu" (מִ̣, 664, vgl. 675ff) und ders., Har and Midbār), vgl. auch die den negativen Aspekt der "Einठde, Wildnis" unter-

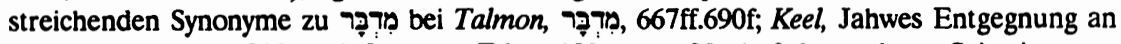
Ijob, 58 mit Anm. 208 und Ottosson, Eden, 182 Anm. 20. Auf der anderen Seite ist term. techn. für das "Weideland", enthălt also positive Konnotationen, vgl. Talmon, aaO 664.677f.691; Weippert, Amos, 2 Anm.4 und Wyatt, Sea and Desert, 385ff. Daß im Kontext von Lev 16,10.21f der negative Sinnaspekt dominiert, zeigt das parallele אריץ (V.22a), das das "(vom Wasser) abgeschnittene, unfruchtbare Land" meinen kann (vgl. Reymond, L'eau, 71, ferner HAL, 180 s.v. ${ }^{*}$ Ig: GB; GB $^{18}$, 211 s.v. Midbär, 127), "vielleicht aber auch ein Gebiet (bezeichnet), das strikt getrennt vom kultisch relevanten Lagerbereich liegt" (Görg, ר: 1003). Als von der menschlichen Kultur- und Sozialwelt abgeschnittenes 'Jenseits- oder Unterweltsgelănde' wird der Ausdruck von Tawil, 'Azazel verstanden, s. dazu aber Wright, Disposal of Impurity, 30. Ob die von Tawil behauptete Analogie zwischen Azazel und dem kanaanäischen Mot (vgl. aaO bes. 58f) das Richtige trifft, und der Azazel-Name (עוזאל > עִעדאוֹל "a fierce God") ein Epitheton für Mot ist, ist doch mehr als zweifelhaft, s. dazu Loretz, Leberschau, $52 \mathrm{ff}$ und Wright, aaO $25 \mathrm{ff}$, unkritisch dagegen Strobel, Sündenbock-Ritual, $165 \mathrm{f}$. 
ל ליל ליהוה demtspricht. Wie bei diesem die örtliche Bedeutung für ausscheidet, so auch bei jenem. Für Jahwe und für Azazel wird das Los geworfen (VV.8,10). Für Azazel wird der Bock entfernt in die Steppe (המדברה); in letzterem Ausdruck ist das Ziel angezeigt ${ }^{n 18}$. Mit wachem Blick für die überlieferungs- und kultgeschichtlichen Gegebenheiten haben dann M. Noth ${ }^{19}$ und $\mathrm{K}$. Elliger ${ }^{20}$ die Wachstumsstufen in Lev 16 und besonders das Nebeneinander von "Sündenbock"-Ritus und Azazel-Gestalt analysiert ${ }^{21}$.

Dessenungeachtet hat jene traditionelle Theorie der Verbindung von "Sündenbock"-Ritus und Azazel-Gestalt auch in neuerer Zeit ihre (zahlreichen) Anhänger gefunden und unser Bild der frühisraelitischen Religion mitgeprägt. Die eliminatorische Funktion des "Sündenbock"-Ritus, die noch S. Landersdorfer deutlich $\mathbf{s a h}^{22}$, geriet dabei allerdings immer mehr aus dem Blick ${ }^{23}$. In zusammenfassenden Darstellungen zur Religion und Gesellschaft der Frühisraeliten findet sich zuweilen die These, daß neben der Verehrung des Vätergottes noch einige Spuren religiöser Praxis vorhanden sind, die "nicht direkt zum Vätergottglauben, sondern zum Dämonenglauben der Frühisraeliten"24 gehören. So dürften nach W. Thiel neben der Beschneidung Ex 4,24-26 das PassaOpfer Ex 12,21b-23 und der "Sündenbock"-Ritus Lev 16,10.21f ursprünglich Kulthandlungen der Nomadenzeit gewesen sein:

"Es (sc. das Passaopfer) war ein apotropäischer Ritus, der vor dem Aufbruch zu den Sommerweiden im Frahjahr vorgenommen wurde und Menschen und Herden vor den Einwirkungen dămonischer Elemente der Wüste schützen sollte. Vielleicht stellte auch das im Ritual des Versohnungstages von Lev. 16 enthaltene Austreiben eines Sündenbocks in die Wüste einen entsprechenden Ritus im Herbst, vor Antritt der Wanderung zu den Winterweiden in der Steppe dar"25.

18 Damonen, 88 (Hervorhebung im Original), anders zuletzt wieder Strobel, aaO 163, vgl. zur Sache Loretz, aaO 51f, dort auch zum Verstăndnis von Lev 16,10.

19 Leviticus, 107: "Ganz ratselhaft bleibt die Gestalt des 'Asasel', die merkwürdigerweise in dem Hauptabschnitt V.20b-22 nicht genannt wird, sondern nur in dem vorbereitenden Abschnitt V.7-10 so vorkommt, daß von den beiden Ziegenböcken der eine 'für Asasel' ausgelost (V.8.10a $\alpha$ ) und dann bereitgestellt wird, um 'für Asasel' in die Wüste geschickt zu werden

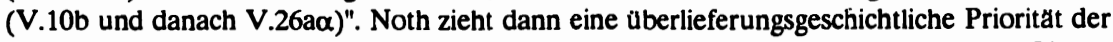
"Hingabe des Bockes 'für Asasel'" gegenüber der "Befrachtung des Bockes mit den Verschuldungen Israels" in Betracht.

20 Leviticus, 212, vgl. im folgenden.

21 Vgl. zur Sache auch Aartun, Versohnungstag, 82 mit Hinweisen auf ăltere Literatur.

22 Vgl. oben 111 Anm. 9.

23 Vgl. nur die entsprechenden Lexikonartikel von Koch, Asasel, 135f; van den Born, Azazel, 155f; Otto, Asasel, 53 u.a., anders z.B. Kutsch, Sündenbock, 506 f.

24 Thiel, Soziale Entwicklung Israels, 46.

25

Ebd. 
Pate steht bei dieser Deutung die Hypothese L. Rosts ${ }^{26}$, Passa-Ritus und "Sündenbock"-Ritus seien zwei korrespondierende, dem religiösen Besitzstand der frühisraelitischen Wanderhirten angehörende Kulthandlungen. Deren ursprünglichen Sitz im Leben hatte L. Rost 1943 auf den Rhythmus des halbjährlichen Weidewechsels (Transhumanz) bezogen und wie folgt skizziert:

"Jedenfalls ... stehen nun zwei Riten in Parallele, der des Passah als Feier vor dem Antritt der Wanderung in die Sommerweide mit der Absicht, die Menschen und Herden vor dem 'Verderber', der wohl im Kulturland hausend gedacht wurde, zu schützen, und die in das Ritual des Versohnungstages hineingebaute Begehung, die die Herde durch Abgabe eines Bockes an den Herrn der Wüste vor Antritt der Wanderung in die Winterweide schützen sollte, die ein halbes Jahr spăter gefeiert wurde" 27 .

Die Hypothese L. Rosts läßt sich durch folgendes Schema veranschaulichen:

\begin{tabular}{|c|c|c|}
\hline \multicolumn{3}{|c|}{ Zone des Ubergangs } \\
\hline Kulturland & & Wüste/Steppe \\
\hline 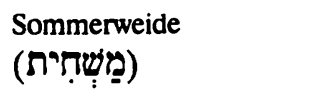 & $<-$ & $\begin{array}{l}\text { Passa-Ritus im Frühjahr } \\
\text { (abwehrend) }\end{array}$ \\
\hline $\begin{array}{l}\text { "Sündenbock"-Ritus } \\
\text { im Herbst (besänftigend) }\end{array}$ & 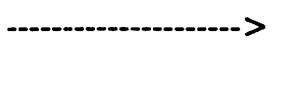 & 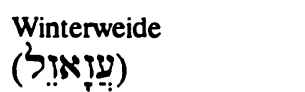 \\
\hline
\end{tabular}

Nun ist ein Festhalten an der Position L. Rosts schon deshalb nicht empfehlenswert, weil sich das Nomadenproblem ${ }^{28}$ und die "Väterreligion"29 heute erheblich komplexer darstellen als bisher. Hinzukommt, daß auch die These einer Verbindung des Passa-Ritus mit dem sog. Weidewechsel heute nicht mehr

26 Weidewechsel, 101-112.

27 AaO 108, vgl. ders., Versohnungstag, 2098 und die Aufnahme bei Otto, Fest, 74; ders., Asasel, 53; Wyatt, Atonement Theology, 425 und D. Michel, in: ders. / Lang, Art. Fest, NBL I (1991) 666-668, hier: 667f. Eine Variante der These findet sich bei Wefing, Entsühnungsritual, 74ff, s. dazu die Kritik von Loretz, Leberschau, 57 Anm. 34.

28 Die verănderte Forschungslage hat sich inzwischen in den Lehrbüchern niedergeschlagen, s. bes. Donner, Geschichte des Volkes Israel, $47 \mathrm{ff} .57 .77 .81 .122 \mathrm{ff}$ und Albertz, Religionsgeschichte Israels, 60ff.104ff, vgl. Herrmann, Israels Fruhgeschichte; Thiel, Geschichte Israels, 96ff; Otto, Historisches Geschehen, 63-80; ders., Israels Wurzeln, 3-10; ders., Stadt und Land im spattbronzezeitlichen und früheisenzeitlichen Palästina. Zur Methodik der Korrelierung von Geographie und antiker Religionsgeschichte, in: $K$ Rudolph / G. Rinschede (Hg.), Beitrăge zur Religion / Umwelt-Forschung I (Geographia Religionum 6), Berlin 1989, 225-241.

29 Zur Forschungsgeschichte s. Westermann, Genesis 12-50, 97ff, zur veränderten Forschungslage s. Bluın. Komposition der Vătergeschichte, $492 \mathrm{ff}$ und Köckert, Vătergott $150 \mathrm{ff}$. $309 \mathrm{ff}$. 
aufrechtzuerhalten ist ${ }^{30}$ und dessen Korrespondenz mit dem "alten Nomadenritus" (L.Rost) der Abgabe eines Ziegenbocks an den Wüstendämon Azazel ein unausgewiesenes Postulat bleibt ${ }^{31}$. Der Ritus mit dem "Sündenbock" ist nicht mit dem Weidewechsel frühisraelitischer Wanderhirten zu verbinden ${ }^{32}$ und im übrigen von der überlieferungsgeschichtlich späten Azazel-Gestalt ${ }^{33}$ zu trennen.

L. Rosts 'Nomadenhypothese' ist jüngst von A. Strobel ${ }^{34}$ aufgenommen und - unterstützt von topographischen Erwägungen zur Absturzstelle des "Sündenbocks" auf dem Ğebel el-Munțär (11 km sö von Jerusalem in der judäischen Wüste) - variiert worden. Die Variation drückt sich in der Annahme aus, daß man das Azazel-Ritual "zweifellos nicht sekundär aus einem anderen Religionsund Kultbereich übernommen hat, sondern das schon immer im palästinischjudäischen Raum zu Hause gewesen sein muß"35. Daß es einem "Grundmuster primitiver Religiosität" ${ }^{16}$ entspricht und "uralte Lokalbildung"37 verrät, zeigt sich nach Strobel vor allem

- an der hinter der Figur des "Wüstendämons" Azazel stehenden "ambivalenten Gottheit"38 und deren Namen ' $z$ ' $z l<{ }^{\prime \prime} z z^{\prime} l$ (vgl. ug. ' $\left.z b^{\circ} l\right)^{39}$, der ursprünglich auf eine "ungestüme" göttliche Macht hinweist ${ }^{40}$;

- an der Einbindung dieses vorisraelitischen (El-)Rituals ${ }^{41}$ in den Jahresablauf, speziell zur Zeit des Spätherbstes, wenn "der heiße Wüstenwind aus

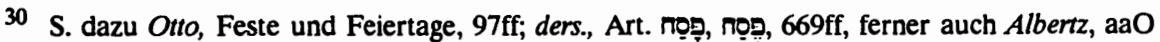
61 mit Anm. 47, der die Frage wieder im Sinn der Rost'schen These beantwortet.

31 Lev 16 laßt überdies nichts von einer dem apotropaischen Blutritus des Passa analogen Funktion des "Sündenbock"-Ritus erkennen. Auch "von einem eigentlichen Opfer ist im Text (sc. Lev 16) nichts zu spüren ..." (Elliger, Leviticus, 212), vgl. Landersdorfer, Sündenbock, 27; Blome, Opfermaterie, 104f.199ff; Kümmel, Ersatzkönig, 311, u.a.

Vgl. auch Elliger, ebd.; Fohrer, Religion, 394f; Loretz, Leberschau, 48, u.a.

33 U.E. steht hinter der Große "Azazel" ursprïnglich etwas anderes (ein Unreinheitsbegriff) als das, was die spätere Überlieferung in Lev 16,8.10.26 daraus gemacht hat (eine dămonische Gestalt), s. dazu unten Abschn. III.

Sündenbock-Ritual.

Ders., aaO 162. Einen lokalen Hintergrund ( Three Technical Terms in the Pentateuch, JSS 1 (1956) 97-105, hier: 97f für den AzazelNamen (< Wurzel ' $Z Z$ + Bildeelement $/ I I /$ ) angenommen, vgl. dazu noch HAL, 762 s.v.

39 S. dazu unten Exkurs 2.

$40 \mathrm{Vgl}$. ders., aaO $165 \mathrm{f}$.

41 Vgl. ders., aaO 167. 
dem Osten ohne rechtzeitigen Regen für das judäische Land eine Bedrohung darstellte" ${ }^{\text {"42 }}$.

Unter Berücksichtigung dieses Hintergrunds - der allerdings weitgehend durch textferne Kombinatorik erschlossen wird ${ }^{43}$ - hält es Strobel für "denkbar, daß der ursprüngliche Sündenbock-Ritus ... der magischen Entfernung der bösen, natürlich schuldhaft empfundenen Vorgänge und Einflüsse diente ${ }^{n 4}$. Sein Einbau in die Überlieferung des großen Versöhnungstages hat diese umstrukturiert: "Der jerusalemische Jahwekult hat mit diesem Ritual am Anfang des Jahres aller Wahrscheinlichkeit nach einem nicht-israelitischen, aber doch einheimischen El-Kult entsprochen. Dessen Anliegen wurde in die eigene Feier des großen Versöhnungstages aufgenommen und soweit als möglich integriert, wobei aber freilich die Gestalt der nicht-israelitischen Gottheit 'dämonisiert' wurde" ${ }^{\text {"45 }}$.

\section{b) Zum dämonischen Charakter Azazels}

Wie der bisherige Überblick zeigt, ist die These vom Wüstendämon Azazel ob ausgesprochen oder nicht - fast immer mit einer Theorie über die nomadische Vergangenheit Israels verknüpft. Vermutungen über den 'dämonischen Charakter' Azazels erhalten auch dann Auftrieb, wenn die Bezeichnung "Ziegenbock" für das "für Azazel" ausgeloste Tier (Lev 16,10) mit den שِّự von Lev 17,7 ; Jes 13,$21 ; 34,14 ; 2$ Chr $11,15^{46}$ in Verbindung gebracht wird ${ }^{4 j}$, so daß sich für den "Sündenbock" wie von selbst die Vorstellung von einem bocksartigen, haarigen Dämon ergibt: "Azazel ist Fürst der Bockdämonen, der in der Steppe seinen Wohnsitz hat. Durch seine Zugehörigkeit zum Bereich Azazels wird auch der Bock ein dämonisches mit dem Sündenstoff behaftetes Tier"48. Abgesehen davon, daß auch der Bock "für JHWH" ein שִ ist (Lev 16,5.7ff), ist die entscheidende Frage immer wieder, ob die Azazel-Gestalt überlieferungsgeschichtlich ursprünglich oder "erst sekundär, möglicherweise erst in nachexilischer Zeit, in das Ritual (sc. von Lev 16) eingedrungen

42 Ders., aaO 162, vgl. 165f.167.168.

43 S. dazu nur aaO 162 Anm. 73-74 und die an J.G. Frazers 'Komparatistik' (vgl. oben Anm. 5 und Lang, Spione im gelobten Land, 159ff.161ff) erinnernden Ausführungen aaO 164f.166. Strobel, aaO 162, vgl. 164.167f.

45 Ders., aaO 162.

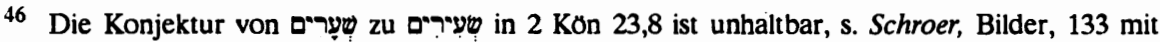
Anm. 292.

47 S. etwa Wohlstein, Tier-Damonologie, 487ff, u.a.

48

Ders., aaO 487, vgl. Staubli, Nomaden, $177 f$. 
(ist $^{\text {n49 }}$. Skepsis ist in diesem Zusammenhang auch gegenüber dem erstmals von O. Eißfeldt gemachten Vorschlag am Platz, das Elfenbeinblatt aus Megiddo Loud, Megiddo Ivories, Pl. 5, No. 4-5 als ikonographischen Beleg für die Begegnung Azazels mit dem "Sündenbock" zu verstehen.

\section{Exkurs 1: Kanaanäische Bilder zum Thema "Azazel und der Sündenbock"?}

Unter den von G. Loud publizierten spätbronzezeitlichen Elfenbeinarbeiten aus Megiddo befindet sich ein $13 \mathrm{~cm}$ hohes, $5-6 \mathrm{~cm}$ breites und $1,5 \mathrm{~mm}$ dickes Blatt mit eingeritzter Zeichnung (Abb. 2a), die ikonographisch wie religionsgeschichtlich bemerkenswert ist. Sie zeigt nicht nur ein "composite human, animal, and bird figure and ibex ${ }^{n 50}$, sondern bringt die beiden dargestellten Wesen auch in eine dramatische Beziehung zueinander: Ein Mischwesen aus Menschenkopf, Adlerflügeln und Raubtierleib hat sich auf einen Steinbock (capra ibex) geworfen, der unter der Wucht des Angriffs zusammenbricht. O. Eißfeldt hat diese Szene so beschrieben: "Es handelt sich offenbar um die Überwältigung eines Steinbocks durch ein dämonisches Wesen, nicht etwa, woran man auch wohl denken könnte, um einen Ritt dieses auf jenem; denn der Steinbock liegt niedergebeugt da"si . Dieselbe Haltung nimmt auch der Steinbock auf dem erheblich fragmentarischeren Elfenbeinblatt Loud, Megiddo Ivories, Pl. 5 No. 5 (Abb. 2b) ein. Bemerkenswert gegenüber vergleichbaren Tierkampf-Darstellungen ${ }^{52}$ dürfte der Sachverhalt sein, "daß hier bei dem angreifenden Mischwesen die menschlich-dämonische Seite vor der tierischen

49 Elliger, Leviticus, 212, s. dazu im folgenden.

50 So die knappe Beschreibung von Loud, Megiddo Ivories, 13.

51 Elfenbeinarbeiten von Megiddo, 91.

52 Der Angriff gefährlicher Tiere (Lơwe, Hund) oder dämonischer Mischwesen auf zahme oder ungefăhrliche Tiere (Rind, Steinbock, Gazelle) wird in der syro-palästinischen (Elfenbein-) Kunst des 2./1. Jt.s v.Chr. ofter dargestellt. Eißfeldt, ebd. verweist innerhalb der MegiddoSammlung noch auf Loud, aaO Taf. 16, Nr. 4a-b.c (Elfenbeinkamm mit Steinbock, der von einem Hund attackiert wird), vgl. dazu H.J. Kantor, Syro-Palestinian Ivories, JNES 15 (1956) 153-174, hier: 169f; Decamps de Mertzenfeld, Inventaire, 19ff, bes. 20 (zu pl. XL, no. 389) und R.D. Barnett, Ancient Ivories in the Middle East (Qedem 14), Jerusalem 1982, 26. Weitere Beispiele aus der altorientalischen Kunst, deren Vergleichswert aber nicht zweifelsfrei ist, bei R. Mayer-Opificius, Die geflügelte Sonne. Himmels- und Regendarstellungen im Alten Vorderasien, UF 16 (1984) 189-236, hier: 232 Abb. 23 (neuass. Rollsiegel mit steinbockkopfigem Mischwesen) und Schroer, Bilder, 134 Abb. 58 (neubab. Rollsiegel mit steinbockköpigem Mischwesen mit Menschengesicht, das von einem geflügeltem Genius gebăndigt wird). 
das Übergewicht zu haben scheint" ${ }^{43}$. Der dargestellte Dämon ist also ein Mischwesen: ein mit menschlichen Zügen ausgestattetes $\operatorname{Tier}^{54}$.
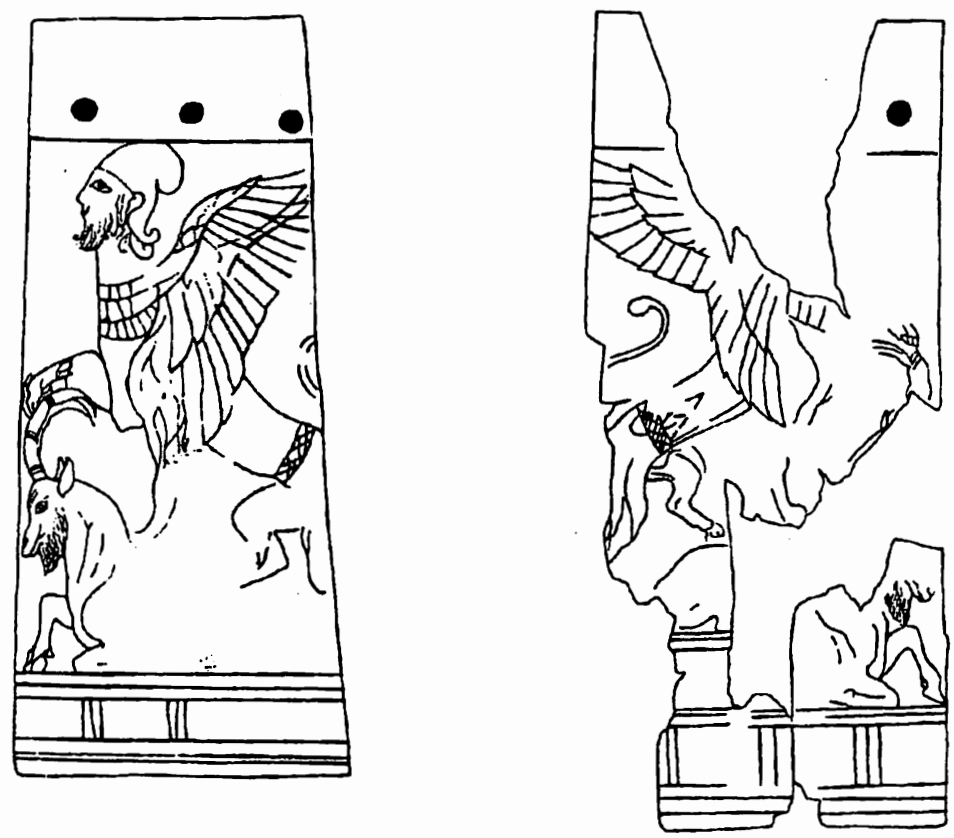

Abb. 2 Elfenbeinblatt aus Megiddo (SB IIB): (a) Loud, Meglv, Pl. 5,4 - (b) Loud, Meglv, PI. 5,5

Soweit wir sehen, war es ebenfalls O. Eißfeldt, der als erster die beschriebene Bildkomposition - in aller Vorsicht - mit der Überlieferung des Azazel-Ritus Lev 16,5.10.20-22 in Zusammenhang brachte: "Bei dem auf unserem Elfenbeinblatt dargestellten Dämon handelt es sich vielleicht um eine Gestalt von der Art des - uns im übrigen völlig unbekannten und rätselhaften - Asasel. Davon, $\mathrm{da} ß$ die Wüste nicht nur gefährliche Tiere, sondern auch unheimliche Misch-

53 Eißfeldt, aaO $91 \mathrm{f}$.

54 Schroer, aaO 134. 
gestalten beherbergt, weiß das Alte Testament an mehreren Stellen zu sagen (5. Mose 8,15; Jes 13,21; 30,6; $34,14)$. Solch ein Wesen könnte auf unserem Stück dargestellt sein, ein Dämon, der dem in der Wüste lebenden Wild nachstellt, wie der Asasel von 3. Mose 16 offenbar als Feind des ihm zugejagten Ziegenbocks gilt"55. O. Keel' ${ }^{56}$ und neuerdings S.Schroer ${ }^{57}$ sind diesem Deutungsversuch mehr oder weniger deutlich gefolgt $^{58}$. Darüberhinaus hat Keel darauf hingewiesen, $\mathrm{da} B$ das Amulett I von Aslan Tas KAI 27 (7. Jh. v. Chr.) ${ }^{59}$ zwar einige Jahrhunderte jünger ist als das spätbronzezeitliche Elfenbeinblatt aus Megiddo,

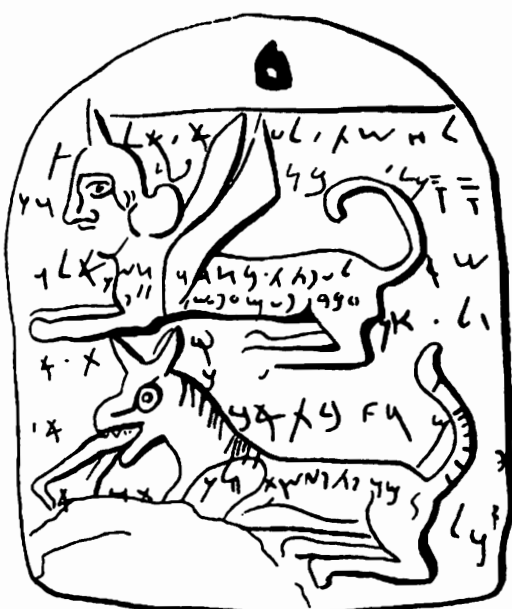

Abb. 3 Beschwơrungsamulett I von Arslan Tas (7. Jh. v. Chr.) aber "der gleichen Tradition anzugehören (scheint)" ${ }^{\text {660 }}$. Dieses Gipstäfelchen (Abb. 3) zeigt auf seiner Vorderseite zwei teriomorphe weibliche Dämonen: oben eine dem linken Tafelrand zugewandte geflügelte Sphinx mit helmartiger Kappe ("Hörnermütze") und leicht geschwungenem Horn; darunter eine liegende Wölfin mit Skorpionschwanz, die ihr Maul aufgerissen hat und ein Kind verschlingt, von dem noch ein Teil des

55 AaO 92.

56 AOBPs $^{4}$, 73. Keel beschrănkt sich auf ein Kurzreferat der Eißfeldt'schen Hypothese.

57 AaO 134, vgl. die lapidare Bemerkung ebd. Anm. 296: "Dieses Bild erinnert an den 'Sündenbock' für den Dämon Asasel (Lev 16,5-10.21ff)".

Vgl. bereits van den Born, Azazel, 156.

Zur Lit. s. de Moor, Demons, 108 Anm. 12.

$60 \mathrm{Keel}$, ebd. Brieflich (vom 7.9.1989) weist mich O. Keel noch auf ein spătbronzezeitliches Rollsiegel vom Tell el-Ağgul hin, das zeitlich dem Megiddo-Elfenbein nahesteht: W.M.F. Petrie, Ancient Gaza IV, London 1934, PI. XII,1, vgl. auch Keel, AOBPs ${ }^{4}, 336$ Abb. 485 mit folgender Beschreibung: Das Rollsiegel "zeigt einen geflügelten Dämon, der einen Mann angefallen hat ... Der Gott, der den Lơwen am Schwanz halt, dürfte ein Heilgott sein. Ischtar, die als Heilgöttin berühmt ist ... erscheint häufig mit einem gebăndigten LOwen ... wir hătten hier also die Darstellung einer Befreiung aus schwerer Krankheit ...". In der englischen Ausgabe von AOBPs: "The Symbolism of the Biblical World. Ancient Near Eastern Iconography and the Book of Psalms", New York / NY .1978, 83 fig. 96 wird das Stück mit dem Megiddo-Elfenbein (dort fig. 97) kombiniert. 
Rumpfes und die Beine zu sehen sind. ${ }^{61}$ Die Plakette ist beidseitig beschrieben. Der Text enthält eine Beschwörung gegen die abgebildeten weiblichen Tierdämonen, wobei verschiedene göttliche Wesen als wirkmächtige Helfer gegen sie angerufen werden. Die Invocatio (Z. 1-5a) dieses Textes beginnt folgendermaßen:

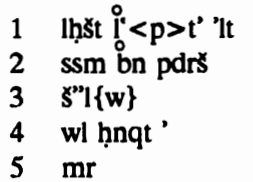

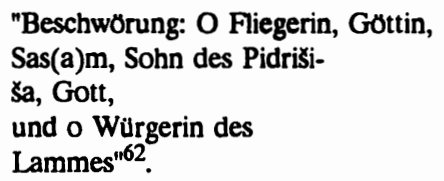

Die weiblichen Tierdämonen des Arslan Tas-Amuletts belegen anschaulich, wie lebendig auch im Kanaan des 2./1. Jt.s v.Chr. die Furcht vor unheilbringenden Dämonen gewesen sein mu $\beta^{63}$.

Die Konstellation: angreifender (Wüsten-/Steppen-)Dämon / überwältigter Capride, die seit $O$. Eißfeldt der Vermutung einer ikonographischen Parallele zur Ritualüberlieferung Lev 16,5ff.20ff Auftrieb gab, hat in der Tat etwas Suggestives. Sollte diese Deutung zutreffen, "so wäre damit bewiesen, da $\beta$ - wie man aus allgemeinen Erwägungen und mannigfachen Analogien längst angenommen hat - die nach 3. Mose 16 zum Ritual des großen Versöhnungstages gehörende Aussendung eines Ziegenbocks für den Wüstendämon Asasel von Vorstellungen und Bräuchen abhängig ist, die bereits vor dem Eindringen Israels in Kanaan hier heimisch waren" ${ }^{164}$. Es spricht aber so gut wie alles gegen eine solche Deutung. Denn zum einen kann die These vom "Wüstendä-

61 Von der Blutgier der Dämonen weiß auch das Alte Testament: "Sie (sc. die Israeliten)

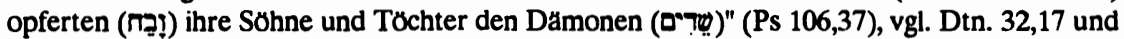
Wanke, Dămonen, 275f; de Moor, aaO 119. Beide Stellen haben den westsemitische Brauch des Kinderopfers im Blick, s. dazu O. Kaiser, Den Erstgeborenen deiner Söhne sollst du mir geben. Erwägungen zum Kinderopfer im Alten Testament, in: ders., Von der Gegenwartsbedeutung des Alten Testaments. Gesammelte Studien zur Hermeneutik und zur Redaktionsgeschichte, hg. von V. Fritz, K.F. Pohlmann und H.-C. Schmitt, Göttingen 1984, 142-166, hier: $148 \mathrm{f}$ u. . . und H. Spieckermann, Juda unter Assur in der Sargonidenzeit (FRLANT 129), Gơttingen 1982, 101ff, vgl. $O$. Keel, Kanaanäische Sühneriten auf agyptischen Tempelreliefs, VT 25 (1975) 413-469, hier: 462f.

62 Übersetzung W. Röllig, Die Amulette von Arslan Tas, NESE 2 (1974) 17-36, hier: 18.

63 S. dazu de Moor, Demons; ders. / K Spronk, More on Demons in Ugarit (KTU 1.82), UF 16 (1984) 237-250 und $W$. Fauth, Lilits und Astarten in aramaischen, mandaischen und syrischen Zaubertexten, WO 17 (1986) 66-94. Durch das dort dargebotene Material wird das Urteil von Keel, AOBPs 4 , 73: "Über kanaanäische Dämonen wissen wir nicht viel" (vgl. auch Schroer, Bilder, 134 Anm. 293, ferner W. Röllig, Art. Dämonen, WM I [1965] 274-276, hier: 274) deutlich relativiert.

64

Eißfeldt, Elfenbeinarbeiten von Megiddo, 92. 
mon Azazel", der "offenbar als Feind des ihm zugejagten Ziegenbocks gilt ${ }^{\text {n65 }}$, nicht unhinterfragt bleiben $^{66}$; und zum anderen zeigt auch die Darstellung auf dem Elfenbein aus Megiddo (Abb. 2a-b) nicht die Konstellation: angreifender (Wüsten-, Steppen-)Dämon / überwältigter Capride, sondern gehört zur Gruppe der Kampfszenen: (männlicher) Sphinx gegen Tier (Capride, Bovide u.a.). Dafür gibt es - z.B. in der mittelassyrischen Glyptik (Abb. 4) - überzeugendere Parallelen ${ }^{67}$ als das Amulett von Arslan Tas oder andere Stücke ${ }^{68}$.

\section{Die These eines ägyptischen Ritualtyps}

Die Annahme, die Azazel-Gestalt sei "dem Ritus (sc. mit dem 'Sündenbock') selbst nicht immanent"69 und erst zu einem späteren Zeitpunkt in die Überlieferung des großen Versöhnungstages gelangt, erfordert eine Antwort auf die Frage, wie die Einfügung dieser Gestalt und ihre Namengebung zu erklären ist. Diese Antwort hat M. Görg in seinen "Beobachtungen zum sogenannten Azazel-Ritus" unter Zuhilfenahme ägyptischer Vorstellungen zu geben versucht, ohne dabei "die prinzipielle Abkunft des Sündenbockritus aus palästinisch-syrischem Umfeld ${ }^{70} \mathrm{zu}$ bestreiten ${ }^{71}$.

65 Ders., ebd.

66 S. dazu oben $112 \mathrm{ff}$.

67 Vgl. Mayer-Opificius, Bemerkungen, 163 (zu 169 Abb. 10). Brieflich (vom 2.11.1989) macht mich Th. Podella noch auf ahnliche Darstellungen bei $A$. Moortgat, Assyrische Glyptik des 12. Jahrhunderts, ZA 48 (1944) 23-44, hier: 31 Abb. 19.20, vgl. 32 Abb. 23-25, aufmerksam. S. dazu oben Anm. 60.

69 Elliger, Leviticus, 212, vgl. Loretz, Leberschau, 50 und auch Görg, Azazel-Ritus, 11f.15.

$70 \mathrm{AaO} 12$.

71 Im folgenden wird die Argumentation von Janowski, Azazel, 102ff ubernommen. 
a) Azazel - biblisches Gegenstück zum ägyptischen Seth

Zur religionsgeschichtlichen Einordnung der Azazel-Gestalt greift Görg auf ägyptische Vorstellungen vom Gott Seth und seiner tiergestaltigen Repräsentation (Abb. 5) zurück: "Das geradezu klassische Beispiel für die Personalisierung eines Unheilträgers ist ... bekanntlich der sog. typhonische Seth, jene Negativcharakteristik des Gottes, der die nach ägyptischer Anschauung in der Wüste hausende Dämonie des Chaotischen repräsentiert"72. Vom verehrten zum verfemten Gott, zum "god of confusion who disturbs the order"73 wurde Seth endgültig erst in der 25 . Dynastie (712-664 v. Chr. $)^{74}$. Das legt nach Görg die Vermutung nahe, da $\beta$ "auch die Zeitgenossen auf dem Boden Palästinas (Juda/Jerusalem), die, besonders aus priesterlichen Kreisen, mit den Ägyptern Kontakt hielten, um die Vorstellung wußten, daß man in Ägypten in der Gestalt des Seth - wohl vor allem im Zusammenhang mit der Invasion Assurs - den 'Landesfeind' schlechthin und die 'Verkörperung alles Schlechten' zu erkennen glaubte" ${ }^{\prime \prime 5}$.
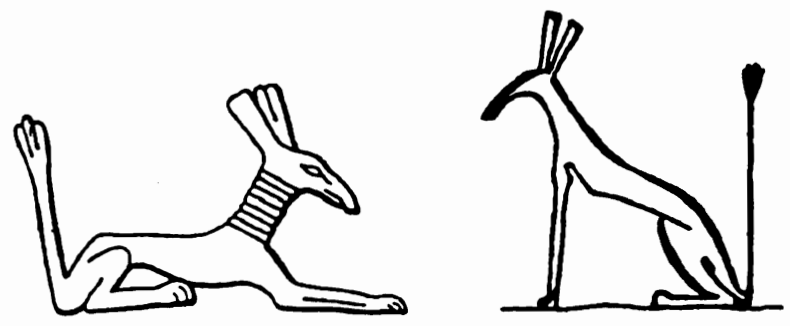

Abb. 5 Das Seth-Tier mit seinen typischen Merkmalen

72 Ebd.

73 te Velde, Seth, 909. Zu Seth und zum Seth-Tier s. die dort 911 genannte Lit., ferner Brunner, Seth und Apophis; te Velde, Egyptian Hieroglyphs und Fischer, Ancient Attitude. Die zahlreichen Versuche, die zoologische Spezies des Seth-Tieres zu bestimmen, haben kein überzeugendes Ergebnis erbracht. Der einzige sichere Schluß ist, "that the Seth-animal was a fabulous animal of the desert" (te Velde, Egyptian Hieroglyphs, 68).

Erste Ansátze zu einer wirklichen Verfemung des Seth sieht Hornung, Seth, 51 bereits im Amduat, dem âltesten Unterweltsbuch.

75 Azazel-Ritus, 12f. Das Zitat im Zitat bezieht sich auf Bonnet, Seth, 711. 
Wenn nun die Azazel-Gestalt mit Seth zu vergleichen ist, ja das biblische Gegenstück zum ägyptischen Seth ${ }^{76}$ darstellt, dann muß es auch ein tertium comparationis geben. Dieses ist Görg zufolge in der Apostrophierung des Seth - und mutatis mutandis des Azazel - als der "Verkörperung alles Schlechten" (H. Bonnet) zu sehen, die ihrerseits "mit einer Vorstellung zu tun hat, die die Wüstenregion negativ qualifizierte und sie als den Ort beschrieb, in den man das andrängende Chaos immer wieder zurückzuverweisen habe ..."

Das von Görg unterstellte Deutungsmuster "der Schuldiggesprochene gehört dorthin, wo die Schuld letztlich herstammt ${ }^{78}$ - nämlich aus der (östlichen) Wüste - mag auf die Seth-Gestalt zutreffen - aber auch auf Azazel? U.E. kaum, weil es nicht zur Perspektive der Ritualüberlieferung von Lev 16 paßt: "schuldig" ist dort nicht Azazel, sondern Israel, dessen Schuld mittels eines rituellen Unheilsträgers, des "Sündenbocks" (und nicht Azazels!), aus der Gemeinschaft eliminiert wird $^{79}$. In dieser Apostrophierung Azazels als "Personalisierung eines Unheilsträgers" ${ }^{10}$ bzw. als "Personifikation der Schuldbeladenheit"81 nach dem Vorbild des ägyptischen Seth liegt die erste Schwierigkeit der vorgeschlagenen Deutung. Görg fragt:

\begin{abstract}
"Ob sich in der Azazelgestalt als Personifikation der Schuldbeladenheit ebenfalls eine mythologische Verdichtung der von der (ostlichen) Wüste kommenden und in sie zu bannenden Gefahren zeigt? Wird hier die 'Sünde' von Priester und Gemeinde als Einbruch der Unordnung gefaßt, die ihrerseits in den ihr angemessenen Raum der Wüste zurückbeordert werden muß?" 82
\end{abstract}

- und beantwortet beide Fragen vom ägyptischen 'Vergleichsmaterial' her. Argumentiert wird dabei mit der Vorstellung einer "Vertreibung" des Bösen bzw. "Verurteilung" des Schuldigen, wie sie in der Phrase dr jzft ("Böses vertreiben") ${ }^{83}$, vor allem aber in der ramessidischen Amunsprädikation wp.f $p 3$ ¿d3 dj.f sw $r h^{\circ}(w)$ p3 $m^{*} 3 . t j$ r jmnt.t pAnastasi II 6,7 ("er richtet den Schuldi-

\footnotetext{
76 Vgl. Görg, aaO 13.

77 Ebd.

78 Ebd.

79 S. dazu im einzelnen Janowski, Sühne als Heilsgeschehen, 209ff. $211 \mathrm{ff} .265 \mathrm{ff}$.

80 Görg, aaO 12.

81 Ders., aaO 13.

82 Ebd.

83 Zum Topos "Vertreiben (hsr, dr) der Finsternis und ihrer Exponenten" s. Janowski, Rettungsgewißheit, 146 mit Anm. 744; 149 (Lit.) und Keel, Identifikation des Falkenköpfigen, 268ff. Die Frage ist nicht, ob die Phrase $d r$ jzft auf Seth angewandt wird (entsprechende Belege bei Homung, Licht und Finsternis, 78f, vgl. ders., Dunkelheit, 1154 mit Anm.4), sondern ob die agyptische Vorstellung einer "Vertreibung". des Schlechten die biblische Azazel-Gestalt zu erklären vermag, $s$. auch im folgenden.
} 
gen und überweist ihn dem Aufgang; den Gerechten aber dem Westen") ${ }^{84} \mathrm{zu}$ Tage tritt. Damit ist implizit die zweite Schwierigkeit genannt, die der Plausibilität der vorgeschlagenen Deutung im Wege steht. Sie besteht in der Annahme,

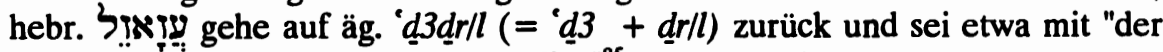
beseitigte bzw. ferngehaltene Schuldige ${ }^{\mathrm{n} 85}$ wiederzugeben.

\section{b) Zum ägyptischen Hintergrund des Azazel-Namens}

Eine erneute Überprüfung des Azazel-Namens ist nach Görg deshalb er-

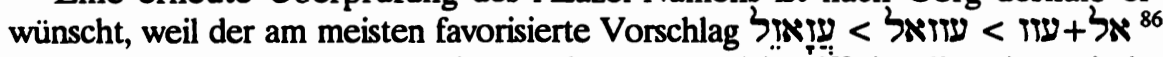
mit einer Konsonantenmetathese, also einem Eingriff in die phonetische Gestalt des Namens rechnen muß. Die unterstellte Analogie zwischen dem biblischen Azazel und dem ägyptischen Seth bietet für die etymologische Rekonstruktion den konzeptionellen Rahmen - auch wenn, wie der Autor vorsichtig formuliert, "nach wie vor Zurückhaltung am Platze" ${ }^{47}$ ist. Der Verdacht auf einen ägyptischen Ursprung von hebr. die Kombination der beiden Elemente ' $d 3$ ("Unrecht; Frevler, Schuldiger") und $d r$ ("vertreiben") bzw. $d r$ ("fernhalten, beseitigen") konkretisiert. Das Element ' $d 3$ (Wb I 240f) entnimmt er dabei der bereits zitierten Amunsprädikation pAnastasi II 6,7, während das zweite Element $d r$ (Wb V 473f) verbaler Bestandteil der Phrase dr jzft ("Böses vertreiben") ist, zu dem Wb V 595,5-9 ein altes Synonym $d r$ (vgl. kopt. dölĕ "hindern") nachweist. Durch Kombination beider Elemente zu ' $d 3 d r / l$ "erhält man einerseits ein phonetisch exakt passendes Äquivalent zu עי עז und andererseits einen Ausdruck, der grammatikalisch als Nomen + Part.pass zu verstehen und etwa mit 'der beseitigte bzw. ferngehaltene Schuldige' wiederzugeben wäre, so daß auch in semantischer Hinsicht gerade die der Azazelgestalt eigene Funktion in der Namengebung transparent werden würde" ${ }^{\prime 88}$.

Diese neue Etymologie des Azazel-Namens ist phonetisch vielleicht nicht unmöglich, wenn auch ein wenig abenteuerlich. Aber nicht alles, was phonetisch möglich scheint, ist auch kontextuell sinnvoll oder wahrscheinlich. Auf eine kontextbezogene Deutung der Azazel-Namens legt Görg zu Recht großen Wert. Gerade diese ist u.E. aber nicht von der Amunsprädikation pAnastasi II

\footnotetext{
84 S. dazu im folgenden.

Görg, aaO 14.

86 S. dazu Janowski, Sühne als Heilsgeschehen, 268 Anm. 447 (Lit.), ferner HAL 762 s.v.; Loretz, Leberschau, 48ff; Görg, aaO $13 \mathrm{f}$ und Wright, Disposal of Impurity, $21 \mathrm{ff}$.

87 Görg, aaO 14.

$88 \mathrm{AaO} 14 \mathrm{f}$.
} 
6,7 her zu gewinnen, auf die Görg zweimal ${ }^{89}$ ausdrücklich Bezug nimmt. Nach pAnastasi II 6,5-7 par. pBologna 1094:2,3-7 = ÄHG 174,1-10 werden die Feinde des Sonnengottes Amun-Re dem "Aufgang (sc. der Sonne)", die Gerechten aber dem "Westen" (= Totenreich) überwiesen. Der entscheidende Passus pAnastasi II 6,6f = ÄHG 174,7-10 lautet:

7 "Amun richtet (wpj) das Land mit seinem Finger,

8 er spricht, was dem Herzen gemäß ist,

9 er richtet (wpj) den Schuldigen und uberweist ihn dem (Sonnen-)Aufgang $\left(h^{\circ}\right)$;

10 den Gerechten aber dem Westen (jmnt.t $)^{490}$.

Wie S. Morenz ${ }^{91}$, eine Vermutung R.A. Caminos ${ }^{92}$ bestätigend, nachgewiesen hat, ist $h^{e}$ "Aufgang (sc. der Sonne)" pAnastasi II 6,7 (= ӒHG 174,9) ein mythopoetischer Ausdruck für den "Osten", der hier als Strafort für die Frevler fungiert: "An diesem östlichen Ort des Aufgangs wird die Strafe durch Feuer vollzogen, das dem 'Aufgangsort' inhärent sein muß; d.h. aber die Strafe wird vom heißen Sonnengott eo ipso gewirkt" ${ }^{\text {"93 }}$. Der östliche Aufgangsort der Sonne hat demnach die Konnotation "Gerichtsstätte für die Feinde des Sonnengottes". Der Schuldige ( $d 3$ ) wird also dort gerichtet, wo die Strahlen der Sonne (= der/die "Finger" Amuns pAnastasi II 6,6 par. pBologna 1094:2,5 $=$ ÄHG 174,7) alles Schlechte, d.h. Schöpfungswidrige zuerst und am nachhaltigsten 'durchschauen'94. Wenn Görg die in pAnastasi II 6,7 formulierte "kritische Distinktion zwischen Gutem und Bösem mit lokalen Assoziationen" mit der Bemerkung kommentiert: "Der Schuldiggesprochene gehört dorthin, wo die Schuld letztlich herkommt" ${ }^{\prime 95}$ und die dortige Ortsangabe $h^{*}(::$ jmnt.t) als Heimat der Seth- bzw. der Azazel-Gestalt deklariert, dann liegt dem eine Verwechslung von $h^{*}$ "Aufgang (sc. der Sonne) $\rightarrow$ Osten" mit der östlichen,

89 AaO 13.14.

90 S. zu diesem Text Janowski, Rettungsgewißheit, 171f. Der Paralleltext pBologna 1094:2,3-7 liest statt Singular $\underline{d} b^{\circ} . f$ den Plural $\underline{d} b^{\text {}} w . f$ "seine Finger".

91 Rechts und links, 282ff.

92 Late Egyptian Miscellanies, 50, wo pAnastasi II 6,7 wie folgt übersetzt wird: "He judges the guilty and assigns him to the East (?) and the just to the West". Bei Görg, aaO 13 wird Caminos' Wiedergabe von äg. $h^{\prime}(w)$ mit "East(?)" uminterpretiert zu "Ostliche Wüstenregion", s. dazu im folgenden.

93 Morenz, aaO 283f, vgl. ders., ZDMG 106 (1956) 365-367, hier: 366f und zur Sache Fecht, Literarische Zeugnisse, 40; Kessler, Himmelsrichtungen, 1213; Grieshaminer, Rechts und links, 192 und Fischer-Elfert, Literarische Ostraka, 9 mit Anm.1.

94 Auch Seth wird nach pSalt 825 IV, 7 vom aufgehenden Sonnengott an der ostlichen Gerichtsstătte verurteilt, s. dazu Morenz, aaO 284 mit Derchain, Papyrus Salt 825 (B.M. 10051), 157f. 
negativ qualifizierten Wüstenregion zugrunde. ${ }^{96}$ Die Konnotation "(östliche) Wüste" - in die man das andrängende, in der Seth- bzw. Azazel-Gestalt personifizierte Chaos zurückverwies - ist dem Ausdruck $h^{\prime}$ nicht inhärent.

Azazel als "der beseitigte bzw. ferngehaltene Schuldige" - Görg zufolge würde nicht nur in grammatischer, sondern "auch in semantischer Hinsicht gerade die der Azazelgestalt eigene Funktion in der Namengebung transparent werden ... ${ }^{n 97}$. Die Einwände gegen diese (ägyptische) Herleitung des AzazelNamens und der Azazel-Gestalt sind u.E. gravierend, und die Annahme einer

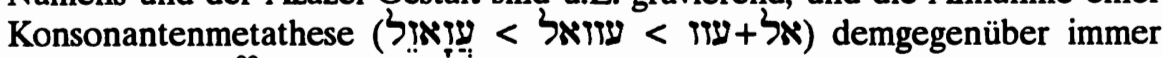
noch plausibler ${ }^{98}$. Azazel ist nicht "der beseitigte bzw. ferngehaltene Schuldige", sondern - jedenfalls auf der Ebene der Endgestalt von Lev 16 - ein Wesen, für das am großen Versöhnungstag ein Ziegenbock ausgelost wurde (Lev 16,8.10a, vgl. V.26), der die ihm 'aufgeladenen' Verschuldungen Israels "in die Wüste" bzw. "in eine abgelegene Gegend" forttragen soll (Lev 16,10b.21f). Görgs These macht nur unter der Voraussetzung Sinn, daß die Azazel-Gestalt mit dem "Sündenbock" zusammenzusehen ist, jene also wie dieser ein ritueller Träger des Unheils oder - wie er im Blick auf die vermeintliche Parallelität Seth/Azazel formuliert - die "Personalisierung eines Unheilsträgers" bzw. "Personifikation der Schuldbeladenheit"99 war. Genau das scheint die Intention seiner "Beobachtungen" zu sein, wie am Ende des Aufsatzes auch explizit deutlich wird. Görg rekurriert dort auf die alten Versionen (LXX, $\alpha^{\prime} \sigma^{\prime}{ }^{\prime}$ ',

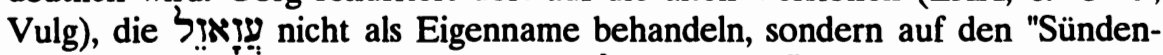

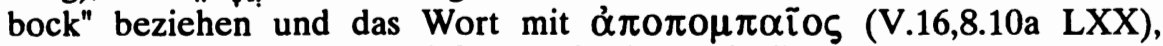

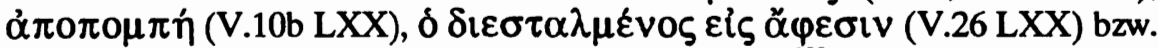
caper emissarius (Lev 16,8.10a.26 Vulg) wiedergeben ${ }^{100}$. Für die "Verbindung des Ausdrucks

96 Vgl. wiederum Görgs - suggestive - Frage: "Ob sich in der Azazelgestalt als Personifikation der Schuldbeladenheit ebenfalls (sc. wie bei Seth) eine mythologische Verdichtung der von der (Ostlichen) Wüste kommenden und in sie zu bannenden Gefahren zeigt?"(ebd.).

97

98

allerdings nicht davon dispensiert, den Namen Azazels und die Motivation fur das Einbringen dieser Gestalt in Lev 16 zu erklären, s. dazu unten Abschn. IV. Zur Kombination ᄁᄁִ +3 s. auch Loretz, Leberschau, 54.55; Wright, Disposal of Impurity, 22, u.a., s. zur Namensform auch $R$. Zadok, Phoenician Philistines and Moabites in Mesopotamia, BASOR 230 (1978) 57-65, hier: 58. Zu den $P l$-haltigen, mit der Wurzel ' $Z Z$ gebildeten semitischen Personennamen s. J.H. Tigay, You shall have no other Gods. Israelite Religion in the Light of Hebrew Inscriptions (HSS 31), Atlanta/GA 1986, 83ff; J.D. Fowler, Theophoric Personal Names in Ancient Hebrew. A Comparative Study (JSOT.S 49), Sheffield 1988, 82.152f.354f; J.C. de Moor, The Rise of Yahwism. The Roots of Israelite Monotheism, Leuven 1990, 13ff; u.a.

99

${ }^{100}$ Einzelheiten bei Landersdorfer, Versöhnungstag, $18 \mathrm{ff}$. 
schen Vorstellung einer "Verknüpfung des Seth mit dem 'Seth-Tier"" an, "als welches seit dem $\mathbf{M}$ (ittleren) $R$ (eich) der Esel gilt"101. Wie immer die innerägyptische Entwicklung der Seth-Gestalt ausgesehen hat - wegen der Unvergleichbarkeit der Azazel- mit der Seth-Gestalt ist die Erklärung jener Übersetzungspraxis durch S. Landersdorfer u.E. immer noch die wahrscheinlichere: Die alten Versionen "... wollen von Azazel nichts wissen, sie kennen ihn nicht oder wollen ihn nicht kennen, wenigstens zum größeren Teil. Die Deutung dieser Erscheinung liegt nahe genug, als da $ß$ man sie nicht schon längst gefunden hätte: Man habe eben den unbequemen Dämon aus dem Gesetze draußen haben wollen"102.

\section{Die These eines südanatolisch-nordsyrischen Ritualtyps}

Unsere bisherige Skizze zur Erforschung der Ritualgeschichte von Lev 16, 10.21f hat zu einem negativen Ergebnis geführt, denn die Einwände, die gegen die These eines nomadischen wie eines ägyptischen Ritualtyps sprechen, sind text-, überlieferungs- und religionsgeschichtlich gewichtig. Was der in Lev $16,10.21 \mathrm{f}$ geschilderte Vorgang dagegen klar erkennen läßt, ist die eliminatorische Funktion des "Sündenbocks", für die es zahlreiche Parallelen innerhalb (Lev 14,2b-8.48-53: kathartischer Ritus mit zwei Vögeln; Sach 5,5-11: Einschließung der "Bosheit" im Epha und dessen Wegschaffung durch zwei weibliche Wesen mit Storchenflügeln) und auch außerhalb des Alten Testaments gibt $^{103}$. Sie weisen ursprünglich in den Bereich südanatolisch-nordsyrischer Ritualtradition, von wo aus dieser Eliminationsritus in den palästinisch-israelitischen und in den ionisch-griechischen Überlieferungsbereich (PharmakosRiten $)^{104}$ vordrang. Sein Charakteristikum ist die räumliche Entfernung

$101 \mathrm{AaO}$ 15. Görg nimmt hier Bezug auf Brunner-Traut, Esel, 28.

$102 \mathrm{AaO} 20$.

103 S. dazu den Überblick bei Janowski, Sühne als Heilsgeschehen, 211ff; Loretz, Leberschau, 35ff.40ff.50ff und Wright, Disposal of Impurity, 31ff; ders., Deuteronomy 21:1-9, 398ff.

104 S. dazu außer der klassischen Studie von Gebhard, Pharmakoi, jetzt v.a. Burkert, Griechische Religion, 139ff.398; ders., Structure and History, 59ff; W. Fauth, Art. Opfer, KP IV, 309f; $D$. Wachsmuth, Art. Thargelia, KP V, 650 (jeweils mit der alteren Lit.); Bremmer, Scape-Goat, ferner Kilmmel, Ersatzrituale, 197f; ders., Ersatzkonig, 312f; Hengel, Atonement, 24ff und zu

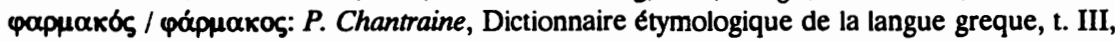
Paris 1974, 1177-1179. Offenbar hăngt der Mythos vom Troianischen Pferd mit solchen Riten zusammen, s. Burkert, Homo Necans, 178ff. Einen - nicht unumstrittenen - Versuch, den sophokleischen "König Ödipus" mit Hilfe des Pharmakos-Modells zu deuten, hat Vernant, Ambiguite et renversement vorgelegt, s. dazu auch Girard, Das Heilige, 104ff und die Kritik von H. Flashar, Konig Ödipus. Drama und Theorie, Gymnasium 84 (1977) 120-136, hier: $131 \mathrm{ff}$ und $F$. Schuh, Bemerkungen zur Tragodienforschung. Aus Anlaß der Lekture Vernants 
(eliminatio) des substanzhaft verstandenen Unheils ('Unreinheit, Makel, Sünde') mittels eines lebenden / mobilen Substituts.

\section{a) Lev 16,10.21f und die südanatolische Ritualtradition}

Die Erforschung der als Parallele zum Azazel-Ritus Lev 16,10.21f in Frage kommenden kleinasiatischen Ritualtradition ist vergleichsweise jung. Sie beginnt 1919 mit einem Aufsatz von A.H. Sayce ${ }^{105}$ und erfährt 1967/1968 durch zwei Arbeiten von H.M. Kümmel ${ }^{106}$, der punktuell auf Vorarbeiten von M. Vieyra (1939) ${ }^{107}$ und N. van Brock $(1959)^{108}$ zurückgreifen kann, eine erste umfassende überlieferungs- und religionsgeschichtliche Einordnung ${ }^{109}$. Kümmel hat auch schon die Verbindung dieses 'Sündenbockmotivs' mit analogen Ritualtypen des antiken Mittelmeerraums und Syrien-Palästinas aufgezeigt. Sein Substrat der magischen Elimination von Unheil haben dann 1974 und 1982 V. Haas und G. Wilhelm ${ }^{110}$ als im hurritischen Milieu Kizzuwatnas (Südwestanatolien) beheimatet erkannt und auf diesem Hintergrund den Azazel- Ritus Lev 16,10.21f in ein archaisches religiöses Konzept der Identität von göttlichem Zorn und magischer Unreinheit einzuordnen vermocht. Teil III der vorliegenden Studie stellt das relevante Material auf dem gegenwärtigen Stand der hurritologischen Forschung dar.

'Mythe et tragédie', Hephaistos 5/6 (1983/85) 237-278, hier: 267ff. Zum "Sündenbock"-Motiv in den rituellen Überlieferungen der Etrusker s. P. Blome, Das Opfer des Phersu: ein etruskischer Sündenbock, MDAI.R 93 (1986) 97-108 (mit Taf. 22-24), bes. $103 f$.

105 Scapegoat, vgl. Gurney, Some Aspects, $48 \mathrm{f}$.

106 Ersatzrituale; ders., Ersatzkonig, vgl. auch ders., Religion der Hethiter, 83f; ders., Rituale in hethitischer Sprache, in: TUAT II/2 (1987) 282ff.285f.

107 Rites de purification hittites, vgl. auch Landersdorfer, Sündenbock, 24ff, der bereits 1931 auf das hethitische 'Pestritual' KUB IX 32 als Sachparallele zu Lev 16,10.21f hingewiesen und mit der Möglichkeit einer Entlehnung der "Grundidee", nicht aber des Ritus als solchem gerechnet hat (aaO 27ff).

108 Substitution rituelle.

$109 \mathrm{~S}$. dazu ausführlicher unten Abschn. III/1.

${ }^{110}$ Haas / Wilhelm, Riten, 138f; Wilhelm, Hurriter, 104. 
b) Zum kanaanäischen "Sündenbock"-Ritus KTU 1.127: 29-31

Als C.F.A. Schaeffer ${ }^{111} 1963$ das keilalphabetisch beschriftete Tonlungenmodell RS $24.277^{112}$ aus dem Haus eines ugaritischen "Opferschaupriesters" erstmals vorgestellt hatte (Publikation: M. Dietrich / O. Loretz, Ug. 6 [1969] 166 $=\mathrm{KTU} 1.127)^{113}$, konnte die Frage eines missing link zwischen der hethitischen Ritualtradition - repräsentiert etwa durch das "Pestritual" KUB IX 32 (mit Duplikaten) ${ }^{114}$ - und dem "Sündenbock"-Ritus Lev 16,10.21f endlich beantwortet werden. Erste Hinweise zu dieser Einordnung von KTU 1.127 gab 1976 und $1980 \mathrm{~K}$. Aartun ${ }^{115}$. Er machte geltend, daß in Z. 25-31 von einer Ziege die Rede sei, die als "Sündenbock" in die Wüste geschickt werde, so daß hier eine Parallele $\mathrm{zu}$ anderen altorientalischen Texten und insbesondere zu Lev 16 vorliege ${ }^{116}$.

In der Tat liegen - die annähernde Richtigkeit der folgenden Übersetzung vorausgesetzt - die Analogien zwischen KTU 1.127 und Lev 16 hinsichtlich des Vorgangs der rituellen Elimination auf der Hand. Denn nach dem Text, der in Z. 13-28 nur sehr fragmentarisch erhalten ist, soll anläßlich einer lebensbedrohlichen Not (Auftreten einer Seuche / Pest) ${ }^{117}$ - und als Antwort des Opferschaupriesters auf eine entsprechende Anfrage - eine Ziege zur Abwehr des Unheils "in die Ferne" (mrhqm Z. 31) getrieben werden:

\section{9 hin qrt tuhd} hm mt y'l bns

"Wenn die Stadt gefaßt/in Bedrăngnis gebracht wird, wenn ein Mann/Krieger die Leute des Palastes verdirbt/unrecht behandelt,

30 bt bn bnš yqh' $z$ dann soll ein Mann/Bürger eine Ziege nehmen

$31 w$ yhdy mrhqm und in die Ferne treiben!"118.

\footnotetext{
111 Neue Entdeckungen in Ugarit, AfO 20 (1963) 215.

112 Allgemein zur Hepatoskopie und zu den Tonleber-/-lungenmodellen von Ugarit s. Dietrich/ Loretz, Mantik, 2ff, zu den archäologischen, epigraphischen und hepatoskopischen Einzelfragen s. J.-W. Meyer, in: Dietrich / Loretz, aaO 241-280 (bes. 270f zu KTU 1.127).

113 S. die Angaben zum Text und zur ălteren Literatur (1963-1989) bei Dietrich / Loretz, aaO 18, ferner dies., aaO 19-38, vgl. Loretz, Ugarit, 115ff, bes. $118 \mathrm{ff}$.

114 S. die Bearbeitung von H.M. Kümmel, in: TUAT II (1991) 285-288, vgl. zur Sache unten III/1.

115 Parallele aus Ugarit; ders., Versöhnungstag.

116 Wahrend M. Dietrich / O. Loretz, in: TUAT II (1991) 100f diese Deutung übernehmen, pladiert J.-M. de Tarragon, in: Textes Ougaritiques II (LAPO 14), Paris 1989, 212-215, bes. 215 Anm. 214 dafür, in KTU 1.127, 29-31 einen Hinweis auf eine Eingeweideschau (Inspektion der Lunge einer Ziege) zu sehen, s. dazu jetzt Dietrich / Loretz, Mantik, $20 f$.

$117 \mathrm{Vgl}$. Meyer, aaO $270 \mathrm{f}$.

118 Ubersetzung von Dietrich / Loretz, Mantik, 22, zur Interpretation s. zuletzt dies., aaO $32 \mathrm{ff}$.
} 
Aus dem Vergleich von Lev 16,10.21f mit KTU 1.127:29-31 "ergibt sich besonders anschaulich, daß das biblische Ritual am Ende eines langen Entwicklungsweges steht, der sich im altsyrisch-kanaanäischen Bereich bis nach Ugarit zurückverfolgen läßt"119. Unbeschadet der Differenzen - im Gegensatz zum ugaritischen Ritualtext verbindet Lev 16,10.21f die Aussendung des "Sündenbocks" mit der Azazel-Gestalt - stehen wir hier einer breiteren Ritualtradition der magischen Elimination von Miasma gegenüber, die ihren Ursprung wahrscheinlich in Südanatolien-Nordsyrien (Kizzuwatna, Ugarit) hatte und von dort in den palästinisch-israelitischen und in den ionisch-griechischen Bereich ausstrahlte $^{120}$.

\section{Exkurs 2: 'z'zl / 'zz'l - eine "niedere Gottheit"?}

Nach O. Loretz ${ }^{121}$ lassen sich auch der Name und die Gestalt Azazels von ugaritischen Texten her erklären. ${ }^{122}$ Damit wird die Annahme etwa $\mathrm{K}$. Elligers, wonach die Azazel-Gestalt dem Eliminationsritus Lev 16,10.21f selbst nicht immanent, sondern "erst sekundär möglicherweise erst in nachexilischer Zeit, in das Ritual eingedrungen"123 sei, zwar grundsätzlich bestätigt, hinsichtlich des Alters und der Kontur dieser Gestalt aber präzisiert. Analog zu ' $z b^{\prime} l$ (Z. 27) in der Götterliste KTU 1.102:15-28, gehöre auch ' $z z^{\prime} l\left(<^{*}{ }^{\prime} z l\right)$ dem Kreis der göttlichen Wesen um El zu: Die großen Götter El und Ba'al, die sich mit anderen Gottheiten zur Versammlung der Götter zusammentaten, waren selbst wiederum von dienstbaren göttlichen Wesen, den inš ilm "Mannen, Dienern der Götter", umgeben, deren Namen ihre Beziehung zu El oder Ba'al zum Ausdruck bringen und denen selber Opfer zugedacht werden (vgl. KTU 1.106:2-5) ${ }^{124}$. Somit ergibt sich für die Azazel-Gestalt, "daß in der Spätphase der Entwicklung und vom Standpunkt des sicheren nachexilischen Monotheismus aus, eine Figur aus dem Bereich der niederen Götter der inš ilm im

119 Loretz, Ugarit, 120.

${ }^{120} \mathrm{Vgl}$. dazu bereits Kümmel, Ersatzkönig, 311f; Janowski, Sühne als Heilsgeschehen, 211ff; Loretz, Leberschau, $48 \mathrm{f}$ und oben 128, 245 mit Anm. 104 und unten Abschn. III/1 und IV.

$121 \mathrm{AaO} 55 \mathrm{ff}$.

$122 \mathrm{Zu}$ dem Versuch von Tawil, 'Azazel, 43ff - und entsprechend Strobel, Sündenbock-Ritual, 165f; M.C.A. Korpel, A Rift in the Clouds. Ugaritic and Hebrew Descriptions of the Divine (UBL 8), Münster 1990, 355f -, die Azazel-Gestalt von der ugaritischen Tradition über Mot abzuleiten, s. ders., aaO $52 \mathrm{ff}$ und Wright, Disposal of Impurity, $25 \mathrm{ff}$, vgl. oben Anm. 17. Wyatt, Atonement Theology, 429 sieht in עזאז eine Bezeichnung für Attar, s. dazu aber Loretz, aaO 54.

${ }^{123}$ Elliger, Leviticus, 212, s. dazu oben 114.

${ }^{124}$ S. dazu Loretz, aaO 55f, vgl. ders., Ugarit, $89 f$. 
Judentum notwendig zu einer guten oder bösen dämonischen Macht werden mußte ${ }^{\text {n125. }}$.

Diese Hypothese ist wegen ihres semitisch-kanaanäischen Kolorits bedenkenswert, scheitert u.E. aber - abgesehen von dem Selbsteinwand ihres Verfechters $^{126}$ - an einer zweifachen Überlegung:

1. Nach der Götterliste KTU 1.106:2-5 werden den niederen Göttern Brandopfer zuteil. Auch der ihnen nahestehende Gott ' $z z$ 'l wäre nach der Annahme von O. Loretz Empfänger einer solchen Opfergabe. Im Gegensatz dazu sind die "Sündenbock"-Riten KTU 1.127:29-31 und Lev 16,10.21f aber keine Opfer an eine Gottheit, sondern auf der magischen Entfernung von Miasma durch ein lebendes Substitut beruhende Eliminationsriten. Die These von $\mathrm{O}$. Loretz läuft auf die Annahme hinaus, daß der "Sündenbock" ursprünglich so etwas wie eine Abgabe/Opfergabe an eine (niedere) Gottheit war.

2. Dem steht aber die Tatsache entgegen, daß die niederen Götter der Götterlisten KTU 1.102:15-28; 1.106:2-5 - und auch eine ihnen nahestehende Gottheit ' $z z$ ' $l$ - sich gerade nicht im Kontext eines Eliminationsritus wie KTU 1.127:29-31 finden, beide Größen in Ugarit also nicht kompiliert werden. Auch für Lev 16,10.21f hat die Vermutung, daß "die Asasel-Gestalt ... dem [Eliminations-]Ritus selbst nicht immanent (ist) ${ }^{\prime 127}$, sondern erst sekundär in das Ritual eindrang, die größere Wahrscheinlichkeit für sich.

Die referierte Hypothese ist also mit zuvielen Schwierigkeiten (v.a. konzeptioneller Art) belastet. ${ }^{128}$ Es gibt demnach Gründe, nach einer anderen Erklärung Ausschau zu halten.

\footnotetext{
125 Loretz, Leberschau, 57.

126 Ebd.

127 Elliger, ebd., s. auch oben 114.131 und unten Abschn. IV.

128 Dazu gehơrt auch die u.E. noch immer offene Frage, ob die besagten Namen nicht doch vergöttlichten Konigen von Ugarit zuzuweisen sind, s. dazu $G$. del Olmo Lete, Los nombres 'divinos' de los reges de Ugarit, AulOr 5 (1987) 39-69 und Loretz, Ugarit, 90.
} 


\section{Rituale des "Sündenbocktyps" in Anatolien und Nordsyrien als Vergleichs- material zu Lev 16}

\section{Forschungsgeschichtliche und methodologische Aspekte}

Die hethitischen Rituale gegen Seuchen in Land und Heer, die sogenannten Pestrituale, schreiben mehrfach vor, Widder mit verschiedenfarbenen Wollfäden zu versehen und ins Feindesland zu treiben. Die Anbringung von Wollfäden ist eine bekannte, vor allem in Ritualen südwestanatolischer Herkunft bezeugte magische Praxis zur Übertragung von Miasmen. ${ }^{129}$ Tritt die Krankheit im Heerlager auf, legen die Generäle zuvor ihre Hand auf die Widder und empfehlen dabei der erzürnten Gottheit die Tiere als Substitut für die vom göttlichen Zorn bedrohten Menschen. ${ }^{130}$ In einem Ritual dieses Typs, in dem ein Esel die Rolle des Substituts zu übernehmen hat, wird die Bedeutung des Ritus klar: "Du, Jarri, hast diesem Lande und dem Heerlager Böses getan. Das soll nun dieser Esel aufnehmen, und er soll es in das Feindesland bringen!"131.

Bereits in der Pionierphase der Hethitologie ist 1919 von A.H. Sayce ein Zusammenhang zwischen diesem eliminatorischen Ritus der hethitischen Magie und dem sogenannten "Sündenbockritus" in Lev 16 hergestellt worden. ${ }^{132}$ Dieser Zusammenhang wurde in der Folgezeit öfter wieder aufgegriffen, zuerst von V. Gebhardt, ${ }^{133}$ in neuerer Zeit von H.M. Kümmel ${ }^{134}$ und O.R. Gurney. ${ }^{135}$

Gurney hat dabei eine kategoriale Differenzierung zwischen "Substitut" und "Träger" ("carrier") vorgenommen. Ein Substitut wird an Stelle einer Person oder Sache dem Zugriff der numinosen oder dämonischen Mächte ausgesetzt, nachdem es durch magisch-rituelle Übertragung das Miasma des zu Reinigen-

129 Goetze, Kleinasien, 156; Haas, Magie, 246a; Moyer, Ritual purity, 130-133; Engelhard, Magical practices, 136-140; Szabó, Entsühnungsritual, 95-100; Gurney, Aspects, 48f; Hutter, Behexung, 132.

${ }^{130}$ Friedrich, Heth. Schrifttum, 2. Heft, 11f; Gurney, Aspects, 48f; Haas, Berggötter, 173f; Dinçol, Ashnella.

131 Ritual des Auguren Dandanku KUB VII 54 III 15-18: [z]i-ik-ua $\mathrm{D}_{I-i a-a r-r i-i s ̌} k e-\lceil e\urcorner-d a-n i$ [K]UR-e KARAŠHI.A-ịa i-da-lu i-ia-at [n]u-ua-ra-at ka-a-aš ANŠ́E kar-ap-du [n]u-ua-ra-at INA KUR LÚ KÚR pé-e-da-a-ú; vgl. Goetze, Kleinasien, 159; Gurney, Hittites, 135; Kümmel, Ersatzrituale, 121; Klengel, Ablenkungszauber; Gurney, Aspects, 49.

132 Sayce, Scapegoat.

133 Gebhardt, Sündenbocke.

134 Küminel, Ersatzrituale, 191-196.

135 Gurney, Aspects, 47-52. 
den in sich aufgenommen hat. Das Substitut kann ein Mensch, ein Tier oder eine Nachbildung derselben sein. Die Zerstörungshandlung wird oft von dem Beschwörer selbst, etwa durch Verbrennen, durchgeführt. Von einem Träger kann gesprochen werden, wenn die Übertı agung des Miasmas von der befleckten Person oder Sache auf ein Tier (in seltenen Fällen auch auf eine Person) stattfindet, welches die bloße Funktion hat, das Miasma fortzuschaffen. Gurney betont aber zu Recht, daß die beiden Konzepte zusammenfließen können, wie dies bereits in dem anfangs erwähnten Ritual gegen Krankheit im Heerlager der Fall ist, wo das Fleisch der als "Träger" vorgesehenen Widder ausführlich als vorzüglicher Ersatz, also als Substitut, für das Fleisch der Menschen beschrieben wird. ${ }^{136}$ In dem hier zu erörternden Zusammenhang steht die Elimination eines "Trägers" im Mittelpunkt, doch soll hierbei nicht außer acht gelassen werden, da $\mathrm{B}$ es sich um einen Sonderfall der Kathartik handelt, der mit anderen Formen der Kathartik verschmolzen oder kombiniert werden kann.

Kümmel ${ }^{137}$ hat die anatolischen eliminatorischen Riten des eingangs beschriebenen Typs mit dem ionischen und athenischen $\vartheta \alpha \rho \gamma \eta \dot{\eta} \lambda \iota \alpha-F e s t$ (Mai/Juni) in Verbindung gebracht, in dem mit der Austreibung des $\varphi \alpha \rho \mu \alpha \kappa \delta \zeta \varsigma$ in Gestalt zweier Männer ein vergleichbarer eliminatorischer Ritus durchgeführt wird. Damit ergibt sich für Kümmel etwa dieselbe Verbreitung für den Eliminationsritus wie die für Brandopfer und Menschenopfer, nämlich der westliche Vordere Orient. ${ }^{138}$

Eine lokale Präzisierung nahm O.R. Gurney ${ }^{139}$ vor, indem er darauf verwies, daß die hethitischen Pestrituale, die mehrere Belege für den eliminatorischen Ritus liefern, von Verfassern des südwestanatolischen Landes Arzawa stammen: Das erste der "Rituale gegen eine Epidemie in der Armee" (CTH 425) geht nach der Textüberschrift auf den Vogelschauer Maddunani von Arzawa zurück, und gleichfalls aus Arzawa stammt der Verfasser eines Rituals gegen eine Seuche im Lande, Uhha-muwa (CTH 410). Das Land Hapalla, das zu den Arzawa-Ländern gehört, ist die Heimat des Ašḩella, des Verfassers eines anderen Pestrituals (CTH 394).

Die Elimination von Miasma durch einen Träger ist auch in den hethitischen Ersatzkönigsritualen belegt, die, wie H.M. Kümmel überzeugend aufgezeigt hat, in der zentralen Vorstellung der temporären Königssubstitution bei bedrohlichen Omina zwar mesopotamischer Herkunft sind, in der Form der Elimination

\footnotetext{
136 Gurney, aaO 52.

137 Küınmel, Ersatzkönig, 312 mit Lit., vgl. noch Burkert, Griechische Religion, 139-142 mit weiteren Parallelen aus dem griechischen Raum; Gebhard, Pharmakoi.

138 Küınınel, Ersatzrituale 24; ders., Ersatzkönig 312.

139 Gurney, aaO 51.
} 
aber dort keine Entsprechung haben. In dem Ritual KUB XXIV $5+{ }^{140}$ wird der Kriegsgefangene, nachdem er förmlich mit dem König die Rolle getauscht hat, in das Feindesland zurückgeführt, während der König sich verschiedener Reinigungsriten unterzieht und Opfer darbringt. Der Kriegsgefangene wird mit einem luwischen Wort als tarpalli- bezeichnet, das etwa als "Substitut" wiedergegeben werden kann. Das "Substitut" erfüllt hier gleichzeitig die Funktion des "Trägers", durch den das Unheil fortgeschafft wird. tarpalli- bezeichnet sonst aber zumeist das bloße Substitut, das verbrannt oder vergraben wird. ${ }^{141}$

Als eine Bezeichnung für den bloßen "Träger" von Miasma, der in die feindliche Sphäre, Steppe oder Feindesland, geführt oder getrieben wird, kann in Texten der südostanatolischen, in sprachlicher Hinsicht hurritisch und luwisch geprägten Zone das Wort nakkušsi- verwendet werden, das früher dem Hurritischen, ${ }^{142}$ neuerdings dem Hethitischen bzw. Luwischen ${ }^{143}$ zugerechnet wird. ${ }^{144}$ Besonders deutlich wird dies an der folgenden Stelle des Rituals der Stadt Šamuha KUB XXIX $7^{145}$ :

\section{Rs. 59' rku-it ku-it i7-da-a-lu ut-tar NI-IŠ DINGIR ${ }^{L I M}$ hu-u-ur-ta-iš \\ 60' [pa-ap-]ra-a-tar PA-NI DINGIR ${ }^{L I M}$ i-lia-an na-at ke-e na-ak-ku-uš-si-e-eš A-NA DINGIR ${ }^{L M}$ pé-ra-an ar-ha \\ 61' [p]é-reT-da-an-du DINGIR ${ }^{L U M}$-ma EN.SÍSKUR-ina a-pé-e-ez ud-da-a-na-az pár-ku-ua-e-es a-sa-an-du}

"Welche böse Sache auch immer, ein (Mein-)Eid, ein Fluch, eine Unreinheit, vor der Gottheit begangen ist, die sollen diese nakkušši- (N. pl.) vor der Gottheit wegschaffen; die Gottheit aber und der Ritualmandant sollen von jener Sache rein sein!"

140 Kümmel, Ersatzrituale, 7-37.

141 Ders., aaO 19-22.146f.

142 van Brock, Substitution 132ff; Kümmel, aaO 146-149; Gurney, aaO 51.

143 Laroche apud Hoffner, Incest, 86 Anm. 31; Lebrun, Samuha, 135; Laroche, Glossaire, 177; Laroche, nakkus [vgl. dazu Wilhelm, ZA 79, 131; 132, 6. Zeile von unten: lies "Inzitation" statt "Inititation"; Mskr. und Fahnenkorrektur richtig]; CHD L-N 376f; Starke, Stammbildung, $168 \mathrm{f}$ (frdl. Hinweis E. Neu bereits vor Erscheinen).

144 Die Bestimmung von nakkušši- als "magischer Trăger von Unreinheit" (Kammenhuber, $\mathrm{HW}^{2}$ E, 73a: "ritueller Sündenbock"; CHD L-N 376 "scapegoat, carrier [to remove evils]") ist problematisch an einer bereits von van Brock, Substitution, 127, behandelten Stelle des Rituals der Beschwörerin Mastikka aus Kizzuunatna, vgl. Rost, Familienzwist, 360-363, Z. 38-43. Hier findet sich die Vorschrift, ein Schaf, das als nakkušsi- bezeichnet wird, dem Sonnengott als Opfer anzubieten (he(n)k-), es zusammen mit Brot- und Weinopfern als Opfer darzubringen (sipant-), es dabei aber keineswegs zu töten. Vielmehr nimmt die Beschwörerin es an sich, ohne daß es im weiteren Ritualverlauf noch eine Rolle spielt. Auch fehlen, wie nicht selten auch sonst im Zusammenhang mit einem nakkušši-, alle Vorschriften für die Übertragung von Miasma auf das nakkư̌ši-Schaf ebenso wie solche für die sichere Elimination desselben.

145 Vgl. Lebrun, aaO 125.132 Z. 68-70. 
In dem folgenden Ritualfragment wird als Ziel der Elimination das Gelände außerhalb von Siedlung und Feldflur (gemeinhin als "Steppe" übersetzt) angegeben:

KBo XXIV 16 lk. Kol.

9" | jna-aš LíL-ri pé-e-da-an-zi

10" na-ak-k]u-uš-si-uš-ša [L]ÍL-ri pé-en-na-an-z[i

11" ] a-še-ša-an-zi

"[...] Sie schaffen sie in unkultiviertes Gelande; [...] auch die [nakk]ušsi- (Akk. pl.) treiben sie in unkultiviertes Gelande; [...] setzen sie [sie ? hin]."

In einem Ritual gegen die verunreinigende Wirkung der Sodomie (KUB XLI 11 Rs. 2'-30'146), das in der Tradition der Kizzuuatna-Rituale steht, wird ein Schaf als nakkušši- freigelassen, nachdem es wie eine Braut aufs kostbarste ausgestattet wurde. Dabei sagen die Priester:

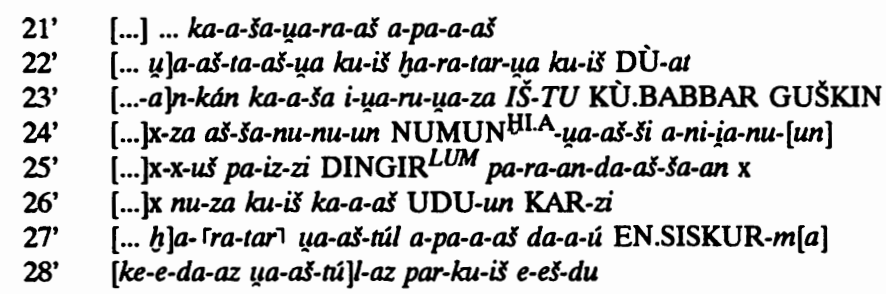

"(21') Siehe, jenes (sc. das Schaf) ist )22') [...], derjenige, der sündigte, derjenige, der ein Ärgernis verursachte. [...], siehe, mit einer Mitgift von Silber (und) Gold [...].. habe ich es ausgestattet, Saatgut habe ich ihm gesat. [...].. geht es. Die Gottheit [...] sein ... Wer dieses Schaf findet, der möge Ärgernis (und) Sünde (auf sich) nehmen, der Opfermandant aber möge [von] dieser [Sünd]e rein sein!"

Alle angeführten Belege (und mehrere weitere) verweisen auf den südanatolischen Raum, grosso modo das Gebiet von der Ägäis bis zum Euphrat, als Verbreitungsgebiet des in Frage stehenden Eliminationsritus. Dieser südanatolische Eliminationsritus des "Sündenbocktyps" stellt den Lev 16 vorgeschriebenen Ritus in einen breiteren religionsgeschichtlichen Zusammenhang und fördert das Verständnis seiner religiös-magischen Struktur. Keine Klärung hat jedoch bisher die vieldiskutierte änigmatische Zweck- oder Zielbestimmung $l$-' $z z^{\prime} l$ in Lev 16 gefunden. Ältere Deutungen sind von B. Janowski im zweiten Teil dieses Aufsatzes behandelt worden. Innerhalb der neueren altorientalistischen Literatur haben sich insbesondere Kümmel und Gurney hierzu geäußert. Kümmel ist der Meinung, "die Nennung eines Empfängers, des Wüstendä-

146 Hoffner, Incest. 
mons(?) Aza'zel, dürfte auch hier spätere Zutat sein", ${ }^{147}$ und beruft sich auf den Leviticus-Kommentator K. Elliger, der den Eliminationsritus selbst für das älteste und wohl sogar ursprünglich einzige Hauptstück des Sühnerituals am Versöhnungstag, ${ }^{148}$ die Wendung $l$-'zz'l dagegen für eine späte Zutat hält, da "die Asaselgestalt ... dem Ritus selbst nicht immanent" sei. ${ }^{149}$ Dabei wird indes als gegeben angesehen, daß $l-{ }^{\prime} z z$ ' $l$ sich auch ursprünglich, also nicht erst sekundär, auf einen Dämon bezieht, den die "Volksphantasie" als "Herrn der Wüste" imaginiert, ${ }^{150} \mathrm{da}$ es sich also nicht etwa um die spätere Ausdeutung eines Terminus handelt, dessen ursprünglicher Sinn dunkel geworden war. Wäre dies richtig, so könnte das kleinasiatische Material des 2. Jts. v.Chr. nicht zur Erklärung herangezogen werden. Gerade die Tatsache, daß die Wendung $l-' z z ' l$ als fremdartig empfunden wurde und daher zu kontroversen Ausdeutungen $A$ nla $B$ gab, verweist auf sein archaisches Gepräge. Dies scheint auch die Auffassung von O.R. Gurney zu sein, der ebenso wie Kümmel an der Bestimmung von Azazel als Wüstendämon zweifelt, aber implizit ein hohes Alter des Azazel-Ritus annimmt, wenn er sagt: "The Hittite evidence may be of some relevance here."151 Allerdings gelangt auch er in der Frage der Bedeutung von $l$-'zz'l zu keiner weiterführenden Erkenntnis aus dem altkleinasiatischen Material.

T.H. Gaster hat - worauf Gurney hinweist ${ }^{152}$ - gegen die Bestimmung von Azazel als Wüstendämon eingewandt, den bekannten "Sündenbockritualen" sei die Vorstellung, daß der Träger des Miasmas einem Dämon geopfert werde, fremd. ${ }^{153}$

Die Untersuchung im Abschnitt II dieses Aufsatzes hat gezeigt, daß es jedenfalls keine textinternen Indizien für die Annahme gibt, die Wendung $l$-'zz' $l$ sei eine spätere Interpolation. Gerade weil die Wendung $l$-'zz'l Interpretationsprobleme bereitet, darf man vermuten, daß sie zum ältesten Kern des Rituals gehört, das seinerseits aufgrund der Vorstellung magisch mobilisierbarer Miasmen religionsgeschichtlich außerordentlich archaisch ist.

Ein Lösungsversuch hat daher mehreren methodischen Anforderungen zu genügen: Eine Deutung der Wendung $l \cdot{ }^{\prime} z z ' l$ muß diese als integralen Bestandteil des Ritus verstehen und ihre Funktion im Rahmen des zugrundeliegenden magischen Vorstellungszusammenhangs erklären. Sie muß also nicht nur nach

\footnotetext{
147 Kümınel, Ersatzkönig, 311.

148 Elliger, Leviticus, 215.

149 Ders., aaO 212.

150 Ders., aaO 212.

151 Gurney, Aspects, 47.

152 Ders., aaO 47.

153 Gaster, Azazel, 326.
} 
der Behandlung des "Trägers", sondern darüberhinaus nach Zweck- oder Zielbestimmungen aller Art in einem magischen Eliminationsritual fragen, wobei, wie gleich deutlich werden wird, auch die Elimination auf einem breiteren Hintergrund gesehen werden muß. Weiterhin ist dem Kulturraum besonderes Augenmerk zu schenken, in dem gleichartige oder ähnliche Eliminationsriten von mindestens ähnlich hohem Alter bezeugt sind, also dem südanatolischen. Hieraus ergibt sich die Frage nach konkreten kulturellen Verbindungen zwischen diesem Raum und dem Raum des alttestamentlichen Ritus. In diesem Zusammenhang kommt dem nordsyrischen Raum als dem natürlichen geographischen Bindeglied erhöhte Aufmerksamkeit zu. Schließlich muß eine morphologische und semantische Bestimmung von $l$ ' $z z ' l$ mit den sprachlichen Gegebenheiten im südanatolisch-syrisch-palästinischen Kulturraum harmonieren.

\section{Gotteszorn als Miasma}

In den zahlreichen magischen Ritualen südanatolischer Herkunft, die uns aus den Bibliotheken der Hethiterhauptstadt Hattuša bekanntgeworden sind, ist Elimination mittels eines Trägers eine spezifische magische Technik neben anderen, die alle dem einzigen Zwecke der Katharsis dienen. Alle diese Techniken zielen darauf ab, Unreinheit abzulösen, zu mobilisieren und in irgendeiner Weise unschädlich zu machen. Unreinheit ist dabei substanzhaft gedacht, insofern als sie abgestreift, abgewischt, ausgekämmt, abgebürstet, abgeleckt werden kann. ${ }^{154}$ Freilich darf die Substanzhaftigkeit nicht als Qualität eines bloßen Objekts gesehen werden. Unreinheit kann vielmehr auch personale, nämlich dämonische Züge zeigen, sie kann als negative Befindlichkeit verstanden werden, die durch schwarzmagische Bindungskraft erzeugt ist, und weiterhin kann sie als hypostasierter psychischer Zustand betrachtet werden, nämlich als Zorn der Gottheit.

Die letztere Auffassung ist von besonderem Interesse, da ihr die uns so geläufige Disjunktion von Religion und Magie ganz fremd ist und ihr eine Aussage wie die des Kreon in der Antigone des Sophokles: "... denn wohl weiß ich, daß die Götter zu beflecken irgendein Mensch nicht vermag"155, unverständlich wäre. In der Vorstellung der alten Anatolier konnte ein Mensch sehr wohl, etwa durch eine Kultverfehlung, die Wirkungskraft einer Gottheit beeinträchtigen. Freilich konkurrieren hier eine religiöse und eine magische Sicht

\footnotetext{
154 Haas, Magie, $248 \mathrm{f}$.

155 Antigone 1043f:

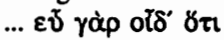

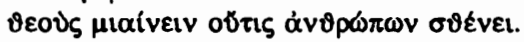


des Sachverhalts: Wenn die Gottheit in der einen Sichtweise auf die Verfehlung mit Zorn reagiert, unter Manifestation ihrer göttlichen Mächtigkeit straft und durch Gebet und Opfer besänftigt werden muß, so betrachtet die magische Interpretation den Zorn der Gottheit als ein Miasma, das die Gottheit bindet und an der Entfaltung ihrer Segenskraft hindert, das aber mit magischen Mitteln von der Gottheit abzulösen ist. Als Beispiele für den als mobilisierbares Miasma verstandenen Götterzorn seien einige Passagen aus Beschwörungsritualen, Gebeten und Mythen angeführt:

In dem Ritual HT 6 + KBo IX 125 heißt es Rs. IV 5-7 ${ }^{156}$ :

5 nu-uš-si MUNUŠ̌U.GI E[ME!?-an? p]a-ra-a e-ep-zi na-at II-šU al-la-a[p-pa-ah-hi]

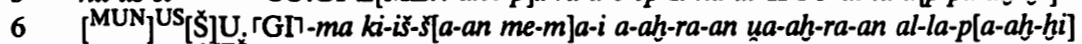

7 [DINGIR ${ }^{M E S}$-jna-as 「kar?-pi-in [a]l-[l]a-pa-ah pa-an-ga-u-as EME-an a[l-la-pa-ah]

"Die Beschwơrerin hălt ihm eine Zu[nge(?)] $]^{157}$ hin, und er spu[ckt] zweimal darauf. Die Beschwörerin aber [spric]ht folgender[maßen:] «ahra- (und) uahra- spu[ckt er aus.] Den Zorn der [Götte]r spucke aus! Die Rede der Menge s[pucke aus!»]"

Danach ist mit A. Kammenhuber ${ }^{158}$ das verwandte Ritual KUB XXXV 80 Rs.(?) 7'-14' zu ergänzen:

$\begin{array}{ll}7^{\prime} & \text { [nu an-ni-iš-ki-iz-z]i ku-in an-tu-uh-ša-an n[a-an-kán } \check{S} U M-\check{S} U] \\ 8^{\prime} & \text { [te-ez-zi ka-a-ǎs-u]a!? an-tu-uh-ša-aš i-da-a-la-「uT-[ua-az] } \\ 9^{\prime} & \text { [UD.KAM-za ma-ni-i]n-ku-ua-an-ta-az MU-za x[ ] ] }\end{array}$

10' [DINGIR ${ }^{\text {MEŠ }}$-aš kar-pi-az] pa-an-ga-u-ua-az EME-az x[

11' [pa-ra-a e-ep]-zi na-aš III-SU al-la-pa-ah̆-hi [MUNUŠ̌U.GI-ma]

12' [ki-ǐ̌-sa-an $m$ ] e-ma-i a-ah-ra-an ua-ah-ra-a[n al-la-pa-ah-hi DINGIR MEŠ-aš kar-pí-in]

13' [III- $\breve{S} U$ IV- $\breve{S} U]$ al-la-pa-ah pa-an-ga-u-ua-aš E[ME-an]

14' [III- $\breve{S}$ IV-ŠU al-l]a-pa-ah

"[Sie (die Beschwörerin) spricht den Namen] des Menschen, den [sie behandel]t, [aus: «Dieser] Mensch [sei befreit (o.á.)] von dem bos[en Tag,] von [dem kur]zen Jahr.

[Von dem Zorn der Götter,] von der Rede der Menge [sei befreit (o.á.).» Sie hâl]t [sie (Figürchen, Zungenmodelle ?) hin.] Er spuckt dreimal darauf. [Die Beschwörerin aber

\footnotetext{
156 Vgl. Karnmenhuber, Ketten, 87.

${ }^{157}$ Für eine Ergănzung išs-na-aš ...] "...-Objekt aus Te[ig]" (dies., aaO 87) reicht der Raum anscheinend nicht.

${ }^{158}$ Dies., aaO $87 \mathrm{f}$.
} 
s]agt [folgendermaßen:] «ahrra- (und) uahra- [spuckt er aus. Den Zorn der Götter] spucke [drei- und viermal aus! Die] R[ede] der Menge [sp]ucke [drei- und viermal aus!n]"159

Ist an diesen Stellen der Zorn der Götter als Miasma im Körper des Ritualmandanten gedacht, so kann er auch als negative Befindlichkeit der Gottheit selbst gedacht werden, die magisch von ihr abgelöst werden muß. Dies ist etwa der Fall in dem folgenden Auszug aus einem Ritual gegen eine Seuche (KUB LV 23 Vs. // 516/2 ${ }^{160}$ ):

10' [ku-i(š-ma DINGIR ${ }^{L I M} k i-i \mathrm{UG}_{6^{-}}$'kán) i-i] a-at nu-ua-kán kar[(-pi-i)n]

11' [(kar-tim-mi-ịa-at-ta-an ke)]-「e?-da-ni A-NA MÁŚ.GAL [(kat-t)a

"Der Gott aber, der diese Seuche gemacht hat -, Groll (und) Zorn [...] auf diesen Ziegenbock herab [...]."

In einem Fest für die Göttin Išḩara (KBo XXIII 41 Rs.(?) 4' ff.) wenden sich die Priester mit folgenden Worten an die Gottheit:

\begin{tabular}{|c|c|}
\hline 9 & [ma-a-an $z[i-i] k$ DINGIR ${ }^{L M}$ TUKU.TUKU-u-an-z[a] \\
\hline 10 ' & u-na-ti-ua-li-i[s m]a-a-an-ták-kán ZI-ni ku-it-ki i-da-a-lu \\
\hline 1 ' & za kar-aś-du da-aš-šu-uš hal-ki-iš \a- $\ulcorner l i \backslash u$-ua-ni-ia-aš li-im[-ma] \\
\hline & $\begin{array}{l}{[t u-u] k A-N A \text { DINGIR }{ }^{L M} \text { TUKU.TUKU-at-ta-an } \backslash d u \text {-si-in a-pu-us da-an-zi na-an a- }} \\
p[u-u s]\end{array}$ \\
\hline & 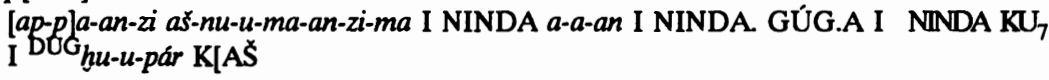 \\
\hline
\end{tabular}

"«... Wenn du, o Gottheit, zornig bist oder unatiuali-, wenn dir irgendetwas Boses im Sinne ist, moge er (es) mit gangati-Kraut abschneiden. "Schwere"161 Gerste, ali-, uuaniia162 (und) $\lim [m a]-T r a n k$, jene werden dir, der Gottheit, Zorn (und) duši- nehmen, und je[ne] (= "schwere" Gerste etc.) werden ihn (= Zorn (und) dusi-) [ergrei]fen.» Zum Versorgen aber: ein $a$-a-an-Brot, ein Hülsenfruchtbrot, ein Süßbrot, eine Schale B[ier ...]."

Ein etwaiger Zorn der Gottheit soll der hier zugrundeliegenden Vorstellung zufolge mit einer kathartischen Pflanze (gangati-) von der Gottheit abgelöst werden und auf Feldfrucht und Trank übergehen, die aufgrund ihrer magischpositiven Beschaffenheit den magisch-negativen Zorn der Gottheit attrahieren.

159 Dies., aaO 87f; für weitere Belege von DINGIR ${ }^{\text {MES }}$-aš karpi- "Gơtterzorn" vgl. auch Hutter, Behexung, 28f.40f.44ff.

160 Die Kenntnis dieses Fragments verdanke ich H. Otten, dem ich darüberhinaus für die Genehmigung zur Konsultation der Sammlungen der Arbeitsstelle Hethitologie der Akademie der Wissenschaften und der Literatur zu Mainz zu Dank verpflichtet bin (G.W.).

161 V. Haas (briefl.) schlagt überzeugend vor, dies im Sinne von "reifer Gerste" zu verstehen.

$162 \mathrm{Vgl}$. Beckman, Birth rituals, 83. 
Ohne daß dies hier weiter verfolgt werden kann, sei doch darauf hingewiesen, $\mathrm{da} B$ diese Stelle eine höchst eigentümliche Interpretation des Sühnopfers erkennen läßt.

Auch in dem Gebet Muuattallis II. an den Gott Teššup von Kummanni KBo XI $1^{163}$ kommt die Vorstellung, göttlicher Zorn könne "gelöst" werden, zum Ausdruck:

1 DU EN AN KI LUGAL DINGIR MEŠ hal-zi-ina-u-en [nu-uș-si ḩa-ra-a-tar una-aš-túlrla!1 p[e-r]a-an ta[r-na-u-e-ni nu $\check{S}_{A}$ DU TUKU.TUKU-an pe-ra-an la-a-u-e-ni]

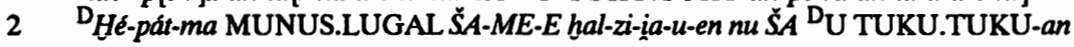
péra-an [I]a-a-[u-e-ni ...]

"Den Wettergott, den Herrn des Himmels und der Erde, den König der Götter, riefen wir, und Ärgernis und "Sünde" (uaštul) ges[tehen wir] ihm, [und des Wettergottes Zorn lösen wir.]

Hepat auch, die Konigin des Himmels, riefen wir, und den Zorn des Wettergottes $10[$ sen wir]."

Die Vorstellung des die Wirkungskraft der Gottheit einschränkenden Zorns und seiner magischen Lösbarkeit beherrscht auch den Mythos vom Wettergott und Fruchtbarkeitsbringer Telipinu und die verwandten Mythen. In dem rituellen Bemühen, den zornigen Gott von seinem Zorn zu befreien, ihn zur heilstiftenden Ausfüllung seiner Wirkungssphäre zurückzubringen und damit die durch das Verschwinden des erzürnten Gottes ausgelöste Unheilszeit zu beenden, sagt die Göttin Kamrušepa (Telipinu-Mythos, 1. Version = KUB XVII 10 III) ${ }^{164}$ :

$8 \quad n{ }^{\mathrm{D}}$ Te-li-pi-nu-i še-e-er ar-ha du-ua-a-an ua-ar-nu-nu-un

9 tu-ua-an-na ua-ar-nu-nu-un na-aš-ta ${ }^{\mathrm{D}}$ Te-li-pi-nu-i

10 tu-ug-ga-az-še-e-et i-da-a-lu-uš-š-it da-a-ah-hu-un uš-[d]u-ul-še-et

11 da-a-ah-hu-un kar-pi-iš-ša-an da-a-ah-hu-un kar-di-mi-ia-iat-ta-ša-an

12 da-a-ah-hu-un |va-ar-ku-us-sa-an da-a-ah-hu-un ša-a-u-ar da-a-a[h-hu-un]

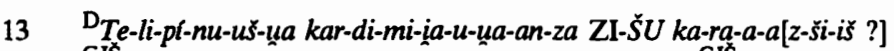

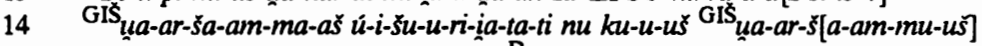

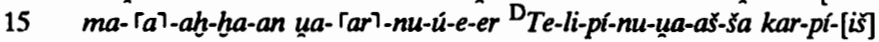

16 kar-di-mi-ina-az ua-aš-tu-ul ša-a-u-ar QA-TAM-MA ua-ra-a[-nu

"Ich habe für Telipinu hierhin und dorthin (Raucherwerk ?) verbrannt und Telipinu sein Boses aus seinem Leib genommen: Seine "Sünde" habe ich genommen, seinen Groll habe

${ }^{163}$ Houwink ten Cate / Josephson, Prayer, vgl. auch CHD L-N, 3b sub 2'; 4a sub 9c.

${ }^{164}$ Laroche, Mythologie, 94f; Kühne, Heth. Texte, 185. 
ich genommen, seinen Zorn habe ich genommen, seinen Grimm habe ich genommen, seine Wut habe ich genommen.

Telipinu ist zornig, sein Sinn und [seine] Eingeweide sind gebunden (wie) Reisig. Wie man nun dieses Reisig verbrannt hat, sollen auch Telipinus Groll, Zorn, "Sünde" und Wut aufbrennen!".

\section{Techniken der Mobilisierung von Miasma}

Zur Ablösung von Unreinheit stehen der südanatolischen Magie verschiedene Techniken zur Verfügung wie die eingangs erwähnte Anbringung verschiedenfarbener Wollfäden, durch die das Miasma abgeleitet wird, oder durch Ausspeien wie in den oben zitierten MUNUŠ̌U.GI-Ritualen.

Die Ablösung ist zumeist verbunden mit der Bereitstellung eines Lebewesens oder Gegenstandes, welche für die Unreinheit in besonderer Weise empfänglich sind oder durch magische Praktiken empfänglich gemacht werden. Hier sind zunächst Objekte zu nennen, die aufgrund ihrer natürlichen Reinheit, ihrer Ausgegrenztheit aus der Sphäre des Unreinen, dieses vorzüglich zu attrahieren und aufzunehmen vermögen. Reine Pflanzen finden in diesem Sinne Verwendung oder die elementare Reinigungssubstanz Wasser, die einen besonderen Reinheitsgrad dadurch erlangen kann, daß man zuvor Zweige reiner Pflanzen wie Tamariske und Ölbaum ${ }^{165}$ oder Stücke des als rein betrachteten Metalls Silber hineinlegt. ${ }^{166}$ Es kommen aber auch Tiere, seltener Menschen, oder deren figürliche Nachbildungen zur Aufnahme der abgelösten Unreinheit in Frage. Die Übertragung des Miasmas von der befallenen Person oder dem kontaminierten Objekt auf einen Träger oder - als Sonderfall des Trägers - ein Substitut geschieht durch verschiedene Techniken, die alle auf den Beziehungen der Analogie oder der Kontiguität beruhen. Der einfachste, wenn auch nicht der häufigste Übertragungsritus ist die Handauflegung, ${ }^{167}$ wie sie in dem eingangs genannten Pestritual des Ašḩella ${ }^{168}$

$165 \mathrm{Vgl.} \mathrm{KBo} \mathrm{V} 2$ III 42-45: (42) nu PA-NI KÁ.GAL ZAG-az Si-hni-i-il-<li->ịa-aš ú-i-da-a-ar (43) IŚ-TU GAL ar-ta-ri nu-kán GIŠšsINIG an-da ki-it-ta-ri (44) GÙB-la-az-ma I DUG.GAL GA.KU 7 ar-ta-ri (45) na-aš-ta ${ }^{\text {GIS }} S_{20^{-}}$ER-DUM an-da ki-it-ta-ri "Vor dem Tor steht rechts reines Wasser mit einem Becher, und (ein Zweig der) Tamariske ist hineingelegt; links aber steht ein Becher Süßmilch, und (ein Zweig vom) Ölbaum ist hineingelegt."

${ }^{166}$ KUB XXIX 8 III 56ff = Haas, itkahi und itkalzi, 97: EGIR-šU-ma-kán KÙ.BABBAR ku-it še-he-el-li-aš rú-i-te?-na-aš (57) an-da ki-it-ta-ri na-at-za-kán EN.SÍSK[UR] (58) an-da una-ahnu-zi "Danach aber schwenkt der Opfermandant das Silber, welches in reinem Wasser liegt, um sich herum." Für Silber als kathartische Substanz vgl. Haas / Wilhelm, Riten, 38-41.

${ }^{167}$ Eine andere Funktion hat die gleiche Geste im Zusammenhang eines Opfers. Hier legt der Opfermandant die Hand an das vom Priester darzubringende Opfer, um sich der Gottheit gegenüber als der Spender des Opfers auszuweisen; z.B. Rost, Familienzwist, 348f, Z. 19'; Salvini / Wegner, Rituale, Nr. 1 passim, 35-69. Zum Handauflegungsritus in der hebraischen Bibel und 
oder in der folgenden Passage aus dem Ritual gegen die Aphasie König Muršilis II. ${ }^{169}$ vorgeschrieben ist (KBo IV 2 III 53 ff. // KUB XV 36+ Vs. 7 ff. // KUB XII 31+ Vs. 5 ff. = Götze, Sprachlähmung, 6 f., Z. 15-17):

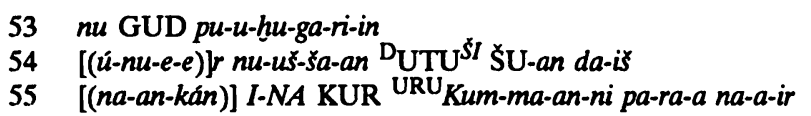

"Ein Rind schmückte man als Substitut (puhugari-), und die Majestăt legte die Hand darauf. In das Land Kummanni schickte man es los."

Die Handauflegung darf als Archetyp eines Übertragungsritus betrachtet werden, der in der außerordentlich elaborierten magischen Ritualistik Altanatoliens selten ist, ${ }^{170}$ weil hier wesentlich kompliziertere Übertragungsriten bevorzugt werden. Man vergleiche etwa die drei Tage währenden kunstvollen Manipulationen der Weisen Frau Alli aus Arzawa, die alle darauf abzielen, die durch Behexung an einem Menschen haftende Unreinheit von diesem auf Substitutspuppen zu transferieren. ${ }^{171}$

Die Beseitigung des nach der Übertragung der Unreinheit nunmehr kontaminierten Trägers ist der notwendige Abschluß der Handlung. Es ist dabei sorgfältig darauf $\mathrm{zu}$ achten, daß nicht dritte erneut kontaminiert werden, wie dies vom Hethitischen Gesetzbuch unter Strafe gestellt wird: "Wenn jemand einen Menschen (magisch) reinigt, schafft er auch die (Ritual-)Rückstände zum (Platz) der Verbrennung. Wenn er sie auf jemandes Feld oder Haus(wesen) schafft, (ist es) Behexung (und) gehört vor das Königsgericht." ${ }^{\text {172 }}$ Die Beseitigung kann durch Verbrennen oder Vergraben erfolgen oder durch Deponierung in unbebautem Land.

168

169 Götze / Pedersen, Sprachlahmung; mit Zusatzstücken neu bearbeitet von Lebrun, L'Aphasie (zur Handauflegung 133).

170 Vgl. noch die 3. Version des Maštigga-Rituals KBo XXIV 1 Vs. I 24 mit der Ergänzung von CHD L-N 376b: [nu-uš-sa-an I-NA SAG.DU ŠA] IUDU1 QA-TAM da-a-i nu UDU pa-ra-a 「tar-na $\rceil_{-a[n-z i]}$ "Sie (sc. die Beschwörerin) legt die Hand [auf den Kopf des Scha]fes, und man läßt das Schaf los."

171 Jakob-Rost, Malli. Für die außer dem Ausspeien oft praktizierte Übertragung mittels Wollfăden vgl. oben Anm. 1; für den Übertragungsritus des Schwenkens eines Trăgers über dem zu Reinigenden vgl. Haas / Wilhelm, Riten, 42-49; Haas, Magie, 245.

172 Friedrich, Gesetze, 30f, § 44b, vgl. Haas, Magie, 253. 


\section{Kathartische Rituale mit Vogelopfern und hurritischen Opfertermini}

In hethitischen kathartischen Ritualen, die aufgrund hurritischer Termini, teilweise auch aufgrund von Verfasserangaben, auf südanatolisch-hurritische Traditionen zurückzuführen sind, werden oft Vögel als Brandopfer, seltener als Blutopfer, dargebracht. In den Ritualanweisungen erscheinen dabei zahlreiche nicht-hethitische Wörter, die zumindest zu einem beträchtlichen Teil der hurritischen Sprache zugewiesen werden können. Sie sind zuerst von F. Sommer und $\mathrm{H}$. Ehelolf behandelt worden, die an Zweckbestimmungen oder Bezeichnungen für Gegenstände, Lokalitäten und vergöttlichte Abstrakta oder auch Götterbeinamen dachten. ${ }^{173} \mathrm{~A}$. Götze glaubte eine Präzisierung im Sinne von "Örtlichkeiten im Heiligtum" vornehmen zu dürfen. ${ }^{174}$ Angesichts der großen Zahl noch ungedeuteter Wörter dieser Art sowie der inzwischen semantisch geklärten Begriffe empfiehlt es sich, neutraler von "Opfertermini" zu sprechen. ${ }^{175}$ Eine beträchtliche Zahl der Opfertermini läßt sich aufgrund der deutbaren Wörter unterschiedlichen Wortfeldern zuordnen. So können Termini der Heils- und Herrschaftssphäre von solchen der Sünden- und Unreinheitssphäre in zahlreichen Fällen sicher abgegrenzt werden. Dazu kommen Termini, die Kultinventar und vielleicht auch kultische Örtlichkeiten bezeichnen. ${ }^{176}$

Als Beispiel sei wiederum eine Passage aus "Muršilis Sprachlähmung" geboten. Die Vogelbrandopfer finden hier statt, nachdem der König, der infolge göttlichen Eingriffs sein Sprechvermögen verloren hatte, einem Orakelbescheid folgend, ein Rind als Substitut gestellt und sich sieben Tage lang durch Waschungen gereinigt hatte. Die Vögel werden anscheinend am Aufenthaltsort des Königs verbrannt, während das zum Träger der Unreinheit gewordene Substitutsrind noch an den Kultort des erzürnten Gottes geführt wird. Der König ist zu diesem Zeitpunkt bereits gereinigt, doch ist die Unreinheit noch nicht aus der Welt. Nach der erst einige Tage später zu denkenden Ankunft des Rindes an seinem Bestimmungsort wird es verbrannt. Die Vogelopfer haben, wie im folgenden genauer auszuführen ist, die Funktion, zur dauerhaften Beseitigung der Unreinheit beizutragen.

\footnotetext{
173 Sommer / Ehelolf, Pāpanikri, 45.

174 Götze / Pedersen, Sprachlahmung, 43.

175 Haas / Wilhelm, Riten, 59-137, vgl. dazu Lebrun, L'Aphasie, 116-120.

${ }^{176}$ Haas / Wilhelm, aaO 59-137; die Liste der Opfertermini 317-319 laßt sich inzwischen noch erganzen: a-ga-an-t[i- KUB XLV 80:5' (vgl. in ugarit. Alphabetschrift agndym RS. 24.261:4-5 = Ugaritica 5, 499 = KTU Nr. 1.116), a-di-hi-ia KBo XXVII 201:10', iz-zi-hi-ia ibid. 9', naa-di-ia ma-al-di[- ibid. 3' u.a.m. Auch das rein hurritischsprachige Material liefert noch Ergănzungen.
} 
KBo IV 2 IV 1 ff. // KUB XV 36+ Vs. 23 ff. [28 f. abweichend] // KUB XII 31 Vs. 22 ff. = Götze, Sprachlähmung, 6-9, Z. 31-39:
1 MUŠEN
2 I MUŠEN a-ri-ija i-ta-ar-ki-įa I MUŠEN a-ri-ja mu-ut-ri-ja
3 I MUŠEN i-ni-ia i-ri-ri-ja I MUŠEN il-mi-ia pár-mi-ia
4 I MUŠEN $i$-ri-ill-te-hi-ia I MUŠEN $u$-la-hu-ul-zi-ia
5 I MUŠEN du-ua-an-te-hi-ia I SILA 4 ta-ha-si-ia du-ru-si-ia
6 I MUŠEN ki-bi-ǐ̌-si-ia pu-nu-hu-un-Si-ia I MUŠEN ga-me!-er-si-i-ja
7 I MUŠEN ta-ti-ia du-üa-ar-ni-ia II MUŠEN se-eri-di-hi-ia
8 se-ra-bi-hi-ia I MUŠEN $a-<n a->n i-i s ̌-h i-i a$ rbe $-e[n-d]$ i-[hi-i] $] a$
9 I SILA $A_{4} z u-z u-m a-k i-i a$ 「IŠ - $[(T U)$ IZI (una-ar-nu-m)]a-[a]n-zi
10 ki-ǐ̌-sa-an SIxSÁ-an-da-at

"Vögel aber verbrannte er folgendermaßen: Einen Vogel enummaš $(\zeta)$ iiina, einen Vogel ariia itarkiia, einen Vogel ariia mutriia, einen Vogel iniia iririia, einen Vogel ilmiia parmiia, einen Vogel iriltehiia, einen Vogel ulahulziia, einen Vogel tuuantehiia, ein Lamm $\operatorname{tah}(h) a^{\zeta}(\xi)$ iia turuš(s)iia, einen Vogel kibišsiia punuhunšiia, einen Vogel kameršiia, einen Vogel tatiia duuarniia, einen Vogel šerdihïa šerabihiia, einen Vogel $a<n a>n e s h i i i a ~ p e n d i h i i a$, ein Lamm zuzumakiiia; mit Feuer verbrannt zu werden, wurden sie auf diese Weise durch Orakel festgestellt."

Als weiteres Beispiel kann die folgende listenartige Ritualpassage gelten:

\section{KBo XXVII $191^{177}$ Vs. II}

$1 \quad A-N A{ }^{\mathrm{D}} U \zeta$-ki-du I MUŠEN na-a-si-ina [am-ba-aš-ši I UDU]

2 ke-el-di-iáa-ia-aš-ši ḩu-una-al-zi-[ia I UDU ?]

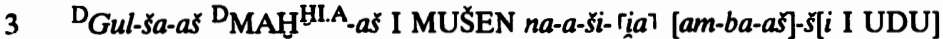

4 ke-el-di-ina-ia-as-ma-aš hu-u-ua-al-zi-ina [I ÛDU ?]

$\left\lceil A 1-N[A] \Gamma^{[}[\zeta s-h a 1-a-r a\right.$ I MUŠEN na-a-si-ia am-ba-aš-sii I UDU KI.MIN

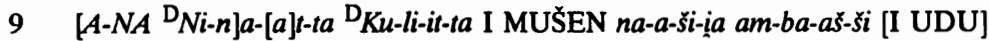

10 [ke-el-d]i-ia-ia-aš-ma-aš hu-una-al-zi-ina [I UDU ?]

11 [A-NA] $\mathrm{r}^{\mathrm{D}} \mathrm{É}, \mathrm{A}^{\mathrm{D}}$ Dam-ki-en-na I MUŠEN na-a-si-ina am-b[a-aš-ši I UDU KI.MIN]

${ }^{177}$ Eng verwandt sind KBo XIV 143 und KBo II 18 (vgl. Haas / Wilhelm, aaO 248-250); nach dem letzteren Text wurden die Zeilenenden ergănzt. 
"(1-2) Für (die Gottheit) Uskidu: ein Vogel našiia, [als Brandopfer ein Schaf,] und ihr zum keldi-Opfer huualzi[ia 1 Schaf(?)].

(3-4) Für die gulss- und MAH-(Schicksals-)Gottheiten: ein Vogel našịa, [als Brand]o[pfer ein Schaf,] und ihnen zum keldi-Opfer huualziia [1 Schaf(?)].

(5) Für (die Göttin) Işbara: ein Vogel našiia, als Brandopfer ein Schaf, desgl. (= und ihr zum keldi-Opfer huualziia 1 Schaf(?)).

(9-10) [Fur (die Göttinnen) Nin]atta (und) Kulitta: ein Vogel nasiia, als Brandopfer [ein Schaf], und ihnen zum [keld]i-Opfer buualziia [1 Schaf(?)].

(11) [Fur] (das Gơtterpaar) Ea und Damkina: ein Vogel našiia, als Brand[opfer ein Schaf, desgl.]."

Die bisher semantisch gedeuteten hurritischen Opfertermini in hethitischen Ritualen sind die folgenden: ${ }^{178}$ arni "Sünde" (< akkad. arnu, entspricht heth. uaštul), ilmi "(Mein-)Eid" (entspricht heth. lengai-), parili "Anstoß, Ärger" (entspricht heth. haratar); šarrašse "Königtum", allašše "Königinnentum", hanumašše "Gebärkraft"(??), uštašše "Heldentum"; hassissi "Weisheit" (< akkad. hasisu), itkalzi "Reinheit", issurzi "Schnelligkeit"(??), keldi "Heil, Wohlbefinden", pagrunzi "Güte"(?), pendigi "Recht, Gerechtigkeit", tag/hhašse "Männlichkeit", talah(h)ulzi "Reinigung", ${ }^{179}$ turušše "Mannhaftigkeit", tadi "Liebe"(?); agrušhi "Räuchergefäß", hubruş̧hi "Räucherofen, Gefäßständer", kešhi "Thron", nahhidi "Sitz"180, tuni "Fußschemel"(?), tabri "Stuhl"(?), ugri "Fuß (eines Thrones)"; hamri e. Heiligtum.

Alle Opfertermini zeigen den Ausgang -ia (-iia), der bereits von Sommer $^{181}$ und Götze ${ }^{182}$ als hethitische Endung des Dativ-Lokativ bei $i$-Stäm-

${ }^{178}$ Die Umschrift folgt dem in der Hurritologie verbreiteten Verfahren Speisers und Diakonoffs, bei dem die Unterscheidung von Mediae und Tenues, wie sie von semitischen Schreibern gehört wurden, berücksichtigt wird, obwohl es sich dabei im Hurritischen um nicht-phonemische, kombinatorische Varianten handelt. Es geht allerdings nicht an, die Allophonie nur bei solchen Konsonanten zu notieren, für die das deutsche Alphabet einen Buchstaben zur Verfugung stellt; wer also den Wettergott "Teß̌sub" (besser: Tēssob) umschreibt, muß auch den Mondgott als "Kužug" wiedergeben.

179 Dieser neue Bedeutungsansatz ist aus der von der hurritisch-hethitischen Bilingue KBo XXXII 15 IV/III 19 gebotenen Wiedergabe von hurr. $t a l=a h h$ - durch heth. uašrulaz parkunu- "von der Sünde reinigen" gewonnen und differenziert so die bereits von Haas / Wilhelm, Riten, 81f vorgenommene Zuordnung des Opferterminus zu den "Heilsbegriffen". Damit darf auch die Funktion des Vokals vor -lzi als geklärt gelten: - $a$ - steht bei "intransitven" Verben, -0- bei "transitiven", vgl. G. Wilhelm, Verbalsystem. Die Ritualbezeichnung itkalzi bedeutet demnach nicht "Reinigung", sondern "Reinheit".

180 Zur Bedeutung der Wurzel nahh- ("setzen; sich setzen") vgl. Neu, Das Hurritische $6 f .15$ Anm. 36.

181 Sommer / Ehelolf, Pāpanikri, 45.

182 Götze, Sprachlahmung, 42. 
men gedeutet wurde. Es steht außer Zweifel, daß diese Erklärung insofern richtig ist, als die Opfertermini auf -ia in hethitischen Texten der Großreichszeit sicherlich in diesem Sinne verstanden wurden. Hierfür sprechen Stellen in hethitischen Texten, die nicht-i-stämmige hethitische Entsprechungen hurritischer Opfertermini im Dativ-Lokativ auf $-i$ oder hurritische Opfertermini auf -ia mit vorangestellter akkadographischer Dativ-Lokativ-Kennzeichnung $A N A$ aufweisen, wie die folgenden Stellen des Pāpanikri-Rituals (KBo V ${ }^{183}$ ):

Kol. II

$2 n u$ II MUŠEN ha-ra-at-ni una-aš-du-li ua-ar-nu-ua-an-zi

"2 Vơgel verbrennen sie für Ärgernis (haratar) (und) Sünde (uastul)."

Kol. III

$27 n u$ MUŠEN.GAL A-NA ke-el-di-ina ku-un-za-ga-aš-si-ina

28 si-pa-an-ti

"Eine Ente opfert er für keldi (und) kunzagašşi."

V. Haas und G. Wilhelm haben allerdings darauf hingewiesen, da $\beta$ die hethitische Interpretation der Endung -ia bei hurritischen Opfertermini sekundär sein muß, da sie auch in (hurro-)akkadischen und hurritischen Texten auftritt, bei denen hethitische Beeinflussung ausgeschlossen werden kann. ${ }^{184}$ Die Endung bedarf daher auch einer hurritologischen Erklärung.

Das hurritische Kasusystem kennt einen "Essiv" auf $-a^{185}$, der in den Texten aus der osthurritischen Stadt Nuzi oft auch die Funktion eines Destinativs ("für", "zu") ausfüllt und mit der akkadischen Präposition ana verbunden wird. ${ }^{186}$ Die Essivendung - $a$ verdrängt einen vorausgehenden Vokal: $h i$ iarohhe "Gold" : hïiarohha "aus Gold". Ein vorausgehender Vokal kann nur erhalten bleiben, wenn er durch einen (Halb-)Konsonanten, z.B. - $\underline{i-}-$, geschützt

183 Sommer / Ehelolf, Pāpanikri.

184 Haas / Wilhelm, Riten, 130-134, vgl. Lebrun, L'Aphasie, 116f; Beckman, Birth rituals, 101.

185 Speiser, Introduction, § 156, bezeichnet den Kasus als "Stative"; ebenso Bush, Grammar, 145 148 und Diakonoff, Hurrisch, 96. Zur Bezeichnung "Essiv(-Destinativ)" vgl. Haas / Wilhelm, aaO 133; Neu, Essiv.

186 Vgl. Haas / Wilhelm, aaO 133. Die auf Speiser zurückgehende Annahme einer hurritischen Kasusendung auf -ia (Lokativ) beruht nur auf einer einzigen Stelle in fragmentarischem Kontext und ist durch das seitdem stark gewachsene hurritische Sprachmaterial nicht bestätigt worden, vgl. Speiser, Introduction, § 155; Bush, Grammar, 143-145; Diakonoff, Hurrisch 93-94; dagegen Laroche, Glossaire, 26; Wilhelm, Lexikographie, 488. Die Opfertermini selbst konnen nicht zur Bestătigung einer hurritischen Kasusendung -ia herangezogen werden (so Bush, Grammar 144), da in hurritischem Kontext Opfertermini erscheinen, die zusatzlich zu -ia(auch -ie-) noch die Ablativ-Instrumentalis-Endung -ne/i aufweisen, vgl. Wilhelm, AblativInstrumentalis, 110-112 (gegen Haas / Wilhelm, aaO 133). In diesen Fallen muß -ia- mit dem Possessivsuffix der 3. Ps. sg. (dazu vgl. Diakonoff, Hurrisch, 109) identifiziert werden, das bekannter ist in seiner hăufig im Mittani-Brief in nicht-akzentuierter Silbe begegnenden Form -ii.. 
ist. Es liegt demnach nahe, die Endung -ia (-iia) der Opfertermini als Folge von -ii (a)- (Poss.-suffix 3. Ps. sg.) und - $a$ (Essivendung) zu betrachten. Eine gewisse Bestätigung erfährt diese Deutung durch eine Stelle des bereits erwähnten und im folgenden noch ausführlich zu besprechenden Ritualtextes aus Alalah AlT. *126, wo der hurritische Opferterminus keldi "Heil, Wohlbefinden" in akkadischem Kontext erscheint. Es heißt dort (Z. 21-23, s. unten):

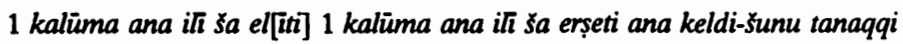

"Ein Lamm für die Gơtter der Hơhe (und) ein Lamm für die Gơtter der Unterwelt opferst du fur ihr (3. Ps. pl. m.) Wohlbefinden."

Ob den Verfassern und noch mehr den Rezipienten der großenteils wohl erst in der hethitischen Großreichszeit, also im 13. Jh. v.Chr., entstandenen oder kompilierten einschlägigen Rituale die ursprüngliche grammatische Form der Opfertermini noch durchsichtig war, darf bezweifelt werden. Wie schon gesagt, betrachteten sie sie wohl durchgängig als hethitische Dativ-Lokativformen von $i$-Stämmen. ${ }^{187}$ Vereinzelt werden die Opfertermini auch genetivisch auf die zu opfernden Vögel bezogen. Dabei können die hurritischen Lexeme als termini technici übernommen werden, wie es in den folgenden beiden Beispielen der Fall ist:

KUB XLV 51 II

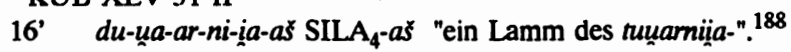

HT $24(+81)^{189}$ Vs. II

5 MUŠEN ${ }^{\text {HI.A }}$ pa-ar-li-ia-aš

$6 \quad \Gamma \Pi-N A$ É ${ }^{\mathrm{D}} \mathrm{U} \mathrm{URU}_{M a-n u-u[z-z i-j a]}$

${ }^{187}$ Es darf als ein Indiz für die Bestimmung der Opfertermini auf -ia in hethitischem Kontext als hethitische Dativ-Lokative gewertet werden, daß auch in Fallen eines pluralischen Bezugswortes die Endung -ia auftritt, wăhrend hier nach hurritischer Grammatik zusătzlich zu dem Possessivsuffix der 3. Ps. ein Pluralzeichen -az- erscheinen müßte, wie ja auch an der soeben zitierten Stelle ATT. *126:23 das akkadische Possessivsuffix der 3. Ps. pl. -šunu auf die Pluralităt der Götter Bezug nimmt. Zahlreiche Belege für die Endung -ia bei einer Pluralităt von zu reinigenden Gottern bietet das Evokationsritual für syrische Gottheiten KUB XV 34, z.B.

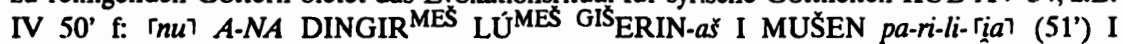
MUŠEN ar-ni-ịa ua-ar-nu-an-zi "Den männlichen Göttern "der Zeder" (sc. "des Zedernlandes", Nordsyriens) verbrennt man einen Vogel für Ärgernis (und) einen Vogel für Sünde."

ruuarni- ist ein Opferterminus unbekannter Bedeutung, der der positiven Sphäre ("Heilsbegriff") zuzuordnen ist, vgl. Haas / Wilhelm, Riten, 98-99.

189 Der Text ist, gewiß wegen der Erwăhnung der beiden Gottheiten Tešsub von Manuzzija und Lelluri, sub CTH 628 dem hišuua-Fest zugeordnet worden. Die Prateritalform in Z. 8 laßt aber eher an einen Bericht über die Durchführung eines Rituals nach Art des Textes ubber Mursilis Sprachlahmung denken, in dem dieselben Gottheiten im Mittelpunkt stehen, vgl. Götze, Sprachlahmung; Lebrun, L'Aphasie. 
$\begin{array}{ll}7 & \text { гĭ I-NA É }{ }^{\text {De-el-[lu-ri] }} \\ 8 & {[\text { La-a]r-nu-ut }}\end{array}$

"Vogel des Ärgernisses (parli-) [verbr]annte er im Tempel des Wettergottes von Manu[zzija] und im Tempel der Lel[luri]."

parli- geht auf hurritisches parili zuruck, das seine hethitische Entsprechung in haratar "Ärgernis, Anstoß" hat.

Einige Texte verbinden Vogelopfer nicht mit hurritischen, sondern mit hethitischen Opfertermini, bei denen es sich anscheinend um Übersetzungen handelt. Sie zeigen, daß die Semantik der Opfertermini den hethitischen Ritualverfassern der Großreichszeit noch bekannt war. Auch hier sind Sündenund Unreinheitsbegriffe neben solchen für die Heilssphäre zu finden:

\section{HT 24 + 81 Vs. II 8: MUŠEN ${ }^{\text {HI.A }}$ TUKU.TUKU-a[\$] "Vögel des Zorns".}

In dem bereits oben angeführten Ritual gegen eine durch Sodomie verursachte Unreinheit KUB XLI 11 Rs. 2'-30' heißt es: ${ }^{190}$

6. $\quad$... I UDU I MUŠEN ua-aš-t[ül-ä]

7. [I UDU I MUŠE]N hur-ti-ia-aš I MUŠ́EN $\mathrm{NA}_{4}$ 1-i RA-an-zi

8' [I UDU I MUŠEN-i]]a tâk-šl-la-aš I MUŠEN [a]m:si hur-ti-ia-ašs 0 ]

9' [I UDU I MUŠ] EN ua-aš-túl-aš I UDU! I MUŠEN [şa-a-an-da-aš

10' [x X I MUŠE]N NA ${ }_{4}^{-i}$ RA-an-zi I [MUŠ]EN hur-ti-riaj-aš

11' [I MUŠEN am-b]a-ǎs-ši ták-šu-la-ă̌ I [UD]U I MUŠEEN ku-ut-ru-e-eš-ni

12' [I MUŠEN iš-b]a-ah-ru-una-aš [I U]DU I MUŠEN na-ak-ku-us-sa-an tar-na$a[n-z i]$

"(6') ... Ein Schaf (und) ein Vogel [der] Sün[de,] (7') [ein Schaf (und) ein Voge]l der Verfluchung; den einen Vogel schlagt man auf den Stein. ( ${ }^{\prime}$ ) [Ein Schaf] un[d ein Voge]I des Friedens, ein Vogel der Verfluchung als ambašsi-Opfer, ( $9^{\prime}$ ) [ein Schaf (und) ein Vog]el der Sünde, ein Schaf (und) ein Vogel des Zorns; (10') [den einen Voge]l schlagt man auf den Stein. [Ein Vog]el der Verfluchung, (11') [ein Vogel] des Friedens als [amb]ǎšsi-Opfer; ein [Scha]f (und) ein Vogel am/für kutrueššar ${ }^{191}$, (12') [ein Vogel] der [Tr]anen; [ein Sch]af (und) einen Vogel läß[t man] als nakkušsa- los."

An dieser Stelle könnte der Einwand erhoben werden, daß wir uns mit der Erörterung bestimmter Opferformen von der Diskussion eliminatorischer Riten weit entfernt haben. Dies ist jedoch nur scheinbar der Fall. Eine Untersuchung der Funktion und Zweckbestimmung der Vogelopfer im Rahmen eines kathartischen Rituals führt nämlich, wie oben bereits angedeutet wurde, zu dem

$190 \mathrm{Vgl}$. Hoffner, Incest, 86f.

191 Vgl. ders., aaO 86: "(place of divine) witness". 
Ergebnis, daß das Vogelopfer im engsten Zusammenhang mit der Elimination steht.

Die für diese Auffassung entscheidende Textstelle entstammt einem Ritual zur Beseitigung der magischen Verunreinigung eines Hauses. ${ }^{192}$ Darin werden die Götter der Unterwelt aufgefordert, die zu eliminierende Unreinheit in Empfang zu nehmen und in der Unterwelt sicher zu verschließen. Die Herbeirufung der unterirdischen Götter findet an einer zuvor gegrabenen Grube (ābi-) statt. Dabei werden ihnen sowie der göttlichen Personifikation der Grube Vogelopfer mit folgenden Worten dargebracht:

\section{KBo X 45 Rs. III 41-47 (// KUB XLI 8 Rs. III 32-37):}

41 nu-za III MUŠEN da-a-i n[u-k]án II MUŠEN $A-N A{ }^{D^{2} \text { A.NUN.NAKE }} 4$

42 BAL-an-ti I MUŠEN-ma-kan $\Gamma_{A}$ ?-NA $\mathrm{D}_{A-a-b i} \mathrm{BAL}-a n-t i$

43 nu ki-iž-ša-an te-ez-zi šu-ma-aš-kán ka-ru-ú-i-li-eš-sa(-)mi-i $[t(-)$

44 Ú-UL-aš-ša-ma-aš-kán GUD-uš UDU-uš ki-it-ta-ri

45 DU-aš-ša-ma-aš-kán k[u]-ua-pi GAM-an-ta $\mathrm{GE}_{6}-i$ ták-ni-i

46 pé-en-né-eš-ta nu-[u]š-ma-aš-kán ki si-ip-pa-an-du-ua-ar

47 da-a-is

\section{$48 n u$ MUŠEN ${ }^{\mathrm{HI} . \mathrm{A}}$ IZI-it [za]-nu-zi na-as PA-NI DINGIR ${ }^{L M}$ da-a-i}

"Dann nimmt er drei Vơgel; zwei Vơgel opfert er den Unterirdischen, einen Vogel aber opfert er der Grubengottheit $(\bar{A} b i)$. Folgendermaßen spricht er: «Euch uralten .[... Nicht wird euch ein Rind (oder) ein Schaf hingestellt. Als der Wettergott euch hinab in die dunkle (Unter-)Welt trieb, da hat er euch diese Opferspende festgesetzt.»

Und er brat die Vogel am Feuer und legt sie vor die Gottheit." ${ }^{193}$

Diese Textstelle läßt den Schluß zu, daß die Vogelopfer in kathartischen Ritualen für die unterirdischen Götter bestimmt sind, die die Elimination und sichere Verwahrung der Unreinheit vornehmen sollen. ${ }^{194}$ Die im Zusammenhang mit den Vogelopfern auftretenden Reihen von Heils- und Unheilstermini sind daher auf das Objekt der Reinigung zu beziehen und als elliptische Ausdrücke im Sinne von "zur Bewahrung/Wiederherstellung seiner [Positivbegriffe] und zur Beseitigung seiner [Negativbegriffe]" aufzufassen.

\footnotetext{
192 Vgl. Otten, Beschworung.

193 Vgl. ders., aaO 130-133.

194 Vgl. Haas / Wilhelm, Riten, 53.
} 
5. Der hurritische Opferterminus azashu in dem altbabylonisch-hurritischen Vereidigungsritual AlT *126.

In einem teilweise noch schwer verständlichen akkadischsprachigen Ritual aus der nordsyrischen Residenzstadt Alalah am Orontes erscheinen Opferpraktiken zusammen mit hurritischen Opfertermini, die diesen Text in die Nähe der kathartischen Rituale mit Vogelopfern aus Hattuša stellen. Dies ist bedeutsam, weil der Text aus der Schicht VII von Alalah stammt, die von dem ältesten durch Eigenbezeugungen bekannten hethitischen König, Hattušili I., bereits um 1570 v.Chr. zerstört wurde. Der Text ist damit rund zwei Jahrhunderte älter als die ältesten Texte mit hurritischen Opfertermini aus Hattuša. Hiermit erweist sich auch für den speziellen Fall dieser hethitisch-hurritischen Textgruppe, da $B$ die zugrundeliegende Ritualtradition aus dem nordsyrischen Kulturraum stammt, eine Herkunft, wie sie für den größeren Teil des literarischen und religiös-magischen hurritischsprachigen Schrifttums aus Hattuša mit guten Gründen angenommen wird. Zuletzt haben die 1983 in Boğazköy gefundenen hurritisch-hethitischen Bilinguen ein Schlaglicht sowohl auf die hurritischsprachige Kultur Syriens in der ausgehenden Mittelbronzezeit als auch auf die Übernahme dieser Kultur durch die Hethiter in der Zeit um 1400 v.Chr. geworfen. ${ }^{195}$

Der Text AlT. *126 besteht, soweit verständlich, aus rituellen Vorschriften und ist daher als Ritual zu bestimmen. ${ }^{196}$ Die Einleitung läßt erkennen, daß es sich um ein Vereidigungsritual handelt:

Vs. ${ }^{\text {m }}$ Ia-ri-im-ii-im LUGAL

2 KI LÚ-lim a-hi-im ni-ǐ̌ dIŠKUR

3 ù $\mathrm{d} I S T A R$ i-pu-uš-m[a]

"Leistet der König Jarim-lim mit einem auswărtigen(?) Fürsten einen Eid beim Wettergott und bei Istar, ..."

Die erste Ritualhandlung wird anscheinend von einem oder für einen LÚ DUMU nakkušši durchgeführt. Da nakkušši nicht wie die im Text begegnenden Personennamen (Z. 1 und 8) determiniert ist, wird es sich um ein Appellativ, nicht ${ }^{197}$ um den in Alalah sonst gut bezeugten gleichlautenden Personennamen Nakkušše handeln. Die erste Ritualanweisung lautet folgendermaßen:

\footnotetext{
195 Vgl. Otten, Geistesweit; Neu, Das Hurritische. Für den Keilschrifttext vgl. H. Otten und Ch. Rüster, Bilingue; eine Bearbeitung von $\mathrm{E}$. Neu ist in Vorbereitung.

196 Gegen CAD A/1, 222b, wo der Text als Staatsvertrag ("OB treaty") bestimmt wird.

197 pace CAD N/1, 187a.
} 
10 ... ni-iq-qi LÚ DUMU na-ak-ku-si

11 [ 1 L]I 2 me-tiun MUŠEN.HI.A 4 ÙZ.HI.A

12 [x SI]LA 4 .HI.A 12 DUG hu-up-ru-us-hi

$131 M E$ DUG.GAL 3 ME DUG.ah-ru-uš-hi

14 ša İ.GIŠ ù İ.ŠAH ma-\{ú-\}lu-ú

15 SILA $_{4} u$ ÙZ.HI.A IZI $i-i k-k d-a l$

16 ni-iq-qi LÚ DUMU na-ak-ku-ứ-si

"(10) ... Das Opfer des mär nakkư̌ši: (11) [1]200 Vogel, vier Zicklein, (12) [x] Lămmer, zwölf Gefaßstănder, (13) 100 Becher, 300 Răuchergefăße, (14) welche mit Öl und Schweinefett ${ }^{198}$ gefült sind. (15) Die Lämmer und die Zicklein verzehrt das Feuer. (16) Opfer des mär nakkušši."

Nach einem Abschnittsstrich folgt eine ähnliche Ritualhandlung, die als "Opfer des azashum"199 bezeichnet wird:

17 i-na ni-iq-qi a-za-as-hi-[im]

181 LI 2 ME MUŠEN.ḦI.A 6 ÙZ.[HI.A]

u.Rd 19 ÙZ.HI.A IZI $i-i k-k d-[a l]$

Rs. 2012 DUG hu-up-ru-u[s-hi]

211 SILA $_{4}$ a-na DINGIR.MEŠ ša e-l[i-ti]

$221 \mathrm{SILA}_{4}$ a-na DINGIR.MEŠ sa er-șe- $\left.\lceil i\rceil\right]$

23 a-na ke-el-ti-šu-nu ta-na-aq-qi

24 šum-ma a-za-as-ḩa-am te-ep-pu-uš

25 [i-na] 「É1 LÚ-lim šu-ul-mu

"(17) Im Opfer des azashum: (18) 1200 Vogel, sechs Zicklein. (19) Die Zicklein verzehrt das Feuer. (20) Zwölf Gefaßstander. (21) 1 Lamm für die Gơtter der Ho[he] (22) 1 Lamm für die Götter der Unterwelt (23) opferst du für ihr Wohlbefinden (keldi). (24) Wenn du das azashum(-Opfer) durchfürst, (25) (wird) [im] Hause des Fürsten Wohlbefinden (šulmu) (sein)."

\section{Der folgende Paragraph endet mit der Warnung:}

$28[s u] m-m a$ a-za-as-ḩa ú-ul te-ep-pu-uš

29 aš-šum ni-ǐ̌ d IŠTAR en-na ú-ul ti-šu

"(28) Wenn du das azashum(-Opfer) nicht durchführst, (29) wirst du betreffs des Eides bei Istar keine Gnade haben."

198 Vgl. CAD A/1, 195a: "lard".

199 azashum wird hier nach dem oben Anm. 50 beschriebenen hurritologischen Umschriftverfahren wiedergegeben. Im Hurritischen sind Konsonanten (außer $r, l, m, n$ ) in Kontaktstellung stets stimmlos. Bei Annahme eines nicht-hurritischen Etymons ist daher zu beachten, daß die hurritische Form keinen Rückschluß zuläßt, ob dem zweiten Sibilanten die Media $|z|$, die Tenuis $/ s /$ oder die pharyngalisierte Tenuis $/ s ̦ /$ zugrundeliegt. 
Im nächsten, stark zerstörten Abschnitt ist wiederum von Vögeln, Zicklein, Bechern und einem Räuchergefäß die Rede. Der Abschnitt schließt mit einem hurritischen Opferterminus auf -ia: $1 \mathrm{SILA}_{4}$ ke-el-di-ia "1 Lamm für sein Wohlbefinden". Den Abschluß des Textes bildet eine Reinheitsvorschrift:

\section{o.Rd. 38 qa-ta-ka ú-ul me-si ${ }_{17}$}

39 a-na É dISTTAR te-ru-ub

I.Rd. $\quad 40$ i-na a-wa-ti ša-te t[a-sa]-an-ni-iq

"(38) Sind deine Hănde nicht gewaschen, (39) wenn du in den Tempel der IStar gehst, (40) stellst du diesen (Ritual-)Wortlaut in Frage."

Der Text beschreibt, soweit verständlich, nicht die Eidleistung, sondern die rituellen Vorkehrungen, die dabei im Tempel der Ištar als dem Ort der Vereidigung zu beachten sind. Die Riten selbst sind nur in knappster Form dargestellt, größtenteils werden nur die benötigten Opfertiere und Ritualgeräte aufgezählt. Dies unterscheidet den Text deutlich von den sehr genau und ausführlich beschreibenden Ritualen Anatoliens und spricht für die Vertrautheit der Ritualaktanten mit den auszuführenden Riten ebenso wie für eine frühe Position des Textes innerhalb der Formgeschichte der altorientalischen Ritualaufzeichnungen.

Die folgenden Merkmale verbinden den Text mit hethitisch-hurritischen kathartischen Ritualen südostanatolisch-nordsyrischer Herkunft:

1. Vögel und Lämmer als Opfertiere, wobei allerdings die außerordentlich hohe Zahl der Vögel ohne Parallele ist;

2. das Brandopfer, für das aber nur Zicklein und Lämmer ausdrücklich vorgesehen sind. Die Behandlung der Vögel wird nicht beschrieben, so daß wohl mit einer Schlachtung oder einem Brechen des Halses zu rechnen ist;

3. die mit hurritischen Wörtern bezeichneten Kultgeräte hubrušhi und agrušh i; 4. die Beopferung nicht nur der herrschenden Götter, sondern auch der Götter der Unterwelt;

5. die hurritischen Ritualtermini keldi "Heil, Wohlbefinden" und azashum, das im nächsten Abschnitt zu besprechen ist.

Diese Übereinstimmungen zwischen AIT. ${ }^{*} 126$ und den kathartischen Ritualen mit Vogel- und Lämmeropfern südostanatolischer Herkunft werfen die Frage nach der funktionellen Verwandtschaft zwischen beiden auf. Die allgemeinste Absicht kathartischer Riten ist, wie oben dargestellt, die Mobilisierung von Unreinheit. Ein Vereidigungsritual hat ebenfalls die Mächte der Unreinheit einzubeziehen, da der Eid im Alten Orient seinem Wesen nach ein Fluch, und zwar genauer eine bedingte Selbstverfluchung ist. Es werden Unheilsmächte mobilisiert, die im Falle des Eidbruchs den Vereidigten befallen sollen. Daher erscheint der Eid (hurr. e/ilmi) in hethitisch-hurritischen katharti- 
schen Ritualen oft in Reihen von Unheilsbegriffen wie "Sünde" (hurr. arni), "Blut(tat)" (hurr. surgi) und "Fluch" (hurr. sidarni). ${ }^{200}$

Angesichts der terminologischen und strukturellen Übereinstimmungen darf ein ritualgeschichtlicher Zusammenhang zwischen AIT. *126 und den hethitisch-hurritischen kathartischen Ritualen mit Vogelopfern südostanatolischer Herkunft als gegeben betrachtet werden. Die Priorität liegt dabei auf seiten des nordsyrischen Raumes, und dies nicht nur aufgrund des etwa um zwei Jahrhunderte höheren Alters der Tafel aus Alalah gegenüber dem ältesten vergleichbaren Material aus Boğazköy. Vielmehr spricht auch die Gesamtheit der kulturgeschichtlichen Beziehungen zwischen Nordsyrien und Anatolien im 2. vorchristlichen Jahrtausend für eine solche Priorität.

Das zweite Opferritual in AlT. ${ }^{*} 126$ wird als niqqi azashim "Opfer des a." (Z. 17) oder einfach als azashu $(m)($ Z. 24, 28) bezeichnet.

Mit seinen Endungen $-i($ Gen.) und $-a(m)$ (Akk.) erweist sich der Terminus zwar als akkadisch flektiert, doch fügt sich das Lexem azash- in kein akkadisches oder nordwestsemitisches Paradigma der Nominalbildung ein. Es liegt vielmehr nahe, an die zahlreichen Opfertermini zu denken, die auf -hi auslauten. Von den 206 bei Haas - Wilhelm, Riten, 317-319 als Opfertermini verbuchten Wörtern sind dies allein 60 . Ein großer Teil dieser -hi-Bildungen darf den hurritischen Zugehörigkeitsadjektiven auf $-\underline{h}(\boldsymbol{h}) e / i$ (nach Vokal, Nasal oder Liquida: -ge/i) zugerechnet werden. Es ist in unserem Zusammenhang besonders zu beachten, daß das Hurritische gelegentlich Wörter aus anderen Sprachen unter Suffigierung von -hi/e entlehnt hat. ${ }^{201}$

Als Ausgangslexem verbleibt demnach azas/z-. Ein solches Lexem ist in hurritischem Kontext oder in der hurritischen Nebenüberlieferung, abgesehen von den gleich zu besprechenden weiteren Belegen für dieselbe Weiterbildung auf -hi, nicht belegt. Zweisilbige hurritische Lexeme können sowohl bei Nomina als auch bei Verba in aller Regel auf ein einsilbiges Basislexem und eine semantisch modifizierende Wurzelerweiterung zurückgeführt werden. Eine Verbalwurzel az- unbekannter Bedeutung ist im Hurritischen vorhanden, doch ist sie nur selten bezeugt. ${ }^{202}$ Eine Wurzelerweiterung *-as/z- ist jedoch unbe-

$200 \mathrm{VgL}$ Haas / Wilhelm, Riten, 59-65.

201 Vgl. nathi zu sumer. ná(d) "Bett"; weniger wahrscheinlich uruthi zu sumer. urudu "Kupfer"; mehrere Pflanzennamen, zu denen akkadische Isoglossen vorhanden sind, gehen wohl nicht auf das Akkadische, sondern auf eine unbekannte sprachliche Quelle zurück, aus der auch das Akkadische geschöpft hat; dazu gehören: kanagithi zu akkad. kanaktu (e. aromatischer Baum), nurandigi zu nurimtu "Granatapfel"; šermingi zu akkad. šurnēnu "Zypresse".

202 Am deutlichsten in der Form $a z=\bar{a} \breve{t} t=o=m$ HT 93 r. Kol. 7, 8. Für weitere hier anzuschlieBende Formen meist unklarer Bildung vgl. Laroche, Glossaire, $66 \mathrm{f}$. 
kannt. Man könnte zwar an eine phonetische Umbildung des Morphemkomplexes $-a \zeta_{h} / i^{203} \mathrm{zu}^{*}$-ashe/i denken, wie sie tatsächlich vereinzelt bezeugt ist: ${ }^{204}$ da ein Abstraktum nicht direkt von der Verbalwurzel gebildet werden kann, müßte man allerdings ein Nomen *azi/a- ansetzen, das indes nicht belegt ist.

Eine hurritische Ableitung des Ausgangslexems azas/z- ist also nicht unproblematisch. Da außerdem der älteste Beleg des Wortes azashum aus einem semitischsprachigen Milieu stammt und das Hurritische nicht wenige Wörter darunter auch solche der religiösen Terminologie ${ }^{205}$ - aus dem Akkadischen entlehnt hat ${ }^{206}$, erscheint es legitim, auch eine semitische Etymologie in Betracht zu ziehen.

Der Terminus azashum erscheint ohne die akkadische Deklinationsendung und mit zwischen $a$ und $u$ schwankendem mittleren Vokal öfter in hurritischen Ritualen aus Boğazköy, die eine semantische Eingrenzung des Terminus ermöglichen. Er erscheint dort nämlich in einer Reihe von Opfertermini, welche deutlich der Negativsphäre angehören. Zunächst sind hier fünf Belege aus dem großen Ritualkompendium des Beschwörungspriesters ( $\left.{ }^{\mathrm{LU}} \mathrm{AZU}\right)$ zu nennen, das schon in seinem Titel itkalzi (hurr. "Reinheit") die Zugehörigkeit zu dem Gesamtkomplex der hier behandelten kathartischen Rituale erkennen läßt:

ar-ni a-zu-uz-hi [...].. zu-úr-ki KBo VIII 154 (= Haas, itkalzi, Nr. 38) 6-7

ar-ni az-zu-uz-hi KUB XXIX 8 (= Haas, itkalzi, Nr. 9) Rs. IV 14

ar-ni a-zu-uz-hi el-mi si-tar-ni KUB XXIX 8 (= Haas, itkalzi, Nr. 9) Rs. IV 20f

Vgl. noch in unverstăndlichem Kontext az-zu-uz-hi KUB XXIX 8 (= Haas, itkalzi Nr. 9)

Rs. IV 6; $a z-z u-u z-h a$ ibid. 16.

arni erweist sich durch die akkadisch-hurritische Bilinguis aus Ugarit ${ }^{207}$ als Lehnwort aus akk. arnu "Schuld", "Sünde". surgi ist von E. Laroche überzeugend als hurritische Entsprechung zu heth. ešhar "Blut" bestimmt worden. ${ }^{208}$ elmi wird gewiß zu Recht mit elami identifiziert, für das sich aus der genannten

$203 \mathrm{Vgl.} \mathrm{aštašhe} \mathrm{"weibliche} \mathrm{Attribute",} \mathrm{tah̆(h)ašhe} \mathrm{"mănnliche} \mathrm{Attribute";} \mathrm{aus} \mathrm{-ašše,} \mathrm{dem} \mathrm{Abstrakta}$ bildenden Suffix, und -ge, dem Suffix der Zugehorigkeitsadjektive, vgl. Wilhelm, Grundzüge, 73.

204 Der Opferterminus hano/umbashi ist wahrscheinlich ein Zugehorigkeitsadjektiv zu der ebenfalls als Opferterminus bezeugten Abstraktbildung hano/um(m)aše "Gebăr-/Zeugungskraft"; vgl. ohne Erklärung Haas / Wilhelın, Riten, 136f; Laroche, Glossaire 93. Ebenso sind dann wohl alo/umbashi, alo/ummashi und kilo/umbashi (beide unbekannter Bedeutung) zu analysieren.

205 Vgl. arni "Sünde" aus akk. arnu, hassissi "Weisheit" aus akk. hasisu.

206 Vgl. Diakonoff, Hurrisch, 77-80.

207 Nougayrol / Laroche, Bilingue.

208 Laroche, Études, 95-99, vgl. auch den Beitrag von V. Haas in diesem Band. 
Bilinguis eine Bedeutung "Eid", "Bann" (akkad. mamitu) ergibt. Daß dieses Wort in einem Negativzusammenhang erscheint, ist aus dem erwähnten Charakter des altorientalischen Eides als bedingte Selbstverfluchung abzuleiten. sidarni schließlich ist durch das viersprachige Syllabar aus Ugarit ${ }^{209}$ als "Fluch" (akk. arratu) bestimmt.

Die Identität der in AlT. ${ }^{*} 126$ bezeugten Form azashu(m) mit dem Unheilsterminus azushi des itkalzi-Rituals wird definitiv bestätigt durch das Fragment eines kathartischen Rituals für König und Königin, in dem die AusstoBung der Unreinheit durch Ausspeien erzielt wird ${ }^{210}$. In Rs.(?) 24' werden "9 Gefäßständer" (hubrušhi-s) genannt, wie sie auch in dem Ritual aus Alalah verwendet werden. In sonst weitgehend unverständlichem hurritischen Kontext begegnet eine Reihe von Negativbegriffen, die derjenigen der oben zitierten itkalzi-Passagen völlig parallel läuft, in der aber statt azushi das der akkadisierten Alalah-Form zugrundeliegende azashi steht:

Haas - Wegner, Beschwörerinnen, Nr. 111 Rs.? 20':

a-ar-ne a-za-az-hi e-el-me si-i-tar-ne [

"Sünde, azashi, (Mein-)Eid, Fluch".

In demselben Ritualkomplex, der von den Herausgebern, V. Haas und I. Wegner, mit der Beschwörerin MUNUŠ̌U.GI in Zusammenhang gebracht wird, begegnet das Wort azashi noch einmal in unklarem Zusammenhang (Nr. 59 Rs. III 22' (?), 108 Rs. 22'), einmal auch mit weiteren hurritischen Suffixen (azashe $=n e=v e=n a$ "die des $a . "$ Nr. 79 Vs. I 5').

\section{Hurritisch aza/ushi und semitisch' $z z$.}

Aufgrund der Schwierigkeit, azas/z- aus dem Hurritischen abzuleiten, sowie der Möglichkeit, daß es sich um ein semitisches Lehnwort handelt, weiterhin wegen der lautlichen Ähnlichkeit und der Bezeugung in funktional gleichem Kontext und im Kulturraum Nordsyriens, der dem Raum des Alten Testaments nicht fernsteht und mit diesem auch sonstige Verbindungen zeigt, erscheint es legitim, einen Zusammenhang zwischen aza/ush $u(m)$ und Azazel in Betracht zu ziehen.

\footnotetext{
209 Laroche, Documents, 455.

${ }^{210}$ Haas / Wegner, Beschwörerinnen, Nr. 111 Rs.(?) 9': al-la- 「ap?-[pa-ah-hii].
} 
Der Vokalwechsel in azas/z- und azus/z- ist auffällig; möglicherweise deutet er auf einen $o$-Vokal, den die akkadische Keilschrift normalerweise nicht zum Ausdruck bringt, da $O$ im Akkadischen keinen Phonemstatus hat. ${ }^{211}$

Bei einer semitischen Etymologie für azas/z- wird man zuerst an die Wurzel ' $z$ denken, von der auch die am meisten überzeugende Deutung der Wendung l-'zz'l ausgeht. Die semitische Wurzel ' $z z$ ist im Akkadischen durch das Verb ezēzu "zürnen/in Wut geraten" und Ableitungen wie ezzu "zornig", ezzetu "Wut", uzzu, uzzatu "Zorn" u.a.m. repräsentiert. Im Akkadischen bezieht sich die Wortsippe vor allem auf die Gefühlsäußerung von Göttern, Dämonen und Königen als Ausdruck einer ihnen innewohnenden besonderen Qualität. ${ }^{212}$ In Ebla ist ein Personenname A-zi-za öfter belegt, der gewiß zu Recht zu der Wurzel ' $z z$ gestellt wurde. ${ }^{213}$ Die Wurzel begegnet im phönizischen und syrisch-arabischen Raum in verschiedenen Ableitungen als Gottesname, z.B. als phönizisch 'Azöz, wozu wohl der im 7. Jh. v.Chr. keilschriftlich bezeugte Personennamen $A b-d i-{ }^{\mathrm{d}} A-z u-z i$ zu stellen ist, ${ }^{214}$ als Azizos in Edessa, Palmyra und sonst $^{215}$ oder als Name der noch bis in frühislamische Zeit verehrten Göttin $a l-' U z z \bar{a}$. Im Westsemitischen, so im Ugaritischen und Hebräischen, bezeichnet die Wurzel ebenfalls oft eine göttliche Qualität, die aber nicht in der Weise des Akkadischen negativ festgelegt ist, sondern auf die Macht und Stärke abhebt, die sich freilich auch hart und zornig veräußern kann.

Für den hurritischen Opferterminus aza/ushi paßt die akkadische Bedeutung der Wurzel ' $z z$ vorzüglich zu den parallelen Ausdrücken in der Serie von Unreinheitsbegriffen, da, wie oben ausgeführt, der Zorn der Gottheit als eine rituell ablösbare Unreinheit verstanden werden kann.

211 Zur Problematik schwankender $a$ - und $u$-haltiger Schreibungen, die als Wiedergabe von phonetischem $o$ bewertet wurden, vgl. von Soden / Röllig, Syllabar, XXIV, vgl. dazu B. Groneberg, Schreibungen. Das Hurritische kennt in seinem Phoneminventar zwar ein /o/, doch wird dieses nur in der Schule, aus der der sog. "Mittani-Brief" des Königs Tušratta (EA 24) hervorgegangen ist, durch das Vokalzeichen $U$ von dem Phonem $/ u$ / unterschieden, das durch das Zeichen Ú dargestellt wird. Die hurritischen Texte aus Bogazköy - mit Ausnahme der neuen hurritisch-hethitischen Bilinguen - kennen diese Unterscheidung ebensowenig wie die hethitischen Texte, in denen vielmehr $U$ und Ú promiscue verwendet werden. Vgl. aber jetzt A. Westenholz, The Phoneme /o/ in Akkadian, ZA 81 (1991) 10-19.

212 CAD E 428 b mit Lit.

213 Vattioni, Osservazioni, 200-203.

214 Vgl. Zadok, Phoenicians, 57f.

215 Vattioni, Osservazioni, 200f; Deiana, Azazel, 28 mit Anm. 60. 


\section{Von *"zz'l zu Azazel}

Die in Abschnitt III durchgeführte Untersuchung eliminatorischer Riten nach Texten des 14.-13. Jhs. v.Chr. aus der hethitischen Hauptstadt Hattuša hat gezeigt, daß dort eine spezifische ritualgeschichtliche Tradition greifbar wird, die im luwischsprachig-südanatolischen und im hurritischsprachig-nordsyrischen Raum wurzelt. Die hethitischen Ritualtexte syro-hurritischer Provenienz sind durch eine umfangreiche Terminologie von Reinheits- und Unreinheitsbegriffen charakterisiert, die herkömmlicherweise als "Opfertermini" bezeichnet werden, da sie im Rahmen eines kathartischen Rituals mit Opfern, und zwar vorzugsweise mit Vogelbrandopfern, verbunden sind. Diese Opfer sind den unterirdischen Gottheiten zugedacht, die durch Gebet und Magie dazu veranlaßt werden, die zu eliminierende Unreinheit sicher in der Unterwelt zu deponieren.

Viele der Opfertermini in hethitischen Ritualen sind aus der hurritischen Sprache abzuleiten, manche von ihnen finden sich auch in hurritischen Texten aus Hattuša. Die Bedeutung dieser Termini erhellt aus der Funktion des Entsühnungsrituals, nämlich "Unreinheit" zu eliminieren und "Reinheit" (wieder-)herzustellen. Zu den Unreinheitsbegriffen gehört auch das mehrfach in hurritischem Kontext begegnende Wort azashi oder azushi, dessen Endung -hi hurritisch ist, ohne daß das Lexem selbst aus dem Hurritischen abgeleitet werden könnte. $\mathrm{Da}$ das Hurritische der in Hattuša tradierten Rituale nicht wenige Lehnwörter semitischer Herkunft enthält, darf eine semitische Ableitung des Lexems azaz-, azuz- erwogen werden. Dabei ist vor allem an die akkadische Semantik dieser Wurzel zu denken (ezézu "zornig sein/werden"). Zorn der Gottheit ist nach hethitischen Quellen einerseits ein Gemütszustand der Gottheit in Reaktion auf eine menschliche Verfehlung, er wird aber auch selbst als ein Negativum betrachtet, das es im Ritual magisch zu eliminieren gilt. Es ist in dieser Perspektive nur natürlich, daß er neben "Sünde", "(Mein-) Eid" und "Fluch" genannt wird, wie dies für aza/ushi mehrfach belegt ist.

Nicht nur die hier vorgeschlagene Etymologie, sondern auch die Belegsituation weisen auf eine nordsyrische Herkunft dieses Wortes. Den ältesten Beleg bietet ein akkadischsprachiges Vereidigungsritual aus Alalah, für dessen Niederschrift die Zerstörung dieser Stadt in der ersten Hälfte des 16. Jhs. v.Chr. einen terminus ante quem darstellt. Der Text enthält mehrere hurritische Ritualtermini und weist in seinen rituellen Praktiken weitreichende Übereinstimmungen mit den rund drei Jahrhunderte jüngeren hethitischen Ritualen hurritischnordsyrischer Prägung auf. 
1. Die Präsenz des "Sündenbock"-Motivs im südanatolisch-nordsyrischen Raum

Nordsyrien (es ist hier die Rede von dem Raum zwischen dem Euphrat und dem Mittelmeer, dessen wichtigste Stadt seit dem frühen 2. Jt. v.Chr. Halab/ Aleppo ist) hatte bereits zur Zeit der altassyrischen Handelskolonien - zumindest in deren jüngerer Phase um 1730 v.Chr. - einen starken Bevölkerungsanteil mit hurritischen Personennamen ${ }^{216}$. Im Laufe der Mittleren Bronzezeit (1. Hälfte des 2. Jts.) bildete sich eine nordsyrische Kultur heraus, die alte bodenständige, in sprachlicher Hinsicht westsemitische Traditionen mit babylonischer Schriftkultur sowie mit der Sprache und in geringerem Maße den religiösen Traditionen hurritischer Zuwanderer verband. Diese heterogene, polyglotte Kultur war es, auf die die Hethiter bei ihren Versuchen stießen, sich das wirtschaftlich prosperierende Nordsyrien zu unterwerfen. Mit jeder Eroberung des Landes übernahmen sie Elemente seiner Kultur, am stärksten wohl im späten 15. und frühen 14. Jh. im Gefolge der Eroberungen Tuthalijas II.

Eine wichtige Vermittlerrolle nahm dabei das Land Kizzuuatna ein, das dem ebenen Kilikien und dem südlichen Teil Kappadokiens entspricht. Dieses Land war nicht lange nach 1500 v.Chr. vom Alten Reich der Hethiter abgefallen und in die Einflußsphäre des hurritischen Mittani-Reiches geraten, das im 15. Jh. das gesamte südlich des Taurus gelegene Regenfeldbaugebiet zwischen Mittelmeer und Zagros kontrollierte. In dieser Zeit wurden in Kizzuuatna Kulte und Riten aus den angrenzenden nordsyrischen Stadtstaaten, insbesondere Alalah und Halab, übernommen. Nach der Wiedereingliederung Kizzuuatnas in den hethitischen Staatsverband fanden diese Kulte und Riten auch in Hatti Verbreitung und Wertschätzung, zumal das hethitische Königshaus in dieser Zeit möglicherweise durch Heiratsverbindungen mit der Elite Kizzuunatnas - so weitgehend unter hurritischen Kultureinfluß geriet, daß Angehörige des Königshauses nicht selten hurritische Namen trugen und erst im Falle ihrer Thronbesteigung einen anatolischen Namen wählten.

Die Annahme, die in den elaborierten hethitisch-hurritischen Ritualen aus Boğazköy verarbeiteten Riten seien von nordsyrischen Vorbildern abhängig, harmoniert mit diesem Bild einer "Kulturtrift" von Syrien über Kizzuunatna nach Inneranatolien aufs beste. Dies bedeutet aber auch, da $B$ in den Texten aus Hattuša ein reiches Material für die Rekonstruktion sehr alter Ritualtraditionen des nordsyrischen Raumes vorliegen, die in einer Untersuchung alttestamentlich bezeugter kanaanäischer Ritualtraditionen nicht unberücksichtigt bleiben dürfen.

216 Dies geht am deutlichsten aus einem noch unverơffentlichten, im Kārum Kaniš (Kültepe) gefundenen Brief ( $k t k / k$ 4) nordsyrischer Herkunft hervor, den K. Hecker auf dem First International Congress of Hittitology in Çorum 1990 behandelt hat. 
Für den Ausdruck $l-2 z$ ' $l$ führt die seit langem vorgeschlagene Ableitung von ' $z z$ auf dem Hintergrund der hethitisch-hurritischen kathartischen Rituale nordsyrischen Ursprungs und des dort bezeugten wahrscheinlich wurzelidentischen Opferterminus aza/ushi zu einer sachlich befriedigenden Deutung, wenn man von der engeren akkadischen Semantik der Wurzel ausgeht. Der Ausdruck $l_{-}^{\prime} z z$ ' $l$ wäre dann auf eine ursprüngliche Zweckbestimmung des Eliminationsritus zurückzuführen, deren Bedeutung man etwa mit "für die Beseitigung von Gotteszorn" umschreiben könnte. $\mathrm{Da}$ im Mittelpunkt des Versöhnungstages ein Ritual zur Elimination göttlichen Zorns steht, dessen zentraler Terminus wiederum den göttlichen Zorn selbst bezeichnet, ist nach der zuvor dargelegten außerordentlich archaischen, aber im 2. Jt. v.Chr. gut bezeugten Auffassung vom Gotteszorn als einem magisch manipulierbaren Miasma sehr plausibel.

\section{Die Integration des "Sündenbock"-Motivs in die Ritualüberlieferung Lev 16}

Der ursprüngliche Kern des Eliminationsritus Lev 16,10.21f hat in der vorgetragenen Deutung Anteil an der religiös-magischen Vorstellungswelt Nordsyriens, wie sie in den von dort nach Anatolien entlehnten Ritualtraditionen greifbar werden. Der in diesem Zusammenhang tradierte zentrale Terminus dürfte allerdings schon früh nicht mehr verstanden worden sein. Bei dem Bemühen um sein Verständnis mag das Muster der gerade auch zur Bezeichnung dämonischer Wesen verwendeten El-Namen und der seit der jüngeren Königszeit verbreitete Namentyp "a $z a z-j a \bar{a} h \bar{u}^{217}$ von Bedeutung gewesen sein und die Interpretation im Sinne eines Wüstendämons vorbereitet haben.

Wie immer man sich den Überlieferungsweg dieser Ritualtradition vom spätbronzezeitlichen Nordsyrien ins eisenzeitliche Palästina/Israel im einzelnen vorzustellen hat ${ }^{218}$ - deutlich ist, da $\mathrm{B}$ sie religionsgeschichtlich $\mathrm{zu}$ dem hinter Lev 16,10.21f stehenden Konzept der rituellen Elimination von Unheil paßt, wie es auch in Ugarit und in Griechenland belegt ist ${ }^{219}$. Sollte dies zutreffen,

${ }^{217}$ Noth, Personennamen, 21.190.253 (Nr. 1043), vgl. Fowler, Personal Names, 82.354f u.ð. Zu $\mathrm{fl} /$ in Namen von Gottheiten, Engeln und Damonen s. J. Lewy, The Late Assyro-Babylonian Cult of the Moon and its Culmination at the Time of Nabonidus, HUCA 19 (1945/46) 405 489, hier: 429 Anm. 134, ferner Noth, aaO 82ff; Loretz, Leberschau, 54; Tigay, Gods, 83ff; Fowler, aaO 38ff.

218 Nicht das Faktum, wohl aber die năheren Umstände eines solchen "Ritualtransfers" sind strittig, s. zur Sache Moyer, Cultic Practices, 20f und Hoffner, Hittites, 213ff, bes. 218.

$219 \mathrm{~S}$. dazu oben 128 . 
so wäre damit zu rechnen, daß man die ursprüngliche Bedeutung des Ausdrucks לעואזל Lev 16,8.10(bis).26 als Zweckbestimmung jenes Eliminationsritus (= "für [die Beseitigung von] Gotteszorn") früh nicht mehr verstand und im Zuge der Überlieferungsbildung von Lev 16 von genuin israelitischen Verstehensvoraussetzungen her als Namen eines Dämons mit theophorem Element $/ 2 l /$ interpretierte ${ }^{220}$. Die Einbringung der "Azazel" genannten Gestalt hätte sich dann vermutlich am Motiv der "Wüste/Steppe" bzw. der "abgelegenen Gegend"221 entzündet, in die der - ursprünglich $l^{\prime} z^{\prime} z l$ "für (die Beseitigung von) Gotteszorn" bestimmte - Bock entlassen wird (Lev 16,8.10.26). Man käme bei diesem Vorschlag "sowohl ohne Eingriff in die phonetische Gestalt wie auch ohne kontextfremde Interpretation des Azazelnamens"222 aus und könnte auch die Überformung einer ursprünglich kanaanäischen Ritualtradition durch den nachexilischen Dämonenglauben - durchaus im Sinn der traditionellen Interpretation ${ }^{223}$ - plausibel machen.

Eine andere Frage, die jenseits der hier vorgetragenen Überlegungen liegt, ist die nach der Funktion des "Sündenbock"-Ritus auf der Ebene der Endgestalt von Lev $16^{24}$ - für die die Symmetrie der beiden Böcke hinsichtlich der Adressierungen - "für JHWH" und "für Azazel" (V.8-10) - charakteristisch ist. Es wäre eine eigene Aufgabe, die mit dem Bock "für JHWH" verbundenen Blutriten und den mit dem "Sündenbock" verbundenen Eliminationsritus Lev $16,10.21 \mathrm{f}$ als komplementäre Akte zu interpretieren ${ }^{225}$, die dem komplexen Gefüge Lev 16 seine unverwechselbare Gestalt und seine nachhaltige Wirkung verliehen haben.

\footnotetext{
220 Vgl. dazu oben Anm. 217.

$221 \mathrm{Vgl}$. dazu oben 113 mit Anm. 17.

222 Görg, Azazel-Ritus, 15.

223 Vgl. etwa Elliger, Leviticus, 212: "Nach dem Zusammenhang ist er (sc. Azazel) in der Wüste beheimatet und mindestens im Zeitalter des nachexilischen Monotheismus gewiß nichts anderes als ein Dämon", ferner z.T. Strobel, Sündenbock-Ritual, $161 \mathrm{ff} .165 \mathrm{ff}$, s. dazu aber oben $116 \mathrm{ff}$ und zur Sache auch die wichtigen Überlegungen von Wright, Disposal of Impurity, 24f; ders., Azazel.

$224 \mathrm{Zu}$ Lev 16 s. zuletzt Kiuchi, Purification Offering, 77ff.143ff; Gorman, Ideology, 61ff und $J$. Milgrom, Leviticus 1-16 (AB), New York 1991, $1009 \mathrm{ff}$.

225 S. dazu die Hinweise bei Leach, Kultur, 106ff, vgl. Janowski, Sühne als Heilsgeschehen, $268 \mathrm{f}$ mit Anm. 448.
} 
Quellennachweis zu den Abbildungen

1 C.M. Jones, Old Testament Illustrations, Cambridge 1971, 172 Fig. 196. Farbige Wiedergabe in: Bilder sind nicht verboten. Stădtische Kunsthalle Düsseldorf, Ausstellung vom 28.8.24.10.1982, Abb. 53.

2 a-b: Loud, Megiddo Ivories, Pl. 5, No. 4-5, vgl. Decainps de Mertzenfeld, Inventaire, 86 (zu pl. XXVIII, no. 320) und Keel, AOBPs ${ }^{4}, 73 \mathrm{Abb} .97$.

3 Keel, AOBPs ${ }^{4}, 74$ Abb. 97a.

4 Mayer-Opificius, Bemerkungen, 169 Abb. 10; Foto: aaO PI. 30 Ill. 1.

5 te Velde, Seth, 16 Fig.6.

\section{Bibliographie}

Aartun, K, Eine weitere Parallele aus Ugarit zur kultischen Praxis in Israels Religion, BiOr 33 (1976) 285-289

- Studien zum Gesetz über den großen Versöhnungstag Lev 16 mit Varianten. Ein ritualgeschichtlicher Beitrag, StTh 34 (1980) 73-109

Albertz, R., Religionsgeschichte Israels in alttestamentlicher Zeit I (GAT 8/1), Götingen 1992

Becknam, G.M., Hittite Birth Rituals (StBoT 29), Wiesbaden 1983

Blome, F., Die Opfermaterie in Babylonien und Israel, Rom 1934

Blum, E., Die Komposition der Vatergeschichte (WMANT 57), Neukirchen-Vluyn 1984

Bonnet, $H$., Art. Seth, RÄRG, 702-715

van den Borm, A., Art. Azazel, BL ${ }^{2}$ (1968) $155 f$.

Bremmer, J., Scape-Goat Rituals in Ancient Greece, HSCP 87 (1983) 299-320

van Brock, N., Substitution rituelle, RHA 17 fasc. 65 (1959) 117-146

Brunner, H., Seth und Apophis - Gegengotter im agyptischen Pantheon?, Saec. 34 (1983) 226-234

Brunner-Traut, E., Art. Esel, LÄ II (1977) 27-30

Burkert, W., Homo Necans. Interpretationen altgriechischer Opferriten und Mythen (RGVV 32), Berlin / New York 1972

- Opfertypen und antike Gesellschaftsstruktur, in: G. Stephenson (Hg.), Der Religionswandel unserer Zeit im Spiegel der Religionswissenschaft, Darmstadt 1976, 168-187

- Griechische Religion der archaischen und klassischen Epoche (RM 15), Stuttgart / Berlin / Koln / Mainz 1977

- Structure and History in Greek Mythology and Ritual, Berkeley / Los Angeles / London 1979

- Anthropologie des religiösen Opfers. Die Sakralisierung der Gewalt, in: H. Rössner (Hg.), Der ganze Mensch. Aspekte einer pragmatischen Anthropologie (dtv 4447), München 1986, 205 227

Bush, F.W., A Grammar of the Hurrian Language, Dissertation Brandeis University 1964

Caminos, RA., Late Egyptian Miscellanies, Brown Egyptological Studies 1 (1954) 
Davies, D., An Interpretation of Sacrifice in Leviticus, ZAW 89 (1977) 387-398

Deiana, G., Azazel in Lv 16, Lat. 54 (1988) 16-33

Decamps de Mertzenfeld, $C$., Inventaire commenté des ivoires phéniciens et apparentés découverts dans le Proche-Orient, Texte, Paris 1954

Derchain, Ph, Le Papyrus Salt 825 (B.M. 10051), rituel pour la conversation de la vie en Egypte, Fasc.I, Bruxelles 1965

Diakonoff, I.M., Hurrisch und Urartäisch (MSS Beih. 6 N.F.), München 1971

Dietrich, M. / Loretz, O., Mantik in Ugarit. Keilalphabetische Texte der Opferschau - Omensammlungen - Nekromantie. Mit Beiträgen von H.W. Duerbeck, J.-W. Meyer und W.C. Seitter (ALASP 3), Münster 1990

- Ugaritische Omentexte, in: TUAT II (1991) 94-101

Dinçol, A.M., Aşbella rituali (CTH 394) ve Hititlerde salgın hastalıklara karsı yapılan majik ișlemlere toplu bir bakıs, Belleten 49/193 (1985) 1-40

Donner, $H$., Geschichte des Volkes Israel und seiner Nachbarn in Grundzügen (GAT 4), Göttingen 1987

Duhm, H., Die bősen Geister im Alten Testament, Tübingen / Leipzig 1904

Ehelolf, $H . \rightarrow$ Sommer, $W$.

Eiffeldt, O., Zur Deutung von Motiven auf den 1937 gefundenen Elfenbeinarbeiten von Meggido (1950), in: ders., Kleine Schriften III, Tübingen 1966, 85-93

Elliger, $K$, Leviticus (HAT I/4), Tübingen 1966

Engelhard, D.H., Hittite Magical Practices: An Analysis, Dissertation Brandeis University 1970

Fecht, G., Literarische Zeugnisse zur "Persönlichen Frömmigkeit" in Ägypten, AHAW.PH Jahrgg. 1965, 1.Abh.

Fischer, H.G., The Ancient Egyptian Attitude Towards the Monstrous, in: Monsters and Demons in the Ancient and Medieval Worlds (FS E. Porada), ed. by A.E. Farkas, P.O. Harper and E.B. Harrison, Mainz 1987, 13-26 (mit PI. I-VI)

Fischer-Elfert, H.-W. (Hg.), Literarische Ostraka der Ramessidenzeit in Übersetzung, Wiesbaden 1986, 8-12

Fohrer, G., Geschichte der israelitischen Religion, Berlin 1969

Fowler, J.D., Theophoric Personal Names in Ancient Hebrew. A Comparative Study (JSOT.S 49), Sheffield 1988

Frazer, J.G., Der goldene Zweig. Eine Studie über Magie und Religion, Köln / Berlin 1968

Friedrich, J., Aus dem hethitischen Schrifttum. Übersetzungen von Keilschrifttexten aus dem Archiv von Boghazkoi, 2. Heft: Religiose Texte (AO 25/2), Leipzig 1925

- Die hethitischen Gesetze (DMOA 7), Leiden ${ }^{2} 1971$

Gaster, Th.H., Azazel, IDB I (1962) 325f

Gebhard, V., Die Pharmakoi in Ionien und die Sybkachoi in Athen, Amberg 1926

- Hethitische Sündenbocke, ARW 29 (1931) 243

Girard, R., Der Sündenbock, Zürich 1988 (frz.: Le bouc émissaire, Paris 1982)

Görg, M., Art. ר⿱ִ usw., ThWAT I (1973) 1001-1004

- Beobachtungen zum sogenannten Azazel-Ritus, BN 33 (1986) 10-16

- Art. Asasel, Neues Bibellexikon I (1991) 181f

Goetze, A. / Pedersen, H., Mursilis Sprachlahmung (DVSS.PH 21/1), København 1934

- Kulturgeschichte Kleinasiens (HdA III/2), München ${ }^{2} 1957$

Gorman, F.H., The Ideology of Ritual. Space, Time and Status in the Priestly Theology (JSOT.S 91), Sheffield 1990

Grabbe, L.L., The Scapegoat: A Study in Early Jewish Interpretation, JSJ 18 (1987) 152-167 
Grieshammer, R., Rechts und links (Symbolik), LÄ IV (1984) 191-193

Groneberg, B., Zu den "Gebrochenen Schreibungen", JCS 32 (1980) 151-167

Gurney, O.R., Some Aspects of Hittite Religion. The Schweich Lectures of the British Academy 1976, Oxford 1977

- The Hittites (Penguin Books), London 1990 (rev. Ausgabe von ${ }^{2} 1954$ )

Haas, $V$. , Hethitische Berggotter und hurritische Steindămonen. Riten, Kulte und Mythen (Kulturgeschichte der Antiken Welt 10), Mainz 1982

- Die Serien itkahi und itkalzi des AZU-Priesters, Rituale für Tašmišarri und Tatuhepa sowie weitere Texte mit Bezug auf Tašmišarri (Corpus der hurritischen Sprachdenkmäler I/1), Roma 1984

- Magie und Zauberei. B. Bei den Hethitern, RIA VII/3-4 (1987-90) 234b-255a

- / Wegner, I., Die Rituale der Beschwörerinnen SALŠU.GI (Corpus der hurritischen Sprachdenkmäler I/5), Roma 1988

- / Wilhelm G., Hurritische und luwische Riten aus Kizzuwatna. Hurritologische Studien I (AOATS 3), Kevelaer / Neukirchen-Vluyn 1974

Heinz, H. / Kienzler, K. / Petuchowski, J.J. (Hg.), Versöhnung in der jüdischen und christlichen Liturgie (QD 124), Freiburg / Basel / Wien 1990

Hengel, M., The Atonement. A Study of the Origins of the Doctrine in the New Testament, London 1981

Herrmann, S., Israels Frühgeschichte im Spannungsfeld neuer Hypothesen, Opladen 1988

Hoffner, H.A. Jr., Incest, Sodomy and Bestiality in the Ancient Near East, in: Orient and Occident. Essays presented to Cyrus H. Gordon (AOAT 22), Kevelaer / Neukirchen-Vluyn 1973, 81-90

- The Hittites and Hurrians, in: D.J. Wiseman (Ed.), Peoples of Old Testament Times, Oxford $2_{1975,197-228}$

Hornung, E., Licht und Finsternis in der Vorstellungswelt Altägyptens, StGen 18 (1965) 73-83

- Art. Dunkelheit, LÄ I (1975) $1153 f$

- Seth. Geschichte und Bedeutung eines ägyptischen Gottes, Symbolon 2 (1975) 49-63

Houwink ten Cate, Ph.H.J. / Josephson, F.J., Muwatallis' Prayer to the Storm-God of Kummanni (KBo XI 1), RHA 25 fasc. 81 (1967) 101-140

Hutter, M., Behexung, Entsühnung und Heilung. Das Ritual der Tunnawiya für ein Königspaar aus mittelhethitischer Zeit (KBo XXI 1 - KUB IX 34 - KBo XXI 6) (OBO 82), Freiburg (Schweiz) / Gottingen 1988

Janowski, B., Sühne als Heilsgeschehen. Studien zur Sühnetheologie der Priesterschrift und zur Wurzel KPR im Alten Orient und im Alten Testament (WMANT 55), Neukirchen-Vluyn 1982

- Rettungsgewißheit und Epiphanie des Heils. Das Motiv der Hilfe Gottes "am Morgen" im Alten Orient und im Alten Testament, Bd.I: Alter Orient (WMANT 59), Neukirchen-Vluyn 1989

- Azazel - biblisches Gegenstück zum agyptischen Seth? Zur Religionsgeschichte von Lev 16,10.21f., in: Die Hebraische Bibel und ihre zweifache Nachgeschichte (FS R. Rendtorff), hg. von E. Blum, Chr. Macholz und E.W. Stegemann, Neukirchen-Vluyn 1990, 97-110

Josephson, F.J. $\rightarrow$ Houwink ten Cate, Ph.H.J.

Kammenhuber, A., Ketten von Unheils- und Heilsbegriffen in den luwischen magischen Ritualen (anlaßlich der neuen luwischen Fragmente aus KBo XXIX [1983], II §§4-6), Or. 54 (1985) 77 105

Kaupel, H., Die Damonen im Alten Testament, Augsburg 1930 
Keel, O., Jahwes Entgegnung an Ijob. Eine Deutung von Ijob 38-41 vor dem Hintergrund der zeitgenossischen Bildkunst (FRLANT 121), Gottingen 1978

- Die Welt der altorientalischen Bildsymbolik und das Alte Testament. Am Beispiel der Psalmen, Zürich / Einsiedeln / Köln / Neukirchen-Vluyn ${ }^{4} 1984$

- Zur Identifikation des Falkenkopfigen auf den Skarabäen der ausgehenden 13. und 15. Dynastie, in: ders. / H. Keel-Leu / S. Schroer, Studien zu den Stempelsiegeln aus Palästina/Israel, Bd.II (OBO 88) Freiburg (Schweiz) / Göttingen 1989, 243-280

Kessler, D., Art. Himmelsrichtungen, LÄ II (1977) 1213-1215

Kienzler, $\boldsymbol{K} \rightarrow$ Heinz, $H$.

Kiuchi, N., The Purification Offering in the Priestly Literature. Its Meaning and Function (JSOT.S 56), Sheffield 1987

Klengel, $H ., \mathrm{Zu}$ einem Ablenkungszauber bei Krankheit im hethitischen Heer (KUB LIV 65), AoF 11 (1984) 174-176

Koch, K, Art. Asasel, BHH I (1962) $135 f$

Köckert, M., Vătergott und Văterverheißungen. Eine Auseinandersetzung mit Albrecht Alt und seinen Erben (FRLANT 142), Göttingen 1988

Kühne, $C$., Hethitische Texte, in: Religionsgeschichtliches Textbuch zum Alten Testament, hg. $W$. Beyerlin (GAT 1), Gơttingen ${ }^{2} 1985,169-204$

Kümmel, H.M., Ersatzrituale für den hethitischen König, StBoT 3 (1967)

- Ersatzkơnig und Sündenbock, ZAW 80 (1968) 289-318

- Die Religion der Hethiter. Grundzüge und Probleme, in: U. Mann (Hg.), Theologie und Religionswissenschaft. Der gegenwartige Stand ihrer Forschungsergebnisse und Aufgaben im Hinblick auf ihr gegenseitiges Verhaltnis, Darmstadt 1973, 65-85

Kutsch, E., Art. Sündenbock, RGG $^{3}$ VI (1962) $506 f$

Landersdorfer, S., Studien zum biblischen Versohnungstag, ATA 10,1 (1924)

- Keilschriftliche Parallelen zum biblischen Sündenbock (Lev 16), BZ 19 (1931) 20-28

Lang, B., Spione im gelobten Land: Ethnologen als Leser des Alten Testaments, KZS 26 (1984) 158-177

Laroche, $E$. Textes mythologiques hittites en transcription (1): Mythologie anatolienne, RHA 23 fasc. 77 (1965) 62-176

- Documents en langue hourrite provenant de Ras Shamra, in: Ugaritica 5 (= MRS 16), Paris $1968,447-544$

- Etudes de linguistique anatolienne, RHA 31 (1973) 84-99

- Glossaire de la langue hourrite (Etudes et commentaires 93), Paris 1980

- Hittite nakkuš - nakư̌šiš, in: Kanišuwar. A tribute to Hans G. Güterbock on his seventy-fifth birthday (AS 23), Chicago 1986, 137-140

- $\rightarrow$ Nougayrol, $J$.

Leach, E., Kultur und Kommunikation. Zur Logik symbolischer Zusammenhänge (stw 212), Frankfurt a.M. 1978

Lebrun, $R$, Samuha. Foyer religieux de l'empire hittite (PIOL 11), Louvain-La-Neuve 1976

- L'aphasie de Mursili II = CTH 486, Hethitica 6 (1985) 103-137

Lewy, J., The Late Assyro-Babylonian Cult of the Moon and its Culmination at the Time of Nabonidus, HUCA 19 (1945/46) 405-429

Lohfink, N. (Hg.), Gewalt und Gewaltlosigkeit im Alten Testament (QD 96), Freiburg / Basel / Wien 1983

- "Gewalt" als Thema alttestamentlicher Forschung, in: ders. (Hg.), Gewalt und Gewaltlosigkeit im Alten Testament (QD 96), Freiburg / Basel / Wien 1983, 15-50

- Der gewalttătige Gott des Alten Testaments und die Suche nach einer gewaltfreien Gesellschaft, JBTh 2 (1987) 106-136 
Loretz, O., Leberschau, Sündenbock, Asasel in Ugarit und Israel. Leberschau und Jahwestatue in Psalm 27, Leberschau in Psalm 74 (UBL 3), Altenberge 1985

- Ugarit und die Bibel. Kanaanäische Gotter und Religion im Alten Testament, Darmstadt 1990

- $\rightarrow$ Dietrich, $M$.

Loud, G., The Megiddo Ivories (OIP 52), Chicago 1939

Mayer-Opificius, $R$, Bemerkungen zur mittelassyrischen Glyptik des 13. und 12. Jahrhunderts v. Chr., in: Insight through Images (FS E. Porada), ed. by $M$. Kelly-Buccellati in Collaboration with P. Matthiae and M. van Loon (Bibliotheca Mesopotamica 21), Malibu/CA 1986, 161-169 Meinhold, J., Joma (Der Versöhnungstag). Text, Übersetzung und Erklärung (Die Mischna II/5), Gießen 1913

de Moor, J.C., Demons in Kanaan, JEOL 27 (1981-82) 106-119

Morenz, S., Rechts und links im Totengericht, in: ders., Religion und Geschichte des alten Ägypten. Gesammelte Aufsatze, hg. von E. Blumenthal und S. Hermann, Koln / Wien 1975, 281-294

Moyer, J.C., The Concept of Ritual Purity among the Hittites, Dissertation Brandeis University 1969

- Hittite and Israelite Cultic Practices: A Selected Comparision, in: W.W. Hallo / J.C. Moyer / L.G. Perdue (Ed.), Scripture in Context II. More Essays on the Comparative Method, Winona Lake/IN 1983, 19-38

Neu, E., Das Hurritische: Eine altorientalische Sprache in neuem Licht (AAWLM.G 1988/3), Mainz / Stuttgart 1988

- Zum hurritischen "Essiv" in der hurritisch-hethitischen Bilingue aus Hattuša, Hethitica 9 (1988) $157-170$

Noth, M., Die israelitischen Personennamen, Stuttgart 1928

- Das dritte Buch Mose. Leviticus (ATD 6), Gottingen ${ }^{2} 1966$

Nougayrol, J. / Laroche, E., Le bilingue accado-hourrite, in: PRU 3 (= MRS 6), Paris 1955, 310324

Otten, H., Eine Beschwơrung der Unterirdischen aus Bogazköy, ZA 54 (1961) 114-157

- Blick in die altorientalische Geisteswelt. Neufund einer hethitischen Tempelbibliothek (JAWG 1984), Gottingen 1985, 50-60

Otto, E., Art. Asasel, $\mathrm{RBL}^{4}$ (1978) 52

- Feste und Feiertage II, TRE XI (1983) 96-106

- Historisches Geschehen - Uberlieferung - Erklarungsmodell. Sozialhistorische Grundsatz- und Einzelprobleme in der Geschichtsschreibung des frühen Israel - Eine Antwort auf N.P. Lemches Beitrag zur Diskussion um eine Sozialgeschichte Israels, BN 23 (1984) 63-80

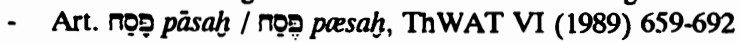

- Israels Wurzeln in Kanaan. Auf dem Weg zu einer neuen Kultur- und Sozialgeschichte des antiken Israels, ThRv 85 (1989) 3-10

- (/ T. Schramin), Fest und Freude (Biblische Konfrontationen), Stuttgart / Berlin / Köln / Mainz 1977, 9-76.162-165

Ottosson, M., Eden and the Land of Promise, VT.S 40 (1988) 177-188

Pedersen, $H$. $\rightarrow$ Goetze, $A$.

Petuchowski, J.J. $\rightarrow$ Heinz, $H$.

Reymond, Ph., L'eau, sa vie et sa signification dans l'Ancien Testament (VT.S 6), Leiden 1958 
Ritter, H.-A., Der Sündenbock. Mechanismus oder Schuldverarbeitung?, PTh 75 (1986) 110-115 Röllig. $W$. $\rightarrow$ von Soden, $W$.

Rogerson, J.W., Sacrifice in the Old Testament, in: M.F.C. Bourdillon / M. Fortes (ed.), Sacrifice, London 1980, 45-59

Rost, L., Weidewechsel und altisraelitischer Festkalender (1943), in: ders., Das kleine Credo und andere Studien zum Alten Testament, Heidelberg 1965, 101-112

- Art. Versöhnungstag, BHH III (1966) 2098

- Ein hethitisches Ritual gegen Familienzwist, MIO 1 (1953) 345-379

- Das Ritual der Malli aus Arzawa gegen Behexung (KUB XXIV 9+) (THeth 2), Heidelberg 1972

Salvini, M. / Wegner, I., Die Rituale des AZU-Priesters (Corpus der hurritischen Sprachdenkmäler I/2), Roma 1986

Sayce, A.H., The Scapegoat among the Hittites, ET 31 (1919) $283 \mathrm{f}$

Schramm, T. $\rightarrow$ Otto, E.

Schroer, S., In Israel gab es Bilder. Nachrichten von darstellender Kunst im Alten Testament (OBO 74), Freiburg (Schweiz) / Göttingen 1987

Schwager, $R$., Brauchen wir einen Sündenbock? Gewalt und Erlosung in den biblischen Schriften, München 1978

von Soden, W. / Röllig, W., Das akkadische Syllabar (AnOr 42), Rom ${ }^{4} 1991$

Sommer, F. / Ehelolf, H., Das hethitische Ritual des Päpanikri von Komana (KBo V 1 = Bo 2001) (BoSt 10), Leipzig 1924

Speiser, EA., Introduction to Hurrian (AASOR 20), New Haven 1941

Starke, $F$., Untersuchung zur Stammbildung des keilschriftlich-luwischen Nomens (StBoT 31), Wiesbaden 1991

Staubli, Th, Das Image der Nomaden im Alten Israel und in der Ikonographie seiner seßhaften Nachbarn (OBO 107), Freiburg (Schweiz) / Göttingen 1991

Strobel, A., Das jerusalemische Sündenbock-Ritual. Topographische und landeskundliche Erwägungen zur Überlieferungsgeschichte von Lev. 16,10.21f., ZDPV 103 (1987) 141-168

Szabo, G., Ein hethitisches Entsühnungsritual für das Konigspaar Tuthaliia und Nikalmati (THeth 1), Heidelberg 1971

Talmon, Sh, Art. מִרְּר, ThWAT IV (1984) 660-695

- Har and Midbār. An Antithetical Pair of Biblical Motifs, in: M. Mindlin / M.J. Geller / J.E. Wansbrough (ed.), Figurative Language in the Ancient Near East, London 1987, 117-142

Tawil, H., 'Azazel. The Prince of the Steppe: A Comparative Study, ZAW 92 (1980) 43-59

Thiel, W., Die soziale Entwicklung Israels in vorstaatlicher Zeit, Neukirchen-Vluyn ${ }^{2} 1985$

- Geschichte Israels, in: W.H. Schmidt / W. Thiel / R. Hanhart, Altes Testament. Grundkurs Theologie 1 (UB 421) Stuttgart / Berlin / Koln / Mainz 1989, 89-140

Tigay, J.H., You shall have no other Gods. Israelite Religion in the Light of Hebrew Inscriptions (HSS 31), Atlanta/GA 1986

Vattioni, F., Osservazioni ai testi di Ebla, in: Ebla 1975-1985. Dieci anni di studi linguistici e filologici, Atti del convegno internazionale (Napoli, 9-11 ottobre 1985), ed. L. Cagni (Istituto Universitario Orientale - Dipartimento di Studi Asiatici, Series Minor 27), Napoli 1987, 199. 219

de Vaux, $R$, Das Alte Testament und seine Lebensordnungen II, Freiburg / Basel / Wien ${ }^{2} 1962$ te Velde, H., Seth. God of Confusion, Leiden 1967

- Art. Seth, LÄ V (1984) 908-911

- Egyptian Hieroglyphs as Signs, Symbols and Gods, Visible Religion 4-5 (1985/86) 62-72 
Vernant, J.P., Ambigulté et renversement. Sur la structure énigmatique d'Oedipe-Roi, in: ders. / $P$. Vidal-Naquet, Mythe et tragédie en grèce ancienne, Paris 1972, 99-131

Vieyra, M., Rites de purification hittites, RHR 119 (1939) 121-153

Wanke, G., Art. Dämonen II, TRE VIII (1981) 275-277

Wefing, S., Untersuchungen zum Entsühnungsritual am großen Versöhnungstag (Lev. 16), Diss. masch. Bonn 1979

Wegner, $I$. $\rightarrow$ Haas, $V$.

$\rightarrow$ Salvini, $M$.

Weippert, H., Amos: Seine Bilder und ihr Milieu, in: dies. / K Seybold / M. Weippert, Beiträge zur prophetischen Bildsprache in Israel und Assyrien (OBO 64), Freiburg (Schweiz) / Götingen $1985,1-29$

Westermann, C., Genesis 12-50 (EdF 48), Darmstadt 1975

Wilhelm, G. Grundzüge der Geschichte und Kultur der Hurriter (Grundzüge 45), Darmstadt 1982

- Der hurritische Ablativ-Instrumentalis /ne/, ZA 73 (1983) 96-113

- Hurritische Lexikographie, Or. 54 (1985) 487-496

- Rez. zu: Kanišuwar (FS G. Güterbock, Chicago 1986), ZA 79 (1989) 130-132

- Zum hurritischen Verbalsystem, in: Texte, Sătze, Worter und Moneme (FS K. Heger), Heidelberg 1992, 659-671

\section{- $\rightarrow$ Haas, $V$.}

Wohlstein, H., Zur Tier-Dämonologie der Bibel, ZDMG 113 (1963) 483-492

Wright, D.P., The Gesture of Hand Placement in the Hebrew Bible and in Hittite Literature, JAOS 106 (1986) 433-446

- Deuteronomy 21:1-9 as a Rite of Elimination, CBQ 49 (1987) $387-403$

- The Disposal of Impurity. Elimination Rites in the Bible and in Hittite and Mesopotamian Literature (SBLDS 101), Atlanta/GA 1987

- Art. Azazel, The Anchor Bible Dictionary I (1992) 536f

Wyatt, N., Atonement Theology in Ugarit and Israel, UF 8 (1976) 415-430

- Sea and Desert: Symbolic Geography in West Semitic Religious Thought, UF 19 (1987) 375 389

Zadok, R, Phoenicians, Philistines, and Moabites in Mesopotamia, BASOR 230 (1978) 57-65 



\section{Klaus Koch}

\section{Hazzi-Safôn-Kasion}

Die Geschichte eines Berges und seiner Gottheiten

Berge spielen in zahlreichen Religionen der Erde eine mythische Rolle. Insbesondere dort, wo ein Massiv aus seiner Umgebung steil aufragt und über größere Entfernungen sichtbar wird, legt sich urtümlichen Kulturen nahe, dem Berg eine numinose Bedeutung beizulegen; verbindet sich doch für die Menschen aller Zeiten - so noch in unserer Umgangssprache - mit dem Gedanken an das, was 'oben' ist, zugleich die Einschätzung besserer Qualität und überlegener Macht. Häufig kommt für solche Wertung von Bergen hinzu, daß sie für menschliche Bebauung ungeeignet sind, menschlichen Verkehrswegen ein Hindernis in den Weg legen, also dem Altag entrückt sind. "Die fernen, unzugänglichen Berge ... stehen abseits vom Altag und tragen daher die Macht des ganz Andern"1. Noch vielen säkularisierten Zeitgenossen vermittelt die Höhe des Gebirges ein eigentümliches Hochgefühl, das sie über alles Gewöhnliche weit hinaus zu heben scheint.

Freilich läßt sich keine durchgängig einheitliche Art der Bergverehrung und kein gleicher Typ von Berggottheiten in den Religionen aufweisen. Der Eindruck numinoser Mächtigkeit wird sprachlich unterschiedlich artikuliert. Wird ein Berg potentiell lebendig gedacht, so wird er personifiziert und auf einem in $\mathrm{ihm}$ geheimnisvoll anwesenden Berggeist geschlossen; das aber setzt voraus, da $B$ aktive Bewegung nicht auf Tiere und menschenähnliche Wesen beschränkt ist, wie es andere Sprachen mit ihrer Ontologie voraussetzen. In Regenbaukulturen führt die Beobachtung, da $\beta$ Wolken sich um Gebirge zusammenballen, von da beschleunigt und unbehindert weiterziehen, zum einleuchtenden Schluß, daß die für das Leben maßgeblichen Wettergötter an Berge gebunden sind. Wird Gestein als Beweis des schlechthin Beständigen und Zeitüberlegenen wahrgenommen, verbindet sich mit Bergen leicht der Gedanke von unerschütterlichen Grundfesten der sonst so unbeständigen Erde. Daraus kann die Vorstellung von einem zentralen Gebirgsstock als Mitte der Welt und als Himmel und Erde verbindende Achse abgeleitet werden. Wo man maßgeblich göttliche Mächte im Himmel verortet, bieten sich die Berge als Mittel zum Auf- oder Abstieg der Götter an. Wird Lehre und intuitive Offenbarung in einer Religion zu einem ausschlaggebenden Faktor, wird ein Berg wegen seiner Abgeschiedenheit gern zur Offenbarungsstätte, wie das Beispiel Mose oder Mohammed belegt. Das Phänomen Berg regt also zu unterschiedlichen mythologischen Folgerungen an. Die herausgegriffenen Beispiele genügen, um deutlich werden zu lassen, daß von einer gleichmäßigen religiös-mythischen Einschätzung des Phänomens Berg nicht die Rede sein kann. Zudem kann die Auffassung über

Van der Leeuw, Phănomenologie, 41. 
die Rolle von Bergen in ein und derselben Religion im Laufe der Zeit erstaunlich wechseln, wie sich noch ergeben wird.

Meine Darstellung wendet sich der mythischen Einschätzung eines einzigen Berges in Nordsyrien zu, der im Altertum mit besonders mächtigen Göttern oder mit einem höchsten Gott verknüpft worden ist, und das bei Israeliten, Syrern, Kleinasiaten und - obgleich in abgeschwächter Weise - bei Griechen. Der betreffende Berg wird mit Wetter und Vegetation verbunden, was uns einsichtig ist, aber auch mit politischer Herrschaft, was unsereinem weniger einleuchtet. Vorauszuschicken ist, $\mathrm{da} B$ in den eben genannten Religionen über diesen einen Fall hinaus große Götter überhaupt an heilige Berge gebunden werden. Anderen Teilen des altorientalischen Altertums, insbesondere den Hochkulturen des Niltals und des Zweistromlandes, liegt eine solche Verankerung führender Gottheiten fern. Zwar gibt es dort regional bedeutsame numinose Wesen, die mit vorhandenen geografischen Erhebungen zusammenhängen wie z.B. die ägyptische Göttin Meresger, die mit einer Bergspitze in ThebenWest zusammengehört ${ }^{2}$. Oder es finden sich Götter- und Tempeltitel mit dem Lexem "Berg" als Epitheton, womit aber an keine reale Gegebenheit angeknüpft wird, so wird etwa der im Flachland von Nippur verehrte Enlil als "großer Berg", kur gal, und sein Tempel als "Berghaus", é-kur, gepriesen ${ }^{3}$. Doch die ägyptischen oder mesopotamischen Götter bedürfen nicht grundsätzlich der realen Berge, um zu residieren. Anders der Befund in Syrien, Palästina, Kleinasien bis hin zu den "olympischen Göttern" ${ }^{14}$ in Hellas. In diesen Kulturen erscheint der Bezug der für das Leben auf Erden entscheidenden Götter zu tatsächlich vorhandenen Bergmassiven konstitutiv zu sein. Insofern gibt es in diesem Falle für die Religionsgeschichte so etwas wie einen "levantinischen Halbmond" im Unterschied zum vielberufenen "fruchtbaren Halbmond", mit dem sonst die Religion Israels (und Syriens) gern zusammengestellt wird.

Ausgehen werde ich von Aussagen der Bibel. Vorgängig ein Wort zum alttestamentlichen Einsatz. Entgegen verbreiteter christlicher Meinung kennt die Bibel kein "Heiliges Land", schreibt aber häufig und betont vom "heiligen

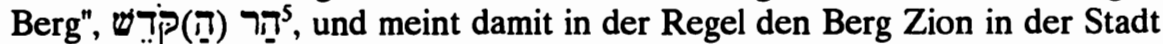
Jerusalem, von Salomo mit einem prächtigen Tempel geschmückt und zum Thronsitz Jahwäs erklärt (1 Kön 8,12f). Nach israelitischer Überzeugung west hier Jahwä wie nirgends sonst auf Erden an. Nachbarvölker stuften deshalb Jahwä als "Gott der Berge" ein; wenn sie damit auch falsche und beschränkte Vorstellungen verbinden (1 Kön 20,23.28), so haben sie doch ein entscheiden-

\footnotetext{
2 LÄ I (E. Otto, Bergspitze), 710.

3 RLA 2, 283; WM I 60; andere mesopotamische Beispiele bei Douglas van Buren, MountainGods, 76-84.

4 KP 4, 290f; Nilsson, Geschichte I, 353f.

5 ThWAT 2, 481.
} 
des Merkmal des Gottes erkannt. (Die Bergverbundenheit Jahwäs war schon vor der Einnahme Jerusalems und des Zions gegeben. Sie gehörte bereits zur Herkunft dieses Gottes vom Sinai/Horeb in der südlichen Wüste. Doch dem ist hier nicht nachzugehen.)

Die folgende Untersuchung beschränkt sich auf eine einzige Bezeichnung

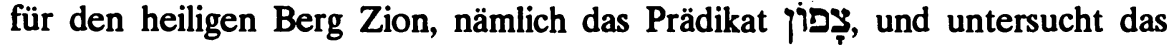
semantische Feld. Auf den ersten Blick wird damit ein belangloser Einzelzug behandelt. Genauere Hinsicht zeigt, daß es ein bezeichnendes Element im israelitischen Gottes- und Weltverständnis charakterisiert und zugleich Gemeinsamkeit wie Unterschiedenheit der alttestamentlichen Religion zu ihren nördlichen und nordöstlichen Nachbarn überraschend erkennbar werden läßt.

Wie weithin anerkannt, besteht Anlaß, den Namen צִ für den Zion mit dem des nordsyrischen Berges sapanu in Beziehung zu setzen, der nach den ugaritischen Texten ebenfalls Sitz einer überragenden Gottheit gewesen ist. Das gleiche Bergmassiv wird im 2.Jt.v.Chr. unter dem Namen $\mathrm{Haz}(\mathrm{z}) \mathrm{i}$ bei Hurritern und Hethitern verehrt. Im 1.Jt. wird der Name dieser Höhe in Kas(s)ion abgewandelt, die dazugehörige Gottheit bleibt weiterhin bedeutsam, ihr Kult breitet sich über den gesamten Mittelmeerraum aus.

Vom alttestamentlichen Befund ausgehend, werden die ugaritischen, dann die hethitisch-hurritischen und schließlich die phönikisch-hellenistischen Bezeugungen untersucht und verglichen. Im Hintergrund steht die Frage, warum gerade der nordsyrische Berg eine so exzeptionelle Stelle in Mythologie und Kult erhält, daß sein Ruhm selbst auf den Zion und die Jahwä-Monolatrie abfärbt.

\section{I. Șafon als hebräischer Bergname und Thronsitz Jahwäs}

Das Lexem צִ bedeutet im AT zumeist die Himmelsrichtung Norden. An etwa 5-8 Stellen scheint es jedoch einen oder mehrere Berge mit besonders numinosem Charakter zu bezeichnen. Das eindeutigste Beispiel findet sich Ps 48. Dieses Zionslied preist eingangs die Anwesenheit Gottes in seiner heiligen Stadt, vermutlich mit wuchtigen Trikola (vgl. BHS):

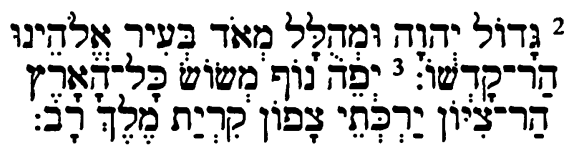

"Groß ist Jahwa / und sehr preiswürdig / in der Stadt unseres Gottes.

Der Berg seiner Heiligkeit, / der schöste der Hügel (?), / (ist) die Wonne der ganzen Erde.

Der Berg Zion, / der ăußerste Auslăufer des șapôn, / (ist) die Stadt eines Großkönigs." 
Der hymnische Preis richtet sich auf Jahwäs Anwesenheit in seiner heiligen Stadt, und diese rückt für den Sänger alsbald mehr in den Vordergrund als der Gott selbst. Ihre Auszeichnung ist ein heiliger Berg, der durch seine Schönheit besticht und die gesamte Erde mit Freude erfüllt. Die Psalmenaussage überrascht, sobald man die für ein gewöhnliches Auge keineswegs überragende Größe des Stadtberges von Jerusalem in Betracht zieht. Für den Psalmisten kommt dem Zion jedoch globaler Rang zu, weil er den צ̧ repräsentiert und die קריר eines Großkönigs bildet. Der letzte Titel bezieht sich auf den hintergründigen göttlichen Herrscher ${ }^{6}$ über die Völkerwelt vgl. Ps 47,3.8; im Vergleich $\mathrm{zu}$ ihm wird jeder irdische Herrscher zweitrangig. Das Weltregiment

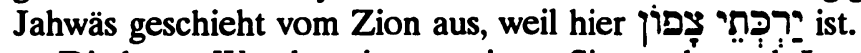

Die letzte Wendung ist umstritten. Sie taucht auch Jes 14,$13 ; \mathrm{Ez} 38,6$ auf, ist also geprägter Art. Unter Ableitung von ירכי: "Hinterseite, Hinterteil (vom Gebäude, Gebirge, Schiff)" ${ }^{\prime 7}$ läßt sich notfalls" auf "äußerster Norden" schlie$\mathrm{Ben}^{8}$, was jedoch für einen in Jerusalem lebenden Hebräer wenig Sinn macht. Oder man denkt an ein extremes Ende im vertikalen Sinn als Gegenpol zu

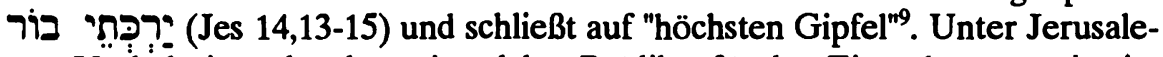
mer Verhältnissen leuchtet ein solches Prädikat für den Zion ebensowenig ein, denn der Berg ähnelt einem Hochplateau, ihm fehlt jede Spitze. Dahood hingegen $^{10}$ geht von 7 "... "Lende" aus, schließt von da auf einen Hinweis für das eigentliche Zentrum, "the heart of Zaphon". Das aber postuliert eine erhebliche Bedeutungsverschiebung, die auch durch Verweis auf das ugaritische sirt spn (dazu unten) nicht wahrscheinlicher wird. So legt sich am ehesten nahe, an einen "äußersten Ausläufer des Șafon" zu denken; der eigentliche Șafon wäre dann tatsächlich ein Berg im Norden, der Zion aber stünde mit ihm in geheimnisvoll-untergründiger Verbindung, ohne jenen völlig zu ersetzen. Entgegen der üblichen Auslegung bleibt also zu bezweifeln, daß Ps 48,3 den Zion mit dem Șafon völlig gleichsetzt. Die Psalmen verwenden sonst diesen Ausdruck überwiegend für die nördliche Himmelsrichtung, מִִּּפון heißt z.B. Ps 107,3 nicht "vom Zion", sondern "vom Norden her". In der Sprache des Jerusalemer Priesters Ezechiel bezeichnet צִ eindeutig jene Richtung und nicht eine Orientierung am Jerusalemer Berg Ez 8,3.5; 40,40 u.ö. So wird denn Ps 48 wie Ri 19,1.18; 2 Kön 19,23; Jes 37,24 "entlegenster Teil e[ines] Gebirges"11 gemeint sein. Demnach wäre der Zion die letzte, südlichste Erstreckung eines

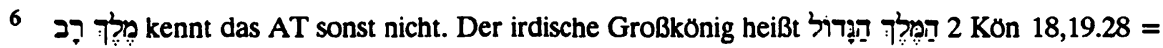
Jes 36,4.13.

7 Vgl. akk. (w)arkatu(m), AHw, 1467f.

8 Lauha, Zaphon, 40; HAL 419.980.

9 Eißfeldt, Baal, 14f; Robinson, Zion, 118-123.

10 Psalms I, 288.290.

11 HAL, 419. 
wֵ הַר צִיטון

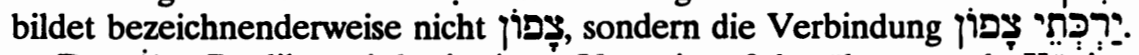

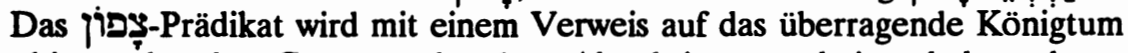
des hier waltenden Gottes verbunden. Also bringt anscheinend der seltene Name für den Zion die Konnotation eines autoritativ wirkenden und übernational bedeutsamen Herrschaftssitzes mit sich. In den folgenden V. 4-8 wird dann der so benannte Bergausläufer als eine Festung geschildert, gegen die eine Schar anonymer Könige anstürmt, an der sie aber mit ihren TarschischSchiffen zerschellt. Die Feindmacht ist also über das Meer gegen den Zion gesegelt; was zur Geografie Jerusalems ebenso wenig paßt wie eine Lage im Norden. Handelt es sich um ein schon anderwärts mit dem צ̧ gֵ gekoppeltes, in Jerusalem übernommenes und mythisch überhöhtes Motiv? Wird daraus die Angst vor einer globalen Überschwemmung, bei der das Meer bis zum ZionȘafon ansteigt?

Warum wird an einer so feierlichen Stelle im Gesang - vermutlich während eines kultdramatischen Auf- und Umzugs (V.9.13f) - der Zion als צָ gepriesen? Ein Lexem, das sonst eine nördliche Himmelsrichtung bedeutet, bezieht sich auf einen Berg, der nicht im Norden liegt. Die Kommentatoren hatten deshalb seit langem eine Erinnerung an einen mythischen Gottesberg im Norden vermutet, die hier sekundär auf das Jahwäheiligtum übertragen werde $^{12}$. Dafür gab es in der altorientalischen Literatur keinerlei schlüssige Parallele, bis in den 30er Jahren bekannt wurde, daß die Texte von Ras Schamra-Ugarit einen Berg Sapanu als Residenz des Gottes Haddu-Ba'lu häufig nennen. Seitdem wird in den Kommentaren auf die Übertragung eines ursprünglich kanaanäischen Mythologumenons auf den heiligen Berg Jahwäs geschlossen ${ }^{13}$. In der Tat sind die Übereinstimmungen mehr als auffällig. Nicht nur, daß der mit dem heutigen ğebel el-aqra“ identische ugaritische Sapanuberg von Jerusalem aus in einer Nordrichtung liegt, dieser Berg Baals gilt darüber hinaus in Ugarit als dessen wichtiger Königssitz und zugleich als die Stätte einer Auseinandersetzung mit dem Ansturm des Meergottes Jam, was zur Fortsetzung in Ps 48,4-9 durchaus paßt. Es ist jedoch nicht auszuschließen, daß der Psalmist infolge des ausgeweiteten Horizonts einer späteren Zeit gar nicht mehr an den Ausläufer eines in Nordsyrien liegenden Berges, sondern aufgrund der gängigen hebräischen Verwendung von צ̦ als Himmelsrichtung beim Zion an einen entlegenen Bestandteil eines weit jenseits Syriens liegenden Gottesberg in einem geografisch nicht fixierbaren Norden denkt, wie es jedenfalls Jes 14 voraussetzen wird (dazu unten).

Die In-Beziehung-Setzung eines entfernt liegenden heiligen Berges mit dem Zion hat im Psalter selbst eine Parallele in der sonderbaren Aussage Ps 68,9.18,

12 Baethgen, Psalmen, 138f; Gunkel, Psalmen, 106; Staerk, Lyrik, 16-18.

13 Schmidt, Psalmen, 92; Kraus, Psalmen, 513; Dahood, Psalms I, 289f. 
$\mathrm{da} ß$ während des Festes der Sinai im Heiligtum von Jerusalem anwesend ist ${ }^{14}$. Dies wird ebensowenig meinen, daß der Berg in der südlichen Wüste nunmehr des Gottes leer ist, sondern darauf abzielen, daß dem Sinai eine untergründige "Verlängerung" bis zum Zion hin zukommt; ähnliches ist vielleicht in umgekehrte Richtung für den Șapanu vorauszusetzen. Der Titel dieses Berges ist übrigens um die Wende zum ersten vorchristlichen Jahrtausend von phönikischen Seefahrern auch auf einen Hügel am sirbonischen Meerbusen des Mittelmeers bei Pelusium übertragen worden. Anscheinend wird also beim Sapanu mit "Dependancen" in anderen Gegenden gerechnet. Diesen an der Grenze zu Ägypten liegenden Ort Baal Șefon setzt die Priesterschrift Ex 14,2.9; Num 33,7 als Ort des Meerwunders beim Auszug der Exodusgruppe voraus (vgl. unten unter IV.).

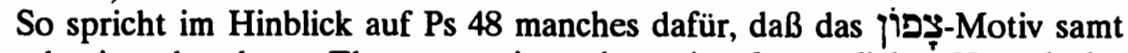
den damit verbundenen Elementen eines übernationalen göttlichen Herrschaftssitzes und der Abwehr eines mythisch-anonymen feindlichen Ansturms aus dem nordsyrischen Bereich stammt. Ehe die Frage nach dem möglichen Zeitraum einer solchen Übernahme nach Jerusalem zu erörtern ist, sind einige andere alttestamentliche Belege zu berücksichtigen.

Nicht ganz so sicher wie in Ps 48 ist die Koppelung des Zion an den Șafon im Königspsalm Ps 89,12-15. Nachdem von der Besiegung des hochfahrenden Meeres und der Rahab die Rede war V.11ff, fährt der Sänger fort:

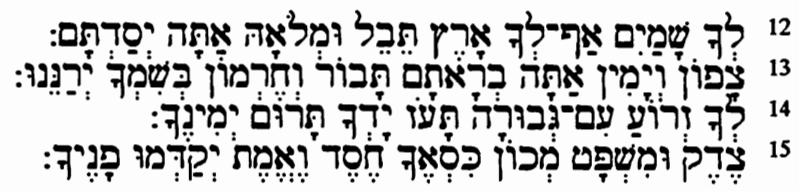

"Dir gehort der Himmel und dir gehort die Erde, / das Fruchtland und seine Fülle, du hast sie gegründet.

Șafon und Jamin, du hattest sie geschaffen, / Tabor und Hermon, in deinem Namen jubeln sie.

14 Ps 68,9 wird beim Auszug Gottes vor seinem Volk ein Erbeben der Erde und ein Sich-Aus-

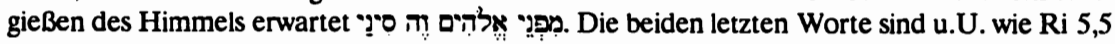
als altertümliche Konstruktusverbindung "Der vom Sinai" verstehen, so die Einheitsübersetzung (vgl. Dahood, Psalms I, 130), und nicht als Nominalsatz "dies ist ein Sinai" (Buber).

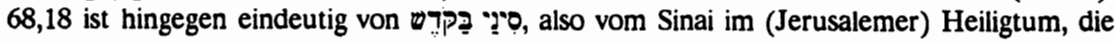
Rede. Das wird von vielen Kommentatoren wegemendiert, stellt aber lectio difficilior dar. Bezeichnend, aber kaum überzeugend die Erklarung in der Neuen Jerusalemer Bibel 1985 (S.809): "In der Zeit des zweiten Tempels wurde der hebräische Text ... bearbeitet ... Der Sinai wurde damit mit dem Zion identifiziert, von dem jetzt das Gesetz ausgeht, Jes 2,3." Genau genommen besagt die Wendung aber nicht, daß der Zion zugleich der Sinai ist und dieser Berg also nicht mehr existiert, sondern daß der Sinai geheimnisvoll sich bis in das Jerusalemer Heiligtum hinein erstreckt. 
Dir ist ein Arm mit Heldenkraft, / du machst kraftig deine Hand, erhebst deine Rechte (מיָ:)

Șădăq und Mišpaț sind die Stützen deines Thrones, / Hăsăd und Ämăt stehen vor deinem Angesicht."

Der hymnische Preis gilt diesmal nicht dem Gott in der Stadt, sondern dem Gott auf dem Thron. Beides aber dürfte miteinander zusammenhängen. Wie weit wird der zur Schöpfung anscheinend nötige Thron V.13 mit Bergen in Beziehung gesetzt? Der Schöpfungsaspekt, der hier im Vordergrund steht, war schon Ps 48,9 im Blick auf den Zionsberg erwähnt worden. Da יְיִ sonst

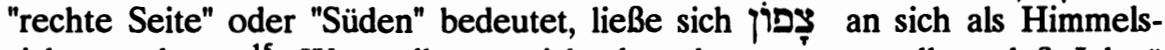
richtung deuten ${ }^{15}$. Was soll man sich aber darunter vorstellen, daß Jahwä Himmelsrichtungen "geschaffen" habe (ברא)? Tabor und Hermon nachher auf reale Schöpfungen verwiesen. Für den dazwischenstehenden V.13a könnte man notfalls an nördliche und südliche Ländermassen des Erdkreises denken. Wegen des Wechselgliedes, das die Berge Hermon und Tabor nennt, liegt näher, auch für den Versanfang von V.13 an zwei Berge zu denken. Von den Kommentatoren wird deshalb für häufig auf den Amanus und damit ein dem syrischen Șapanu benachbartes Gebirgsmassiv verwiesen, sei es, daß man zu es, da $B$ man den Text beibehält und mit dialektischer Verschiebung rechnet ${ }^{17}$. Auch auf einen in Texten aus Ugarit neben den Hazzi-Șapanu erscheinenden Berg Nana ist verwiesen worden ${ }^{18}$. Solche Erklärungen weisen auf einen weiteren Berg im Norden, der von Jerusalem noch weiter ab liegt als der Dschebel aqra'. Leichter erscheint die Annahme, daß das Lexem ןִיִ, das sonst die Himmelsrichtung Süden bedeutet, in diesem Psalm auf einen beherrschenden Berg in eben dieser Gegend gemünzt ist. Dieser ist vielleicht mit dem Sinai identisch $^{19}$ oder/und - mit t-Präfix - im Namen Theophanie Hab 3,3 und in dem Prädikat מהוה תמן auf dem Pithos B von Kuntillet Adschrud ${ }^{20}$ erhalten. Noch Jub 4,25f nennt unter den vier tragenden Bergen der Erde neben Eden, Sinai und Zion einen "Berg des Südens"21. Wenn "ִִין" sich als Berg deuten läßt, dann natürlich eher noch Șafon. Falls Șafon im Kontext von Ps 89 den Zion betrifft, wäre von vier Bergen die Rede,

HAL 980; ThAT II 579.

16 Schmidt, Psalmen, 166; HAL, 62 vgl. Niehr, Der höchste Gott, $110 f$.

17 Dahood, Psalms II, 315; vgl. Kraus, Psalmen II, 788.

18 Bordreuil, Arrou Ǵourou, 274; vgl. Eißfeldt, Baal, 12f, der den Antikasion in Erwägung zieht.

19 Eißfeldt, Baal, $12 \mathrm{f}$ (?).

20 TUAT 2, 562 mit Lit.

21 Berger, Jubilaen, 346 und Anm. zu V.26.
} 
welche den Jahwä-Verehrern tatsächlich zur Wallfahrt zugänglich waren. Dabei liegen dann Hermon und Tabor im Norden, Șafon (= Zion) - trotz des Namens - und Jamin im israelitischen Süden ${ }^{2}$. Eine phönikische Analogie findet sich bei Philo Byblios, der von den vier Bergen Kassion, Libanon, Antilibanon und Brathy als Träger einer eigenständigen Göttergeneration spricht, wobei der letzte Name vielleicht aus thabyr-Tabor verschrieben ist ${ }^{23}$. Da Kassion dem Șapanu, Antilibanon dem Hermon entspricht, fehlt dann bei Philo, anders als Ps 89, der Amanus oder der "Südberg", an dessen Stelle der Libanon erscheint; Berge südlich des phönikischen Siedlungsraums werden bei ihm nicht in Betracht gezogen.

Gottes Thron wird sonst im Alten Testament mit dem Zion verbunden (Jes 6 u.ö.), ragt also, sobald er irdisch verankert wird, über einem Berg und Fels empor. Wird das in Ps 89 ähnlich vorausgesetzt, aber ausgeweitet? Wo ist überhaupt der Thron Gottes zu suchen, von dem V.15 in der Einzahl spricht, in welchem Verhältnis steht er zu den vorgenannten Bergen? Denkt der Psalmist sich die Sache so, daß die vier Füße des himmlischen Thrones je auf einem von diesen stehen? Den vier Bergen scheinen jedenfalls die vier Wirkgrößen Șädäq, Mišpaț, Ḥäsäd und Ämät zu entsprechen, die sich vom Thron her über die Erde erstrecken. Der Verweis auf solche geheimen Kräfte einer positiven Lebens- und Gesellschaftsordnung, der in den folgenden Versen aufgenommen wird, hat seine Entsprechung in Ps 48,12.

Wie in Ps 48 werden mit der Nennung des unter andere Berge eingereihten צִ zָפוֹ zwei spezielle Themen verknüpft, einmal der Kampf Jahwäs gegen eine gefährliche mythische, mit dem Meer verbundene Macht, zum anderen eine universales Herrschaftsmotiv, das hier durch den Thron symbolisiert wird. Die vier heiligen Berge werden als markante Zeugnisse einer Schöpfermacht angeführt, die die Macht des göttlichen Namens ausweisen. Auch andere alttestamentliche Stellen (z.B. Ps 90,2) setzen voraus, daß große Berge das erste waren, was Jahwä auf Erden geschaffen hat, als Stützpfeiler, mit denen die Erdscheibe im Urmeer befestigt ist ${ }^{24}$.

In den Umkreis der Psalmensprache gehört trotz anderen literarischen und zeitlichen Zusammenhangs Hiob 26,6-12. Mitten in einem der Streitgespräche

22 Trifft die Deutung zu, wird Ps 89 der Zion nicht nur mit dem Șafon im Norden in Verbindung gebracht, sondern völlig identifiziert, so daß kein göttlicher Berg im Norden weiterhin vorausgesetzt wăre.

23 Euseb, Praep. evang. I, 10,9 (ed. Mras 1954, GCS 8,44); Eißfeldt, Der Gott des Tabor und seine Verbreitung, ARW 31 (1934) 14-41, hier 28ff = Kleine Schriften II (1963), 29-54 hier 31.243; anders Ebach, Weltentstehung, 134-142 und Lipiniski, El's abode, 59, der an Amanus denkt.

24 Zu Bergen als urzeitliche Schopfung, als "Grundfesten der Erde und heiliger Raum", Talmon, ThWAT 2, 474f. 
des Buches steht ein in das Buch eingestellter, wohl erheblich älterer hymnischer Abschnitt über die Macht des Schöpfers:

"Bloß liegt die Scheol vor ihm, / und keine Bedeckung hat der Abgrund.

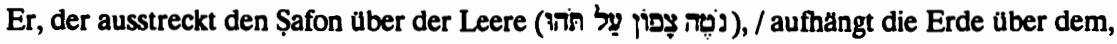
was nicht ist ...

Verdeckt die Ansichtsseite des Throns ${ }^{25}$, / ausbreitet daruber seine Wolken.

Eine Ordnung zieht er als Kreis um das Wasser / bis an den Rand von Licht und Finsternis ...

Durch seine Kraft ist das Meer zur Ruhe gebracht worden, / durch seine Klugheit Rahab zerschmettert."

Ähnlich wie in Ps 89 wird auf den Urmeerkampf im Zusammenhang mit נטה צד uñ Thron Jahwäs hingewiesen. Da das eingangs gebrauchte Verb mehrfach im Alten Testament mit צ̦ als Wechselglied zur Erde den Himmel verstehen ${ }^{26}$. Das ist aber reichlich spekulativ angesichts der sonst belegten Wortbedeutungen jenes Nomens. An ein "Spannen" des "Nordens" als Himmelsrichtung zu denken (so wieder die Einheitsübersetzung), ist zwar lexikalisch möglich, entspricht aber kaum hebräischem Denken; wie söllte eine Himmelsrichtung zu Tage treten ohne materiellen Bezugsrahmen? So entspricht auch hier die Deutung auf einen für den Bestand der Welt gewichtigen Berg dem Text am ehesten ${ }^{27}$. An ihm, der anscheinend an einem (nördlichen?) Eckpunkt liegt, ist die Erde aufgehängt. $\mathrm{Ob}$ dabei einmal an den Zion gedacht war, bleibt angesichts der ungesicherten Herkunft der hymnischen Überlieferungen im Hiobbuch unsicher. Die Stelle läßt besonders deutlich hervortreten, was generell vom hebräischen Weltbild zu sagen ist: "Im AT findet sich die auch in anderen semitischen und nichtsemitischen Kulturen vorhandene Vorstellung, daß Berge oder ein bestimmter Berg die Weltachse ist, das Band, das senkrecht die drei Komponenten des Kosmos ... verbindet ${ }^{128}$.

Eine weitere für unseren Zusammenhang belangreiche Stelle findet sich in einem profetischen Spottlied über den Fall des Königs von Babel Jes 14,12-15:

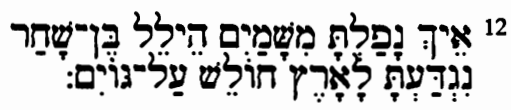

25 Die ungewöhnliche Schreibung Toכ hat die Kommentare dazu geführt, אְִֶ zu lesen; Hölscher, Hiob, 62; Fohrer, Hiob, 382; HAL, 463f. Die Bedeutung "Mond" entspricht aber dem Zusammenhang weit weniger als das überlieferte "Thron" (so LXX; Luther).

Fohrer, Hiob, 382.384, vgl. de Savignac, Note, 95f; HAL, 980.

27 Eißfeldt, Baal, $11 \mathrm{f}$.

28 Talmon, ThWAT 2, 473 


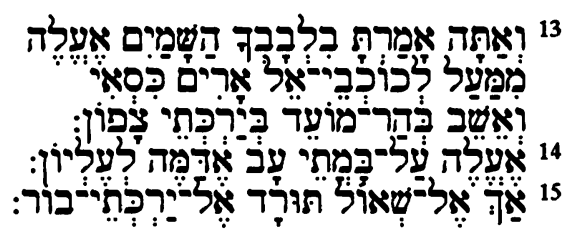

"Wie bist du vom Himmel gefallen, / Helel băn Schahar!

Du bist herabgehauen zur Erde, / Sieger über Volker!

Du hattest in deinem Herzen gedacht: / Zum Himmel will ich hinaufsteigen!

Oberhalb der Sterne Els / will ich meinen Thron aufrichten ${ }^{29}$.

Ich will sitzen auf dem Berg der Zusammenkunft, / auf dem außersten Auslăufer des Ṣafon! Hinaufsteigen will ich uber (auf) Hohen von Wolken, / mich Äljon gleichstellen! Jedoch zur Scheol bist du hinabgestürzt worden, / in die außßerste Grube!"

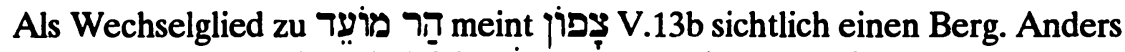

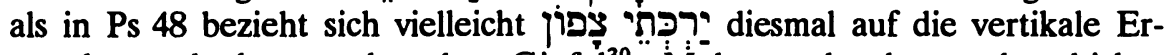
streckung, bedeutet also den $\mathrm{Gipfel}^{30}$. Mehr noch als an den bisher behandelten Stellen nimmt Șafon einen kosmischen Rang als Weltachse ein, ragt über Wolken, ja über Sterne hinaus bis in den Himmel und bildet das Fundament für den Thron des Allerhöchsten, des Äljon. Dieser gilt als Spitze des Pantheons; an seinem Ort finden regelmäßige festliche Zusammenkünfte ${ }^{31}$ statt, was Götterversammlungen voraussetzt. Weil die wichtigste Erhebung auf Erden, hat Șafon als Gegenpol die äußerste Grube der Unterwelt V.14. Wer sich in menschlicher Hybris zu jener Götterhöhe hinaufschwingen will, landet in tiefster Verdammnis. Damit spielt, wie gemeinhin angenommen, der Sänger auf einen den Zuhörern bekannten, von uns leider nur zu erahnenden Mythos an. Der Großkönig, dem hier das Scheitern vorausgesagt wird, wiederholt ein Geschick, das einst dem Sohn der Morgendämmerung zuteil geworden war, wohl dem Morgenstern ${ }^{32}$. Wieder taucht das Motiv des mythischen Kampfes auf. Doch handelt es sich diesmal nicht um einen mit Wasser und Meer verbundenen Feind, der den Berg bedrängt. Vielmehr geht es um einen einzigen menschlichen Herrscher, der den צָ besetzen und dadurch das Regiment über die Himmelsmächte erringen will. Das führt über die ugaritischen Parallelen hinaus und führt in die Epoche einer aufkommenden Astralreligion. Anders als in den Psalmen wird hier mit dem Thronberg des Götterkönigs eine

\footnotetext{
$29 \mathrm{Zu}$ על רום hi. als Thronbesteigungstermini s. Janowski, Königtum Gottes, $433^{178}$.

30 Oder ist an die Eroberung von Jerusalem als Stătte des gottlichen Hofstaats gedacht?

31 ThWAT 4, 744-750.

32 Wildberger, Jesaja, 1978, 534f.550-555; Loretz, Mythos, 132-136; Kaiser, Jesaja, 34-36; Prinsloo, Isaiah $14,12-15,435-439$.
} 
Versammlungsstätte aller Götter verbunden. Damit fließt, ugaritisch gesehen, der Șapanuberg Baals mit dem Berg Lel des Göttervaters El, wo sich der phr $m^{\prime} d$ trifft, in eins zusammen ${ }^{33}$.

Wo wird hier der kosmische Șafon verortet? Daß der Verfasser Șafon mit dem Zion gleichsetzt, bleibt zu bezweifeln, wenngleich es nicht auszuschließen ist. Zwar ist nach den Psalmen Äljon auf dem Zion beheimatet (Ps 46,5; 47,3 u.ö.), doch von einem Luzifer-Mythos finden sich dort keine Spuren und als Herrschaftssitz eines babylonischen Großkönigs (ursprünglich assyrischen?) liegt der Ort vielleicht zu weit ab. Aber auch ein in Nordsyrien gelegener Dschebel aqra' genügt den kosmischen Ausmaßen dieses Textes kaum ${ }^{34}$. Vermutlich wird infolge des weiter gewordenen geografischen Horizonts hier nun der Șapanu wirklich im den Menschen unerreichbaren Norden der Erde vermutet. Zu solcher Ansetzung passen einige Texte aus dem Umkreis des Jerusalemer Tempels, die mit einer Theofanie Jahwäs von Norden her zu seinen israelischen Verehrern rechnen. So der altertümliche Ps 29, der den Gott von den Wassern her über Libanon und Sirjon bis zu seinem הֶיכָ heranbrausen läßt, ähnlich wohl Jes 2,9-21; Ez 1,4-28 und der von der Komposition in das Amosbuch 4,13; 5,8; 9,5 eingefügte Hymnus, der Jahwä nach der Erschaffung der Berge über die Höhen der Erde sich Israel nahen läßt ${ }^{35}$.

Bei jüngeren Schriftprofeten läßt sich eine auffällige Verschiebung der צִ Thematik beobachten. Im Jeremiabuch spielt in den ersten Kapiteln ein anonymer Feind aus dem Norden eine entscheidende Rolle, der nun im Auftrag

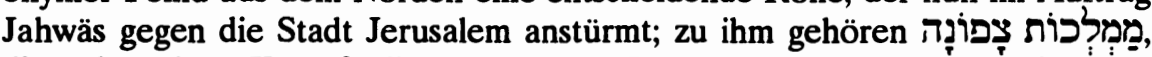
die während des Kampfes ihren Thron vor Jerusalem aufstellen Jer 1,15. Bahnt sich hier ein Umschwung an, wird aus einem (Völker-)Meer, daß den Șafon als Jahwäs eigenen Berg bedroht, ein Șafon-Heer, daß von Norden mit Jahwäs Hilfe gegen den Zion anstürmt? Deutlicher noch tritt eine solche Umkehr in der von Jeremia abhängigen ${ }^{36}$ Gog-Weissagung Ezech 38-39 zutage. Gog, hinter dem sich vielleicht eine mythische Überzeichnung des Königs Gyges (um

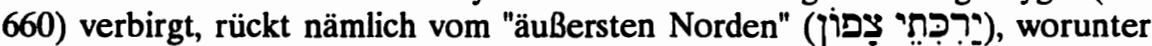
diesmal weder eine Himmelsrichtung noch ein Berg, sondern Kleinasien als Ländermasse begriffen wird, gegen die Berge Israels an, nun aber gegen die Absicht Jahwäs, und wird dort vernichtet - wie in der Psalmentradition die

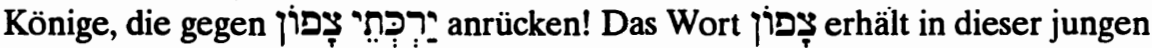

33 Schmidt, Königtum, 34f. Lipiñski übersetzt ğr ll "Berg der Nacht" und lokalisiert ihn aufgrund akkadischer Anspielungen an der Eufratquelle im armenischen Bergland. Die gleiche Verortung schlägt er für Jes 14, das er auf Sargon II. bezieht, und Ps 48 vor; El's abode, bes. S.55f.

34 Lauha, Zaphon, 41.

35 Koch, Rolle.

Vgl. Zimmerli, Ezechiel (BKAT XIII 2), 1969, 939. 
Weissagung einen negativen Ton. Das ist deshalb besonders bemerkenswert, weil um die gleiche Zeit sich im außerisraelitischen Bereich ein Übergang von einem positiv gewerteten Sapanu in einen negativ-chaotisch bestimmten Typhon zu vollziehen scheint (dazu unten). Freilich behält der Norden eine ambivalente Bedeutung; so wird noch in der Apokalyptik das Paradies dort gesucht $^{37}$; und in Qumran werden die Gräber nach dieser Himmelsrichtung ausgerichtet ${ }^{38}$.

Ergebnis: In alttestamentlichen Stellen, die צִ ą als Bergbezeichnung benutzen, zeigen sich die Umrisse einer einheitlichen Konzeption, die mit einem für den Bestand der Erde seit den Tagen der Schöpfung unentbehrlichen kosmischen Pfeiler rechnet, der zugleich für das Königtum der überragenden Gottheit zum Träger des Thrones wird. Die genaue Verortung des צ̧ und seine religiöse Einschätzung wandeln sich im Laufe der Zeit, bis letztere in der Gog-Weissagung nahezu in ihr Gegenteil verkehrt wird. Dabei weisen eine Reihe von Indizien auf kanaanäische Herkunft und auf einen ursprünglichen Bezug zum nordsyrischen Șapanuberg. Darin sind sich die Ausleger heute weithin einig.

Strittig aber ist der Zeitpunkt einer möglichen Übernahme in die israelitische Kultsprache. Im Zuge einer modern werdenden Spätdatierung des alttestamentlichen Schrifttums mehren sich neuerdings Stimmen, die für eine nachexilische Entlehnung plädieren. Der erste, der sich entschieden in dieser Richtung äußerte, war G.Wanke. Zwar setzt auch er noch voraus: "Auf Ps 48 haben vor allem die nordsyrischen Vorstellungen vom Zaphonberg eingewirkt"; aber dann weist er darauf hin, daß sich das Gottesbergmotiv im Alten Testament sonst nur in jüngeren eschatologischen Aussagen findet und schließt daraus: "Eine Übertragung außerisraelitischer Motive auf den Zion ist ... nur für die exilische

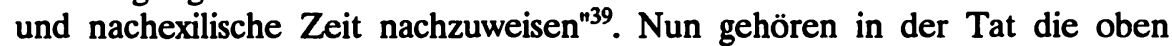
vorgeführten Textbelege meist zum (nach)exilischen Schrifttum. Ps $89^{40}$ in der Endfassung und Jes 14 setzen den Zusammenbruch des davididischen Königtums und das Exil voraus. Ijob 26 weist auf noch spätere Zeit. Nur für Ps 48 bleibt vorexilische Entstehung erwägenswert. Damit sind jedoch keine absoluten Daten gegeben. In kultisch geprägten Schriften ist zumeist das Datum der Verschriftung gerade nicht das der Entstehung entsprechender Konzeptionen. Und der Literarkritiker ist gut beraten, seine hypothetischen Ansetzungen auf

37 Volz, Eschatologie, 410.414.

38 TRE 4, 445.

39 Wanke, Zionstheologie, 64-66.

40 Veijola, Verheißung. 
dem Hintergrund der Überlieferungs- und Religionsgeschichte zu überprüfen $^{41}$. Von da aus gesehen, erscheint eine Entlehnung dieser kanaanäischen Vorstellungen durch das nachexilische Israel aus mehreren Gründen als unwahrscheinlich, und dies sowohl hinsichtlich der kanaanäisch-phönikischen wie der judäischen Verhältnisse:

1. Der sich nachexilisch ausbildende israelitische Monotheismus weist keine heidnische Gottesanschauung so vehement ab wie die Baalsverehrung, man vergleiche nur das deuteronomistische Geschichtswerk. Sollte ausgerechnet in jener Zeit die für den kanaanäischen Baal zentrale Bergmythologie im wesentlichen ungebrochen übernommen worden sein? Das wäre höchstens bei synkretistischen Kreisen denkbar, die in Opposition zum Hauptstrom der Jahwäreligion stehen, aber davon ist in vorhellenistischer Zeit keine Spur zu erkennen.

2. Um die Mitte des ersten vorchristlichen Jahrtausends ist der Gott Baal Șafon bei Phönikern und Aramäern zu einer zweit-, wenn nicht drittklassigen Gottheit herabgesunken, die für die Seefahrt, aber keineswegs mehr für Weltherrschaft in Anschlag gebracht wird (dazu unten). Wie sollte es zu erklären sein, daß nachexilische Israeliten auf eine längst museal gewordene Stufe der kanaanäischen Gottesvorstellungen zurückgegriffen hätten? Ein solcher Vorgang erscheint absurd.

3. Bislang nicht bedacht, aber für den Zusammenhang von Bedeutung ist der Zeitpunkt der Übertragung der SSafon-Bezeichnung von einem Berg auf eine Himmelsrichtung. Seit Eißfeldt ${ }^{4 \dot{2}}$ wird angenommen, daß der ursprüngliche Name des nordsyrischen Berges nachträglich zur abstrakten Bezeichnung einer

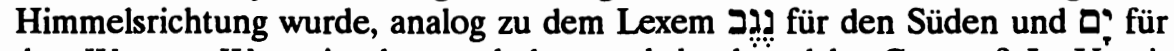
den Westen. Wann ist das geschehen und durch welche Gruppe? In Ugarit dient spn noch nicht als Richtungsangabe, auch das Phönikische und Altaramäische scheinen solche Verwendungen nicht zu kennen ${ }^{43}$. Paradoxerweise hat sich also nur in Palästina diese Bedeutungserweiterung durchgesetzt, also in einer Landschaft, von der aus der ğebel el-aqra' überhaupt nicht sichtbar ist. Das kann nur durch einen Verband geschehen sein, dem der nordsyrische Berg

41 Diesen Grundsatz vertritt zu Recht Niehr, Der höchste Gott. Doch in der Einzeluntersuchung laßt er sich zu sehr von literarkritischen Vorgaben leiten. Wie anders laß sich seine Behauptung aufrecht erhalten, nach der im westsemitischen ersten Jahrtausend der Șafon als Gottesberg schlechthin gegolten habe? Von daher folgert er, die "nachexilische BürgerTempel-Gemeinde" habe "ungeachtet aller geographischen Realitat" den Namen auf den Zion übertragen, "wobei צפון seine geographische Konnotation, die entweder den Norden oder einen bestimmten Berg im Norden meint, verloren hat und nurmehr das mythische Kolorit des Gottesberges transportiert" (S.107).

42 Eißfeldt, Baal Zafon, $17 \mathrm{f}$ vgl. KBL 812.

43 Zum jüdisch-aramăischen צִ mị mit rătselhafter Schărfung des mittleren Radikals Jastrow, Dictionary, 1950, 1278; DISO 246. - Zum akkadisch einmal belegten șa-pu-nu für den (Nord-) Westen des von Aramaern bewohnten Meerlandes Dietrich, Aramaer, 49-50;161 ${ }^{1}$. 
bekannt und heilig war. Entweder handelt es sich dabei um Einwanderer aus Syrien nach Palästina oder um eine in Palästina ansässige Bevölkerung, die um Baals willen zum Șapanuberg $\mathrm{zu}$ wallfahren pflegte ${ }^{44}$. In beiden Fällen läßt sich schwerlich an Israel zugehörige Kreise denken.

So hat die vor allem von Eißfeldt verfochtene und von den neueren Kommentaren übernommene Erklärung einer Vermittlung durch das vorisraelitische Jerusalem nach wie vor alle historische Wahrscheinlichkeit für sich ${ }^{45}$. Für eine vorexilische Wertschätzung des Șafon in Jerusalem spricht schon der Eigenname des Profeten Zefanja "Șafon ist Jahwä"46. Zefanja ist gewiß nicht der Typ, der nach kanaanäischen Vorbildern sich ausrichtet, und dasselbe wird man für den Kreis seiner Herkunft voraussetzen. So war vermutlich die Beziehung Zion = Șafon zur Zeit seiner Geburt schon selbstverständlich. Dann aber bleibt das jebusitische Jerusalem als Subjekt der Übernahme die einfachste Lösung. Offenbar lag diesen Jerusalemern daran, die weltweite Bedeutung ihres Stadtberges und die weitreichende Königsmacht ihres Äljon-Gottes gegenüber kanaanäischen Nachbarn herauszustreichen. Demnach war schon die Verwendung von צ̦ für die Himmelsrichtung einer Orientierung am nordsyrischen Berg entsprungen ${ }^{47}$. Sollte das der Fall gewesen sein, war wohl kaum eine empirisch feststellbare Bedeutung des Berges für Kanaanäer in Palästina der Anlaß zum Gebrauch des Wortes in diesem Sinne. Denn nördlich von Palästina gibt es weit herausragendere Berge als den Dschebel aqra'. Eher dürfte sein mythischer Rang auch der Auslöser für die umgangssprachliche Abwandlung der Wortbedeutung gewesen sein. Dann aber wäre die jebusitische Übertragung auf den Jerusalemer heiligen Berg nur ein weiterer Schritt in einer schon eingeschlagenen Richtung gewesen ${ }^{48}$.

44 Eine ăhnliche Ubertragung wie auf den Zion scheint am Ostrand des Jordantals geschehen zu sein, wo eine wohl schon EA 274,15 erwăhnte Stadt șapuna/yִ̦ wohl an einer Erhebung, liegt Jos 13,27 vgl. Ri 12,1; HAL 980. Ist der Name der gaditischen Sippe Șifjon Gen 46,16; Num 26,15 mit dem ostjordanischen Șapon zu verbinden? So de Moor, Ugarit and Israelite Origins (Pariser Vortrag).

45 Metzger, Wohnstatt, 146-179.

46 HAL 982.

47 HAL 980

48 Eine ahnliche Ưbertragung auf einen Berg im Ostjordanland laßt der "Ijobstein" von Schēch Sa'ad (nahe dem alten Aštarot-Qarnaim) vermuten. Auf dieser Stele uberreicht Ramses II. eine Maatfigur an einen Gott, dessen Titel nach der Inschrift mit $\underline{d} 3 p 3 n 3=$ sapan endet. Leider ist die Lesung der vorangehenden Wörter unsicher (Stadelmann, Gottheiten, 44-46). Der Fundort läßt darauf schließen, daß in Basan ein heiliger Berg als "Ableger" des syrischen Sapanu verehrt wurde, zumal das benachbarte Astarot enge Verbindungen zur ugaritischen Mythologie bessesen hat (KTU 1.108,2). 


\section{II. Șapanu-Hazzi als Gottessitz in Ugarit}

Viel direkter als durch צִ im im Alten Testament wird in ugaritischen Texten ein Berg Șapanu nicht nur als Sitz, sondern als Wesensbestandteil einer mächtigen Gottheit beschrieben. Der am häufigsten erwähnte und dynamischste aller ugaritischen Götter, Ba'al, wird so sehr mit diesem Berg verbunden, daß ba'lu șapani "Herr/Meister des Șapanu" seine Bezeichnung wird und den vermutlich älteren Eigennamen Haddu verdrängt. Der Berg verdeutlicht also stärker als alles andere das Wesen dieses Hauptgottes. Weithin wird angenommen da $B$ dort, wo Ba'al absolut gebraucht wird, die Ugariter dies nur als Abkürzung für eben diesen "Meister des Șapanu" verstanden haben. So wirkt der Bezug des ugaritischen Gottes zu einem Berg erheblich enger als derjenige Jahwäs zum Zion oder gar zum Șafon, denn eine Konstruktus-Verbindung "Jahwä des Zion" ist dem Hebräer unbekannt. Wieweit lassen sich überhaupt Parallelen zwischen dem Jerusalemer und dem ugaritischen Gott im Blick auf die Funktionen des jeweiligen Șafon-Berges aufweisen?

Erwähnungen des Ba'al vom Șapanu finden sich vor allem in zwei ugaritischen Textgruppen, in Rituallisten sowohl wie in mythischen Erzählungen. Es empfiehlt sich, dem gesondert nachzugehen, da möglicherweise die Gottesauffassung unterschiedlich ist. Begonnen wird mit den kultischen Listen, weil die erzählenden Texte es einer ausschmückenden Phantasie erlauben, den Stoff spannender und farbiger zu gestalten, und deshalb nicht auf jedes Wort festgelegt werden wollen. Rituallisten hingegen spiegeln tatsächlich vollzogenen Kult; hier also war es den Ugaritern auf jeden Fall Ernst mit den genannten Göttern, sind sie doch in diesem Falle zu eigenem Einsatz und erheblichen wirtschaftlichen Aufwendungen bereit.

\section{Ba'al und Șapanu in Götter- und Opferlisten}

Die beiden keilalfabetischen Götterlisten KTU 1.47 und 1.118 wie die akkadische Entsprechung RS 20.24 darf man wohl mit Dietrich-Loretz als "Memoranda für Opfer und Feste" einreihen. Die von den beiden Gelehrten gebotene Tabelle ${ }^{49}$ liefert einen anschaulichen Einblick für das in Frage stehende Problem.

49 TUAT II, $302 \mathrm{f}$. 


\begin{tabular}{|c|c|c|c|}
\hline \multicolumn{2}{|c|}{ Rs I.17/RS $24.264+280$} & \multirow{2}{*}{$\begin{array}{l}\text { Aussprache, Úbersetzung } \\
\text { Gotter des Sapan: }\end{array}$} & \multirow[t]{2}{*}{$\underline{\text { RS } 20.24}$} \\
\hline 1 & il șpn & & \\
\hline $2 / 1$ & ilib & Gott des Vaters & 1 Gott des Vaters \\
\hline $3 / 2$ & il & $\mathrm{El}$ & 2 Gott \\
\hline $4 / 3$ & dgn & Dagan & 3 Dagan \\
\hline $5 / 4$ & b'l sppn & Ba'al vom Sapan & $\begin{array}{l}4 \text { Addu, Herr über } \\
\text { den Hazi }\end{array}$ \\
\hline $6 / 5$ & $b^{\prime} \operatorname{lm}$ & noch ein Ba'al & 5 Addu II \\
\hline $7 / 6$ & $b^{\prime} \operatorname{lm}$ & noch ein Ba'al & 6 Addu III \\
\hline $8 / 7$ & b'lm & noch ein Ba'al & 7 Addu IV \\
\hline 9/8 & b'lm & noch ein Ba'al & 8 Addu V \\
\hline $10 / 9$ & $b^{\prime} \mathrm{Im}$ & noch ein Ba'al & 9 Addu VI \\
\hline $11 / 10$ & $b^{\prime} \operatorname{lm}$ & noch ein $\mathrm{Ba}^{\prime} a \mathrm{l}$ & 10 Addu VII \\
\hline $12 / 11$ & arș w šmm & Erde und Himmel & 11 IDIM und IDIM \\
\hline $13 / 12$ & ktrtt & Kuscharat & 12 Muttergottinnen \\
\hline $14 / 12$ & yrb & Yarich & $13 \mathrm{Sin}$ \\
\hline $15 / 14$ & sppn & Sapan & 14 Berg Hazi \\
\hline $16 / 15$ & kțr & Koschar & $15 \mathrm{Ea}$ \\
\hline $17 / 16$ & pdry & Pidray & 16 Hebat \\
\hline $18 / 17$ & 'țtr & Aschtar & 17 Aschtabi \\
\hline $19 / 18$ & grm w ['mqt] & Berge und Tăler & 18 Berge und Tăler \\
\hline $20 / 19$ & atrrt & Ascherat & 19 Aschratum \\
\hline $21 / 20$ & 'nt & Anat & 20 Anatum \\
\hline
\end{tabular}


Was auffällt, ist das dreimalige Vorkommen des Lexems spn für verschiedene Gestalten innerhalb der Göttergemeinschaft. Dreimal ist es freilich nur in KTU 1.47 mit Sicherheit vorauszusetzen; diese Tafel weist zwar an 15. Stelle eine Lücke auf, die aber kaum anders als mit spn zu füllen ist. In KTU 1.118 steht diese Entsprechung, doch es fehlt das Anfangsglied; die Ergänzung des Eingangs bleibt hypothetisch. Das erste Glied der Liste wirkt wie eine Art Überschrift, il spn meint wohl einen Plural "Götter des Șapanu"48. Das vorangestellte il als bloßes Adjektiv zu fassen "my godlike, towering mountain"49 erscheint beim Beginn der Götterliste mehr als unwahrscheinlich. Demnach gelten alle maßgeblichen Götter in bestimmter Weise als Götter des Șapanu.

Doch zweimal wird spn als Eigenname oder als Teil dessen verwendet. Dabei überrascht, daß der hinter ilib und $i l$ als Nr.5/4 genannte Ba'alu șapani nicht nur von Nr.15/14 Șapanu als eigener Gestalt unterschieden wird, sondern beide verhältnismäßig entfernt von einander aufgeführt werden. Jener Gott steht unmittelbar hinter (seinem Vater) Dagan und vor anderen Ba'alsausprägungen. Șapanu hingegen ist in einer mit Nr.12/11 beginnenden Reihe kosmischer Größen eingereiht, die Nr.19/18 mit Bergen und Tälern insgesamt endet, ehe dann zu einer Gruppe von Göttinnen übergegangen wird. Offensichtlich repräsentiert Șapanu Nr.15/14 einen zentralen, numinosen Hauptberg, im Vergleich zu dem die später genannten Erhebungen göttlicher Art ins zweite Glied rücken. Zwischen dem einen Berg und den vielen Bergen werden einige Gottheiten erwähnt, die wohl auf den Șapanu zu beziehen sind. Dazu gehört zuerst der zauberkräftige Handwerkergott Kotar, bei Philon von Byblos ein Meister der Magie und des maritimen Lebens ${ }^{50}$, dann die weibliche göttliche Regenwolke Pidray ${ }^{51}$; das sind zwei Gestalten, die in den Mythen zur Umgebung des $\mathrm{Ba}^{\prime}$ alu șapani gehören. Als dritter erscheint ein Gott Atttar, vielleicht Gott der künstlichen Bewässerung ${ }^{52}$, der in den Opferlisten selten auftaucht und in den Mythen einen erfolglosen Nebenbuhler $\mathrm{Ba}^{\prime}$ als spielt. Wenn aus der Folge in der Götterliste auf verwandte Aufgaben geschlossen werden darf, ist der voranstehende göttliche Șapanuberg am ehesten als Ursprung lebensnotwendigen Wassers angesehen worden.

Vergleicht man die in der obigen Tabelle daneben gebotene akkadische Liste RS 20.24, so fällt auf, daß sie nach huršan hazi akkadische Götternamen anführt, die keinen so eingeschränkten Aufgabenbereich wie die ugarititschen Entsprechungen wahrnehmen und mit dem Wirken eines göttlichen Berges weit

48 TUAT, ebd.

49 Vgl. CML $49^{9}$ zu KTU 1.3 III 29 nach Dahood, Psalms I, 220 zu Ps 36,7.

50 Euseb, Praep. ev. I, 10,11; einschrănkend jedoch Ebach, Weltentstehung, 178-190.

51 WM I 303; TOu I 78f nach dem Arabischen. Anders Geșe, Religionen, $164 f$.

WM I 249, anders Gese, Religionen, 138. 
weniger zusammengeschaut werden können. Das gilt für Ea als Gott der Weisheit und Garant des bewässerten Kulturlandes ebenso wie für die hurritische Universalgöttin Hebat, erst recht für den ebenfalls hurritischen Aschtabi, der als Kriegsgott mit Attar wenig gemein zu haben scheint. Eine dreimal in hurritischer Fassung erhaltene Götterliste mit vergleichbarer Rangfolge ${ }^{53}$ nennt hinter El zwar Teschub und damit die zu erwartende Entsprechung zu $b^{\circ} l$ spn, läßt aber jeden Hinweis auf seine Verbindung zu einem Berg aus und führt auch später keinen eigenen Berggott an. Demnach dürfte die Selbständigkeit eines Berggottes und die Zuordnung von "Wassermächten" zu ihm einer einheimischen nordsyrischen Gottesauffassung entsprechen. Warum steht aber dann der Ba'al des Șapanu von dem dazugehörigen Berggott im engeren Sinn so weit ab? Ist der Berg selbst sekundär als eine Art Hypostase aus dem umfassenderen Gott ausgegliedert und zum Gegenstand eigener kultischer Verehrung geworden? Oder spiegelt sich hier ein kultgeschichtlicher Proze $B$, bei dem Ba'al erst nachträglich mit jenem Bergmassiv nördlich von Ugarit in Beziehung gesetzt worden ist? Zeigt sich also an der Doppelung von spn in der Liste eine Tendenz, den älteren Berggott durch einen beweglicheren göttlichen "Bergmeister" zu verdrängen? Auf keinen Fall lassen sich Ba'alu șapani und Șapanu selbst in dieser Liste zu ein und derselben göttlichen Person zusammenfassen.

Den keilschriftalfabetischen Götterlisten entspricht eine Opferliste KTU $1.148^{54}$ über "Schlachtopfer für den Șapanu ( $d b h$ spn)", vermutlich anläßlich einer besonderen Festbegehung. Auch diesmal wird Șapanu mit Kotar, Pidray, Bergen und Tälern zusammen beopfert, sie erhalten je ein Schaf; nur Attar fehlt, während Baal șapani weiter vorne erscheint und neben einem Schaf noch einen Stier erhält. Damit lassen sich einige bezeichnende Unterschiede für die uns interessierenden göttlichen Gestalten erkennen, die in anderen Ritualen ebenso deutlich hervortreten werden.

In einer Anzahl von Opferlisten spielt der Șapanu und seine Götter eine herausragende Rolle, doch so, daß sich durchgängig zwei oder mehrere auf den Berg bezogene Gottheiten voneinander abheben. Zusammenfassend einige Beobachtungen:

1. Wo für $\mathrm{Ba}^{\prime}$ alu șapani ein Opfer gefordert wird, steht daneben ein weiteres für Șapanu. Es wird also an zwei eigenständige Wesen gedacht. Dabei erhält der "Meister" des Berges eine größere Zuwendung als der Berggott selbst, etwa

- eine Kuh gegenüber einem Schaf 1.41,32f.41f $=1.87,36 \mathrm{f} .41 \mathrm{f} .{ }^{55}$

- ein Stier und ein Schaf gegenüber nur einem Schaf 1.46,14f; 1.109,9f.

53 AO 17.269; 25.167; RS 24.295; TUAT II 304.

54 TUAT II, 305; TOu II, 224ff.

55 Die Stellen im Folgenden nach KTU, sofern nicht anders vermerkt. 
- ein Stier gegenüber einem Vogel 1.105,10; 1.130,22f.

2. Gelegentlich wird Șapanu allein beopfert, dann mit einem Vogelopfer $1.41,24-26=1.87,24-26^{56}$. Leider verlautet über die Behandlung der Vögel nichts. Werden sie freigelassen in der Erwartung, daß sie in Richtung des heiligen Berges fliegen? Oder dienen sie einem Reinigungsritus ${ }^{57}$ ?

3. Mehrfach taucht hinter beiden Göttern ein besonderer Ba'al von Ugarit auf, dann mit einer Gabe, die wertvoller ist als diejenige an Șapanu und der des $\mathrm{Ba}^{\prime}$ alu șapani gleichkommt 1.41,33-35.41f $=1.87,36-38.41 \mathrm{f} ; 1.46,14-16$; $1.119,9$ 11. Zusätzlich wird $1.148,26 \mathrm{f}$ ein Opfer an Ba'al von Aleppo (? hllb ${ }^{58}$ ) vor dem an jene beiden Götter eingefügt.

4. Ba'al, absolut gebraucht und ohne Ortsbezug, wird häufig gesondert erwähnt. Dabei wird er dort mit dem Ba'alu șapani identisch sein, wo er vor Șapanu selbst erscheint 1.105,10; RIH 78/11. An anderen Stellen jedoch handelt es sich um eine von Ba'alu șapani abgehobene, dann gern mit Dagan zusammengestellte, selbständige Gestalt, da $b^{\prime} l$ spn mit anderen Opfern geehrt wird $1.41,15=1.87,16 ; 1.109,20 ; 1.130,17-24$. In 1.130,3-11, 1.148,10-12 werden Opfer an mehrere $\mathrm{Ba}$ 'ale angeführt, deren näherer Bezug aber nicht eindeutig zu ermitteln ist ${ }^{59}$.

5. Als eine mit dem Berg verbundene Gottheit taucht in rituellen Texten auch Anat des Șapanu auf, u.U. zusammen mit Pidray, doch dann innerhalb der Liste mit einem gewissen Abstand zum Ba'al șapani und zum Șapanu selbst 1.109,9-14.16f; 1.130,3-15. Anats Bindung an den Berg wird durch einen solchen Titel nur in den rituellen Texten ausdrücklich, die mythischen Texte kennen eine Zusammenstellung ' $n t$ spn nicht.

Über die näheren Umstände solcher Opfergaben an Gottheiten des Berges und ihren Zweck geben die Texte nur kärglich Aufschluß. Einige der Begehungen finden an Vollmond statt $1.41,8 \mathrm{ff}=1.87$, $8 \mathrm{ff} ; 1.46,11 \mathrm{ff} ; 1.109$; da jeweils auch andere Gottheiten mit einbezogen sind, läßt sich daraus kaum auf ein besonderes Verhältnis der Berggottheiten zu diesem Gestirn oder zu Zeitspekulationen schließen. Eher lassen sich Bezüge zum Königtum und seiner sakralen Stärkung vermuten. In 1.41,6ff; $1.105,3 \mathrm{ff}$ geht den entsprechenden Opfern eine Handlung des Königs selbst voran, und bei dem $d b h$ spn $1,91,3 \mathrm{ff}^{60}$ vgl. $1.148,1$ handelt es sich wohl um Palastriten. In welchem Maße

\footnotetext{
56 Satztrennung nach TUAT II 312 gegen TOu II 156.

57 Vgl. den Beitrag von V. Haas in diesem Band.

58 Moglich ist auch der Bezug zur Stadt hlb sppn vgl. 4.68,150f; 4,94,15. So Laroche, Ugaritica V, 520 (und Röllig, RLA 4, 242) unter Verweis auf den "Tešsub von Halba" im hurritischen Text $1.42,10$.

59 Vgl. TOu II, $216 f$.

60 TUAT II 321.
} 
aber die Königsmacht an den Berg gebunden ist, und wie die einzelnen Mächte zu der Stabilisierung des Regimes beitragen, wird nicht gesagt.

Was die Opferstätten betrifft, so werden alle genannten Opfer anscheinend in der Stadt Ugarit und nicht auf dem Berge selbst dargebracht. Auf dem Dschebel aqra' haben sich bekanntlich keine Spuren einer spätbronzezeitlichen Kultübung gefunden. Da im Ugaritischen keine Kultanweisungen wie in akkadischen Texten, sondern nur Listen des Opferbedarfs überliefert sind ${ }^{61}$, bleiben die genaueren Bestimmungen schwierig. Eine vage Andeutung findet sich 1.105,7-10:

'Im tzg g b sppn

nskt ksp whrs ț th $\mathrm{sm} I \mathrm{btbt}$

alp wš Šrp alp ṠImm I b'I 'ṣr I 'ṣpn

"Dann: $t z \hat{g}-$ Opfer im $\mathfrak{g} b$ des Șapanu

Eine Statue?62 aus Silber und Gold; ein Opfer: zwei Schafe für Betbet.

Ein Stier und ein Schaf als Brandopfer sowie ein Stier als $\$ l m m^{63}$ für Baaal, ein Vogel für Șapanu."

Das $t z g$, vermutlich eine hurritische Opferart ${ }^{64}$, wird auch 1.91,3f; $1.105,7$ mit dem Berg in Zusammenhang gebracht. Die Lokalisierung $g b$ bleibt vieldeutig; Dietrich-Loretz denken an eine "Opfergrube" ${ }^{165}$. Eine gleichartige Opferstätte wird einige Zeiten später für Rašap mhbn genannt Z.14. Klar ist nur, daß $g b$ sich außerhalb des Tempels des Ba'als von Ugarit findet, denn dieser wird Z.19 als Ort von Opfern an diesen Gott eigens eingeführt. Innerhalb des Ba'alstempels werden 1.109,11-18 Anat șapani und Pidray beopfert. An einem Ba'alaltar - außerhalb des Tempels? - finden Opfer an den Șapanu statt 1.41,41. Den dürftigen Hinweisen läßt sich immerhin entnehmen, daß der fernliegende Berg Sapanu durch Opfer in der Stadt selbst erreichbar war, demnach also bestimmte Stätten in der Stadt gleichsam "Ausläufer" des Berges darstellen mußten; darf man das womöglich mit dem alttestamentlichen Zion als

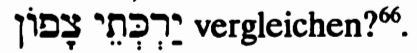

61 Koch, Rituale, 75-85.

62 TUAT II 314,8a.

63 Janowski, Erwăgungen.

64 TOu II, $175^{105}$.

65 TUAT II, 131; zu anderen Deutungen Tarragon, Culte, 21-23.

66 An Opfer auf dem Dach des Ba'alstempels als "kultische(r) Entsprechung des Berges" denkt Gese, Religionen, $124^{201}$. Der schwierige Text $1.65,10 \mathrm{f}$. erwăhnt vielleicht Opfer für El, die im Thronsaal $\left(b^{\prime} d\right)$ von Ugarit als Thronsaal des Șapanu dargebracht werden; TUAT II 319. 


$$
\text { Hazzi - Șafôn - Kasion }
$$

Was läßt sich dem Befund entnehmen? Er verwehrt es zunächst, den Gott Ba'al, wie es sich vom Alten Testament her nahelegen mag, als eine in sich geschlossene göttliche Person aufzufassen. Weit mehr als bei irgendeiner anderen Gottheit tritt der komplexe Charakter von $b^{\prime} l$ in den ugaritischen Texten hervor, dem eine "multiplicité de ses hypostases" Doch ist der $\mathrm{Ba}^{\prime}$ al șapani nicht eine Hypostase unter vielen, sondern wird von der Reihe der übrigen Ba'ale in der Götterliste ausdrücklich abgehoben. Die maßgebliche Erscheinungsform der $\mathrm{Ba}$ 'al-Mächtigkeit ist zweifellos der göttliche Meister des Șapanuberges. Dennoch bildet er für die Kultgemeinschaft nicht einfach den alleinigen Ansprechpartner für seine Gruppe, zumindest der Ba'al von Ugarit kommt ihm vielerorts gleich. Überraschenderweise taucht ein Eigenname Haddu - so in mythischen Texten - in den Ritualtexten nirgends auf. Dagegen nimmt der hurritische Teschub eine vergleichbare Stelle in entsprechenden Ritualen ein, ermangelt aber dann einer ausdrücklichen Beziehung zum Berg 1.110,3; 1.111,4.9; 1.116,13. Wenngleich das tzǵ-Opfer und vielleicht auch die Vogeldarbringung an hurritischen Einfluß denken läßt, so ist doch die Lokalisierung des Ba'algottes auf dem Șapanuberg nicht durch eine Teschub-Konzeption hervorgerufen worden.

\section{Die Auseinandersetzung um den Berg in mythischen Texten}

Die mythischen Texte kennen wie die rituellen ein enges Verhältnis Ba'als zum Șapanu, benutzen dafür aber eine Anzahl von Wendungen und Titeln, die in den Opferlisten keine Entsprechung haben. Der Anat-Ba'al-Zyklus KTU 1.11.6 kreist um nichts anderes als um den Besitz des Berges, den Ba'al mit Recht beanspruchen kann und den andere Götter ihm streitig machen. So greift wenn wir der Ordnung der Tafel in KTU mit den meisten Interpreten folgen der Meergott Jam ihn deshalb mit Billigung Els an, um ihn vom dortigen Thron seines Königtums zu vertreiben 1.1 IV 24f. Nachdem dieser Angreifer abgeschlagen ist, erhält $\mathrm{Ba}^{\prime}$ al die Erlaubnis, auf dem Berg einen Palast zu errichten, um das rechtzeitige Eintreffen von Regen, Schnee und Wolken zu gewährleisten. Der Handwerkergott Kotar-wa-hasis bringt das mittels Feuer und Edelsteinen zustande und stattet ihn - nach anfänglichem Widerstreben $\mathrm{Ba}$ 'als - mit einem rätselhaften Fenster aus. Als der nächste gefährliche Gegner Mot auftaucht und $\mathrm{Ba}^{\prime} \mathrm{al}$ in die Unterwelt verschleppt hat, erscheint es den übrigen Göttern nötig, einen anderen als König auf dem Șapanu einzusetzen. Doch Attar, den man dazu bestimmt auf șrt spn steigen und den Thron des $B a$ 'al besetzen läßt, ist aufgrund seiner körperlichen Unzulänglichkeit zum Regieren da oben nicht im Stande und wird dann auf ein Königtum "über die

67 Tarragon, Culte, 177. 
ganze Erde Els" ('rș il klh) beschränkt 1.6 I 65. Als dann Ba'al wiederkehrt und Mot ihm ein zweites Mal seine Herrschaft streitig machen will, begibt sich der Unterweltsherrscher auf die Höhe des Șapanu, wo dann der entscheidende Zweikampf zwischen den beiden Rivalen stattfindet 1.6 VI 13ff und $\mathrm{Ba}^{\prime} \mathrm{al}$ endgültig sich als siegreich erweist. Der Sapanu ist also in diesem Zyklus beherrschendes Zentrum der Welt, das durch keine andere Stätte ersetzt werden kann. Er ist zwar - anders als in der alttestamentlichen Nachwirkung Jes 14 - nicht der offizielle Versammlungsberg der Götter oder der Sitz des Götterpräsidenten $\mathrm{El}^{68}$, nicht die Stätte, von der aus irdische und göttliche Welt zugleich regiert werden. Doch der sichtbare Bereich wird von dort gesteuert, und auch auf diesem Berg finden sich gern Götter zu gemeinsamen Schmaus zusammen KTU 1.4 VI 44ff.

Wie spiegelt sich das nähere Verhältnis des Șapanumeisters zu seinem Berg in Titeln und geprägten Wendungen, die im Mythos gern wiederholt werden? In den als Mythen eingestuften Keilschrifttafeln wird b'l etwa $150 \mathrm{mal}$ ohne Näherbestimmung gebraucht und ist somit die am häufigsten erwähnte Gottheit. 24 mal wird - nach der Konkordanz von Whitaker - die Gestalt Haddu, dagegen nur 9mal $b l$ spn geheißen. Zum letzten Ausdruck treten einige Varianten. So taucht mehrfach b' mrym spn "Ba'al der Höhe des Șapanu" auf 1.3 IV 82.85; 1.4 V 23; 1.100,9 u.ö. Ähnlicher Hervorhebung dient b`l bșrrt spn 1.3 I 21f, ebenda wird der Palast ( $h k l)$ des Gottes errichtet $1.4 \mathrm{~V}$ 54f. Das läßt sich nach akkadisch surru "Herz, Inneres" als entlegener Zufluchtsort ${ }^{69}$ oder als "Hochland"70 oder nach hebräisch șwr/șrr als "Feste"71 deuten.

Die Höhen des Șapanu sind der "Thron seines Königtums ( $k s^{\prime} u$ mlkh), das Kissen auf dem Sitz seiner Herrschaft (nht lkht drkth)" 1.3 IV 2f. Anderwärts wird der Berg gerühmt als "Fels" (gr $r)$ oder "Hügel" $\left(g b^{\prime}\right)$ seiner Mächtigkeit (tliyt) 1.10 III 30f; 1.101,1f; 1.3 III 31; 1.6 V 5f; VI 33-35 usw., gelegentlich auch als der "Liebreizende" ( $n^{\prime} m$ ), dann parallel zu einem Berg Araru, der sonst nur in administrativen Texten vorkommt ${ }^{72}, 1.10$ III 28-30.

Einige Stellen im Zyklus geben über das Verhältnis zwischen Ba'al und Berg näheren Aufschluß. So ruft im Zusammenhang mit dem sehnlich erwünschten Palastbau Ba'al seine Partnerin Anat zu sich und stellt ihr eine geheime Mit-

68 Vgl. aber Lipiniski, El's abode.

69 CML, 156; TOu I, 156'.

70 ARTU 4: "highlands".

71 Dietrich / Loretz, șrrt șpn, 394f. Anders jetzt dieselben in Ugaritisch șrrt, 79-85: "Höhepunkt, Gipfel" nach akk. șaru.

72 TOu I, 288; nach Bodreuil, Arrou Ǵourou (passim) bezeichnet arr 4.384,1; 4.683,1; 6.27,2 vgl. RIH 83/7,3 eine Stadt oder einen Bezirk südlich von Ugarit "dans la plaine cotière méridionale" S.8. Das macht allerdings die Gleichung mit dem oben genannten Berg zweifelhaft. 
teilung in Aussicht, über die bereits Bäume, Berge und Fluten flüstern. Dabei betont $\mathrm{Ba}^{\prime}$ al sein Besitzrecht an der Stätte KTU 1.3 III 28-31 vgl IV 19-20:

atm w ank 29 ibgyh

btk gry il șpn

30 bqds bgr nhilty

31 b n'm bgb' tlyit

"Komm, ich will es enthullen/untersuchen"3.

Inmitten meines Berges, des il șapanu/i,

auf dem Heiligtum, auf dem Fels meines Erbteils,

auf dem Liebreizenden, auf dem Hügel meiner Măchtigkeit."

Der felsige Berg macht Ba'al erst zu dem, was er ist. Dessen tliyt läßt ihn zum aliyn $b$ l werden, wie sein Titel gern lautet. Der Berg, dessen Charakter dadurch hervorgehoben wird, daß das entsprechende Stichwort $g r$ in zwei aufeinander folgenden Zeilen auftaucht, gilt als heilige Stätte, an der Geheimnisse enthüllt werden können, die anderswo nicht laut werden dürfen.

Der Șapanu ist eine Stätte, die Ba'al als Erbbesitz zugehört, wie Ex 15,17

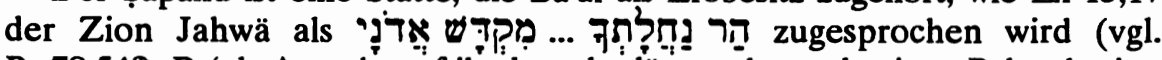
Ps 78,54f). Ba'als Anrecht auf ihn besteht, längst ehe er da einen Palast besitzt und königlich zu walten vermag. Eine ähnliche nhlt wird bei anderen Göttern vorausgesetzt. So hat der göttliche Handwerker Kotar-wa-Hasis als Erbteil $h$ hpt, was vielleicht das ägyptische Memphis meint 1.3 VI 13-15; 1.17 V $21^{74}$. Mots "Land des Erbteils" heißt hmry 1.4 VIII 2-14. Solche Verweise lassen sich kaum anders begreifen denn als Hinweis auf eine urzeitliche Landverteilung durch die oberste Gottheit unter den einzelnen göttlichen Wesen, wie sie im Alten Testament Deut 32,8f voraussetzt:

"Als Äljon die Volker verteilte, als er die Menschheit aufteilte, legte er die Grenzen der

Volker fest nach der Zahl der 'Gottessơnne"75.

Fürwahr, Anteil Jahwäs ist sein Volk, Jakob das Los seines Erbteils (נחלה)." Aufgrund einer solchen Zuteilung gehört Ba'al deshalb zum Berg, ehe er dort einen Palast besitzt und seinen Thron besteigt. An dieser Stelle erscheint der Berg als ein verfügbares Eigentum Ba'als, von einem göttlichen Eigenwillen bei Şapanu selbst ist nichts erkennbar.

73 Nach arab. faga "enthüllen", TOu I, 166"; "untersuchen" nach בעה CML 49; Smith, Baal's Cosmic Secret, 295-298.

74 CML, 146; ARTU, 19; anders TOu I, 99.

75 BHS z.St. 
Neben $\mathrm{Ba}$ 'al stehen auch andere überirdische Wesen zu diesem Berg in Beziehung. Anders als in den rituellen Texten gehört Anat nicht unmittelbar hierher. Sie besucht zwar da ihren Partner, wohnt aber weit entfernt 1.3 IV 3539. Doch nach Ba'als Tod trägt sie zusammen mit Šapšu Ba'als Leiche auf die șrt spn, beweint sie dort und begräbt sie in einer Höhle der ilm arș und bringt dann gewaltige Totenopfer dar 1.6 I 14-18(-31). Was sind das für "Götter der Erde"? Offensichtlich haben sie eine Beziehung zu den Toten, wenigstens dann, wenn diese ordnungsgemäß bestattet sind. Ihre Bindung an den Șapanu scheint aber keine ausschließliche zu sein. Denn Mot hatte zuvor gedroht, seinerseits Ba'al bhrt ilm ars zu legen $1.5 \mathrm{~V}$ 5f und dabei ist sicher nicht der gleiche Platz gemeint gewesen, den später Anat wählt. Demnach werden die hier genannten ilm wohl die in der Unterwelt weilenden Toten $\operatorname{sein}^{76}$. Anscheinend ist es von Belang, an welcher Stelle unter der Erde sich Tote aufhalten. Jedenfalls ist für $\mathrm{Ba}^{\prime} a l$ der Șapanu der günstigste Ort. Von da aus kann er später wiederkehren und seinen Thron neu besetzen.

Daneben taucht, wenn auch seltener als in den Ritualtexten, spn als eigener Gott auf. Im Aqhatepos 1.19 II 34f wird vielleicht Șapanu für sich in einem Ausruf erwähnt: "In der Hand des Șapanu ist unser Sieg (oder: sind sie Siegende, bm yd spn hm tliym $)^{77}$."

Im Keretepos 1.16 I geht die Totenklage vom Șapanu selbst aus, der hier sehr viel selbständiger auftritt als im $A B-Z y k$ lus $^{78}$ :

6 tbkyk ab gr b'l

7 șpn bilm qdS

8 any bylm adr

"Es beweint dich, Vater, der Berg des Ba'al,

Şapanu, die Umwallung der Heiligkeit.

Es klagt die măchtige Umwallung."

Auch im akkadischen Gilgameschepos VIII, I 11 weinen die Berge nach Enkidus Tod. Der ugaritische Text setzt voraus, daß der Berggott im Zusammenhang mit dem Königtum steht. Stirbt ein König, ist dieser Berg betroffen und zur Totenklage gefordert ${ }^{79}$. Der Șapanu ist demnach so etwas wie die

76 CML, $72^{3}$ vgl. 1 Sam 28,13. Darf man den Ausdruck mit ARTU, $77^{368}$ auf "deified ancestors" beschrănken? TOu I, 254: "le cimetière divin, la terre".

77 CML, 116 liest thyt Z.83f. Zur zweiten Übersetzung ARTU, 254. Der Text ist unsicher und bleibt TOu I, 448 unübersetzt.

Dietrich / Loretz, Wehklage, 189-192.

79 Der Name Keret bezeichnet vermutlich von Haus aus einen nichtsemitischen Konig von Chubur. Ihm tritt ein Gott Baal als Fürsprecher zur Seite. Sein (drohender) Tod wird von Șapanu beweint; er hat ein Ausbleiben des Regens zur Folge. 
Gewährleistung staatlicher Stabilität. Bordreuil möchte Z.8 nny statt any lesen und schließt dann auf einen Berg Nana, der in der Grenzliste RS $17.340=$ PRU IV 51.Z.6' in der Gegend des Șapanu genannt wird, in hethitischen Texten als $\mathrm{Na}(\mathrm{m})$ ni häufig neben Hazzi = Șapanu erscheint, und deutet das auf einen Zweitgipfel, der später bei Strabo Anticasius heiß ${ }^{80}$. Da jedoch in den religiösen Texten aus Ugarit eine solche Doppelung höchstens noch 1.10 III 28-31 auftaucht und dort der zweite Berg arr heißt, bleibt eine solche Textänderung fragwürdig.

Weder zu den rituellen noch zu den mythischen Texten im strikten Sinne gehört das Beschreibungslied 1.101, das vermutlich als "Sieges- und Thronbesteigungslied" zu bestimmen ist ${ }^{81}$. Die Beziehung des göttlichen Meisters zum Berg als Thronsitz tritt gleich eingangs betont hervor ${ }^{82}$.

\section{1 b'l ytatb kțbt gr}

hd $\mathrm{r}[\mathrm{b} s] \mathrm{km} \mathrm{db}$

b tk grh il spn

b tk 3 gr tliyt

"Ba'al hat sich thronend gesetzt, denn ${ }^{83}$ ein Thron ist der Berg.

Haddu lag[ert] wie ein Bar $\left(?^{84}\right)$

inmitten seines Berges, des göttlichen (?) Șapanu,

inmitten des Berges seiner Macht."

Die Wendung il spn war schon oben im Zitat aus 1.3 III aufgetaucht. Sie läßt sich an beiden Stellen auf mehrfache Weise deuten.

a) Șapanu könnte eine Näherbestimmung zu El, entweder als Konstruktusverbindung oder als appositionelle Wendung, sein und den Berg diesem Hochgott als Erscheinungsform zuweisen, analog hebräischem El Betel Gen 35,7 oder El Äljon Gen 14,18 u.o.. ${ }^{85}$.

80 Bordreuil, Arrou Ǵourou, 275-279, vgl. Klengel, II 354; III 34f. So jetzt auch Dietrich / Loretz, Ugaritisch șmt, UF 22 (1990) 79-85.

81 So der Titel bei Dietrich / Loretz, Sieges- und Thronbesteigungslied Baals, 129-146, vgl. Loretz, KTU 1.101, 415-421; Fisher / Knutzon, Enthronement Ritual, 157-167; Lipinski, Épiphanie, 8192; Pope / Tigay, Description, 117-130; Margulis, Weltbaum, 1-3; de Moor, Contributions, 639; ARTU 1f.

82 Zur Zeilenordnung s. UF 17, 129.

$83 k$ begründend, Lipiński, UF 3, 82f.

84 So Dietrich / Loretz nach hebr. 27. Den Anfang von Z.2 abzutrennen k.mdb "wie ein Ozean" so ARTU, TOu - ergibt keinen befriedigenden Sinn. Andererseits zwingt die Lesung "Bär" nicht dazu, mit Dietrich / Loretz in der vorangehenden Zeile auch in tbt ǵr eine Tierbezeichnung zu vermuten.

So vermutet es Lipinski, El's Abode, 64 für Ugarit zeitweise. Vgl. Cazelles, Review, 500. 
b) il spn ist nichts als ein Titel Ba'als, hier als Nominativ parallel Haddu, was freilich zu einer anderen Zeilenabtrennung nötigt, die mit dem Parallelismus weniger gut übereinstimmt ${ }^{86}$.

c) il ist eine Art Determinativ, welches Șapanu als eigenständige Gottheit ausweist analog il hd 1.10 III 9 u.ö., bzw. ein Adjektiv "göttlich"87.

Die dritte Lösung entspricht dem Nebeneinander von Ba'al șapani einerseits und Șapanu andererseits in den rituellen Texten und empfiehlt sich daher am ehesten ${ }^{88}$.

Die weiteren Zeilen in 1.101 deuten die Macht, die der Berggott dem über ihm thronenden Meister vermittelt, als die Ursachen von Blitzen und Donner. Sitzt Ba'al auf dem Șapanu, so ragt vielleicht nach Z.7 sein Haupt mit den Hörnern in den Himmel ${ }^{89}$. Der thronende Götterkönig füllt also mit seinen riesigen Maßen das Weltall aus, und der Sapanu stellt den zentralen Weltberg dafür bereit, eine Vorstellung, die wohl Jes 6 ihre alttestamentliche Parallele hat, wo der über dem Zion thronende Jahwä nur mit seinem Saum den Tempel auf dem Berg bedeckt und demnach mit seiner Gestalt hoch in den Himmel emporragt.

Abschließend der Versuch eines Vergleiches der beiden ugaritischen Textgruppen. Übereinstimmend setzen die rituellen wie die mythischen Tafeln den engen Bezug eines $\mathrm{Ba}^{6} \mathrm{al}$ genannten Gottes zum Berg Șapanu voraus, der aller Wahrscheinlichkeit nach dem heutigen Dschebel (el) aqra' entspricht. Jener Gott ist zuständig für die Fruchtbarkeit der Erde durch Regen und Gewitter, aber ebenso für den Bestand von Königtum, Palast und Herrschaft im Staate. Dennoch zeigen sich innerhalb der beiden Textgruppen charakteristische Abweichungen.

a) In den Opferlisten erscheint $\mathrm{Ba}^{\prime}$ al mehrgestaltig, wird als "Meister des Șapanu", aber auch als der von Ugarit oder Halab (Aleppo?) genannt; nur an wenigen Stellen taucht $\mathrm{Ba}^{\prime} \mathrm{al}$ ohne Näherbestimmungen auf. Hingegen herrscht solcher absoluter, "eingestaltiger" Gebrauch von Ba'al in den Mythen vor, dort wird zwar daneben gelegentlich $b l$ spn, häufiger aber noch ein Eigenname Haddu gebraucht, den die erste Textgruppe auffälligerweise vermeidet. In den Mythen ist $\mathrm{Ba}^{\prime}$ al eine entscheidende Potenz und der Berg vornehmlich sein Eigentum, Wohnsitz, Thronstätte. Als nahlatu ist ihm dieser Teil der Erde seit Urzeiten (von El?) zugewiesen, von hier aus dirigiert er Wolken und Wetter.

b) Hier wie dort wird ein nachgeordneter Berggott vom göttlichen "Bergmeister" unterschieden, ohne daß eine genealogische Verknüpfung erkennbar wird.

86 Virolleaud, Ugar. V, 558; Gese, Religionen, 123 ${ }^{192}$; vgl. CML, 142 s.v. il-spn.

$87 \mathrm{Zu}$ den verschiedenen Deutungen Tarragon, Culte, $152 \mathrm{f}$ (Lit.).

88

89 Anders ARTU 2. Zu den unterschiedlichen Deutungen Dietrich / Loretz, Sieges- und Thronbesteigungslied Baals, 137-142, vgl. TOu II, 49. 
Während aber bei den Anordnungen für die Opfer Șapanu absolut eingeführt wird, als ein durchaus gewichtiger Opferempfänger, und il spn nur dort auftaucht, wo es wohl einen Plural von Göttern, die mit dem Șapanu in Beziehung stehen, meint, wird in den anderen Texten der Berggott meist mit il - als Determinativ? - eingeführt, über eine eigene Funktion des Șapanu verlautet aber nichts, abgesehen von der Totenklage, die er nach dem Keretepos anstimmt.

c) Eine Göttin gehört nach den rituellen Listen als 'nt spn ebenso eindeutig zum Berg wie $\mathrm{Ba}$ 'al. Wo die mythischen Erzählungen von ihr berichten, wohnt Anat weit ab vom Berg, ist freilich emsig um den Gott besorgt, der auf dem Berge thront.

\section{Hazi in akkadisch-sprachigen Texten}

Die akkadischen Tafeln aus Ugarit bilden eine dritte Textgruppe, denen aber wenig Einzelheiten zu entnehmen sind. In ihnen wird statt Șapanu ein gursagHazi erwähnt, was deutlich den gleichen Berg meint: In den Schwurgötterlisten, welche Anordnungen des hethitischen Großkönigs an den Herrscher von Ugarit schließen, wird meist am Ende und nach anderen Adad-Gestalten der Adad des Hazi angeführt ${ }^{90}$. Da es sich dabei um Urkunden hethitischer Könige handelt, läßt sich aus diesen Texten nur bedingt auf ugaritische Anschauungen schließen. Wo ugaritische Könige eine Stiftung oder ein Vermächtnis festlegen, rufen sie "ba'al bêl huršân hazi als göttlichen Garanten $a^{91}$. An diesen Stellen erscheint $b a$ 'al so sehr als Eigenname, daß seine Zuordnung als Herr des Berges durch ein zusätzliches bel unterstrichen werden muß. Gott (und Berg) gelten als die Mächte, die königlichen Anordnungen unverbrüchliche Wirkung verleihen. Dieser Aspekt Ba'als tritt in den keilalfabetischen Texten nicht zutage. Im keilalfabetischen Entwurf für einen gewiß in akkadischer Sprache abgesandten Brief des ugaritischen Königs an den Pharao wird Ba'al șapani als $b^{\prime} l$ des einheimischen Herrschers parallel zu Amon als Garant des ägyptischen Königs, der übrigens ebenso ein $b^{\prime} l$ für den Ugariter ist, eingereiht. Der als einziger Landesgott genannte Gott des Șapanuberges gewährleistet also Bestand und Erfolg des Staates ${ }^{92}$. Ein Tempel des ${ }^{\text {IM }}$ vom Hazzi wird PRU III 70:16.276,21 erwähnt; ist damit der Ba'alstempel in der Stadt Ugarit gemeint?

90 PRU IV 52: 17.340,21'; 65: 17.237,15'; 99: 17.79+374,56'(?); 137: 18.06 + 17.365,7'.

91 PRU III 76: 16.144,12; 84: 16.157,27; 108: 16.238,18.

92 Eißfeldt, Ba‘al Șaphon, 53-7; PRU II, 33-5. Vgl. auch Stele und Inschrift des ägyptischen Gesandten Mami mit Weihung an Ba'al șapani Ug I fig.30; ANEP, 485; Stadelmann, Gottheiten 37-9. 
So ergibt sich, daß das Nebeneinander von Berggott und göttlichem Bergmeister in Texten aus Ugarit zwar überall vorausgesetzt, aber keineswegs einhellig vorgestellt wird. Da rituelle Vorschriften in der Regel ein besonderes Beharrungsvermögen besitzen, darf man wohl die mythischen Aussagen, sofern sie sich von jenen unterscheiden, als eine jüngere Weiterentwicklung ansehen. Danach gab es in Ugarit eine fortschreitende Tendenz, Ba'al mehr und mehr als den "Meister schlechthin" zu betonen, also wohl als den Gott, der über und hinter allen hierarchisch-institutionellen Verhältnissen der Gesellschaft wie der Natur steht. Der eigentliche Berggott verliert auf der jüngeren Stufe an Bedeutung ${ }^{93}$. Stellt man in Rechnung, da $B$ allem Anschein nach im beginnenden zweiten Jahrtausend in Syrien noch gar kein Gott Ba'al unter solchem absoluten Namen verehrt wurde, sondern nur unterschiedlichen Gottheiten je ein Epitheton "Herr von $\mathrm{X}^{\text {" }}$ zugelegt worden war $^{94}$, so wird der Berggott Șapanu/Hazi einst für sich gestanden und gewaltet haben und als solcher für den Ursprung von Wetter und Fruchtbarkeit gehalten worden sein ${ }^{95}$.

Zum Berg kam Ba'al als dessen eigentlicher Herrscher wohl nicht aufgrund reiner Spekulation oder einer singulären Wandlung in der Gottesauffassung. In den rituellen Texten wird absolut gebrauchtes $\mathrm{Ba}^{\prime} \mathrm{al}$ mehrfach an Dagan nahe herangerückt ${ }^{96}$. Da Dagan ursprünglich am mittleren Euphrat verehrt worden ist $^{97}$, ist vielleicht auch die Ba'alkonzeption vom Osten her zum Sapanuberg hingelangt. Undeutlich bleibt, ob dabei die Konzeption einer eigenen göttlichen Repräsentation von Herrschaft und Meisterschaft schlechthin bereits mit dem Eigennamen Adad/Haddu gekoppelt war. In den Texten tritt diese Verbindung hinsichtlich des Berges nur selten zutage. Weniger noch ergibt die Parallele des hurritischen Wettergottes Teschub. Der taucht zwar in Ugarit auf, wird aber

93 Die verblassende Rolle des Șapanu erklărt, warum das Wort kaum je als theophores Element auftaucht, Gröndahl, Personennamen, 80.189; zu hazi S.231.

94

Gese, Religionen, 123; Koch, UF 11 passim.

95

Die alteste Erwăhnung eines Berges Hazzi findet sich in der Inschrift des Idrimi Z.33; Dietrich / Loretz, Inschrift, 201-269 und TUAT I 501-504. Ein Hinweis auf eine Stadt șapanum ${ }^{k i}$ findet sich vielleicht schon in Ebla (MEE I Nr.180), Bonnet, Typhon, 101f, was freilich Lipinski, ThWAT 6, 1095 bezweifelt. - Das gern verhandelte Problem der Etymologie von spn kann hier auf sich beruhen. Versuchte Ableitungen von spj "spähen", sp "floßen" oder spn "verbergen" betreffen eine graue Vorzeit, die für den semantischen Befund weder im Ugaritischen noch im Hebrăischen etwas austrägt; vgl. HAL, 979a und ThWAT 6, 1095f. Hazzi scheint der altere (wegen der $i$-Endung hurritische?) Name gewesen zu sein (Idrimi), er ist vielleicht volksetymologisch mit $h z j$ "schauen" verbunden worden, dies wieder mit șpj "ausspăhen", was die Adaption des Namens Șapanu ermöglichte, ThWAT 6, 1096. Vgl. die Zusammenstellung beider 1.123,4.

97 WM I 49. 
nirgends mit dem Berg zusammengestellt. So bleibt die Annahme Kapelruds ${ }^{98}$ erwägenswert, daß Ba'al als selbständige Gottheit ursprünglich weder etwas mit Haddu/Adad noch mit Șapanu zu tun hatte.

Ergebnis: Innerhalb der ugaritischen Texte zeigt sich eine Tendenz, die Wirksamkeit Ba'als auf Kosten des ursprünglich eigenständigen Berggottes mehr und mehr herauszustellen. Somit bahnt sich hier eine Linie an, die im Alten Testament gewissermaßen eine Fortsetzung findet, wenn dort Jahwä zwar auf dem Șafon-Zion thront, dieser aber keinerlei eigenständige Bedeutung mehr besitzt. Ein ähnliches Gefälle läßt sich hinsichtlich der maßgeblichen Funktionen beobachten. Der ugaritische Gott mag zum Berg gekommen sein wegen seiner Wirksamkeit für Wolken und Regen. Dort einmal verortet, wird er mehr und mehr zum Inbegriff irdischer Herrschaft, wobei die Wettergottaufgaben zurücktreten. Die Verschiebung des Schwergewichts auf den Thron eines Weltkönigs tritt dann beim Jerusalemer Gott noch deutlicher hervor.

\section{Hazzi und Nanni als göttliche Berge bei Hethitern und Hurritern}

Der Berg $\operatorname{Haz}(z) i$, den die keilalfabetischen ugaritischen Texte Șapanu nennen, spielt als sakrale Größe in Texten aus Boğazköy eine Rolle, die derjenigen in der nordsyrischen Stadt weithin gleichkommt. Aus dem vielschichtigen Material sind einige Aspekte herauszugreifen, die zum Verständnis der Gottesanschauung in Syrien-Palästina und ihrer Vorgeschichte einen Beitrag zu liefern versprechen.

\section{Schwurgötterlisten}

In den sogenannten Staatsverträgen in hethitischer oder akkadischer Sprache, die in der Regel keine echten Verträge sind, sondern Bündnisformulare, die der Großkönig setzt, der Vasall zu beschwören und an einem Heiligtum zu deponieren hat ${ }^{99}$, nimmt der in Frage stehende Berg zusammen mit einem anderen namens Nanni/Namni von Suppiluliuma I. an bis Hattušili III. eine herausragende Stellung unter den Schwurgöttern ein ${ }^{100}$. Angerufen wird im entsprechenden Abschnitt bei syrisch-mesopotamischen Bündnispartnern zuerst der Sonnengott des Himmels, die Sonnengöttin von Arinna (und der Wet-

98 Kapelrud, Baal, 51. Zur nachträglichen Bindung Ba‘als an den Berg s. Eißfeldt, Wohnsitze, 506 und Koch, Entstehung, 189ff.

99 Von Schuler, Staatsverträge, 34-53. Zum einschlägigen Begriff išhiul s. Otten, Vertrag, 130.

100 Übersicht bei Goetze, Kleinasien, $130 \mathrm{f}$. 
tergott des Himmels); dann folgen der Wettergott von Hatti, Šeri und Hurri, Nanni und Hazzi. Erst danach werden weitere Wettergötter, oft mehr als ein Dutzend, aufgezählt. Dem schließen sich dann Gottheiten anderer Kategorie sowie diejenigen des Hethiterlandes und des Vertraglandes überhaupt an.

Was auffällt, ist die herausgehobene Stellung der beiden Berggötter, die zusammen mit den göttlichen Stieren Šeri und Hurri ${ }^{101}$ eine lange Reihe der Wettergötter unterbrechen. Jene sind anscheinend dem hattischen Wettergott so eng verbunden, daß sie ihm in einer solchen Liste unmittelbar beigesellt werden müssen. Das überrascht, weil zumindest der Berg Hazzi gar nicht im Land Hatti liegt und überdies göttliche Berge allgemein und anonym, zusammen mit Flüssen, am Ende der Schwurgötterliste zusätzlich auftauchen ${ }^{102}$. Bei Bündnisformularen für syrische Vasallen können weitere syrische Berge aufgeführt werden, dann aber weit ab von den eingangs angerufenen Nanni und Hazzi, etwa Libanon (lablana), Sirjon (sariyana), Pišaiša; ihnen folgen die Lulahhi-Götter, die Habiri-Götter, Ereschkigal, die Götter und Göttinnen des Hattilandes, die Götter und Göttinnen des Amurrulandes ${ }^{103}$. Warum werden jene beiden Berge aus ihrem geografischen Kontext gelöst und dem Wettergott von Hatti zugeordnet, jedoch nicht dem nach Syrien weisenden Wettergott von Aleppo, der später erscheint ${ }^{104}$ ? Oder dem umfassenderen Wettergott des Himmels? Auch der an sich nach Syrien weisende Teššub wird wohl vom Hazzi getrennt aufgeführt ${ }^{105}$.

In dem (einem älteren Formular folgenden?) Vertrag Šuppiluliumas mit Niqmadu II. von Ugarit ist die Götterliste noch kurz, lautet die Reihe: Wettergott von Hatti, Sonnengöttin von Arinna, Hebat von Kizzuwatna usw., gegen Ende erscheint der Wettergott des Hazzi. Hier wird nur ein Berg genannt, aber nicht als eigener Gott, sondern nur mit dem zugeordneten Wettergott als einer einheitlichen Gestalt ${ }^{106}$ !

Selbst bei Verpflichtungen von westanatolischen Vasallen können Nanni und Hazzi, mit Šeri und Hurri zusammen, ans Ende der Reihe der Wettergötter treten, aber auch hier von Bergen und Flüssen allgemein unterschieden ${ }^{107}$.

\footnotetext{
101 WM I, $195 f$.

102 So z.B. die Vertrăge Šuppululiuma-Mattiwaza von Mitanni Weidner, Dokumente, 3-37, hier: 28-31 (vgl. S.48f) = ANET 205f; Suppululiuma-Texte von Nuhaši Weidner, 58-71, hier: 66-69.

103 Vertrag Muršili II.- Duppi-Tesub von Amurru, Friedrich, Staatsverträge 1-48, bes. 22-25, = ANET 203-205; vgl. Suppululiuma-Aziru von Amurru Weidner, Dokumente, 74f.; Muršili II.Niqmepa von Ugarit: G. Kestemont, UF 6 (1974) 85-127; s. Klengel, Geschichte III, $44^{16}$.

104 Mattiwaza-Vertrag Z.42; Weidner, Dokumente, $28 \mathrm{f}=$ ANET 205.

105 Ebd. R.36.54-57; ANET 206, vgl. Weidner, 29-30.

106 PRU IV, 48ff; TUAT I, 131f.

107 Muwattalli-Alaksandu von Wilusa Friedrich, Staatsverträge II, 78-81.
} 
Die numinose Ausstrahlung der nordsyrischen Berge reicht also über das zentralanatolische hethitische Kernland hinaus.

Eine sichere Verortung des meist zuerst angeführten Berges Namni/Nanni ist noch nicht gelungen. H.Th. Bossert ${ }^{108}$ dachte an den zentralen Berg Mittelanatoliens, den Erciyas dağ, was zur Zusammenstellung mit dem Wettergott von Hatti passen könnte; doch das hat bislang keine Nachfolge gefunden. E. von Schuler zieht den Amanus in Erwägung ${ }^{109}$, was den geografischen Gegebenheiten Nordsyriens entspricht, wo dieses bis $2200 \mathrm{~m}$ hochragende Gebirge den Eindringlingen aus dem Norden nicht weniger imponiert haben wird als der ğebel el-aqra ${ }^{110}$. H.Klengel schlägt den Anticasius vor, ein dem Hauptgipfel des eben genannten Berges vorgelagerter Nebengipfel. Er setzt ihn mit dem als ugaritischen Grenzfixpunkt PRU IV 51 = RS 17.340: 6' erwähnten huršan nanä gleich ${ }^{111}$. Im letzten Fall bleibt schwierig, warum in den ugaritischen Ritualen dieser Berg nie eine Rolle spielt und zudem gerade in den Staatsverträgen mit Ugarit die Berufung auf diesen Berg ausfällt. Auch in den Texten von Emar kommen jene beide Berge nebeneinander vor ${ }^{112}$. So wird wohl eine zweite selbständige Erhebung im nördlichen Syrien am ehesten wahrscheinlich sein ${ }^{113}$.

Wie es sich auch immer mit Namni/Nanni verhält, warum wird ausgerechnet der nordsyrische Berg Hazzi dem Wettergott des Hattilandes beigesellt? Hethitische Texte pflegen Wetter- und Berggötter häufig zu kombinieren; dann aber handelt es sich um Berge, die im Einzugsbereich der betreffenden Region und ihrer Kultstätten liegen. Der Zusammenhang stimmt also zu meteorologischen Beobachtungen. Hier aber handelt es sich um einen weit abliegenden Berg im Südosten, der mit dem Wetter in Zentralanatolien nichts zu schaffen hat und mit einem wohl hurritischen Namen bezeichnet wird. Wenn das ebenfalls von den Hurritern überlieferte göttliche Stierpaar aufgeführt wird, gab es einst Sinn, weil dadurch die Beweglichkeit des syrischen Wettergottes angezeigt wurde ${ }^{114}$. Nichtsdestoweniger, der syrische Berg an so prominenter Stelle in den Bündnisformularen ruft nach Erklärung. Handelt es sich um einen besonderen Aspekt großköniglicher Macht, den allein er vermittelt? Bildet der Berg

108 Das hethitische Felsrelief bei Hanyeri (Gezbeli), $135 \mathrm{f}$.

${ }^{109}$ WM I (1965), 171; ebenso Lipiński, ThWAT 6, 1097.

110 Der Amanus wird hethitisch gewơnnlich wohl Am(m)ana genannt, was vielleicht aber nur den nordlichen Teil des Gebirges meint; Otten, 1969, 251; vgl. ugaritisch gr amn KTU 2.33.

111 Klengel, Geschichte III, 34f vgl. Bordreuil, Arrou Ǵourou, 20 und Dietrich / Loretz / Sammartin, Ugaritisch șmt sppn, $79 \mathrm{ff}$.

112 ThWAT 6, 1097; s.u.

113 Gonnet, Montagnes, 146f.148f; del Monte / Tischler, Orts- und Gewässernamen, 106.280.

114 Das gilt nur für eine Zeit, in der der Ochsenkarren noch nicht vom Streitwagen überflügelt wurde. 
das mythische Zentrum Syriens, "on possession of which the Hittite claim for world rulership rested"115? Wird wie im Alten Testament an den Thronsitz eines weltweit herrschenden göttlichen "Großkönigs" gedacht?

\section{Kultbegehungen}

Auch rituelle Texte kennen beide göttliche Berge ${ }^{116}$. Während des (h)isuwa-Festes verehrt das Königspaar Hुattušili III. und Puduheba eine (Berg-)Göttin Liluri und den Wettergott als Garanten königlicher Macht. Bei dieser Begehung wird den Bergen Amanus, Manuzija u.a., aber auch Namni und Hazzi, vom König libiert ${ }^{117}$, die in der Mitte einer Liste von 40 in Nord-Süd-Richtung aufgeführten Bergen erscheinen. Unter den aus Kizzuwatna stammenden Texten findet sich ein besonderes Ritual für den Berg Hazzi, wobei dem Wettergott Teššub geopfert und ein "Lied des Königtums" offensichtlich während einer Thronbesteigungsfeier (des Großkönigs oder des Wettergotts?) gesungen wird $^{118}$. Die Festhandlungen setzen wohl voraus, daß der Berg in Nordsyrien in besonderer Weise den Bestand des Königtums im Hattiland gewährleistet. Darüberhinaus werden beide Berge in hurritischen Beschwörungen als besonders fluchkräftig angerufen ${ }^{119}$.

Selbst in den "Riten der Götter des Hattilandes" in Emar-Meskene werden die Götter bzw. Berge Hazzi und $\mathrm{Na}(\mathrm{m})$ ni zusammen mit dem Wettergott des Himmels und dem Stierpaar Hurraš-Seliš mit Opfern geehrt ${ }^{120}$. Die Hethiter verbreiten also den Kult der beiden Berge nicht nur nach Westen hin, sondern auch ostwärts.

115 Goetze, CAH ${ }^{2}$ II (1965), 28. Im Blick auf den Erciyas dag formuliert Börker-Klahnn: "Auch wenn das expressis verbis nicht festgehalten ist, darf es als Selbstverstăndlichkeit gelten, daß auf dem höchsten inneranatolischen Berge der Große Wettergott den wichtigsten all seiner Sitze hatte: HUR.SAG ${ }^{D_{U}}$, 'Berg des Wettergottes', ist neben all den kleinen lokalen Erhebungen zuvơrderst der Argaios" (Mons, 244). Für die Staatsvertrăge trifft das nicht zu. Aber warum nicht?

116 Stellen bei Klengel, Geschichte III, $44^{15}$.

117 Otten, 1969; Haas, Berggotter, 103f.226242.

${ }^{118}$ Haas / Wilhelm, Riten, 260f. Haas, Berggotter, 117 vermutet, daß das Fest direkt auf dem syrischen Berg begangen wurde.

119 Haas, 1982, 143.

${ }^{120}$ Arnaud, Emar VI/3, Nr. 472,57'; 473,8'-9'; 476,2'; 488,3'. Den Hinweis verdanke ich G. Wilhelm. 


\section{Mythen}

Es nimmt nicht Wunder, daß der Berg Hazzi auch in Mythen hurritischen Ursprungs eine Rolle spielt, sind doch wohl die hurritischen Einflüsse von Nordsyrien her in Südanatolien eingedrungen. Im Ullikummi-Lied war berichtet, wie der vom Wettergott gestürzte frühere Götterkönig Kumarbi einen Steinunhold Ullikummi gezeugt und diesen auf die Schulter einer Atlasgestalt gestellt hatte. Von da aus wuchs er unaufhaltsam und bedrohlich in den Himmel. Um die Lage zu überblicken, steigen Teššub, sein Bruder Tašmišu und seine Schwester Sawuška auf den Hazzi und werden des - wohl aus dem Meer oder der gegenüberliegenden Küste aufragenden - Unholdes angsterfüllt gewahr ${ }^{121}$. Dessen Überwindung, die dem Wettergott zunächst mißlingt, dann aber durch einen Rat des Weisheitsgottes $\mathrm{Ea}$ ins Werk gesetzt wird, hat mit dem Berg nichts mehr zu tun. Doch erscheint belangreich, daß Hazzi ein notwendiger kosmischer Beobachtungsposten für den Wettergott darstellt ${ }^{122}$. Es ist vermutet worden, da $\beta$ mit der Erwähnung des Hazzi ein kanaanäisches Motiv in einen älteren hurritischen Sukzessionsmythos eingebaut worden ist $^{123}$. Wenn der Wettergott vom Berg aus seiner Ohnmacht gewahr wird, erinnert das allerdings weniger an ugaritische $\mathrm{Ba}^{\prime}$ almythen als an jüngere Überlieferungen vom Schicksal des Zeus am Berge Kas(s)ion gegen den Unhold Typhon (s.u.).

Den ugaritischen Texten näher steht eine Reminiszenz in der Mythe von Ištar und dem Berg Pišaisa, wo am Ende des erhaltenen Fragments von einem Kampf des Wettergottes gegen das Meer gesprochen und in diesem Zusammenhang auf die Götter Namni und Hazzi verwiesen wird $^{124}$.

Von einem für die Handlung entscheidenden Berg ist zwar in dem - ursprünglich hattischen ${ }^{125}$ ? - Bericht vom Kampf des Wettergottes gegen den Drachen Illujanka nicht die Rede. Der Text gehört zum Purulli-Fest im nordanatolischen Nerik. Doch in einer zweiten Fassung findet der schließliche Sieg des Wettergottes am Meer statt ${ }^{126}$. Die Verwandtschaft mit syrischen Lotan-

\footnotetext{
121 ANET, 122; Quellen des Alten Orients, 167; Haas, Berggötter, 154; Güterbock, JCS 6 (1952) $27 \mathrm{ff}$.

122 Besteht u.U. ein Zusammenhang zum Namen șapanu uber dessen Anklang an die Wurzel șpj "spahen"?

${ }^{123}$ Gese, Religionen, 63f; Quellen des Alten Orients, 160; WM I, 171f; Haas, Berggötter, 142-148 hingegen lokalisiert den ursprünglichen Kumarbi-Zyklus im althurritischen Siedlungsgebiet um Tigrisquellen und Vansee und hălt den Hazzi für einen nachtrăglichen Ersatz eines entsprechenden Berges im Osten infolge einer Westwanderung der Hurriter.

124 Laroche, RHA 82,72 = Textes 186,19f.

125 WM I, 151.

126 ANET, 126; RTAT, 180; Haas, Magie, 113.
} 
Leviathan-Überlieferungen und dem griechischen Typhonmythos lassen vermuten, daß dabei an das Mittelmeer und die Gegend des Hazzi gedacht ist ${ }^{127}$. Güterbock vermutet, daß der am Eingang der Tafeln als Verfasser genannte Beschwörungspriester "die südanatolische Geschichte in dem nördlichen Nerik eingeführt hat" ${ }^{\text {"128 }}$. Ebenso denkbar ist aber, da $B$ ein ursprünglich als Landungeheuer vorgestelltes feindliches Wesen an syrische Überlieferungen angeglichen und deshalb in der Nähe des Meeres angesiedelt wurde.

Wie immer die überlieferungsgeschichtlichen Fragen bei diesen Mythen zu entscheiden sind, ihre Verortung von wesentlichen Episoden um den Wettergott im nordsyrischen Bereich fällt auf. In diesen Texten scheint sich eine zunehmende Tendenz abzuzeichnen, nach der die Feinde des Wettergottes und der (groß)königlichen Herrschaft gerade in dieser Region und in Zusammenhang mit dem Mittelmeer zu suchen sind.

\section{Hethitische Glyptik}

Bedeutsam sind ferner bildliche Wiedergaben von Gottheiten. Bei der berühmten "Prozession" von Yazılkaya sind auf der Nordwand die um die zentrale Begegnung von Teššub und Hुebat gereihten Gestalten Nr.40-44 auf Bergen dargestellt.

Wie in den Schwurgötterlisten werden hier dem Wettergott zwei anthropomorfe Berggötter beigegeben, mit Schuppen, Keilbart, Spitzmütze und Hörnern, daneben allerdings nur ein Stier, während ein zweiter Stier der gegenüberstehenden Hebat beigegeben ist. Unter dieser Göttin befindet sich zunächst ein Panther (oder Löwe), dann aber über vier abgeplatteten Bergen (als Symbol der vier kosmischen Stützen vgl. Ps 89?). Auf einem ähnlichen Tier bewegt sich der hinter ihr stehende Šarruma fort, obgleich diesmal nur zwei seltsam gespaltene Felsen den Untergrund abgeben. Links von Teššub steht ein weiterer Wettergott, vielleicht Šuwalijat-Tašmišu, auf zwei besonders hoch aufragenden Erhebungen. Dahinter folgt Nr.40 (auf der Abbildung nicht sichtbar) Kumarbi, hier als Gott der Fruchtbarkeit mit Zweig, ebenfalls auf zwei abgestumpften Bergen. Die unterschiedlichen Formen der Gebirge deuten darauf hin, daß deren göttliche Mächte für hethitische Betrachter unterschiedlicher Art gewesen sind. Vermutlich ist es von Belang, daß der auf einer gegenüberliegenden Felswand dargestellte, vergöttlichte ${ }^{129}$ König Tudḩalija IV. ebenfalls auf zwei Bergen von wieder anderer Art (schuppig und oben abgerundet) steht. Sechs weitere, kleine Berggötter bilden Nr.13-17 in der Prozession ab, wobei ver-

\footnotetext{
127 Eißfeldt, Baal Zaphon, 23; WM I 178.

128 Hethitische Literatur, 248.

129 Gïterbock bei Bittel, Yazilikaya, 187.
} 


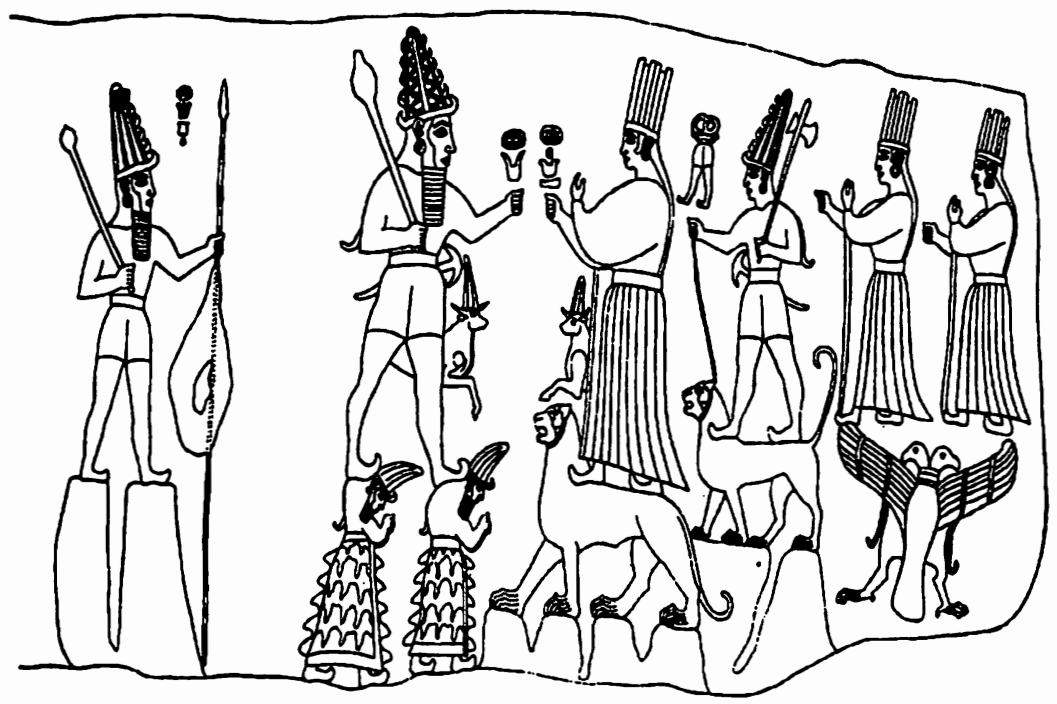

Abb. 1 Mittelszene von Yazilikaya (Akurgal, Kunst 79, Abb. 19)

mutlich Nr.17 die Beischrift Namni trägt ${ }^{130}$. Die beiden Teššub zugeordneten, menschenähnlichen Gebilde übertreffen sichtlich an Rang die vergleichbaren Größen, die den anderen großen Gottheiten beigegeben sind. In einem Kultinventar werden einer goldüberzogenen Statue des Wettergottes des Himmels "zwei Berge in Männnergestalt, die mit Silber überzogen sind" zugeordnet ${ }^{131}$. Da sonst nach den Kultinventaren Berge meist als "Eisenmänner" dargestellt werden, werden hier vielleicht dem höchsten Wettergott wieder zwei Größen zugeordnet, die wie in Yazılıkaya durch ihre numinose Macht sich von derjenigen anderer Berge abheben.

Das Pantheon von Yazllkaya weicht unverkennbar von dem der Bündnisformulare und Schwurgötter ab. Die Beischriften geben den Reliefs nur hurritische Namen, und die Anordnung ist von hurritischer Götterauffassung geleitet. Das spiegelt eine Kultreform wieder, die Tudhaliya IV. (oder schon Hattušili III. unter dem Einfluß seiner Gemahlin Puduheba ${ }^{132}$ ) vorgenommen hat. Dabei bleibt aber die Zuordnung zwei besonders mächtiger Berggipfel zu dem

130 van Loon, Anatolia, 21.

131 Brandenstein, Hethitische Götter, 6f; Bittel, Die Hethiter, 218; vgl. Haas, Berggötter, 49-52; Güterbock, Hethitische Gơtterdarstellungen, 302ff.

132 van Loon, Anatolia, $19^{80}$; Alexander, Sculpture, $137 \mathrm{f}$. 
nun an die Spitze des Pantheons rückenden Teššub gewahrt. Man wird nicht fehlgehen, in ihnen Hazzi und Namni zu vermuten ${ }^{133}$. Insofern bleibt die andauernde Vorordnung nordsyrischer Berge vor einheimischen Bergmächten im Reichsheiligtum bemerkenswert.

Eine allgemeine Koppelung von Wetter- und Berggott ist freilich in der hethitischen Glyptik der Großreichszeit ein verbreitetes Motiv. So findet sich der Wettergott mit einem einzigen männlichen Berggott abgebildet sowohl in Fasıllar ${ }^{134}$ wie auf der großartigen Zeremonialaxt aus Sarkışla, diesmal mit einer Sonnenscheibe und Mischwesen, die sie tragen ${ }^{135}$. Auf dem großen Felsbild von Imamkulu (Abb.2) fährt der von einem Stier gezogene Wagen des Wettergottes über drei sich bückende Bergmänner ${ }^{136}$.

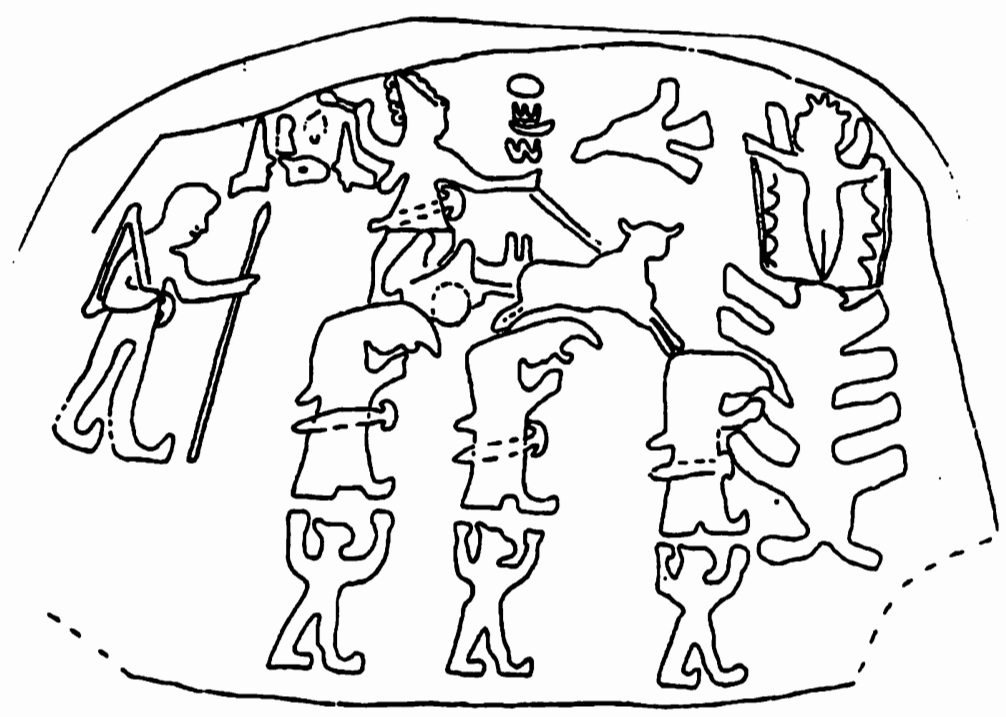

Abb. 2 Imamkulu (nach Kohlmeyer)

\footnotetext{
133 Klengel, Geschichte III, 33; WM I, 171.

${ }^{134}$ Bittel, Die Hethiter, Abb. 264.

135 Ebd., Abb.341.

${ }^{136}$ Kohlmeyer, Felsbilder, Fig.33 und S. 80-86 (Lit.); Bittel, Die Hethiter, 182-186 mit Abb.203; vgl. das benachbarte Relief von Hanyeri mit einem Prinz vor zwei über Stieren stehenden Berggottern, Abb.201. Umgekehrt erscheinen Stiere über je 4 Bergen auf einer Bronzeplakette aus Alaça Hüyük, ebd. Abb.246.
} 
Die Begegnung zwischen männlicher und weiblicher Hauptgottheit wird mythologischer als in Yazllkaya abgebildet. Der Wettergott des Himmels $\left(?^{137}\right)$ hat den Stier hier so bei sich, daß er den Wagen zieht, mit dem er auf seine Partnerin zueilt, die sich vor ihm über einem Baum entschleiert. Getragen wird die Szene von drei gebeugten Berggöttern im Mittelfeld. Sie sind nicht schuppenartig dargestellt, tragen aber wie in Yazllukaya lange konische Mützen und Hörner, hier zusätzlich je ein Schwert. Vielleicht deutet der größere Abstand zwischen dem Berggott rechts und den beiden linken an, daß nur diese zwei unmittelbar dem Wettergott zugehören. Die drei personifizierten Berge haben deutlich eine kosmische, die entscheidende Vereinigung von Wettergott und Göttin allererst ermöglichende Aufgabe. Sie werden ihrerseits von Mischwesen unterstützt, die wohl in der Unterwelt vorzustellen sind. Insofern gibt es hier nicht nur eine notwendige enge Koppelung von Berggott und dazugehörigem Wettergott wie in Ugarit und Yazılıkaya, sondern eine zusammengehörige Dreiergruppe bzw. Vierergruppe, wenn der Stier hinzuzuzählen ist. Auch in diesem Fall dient das mythische Geschehen einer Stärkung königlicher Macht, wie die beigegebene Gestalt eines Königssohns (ganz links) ausweist.

\section{Seitenblick auf die syrische Glyptik}

Nach der Schilderung der bildlichen Wiedergaben in Kleinasien, lohnt es sich, nach Syrien und Ugarit zurückzublicken. Die ikonografischen Denkmäler aus diesem Bereich waren vorerst ausgeklammert worden. Denn die syrischen Fundstücke fügen sich eher den hethitischen Textäußerungen ein als einheimisch-syrischen oder akkadischen, sofern sie der hethitischen Großreichszeit zugehören. Insbesondere zwei Siegel aus Ugarit sind aufschlußreich. Das eine gehört dem hethitischen Vizekönig Initeššub von Karkemisch (13.Jh.v.Chr. Abb.3). Es zeigt links eine bildluwische Inschrift mit Namen und Titeln des Herrschers sowie einen Gott mit Keule, einer Spitzmütze und mehreren Hörnerpaaren. Hier handelt es sich eindeutig um einen Wettergott, vermutlich um Teššub entsprechend dem Namen des Siegeleigners. Er schreitet über zwei an Koniferen erinnernde konische Gebilde hinweg, von denen sich vielleicht das rechte nach vorn bückt, beide versinnbildlichen gewiß Berge. Ihm gegenüber steht eine ähnlich gekleidete und ebenso eine Keule tragende Gestalt mit nur einem Horn an der Spitzmütze, darunter ein stützendes Mischwesen, vielleicht ist jene Initeššub selbst, vielleicht ein zweiter Wettergott. Ganz links bäumt sich ein Stier über einem Kegelstumpf auf, der vielleicht einen dritten Berg bedeutet, dann aber von anderer Art als die beiden tannenähnlichen Gebilde rechts

${ }^{137}$ Die Doppelung des w-artigen Zeichens für "Wettergott" ist schwer erklărlich. 
daneben. Die Stellung eines Stieres neben dem Wettergott erinnert an Yazilukaya.

Die beiden Berge unter seinen Füßen sind gewiß Hazzi und Namni, was sich für einen Herrscher von Karkemisch mehr noch nahelegt als für den von Hattuša. Ganz rechts trägt ein weiterer Stier eine Gestalt ohne Hörnerschmuck, die mit einem Löwen kämpft, was hier unberücksichtigt bleiben kann.

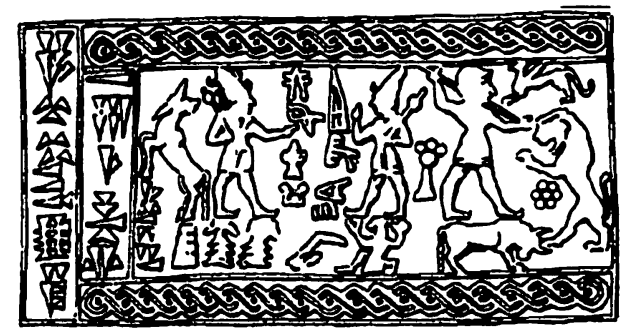

Abb. 3 Zylindersiegel des Initešub (Schaeffer, Ugaritica III fig.32 und S.23-26.85, vgl. Bittel, Die Hethiter, Abb.182)

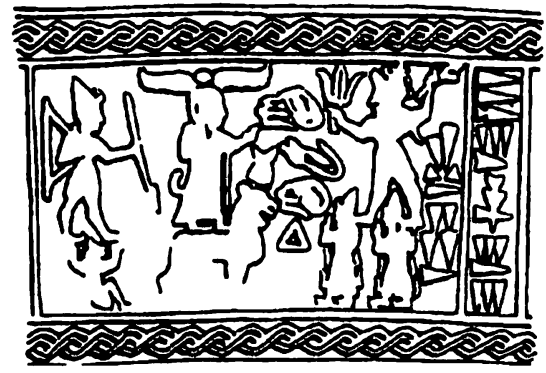

Abb. 4 Zylindersiegel des Amanmaschu (Ugaritica III fig.68 und S.42-50, vgl. Bittel, Die Hethiter, Abb.183) den, sind die Motive auf beiden Siegeln hethitisch bestimmt. Dagegen zeigen die originalen ugaritischen Wettergottfiguren kaum je eine Koppelung zwischen diesen und einem Berg ${ }^{138}$. Außerhalb von Ugarit, wohl im syrisch-anatolischen Grenzbereich, ist ein Rollsiegel gefunden worden, das einen Wettergott mit Keule und Hörnerkrone über zwei männlichen Berggöttern aufweist, die halb im Erdboden verborgen bleiben, aber die gleiche Art von Zweigen

Laroche, Ugaritica III, 85 f. der einen ägyptischen Namen trägt und wohl im Dienste des Königs von Karkemisch steht. Rechts steht ein Wettergott mit Blitzbündel und Keule und doppeltem Hörnerpaar auf den Schultern zweier Männergestalten mit Spitzmütze und anscheinend je einem Hörnerpaar. Gegenüber erhebt sich über einem Löwen eine Gestalt ohne Hörner (?), ein Gott oder ein Großkönig, mit einer Sonnenscheibe über dem Haupt. Obwohl in Ugarit gefun-

Nicht minder sprechend ist das Siegel des Amanmaschu (Abb.4), 


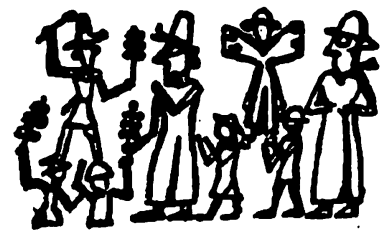

Abb. 5 Syrisches Rollsiegel (Nach Vanel)

hochheben wie der Wettergott selbst $\left(\right.$ Abb.5) ${ }^{139}$. Selbst ein weit im Süden in Megiddo gefundenes Elfenbein mit bildluwischer Beischrift zeigt Stiere und Berggötter, die Gottheiten tragen, über denen sich zwei Sonnenscheiben befin$\operatorname{den}^{140}$. Die hethitische Art, das Thema zu erfassen, macht demnach auch in Palästina Eindruck.

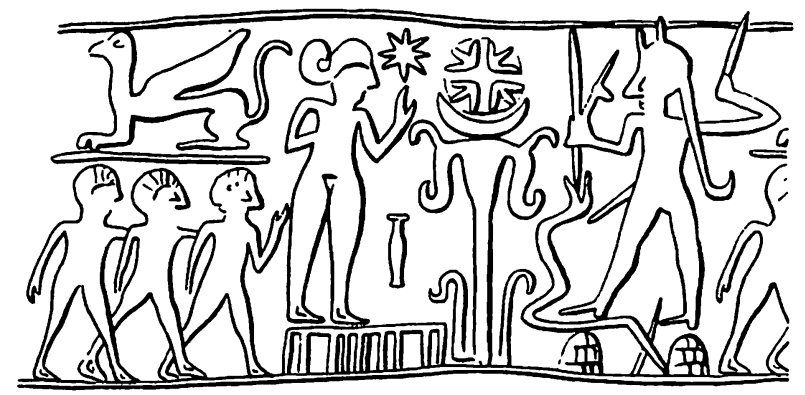

Abb. 6 Altsyrisches Rollsiegel (Nach U. Winter s. Anm. 142)

Doch das Motiv des auf Bergen stehenden Wettergottes ist, wenn man der Deutung von Vanel folgen darf, in Syrien älter als in Anatolien. Schon zwei Siegel aus dem syrischen 18.Jh. v.Chr. bilden es ab, allerdings ohne anthropomorfe Gestalt der Berge ${ }^{141}$.

\footnotetext{
139 Vanel, Iconographie, Abb.52; nach H.Seyrig, Cachets d'archieves publiques de quelques vielles villes de la Syrieromaine, Mélange de l'Université Saint Joseph (Beyrouth) 33 (1940), $93 \mathrm{f}$ und pl.V (mir unzuganglich).

140 Orthmann, Der alte Orient, Abb. 372a; Loud, Ivories, 10. Eingehende Beschreibung Alexander, Sausga.

141 Vanel, Iconographie, Abb.34 und 35 mit S.78f vgl. Abb.17 und S.39, nach Frankfort, Seals, 270 fig.86 und E. Porada, The Collection of the Pierpont-Morgan Library, Corpus of Ancient Near Eastern Seals in North American Collections I, 1948, pl. CXIVI 967 und CA. Eisen, Ancient Oriental Cylinder and other Seals with a Description of the Collection of Mrs. William H.Moore, OIP 47 (1940) pl.XV 158. Vgl. das Siegel von Tell el-Daba'a (18.Jh.) bei Bordreuil 1991, 23 Fig.4.
} 
Auf einem davon stößt der Gott seinen Blitz in den Rachen einer Schlange und schreitet auf eine ihm gegenüberstehende (Abb.6) (nackte?) Göttin zu, die auf einem Podest steht $^{142}$. Auch die berühmte, wohl aus dem 18./17.Jh. stammende ugaritische Stele "Ba'al au foudre", die wohl besser "Hadad mit dem Blitz" heißen sollte, da die absolut gebrauchte Gottesbezeichnung $\mathrm{Ba}^{\prime} \mathrm{al}$ in so früher Zeit noch nicht belegt ist, gehört in diesen Motivzusammenhang (Abb.7). Jedenfalls legt es sich von den Siegelparallelen nahe, die oberen Wellenlinien unter dem Podest, auf dem der Gott steht, auf vier Berggipfel zu beziehen $^{143}$. Welcher Gottesname freilich ursprünglich mit dem auf einem Berg - welchem? - hausenden Wettergott in Syrien verbunden war, läßt sich nicht mehr klären. War es Hadad/Haddu oder Teššub oder ein dritter, den wir nicht kennen? Die älteren kappadokischen Siegel heben sich davon ab. Auf ihnen schreitet zwar gern ein Wettergott - oder mehrere seiner Art -, auf Stier oder Drache

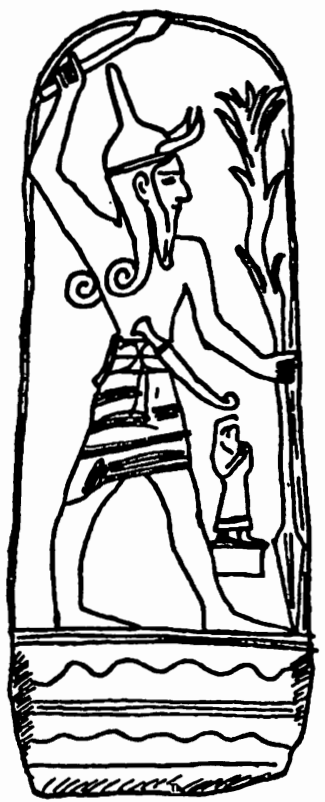

Abb. 7 Hadad mit dem Blitz (Nach Gese, Religionen, 131 Abb.7) stehend einer thronenden Gottheit entgegen $^{144}$. Beide Gestalten werden hier deutlich auseinandergehalten, selbst wenn der Thron als Berg gedacht wäre.

Was ergibt sich für die Herkunft des ikonografischen Typs? Ergebnis: Die Kombination "Wettergott auf zwei Berggöttern" stammt anscheinend aus Syrien, ist aber in Anatolien begeistert aufgenommen worden. Sie wird in Ugarit auf den Bezug zu einem Berg reduziert; in Kleinasien wird der Rang der Berggötter durch anthropomorfe Züge klarer herausgestellt, wobei diese Art von Hochschätzung überraschenderweise mehr syrischen Bergen als anatolischen gilt. Dabei spielt zweifellos "die numinose Kraft, welche die Hethiter in Stein und Fels sahen"145 eine fördernde Rolle. Vermittelt worden ist dieses $\mathrm{Zu}$ -

142 Nach O. Keel, Die Welt der altorientalischen Bildsymbolik und das Alte Testament am Beispiel der Psalmen, Neukirchen - Vluyn ${ }^{4} 1984,42 f$ und Abb.46; U. Winter, Frau und Gottin (OBO 53), Freiburg (Schweiz) / Götingen 1983 Abb.123 (Lit.).

143 Vgl. Bordreuil, Baal, 17-24.

144 Vanel, Iconographie Abb.28.29 und S.63f.

145 Bittel-Boessneck, Yazilikaya, 249. 
einander von Wetter- und Berggott in Kleinasien allem Anschein nach durch eine Art Kulturdiffusion der Hurriter, die von Syrien her erfolgte. Gelegentlich hat man auf eine hurritische Herkunft der Großreichsdynastie als ausreichenden Grund für solche Übertragungen geschlossen ${ }^{146}$. Eine andere Möglichkeit wäre, daß Hattušili I. nach seinem siegreichen syrischen Feldzug hurritische Gottheiten von dort nach Hattuša überführt und fortan hier kultisch verehrt hat ${ }^{147}$. Doch zeigen die Unterschiede der Rangfolge zwischen den Göttern der Staatsverträge, wo das Formular älter ist, und der Reihe in Yazllkaya, daß es in Hattuša eine zweite Welle der Hurritisierung gegeben hat, die wohl mit Hattušili III. und Puduheba verbunden war. Jetzt wird der Wettergott von Hatti Teššub gleichgesetzt. An der Hochschätzung der Berge Namni und Hazzi, wenn wir sie zu Recht für Yazılıkaya ansetzen, hat sich jedoch nichts verändert. Wie die mittelalterlichen Kaiser zwar durch Fürsten in Deutschland gewählt worden sind, aber ihre eigentliche Legitimation durch die Anerkennung im südlichen Rom gefunden haben, scheint die Würde des hethitischen Großkönigtums nicht primär durch anatolische Gegebenheiten legitimiert zu sein, sondern an seiner engen Bindung zu nordsyrischen Bergen zu haften ${ }^{148}$.

Ein Blick auf die Zeit nach 1200. Mit dem Untergang des Großreichs sind weder die hethitische Kunst noch die hethitische Religion verschwunden, wie die späthethitischen Staaten in Anatolien und Nordsyrien erkennen lassen. Doch die enge Verklammerung von Berggott und Wettergott scheint vergessen. Auf den Reliefs wird dargestellt, wie der König dem Wettergott opfert, so in Malatya (Arslantepe) und Ivriz ${ }^{149}$; oder es werden (den Himmel stützende?) Berggötter ohne Wettergott abgebildet, wie in Ain Dara oder Yesemek ${ }^{150}$. Beide Götterarten stehen also für sich. Vollends von Hazzi und Nanni ist in den - freilich nur spärlich erhaltenen - Inschriften nicht mehr die Rede. Anscheinend hat sich die kosmologische Theorie gewandelt und dadurch der Wettergott eine mit Bergen gekoppelte Funktion verloren.

\footnotetext{
146 Güterbock, Historia Einzelschriften 7, Wiesbaden 1964, 57.

147 Wilhelm, Hurriter, 31; Klengel, Geschichte III, 33f.

148 Die Hurriter haben vielleicht die Koppelung von Wetter- und Berggott sich erst in Nordsyrien angeeignet. Das jedenfalls würde erklären, warum die hurritischen Texte aus Ugarit den ursprünglich hurritischen Tetub zwar mit Halab, nicht aber mit Hazzi verbinden, vgl. Ugaritica $5,518 \mathrm{ff}$.

149 Bittel, Die Hethiter, Abb.276.327f.

${ }^{150}$ Ebd. Abb.318.319
} 
IV. Der Niedergang der Verehrung des Șapanuberges im 1. Jahrtausend und das Wiederauftauchen als Kas(s)ion

\section{Wandlung zum Gott der Seefahrt}

Nach dem Fall von Ugarit scheint auch der Gott des heiligen Berges an Rang eingebüßt zu haben. Jedenfalls wird der Berg selbst nur noch wenig erwähnt. Stattdessen rückt ein $b$ l šamem/n an die Spitze des Pantheons bei den Phönikern und Aramäern, so schon im 10.Jh. bei Jehimilk von Byblos ${ }^{151}$. Als Assarhaddon 677 (?) mit dem König Baal von Tyrus einen Vertrag schließt, wird unter den göttlichen Zeugen zunächst Baal-sameme, dann Baal-malage und erst dann Baal șapan ('ba-al-za-pu-nu) angeführt; die drei stellen Mächte dar, welche die Schiffahrt gefährden und Meeresfluten heraufführen können ${ }^{152}$. Selbst im weit südlich liegenden Tyrus spielt der ehemals ugaritische Gott also eine Rolle, steht freilich nicht mehr an erster Stelle im Pantheon; der Gott, der Meisterschaft und Herrschaft verkörpert, ist nunmehr für Phöniker (wie Aramäer) in den Himmel als Ba'al Šamem umgezogen ${ }^{153}$. Aus dem gleichen Tyrus stammt ein Siegel des 6.Jh. mit einer Widmung an Baal Hamon und Baal Șapon als segenspendende (brk) Götter ${ }^{154}$. Diesmal erhält Baal Șapon für das individuelle Leben Bedeutung, steht aber wieder nicht an erster Stelle. Der dort genannte Baal-Hamon war wahrscheinlich von Haus aus der "Baal des Amanus", dieses Gebirge ist demnach bedeutsamer geworden als der Șapanu-Berg ${ }^{155}$. Die wenigen phönikischen Zeugnisse aus dem 1.Jt.v.Chr. erweisen also eine fortdauernde Verehrung des bei den Ugaritern so hoch angesehenen Gottes, verweisen ihn aber auf eine mindere Rangstufe. Als bloße Ortsangabe taucht balișapuna bei Feldzugberichten der Könige Tiglat-Pileser III. und Sargon II. auf ${ }^{156}$.

Der geringeren Wertschätzung in Syrien korrespondiert nun freilich in dieser Zeit eine Verlagerung seines Kultes nach Ägypten. Im Hafen von

\section{KAI Nr.4.}

152 ANET, 534; TUAT I, 159; Borger, Inschriften, § 69.

153 Gese, Religionen, 182f; WM I 429f; Vattioni, Aspetti. KTU 1.5 I 4 war vielleicht schon ugaritisch der Himmel als "Gewand" Baals angesehen worden, ARTU $70^{326}$.

154 Bordreuil, Attestation. Vgl. den neuassyrischen Namen Harușapanu, den Zadok auf har-șapōn zurückfuhrt und einem Syrer zuschreibt: Phoenicians, 59; anders Lipinski, ThWAT 6, 1097. Die bei Benz, Personal Names, gelisteten spn-Namen stammen alle aus Ägypten oder Karthago, 401f. Ein Eigenname Abdșapon taucht im palästinischen Nebi - Junis (3.Jh. v.Chr.?) auf, TUAT II 597 (Lit.). Einen grăzisierten Namen Barsephönēs hat $H$. Seyrig nachgewiesen: Antiquités syrienne, Syr 40 (1963) 31 Nr.34, 12-14.

155 Cross, Canaanite Myth, 26f.

156 Bonnet, Typhon, 110, Lipinski, El's Abode, $63^{252}$. 
Memphis gibt es schon im 13.Jh.v.Chr. eine Verehrung von Baaltis, Qudschu und Baal Șapon ${ }^{157}$. Seit dem 1.Jt. wird eine Erhebung am sirbonischen Meerbusen Baal Șapon geweiht, und deren Gott wird zu einer gewichtigen Gottheit im östlichen Delta, in Tahpanhes und Pelusium ${ }^{158}$. Ein phönikischer Brief des 6.Jh. wünscht "Segen (brk) vom Baal Șapon und allen Göttern vom Tahpanhes" ${ }^{\text {"159 }}$. Ein demotisches Onomastikon nennt dpn(=șapon) neben Pelusium und hrhrt (= Pi-hahirot Exod 14,2) ${ }^{160}$. Noch im Pap. Amherst aus dem 4.-2.Jh.v.Chr. wird Baal um Segen vom Șapon angegangen. An anderer Stelle bietet derselbe Papyrus Psalm 20 in heidnischer Variante, wobei "Zion" mit Sapon und der Jahwäname mit Horus wiedergegeben wird $^{161}$. Dieser neue heilige Berg in der Nähe Ägyptens wird für die jüngere biblische ExodusÜberlieferung wichtig. Die P-Schicht des Pentateuch verlegt nämlich den Durchzug der Israeliten durch das Schilfmeer in die Nähe des ba'al șepon Exod 14,2.9; Num 23,7. Will man darin nicht eine richtige historische Erinnerung nachwirken sehen, was angesichts der jungen Entstehungszeit von $\mathbf{P}$ schwierig ist, müssen priesterliche Kreise der Exilszeit dies als eine beziehungsvolle Ortsangabe betrachtet haben. Vielleicht hat ihrer Meinung nach Jahwä das Meer ausgerechnet am Berg des Ba'al Șephon besiegt, um den heidnischen Gott der Ohnmacht zu überführen, dem seine Verehrer besondere Gewalt über das Meer zugeschrieben hatten.

Die Verlagerung des Șapon und seines Gottes an den Südrand des Mittelmeeres hangt gewiß damit zusammen, daß der Ba'al des Berges zum Schutzgott der Seefahrt geworden war. Davon war in Ugarit noch nichts zu bemerken, wenn man nicht mit Bonnet ${ }^{162}$ mittelbronzezeitliche Steinanker im Gemäuer des Ba'altempels in Ugarit dafür in Rechnung stellen will. Die Sorge für gelingende Seefahrt steht gewiß auch hinter der Errichtung eines Ba'al-ȘaponTempels in Kathargo, über dessen Vorhandensein der berühmte Opfertarif von Marseille Auskunft gibt ${ }^{163}$.

\footnotetext{
157 ANET 249f; LÄ 4, 590f; Stadelmann, Gottheiten, 32-47.

158 Als Filiale des syrischen Kultes gilt das Heiligtum bei Pelusium seit Baudissin, Studien II, $238 \mathrm{ff}$.

$159 \mathrm{KAI}, \mathrm{Nr} .50$; RTAT 269f.

160 Chuvin / Yoyotte, Documents, 48f.

161 Bonnet, Typhon, 116; Steiner / Nims, Sacrifice, 89-114; TUAT II, $933 \mathrm{f}$.

162 Bonnet, Typhon, 107.

163 KAI Nr.69.
} 


\section{Kasion und Typhon}

Das spannendste Kapitel in der Geschichte des Berges und seines Gottes spielt sich um die Mitte des ersten vorchristlichen Jahrtausends ab. Eine tiefgreifende Umwertung vollzieht sich. Das läßt sich zunächst an einer scheinbaren Äußerlichkeit, nämlich einer erneuten Umbenennung wahrnehmen. Die Bezeichnung sapon für den Berg scheint zu verschwinden, in Syrien eher als in Ägypten. Stattdessen taucht der uralte Name hazzi wieder auf, nunmehr in der gräzisierten Form kásion; der Wechsel von anlautendem $h$ zu $K$ läßt sich auch sonst beobachten ${ }^{164}$.

Der nunmehr kasion geheißene Berg bleibt heilig und göttlich. Der darauf waltende Gott aber wird für die Griechen, die nunmehr den östlichen Mittelmeerraum beherrschen, zum Zeus (kas(s)ios ${ }^{165}$ ), und das besagt doch wohl für diese Zeit, daß seine Funktion für Wetter und Vegetation zurücktre$\operatorname{ten}^{166}$. Wie ehedem in Ugarit bleibt er aber für die Herrscher wichtig. Seleukos I. besucht ihn und gründet seine Stadt Seleukia zu dessen Füßen auf ein entsprechendes Orakel hin, so wenigstens will es die Sage. Seleukidische Münzen werden mit dem Steinmal des Gottes geschmückt ${ }^{167}$. Später wallfahren die römischen Kaiser Trajan und Hadrian auf seinen Gipfel ${ }^{168}$. Zugleich bleibt Zeus Kasios Patron der Seefahrt. Das entsprechende Heiligtum des ägyptischen Baal Șapon war schon zu Herodots (III 5) Zeiten "umgetauft", obwohl sich der alte Name bei den Ägyptern daneben länger behauptete als in Syrien. Die Seefahrer verbreiten den Kult des Zeus Kasios weit über die Reichweite des älteren Baal Șapon hinaus nach Delos, Korfu, ja nach Germanien und Spanien $^{169}$. Für die Einschätzung des so benannten Gottes in Syrien ist seine Einordnung bei Sanchunjaton - Philo von Byblos bezeichnend (nach Euseb,

\footnotetext{
164 Bonnet, Typhon, $125^{133}$.

165 Zum Wechsel zwischen $s$ und ss Adler, Kasios, 2265. Reichhaltiges Belegmaterial bei Fauth, Kasion-Gebirge.

166 Auf der Stele von Amrit aus dem 6./5. Jh.v.Chr. wird der Gott Šadrapa uber einem Lơwen und dieser uber zwei Bergen abgebildet. Dabei werden Berge noch mit einem Fruchtbarkeitsgott verbunden, der aber eher chthonisch als metereologisch wirksam gedacht wird; Gese, Religionen, 198-200; ANEP 486.

${ }^{167}$ Haas, Berggotter, 116; Gese, Religionen, 126; Bonnet, Typhon, 126. Bezeichnenderweise scheinen Münzen mit dem Donnerkeil und der Beischrift Zeus Keraunios sich nicht auf den Berg, sondern einen Kult in der Stadt zu beziehen; Adler, Kasios, 2265. Der Wettergott thront nicht mehr auf dem Berg. - Lipińskis These: "Der Gott vom Șaphon nahm jedenfalls einen ausreichend wichtigen Platz im Pantheon der Seleukiden ein, daß sie den archaisierenden Titel 'König des Șaphon' in Dan 11 tragen konnten" (ThWAT 6, 1101), hat gegen sich, daß für die Zeit des Danielbuches צִ nִמicht mehr als Name des Berges zu belegen ist.

168 Bonnet, Typhon, 126.

169 Adler, Kasios, 2267.
} 
Praep. Evang.I. 10, 9). Danach gingen aus Licht, Feuer und Flamme riesenhafte Söhne hervor, die über die Berge Kassion, Libanon, Antilibanon und Brathy (Tabor?) herrschten. Das bezieht sich gewiß auf die Baale dieser vier syrischen Bergmassive. Doch ihnen wird keine bemerkenswerte Funktion beigelegt, sie sind nur eine Stufe innerhalb einer weitreichenden Generationenfolge. Viel später taucht $(I$ 10,31) darin neben der "größten" Astarte ein Adonos, König der Götter, auf, also eine Haddufigur, die aber mit dem Kasion nichts mehr zu tun hat.

Eine solche Gräzisierung orientalischer Gottheiten wie der Austausch von Baal gegen Zeus ist bekanntlich damals nichts Ungewöhnliches. Doch die Neubzw. Wiederbenennung ist in diesem Fall nur die eine, äußere Seite. Ihr parallel läuft eine Umsetzung der mythischen Gewichte. Der Titel Șapon verschwindet anscheinend nicht spurlos, sondern wird fortan als Name Typhon für ein chaotisch-bedrohliches Ungeheuer benutzt, das gegen den Zeus des Berges anstürmt! So jedenfalls verhält es sich, wenn die weit verbreitete These zutrifft, $\mathrm{da} ß$ der griech. typhöeus - typhaōn - typhōn - typhös genannte Götterfeind auf östliche Mythen zurückweist und der Name als Abwandlung von sapon, womöglich auf dem Weg über aram. șippun, zu begreifen sei ${ }^{170}$. Vielleicht wurde zumindest in dieser Spätzeit spn mit der Wurzel "verbergen" zusammengebracht. Denn in der Folge ist hinsichtlich Typhon mehrfach von seiner Verborgenheit die Rede.

Über die Wortähnlichkeit hinaus gibt es in den Überlieferungen von Typhon eine Reihe von Anklängen an die Baalsmythologie ${ }^{171}$. Zwar bleibt es fraglich, ob der Verweis in der Ilias 2,783, daß Typhōeus ein arimois lagere, auf die Aramäer und damit auf Syrien bezogen werden darf ${ }^{172}$. Ergiebiger ist schon Hesiod, Theogonie 820ff. Danach zeugte einst Tartaros mit der Erde ein Unwesen Typhōeus, das mit 100 Drachenköpfen, entsetzlichen Stimmen und Feuer eines Tages den Olymp zum Beben brachte. Doch Zeus hat es von dort aus mit Donner und Blitz erschlagen und in den Tartaros gestürzt. Hiernach findet die Auseinandersetzung an einem Gottesberg statt und wird mit den Mitteln des Wettergottes entschieden, nur daß die Lokalität einen griechischen Horizont erhalten hat. Andere Nachrichten aber nennen ausdrücklich den kasion. Herodot III 5 weiß schon von einer Sage, nach der Typhon sich im sirbonischen See gegenüber dem ägyptischen Kasion verborgen hält. Dabei spielt gewiß der Umstand eine Rolle, daß der ägyptische Gott Seth, der oft mit Baal gleichgesetzt wird, im Lauf des 1.Jt.v.Chr. zunehmend verteufelt wird. Noch ein magischer Text der Römerzeit nennt "Seth, Herr des Kasion" auf

170 WM I, 171; Haas, Berggotter, 121. Die Gleichsetzung findet sich schon 1835 bei Gesenius, Thesaurus linguae hebraicae, s. de Savignac, Note, 216.

171 Belege bei Fauth, Kasion-Gebirge.

172 Vian, Mythe, 20-23. 
einem "Berg des Verbrechens" ${ }^{\text {173 }}$. Strabo (XVI 2,7174) berichtet, daß der Orontes, der in der Nähe des syrischen Berges entlangfließt, früher Typhon geheißen habe und dieser sich nach seiner Niederlage gegen Zeus dort eingewühlt habe. Eindeutiger noch ist die Verortung bei Apollodor (I 39-44): Im schrecklichen Kampf habe zeitweise Typhon die Oberhand gewonnen und am syrischen Kasion Zeus gelähmt und nach Kilikien gefangen geführt ${ }^{175}$. Damit wird der Sieg am Berg näher an den Gottesfeind als an den höchsten Gott herangerückt. Es gibt also eine Reihe von zwar unzusammenhängenden, aber dennoch kennzeichnenden Indizien für die Gleichung Typhon = Șapon. Sie schließt nicht aus, daß es vordem schon eine griechische Überlieferung über ein Ungeheuer ähnlichen Namens gegeben hat; es könnte sich also um eine nachträgliche volksetymologische Gleichsetzung mit dem nordsyrischen Bergesnamen handeln ${ }^{176}$. Auch das würde hinreichend erklären, warum șapon im ausgehenden 1.Jt.v.Chr. die Bedeutung einer positiven göttlichen Macht verliert.

Danach vollzieht sich also um die Mitte des 1.Jt.v.Chr. eine Wendung um $180^{\circ}$ in der Einschätzung des alten Berggeistes. Der neben dem göttlichen Meister des Berges in ugaritischen Texten belegte Berggott selbst war vielleicht schon im 2.Jt. für die Syrer ein "Minister ohne Geschäftsbereich". Diese mit dem Namen șapon benannte Wesenheit wird in der Folgezeit offensichtlich vom Baal oder Zeus des Berges so weit abgehoben, daß sie auf die Gegenseite gerät. Aus dem Nebeneinander des Bergherrn und des Berggottes und gemeinsamer Abwehr des feindlichen Meergottes und seiner dämonischen Helfer wird ein Gegeneinander. Sapon-Typhon verschmilzt zwar nicht mit Jam, wohl aber mit einem Ungeheuer in dessen Umkreis, von dem uns verlorene ugaritische Mythen erzählt haben werden, wie die knappen Anspielungen auf vorzeitliche Kämpfe mit Lotan-Leviathan und den Drachengeistern ${ }^{177}$ nahelegen. Vielleicht wird Ba'al-Șapon nun gedeutet als "Herr/Bezwinger des (Unholds) Șapon".

Wo liegen die Ursachen für einen so tiefen Wandel? Hangen sie mit mythologischen Überhöhungen bestimmter politischer Geschehnisse zusammen, von denen keine Nachricht erhalten ist? Oder hat die um die Mitte des 1.Jt.s in der

173 Chuvin / Yoyotte, Documents, $44^{13}$; Donner, Beschwörung, 89-91.

174 Bonnet, Typhon, 135.

175 Der Fels, von dem aus Ullikummi aufragt, ist vom Hazzi-Kasion aus für einen Gott sichtbar. Ist ein Berg in der Nahe der korykäischen Grotte schon im hethitischen Mythos gemeint? Vgl. den Berg Ulika(m)ma im Hišuwa-Ritual, Otten, Berg- und Flußlisten, 254.

176 So Vian, Mythe, der freilich den Berg mit dem darauf thronenden Ba'al verwechselt: "on comprend mal pourquoi le dieu fulgurant du Casios serait devenu un monstre reprouve" (27). Eben das geschieht gerade nicht.

177 KTU 1.5 I 1f,28-30; 1.6 VI $51 \mathrm{f}$. 
israelitischen Schriftprofetie auftauchende Umwertung des șapon zu einer Unheilsgegend - vgl. Jeremias Ankündigung vom Feind aus dem Norden einen uns bislang nicht greifbaren altorientalischen Hintergrund? Eine zureichende Antwort auf solche Fragen steht noch aus.

Der Wandel vom ugaritischen șapon zum griechischen typhon zeigt an einem sprechenden Beispiel, wie unangebracht die verbreitete Ansicht von einer in sich gleichbleibenden syrisch-kanaanäischen Religion als Antipode zu biblischen Ideen sein dürfte. Die phönikisch-aramäische Religion des 1.Jt. hat sich auf andere Pfade begeben als die Vorgängerin im syrischen 2.Jt. Das wird spätestens in hellenistischer Zeit deutlich, als die Quellen wieder lebhafter zu sprudeln beginnen.

Der Wandel der religiösen Einschätzung, der sich in der Namensübertragung von șapon zu typhon niederschlägt und eine religiöse revolutionäre Umorientierung in sich birgt, ruft nach Erklärung. Zunächst legt es sich nahe, an einen Wechsel der Berg und Gott verehrenden Bevölkerung zu denken. Welcher Wandel des Verehrerkreises sich aber in dem Umkreis des nordsyrischen Berges im 1.Jahrtausend vollzogen hat, bleibt bislang verborgen.

Eine zweite Erklärungsmöglichkeit, welche die eben angeführte nicht ausschließt, liegt in einer Umorientierung der kosmologischen Auffassung. Anscheinend werden im ersten vorchristlichen Jahrtausend in den nahöstlichen Kulturen keine Berge mehr als unentbehrliche Grundpfeiler des Alls vorausgesetzt. Ebensowenig wird mehr mit Wettergöttern gerechnet, die vom Berggipfel aus mit Regen und Blitz Fruchtbarkeit gewährleisten. Stellt man den nunmehr im Kult aufkommenden und schnell dominierenden Himmelsmeister, den Ba'alŠamem bei Phönikern und Aramäern angemessen in Rechnung, so wird nunmehr dem Himmel und seinen numinosen Mächten eine erhöhte Aufmerksamkeit zuteil. Das läßt vermuten, daß die im ersten vorchristlichen Jahrtausend in Mesopotamien rasant voranschreitende Astralisierung und Astrologisierung der Religion auch auf Syrien abgefärbt und das Weltbild gründlich verändert hat. Wo der gestirnte Himmel das Schicksal maßgeblich bestimmt und dies durch Berechnung himmlischer Umwälzungen von Menschen entschlüsselt zu werden vermag, wird die Erde zur runden, homogenen Kugel, ohne daß damit schon das geozentrische Weltbild hinfällt. Darauf ist die wohl bei den Kaldäern entstandene neue kosmologische Idee hinausgelaufen. Dann aber fällt die Notwendigkeit von Bergen als Himmels- und Erdträger dahin. Wenn sie aber nicht mehr den Bestand des Kosmos bedingen, entfällt auch eine ausschlaggebende Rolle für die monarchische Ordnung; infolgedessen lassen sich auch keine großköniglichen Ansprüche von Bergen her begründen. Sie bleiben aber Symbole der Dauer, der Wegweisung, Stätten von Orakelkündung.

Um die Mitte des ersten vorchristlichen Jahrtausends haben ähnliche Ideen wohl auch Israel erreicht und sein Weltbild verändert. Die astralen Symbole und Riten im Umkreis des Ascherakultes auf dem Zion im ausgehenden 
assyrischen Zeitalter nach 2.Kön 23 sind freilich Episode geblieben ${ }^{178}$. Doch die Tendenz nachfolgender Jahrhunderte, Jahwäs Wohnsitz vom Zion zu lösen und mehr und mehr in den Himmel zu verlagern, erinnert an das Gefälle der syrischen Religionsgeschichte im gleichen Zeitalter. Die mythologische Verlagerung zeigt sich bereits in der Relativierung der Jerusalemer Tempel-kabod und einer stattdessen behaupteten Yem-Anwesenheit in deuteronomistischen Kreisen ${ }^{179}$. Sie zeigt sich wohl aber auch darin, daß die Priesterschrift das allein gültige Heiligtum von seiner Bindung an den Zionsberg löst und zu einer schon durch die Wüste wandernden Stiftshütte werden läßt ${ }^{180}$, was sich bei Ezechiel schon vorbereitet hat. An einem gewissen Endpunkt dieser veränderten Kosmologie steht dann die verbreitete Rede von Jahwä als "Gott des Himmels" der Perserzeit. Zu ihr gehört wohl auch der Verweis auf Satan als widergöttlicher Drache. Solche Thesen bedürften natürlich einer eingehenden Begründung. Es könnte aber sein, daß die Veränderungen innerhalb der israelitischen Religion mit den Vorgängen im benachbarten syrischen Raum erstaunlich parallel laufen.

Zusammenfassung: Meine Erwägungen zur mythischen Bedeutung eines nordsyrischen Berges und die Wandlungen seiner Einschätzung in benachbarten Kulturen wollte deutlich machen, daß nicht nur die israelitische, sondern auch die syrisch-kleinasiatische Religionsgeschichte in den zwei vorchristlichen Jahrtausenden eine durchaus dramatische Angelegenheit sind. Mit einer pauschalen Klassifizierung als "Naturreligion" ist den komplexen Phänomenen dieser Religion nicht beizukommen. Das zeigt sich gerade dort, wo der Ansatz zur Ausbildung einer mythischen Überlieferung in einer so realen Naturgegebenheit wie einem Bergmassiv liegt. Daran knüpfen sich nicht nur Wettergottmotive, sondern mehr und mehr auch Motive eines kosmischen wie politischen Machtzentrums an, bis dann ein veränderter kosmologischer Gesamtentwurf die überkommene numinose Einschätzung aus den Angeln hebt und die Mythologie sich von Grund auf verändert. Was die Entwicklungen um das Ansehen des Berges Hazzi-Safon-Kasion für den Bibelwissenschaftler interessant macht, sind die Parallelen zu Wandlungen innerhalb der alttestamentlichen Religion. Sie sind so eng, daß sich der Schluß nahelegt, das Gefälle der alttestamentlichen Überlieferungsgeschichte sei ohne eine Berücksichtigung der nordwestsemitischen Religion gar nicht zureichend zu erfassen.

[Nach Abschluß des Manuskripts erschien der Beitrag von M. Dijkstra, The Weather-God on Two Mountains, UF 23 (1991) 127-140, der u.a. 9 Abbildungen zum Thema enthält.]

\footnotetext{
178 Koch, Aschera.

179 von Rad, Schem-Theologie, 127-132.

${ }^{180}$ Koch, Eigenart.
} 
Bibliographie

Adler, A., Kasios, PRE X,2 (1919) 2264-2267

Akurgal, E. / Hirmer, M., Die Kunst der Hethiter, München 1961

Albright, W.F., Baal-Zephon, FS A.Bertholet (hg. v. W.Baumgarten u.a.), Tübingen 1950, 1-14 Alexander, R.L., The Sculpture and Sculptors of Yazilikaya, Newark / London / Toronto 1986

- Sausga and the Hittite Ivory from Megiddo, JNES 50 (1991) 161-182

Amaud, D., Emar VI/3. Recherches au pays d'Aštata, Paris 1986

Baethgen, $F$., Die Psalmen (HKAT II 2), Gottingen ${ }^{3} 1904$

Graf Baudissin, W.W., Studien zur semitischen Religionsgeschichte II, Leipzig 1878

Benz, F.L., Personal Names in the Phoenician and Punic Inscriptions (Studia Pohl 8), Rom 1972 Berger, $K$, Das Buch der Jubilaen (JSHRZ II 3), Gütersloh 1981

Bittel, $K$, Die Hethiter. Universum der Kunst, München 1976

- Hattuscha. Hauptstadt der Hethiter, Koln 1983

/ Boessneck, J. u.a., Das hethitische Felsheiligtum Yazilikaya, Berlin 1975

/ Naumann, R. / Otten, H., Yazilikaya. Architektur, Felsbilder, Inschriften und Kleinfunde (VDOG 61), Osnabrück $1941=1967$

Börker-Klähn, J., Mons Argaius und Papana, "die Berge", in: $K$ Emre, B. Hrouda u.a. (Hg.), Anatolia and the Ancient Near East, Studies in Honor of Tahsin Özgalc, Ankara 1989, 237-255

Bonnet, C., Typhon et Baal Șaphon, Studia Phoenicia 5 (1987) 101-41

Bordreuil, $P$., Arrou Gourou et Șapanou. Circonscriptions administratives et géographie mythique du royaume d'Ougarit, Syria 61 (1984) $1-10$

Attestations inédites de Melqart, Baal Ḥamon et Baal Șaphon a Tyr, Studia Phoenicia 4 (1986) 77-86

A propos de la topographie économique de l'Ougarit, Syria 66 (1989) 263-274

- La deesse 'Anat et les sources du Șapon, in: Techniques et practiques hydro-agricoles traditionelles en domaine irrigue (BAH 136) 1990, 257-267

- Où Baal a-t-il remporté la victoire contre Yam?, Sem. 40 (1991)17-30

Borger, R., Die Inschriften Assarhaddons. Konigs von Assyrien (AfOB 9), Graz 1956 (1967)

von Brandenstein, C.G., Hethitische Götter nach Bildbeschreibungen in Keilschrifttexten (MVAeG 46), Leipzig 1943

Caquot, A. / Sznycer, M. / Herdner, A. und Caquot, A. / Tarragon, J.M. / Cunchillos, J.L., Textes Ougaritiques I.II (Littératures anciennes du Proche Orient), Paris 1974.1989 (TOu)

Cazelles, H., Review: Ugaritica V, VT 19 (1969) 499-505

Chuvin, P. / Yoyotte, J., Documents relatifs au culte Pélusien de Zeus Casios, RevArch 1 (1986) 41-63

Clifford, R.J., The Cosmic Mountain in Canaan and the Old Testament (HSM 4), Cambridge 1972 Cross, F.M., Canaanite Myth and Hebrew Epic, Cambridge/MA 1973

Dahood, M., Psalms I-II (AB 16-17), Garden City/NY 1965.1968

Demircioğlu, H., Der Gott auf dem Stier, Phil. Diss.Berlin 1939

Dietrich, M., Die Aramáer Südbabyloniens in der Sargonidenzeit (AOAT 7), Kevelaer / Neukirchen-Vluyn 1970

Zur ugaritischen Lexikographie VII 65: gr hd in RS 24.245,1-3 = Ug. 5, S.556f, UF 5 (1973) 96-99

- / Loretz, O., Die Wehklage über Keret in KTU 1.16 I 2-23 (II 35-50), UF 12 (1980) 189-192 
- / Loretz, O., șrt șpn - "Feste des Șapanu", UF 12 (1980) 394f.

- / Loretz, O., Die Inschrift der Statue des Konigs Idrimi von Alalab, UF 13 (1981) 201-269

- / Loretz, O., Sieges- und Thronbesteigungslied Baals (KTU 1.101), UF 17 (1986) 129-146

- / Loretz, O. / Sanmartin, J., Ugaritisch șmt sppn, șmy und hebraisch jrkty șpn, UF 22 (1990) 79. 85

Douglas van Burem, E., Mountain-Gods, OrNS 12 (1943) 76-84

Donner, H., Die Beschwörung des großen Gottes, ZÄS 100 (1974) 89-91

Ebach, J., Weltentstehung und Kulturentwicklung bei Philo von Byblos (BWANT 108), Stuttgart / Berlin / Koln / Mainz 1979

- Art. Kasion, LÄ 3 (1980) 354

Eißfeldt, O., Baal Zaphon, Zeus Kasios und der Durchzug der Israeliten durchs Meer ( BRGA 1), Halle 1932

- Die Wohnsitze der Gơtter von Ras-Schamra, FF 20 (1944) 25-27 = Kleine Schriften II, 1963, 502-506

- Ba‘al Șaphon von Ugarit und Amon von Ägypten, FF 36 (1962) 338-340 = Kleine Schriften IV, Tubingen 1968, 53-57

Frankfort, H., Cylinder Seals, Frankfurt 1939

Fauth, W., Das Kasion-Gebirge und Zeus Kasios, UF 22 (1990) 105-118

Fisher, L. / Knutzon, B., An Enthronement Ritual at Ugarit, JNES 28 (1969) 157-167

Fohrer, G., Hiob (KAT XVI), Gutersloh 1963

Friedrich, J., Staatsvertrage des Hatti-Reiches in hethitischer Sprache I.II (MVAG 1926, 31,2 und 34,1), Leipzig 1930

Gese, H., Die Religionen Altsyriens in: $H$. Gese / M. Höfner / $K$ Rudolph, Die Religionen Altsyriens, Altarabiens und der Mandăer (RdM 10/2), Stuttgart / Berlin / Koln / Mainz 1970

- Vom Sinai zum Zion, Müchen 1974

Gibsom, J.C.L., Canaanite Myths and Legends, Edinburgh ${ }^{2} 1978$ (CML)

Goetze, A., Kleinasien, Handbuch der Altertumswissenschaft 3, 1,3,3,1, Munchen ${ }^{2} 1957$

Gonnet, $H$., Les Montagnes d'Asie Mineure, RHA 83 (1968) 146-151

Grave, C., The Etymology of Northwest Semitic șapanu, UF 12 (1980) 221-9

Gröhndahl, H., Die Personennamen der Texte aus Ugarit (Studia Pohl 1) Rom 1967

Gunkel, $H$., Die Psalmen (HKAT II 2), Gottingen ${ }^{4} 1926$

Güterbock, H.G., Hethitische Literatur, Neues Handbuch der Literaturwissenschaft I: Altorientalische Literaturen, Wiesbaden 1978, 211-254

Haas, $V$., Hethitische Berggötter und hurritische Steindämonen (Kulturgeschichte der Antiken Welt 10), Mainz 1982

- Vorzeitmythen und Gotterberge in altorientalischer und griechischer Überlieferung (Konstanzer Universitătsreden 145), Konstanz 1983

- / Wäfler, M., Yazılikaya und der große Tempel, OrAnt 13 (1974) 211-226

- / Wilhelm, G., Hurritische und luwische Riten aus Kizzuwatna (AOATS 3), Kevelaer / Neukirchen-Vluyn 1974

Helck,W., Die Beziehungen Ägyptens zu Vorderasien im 3. und 2. Jahrtausend v.Chr. (ÄA 5), Wiesbaden 1962, ${ }^{2} 1971$

Herdner, A. $\rightarrow$ Caquot, $A$.

Hillmann, $R$., Wasser und Berg. Kosmische Verbindungslinien zwischen dem kanaanaischen Wettergott und Jahwe, Theol. Diss. Halle 1965

Hölscher, G., Das Buch Hiob (HAT 17), Tübingen ${ }^{2} 1952$ 
Janowski, B., Erwăgungen zur Vorgeschichte des israelitischen §elamîm-Opfers, UF 12 (1980) 231259

- Das Konigtum Gottes in den Psalmen, ZThK 86 (1989) 389-454

Kaiser, O., Der Prophet Jesaja Kap 13-39 (ATD 18), Gottingen 1973 Kapelrud, A., Baal in the Ras Shamra Texts, Kopenhagen 1952

Klengel, H., Geschichte Syriens im 2Jahrtausend v.u.Zt., Berlin 2, 1964; 3, 1970, $32-35$

Knutzon, $B$. $\rightarrow$ Fisher, $L$.

Koch, $K$, Die Eigenart der priesterschriftlichen Sinaigesetzgebung, ZThK 55 (1958) 36-50

- Die Rolle der hymnischen Abschnitte des Amos-Buches, ZAW 86 (1974) 504-537

- Zur Entstehung der Baal-Verehrung, UF 11 (1979) 465-473 = E. Otto (Hg.), Studien zur alttestamentlichen und altorientalischen Religionsgeschichte, Göttingen 1988, 189-205

- Aschera als Himmelskonigin in Jerusalem, UF 20 (1988) 97-120

- Alttestamentliche und altorientalische Rituale in: E. Blum / C. Macholz / E.W. Stegemann (Hg.), Die Hebraische Bibel und ihre zweifache Nachgeschichte (Fs. R.Rendtorff), Neukirchen-Vluyn 1990, 75-85

Kohlmeyer, K, Hethitische Felsbilder, Berlin 1981

Kraus, H.-J., Psalmen 1-2 (BKAT XV/1-2), Neukirchen-Vluyn ${ }^{5} 1978$

Laroche, E., Les dieux de Yazılıkaya, RHA 84-85 (1969) 61-109

- Textes mythologiques hittites en transcription, RHA 77 (1965) 63-176; 82 (1968) 8-90

Lauha, A., Zaphon. Der Norden und die Nordvolker im Alten Testament (AASF.B 49), Helsinki 1943

van der Leeuw, G., Phănomenologie der Religionen, Tübingen ${ }^{2} 1956=1970$

Lipinski, E., El's Abode, OLOP 2 (1971) 13-69

- Épiphanie de Baal-Haddu RS 24.245, UF 3 (1971) 81-92

- Art.

van Loom, M.N., Anatolia in the Second Millenium B.C. Iconography of Religions XV,2, Leiden 1985

Loretz, O., Der kanaanäisch-biblische Mythos vom Sturz des Šạar-Sohnes Hêlēl, UF 8 (1976) 132-136

- KTU 1.101: 1-3a und 1.2 IV 10 als Parallelen zu Ps 29,10, ZAW 99 (1987) 415-421

- $\rightarrow$ Dietrich, $M$.

Loud, G., The Megiddo Ivories III (OIP 52), Chicago 1939

Margulis, B. (Margalit), Weltbaum und Weltberg in Ugaritic Literature: Notes and Observations on RŠ 24.245, ZAW 86 (1974) 1-23

Metzger, M., Himmlische und irdische Wohnstatt Jahwes, UF 2 (1970) 139-158

- Konigsthron und Gottesthron (AOAT 15, 1.2), Kevelaer / Neukirchen-Vluyn 1985

de Moor, J.C., Contributions to the Ugaritic Lexicon, UF 11 (1979) 639-653

- An Anthology of Religious Texts from Ugarit (Nisaba 16), Leiden 1987 (ARTU)

- Ugarit and Israelite Origins (IOSOT-Vortrag in Paris, erscheint in VT.S)

Niehr, H., Der höchste Gott (BZAW 190), Berlin / New York 1990

Nilsson, M.P., Geschichte der Griechischen Religion I, München ${ }^{2} 1955$

Orthmann, W., Der Alte Orient (Propyläen Kunstgeschichte 14), Berlin 1975

Otten, H., Ein althethitischer Vertrag mit Kizzuwatna, JCS 5 (1951) 129-132

- Die Berg- und Flußlisten im Hišuwa-Festritual, ZA.NF 25 (1969) 247-260

Otto, E., Jerusalem. Die Geschichte der Heiligen Stadt (UB 308), Stuttgart / Berlin / Köln / Mainz 1980 
Pope, M.H. / Tigay, J.H., A Description of Baal, UF 3 (1971) 117-130

Porzig, W., Illujankas und Typhon (KAF I), Weimar 1930, 379-386

Priebatsch, H.Y., Wanderungen und Wandlungen einer Sage. Von Ugarit nach Hellas, UF 16 (1984) 257-266

Prinsloo, W.S., Isaiah 14,12-15. Humiliation, Hubris, Humiliation, ZAW 93 (1981), 435-439

Quellen des Alten Orients. Die Schøpfungsmythen, hg. v. M. Eliade, Einsiedeln 1964

von Rad, G., Die deuteronomische Schem-Theologie und die priesterschriftliche kabod-Theologie. Deuteronomiumstudien (FRLANT 58), Göttingen 1947, 25-30 = Ges. Studien zum AT II, (ThB 48), Munchen 1973, 127-132

Roberts, J.M., ȘÄPÔN in Job 26,7, Bibl. 56 (1975) 554-557

Robinson, A., Zion and Saphon in Ps 48,3, VT 24 (1974) 118-123

Röllig, $W$., Art. Hazzi, RLA 4, $241 \mathrm{f}$

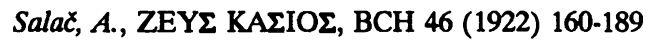

Sanmartín, $J . \rightarrow$ Dietrich, $M$.

de Savignac, J., Note sur le sens du terme șâphôn dans quelques passages de la Bible, VT 3 (1953) 95-96

- Le sens du terme șaphōn, UF 16 (1984) 273-278

Schmidt, H., Die Psalmen (HAT I 15), Tübingen 1934

Schmidt, W.H., Konigtum Gottes in Ugarit und Israel (BZAW 80), Berlin / New York ${ }^{2} 1966$

von Schuler, E., Staatsverträge und Dokumente hethitischen Rechts, Historia Einzelschriften 7 (1964) 34-53

- Art. Hazzi, WM I (1965) $171 \mathrm{f}$

Seyrig, $H$., Cachets d'archives publiques des quelques vieilles villes de la Syrie romaine, Mélanges de l'Université Saint-Joseph (Beyrouth) 23, 1940

Smith, M., Baal's Cosmic Secret, UF 16 (1984) 295-298

Sznycer, $M$. $\rightarrow$ Caquot, $A$.

Spieckermann, H., Heilsgegenwart. Eine Theologie der Psalmen (FRLANT 148), Göttingen 1989 Stadelmann, $R$., Syrisch-palästinensische Gottheiten in Ägypten (Probleme der Ägyptologie ${ }^{5}$ ) Leiden 1967

Staerk, $W$., Lyrik (SAT 3,1), Gottingen ${ }^{2} 1920$

Steiner, R.C. / Nims, C.F., You Can't offer Your Sacrifice and Eat It Too: A Polemical Poem from the Aramaic Text in Demotic Script, JNES 43 (1984) 89-114

Talmon, S., Art. רת, ThWAT 2 (1977) 459-483

de Tarragon, J.-M., Le Culte à Ugarit (CahRB 19), Paris 1980

Tigay, J.H. $\rightarrow$ Pope, M.H.

Vanel, $A$., L'iconographie du dieu de l'orage (CahRB 3), Paris 1965

Vattioni, $F$., Aspetti del culto del signore del cieli, Aug.12 (1972) 480-515; 13 (1973) 37-73

Veijola, T., Verheißung in der Krise. Studien zur Literatur und Theologie der Exilszeit anhand des 89. Psalms (AASF 220), Helsinki 1982

Vian, $F$., Le mythe de Typhée et le problème de ses origines orientales, in: Éléments orientaux dans la religion grecque ancienne (Bibliothèque des Centres d' Études supérieures spécialisés), Paris 1960, 17-37

Volz, $P$., Die Eschatologie der Jüdischen Gemeinde im neutestamentlichen Zeitalter, Tübingen ${ }^{2} 1934=1966$ 


$$
\text { Hazzi - Șafôn - Kasion }
$$

Walser, G. (Hg.), Neuere Hethiterforschung (Historia Einzelschriften 7), Wiesbaden 1964 Wanke, Die Zionstheologie der Korachiten in ihrem traditionsgeschichtlichen Zusammenhang (BZAW 97), Berlin / New York 1966

Weidner, E.F., Politische Dokumente aus Kleinasien (BoSt 8.9), Leipzig $1923=1970$

Wildberger, $H$., Jesaja 13-27 (BKAT X/2), Neukirchen-Vluyn 1978

Wilhelm, G., Grundzage der Geschichte und Kultur der Hurriter (Grundzüge 45), Darmstadt 1982

Xella, $P$., Baal Safon in KTU 2.23, RSF 15 (1987) 111-114

Yoyotte, $J . \rightarrow$ Chuvin $P$.

Zadok, R, Phoenicians, Philistines, and Moabites in Mesopotamia, BASOR 230 (1978) 59-65 van Zijl, P.J., Baal (AOAT 10), Kevelaer / Neukirchen-Vluyn 1972 



\section{Cord Kühne}

\section{Zum Vor-Opfer im alten Anatolien}

Abgesehen von Indien und seiner vedischen Literatur sowie vielleicht noch vom Judentum und seiner mischnischen Tradition zum Dienst im Zweiten Tempel, findet sich unter den Provinzen der vergleichenden Religionskunde des Altertums keine, die bezüglich ihrer kultischen Gegebenheiten im Detail besser bezeugt wäre als das von den Hethitern beherrschte Anatolien des mittleren 2. Jahrtausends v.Chr. Geb. Gleichwohl und obschon bereits einzelne vorzügliche Darstellungen und Spezialstudien vorliegen, steckt die Erforschung der altanatolischen Kulte und ihrer religiösen Grundlagen noch in den Anfängen. Erst ein Teil des (überdies noch nicht vollständig edierten) einschlägigen Quellenmaterials ist philologisch erschlossen, was vor allem daran liegt, daß die vielbeschäftigte junge Hethitologie es sich lange Zeit leisten konnte, die schlecht erhaltenen, meist nur streckenweise rekonstruierbaren, sprachlich oft trocken und spröde wirkenden sogenannten Festbeschreibungen zugunsten ansprechenderer Texte weitgehend zu vernachlässigen. Seit etwa zwei Jahrzehnten zeichnet sich hier freilich ein Wandel des Forschungsinteresses ab. Neue grundlegende Bemühungen um die textuelle Wiedergewinnung jener verschrifteten Rituale kultischer Feste (dem Überrest, wie es scheint, eines der umfangreichsten Textgenres, die in Hattušas Tempelbibliotheken wie auch in den Archiven der hethitischen Königsburg gesammelt wurden) bahnen den Zugang zu einer Fülle von religions- und allgemein kulturgeschichtlichen Daten. Mit zunehmender Kenntnis der rituellen Formenwelt der Texte wächst die Aussicht, auf religionsvergleichendem Wege einmal zwischen Universalien und Sondererscheinungen, sodann aber auch genauer als bisher zwischen autochthon-anatolischem und indo-europäischem Erbe, hurritischen, sumerischbabylonischen oder eventuellen syrisch-kanaanäischen Komponenten unterscheiden zu können und damit sowohl zu einer Einschätzung der formprägenden Kraft und Eigenleistung Altanatoliens auf diesem Gebiet zu gelangen als auch gleichzeitig, im Blick auf die griechischen und römischen Kultaltertümer (und angesichts wahrscheinlicher hethitisch-luwisch-achäischer bzw. späterer kleinasiatisch-griechischer Kontakte), einen wenigstens ungefähren Eindruck von Anatoliens diesbezüglicher Brücken- und Vermittlerfunktion zwischen Ost und West zu gewinnen ${ }^{1}$.

1 Bislang wiegt der Eindruck vor, daß Anatolien im 2. Jahrtausend v. Chr. nicht Brücke nach Europa, sondern Sackgasse und - trotz seines besonderen kulturellen Erbes und seiner Errungenschaften - orientalischer Appendix ist und daß orientalische Einflüsse uber (ggf. luwisch-)phönizische Kontakte nach Westen getangten, vgl. zuletzt etwa Oettinger, 'Dunkle Erde', 96f; anders Burkert, Structure, 127; Neu, Bochumer Altertumswiss. Colloquium 2 (1990) 110f. S. auch im folgenden unten, S. 276 m. Anm. 233. Endgültige Aussagen zu diesem Thema, das kaum von dem Problem des Nachlebens mykenischer Tradition abzukoppeln ist, sind freilich noch nicht moglich. Mit unmittelbarem anatolisch-griechischen Austausch ist 
Verfaßt als Referenzliteratur zur Unterstützung des Kultpersonals der Tempel wie auch zur Information des landesweit höchstpriesterlich fungierenden hethitischen Königs und seiner in Zeremoniell und Ritual erfahrenen Umgebung, sind die entsprechend der Komplexität und Dauer der Kultbegehungen gelegentlich sehr umfangreichen Festbeschreibungen um eine sowohl genaue wie andererseits aber auch knappe Darstellung bemüht. Handlungsdetails etwa, die dem Benutzerkreis geläufig oder die im betreffenden Ritus öfter $\mathrm{zu}$ wiederholen waren, werden bisweilen stillschweigend vorausgesetzt oder, vielleicht häufiger, in formelhafter Kürze angedeutet. Derartige Verkürzungen und gewisse, gerade in solchem Zusammenhang auftretende technische Termini erschweren dem modernen Bearbeiter nicht selten das Verständnis der Vorgänge. Verfügt man über einige Kenntnis des Textgenres, können sich freilich zwei Umstände als hilfreich erweisen: zum einen fallen die Darstellungen gleicher ritueller Einzelschritte nicht immer stereotyp aus (von Varianzen im Mikrobereich ganz abgesehen) und zum anderen erscheinen jene Details gewöhnlich in einer mehr oder weniger festen Handlungsabfolge, die in den Texten auch dann zumeist noch erkennbar bleibt, wenn eine oder selbst mehrere Teilaktionen nicht erwähnt werden. So mag sich denn eine aufgrund von Wortwahl, Idiomatik oder knapper Formulierung zunächst unverständliche Einzelheit anhand des Kontexts als Entsprechung eines Sachverhaltes zu erkennen geben, der in anderen Texten, gar anderswo im gleichen Text, sprachlich abweichend, aber verständlich(er) realisiert wird.

Unlängst habe ich Dank dieser Gegebenheit mehrere einander gegenseitig beleuchtende elliptische Ausdrucksweisen aus dem Formelrepertoire der Festbeschreibungen identifiziert und sie zugleich als Anspielungen auf einen für Anatolien bis dahin nur von wenigen Forschern vermuteten, von Komparatisten geleugneten Blutritus als einen Handlungshöhepunkt des Tieropfers bestimmt ${ }^{2}$. Es zeigte sich, daß dieser weithin gültige Befund ${ }^{3}$ Parallelen in Mesopotamien

jedenfalls spătestens seit der orientalisierenden Periode Griechenlands in der ersten Hălfte des 1. Jt. zu rechnen, und zwar parallel zur phönizischen Einflußnahme.

2 Kühne, auli, 85-117 (einschlägig die Mehrzahl der ib., $115^{118}$ aufgeführten Ausdrücke). Zur bisherigen Diskussion vgl. ib., $115^{120}$, ferner Sommer / Ehelolf, Papanikri, 16; Furlani, Religione, 299. 319f. $338^{63}$ sowie den Literaturhinweis bei Gurney, Aspects, $28^{4}$.

$3 \mathrm{DaB}$ er nicht für alle Kulte bzw. Opferkategorien gültig war, zeigen Beispiele, welche nach der Weihe des Opfertiers an heiliger Stătte dessen Entfernung und Schlachtung an anderem Ort vorsahen (etwa KUB XXXII 49b+ = Salvini / Wegner, Rituale, Nr. 1 II 60-65, dazu s.u.; KUB XXXIX 71 [CTH 718] III 11-14. 31f, s. ebenfalls u.). 
und Griechenland hat ${ }^{4}$, und ebenso drängt sich ein Vergleich mit der Rolle des Blutes im alttestamentlichen Opferkult auf.

Mit den im folgenden vorzutragenden Beobachtungen soll die Betrachtung des altanatolischen Tieropfers fortgesetzt werden. Das Interesse gilt diesmal den rituellen Handlungen, die der Opferweihe und dem Blutritus vorausgehen. Der von mir als Terminus für diesen, den einleitenden, Teil des Opfers verwendete Begriff des Voropfers stellt eine Anleihe an die spätere griechische Systematik dar, welche diejenigen rituellen Handlungen, die an der Opferstätte dem Weihgebet voraufgingen, als próthyma bezeichnet (entsprechend das schon früh einschlägig gebrauchte Verbum katárchesthai "<zu opfern> anfangen").

Weder das heute in mancher Hinsicht ergänzungs- und differenzierungsbedürftige, gleichwohl in seiner Darstellung immer noch unübertroffene Kapitel über das Opfer und die Gaben in Giuseppe Furlanis Religione degli Ittiti von 1936 noch m.W. irgend eine später erschienene Studie versuchen das Boğazköy-Material speziell nach dem Hergang und der Abfolge der rituellen Handlungen zu befragen, mit denen das Tieropfer eingeleitet wurde ${ }^{7}$. Die Heterogenität der Kulte und möglicherweise auch unterschiedliche Funktionen der Tieropferrituale lassen nun freilich auch gar nicht erwarten, daß in allen Fällen ein bis in die Details einheitliches Handlungsschema befolgt wurde. Angesichts der bislang erst partiell erschlossenen Fülle des überlieferten Materials wäre es zudem verfrüht, eine erschöpfende Untersuchung des Themas leisten zu wollen. Stichproben, d.h. eine Auswahl aus den verfügbar vorliegenden einschlägig

4 Vgl. die Blutlibation unmittelbar aus den Hals eines dekapitierten Böckchens vor einer Statue, dargestellt auf der Ur-Nammu-Stele (sumerisch, Ende 3. Jts.), z.B. Kilhne, auli, 93 Abb. 4. Zur Blutlibation in Hellas vgl. Stengel, Opferbrauche, 17ff(.69); Eitrem, Opferritus, 434f. - Ob die frühe Sekundarverwendung des akkad. Verbums naqum "libieren" (und wohl gleichfalls seiner sumer. Entsprechung dé) im Sinne von "(Tiere) opfern" auf den technischen Aspekt des zweifellos bekannten Blutritus zurückzuführen ist (vgl. Kühne, auli, $115^{120}$, ausgeführt unter dem Eindruck der Ur-Nammu-Stele, des neu erhobenen heth. Befundes sowie der sprachlichen Beobachtungen ib., 100f) oder ob es genügt, den Spezialgebrauch mit einer dann schon sehr früh erfolgten, später nachweislichen, Erweiterung des ursprünglichen Libationsbegriffs auf die nichtflüssigen Opfer zu erklăren (zur Frage bereits Dhorme, Les religions, 225) bedarf weiterer Untersuchung. Diese sollte auch die Tatsache berücksichtigen, daß das Blutfließen bzw. -vergießen das augenfälligste Merkmal der üblichen rituellen Opfertơtung ist, die nicht von ungefahr in der Regel oder doch weitgehend im Kult (vgl. Thureau-Dangin, Rituels accadiens, 78, 8ff; 120, 5f; Menzel, Tempel II, 193*3150.3145; Arnaud, Textes 3, no. 369, 11 u.ర.) vollzogen wird.

5 Es genüge hier der Hinweis auf Lev 17, 11 und Dt 12, 26f, Kernaussagen, zwischen denen und um die sich das Feld der at.lichen kultischen Vorschriften über das Blut erstreckt.

6 Vgl. Stengel, Opferbrauche, 17f.31.38.40ff; Ziehen, Griechische Opfer, 600-04.

7 Furlanis Skizze eines Opfervorgangs (Religione, 312-316) bezieht das Tieropfer erst mit dessen Schlußphase, der Verteilung der Fleischstücke, ein, überspringt also die voraufgegangenen spezifischen Handlungen. 
informativen Tieropferbeschreibungen, dürften aber genügen, die Umrisse des Sachverhalts erkennbar zu machen. Es versteht sich dabei von selbst, daß jene Auswahl dem Horizont der zeitlich und vor allem ethnisch unterschiedlichen Ursprünge der in Hattuša gesammelten und zumindest irgendwo im Reich beachteten Kulttraditionen einigermaßen entsprechen sollte.

Ich werde zehn unter solchen Gesichtspunkten ausgewählte Textzeugnisse mit den notwendigen Angaben vorstellen, wobei ich dort auf Umschrift und Übersetzung verzichte und mich auf Paraphrasierungen mit beigefügten Originaltermini beschränke, wo es sich um Interpretamente handelt, deren Umschrift bzw. Bearbeitung bereits in der Literatur zugänglich sind. Anschließend werde ich eine erste Auswertung dieses Stichprobenmaterials vornehmen und - in Ansätzen - eine Deutung und religionsvergleichende Einordnung versuchen. Zur Frage der Opfertypologie ${ }^{8}$ sei vorausgeschickt, daß angesichts der, wie üblich, unvollständigen Textüberlieferung oft keine absolut sichere Kategorisierung erfolgen kann, doch möchte ich - von gewissen Ausnahmen in den beiden letzten Texten unserer Auswahl abgesehen - vermuten, da $B$ es sich stets um Fleischspeiseopfer handelt, die bestimmten Göttern, Göttergruppen oder Numina dargebracht, aber wahrscheinlich zum (größten) Teil dem Verzehr durch die Opfernden bzw. durch die Kultgemeinde zugeführt wurden.

\section{CTH 631: KBo XVII $11(+)$ XX $22+\ldots$ I 39-44}

Das von E. Neu in StBoT 12 bearbeitete und noch einmal in StBoT 25 sub Nr. 25 transkribierte ${ }^{9}$ althethitische Gewitterritual KBo XVII $11+$ mit seinem z. T. weiterführenden jüngeren Duplikat KBo XVII $74+$ XXI $25+$ ABoT 9 wird hinsichtlich seines Sitzes im Leben als bei bzw. nach einem Gewitter durchzuführende kathartisch-apotropäische Gelegenheitshandlung des Staatskults betrachtet ${ }^{10}$. E. Neu hat bereits auf die Verwurzelung des Rituals im

8 Für eine pragmatische, nur gelegentlich mit Abgrenzungsproblemen behaftete Einteilung des Opfers in Fleischspeise-, Vernichtungs-, Preisgabe- und Gabenopfer vgl. etwa Burkert, Glaube, 104ff; Cancik / Mohr, Handbuch I, $109 \mathrm{f}$.

9 Nachtrăge bei Neu, Glossar, $323 f .369$ (KBo XXX 25. 31). Eine für unsere Passage den aktuellen Befund des Duplikats zugrundelegende und die Ergănzung der Lücke in Kol. I [41f] des Originals bietende Umschrift und Übersetzung bei Alp, Tempel, 208-225.

$10 \mathrm{Neu}$, Gewitterritual, 44ff (47). Für eine evtl. befriedigendere alternative Deutung auf ein dem Wettergott im Rahmen des Staatskults gewidmetes altes Frühlings(anfangs)fest, hier mit kalendarisch beweglicher meteorologischer Terminierung - für die Verbindung von Frühling und Gewitter im ländlichen liturgischen Kalender ("wenn es Frühling wird und es donnert, ..." u.a.) vgl. KBo II 7 Vs.9. Rs.(4.) 16; KUB XXV 23 I 8.38.II(15.)IV (8.)51; XVII 35 II 12f -, ließe sich mit der ursprünglich für ein Jahreszeitenfest (Frühlings- oder Herbstfest, s. Archi, Fêtes, 14ff) typischen Anwesenheit von Vorratsgefäßen (haršizalli) argumentieren, die im 
autochthonen, d.h. protohattischen, Kultstratum hingewiesen ${ }^{11}$, die sich außer im Theonomastikon auch in der speziellen Terminologie ${ }^{12}$ kundtut.

Das Ritual sieht für den frühen Morgen nach dem Tag des handlungsauslösenden Gewitters u.a. ein Opfer von 9 schwarzen Schafen und zwei schwarzen Stieren vor. Lokalität des Geschehens ist das halentu-Gebäude, dessen weithin akzeptierter Deutung als "Palast" S. Alp seinen Ansatz "Hauptkultraum (scil. eines Tempels)" entgegensetzt ${ }^{13}$. Beteiligt sind der König als Zelebrant, der im Ornat neben dem Thron Aufstellung genommen hat, sowie Tafeldecker, Köche und Lanzenträger. Empfänger des Opfers ist der als gerade im Gewitter sich wirkungsmächtig bezeugend gedachte Wettergott, als dessen spezieller bleibender Ort der Vergegenwärtigung eine Wand eben jenes (Thron)raumes gilt. An ihr werden denn auch im Verlauf des Rituals die Tiere geschlachtet und der Gott mit Brot- und Trankspenden bedient ${ }^{14}$.

Nachdem zwei Vorratsgefäße hereingetragen und mit je 15 Schwarzbroten belegt worden sind, entnimmt der Oberkoch dem (aller Wahrscheinlichkeit nach in Funktion befindlichen) Herd (hašs̆a-) einen als hulliš bezeichneten Gegenstand ${ }^{15}$, der anhand des Belegmaterials als brennbares dendro-vegetabiles Produkt auszumachen ist, wobei die Interpretation bisher zwischen einem (schwelenden) Koniferenzapfen ${ }^{16}$ und glühender (Holz)kohle ${ }^{17}$

vorliegenden Ritual gemäß Kol. I 37'f eigens an die Opferstatte geschafft werden. Sie dienen zur vorubergehenden Ablage der noch nicht zum Opfer gebrochenen Brote (s. Z. 51"f). Zum Problem vgl. noch Archi, l.c., $13^{34}$.

$11 \mathrm{Neu}$, Gewitterritual, 44.

12 Vgl. das Vorkommen des protohatt., hier als -i-Stamm hethitisierten Funktionărsbegriffs šahtarili-, der Brotsortenbezeichnung zippulašni-, allenfalls auch des Gefäßnamens iškaru/iḩ(sofern hierfür eine nicht unproblematische hethitische Herleitung entfallt, vgl. Kronasser, Etymologie I, 329; Neu, Gewitterritual, 37).

13 Tempel, $1 \mathrm{ff}$ (mit Literaturreferat).

14 Kol. I 44".51"(!) sowie z.B. III 10' (zu erg. gemaß KBo XVII 74 + III 29'). Mogglich, daß die Wahl der Wand als Kultstelle durch einen in der Vergangenheit ebendort erfolgten Blitzschlag bestimmt wurde.

15 Ansatz als N./A. Sg. n. mit Neu, Glossar, 69. Vgl. KBo XXI 33 (+) IV 18'(= Salvini / Wegner, Rituale, Nr. 1 IV 54): I hu-ul-li-is (A.). Doch wird man gelegentlich eine kollektivische oder pluralische Auffassung nicht ganz ausschließen wollen, vgl. (zu KUB VII 53 + XII 58 II 26; XXVII 67 II 3-6) Kronasser, Etymologie I, 328 (A. PI. n.).

16 Goetzes seit Friedrich, HW', 74b meist nur mit "?" ubbernommener Ansatz "pine cone" (Tunnawi, 79-84) gründete sich wesentlich auf die lexikalische Gleichung $B] U-R A-\check{S} U=h u-u a-$ al-ịa-x[ in KUB III 93 I 6'(MSL XVII, 124), wobei Goetze akkad. buräsum (jetzt nach AHw und CAD "phönikischer Wacholder") mit Thompson, Dictionary, s.v., als "pine" faßte. Da Wacholder (wenn wir es denn mit einer exakten Gleichung der hethitischen Lexikographen und mit semantischer Bestăndigkeit des von buräšum vertretenen Etymons zu tun haben) als solcher nicht zu den coniferae zăhlt, bleiben zugunsten des "Tannenzapfens" nur noch ein paar noch brüchigere Spekulationen (referiert bei Tischler, Etymologisches Glossar I, 326f). 
schwankt. Dieses hullis wirft der Oberkoch in bereitgehaltenes Wasser, aus dem er es alsbald, d.h. nachdem er es so gelöscht hat, wieder herausholt. Dann "reinigt" oder "heiligt" (suppiiahh anderen alten Ritual mit wiederholtem Sprengen von Wasser in Zusammenhang gebracht und wohl damit identifiziert wird ${ }^{18}$. Addierend verbindet unser Text damit die Bestimmung, daß der Oberkoch dem König das tuhhuišar vorhält, ein sonst meist als tuhhueššar wiedergegebenes, in vielen Ritualen sowohl zur eben erwähnten passiven (suppiiahh-) wie auch zur aktiven kultischen Feuchtreinigung verwendetes ${ }^{19}$, verschiedentlich als fest ${ }^{20}$, entgegen anderslautenden Behauptungen jedoch nirgendwo mit Sicherheit als flüssig ${ }^{21}$ er-

17 So ("hot embers") Güterbock in: Cavigneaux et al., MSL XVII, 124, $6^{3}$, was eine Probe bei KUB XXVII 67 (CTH 391) II 3ff zu bestattigen scheint. Man vergleiche noch die Bestimmung in Salvini / Wegner, Rituale I/2, Nr. 1 (s.o. Anm. 15) IV 54f, die vorsieht, daß man auf einem Fladenbrot eine Rippe, ahharra-Holz, ein hulli- und Zedernholz als Opfergabe aufs Dach legt und dazu einen Becher Wein libiert. Gluhende Kohle ist hier freilich nur dann denkbar, wenn mit der Libation der Nebenzweck verbunden war, die sonst allzu gefahrliche Glut zu losschen. Aber vielleicht darf man gegensinnig daran erinnern, daß in vielen Sprachen das Wort für "Kohle" an sich hăufig die Konnotation von Glut und Hitze birgt, vgl. akkad. pēmtum (z.B. Belege in AHw, s.v.), hebr. pahăm neben "gahal (zuletzt Segert, Live Coals, 163) oder selbst unser "auf Kohlen gehen/stehen" usw.

KBo XX 10 + (CTH 669; Neu, Ritualtexte, Nr. 59; teilw. ubersetzt von Alp, Tempel, 245ff) I 10f.II 8f: ta LUGAL-un šu-up-pi-ah-hi una-tar III-šU iš-pár-nu-zi.

19 Ausführlich Kammenhuber, tuhhueššar, 63ff; Otten, Festritual, 26.

20 t. wird (nach seiner rituellen Nutzung) auf ein Leintuch gelegt (KUB XX 59 I 19f, s.u., CTH 616) und aus (bzw. mit?) einem solchen genommen (KUB X 4 I 5'-7'). Vgl. ferner KUB XX 85 + (CTH 593, s.u.) I 11-17: in das Wasser, das in ein Gefaß gegossen worden ist, wird $t$. gelegt, bevor die Reinigungsprozedur geschieht (s. auch KUB XX 59 [CTH 616, s.u.] I 7'ff; VBoT 31, 6'). Entsprechend sieht die altheth. Ritualbeschreibung KBo XVII 15 (CTH 645; $\mathrm{Neu}$, Ritualtexte, Nr. 27) Rs.!' 17' vor, daß (zusammen)gebundenes $t$. in einem mit Wasser angefültten Trinkgefaß liegt. Gemaß KUB IX 28 (und Dupl., CTH 442) III $15 f$ wird mit tiiammar- zusammengebundenes (s. CHD III, 249b s.v. milas) $t$. in einer magischen Handlung anscheinend mit Urin übergossen. Für feste Konsistenz spricht auch, daß $t$. getrennt von dem Becher, in dem es sich zuvor offenbar befunden hat, angeboten und übergeben werden kann: KUB LVIII 50 (CTH 645) IV 3'-14'. Ich übersetze die von Otten in Festritual, $27^{28}$ transkribierte Passage: "... nimmt? er ${ }^{3}$ [und r]einigt (šuppiiahh-)[den Konig?.] ${ }^{4}$ 'Den [B]echer[

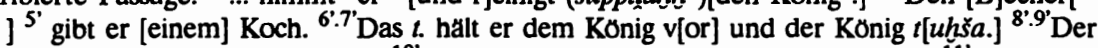
Ober-Koch gibt das $t$. dem Koch. ${ }^{10^{\prime}}$ Ein Page gib[t] dem Konig ein Leinentuch. ${ }^{11}$ 'Der König wisch[t] sich die Hände (daran) ab. ${ }^{12}$ Der Koch gibt den Becher ${ }^{13}$ und das $t .{ }^{14^{\prime}}$ dem hešta(Haus-)Funktionăr."

21 Für $t$. als Bezeichnung auch einer Flüssigkeit berufen sich Jakob-Rost, Ritual der Malli, 69 und Alp, Wesen, 15f auf KUB XII $40\left({ }^{*} \mathrm{CTH} 669,32\right)$ I 19'f. Ihr Verstăndnis der Stelle ist freilich alles andere als zwingend. Der Text besagt lediglich, daß der Oberkoch Wasser in einem Becher bereithălt, das er dann auf des Kơnigs Hand bzw. zur koniglichen Hand(reinigung) para [ ] tuhhuešnit III-ŠU lahuuai, d.h. "vernittels des/mitsamt dem $t$. in drei Güssen ausleert". (Wie $A l p$, l.c., $16^{2}$ feststellt, andert sich hinsichtlich der Deutung von $t$. nichts, falls in der an- 
schließbares Medium. Es handelt sich hierbei entweder um jenes rituell gelöschte hullis, das nunmehr unter einem neuen Namen erschiene, oder um ein bislang unerkanntes, vielleicht ebenfalls vegetabiles(?) Produkt ${ }^{22}$, das gegebenenfalls wie das hullis zur Potenzierung der kathartischen Kraft des Wassers, d.h. zur Erzeugung von Weihwasser, diente. Offenbar wurde es aber ganz wesentlich zu dessen Applikation benutzt: nachdem es, vom Wasser umgeben, in einem Becher gelegen hatte ${ }^{23}$, wurde es (bei besagter passiver Reinigung) wohl entweder zu guß- bzw. schwuppweiser Leerung desselben gebraucht ${ }^{24}$ oder, normalerweise, dem Becher entnommen, zum Versprengen des anhaftenden Wassers geschwungen und schließlich (bei der aktiven Reinigungszeremonie) zur Berührung und damit zu unmittelbarer Abgabe seiner erworbenen Feuchtigkeit angeboten (s. sogl.). Dann legte man es auf ein Tuch und trug es fort ${ }^{25}$. Sein an einer Textstelle bezeugter Gebrauch als Ingredienz einer (außerdem Mehlteig, Kot, Milch, Gips, Pflanzenfasern, -blüten, -samen und abfälle enthaltenden) magischen knetbaren Mixtur $^{26}$ schließt aus, daß tuhhueš̉sar zunächst etwas anderes war als eine Substanz, ein (Natur')produkt. Doch berechtigt der zweimalige Hinweis auf eine gebündelte Verwendung $(i s h \text { hiian })^{27}$ auch zu dem entgegengesetzten oder einschränkenden Schluß, daß

scheinend zu kleinen Lücke nach para, wie er vorschlägt, e-ep-zi zu ergânzen sein sollte.) Für eine rein instrumentale Rolle des $t$. s. sogl.; insofern rückt die als Alternative mit angebotene soziative Übersetzung der Stelle in den Hintergrund.

Güterbock, Notes, $106 f$ (vgl. z.B. noch 1986 in CHD, 249b; inm folgt z.B. Archi, Rez. Otten, Festritual, 172f) hat sich für einen Ansatz $t$. = "Weihrauch" ausgesprochen [wobei angesichts der Unwahrscheinlichkeit der Verwendung echten Weihrauchs in Hatti - s.u., Anm. 177 - eher an eine Art heimischen Raucherwerks zu denken wăre, für das der Terminus tah(at)tumar reklamiert wird, s. Anm. 174]. Die textuelle Evidenz für den Gebrauch des $t$. spricht, wie bereits Otten, Festritual, 27 herausgestellt hat, gegen diesen Vorschlag. Unbenommen bleibt, daß - aber dann eben nicht zu Räucherzwecken eingesetztes - harziges Material wegen seiner potentiellen aromatischen Wirkung als kathartische Substanz unter mehreren fur die Deutung von $t$. infrage kommenden Vorschlägen diskutiert werden sollte. Leider wird $t . \mathrm{m}$. W. nie mit Determinativ geschrieben; ein unmittelbarer, selbst groberer, Anhalt für seine stoffliche Zuordnung fehlt somit. - Es sei an dieser Stelle darauf hingewiesen, daß die Hethiter außer Wasser, hullis (und vermutlich $t$.) noch andere Reinigungssubstanzen kannten, wie Blut, Öl, Wein, Mehl; vgl. etwa Furlani, Religione, 237. Hierher gehort moglicherweise auch die althethitisch bezeugte, Serha- genannte Materie: $\mathrm{Neu}$, Glossar, $165 \mathrm{~m}$. A. 484.

KUB XX 85 + I 13f; 59 I 7'ff, wozu o., Anm. 20.

KUB XX 59 I 19'f; X 4 I 6'f, vgl. o., Anm. 20.

KUB XXIV 14 (CTH 397) I 5-8: ein Teil der Zubereitung wird dem von Zauber zu losenden Mandanten in Gestalt zweier Ersatzfigürchen auf die Schultern gesetzt, der Rest wird ihm auf (den Kopf) gedrückt (Zz. 11-16). Zur Stelle vgl. Güterbock, Tradition, 81 $^{3}$; Puhvel, Etymological Dictionary I/II, 32.

27 KBo XVII 15 Rs. 17'; KUB IX 28 III 15f, vgl. o., Anm. 20. 
das tuhhuě̌̌̌ar der Reinigungszeremonie, wenigstens teilweise, kollektivisch und als Produktaurichtung zu deuten ist, etwa als ein Wedel ${ }^{28}$, ein Pinsel, ein Spanbündel, allenfalls ein Säckchen mit $t$. als einer darin eingebundenen eher stückigen Substanz. Wesentlicher Bestandteil dieser Zurichtung blieb das namengebende, möglicherweise als kathartisch wirksam betrachtete Material. Die alternative Annahme, das tuhhuešsar habe seinen Namen synekdochisch dem Weihwasser überlassen ${ }^{29}$, wird hinsichtlich der Zusammensetzung der erwähnten magischen Mixtur eine aber auch nur für diesen Fall in Betracht zu ziehende (eher schwache) Möglichkeit bleiben ${ }^{30}$. Angesichts der im Opferritual vor und nach der Reinigungszeremonie als fest bezeugten Konsistenz des tuhhuešsar ${ }^{31}$ haben wir die im Ritualjargon gebräuchliche Formel tuhhuešnit suppiiahh - "mit dem $t$. rituell reinigen ${ }^{\text {n2 }}$ als terminus technicus elliptisch zu verstehen als "mit dem (vorher angelagertes Weihwasser abgebenden, zudem vielleicht auch noch selbst wirkkräftigen) $t$. rituell reinigen". Es handelt sich also um denselben Vorgang der, diesmal ohne Nennung des ausführenden Instruments, ausgedrückt werden kann durch die gelegentlich bezeugte Verbindung des Verbums šuppiiahh - mit erläuterndem uatar išparnu-, "rituell reinigen, indem man (mit) (Weih)wasser (be)sprengt ${ }^{t 33}$.

Soviel zur Deutung des Mediums, das der Oberkoch vermutlich benutzt, den König mit dem geweihten Wasser zu besprengen, und das er jedenfalls anschließend dem König darreicht. Dieser vollzieht daran (durch Berührung mit Hand oder Lippen) ${ }^{34}$ eine als symbolische Selbstreinigung interpretierbare Handlung, die durch das mediale Verbum tuhšs- bezeichnet wird und die inhalt-

28 Hieran dachte bereits Forrer ap. Kretschmer, Indra, 299 ("Flederwisch?").

29 Alp deutet $t$. aufgrund seines 0 ., Anm. 21 behandelten Textverstăndnisses uberwiegend als (durch Einwässern erhitzter Tannenzapfen hergestellte) "Rauucher(harz)lotion".

30 Wenn man eine auf die Konsistenz der ( $Z$ z. 5-8 aufgeführten) Zutaten gerichtete Gradation voraussetzen will (Aufzahlung vor der Ziegenmilch, dem Gips, den Pflanzen usw.).

31 Vgl. nochmals Anm. 20, wo besonders für das Davor und Danach auf die zwar beschädigte, in der Literatur jedoch ubereinstimmend beurteilte Passage KUB XX 59 I 7'-21' (dazu Kammenhuber, tuhhuešsar, 68; Popko / Taracha, 28. und 29. Tag, 88) sowie auf KUB LVIII 50 verwiesen sei.

32 KBo IV 13 (CTH 625,1) II 5'f [s.u.]; LX 138 (CTH 625),(2'); XV 33 (CTH 330) III 7.18f [s.u.]; XIX 128 (CTH 625,2) I 31f; XXX 77 III 12'f; KUB II 8 (CTH 612) I (15'f); XX 99 (CTH 636) II 6f [s.u.]; XXV 20 + XIVI 23 (CTH 618) III! 17'; IBoT III 1 (CTH 609) Rs. 42; Bo 4929 V 6'f (Otten, Festritual, $26^{27}$ ).

33 Belege bei $A l p$, Wesen, $18 f^{7}$. S. auch o., Anm. 18. In dem althethitischen Fragment HT 94 (CTH 676>744,2; Neu, Ritualtexte, Nr.78), 7'-9' wird suppïahh- moglicherweise durch papparš- "verspritzen" erlăutert, vgl. Neu, Glossar, 26, 136. - Zur Deutung des tuhhueš̌šr als Instrument vgl. jetzt noch die im Korrektur-Zusatz S. 278 angeführte Parallele.

34 Belege bei Kammenhuber, tuhhueššar, 70. 
lich wohl kaum mit dem gleichlautenden Verbum "abschneiden, trennen"35 zusammenzubringen ist ${ }^{36}$. Nach der Prozedur wird dem König ein leinenes Tuch gereicht, mit dem er sich, wie parallele Stellen $z^{z e i g e n}{ }^{37}$, die Hände abwischt, so nach Empfang der erwünschten Reinheit die offenbar nicht mehr essentiellen feuchten Spuren ihrer Übertragung tilgend.

Ein Hinweis auf die - wie wir sehen werden, in anderen, jüngeren, Ritualbeschreibungen erwähnte - Reinigung und Weihe der Opfertiere fehlt in unserem Text. Dieser behandelt (übrigens ähnlich wie CTH 669,19, s. u.) erst jetzt, d.h. unmittelbar vor der Schilderung des uns hier nicht mehr beschäftigenden Schlachtvorgang ${ }^{38}$ und als dessen letzte Vorbereitungen, das Herbeischaffen der Opfertiere sowie die Aufstellung des beim Schlachten ggf. gebrauchten, zintiia - genannten Gestells(?) ${ }^{39}$. Die für den Verlauf des Rituals nach einer größeren Textlücke verbürgte Anwesenheit der mahlfähigen Würdenträger (IV 6': LÚ.MES'DUGUD NAPTANI "W. der Mahlzeit") läßt auf die Abhaltung eines rituellen Essens im Kreis einer, wenn auch begrenzten, Kultgemeinde schlieBen. Bei einem offenbar entsprechenden Kultmahl wird am Folgetag Fleisch aufgetragen $^{40}$, ein Hinweis, der auf die Verwendung des Opfertierfleisches gerade auch zum menschlichen Genuß deutet. Der somit vorliegende Typus "Fleischspeiseopfer" scheint die gewöhnliche Opferart der Hethiter gewesen zu sein und entspricht grundsätzlich den an den traditionellen lokalen Jahreszeitfesten dargebrachten Opfern, die wir in knappster Beschreibung aus den sogen. "Kultinventaren" des 13. Jh. kennen ${ }^{41}$.

So Neu, Glossar, 199 m. Anm. 577.

Unnal / Kammenhuber, Losorakel, 177 "sich in bestimmter Weise (mit dem tuhhueššr) kultisch reinigen"; Alp, l.c., 18 "sich lotionieren". - Außer für den König ist das Motiv gelegentlich bezeugt für die mitzelebrierende Konigin bzw. für den Prinzen (der wohl stellvertretend für den nicht überallhin abkömmlichen König fungiert), vgl. Kammenhuber, tuhhueššar, 65 mit Belegen sowie (leider sehr fragmentarisch) altheth. KBo XXV 36 (= Neu, Ritualtexte, Nr. 36) Kol. II mit interessanter Motivfolge.

Z.B. KBo IV 9 (CTH 612) II 23-25 (cf. 34-36); XIX 128 (CTH 625,2) I 35f (s.u.).

$\mathrm{Zu}$ diesem s. Kühne, auli, 97-100.

39 Vgl. dazu Kühne, auli, 98 51 . Was das Herbeischaffen der Tiere betrifft, erweckt der Text freilich nur im Blick auf die Stiere den Eindruck, daß diese erst jetzt an die Opferstatte gebracht werden.

40 Kol. IV 24'-33' (erg. nach Dupl. IV 31'-40'), wobei ich Z. 28'f als zweiten, auf eine Speisung des Königs folgenden, für die Speisung der restlichen Kultgemeinde bestimmten Mahlabschnitt betrachte, dem als dritter eine Libationsrunde folgt. Vgl. noch CHD III, $300 f$.

Z.B KBo II 13; KUB XVII 35; XXV 23, wozu vgl. o., Anm. 10. 


\section{CTH 647:}

Das einstweilen unter dieser Katalognummer einzuordnende kleine althethitische Fragment Bo 5478, transkribiert bei E. Neu, Ritualtexte, als Nr. $46^{42}$, beschreibt auf dem erhaltenen Teil einer I. Kolumne in äußerster Kürze ein umfangreiches Tieropfer. Aus Zeile 3'f geht hervor, daß ein Priester im Range eines "Gesalbten" ( ${ }^{\mathrm{LU}} \mathrm{GUDU}_{12}$ ) an dem (evtl. mit dem König kon)zelebrieren$\operatorname{den}^{43}$ Prinzen das hier nicht näher ausgeführte suppiiahh-, also die passive Reinigung, vollzieht, bevor die Opferschlachtung beginnt. Der stark beschädigten Zeile 2' möchte ich entnehmen, daß der Prinz sich vor dem Reinigungsakt mit einer Verbeugung huldigend vor der (an heiliger Stätte vergegenwärtigten) Gottheit einzuführen hatte ${ }^{44}$. Dieser wäre - unbeschadet der Verteilung einzelner Opferlebern an eine Reihe numinoser 'Örter'(Vs. 9'f) - gemäß dem üblichen Vorgang ${ }^{45}$ die Hekatombe zugedacht. Da der Text abbricht, erfahren wir nichts über das wahrscheinlich anschließende rituelle Fleischmahl der Festteilnehmer.

Die im Folgenden zu verhandelnden vier Passagen sind sicher, bzw. in einem Fall nur mit gewissem Vorbehalt, dem AN.TAH.ŠUM-Fest zuzuschreiben. Dieses Fest wurde möglicherweise erst im 14. Jh. v. Chr. konzipiert bzw. auf der Grundlage älterer Einzelrituale ${ }^{46}$ nach zeitgemäßen, praktischen religionsund reichspolitischen Gesichtspunkten gestaltet ${ }^{47}$. Auf dem wenigstens seit

Zur Duktusbestimmung s. den Nachtrag bei $\mathrm{Neu}$, Glossar, 364.

43

Das abgebrochene, LU[GAL gelesene Zeichen in Kol. I 8' laßt die Möglichkeit offen, daß der Konig selbst das betr. Fest geleitet hat. Sonst vgl. Anm. 36 (Ende).

Ich vermute I 2' eine Lesung $a$-]ru'-ua-iz-zi "er verneigt sich" und verweise auf $z$.B. auf KBo XXV 51 (Neu, Ritualtexte, Nr. 51) I' [9'.]14'; 36 (ibid., Nr. 36) II 3'(weitere altheth. Belege s. Neu, Glossar, 29.302); jüngere Entsprechungen z.B. in KUB II 8 (CTH 617) I 12'; XXX 41 (CTH 669, s.u.) I 7'; KBo XV 33 (CTH 330, s.u.) II 40'(.III 8) usw.

45 Für Beispiele s. die vorige Anm..

46 So diente das über seinen Vertreter KBo XVII 15 für den althethitischen Kult reklamierbare Ritual CTH *645,6 als Basis für CTH 609. Vgl. auch unten, Anm. 51.

47 Hinter einer von den meisten Textvertretern bezeugten spăter-junghethitischen Überlieferung (2. Halfte 13. Jh.) steht eine wohl von Muršili II. (um 1300) veranlaßte Redaktion, die vermittels der in CTH 568 auf uns gekommenen Orakelanfrage Unklarheiten einer damals bereits vorliegenden Fassung(?) zu beseitigen suchte. Hierzu wie auch zu der konzeptionell gleichzeitigen Gestaltung des herbstlichen nuntarriasha-Festes (CTH 626) vgl. Houwink ten Cate, Brief comments, 99ff. - Wenn etwa Yoshida, Mediop.End., 160ff (Melcherts Vorgang von 1977 folgend, vgl. ib., 6) für beide Feste althethitischen Ursprung annehmen zu können meint, dürfte er dem Vorkommen gewisser alter Elemente wie der Konjunktion ta in den betr. Texten mehr Beweiskraft zutrauen als dies bei einer historisierenden Haltung des wahrscheinlich sowohl kompilierenden als auch nach- und neuschaffenden Ritualautors ratsam ist. Realistischer m.E. Popko / Taracha, 28. und 29. Tag, 82. 
Auf dem besagten Berg angekommen, begibt sich der König in ein vorbereitetes Zelt, wo ihm Pagen mit "Hand(wasch)wasser" aufwarten. Nach der Waschung trocknet der König die Hände in einem vom Oberpagen bereitgehaltenen Tuch. Der Oberkoch hält einen Becher, in den zunächst das Wasser eingefüllt und dann das tuhhuešsar hineingelegt wird. Der Oberkoch reinigt (suppiiahh-) als erstes die Kultstele (Betyle: ${ }^{N A} 4 h u u a s i-{ }^{52}$ ) scil. der Berggottheit, dann die verschieden(artig)en Opfertiere. Hierbei rezitiert er den (oder einen) leider nur sehr schlecht erhaltenen Reinigungsspruch (šuppiiahhuuaš INIM $\left.^{\mathrm{HI} . \mathrm{A}}\right)^{53}$. Für die folgende 30 - bis 40 -zeilige Textlücke wird kaum noch die passive, vermutlich aber die aktive Reinigung des Königs sowie eine erste Brotund Trankopferrunde zu rekonstruieren sein. Der erhaltene weitere Text handelt dann ab Z. 3" von der Schlachtung der erwähnten Tiere, deren Fleisch an der Kultstele niedergelegt und späterhin vielleicht von der Kultgemeinde rituell verzehrt wurde.

\section{CTH 616, 2: KUB XX 59 I 4'-21'}

Das seiner Schrift nach ebenfalls aus dem 13. Jh. stammende Textbruchstück ist 1988 von Popko und Taracha in einer Studie über den 28. und 29. Tag des AN.TAH.ŠUM-Festes (in AOF 15 [1988] 87ff) bearbeitet worden. Es handelt vom 29. Tag des AN.TAH.SUM-Festes und betrifft die (in ihrem Stil an das Gesamtfest angepaßte) Feier des durch hurritische Vermittlung auch in Hatti verehrten, in Hattuša mit einem Heiligtum ausgestatteten mesopotamischen Gottes Ea (sumerisch Enki) und seines Götterkreises.

Unserem z.T. rekonstruktionsbedürftigen Interpretament gemäß finden wir den König im Begriff, an einem Pfeiler (sarhu[li-) des Tempels ein Schlachtopfer darzubringen. Das Opferkontingent (hukeš $[a r]^{54}$ ) [wird hereingetrieben,

des Kaneš-Săngers, evtl. auch das 'Trinken' der Gottheiten "drinnen") zunăchst das größere Gewicht beimessen. Zweifel an der Zusammengehörigkeit ergeben sich dennoch aus dem Umstand, daß die Programmtafel des AN.TAH.ŠUM-Festes gar nicht von einer Besteigung des Tapala spricht. Das Ritual könnte die Feier aus Gründen der Zeitersparnis in den hauptstädtischen Bereich verlegt haben. Dann wăre unser Fragment Zeugnis des alteren Kultzustandes.

Vgl. zuletzt Dietrich / Loretz / Mayer, Sikkanum, 133ff (138f).

53 Zz. 20'-32'. Eine gekürzte(?) Version scheint, nicht minder schlecht erhalten, in KUB XXV 18 (CTH 618) II 21"-31" vorzuliegen.

54 Trotz der für das Wort ungewöhnlichen Pleneschreibung des $u$ (die allerdings für die Wiedergabe seines verbalen Grundwortes typisch ist), schlage ich diese Ergănzung in Z. 5' vor; Popko / Tarachas $h u-u-k i-e ̨ \zeta-k[i-i z-z i$, unerwarteterweise unpersönlich übersetzt als "man schlacht[et(?)", ergibt zu diesem Zeitpunkt des Geschehens noch keinen Sinn. Für ḩukešsar "Schlachtopfer" i. S. von "Schlachtopferkontingent" vgl.u. S.240 22.241 zu KBo XV 33 (CTH 330) III 4. 
wohl dem fortgeschrittenen 13. Jh. zuzuschreibende Neuerung ${ }^{60}$ veranschau; licht im Kleinen die Möglichkeit der königlichen, zugleich ja höchstpriesterlichen, Einflußnahme auf die Gestalt des Ritus und, damit zusammenhängend, auch auf seine Überlieferung.

Unser Textabschnitt setzt, nach Verlust der ersten Kolumnenhälfte, bei einem Trank- und Brotopfer ein und leitet nahtlos zu einer Reinigungszeremonie über. Deren Bestimmungen sehen vor, daß der [Ober]koch Altar und Opfertiere ${ }^{61}$ vermittels des tuhhuešsar [dreim]al ${ }^{262}$ reinigt (šuppiïahh -) und daß dann der König mit dem ihm vom Oberkoch dargebotenen tuhh̆ueššar den tuhš-Ritus ausführt. Auch hier fehlt eine vorausgehende passive Reinigung des Königs. Zwischen den Reinigungsakt und die gemäß Kol. III 27'-IV 4 vom König vollzogene Opfertierweihe (-kan šipand-) schieben sich drei Runden unblutiger Beopferungen (Speise- und Trankspenden), von denen die ersten beiden als jüngere Zutat einzuschätzen sein dürften ${ }^{63}$. Kol. IV 30f erwähnt bereits die Vorlage der rohen und der gekochten Opferfleischteile. Daran schließt sich eine Notiz über das Auftragen von Topfgerichten und das Aufstellen von Tischen, doch wohl zur Speisung der mahlfähigen Anwesenden ${ }^{64}$.

\section{CTH *625, 2: KBo XIX 128 I 12-38}

Die vorliegende, von Otten 1971 bearbeitete junghethitische Tafel behandelt den 2. Tag desselben AN.TAH.ŠUM-Teilfestes, zu dessen Riten das soeben betrachtete, zeitlich noch nicht näher plazierbare Tieropfer gehört.

Unser Text führt aus, daß der König beim Betreten des "Großen Hauses" mit einem Teppich von hingestreuten Nahrungsmitteln empfangen wird. Nachdem der König Platz genommen hat, wäscht er sich die Hände. Darauf halten

$60 \mathrm{Vgl}$. ahnliche Vermerke in anderen Vertretern der AN.TAH.ŠUM-Festüberlieferung, z.B. KUB XXV 18 (CTH 618) I 18-20. III 8-10 (cf. I 1: Tudhaliia [IV.]). Wahrscheinlich sind weitere Hinweise auf beschränkte Verbindlichkeit wie in unserem Text Kol. II 25' (mit Bezug auf die Brotopferrunde II $8^{\prime} \cdot 24^{\prime}$ ) oder III 17' (hinsichtlich der bis Z. 16' beschriebenen Opferrunde) Indikatoren für sekundäre Erweiterungen des Rituals.

61 Bei Berücksichtigung von Kol. III 27'ff handelt es sich um 1 Stier (IV 4), 6 Schafe (III 28'30'.32'f) und 2 Ziegenböcke, vgl. noch KBo XIX 128 I 37 (Otten, Festritual, 29f).

62 Für die Ergănzung vgl. KBo XIX 128 I 32, wo sich die Zahl freilich nur auf die Behandlung des Altars bezieht, was in unserem Fall wohl auch intendiert war, aber durch die abgekürzte Formulierung verunklărt worden ist. - Mehrfache, d.h. vor allem dreimalige, Reinigung, d.i. Besprengung, wurde an Sachen oder Wesen von besonderem Heiligkeitsrang vollzogen, vgl. etwa KUB XX 59 (CTH 616, s.o.) II 10' oder die oben, Anm. 18. 33 angezogene Evidenz.

63 Vgl. O., Anm. 60.

64 Die etwa gegen Mahlende (?, vgl. Kol. V 20) stattfindende Abspeisung der Obersten der Palastwache (V 14ff) ist davon deutlich getrennt. 
"Seher" ( $\left.{ }^{\text {LÚMES }} \mathrm{AZU}\right)$ ihm drei Sauerteigbrote vor, an deren jedes er als Opferstifter Hand anlegt (QATAM dai- $)^{65}$. Die Seher brechen die Brote und legen sie auf einem Flechtwerktisch vor dem Altar ab. Einer der Seher führt eine Libationsrunde mit Bier an numinosen Teilen und Gegenständen des Kultraums, den sogen. "Örtern" ( $\left.{ }^{*} p e d a, A \breve{S} R \bar{U}\right)$ durch. Der Oberkoch nimmt am Altar eine dreimalige, an den Opfertieren eine einfache Reinigung (suppiiahh-) mit dem tuhhueššar vor. Dann hält er dem König das tuhhueššar hin, der sich damit über die Lippen fährt (puriuš anš-) ${ }^{56}$. Nach der Zeremonie trocknet sich der König die Hände am bereitgehaltenen Tuch ab und weiht(! sipand-, hier ohne -kan!) den Hauptgöttern des Pantheons 6 Schafe, 2 Böcke und einen Stier, die (wie wir, trotz des nun einsetzenden Textverlustes, dem Handlungsstand der folgenden II. Kolumne entnehmen können), anschließend geschlachtet werden. Während Herz und Leber der Opfertiere den Göttern vorbehalten sind (II 15ff), dürften die Fleischteile (u.a.?) in die Topfgerichte eingegangen sein, die man im Verlauf des Rituals den königlichen Prinzen vorsetzt(IV 11'$\left.13^{\prime}\right)^{66}$.

Noch keinem der bekannten Feste sicher zuweisbar ${ }^{67}$ ist die Schlachtopferbeschreibung des als CTH 669, 19 registrierten, paläographisch späten Fragmentes KUB XXX 41, dort Kol. I 5 'ff ${ }^{68}$.

Nach Verlust der ersten Kolumnenhälfte setzt dieser Text ein bei einer Handwaschung des Königs. Nach dem Trocknen der Hände verbeugt sich (hink-) der König vor dem Wettergott, indes die mitwirkenden Funktionäre ihre Plätze aufsuchen. Der König tritt in die Tür scil. des Tempels oder der Cella, wo ihm der Oberkoch das tuhhuešsar reicht und der unaufmerksame

Zum Gestus und seiner Bedeutung s. Wright, Gesture, 433-446. Zum "Seher" vgl. u., Anm.75.

Stillschweigender Einschluß der "Herren" in diesem Mahlabschnitt ist wohl zu bezweifeln. Dieser Personenkreis wird jedenfalls bei spateren Trank- und Brotopferrunden (Kol. V 44f. VI 14'-16') mit Trank versehen.

67 Eine Anzahl von Einzelheiten scheinen freilich auf eine Zugehörigkeit zum AN.TAH.ŠUModer nuntarriiashha-Fest zu deuten. Das Ritual selbst hat protohattischen religiosen Hintergrund.

5' [UGULA LÚMUHALDIM LUGAL-i ME-]E QA-TI péf[-e-d]a-i <LUGAL-uš ŠU MEŠš́ $a$-ar-ri> 6' [UGULA LÚ MUHALDIM LU]GAL-i GADA-an pa-a-i LUUGA-]uš ' 'ŠU MES'.

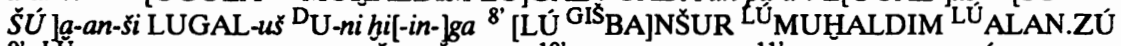

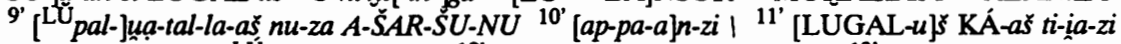
nu-ušs-și UGULA LU MUHALDIM ${ }^{12}$ [tüh-h]u-i-šar pa-ra-a e-ep-zi ${ }^{13}$ ' [LU]GAL-uššsa-an

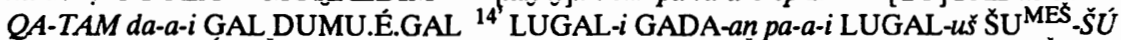

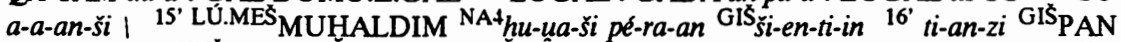

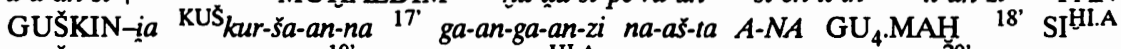
GUŠKIN ar-ha da-an-zi ${ }^{19^{\prime}} n u$ [ ]III UDU ${ }^{\mathrm{HI} . A}$ hu-u-kán-zi GU G.MAH-ia $^{20}$ hu-u-kán-zi LUGAL-lľs-za e-sa $\mid$. 
Schreiber den König - zwar sachlich nicht unzutreffendermaßen, doch im Gegensatz zur geltenden Sprachregelung - Hand an das Hingehaltene legen ( $Q A T A M$ dai-), statt daran die durch das Verbum tuhs- ausgedrückte Selbstreinigung vollziehen $\mathrm{läBt}^{69}$. Da der König anschließend beide Hände abermals an einem Tuch abtrocknet, besteht an der Art der Handlung kein Zweifel. Wir erfahren sodann von der Aufstellung des $̌ / z e n t i-$ Gestells, das hier seinen Platz vor der Kultstele als dem Orientierungspunkt der folgenden (1.) Opferhandlung erhält. Am senti- werden ein goldener Bogen und eine Jagdtasche ${ }^{70}$ aufgehängt. Opfertiere, von deren ritueller Reinigung keine Rede ist ${ }^{71}$, wie auch über ihre Weihe kein Wort verloren wird, stehen zur Schlachtung bereit: ein Stier, dem man den Goldbelag seiner Hörner abnimmt, und Schafe, die wie üblich beim Schlachten den Vortritt erhalten. Wahrscheinlich wurde das der Gottheit vorgelegte Opferfleisch (III 7'ff) wiederum zum großen Teil rituellem Verzehr zugeführt.

\section{CTH 330: KBo XV 33 II 35'-III $9^{72}$}

Im primär luwischen Kult des Wettergottes von Kuliuišna ist das Ritual des regulären, jährlich (uetti meiani) gefeierten Festes (Typ Frühlingsfest) mit einem textuell getrennt überlieferten, stärker hurritisch beeinflußten Invokationsritual gekoppelt worden. Die in E.Laroches Catalogue unter den Num-

69 Vgl. schon Wright, Gesture, $442^{57}$.

70 Hat der Wettergott diese Requisiten von der männlichen Schutzgottheit abernommen (Konflation?)?

71 Sie hătte normalerweise vor der Selbstreinigung des Kơnigs stattgefunden; ist sie nur zufăllig nicht erwăhnt, weil die Tiere erst jetzt ins Blickfeld rücken? An sich ist es ja nicht unwahrscheinlich, daß das bei der Selbstreinigung des Königs benützte tuhhueššar zuvor, wie sonst ublich, zur Besprengung eingesetzt war.

72 35' $n u$ LÚ EN É EIM I-NA É.ÚS.DU ${ }_{10}$ SA(!) pa-iz-zi nu-za Ú-NU-UT HI.A da-a-i 36' LÚ.MES NINDA.DÙ.DÜ-ma-za NINDA.GUR 4 .RA I-NA É.Ṡ̀̀ DINGIR ${ }^{L I M} z a-n u-m a-a n-z i$ ap-pa-an-zi 37' LÜ.MES MUHALDIM-ma-aš-ša-an MU ${ }^{T I}$ me-e-ia-ni-aš I UDU.ŠIR I $\mathrm{GU}_{4} \mathrm{MAH}-i a{ }^{38^{\prime}}$ hu-i-ku!-an-zi ${ }^{\prime} \mathrm{S}_{z i-i n-t i-n a}$ pé-e-di ha-an-da-a-an-zi $^{39^{\prime}}$ ma-a-ah-ha-an-ma-

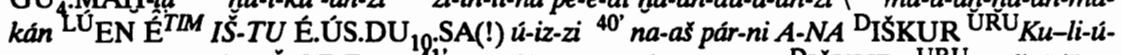
iš-na iš-ta-na-a-ni UŠ-GE-EN \&i' nu iš-ta-na-a-ni pé-ra-an DIŠKUR URU Ku-li-ú-iš-na

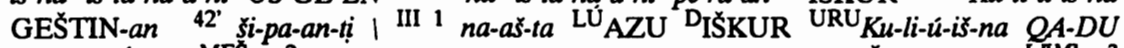

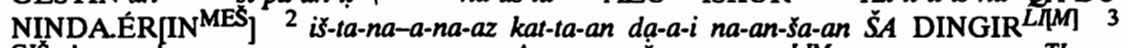

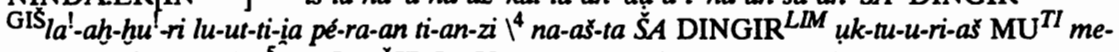
$e$-ia-ni hu-ke-eš-šsar ${ }^{5}$ I UDU.ŠIR I GU ${ }_{4}$.MA[H a]n-da u-un-ni-an-zi nu-uš-ma-aš p[é]-ra-an

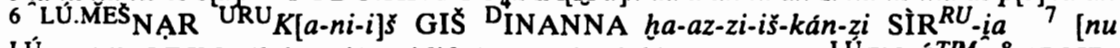
LÚ MUH]ALDIM tüh-hu<<-iš>-ni-[it] šu-up-pi-ia-ah-hi nu-tus-ma-aš LÚ EN ÉTIM ${ }^{8}$ [EGIR-

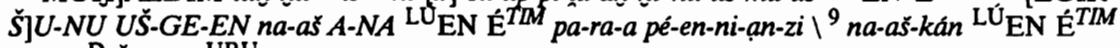

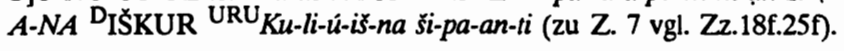


mern 329 und 330 bunt zusammengewürfelten Fragmente beider Texte sind im Prinzip leicht auseinanderzuhalten. Das hier anzuziehende Beispiel für das Voropfer stammt aus dem im Kern luwischen Festritual, das uns in (mittel)hethitischer Fassung ${ }^{73}$ in Exemplaren des frühen 14. bis späteren 13. Jh. bruchstückhaft vorliegt. Es geht um ein ursprünglich wohl als öffentliches Anliegen betrachtetes Kultfest, das ein Privatmann zu Ehren der Gottheit, nun, wie es scheint, nur mehr im eigenen Interesse, auf eigene Kosten ausrichten konnte. Originelle, wohl z.T. der südanatolischen Herkunft verdankte Details und im Vergleich zu Beschreibungen hethitischer Reichsfeste gelegentlich größere Ausführlichkeit in der Darstellung von Standardmotiven ${ }^{74}$ machen dieses und ähnliche Rituale bemerkenswert.

Unserem, einer frühen Niederschrift entnommenen, Interpretament zufolge begibt sich der feiernde Festveranstalter ("Hausherr") nach Besichtigung des Opferbrotteiges in aller Morgenfrühe ins Badehaus, wo er (wie das im Reichsritual der König auch tut) seinen Festtagsstaat anlegt. Handlungsort ist das Tempelareal. Während das Abbacken der Brote anläuft, sorgen Tempelköche dafür, daß die zum Opfer beschafften vorgeschriebenen Tiere, ein Widder und ein Stier, zur Stelle sind und daß an der Schlachtstätte das zinti-Gestell bereitsteht. Der "Hausherr" betritt den Kultraum, verneigt sich (Verbum $\check{S} U K \hat{E} N U$ ) vor dem Altar des Wettergottes und bringt daselbst vor dem Gottesbild eine Weinspende aus. Darauf räumt ein Seher $\left({ }^{\mathrm{LU}} \mathrm{AZU}\right)^{75}$ das Idol und das (entweder mit dem Wein dargebrachte oder vom Vortag stammende) Opferbrot vom Altar (ištanana-) auf einen vor einem Fenster aufgestellten Ständer ( ${ }^{\mathrm{G} I S}$ lahhura-). Dann werden die Tiere als "des Gottes reguläres Jahres-Schlachtopferkontingent ${ }^{176}$ hereingetrieben, wobei ihnen Musiker mit liturgischem Gesang und Saitenspiel vorausschreiten ${ }^{n}$. Ein Koch vollzieht die Reinigung (šuppi-

73 D.h. in nach geltenden liturgischen Gesichtspunkten redigierter Übersetzung. Hinsichtlich deren Datierung hat sich auch CHD III seit dem Eintrag p. 76b ("OH/") inzwischen korrigiert, vgl. ib., 230b, wobei ich freilich den dort gegebenen Ansatz unseres Exemplars als junghethitisch ("NS") nicht teile.

74 Vgl. etwa meine o., Anm. 2 zitierte Untersuchung.

75 Als Kultfunktionăr nicht autochthon-anatolisch und (wenigstens bislang) für die althethitische Schicht nicht nachweisbar (vgl. auch Kammenhuber, Orakelpraxis, 199). Seine Rolle im vorliegenden Ritual (im Unterschied etwa zu der in CTH 701, s.u.) erscheint allerdings eher blaß, fast statistenhaft. Ähnlich bereits in CTH 625,2, wo ein bzw. mehrere Seher ebenfalls nur am Beginn der Handlungen in Erscheinung treten: KBo XIX 128 I 20-30.

76 Für eine unterstellte Kasusmetathese in III 4 vgl. CHD III, 230b.

77 Wenn unser Text die Kultmusikanten als "Sănger von Kanišn, d.h. als Vortragende hethitischer Gesănge, klassifiziert (III 6), wird der Eingriff des hethitischen Redaktors deutlich. Hat er die traditionsgeheiligte, auf die gedachte (luwische) Muttersprache des Gottes festgelegte Liturgie kurzerhand übersetzt oder hat er sie, da sie ihm entging oder unverständlich war, durch eine situationsentsprechende hethitische ersetzt? 
¿̇ahh-) mit dem tuhhueššar, woran, wird nicht gesagt, doch sind gemäß den Parallelen $\mathrm{Zz}$. 18f. $25 \mathrm{f}$ die Tiere, wohl nicht auch der Opfernde, gemeint. Der "Hausherr" schließt sich als der gabenbringende Adorant dem (zum Altar und wohl auch zum Gottesbild hin ${ }^{78}$ ausgerichteten) Zuge an, verneigt sich hinter den Tieren und nimmt die Opferweihe vor (-kan šipand- $)^{79}$. Angesichts der fragmentarischen Textüberlieferung bleibt die Einordnung als 'Fleischspeiseopfer' eine, wenn auch wahrscheinliche, Vermutung.

\section{CTH 701: KBo XXI 33+XXIII 12+KUB XXXII 49a.b+KBo XXIV 66I 1ff}

Das mittelhethitische, von Salvini und Wegner, Rituale, als Nr. 1 (Dupll. Nrn. 2-6) bearbeitete (Teil)ritual eines Opfers für den Thron Hebats, der weiblichen Hauptgottheit des westhurritischen Pantheons, ist wiederum konzipiert für die idividuelle religöse Initiative oder vielleicht besser: das Bedürfnis des Privatmannes (sicherlich konnte aber auch der König das Ritual für sich in Anspruch nehmen). Es weicht erheblich ab von den bisher von uns zitierten Festbeschreibungen und weist typische Züge der hurritischen Kultpraxis auf. Die erhalten gebliebene zweite Tafel der nach Übernahme des Rituals etwa zu Beginn des 14. Jh. angefertigten und noch im 13. Jh. kopierten bzw. redigierten hethitischsprachigen Beschreibung enthält als Hinweise auf liturgische Einlagen zahlreiche in den Text eingestreute Stichzeilen (gelegentlich wohl auch den vollen Wortlaut) uns noch teils unverständlicher hurritischer Sprüche, bei denen es sich wesentlich um Bittgebete handeln dürfte ${ }^{80}$. Die Tafel beschreibt die am zweiten Ritualtag stattfindende sukzessive, weitgehend nach demselben Verfahren eingeleitete Opferung von insgesamt 7 "großen Vögeln" (MUŠEN $\left.\mathrm{GAL}=\mathrm{Gans}^{?} / \mathrm{Ente}^{2}\right)$ und einem Schaf, wobei das letztere an zweiter Stelle dargebracht wird. Gelten die ersten drei Opferungen (hier "A", "B", "C") sei es dem Thron als Ganzem, sei es der Göttin(?), sind die folgenden fünf summarisch abgehandelten Vogelopfer ("D-H") nacheinander dem huppi zinzaunušš (unklarer hurrit. Terminus) und den vier Beinen des Throns zugedacht. Zur Verdeutlichung biete ich eine Synopse der Ausführungen über das jeweilige Voropfer, wobei ich die Abweichungen der Vogelopfer (A,C[-H]) vom Schafopfer (B) in Klammern vermerke.

Die Z. 13 beschriebene Schlachtung findet am Altar, dem regularen Standort des Idols, statt. Die Verbeugung (s.sogl.) gilt doch wohl dem jetzt auf dem Stănder vor dem Fenster befindlichen Idol. Die Richtung des Opferzuges und diejenige des Huldigungsgestus stimmten gewiß überein.

79 Zum Weiteren s. Kühne, auli, 88f (S. 89 "Opfertisch" = Altar).

80 Dazu Salvini, Note, 227ff; Kammenhuber, Opfertexte, 106 4 .113ff.390ff. 
Noch nicht das eigentliche Voropfer betreffen einleitende Bestimmungen (I 1-13): Bei Tagesanbruch waschen sich Opferstifter (BEL SÍSKUR "Opferherr") und Seher ( $\left.{ }^{\mathrm{LU}} \mathrm{AZU}\right)$. Der Letztere betritt den Kultraum und entfernt die am Vortag vor dem Götterbild aufgetischten Brotspenden und die Rhyta, mit deren Inhalt er bei dieser Gelegenheit noch libiert. Anschließend wird der Raum feucht geputzt. Auf den Opfertisch aus Flechtwerk ${ }^{81}$ legt der Seher frische Fladenbrote, die er mit Obst belegt und mit Salz bestreut. Je einen Becher mit Wasser bzw. mit Wein sowie einen frisch angefüllten Öltopf ${ }^{82}$ ( ${ }^{D U G}$ ahrušȟi-) stellt er dazu. In den Öltopf legt er Zeder(nspäne oder -zweige?) ( ${ }^{G S}$ ERIN) als kathartische, ggf. zur Erzeugung von Wohlgeruch verbrennbare Materie $\left(^{G i s ̌ l u e s ̌ s ̌ r ~}{ }^{83}\right.$. Auf einem irdenen mobilen Herdeinsatz bzw. Feuertiegel eines tragbaren Ofens (huprushi-) ) $^{84}$ zündet er trockenes Holz an. Dann führt er den Opferherrn herein "vor die Gottheit" und reicht ihm einen der Zedernholzspäne (oder -zweige) aus dem Öltopf. Diesen Span (oder Bruch) wird der Opferherr für die Dauer des jeweiligen Tieropfers in der Hand halten ${ }^{85}$.

Mit der sicherlich kathartische Zwecke verfolgenden Überreichung des Zedernspans an den Opferherrn ist die Grenze zwischen Präliminarien und Voropfer bereits überschritten. Der Opferherr verbeugt sich (Verbum $\check{S} U K E N U$ ) scil. vor der Gottheit, indes der Seher ihn mit einem Spruch vorstellt bzw. empfiehlt (B: II 17-19; A: I 14-16; C läßt diese Zeremonie aus). Nun ergreift der Seher mit der Linken ein Messer (gemäß $A$ und $C$ jedoch einen großen Vogel; B: II 20a vs. A: I 17a; C: II 69b-71a) und nimmt mit der Rechten einen Zedernspan aus dem Öltopf, während das Schaf hereingetrieben und zur Rechten des Opferherrn aufgestellt wird. Der Seher legt dem Tier den Span auf den [Kopf] (nur B: II 20b-23 ${ }^{86}$ ). Mit der (bei B nun wieder, bei A und $C$ noch) freien rechten Hand entnimmt der Seher dem Öltopf einen (bei B: weiteren) Span und läßt das davon abrinnende Öl in den bereitstehenden Becher Wasser hineintropfen (-ašta anda zapnu-). Er vollzieht nun auf hurri-

81 I 7: $\check{S} A$ DINGIR ${ }^{L M} \check{S} A$ SÍSKUR $A-N A$ GIŠ BANŠUR AD.[K]ID "auf den Korbtisch des Opfers (gehörig) der Gottheit".

82 I 8f: DUG ahrušḩin İ.[(GIŠ)] damai "ein $a$ anderes Öl"; İ.GIŠ ist Neutrum, vgl. auch II 14. III 68.

83 Ich fasse lueššar als Oberbegriff; vgl. fragend bereits CHD III, 74b z. St.

84 Vgl. Wilhelin, Hubrušhi, 478; Kammenhuber, Opfertexte, 107.

85 Vgl. I $14 \mathrm{f}$ mit II 7f. Ferner II 17f, doch ohne Erwahnung am Schluß des betr. Opfervorgangs (II 65ff) sowie am Beginn des nacchsten (ab II 69b). Das Motiv ist dennoch als selbstverständlich für alle Teilopfer vorauszusetzen, vgl. IV $63 \mathrm{f}$ sowie die Ausnahmeregelung III $69 \mathrm{f}$.

Die Ergănzung in Z. 23 gemaß der bei Salvini / Wegner, Rituale, 49 Anm. nachgewiesenen Parallele, wobei der Raum der Lücke (vgl. auch KUB XXXIl 49a) für "Kopf" nur ein Zeichen zulaßt: also SAG? 
tisch das katkisa-, die Anrufung ${ }^{87}$, der Hebat: den Span legt er in den Wasserbecher und gießt (lahu-) etwas von dem Wasser in Richtung auf das Götterbild, seine Handlungen mit der Rezitation der Anrufungsformel ${ }^{88}$ begleitend (B: II 25-32; A: I 17b-25a; knapper gefaßt C: II 71b-III 7). Anschließend gießt er von dem Wasser auf das Schaf und aufs Messer, beide Male einen besonderen Spruch rezitierend (beide Handlungen nur bei B: II 33-37a). Der letzte Guß gilt dem Opferherrn (bei B seinen Händen: II 37b-38a. A, C: der S. gießt vor dem O. aus: I 25b-26a; III 8). Dann stellt der Seher den Wasserbecher auf den Flechtwerktisch zurück (B: II 38a-39; A: I 26b-27; C: III 9-10a).

Wieder nimmt der Seher einen Span aus dem Öltopf, wirft ihn jedoch nunmehr zur Verbrennung (als Rauchopfer) auf den auf dem Herd bzw. im Tragöfchen schon in Aktion befindlichen Feuertiegel. Dabei rezitiert er einen das Räuchern kommentierenden Spruch (B: II 40-42; A I 28-30a; C: III 10b-13a).

Der Opferherr legt jetzt zum Zeichen seiner Eigenschaft als Spender seine Hand an das Opfertier ( $Q A T T A M$ dai-. Bei A hält ihm der Seher den Vogel dazu eigens hin: I 30b-31). Der Seher schneidet mit dem Messer (GÍR-it dai-) eine Kostprobe bzw. einen Anbruch (anahi) von (nicht aus ${ }^{89}$ ) dem Kopf des anschließend noch durchaus intakten und leitbaren, d.h. nicht irritierten, Schafes $^{90}$ (bzw. nimmt er bei $\mathrm{A}$ und $\mathrm{C}$ die Probe, ohne ein Messer zu benutzen, von der Brust des Vogels). Es kann sich bei solchen 'Kostproben' nur um entbehrliche Teile gehandelt haben, also um Haare (bzw. Federn). Auf Parallelen kommen wir noch zu sprechen. Die Probe, zusammen mit dem Zedernspan, der auf des Schafes Kopf lag ${ }^{91}$, taucht der Seher in (-šan anda suniia-) den Inhalt des Öltopfes. Sodann bricht er, wiederum rezitierend, ein Fladenbrot, nimmt auch hiervon eine Probe, taucht sie ins Öl und wirft, einen weiteren Spruch hersagend, diese sowie die (Stirnlocken-)Probe und den Span zur Verbrennung auf den Feuertiegel (B: II 43b-56; bei Opfer A wird die <Feder$>$ Probe ohne Span und Brot nach dem Ölbad verbrannt: I 32-35, während ihre Verbrennung bei C einer Textstraffung zum Opfer fällt: III 15f).

87 Vgl. Salvini / Wegner, Rituale, 4. Das Verbum irhai-, primăr "umgrenzen, umrunden", im Ritual oft "die Gơtterrunde reihum beopfern", ist hier blasser i. S. von "erledigen" zu fassen. Wie die Einflechtung des Incipit der Anrufungsformel zu zeigen scheint, erfolgt die Anrufung noch nicht beim Eintropfen des Öls.

Zum Inhalt des Spruches s. Salvini / Wegner, Rituale, 2. Dafür, daß die kommentierte Handlung kathartische Bedeutung hat und eine Handwaschung der Gottheit symbolisiert, s.unten. So Salvini / Wegner, Rituale, 50; Kammenhuber, Opfertexte, 397. Die Konstruktion hier und an den Parallelstellen erfolgt regelmåßig mit -aštal-kan da- "nehmen" und dem Dativ.

90 Vgl. I 65, wo davon die Rede ist, daß das Schaf vom Kultraum (zum Schlachtplatz) getrieben wird. Es stellt eine Verunklärung des Tatbestandes dar, wenn das hierfür benutze Verbum penniüa- als "hinschaffen" (Salvini / Wegner, Rituale, 52 u.o.; Kammenhuber, Opfertexte, 411 [vgl. auch ib., p. 393 unniia a-]) übersetzt wird.

91 Diente er nebenbei der Fixierung der abzuschneidenden Stirnlocke? 
Nun ergreift der Seher den Becher mit dem Wein und spendet (ふipand-) daraus in Richtung auf die Gottheit auf den Feuertiegel hinab. Er rezitiert dabei erneut und vollzieht damit die Opferweihe (-kan sipand-), die, wo immer sie in den zuvor betrachteten Interpretamenten behandelt worden war, ein Vorrecht des Opferherrn war. Mit beendeter Weihe setzt der Seher den Becher wieder auf dem Korbtisch ab (B: II 57-61; A: I 36-40a; C: III 17-21). Erst nachdem der Opferherr erneut die Hand an das Schaf (oder den Vogel) gelegt hat - hier wird die Funktion des Gestus als Ersatz für die durch den Spender sonst selbst vorgenommene Weihe deutlich -, wird die Opferschlachtung eingeleitet, d. h. zunächst wird das Schaf zur Schlachtstätte hinausgetrieben (B: II 62ff; die Vögel werden am Ort getötet, wo A [Herz, Flügel, der restliche Körper] zur Gänze, von C-H jedoch nur die Herzen auf dem Feuertiegel verbrannt werden, A: I 40b-55; C: III 22-40; D-H: III 45ff). Die Fleischteile (des Schafes) werden gekocht und der Gottheit vorgelegt; Brust und Rippenstücke sind für die Götter bestimmt, das Übrige ist vermutlich dem Verzehr der Opfernden vorbehalten (III 59-64. IV 42-44.46f.54-57) ${ }^{92}$. Das Ritual dürfte also Vernichtungs- (scil. A) und Fleischspeiseopfer kombinieren.

\section{CTH 718: KUB XXXIX 71 II 7 - III 32 und Duplikate ${ }^{93}$}

Als letztes Beispiel behandele ich im Ausschnitt das durch hurritische Vermittlung ${ }^{94}$ nach Hattuša gelangte Sühne-Ritual ${ }^{95}$ aus einem Kult der Pirinkir, einer als 'Herrin der Länder' und 'Königin der Götter' apostrophierten, synkretistisch mit Ištar geglichenen Göttin, die im 3. Jahrtausend als Haupt des elamischen Pantheons verehrt wurde, in späteren Jahrhunderten jedoch ihre

92 III 59-61 übs.: "Wenn er mit gekochtem Fleisch zu opfern die Runde macht, (geschieht das so:) sobald das (im) Topf (zuzubereitende) Fleisch gar ist, ...". Für die auf der verlorenen Folgetafel beschriebene Verwendung der noch nicht ausgeteilten Fleischstücke vgl. evtl. KUB XII 11 = Salvini / Wegner, Rituale, Nr 46 III ${ }^{\text {? }}$ 11-16: Fleischmahlzeit des Opferherrn und der Mitwirkenden (dort in zwei raum- und d.i. rangmaßig getrennten Gruppen).

Bzw. Passagen aus Parallelfassungen. Aus Raumgründen verzichte ich auf eine Umschrift. Eine Bearbeitung des Rituals hat G.M. Beckman angekündigt.

$94 \mathrm{Vgl}$. die in Bogazkői ausgesprochen selten belegbare, im Textensemble passim erfolgte (hethitisierende) Übernahme der hurritischen Lehnbildung $\check{s} a(n) k u n n i$ zu akkad. šang $\hat{a}<$ sumer. sanga "Priester" (cf. Laroche, Glossaire, 214). Vgl. ferner šehelliųaš unatar (KUB XXXIX 71 I 24), Laroche, ib., 221.

95 Der Charakter der Begehung ergibt sich aus der Darbringung von (6) Sündenträger-Schafen (UDU nakkaššš: KUB XXXIX 71 I 21; vgl. IV 22.26). Er klingt auch in einigen der akkadischen Rezitationen an. 
Vorrangstellung verlor ${ }^{96}$. Die zahlreichen, wohl erst am Ende des Überlieferungsweges stark verballhornten akkadischen Sprüche (Gebetsformulare) ${ }^{97}$, welche die verschiedenen Fassungen der vielleicht erst im 13. Jh. entstandenen hethitischen Ritualbeschreibung ${ }^{98}$ enthalten, weisen auf eine noch zu lokalisierende, etwa an Babyloniens Peripherie angesiedelte (mittel)babylonische Tradition $^{99}$, die noch von der alten hegemonialen Stellung der Göttin weiß und jedenfalls deren Identifikation mit Ǐstar stützt ${ }^{100}$.

Nach einer längeren Lücke am Ende der I. Textkolumne führt der Beginn der II. Spalte des Hauptexemplars in einen Handwaschritus. Der Priester läßt aromatisches Holz ( ${ }^{\mathrm{Gl}}$ lueššar) auf irgend etwas hinab ${ }^{101}$ und hält der Gott-

96 Die originale Namensform lautete Pini(n)kir, vgl. Hinz, Das Reich Elam, 35-37.45; Wegner, Gestalt, $165.46^{183}$.

97 Eine erste Bearbeitung der akkadischen Zitate hat Goetze, Rez. Otten KUB XXXIX, 94-96 vorgelegt. Varianzen zwischen den Textvertretern zeigen mehrfach, daß Textfehler erst innerhalb der Bogazköi-Tradition auftauchen, vgl. Goetze, ib., fn.3f.10. Hinsichtlich der Sprüche, die einzelne Riten begleiten, ergeben sich gewisse, eher vage, Anklänge an Formeln bekannter akkadischer 'Gebetsbeschwörungen' (s. bereits Mayer, Untersuchungen, 158 ${ }^{4}$ ) und aus entsprechenden Fragmenten des assyrischen Ordo (z.B. Menzel, Tempel II, Nr. 28 Vs. 12 u.ă.), doch fragt es sich, ob mehr als von der Sache her selbstverständliche Parallelen vorliegen.

98 Ich kenne kein Fragment, dessen Niederschrift vor dem 13. Jh. anzusetzen wăre. Ob gelegentlich auftauchende altere Zeichenformen wie in KUB XXXIX 76 Vs. 8 (ŠA) und 11 (DA) ausreichen, eine altere Vorlage zu postulieren, bleibt abzuwarten. Junghethitisch überliefert ist auch das eng mit unserem Text verwandte Ritual KUB XXIX 4 usw. (CTH 481), dessen historischer Anlaß mit dem in KUB XXXII 133 (CTH 482) I 1 ff beschriebenen identisch sein könnte (s. dagegen jedoch Kammenhuber, Historisch-geographische Nachrichten, $170^{37}$ ), der freilich bereits vor dem Beginn des 14. Jh. anzusetzen ist: z.B. Kühne, Politische Szenerie, $264^{233}$.

99

Babylonische Gelehrsamkeit kennt Pinikir zwar als einen der Namen Istars (König, Pinikir, 101), doch dürfte der Kult der elamischen Gơttin in Babylon selbst keine Rolle gespielt haben. Seine Aufnahme in Mesopotamien könnte in einem Zentrum der IStar-Verehrung (z.B. Ninive) erfolgt sein, wobei seine Verbreitung nach Norden eher am Ostrand des babylonischen Sprachgebiets bzw. in Nordsyrien zu erwarten wäre, wo eben auch Hurriter saßen (für deren Kontakte mit Elam im 3. Jt. vgl. Kammenhuber, Historisch-geographische Nachrichten, 157ff.169). Vielleicht erfolgte hier auch schon die Verănderung des Namens in Piri(n)kir. Man vergleiche auch die wohl von Hurritern selbst vorgenommene Gleichung der Göttin mit Allani (hurr. "die Herrin", Hypostase Šauska=Iక̌tars, s. CTH 57.44. - Das Wort kubätu (KUB XXXIX 71 II 22), sonst ist erst in späten Texten greifbar, ist jetzt für das 13. Jh. auch in Emar als Kultterminus bezeugt (Arnaud, Textes 3, 369, 9f; 373,34).

100 In diesem Sinne ist wohl auch die Verwendung des Zeichens IŠTAR (Rüster / Neu, Zeichenlexikon, Nr.263) in einigen Exemplaren zu verstehen.

101 Es liegt nahe, daß das Holz mit dem Z. 18 u.o. erwăhnten brennenden lueššar identisch ist. Nun ist aber "hinablassen" (katta tarna-) nicht der normale Ausdruck für das Beschicken eines Feuers, wăhrend man ein an sich auch denkbares Wasserbad wohl mit anda tarna- "(ins Naß) hineinlassen" formuliert hătte. Die Art der Ablage scheint eine besondere Vorbehandlung des Holzstücks vorauszusetzen. Dabei ist an die Möglichkeit zu denken, daß das Holzstück (zur 
heit das Handwaschwasser in einem silbernen Gefäß (ZA.HUUM "Kanne?) ${ }^{102}$ vor (para ep-), um dann dem Opferherrn etwas davon herauszugießen (para lahuua-). Diese Handlung ist eingerahmt von zwei Aufforderungen an die Göttin, ihre Hände zu waschen und ihre so gereinigten Finger zur Einnahme der warmen Mahlbrocken zu benutzen (II 3-13). Darauf gibt der Priester dem Opferherrn eine andere, mit Bier gefüllte, Silber-Kanne? in die Hand. Während (das erwähnte?) luě̌̌ar-Holz brennt, trägt ein Sänger einen Hymnus vor, der zum Ausdruck bringt, daß die Begehung des Rituals von der Göttin gewollt sei und daß der Opfernde, dank bereits erfahrener Gnadenerweise, diesem Willen in guter Zuversicht nachkomme (II 14-28 ${ }^{103}$ ).

Der Priester beginnt nunmehr mit dem (Vorweg-)opfer (Šipanduuanzi ep-). Er nimmt zunächst ein Brot, zerbröselt es und legt es auf das (brennende) lueššar. Er ergreift einen Fisch, schwenkt (-kan šer arha uahnnu-) ihn über (dem Bild) der Göttin und legt ihn gleichfalls auf das lueššar. Ebenso verfährt er mit einem weiteren Fisch, den er dieses $\mathrm{Mal}$ jedoch über dem Opferherrn schwenkt. Dann nimmt er eine Opferschale (auf der vermutlich eben das lueššar und die Fische liegen), hält ein wollenes kišri- darunter und bietet sie dem Opferherrn dar. Anschließend nimmt der Priester ein weißes Tuch und legt es über die vom Opferherrn gehaltene silberne Kanne? mit dem Bier (II 29-40).

Sobald das luešsar-Holz ${ }^{104}$ herunter[gebrannt ist ${ }^{105}$ ], schwenkt der Priester es über (dem Bild) der Göttin sowie [über dem Opferherrn ${ }^{106}$ ], wäh-

Steigerung seiner kathartischen Potenz zuvor in das im Kontext erwăhnte Wasser getaucht) naß auf die etwa mit Glut gefüllte Opferschale gebracht wurde, die gemaß Z. $38 \mathrm{f}$ mit einem wollenen kešri-, doch wohl im Sinne einer Wärmeschutzmaßnahme, angefaßt werden mußte, um hochgehalten werden zu können.

102 Die mesopotamische Evidenz für sum. ZA.HUM = akkad. s/sähum deutet auf ein schalenoder kesselformiges (u.a. den Typus ŠEN spezifizierendes) Gefäß, vgl. AHw, 1132f "eine (Wasch-)Schale". CAD Š/1 umschreibt mit "drinking or cooking vessel". Hinsichtlich des hethitischen Schreibergebrauches wird für das Sumerogramm die Deutung "Kanne?" vertreten (s. zuletzt Rüster / Neu, Zeichenlexikon, Nr. 366), was sich aus praktischen (bei Ritualen freilich nicht unbedingt zwingenden) Gründen zu der in unserem Fall bezeugten Benutzung als Ausschenk-Gefăß fügen würde. Unser Text setzt dabei voraus, daß die Öffnung des Gefäßes sich für die Einführung eines Fladenbrots eignet (III $2 \mathrm{f}=\mathrm{KUB}$ XXXIX 70 I 17 ' $\mathrm{f}$ ). Das ist bei einer Kanne dann denkbar, wenn ihr Hals nicht zu eng und der Fladen zusammengerollt eingetaucht wurde.

${ }^{103} \mathrm{Zu}$ dem schwierigen akkadischen Text s. Goetze, Rez. Otten KUB XXXIX, 95 .

104 Hier (II 44) steht die "personifizierende" (zuletzt Neu, Alter, 1ff) -ant-Erweiterung luešnanz(a); KUB XXXIX 70 I 2 ' scheint das nomen simplex zu bieten.

105 Ich erganze ar-h[a ua-ra-a-ni, übersetze jedoch mit Rücksicht auf den unmittelbaren Zusammenhang sowie auf Z. 55 (I KUB XXXIX 70 I 13') nicht absolut ("verbrennt").

106 Ergánzung des Duplikattextes (I 5') im Sinne des II 34-37 (s.o.) geschilderten Verfahrens. 
rend der Sänger dazu eine im Namen des Mandanten an die Göttin gerichtete Bitte um Sündentilgung vorträgt. Dann legt [ein zweiter] Priester das lueššar auf das (zuvor schon Kol. I 36 erwähnte) Tablett, indes der erste Priester dem Opferherrn die Kanne? mit dem Bier abnimmt, dasselbe 'hinab'spendet (kattanda Sipand-) und damit gleichzeitig das lueššr löscht, das sein sekundierender Kollege nun aufhebt und ins Feuer wirft (II 44-57 \| KUB XXXIX 70 I 1'-14').

Auf dem Tablett stellt der Priester ein Fladenbrot sowie je eine mit Bier bzw. Wasser gefüllte silberne Kanne? bereit. Über das Fladenbrot streut er Salz und legt ein Messer darauf. Dann ruft er den inzwischen beiseite getretenen Opferherrn herbei ${ }^{107}$. Unterdessen treibt man ein Opferschaf herein. Der Priester ergreift die mit Wasser gefüllte Kanne?, tunkt (-kan anda ep-) das gesalzene Fladenbrot ins Wasser und präsentiert (para ep-) letzteres der Gottheit als Handwaschwasser, sprengt (pappars-) davon - etwa mit Hilfe des aufgerollten ${ }^{\text {?102 }}$ Fladen - auf das Schaf und auf [das Messer(? $)^{108}$ ], bevor er den Rest zur Handwaschung vor dem Opferherrn ausgießt (para lahuua-). Dabei wiederholt er den bei der einleitenden Handwaschung rezitierten Spruch (II 58 - III 10 | KUB XXXIX 70 I 14'-19'\| 77, 1-8 \| XXXII 1 II ${ }^{2} 1-8$ || HT $\left.5,7^{\prime}-15^{\prime}\right)$.

Der Priester reicht dem Opferherrn nun die mit Bier gefüllte Kanne? und hält selber das gesalzene Fladenbrot sowie das Messer über das Schaf, während der Opferherr (das Bier spendend) die Weihe vollzieht (-kan sipand-). Die dazugehörige Bitte um Annahme des Opfers richtet der Priester für ihn an die Göttin (III 11-17 || HT 5, 16'-22' || XXXII 1 II' 9-13, vgl. IV' 1'ff).

Darauf legt der Priester dem Schaf (ein Klümpchen) Salz ins Maul und sagt: "Möge dir das Salz ${ }^{109}$ angenehm sein, meine Herrin, große Königin!". Er ergreift das Messer ${ }^{110}$ und nimmt vom Kopf und von der rechten Schulter des Schafes (scil. Haare als) Anbruch (anahi), legt den auf das Fladenbrot und

107 Erg. Kol.II 58 bzw. 65 nach III 29 bzw. 38.

108 Kol. III 4 setzt ein weiteres Objekt voraus, im Gegensatz zu HT 5, 12'f, wo offenbar nur von der Besprengung des Schafes die Rede ist (die Lücke in Z. 13' reicht gerade für das zu erwartende se-er).In dem vorher betrachteten Ritual CTH 701 waren Schaf und Messer auf diese Weise rituell gereinigt worden (dort II 33ff). In unserem Fall darf man gewiß nur dann mit der Besprengung des Messers rechnen, wenn dieses (das doch gerade zuvor auf das Brot gelegt worden war) nicht zusammen mit dem Brot in das Wasser eingetaucht worden war. Tatsăchlich spricht der weitere Kontext (zu III 12f vgl. III 25-27 und die Anm. 110 zitierte Varianz) eher für eine getrennte Behandlung von Brot und Messer. Für die Lücke mit einem Hinweis auf die etwa in den genuin anatolischen Ritualen gern geübte (der aktiven vorausgehende) passive Reinigung des Opferherrn zu rechnen, empfiehlt sich m.E weniger.

109 Kol. III 22 eigentlich "Gutes" (Pl. tābătu, als Wortspiel?); die (in Bezug auf die leicht verballhornte Verbform korrigierten, aber zugleich verkürzten) Parallelen haben das erwartete MUN (=țābtu) "Salz".

110 Zusatz FHG 3 + KUB XXXII 2 II 7'f. 
verbrennt beides auf dem Feuertiegel (huprushi-). Dann nimmt er dem Opferherrn die Kanne mit dem Bier ab und dieser tritt, da nun die Weihe beendet ist, von der Opferstätte zurück. Das Schaf wird zur Schlachtung hinausgetrieben (III 23-32 || HT 5, 23'f \| KUB XXXII 2 + FHG 3 II 1'-12' || XXXIX 70 V 1-16 \| 89, 1'-6'). Sein Fleisch, teils in rohem, teils in gekochtem Zustand, und seine Leber werden anschließend der Gottheit vorgelegt (III 36-61). Der Umstand, daß bei der folgenden Handwaschungszeremonie neben der Gottheit auch der Opferherr berücksichtigt wird (III 38-42), könnte darauf hinweisen, daß dieser im Rahmen einer (infolge Textverlusts noch hypothetischen) kultischen Mahlzeit am Verzehr des Fleisches beteiligt wird. Bei dem in der Folge beschriebenen, leider nur allzu fragmentarisch bezeugten, für die Gottheit und den Opferherrn an und mit je einem ${ }^{111}$ Schaf vollzogenen nakkušse-Ritus (IV 22ff) handelt es sich, soweit Parallelen erschließen lassen ${ }^{112}$, um ein (vorhandenes Übel aufnehmendes und fortschaffendes) Preisgabeopfer. Die Kombination mehrerer Opfertypen, bereits für CTH 701 erwogen, steht für unser Ritual ohnehin fest, wenn wir die Verbrennung der Fische im Rahmen des uns hier eigentlich interessierenden Voropfers konsequenterweise als Vernichtungsopfer ansprechen.

Vergleichen wir nach der Betrachtung der einzelnen Textzeugnisse dieselben nunmehr mit einander, erkennen wir, wie erwartet, neben mancherlei vor allem herkunftsmäßig bedingten Verschiedenheiten in der rituellen Formensprache ein gemeinsames, in den Begehungen (bzw. in deren Beschreibungen) mehr oder weniger stark zum Ausdruck gebrachtes Bemühen um eine der Opferweihe, zumindest der Opferschlachtung, vorausgehende rituelle Vorbereitung des Tieropfers. Nach dem Erledigen der technischen Voraussetzungen des Opfers, d.h. nach Bereitstellung der Opfermaterie und des für die Handlungen benötigten Geräts wie auch nach einer durch Waschung und Anlegen von Festkleidern äußerlich bekundeten Vorbereitung der Person des Opfernden und ggf. der (Mit)zelebrierenden sowie nach ordentlicher Herrichtung bzw. Reinigung der Kultstätte und ihrer Gegenstände, gilt es noch, Vorkehrungen gleichsam auf einer höheren Ebene zu treffen. Opfer, Opfernde, ggf. auch bestimmtes Gerät, ja selbst die Kultgegenstände, obwohl schon festlich hergerichtet, sind offenbar immer noch entweder Teile des Profanen oder doch mit Spuren von Profanität behaftet, weshalb man sie der angestrebten Begegnung mit dem übermächtigen Heiligen nicht ohne weiteres aussetzen will. Profan und heilig stehen als größte denkbare Gegensätze unter gefährlicher Spannung. Soll es bei dem gewünschten Kontakt nicht zu einer die menschliche Seite vernichtenden Entladung

${ }^{111}$ Kol. IV 22ff. Das Gesamtritual erfordert jedoch gemåß Kol. I 20 den Einsatz von 6 nakkuššeSchafen.

112 Vgl. van Brock, Substitution rituelle, 126ff; Kü̈mmel, Ersatzrituale, 146-149. 
kommen, müssen hier sei es qualitativ verändernde, sei es schützende Maßnahmen ergriffen werden. Auch wenn das initiatorisch erwartungsvoll unter dem Aspekt der Gegenseitigkeit (do ut des) geweihte Opfer selbst der Herstellung (in zweiter Linie der Aufrechterhaltung) göttlicher Geneigtheit, d.h. eines Friedens- oder Partnerschaftszustandes, dient, ist doch gerade sein unter dem Zeichen der physischen Annäherung und damit der zunehmenden Spannung stehendes unmittelbares Vorfeld der geeignete Ort für jene Maßnahmen. Sie bestehen einmal aus (Be)handlungen, welche zur schadlosen Überschreitung der Grenzen des Profanen ermächtigen, indem Mittel, meist kathartische Substanzen, eingesetzt werden, die, als Ausfluß des Heiligen in die Profanität, dem Menschen in seiner Umwelt zur Verfügung stehen und, richtig angewendet, $\mathrm{ihm}$, seinem Opfer und seinem Kultgerät (auch einem vielleicht durch Berührung oder Blicke profanierten Götterbild ${ }^{113}$ ) ihre Kräfte mitteilen. Die Addition wie auch die mehrfache Anwendung dieser Mittel verstärken ihre Wirkung. Neben solchen Maßnahmen, den Reinigungsriten, sieht man die Möglichkeit, durch Vorweg-Opfer, sei es an Brot und Trank, sei es in Gestalt eines kleinen Teils des eigentlichen Opfers, eine günstige Disposition der Gottheit von außen her anzubahnen, einen Gnadenvorschuß und damit einen Abbau der Spannungen auf der Partnerseite zu erwirken.

Eine Zusammenschau der wichtigsten in den exzerpierten Ritualen geschilderten Handlungsschritte zwischen Opfervorbereitung und -weihe, ergibt folgendes Bild:

${ }^{113}$ Zur widersprüchlichen Doppelrolle des Idols als stăndiger Vergegenwărtigung und zugleich als temporărem, etwa auf die Dauer von Kulthandlungen beschrănkten, Aufenthalt der Gottheit vgl. Furlani, Religione, 407. - Ubrigens kann sich nach hethitischer Vorstellung eine Gottheit verfehlen oder mit einer als verunreinigend empfundenen Gemütsbewegung oder einem ebenfalls als Verunreinigung betrachteten Zauber behaftet und dadurch in ihrer Funktionswillig- bzw. -făhigkeit beeintrăchtigt sein. Sofern diese Beeintrăchtigung sich auf den Menschen auswirkt, versucht dieser dem festgestellten Reinigungsbedürfnis der Gottheit abzuhelfen. Das geschieht freilich nicht im normalen Kult, sondern auf dem Wege der Beschwörung. Vgl. dazu die Beschwörungen, die an die (ătiologischen) Mythen 'verschwundener' Gottheiten geknüpft sind (CTH 322ff). 


\section{MOTIVE}

\section{Erōf f nu ng \\ 1 Handwaschung d.Opferherm \\ 2 dto. d.Idolshand (angedeutet) \\ 3 Verbeugung d.Opfh. vor Idol}

Vorweg-Opfer

( A: vor Reinigung;

B: b e i Reinigung;

C: $z$ w i s ch e n Reinigg.u.Weihe;

D: i m Rah men der Weihe)

4 Brotopfer

5 Trankopfer

6 Rauchopfer

7 Brandopfer

Auftrieb der Opfertiere

8 vor Reinigung

9 zur Reinigung

10 zur Schlachtung

11 mit Musikkapelle

Eigentl. rituelle Reinigung
A "passiv"
12 durch (Ober-)Koch
13 durch Priester
Verfahren:

a) unerklärt

b) Besprengen

c) dto. mit dem ruhhuessar

d) GuB auf/in Richtg. auf

e) dto. auf Hände

D Medium Schwenken über

g) Medium Vorhalten

h) Medium in die Hand Geben

i) Medium auf den Kopf Legen

j) Medium Verbrennen

Objekte:
a) Idol
B) Altar/Stele
r) Opfertier(e)
ס) Messer
e) Opferherr

\author{
Medien: \\ 14 ungenannt \\ 15 Wasser + gelöschtes \\ Brennmaterial (hullis) \\ 16 Wasser + \\ ruhhu- \\ ešsar \\ 17 ölbenetztes Zedernholz 11 \\ 18 Fisch (s.a. noch 7) \\ 19 brennendes/glimmendes \\ lueverar \\ 20 Wasser + ÖI + \\ Zedernholz11 \\ 21 Wasser, in das salzbe- \\ streutes Brot \\ hineingehalten wurde \\ B "a k $t$ i v" (Subjekt:Kōnig) \\ 22 tuhs-Ritus \\ 23 dto., Zielorgan: Lippen \\ C Lit u r g i e (in Stichzeilen) \\ 24 Reinigungsspruch
}




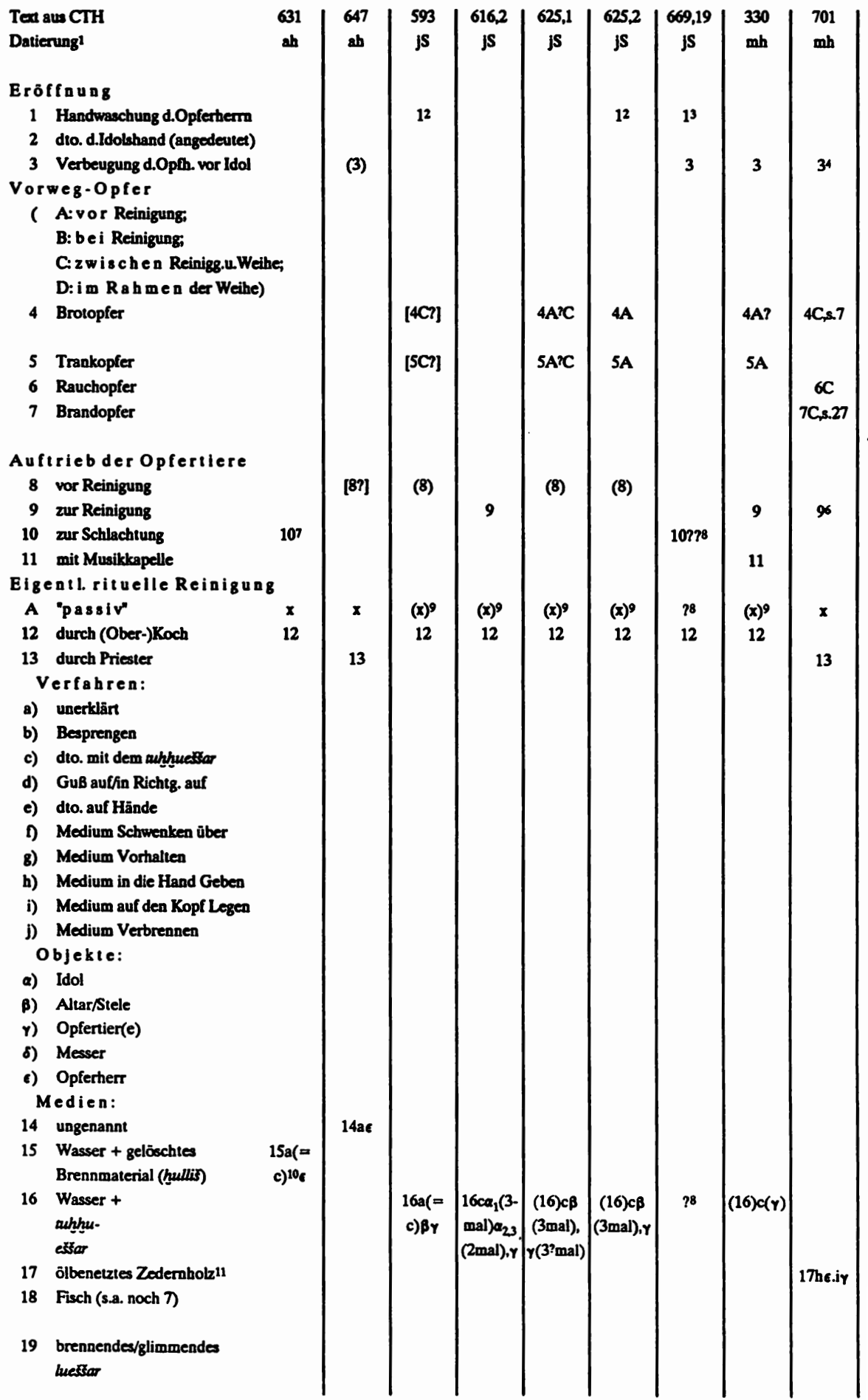


Unsere, wie eingangs dargetan, notwendig selektive Materialvorlage und der knappe Rahmen dieser Studie rechtfertigen bzw. erzwingen den Verzicht auf eine auch nur annähernd erschöpfende religionsvergleichende Auswertung des erhobenen Befundes. Der folgende Kommentar zu einzelnen Motiven der in meiner Tabelle erfaßten Opferabschnitte "Eröffnung" und "Vorweg-Opfer" beansprucht daher nur, Ansätze zu einer Einordnung jenes Befundes beizusteuern. Der Abschnitt "eigentliche rituelle Reinigung" wie auch das Thema der Weihe müssen anderswo verhandelt werden.

\section{Zu Motiv 1: Handwaschung des Opferherrn}

Wegen Textverlusts hier nicht zu beurteilen sind CTH 647; 612,2; 625,1. Das Motiv fehlt als einleitender Ritus in CTH 631, 330 und 701. CTH 631 bietet das Motiv nach dem Vollzug des Opfers in einer späteren Phase, wo es den Beginn eines Kultmahls zu bezeichnen scheint ${ }^{114}$. CTH 701 zufolge erfährt der Opferherr immerhin noch vor der Opferweihe einen Handguß, allerdings mit präpariertem Wasser und in einem Zug mit der Reinigung der Gotteshand, des Opfertieres und ggf. des Opfermessers (Motiv 20). CTH 330 kennt zwar die Handwaschung des Opferherrn ${ }^{115}$, sieht sie jedoch im Rahmen des Tieropfers wohl deshalb nicht vor, weil dieses beginnt, nachdem der Opferherr das Waschungshaus verlassen hat, in dem er seinen Festtagsstaat angelegt und gewiß zuvor die hier gebotenen Annehmlichkeiten zur (jeweils? vorgeschriebenen) körperlichen Hygiene wahrgenommen hat. Genau diese Situation scheint aber auch in der kürzeren, die Morgentoilette auf das Ankleidemotiv reduzierenden Darstellung von CTH $631^{116}$ gemeint zu sein. Da man gerade von der körperlichen Reinigung kam - was übrigens auch für CTH 701 gilt - konnte man auf die opfereröffnende Handwaschung verzichten ${ }^{117}$. Unverzichtbar aber wurde

114 S. Duplikat KBo XVII 74 III 11' (Neu, Gewitterritual, 24).

115 Vgl. indirekt, aber eindeutig, KBo XV 33 III 23' (vor Opferrunde).

${ }^{116} \mathrm{Neu}$, Ritualtexte, 65, 32'.

${ }^{117} \mathrm{Da}$ eine solche Regelung in Hattusa generell kultüblich war, sei damit noch nicht behauptet (möglicherweise anders KUB LVII 63 [Archi, Anrufung, 16ff] I 2-21). Für strengere Prinzipien vgl. das unten zum jüdischen Tempelkult Festzustellende. Bei Homer findet sich die Kombination von Bad und nachfolgender Handreinigung Od. IV 48-54 vor einem Frühmahl (hier war der Dienst der wasserreichenden Dienerin feste Regel, dem in einer größeren Tafelrunde allfälligen Bedürfnis angemessen), wăhrend im gleichen Gesang, 759-61, bei dem voropferartig eingeleiteten Gebet der Penelope das Hăndewaschen vor dem Streuen der Gerste entfallt, doch wohl weil die Beterin gerade gebadet hat. - Im Übrigen ist sicherlich damit zu rechnen, daß eine, namentlich für eine Vielzahl von Fällen als zweckmäßig erkannte und entsprechend bedingt verbindliche Verfahrensweise gerade im kultischen Bereich im Lauf der 
diese offenbar dann, wenn zwischen der morgendlichen Hygiene und dem Opfer Zeit verstrichen und längere Wege bis zum Opferplatz zurückzulegen waren, so nachweislich im Fall von CTH 593 (Feier auf dem Berg Tapala) oder von CTH 625,2 (Opferstätte nach Wagenfahrt erreicht ${ }^{118}$ ). Hier hatte die Handwaschung ihre rituelle Funktion: unvermeidliche kleinere Verunreinigungen zu beseitigen, den Zustand kultnotwendiger ästhetischer Reinheit ${ }^{119}$ nachbessernd wiederherzustellen.

Die in unserer Tabelle vollzogene Trennung des Handwaschungsmotivs von der durch magische Vorstellungen und Manipulationen geprägten "eigentlichen", in sakraler Hinsicht perfizierenden, ursprünglich unterstützenden, rituellen Reinigung folgt dem vorliegenden Befund. In CTH 625,2 schieben sich zwischen beide Akte ein Brotopfer und eine Libationsrunde. In CTH 593, wo ein solcher Einschub fehlt, sowie in 625,2 setzt der zweite Akt nicht beim König, dem Subjekt des ersten Akts, sondern mit der Reinigung der Gottheit bzw. der sie vergegenwärtigenden Stele ein (Motiv 16, s. auch CTH 616,2 und 625,1; der König tritt hier erst später ins Blickfeld, s. Motiv 22/23). Dieser offenbar entwicklungsbedingte Umstand ${ }^{120}$ sowie der zwischen beiden Akten erfolgte Wechsel des Wassers (es handelt sich jetzt nicht mehr um das von Pagen gereichte ${ }^{121}$ "Hand \{wasch\} wasser" [ŠU ${ }^{M E S}$-aš uatar / MU $\left.Q A T I\right]$ !) verstärken den Eindruck, daß es sich um zwei absichtlich von einander abgesetzte Reinigungsakte handelt, deren zweiter eine andere, in seinem Symbolcharakter gesteigerte, sakrale Qualität besitzt (falls dem bei dem zweiten Akt zur Applikation verwendeten tuhhueššr eine eigene kathartische Kraft zugeschrieben wurde, läge darin eine weitere Bestätigung dieser differenzierenden Sicht) ${ }^{122}$. Schließlich wird man auch darin eine konsequente Scheidung der Funktions-

Zeit zur allgemeingültigen Regel erhoben werden konnte.

118 KBo XIX 128 I 3-5.

119 Vgl. die auf allgemeines ästhetisches Empfinden gegründeten Reinlichkeitsprinzipien, welche die Instruktion KUB XIII 4 (Pritchard, ANET ${ }^{3}, 207 f$; Kühne, Hethitische Texte, 201f) den zahlreichen, namentlich auch den untergeordneten, Funktionären des alltäglichen Kultbetriebs für ihren Dienst einschärft.

${ }^{120}$ Im althethitischen Fragment KBo XXV 73 ( Neu, Ritualtexte, Nr. 73) lk. Kol. 4'f ist auch der zweite Akt noch ausschließlich mit dem Konig befaßt. Auch CTH 631 und 647 sehen nur die Reinigung des Konigs bzw. des opfernden Prinzen vor. Zum entsprechenden Textbefund in CTH 669,19 vgl. aber noch 0., S. 240 mit Anm.71.

121 Offen bleibt, ob wie in CTH 718 (HT 5, 14') durch Übergießen appliziert.

122 Aus dem Rahmen fallt das althethitische Fragment KBo XX $10+$ XXV 59 (Neu, Ritualtexte, Nr 59), das Kol. I 10-12. II 7-10 vor einem Kultmahl die Handwaschung des Königs nach seiner durch Besprengung erfolgten sakralen Reinigung vorsieht. Hier scheint eine Vermischung der Motive 1 und 22 vorzuliegen, wobei allerdings die unterschiedlichen Ebenen der Reinigung deutlich bleiben: die Besprengung nimmt der Priester vor, das Handwaschwasser wird von ungenannten Funktionăren gereicht. 
ebenen beider Akte anerkennen wollen, daß der erste (die grundlegende kultische Waschung nachbessernde) einen Teil, eben die Hand, der zweite aber - selbst wenn das Zielorgan die Lippen sind - die ganze Person (wie auch die im gleichen Zuge wohl als ganze besprengten Idole, Altäre und Opfertiere, s. Motiv 16) betrifft. Unverwischt bleibt dieser dimensionale Unterschied übrigens auch in dem nicht autochthonen Ritual CTH 718, wo in jene, dort sehr komplex gestaltete, perfizierende Ganzreinigung - s. Motive 18.19 - eine zweite Handwaschung integriert wird, bei der man, anders als bei der ersten (Motiv 1) und bei einer nach dem Opfer ausgeführten dritten Handwaschung ${ }^{123}$, manipuliertes Wasser verwendet (Motiv 21).

Zeigte bereits der Hinweis auf CTH 718, daß die eröffnende Handwaschung - was kaum erstaunt - kein allein anatolisches Motiv sein kann, so läßt sich dieses z.B. auch an dem in altbabylonischer Zeit in Mari gefeierten Festritual für Ištar nachweisen: der leider nur in seinem Beginn bezeugte zweite, abendliche, Abschnitt des Festes setzt mit einem Wassergußritus ein, der vor den Gottheiten vollzogen (Verbum nadum) und in seiner Bedeutung insofern durchsichtig wird, als dem König als Opferherrn im gleichen Vorgang das gleiche Wasser zur Handreinigung gereicht wird (Verbum nadānum) ${ }^{124}$. Dieser Ritus ist deutlich von einer anschließenden Wasserlibation (Verbum naqûm) getrennt ${ }^{125}$. Ob ein Tieropfer bzw. eine Götterspeisung folgte, bleibt uns aufgrund des Textverlusts verborgen. Abgesehen von der (allerdings kaum beweiskräftigen) Notiz, daß das Wasser aus dem Tempel gebracht wurde, findet sich im Text kein Hinweis auf einen magisch überhöhten Charakter der rituellen Reinigung. Das Händewaschen (mis qäti) scheint in Mesopotamien zu den selbstverständlichen Voraussetzungen religiöser Übungen, vor allem des Gebets und des Götterdienstes ${ }^{126}$, zu gehören und hat jedenfalls in Reinigungsriten auch symbolisch-magischen Charakter ${ }^{127}$.

123 KUB XXXIX 71 III 40-42.

124 Dossin, Rituel, 7 IV 1-14a.

125 ibid. IV 18ff (Z. 14b-17 ein Rauchopfer?).

126 Vgl. die Handwaschung des Oberpriesters vor kultischem Gebet (Opferweihe?) im Anu-Ritual aus Uruk: Thureau-Dangin, Rituels accadiens, 91, 3. Zu Zimmern, Beiträge, Nr. 60 (vgl. dort Zz. 24'.26') s. Menzel, Tempel I, 297; II Nr. 51 (p. T 108). - Die Handwaschung des Königs zu Beginn seines Bußritus im babylonischen Neujahrsfest (Thureau-Dangin, Rituels accadiens, 144,413 ) dürfte der Nachbesserung seiner körperlichen Reinheit dienen. Hand- und Mundwaschung des Opferschauers gehoren schon in altbabylonischer Zeit an den Beginn seiner Ritualhandlungen: Goetze, Old Babylonian Prayer, 25ff), 5 und jünger Zimmern, Beitrăge, Nr. 75,17' (nach Waschung am Weihwassergefäß, Z. 14'), vgl. 96,3.

127 Einzelheiten bei Lambert, Handwaschung, 97f. Der synekdochische Gebrauch von sumer. suluh, bzw. akkadisiert šuluhhıu, "Handwaschung" für den Reinigungskult zeigt, ebenso wie griech. cherniptesthai im speziellen Sinn von "opfern", welche Bedeutung dem Motiv beigemessen wurde. 
Für Ugarit ist einmal ein Handwaschungs(ritus) (hll ydm) in einem königlichen Opferritual bezeugt ${ }^{128}$, wobei freilich angesichts der notorisch überaus knappen Formulierung ugaritischer Opfertexte offen bleibt, ob es sich hier um die Handwaschung des Königs oder (wohl besser:) der beopferten Gottheit (vgl. u., Motiv 2) handelt.

Im alttestamentlichen Kult ist zumindest für die diensttuenden Priester die bei Aufnahme des Tagewerks zu vollziehende Hand- und Fußwaschung vorgeschrieben ${ }^{129}$. Die mischnische Tradition detailliert dazu rückblickend auf die Zeit des Zweiten Tempels, daß vor Betreten des Altarhofs beim morgendlichen Dienstantritt sowie nach jedem längeren Verlassen des Hofes (auch zur Defäkation) ein Tauchbad zu nehmen war, zuzüglich Hand- und Fußwaschung, während kurzzeitige Abwesenheit vom Altarhof (z.B. zur Miktion) oder eine im Dienst zugezogene Verunreinigung der Hände das Waschen (Eintauchen) von Füßen und Händen bzw. der Hände allein erforderte. Ansonsten genügte die beschriebene morgendliche Reinigung für den Dienst des gesamtes Tages ${ }^{130}$. Obwohl die Teilwaschung dem (qualitativ entsprechenden) Ganzbad allemal quantitativ unterlegen ist, wurde die zusätzliche Waschung nach einem Bade hier deshalb erforderlich, weil die Einrichtung für das Tauchbad außerhalb des heiligen Hofbereichs $\operatorname{lag}^{131}$ : wie jede andere, selbst kürzeste, Abwesenheit von dort bedeutete der Weg zwischen Bad und Hof einen zumindest potentiellen Verlust an ritueller Reinheit. Der Zweck von Hand- und Fußwaschung war (im Prinzip wie in Hुattuša, nur strenger im Maßstab), jenen Verlust an den als besonders exponiert geltenden Körperteilen nachbessernd auszugleichen.

Im alten Ägypten setzt jede kultische Handlung rituelle Reinigung(en) voraus. Der Zelebrant läßt sich vor seinem Dienst mit Wasser übergießen, wobei er in einem flachen Becken steht. Vor dem Betreten des Tempels wäscht er sich zusätzlich die Hände ${ }^{132}$.

\footnotetext{
${ }^{128}$ RS 24.260 = KTU 1.115, 6, wozu s. Blau / Greenfield, Ugaritic Glosses, 15; Dietrich / Loretz / Sanmartín, Notizen, 543f; Xella, Testi rituali, 107f; Dietrich, TUAT II/3, 319.

${ }^{129}$ Ex 30, 19-21.

130 Vgl. die zusammenfassende Darstellung im Codex Maimonides VIII, 3, V 4-6.3, übs. M. Lewittes, Code, 103f. Möglicherweise bestanden für den gewöhnlichen Israeliten, d.h. vor allem für den Opfernden, entsprechende Regelungen. Eitrem, Opferriten, 93 erinnert in diesem Zusammenhang an das apokryphe Evangelienfragment Pap.Oxyr. 850, 15, demzufolge Jesus und seinen Jüngern vorgeworfen wurde, das hagneutērion ungebadet und mit ungewaschenen Füßen betreten zu haben. Nach Lampe, Patristic Greek Lexicon (Oxford 1961), 21a bezeichnet $h$. hier denn auch den inneren Tempelhof.

${ }^{131}$ Codex Maimonides VIII 1, VI $10 \mathrm{f}$ (Lewittes, l.c., 23).

$132 \mathrm{Vgl}$. Bonnet, Reallexikon, 632.
} 
Die homerischen Epen zeigen, daß die Handwaschung der Opfernden auch in Hellas bekannter Bestandteil des Voropfers war $^{133}$. In Darstellungen aus dem klassischen Schrifttum vermischt sich mit diesem Motiv einerseits die bei Homer nicht bezeugte rituelle Besprengung (vgl. Motive 15, 16, 21), zum anderen eine Wasserspende (durch Sekundärinterpretation des eigentlich der Reinigung dienenden Gußvorgangs ${ }^{134}$ ), wobei die verwendete Terminologie (Verbum cherniptesthai und Derivate) nie einen Zweifel am primären Sinn des Ritus aufkommen lie $\beta^{135}$. Von einer magischen Überhöhung des rituellen Händewaschens ist zumindest bei Homer nichts zu spüren ${ }^{136}$; für die klassische Periode ist allerdings eine Manipulation des Wassers bezeugt, die darin bestand, daß man das Wasser (neben anderen Lustramina) nach rechts laufend um den Altar trug ${ }^{137}$.

\section{Zu Motiv 2: Handwaschung der Gottheit}

Das Motiv erklärt sich als Parallele (im Sinne eines vermenschlichenden Analogismus) zu Motiv 1 und als verkürztes Gegenstück zu der in nach-althethitischer liturgischer Überlieferung gut bezeugten rituellen (Ganz)waschung von Götterbildern und Kultstelen ${ }^{138}$. In Bogazköy zwar auch seit der mittelhethitischen Periode greifbar, mag es, anders als jenes eher universale Motiv

133 Ilias I 449; den Vorgang als Übergießenlassen der Hănde beschreibend: III 270. Vgl ferner Odyssee III 444f (429.440). Daß auch Homer den Verzicht auf die Handwaschung nach einem vorangegangenen Bad kennt, erwahnten wir 0., Anm. 117 (ad Od. IV 759ff).

134 etwa eine mißverstehende Übernahme der rituellen Reinigung der Gottheit (Motiv 3; vgl. u., Anm. 138.141)? Die namentlich von Eitrem vertretene Herleitung aus dem Totenkult (Opferritus, 78.100.103ff) überzeugt nicht, s. bereits Meuli, Opferbräuche, 264f.

${ }^{135}$ Vgl. Ziehen, Griechische Opfer, 601f. Yerkes, Sacrifice (der mir z.Zt. nur in der franzÖsischen Ubersetzung von 1955 vorliegt) sieht den Ursprung des kultischen Handewaschens in der vor dem gewohnlichen Mahl geübten Gewohnheit (ch. IX/iv m. nte 17, unter Verweis auf Od. I, 146; IV, 52; VII, 172; X, 182.369).

$136 \mathrm{Vgl}$. auch Stengel, Opferbrauche, 14, der zurecht hervorhebt, daß Homers Opferschilderungen keine uber das Physisch-Ästhetische hinausgehende rituelle Reinigung kennen.

${ }^{137}$ Dazu Eitrem, Opferritus, $6^{1}$ (Belegstellen). $7 \mathrm{ff}$. Zur Rechtsdrehung s. ibid., 30.41ff. Burkert, Griechische Religion, 101, betrachtet die Maßnahme nicht als auf das Herumgetragene bezogen, sondern als magische Kreisziehung zum Schutz der Opferstatte, was Eitrem (ib., 9) als weitere Funktion des Ritus erklart.

138 Belege bei Archi, Fêtes, $19^{55} .23$. Ferner $\mathrm{HW}^{2}$ I,230f. Die Bezeugung im Festritual für Telipinu von Hanhana (mittelheth. KUB IX 3 I 17f.20f; Haas / Rost, Festritual, 10ff [60]) laßt vermuten, daß der Brauch bereits in der althethitisch-protohattischen Schicht bekannt war. Für mesopotamische Vorbilder bzw. Parallelen, vgl. etwa Ferwerda, Contribution, 11 (m. Lit.). Auch aus Syrien ist jetzt für das 13. Jh. v. Chr. ein Beleg greifbar: Amaud, Textes 3, no. 370 (p. 340), 84. Für die ägyptische Evidenz s. unten mit Anm. 147. 
der Ganzwaschung des Idols, erst um diese Zeit und in recht begrenztem Umfang in Anatolien bekannt geworden sein $^{139}$. Sein Vorkommen in CTH 718 läßt an östliche Herkunft denken. CTH 718 bezeugt übrigens zwei weitere symbolische Handwaschungen der Gottheit: eine, die mit ebenfalls unbehandeltem Wasser nach dem Opfer und vor der Speisung der Gottheit erfolgt ${ }^{140}$, und die andere, die vor der Weihe in Zusammenhang mit Motiv 21 mit manipuliertem Wasser ausgeführt wird ${ }^{141}$. Jedesmal wird dabei der gleiche Spruch rezitiert, der den Akt als Vorbereitung zum Mahl kennzeichnet.

Wird in CTH 718 die Handwaschung der Gottheit durch Vorhalten (para ep-) des jeweiligen Wassers angedeutet, so dürfte das Ausgießen von manipuliertem Wasser vor (menahhanda lahu-) dem Bild der Hebat in CTH 701 (Motiv 21, in Zusammenhang mit der Besprengung des Opfertieres und mit einem Guß auf die Hände des Opferherrn) ebenfalls eine Handwaschung symbolisieren.

Symbolische Handwaschungen sind klärlich auch die in dem erwähnten altbabylonischen Ritual aus Mari zu Beginn seines abendlichen Abschnitts jeweils dreifach vor den Götter(bilder)n ausgeführten Wassergüsse, die der Handwaschung des im gleichen Vorgang bedienten königlichen Opferherrn unmittelbar vorausgehen ${ }^{142}$. Die spätbabylonische Überlieferung alter Kultrituale aus Uruk belegt z.T. verschiedentlich wiederholte an Götterbildern mehr oder weniger andeutungsweise vollzogene Handwaschungen ${ }^{143}$. Hier scheint zudem allmonatlich am Vollmondstag ein besonderer Handwaschritus (tëbibti $q a \bar{t} t \bar{e})$ gefeiert worden zu sein ${ }^{144}$. In späterer Zeit weiter ausformulierte Bitten

139 Graphisch altester Beleg ist das mittelhethitische Ritualfragment KBo XXI 86 II 9'f, das die Handwaschung der Siebengottheit (Plejaden) bezeugt. In dieselbe Epoche (vgl. Archi, Anrufung, 15) dürfte auch die Urschrift des liturgischen Textes KUB LVII 63 datieren, welcher der Sonnengottin von Arinna und dem königlichen Opferherrn gleichermaßen die aktive Handwaschung vor dem Opfer unterstellt (Kol. I 20f; Archi, l.c., 16). Vermutlich ist des Königs unmittelbar vorher erwăhnte dreimalige Wasserspende vor dem Altar (I 18f) Symbol für den ja sonst nicht darstellbaren Akt der Göttin! Freilich würde die hier im Text gewahlte Ausdrucksweise eine Vermischung von Waschwasser-Guß und Spende implizieren. In den Rahmen des im 13. Jh. erneuerten Kultes von Nerik gehört schließlich der Hinweis auf eine (passive) Gotterhandwaschung in KUB LIX 32 III 8 (Haas, Kult,313).

140 KUB XXXIX 71 III $39 f$.

$141 \mathrm{Zu}$ letzterer s. die Parallele im ebenfalls aus dem hurritischen Osten vermittelten Ritual CTH 701 (Motiv 20).

142 Dossin, Rituel, 7 IV 4-10 (vgl. Anm. 124).

143 Z.B. beim Lever (Thureau-Dangin, Rituels accadiens, 93, 16), vor einem Opfer (ib., 90, 29; 91,20), vor der Götterspeisung (ib., 90, 22.33; 92b, 12; 119, 18), nach der Speisung (ib., 119,32), am Ende einer Prozessionsstation (ib., 100, 24; 103, 11, 115, 8) usw.

144 Thureau-Dangin, Rituels accadiens, 79, 33f (etwa synekdochisch gemeint für die Opferfeier, vgl. oben Anm. 127). 
zur Götterhandwaschung kennen wir aus einem altbabylonischen Opferschaugebet $^{145}$. Erwartungsgemäß gehört das Motiv auch zum rituellen Repertoire des in Assyrien geübten Kultes ${ }^{146}$.

Für einen wahrscheinlichen Götter-Handwaschungsritus in Ugarit, nach dem synekdochisch ein ganzes Ritual benannt wurde, siehe bereits oben zu Motiv 1.

In Ägypten geht der allmorgendlichen Beopferung der in ihrem Bilde vergegenwärtigten Gottheit deren Ganzreinigung (durch Räucherung und Waschung) vorauf und wird überdies zum Schluß der Gottesspeisung wiederholt ${ }^{147}$. Dagegen wird der Begriff der Handwaschung auf einen Wasserguß bezogen, der (wieder in Zusammenhang mit einer Räucherung) vor der rituellen Speisung im Totenkult dargebracht wird ${ }^{148}$.

\section{Zu Motiv 3 und 25: Verbeugung des Opferherrn vor dem Götterbild}

Ob der hier verwendete Begriff der Verbeugung auch die an sich im Alten Orient geläufige Prostration umfaßt, kann ohne eine eingehende lexikalische Untersuchung, möglichst unter Einbeziehung aller hethitischen Ausdrücke für Ehrfurchtsbezeugungen ${ }^{149}$, nicht entschieden werden. Es scheint, daß die hethitischen Verben hink- und vor allem aruuai- die in den Texten (auch in Motiv 3 und 25) beide mit den allographisch verwendeten entsprechenden Formen des akkadischen Verbums šukênu "sich niederwerfen" wechseln, wenigstens an einigen aussgekräftigen Stellen ${ }^{150}$ eher "neigen, sich verneigen" als "sich niederwerfen" bedeuten und daß zudem das akkadische Allogramm alt- bis junghethitisch (allerdings sehr selten) auch dann benutzt wird, wenn die be-

145 Vgl. Goetze, Old Babylonian Prayer, 26, 19-21 mit Zimmern, Beiträge, Nrn. 75-78, 5'-11'.53'55'. Hieraus geht hervor, daß das verwendete Wasser mit Duftholz-Spănen versetzt war, mit Materie also, die sonst vorwiegend als Răucherwerk diente und der man kathartische Wirkung zuschrieb (vgl. unten, S. 267f).

146 Vgl. etwa Menzel, Tempel II, Nr. 28[=T 42ff] Vs. 11; 30 [=T 49ff] Vs. 7.19; 36 [=T 72ff] A II (12').B II 18'; 45 [=T 98ff]) IV 13'; 46[=T 102]) Vs. 17f.

147 Bonnet, Reallexikon, 640; Barta, Kult, 842f.

148 Bonnet, l.c., 555 (vgl. auch das Vorhandensein eines Handwaschbeckens unter den im Alten Reich als Grabbeigaben deponierten Scheingefaßßen, ibid., 556).

149 Hierher gehoren haliia- "knien", kaniniia- (dazu vgl. Neu, genu- / ganu-, 291f; Oettinger, ganenant-, 143ff) "sich beugen" und wohl auch paršnai- "hocken".

150 Etwa KBo XVII 74 (CTH 631) III 19': ... క̌ara] tienzi కer=pat aruuanzi "sie stehen [auf] und oben (d.h. im Stand) machen sie aruuai-". Wenn wir das Kredenzen von Getrănk mit unmittelbar vorausgehendem GİR ${ }^{\text {MEŚ }-a s ̌ ~ k a t t a n ~ h i n k i s ̌ k-~ i n ~ K U B ~ X X X I I I ~} 120$ (CTH 344) I 10.17 als zusammenhăngende Bewegungsfolge fassen dürfen, liegt eine tiefe Verbeugung aus praktischen Gründen năher als eine Prostration. 
zeichnete Bewegung "sitzend"151 oder "stehend"152 ausgeführt wird, was an sich, d.h. ohne Annahme mißverständlich abkürzender Ausdrucksweise ${ }^{153}$, eine Prostration ausschließt ${ }^{154}$.

Welche der beiden Haltungen in den Motiven 3 und 25 auch gemeint sein mag: mit ihr drückt der Opferherr seine Ergebenheit vor der zu beopfernden, in ihrem Bilde vergegenwärtigten Gottheit aus. Es handelt sich um die mehr oder weniger betonte Geste und Grußhaltung des niedriger Gestellten gegenüber einem Höherrangigen, speziell des Dieners gegenüber seinem Herrn und des Untertanen gegenüber seinem Herrscher, die universell und so eben auch im anatolischen wie etwa im mesopotamischen Raum die Selbsteinschätzung des Menschen gegenüber einem göttlichen Machtwesen veranschaulicht und gleichzeitig als Gebetshaltung dient. In Motiv 3, am Beginn des Opferritus, bei oder nach dem Eintreten des Opferers in den heiligen Bereich, steht wohl die Grußfunktion des Gestus im Vordergrund, seine Wiederholung in Motiv 25 begleitet die Präsentation des Opfers: die Haltung dessen, der hinter seiner Gabe die Anbetung vollzieht ${ }^{155}$, wird dem Huldigungsgestus entsprechen, den der Vasall bei der Tributübergabe vor seinem Oberherrn ausführt. Bisweilen (in praxi vielleicht öfter als in den Texten verzeichnet) wird die Verbeugung von einer namentlichen Vorstellung des Opferherrn (und ggf. des ministrierenden Priesters) begleitet ${ }^{156}$. Bei freiwilligen und Gelegenheitsopfern kann in diesem Zusammenhang auch der Anlaß genannt und die Gottheit zur Überprüfung der Gaben aufgefordert werden ${ }^{15}$.

151 KBo XX 10+ (StBoT 25, Nr. 59) II 15f sowie die jungen Belege KUB XX 62, 3'; IBoT II 21 (CTH 678) VI 8'; 65 (CTH 663), 8'; III 23 III 14.

152 Junghethitisch HT 19, 4'; IBOT II 65, 5'(beide CTH 663).

153 etwa für: 'vom Sitzen/Stehen aus zur Prostration übergehen'. In diesem Sinne Puhvel, Etymological Dictionary I/II, 183.

154 Die bisher umfangreichste Studie hierzu, der Artikel aruuai- in $\mathrm{HW}^{2}$ (I, 355ff mit alt Lit.) sieht keinen Grund, eine Neben- (oder gar Grund)bedeutung "sich niederwerfen" anzusetzen und erweitert dieses Urteil auch auf das synonyme hink-. Es fragt sich allerdings, ob und warum den Hethitern die in solchem Fall sich auftuende semantische Divergenz gegenüber akkad. šukênu entgangen oder unwichtig gewesen sein könnte. Dieser Umstand muß zugunsten des jüngst wieder von Puhvel (1.c., 183ff) vertretenen Ansatzes aruuai- = "sich niederwerfen" angeführt werden.

155 KBo XV 33 (CTH 330) III 8 (die Opfertiere werden vor dem Opfernden her, in Richtung auf den Altar getrieben). 20; KBo XXIX 72 III! 3'. Das Motiv findet sich auch als ÜbergabeGestus im Sündenbock-Ritual KUB IX 32 (CTH 394; Küımmel, zuletzt TUAT II/2, 285ff) Vs. 23f.

156 Vgl. KUB I 17 (CTH 591) VI 17-19; KBo XXIX 72+ Rs. (')2'-4'.

157 Z.B. KBo XV 33 (CTH 330) III 18-22 (s. CHD III, 287a). 
Die Bezugnahme auf ein hurritisches Formulargebet ('[Worte] des Sich-Verneigens auf Hurritisch') in Zusammenhang mit Motiv $3^{158}$ in einem von den östlichen Nachbarn her übernommenen Ritual weist auf den festen Platz, den die rituelle Ehrfurchtsbezeugung auch im hurritischen Opferkult einnimmt und zwar nicht als eine das Gebet begleitende, sondern dieses dominierende, eigene Form (Anbetung als Haltung bzw. Gestus und in dieser Form als Akt).

Anzumerken ist noch, daß die rituelle Verbeugung bei Reihumbeopferungen mehrerer Götter ('Opferrunden', bei denen z.B. Getränke durch Zutrunk gespendet werden) vor jeder oder auch nur vor bestimmten Gottheiten, d.h. manchmal recht häufig und gelegentlich jeweils mehrfach vollzogen werden kann, daß sie z.B. auch vor heiligen oder geweihten Gegenständen und beim Verlassen der Kultstätte ausgeführt wird und da $B$ all dieses auch vorgesehen sein kann, obwohl dem Opferherrn im betreffenden Ritual weder bei der Einleitung (Motiv 3) noch vor der Tieropferweihe (s. Motiv 25) eine Verbeugung vorgeschrieben wird ${ }^{159}$.

Die in hethitischen Ritualen, wie schon festgestellt, dem wortnächsten Verständnis gemäß gelegentlich im Stehen oder Sitzen auszuführende Verbeugung scheint als eigenständige rituelle Ehrfurchtsbezeugung und Gebetshaltung in den Kulten des Alten Orients sonst so gut wie unbekannt zu $\operatorname{sein}^{160}$. Die

158 KUB XLV 3 (Salvini / Wegner, Rituale, Nr. 40) I 2 f.

159 Ein Hinweis auf die vielen Verbeugungen in CTH 631 möge in diesem Zusammenhang genügen: vgl. Neu, Gewitterritual, 82 s.v. aruuai- (in CTH 625,2 wird dagegen nur einmal eine Verbeugung erwahnt: KBo XIX 128 36'f). Für das reiche Belegmaterial s. ansonsten $\mathrm{HW}^{2}$, I.c.

So sind als Gebetshaltungen außer der Prostration (sumer. ki-a za-za) das Stehen oder Knien (im Zweistromland auch Hocken), beides ggf. mit erhobenen Hănden, üblich, vgl. v.Soden, Gebet, 161; Brunner, Gebet, 453; Westermann, Gebet, 1213; Boecker, Gebet, 521f. Eine besondere Form der Gebetshaltung stellt in Mesopotamien (und etwa im achămenidischen Persien) die im Stehen ausgeführte Anbetung mit ungefahr unter die Nasenspitze geführter (ggf. blütenstengelhaltender bzw. Kuß-)Hand (sumer. kir $_{4}$-su-gál; akkad. labän appi, dieses das ursprüngliche griech. proskynein) dar, vgl. Gruber, laban appi, 73ff; Fauth, Proskynese, 1189; Calmeyer, Gottlichkeit, $58 \mathrm{~m}$. Anm. 14). Mit verschiedenen Autoren ist zu vermuten, daß man diese Haltungen auch ggf. nacheinander, also in Kombination, einnahm. - Akkad. kanāšu "sich unterwerfen" wird selten in strikt rituellem Sinn faßbar, wobei der von den Wörterbüchern hierzu angebotene Ansatz "sich beugen" möglicherweise als "sich zur Prostration beugen" zu präzisieren wăre (Myhrman, Hymns, 2, 37; Lambert, Babylonian Wisdom, 108, 13 ?). qadädu "sich beugen", absolut und in rituellem Kontext gebraucht, ist außerst rar (ina qaqqari "zur Erde": Ebeling, Tagewerk, 5, 14). Die hebr. Entsprechung qadād steht einmal (Mi 6,6: kultischer Zusammenhang!) parallel zu gleichbedeutendem näkap ( $\sqrt{ } k p p)$, kommt jedoch in der Regel in unmittelbarer Verbindung mit "sich niederwerfen" (hištah $\left.{ }^{a} w \bar{a}\right)$ vor. - Das Sitzen (iberhaupt!) im Bereich und selbst im Anblick des Tempelhofes und des Heiligtums gilt nach mischnischer Tradition als ehrfurchtslos; 2 Sam. 7, 18 wird (sic!) im Sinn einer Ausnahmeregelung zugunsten des Königs interpretiert, vgl. Cod. Maimonides VIII 1, 7, $6 \mathrm{f}$ (Lewittes, Code, 30f). - Eine Verbeugung, die als Haltung offenbar jeweils für längere Zeit eingenommen wurde, findet sich neben anderen Ehrfurchtsbezeugungen (Grußhand bei nur leicht vorgebeugtem 
allographische Verwendung von akkad. šukênu gerade auch im Zusammenhang solcher Aussagen über die einzunehmende körperliche Ausgangsstellung zeigt, da $B$ die Hethiter ihren Verehrungsgestus als Entsprechung zu der von ihren Nachbarn geübten Prostration aufgefaßt haben. $\mathrm{Zu}$ dieser im folgenden ein kurzer Seitenblick.

Im mittelassyrischen Krönungsritual wirft sich der König beim Betreten des Assurtempels nieder (Verbum šuka"unu) und küßt den Boden (naqarruru "sich krümmen, kriechen" hier etwa in diesem Sinn), beginnend bei den Räucherschalen bzw. Tragöfchen, die vor Assur stehen. Er besteigt dann den Hochsitz, wirft sich wieder auf die erwähnte Weise nieder, deponiert Priester-Ehrengeschenke zu Füßen des Reichsgottes und richtet diesem den Opfertisch zu; darauf folgt das Fleischopfer ${ }^{161}$. Mag die Prostration in diesem Ritus wesentlich unter dem Aspekt von Gruß und Huldigung des Königs als neuem Statthalter Assurs (so ja sein älterer religiöser Titel) zu sehen $\operatorname{sein}^{162}$, findet sich der Gestus als mehr oder weniger kultübliche Form auch in anderen Ritualen $^{163}$ wie ebenfalls in historischen Nachrichten aus dem Zweistromland bezeugt $^{164}$. Eine in neuassyrischer Überlieferung vorliegende rituelle Anweisung verbindet, nach Räucheropfer und Spende von Brot und Bier durch den Opferherrn, dessen Prostration vor der Vermittler-Gottheit mit der vom Priester vorgetragenen Bitte um deren engagierte Fürsprache bei Ištar ${ }^{165}$.

Oberkorper im Stand oder im Knieen, Prostration) in ägyptischen Darstellungen des Gefolges (oder von sonstigen Untertanen) des Pharaos bei Staatsaktionen, auch bei solchen rein kultischer Art, so etwa in Amarna (vgl. Davies, Amarna I pl. VI. VIII; IV pl. VIf; VI pl. II). Dabei wird ein Fuß vorgesetzt, die Rückenlinie verlauft etwa waagrecht, der Kopf ist angehoben, die Arme hăngen schlaff herab. Es scheint sich hierbei allerdings um einen dem König geltenden Ergebenheitsgestus und nicht um eine kultübliche Form der Anbetung zu handein.

161 KAR 135 + (Muller, Konigsritual, 8) I 30ff.

162 Im gleichen Ritual huldigen spăter auf dieselbe Weise die Großen des Reiches und die Camarilla dem inzwischen inthronisierten König: Kol. III 13. Zur (ungelosten) Frage, ob sich der König dem Ritus nur einmal wăhrend seiner Regierung oder in jăhrlicher Wiederholung unterzog, s. Menzel, Tempel I, 41 .

163 Vgl. Thureau-Dangin, Rituels accadiens, 100, 13f für die Prostration des Königs beim Betreten der Cella anlaßlich des (Frühlings)-Prozessionsfestes in Uruk.

${ }^{164}$ Sargon von Akkad zollt als Eroberer Syriens Dagan von Tuttul Anbetung und Huldigung durch Prostration (sum. ki-a mu-na-za, Gelb / Kienast, Konigsinschriften, 164, 17-23). Der siegreiche Salmanassar III. wirft sich in Kutha bzw. Borsippa jeweils beim Opfer vor Ninurta bzw. Nabû nieder: Michel, Assur-Texte, 32 V 5. VI 2. Uberhaupt scheint es zur religiösen Routine der Könige zu gehören, beim Aufenthalt in einer Stadt, der dortigen Gottheit mit solcher Ehrfurchtsbezeugung aufzuwarten, vgl. das altbabylonische Beispiel in Kupper, KibriDagan, 44, 14. - Aus Syrien (Emar, 13. Jh.) ist das Niederfallen (šuhehuunu) der Priesterin vor der Gottheit bezeugt: Amaud, Textes 3, 340, 83'.

165 Menzel, Tempel II, Nr. 1 Vs. 9 ff. 
In Ägypten wirft sich der Priester beim täglichen Kult nach der Eröffnung des Schreins, in dem das Götterbild aufbewahrt wird, vor diesem nieder und küßt den Boden. Danach (und nach Anstimmen eines Hymnus) nimmt er es heraus, reinigt es, bekleidet es neu und setzt ihm die Opferspeisen vor ${ }^{166}$.

Normative Angaben (Vorschriften) über die genauen Umstände und Indikationen des in Israel geübten kultischen Sich-Niederwerfens finden sich im Alten Testament nicht. Immerhin ist dem Bericht des Chronisten über eine Opferfeier zu entnehmen, daß nach dem Schlachten des Sündopfers, dem Sprengen des Blutes und zur Darbringung der Opferteile einer Hekatombe auf dem Brandopferaltar ein instrumental begleiteter Chorgesang einsetzte, indes die Kultgemeinde sich - bis zum Abschluß des über das Ende der Opferhandlungen hinaus verlängerten Gesanges - mehrfach niederwarf ${ }^{167}$. Hilfreich für das Detailverständnis der Stelle sowie überhaupt informativ bezüglich der Prostration ist die mischnisch-rabbinische Überlieferung zum (zweimal-)täglichen Opferdienst im Zweiten Tempel. Ihr zufolge wurden in der Zeit zwischen der Schlachtung des Brandopfers, dem Sprengen seines Blutes und der Präsentation der Opferteile am Brandopferaltar nacheinander von vier Priestern vier Verrichtungen zur Reinigung und Beschickung des Räucheraltars im 'Heiligen', der vorderen Abteilung des Tempels, vollzogen. Währenddessen versah dortselbst ein fünfter Priester den entsprechenden Dienst am siebenarmigen Leuchter. Jeweils am Ende seiner Verrichtung warf sich der jeweilige Priester zu Boden und ging hinaus auf die Stufen, die zum Altarhof hinabführten. Sobald der vierte und fünfte Priester auf der Treppe erschienen, begannen sie und ihre dort wartenden Kollegen auf ein akustisches Zeichen hin mit der Rezitation der Segensliturgie. Gleichzeitig wurde das Brandopfer den Flammen übergeben, danach die Spenden von Mehl, Opferkuchen und Wein. Nun setzte der den Dienst abschließende, instrumental unterstützte Gesang der Leviten ein. Inhaltlich von Wochentag zu Wochentag unterschieden, war er in neun Strophen gegliedert. Am Ende einer jeden Strophe ertönte ein Trompetenstoß, auf den hin sich alle Anwesenden zur Anbetung auf den Boden warfen ${ }^{168}$. Prostration vor der Ausführung eines Opfers scheint nur für den Versöhnungstag bezeugt zu sein und ist dort begründet und verbunden mit dem Vernehmen des Gottesnamens, den der Hohepriester jeweils dreimal erwähnte, wenn er für sich und die Priesterschaft sowie andererseits für das Volk das Sündenbekenntnis über dem jeweiligen Sündopfertier sprach ${ }^{169}$.

166 Barta, Gebet, 842-844 (nach der Speisung folgen erneut Prostration und Hymnus).

1672 Chr. 29, 27-30.

168 Zum Mischna-Traktat Tamid V, 4 - VII $2 a .4$ vgl. Cod. Maimonides VIII, 6, III 4-17; VI 1-7 (Lewittes, Code, 259-262. 271-274).

$169 \mathrm{Zu}$ Traktat Joma VI, 2 vgl. Cod. Maimonides VIII, 8, II 6f (Lewittes, l.c., 392f). 
Für bildliche Darstellungen von Gebet oder von Kultszenen ist im mykenisch-minoischen Bereich das Stehen, seltener das Knien, jeweils mit erhobenen Händen, charakteristisch ${ }^{170}$. Homers Opferschilderungen kennen als Gestus des (wohl wie die übrigen Verrichtungen im Stehen vollzogenen) Weihgebets lediglich das Erheben der Hände ${ }^{171}$. Kniefall vor Göttern und Prostration vor Altären und Kultbildern finden sich bei Homer und den Klassikern nur im Zusammenhang meist verzweifelten Flehens ${ }^{172}$, d.h. außerhalb des eigentlichen Kults.

\section{Zu Motiv 6: Rauchopfer}

Hinweise auf Rauchopfer bieten in unserer Textauswahl nur die beiden nicht-autochthonen Rituale CTH 701 und 718. Dies erscheint symptomatisch, obwohl die Voraussetzung für das Räuchern, die Gegenwart von Feuer an der Opferstätte, wohl auch für das anatolische Ritual allgemein anzunehmen ${ }^{173}$ und die Möglichkeit einer (etwa beabsichtigten) Rauchentwicklung und sei es nur durch das Verbrennen von feuchtem Holz, nicht auszuschließen ist. Geht man von den ausdrücklichen Erwähnungen des Räucherns in den hethitischen Ritualtexten aus ${ }^{174}$, so scheint der etwa in Mesopotamien gut bezeugte

170 Z.B. Sakellariou, Siegel, xxii s. "Kultszene"; Townsend-Vermeule, Gotterkult, $13 \mathrm{f}$ (ob die unvollstăndig erhaltene Darstellung eines Mannes vor einem Altar(?) auf einem Freskenfragment aus Tiryns [Rodenwaldt, Tiryns II, Tf. 2,7] im Sinn einer rituellen Verbeugung zu deuten ist [so Townsend-Vermeule, l.c. V 50], bleibe offen.

171 Ilias I 450; III 275.

172 Ilias IX 570 (Kniefall im Fluchgebet vor Hades und Persephone); Sophokles, Trachinierinnen, 904; Oedipus Coloneus, 1157f (Prostration vor Altar u.a. des Poseidon); Aristophanes, Ritter, 31 (dto., vor Kultbild). Vgl. noch Burkert, Griechische Religion, 128f.

173 Vgl. die Gegenwart eines Herdes (hašsa- bzw. sumerographisch GUNNI) in den Ritualen anatolischer Herkunft: für CTH 631 s. Neu, Gewitterritual, 84; für CTH 647 (Neu, Ritualtexte, Nr. 46) Vs. [9'] zu erwarten; [CTH 593: Textverlust!] CTH 616,2 (assimiliertes Ritual eines uber hurritische Tradition empfangenen Kultes) s. KUB XX 59 IV 8f. V 22. VI 4.7.9.19.22[.24]; CTH 625,1 s. KBo IV 13+ III 22'f.26'. V 6f.10; CTH 625,2 s. Otten, Festritual, 55.64; CTH 669,19 s. IV 1.3.14.16. In KBo XV 33 (CTH 330) dürfte die fehlende Erwăhnung des Herdes durch Textverlust zu erklären sein.

174 Das bei $\mathrm{Neu}$, Interpretation, 149f zusammengetragene Belegmaterial für "răuchern" (Verbalstămme samenu-, šamešiia-, šamešanu- [add. noch si'mišiia-, KUB XXIV 14 I 19], graphisch mit einer Ausnahme (mittelheth. KUB XXXVI 44) jung: insgesamt 13 Belege!) verteilt sich auf 7 kathartische Beschwörungen (CTH 323.395.397.456.780, davon 3 mit hurritischem [780] bzw. luwo-hurritischem Hintergrund [395.397]), 1 Evokation (CTH 423, luwo-hurrit.), 2 Festrituale (CTH 627: ursprgl. altheth. KI.LAM-Fest [IBOT I 13 IV 13']; CTH 672: jungheth. Monatsfest [KBo II 4 IV 26']), 2 Mythen (CTH 345.*348,6: hurrit. Kumarbi, mit 3 Belegen) und 2 Inedita rituellen Charakters. - Die ebenfalls von Neu (Gewitterritual, 69f) gesammelten 
Brauch, vor allem wohlriechende Hölzer und Kräuter vor der Gottheit bzw. im Kult zu verbrennen, in Hattuša, wohlgemerkt außerhalb der hurritischen bzw. der luwo-hurritischen Schicht, nur eine recht geringe Rolle zu spielen ${ }^{175}$. Für das Verständnis der schmalen dem Staatskult zugehörigen, meist überaus knapp formulierten Evidenz $z^{176}$ sind wir auf einschlägige Angaben aus der jüngeren Tradition des althethitischen KI.LAM-Festes (CTH 627) angewiesen. Danach wurde das Räucherwerk - man sollte es vermeiden, von 'Weihrauch' zu sprechen $^{177}$ - von Funktionären des königlichen Totentempels aus dieser ihrer Institution her zur Stätte der rituellen Handlung gebracht und dem zelebrierenden König präsentiert. Köche (vgl. unser Motiv 12) und Tafeldecker räucherten sodann damit vor dem König ${ }^{178}$. Die Applikation oder Verteilung des Rauches mag gemäß einer Anweisung vermutlich desselben Rituals durch 'Rings-

Belege für tah (at)tumär, jünger tahtumara, pl. tant. n. "Raucherwerk" (ab altheth., insgesamt ebenfalls ca. ein Dutzend Belege) finden sich in vier Festbeschreibungen, von denen zwei, CTH 627 (s.o.) und 631, der alten und die übrigen zwei, das AN.TAH.ŠUM- und das nuntarriašhaFestritual (CTH 604ff [Belege bes. 609.612] und 626), der nach-althethitischen Schicht (vgl. oben, S.234 m. Anm.47) angehören. Synonym zu $t$. kann das substantivierte Adjektiv sanezzi(n., kollektiv) "Wohlriechendes" (eig. "Angenehmes, Sußes") verwendet werden (z.B. KUB VII 60 [CTH 423, s.o.] II 12; XXXVI 44 [CTH 323, s.o.] VI 6'; VBoT 58 [323, s.o.] IV 37.40). In nach-althethitischen Texten erscheint für $t$. auch das u.a. aromatische Pflanzen(produkte) indizierende Sumerogramm ŠIM (z.B. KBo II 4 [CTH 672, s.o.] IV 24'; KUB IX 15 [CTH 456, s.o.] III 15).

175 Das Material von Anm. 174 erbrachte einen Anteil von 5 Festritualen (darunter das sehr komplexe AN.TAH.ŠUM-Ritual), die das Rauchern oder zumindest das Herbeischaffen von Raucherwerk erwăhnen. Es fallt dabei auf, daß das Rauucherwerk in der überwiegenden Mehrheit der Fälle (CTH 609. 612. 626. 627. 631, s, die folgende Anm.) aus dem (königlichen) Totentempel/Mausoleum, É(HI.A) $\mathrm{NA}_{4}$ bzw. Ẻ Esta-, gebracht wird, im dortigen Kult vermutlich besondere Verwendung fand, vielleicht auch dort zusammengestellt wurde. Wir werden unten darauf zurückkommen.

${ }^{176}$ Es sind dies Festritualstellen, die fast stereotyp nur vom Herbeibringen des Raucherwerks aus dem Totentempel sprechen: KBo XVII 74+ (CTH 631) II 40f; XX 33 (627) Vs. 5; KUB II 5 (612) I 38f; IX 34 (626) I 46f; XXV 1 (612) III 11f; IBoT III 1 (609) Rs.71.73. Zu KBo XXX 56 V 22'f s. sogl.. Noch stărker verkürzt KUB LIX 2 (609?) III 8.

${ }^{177}$ M.W. liefert das hethitische Schriftum keinen gesicherten Hinweis auf die Verwendung, ja selbst die Kenntnis, des Weihrauchs (vgl. 0., Anm. 22 und allgemein Müller, Weihrauch, 753). Gerăuchert wurden mehr oder weniger einheimische aromatische Hölzer (Zedernholz der Bezeugung nach wohl erst im Gefolge der massiven Übernahme hurritischer Kulte zu Ende des 15. Jh.), Blüten, Blatter und Samen sowie etwa die als "Ambra??" (zuletzt Polvani, terminologia, 18ff) angesetzte Substanz, und zwar gern zerkleinert (ǐkkalla-, kinae-), als Mixtur und mit Öl u.a.m. versetzt. Vgl. KUB XXXVI 44 (323) IV 23f; IBoT II 39 (CTH $777=$ Haas, itkahi - itkalzi, Nr.3) Rs.20ff.

${ }^{178}$ IBoT I 13 IV 6'-13'. Umschrift bei Singer, KI.LAM-Festival, 50. 
herum-Schwenken'(arahzanda uahnu-) erfolgt $\operatorname{sein}^{179}$. Insofern der von der Formulierung her ganz eindeutig erweckte Eindruck zutrifft, daß der König Ziel der Aktion ist, dürfte es sich dabei nicht um ein Opfer, sondern vielmehr um eine besondere Reinigungszeremonie handeln, etwa entsprechend Motiv 19 unserer Tabelle, das man hypothetischerweise als Fortsetzung eines alten kathartischen Jagdbrauchs ansprechen könnte ${ }^{180}$. Eher lustratorisch als latreutisch gemeint ist wohl auch das von beschwörenden Rezitationen begleitete Räuchern in dem textuell in althethitischer Tradition stehenden Ritual für die verschwundene Sonnengottheit ${ }^{181}$.

Kultisches Räuchern als Reinigungszeremonie ist seit alters auch für Mesopotamien gut bezeugt ${ }^{182}$.

${ }^{179} \mathrm{KBo}$ XXX 56 V 25'f. Dazu wurden offenbar nicht wie in Ägypten seit dem Mittleren Reich (Lit. bei Bittel, Bogazkoy III, $40^{13}$; Miller-Karpe, Handbuch IV 3 , Tf. 9,19; 74,3; 75,2; 78, J; 87, 1.4.6 usw.) sogen. Raucherarme benutzt. Die diesen auf den ersten Blick sehr ahnlichen, zahireich vertretenen Gefaße aus BogazkOy (Fischer, Die hethitische Keramik von Bogazköy. BogazkÖy-Hattusa, IV [WVDOG 75] 1963, 72f. Tf. 122.124), weisen keine Schwărzungen auf und werden als Libationsgefaße betrachtet.

${ }^{180}$ Vgl. Meuli, Opferbrăuche, 226.253f: jagdvorbereitende Răucherung des Jăgers als Mittel, seine Witterung zu uberdecken. S. aber Kritisches zu Meulis Vorgehen bei Kirk, z.B. in Pitfalls, $61.70 \mathrm{ff}$.

181 VBoT 58 (CTH 323) IV 36f.40f; KUB XXXVI 44 (dto., zur Datierung z.B. CHD III, 329b) IV! $5^{\prime} f .11^{\prime}\left[.18^{\prime}\right]$. Der Vorgang ist zwar jeweils gekoppelt mit Speise- und Trankopferdarbringungen, und man kÖnnte in den (nicht zitierten) Beschwörungsformeln bloße Herbeirufungen zu einem zusătzlich mit Răucherwerk ausgestatteten mehr oder weniger 'normalen' Opfer vermuten, doch läßt eine vergleichende Berücksichtigung der Ätiologie des Rituals auf ein Reinigungsbedürfnis der verschwundenen Gottheit schließen, dem hier - vor dem Opfer - mit Răucherung und Zauberspruch entsprochen worden sein könnte (vgl. das Schwenken brennender animalischer Substanz zur Reinigung des zuvor verschwundenen Telipinu im ebenfalls ursprünglich alten Ritual, das uns in KUB XVII 10 [CTH 324] vorliegt, s. dort Kol. III 3-12).

182 Den altesten mir aus Mesopotamien bekannten Hinweis auf kathartisches Rauchern bietet Gudeas Zylinder B IV 4f (TCL VIII 34): mythische Einweihung eines Tempelneubaus, vgl. Falkenstein, Inschriften I, 89.180. Die oben, Anm. 180 zitierte Anschauung impliziert prăhistorischen Ursprung des Reinigungsbrauches. Für dessen hohes Alter spricht auch die ägyptische Evidenz, s. sogl. Hinsichtlich ihres Einsatzzweckes im Kult ungeklärt, in ihrer Funktion als (Teile von) Thymiaterien aufgrund des Befundes aus den frühesten Schichten der Cella des archaischen Istar-Tempels in Assur einigermaßen gesichert sind (auch in Syrien und Palästina verbreitete) frühdynastische zylindrische bis konische röhrenförmige Terracotta-Stănder mit in der Regel durchbrochener Wandung und zugehörigen Schalen mit durchbrochenem Boden, vgl. Andrae, Ischtar-Tempel, (41-)44f. Tf. 18.20; H. Kühne, Die Keramik vom Tell Chuëra (Vorderasiatische Forschungen der Max Freiherr von Oppenheim-Stiftung, 1) Berlin 1976, 77f; Müller-Karpe, Handbuch III/2, 850. - Für kathartisches Răuchern im babylonisch-assyrischen Kult vgl. z.B Thureau-Dangin, Rituels accadiens, 102 III 16f; 119, 10; 140, 343-356; ferner Menzel, Tempel I, 155.164 jeweils sub 4. Bei der Ausarbeitung des vorliegenden Abschnitts konnte ich die Studie von $W$. Zwickel, Răucherkult und Räuchergerăte. Exegetische und 
Die zum Räuchern verwendete Materie verdankte ihre Wertschätzung als kathartische Substanz wohl in der Regel ihren als wohlriechend empfundenen aromatischen Bestandteilen, die oft schon in unmanipuliertem Zustand dem Geruchssinn wahrnehmbar sind, sich gegebenenfalls beim Zusatz von Flüssigkeiten diesen mitteilen ${ }^{183}$, die sich zu extensiver Wirkung jedoch am leichtesten durch die beim Räuchern entstehende Erwärmung freisetzen lassen. Der sich mit dem Rauch verbreitende angenehme Geruch (das Hethitische kennzeichnet das Räucherwerk mit dem Appellativ sanezzi geradezu als einen Inbegriff der Wonne ${ }^{184}$ ) veranlaßte auch den profanen Einsatz des Räucherns bei festlichen Gastmählern. So entnehmen wir dem aus hurritisch-nordsyrischer Tradition stammenden Ullikummi-Mythos, daß (jedenfalls in diesem Kulturkreis) zu einer großzügigen Bewirtung neben mancherlei Speisen, Trank und Tafelmusik auch das zerkleinerte Zedernholz gehörte, das - zweifellos als Räucherwerk genutzt - mit seinem Duft den Genuß der Mahlzeit erhöhen sollte $^{185}$. Dieser angenehme Aspekt des Räucherns, das übrigens auch im assyrischen Zeremoniell für das königliche Gastmahl seinen festen Platz hat ${ }^{186}$, erklärt die von der vermutlich ursprünglichen und auch fortbestehenden kathartischen Funktion ${ }^{187}$ abgelöste Bedeutung des Verbrennens von Räuchermaterie als Opferhandlung.

Jener andere, wohl sekundäre, Aspekt rituellen Räucherns, die Überzeugung, durch den Einsatz von Räucherwerk [sumer. na(.izi), akkad. qutrēnum $]^{188}$ und den dabei entstehenden Wohlgeruch göttliche Zuwendung

archăologische Studien zum Răucheropfer im Alten Testament (OBO 97), Freiburg (Schweiz) / Gottingen 1990 (mit teilweise anderer Deutung des archäologischen Befundes) nicht benutzen.

183 Es mag genugen, zu dieser Praxis einige mesopotamische Beispiele anzufüren, etwa Zimmern, Beiträge, 75-78, 5'ff. 53f (0., Anm. 144); 84-85, 7ff; Biggs, Saziga, 64 Rs. 3; Müller, Königsritual, $62 \mathrm{II}(20 \mathrm{f})$. In diesem Zusammenhang sind auch das rituelle Kauen und sonstige Anwendungen von Zedernholz zu erwahnen, vgl. etwa Goetze, Old Babylonia Prayer, 25 (u., Anm. 189) Vs. 1ff; Zimmern, Beitrăge, Nr. 11 Rs. II 6 (7'); Nrn. 75-78, 16'.

184 S. o., Anm. 174. Dafür, daß die gerăucherte Substanz nicht immer Wohlgeruch implizierte, S.u., Anm. 191 Ende.

185 KUB XXXIII 98 (CTH 345) II 8f(f), s. Güterbock, Song, 148ff. Man vergleiche die noch heute in Landern des Orients, aber auch im klassischen Griechenland (dazu etwa Müller, Weihrauch, 755f) geubte Sitte, Weihrauch bei Festmăhlern zu verbrennen (s. auch u., Anm. 208 für Israel).

${ }^{186}$ K. 8669 II 1-6. III 43-45, vgl. Müller, Königsritual, 62.64. Für ein konkretes Zeugnis aus dem Beginn des 9. Jh. s. Wiseman, Stela, 35, 139.

187 Vgl. nochmals Anm. 180.

188 Auch metonymisch für den Akt der Anwendung (nach CAD Q, s.v., auch für das Rauchergerăt [?]) gebraucht. Vgl. ferner akkad. riqum (sum. Sim) und qu/atäru (nebeneinander in $\mathrm{K}$. 8669: II 4. III 44 vs. III 34.36, wozu oben Anm. 186) sowie urî (sum. ḩe-e ${ }^{\text {sar }}$ ) für Răucherma- 
und Geneigtheit (und damit das Ziel jeglichen Opferns) zu erlangen, läßt sich für Mesopotamien zumindest von der altbabylonischen Periode an nachwei$\operatorname{sen}^{189}$. Texte aus Emar belegen für das 13. Jh. v. Chr., daß auch in Syrien die Verwendung von Räucherwerk (ŠIM, ŠIM ${ }^{\text {MEŚ }}$, qutrēnu) zu Opferzwecken im Tempeldienst bekannt war ${ }^{190}$. Was Anatolien betrifft, dürfen wir solch latreutisches Räuchern wohl zumindest für das im späteren 13. Jh. regulierte Monatsfest von Nerik sowie für bestimmte Riten luwo-hurritischer Herkunft (vgl. z. B. unten zu Motiv 33) feststellen ${ }^{191}$.

terie. - Sehr oft wurde (wie ggf. beim alttestamentlichen Speisopfer) Răucherwerk zusammen mit Mehl (maşhatum) verbrannt (z.B. Thureau-Dangin, Rituels accadiens, 119, 21. $26 \mathrm{f}$ oder die luwo-hethitische Beschwơrung KBo XI 14 [CTH 395] I 17-20: Zì.DA ZíZ und Salz auf Zedernholz, Butterschmalz, Honig, bust-). Die Trennung zwischen Rauch- und Brandopfer wird hier fraglich, was ja auch für das betr. Opfergerăt gilt, s. Anm. 190.

189 Altbabylonische Zeugnisse liegen vor im Beschwörungsgebet Goetze, Old Babylonia Prayer, 26 Vs. 14-16 s. CAD Q, 324a), im Atram-basis-Epos (III v 41 mit jüngerer Parallele im Gilgames-Epos Tf. XI, 167, wozu Tigay, Evolution, 219.227) sowie im Privatbrief (Alexander, Letters) 41 Zz. 7-10, wo vom Răuchern im Sinne eines Dankopfers die Rede ist. - Für die reichlichere jüngere Bezeugung mögen als Beispiele Thureau-Dangin, Rituels accadiens, 92, 4.6; 115, 16f; 119, $21.26 \mathrm{f}$ (sämtlich aus Uruk); 142, 392f (Babylon); ferner (für Assyrien) wohl auch Menzel, Tempel II, Nr. 35 VIII 23'-29'(mit Komm. T 71); 43 IV 1f genügen.

190 Arnaud, Textes 3, no. 370 (p. 340), 72.80; 385 (p. 379), 3f; 452 (p. 430f), $5.27 ; 472$ (p. 458), 21'. Merkwürdig ist die virtuelle Verwendung des Raucherbeckens zur Verbrennung des Tieropfers: ib., no. 385 (p. 380),12, vgl. no. 370 (p.338), 23'.25'; 394 (p. 395), 29. Man vergleiche dazu Parallelen aus Ugarit (zu KTU 1.109, 30: qzpt, vgl. Xella, Testi rituali I, 50f.54) und Assur (zur Verwendung der sēhtu vgl. Menzel, Tempel II, Nr. 35 VIII 23'ff m. Kommentar p. 71). So erklärt sich wohl auch die Nachdrücklichkeit, mit der Ex 30, 9 die Funktion des goldenen Raucheraltars auf den in seiner Bezeichnung ja angedeuteten Gebrauch beschrănkt. - Für frühgeschichtliche Funde von Răucherstăndern in Syrien s. bereits Anm. 182.

191 KBo II 4 (CTH 672) IV 24-26. Zum Raucherwerk (Zedernspane) im Brandopfer in Motiv $33 \mathrm{~s}$. unten S. 279ff. Zu untersuchen bleibt, ob sich in dem Anm. 174 nachgewiesenen (hinsichtlich unserer Frage sproden) Material noch weitere Festrituale mit latreutischer Funktion des Răucherns finden (etwa IBoT III 1 [CTH 609] Rs. 73ff?). Für die alte Beschwörung CTH 323 s. versuchsweise oben m. Anm. 181. - Der mythologische Beleg KUB XXXIII 100 (CTH *348,6) III (11'), s. Siegelová, Appu-Mărchen, 46, dürfte auf das anzunehmende hurritische Original zurückgehen. Auch der Einsatz u.a. von Răucherwerk als Lockmittel für Gơtter im Evokationsritual KUB VII 60 II 12 (Haas / Wilhelm, Riten, 234) sowie in der Beschworung KBo XI 14 (CTH 395) I 17-22 entspricht zunächst der Ostlichen, luwo-hurritischen, Tradition dieser Texte. - Der gleichen geistigen Heimat ist die kathartische Beschwörung CTH 397 verpflichtet. Wenn dort (KUB XXIV 14 I $23 \mathrm{f}$ u. Dupl.) von einer Raucherung (Verbalform simišiianun) mit Hundekot, -fleisch und -knochen die Rede ist, so scheint diese zunăchst der Behandlung des Verzauberten zu dienen, tatsächlich gilt sie dem an den zauberischen Beschwerden beteiligten Damon, der mit diesem üblen 'Opfer' vertrieben wird. Hier kehrt die unreine und in dieser ihrer Qualitat der beopferten Macht entsprechende Materie den Sinn des Opfers um: der Zweck ist Trennung, Katharsis durch Dreck. Womit sich die Verbindung zur kathartischen Funktion des Raucherns ergibt. 
Während die bereits frühe Verwendung von Räucherwerk zu Orakelzwekken - veranlaßt durch die Vielfalt der Formen und Bewegungen des erzeugten Rauches $^{192}$ - hier nicht weiter interessiert, muß das vom Götterdienst übernommene, relativ spät und bislang schwach bezeugte Räuchern im Totenkult Mesopotamiens erwähnt werden. Einen ersten Anhalt bietet die mythologische Erzählung von Ištars Gang in die Unterwelt: der Geruch des Rauchopfers wird als für die Abgeschiedenen offenbar besonders begehrenswert dargestellt ${ }^{193}$. Den meines Wissens einzigen konkreten Beleg für den Brauch liefert die Adad-guppi-Inschrift Nabonids aus Harran, und zwar für den königlichen Totenkult ${ }^{194}$. Vielleicht täuscht die Beleglage hinsichtlich des Alters dieses Brauches.In Syrien jedenfalls scheint das Räuchern im Ahnenkult im mittleren 2. Jt. üblich gewesen zu sein ${ }^{195}$. Ein solcher Hintergrund erklärt denn auch den merkwürdigen Umstand, daß Räucherwerk in den traditionellen hethitischen Ritualen, in denen es überhaupt eine Rolle spielt, in der Regel aus dem Totentempel beschafft wird ${ }^{196}$.

Auch in Ägypten, wo schon im 3. Jahrtausend echter Weihrauch und andere Harze in rituellem Gebrauch sind, wird sowohl zu kathartischen als auch zu latreutischen Zwecken geräuchert. Weihrauch gilt als Emanation der Götter und wird etwa im Voropfer neben der Libation von Wasser zur Reinigung der Opfergaben verwendet. Entsprechend befreit er das beräucherte Götterbild oder den so behandelten Menschen von jeder denkbaren Befleckung ${ }^{197}$. Von Göttern sagt man, sie schätzten den Weihrauch und atmeten ihn als 'Festduft' $\operatorname{ein}^{198}$, während ihm andererseits - und dieses erklärt seine besondere Rolle

192 Für Zeugnisse der alt- bis jungbabylonischen Libano- bzw. besser: Kapnomantie vgl. s.v. qutrēnuin AHw, 930b; CAD Q, 324b.

193 CT XV 47, 138, Ebeling, Keilschrifttexte, 1 Rd.II 1 (Speiser in ANET, 106f), vgl. zuletzt van der Toorn, Funerary Rituals, $65 f$.

194 Zz. 12-19 (Landsberger, Basaltstele, 115ff, Gadd, Inscriptions, 35ff), wozu Bayliss, Cult, 123.

${ }^{195}$ Zu KTU 1.17 (Aqht) I 27 vgl. zuletzt etwa Xella, Archeologia, 134; Avishur, 'Duties of the Son', 52.57; Healey, Pietas, 355f. Man beachte, daß Dahood, Rez. Dietrich / Loretz, 448) und, inm folgend, Xella (Testi rituali, 301) KTU 6.44, 2 ( $\mathrm{mm}$ qbr) als Beleg für die Verwendung von Myrrhe bei der Bestattung deuten, doch muß es sich hier noch nicht notwendig um Raucherung handeln.

196 Vgl. o., Anm. 175. Dagegen, soweit bislang erkennbar, Fehlanzeige für das Rauchern in den sog. Toten-(d.h. Beisetzungs)ritualen!

197 Vgl. o., Anm. 147.

$198 \mathrm{Vgl}$. Bonnet, Reallexikon, 624f. 
im Totenkult - belebende Wirkung auf die Toten zugeschrieben wird, denen er sogar Zugang zur göttlichen Sphäre verschaffe ${ }^{199}$.

Im alttestamentlichen Kult dient das Räuchern ganz überwiegend latreutischen und anscheinend ${ }^{200}$ niemals kathartischen Zwecken ${ }^{201}$. Reiner Weihrauch (l'bōnā) wird 'ansage-/bestimmungsgemäß ... als Duft der Besänftigung' zusammen mit Feinmehl (oder daraus hergestelltem Backwerk), Öl und Salz, aber im Unterschied zu diesen als vollständig zu verbrennender Teil der Speisopfer ${ }^{202}$ auf dem Brandopferaltar dargebracht ${ }^{203}$. Dasselbe gilt für den Weihrauch, den man an jedem Sabbat den Schaubroten (unverbrannt) beigab, mit denen zusammen er eine Woche lang in der nur für Priester zugänglichen vorderen Abteilung ('Heiliges') des Zentralheiligtums dargeboten wurde ${ }^{204}$. Ausschließlich für das Räuchern innerhalb jener vorderen sowie in der nur dem Hohenpriester zugänglichen inneren Abteilung ('Allerheiligstes') wurde eine eigens hergestellte Mixtur aus Weihrauch, weiteren Harzen und bestimmten Kräutern verwendet ( $q^{e}$ toörat "Räucherwerk") ${ }^{205}$. Hierbei hatte die an jedem Morgen und Abend auf dem goldenen Räucheraltar im 'Heiligen' dargebrachte Räucherung wiederum eindeutigen Opfercharakter. Die am jährlichen Versöhnungstag vom Hohenpriester mit Hilfe eines mobilen Räuchfasses vorgenommene Räucherung im 'Allerheiligsten' diente dagegen der Verhüllung der Thronlade, wie der Text ${ }^{206}$ erklärt, zum Schutz des als Sühnemittler eintretenden Hohenpriesters selbst ${ }^{207}$. Die Verwendung von Räucherwerk beim Bestattungsbrand ( $\boldsymbol{s}^{e}$ réfä $)^{208}$ gehört der Ebene des herrscherlichen, aber darüber hinaus wohl auch volkstümlichen Brauchtums an und dürfte sowohl an das

${ }^{199}$ Vgl. o, Anm. 148. Zeitlich der 5. und 6. Dynastie zuzuweisende bildliche Darstellungen des zuvor schon in den Pyramidentexten belegten Raucherns im Totenkult etwa bei Müller-Karpe, Handbuch III/3, Tf. 44, 8 (unterste Zone); 45 A (links, mittl. Zone); 95 B 1 (links); 41 D. 48, 2; 67,9; 98 D.G (vgl. ib., III/1, 573.679.683).

200 Vgl. aber noch u., Anm. 207.

201 Das gilt offenbar auch für den nicht anerkannten Kult, vgl. 1 Kön 3, 2; 2 Kon 14, 4; 18, 4; 22 , 17 u.o.

202 Anders das nur ahnliche, reduzierte Sündopfer (Lev 5, 11) und das Eiferopfer (Num 5, 15), die ohne Beigabe von Weihrauch darzubringen waren.

203 Lev 2, 1f.13-16; 6, 8

204 Lev 24, 5-9.

205 Lev 30, 34-38.

206 Lev 16, 13.

207 Vgl. aber Löhr, Răucheropfer, [36], der erwagt, daß hier die Meinung von der kathartischen Wirkung des Rauucherns zugrunde liegen kơnne.

$2082 \mathrm{Chr} 16,14$; vgl. 21, 19; Jer 34, 5. Dafür, daß es sich hier nicht um Leichenverbrennung handelt, s. etwa Löhr, ib., [13](zu Am 6, 10 s. $\left.\mathrm{HAL}^{3}, 1267 \mathrm{a}\right)$. 
sicher auch in Israel bekannte Verbrennen von Aromata bei Festen ${ }^{209}$ als auch besonders an Gedankengut aus dem Totenkult der Nachbarvölker (s.o.) anknüpfen.

Während zumindest für den Totenkult bzw. für die Beisetzung im minoischen Kreta das Räuchern mit einem (gelegentlich als Weihrauch bezeichneten $^{210}$ ) Harz archäologisch nachgewiesen werden konnte ${ }^{211}$, rechnet man aufgrund (spärlicher) homerischer Hinweise für das mykenische Hellas mit dem Einsatz von einheimischen wohlriechenden Hölzern bei profanen und latreutischen Räucherungen ${ }^{212}$. Das Fehlen des Räucherns als zumindest erwähnenswerter Teil der von Homer beschriebenen Opferhandlungen ist immerhin bemerkenswert und erinnert an das bei einem Großteil der hethitischen Evidenz Beobachtete. Die Leichenbrandschilderungen der Ilias ${ }^{213}$ enthalten ebensowenig Hinweise auf den Einsatz von Räucherwerk wie die hethitischen Beisetzungsrituale.

Zu Motiven 7 bzw. 27. 33: Brandopfer von tierischem anahi (Haare/Federn als Kostprobe)

Das Ritual (west)hurritischer Herkunft CTH 701 und das u.a. durch hurritische Vermittlung nach Hattuša gelangte Pinikir/Pirinkir-Ritual (CTH 718) bestimmen beide, das eine unmittelbar vor, das andere zu Ende der Opfertierweihe, die rituelle Verbrennung einer 'Kostprobe' (anahi) vom Kopf und ggf. von der Schulter des Schafes oder von der Brust des Opfervogels. Die bisher in der Literatur vertretene Meinung, daß es dabei um blutige Eingriffe, d.h.

${ }^{209}$ Löhr, ib. [12f], der als erster auf at.liche Indizien für frühes profanes Rauchern hinwies, sah hierin den alleinigen Ursprung des Einsatzes von Duftstoffen bei der Bestattung.

210 Vgl. Eitrem, Opferritus, 199 m. Anm. 4, auf eine Notiz G. Karos zurückgreifend.

211 Zusammen mit tơnernen Raucherpfannen und Holzkohlenresten im Grabkontext gefunden und als 'Kolophon' identifiziert, vgl. Evans, Palace II, $174^{3}$ (Frühminoisch III); IV, $1011 \mathrm{~m}$. fn. 3 sowie id., Tomb of the Double Axes, 13 fig. 18 (Spatmin. II).

212 Vgl. Pfister, Rauchopfer, 268-70; W.W. Muller, Weihrauch, 742 (mit Verweis auf Ilias IX, 499).

Wegen des angeblichen Weihrauchfundes in Knossos (s. Anm. 210), denkt Eitrem, 1.c.,199f bereits an Import fremder Aromata. Wenn Townsend-Vermeule, Gotterkult, 100 vom Gebrauch des Weihrauchs (incense) beim homerischen Opfer spricht und sich dafür auf das bisweilen für die Beschreibung eines Altars verwendete Attribut thyeeeis beruft, kann sie damit natürlich nur die wohlriechende Eigenschaft einer verbrannten Substanz, nicht aber die Identităt der letzteren festmachen.

213 XXIII, 110ff.163ff; XXIV, 782-99. 
Entnahmen von Fleisch gehe ${ }^{214}$, konnten wir nicht teilen. Die Texte gehen davon aus, daß etwa die der anahi-Prozedur unterworfenen Schafe mobil und manipulierbar blieben: es war nicht nur möglich, an ihnen weitere Riten (gemäß CTH 701 Weihe und Handauflegung) zu vollziehen; die Tiere legten auch den Weg an die anderswo gelegene Schlachtstätte in eigener Kraft zurück. Dieser Umstand führte uns zu dem Schluß, daß jene korporalen Kostproben schmerzlos entbehrliche Teile betroffen haben müssen, daß somit allein Haare (bzw. bei Vögeln Federn) gemeint sein können ${ }^{215}$. Diese Materie wird - gemäß CTH 701 zusammen mit einem Zedernspan und der Kostprobe von einem Fladenbrot sowie nach einem Ölbad, gemäß CTH 718 ohne Span und Ölbad dem Feuer des für Rauch- und Brandopfer benutzten huprušhi-Tiegels übergeben. Parallelen finden sich in anderen Ritualen mit (west)hurritischem Hintergrund $^{216}$. Wollbüschel ( ${ }^{\text {SiG }}$ huttulli-) und Federn (? partauar ${ }^{217}$ ) gelten als für luwische Riten signifikante ${ }^{218}$ materiae magicae und werden als solche (unverbrannt) bei der Herbeiziehung von Göttern eingesetzt. Sie stehen dabei pars pro toto für das Opfertier, das für den induzierten bzw. als immer latent vorhanden angesehenen Götterappetit schon bereitgestellt wurde ${ }^{219}$. Inhaltlich ist die Darbietung des härenen Lockmittels, die wir wahrscheinlich schon in der abschließenden Begleithandlung zum Opferschaugebet des altbabylonischen

214 Z.B. HW²,73a; A. Kammenhuber, Opfertexte, 106. S. auch die Zitate Anm. 89. Fleisch-Kostproben werden dagegen ggf. von Teilen geschlachteter Tiere genommen, z.B. KBo XXI $28+$ FHG 12 II 27 (Salvini / Wegner, Rituale, 157): anahi peran arha dai-.

215 O., S.244.248f (dort auch jeweils die Stellennachweise).

${ }^{216}$ Z.B. KBo XXIII 34 + (Salvini / Wegner, Rituale, Nr. 43) Vs. 16'-26'(Schaf; Schlachtung Z. 38'); KBo XXI 28 + (ib., Nr. 17) I (40'-42') (Zicklein, vgl. Dupl. ib., Nr. 16 I $22 \mathrm{ff} . I I$ [3ff]]; KUB XXXII $43+42$ (ib., Nr. 32) I' 13'-17'(Vogel).

217 "Flugel, Schwinge, Feder", wobei die Unterscheidung zwischen der großeren und der kleineren Einheit allerdings oft nicht zu treffen ist.

218 Haas / Wilhelm, Riten, 11ff. Freilich in anderem Zusammenhang spielen (wie anderswo) auch in der mesopotamischen Magie ausgerissene Kopfhaare (auch von Tieren) gelegentlich eine Rolle, vgl. CAD N ${ }^{2}, 6 a 2 c$.

219 Z.B. KUB XV 31 (CTH 484) I 34f, wozu Haas / Wilhelm, Riten, 148ff. 173f(dort weitere Belege). Es werden dabei im weiteren Verlauf der Handlungen immer auch Schafe und Vogel geopfert, freilich keine Adler, was man bei einer pars-pro-toto-Deutung (hierzu Haas / Wilhelm, ib., 176) des neben der Wollflocke gleichsam obligaten 'Lockmittels Adlerfeder bzw. schwinge'(haranaš $/ \mathrm{TI}_{8}{ }^{\mathrm{MUSEN}}$-aš partauar) zunăchst annehmen würde. - Als eine Art 'Verpackung' für die zur Anlockung des Schild-Schutzgottes von einer Jungfrau dargebotenen Gotter-Tafelgenüsse galaktar und parhuena- dient die frisch vom lebenden Schaf gezupfte Wolle im Ritual VBoT 24 III 4ff (CTH 393,2): III 31-45, vgl. IV 19f. Hier wird allerdings kein Schaf, sondern ein Ziegenbock geschlachtet: IV 22. - Noch unklar ist die zweifellos rituelle Funktion der Wolle, welche die Beschworrerin dem kleinen hurro-hethitischen Fragment KBo XVII 92 (Haas / Wegner, Rituale, Nr. 108), 6'-15' zufolge aus der rechten Schulter eines in der Hürde stehenden weiblichen Jungschafes zupft (huittiia-, transitiv-medial). 
Wahrsagers vorfinden ${ }^{200}$, unserem Motiv aufs engste verwandt. In unserem Fall sind freilich der Bezug zwischen dem härenen Teil und dem Tier als Ganzem und zum anderen der Opfercharakter durch das umgehende Verbrennen des Teils deutlicher angezeigt und durch den terminus festgelegt worden, den wir mit den Begriffen "Kostprobe" oder "Anbruch" wiedergeben können. Das Wort anahi, d.i. hethitisiertes luwisches anahit-, unter welcher Stammform es in aller Regel auch ins Hurritische (bzw. in dessen ostkleinasiatischen Dialekt) übernommen wurde ${ }^{221}$, läßt sich seit der mittelhethitischen Sprach- und Schriftstufe in Ritualen mit hurritischen Sprüchen nachwei$\operatorname{sen}^{222}$. Es bezeichnet dort außer härenen Kostproben auch solche vom Fleisch geschlachteter Opfertiere sowie von Brot, wobei noch zu bemerken ist, $\mathrm{da} B$ diese Proben meistens auf dem Feuertiegel verbrannt werden ${ }^{223}$. Allerdings zeigt uns etwa das Ritual CTH 701 sehr deutlich, daß nicht alle anahiBrandopfer zum Voropfergeschehen gehören. So werden nach der Opfertierschlachtung im Rahmen der Beopferung der Gottheit mit dem gekochten Fleisch, den rohen Innereien (Herz und Leber) sowie einigen Broten, das halbe Herz, die halbe Leber und danach Kostproben von allen Broten und einem Rippenstück in den Öltopf gelegt und anschließend verbrannt, während man der Gottheit das Übrige mit einer Libation präsentiert und auch die anderen Götter mitversorgt ${ }^{224}$. Die uns interessierenden Kostproben vom lebenden Tier sind ebenfalls Brandopfer dabei aber sämtlich dem Voropfer zuzuwei$\operatorname{sen}^{225}$.

220 v. Dijk / Goetze / Hussey, Inscriptions and Rituals, no. 23, 4f.133-135 (vgl. Starr, The Rituals of the Diviner, Malibu 1983, ch. III). Ein Vergleich der beiden Textstellen legt m.E. nahe, daß das Auszupfen der Wollflocken von der rechten und linken Seite des Schafbockchens noch im Zusammenhang der Weihe (karäbum, Objekt puhädum, in Zz. 129.135 "weihen"; anders Starr: "perform an extispicy") erfolgt sein mag.

221 Zuletzt Starke, Untersuchung, $158 \mathrm{f} \mathrm{m}$. Lit. entgegen zuletzt $\mathrm{HW}^{2}, 72 \mathrm{ff}$, wo der terminus als genuin hurritisch betrachtet wird. - Ein entsprechend geläufiges akkadisches Äquivalent ist m.W. nicht belegt. Das von Mayer (Untersuchungen, 200) als "Kostprobe" aufgefaßte liqtum ist nur einmal einschlagig bezeugt Goetze, Old Babylonian Prayer, 29: Goetzes "pick", "choice gift" [Sipant-, 29] visierte ein Synonym zu nisiqtum/nisqum an). Das gleiche gilt für das neuassyrische ša le’ämi (vgl. Menzel, Tempel II,T 79 geg. CAD 1, 127a). Auch der für bestimmte Fleischstücke verwendete Begriff nishu (AHw, 749b I 4; CAD N², 267) dürfte als Entsprechung kaum in Frage kommen.

222 Es genüge hier, unser mittelhethitisches Ritual CTH 701 anzuführen.

223 Für das Material s. HW2, 72f. Vgl. auch Kammenhuber, Opfertexte, 105-130.390-423.

224 KUB XXXII 49a + KBo XXIV 66+ KBo XXI 33+ (Salvini / Wegner, Rituale, Nr. 1) III 59IV 62. Vgl. ferner KUB XXXII 44 (ib., Nr. 27) Vs. 6ff.

${ }^{225} \mathrm{Zu}$ unseren Beispielen aus CTH 701 (oben, S. 244) und 718 (oben, S. 248f) vgl. noch KBo XXIII 15 (Salvini / Wegner, Rituale, Nr. 8) I (20'-26'); KBo XXIII 34 + XXIV 58 (ib., Nr. 43) Vs. (16')-26' und die anahi-Opfer von der Brust von Vogeln KBo XIX 136 (+) VBoT 4 (ib., Nr. 31) I (25'-27').IV 8'f mit 5 Duplikaten (ib., Nrn. 32.35-37.39). Anders KUB XIV 3 
Die härene, das Mahlopfer ankündigende und daher Götter anlockende Kostprobe des Opfertieres fanden wir in unverbranntem Zustand in luwischen Evokations- und Zitationsritualen und wohl auch im babylonischen Opferschauritual vor. Das Verbrennen der Wollbüschel (oder Federn), offenbar zum gleichen Zweck, wird meines Wissens sonst im Alten Orient nicht geübt und könnte eine (ost)anatolische Motivvariante sein, die hier zudem in der Regel in erweiterter Form auftritt insofern konsequenterweise Gebäckproben zur Vertretung der vegetabilischen Opferkomponente mit verbrannt werden ebenso wie die Zedernspäne, deren Rauch der Geruchsverbesserung dient -, während das fast regelmäßig voraufgehende, für die hurritischen Rituale typische Ölbad sowohl den Fettreichtum des Opfers ankündigen als auch den Brand beleben soll ${ }^{26}$.

Es ist interessant, daß unser Motiv seine nächste Parallele bei Homer und später im klassischen Griechenland findet oder besser noch: daß es mit der griechischen Evidenz konvergiert. Ihr zufolge schneidet der Opfernde dem noch lebenden Opfertier die Stirnhaare ab - übrigens auch mit dem Schlachtmesser ${ }^{27}$, wie sein Kollege in CTH 701 und 718 -, um das Haar anschließend ins Feuer zu werfen, ein Brauch, dessen Bedeutung vom Kontext seiner Überlieferung her nie ganz erklärbar war28. Hier wie in Bogazköy unterscheiden sich die Zeugnisse hinsichtlich der genauen Terminierung des Akts: so wie CTH 701 das Verbrennen der (härenen) Probe vor der Opferweihe einordnet, während CTH 718 das Motiv ans Ende der Weihe rückt, bietet die Odyssee zwei Modelle. Bei seinem Schweineopfer wirft Eumaios die vom Kopf des

+ XLVII 43 (ib., Nr. 40), 23-27; KBo XXVII 148 (ib., Nr. 34), 1'-4', wonach dem Vogel rechts eine Schwungfeder bzw. der Flügel (partauar) "genommen" wird.

${ }^{226}$ Kammenhuber, Opfertexte, 403, vermutet hinter dem Ölbad Konservierungsabsichten und übersetzt İ.GIŠ als "Zedernöl" (vgl. dag. Riuster / Neu, Zeichenlexikon, Nr. 72; Borger, Zeichenliste, Nr.231), was beides nicht überzeugt. Die suggestive Bezeichnung ahrušhi für den Öltopf rührt wohl daher, daß dieser die meiste Zeit zum Einlegen der Spăne wohlriechender Hölzer diente, bevor sie zum Rauchopfer verwendet wurden.

227 Euripides, Elektra, 810f. Improvisiert wird Ilias III, 271f; XIX, 252f.

228 Erklärungen versagen sich etwa Ziehen, Griechische Opfer, 603f und Meuli, Opferbräuche, $265 f$ (S. $266^{1}$ weist auf eine in B. de Sahaguns Geschichte Neu-Spaniens überlieferte aztekische Parallele: dem zum Opfer bestimmten Menschen wird Haar vom Scheitelwirbel genommen). Eitrem, Opferritus, 374 zitiert antike Erklărungsversuche (u.a. im Sinne von Wetterzauber), die er aber zugunsten einer Deutung als selbstăndiges Opfer an chthtonische Măchte/Totengeister verwirft. Burkert, Homo necans, 12, erkennt in dem Akt den Anfang des Tieropfers (die Unversehrtheit des Tieres ist unumkehrbar aufgehoben), was rational richtig, aber nur die halbe Wahrheit ist. Sehr nahe daran Stengel, Opferbráuche, $44^{2}$ (mit dem pars pro toto geltenden Stirnschopf weiht man den Göttern das Tier, dessen Fleischteile spăter in dem gleichen Feuer verbrannt werden. 
Tieres genommenen Borsten vor dem Gebet in die Flamme ${ }^{229}$; Nestor dagegen gibt das Stirnhaar der Kuh erst nach dem Weihgebet ins Feuer ${ }^{230}$. Spätere Zeugnisse ${ }^{231}$ schweigen zur Abfolge der beiden Handlungen. Indessen wird man das Haaropfer trotz des beobachteten Schwankens in der Überlieferung den Voropfer-Riten zurechnen ${ }^{232}$ und die Wahrscheinlichkeit einer Beziehung zum (ost)anatolischen(?) härenen Kostproben-Brandopfer annehmen wol$\operatorname{len}^{233}$. Der Brauch wäre mithin zu verstehen als ein kunstvoller, das eigentliche Opfer avisierender Anreiz für die Gottheit, ihre Distanz zu dem ihrer Zuwendung bedürftigen Menschen zu überwinden und ihn umso gewisser beim Opfermahl mit ihrer segenverheißenden Gegenwart zu belohnen.

\section{Zu Motiven 8 - 11: Auftrieb der Opfertiere}

Eine ausführliche und systematische Untersuchung der Aspekte dieses Themas muß ich mir hier versagen. Ich begnüge mich damit, ein in seinen Umkreis gehöriges Detail zu streifen.

In CTH 669, 19 ist davon die Rede, daß man dem zum Opfer bereitstehenden Stier vor der Schlachtung die 'goldenen Hörner' abnimmt, was wir als das Entfernen eines Gold(blech)belags der Hörner und damit implizit als Indiz für zumindest gelegentliches Schmücken der Opfertiere im Vorfeld des Opfers deuten ${ }^{234}$. Tatsächlich ist das schmückende Herausputzen der für die kultische Handlung ausersehenen Tiere sowohl sonst in Altanatolien bekannt ${ }^{235}$

${ }^{229}$ Od. XIV,422-424. Entsprechend die Reihenfolge bei den Eidopfern in der Ilias (III, 271-292 (hier wird das Stirnhaar der Lammer freilich an die verschiedenen Eidleistenden verteilt]; XIX, 252-266), wobei der Dichter jedesmal das Verbrennnen der Haare übergeht.

${ }^{230}$ Od. III, 446. Da die folgende Zeile das eigentlich vor dem Haaropfer zu erwartende Gerstestreuen der anderen Opferteilnehmer nach dem Gebet auffuhrt, bezweifelt Ziehen, Griechische Opfer, 603, zu Recht, ob es angemessen sei, die ohnehin auswăhlenden, impressionistischen, Schilderungen des Dichters einer allein nach grammatischen Kategorien vorgehenden Exegese zu unterwerfen.

${ }^{231}$ Im wesentlichen Euripides (Elektra, 810-812; vgl. auch Alkestis, 74-76); Weiteres bei Ziehen, l.c.

232 Vgl. besonders Ziehen, l.c., und jetzt etwa Burkert, Griechische Religion, 102.

233 Sie wird auch in gewisser Weise verstärkt durch den u. zu Motiv 8-11 beobachteten Fall hethitisch-griechischer Übereinstimmung. Bei einem anderen von mir nachgewiesenen Beispiel (Kïhne, auli 97ff) fehlt auf der griechischen Seite noch ein frühgriechisches Verbindungsglied.

234 O., S. 240 zu KUB XXX 41 I, 17'f. Für ein weiteres Beispiel s. Anm. 241.

235 Beim 'Lose'fest' wird je ein vom neuen Priester geweihtes Schaf dem Wettergott und der Siebengottheit geopfert; ein weiteres, mit 'Obst', d.h. wohl einer Obst(baumbluten?')girlande, geschmücktes (unuuant-) Schaf treibt man vom (hauuslichen?) Heiligtum des alten Priesters vor der (in ihr neues Heim umziehenden) Gottheit her zum Heiligtum des neuen Priesters und 
als auch aus Ägypten und aus der homerischen sowie aus der klassischen Antike gut bezeugt. In Ägypten finden sich seit dem Alten Reich Darstellungen von Opferstieren mit Halsschmuck; später kommen, zum Teil in Kombination mit dem Halsbehang, Dekorationen auf, die zwischen den gelegentlich mit Aufsätzen versehenen Hörnern verspannt sind und die mit ihren wippenden StrauBenfedern oder mit ihren echten oder imitierten Blüten an den Kopfputz von Pharaos Wagenpferden oder an die kunstvollen Aufsätze von Prunkgefäßen erinnern ${ }^{236}$. Im klassischen Griechenland bekränzte man die Opfertiere ${ }^{237}$, in Rom hat man sie entsprechend häufig mit Binden aufgeputzt ${ }^{238}$; in beiden Fällen hat wohl der kathartisch-apotropäische Aspekt dieser Behandlung den Vorrang vor dem schmückenden Zweck gehabt ${ }^{239}$. Die unserem hethitischen Beispiel am nächsten stehende, ja praktisch identische, Schmückung finden wir indes bei Homer in seiner Beschreibung von Nestors Kuhopfer: hier überzieht der mit seinen Geräten herbeigeholte Goldschmied gleich an der Opferstätte das Gehörn mit dem glänzenden Metall ${ }^{240}$. Im hethitischen Ritual wird das Gold eigenartigerweise noch vor der Schlachtung entfernt. Es diente also lediglich zur Verschönerung des noch lebenden Tieres bei seiner (im Text still-

'entlaßt' (arha tarna-) es dort ohne es zu toten, womit allenfalls ein Preisgabeopfer, eine apopompè, gemeint sein mag: KUB XVII 35 I 23-32. - Aus dem Bereich der königlichen Ersatzrituale darf auf den an den Ohren geschmückten Stier und auf das geschmückte Schaf hingewiesen werden, die, beide aus dem Feindland stammend, bei Ausbruch einer Seuche im Heer, zusammen mit zwei geschmückten Kriegsgefangenen, einem (den hethitischen König ersetzenden) Mann und einer Frau, als Ersatzopfer ins Feindesland zurückgeschickt werden: KBo XV 1 I 23-40 (s. Kilmmel, Ersatzrituale, 112ff). - Beide Beispiele sind zwar jungen Texten entnommen, doch ist daraus nicht notwendig auf einen erst jungen Brauch des Schmückens zu schließen.

236 Vgl. etwa Wreszinski, Atlas, Tf. 67 (Grab des Manofer, Altes Reich); Davies, Amarna I, 29. PI. XIIIf; VI, pl. XVIII (14. Jh.; für den Pferdekopfputz s. z.B. Müller / Karpe, Handbuch IV/3 Tff. 31,3; $36 \mathrm{A1} ; 54$ D. Zu den floralen oder floriformen Aufsatzen von Metallgefaßen z.B. Wreszinski, ib., Tf. 46a.b; 88c).

237 Vgl. Euripides, Iph. Aul., 1080; Aristophanes, Frieden, 1044 u.ర.; Ganszyniec, Kranz, 1600.

$238 \mathrm{Vgl}$. Suovetauriliendarstellungen wie auf dem Altar des Gn. Domitius Ahenobarbus, Rom (Bianchi-Bandinelli, Rom, Zentrum der Macht, München 1970, 55), auf dem Spolienrelief Marc Aurels am Konstantinsbogen (ib., 315, Abb. 354), auf dem Relief vom Palazzo di S.Marco, Rom, im Louvre oder auf Diokletians Dezennalienbasis, Rom (Curtius / Nawrath, Das antike Rom ${ }^{3}$, bearb. E. Nash, Wien-München 1954, Abb. 29).

239 S. besonders Eitrem, Opferritus, $64 \mathrm{ff}$.

240 Od. III, 425f.432-38. - In die Zeit der Wende vom 2. zum 1. Jt. weist die bei Polyainos (Strategemata VIII 43) überlieferte Gründungssage des kleinasiatischen Erythrai: sie berichtet von einem (im Rahmen einer List) als Preisgabeopfer gestellten Stier, der im Schmuck von Binden und Purpur und mit goldüberzogenen Hörnern losgesandt wurde. Als Parallele zu KBo XV 1 (vgl. Anm. 235) bereits ausgewertet von Burkert, Structure, 60f. 
schweigend vorausgesetzten) Weihe ${ }^{241}$. Vermutlich kein Schmücken ist gemeint, wenn die Mischna beschreibt, daß dem Sündenbock nach seiner Auslosung am Versöhnungstage ein scharlachfarbenes Band am Kopf befestigt wurde $^{242}$. Auch der übrige Kult Israels kennt keine geschmückten Opfertiere.

Korrektur-Zusatz: Zur passiven Reinigung mit dem tuhhueššar findet sich eine interessante Parallele in KUB LVIII 1 III 8, einem jungen Duplikat des althethitischen Kaštama-Festrituals KBo XX 10 + XXV 59 (StBoT 25, Nr. 59). Wo der alte Text ta LUGAL-un šuppiijahhi u[a]tar III-ŠU išparnuzzi bietet (I 11f), schiebt KUB LVIII 1 III 8' hinter uatar ein dan-na-ú-eš-ni-it ein, so daß zu übersetzen ist: "und er reinigt den $\mathrm{K}$. (indem) er Wasser mit dem dannaueššr sprengt". Das m.W. hier erstmals belegte dannauě̌šar bezeichnet ein Instrument zur rituellen Besprengung etwa entsprechend dem von uns als solches gedeuteten tuhhueššr.

$241 \mathrm{Vgl}$. oben S. 240. Bei der raschen Entfernung des Zierats handelt es sich vielleicht um eine praktische Maßnahme zum Schutz des Metalls vor spăterer Veruntreuung durch Kultdiener eine Gefahr, die bei dem vor Nestors Megaron im erweiterten Familienkreis dargebrachten Opfer nicht bestand. Erst nach der Schlachtung entfernt (?) werden die silbernen Höner der Opfertiere im königlichen Bestattungsritual KUB XXXIX 14 III 6-9 (vgl. Otten, Totenrituale, 80).

242 Traktat Joma, IV 2a [Fehlanzeige in Lev. 16!] Dieses rote Band (sekundarr eingeführt, wohl um eine Verwechselung mit dem für Jahwe ausgelosten Bock zu vermeiden) wird als Symbol für die aus der Gemeinde entfernte Sünde (vgl. Jes, 1, 18) gedeutet, und die Rabbinen erzahlen, daß es sich im Augenblick des Todes eben des Bockes für Azazel entfärbte: Joma, VI 8d. Anders (und ohne Legendenhaftes) Cod. Maimonides VIII, 8, III, 4.7 (Lewittes, Code, 395f), wonach auch der andere Bock mit einem Band (ungenannter Farbe) versehen wird. 
Bibliographie

Alexander, J.B., Early Letters and Economical Texts (BIN 7), New Haven 1943

Alp, S., Beitrage zur Erforschung des hethitischen Tempels. Kultanlagen im Lichte der Keilschrifttexte (TTKY 6/23), Ankara 1983

- Zum Wesen der kultischen Reinigungssubstanz tuhhuešsar und die Verbalform tubša, Or. 52 (1983) 14-19

Andrae, W., Die archaischen Ischtar-Tempel in Assur (WVDOG 39), Leipzig 1922

Andronikos, M., Totenkult, in: Archaeologia Homerica, Bd. III, Kap. W. Die Denkmäler und das frühgriechische Epos. Im Auftrag des Deutschen Archäologischen Instituts, hg. v. F. Matz und H.-G. Buchholz, Gottingen 1968

Archi, $A$., Fêtes de printemps et d'automne et réintégration rituelle d'images de culte dans l'Anatolie hittite, UF 5 (1973) 7.27

- Rezension H. Otten, Festritual, OA 14 (1975) $172 f$

- Eine Anrufung der Sonnengottin von Arinna, in: Documentum Asiae Minoris Antiquae (FS H. Otten), hg. von E. Neu und Chr. Rilster, Wiesbaden 1988, 5-31

Arnaud, D., Les textes sumériens et accadiens, 1-4 (RPAE VI) 1985-87

Avishur, $Y$., The 'Duties of the Son' in the 'Story of Aqhat' and Ezekiel's Prophecy on Idolatry (Ch. 8), UF 17 (1985) 49-60

Barta, W., Art. Kult, LÄ III (1980) 182-244

Bayliss, M., The Cult of Dead Kin in Assyria and Babylonia, Iraq 35 (1973) 115-125

Beyerlin, W. (Hg.), Religionsgeschichtliches Textbuch zum Alten Testament (GAT 1), Gottingen $1975 / 21985$

Biggs, R.D., SÀ.ZI.GA: Ancient Mesopotamian Potency Incantations (TCS 2), Locust Valley/NY 1967

Bittel, K, Bogazkoy III, Berlin 1957

Blau, J. / Greenfield, J.C., Ugaritic Glosses, BASOR 200 (1970) 11-17

Boecker, H.J., Art. Gebet, BHH 1 (1962) 518-524

Bonnet, $H$., Reallexikon der agyptischen Religionsgeschichte, Berlin 1952

Borger, $R$, Assyrisch-babylonische Zeichenliste (AOAT 33/33A), Neukirchen-Vluyn ${ }^{2} 1981$

van Brock, N., Substitution rituelle, RHA XVII/65 (1959) 117-146

Brunner, $H$., Art. Gebet, LÄ II (1977) 453-459

Burkert, $W$., Homo necans. Interpretationen altgriechischer Opferriten und Mythen (RGVV 32), Berlin / New York 1972

- Griechische Religion der archaischen und der klassischen Epoche, Stuttgart 1977

- Structure and History in Greek Mythology and Ritual (Sather Classic Lectures 47), Berkeley / Los Angeles / London 1979

- Glaube und Verhalten. Zeichengestalt und Wirkungsmacht von Opferritualen, in: Le sacrifice dans l'antiquité. Entretiens sur l'antiquité classique XXVII (ed. O. Reverdin / B. Grange), Vandoevres / Genève 1981, 91-125

Calmeyer, P., Zur bedingten Göttlichkeit des Großkönigs, AMI 14 (1981) 55-60

Cancik, H. / Mohr, H., Handbuch der religionswissenschaftichen Grundbegriffe, Bd. I, Stuttgart u.a. 1988

Cavigneaux, $A$. et al., The Series Erim-hus $=$ anantu and An-ta-gal = saqu. Materials for the Sumerian Lexikon (MSL) XVII, Rom 1986 
Dahood, M., Rez. zu M. Dietrich / O. Loretz, Elfenbeininschriften, Or. 48 (1979) 448 Davies, N. de G., The Rock Tombs of El Amarna I - VI, London 1903-08

Dhorme, E., Les religions de Babylonie et d'Assyrie, Paris 1949

Dietrich, M. / Loretz, O. / Mayer, W., Sikkanum "Betyle", UF 21 (1989) 133-39

Dietrich, M. / Loretz, O. / Sanmartín, J., Notizen zum Opfertext RA $24.260=$ Ug 5, 586, Nr. 5, UF 7 (1975) $543 f$

- Die keilalphabetischen Texte aus Ugarit, Teil 1: Transkription (AOAT 24), Neukirchen-Vluyn 1976 ( = KTU)

Dijk, J. van / Goetze, A. / Hussey, M.I., Early Mesopotamian Incantations and Rituals (YOS XI), New Haven / London 1985

Dossin, G., Un rituel du culte d'IStar provenant de Mari, RA 35 (1938) 1-13

Ebeling E., Keilschrifttexte aus Assur religiosen Inhalts I.II (WVDOG, 16. 31), 1919.1923

- Aus dem Tagebuch eines Zauberpriesters (MAOG V/3), Leipzig 1931

Eitrem, S. Opferritus und Voropfer der Griechen und Romer, Kristiania 1915

Evans, A., The Palace of Knossos, London 1921-36

Falkenstein, A., Die Inschriften Gudeas von Lagas. I. Einleitung (AnOr 30), Rom 1966

Fauth, W., Art. Proskynesis, KJPauly IV (1972) 1189

Ferwerda, G.Th, A Contribution to the Early Isin Craft Archive (TLB/SLB V), Leiden 1985

Friedrich, J., Hethitisches Worterbuch, Heidelberg 1952 (= HW ${ }^{1}$ )

- / Kammenhuber, A., Hethitisches Worterbuch, Heidelberg ${ }^{2} 1975 \mathrm{ff}\left(=\mathrm{HW}^{2}\right.$ )

Furlani, G., La religione degli Ittiti (Storia delle religioni XIII), Bologna 1936

Gadd, C.J., The Harran Inscriptions of Nabonidus, AnSt 8 (1958) 35-92

Ganszyniec, Art. Kranz, RE 1. Serie XI/2 (1922) 1588-1607

Gelb, I. / Kienast, B., Die altakkadischen Königsinschriften des dritten Jahrtausends vor Chr. (FAOS 7), Stuttgart 1990

Goetze, A., Verstreute Boghazkoi-Texte, Marburg 1930 (= VBoT)

- The Hittite Ritual of Tunnawi (AOS 14), New Haven 1938

- Rezension zu H. Otten, KUB XXXIX, JCS 18 (1964) 94-96

- An Old Babylonian Prayer of the Divination Priest, JCS 22 (1968) 25-29

- Hittite sipant-, JCS 23 (1971) 77-94

Güterbock, H.G., Die historische Tradition und ihre literarische Gestaltung bei Babyloniern und Hethitern bis 1200 v.Chr., ZA 44 (1938) 45-149

- The Song of Ullikummi (I), JCS 5 (1951) 135-161

- Lexicographical Notes II, RHA XXII/74 (1964) 95-113

Gurney, O.R, Some Aspects of Hittite Religion. The Schweich Lectures, Oxford 1977

Haas, V., Der Kult von Nerik (StP 4), Rom 1970

- Die Serien itkahi und itkalzi des AZU-Priesters. Rituale für Tašmišarri und Tatubepa sowie weitere Texte mit Bezug auf Tašmišarri (ChS I/1), Rom 1984

- / Rost, L, Das Festritual des Gottes Telipinu in Hanb̧ana und in Kašha, AOF 11, 1984, $10-91$. 204-36

- /Wegner, I., Die Rituale der Beschwörerinnen SALŠU.GI I.II (ChS I/5), Rom 1988

- / Wilhelm, G., Hurritische und luwische Riten aus Kizzuwatna. Hurritologische Studien I (AOATS 3), Neukirchen-Vluyn 1974

Healey, J.F., The Pietas of an Ideal Son in Ugarit, UF 11 (1979) 553-556

Hinz, W.. Das Reich Elam, Stuttgart 1964 
Houwink ten Cate, Ph.H.J., Brief Comments on the Hittite Cult Calendar: the Outline of the AN.TAH.ŠUM Festival, in: Kanił̌uwar (FS H.G. Guterbock), ed. by H.A. Hoffner - G.M. Beckman (AS 23), Chicago 1986, 95-110

Jakob-Rost, L, Das Ritual der Malli aus Arzawa gegen Behexung (THeth 2), Heidelberg 1972 - $\rightarrow$ Haas, $V$.

Kaiser, O., Texte aus der Umwelt des Alten Testaments (TUAT), Gütersloh 1982ff

Kammenhuber, A., Hethitisch tuhhuěšar, MSS 1 (1956) $62-70$

- Historisch-geographische Nachrichten aus der althurrischen Uberlieferung, dem Altelamischen und den Inschriften der Könige von Akkad für die Zeit vor dem Einfall der Gutäer (ca. 2200/2136), in: J. Harmatta / G. Komoroczy (Hg.), Wirtschaft und Gesellschaft im Alten Vorderasien (AcAn XXII/1-4), Budapest 1974, 157-247

- Orakelpraxis, Träume und Vorzeichenschau bei den Hethitern (THeth 7), Heidelberg 1976

- Hethtische Opfertexte mit anahi, ahrushi und huprushhi und hurrischen Sprüchen, Or. 55 (1986) 105-30. 390-413

- / Ünal, A., Das althethitische Losorakel KBo XVIII 151, KZ 88 (1974) 157-180

Kirk, G.S., Some Methodological Pitfalls in the Study of Ancient Greek Sacrifice (in Particular), in: Le sacrifice dans l'antiquite, Entretiens sur l'antiquite classique XXVII (ed. O. Reverdin I B. Grange), Vandoevres / Genève 1981, 41-80

König, F.W., Pinikir, AfO 5 (1928/29) 101-103

Kretschmer, P., Indra und der hethitische Gott Inaras, in: $F$. Sommer / H. Ehelolf, Kleinasiatische Forschungen I, Weimar 1930, 297-317

Kronasser, H., Etymologie der hethitischen Sprache I-II, Wiesbaden 1963-66;1987

Kïhne, $C$., Politische Szenerie und internationale Beziehungen Vorderasiens um die Mitte des 2. Jahrtausends v. Chr. (zugleich ein Konzept der Kurzchronologie). Mit einer Zeittafel, in: H.-J. Nissen / J. Renger, Mesopotamien und seine Nachbarn (BBVO 1), Berlin 1982, 203-264

- Hethitische Texte, in: $W$. Beyerlin, Religionsgeschichtliches Textbuch zum Alten Testament (GAT 1), Gottingen ${ }^{2} 1985$, 169-204

- Hethitisch auli- und einige Aspekte altanatolischer Opferpraxis (ZA 76) 1986, 85-117

Kümmel, H.M., Ersatzrituale für den hethitischen König (StBoT 3), Wiesbaden 1967

Kupper, J.R, Correspondance de Kibri-Dagan, Archives royales de Mari III (Traductions), Paris 1950

Lambert, W.G., Art. "Handwaschung", RLA IV (1972-75) 97f

- Babylonian Wisdom Literature, Oxford 1960

- / Millard, A.R., Atra-Hasis, the Babylonian Story of the Flood, Oxford 1969

Landsberger, B., Die Basaltstatue Nabonids von Eski-Harran, in: Halil Edhem Hâtıra Kitabı - GS H. Edhem (TTKY VII/5), Ankara 1947, 116-151

Laroche, E., Recherches sur les noms des dieux hittites, RHA VII/46 (1946/47) 7-139

- Fragments hittites de Genève, RA 45, 1951, 183-94; 46, 1952, 42-50 (= FHG)

- Catalogue des textes hittites ${ }^{2}$, Paris 1971 (erganzt und fortgefuhrt in RHA XXX [1972], 94ff; XXXIII [1975] 68ff) $(=$ CTH)

- Glossaire de la langue hourrite (RHA XXXIV-XXXV), Paris 1976/7

Lewittes, M., The Code of Maimonides, Book Eight: The Book of the Temple Service (YJS XII), New Haven 1957

Löhr, M., Das Răucheropfer im Alten Testament (SKG.G 4/4), Halle 1927

Mayer, W., Untersuchungen zur Formensprache der babylonischen "Gebetsbeschworrungen" (StPSM 5), Rom 1976 
Menzel, B. Assyrische Tempel, 2 Bde. (StPSM 10/1.2), Rom 1981

Meuli, K, Griechische Opferbrăuche, in: Phyllobolia (FS P. v. d. Mühll), hg. v. O. Gigon, K. Meuli et al, Basel 1946, 185-287

Michel, E., Die Assur-Texte Salmanassars III/11. Forts., WO 4 (1967/68) 29-37

del Monte, G.F. / Tischler, J., Die Orts- und Gewasssernamen der hethitischen Texte. Repertoire géographique des textes cunéiformes 6 (Beih. z. Tübinger Atlas des Vorderen Orients B 7,6), Wiesbaden 1978

Muller, K-F., Das Assyrische Ritual, Teil I: Texte zum assyrischen Königsritual (MVAeG 41/3), 1937

Muller, W.W., Art. Weihrauch, RE Spl XV (1978) 700-777

Müller-Karpe, $H$., Handbuch der Vorgeschichte, I-IV, München 1966-80

Myhrmann, D.W., Babylonian Hymns and Prayers (UM I/1), Philadelphia 1911

Neu, E., Interpretation der hethitischen mediopassiven Verbalformen (StBoT 5), Wiesbaden 1968

- Ein althethitisches Gewitterritual (StBoT 12), Wiesbaden 1970

- Hethit. genu-/ganu- "Knie", KZ 86 (1972) 287-295

- Althethitische Ritualtexte in Umschrift (StBoT 25), Wiesbaden 1980

- Glossar zu den althethitischen Ritualtexten (StBoT 26), Wiesbaden 1983

- Zum Alter der personifizierenden -ant-Bildung, KZ 102 (1989) 1-15

- $\rightarrow$ Rüister, Chr.

Oettinger, N., Hethit. ganenant- "gebeugt, durstig", MSS 40 (1981) 143-153

- Die 'dunkle Erde' im Hethitischen und Griechischen, WO 20-21 (1989/90) 83-98

Otten, $H$., Hethitische Totenrituale (Veröfentlichungen des Instituts für Orientforschung 37), Berlin 1958

- Ein hethitisches Festritual. KBo XIX 128 (StBoT 13), Wiesbaden 1971

Pfister, A., Art. Rauchopfer, RE I/1 (1914) 267-286

Polvani, A.M., La terminologia dei minerali nei testi ittiti (Collana di studi sulle civiltà dell'Oriente antico 3), Florenz 1988

Popko, A.M. / Taracha, P., Der 28. und der 29. Tag des hethitischen AN.TAH.ŠUM-Festes, AOF 15 (1988) 82-113

Puhvel, J., Hittite Etymological Dictionary, Berlin 1984ff

Pritchard, J.B. (ed.), Ancient Near Eastern Texts Relating to the Old Testament, 3rd ed. with Supplement, Princeton 1969

Reverdin, O. / Grange, B., Entretiens sur l'antiquité classique XXVII: Le sacrifice dans l'antiquité, Vandoevres / Genève 1981

Rodenwaldt, G., Tiryns. Die Ergebnisse der Ausgrabungen des Kaiserlichen Deutschen Archaeologischen Instituts in Athen, Bd. 2, Athen 1912

Rüster, Chr. / Neu, E., Hethitisches Zeichenlexikon (StBoT Beih. 2), Wiesbaden 1989

Sakellariou, A., Die minoischen und mykenischen Siegel des Nationalmuseums in Athen (CMS I), Berlin 1964

Salvini, M., Note sulle «sentenze» hurriche nei rituali ittiti di KBo XXI e XXII, OA 14 (1975) $227-41$

- I Wegner, I., Die Rituale des AZU-Priesters I.II (ChS I/2), Rom 1986

Segert, S., Live Coals Heaped on the Head, in: Love and Death in the Ancient Near East (FS M.H. Pope), ed. by J.H. Marks and R.M. Good, Guilford/CT 1987, 159-164

Siegelová, J., Appu-Mărchen und Huedammu-Mythus (StBoT 14), Wiesbaden 1971 
Singer, I., The Hittite KI.LAM Festival I.II (StBoT 27.28), Wiesbaden 1983/4

von Soden, W., Art. Gebet II (babylonisch und assyrisch), RLA III (1957-71) 160-170

Sommer, F. / Ehelolf, H., Das hethitische Ritual des Papanikri von Komana (BoSt 10), Leipzig 1924

- / -, Kleinasiatische Forschungen, Bd. I, Weimar 19(27-)30

Starke, F., Untersuchung zur Stammbildung des keilschriftlich-luwischen Nomens (StBoT 31), Wiesbaden 1990

Stengel, P., Opferbrăuche der Griechen, Leipzig / Berlin 1910

Thompsom, RC., A Dictionary of Assyrian Botany, London 1949

Thureau-Dangin, $F$., Rituels accadiens, Paris 1921

van der Toorn, $K$, Funerary Rituals and Beatific Afterlife in Ugaritic Texts and in the Bible, BiOr 48 (1991) 40-66

Townsend-Vermeule, E., Götterkult, in: Archaeologia Homerica, Bd. III, Kap. V. Die Denkmaler und das fruhgriechische Epos. Im Auftrag des Deutschen Archăologischen Instituts, hg. v. $F$. Matz und H.-G. Buchholz, Göttingen 1974

Wegner, I., Gestalt und Kult der Ištar-Sawuskka in Kleinasien (AOAT 36), Neukirchen-Vluyn 1981 - / Salvini, M., Die hethitisch-hurritischen Ritualtafeln des (b)išuwa-Festes (ChS I/4), Rom 1991 Westermann, C., Art. Gebet, RGG ${ }^{3}$ II (1958) 1213-1217

Wilhelm, G., Art. Hubrušhi, RLA IV (1972-75) 478

Wiseman, D.J., A New Stela of Ašur-Nașir.Pal II, Iraq 14 (1952) 24-44

Wright, D.P., The Gesture of Hand Placement in the Hebrew Bible and in Hittite Literature JAOS 106 (1986) 433-446

Xella, $P$., Archeologia del Inferno, Verona 1987

Yerkes, $R . K$, Sacrifice in Greek and Roman Religion and Early Judaism, New York 1952

Ziehen, L., Art. Griechische Opfer, $\mathrm{RE}^{2}$ XVIII (1939) 579-630

Zimmern, H., Beitrage zur Kenntnis der babylonischen Religion (AB 12), Leipzig 1901 



\section{Nekromantie und Totenevokation in Mesopotamien, Ugarit und Israel}

Die Beziehungen der Lebenden zu ihren verstorbenen Vorfahren im alten semitischen Orient rücken seit einiger Zeit zu einem wissenschaftswürdigen Gegenstand auf. In diesem Wandel kündigt sich nicht nur eine Erweiterung der Forschung aufgrund neuen Materials an, sondern vor allem eine Veränderung der Forschungsmentalität selbst und der bisher geltenden wissenschaftlichen Wertschätzungen. ${ }^{1}$ Rückblickend kann man sich kaum des Gedankens erwehren, da $\beta$ auch in der Altorientalistik langsam die mentalen Blockierungen abgebaut werden, die von der jüdischen und der christlichen Tradition her eine Auseinandersetzung mit dem Verhältnis des altorientalischen Menschen zum Tod und zu den Toten der Familie, den Ahnen, als wenig ergiebig und nebensächlich erscheinen ließen. Dieser Vorgang einer Neubewertung hat auch die Bibelwissenschaft ergriffen. Die Vorläuferrolle einiger Gelehrter, die schon vor Jahrzehnten gewagt hatten, gegen die herrschende Meinung auf leicht erkennbare biblische Aussagen zum Ahnenkult und Diskrepanzen zwischen alter Tradition und späteren dogmatischen Korrekturen hinzuweisen ${ }^{2}$, wird nun in milderem Licht gesehen.

Der entscheidende Anstoß zu diesem Mentalitätswandel geht hierbei offensichtlich von den Texten aus Māri und Ugarit aus. Eine zentrale Role spielen hierbei die Ugarit-Texte, die uns mit ihren Aussagen über die rpum die Möglichkeit verschafft haben, die Rephaim der Bibel als eine dogmatisch bedingte Historisierung des einst auch in Israel gepflegten kanaanäischen Ahnenkultes zu begreifen. ${ }^{3}$

Im Rahmen des Ahnenkultes nimmt die Nekromantie in mehrfacher Weise eine Sonderstellung ein. Sie stellt nicht nur ein abgrenzbares Sondergebiet der Beziehung zwischen den Toten und Lebenden dar, sondern spielt auch in der Überlieferung eine besondere Rolle. Denn die Erinnerung an die altorientalische Nekromantie lebte dank der Erzählung über den nächtlichen Besuch Sauls bei der Totenbefragerin von Endor (1 Sam 28,3-25) zu allen Zeiten fort und faszinierte Phantasie und Gedanken der einfachen Bibelleser kaum weniger als die der Theologen. Diese Überlieferung ist jedoch nicht ganz ungetrübt. Die

Der Paradigmenwechsel wird von Hallo, Worship, 381-401, zusammenfassend beschrieben.

Siehe zur Forschungsgeschichte Spronk, Afterlife, 25-83; Tropper, Nekromantie, 3-12.

Vereinzelt wird noch versucht, die Rephaim im Anschluß an die biblischen Schriften als eine kanaanäische Bevolkerung zu erweisen, die vor dem Einzug der Israeliten im Lande gewohnt habe, siehe z.B. Talınon, repä'îm; Margalit, Ugaritic poem, 81.300.474. Es dürfte jedoch kein Zweifel daran bestehen, daß in den biblischen Schriften die vergottlichten Ahnen (rpum = Rephaim) teilweise als historische Menschen erscheinen. In diesen Fällen liegt eine Historisierung des kanaanäisch-israelitischen Totenkultes vor. 
biblischen Tradenten münzten durch ihre negative Bewertung das Ereignis in eine verbotene und seltene Handlung um. Sauls Bittgang nach Endor gleicht in der literarischen Endfassung dem unglücklichen Ausrutscher eines Mannes, dessen Schicksal ohnehin schon besiegelt war. Der Fehlschlag dieses nächtlich geheimen Unternehmens scheint so alle anderen biblischen Aussagen zu bestätigen, die die Befragung der Toten als ein seit den Anfängen Israels verbotenes Ansinnen von einigen wenigen hinstellen, als Teil eines Volksglaubens, der angeblich schon längst vom mosaischen Monotheismus überwunden war.

Die Einschätzung der biblischen Aussagen über die Nekromantie als eines niedrigen Volksglaubens und die Ansicht, da $B$ es in Israel keinen Ahnenkult gegeben habe, beherrscht noch die gegenwärtige Bibelwissenschaft. ${ }^{4}$ Die Exegeten eilen damit auch der christlichen Kirchengeschichtsschreibung und Dogmatik zu Hilfe, zumal diese Disziplinen weiterhin mit der Schwierigkeit kämpfen, daß das biblische Verbot des Verkehrs mit den Ahnen auf tiefgreifende und wohl oft auch verhängnisvolle Weise die Auseinandersetzung mit fremden Kulturen in Asien und Afrika beeinflußt oder sogar verhindert hat.

Gegenwärtig bahnen sich jedoch Entwicklungen an, die für Europäer früherer Generationen undenkbar waren und die all jene Probleme wieder auffrischen könnten, die einst in Israel zur Tabuisierung des Totenkultes geführt haben. Sollte es jetzt möglich sein, z.B. afrikanischen Christen eine Kultform zu gestatten, die Jahrhunderte lang von der Bibel her als streng verboten und als überholt verkündet wurde? ${ }^{5}$

An diesem Punkt ist ohne Aufschub auch daran zu erinnern, daß die von den biblischen Autoren angeblich positiv bestandene Auseinandersetzung mit dem altorientalischen Toten- und Ahnenkult auf Grund vieler Hinweise im Alten Testament selbst de facto nur einem Teil-, wenn nicht sogar einem Pyrrhussieg gleichkam. Denn weder den Juden noch dem Christen gelang jemals eine vollkommene oder nur ansatzweise Überwindung der bekämpften Traditionen. Kaum auf einem anderen Gebiet der geistigen und religiösen Auseinandersetzungen dürften dogmatischer Anspruch und tatsächliches Leben

4 Hossfeld / Kalthoff, Lexikon der Religionen, 14, geben zwar zu, daß es in Israel Totenbefragung gegeben hat, bestreiten aber einen Ahnenkult. Die Verbote in Dtn 14,1f; 18,11; 26,14 seien gegen die Übernahme kanaanitischer Sitten, nicht gegen die Ausübung eigener Praxis gerichtet. Vgl. dagegen Lewis, Ancestor Worship, 240-242.

Pohl, Missionen, 56, führt z.B. aus, daß in Zaire der Priester in Hauptlingstracht wăhrend der Eucharistiefeier Christus, den "Großhauptling" aller Menschen und den Ur-Ahn der Menschheit vertritt. Die toten Vorfahren gehorren wesentlich zum Leben der Lebenden und bestimmen es. Dem hier wandelnden Gottesvolk fließt über die Verstorbenen bis hinauf zum UrAhn Christus von Gott her das Leben zu. Zur gegenwärtigen Diskussion über das Verhăitnis zum Ahnenkult in der christlichen Missionswissenschaft siehe u.a. Borengässer / Bujo / Malek / Waldenfels, Lexikon der Religionen, 15-19; Malek, Ahnenverehrung, 19-22. 
zu allen Zeiten so auseinandergeklafft sein. Im täglichen Leben richteten sich die Menschen in einem modus vivendi ein, der es ihnen bequem erlaubte, gegensätzliche Anschauungen und Gefühle zu vereinen.

Im Rahmen des Glaubens an das Weiterleben der Ahnen nimmt die Nekromantie eine zentrale Stelle ein. Sie kann im engeren Sinn als Befragung eines Verstorbenen im Rahmen eines Orakelvorgangs mit dem Ziel, einen Orakelspruch zu erhalten, ausgeübt werden und im weiteren Verständnis Kontaktaufnahme mit einem Toten mit dem Zweck bedeuten, diesen zu einem positiven Eingreifen in das Schicksal eines Menschen zu bewegen. ${ }^{6}$ Eine Nekromantie ist zumeist mit einer Totenbeschwörung verbunden: Durch evozierende Totenbeschwörung wird ein Totengeist aus der Unterwelt hochgerufen und durch eine exorzierende entweder abgewehrt oder nach einer Evokation bzw. nach Vollendung eines Rituals gebannt und zur Rückkehr ins Totenreich bewegt. Im Alten Orient war die Nekromantie unter Mithilfe eines Ritualfachmannes, der nicht als Medium dient, sondern den Totengeist rituell beschwört und zum sichtbaren Erscheinen auffordert, verbreitet. Die Befragung des Totengeistes konnte vom Beschwörer oder vom Anfragesteller selbst vorgenommen werden. Die Indienstnahme eines Beschwörers dürfte wegen der erforderlichen Kenntnisse der Normalfall gewesen sein.

Zeugnisse aus Mesopotamien, Ugarit und Israel geben zu erkennen, daß Nekromantie und Verkehr mit den Toten in diesen Gebieten verbreitet waren und als ein gemeinsames Kennzeichen dieser Kulturen anzusehen sind.

Im folgenden wenden wir uns zuerst der Nekromantie in Ugarit zu und untersuchen dann, ob Querverbindungen nach Mesopotamien und nach Israel festzustellen sind.

\section{Nekromantie und Verbindung mit den Ahnen in Ugarit}

In der Ugaritistik gewinnt zusehends die Anschauung Gewicht, daß der Nekromantie in den Texten aus Ras Schamra eine große Bedeutung beizumessen ist. Als maßgebliche Zeugnisse werden die vier Texte KTU 1.17 I 27b-28a; 1.20-22; 1.116 und 1.124 angesehen.?

Tropper, Nekromantie, 13-21, bietet eine ausführliche Begriffserklarung.

7 Siehe zusammenfassend Tropper, Nekromantie, 129-160. 


\section{Nekromantie als Sohnespflicht - KTU 1.17 I 27b-28a}

Innerhalb des Katalogs der Sohnespflichten KTU 1.17 I 25-33 folgt auf die an erster Stelle aufgezählte Pflicht, für die Ahnen einen Kultstein $(s k n)^{8}$ und ein $z t r^{9}$ (26b-27a) zu errichten, an zweiter Stelle unter den sechs Doppelpflichten die Aufgabe, seinen Schutzgeist zu befragen:

l arș mơșu qțh

$l$ pr dmr atrh
Der aus ${ }^{10}$ der Unterwelt seinen 'Rauch' herausführt, aus dem Staub die/den Beschutzer seines Ortes.

Den ersten Interpreten des Aqhat-Epos lag der Gedanke an eine Aufforderung zur Nekromantie unter den Sohnespflichten fern. Sie wurde vielmehr als Aufforderung zum Schutz des lebenden Vaters verstanden. ${ }^{11}$ Erst allmählich brach sich die Erkenntnis Bahn, daß es ebenfalls zum Pflichtenkatolog des Sohnes gehört, die Ahnen zu konsultieren, auf ihren Rat und ihre Hilfe zu rechnen. ${ }^{12}$ Diese Anmahnung der Nekromantie setzt folglich die den Katalog einleitende Aufforderung zur Errichtung eines Kultsteines für den Ahn sinnvoll fort.

8 Dietrich / Loretz / Mayer, Sikkanum, 133-139.

9 Bedeutung unbekannt bzw. umstritten.

$10 \mathrm{Zu} l$ "von (...weg)" siehe z.B. HAL 483: $l$ I 5.

11 Ginsberg, ANET, 150; Caquot / Sznycer, Textes Ougaritiques I, 422, "qui délivrera de la terre son ame I (et) de la poussière gardera ses pas"; Gibson, Canaanite Myths, 104, "one to free his spirit from the earth, I to protect his tomb from the dust"; Del Olmo Lete, Mitos, 369, "que de la 'tierra' libere su 'espiritu', I del 'polvo' proteja su(s) resto(s)"; Lewis, Cults, 54.6065.

12 Margalit, Ugaritic Poem, 272-273; Tropper, Nekromantie, 129-134; de Moor, Rise of Yahwism, 247-249. Unklare Deutung noch bei de Moor, Ancestral Cult, 409; ders., Anthology, 228; Spronk, Afterlife, 146.149. Ein Bezug zur Nekromantie wird von van der Toorn, Rituals, 44-46, bestritten. Er sieht als Kern der Aussage von KTU 1.17 I 26-28 das Thema des Herdfeuers an. Das Herdfeuer sei eine Metapher für das Weiterleben der Familie. Er schlagt deshalb als Úbersetzung vor: "On earth, one who makes his smoke go up, I On the dust, one who protects his place" (a.a.O., S. 46). Seine Interpretation lautet: "The bicolon expresses the idea that Daniel's son will keep the family alive" (aaO S. 46). In dieser Argumentation wird übersehen, daß neben den parallelen Wortpaaren $l$ ars $\mathbf{I} l$ 'pr und qțr $\mathbf{I}$ dmr atrh dem Element inšsu im ersten Kolon eine Doppelfunktion zukommt. Die vorgeschlagene Deutung von KTU 1.17 I 26-28 als Metapher für das Weiterleben der Familie dürfte folglich abzulehnen sein. Eine wenig befriedigende Übersetzung dieses Bikolons wird auch von Lewis, Cults, 54.60-65, vorgetragen: "One who delivers his life from the Underworld, I One who guards his footsteps from the Dust." T.J. Lewis laßt gleichfalls die Doppelfunktion von mšșu außer acht. $\mathrm{Er}$ folgt in seiner Interpretation A. Caquot und M. Sznycer und sieht in dem Bikolon die einfache Aussage, daß der Sohn seinen Vater von todlicher Gefahr fernhalte: "This bi-colon asserts that the ideal son will keep his father from mortal danger while he is living" (a.a.O., S.65). 
Nachdem im ersten Bikolon Z. 26b-27a die mit ilib \| 'm "göttlicher Vater" ॥ "Stamm" bezeichneten Ahnen eingeführt wurden, geht der Katalog zur Beschreibung ihrer Erscheinungsform und Funktion, wenn sie aus der Unterwelt (arș $\| p r)^{13}$ erscheinen, über: qț $\| d m r$ "Rauch" \| "Beschützer". Sie treten in die Welt der Lebenden in Form eines Rauches wieder ein, besitzen also nur eine schattenhafte Existenzform (KTU 1.161:1, zl "Schatten"), die auch den Dämonen nachgesagt wird. ${ }^{14}$ Diese Ahnengeister beschützen das Haus oder den Kultraum, in dem der Ahnenkult gepflegt wird, und sie sorgen auf diese Weise wirksam für das Wohlergehen der lebenden Familienmitglieder.

Der seinen Pflichten nachkommende Sohn sieht es als seine Aufgabe an, die Ahnengeister aus der Unterwelt "herauskommen zu lassen" (ys' '̌).$^{15} \mathrm{Die}$ sorgsame Formulierung läßt offen, ob der Sohn selbst oder ein Ritualfachmann die Evokation der Ahnen vornimmt. Die Verpflichtung eines Ritualfachmannes dürfte wegen der erforderlichen Kenntnisse jedoch wahrscheinlicher sein. Da die Erfüllung dieser Sohnespflicht sicher mit erheblichem Aufwand und Kosten z.B. für Opfer verbunden war, sanktionierte und sicherte man sie durch ein moralisches Gebot.

KTU 1.17 I 26b-28a zeigt uns folglich, daß wenigstens die Mitglieder wohlhabender Familien, die sich einen Kultstein (skn) leisten konnten, auch die Kosten für Nekromantie aufbringen sollten, falls dies das Wohl der Familie erforderte.

\section{Der Orakelentscheid des Ditanu - KTU $1.124^{16}$}

In der vierundzwanzigsten Kampagne des Jahres 1961 fanden die Ausgräber einen nur sechzehn Zeilen umfassenden Text, der schon früh als ein Bericht über ein Orakel erkannt wurde. Von besonderer Bedeutung sind hierbei die ersten drei Zeilen des Dokumentes, die folgendermaßen lauten: $k$ ymgy adn ilm rbm ' $m$ dtn w yšal mtpt yld (KTU 1.124:1-3).

Trotz der Zuordnung des Textes zu den Orakeltexten, blieb unter den Autoren das zwischen den personae dramatis herrschende Verhältnis umstritten. Obwohl diese als solche klar erkennbar und mit den Bezeichnungen adn ilm

13 Siehe zu diesem Wortpaar Dahood, in: Ras Shamra Parallels I, 124-125, Nr. 67; ders., in: Ras Shamra Parallels III, 183, Supp 16; Avishur, Stylistic Studies, 9.11.42.301.352.

14

Zu qtr "Rauch" als Bezeichnung von Geistern siehe u.a. de Moor, Ancestral Cult, 409; Tropper, Nekromantie, 132-133, schlägt als Übersetzung von q!̣ "die 'Beraucherten", "Wesen, denen man Rauchopfer darbringt" oder "dunkle/finstere Wesen (der Unterwelt)" vor.

15 Diese Formulierung erinnert an das akkadische mušēlû "Totenbeschwơrer" und mušelitu "Totenbeschwörerin" (AHw 682: mušẹla 1c; CAD M/2 265: mušèlâ B 3).

Siehe zu diesem Text ausführlich Dietrich / Loretz, Mantik, 205-226. 
rbm "Herr der großen/vielen Götter", dtn "Ditanu", mythischer Ahnherr der Könige von Ugarit, yld "Knabe" und mlakk "dein Bote" eingeführt werden, erlangten die Interpreten weder Klarheit in der Frage, wer von wem ein Orakel erbittet, noch konnten sie sich über die Identität des adn ilm rbm einigen. Die verworrene Situation wird am besten deutlich, wenn wir frühere Deutungen übergehen und uns auf die wichtigsten von 1986 an beschränken.

K. Spronk übersetzt die entscheidenden ersten drei Zeilen wie folgt: "When arrived the Lord of the Great Gods with Ditan and he asked a judgment of the child". ${ }^{17}$ Diese Übersetzung setzt voraus, daß Baal als Herr über die verstorbenen Könige zusammen mit Ditanu zu einer spiritistischen Sitzung kommt und der Bote ihn um ein Urteil über den Knaben bitte. Ditanu als großer $r p u$ "Heiler" werde um sein wohltätiges Eingreifen als Richter ersucht. ${ }^{18}$

D. Pardee gibt dagegen den Anfang von KTU 1.124:1-3 so wieder, da $B$ daraus eine Aussage über den Besuch des adn ilm rbm bei Ditanu wird: "Quand se rend le seigneur des dieux nombreux auprès de Ditānu et qu'il (lui) demande une décision au sujet de l'enfant." ${ }^{\text {19 }}$ Zur leidigen Frage nach der Identität des adn ilm rbm stellt er fest, daß sie ein Mysterium bleibe. ${ }^{20}$ Gleichzeitig verbindet er mit dieser Feststellung jedoch die Vermutung, daß die ilm rbm "zahlreichen Götter" vielleicht die verstorbenen und vergöttlichten Könige von Ugarit sein könnten, als deren Chef $(a d n)$ der Dynastiegründer Yaqaru anzusehen sei. ${ }^{21}$ Die Gattung von KTU 1.124 bestimmt er von seinem Neologismus "les textes para-mythologiques" her. Diese Textgruppe hat er unter den Funden der vierundzwanzigsten Kampagne ausgemacht und damit die Ugaritistik wohl in eine grundsätzliche Verlegenheit und in einen nutzlosen Gegensatz zur Mythenforschung gebracht. Er charakterisiert KTU 1.124 im Gegensatz zu allen anderen Interpreten folgendermaßen: "Nous avons le récit d'une consultation exprimée en termes mythologiques. Il n'est pas exprimé comme accompli, mais avec des formes verbales à l'inaccompli, ce qui laisse penser que chaque fois qu'une telle situation se présenterait, le résultat serait le même."22

A. Caquot schließt in seiner Kommentierung KTU 1.161; 1.108 und 1.124 zur Gruppe "Vestiges du rituel et du mythe des Mânes" zusammen. ${ }^{23}$ Aus den ersten drei Zeilen liest er heraus, daß Ditanu den $a d n$ ilm rbm befrage. Er übersetzt deshalb den Anfang so: "Quand le maître des dieux nombreux viendra

\footnotetext{
17 Spronk, Afterlife, 193.

18 Spronk, Afterlife, 193-195.

19 Pardee, Textes para-mythologiques, 183.

20 Pardee, Textes para-mythologiques, 184.

21 Pardee, Textes para-mythologiques, 191.

22 Pardee, Textes para-mythologiques, 191.

23 Caquot, Textes Ougaritiques II, 101.119-123.
} 
chez Ditanu, celui-ci demandera la décision concernant l'enfant." ${ }^{14} \mathrm{Er}$ bestimmt zugleich den adn ilm rbm als den Erzeuger der zahlreichen Götter und identifizierte ihn deshalb mit dem Göttervater El. Dieser werde von Ditanu, dem niedriger Stehenden in der Hierarchie der Götter, anläßlich eines Besuches um eine Entscheidung gebeten. KTU 1.124 sei ein mytho-magisches Dokument und als ein Rezept zur Erweckung oder Vervielfältigung von Geburten gedacht. Der divinisierte Ahn Ditanu befrage El wegen eines Kindes, dessen Geburt erwartet werde. Die Intervention Ditanus in dem von Sterilität bedrohten Bereich der Menschen beleuchte die Rolle der Manen für die Fruchtbarkeit in Ugarit, wie dies wenigstens für die des Königshauses anzunehmen sei. A. Caquot zog zugleich auch eine Parallele zwischen dem Besuch Els bei Ditanu und dem der drei Engel bei Abraham (Gen 18,1-15). ${ }^{25}$

Einen anderen Weg in der Auslegung und Übersetzung von KTU 1.124 haben $1988 \mathrm{M}$. Dietrich und O. Loretz eingeschlagen. Der adn ilm rbm sei als ein menschlicher Akteur und Meister über die ilm rbm, als ein Beschwörungspriester der Ahnen zu verstehen. Die Übersetzung der Anfangszeilen habe folglich zu lauten: "Als der Herr über die großen Göttlichen vor Ditanu trat und nach dem Schicksalsspruch über das Kind fragte, da antwortete ihm Ditanu:....".

KTU 1.124 konnte so den Evokationen der königlichen Ahnen von Ugarit zugeordnet und als Protokoll einer Anfrage anläßlich der Geburt eines Prinzen interpretiert werden. ${ }^{27} \mathrm{Da}$ sich die Anfrage an Ditanu richte, handle es sich nicht um eine Aktion anläßlich der Niederkunft irgendeiner Frau, sondern um die der Königsgattin, von der sich der Herrscher einen Thronfolger erhoffe. Der positive Spruch Ditanus betreffe Geburt und Lebensfähigkeit des Thronfolgers.

Dieser Deutung hat sich J. Tropper angeschlossen. ${ }^{28}$ Er stellt zwei aufeinander folgende Orakelszenen fest, in denen jeweils Ditanu, der mythische Ahnherr der Dynastie Ugarits, befragt werde. Der Text erwähne zwei Subjekte der Befragungen, nämlich einen gewissen adn ilm rbm (Z. 1) und den mlakk "dein Bote" (Z. 11), beschreibe zweimal die Umstände der Orakelanfrage (Z. 1-4 und 10b-14a) und zitiere zweimal einen Orakelspruch in Form einer wörtlichen Rede (Z. 5-10a.14b-16). Er sieht in der Formulierung adn ilm rbm eine Bezeichnung des (obersten) Beschwörungspriesters der königlichen Ahnen, des kultischen Vorstehers des bt ilm rbm (KTU 4.149:1-2). Eine formale wie

Caquot, Textes Ougaritiques II, 121.

Caquot, Textes Ougaritiques II, 120.

Dietrich / Loretz, TUAT II/3, 330; van der Toorn, Funerary rituals, 60-62, versucht auf wenig überzeugende Weise, im $a d n$ ilm rbm einen Gott zu sehen.

27 Dietrich / Loretz, TUAT II/3, 328-330.

Tropper, Nekromantie, 151-156. 
inhaltliche Parallele zu diesem Titel scheine $b^{\circ} l t$ ' $w b$ "Herrin über den Totengeist" (1 Sam 28,7) zu sein, die biblische Bezeichnung für die Totenbeschwörerin.

Wenn wir die Frage nach der Identität des adn ilm rbm als beantwortet ansehen - die Rolle des Ditanu als eines vergöttlichten Urahns der Könige von Ugarit ist inzwischen ohnehin durch eine Reihe von Stellen in den ugaritischen Texten gesichert -, eröffnet sich auch ein Zugang zu weiteren termini technici der Orakelkunst in KTU 1.124. Denn neben $\zeta^{\prime} l$ "anfragen" (Z. 3) finden wir auch "ny "eine (Orakel-)Antwort erteilen" (Z. 4) und das Nomen mtpt "Orakelentscheid" (Z. 3) vor. Parallelen zu dieser Fachterminologie finden wir in der mesopotamischen und israelitischen Überlieferung. Es ist z.B. nur an die sogenannte Richterin Deborah zu erinnern, die unter einem Baume nicht Gerichtsurteile verkündete, sondern der Orakelkunst oblag. ${ }^{29}$

Für KTU 1.124 dürfte deshalb folgende Übersetzung vorzuschlagen sein:

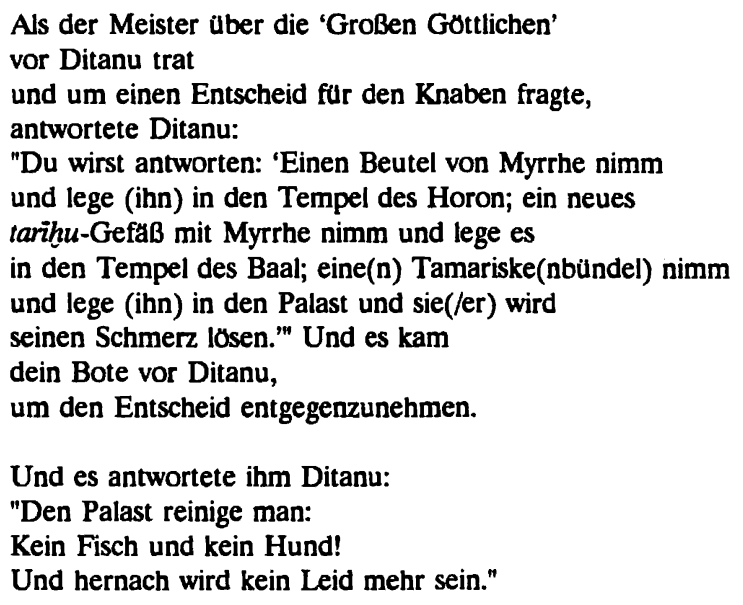

Strittig ist ferner der Hintergrund, auf dem KTU 1.124 zu sehen ist. Entgegen anderen Vorschlägen ${ }^{30}$ hat z.B. D. Pardee versucht, KTU 1.124 als ein genuines Werk aus dem westsemitischen Bereich ohne Verbindung mit Mesopotamien zu erklären. ${ }^{31} \mathrm{Da}$ er jedoch die Gattung des Textes verkennen

29 Siehe zu Ri 4,5 u.a. Dietrich / Loretz, Mantik, 238.

30 Pardee, Textes para-mythologiques, 191, wendet sich vornehmlich gegen P. Xella, der eine Anbindung von KTU 1.124 an die mesopotamische Tradition vorschlagt.

31 Pardee, Textes para-mythologiques, 191-192. 
dürfte, ist es ihm verwehrt, die offensichtliche Verwandtschaft des Protokolls mit der mesopotamischen Nekromantie zu registrieren. Trotz der Querverbindungen mit keilschriftlichen Totenbeschwörungen zeichnet sich auch KTU 1.124 durch spezifisch ugaritische Züge aus, die besonders in der Vorrangstellung Ditanus als Haupt der rpum "Heilenden" zu erblicken sind.

\section{Die Beschwörung des rpu mlk 'lm - KTU 1.108}

KTU 1.108 zählt gleichfalls zu den Paradestücken der Nachrichten über die rpum "Heilenden"32 aus der vierundzwangzigsten Kampagne des Jahres 1961. Einzelaussagen und Gattung des jetzt nur noch siebenundzwanzig Zeilen umfassenden Ritualstückes bilden dementsprechend einen Zankapfel der Ugaritologen. Eine Zusammenfassung der Diskussion seit 1986 zeigt auch in diesem Fall auf genügende Weise die herrschenden Differenzen und Grundrichtungen innerhalb der wichtigsten Interpretationen auf.

K. Spronk bestimmt KTU 1.108 als ein Ritual, das die Wohlfahrt von Ugarit sichern solle. ${ }^{33}$ Es sei Teil des Neujahrsfestes im Herbst zur Zeit des neuen Weines. Falls in Z. 17 die Ergänzung rpum stimme, handelten Z. 16-17 von der Ankunft der rpum anläßlich der Rückkehr Baals aus der Unterwelt. Der an erster Stelle in der Reihe der Gottheiten erwähnte rpu mlk ' $l m$ (Z. 1) sei Baal. Die Vogelgestalt der Göttin 'Anat (Z. 6-9) weise Beziehungen zum ägyptischen Totenkult auf.

J.C. de Moor führt KTU 1.108 unter den Beschwörungen auf. ${ }^{34}$ Königliche Ahnen würden zur Teilnahme am Neujahrsbankett eingeladen. Der König von Ugarit bitte Baal, den großen rpu "Heiler", die Stadt für das neue Jahr zu segnen. Die rpum "Heiler" würden zusammen mit ihrem Meister Baal beschworen, um die Machenschaften der bösen Geister abzuwehren.

Nach J. Tropper ist der Text vornehmlich an Baal gerichtet und nicht an die rpum "Heiler"35. Er übersetzt deshalb Z. 23b-24a mit "O Rapiu der Unterwelt" und folgert, daß die rpum "Heiler" in KTU 1.108 nicht angesprochen würden. Es gebe keine Anhaltspunkte dafür, daß sie zusammen mit Baal in diesem Text evoziert werden und die Stadt Ugarit segnen.

32 Es wird weiterhin diskutiert, ob rpum mit "Heilende" oder "Beschützer" zu übersetzen ist; siehe z.B. Healey, Ugarit, 72; Brown, Healer, 147.175, leitet rpum von rp' II "to be great, strong" ab.

Spronk, Afterlife, 179-189.

34 de Moor, Anthology, 187-190.

35

Tropper, Nekromantie, 142-144. 
D. Pardee unterscheidet in KTU 1.108 zwischen zwei Teilen. ${ }^{36}$ Im ersten handle es sich um ein Fest oder ein Trinkgelage und im zweiten um eine Benediktion. Die starken mythologischen Elemente beider Teile verböten es, diese den praktischen Kulttexten beizuordnen, zumal auch keine Anweisungen gegeben würden. Der Text sei sui generis und als "para-mythique" einzustufen. Der Beter sei ein König von Ugarit, der sich an Baal(?) wende. Hierbei erweise sich die Vermittlung des rpu "Räpi'u", den er versuchsweise mit Milku gleichsetzt, als unerläßlich. Die königlichen Ahnen (rpum) vermittelten als Bindeglieder zwischen dem König von Ugarit und den großen Göttern Baal und Räpi'u.

A. Caquot behandelt KTU 1.108 zusammmen mit KTU 1.161 und 1.124 innerhalb der Gruppe "Vestiges du rituel et du mythe des Mânes". ${ }^{37}$ Er geht davon aus, daß das fehlende Mittelstück eine genügend sichere Charakterisierung des Textes verhindere. Von KTU 1.161 her gesehen handle es sich wohl um eine Liturgie im Rahmen der Verehrung der toten Könige. Das auf der Vorderseite in mythischer Transposition beschriebene Gastmahl der Manen präsidiere Räpi'u, der Eponym und Chef der rpum "Heilenden". Die Rolle der "Anat sei wohl mit ihrer Funktion im Aqhat-Epos zu vergleichen. Die den Text beschließende Benediktion sei für den König und seine Stadt Ugarit gedacht.

Die gegenwärtig strittigen Fragen in der Interpretation von KTU 1.108 kreisen alle in erster Linie um das Verständnis der Wörter $r p u$, mlk 'lm, gtr wyqr und die parallelen Wortpaare $i l\|i l, y \underline{t} b\| t p t$ und "ttrt $\|$ hdr'y in den ersten drei Zeilen.

Der an erster Stelle angerufene $r p u$ mlk $/ m$ wird mit El, Baal, Milku, Rešep ${ }^{38}$ und einem König der Raphaiter, den Gründern des Königshauses von Ugarit, die aus der Gegend des Stammes der Raphaiter/Rephaim ${ }^{39}$ im Transjordanien nach Ugarit eingewandert seien ${ }^{40}$, in Verbindung gebracht. ${ }^{41}$ Es

36 Pardee, Textes para-mythologiques, 75-118.

37 Caquot, Textes Ougaritiques II, 111-118.

38 Cooper, Love and Death, 3-5.

39 Hier ist zu berucksichtigen, daß Margalit, Ugaritic poem, 251-258.268.467, die biblischen Rephaim den rpum gleichstellt und beide als ein Ethnikon versteht. Diese Konzeption trifft jedoch nur insoweit zu, als in der Bibel nach dem Verbot des Toten- und Ahnenkultes die rpum historisiert worden sind.

40 Margalit, Ugaritic poem, 251-258.438.

41 Margalit, Ugaritic poem, 438, stützt seine Hypothese von der transjordanischen Herkunft des ugaritischen Konigshauses und der Ugariter auf eine verfehlte Kolometrie von KTU 1.108:13a. Durch seine Aufteilung des Doppelnamens gir wyqr auf zwei Zeilen zerstört er zugleich auch die perfekte Symmetrie der folgenden zwei Kola: $i l$ ytb $b$ "ttrt I il tpt $b$ hdr'y. Er hat sich so den Weg zu der Erkenntnis verriegelt, daß in Z. 1-3a drei Gottheiten zum Trinken aufgefordert werden: an erster Stelle $r p u$ mlk $/ m$, an zweiter das Paar gtr $w y q r$ und an dritter der il "Gott" von "trt - hdry. Daß es sich beim letzteren um den auch in Ugarit bestens bekannten Gott Milku handelt, geht ferner aus KTU 1.100:41; 1.107:17; RS 1986.2235 hervor. 
dürfte jedoch jenen zuzustimmen sein, die in $r p u$ mlk $/ m$ den Eponym und (die) mythischen vergöttlichten König(e) von Ugarit sehen. ${ }^{42}$ An zweiter Stelle wird das Götterpaar Gatru $u^{43}$-Yaqaru zum Trinken aufgefordert. Die Elemente des Ahnenkultes gehen in dieser Beschwörung allein aus dem Gebrauch des Königsnamens Yaqaru zur Genüge hervor. An dritter Stelle wird der berühmte und auch in Ugarit verehrte Gott Milku von "Attarot-Edrei in Transjordanien zum Bankett geladen. Nachdem die Göttin 'Anat und andere göttliche Wesen in Z. 6-13 herbeigebeten wurden, beruft sich der Sprecher des Segens in Z. 19-24 dreimal auf den rpu mlk $\mathrm{lm}$ (Z. 19-20.21.22) und einmal auf den rpu arș (Z. 24), wobei letztere Formulierung nur als eine Variante der ersteren anzusehen ist. ${ }^{44}$

Dieser ilib "göttliche Vater" von Ugarit wird in den letzten Zeilen des Textes mit folgenden Worten angefleht:

O Rāpi'u der Unterwelt!

Deine Stărke, dein Schutz, deine Macht, deine Herrschaft

(und) deine Segenskraft sei inmitten von Ugarit

für (alle) Tage der Sonne und des Mondes und die lieblichen Jahre Els!

(KTU 1.108:23b-27)

Der Schluß von J. Tropper, daß in KTU 1.108 die rpum "Heiler" nicht erwähnt würden, sondern man nur Baal evoziert habe und deshalb keine Nekromantie vorliege, bedarf folglich einer Korrektur. An erster und letzter Stelle in KTU 1.108 richtet sich der Beschwörer an den großen rpu "Heiler" von Ugarit, der treffend das Epitheton mlk "lm "ewiger König" erhält und in dem so alle königlichen Ahnen der Dynastie zusammengefaßt sind. ${ }^{45}$ Diese Deutung von KTU 1.108 wird durch das Begräbnisritual KTU 1.161 bestätigt (siehe I.4).

Wenn folglich KTU 1.108 auch nicht als eine Totenbefragung zu gelten hat, so zeigt dieser Text doch auf besonders deutliche Weise, daß die Toten zum Nutzen und Segen der Lebenden aufgerufen werden.

42 Caquot, Textes Ougaritiques II, 113 mit Anm. 346.

43

44

$\mathrm{Zu}$ gtr und dem Ahnenkult siehe Dietrich / Loretz, Mantik, 39-74.

4 Tropper, Nekromantie, 143, übersetzt zu Recht "O Rapiu der Unterwelt!", bezieht diesen Ausruf aber auf Baal.

45 Hier ist an die DINGIR MA.LIK ${ }^{\text {mes }}=$ mlkan zu erinnern; siehe hierzu Dietrich / Loretz, Neue Studien, 69-74; Hallo, Worship, 400-401. 


\section{Die Beschwörung der żlm "Schatten" - KTU 1.161}

In der Frage der Definition der Gattung von KTU 1.161, ein Fund aus dem Jahre $1973^{46}$, sind die Meinungen geteilt. Wenn auch für alle Interpreten ein direkter Zusammenhang mit dem Totenkult im Königshaus von Ugarit feststeht, so bestehen in der engeren Auslegung dieses Sachverhaltes doch noch erhebliche Differenzen.

K. Spronk spricht von einem Begräbnisritual, in dem alle verstorbenen Glieder des ugaritischen Königshauses angerufen werden. ${ }^{47}$ Die Ahnen erhielten Opfer und es werde von ihnen erwartet, daß sie den lebenden König dafür segneten. Im Rahmen des Rituals werde der tote König mit den für die Unterwelt benötigten Möbeln versehen.

Nach A. Caquot enthält die Tafel die Totenfeier für einen soeben verstorbenen König oder die Gedenkfeier über das Verscheiden dieses Herrschers. ${ }^{48} \mathrm{Da}$ nach den Rephaim (rpum) die Könige 'Ammistamru und Niqmaddu erwähnt werden, müsse der verstorbene König Niqmaddu III., der Vorgänger des letzten Königs 'Ammurapi ${ }^{\text {'49 }}$ von Ugarit ${ }^{50}$, gewesen sein. Der Text sei von außerordentlicher Bedeutung für die religiöse Geschichte. Denn er informiere uns nicht nur über den Totenkult im ugaritischen Königshaus, sondern bringe auch den endgültigen Beweis dafür, daß die rpum "Heilenden" die Manen der Verstorbenen sind und ihre Anrufung als glückbringend angesehen wurde.

Nach J. Tropper ist das Begräbnisritual das wohl beste Zeugnis für eine Evokation der rpum "Heilenden" am königlichen Hof. ${ }^{51}$ Anläßlich des Todes Niqmaddus III. veranlaßten dessen Sohn und Nachfolger 'Ammurapi' III. und die Königin Taryelli um $1200 \mathrm{v}$. Chr. ein Totenmahl, zu dem sie alle verstorbenen Glieder der Dynastie Ugarits einluden. In Z. 2-12 erfolgten Anweisungen zur Beschwörung der Ahnen. Nach der Beweinung des königlichen Mobiliars werde dieses symbolisch dem König in die Unterwelt nachgeschickt (Z.13-26). Nach einer Totenopferszene (Z. 27-30) folge ein Segensspruch über das amtierende Königspaar und die Stadt Ugarit (Z. 31-34). Der Ritualtext zeige, daß mit der Beschwörung der verstorbenen Ahnen in Ugarit stets die Bitte um 
Segen oder Hilfe verbunden gewesen sei. Wer die Ahnen herbeigerufen habe, habe von ihnen ein positives Eingreifen in sein Schicksal erhofft. Die letzten Zeilen des Rituals zeigten auch, daß die königlichen Ahnen von Ugarit auch für das Wohlergehen des gesamten Königshauses Sorge zu tragen gehabt hätten.

P. Bordreuil - D. Pardee lehnen es ab, in KTU 1.161 eine westsemitische Beschreibung eines Totenmahls im Sinne des mesopotamischen kispum zu sehen. Denn letzteres sei ein Fest zu Ehren der Toten, KTU 1.161 stehe dagegen in Verbindung mit einem Begräbnis. ${ }^{52}$ Der Text handle nicht von einem Hinabsteigen eines Königsthrones, sondern vom toten König, der unter den Rephaim seinen Platz einnehme und von einem Thron, der zu seinem bereits unter den Toten weilenden Herrn gelange. ${ }^{53}$

Die Tafel KTU 1.161 eröffnet uns bis dahin ungeahnte Einblicke in den Ahnen- und Totenkult am Königshof von Ugarit an Hand einer Beschreibung (spr) eines "Opfermahles für die Schatten" $\left(d b h z_{l} l m^{54}, \mathrm{Z}\right.$. 1). Wir erhalten damit zum ersten Mal Aufschluß über die ugaritischen Vorstellungen zur Existenzform der Ahnen, die auch aus Mesopotamien bekannt sind. ${ }^{55}$ Außerdem breitet der Text vor unseren Augen die Rangordnung der Manen des Königshauses aus: Ihre Reihe führt Did/tanu, der Begründer der alten amurritischen Dynastie, den auch die Dynastie von Ugarit als ihren Stammvater verehrte, an (Z.3.10). Es folgen vier der "alten 'Heiler" (Z. 4-8.23-24) und zuletzt der verstorbene König und sein Vorgänger (Z. 11-13.25-26). Die Unterscheidung zwischen alten und jungen Ahnen, wobei die letztverstorbenen beiden Könige im Mittelpunkt des Kultes stehen, findet in Mesopotamien Parallelen. ${ }^{56}$

Anlaß für das Opfermahl war die Beweinung des Thrones und des Thronschemels, die dem toten Herrscher zur Pflege seines Wohlergehens in die Unterwelt in der Weise nachzusenden waren, daß sie rituell im Grab deponiert

52 Bordreuil / Pardee, Textes, 1991, 163.

53 Bordreuil / Pardee, Textes, 160.

54 Nach de Moor, Incantation, 430.432; ders., Anthology, 185, ist dieses Wort auch in RIH 78/20:15 enthalten: $b$ anst $a p$ zl "When the ghost becomes furious". Zur Bezeichnung der Toten als "Schatten" in Mesopotamien siehe auch CAD M/2 265: mušelu B, LÚ GIŠ.MI-è-de $=m u$-še-li și-el-li.

55 Tropper, Nekromantie, 147-148, verweist auf die Listeneintragung "derjenige, der den 'Schatten' heraufholt" für den Totenbeschwörer.

56 Bayliss, Cult, 121. 
wurden. ${ }^{57}$ Denn nach Jes 14,9 sitzen die verstorbenen Könige der Völker in der Unterwelt auf ihren Thronen. Parallelen für die Nachsendung des königlichen Mobiliars in die Unterwelt sind auch aus der Literatur und der Kunst der Hethiter, Assyrer und Phönizier bekannt. ${ }^{58}$

Das Hinuntersteigen des Thrones in die Unterwelt soll die Sonne, die allein täglich die Sphäre der Lebenden und der Toten durchwandert, veranlassen ( $Z$. 18-26). Die Sonne ist die Herrscherin über die Totengeister. ${ }^{59}$

In Z. 2-12 werden Männer und Frauen abwechselnd zur Beschwörung der Ahnen aufgerufen, also Totenbeschwörer und Totenbeschwörerinnen zur Aktion angefeuert. Die Szene klingt mit einem Segenswunsch für das Königspaar und die Stadt Ugarit aus.

Für KTU 1.161 dürfte demnach folgende Übersetzung anzubieten sein:

Anweisung ${ }^{60}$ für ein Opfermahl für die Schatten:

Ihr habt die "Heiler" der Unter[welt] zu rufen,

ihr habt die Versammlung Di[danus] zu evozieren!

Ruft $U L K N$, den "Heiler"!

Ruft TRMN, den "Heil[er]"!

Ruft $S D N$ und $R D N$ !

Ruft $T R$, den uberaus Weisen ${ }^{61}$ !

Ruft die alten "Heiler"!

57 Dietrich / Loretz, Grabbeigaben, 103-106. Vgl. dagegen z.B. Levine / de Tarragon, Dead Kings, 649-659, die von einer Thronbesteigungsfeier sprechen und zusammenfassend (S. 649) formulieren: "In the authors' view, our text was recited and performed to commemorate the accession of Ammurapi (III), the last king of Ugarit ca. 1200 B.C.E. It initiated the cult of the dead in honor of his father, Niqmaddu (III) who had just died, and served to legitimate the succession."

58 Tropper, Nekromantie, 149; Mc Ginnis, Neo-Assyrian Text, 9, weist nach, daß dem König Bett, Gefaße, Tiere und Kleider zum Gebrauch in der anderen Welt mit ins Grab gegeben werden.

59 McGinnis, Neo-Assyrian Text, 5, verweist auf die Epitheta šar etimmēe "Ruler of Ghosts" und bèl miti "Master of the Dead".

60 spr "Aufzeichnung, Anweisung, Brief, Liste".

61 Tropper, Nekromantie, 144 Anm. 113, 'llmn "überaus weise", 'llmy (KTU 1.22 I 10). Renfroe, Lexicography, 80-81, weist jedoch nach, daß zwischen arabisch "allämiyy "(very) wise" und ugaritisch 'llmy keine direkte Verbindung herzustellen ist. 
Ihr habt die "Heiler" der Unterwelt zu rufen, ihr habt die Versammlung Didanus zu evozieren!

Ruft 'Ammistamru, den Konig! Ruft doch Niqmaddu, den König!

= = = = = = = = = = = = = = =

Oh Thron des Niqmaddu!

Auf? Weint! Auch soll man Tranen vergießen!

Oh Schemel seiner Fuße -

vor ihm soll man weinen!

Oh Tisch des Konigs -

ja, man soll Tränen für ihn verschlucken!

Jammer, jammervoller Jammer!

= = = $=$ = $=$ = = = =

Auf! Sei heiß, Sonne!

Ja, sei heiß, große Leuchte!

Von oben soll die Sonne ausrufen:

"Hinter deinem Herrn, oh Thron, hinter deinem Herrn steige in die Unterwelt hinab, steige in die Unterwelt hinab und sinke in den Staub

zur Stelle $\mathrm{e}^{62}$ von $S D N$ und $R D N$, zur Stelle von $T R$, dem überaus Weisen, zur Stelle der alten "Heiler", zur Stelle von "Ammistamru, dem König, zur Stelle - ach! - von Niqmaddu, dem König!"

Am ersten (Tag) opfert, am zweiten opfert, am dritten opfert, am vierten opfert, am fünften opfert,

62 tht "inmitten von"; zur Diskussion siehe u.a. Levine / de Tarragon, Dead Kings, 650, "Below is ..."; Bordreuil / Pardee, Textes, 155.160.161, die jedoch tht mit "en dessous de" übersetzen und damit einen kaum verstăndlichen Sinn postulieren. 
am sechsten opfert,

am siebten opfert!

Man soll Vogel darbringen!

"Heil, Heil für 'Ammurapi'

und Heil seinem Haus!

Heil für Taryelli ${ }^{63}$,

Heil ihrem Haus!

Heil für Ugarit,

Heil seinen Toren!"

Das Opfermahl für die "Schatten" der Ahnen dauert zusammen mit den Opfern der Vögel ${ }^{64}$ sieben Tage. In ihrem Namen wird am Schluß der Segen über das Königshaus und die Stadt ausgesprochen.

Aus KTU 1.161 erhalten wir somit ein sehr umfaßendes Bild über das Verhältnis des ugaritischen Königshauses zu den Ahnen. Die Geister der verstorbenen Könige werden als "Schatten" zurückgerufen, mit Opfern gespeist und um Segen angegangen. Sie begleiten nach diesem Ritual das Mobiliar des jüngst verstorbenen Königs und diesen selbst in die Unterwelt hinab.

\section{Die Rapiuma-Texte - KTU 1.20-1.22}

Das Verhältnis der Rapiuma-Texte zum Aqhat-Epos wird teils positiv und teils negativ bestimmt. ${ }^{65}$ Es dürfte jenen zuzustimmen sein, die von der Zusamamengehörigkeit dieser Texte ausgehen. Wenn man die Bezeichnung Daniels $m t$ rpi "Mann des Rāpi'u" in KTU 1.17-1.19 ernst nimmt ${ }^{66}$, wird es möglich, KTU 1.20-1.22 als Fortsetzung des Aqhat-Epos anzusehen. Umstritten bleibt

63 Lesung des Namens ist unsicher; siehe van Soldt, Studies, 15-18.

64 Tote werden bildlich als "Bocke" (Jes 14,9) und Vogel dargestellt: Spronk, Afterlife, 193.

65 Siehe zu dieser Diskussion u.a. Spronk, Afterlife, 163-177.196; Dijkstra, Epigraphical Evidence, 49-60; de Moor, Anthology, 224 mit Anm. 3; 266-273; Margalit, Ugaritic poem, 464-469; Tropper, Nekromantie, 134-141.

66 Siehe hierzu Dietrich / Loretz, mt "Môt, Tod", 57-65. 
jedoch weiterhin die Frage nach dem Ziel dieser Einladung der rpum "Heiler" zu einem marzihu ${ }^{67}$-Mahl.

Die Erwähnung eines Sohnes in KTU 1.22 I 2-4 wird als eine geisterhafte Begegnung zwischen dem Vater Daniel und seinem verstorbenen Sohn Aqhat $^{68}$ oder als Verheißung eines Sohnes ${ }^{69}$ gedeutet.

Die Rapiuma-Texte handeln ausführlich von der Evokation der Totengeister und ihrer standesgemäßen Reise auf Streitwagen zum Platz ihrer Bewirtung im Rahmen eines Marzihuu-Mahles. Falls die Deutung zutrifft, daß Daniel von ihnen einen Sohn erbittet, hätten wir auch hier einen weiteren Beleg für die damalige Anschauung, daß die Ahnen für fähig gehalten werden, Kindersegen zu garantieren oder bei El zu vermitteln. ${ }^{70}$

\section{Zusammenfassung}

Die vier Texte KTU 1.17 I 27b-28a; $1.124 ; 1.161$ und 1.20-1.22 enthalten eindeutige Hinweise auf nekromantische Praktiken in Ugarit. Da diese alle in Verbindung mit Königshäusern stehen ${ }^{71}$, gewähren sie uns keinen Einblick in die Verhaltensweisen der niederen Volksschichten. Hier macht sich zweifelsohne ein erheblicher Mangel an Material bemerkbar. Am ehesten hilft über dieses Manko noch der Katalog der Sohnespflichten KTU 1.17 I 26-28 hinweg, der wohl seine gegenwärtige Position im Aqhat-Text einer redaktionellen Hand verdankt und die Sohnespflichten registrieren dürfte, die für begüterte Kreise allgemein gültig waren.

Die Ugariter waren folglich überzeugt, daß die Ahnen Familie und Haus ihrer Nachkommen beschützen, segnend über den Bestand der Familie, des Königshauses und des Königsreiches wachen und daß sie die Geburt von Söhnen sowie Heilung bei Krankheit verheißen.

67 Zur Verbindung des in ugaritischen, biblischen und außerbiblischen Quellen erwăhnten mrzh mit dem Totenkult siehe u.a. die Literaturangaben bei Fabry, ThWAT V, 11-16; Lewis, Cults, 80-94; Spronk, Afterlife, 46-47.

68 Spronk, Afterlife, 171; de Moor, Anthology, 271; siehe auch Margalit, Ugaritic poem, 468.

69 Tropper, Nekromantie, 139.

70 Siehe die Abhandlung dieses zentralen Themas im Keret- und Aqhat-Epos.

71 Es wird vorausgesetzt, daß auch Daniel als Konig anzusehen ist; siehe de Moor, Rise of Yahwism, 185 Anm. 358; vgl. dagegen Margalit, Ugaritic poem, 251, der Daniel folgendermaBen chrakterisiert: "...a well-to-do landowner belonging to the patrician class known as adrm charged with the public administration (metonymously, adjudication)." 
II. Nekromantie in Ägypten, Kleinasien und Mesopotamien

\section{1. Ägypten}

Nekromantische Praktiken sind aus Ägypten nur wenige bekannt. Die hierfür ziterten Dokumente Papyrus Leiden I 348, Chester Beatty III und ein demotischer Papyrus enthalten keine klaren Hinweise auf deren Bekanntheit am Nil. ${ }^{72}$

Dagegen berichten die "Briefe an Tote", die von der sechsten Dynastie bis zum Ende des Neuen Reiches bezeugt sind, über ein besonderes Verhältnis zu den toten Ahnen. ${ }^{73}$

In diesen Schreiben an die Ahnen der Familie folgen auf die Nennung des Adressaten und - seltener - des Absenders motivierende Wendungen, die dem Toten seine Abhängigkeit vom Wohlverhalten des/der Lebenden vor Augen führen oder ihn an die stetige Fürsorge von seiten des Absenders erinnern sollen. Im Hauptteil schildert der Absender seine mißliche Lage, in die er zu Unrecht geraten ist. Der Brief endet mit der Aufforderung, der Tote möchte sich nachdrücklich zugunsten des Absenders und gegen seine Bedrücker einsetzen.

Der Absender des Briefes ist jeweils das lebende Familienoberhaupt, das zum verstorbenen Ahnen in einem verwandtschaftlichen Verhältnis als Sohn, Gattin, Gatte oder Mutter steht. Die drei immer wiederkehrenden Anlässe für die Abfassung eines Briefes an die Ahnen sind die Sorge um den Familienbesitz, ernsthafte Erkrankungen, die auf bösartige Tote oder Dämonen zurückgeführt werden, und das Fehlen eines männlichen Nachkommen.

Die Verfasser der Briefe sind davon überzeugt, daß der angesprochene Tote fähig ist, gegen andere jenseitige Kräfte vorzugehen oder auch direkt in das Leben seiner Nachfahren in positiver oder negativer Weise einzugreifen. Die Lebenden fühlen sich zu ihrer eigenen Aktivität, den Toten aufzurütteln und zum Eingreifen zu bewegen, verpflichtet. Durch das beschwörende Anrufen des Ahnen glauben sie, eine Veränderung des Schicksals zu erreichen. Dieses aktive Mitgestalten des Schicksals durch das Beschwören der Toten ist unserer anfangs festgelegten Terminologie zufolge nichts anderes als Nekromantie.

Zusammenfassend können wir somit festhalten, daß entgegen weitverbreiteter Auffassung auch im alten Ägypten nekromantische Praktiken bekannt waren und im Rahmen des Ahnenkultes ausgeübt wurden.

72 Tropper, Nekromantie, 27-32.

73 Tropper, Nekromantie, 32-46. 


\section{Kleinasien}

Die Forscher M. Vieyra ${ }^{74}$, H.A. Hoffner ${ }^{75}$ und J. Ebach / U. Rüterswör$\operatorname{den}^{76}$ vertreten die Auffassung, daß einige in hethitischer Sprache abgefaßte Ritualtexte, die einen Ritus an einer Grube namens api beschreiben, Anweisungen zur Beschwörung und Befragung von Totengeistern enthalten und folglich nekromantischer Natur sind. Das hethitische Wort api selbst stellen diese Autoren etymologisch mit sumerisch $a b$, akkadisch aptu und $a p u$ sowie hebräisch 'wb zusammen.

Das hethitische api wird als ein hurritisches Lehnwort (abi) angesehen. ${ }^{77}$ Es bezeichnet eine in die Erde gegrabene, verschließbare Opfergrube. Von diesen Gruben handeln Reinigungs- und Evokationsrituale. Die Opfergrube api ist dabei auf Grund der an ihr vollzogenen Opferhandlungen Ort sowohl der Evokations- wie auch der Reinigungshandlungen. Sie dient jedoch in keiner Weise nekromantischen Zwecken. Denn keiner der Texte berichtet von einer Evokation von Toten bzw. Totengeistern mittels einer Grube, noch gibt es Anzeichen dafür, daß die Grube ein Divinationsort oder -objekt sein kann. ${ }^{78}$ Ein mantischer Zweck der hethitischen Grubenriten wurde offensichtlich von einem falschen Vorverständnis von hebräisch ' $w b$ her konstruiert. ${ }^{79}$ Im Zirkelschlußverfahren wird hebräisch ' $w b$ sodann etymologisch von api her erklärt und unter Heranziehung der zweifelhaften Gleichung hethitisch tarpiš = hebräisch trpjm geschlossen, daß sowohl 'wb als auch trpjm mantische Requisiten der Unterwelt seien, in denen man die Quelle wahrer Erkenntnis zu finden glaubte. ${ }^{80}$

Eine weitere Frage ist, in wieweit die wenigen hethitischen Beispiele für eine Orakelbefragung der Toten ${ }^{81}$, die auschließlich der Beschwichtigung der Toten dienten, auch das Bestreben der Hethiter aufzeigen, den Kontakt mit ihren Verstorbenen zu suchen und deren Wohlwollen zu erregen. Nekromanti-

74 Vieyra, IStar, 83-102; ders., Les noms, 47-55.

Hoffner, Antecedents, 385-401; ders., ThWAT I, 141-145.

76 Ebach / Rüterswörden, Unterweltsbeschwörung.

77 Laroche, Glossaire, 3, abi "trou, fosse'. Trou creusé en terre pour communiquer avec les puissances infernales, lat. mundus...". E. Laroche laßt die Frage offen, ob eine direkte Entlehnung aus dem Akkadischen ( $a p u / a b u$ ) oder aus dem Sumerischen ( $a b$ "trou") vorliegt; Tischler, Glossar I, 47, "api - 'Loch im Boden; Opfergrube' über hurr. api aus akk. apu entlehnt."

Dies gilt auch für die neuassyrischen Grubenrituale, siehe Tropper, Nekromantie, 118-121.

Hoffner, ThWAT I, 142-143, beruft sich in seiner Argumentation falschlich auf das akkadische Gilgamesch-Epos und Homers Odyssee; siehe hierzu Tropper, Nekromantie, 117 Anm. 33.

80 Hoffner, ThWAT I, 143.

81 Tropper, Nekromantie, 121-122. 
sche Praktiken dürften deshalb auch für hethitische und wahrscheinlich zugleich hurritische Gebiete anzunehmen sein.

\section{Mesopotamien}

Nach mesopotamischer Vorstellung zerfällt der Mensch (awilum) bei seinem Tod in eine materielle Komponente "Leichnam" (pagru, šalamtu, eșemtu) und eine geisthafte, den sogenannten "Totengeist" (sumerisch GIDIM = akkadisch etemmu ${ }^{82}$ ). Den Charakter der Ungreifbarkeit des Totengeistes heben Bezeichnungen wie zäqiqqu "Windhauch"83 oder șillu "Schatten" hervor und seinen dämonischen Aspekt das Wort $u t u k k u^{84}$. Während der Lebensbereich der Lebenden die Erde ist, halten sich die Toten in der Unterwelt (kigallu, arallu, erșetu, erșet lä täri, ekurru, bït ekleti usw.) auf. Für etemmu "Totengeist" liegt keine überzeugende Etymologie vor. Nach Atramhasis I 214-217 wird der etemmu-Geist dem Menschen bei seiner Erschaffung beigegeben. Daraus wurde geschlossen, daß der etemmu nicht das Lebensprinzip des Menschen - entsprechend etwa hebräisch $n p s$ und griechisch psyche - sein könne, sondern die leblose, schattenhafte Existenzweise der Verstorbenen sei. ${ }^{85}$

Der etemmu "Totengeist" empfängt von den Lebenden seiner Familie die Totenopfer (kispu). Er wird von ihnen verehrt (palähu), um ihn günstig zu stimmen. Ein unversorgter etemmu ist gezwungen, die Unterwelt zu verlassen, auf der Erde unstet herumzugeistern (etemmu murtappidu "umherlaufender Totengeist") und den Menschen in böser Gesinnung aufzulauern (GIDIM HUL/etemmu lemnu "böser Totengeist"). Der Mensch erreicht den etemmu ("Totengeist") durch Beschwörung. Er holt ihn dadurch auf magische Weise für unterschiedliche Zwecke aus der Totenwelt herauf (Totengeistevokation), oder er bannt die bösen Totengeister durch Magie in die Unterwelt (Totengeistexorzismus).

Im folgenden wenden wir uns nur der Totengeistevokation, die zwecks Erlangung von Hilfe für die Lebenden unternommen wird, also der Nekromantie, $\mathrm{zu}^{86}$

$\mathrm{Da} \beta$ die alten Babylonier Nekromantie ausgeübt haben, bezeugt der griechische Schriftsteller Jamblichos (2. Jh. n. Chr.), der uns durch Auszüge im Werk

\footnotetext{
82 AHw 263: eteminu "Totengeist".

83 AHw 1530: ziquiqu, zäqiqu 2.

84 AHw 1445: utukku I 4 "Totengeist".

85 Tropper, Nekromantie, 49-56.

86 Siehe hierzu Tropper, Nekromantie, 56-109; Scurlock, Magic, 465.
} 
des Patriarchen Photius (9. Jh.) erhalten geblieben ist. ${ }^{87}$ In der neueren assyriologischen Forschung wird die Existenz der Nekromantie auf Grund lexikalischer Befunde, der Erzählung von der Beschwörung des Enkidu in den Gilgamesch-Epen, dem altassyrischen Brief TC 1,5 = TCL 4,5, dem neuassyrischen Brief LAS $132=$ ABL 614 und drei Ritualtexten aus spätbabylonischer Zeit befürwortet. ${ }^{88}$

Für den Totengeistbeschwörer sind folgende lexikalische Bezeichnungen erhalten ${ }^{89}$ :

lú gidim-ma

lú sag-bulug-ga

lú balag-ga

SAL IGI.ŠID-e $e_{11}-\mathrm{e}-\mathrm{dè}$

lú gissu-è-[de]

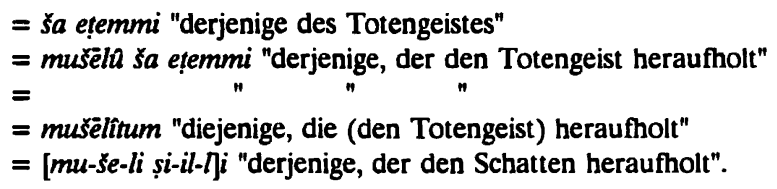

Diesen Bezeichnungen zufolge war der Totenbeschwörer in erster Linie ein Fachmann mit der Fähigkeit, die Totengeister aus der Unterwelt heraufzuholen. Die Befragung der Geister könnte demnach in der Mehrzahl der Fälle von den Auftraggebern einer Beschwörung durchgeführt worden sein. Der Beschwörer als Herr über diese Geister hatte folglich die Menschen vor Übergriffen derselben zu bewahren und ein geordnetes Nebeneinander von Mensch und Totengeist zu gewährleisten.

Da im Gilgamesch-Epos berichtet wird, daß Enkidu auf ausdrückliche Erlaubnis einer Gottheit die Unterwelt verlassen darf und er dann wie ein Windhauch aus einer Mauerluke entweicht, orientiert sich der Erzähler in diesem Fall nicht am Ablauf einer Totenbeschwörung. Obwohl Enkidu auf der Welt mit einem Lebenden zusammentrifft, liegt hier keine Totenbeschwörung vor.

Dagegen bezeugt der Brief TC 1,5 mit der Angabe über die Befragung der Totengeister für den altassyrischen Kulturraum, da $B$ Familien in jener Zeit von den Ahnen in Notsituationen Hilfe erwarteten. Von besonderer Bedeutung ist der neuassyrische Brief LAS 132 aus dem Jahre (Mai) 672 v. Chr., der von einer Nekromantie im assyrischen Königshaus berichtet. Wir sind deshalb wohl zur Annahme berechtigt, daß zumindest in der neuassyrischen Zeit Nekromantie als ein offizielles und allgemein angesehenes Mittel der Divination betrachtet wurde. In LAS 132 werden Totengeister bei der Thronfolgeregelung befragt. Das Totenorakel dient Assurbanipal neben dem Gottesbescheid zur Begründung seines Anspruches auf das Kronprinzenamt. Nachdem die Götter

\footnotetext{
87 Tropper, Nekromantie, 56.

88 Tropper, Nekromantie, 57.

89 Tropper, Nekromantie, 58-59.
} 
Assur und Sonne Assurbanipal zum Thronfolger bestimmt haben, wird auch noch seine verstorbene Mutter befragt. Der Briefschreiber Adad-šumu-ușur berichtet hierüber an den König Asarhaddon das folgende günstige Ergebnis teilweise mit den zitierten Worten des Designierten und seinem eigenen Kommentar: "'Auf Grund ihrer [= verstorbene Königin Ešarra-ḩamat] Pietät bestimmten mich [= Assurbanipal] die Götter Aššur und Šamaš zum Kronprinzen von Assyrien.' Ihr Totengeist segnet ihn entsprechend dem Maße, wie er [= Assurbanipal] den Totengeist verehrt hat: 'Seine Nachkommenschaft (und) sein 'Same' sollen über Assyrien herrschen!' (Es heißt nämlich:) 'Gottesfurcht gebiert Gutes. Ehrfurcht vor den Anunnaki trägt Leben ein'."90

An letzter Stelle sind die sogenannten nekromantischen Beschwörungsrituale gegen böse Totengeister (GIDIM-HULL = etemmu lemnu) zu erwähnen..$^{11}$ Es handelt sich besonders um drei Texte aus dem ersten Jahrtausend v. Chr., von denen der späteste ins vierte oder dritte vorchristliche Jahrhundert datiert werden kann. ${ }^{92}$ Diese Tafeln enthalten jeweils mehrere Beschwörungen und Rituale zur Evokation von Totengeistern aus der Unterwelt, schildern aber kein Gespräch des Beschwörers mit dem Totengeist. Der Zweck dieser Rituale ist deshalb aus den Kennzeilen, Einleitungen und anderen Hinweisen zu erschließen. Diesen zufolge evozierte man einen bestimmten Totengeist zum Zwecke einer Orakelentscheidung (purussâ parāsu) aus der Unterwelt. ${ }^{93}$ Als günstiger Tag gilt der 29. Tag des Monats Abu, der für die Speisung der Totengeister mit kispu-Opferungen von Bedeutung war. Verbunden damit sind Speise- und Trankopfer für die Unterweltsgötter auf Tragaltärchen oder auf dem Boden ausgestreut. Es folgen Libationen von Bier und Wein, das Ausstreuen von Datteln, Mehl und anderen Ingredienzien sowie das Verbrennen von Wacholderweihrauch. Als Beschwörungsmittel werden Tonfigurinen der/des Toten und speziell präparierte Totenschädel benützt. Die evozierenden Rituale werden im Gegensatz zu den exorzistischen nur an einen einzigen, namentlich bekannten Toten gerichtet, der mit "Du" angesprochen wird. In den evozierenden Beschwörungstexten wird außerdem die Zubereitung einer magischen Salbe vorgeschrieben, mit der sich der Beschwörer anschließend die Augen oder das Gesicht einreibt, so daß der Totengeist für den Beschwörer sichtbar wird und das Gespräch beginnen kann. Mit magischer Salbe wird auch die Figur des Totengeistes oder der Totenschädel bestrichen, damit dieser für den Beschwörer magisch erreichbar wird.

\footnotetext{
90

Tropper, Nekromantie, 80.

91 Bottéro, Les morts, 153-203; Finkel, Necromancy, 1-17; Scurlock, Magical Means; Tropper, Nekromantie, 83-109.

92 Trotz der spăten Herkunft dieser Texte ist anzunehmen, daß sie frühere Praktiken weiterführen.

Tropper, Nekromantie, 101.
} 
Sobald die Evokation geglückt und der Totengeist dem Beschwörer (allein) sichtbar ist, stellt er ihm die Orakelanfrage, die der Totengeist auf eine nicht näher beschriebene Weise positiv oder negativ beantwortet. Ist der Beschwörungvorgang beendet, wird der Totengeist unter Anwendung umfangreicher magischer Vorkehrungen und Opferhandlungen wieder in die Unterwelt gebannt.

Nekromantischen Charakter besitzen auch die neuassyrischen Beschwörungen der Totengeister der Familie. Wie in den ägyptischen "Totenbriefen" werden die Ahnen auch in diesen Beschwörungsritualen zum positiven Einsatz für lebende Familienglieder aufgefordert. ${ }^{94}$

Zusammenfassend erhalten wir über Nekromantie im Mesopotamien folgendes Bild: Nekromantie gehört zu den anerkannten Divinationspraktiken, die institutionalisiert und ritualisert sind. Die Listen kennen den Berufszweig des Totenbeschwörers. Da durch Totenbefragung ein Orakelentscheid erreicht werden soll, handelt es sich um eine Form der Mantik. Der Tote weiß auf Grund seines Zustandes in der Nähe zur Götterwelt über den göttlichen Willen Bescheid, oder er kann in die göttliche Bestimmung eingreifen. Die nekromantischen Praktiken sind engstens an den familiären Ahnenkult gebunden. Eine kontinuierliche Pflege der Ahnen bildet die Voraussetzung für eine wirksame Nekromantie. Die Befragung der Ahnen dürfte in Mesopotamien in allen Gesellschaftsschichten üblich gewesen sein. Diese Begrenzung der Nekromantie auf den Bereich der Familie erklärt auch die relative Seltenheit der schriftlichen Bezeugung z.B. gegenüber der Traumdeutung und der Hepatoskopie.

\section{Nekromantie und Verkehr mit den Toten in Israel - Altes Testament}

Aus dem Alten Testament werden traditionell folgende Stellen als Hinweise auf die Praxis der Nekromantie angesehen: aus der erzählenden Literatur die sieben Stellen 1 Sam 28,3b.7.8b; 2 Sam 12,16a; 2 Kön 21,6a; 23,24a; 1 Chron 10,13-14; aus den Gesetzen vier Belege: Dtn 18,11; Lev 19,31a; 20,6a; 20,27; und aus dem Buch Jesaja drei Stellen: Jes 8,19; 19,3b; 29,4b.

\section{1 Sam 28,3-25 - Die Totenbeschwörung von Endor}

Die literarische Vorgeschichte von 1 Sam 28,3-25 ist in der neueren Forschung äußerst umstritten. P.K. McCarter sieht z.B. 1 Sam 28 als eine Erzählung an, die auf einen Bericht über die Beschwörung eines anonymen Totengei-

94 Tropper, Nekromantie, 103-107. 
stes durch König Saul zurückgehe. Die Figur des Propheten Samuel sei erst später damit verflochten worden und habe dem Ganzen den Charakter einer Verwerfungsgeschichte aufgeprägt. ${ }^{95} \mathrm{~W}$. Dietrich ist dagegen der Meinung, daß die Erzählung auf einer altertümlichen, aus dem Norden Israels stammenden Lokalüberlieferung beruhe, die nicht von der Beschwörung und Befragung eines Totengeistes, sondern einer Unterweltsgottheit ('lhjm, Z. 13) erzähle. ${ }^{\% 6}$ Diese Überlieferung, deren Umfang und Wortlaut sich literarkritisch nicht mehr fassen lasse, habe in vordtr. Zeit eine grundlegende Bearbeitung durch nordisraelitische, königskritische Prophetenkreise erfahren. Im Zuge dieser Veränderungen sei die Gestalt Samuels sekundär in die Geschichte eingeführt und die gesamte Erzählung zu einer Verwerfungserzählung umgestaltet worden. Eine letzte, dtr. Bearbeitung (DtrP) füge der Erzählung noch den Passus V. 1719aa hinzu, um sie mit der Verwerfungserzählung 1 Sam 15 ausdrücklich zu verknüpfen. Nach J. Tropper ist die Perikope im wesentlichen ein Werk des zweiten, prophetischen Redaktors des deuteronomistischen Geschichtswerkes, die im nachhinein in den Versen 17-19aa von dem dritten, nomistischen Redaktor (DtrN) erweitert wurde. ${ }^{97}$ Der Stoff der Perikope sei freilich älter und gehe auf eine im nordisraelitischen Ort Endor beheimatete, aus der frühen bis mittleren Königszeit (9./8. Jh.) stammenden Sage zurück. Diese erzähle von einer nächtlichen Kultfeier König Sauls zu Ehren seiner Ahnen und setze sich aus einer Beschwörung und Befragung (Nekromantie) der Ahnen sowie einem abschließenden Kultmahl zusammen. Da die unmittelbaren Vorbilder dieser Erzählung in den Berichten über Ahnenfeste am zeitgenössischen (nord-)israelitischen Königshof und nicht etwa im außerisraelitisch-kanaanäischen Bereich zu suchen seien, stehe außer Zweifel, daß Praktiken des Ahnenkultes und der Nekromantie im Israel der frühen/mittleren Königszeit verbreitet gewesen seien.

In die Erzählung über Sauls Besuch in Endor hat ein Redaktor offensichtlich die These eingearbeitet, daß Saul selbst vorher alle Ahnen- und Totenfiguren aus dem Land verbannt habe (V. 3b). Demzufolge sind auch V. 9-

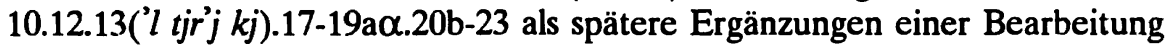
zu kennzeichnen. Der Sinn der verbleibenden Erzählung baut auf dem Gegensatz zwischen dem erfolglosen Bemühen Sauls um ein Orakel durch Traum, Urim oder Propheten (V. 6.15) und der unheilvollen Antwort der Totenbeschwörerin auf. Da auch die Tendenz dieser Erzählung bereits von der Verwerfung Sauls und der deuteronomistischen Wahrsagetheorie ausgeht und die Befragung Samuels nur als letzte Ausflucht erscheint, nach V. 24-25 jedoch ein

\footnotetext{
95 McCarter, I Samuel, 421.423.

96 Dietrich, David, 25-36.

97 Tropper, Nekromantie, 205-227.
} 
positives Ergebnis nicht ausgeschlossen sein dürfte, ergibt sich die Frage, ob der Besuch bei der Frau von Endor im ursprünglichen Bericht nicht zu einem positiven Orakel geführt hatte. Deshalb wird hier vorgeschlagen, nur 1 Sam 28,3a.4-5.7-8.11.13-15baa.24-25 als Kern der ersten Erzählung über Sauls Unternehmen anzusehen.

Die in 1 Sam 28,3-25 beschriebene Nekromantie weist alle wesentlichen Kennzeichen der Praktik auf, die wir bereits in Ugarit und Mesopotamien kennengelernt haben. Sie wird nachts von einer Spezialistin ${ }^{98}$ an einem günstigen $\mathrm{Ort}^{99}$ durchgeführt, und ihr Anlaß ist eine Notlage. Der Totengeist selbst wird als ' $w b^{100}$ und 'lhjm ${ }^{101}$ bezeichnet, und die Befragung wird mit einem Opfermahl abgeschlossen.

Die Praxis der Nekromantie wird in allen Fassungen der Erzählung für die Zeit Sauls vorausgesetzt. Die Frau von Endor ist somit mit Deborah vergleichbar, die unter einem Baum ihre Orakelentscheide gegeben hat.

Der Besuch Sauls bei der Totenbeschwörerin von Endor wurde in den späten Texten I Chron 10,13-14 und Sirach 46,20 aufgenommen. ${ }^{102}$ An letzterer Stelle sühnt das Totenorakel die Sünde des Volkes. Rühmend spricht der Dichter von Samuel:

Auch nach seinem Tode noch wurde er befragt, und er verkündete dem König sein Schicksal.

Aus der Unterwelt erhob er weissagend seine Stimme, um den Frevel des Volkes zu tilgen.

$$
(\operatorname{Sir} 46,20)^{103}
$$

98 Tropper, Nekromantie, 225, verweist auf akkadisch ša etemmi "derjenige des Totengeistes" und ugaritisch adn ilm rbm "der Gebieter über die großen Götter". In 'st b't 'wb wird wahrscheinlich $b^{\prime} l t$ durch 'št erklärt. Es ist kaum mit McCarter, Samuel I, 418, eine Vermischung von ' $s t$ ' $w b$ und $b$ 'lt' $w b$ anzunehmen.

99 Der Ort an einer Quelle ( $j n d w r$ ) eignet sich für Orakeltătigkeit, siehe z.B. auch "jn mtpt (Gen 14,7). Der Endtext erweckt den Eindruck, daß die Frau von Endor die Beschwơrung in ihrem Haus vornimmt.

100 Tropper, Nekromantie, 189-200.312-316.

101 Entgegen allgemeiner Annahme dürfte damit zu rechnen sein, daß $1 \mathrm{ljm}$ eine nachtrăgliche Anpassung an 'lhjm und dessen Umdeutung zu einem Plural absichern sollte. Denn es war für die monotheistischen biblischen Autoren annehmbarer, mehrere Götter aus der Unterwelt aufsteigen zu lassen, als einen 'Ihjm (= Jahwe) allein. Siehe zur Diskussion ferner Hutter, Religionsgeschichtliche Erwăgungen, 32-35; Tropper, Nekromantie, 219-220.

102 Tropper, Nekromantie, 292-297.

103 Skehan / Di Lella, Wisdom, 517.521. 


\section{2. $2 \operatorname{Sam} 12,16 a^{104}$}

Innerhalb der älteren Erzählung 2 Sam 12,15b-24a wird von einer Totenbefragung Davids in folgender Form berichtet: $w$ jbqs dwd 't $h$ 'lhjm $b^{*} d h{ }^{*} r$ (Z. 16a). Die Übersetzungen deuten den Text entweder als Bericht über eine Befragung "Gottes" ('lhjm) wegen des Knaben (im Heiligtum) ${ }^{105}$ oder unter Zuflucht zu einer Texkorrektur ${ }^{106}$ als eine Anfrage an Jahwe. Der Bericht wird auch als Beschreibung eines rituellen Abstiegs Davids in die Unterwelt zwecks Rettung des Knaben gedeutet. ${ }^{107}$ Einige Autoren sprechen von einer Orakeleinholung. ${ }^{108}$

Der Plural 'lhjm "Götter" findet eine Erklärung, wenn darin mit H. Niehr eine Bezeichnung der konsultierten Ahnenfiguren gesehen wird, so wie dies auch für 'lhjm in Ex 21,6 anzunehmen ist. Der König hat folglich in der größten Sorge um den Knaben eine Nekromantie durchführen lassen.

\section{Dtn 18,11 - Verbot der Nekromantie}

Im Rahmen des sogenannten Prophetengesetzes Dtn 18,9-22, das entweder dtr. oder nachdtr. zu datieren ist, wird auch die Nekromantie mit folgenden Worten verboten: "Es soll bei dir keinen geben ..., der einen Ahnen, einen 'Wissenden ${ }^{109}$ befragt, der sich an die Toten wendet." (Dtn 18,10-11) ${ }^{110}$

\section{2 Kön 21,6; 2 Chron 33,6 - Die Untaten des Königs Manasse}

Im Sündenkatalog des Königs Manasse erscheint auch folgender Vorwurf: "Er ließ seinen Sohn durchs Feuer gehen, beschäftigte sich mit Vorzeichendeu-

\footnotetext{
104 Niehr, Text, 301-306.

105 Siehe z.B. Rehm, Samuel, 94; Die Bibel. Altes und Neues Testament. Einheitsübersetzung. Freiburg usw. 1980, 313, "David suchte Gott wegen des Knaben auf..."; Lutherbibel Standardausgabe mit Apokryphen, Stuttgart 1985, 332, "Und David suchte Gott um des Knablein willen...".

106 Schlögl, Bücher, 63-64.

${ }^{107}$ Lewis, Cults, 43.159.

108 Siehe z.B. Podella, Șôm-Fasten, 232, "Und David holte ein Orakel bei Gott für den Knaben ein"; Niehr, Text, 301-302.

$109 \mathrm{Zu} \mathrm{jd'nj}$ als Bezeichnung einer Ahnenfigur siehe u.a. Tropper, Nekromantie, 265.317-319.

${ }^{110}$ Tropper, Nekromantie, 227-242.
} 
tung und stellte Ahnenbilder ('wb w jd'njm) ${ }^{111}$ her." (2 Kön 21,6a) $)^{112}$ Dieser Vorwurf wird in 2 Chron 33,6 ('wb w jd'nj) wieder aufgegriffen. ${ }^{113}$

\section{2 Kön 23,24 - Die Reform des Josia}

Im Reformbericht des Josia (2 Kön 23,4-27) wird dem König die Abschaffung der Ahnenbilder zugute gehalten: "Ferner schaffte Josia die Ahnen ('wbwt - jd'njm)- und Terafimbilder ${ }^{114}$, sowie alle Götzen und Scheusalbilder, die im Lande Juda und Jerusalem zu sehen waren, weg, um die Worte des Gesetzes auszuführen, die geschrieben sind in dem Buch, das der Priester Hilkija im Hause Jahwes gefunden hatte." (2 Kön 23,24)

Wenn es auch mit Recht zu bezweifeln sein dürfte, daß diese Verurteilung des Königs Manasse als ein historischer Bericht zu werten ist, so geht aus ihr doch mit genügender Deutlichkeit hervor, daß zur Zeit der Deuteronomisten die verabscheuten Bildwerke bei den Juden weit verbreitet waren.

\section{Lev 19,31; 20,6.27 - Heiligkeitsgesetz (Lev 17-26)}

Neben Dtn 18,11 wenden sich noch die drei weiteren Gesetzestexte Lev 19,31; 20,6.27 gegen den Kult der 'wbwt und jd'njm. Der Ahnenkult wird in den nachexilischen Stellen Lev 19,31 und 20,6 als Idolatrie abgelehnt. Dagegen wird in Lev 20,27 die Wahrsagerei mittels Bauchrednerei - ein 'wb oder jd'nj befindet sich im Innern eines Mediums - verurteilt. Letztere Stelle kann deshalb nicht vor dem vierten Jahrhundert entstanden sein und weist auf griechischen Einfluß hin. Ähnliche Probleme stellt die in Hi 32,19 erfolgte Eintragung der Bauchrede eines Totengeistes. ${ }^{115}$

\section{Jes $8,19-20$}

An den Bericht von der Verkündigung Jesajas (Jes 8,16-18) hat ein nachexilischer Redaktor folgende Bemerkung angeschlossen:

111 Tropper, Nekromantie, 244.

112 Würthwein, Bücher, 439, übersetzt "Und er ... bestellte Totengeistbeschwơrer und Zeichendeuter".

113 Tropper, Nekromantie, 242-245.

114 Auch die trpjm sind als Ahnenbilder, die bei Totenbefragungen eine Rolle spielten, anzusehen, siehe Tropper, Nekromantie, 332-339; van der Toorn, Nature, 203-222.

115 Tropper, Nekromantie, 297-308. 
"Und wenn sie auch sagen: 'Fragt an bei den Ahnen und den Kundigen[, die wispern und murmeln] $]^{116}$ ! Darf sich eine Stammesgemeinschaft nicht an ihre Totengeister ${ }^{117}$ wenden, zugunsten der Lebenden an die Toten?' Bei Gesetz und Bezeugung! Sie reden etwas, das keine Macht hat." (Jes 8,19-20)

Der Verfasser wendet sich polemisch gegen eine verbreitete nekromantische Praktik, sich in Not an die Ahnen zu wenden. Offen bleibt, ob das Wispern und Murmeln der Ahnen auf eine bestimmte nekromantische Praktik hinweist. Der Nekromantie wird als einzig mächtiges Wort das Gesetz entgegengestellt.

\section{Jes 19,3}

Im Ägyptenspruch Jes 19,1-15 ${ }^{118}$ wird den Bewohnern des Nillandes eine große Verwirrung angedroht, die sie sogar dazu verleiten wird, sich an die Toten zu wenden: "Da werden sie sich hinwenden an die Götzen" ${ }^{119}$ und Totengeister ${ }^{120}$, an die Ahnen und Kundigen!" (Jes 19,3).

Der spätnachexilische Verfasser überträgt mit dieser Drohung Probleme der jüdischen Gemeinde auf die Ägypter, wobei er betont, daß Götzen- und Ahnenkult zusammengehen.

\section{Jes 29,4}

In das Ariel-Lied Jes 29,1-8 wurde u.a. auch V. 4 als Ergänzung eingeschoben. Das unglückliche Schicksal Jerusalems wird darin mit der mißlichen Lage eines Totengeistes verglichen:

Leise wirst du aus der Unterwelt winseln, und aus dem Staub dringt dumpf deine Stimme!

Deine Stimme wird wie die eines Totengeistes aus der Unterwelt sein, und aus dem Staub wird deine Rede lispeln!

(Jes 29,4)

Den Totengeistern wird sowohl Jes 8,19 als auch 29,4 nur ein undeutliches Sprechen nachgesagt. Es ist nicht sicher, ob hiermit gegen Totenorakel polemisiert wird.

\footnotetext{
116 Eine Glosse?

117 'Ihjm könnte auch hier mit "Ahnenbilder" übersetzt werden.

118 Zum literarischen Aufbau von Jes 19,1-15 siehe u.a. Loretz, Topos, 110-111.

119 Das 'ljljm dürfte in Paralle zu 'ṭm ein 'lhjm "Totengeist" voraussetzen.

120 'tm = etemmu; Ges. ${ }^{18}$ 43: 'tjm.
} 


\section{Der Gegensatz zwischen Nekromantie und Thora}

Aus den biblischen Quellen geht hervor, daß in vorexilischer Zeit Nekromantie und Verkehr mit den Toten sowohl von Königen als auch im Volk ausgeübt wurde. In den überlieferten biblischen Schriften wird die Nekromantie jedoch vom Standpunkt des monotheistischen Jahwismus aus beurteilt und als ein Fremdkörper in Israel abgelehnt.

Aus dieser widersprüchlichen Quellenlage ersehen wir nicht nur, daß Nekromantie in Israel weit verbreitet gewesen sein muB, sondern auch, daß sie erst für die nachexilischen Theologen und Historiker zu einem erheblichen theologischen und historischen Problem geworden ist. Es sind nicht die Propheten der vorexilischen Zeit, die gegen sie ankämpfen, sondern erst die nachexilischen Vertreter der Thora. Nachdem das "Gesetz" zur alleinigen Offenbarungsschrift aufgerückt war, mußten andere Formen der Ermittlung göttlicher Führung wie z.B. Nekromantie ausgeschaltet werden. Die Konkurrenz zwischen Ahnenkult und Nekromantie einerseits und Jahweverehrung sowie Thora andererseit war zu groß, als daß beide noch weiterhin nebeneinander innerhalb der jüdischen Gemeinschaft hätten friedlich neben- oder miteinander bestehen können.

An diese Entwicklung schließt laut Lev 20,27 und Hi 32,19 eine weitere an. Denn im Laufe der hellenistischen Zeit scheint sich die kultische Form des altorientalisch-kanaanäischen Ahnenkultes aufzulösen und die Nekromantie den kultischen Rahmen zu verlassen. Sie wird fortan eine rein mantische Angelegenheit von Wahrsagezünften und Bauchrednern (griechisch engastrimythoi, lateinisch pythones). Auch die ältesten Übersetzungen der Bibel deuten Nekromantie als eine Angelegenheit von Bauchrednern und Magiern.

Die Nekromantie hat folglich in Israel eine lange Entwicklung durchlaufen. Sie war in vorexilischer Zeit wohl allgemeine Praxis und stand in keiner Konkurrenz mit der Verehrung Jahwes. Erst die durch die nationale Niederlage und das Exil erzwungene Neuorientierung führte im entstehenden Judentum zur alleinigen und bildlosen Verehrung Jahwes. Von dieser monotheistischen Grundentscheidung her war mit einem Schlage dem Ahnenkult mit seinen Statuen göttlicher Ahnen und der Nekromantie das Urteil gesprochen. Das Verbot der Nekromantie und allgemein des Verkehrs mit den Toten läßt sich folglich nur in Zusammenhang mit dem ersten Gebot "Du sollst dir kein Bildnis machen! ${ }^{1121}$ verstehen. ${ }^{122}$

121 Zum Ursprung und zur Bedeutung des Fremdgotter- und Statuenverbotes im Dekalog (Ex 20,3-4; Dtn 5,7-8) siehe u.a. Loretz, in: Jahwe und seine Aschera, 112-117.

122 Baeck, Wesen des Judentums, 203, stellt zwischen dem ersten Gebot und der Tabuisierung des Totenkultes im Judentum eine enge Verbindung her: "Das Verbot: 'du sollst dir kein Bildnis machen und keinerlei Gestalt' wurde, bewußt oder unbewußt, auch als ein Verbot dessen 


\section{Rückblick auf Nekromantie und Verehrung der Ahnen im Alten Orient und in Israel}

Eine synchrone Erforschung des Ahnenkultes und der Nekromantie in Ugarit, Mesopotamien, Kleinasien und Ägypten sowie das Studium des Nachlebens dieser Tradition in Israel lenken unseren Blick auf eine bedeutsame Lebenswirklichkeit der altorientalischen semitischen und ägyptischen Welt. Aus der Zusammenschau all dieser Quellen gewinnen wir nicht nur ein neues Bild über die Nekromantie in der Umwelt Israels, sondern vor allem eine bessere Einsicht in die Formen des Verkehrs mit den Toten, die im vor- und nachexilischen Israel üblich waren.

Die bisher in der Bibelwissenschaft verbreitete Beurteilung der Verbreitung und des Charakters der Nekromantie baute auf den Angaben der Deuteronomisten auf. Dieser Anschauung zufolge hat Israel von Anfang an den Verkehr mit den Toten verabscheut. Diese Deutung der biblischen Geschichte der Nekromantie gibt den theologischen Standpunkt der Deuteronomisten wider, die sich von ihrem monotheistischen Jahwismus her gezwungen sahen, die Berichte der Vergangenheit zu korrigieren oder gar zu unterdrücken. Erst die Wiederentdeckung des Alten Orients und besonders die der Texte aus Ugarit haben uns einen zensurfreien Zugang zur Geschichte der Nekromantie in Altsyrien-Palästina eröffnet. Auf diesem Wege wird es möglich, die deuteronomistische Behandlung der Nekromantie in Israel und im Judentum geschichtlich zu verstehen und die theologischen Intentionen der jüdischen Theologen auf ihrem historischen Hintergrund zu erfassen.

Die wechselvolle Geschichte der Nekromantie, wie sie uns in der Bibel entgegentritt, macht deutlich, da $\beta$ das Judentum zu keiner befriedigenden Lösung des Problems gekommen ist, das sich aus dem Nebeneinander von Toten und Lebenden in einer menschlichen Gemeinschaft ergibt. Die offizielle Ablehnung der Nekromantie und des Ahnenkultes, die zur Festigung des Monotheismus vonnöten war, wurde vom Judentum mit einer Tabuisierung des Verhältnisses zwischen den Toten und Lebenden erkauft. Der Hiatus konnte später durch die Verehrung der Märtyrer, die in Gottes Hand sind, und die Hoffnung auf Auferstehung ${ }^{123}$ wenigstens teilweise wieder überbrückt werden.

erfaßt, daß die Bilder vom Totenreiche, die Gestalten aus der Unter- und der Überwelt in Israels Gedankenleben eintrăten. Auch die Ablehnung alles dessen war eine Ablehnung des Heidentums und seines Bilderdienstes. Du sollst dir keine Vorstellung machen von alle dem, das lag in der Linie jenes Wortes aus den Zehngeboten." Im Vergleich hierzu begründet z.B. Rahner, Leben, 437, die Ablehnung eines spiritistischen Verkehrs mit den Toten mit deI Zeitlichkeit der noch Lebenden gegenüber den Toten, die bereits in der Ewigkeit sind.

123 Zum innerjüdischen Streit über die Auferstehung ( $q w m$ ) der Toten (Rephaîn) siehe Jes 26,14.19; Ps 88,11. 
Als eine Folgelast dieser Entwicklung sind auch die Auseinandersetzungen im Christentum über die Beziehungen der Lebenden zu den Toten anzusehen ${ }^{124}$, die besonders bei der Begegnung der europäischen Christenheit mit anderen Kulturen, die noch einen Ahnenkult kennen, akut werden. ${ }^{125}$

24 Siehe hierzu u.a. Rahner, Leben, 429-437.

${ }^{25}$ Siehe Anm. 5. 
Bibliographie

Avishur, Y., Stylistic Studies of Word-Pairs in Biblical and Ancient Semitic Literatures (AOAT 210), Kevelaer / Neukirchen-Vluyn 1984

Baeck, L., Das Wesen des Judentums, Berlin ${ }^{4} 1925$

Bayliss, M., The Cult of Dead Kin in Assyria and Babylonia, Iraq 35 (1973) 115-125

Bordreuil, P. / Pardee, D., Les textes en cunéiformes alphabétiques, in: $P$. Bordreuil, Une bibliotheque au sud de la ville. Les textes de la $34^{e}$ campagne (1973) (RSOu VII), Paris 1991, 139 172

Borengässer, N.M. / Bujo, B. / Malek, R, Ahnenkult I. Vorbemerkung, III. In Amerika, IV. In Afrika, V. In Ostasien, VI. Christentum und Ahnenkult, in: H. Waldenfels (Hg.), Lexikon der Religionen, Freiburg 1987, 14.15-19

Bottéro, J., Les morts et l'au-delà dans les rituels en accadien contre l'action des 'revenants', ZA 73 (1983) $153-203$

Brown, M.L., "I am the Lord your Healer." A Philological Study of the Root rapa' in the Hebrew Bible and the Ancient Near East, Ph.D. New York University, New York 1985

Caquot, A., Textes religieux, in: A. Caquot / J.-M. de Tarragon / J.-L. Cunchillos, Textes Ougaritiques II, Paris 1989, 7-123

Caquot, A. / Sznycer, M., Textes Ougaritiques I, Paris 1972

Cooper, A., MLK 'LM: "Eternal King" or "King of Eternity"?, in: J.H. Marks / R.M. Good (eds.), Love and Death in the Ancient Near East (FS M.H. Pope), Guilford/CT 1987, 3-5

Dahood, M., Ras Shamra Parallels I-III (AnOr 49/51), Rome 1972-1981

Del Olmo Lete, G., Mitos y leyendas de Ugarit, Madrid 1981

Dietrich, M. / Loretz, O., Neue Studien zu den Ritualtexten aus Ugarit (I), UF 13 (1981) 63-100

- $m t$ "Môt, Tod" und $m t$ "Krieger, Held" im Ugaritischen, UF 22 (1990) 57-65

- Mantik in Ugarit: Keilalphabetische Texte der Opferschau - Omensammlungen - Nekromantie. Mit Beiträgen von H.W. Duerbeck, J.-W. Meyer, W.C. Seitter (ALASP 3), Münster 1990

- Grabbeigaben für den verstorbenen Konig. Bemerkungen zur Neuausgabe von RS $34.126=$ KTU 1.161, UF 23 (1991) 103-106

- "Jahwe und seine Aschera". Anthropomorphes Kultbild in Mesopotamien, Ugarit und Israel. Das biblische Bilderverbot (UBL 9), Münster 1992

- / Loretz, O. / Mayer, W., Sikkanum "Betyle", UF 21 (1989) 133-139

Dietrich, W., David, Saul und die Propheten. Das Verhalttnis von Religion und Politik nach den prophetischen Überlieferungen vom frühesten Konnigtum in Israel, Stuttgart 1987

Dijkstra, M., Epigraphical Evidence for the Determination of the Column-Order in the Tablets KTU 1.1 and KTU 1.20-22, UF 19 (1987) 49-60

Ebach, J. / Rüterswörden, U., Unterweltsbeschwörung im Alten Testament, Teil I, UF 9 (1977) 57 70; Teil II, UF 12 (1980) 205-220

Fabry, H.-J., mrzh marzeah, ThWAT V (1986) 11-15

Finkel, I.L., Necromancy in Ancient Mesopotamia, AfO 29/30 (1983/84) 1-17

Fisher, L.R. u.a. (Hg.), Ras Shamra Parallels: The Texts from Ugarit and the Hebrew Bible I-III (AnOr 49/51), Rome 1972/81 
Gibsom, J.C.L, Canaanite Myths and Legends, Edinburgh 1978

Ginsberg, H.L., Ugaritic Myths, Epics, and Legends, in: J.B. Pritchard, ANET, ${ }^{3} 1969$, 129-155

Hallo, W.W., Royal Ancestor Worship in the Biblical World, in: M. Fishbane / E. Tov (ed.), Sha'arei Talmon (FS Sh. Talmon), Winona Lake/IN 1992, 381-401

Healey, J.F., Ugarit and Arabia: a balance sheet, Proceedings of the Twenty Fourth Seminar for Arabian Studies held at Oxford on 24th - 26th July 1990, London 1991, 69-78

Hoffner, HA., Second Millennium Antecedents to the Hebrew 'wb, JBL 86 (1967) 385-401

- 'wb, ThWAT I (1973) 141-145

Hossfeld, F.-L. / Kalthoff, B., Ahnenkult II. Im biblischen Umfeld, in: $H$. Waldenfels (Hg.), Lexikon der Religionen, Freiburg 1987, 14-15

Hutter, M., Religionsgeschichtliche Erwägungen zu 'lhjm in 1 Sam 28,13, BN 21 (1983) 32-35

Kuemmerlin-McLean, J.K, Art. Magic - Old Testament, The Anchor Bible Dictionary IV (1992) 468-471

Laroche, E., Glossaire de la langue hourrite, Paris 1980

Levine, BA. / Tarragon, J.-M. de, Dead Kings and Rephaim: The Patrons of the Ugaritic Dynasty, JAOS 104 (1984) 649-659

Lewis, T.J., Cults of the Dead in Ancient Israel and Ugarit (HSM 39), Atlanta/GA 1989

- Art. Ancestor Worship, The Anchor Bible Dictionary I (1992) 240-242

Loretz, O., Der ugaritische Topos $b^{\prime} / r k b$ und die "Sprache Kanaans" in Jes 19,1-25, UF 19 (1987) 101-112

- $\rightarrow$ Dietrich, $M$.

Malek, $R$, Ahnenverehrung (I. Allgemein), in: $K$ Muller / T. Sundermeier, Lexikon missionstheologischer Grundbegriffe, Berlin 1987, 19-22

Margalit, B., The Ugaritic Poem of Aqht (BZAW 182), Berlin / New York 1989

McCarter, P.K, I Samuel (AB 8), Garden City/NY 1980

McGinnis, A Neo-Assyrian Text Describing a Royal Funeral, SAAB I (1987) 1-12, plate I

Moor, J.C. de, An Incantation Against Evil Sprits (Ras Ibn Hani 78/20), UF 12 (1980) 429-432

- The Ancestral Cult in KTU 1.17:I.26-28, UF 17 (1986) 407-409

- An Anthology of Religious Texts from Ugarit, Leiden 1987

- The Rise of Yahwism: The Roots of Israelite Monotheism (BETL 91), Leuven 1990

Niehr, $H$., Ein unerkannter Text zur Nekromantie in Israel: Bemerkungen zum religionsgeschichtlichen Hintergrund von 2 Sam 12,16a, UF 23 (1991) 301-306

Pardee, D., Les textes para-mythologiques de la $24^{e}$ campagne (1961) (RSOu 4), Paris 1988

Podella, T., Șom-Fasten. Kollektive Trauer um den verborgenen Gott im Alten Testament (AOAT 224), Kevelaer / Neukirchen-Vluyn 1989

Pohl, W., Die katholischen Missionen 109,2 (1990) 56

Rahner, $K$, Das Leben der Toten. Schriften zur Theologie IV, Einsiedeln 1960

Rehm, M., Die Bücher Samuel. Echter Bibel, Würzburg 1949

Renfroe, Arabic and Ugaritic Lexicography, Ph.D. Yale University 1989

Schlögl, N., Die Bücher Samuels, Wien 1904

Scurlock, JA., Magical Means of Dealing with Ghosts in Ancient Mesopotamia. Ph.D. Dissertation, University of Chicago, Chicago 1988

- Art. Magic - Ancient Near East, The Anchor Bible Dictionary IV (1992) 464-468 
Skeham, P.W. / Di Lella, A.A., The Wisdom of Ben Sira (AB 39), Garden City/NY 1987

Spronk, $K$, Beatific Afterlife in Ancient Israel and in the Ancient Near East (AOAT 219), Kevelaer / Neukrichen-Vluyn 1986

- De wijn als troost in leven en in sterven. Enkele gedachten over de wijn en de Marzeach in Syrie en Palestina, Phoenix 31,1 (1991) 40-54

Talmon, Sh, repä'îm and Ugaritic rpu/i(m), Hebrew Annual Review 7 (1983) 235-249

Tischler, J., Hethitisches etymologisches Glossar I, Innsbruck 1983

Tropper, J., Nekromantie. Totenbefragung im Alten Orient und im Alten Testament (AOAT 223), Kevelaer / Neukirchen-Vluyn 1989

van der Toom, $K$, Funerary Rituals and Beatific Afterlife in Ugaritic Texts and in the Bible, BiOr 48 (1991) 40-66

- The Nature of the Biblical Teraphim in the Light of the Cuneiform Evidence, CBQ 52 (1990) 203-222

van Soldt, W.H., Studies in the Akkadian of Ugarit: Dating and Grammar (AOAT 40), Kevelaer / Neukirchen-Vluyn 1991

Vieyra, M., Istar de Ninive, RA 51 (1957) 83-102

- Les noms du "mundus" en hittite et en assyrien et la pythonisse d'Endor, RHA 19 (1961) 47 55

Würthwein, E., Die Bücher der Könige 1. Kơn. 17 - 2. Kön. 25 (ATD 11/2), Gơttingen 1984 
Tempel- und Palastbauten im eisenzeitlichen Palästina und ihre bronzezeitlichen Vorbilder

Die Landnahme durch die Israeliten in den Ebenen Palästinas setzt nach Beendigung der Wirren ein, die durch das Eindringen der sogenannten "Seevölker" entstanden sind". Das dadurch bedingte Ende der kanaanitischen Stadtstaaten führt gegen Ende des 2. Jts. v. Chr. zunächst zur Bildung von drei politischen Einheiten im Gebiet Palästinas: im Süden die Ägypter mit Garnisonen bis nach Megiddo, an der Küste die Philister und im zentralen Bereich eine zu Beginn nur sporadische Besiedlung der Täler durch die aus den Bergen kommenden israelitischen Stämme ${ }^{2}$. Diese ersten, unbefestigten Siedlungen (z.B. Tel Masos ${ }^{3}$, Tell Abu Hawam ${ }^{4}$ ) weisen noch dörflichen Charakter auf; erst nach dem Ende der Vorherrschaft der Philister und dem Rückzug der Ägypter kommt es zu einer Konsolidierung der einzelnen Gruppen und mit Gründung des Vereinigten Königreiches unter David zur Entstehung einer Zentralmacht. Von diesem Zeitpunkt an und verstärkt unter Salomo lassen sich, entweder auf den Ruinen der alten kanaanitischen Siedlungen, oder als Neugründungen, erste städtische Zentren nachweisen.

Auffällig ist die einheitliche Struktur dieser Stadtanlagen ${ }^{5}$; sie bestehen aus einer aufwendigen Befestigungsanlage, an die sich unmittelbar eine Häuserzeile der Bebauung durch Privatbauten anschließt. Durch eine Strasse werden diese Bauten von der eigentlichen Innenstadt getrennt, in deren Zentrum sich auch die öffentlichen Bauten befunden haben. Die äußeren Befestigungsanlagen der königlichen Residenzen, wie z.B. in Hazor, Megiddo und Samaria bestehen ebenso aus Kasemattenmauern, wie die Umfassung der im Zentrum gelegenen Zitadellen ${ }^{6}$. In den kleineren Städten, z. B. in Tell Beit Mirsim, Beth Shemesh, Beer-sheba wird ein vergleichbares Bauprinzip dadurch erreicht, daß die Vorratsräume der Privatbauten bis unmittelbar an die Stadtmauer heranreichen

\section{Dazu bereits $A$. $A l t$, Landnahme, 1-35; ders., Erwägungen.}

2 Eine Zusammenfassung der historischen Ereignisse findet sich u.a. bei $B$. Mazar, Philistines; T. Dothan, Philistines, 1-24, mit weiterer Literatur.

3 Schicht 2; A. Kempinski / V. Fritz, Excavations, 136-158.

4 Schicht 4; R.W. Hamilton, Excavations.

5 Vgl. Y. Shiloh, Elements, 36-51; Z. Herzog, Israelite City Planning, auf die von Herzog getroffene Unterscheidung von vier Siedlungstypen mit unterschiedlicher funktionaler Bedeutung kann an dieser Stelle nur hingewiesen werden.

6 Zu den hier erwăhnten Staddten zusammenfassend, Y. Yadin, Hazor, 140.150-170; vgl. ders., Megiddo, 66-96; allgemein zur Verwendung von Kasemattenmauern als Befestigung von kơniglichen Residenzen, Stådten, Dorfern und Grenzposten: N.L. Lapp, Casemate Walls. 
und so in das Fortifikationssystem mit einbezogen werden ${ }^{7}$. Der Bautyp der Kasemattenmauer ist nicht auf ältere kanaanitische Vorbilder zurückzuführen ${ }^{8}$, findet sich aber in Zentren der späthethitischen Staaten, z.B. in Sam'al und Karkemisch': diese Bauweise geht dort vermutlich auf hethitische Tradition zurück (Boğazköy, Alishar) ${ }^{10}$. Für eine Einbeziehung der Privatbauten in die Stadtbefestigung läßt sich bereits aus dem 3. Jts. v. Chr. ein Beispiel aus Nordostsyrien anführen (Halawa) ${ }^{11}$, jüngere Vergleiche fehlen allerdings bisher.

Zusammen mit den Stadtmauern entstehen seit der salomonischen Zeit aufwendige Torkonstruktionen, die aus einem inneren Hauptor und einem Außentor gebildet werden (z.B. Megiddo, Hazor, Gezer) ${ }^{12}$; beide Torbauten sind durch einen Hof miteinander verbunden. Das Innere des Haupttores besteht, wie die Zugänge zu den Zitadellen, aus drei Torkammern. Während diese Bauform möglicherweise eine Weiterentwicklung des syrisch-palästinensischen Torbaus aus dem 2. Jts. v. Chr. darstellt (u.a. Qatna, Alalakh) ${ }^{13}$, lassen sich für die Gesamtkonzeption (innere und äußere Toranlage) aus Palästina keine Vorbilder anführen; große Ähnlichkeiten weist aber das mittelbronzezeitlich zu datierende Südwesttor von Tell Mardikh, Schicht IIIA ${ }^{14}$ auf. Obwohl Beispiele für diesen Bautyp aus der Späten Bronzezeit bisher fehlen, spricht vieles für die Annahme, daß mit den oben erwähnten israelitischen und den vergleichbaren späthethitischen Toranlagen (Sam'al, Karkemisch) ${ }^{15}$ diese Bautradition fortgesetzt oder wieder aufgenommen wurde.

7 Dazu B. W.F. Albright, Excavation, 12-14.39-54; Taf.3; E. Grant, Ain Shems Excavations, Plan; E. Grant / G.E. Wright, Ain Shems Excavations V, 23-26, Abb. 1; Y. Aharoni, Excavations, Abb. 1.

8 Vgl. jedoch Beer-sheba, Schicht VII (11. Jhd. v. Chr.) ebenfalls Kasemattenmauer (in: $Z$. Herzog, Tel Beer-sheba, 169), wahrend Schicht V eine solide Mauer besaß (Y. Aharoni, Beersheba I, 157).

$9 \quad$ R. Koldewey, Ausgrabungen, 133; C.L. Woolley, Carchemish, Taf. 6.7.14.

$10 R$ Naumann, Architektur Kleinasiens, 288-289; $P$. Neve, Büyükkale.

11 J.-W. Meyer, Grabungen.

12 Y. Yadin, Hazor, 140-155 (s. Anm. 6); ders., Solomon's City Wall, 80-86. W.G. Dever et al., Further Excavations, 112-120; ders., Solomonic and Assyrian Period "Palaces", zusammenfassend $Z$. Herzog, Stadttor.

13 Dazu B. Gregori, "Three-Entrance", mit weiterer Literatur; eine vergleichbare Anlage findet sich auch schon im 3. Jts. v. Chr. in Halawa/Syrien, s. J.-W. Meyer, Grabungen, 35-39.

14 Schicht IIIA1; P. Matthiae, Ebla, 123-127, Abb. 24.

15 R. Koldewey, Ausgrabungen, Abb. 23, Taf. 10; C.L. Woolley, Carchemish, Taf. 1; vgl. $R$. Naumann, Architektur Kleinasiens, 250-280. 
Die Konzeption einer Akropolis (wie z.B. in Megiddo, Hazor, Gezer) mit Kasemattenmauer, Torbauten, Palastanlagen und weiteren öffentlichen Bauten $^{16}$, die, mit unterschiedlicher Ausrichtung der Fassadenachsen, um einen großen offenen Platz angeordnet sind, gleicht einem Bauschema, das im 1. Jts. v. Chr. in Nordsyrien häufig belegt (z.B. Hama, Sam'al) ${ }^{17}$ und vermutlich von hethitischen Vorbildern der Großreichszeit abgeleitet ist (Boğazköy ${ }^{18}$ ). Auch die Trennung der Wohn- und Amtsbereiche innerhalb der Zitadelle und ihre Verteilung auf verschiedene Bauten findet sich bereits in Boğazköy; diese Bauweise steht im Gegensatz zu der mesopotamischen Tradition, die einen einheitlichen Palastkomplex bevorzugte (neben den assyr. Palästen z.B. auch in Tell Halaf).

Die Grundrißkonzeption der israelitischen Paläste (u.a in Megiddo, Hazor und Samaria) ${ }^{19}$ weist große Übereinstimmung mit den Hilani-Bauten ${ }^{20}$, und damit ebenfalls mit westlichen Vorbildern auf; charakteristisches Bauelement ist eine Säulenstellung im Eingang (vgl. 1Kön 7,1-12). Die bisher ältesten Belege stammen bereits aus den spätbronzezeitlichen Palastanlagen in Alalakh und in Ugarit. Da die Errichtung dieser Bauten zeitlich vor den Feldzügen der Hethiter nach Nordsyrien anzusetzen ist, kann in der Pfeilervorhalle der hethitischen Tempel (hilammar) und Torbauten möglicherweise nordsyrischer Einfluß gesehen werden. Im 1. Jts. v. Chr. wird diese Bauform für die Architektur der aramäisch-späthethitischen Paläste vorherrschend (u.a. Sam'al, Tell Halaf, Hama, Tell Tayinat) ${ }^{21}$; darüber hinaus wurden in den vergangenen Jahren in den nordsyrischen Grabungsstätten Tell Sheikh Hamad ${ }^{22}$ und Tell Sheikh Hassan ${ }^{23}$ lokale Residenzen freigelegt, deren Grundriß ebenfalls diese Bauform aufweist. Bei diesen Anlagen kann es sich um Gründungen der Assyrer handeln, bei denen die Verwendung dieser Bauweise seit Tiglatpilesar III. (745-727 v. Chr.) durch Texte belegt ist ("wie ein bit hilani nach der Art eines hethitischen Palastes" ${ }^{124}$ ).

16 Y. Yadin, Hazor, 150-165; W.G. Dever, Gezer I, 61-63; ders., Gezer II, Jerusalem 1974, 59-60.

17 E. Fugmann, Hama, 150-269, Abb. 185.244; R. Koldewey, Ausgrabungen, 103-160.

18 R. Naumann, Architektur Kleinasiens, 347-350; P. Neve, Büyükalle, 92-106.

19 D. Ussishkin, King Salomon's Palace, 174-186.

20 Dazu u.a. H. Frankfort, Origin, 120-131; vgl. zuletzt, J. Margueron, Un «Hilani», 153-176 mit weiterer Literatur und Belegen.

21 Dazu R. Naumann, Architektur Kleinasiens, 345-378 (s. Anm. 10); J. Margueron, Un «Hilani», Abb. 9-12 (s. Anm. 20).

22 H. Kühne, Tall Seh-Hamad/Dur-katlimmu, Abb. 53.

23 J. Boese, Excavations, 70-71.

24 H.Winkler / L. Abel, Keilschrifttexte, Z. 423-424. 
Eine Diskussion der frühen israelitischen Tempelformen und der Versuch, sie in eine der orientalischen Bautraditionen einzuordnen, ist problematisch, da aus diesem Zeitraum bisher nur relativ wenig Sakralbauten freigelegt worden $\operatorname{sind}^{25}$. Die beiden Tempel aus der ältesten eisenzeitlichen Bauschicht auf der Akropolis von Beth Shan ${ }^{26}$ sind als Langraumtempel mit einer breit gelagerten Zella anzusehen; sie weisen bereits die für die gesamte Eisenzeit in Israel typische Ost-West-Orientierung auf. Die dem Dagan und der Astarte (dazu: 1 Chr 10,10, 1 Sam 31,10) geweihten Anlagen wurden aber bereits während der Philisterzeit errichtet und im Verlaufe der Eroberung der Stadt durch David (1 Kön 4,12) zerstört, so daß sie nicht als Beispiel für den frühen israelitischen Tempelbau dienen können.

Aus Tell Qasile ist ein weiterer Sakralbau bekannt, dessen Grundriß ein Knickachs-Schema aufweist ${ }^{27}$. Diese aus Assyrien bekannte Bauweise findet sich in Palästina nur in Nahariya (Tempel B) ${ }^{28}$ gegen Ende der Mittleren Bronzezeit (nach Osten orientiert) und in Lachish, im Fosse Tempel A (nach Norden orientiert) ${ }^{29}$ zu Beginn der Späten Bronzezeit. Eine bewußte Rückkehr zu dieser Bauform in früh-israelitischer Zeit ist aber nicht anzunehmen, da die Form dieser Anlage wiederum auf einen Tempel aus der Philisterzeit (Schicht X-XII) zurückgeht; außerdem läßt die Errichtung innerhalb eines Wohnviertels vermuten, daß die Position des Eingangs durch bereits bestehende Bauten vorgeschrieben wurde. Das Gleiche gilt auch für eine möglicherweise als Tempel zu interpretiende Anlage in Ashdod (8. Jhd.v.Chr.) ${ }^{30}$, deren Grundriß keiner bekannten Tempelform entspricht.

Von Bedeutung für die Entwicklung der israelitischen Sakralarchitektur ist eine Tempelanlage in Arad, deren Gründung allerdings umstritten ist ${ }^{31}$. Der Grundri $\beta$ zeigt einen nahezu quadratischen Vorhof, der von Osten zu betreten ist; nach Westen schließt sich eine Breitraumzella mit einer Kultnische (Adyton) an. Im Hof wurde ein kleiner quadratischer Altar freigelegt, der, entsprechend den biblischen Vorschriften, aus unbearbeiteten Steinen (Ex 20,25) errichtet war und dessen Ausmaße von etwa $2,5 \mathrm{~m}$ Seitenlänge ( $=5$ Ellen) mit denen des Tabernakel-Aitars (Ex 27,1) und vermutlich auch mit denen des

Vgl. V. Friz, Tempel und Zelt; ders., Tempel Salomos, 53-68; M. Ottosson, Temples, 107-118.

Schicht V; F.W. James, Iron Age, Abb. 74; M. Ottosson, Temples, 22-24.

Schicht IX; A. Mazar, Temples; vgl. ders., Philistine Temple, 42-48; ders., Excavations, 77-88.

28 I. Ben-Dor, Temple, 1-41; M. Dothan, Excavations, 14-25.

29 O. Tufnell, Lachish II, Taf. 68; M. Ottosson, Temples, 87-92.

30 Schicht VIII; M. Dothan, Ashdod II-III, 86-89, Plan 8.

31 Y. Aharoni, Excavations, 233-249; Z. Herzog et al., Israelite Fortress, 1-34.
} 
Altars im Tempel von Jerusalem (2 Chr. 6,13) übereinstimmen. Nach neueren stratigraphischen Untersuchungen kann weder die Annahme der Errichtung dieser Anlage im 10. Jhd. v.Chr. noch die der Zerstörung im Verlauf der durchgreifenden Kultreform unter Josia (621 v. Chr.) aufrecht gehalten werden; vielmehr muß von einer relativ kurzen Benutzungsdauer während der Schicht VI vom Ende des 7. Jhd. v.Chr. bis zum Anfang des 6. Jhd. v.Chr. ausgegangen werden ${ }^{32}$.

Diesen Befunden nach zu urteilen hat es offenbar für den frühen israelitischen Tempelbau, wie auch im syrisch-kanaanäischen Gebiet, keine verbindliche Form gegeben. Nur in der strengen Ost-West-Orientierung unterscheiden sich die israelitischen Sakralbauten von denen ihrer Umwelt. Auch der Tempel in Jerusalem ${ }^{33}$ war nach Westen ausgerichtet; der schriftlichen Überlieferung zufolge, kann es sich bei diesem Bau nur um einen Langraum-Tempel mit Säulenvorhalle gehandelt haben, vermutlich einen Antentempel (nach 1 Kön 6). Für diese Tempelform gibt es allerdings in Palästina selbst keine direkten Vorläufer ${ }^{34}$ : nur der kleine, mittelbronzezeitlich zu datierende Langraumtempel mit Vorhalle und Säulenstellung auf dem Tell Musa in Jordanien ${ }^{35}$ weist ein vergleichbares Grundrißschema auf, doch fehlt auch hier die Unterteilung der Zella. Dagegen finden sich in Nordsyrien zahlreiche Beispiele für den Antentempel ${ }^{36}$; dort tritt diese Bauform erstmals mit den Tempeln von Tell Chuera auf und läßt sich bis in das 1 . Jts. v. Chr. belegen (Tell Tayinat). Eine Säulenstellung zwischen den vorgezogenen Anten findet sich erstmals in einem der beiden Antentempel von Mumbaqat aus der Späten Bronzezeit. Doch auch in Nordsyrien ist diese Tempelform nie ausschließlich verwendet worden; so

32 D. Ussishkin, Date, 142-157.

33 Dazu zusammenfassend: ThA. Busink, Tempel; vgl. auch die verschiedenen Arbeiten von V. Fritz.

34 Zwar laßt sich im Verlauf des 2. Jts. v. Chr. ein Vordringen des Langraumtempels nachweisen, z.B. in Hazor (Y. Yadin, Hazor, 102-104), Sichem (G.E. Wright, Biography, 80-102), Megiddo (G. Loud, Megiddo II., 102-105; weiterhin: C. Epstein, Interpretation, 204-221; I. Dunayevsky /A. Kempinski, Megiddo Temples, 161-187), doch handelt es sich dabei nicht um die Form des Antentempels. Ein weiterer Unterschied besteht darin, daß diese Langraumtempel keine Unterteilung der Zella aufweisen.

35 E. Eisenberg, Temples, 77-81.

Schon A. Alt, Verbreitung, 100-105 hat auf die Parallelen zwischen dem salomonischen Tempel und syrischen Anlagen hingewiesen; vgl. ferner $A$. Kuschke, Tempel 124-132. Eine Zusammenstellung der entsprechenden Tempelbauten findet sich bei $V$. Fritz, Tempel Salomos, 53-68; hinzuzufügen ist der Antentempel in Halawa/Syrien aus dem 3. Jts. v. Chr., $W$. Orthmann, Halawa, Beilage 10. 
haben während der Eisenzeit u.a. in Karkemisch ${ }^{37}$ und 'Ain Dara ${ }^{38}$ einräumige Anlagen bestanden, deren Grundriß sich aus dem Hilani ableiten läßt.

Die Sonderstellung, die der Tempel in Jerusalem als Nationalheiligtum zweifellos eingenommen hat, wird auch an der räumlichen Nähe zum Palast, d.h. zur staatlichen Macht deutlich. In keinem der anderen königlichen Zentren (Hazor, Megiddo, Samaria) konnte eine so enge bauliche Verbindung zwischen Palast und Tempel nachgewiesen werden. Im kanaanitischen Palästina wurde dieses Baukonzept bereits zu Beginn der Spätbronzezeit aufgegeben ${ }^{39}$. Auch im 1. Jts. v. Chr. läßt sich läßt sich eine derartige Konzeption nur für einen Teil der späthethisch-aramäischen Fürstensitze belegen: während die architektonischen Befunde in Hama, Sam'al und wohl auch in 'Ain Dara gegen diese Lösung sprechen, erscheint sie z.B. in Karkemisch und Tell Halaf wahrscheinlich. Die wohl beste Parallele zu dem vermuteten Baukomplex in Jerusalem findet sich in Tell Tayinat, wo ein Komplex freigelegt wurde ${ }^{40}$, der ebenfalls aus einem Palast vom Hilani-Typ und einem Antentempel besteht.

Schließlich muß noch kurz auf die Form der israelitischen Wohnhäuser eingegangen werden; bereits in den ersten Siedlungen lassen sich zwei Grundrißtypen belegen, die beide kennzeichnend für die spätere Privatarchitektur werden sollen: das Vier-Raum-Haus ${ }^{41}$ (u.a. in Hazor, Tell Beit Mirsim, Jericho, Sichem), und ein als Lagerhaus interpretierter Pfeilerbau ${ }^{42}$ (u.a. in Tell Qasile, Tell Abu Hawam, Beth Shemesh, Hazor). Beide Bauformen finden sich jedoch, trotz der insgesamt geringen Anzahl ausgegrabener Siedlungen, auch im nordsyrischen Gebiet (z.B. Chatal Hüyük, Tell Tayinat, Hama). Aufgrund des Bauschemas sowie aufgrund der Position des Einganges wurde von bereits $\mathrm{J}$. Margueron $^{43}$ auf die Ähnlichkeit dieser Anlagen zu den spätbronzezeitlichen Privatbauten in Anatolien und Nordsyrien (u.a. Emar) hingewiesen.

Bereits aus diesem kurzen Überblick geht hervor, daß die Baukonzeptionen und Bauformen im eisenzeitlichen Israel nicht, oder nur in geringem Maße, den kanaanitischen Traditionen des 2. Jts. v. Chr. folgen. Allein die Grundrißgestaltung der privaten Wohnhäuser beruht offensichtlich auf einer eigenständig

37 C.L. Woolley / R.D. Barnett, Carchemish III, 157-160.

38 F. Seirafi / A. Kirichian / M. Dunand, Recherches, 3-20.

39 So z.B. in Hazor, Schicht 1B, in Megiddo, Schicht IX, in Alalakh, Schicht IV.

40 R.C. Haines, Excavations, 53-55; Taf. 103.

$41 Y$. Shiloh, Four-Room House, 182-190; F. Braemer, Architecture.

42 V. Fritz, Bestimmung, 30-45.

43 J. Margueron, Architecture, 35-36. 
israelitischen Entwicklung, die bereits im 11. Jhd. v. Chr. eingesetzt hat ${ }^{44}$. Dagegen weisen die öffentlichen Anlagen - Tempel, Palast, Stadtmauern vielfach Parallelen zur syrisch-aramäischen Architektur des 1. Jts. v. Chr. auf. Nur durch eine umfassende Untersuchung der in beiden Gebieten verwendeten Bauformen wird es möglich sein, die, eventuell sogar historisch bedingten Verbindungen zwischen beiden Bereichen zu verdeutlichen.

44 Vgl. Y. Shiloh, The Four-Room House, 182-190; ahnlich schon R. Amiran / I. Dunayevsky, Assyrian Open Court Buildings, 25-38; zuletzt $F$. Braemer, L'Architecture. 
Bibliographie

Aharoni, Y., Excavations at Tell Arad. Preliminary Report on the Second Season 1963, IEJ 17 (1967) 233-249

- Beer-Sheba I, Tel-Aviv 1973

- Excavations at Tell Beer-sheba. Preliminary Report of the Fifth and Sixth Seasons, 1973-1974, Tel Aviv 2 (1975) 146-168

Albright, B.W.F., The Excavation of Tell Beit Mirsim, III. The Iron Age, AASOR 21-22 (1941-43)

$A l t, A$., Die Landnahme der Israeliten in Palastina. Reformationsprogramm der Universitat Leipzig, 1925, 1-35

- Erwagungen über die Landnahme der Israeliten in Palastina, PJB 35 (1939) 8-63

- Verbreitung und Herkunft des syrischen Tempeltyps, [in: Kleine Schriften zur Geschichte des Volkes Israel II], München 1953, 100-115

Amiran, R. / Dunayevsky, I., The Assyrian Open Court Buildings and its Palestinian Derivates, BASOR 149 (1958) 25-38

Ben-Dor, I., A Middle Bronze-Age Temple at Nahariyah, QDAP 14 (1950) 1-41

Boese, J., Excavations at Tell Sheikh Hassan. Preliminary Report on the 1987 Campaign in the Euphrates Valley, AAS 36/37 (1986/87), 67-101

Braemer, F., L'Architecture Domestique du Levant a l'Age du Fer (ERC 8), Paris 1982

Busink, ThA., Der Tempel von Jerusalem von Salomo bis Herodes. Eine archăologische Studie unter Berücksichtigung des westsemitischen Tempelbaus, I. Der Tempel Salomos, Leiden 1970

Dever, W.G. et al., Gezer I. Preliminary Report of the 1964-1966 Season, Jerusalem 1970

- Further Excavations at Gezer, 1967-1971, BA 34 (1971) 112-120

- Gezer II: Report of the 1967-1970 Seasons in Field I and II, Jerusalem 1974

- Solomonic and Assyrian Period "Palaces" at Gezer, IEJ 35 (1985) 217-230

Dothan, M., The Excavations at Nahariyah 1954-1955. Preliminary Report, IEJ 6 (1956) 14-25

- Ashdod II-III, The Second and Third Seasons of Excavations 1963, 1965, 'Atiqot 9-10, Jerusalem 1971

Dothan, T., The Philistines and their Material Culture, Jerusalem 1982

Dunand, $M . \rightarrow$ Seirafi, $F$.

Dunayevsky, I. / Kempinski, A., The Megiddo Temples, ZDPV 89 (1973) 161-187

Eisenberg, E., The Temples at Tell Kittan, BA 40 (1977) 77-81

Epstein, $C$., An Interpretation of the Megiddo Sacred Area during the Middle Bronze Age II, IEJ 15 (1965) 204-221

Frankfort, $H$., The Origin of the Bit Hilani, Iraq 14 (1952) 120-131

Fritz, V., Tempel und Zelt. Studien zum Tempelbau in Israel und zu dem Zeltheiligtum der Priesterschaft (WMANT 47), Neukirchen-Vluyn 1977

- Bestimmung und Herkunft des Pfeilerhauses in Israel, ZDPV 93 (1977) 39-45

- Der Tempel Salomos im Licht der neueren Forschung, MDOG 112 (1980) 53-68

- $\rightarrow$ Kempinski, $A$.

Fugmann, E., Hama. Fouilles et Recherches de la Fondation Carlsberg 1931-1933, II,1: L'architecture des périodes pré-hellénistiques, Kopenhagen 1974 
Grant, E., Ain Shems Excavations I-II (Biblical and Kindres Studies 3-4), Haverford 1931/32

- / Wright, G.E., Ain Shems Excavations V, (Biblical and Kindres Studies 8), Haverford 1939 Gregori B., "Three-Entrance" City-Gates of the Middle Bronze Age in Syria and Palestine, Levant 18 (1986) 83-102

Haines, RC., Excavations in the Plain of Antioch, II. The Structural Remains of the Later Phases, OIP 45, Chicago 1971

Hamilton, $R . W$., Excavations at Tell Abu Hawam, QDAP 4 (1935) 1-69

Herzog, Z., Tel Beer-sheba, 1976, IEJ 27 (1977) 168-170

- Israelite City Planning, Expedition 20 (1978) 38-43

- The Israelite Fortress at Arad, BASOR 254 (1984) 1-34

- Das Stadttor in Israel und in den Nachbarlandern, Mainz 1986

James, F.W., The Iron Age at Beth-Shan, Philadelphia 1966

Kempinski, A. / Fritz, V., Excavations at Tel Masos (Khirbet el-Meshash) Preliminary Report of the Third Season, Tel Aviv 4 (1977) 136-158

- $\rightarrow$ Dunayevski, $I$.

Kirichian, $A$. $\rightarrow$ Seirafi, $F$.

Koldewey, $R$, Ausgrabungen in Sendschirli II, Berlin 1898

Kühne, H., Tall Seh-Hamad/Dur-katlimmu 1981-1983, AfO 31 (1984) 166-170

Kuschke, A., Der Tempel Salomos und der "syrische Tempeltypus" (BZAW 105), Berlin / New York 1967, 124-132

Lapp, N.L., Casemate Walls in Palestine and the Late Iron Age II. Casemate at Tell el-Ful (Gibeah), BASOR 223 (1976) 25-42

Loud, G., Megiddo II. Seasons of 1935-39 (OIP 62), Chicago 1948

Margueron, J., Un «Hilani» à Emar, AASOR 44 (1979) 153-176

- Architectur et Urbanisme, in: D. Beyer (éd.), Meskéné - Emar. Dix Ans de Traveaux 19721982, Paris 1982

Matthiae, P., Ebla. Un impero ritrovato, Turin 1977

Mazar, B., The Philistines and the Rise of Israel and Tyre (Proceedings, Israel Academy of Sciences and Humanities 1,7), Jerusalem 1964, 1-22

- A Philistine Temple at Tell Qasile, BA 36 (1973) 42-48

- The Excavations at Tell Qasile 1973-74. Preliminary Report, IEJ 25 (1975) 77-88

- The Temples of Tell Qasile. The Excavations and their Implications for the Study of the Cult and Material Culture in Eretz-Israel During the 12th-10th Century B.C.E., Jerusalem 1977 (hebr.)

Meyer, J.-W., Die Grabungen im Bereich der Stadtbefestigung, in: W. Orthmann, Halawa 19801986 (SBA 52), 1989, 11-18

Naumann, R., Architektur Kleinasiens, Tübingen 1955

Neve, $P$., BogazkOy-Hattusha. Ergebnisse der Ausgrabungen XII. Büyükkale. Die Bauwerke. Grabungen 1954-1966, Berlin 1982

Orthmann, W., Halawa 1980-1986 (SBA 52), 1989

Ottosson, M., Temples and Cult Places in Palestine, Uppsala 1980 
Seirafi, F. / Kirichian, A. / Dunand, M., Recherches archéologiques à Ayin Dara au Nord-Ouest d'Alep, AAS 15 (1965) 3-20

Shiloh, Y., The Four-Room House. Its Situation and Function in the Israelite City, IEJ 20 (1970) $182-190$

- Elements in the Development of Town Planning in the Israelite City, IEJ 28 (1978) 36-51

Tufnell, O., Lachish (Tel ed-Duweir) II. The Fosse Temple, London 1940

Ussishkin, D., King Salomon's Palace and Building 1723 in Megiddo, IEJ 16 (1966) 174-186

- The Date of the Judean Shrine at Arad, IEJ 38 (1988) 142-157

Winkler, H. / Abel, L, Die Keilschrifttexte Sargons, Leipzig 1898

Woolley, C.L., Carchemish. Report on the Excavations at Djerablis. II. The Town Defences, London 1921

- /Barnett, R.D., Carchemish. Report on the Excavations at Djerablis. III The Excavations in the Inner Town, London 1952

Wright, G.E., Shechem. The Biography of a Biblical City, New York / Toronto 1965

Yadin, Y., Solomon's City Wall and Gate at Gezer, IEJ 8 (1958) 80-86

- Megiddo of the Kings of Israel, BA 33 (1970) 66-96

- Hazor - The Head of all those Kingdoms. The Schweich Lectures of the British Academy, London 1972 


\section{Erich Neu}

\section{Knechtschaft und Freiheit}

Betrachtungen über ein hurritisch-hethitisches Textensemble aus Hattuša

1. Die Ausgrabungen des Deutschen Archäologischen Instituts unter Leitung von Peter Neve förderten im Jahr 1983 in der Oberstadt von Hattuša, der Hauptstadt des Hethiterreiches (ca. $150 \mathrm{~km}$ östlich von Ankara bei dem türkischen Dorf Boğazkale, vormals Boğazköy, gelegen), eine über mehrere große Tontafeln verteilte hurritisch-hethitische Bilingue zu Tage ${ }^{1}$, die möglicherweise in einer Tempelbibliothek aufbewahrt war ${ }^{2}$. Eine Nachgrabung im Spätsommer 1985 erbrachte noch einige kleinere Textfragmente. Die von $\mathrm{H}$. Otten und $\mathrm{C}$. Rüster nach den Originalen angefertigten Autographien der Bilingue sind in KBo XXXII (1990) enthalten; dieser Editionsband informiert auch über die Fundlage der einzelnen Tafeln und Fragmente. Die hurritische Fassung steht in der Regel jeweils auf den linken Tafelkolumnen, diesen rechts gegenüber ist die hethitische Übersetzung niedergeschrieben ${ }^{3}$. Nur ein einziges Mal wich ein Schreiber von dieser Textverteilung ab und schrieb den hurritischen und hethitischen Text über die volle Tafelbreite, indem er einem hurritischen Sinnabschnitt unmittelbar die hethitische Übersetzung folgen ließ (KBo XXXII 14 Rs. 23ff).

2. Paläographische Kriterien erweisen das zweisprachige Textensemble als eine Niederschrift aus der mittelhethitischen Schriftperiode, womit die Zeit der unmittelbaren Vorgänger Suppiluliumas I. gemeint ist, sagen wir grob um 1400 v. Chr. Bestimmte hethitisch-sprachliche Phänomene bestätigen diesen Datierungsbefund ${ }^{4}$, so da $\beta$ wir genauer von einer hurritisch-mittelhethitischen Bilingue sprechen dürfen. Die hurritische Sprachform zeigt einige Charakteristika, die in der Sekundärliteratur bislang als "althurritisch" galten 5 . So ergeben sich sprachliche Beziehungen einmal zu der bekannten frühen Gründungsinschrift für einen Tempel in der Stadt Urkeš ${ }^{6}$, andererseits auch zu den hurritischen Texten aus Mari bzw. des nordöstlichen Babylonien (18.-16. Jh. v. Chr.). Daher

1 Vgl. den diesbezüglichen Grabungsbericht von Neve (mit einem Beitrag von Otten) in AA 1984, 329-381; Otten, Textfunde, 114ff.

2 Vgl. Otten, Blick, 59.

3 Vgl. die Abbildung (Farbaufnahme) in Otten, Altorientalistik, 253 (links KBo XXXII 19, Mitte oben Nr. 13, Mitte unten Nr. 15, rechts Nr. 14; jeweils Vorderseite).

4 Vgl. Neu, Zur mittelhethitischen Sprachform.

5 Vgl. Neu, Neue Wege, 296f. 300 (zu prădikativen Partizipien auf -b; zum Transitivitătskennzeichen -u-); id., Das Hurritische, $6 \mathrm{ff}$.

6 Parrot / Nougayrol, Document, $1 \mathrm{ff}$. 
besteht kein Zweifel, daß die Sprachform des hurritischen Textes der Bilingue wesentlich älter ist als die des berühmten Mittani-Briefes, auf dem bisher weitgehend die grammatischen Darstellungen des Hurritischen in all ihrer Lückenhaftigkeit beruhen.

3. Das Lokalkolorit hinsichtlich Orts-, Götter- und Personennamen berechtigt zu der Annahme, daß die hurritische Textkomposition der Bilingue in Nordsyrien entstanden war und von dort nach Hattuša gebracht wurde. Dies könnte bereits zur Zeit des hethitischen Großkönigs Hattušili I. um die Mitte des 16. Jh. v. Chr. (nach der Kurzchronologie) geschehen sein $^{7}$, der in jenem geographischen Raum militärische Operationen durchführte. Allerdings dürfte der hurritische Text der Bilingue erst im Verlauf der mittelhethitischen Sprachperiode mit einer hethitischen Übersetzung versehen worden sein. Zusammen mit der hurritischen Vorlage wurde dann um 1400 v. Chr. die Übersetzung zu der uns überkommenen Bilingue vereint.

4.1 Dieses zweisprachige Textensemble ist vor allem unter zwei Gesichtspunkten von besonderer Bedeutung, zum einen als Literaturdenkmal, zum anderen als hurritisches Textzeugnis, für dessen Erschließung die hethitische Übersetzung gleichsam den Schlüssel enthält.

Der hurritische Text, aber auch die Bilingue insgesamt stellen ein bisher im Alten Orient einmaliges Literaturdenkmal dar, hinter dessen hurritischer Sprachgebung deutlich ein dichterischer Gestaltungswille spürbar wird. Bestimmte Abschnitte der hurritischen Fassung scheinen metrisch strukturiert, was jedoch der hethitische Übersetzer offensichtlich nicht nachempfinden und somit auch nicht nachgestalten konnte ${ }^{8}$.

4.2 Einige erhaltene Kolophone bezeichnen die Textkomposition als "Lied" bzw. "Epos der Freilassung", wobei für "Lied" bzw. "Epos" das Sumerogramm SÌR geschrieben ist, während der Begriff "Freilassung" dort in hethitischer Sprache erscheint, nämlich als parā tarnumar bzw. - von SìR syntaktisch abhängig - im Genitiv als parä tarnumaš ${ }^{9}$. Gelegentlich wird im Kolophon auch ein "Sänger" ( $\left.{ }^{\mathrm{L}} \mathrm{NAR}\right)$ erwähnt ${ }^{10}$.

Auch andere aus dem Hurritischen stammende Texte werden als SìR bezeichnet, so etwa die unter dem Titel "Königtum im Himmel" bekannte, in Verbindung mit Kumarbi stehende Textkomposition oder auch das dem Kumar-

Otten, Blick, 54.59.

$8 \mathrm{Vgl}$. Neu, Varia Hurritica, 246ff.

9 S. die teilweise bruchstückhaften Kolophone von KBo XXXII 11; 12; 13; 15; 19; 62; 66; 87.

10 Vgl. KBo XXXII 13 Rs. 18'; 66, 2' (in einer jeweils ălteren Zeichenform). 
bi-Zyklus zugehörige "Ullikummi-Lied" (SÌR DUlikummi). H.A. Hoffner hat in seiner unlängst vorgelegten Bearbeitung der ebenso zum Kumarbi-Zyklus gehörenden Erzählung vom Silber ${ }^{11}$ ausdrücklich darauf hingewiesen, daß unter jenen Textfragmenten zwar kein Kolophon erhalten sei, es aber immerhin zu Beginn dieses Mythos heiße: išhamihhi=(i)an KÙ.BABBAR-an ..., d.h. "Singen werde ich vom Silber ...", wodurch Hoffner sich dann auch dazu veranlaßt sah, seiner Textbearbeitung den Obertitel "The Song of Silver" zu geben. Auch die bekannte aus dem Hurritischen stammende Erzählung vom Jäger Kešše, eine Art Märchen, wird in einem Tafelkolophon (KUB XLVII 2 lk. Rand) als SìR bezeichnet, von H.G. Güterbock ${ }^{12}$ als "Epos" interpretiert.

5. Neben ihrer Bedeutung als bisher singulär stehendes literarisches Textzeugnis kommt der zweisprachigen Textgruppe, wie wir bereits erwähnten (4.1), eine wichtige Bedeutung auch im rein sprachlichen Bereich zu. Mit der beigefügten hethitischen Übersetzung ist uns nämlich gleichsam ein Schlüssel in die Hand gegeben, der die weitere Erschließung der hurritischen Sprache und damit auch den Ausbau der bisher nur in groben Umrissen bekannten hurritischen Grammatik erlaubt. Auch erfährt das hurritische Lexikon auf unterschiedlichsten Gebieten vielfache Bereicherung. Mit den aus der Bilingue gewonnenen neuen Erkenntnissen im Bereich von Grammatik und Lexikon des Hurritischen wird man dann zu prüfen haben, inwieweit damit auch die Interpretation bisher nur schwer, kaum oder gar nicht verständlicher hurritischer Texte vorangetrieben werden kann.

6.1 Im Kolophon des Tafelbruchstückes KBo XXXII 11 (IV 22') findet sich der Schreibervermerk: "Erste Tafel: Lied des parā tarnumar". Der Kolophon von KBo XXXII 15 (lk. Rand) teilt uns mit: "Fünfte Tafel des parā tarnumar. Un[vollendet]". Daraus ergibt sich, daß die Bilingue mindestens sechs Tafeln umfaßt haben muß, was die Textfunde letztlich auch bestätigen. Neben den großen Tafeln und Tafelstücken ist noch eine Fülle kleiner Textfragmente erhalten, von denen sich die meisten aber inhaltlich den Stoffen der besser erhaltenen Textteile zuordnen lassen. Besondere Erwähnung verdient, daß auch Duplikate vorhanden sind, die ebenso die mittelhethitischen Charakteristika zeigen. Dies muß nicht heißen, daß es ein vollständiges zweites oder gar drittes Exemplar der gesamten Bilingue gegeben hat, da vielleicht nur einzelne Textteile mehrfach aufgezeichnet wurden.

6.2 Der Begriff parã tamumar "Freilassung" zieht sich motivartig durch die gesamte Bilingue und bildet gewissermaßen den Schlüsselbegriff für die Ge-

12 Hethitische Literatur, 240. 
samtdeutung dieses altorientalischen Sprachdenkmals. Der Vergleich der beiden Fassungen erweist den hurritischen Ausdruck kirenzi als Entsprechung zu hethitisch parā tarnumar. Wortbildungsmäßig stellt hethitisch parā tarnumar ein Verbalnomen (-uar) dar, und hurritisch kirenzi hat man als eine verbale $\mathrm{Ab}$ straktbildung aus -si bzw. -še zu verstehen. Vom Worttyp her sind also beide Bildungen wesensverwandt.

6.3 In dem Ausdruck kirenzi liegt ein Terminus der Rechtssprache vor, der sich auch in keilschriftlichen Rechtsurkunden aus Nuzi, einer Stadt im nördlichen Osttigrisland, nachweisen läßt. Die Urkunden, in welchen er dort auftritt, handeln von Unfreien und deren Freilassung ${ }^{13}$ und erlauben eine lexikalische Gleichsetzung von hurritisch kirenzi mit akkadisch anduräru, einem Rechtsterminus, der bereits im Altbabylonischen die Freilassung der infolge Verschuldung zu Sklaven gewordenen Personen bezeichnete. Dieser soziologische Hintergrund ließ dann auch den Begriff kirenzi der Bilingue transparenter werden.

6.4 Das Sumerogramm für andurāru ist AMA.AR.GI ${ }^{14}$ und begegnet bezeichnenderweise in den res gestae des Großkönigs Hattušili I., von dem eingangs (Kap. 3) gesagt wurde, daß die hurritische Fassung der späteren Bilingue in Verbindung mit dessen Kriegszügen im nordsyrischen Raum von dort nach Hattuša gelangt sein könnte. Im Zusammenhang mit dem Bericht über seine Eroberung der nordsyrischen Stadt Hahhhu erwähnt Hुattušili ausdrücklich (KBo X 2 III 16-20), daß er dort Sklaven und Sklavinnen freigelassen hat:

"Ich, der Großkonig Tabarna, habe ihrer, d.h. der Stadt Habhu Sklavinnen Hände vom Mühlstein genommen, und der Sklaven ihre Hande habe ich von (ihrem Tage-)Werk genommen, und sie habe ich von Abgaben (und) Fron befreit. Ihre Bande (wortlich: Hüften) habe ich gelost und sie (d.h. die Sklavinnen und Sklaven) der Sonnengottin von Arinna, meiner Herrin, überlassen".

Die Wendung, in welcher das Sumerogramm AMA.AR.GI innerhalb der akkadischen Fassung gebraucht wird (KBo X 1 Rs. 13f $)^{15}$, hat in der hethitischen Fassung sinngemäß folgenden Wortlaut als Entsprechung: "... und sie habe ich von Abgaben/Lehensdienst (und) Fron befreit". Großkönig Hattušili I. stellt sich uns hier als Sklavenbefreier im Feindesland dar, und vielleicht hat

13 Hierzu wie auch zum folgenden s. Neu, Das Hurritische, $13 \mathrm{f}$.

$14 \mathrm{Vgl}$. Rüster / Neu, Hethitisches Zeichenlexikon, Nr. 57.

15 Es heißt dort: ina šapal šamê AMA.AR.GI-šunu aštakan "unter dem Himmel habe ich ihre Freilassung durchgeführt" (vgl. CHD L-N 90b). Das Zeichen ŠU im Possessivum -šu-nu ist irrtümlich mit zwei Senkrechten geschrieben. 
ein solcher oder vergleichbarer historischer Hintergrund mit dazu beigetragen, daß später in Hattuša das aus dem nordsyrischen Raum stammende hurritische "Epos/Lied der Freilassung" mit einer hethitischen Übersetzung versehen wurde. Hattušili hat zwar nach seiner Aussage im Kriegsgebiet Sklaven befreit, diese aber sogleich wieder in den Dienst der Sonnengöttin von Arinna gestellt. D. Charpin hat 1987 den Begriff anduräru semantisch und etymologisch näher beleuchtet $^{16}$, dabei gelangte er zur Grundbedeutung "Rückkehr zu dem ursprünglichen Zustand". Für einen in Knechtschaft geratenen Menschen bedeutet dies dann "Rückkehr zur Freiheit". Zu dem Sumerogramm AMA.AR.GI (bzw. AMA.AR.GI ${ }_{4}$ ), das sich wörtlich als "Rückkehr zur Mutter" deuten läßt, führt $D$. Charpin ${ }^{17}$ erklärend aus, daß für einen von einer freien Mutter geborenen Sklaven der Begriff AMA.AR.GI ebenso die Rückkehr zur Freiheit bedeute.

6.5 Ausgehend von dem akkadischen Terminus anduräru (neuassyrisch auch durāru), weist das etymologisch dazugehörige hebräische Wort d'rōr "Freilassung" unwillkürlich auf das alte Israel, wo der Begriff $d^{\text {e } r o ̈ r ~ a l s ~ t e r m i n u s ~ t e c h n i-~}$ cus aufs engste mit der Institution des Jobeljahres (dazu ausführlicher Lev 25) verbunden war. Wer zur Schuldknechtschaft gezwungen und somit unfrei geworden war, sollte im Jobeljahr wieder frei zu seiner Sippe zurückkehren können. ${ }^{18}$ Darüber hinaus war aber die Freilassung eines hebräischen Sklaven auf das siebte Jahr festgelegt. ${ }^{19}$

6.6 Mit schon altbabylonischem anduräru, mit dem sprachlich verwandten Terminus derör "Freilassung", mit dem hurritischen Terminus kirenzi auch aus Rechtsurkunden in Nuzi und schließlich mit der, wie man vielleicht vermuten darf, hethitischen Lehnübersetzung parä tarnumar aus Kleinasien greifen wir im Alten Orient zu unterschiedlichen Zeiten und in verschiedenen Regionen Ausdrücke für die Institution des aus der Knechtschaft Entlassens. Innerhalb der Bilingue stellt hurr. kirenzi (= heth. parā tarnumar) den zentralen Begriff dar, durch den die einzelnen Tafeln und zugleich auch die zum Teil recht unterschiedlichen Erzählstoffe klammerartig miteinander verbunden sind. Damit gewinnen wir für das gesamte Textensemble gleichsam dessen Sitz im Leben.

16 Charpin, Décrets Royaux, 36ff.

$17 \mathrm{AaO} 38 \mathrm{~b}$.

18 Zu dem alle fünfzig Jahre in einem Sabbatjahr begangenen Jobeljahr s. die Sekundärliteratur in Neu, Das Hurritische, 14 Anm. 30.

Vgl. Loretz, Habiru-Hebräer, 264f - Beachtung verdient in unserem Zusammenhang die in keilschriftlichen Quellen bezeugte Gruppe der huup̌̌u/ena, der Leute angehörten, die aus der Schuldknechtschaft entlassen worden waren (ebd., 252ff, dort auch zur etymologischen Bedeutung dieser Bezeichnung). 
7. Sieht man einmal vom Proömium (KBo XXXII 11 I 1ff) ab, in welchem die handelnden Personen sowie mit der Nennung von Ortsnamen auch der (nordsyrische) Schauplatz angegeben sind, läßt sich die gesamte Bilingue thematisch grob in vier größere, jedoch inhaltlich miteinander zusammenhängende Gegenstandsbereiche gliedern, für die etwa die folgenden Überschriften gewählt werden können:

A. Fest der Allani, der Sonnengöttin der Erde, in ihrem Palast an den Riegeln der Erde;

B. Fallbeispiele für menschliches bzw. zwischenmenschliches Verhalten;

C. Aufforderung zur Hilfe am Nächsten und

D. Erzählung um die Stadt Ebla.

Auf die Bereiche A, C und D wird einzugehen sein, wenn weiter unten die in der Bilingue auftretenden Gottheiten, auch deren Wirkungskreis, näher behandelt werden. Dort soll auch eine Antwort auf die Frage, wie man sich die Schilderung vom Fest der Allani (A) im Rahmen eines 'Epos der Freilassung' erklären kann, gegeben werden, zumindest versuchsweise. Da in der Erzählung um die Stadt Ebla (D) der Begriff "Freilassung" den Ablauf der Handlung wesentlich mitbestimmt, ergibt sich die Begründung für die Einbeziehung dieser Erzählung unter die Gesamtthematik "Freilassung" von selbst. Der dritte Gegenstandsbereich (C), der mit "Aufforderung zur Hilfe am Nächsten" betitelt ist, steht in unmittelbarer Verbindung mit der Erzählung um Ebla.

8.1 Der zweite Gegenstandsbereich (B) "Fallbeispiele für menschliches bzw. zwischenmenschliches Verhalten", der die gesamte Tafel KBo XXXII 14 und wohl auch Nr. 12 ganz eingenommen hat ${ }^{20}$, ist der einzige größere Textteil, in welchem keine namentlich genannte Gottheit auftritt. In einigen Textabschnitten ist lediglich die Rede von der Gottheit des Vaters, die einen auf die schiefe Bahn geratenen Sohn, der sich zudem noch von seiner Vaterstadt losgesagt hat, für immer verflucht hält (vgl. KBo XXXII 14 Rs. IV/III 1ff, Rs. $48 \mathrm{f}$ bzw. $50 \mathrm{ff}$ ). Statt des Vaters kann in solchen Kontexten auch die Mutter genannt sein (vgl. Nr. 12 Rs. IV 18'ff). Man geht sicher nicht fehl in der Annahme, hinter der Gottheit des Vaters bzw. der Mutter einen Familiengott zu sehen. In einem anderen Fallbeispiel (Nr. 14 Vs. I/II 17ff) ist von einer Stadtgottheit die Rede, die einen Menschen, der der betreffenden Stadt Böses zufügte, für immer verflucht hält. Der hethitische Übersetzer gebraucht auch hier den Plural. Vielleicht hat man es als eine Art von Interpretatio hethitica zu werten, wenn statt "Gott(heit)" des Vaters, der Mutter oder der Stadt in der hethitischen 
Übersetzung der Plural ("Götter/Gottheiten") verwendet wird. Sowohl in der hurritischen Vorlage als auch in der hethitischen Wiedergabe findet sich gemeinsam der Plural "Götter/Gottheiten" dann, als einmal innerhalb eines Fallbeispiels berichtet wird, daß "Gottheiten" einem vom rechten Weg abweichenden Menschen noch rechtzeitig Einsicht zur Umkehr eingegeben haben (Nr. 14 I/II 35f). ${ }^{21}$

8.2 Was hat es nun mit den "Fallbeispielen für menschliches bzw. zwischenmenschliches Verhalten" auf sich? Bei ihnen handelt es sich um eine stattliche Reihe gleichnisartiger Exempla, aus denen Lehren für ein richtiges Verhalten gezogen werden sollten. Die kurzen gleichnisartigen Erzählungen orientieren sich an Vorgängen im Tierreich oder nehmen Bezug auf das alltägliche Handwerkerleben und sollen menschliches Fehlverhalten im beruflichen wie im familiären Bereich illustrieren. Gerade negative Beispiele verleihen der Vorstellung von dem, was unter richtigem oder angemessenem menschlichen Verhalten zu verstehen ist, stärkere Konturen. Diesen Textteil B wird man der Gattung Weisheitsliteratur zuordnen dürfen. Unter den hethitischen Textzeugnissen ist dieses literarische Genre bisher nicht vertreten ${ }^{22}$, wir erhalten aber jetzt an Hand der nach hurritischer Vorlage angefertigten Übersetzung einen ungefähren Eindruck von einem Weisheitstext in hethitischem Gewande. Der deutsche Ausdruck "Fallbeispiel", wofür wir auch "Exemplum" oder "lehrreiches Beispiel" sagen könnten, gibt das hurritische Wort mädi wieder, dem in der hethitischen Übersetzung hattätar "Klugheit, Einsicht", aber wohl auch "Weisheit" entspricht. Die beiden Abstrakta mädi bzw. hattätar wird man aber innerhalb der Bilingue eher konkreter zu fassen haben, was in den hier genannten Bedeutungen wie "Fallbeispiel" oder "lehrreiches Beispiel" zum Ausdruck kommen soll.

8.3 Der Textteil B der "Fallbeispiele" zeigt durchweg eine einheitliche Strukturierung. Jedes Exemplum beginnt mit einer gleichnisartigen Erzählung. Tritt darin z.B. ein Tier handelnd auf, heißt es dann am Ende einer solchen Erzählung, die jeweils mit einem Paragraphenstrich abgeschlossen wird: "Ein Tier (z.B. Hund) ist es nicht, ein Mensch ist es". Dann folgt die Schilderung einer Situation, in die der betreffende Mensch geraten ist, und es wird dessen Verhalten aufgezeigt. Die Handlungsabläufe von gleichnisartiger Erzählung und

21 Vgl. Neu, Wortschatz, 180f; ders., Das Hurritische, 24 mit Anm. 70 (wo es in der Umschrift richtig ma-a-ta-aš-tab heißen muß). Im Hurritischen wird an jener Textstelle der Plural "Gottheiten" durch enzäri in Verbindung mit dem enklitischen Personalpronomen -l(la) zum Ausdruck gebracht, wăhrend in der hethitischen Übersetzung das Sumerogramm DINGIR MES geschrieben ist.

22 Vgl. Neu, Das Hurritische, 19f. 
dem darauf bezogenen menschlichen Geschick verlaufen weitgehend parallel. Mitunter wird das menschliche Verhalten bzw. Fehlverhalten, auch mit dessen Folgen, breiter dargestellt, als durch die gleichnisartige Erzählung schablonenhaft vorgegeben, aber es findet sich auch der umgekehrte Fall, wo die gleichnisartige Erzählung gegenüber der konkreten menschlichen Situation allzu ausgeschmückt wirkt. Eine Textpassage mit jeweils gleichem Wortlaut leitet von einem "Fallbeispiel" zum anderen über. An einem ausgewählten Beispiel ${ }^{23}$, das auch als eine Art Rechtsfall gelten kann, möge dies alles kurz erläutert und veranschaulicht werden. Wir bringen zunächst den hurritischen Text und lassen darauf den hethitischen folgen:

\section{Hurritisch (KBo XXXII 14 IV 9-22)}

9 šu-ul-lu-ú-ub-ri e-er-bi-né-eš e-eb-hée-e-ni

10 ta-la-ah-hu-u-um : ta-la-ah-hu-u-um e-eb-hee-e-ni

11 ha-a-šar-ri bu-ú-zi-hu-um : bu-ú-zi-huu-um

12 ha-a-šar-ri na-ah-h̆a-ab ú-la-a-nu-u-um

13 e-er-bi ma-a-an-nu-u-bur ma-a-an-ni tar-šu-ua-a-ni

14 a-mu-ú-mi-ne-e-ua $m a-a-a n-n i$ e-eb-re-eš

15 na-ah-hi-la-a-i te-li-ip-pa ha-a-u-li-ma-a-i-in

16 a-ar-ti-i-ta-an e-ra-a-na : bu-ú-ru te-e-lu

17 tab-šu-ú a-ar-ti a-mu-lu-ú-tu-u-um du-ú-ni-du

18 bu-ú-ta-an-ka-a-i a-a-bi e-eb-ri-ua a sal-la-e-na

19 ne-eš-še-e-na e-eb-ri-ta bi-še-ě̌-huu-um

$20 k u$-u-le-eš an-ti ti-ib-ša-a-ri u-la-ab-ua $a_{a}$

21 qa-túl-li a-mu-u-ma-a-ab šal-ḩu-u-la ma-ta-ab-una ${ }_{a} q a-t u ́ l-l i$

22

Leerzeile

Hethitisch (KBo XXXII 14 III 9-22)

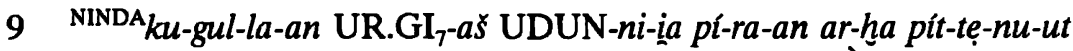

10 pa-ra-a-an-kán hu-it-ti-at UDUN-ni-ia-az na-an-kán İ-i

11 an-da šu-ú-ni-at ša-ak-ni-ina-an-kán an-da

12 šu-ú-ni-at na-aš-za e-ša-at na-an a-da-a-an-na da-iš

13 Ú-UL UR.GI ${ }_{7}-a s ̌ n u$ an-tu-una-ah-ha-aš ma-ni-ia-ah-hi-aš iš-ha-a-an

23 Für weitere Beispiele vgl. Otten, Blick, 56ff; Neu, Das Hurritische, $27 \mathrm{f}$. 
$14 k u$-in BE-EL-šU i-e-zi nu-ušs-sa-an a-pé-e-da-ni (Rasur) 15 URU-ri EGIR-an IGI.DU ${ }_{8}^{\text {HI.A }}$ da-a-an-na ma-ak-nu-ut

16 na-aš me-ek-ki šu-u-ul-li-it na-aš-ta nam-ma URU-an an-da Ú-UL

17 a-uš-zi na-an-za PA-NI BE-LÍ-ŠU i-si-ina-ah-hu-u-an-zi tar-h̆u-ir

$18 n u$ IGI.DU ${ }_{8}^{\text {HI.A }}$ ku-e pa-a-si-iš-ki-it na-at PA-NI BE-LI-ŠU

19 li-il-hu-una-an da-iš

20 ar-ḩa da-a-le-eš-tén a-pa-a-at ut-tar nu-uš-ma-aš ta-ma-a-i ut-tar

21 me-ma-ah-hi ḩa-at-re-eš-šar iš-ta-ma-aš-tén ḩa-at-ta-a-tar-ma-aš-ma-aš me-mi-iš-ki-mi

8.4 Das Verhältnis der hurritischen Vorlage ließ sich mit Hilfe der hethitischen Übersetzung vollständig erschließen ${ }^{24}$. Die beiden Doppelpunkte in der hurritischen Fassung (Zeilen 10,11) symbolisieren jeweils ein keilschriftliches Winkelhäkchen, das zwei gleiche Verbalformen voneinander trennt, nämlich einmal talahhum "er entführte / stibitzte" und zum anderen buzihhum "er tauchte ein". Anders verhält es sich mit dem Winkelhäkchen (=Doppelpunkt) in Zeile 16, das aber auch der Beginn eines räumlich zu früh angesetzten Zeichens bu- sein könnte (vgl. ibid. Rs. 26, ohne trennenden Winkelhaken). Hurr. sullubri (Z. 9) ist eine nicht näher zu bestimmende Gebäcksorte und entspricht heth. ${ }^{\text {NINDA }}{ }^{2}$ ugulla- ${ }^{25}$. Hurr. erbi, hier mit 'Artikel' ${ }^{26}$ und Ergativendung, bedeutet "Hund" (in der heth. Übersetzung: UR.GI T $_{7}$-as); hurr. ebheni, das letzte Wort der Zeile 9, das auch in Zeile 10 auftritt, ist eine Ablativform mit der Bedeutung "von" bzw. "aus dem Ofen", im Hethitischen halblogographisch, einmal durch UDUN-ni-ina (Dat.-Lok.; mit vom Hurritischen abweichender Konstruktion) und einmal durch UDUN-ni-ia-az (Ablativ wie im Hurritischen), wiedergegeben. Hurr. häăari, in Z. 11 und 12 jeweils mit 'Artikel'(worauf die Schreibung - $r$ - weist), bedeutet "Öl, Fett", in der hethitischen Übersetzung durch das Sumerogramm Ì (Dat.-Lok. İ- $i$ ) ausgedrückt. Der gleichnisartige Abschnitt (Zeilen 9-12) der hurritischen Fassung läßt sich nun folgendermaßen übersetzen: "Backwerk (war es, das) ${ }^{27}$ ein Hund aus einem

24 S. auch schon Neu, Das Hurritische, 17f; id., Varia Hurritica, $246 \mathrm{f}$.

Vgl. Neu, Das Hurritische, 17 Anm. 46. In der Übersetzung behelfen wir uns mit dem allgemeinen Ausdruck "Backwerk".

26 Was im Hurritischen als. (bestimmter) Artikel, determinierendes Suffix (o.ă.) bezeichnet wird, deckt sich nicht mit der Funktion etwa des bestimmten Artikels im (Alt-)Griechischen, Deutschen oder Romanischen.

27 Diese Umschreibung wird behelfsweise für die deutsche Übersetzung gewăhlt, um moglichst die Wortstellung der hurritischen Vorlage beizubehalten. 
Ofen entführte. Er entführte (es) aus einem Ofen. In Ö $\mathrm{I}^{28}$ tauchte er es ein. Ein tauchte er (es) in Öl. Er setzte sich und legte (es) zum Fressen hin (hurr. ulänum $=$ heth. $n=$ an adānna dais)" .

Die dichterisch beabsichtigten Wiederholungen jeweils in der Art eines Chiasmus (also ebheni talahhum : talahhum ebheni; hāsarri buzihum : buzihum hā̄sarri) hat der hethitische Übersetzer nicht nachgeahmt; sie schienen ihm wohl nicht recht geheuer. Daher gibt er hurr. talahhum mit zwei verschiedenen Verben wieder: 1. (piran) arha pittenut "er ließ mitgehen" (im Sinne von: "entwendete"); 2. parā huittiat "er zog (aus dem Ofen) heraus" (nämlich das Backwerk; Pronomen -an). Ebenso wählte der heth. Übersetzer für zweimaliges hurr. hăăarri zwei verschiedene hethitische Wörter, nämlich einmal entsprechend der hurr. Vorlage (sumerograph.) İ "Öl, Fett", dann aber ganz unerwartet heth. šakar "Schmutz, Dreck, Kot".

Nach einem Abschnittsstrich folgt in Z. 13 beider Fassungen die knappe Feststellung: "Ein Hund ist (es) nicht, (es) ist ein Mensch". Im Hethitischen hat "ist nicht" (hurr. männuwur) bzw. "ist" (hurr. männi) keine lexikalische Entsprechung; stattdessen werden Nominalsätze gebraucht.

Von Zeile 14-19 wird dann eine konkrete Situation geschildert, wie sie zeitlos immer wieder irgendwo eintreten kann; sie hat menschliches Fehlverhalten zum Gegenstand: "Zum Verwalter (amumineun $a_{a}$ Dat.) hat (ihn) (s)ein Herr (ewres) eingesetzt".$^{29}$ Mit Hilfe des Verbum substantivum (männi "ist") wurde die Dativform betont an den Satzanfang gestellt. ${ }^{30}$ Der hurritischen Wendung "jem. zum Verwalter einsetzen" entspricht in der heth. Übersetzung "jem. zum Verwalter machen" (iia - "machen" mit doppeltem Akkusativ). Aus dem folgenden Satz erfahren wir, daß der Verwalter mit dem Einziehen irgendwelcher Abgaben (heth. sumerograph. IGI.DU 8 HI.A) zu tun hatte: "Die Einnahme von Abgaben (telippa haulimai) aus seiner Stadt ( $a r d i=i=d a n$ ) erweiterte er" (hurr. $e r=a n=a=$ heth. maknut). ${ }^{31}$ Diese Abgaben- (oder Steuer-)Erhöhung hat

28 Der hurritische Absolutiv wird innerhalb der Bilingue auch als Ortskasus gebraucht und steht auf die Fragen "Wohin?", seltener "Wo?"; vgl. meinen diesbezüglichen Beitrag in der FS Sedat Alp (demnăchst).

29 Zur infiniten Verbalform nahhilai s. Neu, Hurritische Verbalformen, $509 \mathrm{ff}$ (dort auf Seite 511 muß es in der siebten Zeile heißen: hal=i=lai). Statt eines hurritischen Dativs wird sonst in vergleichbaren Wendungen der Essiv gebraucht; vgl. Neu, Zum hurritischen 'Essiv', $159 \mathrm{ff} .168$ (Anm. 22). 169 (Anm. 38).

$30 \mathrm{Vgl}$. Neu, Neue Wege, 302.

31 Dazu im einzelnen Neu, Hurritische Verbalformen, 507f. Möglicherweise besteht ein etymologischer Zusammenhang zwischen hurr. teli(ppa) und akkad. "tē $\bar{l}$ - aus $t \bar{e} T i t u(m)$ "Ertrag(sabgabe)" (AHw III 1345); in KBo XXXII 14 Rs. 25 ist te-li-i-ip-pa geschrieben. Von meiner Interpretation abweichend gleicht G. Wilhelm (in seinem Beitrag der Festschrift für Sedat Alp demnăchst) hurr. e-ra-a-na (Z.16) nicht mit der heth. Verbalform maknut (die nach ihm

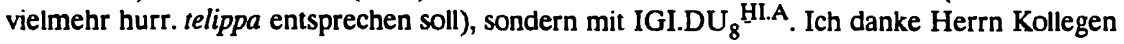


der Verwalter eigenmächtig, ohne Wissen seines 'Herrn', vorgenommen. Dann fängt er auch noch Streit an und verläßt die Stadt, also: hurr. bu-ú-ru te-e-lu tab-šu-ú (Z. 16f) = heth. $n=a s ̌$ mekki šullit (Z. 16) "und er begann heftigen Streit". ${ }^{32}$ Seine Stadt (wo er als Verwalter tätig war) suchte er nicht mehr auf (hurr. ardi $a m=u l=u d=u=m=$ heth. na-aš-ta nam-ma URU-an an-da $U-U L$ $a-u \zeta$-zi "die Stadt besucht er nicht mehr"). Doch man konnte ihn vor seinem Herrn überführen (hurr. du-ú-ni-du bu-ú-ta-an-ka-a-i a-a-bi e-eb-ri-ua $a_{a}=$ heth.

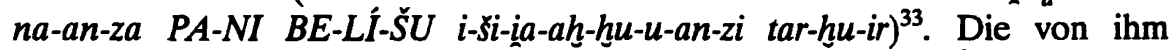
geschluckten Einnahmen/Vergünstigungen (sallaena neššna) ${ }^{34}$ begann er seinem Herrn (ewri=i=ta Direktiv) hinzugießen (hurr. bi-še-eš-hu-um = heth. lilhuuan dais')". Für die Begriffe 'Einnehmen' und 'Herausgeben' sind hier bildhaft die Verben "(ver)schlucken" (heth. pāš-) und "(hin)gießen" (heth. lilhu-) gewählt ${ }^{35}$.

8.5 Wie verhält sich nun die gleichnisartige Erzählung (Zeilen 9-12) zu dem Bericht vom ungetreuen Verwalter (Zeilen 14/13-19)? Der Hund kam (allerdings in Form von Selbstbedienung) in den Besitz eines bestimmten Backwerks. Dem entspricht in der konkreten Situationsschilderung, daß jemand zum Verwalter eingesetzt wurde und so in Brot und Arbeit stand. Der Hund macht sich sein Backwerk dadurch schmackhafter und saftiger, daß er es noch durch Öl schleift (vgl. KUB VI 45 IV 9,19,24,29). Der Verwalter hingegen verschafft sich höheren Genuß dadurch, daß er über das ihm zugestandene $\mathrm{Ma} B$ hinaus Abgaben einzieht und diese in die eigene Tasche steckt. Im Streit trennt er sich von der Stadt seiner Gaunereien, doch man wird seiner habhaft und bringt ihn zu seinem Herrn, der ihn seinerzeit mit dem Verwaltungsamt betraut hatte. In Gegenwart seines Herrn muß er alles das, was er eingenommen hat, wieder herausgeben. Über den Hund aus der gleichnisartigen Erzählung wurde lediglich gesagt, daß er sich nach seinem Beutezug niedersetzte und sich das

Prof. G. Wilhelm sehr herzlich dafür, daß er mir seinen diesbezüglichen Festschriftbeitrag vorab im Manuskript zugánglich machte. Bei Auffassung von telippa als Verbalform bliebe mir deren Analyse dunkel (s. auch ebd. Anm. 5).

32 Das Adverb mekki kann in der hethitischen Übersetzung auch fehlen (vgl. KBo XXXII 14 II 4), ohne daß die hier angegebene Gleichung mit dem Hurritischen gestört wăre. Daher fiele es schwer, etwa hurr. tèlu mit heth. mekki semantisch in Verbindung zu bringen. Dies sei hier mit Blick auf die von G. Wilhelm (s. oben Anm. 30) vermutete Gleichsetzung von hurr. telippa mit heth. maknut (das zur Sippe um mekk(i)- gehört) gesagt.

$\mathrm{Zu} d u n=i=d u$ but $=a n=k a i$ s. ausführlicher $\mathrm{Neu}$, Hurritische Verbalformen, 511f.

Zu hurr. neššena vgl. Laroche, Glossaire, 181: nešše "prospérite?".

Das reduplizierte Verbum lilhu- entspricht funktionell der -sk-Form pa-a-si-ǐ̌-ki-it. 
Backwerk zum Fressen hinlegte ${ }^{36}$. Es bleibt also offen, ob er auch tatsächlich seine Beute verzehren konnte.

Der Bericht vom ungetreuen Verwalter will also zeigen, wie man sich in vergleichbarer Position nicht verhalten darf. Er ist gleichsam ein Aufruf zur Pflichterfüllung.

8.6 Im Anschluß an das Gleichnis und der damit parallel laufenden konkreten Situationsschilderung folgt (Zeilen 20-21/22) der immer gleichgestaltete Textabschnitt, der von einem Fallbeispiel zum anderen überleiten soll; seine Übersetzung lautet: "Laßt ab von jener Geschichte (hurr. $k u$ - $u$-le-es an-ti $t i-i b$ $\Im a-a-r i)$ ! Ich will euch eine andere erzählen (u-la-ab-ua $\left.a_{a} q a-t u ́ l-l i\right)$. Hört euch die Botschaft an (a-mu-u-ma-a-ab sal-hu-u-la)! Ein (weiteres) lehrreiches Beispiel will ich euch sagen (ma-ta-ab-ua $\left.a_{a} q a-t u ́ l-l i\right) "$.

8.7 Den Stellenwert solcher Lebensregeln im Rahmen eines "Epos der Freilassung" darf man vielleicht im Bereich der sozialen Komponente angesiedelt sehen, wie sie von der Forschung ausdrücklich z.B. für das Jobeljahr (mit den dann folgenden Freilassungen) aufgezeigt worden ist. Durch Vorführung negativer und damit abschreckender Beispiele, deren Nachahmung für den einzelnen Bestrafung und andere Nachteile nach sich gezogen hätte, soll bei dem, der damit konfrontiert wird, dort, wo immer ihm in der Gesellschaft sein Platz zugewiesen sein mag, ein korrektes Verhalten hervorrufen.

9.0 Im Rahmen dieses Hamburger religionsgeschichtlichen Symposions ist natürlich von besonderem Interesse die Frage, welche Gottheiten innerhalb der Bilingue auftreten. Somit schließe ich jetzt thematisch gewissermaßen an diejenigen Tagungsvorträge an, bei denen es um Fragen eines Pantheons geht. $^{37}$

9.1 Unter den Gottheiten der Bilingue möge zunächst Allani genannt sein. So erscheint der Name oder auch der Titel in der hurritischen Fassung, der sich als "die Herrin" deuten läßt. Das Gottheitsdeterminativ fehlt gelegentlich (vgl.

36 Die hethitische Konstruktion INFINITIV + daix wird man inhaltlich eher so als "er begann es zu fressen" zu verstehen haben, wäre dann doch auch das Supinum zu erwarten gewesen (zunăchst anders $\mathrm{Neu}$, Das Hurritische, 18).

37 Für die Bilingue sei auf den von C. Rüster zusammengestellten Index der Götternamen verwiesen (KBo XXXII, 1990, XIII), wo jedoch nachzutragen sind: $A$-al-la-a-an-ni (ohne Determinativ) 14 Rs. 35, Is'-ha-ra[- 67 IV? 4' (mit Determ.), Ši-me-ga-i (ohne Determ.) 209,8', ZUEN-mi (Dat.; mit Determ.) 82,4' (s. unten 15.2). 
lingue auch als "großer König von Kumme" bezeichnet wird. ${ }^{42}$ In dieser mythologischen Erzählung treffen also Götter der Unterwelt und der himmlischen Götterwelt zusammen. Die Unterwelt gilt gemeinhin auch als Verbannungsort für Gottheiten, die früher mal die Herrschaft im Himmel ausübten und im Zuge von Sukzessionskämpfen (u.a. auch von Teššub) von dort vertrieben wurden. Es ist die Gruppe der "uralten Götter" (hurr. amattena enna) ${ }^{43}$, die z.B. im Rahmen einer Beschwörung aus Hattuša als Richter aus der Unterwelt herauskommen, das Böse und alles Unheil "an Händen und Füßen" binden und es hinab in die Unterwelt schaffen sollen. "Die Sonnengöttin der Erde", heißt es dort, "möge das Tor öffnen und die uralten Götter, die Herren der Erde, herauflassen!"44 So wird die chthonische Göttin zur eigentlichen Herrin des magischen Geschehens, indem es ihr überlassen bleibt, ob sie die uralten Götter zur Teilnahme an einer Beschwörung nach oben auf die Erde läßt oder nicht. Das Tor, das die Sonnengöttin der Erde im Rahmen jener Beschwörung öffnen soll, wird man mit der Angabe "an den Riegeln der Erde" in Verbindung bringen dürfen.

9.3 Teššub kommt aber nicht allein zum Fest. In seiner Begleitung befindet sich der Gott Suunaliiaz (Nominativ), doch begegnet dieser Name nur in der hethitischen Übersetzung ${ }^{45}$. In der hurritischen Vorlage ist an der betreffenden Stelle kein Göttername genannt, statt dessen steht dort ein Komitativ ${ }^{46}$, dessen inhaltliche Deutung jedoch noch Schwierigkeiten bereitet. H.G. Güterbock, der 1961 der Frage nach der Identität des Gottes Suualiiat (Stammform) einen größeren Beitrag gewidmet hat ${ }^{47}$, kam darin zu der Auffassung, daß Suualiiat mit Tašmišu zu gleichen sei, so daß sich Suunaliiaz als der Bruder Teššubs herausstellte. Der Name Tašmišu kommt jedoch in der gesamten Bilingue, soweit erhalten, nicht vor. O.R. Gurney schließt in seinen Vorlesun-

42 Vgl. KBo XXXII 15 IV 14 bzw. III 13f, 21f; s. Neu, Neue Wege, 294 Anm. 4. Zur Lage der Stadt Kumme s. Wilhelm, Hurrians, 49 (ibid. 63 ist im Anschluß an Otten bereits das Fest der Allani erwähnt). - In der hethitischen Fassung der Bilingue wird der Name Tešsub durch ${ }^{D_{I M}}$ wiedergegeben, wobei die Komplementierung auf ${ }^{\mathrm{D}}$ Tarhunnas, ${ }^{\mathrm{D}}$ Tarhunnan, ${ }^{\mathrm{D}}$ Tarhunni, also auf die indogermanisch-hethitische Bezeichnung des Wettergottes weist. Vgl. Pecchioli Daddi / Polvani, La mitologia ittita, 130 Anm. 13.

43 Vgl. Laroche, Dénominations, 175ff; Haas / Wilhelın, Hurritische und luwische Riten, 50ff.

$44 \mathrm{Vgl}$. Neu, Das Hurritische, 25 mit Anm. 73.

45 KBo XXXII 13 II 9; vgl. Nr. 72,2'.

46 KBo XXXII 13 I 9: ša-at-ta ha-ınu-u-ra "zusammen mit ha.". Man könnte an eine Bedeutung wie Wesir o.ă. denken. Vgl. Nr. 209, 14': š]a-at(-) ha-mu-ú[-

47 Güterbock, God Suwaliyat, 1ff; ders., Religion und Kultus der Hethiter, 56; vgl. Pecchioli Daddi / Polvani, La mitologia ittita, 122.180. 
gen zur hethitischen Religion ${ }^{48}$ die Gleichsetzung von Šuualiiat mit Tašmišu nicht aus. Das Auftreten von Suunaliiat in der Bilingue läßt keinen Zweifel daran, daß wir für diesen Namen ein hurritisches Pendant zu suchen haben; denn A. Goetze ${ }^{49}$ hat schon früh darauf aufmerksam gemacht, daß die Namensform Suualiiat nicht hurritischer, sondern hethitischer Provenienz ist (Dentalstamm). Das würde auch erklären, warum der Name Suunaliiat nur in der hethitischen Fassung der Bilingue vorkommt. Andererseits haben aber hethitische Schreiber in Götterlisten den Namen Šunaliiat mitunter auch dort eingesetzt, wo wir eigentlich einen hurritischen Namen hätten erwarten sollen. In einem kleinen Textfragment der Bilingue (KBo XXXII 37), das inhaltlich wohl nichts mit dem Fest der Allani zu tun hat, wird Suunaliiat als handanza "gerecht" bezeichnet. Die dort nicht erhaltene hurritische Entsprechung wäre mušu(ni) gewesen. Soweit die Tafel mit dem Ablauf des Festes erhalten ist, findet dort Šuualiiat keine Erwähnung mehr. Daß sich die beiden Brüder Teššub und Tašmišu miteinander gut verstanden, darf man vielleicht aus Textstellen des Ullikummi-Liedes schließen, wo beide einmal Hand in Hand aus dem Göttergemach kommen oder ebenso Hand in Hand sich auf eine Reise begeben. $^{50}$

9.4 Besondere Beachtung verdient bei der Beschreibung der Ankunft von Teššub und Šuualiiat in dem Satz "Der Wettergott und Šuualiiat gingen hinab in die dunkle Erde" (KBo XXXII 13 II 9-10) die Angabe "dunkle Erde". Diese formelhafte Wendung (heth.) dankui tekan "dunkle Erde" wurde bisher der indogermanischen Dichtersprache zugeschrieben, und man glaubte dafür auch Parallelen aus anderen indogermanischen Sprachen anführen zu können. Nachdem aber nun die Bilingue die hethitische Formel dankui tekan als eine direkte Übersetzung des Ausdrucks ti-me-er-re-e e-รe-ni $i^{51}$ aus der in Nordsyrien entstandenen hurritischen Vorlage erweist, läßt sich die Auffassung von der indogermanischen Herkunft dieser Wendung kaum mehr rechtfertigen. Die "dunkle/finstere Erde" kann in hethitischen Texten auch personifiziert bzw. dynamisch-aktivisch als dankuiš taganzipaš (auch mit Gottesdeterminativ versehen) auftreten, wenn etwa die Rede davon ist, daß die "dunkle Erde" den

Gurney, Some Aspects of Hittite Religion, 22.

49 Goetze, Theophorous Elements, 267f (mit Anm. 34).

$50 \mathrm{Vgl}$. Güterbock, The Song of Ullikummi, 28 (I 15, f). 40 (II 29).

51 An der genannten Belegstelle werden die beiden Absolutivformen in der Funktion eines Richtungskasus gebraucht: ti-me-er-re-e e-še-ni du-ú-ri "in die dunkle Erde hinab". Das Epitheton timeri "dunkel" steht hier mit dem 'Artikel' (timerre < *timeri $=n e$ ); vgl. KBo XXXII

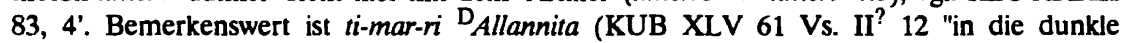
<Erde> zur Allani") - anders Salvini, Sui testi mitologici, 83f, allerdings noch ohne Kenntnis der Bilingue; hierher gehơrig auch ti-ma-ar-ri [-in? e-še-n] i-in du-ú-ri-in KBo XVII 94 III 32'f. 
Regen oder irgendwelche Übel verschlucken soll. Die Formel ist außerdem eng mit dem hurritischen Sukzessionsmythus verbunden, wo es heißt, daß der von Anu besiegte Alalu sich hinab in die dunkle Erde begibt (kattanda dankuuai takni). Als Anu später von Kumarbi besiegt wurde, floh Anu in den Himmel, doch Kumarbi zog ihn vom Himmel herunter, was doch wohl nichts anderes bedeutet, als daß auch Anu in die dunkle Erde verbannt wird, wo er dann zu den "uralten Göttern" gehört.

So gibt es also ernsthafte Gründe, den Ursprung der Wendung "dunkle Erde" zusammen mit diesbezüglichen Vorstellungen im Hurritischen zu sehen. Wenn wir in diesem Zusammenhang an Hesiods Theogonie mit dem dort dargestellten Sukzessionsmythus (in der Götterabfolge Uranos, Kronos, Zeus) oder auch an inhaltliche Beziehungen zwischen der homerischen Nekyia und bestimmten hurritischen Beschwörungsritualen denken, liegt die Vermutung, daß auch die bekannte griechische Formel $\gamma \alpha \tilde{i} \alpha \mu \hat{\varepsilon} \lambda \alpha \iota v \alpha$ altorientalischen Ursprungs ist (Lehnübersetzung), recht nahe. ${ }^{52}$

9.5 Kehren wir jetzt wieder zu dem Fest im Palast von Allani zurück. Teššub, der hier den Titel "König" trägt (KBo XXXII 13 I 3 bzw. II 4) ${ }^{53}$, und Suunaliiat sind inzwischen eingetroffen. Allani hat sich, wie es heißt, umgürtet, also sich für den Besuch zurechtgemacht, und empfängt ihre Gäste. Teššub setzt sich zunächst auf einen eigens für ihn bereitgestellten Stuhl. Oder sollten wir hurr. gešhi bzw. sumerographisches GIŠ̌ Ú.A der hethitischen Fassung eher mit "Thron" übersetzen? Seine Füße legt er auf einen Schemel. Die beigefügten Maßangaben für Sitzfläche und Schemelbreite lassen gewaltige Dimensionen erkennen. ${ }^{54}$ Als die Essenszeit gekommen war (hurr. hiriiia ašuhiniú $a_{a}$ ), begab man sich zu Tisch. Dabei verdient besondere Aufmerksamkeit die

52 S. schon Nel, Der alte Orient: Mythen der Hethiter, 110f. Unter dem Titel "Die 'dunkle Erde' im Hethitischen und Griechischen" behandelt N. Oettinger die hier nur kurz angesprochene Thematik in WO 20/21. Ich danke vielmals Herrn Kollegen Prof. Oettinger, den ich auf das Auftreten dieser Formel in der Bilingue aufmerksam gemacht habe, für die Moglichkeit, seinen diesbezüglichen Aufsatz noch vor der Drucklegung einsehen zu können.

53

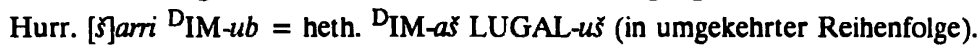

54

Die Sitzflache ist mit dem Feldermaß IKU gemessen (Nr. 13 II 5): (亡̌A) A.ŠÀ IKU. Demnach würde die Sitzflache dem Feld von der Große eines IKU entsprechen, also etwa 3600 gm. Für die Berechnung der Schemeloberfläche bietet uns die hethitische Fassung ein bisher nicht bekanntes Flăchenmaß taualla-, wohl Untereinheit von IKU. Die Schemeloberfläche beträgt A.S̀̀ VII tauallaš (Genitiv) "Feld von sieben $t . "$. Diese Maßangabe gibt das schon aus NuziTexten bekannte Flächenmaß a-bi-ha-ar-ri (mit 'Artikel') der hurritischen Vorlage wieder (s. AHw I ${ }^{2}$ 90a: awiharu). Demnach würde die Schemeloberflache etwa $1800 \mathrm{qm}$, also die Halfte der Sitzflache betragen. Nach der obigen Berechnung ergeben sich etwa 257 qm für 1 tauallaFlächenmaß. Dem Feldmaß IKU der hethitischen Fassung entspricht in der hurritischen Vorlage aw/falli (mit 'Artikel'). Die Maßangaben für Stuhl und Schemel sind wie schon die immense Summe von geschlachtetem Groß- und Kleinvieh märchenhaft übersteigert. 
Aussage, wonach die Gastgeberin die uralten Götter dem Teššub zur Rechten Platz nehmen läßt. Da sonst über die Sitzordnung nichts gesagt ist, kommt dieser eigens erwähnten Plazierung der uralten Götter besondere Bedeutung zu. Das 'Sitzen zur Rechten' wird man als eine besondere Auszeichnung werten dürfen. Der herrschende Gott des hurritischen Pantheons sitzt nun unmittelbar neben den uralten Göttern, zu denen, wie schon zu erwähnen war, auch in die dunkle Erde verbannte Gottheiten früherer Herrschergenerationen gehören, darunter auch der von Teššub verdrängte Gottkönig Kumarbi. Ist schon der Besuch des hurritischen Wettergottes Teššub im Palast der Sonnengöttin der Erde höchst bemerkenswert, wird der Eindruck des Ungewöhnlichen noch weiter verstärkt durch das besondere Arrangement bei Tisch. In den Göttergestalten des himmlischen Wettergottes und der Sonnengöttin der Erde sind, so will es mir scheinen, symbolhaft Himmel und Erde, also Ober- und Unterwelt, harmonisch miteinander vereint, und darin einbezogen sind auch die in der Unterwelt weilenden uralten Götter. Es begegnen sich somit die "unteren Gottheiten" (heth. kattereš Siunes) und die "oberen Gottheiten" (šarazzieš siunes $)^{55}$. Schon andernorts ${ }^{56}$ hat man darauf hingewiesen, daß die Scheidung der Götter in ober- und unterirdische mythologisch eine Folge der Trennung von Himmel und Erde sei. Damit war dann auch die ursprüngliche Einheit des Kosmos beseitigt. Die "oberen Gottheiten" hatten sich damals den Himmel, die "unteren Gottheiten" aber sich die Erde und die Unterwelt genommen. ${ }^{57}$

Diese strenge Unterscheidung von himmlischen und chthonischen Gottheiten versucht Allani zumindest während ihres Festes durch eine besondere Sitzordnung zu mildern. Vielleicht darf man die Feierlichkeiten in ihrem Palast gar als ein Versöhnungsfest ansprechen.

Allani übernimmt zeitweise die Rolle eines Mundschenks, indem sie etwa dem Wettergott in einem Rhyton zu trinken gibt. Dabei hält sie - man achte auf die feinsinnige Detailschilderung - vier ihrer Finger lang ausgestreckt unter das Gefäß, in welchem sich, wie es heißt, (heth.) ašsuuatar "Güte, Qualität", also ein besonders guter Tropfen befindet. ${ }^{58}$ Leider ist die Tontafel mit der Festbeschreibung nur bruchstückhaft erhalten, so daß manch anderes, was uns

$55 \mathrm{Vgl}$. Otten / Siegelová, Guls-Gottheiten, 32f. Dort in Z. 12' sollte es heißen: "So nahm sich jeder etwas" (statt: das Seine).

$56 \mathrm{Vgl}$. Haas, Unterwelts- und Jenseitsvorstellungen, 205f; $\mathrm{Neu}$, Der alte Orient, 108.

$57 \mathrm{Vgl}$. Otten / Siegelová, Gulక-Gottheiten.

58 Dieser Textabschnitt (KBo XXXII 13 I/II 28ff) ist von mir ausführlicher in meinem im Druck befindlichen Aufsatz "Miscellanea Hurritica" (Nuzi and the Hurrians 5) behandelt worden. 
in diesem Zusammenhang noch interessieren könnte, ohne Information bleibt $^{59}$.

10. Man wird sich fragen, welchen Stellenwert die mythologische Erzählung vom Fest der Allani im Rahmen eines Tafelwerks "Lied/Epos der Freilassung" einnimmt. Das versöhnungsvolle Bild der Götterwelt, wie es sich uns auf dem Fest von Allani darbietet, sollte vielleicht Vorbildfunktion für Harmonie und Aussöhnung auch in der Menschenwelt haben. Die Feststellung von Schuldenfreiheit, die Entlassung aus der Knechtschaft oder allgemein aus der Gefangenschaft und damit auch Rückkehr in den Familienverband waren zum Feiern und Fröhlichsein sicher Anlaß genug. Zu einer solchen Stimmung paßte dann auch eine Erzählung wie die vom versöhnungsvollen Fest der Allani, wo symbolhaft gar Himmel und Erde zusammenfanden. Das Fest der Allani kann für uns auch ein Hinweis darauf sein, daß damals mit bestimmten größeren Festen Schuldenerla $\beta$ und somit Freilassung von Menschen einhergingen. ${ }^{60}$

11.1 Der Gott Teššub spielt auch in dem Text einer anderen Tafel der Bilingue (KBo XXXII 15) eine, wie ich meine, höchst bemerkenswerte Rolle. Den betreffenden Textteil (C) hatte ich (Kap. 7) mit "Aufforderung zur Hilfe am Nächsten" überschrieben. Es war bereits die Rede davon (6.5), daß in den Feiern des altisraelitischen Jobeljahrs und seiner Institution des Schuldenerlasses und der Freilassung auch eine soziale Komponente zu sehen ist. Dies wird schon früher im nordsyrischen Raum im Zusammenhang mit ähnlichen, der persönlichen Rettung aus der Not dienenden Anlässen nicht viel anders

59 Es ist nicht auszuschließen, daß das eine oder andere kleine Textfragment, das wegen seiner allzu großen Bruchstückhaftigkeit keinen dafür charakteristischen Wortlaut enthält, inhaltlich doch noch dazugehort.

60

Vielleicht darf man in diesem Zusammenhang an die römischen Saturnalien erinnern (freundlicher Hinweis von Herrn Kollegen Prof. W. Burkert in der anschließenden Diskussion), wo es Brauch war, daß die Sklaven zusammen mit ihren Herren speisten, ja, daß die Herren sogar die Sklaven bei Tisch bedienten. Da die Feiern vor dem Tempel des Saturn am 17. Dezember stattfanden, sprach man mit Blick auf die Sklaven, die zeitweise herrenhafte Freiheit genossen. auch von libertas Decembris. Wie etwa die Feierlichkeiten des altisraelitischen Jobeljahres, mil denen Entlassung aus der Schuldknechtschaft verbunden war, besaßen auch die Saturnalien die mit dem Gleichheitsgedanken an die goldene Zeit unter der Herrschaft des Saturr erinnern wollten, eine deutlich soziale Komponente. Auch hat man mit griechischem Einfluf zu rechnen. Immerhin war auch die Tempelstatue des Saturn dem griechischen Kronos nach gebildet. Mit Kronos, dem im hurritischen Sukzessionsmythus bekanntlich Kumarbi entspricht sind wir dann auch wieder bei der Frage nach moglichem orientalischen Einfluß. Stellver tretend für andere Literatur über die Saturnalien seien hier die diesbezüglichen Artikel in RF II A 1 (1921) 201ff und OCD (1973) 955f genannt; zu den Kronien s. RE XI/2 (1922) 1983 und OCD (1973) 573f; Burkert, Kronia-Feste. 
gewesen sein. In dem besagten Textabschnitt (Nr. 15 I/II 4'ff) wird der Fall gesetzt, Gott Teššub selbst sei in Verschuldung und Not geraten. Man tut alles -zumindest fiktiv - um Teššubs Verarmung zu beseitigen und somit seine Freilassung zu bewirken. Die Schilderung der Rettungsmaßnahmen ist eindrucksvoll gestaltet; durch gewisse Wortwiederholungen erhalten die Aufforderungen an die (Mit-)Menschen eine gesteigerte Dynamik. Zur besseren Veranschaulichung zitiere ich (teilweise übersetzend, teilweise paraphrasierend) eine größere Textpassage:

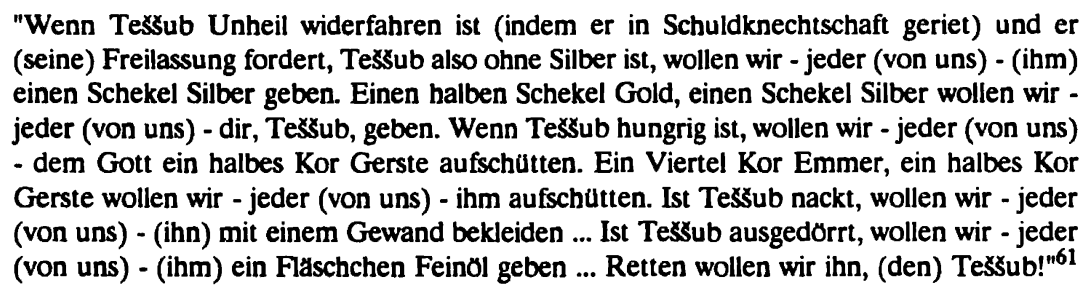

In einer altbabylonischen Dichtung ist übrigens Vergleichbares angesprochen, wenn nämlich dort an einen von seinen Leiden befreiten Menschen appelliert wird, nun seinerseits den in Not Geratenen zu helfen: "... Salbe den Ausgedörrten, speise den Hungrigen, tränke den Durstigen mit Wasser ..."62. A. Archi hat 1979 in der Festschrift für Emmanuel Laroche (39ff) unter dem Titel "L'humanité des Hittites" einige fragmentarisch erhaltene Abschriften althethitischer Texte in Bearbeitung vorgelegt, die zwar historischen Inhalts sind, aber einige Passagen enthalten, die das Thema Nächstenhilfe betreffen. Vielleicht haben gerade diese Textabschnitte mit wohlgemeinten Vorschriften wesentlich dazu beigetragen, daß man von dieser althethitischen Textkomposition im 13. Jh. v. Chr. Abschriften anfertigte. "Einem Hungrigen gib Brot", heißt es dort, "einem Durstigen aber gib Wasser, einem Ausgedörrten gib Öl, einem Nackten aber gib ein Gewand [ ]!" Mit Blick auf einen Kranken wird dort empfohlen: "Falls ihm Wärme lästig ist, schaffe ihn ins Kühle, und stört ihn die Kühle, bringe ihn in die Wärme!"63

\footnotetext{
S. zu diesem Abschnitt auch $\mathrm{Neu}$, Das Hurritische, 16f, wo auch auf einzelne hurritische Wörter eingegangen wurde. - Wenn sich im jüdischen Kulturkreis ein büßender Sünder, der mehrere Jahre "in Elend und bettelnd" durchs Land zog, sich selbst als "Baal Teschuba" bezeichnete (vgl. Friedlander, Sittengeschichte, 184ff), scheint der Ausdruck Teschuba nur außerlich an den in der Bilingue fiktiv als verarmt dargestellten Gott Tešub anzuklingen, da dem Wort Teschuba, wie mir Herr Kollege Prof. M. Weinhold (mündlich) freundlicherweise mitteilte, eine hebraische Wurzel zugrundeliegt. Ich danke Herrn Kollegen Prof. V. Haas, der mich auf den Begriff "Baal Teschuba" und auch auf die Ausführungen Friedländers aufmerksam machte.
}

2 Literaturhinweis s. Neu, Das Hurritische, 17 Anm. 44.

3 S. schon Neu, aaO 17 (mit Anm. 44). 19. 
11.2 Das Besondere an der Aussage der Bilingue ist der Umstand, daß man sich eine Gottheit, und zwar den höchsten Repräsentanten des hurritischen Pantheons, wie einen in Not, Verschuldung und Knechtschaft geratenen Menschen vorstellt, wobei man sich alle Mühe gibt, um Teššubs Rettung herbeizuführen. In der hethitischen Übersetzung jenes Textabschnitts werden die hurritischen finiten Pluralformen der 1. Person zwar auch durch Pluralformen der 1. Person, aber mit einer zusätzlichen Pronominalform, nämlich kuišša "jeder" bzw. "jeder (von uns)", wiedergegeben ${ }^{64}$, wie z.B. in dem schon zitierten Satzgefüge: "Wenn Teššub hungrig ist, wollen wir - jeder (von uns) - dem Gott ein halbes Kor Gerste aufschütten". Was also Teššub erhalten soll, beträgt nicht insgesamt ein halbes Kor Gerste, sondern jeder hat ein halbes Kor Gerste zu geben.

11.3 Zwar haben wir den soeben (11.1-11.2) behandelten Textabschnitt, den wir mit "Aufforderung zur Hilfe am Nächsten" überschrieben hatten, scheinbar wie einen innerhalb der Bilingue eigenständigen Textteil angesprochen, thematisch hebt er sich so auch heraus, aus dem Umstand aber, daß KBo XXXII 15 II 3'ff Duplikat zu KBo XXXII 16 II 16ff ist, ergibt sich, daß unser Textabschnitt $C$ (s. oben 7) zugleich Teil der verhältnismäßig umfangreichen 'Erzählung um die Stadt Ebla' (D) sein muß. In dieser mitunter etwas sagenhaft anmutenden Erzählung mit einem gewiß historischen Kern geht es immer wieder um die von außen an die Stadt herangetragene Forderung nach kirenzi/ parā tarnumar "Freilassung" bestimmter Personen (s. unten 12.3f). Für den Fall, daß diese Freilassung nicht erfolgt, wurden der Stadt Ebla Strafen angedroht. Vielleicht um die Dringlichkeit und Unabdingbarkeit einer solchen Forderung drastisch vor Augen zu führen, wird zu dem fiktiven Beispiel von dem in Not geratenen, infolge Verschuldung unfrei gewordenen Gott Teššub gegriffen - so, als wolle man damit etwa folgendermaßen argumentieren: Wenn Teššub sich in Schuldknechtschaft befände und er würde seine Freilassung fordern, tätet ihr doch sicher alles, um diese zu erwirken; folglich erfüllt so auch unsere Forderung nach der Freilassung bestimmter Personen! - Menschliche Nöte werden also fiktiv auf den Gott übertragen und die Notsituation des Gottes gilt ihrerseits wieder als Aufforderung und Mahnung, in vergleichbarer Situation befindlichen Menschen gegenüber sich nicht anders zu verhalten als gegenüber dem geknechteten Gott.

Zunächst etwas rätselhaft nehmen sich in KBo XXXII 15 II 13' im Anschluß an die Textstelle (s. oben 11.1) "Ist Těšub nackt, wollen wir - jeder (von uns) (ihn) mit einem Gewand bekleiden" die nach einer Rasur etwa in Zeilenmitte

64 Ausführlicher zu diesen Verbalformen s. Neu, Zum hurritischen Verbum, 223ff. 
stehenden Keilschriftzeichen AN UŠ UN aus ${ }^{65}$. Da in der hurritischen Spalte hinter dem Instrumental des Wortes für "Gewand" (a-la-a-la-e) ${ }^{66}$ noch e-ne, also das hurr. Wort für "Gott(heit)", geschrieben ist (I 12'; der Rest der Zeile ist unbeschrieben bzw. weggebrochen), wird für die eben genannten drei Keilschriftzeichen die Interpretation DINGIR-uš UN "(der) Gott (ist) Mensch" nahegelegt, was als eine Art von erläuterndem Zusatz besagen dürfte, daß sich Teššub hier in einer menschlichen (Not-)Situation befindet. ${ }^{67}$ Der gleiche Wortlaut begegnet ibid. II 17' (hurr. Entsprechung weggebrochen) unmittelbar vor dem Satz "Retten wollen wir ihn, (den) Teššub!" (s. oben 11.1).

12.1 Teššub tritt auch noch in einem anderen Textabschnitt der 'Erzählung um die Stadt Ebla' auf, nämlich dort, wo uns ein gewisser Mēki oder, wenn wir für die Umschrift der Sturtevantschen Regel Rechnung tragen, Mēgi begegnet. Dieser Name steht nicht isoliert, sondern findet gerade wieder Anschluß in Ebla, wo in einem Text aus der Zeit der dritten Dynastie von Ur ein Ensi von Ebla mit Namen MeGum überliefert ist. ${ }^{68}$ Hinsichtlich der Namensform sollte hier auch die bekannte Votivinschrift von Ibbit-Lim Erwähnung finden, auf welcher sich dieser Herrscher selbst als me-Ki-im eb-la-i-im bezeichnet ${ }^{69}$, also als Mēgi von Ebla. Schließlich sei noch ein Brief aus Mari hier herangezo$\operatorname{gen}^{70}$, wo im Rahmen der Korrespondenz mit Aplahanda von Karkemisch ein König Mëkim, allerdings ohne Angabe einer Stadt oder eines Landes, erwähnt wird. Unter Hinweis auf diesen Brief hat $\mathrm{H}$. Otten ${ }^{71}$ in seinem Beitrag zur Heidelberger Ebla-Tagung (1986) die Vermutung geäußert, daß, falls dieser Mëgi mit dem Mēgi der Bilingue personengleich sei, dann "zumindest Einzelzüge des 'historischen' Hintergrundes <der Ebla-Erzählung aus der Bilingue> auf die Zeit Šamši-Adads I. datiert werden <könnten>". In der Bilingue, auch

65 Das über die Rasur geschriebene Winkelhăkchen kennzeichnet die Zeileneinrückung. Im Duplikat KBo XXXII 16 II 27 ist am Zeilenende U]N erhalten, wahrend das Duplikat Nr. 52,1 ' noch UjS UN bewahrt hat.

Von der dazugehörigen Verbalform "wir wollen - jeder (von uns) - bekleiden" ist am Ende der Zeile I 11' nur noch der Wortausgang erhalten, doch laßt sich das Verbum mit Hilfe des Duplikats KBo XXXII 58 I 3' wieder herstellen; s. Neu, Zum hurritischen Verbum, 226 (1.5).

Wenn die hier gegebene Interpretation der betreffenden drei Keilschriftzeichen richtig ist, wird man I 12' vielleicht folgendermaßen lesen bzw. ergänzen dürfen: $e$-ne [ma-a-an-ni tar-šu-ua-ani]. Im Duplikat Nr. 16 ist die hurritische Entsprechung zu II 27 leider weggebrochen.

68 S. den diesbezüglichen Beitrag von Owen, MeGum, 263ff, wo in den Anmerkungen 3, 23 und $30 \mathrm{im}$ AnschluB an $\mathrm{P}$. Neve und $\mathrm{H}$. Otten auch schon auf die Bilingue kurz eingegangen ist.

$69 \mathrm{Vgl}$. Owen, MeGum, 269f. 271f, der den Ensi MeGum mit Ibbit-Lim für identisch hălt; Pettinato, Inscription, 19ff.

$70 \mathrm{Vgl}$. Owen, MeGum, 270 mit Anm. 24.

71 Otten, Ebla, 292 Anm. 17. 
in der hurritischen Vorlage, ist der Name Mēgi zwar mit dem Personendeterminativ versehen, doch könnte der Name ursprünglich auf einem Epitheton oder Herrschertitel der Könige von Ebla beruhen ${ }^{72}$. Wie die Dativform ${ }^{\mathrm{m}} \mathrm{Me}-\mathrm{e}$-ga-i KBo XXXII 19 III 34' (vgl. bruchstückhaft II 9) zeigt, wird der Name Mëgi in der hethitischen Fassung wie ein ablautender $i$-Stamm behandelt. Der Nominativ erscheint in der Graphie ${ }^{\mathrm{m}} \mathrm{Me}$-e-ki-is (KBo XXXII 15 III 10, 12, 18).

12.2 Wichtig für die Bilingue aus Hattuša bleibt in jedem Fall der Befund, daß der Name Mẽgi im nordsyrischen Raum durch entsprechende Namensoder Titelbezeugungen einen Anschluß findet, was der Erzählung um die Stadt Ebla immerhin eine gewisse historische Geltung verleiht. Ein Mann namens Zãzalla (Sohn des Pazzanikarri ${ }^{73}$ ), von dem es in der Bilingue heißt, daß er ein Vielredner (heth. mekki memišg/qatallaš KBo XXXII 16 II 6, 8) sei und $\mathrm{da} ß$ am Ort der Ratsversammlung niemand dessen Reden zu übertreffen vermag, dieser Zāzalla tituliert Mègi einmal als "Stern von Ebla"74.

12.3 Diesem Mègi droht man, wenn ich den Textzusammenhang richtig verstehe, nicht nur seine Sklaven und Sklavinnen, sondern auch Sohn und Ehefrau zu nehmen (KBo XXXII 15 IV 2ff bzw. III 3ff). Als Mēgi dies hört, beginnt er laut zu schreien und wirft sich Teššub zu Füßen nieder. Kniefällig spricht er zu Těšub: "(Er)höre mich, Teššub, großer König von Kumme!" Dabei erfahren wir u.a., daß er, Mēgi, seine Stadt Ebla von einer Schuld/einem Vergehen gereinigt hat (uašdulaz parkunut). Da die Tafel im folgenden nur bruchstückhaft erhalten ist, läßt sich für das Geschehen um Ebla leider nicht immer die gewünschte Klarheit gewinnen.

72 Vgl. Owen, MeGum, 270 Anm. 24 (Ende). Auch Herr Prof. J. Renger geht in einem Brief (vom 23.10.1985) an Herrn Prof. Otten (der mich inn freundlicherweise einsehen ließ) von einem Herrschertitel aus und macht auch mit Blick auf die Bezeichnung "Meki, Stern von Ebla" (s. unten 12.2 mit Anm. 73) einen Bedeutungsvorschlag. Im Anschluß an die Inschrift von Ibbit-Lim setzt er eine Nominativform (Partizip) meqïnum an und erwägt für Meki der Bilingue eine verballhornte oder mißverstandene Übernahme dieses Wortes, das er im Sinne von "der zum Aufstehen Bringende" deutet. Herrn Kollegen Renger danken wir sehr herzlich für seine Ausfübrungen. Diese Interpretation hătte dann auch ihre Konsequenz für die Umschrift des Epithetons. Syllabisch: ${ }^{\mathrm{m}} \mathrm{Pa}-a z-z[a-n i-k] a r-r i$. In der hurritischen Fassung ist dieser Name folgendermaßen geschrieben: ' $U a_{a}-a-z a-n i-g a-a r\left(-11 a_{a}-a\right.$ s) $)$ KBo XXXII 15 IV/III 17.

$74 \mathrm{URU}_{E-e b-I[u-] m e-n a-a s ̌}$ MUL-aš ${ }^{\mathrm{m}} M[e-e-k i-i \zeta$ KBo XXXII 16 II 13. Die hurritische Entsprechung ist weggebrochen. Vgl. die Varianten ${ }^{\mathrm{URU}}{ }_{E-e b-l a-u-m a-a s} \mathrm{Nr} .64,6$ ' und ${ }^{\mathrm{URU}} \mathrm{U}_{E-e b-l] u-u-}$ ma-aš Nr. 54, 12'. 
12.4 Die Tafel KBo XXXII 19, die ebenfalls von Mëgi und Ebla handelt, klärt uns darüber auf, wer die Personen sind, die Mēgi, der Herrscher von Ebla, freizulassen hat:

(hurr.) URU I-ki-in-kal-ǐ-hé-na-a-ma (Var. -na-ma) na-ak-ki bu-ut-ki-na ke-el-ta-a-i (Var. ge-e-el-t[a-) na-ak-ki-ma mour-ra-an = (heth.) DUMUMES URU I-ki-in-kal a[r-ha aš-šu-li tar-n(a)] ar-ha-ma-an tar-n $\left[a^{m} \text { Bur-ra-an }\right]^{75}$ "Die Sobne der Stadt Ikinkal ${ }^{76}$ laß im guten $^{77}$ frei! Frei laß aber (auch) ihn, (den) Burra!"

Von Burra heißt es dann u.a. weiter, daß er es ist, der neun (hurr. ta-am-ra, dam-ra) Königen zu essen geben wird. ${ }^{78}$ Offensichtlich gehört eine solche Funktion mit zu seinem Beruf. Was hat es aber mit den neun Königen auf sich?

Aus dem folgenden Textablauf erfahren wir, daß die Stadt Ikinkal(i) "am Thron" drei (hurr. ki-i-ke-e) Könige bewirtet und daß in Ebla sechs (hurr. še-esi-e) Könige "am Thron" bewirtet werden. ${ }^{79}$ Während den neun Königen Essen vorgesetzt wird, tritt ein zehnter (hurr. emmanzene) König vor Mēgi hin und versucht diesen auf gütliche Weise zur Freilassung der genannten Personen zu bewegen. Falls Mẽgi nämlich seiner Aufforderung Folge leiste, seien künftig Eblas Waffen siegreich, die Felder würden zum Ruhme der Stadt blühen und gedeihen. Dann beginnt der König, seinem Gegenüber zu drohen. Falls Mëgi die Freilassung verweigere, werde er nach sieben Tagen zurückkehren und abermals vor Mègi persönlich hintreten. ${ }^{80}$ Seine Drohungen präzisiert er folgendermaßen: "Ebla werde ich wie eine niemals vorhanden gewesene Stadt vernichten. Die Umwallung der Unterstadt (hurr. atašši) von Ebla werde ich wie einen Becher zerschlagen, die Umwallung der Oberstadt (hurr. kirhe)

75 Hurr.: KBo XXXII 19 I 1-3; vgl. IV 26'-27', Nr. 20 IV 15'ff, Nr. 21 I 1'f; Heth.: Nr. 19 II 1-2. vgl. III 26'-27', Nr. 22 II 1'f.

In der hurritischen Fassung ist neben die Bezeichnung für die Bewohner der Stadt Ikinkal(i)

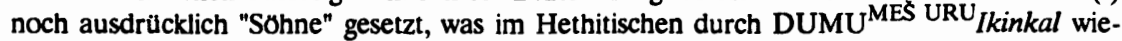
dergegeben wird. Außerhalb dieser Status constructus-Verbindung geht der Ortsname in der hurritischen wie in der hethitischen Fassung auf $i$ aus. Zum Versuch einer Lokalisierung s. Astour, Geographical and Political Structure, 142 (mit Anm. 25).154.

77 Dem heth. Ausdruck aššuli "im guten" entspricht der hurr. Instrumental k/geltai (zu keldi "Heil, Wohl, Gesundheit").

Der Ausdruck $z a z=u l=u s t=e r i$ Nr. 19 I $4=$ Nr. 20 IV 17' gehört als Partizip zum Verbum $z a z=u l$ - "verköstigen, bewirten"; zu den Partizipien auf eri s. Wilhelm, Gedanken, 55ff. Zu weiteren Formen dieses Verbums s. Neu, Zum hurritischen Verbum, 229f Anm. 17.

$79 \mathrm{Zu}$ den hurritischen Zahlwortern der Bilingue s. Neu, Neue Wege, 297f (mit Anm. 12.13).

80 Zur Bezeichnung der Begriffe Korper, Person, Selbst im Hurritischen s. Neu, Hurritisch edi und ištani. 
aber werde ich wie einen Abfallhaufen ${ }^{81}$ zertrampeln. Mitten auf dem Marktplatz aber werde ich (Eblas) Fundament ${ }^{82}$ wie einen Becher zerschlagen". In Ebla wird er also alles von oben nach unten kehren und die Herdstellen in den Fluß werfen (Nr. 19 I/II 38ff)

Das Ausmaß dessen, was hier angedroht wird, ist so gewaltig, daß man dies eher einem Gott als einem Menschen, und sei er auch König, zutraut. Das an das hurritische Zahlwort für "zehnter" angehängte Dativmorphem (Nr. 19 I 9) verstehe ich im Sinne einer Suffixaufnahme im Anschluß an zwei darauf folgende Dativformen, auch schon deshalb, weil sonst das Verbum des Satzes ohne Subjekt gewesen wäre. Bei einer vielleicht theoretisch möglichen Übersetzung "Vor den zehnten <König>, (nämlich) Mëgi, tritt er hin" wäre dann wohl Teššub der Sprechende gewesen. Die hethitische Übersetzung ist an der entscheidenden Stelle weggebrochen (doch s. Nr. 19 III 33'f, -as "er"), und auch das hurritische Duplikat Nr. 20 Rs. IV 20'f schafft wegen Bruchstückhaftigkeit keine Klarheit, allerdings ist dort, aber bereits in IV 12', Teššub genannt (zum dortigen Wortlaut IV 11'f vgl. Nr. 19 IV 24'f sowie unten 12.5).

Von insgesamt zehn Königen, die nach Ebla gekommen sind, - so möchten wir unter Vorbehalt vorerst den Textzusammenhang verstehen - lassen sich neun von ihnen - aufgeteilt in zwei Gruppen von drei und sechs Königen - dort "am Thron" bewirten, während der zehnte von ihnen sich vor Mēgi hinstellt und wohl als Wortführer die Forderungen vorträgt. Oder sollte die Aufteilung der Könige, von denen drei von der Stadt Ikinkal(i) bewirtet werden, besagen, daß vier Könige (einschließlich des Wortführers, des zehnten Königs) Ikinkal(i) und sechs Könige Ebla nahestehen?

Nirgendwo in der Bilingue ist Mēgi als König bezeichnet, doch könnte der Ausdruck "Stern von Ebla" dafür eine orientalisch-blumige Umschreibung sein. Wenn Mēgi aber, wie schon oben (12.1 Ende) erwogen, ursprünglich ein Titel für die Könige von Ebla gewesen sein sollte, würde dies das Fehlen der Bezeichnung "König" sinnvoll erklären. Der Titel wäre dann später irrtümlich als

81 Zur Übersetzung vgl. Otten, Ebla, 292. Zum hurr. Äquativ s. Neu, Varia Hurritica, 236ff. Heth. huššili- (KBo XXXII 19 II 30), hier mit 'Abfallhaufen' übersetzt, wurde auch als 'Lehmgrube' gedeutet, vgl. Eichner, Phonetik und Lautgesetze, 127 (mit Etymologie); BoysanDietrich, Das hethitische Lehmhaus, 7 mit Anm. 2. Herr Kollege A. Archi hat mir bereits früher (brieflich) bestătigt, daß die Beschreibung "Umwallung" der "Ober-/Unterstadt" von Ebla in tatsachlicher Übereinstimmung mit dem diesbezüglichen Grabungsbefund steht.

82 Meine Übersetzung "Fundament" für du-ti-ru-uh-hi (Nr. 214 I 6' du-ru-uh-hê) orientiert sich an turi "inférieur" (Laroche, Glossaire, 273), wăhrend Ottens Bedeutungsvorschlag "Mannschaft" auf turuhhi "male" (ebd. 274) Bezug nimmt. Die hethitische Entsprechung ist nicht erhalten.

Die Nennung eines Flusses in Verbindung mit dem flußlosen Ebla wird man als einen von der tatsăchlichen geographischen Lage unabhăngigen Topos einer allgemeinen Vernichtungsdrohung aufzufassen haben. 
Name verstanden und entsprechend mit dem Personendeterminativ versehen worden. Dies alles wäre mitzubedenken bei der obigen Überlegung, ob Mēgi als der "zehnte (König)" aufzufassen sei.

12.5 Darf man die bruchstückhafte Zeile (KBo XXXII 19 IV/III) 25' dahingehend verstehen, daß Teššub die Forderung des zehnten Königs nach Freilassung von Burra und 'Söhnen' der Stadt Ikinkal(i) unterstützt? Im Anschluß an dortiges heth. ú-e-ua-a]k-ki "er fordert nachdrücklich" ließe sich der hurr. Teil dieser Zeile vielleicht folgendermaßen interpretieren: Teššub ( $\left({ }^{\mathrm{D}} \mathrm{IM}-a s\right.$, Ergativ) weiß (paliia) (es) und fordert nachdrücklich die Freilassung (vgl. Nr. 15 I 4'f, II 5'). Der darauffolgende Wortlaut ist weitgehend parallel zu dem der Tafelvorderseite (ab I/II 1ff), wurde jedoch durch Setzung der Partikel -ua als zitierte Rede gekennzeichnet (s. schon ibid. III 9'). Wie die inhaltliche Entsprechung von Nr. 19 III 51' erst mit der Zeile ibid. II 25 zeigt, muß die zitierte Rede noch über die Tafel Nr. 19 hinausgegangen sein, was im dazugehörigen Kolophon (s. unteren Rand) zur Ergänzung [U.UL Q]A-TI "[nicht f]ertig" berechtigt. Es sei noch angemerkt, daß mir der Wortlaut von Nr. 20 IV 12'-13' zu umfangreich erscheint, um diesen in der bruchstückhaften Zeile (Nr. 19 IV) 25' unterbringen zu können; er ist inhaltlich möglicherweise vor $\mathrm{Nr}$. 19 I $1 \mathrm{zu}$ plazieren.

Wenn Teššub tatsächlich die Forderung des zehnten Königs unterstützt und sich gar dessen Wortlaut gegenüber zueigen macht, erscheinen Mëgis Kniefall vor Teššub und sein Versuch einer Rechtfertigung (12.3) in besonderem Licht.

12.6 Bleibt nun noch die Frage zu beantworten, ob Burra und die 'Söhne' von Ikinkal(i) in Kriegsgefangenschaft oder eher in Schuldknechtschaft des Herrschers von Ebla und seiner Leute geraten waren. Dafür müssen wir noch einmal auf die Tafel KBo XXXII 15 zurückgreifen; sie war bereits Gegenstand bei der Behandlung des Textteils C "Aufforderung zur Hilfe am Nächsten" (11.1). Teššub, wir erinnern uns, wird dort als verarmt, mittellos, ohne Nahrung und Kleidung beschrieben. Dieser Zustand stößt bei den Menschen, den Leuten von Ebla, auf spontane Hilfsbereitschaft. "Wenn Teššub ohne Silber ist, wollen wir - jeder (von uns) - (ihm) einen Schekel Silber geben ... (usw.) ... Retten wollen wir ihn, (den) Teššub". Den, der ihm ein solches Unheil zugefügt hat, werde man nicht freilassen. Nur wenige Zeilen später (I/II 22'ff) lesen wir, wobei die beiden Fassungen teilweise voneinander abweichen (ich gebe den Inhalt nach der hurr. Fassung wieder): "Die 'Söhne' von Ikinkal(i) lassen wir im guten nicht frei." Darüber, so heißt es in diesem Zusammenhang, würde sich weder Mēgi noch Burra freuen (auffallenderweise hat der hethitische Übersetzer in Verbindung mit Burra das Verbum nicht negiert; vgl. hinsichtlich Mēgi die gleiche Diskrepanz in Nr. 15 I/II 20’f). Bedeutet die Feststellung, Mëgi 
werde sich darüber nicht freuen, daß dieser etwa nicht allein über die Freilassung zu entscheiden hat?

Dafür könnte nämlich Nr. 15 IV/III $15 \mathrm{ff}$ sprechen, wo es sinngemäß heißt: Ich, Mẽgi, würde der Forderung schon nachkommen, aber meine Stadt und Zāzalla lehnen eine Freilassung ab. Zāzalla, der an anderer Stelle als Vielredner bezeichnet worden war (s. 12.2 Ende), macht dann auch in Nr. 16 II $12 \mathrm{f}$ Mēgi den Vorwurf der Unterwürfigkeit: ku-ua-at ha-li-ia-tar me-mi-i[š-ki-sii] "Warum sprichst du immer wieder (in solcher) Unterwürfigkeit?"

Die gleichen Leute, die in Text Nr. 15 bereit sind, dem in Not geratenen Teššub zu helfen, den Verursacher dieses Unheils aber ebenso wenig freilassen wollen wie die 'Söhne' von Ikinkal(i), stellen überraschenderweise noch die Überlegung an, was denn wäre, wenn die letzteren von ihnen ihre Freiheit erhielten: "Gesetzt den Fall ${ }^{84}$, wir lassen jene frei, wird auch uns jemand zu essen geben, uns, die wir (doch) unsere eigenen Mundschenken, Servierer, Köche und Aufwäscher sind" (KBo XXXII 15 I/II 26'ff).

Ist mit dieser Fragestellung Ironie verbunden oder hängt diese Aussage mit unserer Information aus Tafel Nr. 19 zusammen, wonach Burra ${ }^{85}$ es zukommt, die neun Könige zu bewirten (12.4)? Eine solche Aufgabe wäre natürlich nicht mit einer persönlichen Verarmung Burras in Einklang zu bringen. Dennoch scheint mir die in Nr. 15 gegebene enge Verbindung der Frage nach Freilassung der 'Söhne' von Ikinkal(i) mit dem dort geschilderten Rettungsbemühen hinsichtlich des in einer persönlichen Notlage befindlichen Teššubs eher für eine Haftung der 'Söhne' von Ikinkal(i) und Burras im sozialpolitischen Bereich als für eine Gefangenschaft im Zusammenhang mit kriegerischen Auseinandersetzungen zu sprechen. Vielleicht hat die Stadt Ikinkal(i) ihre seitens Ebla auferlegten Abgaben nicht im gewünschten Umfang entrichtet, so daß gleichsam in Stellvertretung für die schuldnerische Stadt einige ihrer 'Söhne' zusammen mit Burra ${ }^{86}$ von Mëgi in Schuldknechtschaft genommen worden waren. Dies stieß jedoch bei benachbarten Königen auf Ablehnung, die immerhin zehn? an der Zahl - sich nach Ebla begaben und dort (mit Unter-

Der Satz enthalt faktisches kuit.

In bruchstückhaftem KBo XXXII 10 III 3'f sind Burra und "Gefängnis" in unmittelbarem Zusammenhang genannt. Vom Verstandnis her vorerst unklar bleibt mir die dortige Aussage: $\check{S} A^{\mathrm{m}}$ Bur-ra-aš-s[a-an] hi-in-kán an-da ${ }^{\mathrm{NA} 4}{ }_{k u-u n-k u-n u-z i}$ iš-hi-ina-an[ "des Burra Untergang ist an einen $k$-Stein (= "Diorit?', Basalt") gebunden".

86

Mehrfach begegnet der Name Burra mit einem partizipialen Zusatz; vgl. KBo XXXII 15 II 24' A-NA 'm Bur-ra a-ap-pa pi-an-ti (ohne hurr. Entsprechung), Nr. 19 II $2 \mathrm{f}$ [ ${ }^{\mathrm{m}}$ Bur-ra-an] EGIRpa pi-ia-a[(n-t)a-an] mit der hurr. Entsprechung a-az-zi-i-ri II 3 (vgl. III 27'f). Das Epitheton bedeutet wörtlich "zurückgegeben", das hurr. Partizip auf -iri weist aber eher auf eine aktivische Bedeutung. Die Aufforderung an Mēgi, den "zurückgegebenen Burra" freizulassen, macht nur Sinn, wenn mit "zurückgegeben" gemeint ist: "zurückgegeben an die Stadt Ebla". Oder hat der hethitische Übersetzer ungenau übersetzt? 
stützung Teššubs?) Mēgi mit ihrer Forderung nach Entlassung der genannten Personen hartnäckig bedrängten. Mëgi scheint sich allerdings zu jener Zeit nicht gerade in einer politisch oder militärisch starken Position befunden zu haben, denn der Kniefall vor Teššub wie auch der Versuch einer Rechtfertigung sind doch eher Zeichen von Schwäche, möglicherweise innenpolitisch bedingt durch Rücksichtnahme auf Zāzalla und dessen Anhänger. Diese Überlegungen möge man noch als vorläufig betrachten (zu weiteren Einzelheiten s. StBoT 32).

12.7 Es sei noch erwähnt, da $ß$ zwei in der Bilingue bezeugte Personennamen den Namen der Stadt Ebla in sich tragen, nämlich $A r i b=I b l a$ und $P a i b=I b l a^{87}$. Die Namen lassen sich als "der Ebla gegeben hat" bzw. "der Ebla erbaut hat", deuten ${ }^{88}$. In den betreffenden Kontexten findet sich jedoch kein Hinweis, wie die beiden Personen zu diesen so bedeutsam anmutenden Namen kamen.

13.1 Nachdem wir uns bereits mit Teššub, Suuualiiat (Tašmišu) und Allani befaßt haben, wenden wir uns jetzt noch den übrigen Gottheiten der Bilingue zu. Da ist zunächst die Göttin Išhara, von der wir u.a. wissen, daß sie zusammen mit dem Mondgott (s. unten 15.2) für Eidesleistungen zuständig war. Dafür sprechen etwa die Militärischen Eide der Hethiter ${ }^{89}$ eine beredte Sprache. In der Bilingue jedoch scheint der besondere Bezug der Göttin Išhara zum Eid nicht gegeben. In bruchstückhaftem Kontext begegnet einmal die "Eideshand" bzw. "Schwurhand" (KBo XXXII 215, 7'). Išḩara tritt schon im Proömium des 'Epos der Freilassung' auf (KBo XXXII 11 I 1ff) und wird dort als siduri (si-tu-u-ri) "junge Frau, (engl.) lady" bezeichnet. Leider ist die hethitische Übersetzung zu den auch nur bruchstückhaft erhaltenen hurritischen Textkolumnen weggebrochen, so daß der hurritische Wortlaut im Detail dort noch Deutungsschwierigkeiten bietet. Die ersten drei Zeilen des Proömiums, die durch einen Abschnittsstrich vom darauf folgenden Text getrennt sind, lassen sich wie folgt übersetzen: "Erzählen will ich von Teššub von Kumme, (dem) gr[oßen] König; preisen will ich die jun[ge Frau] an den Riegeln der Erde, Alla[ni]". Wenn unsere Ergänzung si-i $i-t u-u-r i]$ am Ende von Nr. 11 I 2 richtig ist, wird hier auch Allani als siduri bezeichnet. "In Verbindung mit diesen (nämlich Teššub und Allani) will ich sprechen [ ] von der jungen Frau Išḩara", heißt es weiter im Proömium. Sie wird dann, so jedenfalls möchte ich die Zeile 6 verstehen, als eine Göttin, der Weisheit (mädi) eigen ist, beschrieben.

87 Belege s. KBo XXXII, S. XIII.

88 Zur Analyse s. Neu, Grammatik, 113 Anm. 4.

89 S. die diesbezügliche Textbearbeitung von Oettinger, Eide. Zu Išhara und ihrem Verhăltnis zur Medizin s. Burde, Hethitische medizinische Texte, $12 \mathrm{ff}$. 
13.2 Hurr. mädi, wovon schon oben (8.2) die Rede war (= heth. hattätar), begegnet sonst in den Boğazköy-Texten mehrfach als ein Charakteristikum des Gottes $\dot{E}-A$ (vgl. ${ }^{D} E$ - $A$ mädinibi "Ea der Weisheit", auch $\dot{E}-A$ mädunni "der weise $\mathrm{Ea})^{90} . \mathrm{Daß}$ der Göttin Išhara mädi "Weisheit, Klugheit" zugeschrieben wird, geschieht $\mathrm{m}$. W. hier in der Bilingue erstmalig. In Boğazköy-Texten wird Išhara mehrfach in Verbindung mit der Sonnengöttin der Erde genannt. Man hat daher auch Išhara zu den unterirdischen Gottheiten rechnen wollen (vgl. KBo XVII 94 III 26'ff). Das im Alten Orient weitverbreitete und schon sehr frühe Auftreten der Išhara (auch in den Ebla-Texten des 3. Jahrtausends v. Chr.) könnte auf eine alte Substrat-Gottheit schließen lassen.

In dem auf den Abschnitt mit Išhara folgenden, nur bruchstückhaft erhaltenen Paragraphen der Tafelvorderseite wird noch ein Mann namens ${ }^{\mathrm{m}} \mathrm{Bi}$-zi-karra Ni-i-nu-pa-ab-hi "Bizikarra von Ninua/Ninive"11 genannt, dem später eine Rolle in der Erzählung um Ebla zufällt. Ninive, wo Saušga (s. unten 15.3), die Schwester Těšubs, residierte ("Herrin von Ninive"), war ein altes (ost)hurritisches Kultzentrum.

13.3 Auf der fragmentarischen Rückseite der das Proömium enthaltenen Tafel (KBo XXXII 11 IV) findet ein Zwiegespräch zwischen Teššub und Išḩara statt, in dessen Mittelpunkt die Stadt Ebla zu stehen scheint. Zusammen mit Teššub und Suualiiat tritt Išhara auch in der Erzählung um Ebla auf (KBo XXXII 37 r. Kol. 14'). Wenn ich den bruchstückhaften Text richtig interpretiere, erhält Teššub am frühen Morgen eine Nachricht, die ihn veranlaßt, sich sofort aus dem Bett zu erheben. Er eilt zu einem Gespräch mit Tašmišu (Šuualiiat), dabei geht es um eine Freilassung. Offensichtlich wird dann Išhara aufgefordert, in die "Stadt des Thrones" (= Ebla) zu eilen. Išhara als die mit Weisheit Begabte könnte durch besonders kluge Ratschläge hervorgetreten sein. Das kleine Textbruchstück KBo XXXII 67 Rs.? IV bietet wieder einen Ausschnitt aus einem Zwiegespräch zwischen Išhara und Teššub.

14. Hinsichtlich des Lokalkolorits sollte hier aus dem Anfang des Proömiums neben dem schon erwähnten Bizikarra aus Ninua und der Stadt Ebla noch die Stadt Nuhašše genannt werden (KBo XXXII 11 I 9), die man zwischen Aleppo und Hāma zu lokalisieren hat. Der Ortsname tritt im Ablativ auf: URU $\mathrm{Nu-u-ha-}$ $a s ̌-s ̌ e-n i$ "von Nuhašše (nach Ebla)".

15.1 Auch der hurritische Sonnengott Šimigi ist in der Bilingue bezeugt, gleich dreimal in einem allerdings so bruchstückhaft erhaltenen Textstück (KBo XXXII 208 I 3, 13, 15), daß sich vorerst darüber nicht mehr aussagen läßt, als

$90 \mathrm{Vgl}$. Laroche, Glossaire, 163f, als ḩattannaš Lugal--ť̌ jetzt auch in Maşat bezeugt.

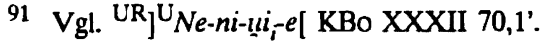


ben. Resümierend handelt es sich also um: Teššub von Kummi, den Großen König, den Herrschergott des hurritischen Pantheons; Šuualiiat, womit Teššubs Bruder Tašmišu gemeint sein dürfte; Ištar-Šaušga, die Schwester Teššubs; Allani, die Sonnengöttin der Erde; Išhara, die mit Weisheit begabte Göttin; Šimigi, den Sonnengott; Kušuh den Mondgott (in der Graphie ${ }^{D}$ ZUEN). Innerhalb des umfangreichen Textteils (B) "Fallbeispiele für menschliches bzw. zwischenmenschliches Verhalten" treten namenlose Familiengottheiten auf, die lediglich als "Gottheit des Vaters" oder als "Gottheit der Mutter" bezeichnet werden. Auch ist im gleichen Textteil allgemein die Rede von einer "Stadtgottheit". Das Gottheitsdeterminativ fehlt gelegentlich in der hurritischen Fassung ( $3 x$ bei Teššub, $2 x$ bei Allani, $1 x$ bei Šimigi). Mit dem Auftreten der genannten Gottheiten ist ein klarer Bezug der hurritischen Textkomposition zum hurritischen Pantheon gegeben. Die zentrale Rolle, die die Stadt Ebla innerhalb der Bilingue spielt, aber auch Ortsnamen wie Nuhašše oder Ikinkal(i) siedeln das Geschehen der Bilingue und damit die Entstehung der hurritischen Fassung im nordsyrischen Raum an.

17. Mit dem hurritischen "Epos der Freilassung" ist eine bisher einzigartige literarische Textkomposition von Nordsyrien nach Kleinasien gelangt. Vielleicht wird es verschiedene Beweggründe gegeben haben, die in Hattuša zur Anfertigung einer hethitischen Übersetzung davon führten. Auf einen möglichen historischen Gesichtspunkt, nämlich "Hुattušili I. als Sklavenbefreier im Ausland" war bereits hingewiesen worden (6.4). Wenn wir uns aber vergegenwärtigen, daß vor allem die mittelhethitische Sprachperiode sich in großem Umfang durch die Abfassung verschiedenster Instruktionstexte auszeichnete, wäre auch zu erwägen, ob nicht etwa die umfangreiche Sammlung von Fallbeispielen für korrektes menschliches Verhalten mit ein Auslöser für die Schaffung einer hethitischen Übersetzung gewesen sein könnte. Die Bilingue aus Hattuša, die gleich für mehrere Disziplinen Interessantes bietet, wird vor allem die hurritologische Forschung bei ihrem Bemühen, die hurritische Sprache noch besser in den Griff zu bekommen, dauerhaft befruchten. 
Bibliographie

Archi, A., L'Humanité des Hittites, in: FS E. Laroche (Florilegium Anatolicum), Paris 1979, 37-48 Astour, M.C., The Geographical and Political Structure of the Ebla Empire (Heidelberger Studien zum Alten Orient 2), Heidelberg 1988, 139-158

Börker-Klähn, J., Die archăologische Problematik der Hurriter-Frage und eine mögliche Lơsung, Xenia 21 (1988) 211-247 (mit Abb.)

Boysan-Dietrich, N., Das hethitische Lehmhaus aus der Sicht der Keilschriftquellen (THeth 12), Heidelberg 1987

Burde, C., Hethitische medizinische Texte (StBoT 19), Wiesbaden 1974

Burkert, W., Kronia-Feste und ihr altorientalischer Hintergrund, Bochumer Altertumswissenschaftliches Colloquium 13 (im Druck).

Charpin, D., Les Décrets Royaux à l'Époque Paléo-Babylonienne. À Propos d'un Ouvrage Récent, AfO 34 (1987) 36-44

Eichner, H., Phonetik und Lautgesetze des Hethitischen - ein Weg zu ihrer Entschlüsselung, in: M. Mayrhofer, M. Peters und O.E. Pfeiffer (Hg.), Lautgeschichte und Etymologie. Akten der VI. Fachtagung der Indogermanischen Gesellschaft, Wien 1978, Wiesbaden 1980, 120-165

Friedlander, D., Zur Sittengeschichte der Juden. 3. Wandernde Büßer, Neue Berlinische Monatsschrift 22 (1809) 184-190

Goetze, A., The Theophorous Elements of the Anatolian Proper Names from Cappadocia, Language 29 (1953) 263-277

Gurney, O.R., Some Aspects of Hittite Religion (The Schweich Lectures 1976), Oxford 1977

Güterbock, H.G., The God Suwaliyat Reconsidered, RHA XIX/68 (1961) 1-18

- Hethitische Literatur, in: $K$ von See, Neues Handbuch der Literaturwissenschaft, Bd. 1: Altorientalische Literaturen, hg. von $W$. Rölig, Wiesbaden 1978, 211-253

- Religion und Kultur der Hethiter (Historia Einzelschriften 7), Wiesbaden 1964, 54-73

- The Song of Ullikummi. Revised Text of the Hittite Version of a Hurrian Myth, JCS 5 (1951) 135-161; JCS 6 (1952) 8-42

- / Hoffner, HA., The Chicago Hittite Dictionary L-N, Chicago 1989

Haas, $V$., Die Unterwelts- und Jenseitsvorstellungen im hethitischen Kleinasien, Or. 45 (1976) 197 212

- Ein Preis auf das Wasser in hurritischer Sprache, ZA 79 (1989) 261-271

- / Wilhelm, G., Hurritische und luwische Riten aus Kizzuwatna. Hurritologische Studien I (AOATS 3), Kevelaer / Neukirchen-Vluyn 1974

Hoffner, HA. Jr, The Song of Silver. A Member of the Kumarbi Cycle of "Songs", FS H. Otten, Wiesbaden 1988, 143-166

- $\rightarrow$ Güterbock, H.G.

Klengel, $H$., Lullubum. Ein Beitrag zur Geschichte der altvorderasiatischen Gebirgsvolker, MIO 11 (1965) 349-371

- Lullu(bum), RLA 7,3./4. Lfg. (1988) 164-168 
Laroche, E., Les dénominations des dieux "antiques" dans les textes hittites, FS Güterbock, Wiesbaden 1974, 175-185

- Glossaire de la langue Hourrite, Paris 1980

Loretz, $O$., Habiru-Hebraer. Eine sozio-linguistische Studie aber die Herkunft des Gentiliziums 'ibri vom Appelativum habiru, Berlin / New York 1984

Neu, E., Zum Wortschatz des Hurritischen aus synchroner und diachroner Sicht, in: W. Meid (Hg.), Studien zum indogermanischen Wortschatz (IBS 52), Innsbruck 1987, 167-188

- Das Hurritische: Eine altorientalische Sprache in neuem Licht (AAWLM.G 3) Mainz / Stuttgart 1988

- Hurritische Verbalformen auf ai aus der hurritisch-hethitischen Bilingue, FS W. Thomas (Specimina Philologiae Slavicae Supp. 26), München 1988, 503-513

- Varia Hurritica. Sprachliche Beobachtungen an der hurritisch-hethitischen Bilingue aus Hattusa (FS H.O. Otten), Wiesbaden 1988, 235-254

- Zum hurritischen 'Essiv' in der hurritisch-hethitischen Bilingue aus Hattusa, Hethitica IX (1988) $157-170$

- Zur Grammatik des Hurritischen auf der Grundlage der hurritisch-hethitischen Bilingue aus der BogazkOy-Grabungskampagne 1983, Xenia 21 (1988) 95-115

- Neue Wege im Hurritischen. XXIII. Deutscher Orientalistentag. Ausgewahlte Vorträge Würzburg 1985 (ZDMG. Supp. VII), Stuttgart 1989, 293-303

- Zum Hethitischen Verbum. Gs E. von Schuler (Or. 59/2), Roma 1990, 223-233

- Der alte Orient. Mythen der Hethiter, Bochumer Altertumswiss. Colloquium 2 (1990) 90-117

- Hurritisch edi und ǐstani in der hurritisch-hethitischen Bilingue aus Hattuگa, Hethitica XI (1992) $129-136$

- Der hurritische Absolutiv als Ortskasus. Zur Syntax der hurritisch-hethitischen Bilingue aus Hattuša (FS S. Alp), Ankara (im Druck)

- Miscellanea Hurritica. Studies on the Civilization and Culture of Nuzi and the Hurrians 5 (im Druck)

- Zur mittelhethitischen Sprachform der hurritisch-hethitischen Bilingue aus Hattusa (GS J. Klíma), Praha (im Druck)

- $\rightarrow$ Rüster, Chr.

Neve, $P$., Die Ausgrabungen in Bogazkoy-Hattusa 1983, mit einem Beitrag von $H$. Otten, AA 1984, 329-381

Nougayrol, J. $\rightarrow$ Parrot, $A$.

Oettinger, N., Die Militărischen Eide der Hethiter (StBoT 22), Wiesbaden 1976

- Die 'dunkle Erde' im Hethitischen und Griechischen, WO 20/21 (1989/90) 83-98

Otten, $H$., Blick in die altorientalische Geisteswelt. Neufund einer hethitischen Tempelbibliothek (JAWG 1984), Gottingen 1985, 50-60

- Ebla in der hurritisch-hethitischen Bilingue aus Bogazkoy (Heidelberger Studien zum Alten Orient 2), Heidelberg 1988, 291-292

- Die Altorientalistik - Quellenforschung und faszinierendes Erlebnis (AAWLMG Jubilaumsschrift 1949-1989), Mainz / Stuttgart 1989, 251-258

- Die Textfunde der Ausgrabungen in Bogazkoy-Oberstadt, X. Türk Tarih Kongresi'nden ayribasım, Ankara 1990, 113-120 (mit Abb.)

- / Rüster, Chr., Die hurritisch-hethitische Bilingue und weitere Texte aus der Oberstadt (KBo XXXII), Berlin 1990

- / Siegelová, J., Die hethitischen Gulš-Gottheiten und die Erschaffung der Menschen, AfO 23 (1970) 32-38 
Owen, D.I., MeGum. The First Ur III Ensi of Ebla, in: L. Cagni (Ed.), Ebla 1975-1985. Dieci anni di studi linguistici e filologici. Atti del Convegno Internazionale, Napoli 1985 (Istituto Universitario Orientale, Dipartimento di Studi Asiatici, Series Minor XXVII), Napoli 1987, 263-291

Parrot, A. / Nougayrol, J., Un document de fondation hurrite, RA 42 (1948) 1-20

Paulys Realencyclopadie (RE) der classischen Altertumswissenschaft, Neue Bearbeitung, Stuttgart 1893ff

Pecchioli Daddi, F. / Polvani, A.M., La mitologia ittita (Testi del Vicino Oriente antico 4/1), Brescia 1990

Pettinato, G., Inscription de Ibbit-Lim, Roi de Ebla, AAAS 20 (1970) 19-22

Ruster, Chr. / Neu, E., Hethitisches Zeichenlexikon. Inventar und Interpretation der Keilschriftzeichen aus den Bogazkoy-Texten (StBoT Beiheft 2), Wiesbaden 1989

- $\rightarrow$ Otten, $H$.

Salvini, M., Die hurritischen Überlieferungen des Gilgamesch-Epos und der Keši-Erzăhlung, Xenia 21 (1988) 157-172

- Sui testi mitologici in lingua hurrica, SMEA 18 (1977) 73-91

Siegelová, $J$. $\rightarrow$ Otten, $H$. 



\section{Edward Noort}

Seevölker, materielle Kultur und Pantheon

Bemerkungen zur Benutzung archäologischer Daten - ein kritischer Bericht

\section{Die Quellen und die Theoriebildung}

Die Fülle und die Diversität des Materials zur Seevölkerfrage drängen zu einer Reduzierung auf die wesentlichen Elemente, die forschungsgeschichtlich zur Theoriebildung beigetragen haben.

Man kann diese Bausteine folgendermaßen gliedern:

1. Die Texte und Reliefs aus dem Totentempel des Ramses III in Medinet Habu und weitere ägyptische Texte. ${ }^{1}$

2. Die Zerstörungshorizonte (Brandschichten) in Kleinasien, Nordsyrien, auf Zypern und an der Küste Palästinas.

3. Die sogenannte Philisterkeramik und ihr Verhältnis zur Myk IIIC $1 \mathrm{~b}$ und Myk IIIB Ware. ${ }^{2}$

4. Neuere Texte aus der Zeit des Untergangs des Hatti-Reiches und aus den letzten Tagen Ugarits. ${ }^{3}$

Von diesen Bausteinen möchte ich an dieser Stelle den 4. Punkt, die hauptsächlich ugaritischen Texte, auf sich beruhen lassen. Diese Texte erhellen die letzten Tage Ugarits und das Verhältnis zwischen Ugarit, Alašia und Hatti, an sie sind aber keine methodischen Fragen zu stellen. In diesem Kontext möchte ich im Vorübergehen nur zwei Punkte hervorheben.

Nelson, Medinet Habu I; Nelson, Medinet Habu II; Wreszinski, Atlas; Edgerton / Wilson, Historical Records; Stadelmann, Abwehr; Kitchen, Inscriptions; Liverani, Memorandum; Widmer, Darstellung; Helck, Seevolker; Spalinger, Military Documents; Edel, Seevölkerbericht; Bleiberg, Historical Texts; Helck, Seevölkerbericht; Cifola, Ramses III; Görg, "Bundesterminologie". - Zur Diskussion um die historische Auswertung des Med. Habu Textes aus dem 8. Jahr des Ramses III: Hölbl, Aussagen, hălt die Reihenfolge der Feindländer für historisch, weil er in dieser Sequenz kein traditionelles Element entdecken kann (contra Helck, Seevölker). Lehmann, der die zur Zeit wohl umfassendenste Übersicht verfaßte, stimmt Hobl im wesentlichen zu (Lehmann, Welt).

Eine Literaturauswahl, die für den heutigen Diskussionsstand wichtig ist:

Position 1: M. Dothan, Ashdod; T. Dothan, Philistines, 94-218; ders., Some Aspects; ders., The Philistines Reconsidered.

Position 2: Mazar, Emergence.

Position 3: Brug, Study; H. Weippert [die die Studie Brugs nicht benutzt], Palästina, 373-382.

3 Literatur mit Texten und Diskussion bei Lehmann, Welt. Hervorgehoben seien: Lehmann, Šikalājū; Hoftijzer, Ugaritische brieven; de Moor, Rise, $146 \mathrm{f}$. 
a) Der Šikalājū-Text von 1978 nennt zum ersten Mal "in einem Dokument der hethitischen Staatenwelt" eindeutig ein Seevölker-Ethnikon mit der zusätzlichen Charakterisierung: "die auf Schiffen wohnen" - im Gegensatz zu allen anderen ugaritischen Texten, die nur von dem "Feind" oder von den "Schiffen des Feindes" reden. ${ }^{4}$

b) Der berühmte hethitische KBO XII $38 \mathrm{Text}^{5}$, in dem Šuppiluliuma II über eine siegreiche Seeschlacht und eine Invasion Alašias berichtet, kann, soweit ich sehe, nicht anders verstanden werden als eine Aktion gegen Gruppen, die mit einer Chiffre "Seevölker" zu versehen sind ${ }^{6}$ und sich auf der Insel festgesetzt haben.

Die Trias unserer Fragestellung "Seevölker", "materielle Kultur" und "Pantheon" möchte ich so angehen, daß zuerst gefragt wird nach

1. dem Aussagewert der literarischen und ikonographischen Überlieferung in Medinet Habu;

2. der Keramik: die sogenannte Philisterkeramik in ihrem synchronen und diachronen Kontext: Myk IIIC $1 \mathrm{~b}$ und Myk IIIB. Von hier aus findet dann eine Gewichtung des feldarchäologischen Befundes in Bezug auf die Zerstörungshorizonte statt.

3. Schließlich soll im Rahmen der ersten beiden Punkte gefragt werden, ob bei den Seevölkergruppen so etwas wie ein eigenständiges Pantheon sichtbar wird.

\section{Medinet Habu}

Der wohl folgenreichste Satz zur Deutung der Ereignisse in der ausgehenden Spätbronzezeit findet sich im Totentempel in Medinet Habu und beschreibt das Auftreten des Ramses III gegen die ihn bedrängenden Nordvölker in seinem 8. Regierungsjahr. Über die Feinde wird dort gesagt:

"Nicht hielt irgendein Land vor ihren Armen stand; (und die Lander) von Hatti, Qadi? Qarqemiš, Arzawa ${ }^{8}$, und Alasia ${ }^{9}$ an waren (nun) entwurzelt [auf einen Schlag]."10

4 Lehmann, Sikalājū, 485.

5 Gïterbock, Hittite Conquest.

6 Vgl. die Kontroverse zwischen Muhly, Role, und Mazar, Settlement.

7 M. Weippert, Beleg, 39ff [KTU 1.40]; Dietrich / Loretz, Land, 390 [KTU 2.36]. Wahrscheinlich befindet sich Qadi Ostlich von Ugarit, kann also nicht mit Kizwadna gleichgesetzt werden.

Süd-West Anatolien, siehe die Karte bei M. Weippert, Beleg, 38. 
Die geographische Anordnung ist hier nicht linear gemeint, sondern nennt zuerst das einzige echte Machtzentrum außerhalb Ägyptens (Hatti), danach die Außenposten des hethitischen Machtbereiches auf der palästinischen Landbrücke in Syrien (Qadi, Qarqemiš) und schließlich die Randbereiche an der Küste, inklusive Zypern (Arzawa und Alašia). ${ }^{11}$ Ein solches, räumliches Denken ist uns auch aus den geographischen Listen des Alten Testaments bekannt. $^{12}$ Hier wie dort liegt bei bestimmten Schemata weder ein lineares Fixpunktsystem und noch weniger ein Itinerar vor, sondern eine Totalitätsbeschreibung, die von dem zentralen Ort oder der Gegend zuerst zu den Randbereichen führt, um von dort aus das Ganze zu erfassen.

Für unseren Satz würde das bedeuten, daß hier weder eine lose Aufreihung noch eine Reihenfolge der dem Feind zu Opfer gefallenen Staaten und Städte in einem Kriegsitinerar geboten wird, sondern die Totalität des nicht-ägyptischen Machtbereiches im Norden. ${ }^{13}$

Eine solche Interpretation wird bestätigt durch den externen Parallelismus mit dem "Zitat" des Vorhabens der Feinde in der Ramsesrede: "Sie legten ihre Hände auf die Länder bis zum Umkreis der Erde; ihre Herzen waren zuver-

9 Zypern, contra Strange, Caphtor/Keftiu, der Caphtor/ Keftiu nach Zypern verlegen möchte und deswegen Alasia (mit Einschrănkung) an der syrischen Küste sucht.

Der ganze Abschnitt findet sich Med.Habu PI.46,16-18; KRI V 39,14-40,5. Die heutige Diskussion des Gesamttextes spitzt sich zu auf die Úbersetzung von jij sdtt: "eine Trennung vollziehen" (mit Fehldeterminierung: Helck, Holbl) oder "ein Bündnis schließen" (Edel und Gơrg, der das akkadische sudutu "Kundmachung" ins Spiel bringt), auf das Hapaxlegomenon jnmkt mit dem Possessivartikel $t 3 y$-w (Edel, Görg, der auch hier eine akkadische Wurzel, magaru(m) N-Stamm "sich einigen", heranzieht), "Bund"(?), auf die Rolle der "Flamme" als Sperre von seiten der Ägypter (Edel) oder als Ergebnis des Vormarsches der Seevölker (Helck). Philologisch sind alle Vorschlage mit Unsicherheiten belastet. Diese Verlegenheit wird bei der historischen Rekonstruktion des Gesamtphănomens zu wenig berücksichtigt. Für die Interpretation unseres Satzes spielt sie aber keine Rolle. Vgl. Helck, Seevölker und ders., Seevölkerbericht; Edel, Seevölkerbericht; Hölbl, Aussagen; Görg, "Bundesterminologie".

11 Obwohl die Historizităt der Feindvolkerliste aus Medinet Habu schon ofter mit Fragezeichen versehen wurde (Janssen, Ramses III), bildete sie de facto das Gerüst der historischen Rekonstruktion einer Zangenbewegung der Seevolkergruppen. So geschieht es noch bei Lehmann, Edel und differenziert bei Holbl. Energischer Protest kam von Helck, der darauf hinwies, daß hier nicht ein Landweg (Hatti, Qadi, Qarqemiš) und ein Seeweg (Arzawa, Alašia) beschrieben werden, sondern zuerst Hatti mit seinem direkten Machtbereich und danach die Staaten, die nicht direkt unter hethitischer Herrschaft standen. Helck hat zweifellos recht mit der Behauptung, daß hier kein Itinerar vorliegt. Ob die agyptische Darstellung jedoch die exakten Machtverhalltnisse listenmaßig erfaßt, darf bezweifelt werden.

12 Noort, Transjordan, 126.

Vielleicht spielt die Fünferzahl hier auch eine Rolle. Es ist auffällig, daß im Alten Testament die Totalităt der Feinde ofter mit einer Fünferzahl ausgedrückt wird: die Konige von Sodom, Gomorra, Adama, Zeboim und Zoar in Gen 14,2; die fünf Konige der Amoriter: Jos 10,5, die fünf Stadtfürsten der Philister: Ri 3,3. 
sichtlich und vertrauensvoll: «Unsere Pläne werden gelingen!»."14 Die Totalität des angeblich im Ansturm eroberten Gebietes korrespondiert mit der der Angriffspläne und mit der Totalität der als Einheit ("Bund") auftretenden Angriffsmacht.

Die Rezeptionsgeschichte zeigt, daß der Text aber direkt historisch umgesetzt wurde. Um bei meinem eigenen Fach zu bleiben: Die "Geschichten Israels" vermittelten und vermitteln noch immer das Bild einer massiven, militärisch- aggressiven Völkerwanderung. ${ }^{15}$

Kurz gesagt: Eine ethnische Gruppe, mit der Chiffre "Seevölker" versehen, bricht auf aus der Ägäis, durchwandert Kleinasien, zerstört das Hethiterreich, verwirrt Nord-Syrien, vernichtet Ugarit und Alalah, erobert Zypern, greift in einer Zangenbewegung vom Meer aus Ägypten an, wird dort jedoch abgedrängt und ist schließlich nur noch archäologisch und literarisch als Philister in Palästina belegt. Die übrigen Gruppen sind nur noch philologisch, nicht aber mehr materiell greifbar. ${ }^{16}$

14 Med.Habu PI.46, 18.

15 So klassisch bei Noth, Geschichte, 39f.41: "Dieser 'Seevolker'- Ansturm war nur der letzte Auslaufer einer umfassenden Volkerbewegung, die von Norden her uber die ostliche Mittelmeerwelt kam... Mit Kind und Kegel kamen diese Wanderer teils auf Ochsenkarren offenbar an den Küsten entlang gezogen, teils auf Schiffen von Insel zu Insel oder lăngs des Ostrandes des Mittelmeeres gefahren. Kleinasien wurde von ihnen durchzogen, und hier wurde das Hethiterreich ein Opfer ihres Ansturms und nahm ein plotzliches Ende. An der syrisch palästinischen Küste zogen sie nach Süden. Auf der anderen Seite scheinen sie auch von Griechenland und den Griechischen Inseln her nach der libyschen Küste Nordafrikas übergesetzt zu sein und von dieser Seite her Ägypten bedroht zu haben. An den Grenzen Ägyptens aber brachen sich die letzten Wellen dieser Bewegung... So liegt der Schluß nahe, daß die Landnahme der Philister nicht ohne die stillschweigende oder sogar ausdrückliche Zustimmung der Pharaonen erfolgte, die damit die Abwehr dieses 'Seevolkes' von Ägypten selbst durch seine Ansiedlung im benachbarten Palästina sicherten." - Dreißig Jahre spatter hat sich das Bild noch nicht sehr geandert: Soggin, History, 53f: "At the end of the thirteenth century and the beginning of the twelfth they were the effective cause of the fall of the Hittite empire and of the Syrian city-states of Ugarit and Alalakh... From Syria they pressed on towards Egypt by land and sea, but were thrust back by Ramses III. The same Pharaoh then settled them in the southern coastal region of Palestine, which in fact took its name from them. They continued to live there, for some time at least nominally the vassals of Egypt." Das gleiche Bild steht de facto auch hinter dem Forschungsbericht A.Strobels: Strobel, Seevölkersturm (sic!). Die einflußreiche Studie: $T$. Dothan, Philistines, beschreibt zwar das feldarchäologische Material in Israel, baut aber gleichfalls auf dem Medinet-Habu Bild auf. Das bedeutet nicht, da $B$ keine Differenzierungen vorgenommen werden. Sie beschrănken sich aber meistens auf das "Abschălen" des "Propagandateils" der Medinet-Habutexte und den Rückgriff auf einen "historischen Kern". - Prinzipiell-kritische Ansătze bei: Brıg, Study; Helck, Seevollkerbericht, 138ff sowie im Standardwerk zur Palästina-Archăologie: H. Weippert, Palăstina, 363-386.

16 Es fehlt aber nicht an Versuchen in der Palăstinaarchăologie, Differenzierungen anzubringen (Dor, Akko), die jedoch von außen an das Material herangetragen werden. 
Wir haben es also mit einer Wanderungstheorie zu tun, die eine archäologische (z.B. Brandschichten) und eine historische (z.B. Fall des Hethiterreiches) Problematik lösen soll, wobei die Quelle hauptsächlich literarisch (Texte sind Reliefs aus Medinet Habu) sind. Umgekehrt wird mit der materiellen, der feldarchäologischen Quelle so verfahren, daß archäologisches Material, das sich von den Formenkreisen seiner Umgebung unterscheidet, kausal mit einer ethnisch beschriebenen Gruppe verbunden wird (z.B. wird die "Philisterkeramik" gedeutet als Zeichen für die Herrschaft und/oder Anwesenheit der Philister). In diesen beiden Kombinationen wird das methodische Problem sichtbar.

Inwieweit besteht nun die Möglichkeit, diese Aussage über die Eroberung der alten Welt von Hatti bis Alašia tatsächlich "ideo-geographisch" -und nicht direkt historisch - zu verstehen?

1. Das Verhältnis von Architektur, Relief und Text in Medinet Habu als Differenzierung der historischen Aussage

Sehen wir uns die Architektur und das damit verbundene Konzept an ${ }^{17}$ und führen wir uns das Verständnis des Tempels als "Abbild der ganzen Welt"18 vor Augen, dann ist es nicht zufällig, daß sich die Kriegsreliefs und Kriegsberichte hauptsächlich auf den Außenseiten der Tempelmauern befinden und die mit dem Kult verbundenen Darstellungen vor allem auf deren Innenseiten.

Dies läßt sich auch durch die geographische Anordnung der Reliefs und Texte unterstützen:

Ausgehend von der Ansicht des Nils als idealer Nord-Süd-Achse ist der Tempel - fiktiv gesehen - von Osten nach Westen ausgerichtet. Weil aber der Nil nun einmal nicht in einer geraden Linie vom Süden nach Norden strömt, zeigt die Kompaßrichtung eine andere Einteilung: Danach liegt der eigentliche

17 Ein medianer Lăngsschnitt durch die Tempelanlage von Südost nach Nordwest zeigt einerseits, $\mathrm{da} B$ der Boden langsam ansteigt, anderseits, da $B$ der erste Pylon höher ist als der zweite, wăhrend die Decken der Răume sich nach hinten stăndig senken. Bei dieser Einteilung spitzt sich alles auf den hinteren Raum mit dem Amunheiligtum zu. Das gleiche gilt für eine Obenansicht des Tempels. Der erste Pylon ist breiter als der zweite, und von dort aus werden die Răume der Breite nach enger. Bei der gleichen Raumausfüllung sind von der Langsachse aus gesehen im zweiten Innenraum vier Săulen an jeder Seite notwendig, im năchsten drei, im darauffolgenden nur zwei und schließlich nur noch eine. Auch hier zeigt sich die architektonische Bewegung auf das Zentrum des Amunheiligtums zu.

Widıner, Darstellung, 70; Arnold, Wandrelief. 
Osten vorne rechts, der wirkliche Norden rechts hinten, der Westen links hinten und der Süden in der vorderen linken Ecke. ${ }^{19}$

So ist der Tempel ein Abbild des Kosmos, in dem der Pharao alle diesen Kosmos bedrohenden Feinde vernichtet.

In der Zeit der 20. Dynastie besteht der Kanon der zu besiegenden Feinde Ägyptens aus folgenden Gruppen: im Westen die Libyer, im Norden die Seevölker, im Süden die Nubier, im Osten die Asiaten.

So haben die großen Reliefs über den Kampf Ramses III gegen die Seevölker einen Platz auf der nördlichen Außenmauer gefunden, der Krieg gegen die Asiaten wird auf der nördlichen Mauer an der Ostecke dargestellt. Die Reliefs über den Kampf gegen die Nubier findet man auf der südlichen Hälfte der westlichen Außenmauer. Der Kampf gegen die Libyer ist Thema auf der nördlichen Hälfte der Westmauer. Die Funktion dieser Reliefs und der dazugehörigen Texte ist also eine andere als die einer rein historischen Berichterstattung. Es wird der Kanon der zu besiegenden Feinde aufgeführt. Daß hier die ideelle Funktion Vorrang hat vor chronistischer Berichterstattung, daß hier ein Kerygma die Geschichte in Dienst nimmt und nicht umgekehrt, zeigen Anfang und Ende der Kriegsberichterstattung. Weder den Krieg gegen die Nubier noch den gegen die Asiaten hat, soweit wir wissen, Ramses III je geführt. Diese Kriegszüge wurden von seinem großen Vorbild, Ramses II, auf ihn übertragen, um den Kanon zu vervollständigen.

Zudem zielt nach der Beobachtung Widmers die merkwürdige Aufteilung des ersten Libyschen Krieges (nördliche Westmauer, westliche Nordmauer und Innenseite des 2. Hofes) auf die deutliche Hervorhebung des Seevölkerkrieges, und zwar auf den zentralen Text des Pl.46: "Als Zentrum der fünf Kriegsberichte hat die Inschrift am zweiten Pylon (Tf. 46) zu gelten: Alle Erzählungen, endend mit der Darbringung der Gefangenen...laufen auf sie zu." ${ }^{20}$

So unterstreicht die Raumgestaltung des Medinet Habu Tempels einerseits die Hervorhebung der Seevölkerreliefs und -texte, andererseits machen die Funktion dieser Seevölkerdarstellung und deren Einbindung in ein übergreifendes Konzept deutlich, daß diese Darstellungen nicht ohne weiteres historisch umgesetzt werden können.

Die formkritische Analyse der Texte ergibt noch eine weitere Differenzierung. $\mathrm{Da} B$ die Inschriften in Medinet Habu bestimmte Formmerkmale aufweisen, ist keine neue Einsicht. Inhaltliche und formelle Gliederungen sind bei

19 Daß diese geographische Orientierung Einfluß auf die bildlichen Darstellungen hat, zeigt der erste Pylon, wo auf der rechten, nach Norden ausgerichteten Seite der Pharao eine Gruppe Feinde festhalt, genauso wie auf der linken, nach Süden ausgerichteten Seite. Auf der nach Norden ausgericheten Seite trăgt er die Krone von Unter-Ägypten, auf der nach Süden ausgerichteten Halfte jedoch die Krone von Ober-Ägypten.

20

Widmer, Darstellung, 71. 
der Beschreibung der religiösen und militärischen Vorbereitung der Kämpfe und des Sieges sowie beim religiösen Abschluß des öfteren vorgenommen worden. ${ }^{21}$ Eine Präzisierung dieser formalen Merkmale hat Barbara Cifola vorgelegt. ${ }^{22}$ Nach einer sorgfältigen Beschreibung der einzelnen Bauelemente des Textes untersucht sie die Verwendung dieser Strukturelemente und vergleicht ihr Vorkommen in den einzelnen Texten der Jahre 5 (A: Libyer, B: Seevölker), 8 (Seevölker) und 11 (A: Libyer, B: Libyer "Gedicht"). Eine Reihe von Unterschieden wird dabei sichtbar. Es handelt sich hier um die Aktionen des Feindes, die Reaktionen und Vorbereitung des Königs, den Feldzug selbst und dessen Ablauf. Die Angaben zu den Libyschen Kriegen liegen zwar völlig im üblichen "Pattern", sind aber präziser als diejenigen zum Seevölkerkrieg, die allgemeiner, vager, thematisch umfassender und widersprüchlicher sind. Dabei sind gerade die Darstellungen der Handlungen des Königs und die See- und Landschlacht betroffen, die in der Wirkungsgeschichte so massive Folgen

21 Widmer, Darstellung, 70, mit der Unterteilung: A1. Der König erhălt den Auftrag von Amun. A2. Der Konig verlaßit den Tempel. B1. Die Mobilmachung der Truppe. B2. Der Konig besteigt den Wagen. B3. Marsch gegen den Feind. C1. Landschlacht / Erstürmung befestigter Anlagen. C2. Jagd. C3. Seeschlacht. C4. Verfolgung der Feinde. D1. Besteigung des Wagens. Packen der Feinde. D2. Vorfuhrung der Gefangenen beim König. D3. Siegesfeier. Inventarisierung der geschlagenen Feinde anhand der abgeschnittenen Hande oder Phalli. D4. Rückkehr im Triumph. E1. Vorführung der Gefangenen bei den Göttern. E2. Opferung der Gefangenen. E3. Der siegreiche Konig betritt den Palast und den Tempel.

Cifola, Ramses III. Ihr Schema des "narrative pattern" (280f) umfaßt folgende Elemente: "Rhetorical Introduction. Narrative: A: Precedents in Egypt: A1: Invasion, with or without destruction; B: Enemy's precedents: B1: Rebellion, with or without aim; B2: Coalition, with or without list of allies; B3: Coming, with or without unitary route; C: Enemy's action: C1: Military activity against outside parties; D: Kings precedents: D1: God's charge; D1': Divine descent, king's destiny and role; D1": God's protection; D2: King's power; D2': Military sphere (=king's military qualities); D2": Political sphere (= King's wisdom); D3: King's wrath; D4: Preparation; D4': King's plans; D4" Military mobilization; D5: King's departure E: King's action; E1: Presence, with or without army; E2: Attack, with or without battle cry; E3: Battle, with or without army; E4: Enemy's defeat; E4': Destructive outcome; E4": Acquisitive outcome; F: Unfortunate situation of the enemy: F1: Flight, with or without pursuit; F2: Curse; F3: Annihilation; F4: Enslavement; F5: Lament; F6: Submission, with or without tribute; G: Fortunate situation of Egypt: G1: Rejoicing; G2: Triumph; G3: Benefits: abstract, material; G3': To the country; G3": To the gods; G4: King's protection. Rhetorical conclusion." 
hatten. ${ }^{23}$ Sie sind so vage, zugleich so stereotyp, daß ihr Wert als historische Aussage erheblich herabgesetzt werden muß.24

Die ältere Forschung hat - mit gewissen Abstrichen - die Medinet-HabuTexte und Reliefs direkt historisch verstanden und umgesetzt. Medinet Habu kam dabei eine vergleichbare Rolle zu wie dem Buch Josua für die Rekonstruktion der israelitischen Landnahme in der alttestamentlichen Exegese in der vorkritischen Zeit.

Neuere Aufsätze differenzieren durch formkritische und Strukturanalysen. Sie benennen Topoi, Patterns und ihre Funktion für die Raumgestaltung des Tempels im Rahmen der Königsideologie. Doch dieses Vorgehen wirft solch breite Barrieren auf, daß ein umgekehrtes Verfahren dem Fundbestand angemessener zu sein scheint.

Danach können dann lediglich diejenigen Elemente für eine historische Auswertung in Betracht gezogen werden, die nicht anders zu erklären sind. Die Beurteilung der Quellen geht von deren ideologischer Funktion aus. Die historische Verwurzelung ist auch vom Gegenstand her das sekundäre Element. Das bedeutet nicht, daß jetzt über die Seevölker nichts mehr auszusagen ist, wohl aber, daß alle Elemente, die anders erklärt werden können, eine historische Reduktion zur Folge haben. Das gilt für die Motive der Totalität, des massiven Angriffes, der feindlichen Bündnisse usw.. Nun waren es aber gerade diese gattungsspezifischen Motive, die zum Bild des Seevölkersturmes geführt haben.

Daß Hatti untergegangen ist, kann nicht bezweifelt werden. Auch die Namen der angreifenden Gruppen in Medinet Habu werden eine historische Basis haben. Die Tatsache, daß der Fremdbericht in Medinet Habu jedoch eher im Rahmen der ägyptischen Weltsicht in der Zeit von Ramses II bis Ramses III zu deuten ist, warnt vor einer direkten historischen Umsetzung. Denn eine Doppelrolle der Seevölkergruppen kann auch anhand des ägyptischen Materials belegt werden. Die گrrdn sind als Leibwache (?) des ägyptischen Vasallen

23 Hierbei ist aber zu bedenken, daß die m.E. schlüssigen Folgerungen der Barbara Cifola sich nur auf einen sorgfaltigen Vergleich der Texte untereinander beziehen und nicht auf das Verhältnis zwischen den Reliefs und den Texten. Gerade hier aber gibt es erhebliche Differenzen zwischen Text und Bild.

24 Cifola, Ramses III, 303: "A conspiracy of mostly unknown peoples, who move from the Aegean Sea... and decide to invade Egypt through the destruction of the Hittite Empire is absolutely unimaginable." Über die Seevolker: "...a description of the enemy so vague that it implies that the enemy force was not a coherent body. All this leads us to think that the encounter related in the text of year 8 is probably nothing but the narrative condensation of a continuous long-lasting process, consisting in small skirmishes and rebuffs of repeated attempts at assault and penetration, into a single great military event, to serve a precise propagandistic purpose." 
der genannten Gruppen nicht nur als Angreifer, sondern in einer längeren Geschichte auch als Hilfstruppen der Ägypter bekannt sind. Die Text- und Bildüberlieferung bezeugt so primär Aufstandsbewegungen von ehemaligen Söldnern und Hilfstruppen sowie einen Anstoß von draußen, der in erster Instanz bei Piratengruppen zu suchen ist. Die wichtigsten Konfrontationen neben der Seeschlacht - scheinen in Syrien stattgefunden zu haben. Alle Gegenmaßnahmen des Ramses III gehen in diese Richtung ("Ich festigte meine Grenze in Dahi"), und im Text des Jahres 8 ist von einem Seevölkerlager in Amurru die Rede. Wenn die Seevölkergruppen aber mit bestimmten Gegenden und Orten verbunden werden können ("die plšt des Flachlandes..."; "die plšt bangen, versteckt in ihren Städten.."(29:15f); "Vernichtung in ihren Städten, auf einmal alles verwüstet, ihre Bäume und all ihre Leute sind zur Asche geworden.."(46:34f)), brauchen die berühmten, von palästinischen Buckelrindern gezogenen Karren mit Frauen und Kindern nicht unbedingt der Beweis einer Völkerwanderung zu sein. ${ }^{40}$ Als Motiv deuten sie die Totalität der Niederlage an, als Gegenstand die Tatsache, daß der Pharao schon angesiedelte, flüchtende Feinde bekämpft.

So liefert Medinet Habu zwar die Ansätze für ein Verstehen der Umwälzungen am Ende des 13. Jh., die tatsächlichen Vorgänge werden aber im Vergleich zu den übrigen Quellen beschrieben werden müssen. Die Bilder und Texte aus Medinet Habu spielen dabei auf der historischen Ebene eine vergleichsweise bescheidene Rolle.

Wechseln wir jetzt von den ägyptischen Texten und Reliefs zu den materiellen Funden, die die Rekonstruktion der Ansiedlung der Philister am stärksten beeinflußt haben, so wird zuerst von der sogenannten Philisterkeramik zu reden sein.

40 So Hölbl, Aussagen, 132. 


\section{Die sogenannte Philisterkeramik und ihr Verhältnis zur Myk IIC 1b und zur Myk IIIB Ware}

\section{Die typologische Beschreibung der "Philisterkeramik"}

Im Keramikhandbuch Ruth Amirans ${ }^{41}$ ist die Einteilung der Philisterkeramik noch recht einfach. ${ }^{42}$ Sie unterscheidet zwischen Form und Dekoration und bei der ersteren zwischen Formen mit mykenischem Charakter und Formen, die lokal-kanaanäisch genannt werden dürfen. Zu der ersten, mykenischen Gruppe wird ein Krater aus Askalon (Abb.269), eine Steigbügelkanne aus Beth-Semeš (Abb.270) und eine Pyxis aus Gezer (P1.90, Nr.6) gerechnet. Interessant und für die weiteren Fragen von Bedeutung ist die Tatsache, daß Amiran für alle drei genannten Beispiele schon Belege in der Spätbronzezeit hat. ${ }^{43}$ Sie geht sogar so weit, daß sie die drei Formen in direkter Kontinuität mit der Spätbronzezeit sieht. Die Philister haben "nur" ihre Dekoration darauf gemalt. $^{44}$

Auf einer viel umfangreicheren Materialbasis hat T.Dothan das Schema erheblich komplizierter gestaltet. ${ }^{45}$ Sie unterscheidet fünf Gruppen mit insgesamt 18 Typen. ${ }^{46}$ Dabei geht die erste, uns hier interessierende Gruppe mit den Typen 1-8, bestehend aus Schalen ${ }^{47}$ Krateren $^{48}$, Steigbügelkannen ${ }^{49}$, Pyxiden $^{50}$, Kannen mit drei Henkeln ${ }^{51}$, Siebausgußkannen ${ }^{52}$, Korbhenkel-

41 Amiran, Ancient Pottery, 266f, Pl.90, Abb.269-274.

42

Dabei ist wohl $\mathrm{zu}$ beachten, daß R.Amiran auch hier (wie bei der "Landnahme") einer Verbindung zwischen Keramikdeutung und literarischer Quelle nicht aus dem Weg geht: Amiran, Ancient Pottery, 266: "Ethnic association of any pottery class is rarely as justified as in this case. The historical and philological aspects are beyond the scope of this book, though they are almost inseparable from the ceramic aspect, which we have to analyse."

43 Amiran, Ancient Pottery, 267: Krater: Pl.57:12 (Megiddo); Steigbügelkanne: Pl.57:10, Abb.191 (Gezer); Pyxis: Pl.57:1, Abb.181.199 (Beth-ŠemeS).

Amiran, Ancient Pottery, 267: "They became part of the local culture to such an extent that it could reasonably be suggested that the three types enumerated in group 1 came down to Iron I as direct descendants of the Late Bronze repertoire, in itself a complex amalgamation. In other words, the stirrup jar was already a native though a 'naturalized' one, when the decorated stirrup-jar started to be made by the newcomers- the Philistines, who decorated it in the style customary in their Aegean homeland."

T. Dothan, Philistines, $94 \mathrm{ff}$.

Eine gute Zusammenfassung bietet auch $H$. Weippert, Palastina, 373ff.

T. Dothan, Philistines, 98-106 Beispiele Bowls(1): figs.1-4, pls.2-7.

Ebenda, 106-115 Beispiele Kratere(2): figs.5-13, pls 8-25.

Ebenda, 115-125 Beispiele Stirrup Jar(3): figs.14-17, pls.26-35.

Ebenda, 125-132 Beispiele Amphoriskos und Pyxis(4) figs.18-19, pls.36-45.

Ebenda, 131f. Beispiel: Three-handled Jar(5): fig.20. 
kannen $^{53}$ und Kannen mit eingeschnürtem Körper ${ }^{54}$ auf mykenische Prototypen zurück.

Gegenüber Amirans Grobeinteilung stellen Dothans materialreiche, differenzierte Gruppeneinteilungen einerseits eine Verfeinerung der typologischen Bestimmung dar, und andererseits wird die Frage nach der Kontinuiät zwischen spätbronzezeitlichen und eisenzeitlichen Formen zugunsten einer Betonung der keramischen Fremdeinflüsse zurückgestellt. Die Deutung dieser Fremdeinflüsse mittels ethnisch zu beschreibender Trägergruppen wird dann innerhalb eines historischen Schemas vorgenommen, das aus den literarischen Quellen gewonnen wird.

\section{Die Myk IIIC $1 b$ Ware}

Typologisch ist es unbestritten, daß die "Philisterkeramik" von der Myk IIIC 1b Ware abgeleitet wurde. Die Myk IIC 1b Keramik (- wobei diese Nomenklatur für eine Verbindung von Form und Dekoration gilt -), wie sie de facto auf Zypern vorlag, ist auch in Palästina gefunden worden, und zwar als lokal gefertigte Ware. In einem wahrscheinlich als Töpferwerkstatt zu interpretierenden Raum in Schicht XIIIB in Asdod wurde Keramik im Stil von Myk IIIC 1b gefunden. Kurz danach (Schicht XIII) ${ }^{55}$ tauchen Scherben der philistäischen Keramik auf. Die Produktion der Myk IIIC 1b setzt sich aber noch in dieser Schicht und in der darauffolgenden (XII) fort. Zwischen beiden Keramiksorten sind sowohl Übereinstimmungen als auch Unterschiede festzustellen. Bei den Unterschieden handelt es sich um Techniken und Motive, die wohl bei der früheren mykenischen Ware gefunden wurden, bei der späteren "Philisterkeramik" jedoch nicht oder kaum vorhanden sind. Zu nennen sind hier: 1 . Myk IIIC 1b ist monochrom, die "Philisterkeramik" ist bichrom. -2. Die Dekoration mit einer wellenartigen, gerundeten horizontalen Linie unterhalb des Randes. - 3. Die vertikale Zickzack-Dekoration als Teil der Triglyphen. ${ }^{56}$

Ebenda, 132-155 Beispiele Strainer-Spout Jug(6): figs.21-31, pls.46-67a.

55 Für die methodische Diskussion ist es wichtig festzuhalten, daß der Unterschied zwischen XIIIB und XIIIA sich nicht deutlich in der Architektur abzeichnet. Der Unterschied, der sich in der Benennung niederschlagt (A-B), ist der Unterschied zwischen Myk IIIC 1b Ware und Philisterkeramik: T. Dothan, The Philistines Reconsidered, 167: "In the upper phase of this stratum at Ashdod, Stratum XIILA, differences from the lower phase (alteres Stratum XIIIb) were notes only in minor details, such as a higher floor. The change is mainly discernible in the finds. In the upper phase, for the first time, we have a number of typical Philistine sherds."

So T. Dothan, The Philistines Reconsidered, 167. 
Die gleiche Kombination, Myk IIIC 1b zusammen mit der "Philisterkeramik", ist auch in Tel Miqne vorhanden. ${ }^{57}$ Auch hier wurde die Myk IIIc 1b Ware lokal gefertigt. ${ }^{58}$ Das gilt ebenfalls für die dort gefundene "Philisterkeramik".

Myk IIIC 1b Ware erscheint weiter in Tell Keisan, Akko, Bet Šean sowie in Tyrus, Sarepta, Byblos, Tell Sukas und vor allem Ras Ibn Hani, wo von manchen mit Hilfe dieser Keramik versucht wird, der Seevölker habhaft zu werden. $^{59}$

\section{Die Myk IIIB Ware}

Die Vorgängerin der Myk IIIC 1b Ware war Myk IIIB. Myk IIIB war Importware, und das Verschwinden dieser und der typisch zyprischen Importkeramik markiert das Ende der Spätbronzezeit. ${ }^{60} \mathrm{Um}$ das Verhältnis zwischen Myk IIIB, Myk IIIC 1b und "Philisterkeramik" annähernd bestimmen zu können, ist es wichtig festzustellen, wann Myk IIIB aufhört. Ausgangspunkt für die Datierung sind noch immer die Arbeiten A. Furumarks ${ }^{61}$. Für das Ende der Myk IIIB Ware stellt er fest, daß die letzt datierbaren Objekte, die zusammen mit Myk IIIB gefunden wurden, aus der Zeit des Ramses II stammen. Deswegen ist das Todesjahr Ramses' II, nach Furumarks Datierung $1232 \mathrm{BC}^{62}$, zugleich das letztmögliche Erscheinungsdatum der Myk IIIB Ware. Furumark läßt also Myk IIIB 1230 BC enden. Durch einen Schwertfund mit der Kartusche des Seti II, der nach Ramses II regierte, sieht er sich darin bestätigt. Dieses Schwert hat eine Parallele in einem Schwerttyp, welches in Mouliana in dem Kontext LM IIIB:2 = Myk IIIC 1 gefunden wurde. Inzwischen hat sich herausgestellt, daß Myk IIIB weiterläuft und nicht schon 1230 (1224 nach der kürzeren Chronologie) BC endet: In der Brandschicht Ugarits findet sich Myk IIIB zeitgleich mit einem Schwert mit der Kartusche Merenptas ${ }^{63}$. Das präzi-

57 IEJ 35 (1985), 68 und IEJ 33 (1983), 127; 32 (1982), 151 .

58 Gunneweg / T. Dothan / Perlman / Gittin, Origin.

$59 \mathrm{Vgl}$. Mazar, Emergence, 101ff; ders., Settlement.

60 T. Dothan, The Philistines Reconsidered, 172: "The primary indicator of the End of the Late Bronze Age was the cessation of Mycenaean IIIB and Cypriote imports to Canaan."

51 Furumark, Mycenaean Pottery, 114f, 116f, $118 \mathrm{ff}$.

52 Ohne auf alle Probleme der agyptischen Chronologie eingehen zu können, sind die Vorteile, die Thronbesteigung Ramses II 1290 und seinen Tod 1224 anzusetzen, großer als die Nachteile: Helck, Geschichte. So auch Donner, Geschichte 2, 466; Veenhof, Geschiedenis, 374. Damit ergeben sich folgende Jahreszahlen für die zur Diskussion stehende Periode: Ramses II 1290-1224; Mer-en-ptah 1224-1204; Tausert 1192-1185; 20.Dynastie: Ramses III 1183-1152.

i3 T. Dothan, The Philistines Reconsidered, 173. 
seste Datum stammt aus Tell Deir 'Allā. Dort fand sich in der letzten spätbronzezeitlichen Schicht LBII Myk IIIB und eine Weihvase mit der Kartusche der Königin Tausret. Eine C-14 Probe des verbrannten Dachholzes ergab 1180 $+/-60$ BC. $^{64}$ V. Fritz hat hingewiesen auf Myk IIIB in der letzten Schicht von Alalah IC, die 1190 endet. ${ }^{65}$ Deswegen reicht das Ende von Myk IIIB bis ins 12. Jh. hinein.

Wie werden nun diese forschungsgeschichtlich bekannten Daten historisch umgesetzt?

Für T. Dothan liegt die Grenze zwischen Myk IIIB und Myk IIIC exemplarisch in Akko vor, wo ein Skarabäus mit dem Namen Tausret, in einer Schuttschicht gefunden, das Ende der Spätbronzezeit bezeugt. ${ }^{66}$ Die Folgeschicht enthielt viel Myk IIIC Ware. In den Orten, wo die Stratigraphie gesichert ist, und das ist ihrer Meinung nach in Asdod (sic) und Tel Miqne der Fall, erscheint die "Philisterkeramik" direkt nach der Myk IIIC Ware. Es gibt kaum einen gleitenden Übergang: Die "Philisterkeramik" ist von Anfang an voll vertreten.$^{67}$ Wegen dieser "scarcity of intermediate vessels" und der Eigenheit der "Philisterkeramik" der Myk IIIC Ware gegenüber sieht Dothan erst hier mit der "Philisterkeramik" die Philister in einer zweiten Seevölkerwelle in Palästina landen. Ihr Schema sieht also folgendermaßen aus: 1. Zwischen Tausret und Ramses III siedelt sich eine erste Seevölkergruppe an. Sie sind die Träger der Myk IIIC 1b Ware. 2. Nach dem 8. Regierungsjahr des Ramses III siedeln die Philister sich in Palästina an, sie sind die Träger der "Philisterkeramik" und haben einen gemeinsamen Hintergrund mit der ersten Gruppe.

Eine Alternative zu dieser Zweiwellentheorie bietet A. Mazar. Nach einer Analyse des chronologischen Fixpunktes für die älteste Philisterkeramik, wie ihn T. Dothan annahm anhand von Megiddo VIIA und Skarabäenfunden mit dem Namen Ramses III, kommt er zu dem Ergebnis, daß die "Philisterkeramik" erst in der Zeit des Ramses IV (1152-1146) oder selbst Ramses VI (etwa 1145-1132) erscheint. ${ }^{68}$ Durch diese chronologische Herabsetzung gewinnt er eine Periode von 30-40 Jahren zwischen Myk IIIC und der "Philisterkeramik". Seine historische Übersetzung sieht deswegen anders aus: Es waren die Philister, die schon lokal Myk IIIC Ware fertigten. ${ }^{69}$ Sie sind nach der Regierungs-

\footnotetext{
64 Franken, Excavations, 19.

65 Fritz, Hazor.

66 IEJ 31 (1981), 111, vgl. T. Dothan, The Philistines Reconsidered, 173.

$67 T$. Dothan, The Philistines Reconsidered, 174.

68 Mazar, Emergence, 102.

69 Eine ahnliche Umsetzung findet sich bei Singer, Beginning, der die Myk IIIC 1b Ware unc "Philisterkeramik" terminologisch zusammenbindet. Bei ihm ist Myk IIIC 1b "Monochrome (o early) Philistine pottery" und die bichrome Keramik "classical (or later) Philistine potte ry"(112).
} 
zeit des Ramses III nach Palästina gekommen. Etwa eine Generation später wächst aus Myk IIIC 1b die "Philisterkeramik". Weil die Bindungen mit Zypern nicht zu übersehen sind, bestimmt er gleichfalls Seevölkergruppen (Philister) auf Zypern als die Produzenten der Myk IIIC Keramik. Es handelt sich also um einen Proze $B$ und nicht um zwei chronologisch unterschiedliche Trägergruppen. ${ }^{70}$ Als Übergangsprodukte zwischen Myk IIIC und "Philisterkeramik" dienen eine Schale aus Askalon ${ }^{71}$ und ein Krug aus Tel Eitun. ${ }^{72}$

Bezüglich des uns hier interessierenden Punktes - der Umsetzung der Keramikbeurteilung und der Keramiktypologie in ein historisches Schema - fällt zuerst auf, daß Dothan die Unterschiede (Myk IIIC / "Philisterkeramik") betont, um so zu ihrer Zweiwellentheorie zu kommen; Mazar dagegen legt großen Wert auf die Gemeinsamkeit der Keramiktypen, die dann für eine lokale Entwicklung spricht. Dabei hat Mazar in zwei Punkten Dothan gegenüber recht: 1. Die Herunterdatierung der "Philisterkeramik" bis etwa 1150 v.Chr. paßt besser in die stratigraphischen Kontexte. 2. Die Weiterentwicklung der "Philisterkeramik" aus der Myk IIIC Ware findet über einen längeren Zeitraum hinweg statt.

Weil Dothan ihre früheste "Philisterkeramik" sehr früh datiert, bleibt ihr wenig Zeit zwischen Myk IIIC und der "Philisterware". So ist sie gezwungen, die zweite Welle der Philister als deus ex machina aufgrund ihrer historischen Deutung der Medinet Habu-Texte auftreten zu lassen.

Beide bleiben jedoch auf das Datum des 8. Regierungsjahres des Ramses III fixiert. Kurz danach muß Dothans zweite Welle ins Land kommen und um diese Zeit herum auch Mazars erste und einzige Welle. Wir haben bei der Analyse des ägyptischen Materials festgehalten, daß es sich um eine Verdichtung von Ereignissen im Rahmen der Königsideologie handelt. Damit würde ein exaktes Datum als Auslöser einer historischen Kettenreaktion entfallen.

Das hat aber nicht nur Folgen für die absolute Chronologie, die bei einer Konzentration auf die archäologischen Daten erst einmal weniger wichtig sein kann. Das Übergewicht der ägyptischen Quellen und ihre Handhabung als Rahmendaten auch für die außerägyptische Geschichte greift bis in die Archäologie hinein. In Asdod wurde die Schicht XII von M. Dothan ${ }^{73}$ mit der Niederlage der Seevölker gegen Ramses III verbunden. Die Argumentation verläuft dann folgendermaßen: 1. Schicht XIIIb (Myk IIIC 1b) und Schicht XIIIa ("Philisterkeramik") werden in XII ohne militärisches Eingreifen abgelöst. Schicht XII enthält viel "Philisterkeramik", deswegen müssen die Siedler Phili-

10 Mazar, Emergence,106ff. Die These wird in ders., Settlement, nur wiederholt.

'1 T. Dothan, Philistines, 100, fig.3; 103, pl.3.

'2 T. Dothan, Philistines, 145, pl.62.

' 3 . Dothan, Ashdod, 131. 
ster gewesen sein. Weil sie erstens siedelten und zweitens Philister waren, werden sie nach der verlorenen Schlacht gegen Ramses III nach Palästina gekommen sein. Deswegen muß der Anfang von Schicht XII kurz nach dem 8. Regierungsjahr des Ramses III datiert werden. Danach folgt der nächste Schritt: Schicht XII unterstütze die Historizität der Medinet Habu-Texte. Damit ist der Zirkelschluß komplett.

Beiden Modellen (Mazar und T. Dothan) ist gemeinsam, daß zuerst die "Philisterkeramik" und dann auch die Myk IIIC $1 \mathrm{~b}$ Ware verstärkt an einen ethnischen Träger, die Philister - oder, allgemeiner, Seevölkergruppen - gebunden werden. Der Befund: Das Verschwinden der Myk IIIB Importware und das Erscheinen der lokal gefertigten Myk IIIC 1b Ware, aus der sich relativ schnell die bichrome Keramik entwickelt, kann aber auch so gedeutet werden, daß die voll entwickelte "Philisterkeramik" als Luxusware die frühere Importware ersetzt. Wie zwingend ist nun die Anbindung der "Philisterkeramik" an ihren ethnischen Träger? Die gleiche Frage gilt noch viel stärker für die Myk IIIC $1 \mathrm{~b}$ Ware. Für die "Philisterkeramik" kann immerhin geltend gemacht werden, daß sie etwa zeitgleich auftritt mit den uns literarisch bezeugten Philistern. Für die Myk IIIC 1b gilt dies nicht. Ihre Verbreitung auf Zypern und an der Küste der Levante wird als Unterstützung der Wanderungstheorie gedeutet. Wenn aber die Daten für eine Wanderungstheorie sich verschieben, ändert sich auch der Deutungsrahmen für die Myk IIIC 1b Keramik.

Gegen die Anbindung der "Philisterkeramik" an eine aus der Ägäis kommenden Seevölkergruppe wendet sich die Dissertation von J.F. Brug. ${ }^{74}$ Ich greife zwei Fragestellungen heraus.

Die erste Frage lautet: Wenn man in allen Grabungen die vom Ausgräber als philistäisch bezeichneten Schichten analysiert, wie verhält sich dann die "Philisterkeramik" statistisch zu der übrigen gefundenen Keramik in der gleichen Schicht? Von den analysierten Orten paßt Asdod am besten in die geläufige Theorie.

Von den 2395 Randstücken der Schichten XII und XI gehören 656 zur "Philisterkeramik", also 27,4\%. Ein solch hoher Prozentsatz wird nur noch in der Philisterneugründung Tell Qasile und in Tel Miqne (Ekron) erreicht. In allen übrigen Grabungen sind Werte von nur 1,5\% (Izbet Sarta) bis $11 \%$ (Beth Šemeš) ermittelt.

Das bedeutet, daß selbst im günstigsten Fall, Asdod, 72,6\% der Keramik de Philisterschicht die normale, kontinuierliche Fortsetzung der Spätbronzezeit kultur repräsentiert. In allen anderen Grabungen erreicht diese kontinuierlich Fortsetzung der Spätbronzezeit Werte von über $90 \%$. Das heißt, die Zusam menstellung des keramischen Repertoire ist, um es vorsichtig zu sagen, nich 
nur von der Bruchsituation und von der Fremdeinwirkung bestimmt, sondern auch von der Kontinuität der SB-Kultur.

Die zweite Frage betrifft die Gruppeneinteilung Dothans. Von ihren 8 Typen, die zu der Gruppe I gehören und dort von mykenischen Prototypen abgeleitet sein sollen, finden sich die wichtigsten Parallelen des Typus 1 (Schalen) und 2 (Kratere) auf Zypern. Die erste Spur führt also nach Zypern. Eine solche Feststellung ist nicht unwichtig. Denn wenn wir für Griechenland/Ägäis, Zypern und Palästina die Buchstaben A, B und $C$ einsetzen, dann liegt nach Dothan eine Reihenfolge $X$ (= Bewegung der Philister) A-B-C- vor. Wenn aber nur die Parallele B-C belegt ist, dann kann es $X$ von A nach B und ein $Y$ von $B$ nach $C$ gegeben haben. Theoretisch ist selbst die Reihenfolge C-B-C möglich, wobei eine Gruppe $\mathrm{Z}$ die Ware von $\mathrm{A}$ nach $\mathrm{B}$ gebracht hat. ${ }^{75} \mathrm{Zu}-$ sammenfassend kann gesagt werden, daß erstens die Form- und Stilmerkmale, die in der Literatur "mykenisch" genannt werden, vom Blickwinkel Palästina aus de facto auf Zypern belegt sind. Hier liegt die erste Verbindung vor, und zwar zwischen der Myk IIIC 1b dort und in Palästina. Nur auf dieser Ebene scheint es zu einer Verlagerung der Töpferindustrie auf Zypern in die Küstenregion Palästinas gekommen zu sein. Die weiteren Einflüsse der keramischen Mischkultur sind typisch für die Region und brauchen keinesfalls mit Wanderungstheorien erklärt zu werden. Der Vorschlag von H. Weippert ${ }^{76}$, die "Philisterkeramik" in "palästinische submykenische Keramik" umzubenennen, ist insoweit berechtigt, als daß damit dem Mißverständnis gewehrt wird, "Philisterkeramik" belege etwa die Anwesenheit oder möglicherweise Herrschaft der Philister, während "submykenisch" die Verbindung zwischen Myk IIIC 1b und "Philisterkeramik" verdeutlicht. Nachteilig wäre bei dieser Benennung, daß damit suggeriert wird, Myk IIIC 1b stamme wirklich aus Mykene. Die größere Kontinuität zwischen SB und EZ, auch in dieser Keramik der Küstenregion, spricht gleichfalls gegen eine solche Umbenennung.

Wie verhalten sich diese Daten zu der Rekonstruktion, die anhand der Brandschichten versucht wurde?

75 Bei den Typen 3 und 4, Steigbügelkannen und Amphoriskoi, sind Prototypen in Myk IIIB belegt, wahhrend die Prototypen der Siebausgußkannen (Typus 6) schon von Furumark in Palästina gesucht wurden. Für die Typen 5,7,8 ist die Beweislage umstritten. Auch Brugs Analyse ist nicht frei von Einseitigkeiten bei dem Versuch, jede mykenische Herkunft zu bestreiten. Gleichwohl wird Dothan nicht behaupten, ihre mykenische Gruppe zeige, daß die Trăger direkt von der Ägăis nach Palästina gewandert sind. Sie versucht, unterschiedliche Elemente als Zeichen einer "long and slow journey" zu bewerten. So hătten die Seevollker Zeit, die Einflüsse aufzunehmen, die wir jetzt in der Keramik antreffen.

'6 Heippert, Palästina, 382. 


\section{Die Frage der Brandschichten}

Wie bei den Landnahmetheorien der nachmaligen Israeliten wurden die Brandschichten in den Städten der Küstenebene dazu benutzt, die Invasionstheorie der Seevölker zu unterstützen. Den Interpretationsrahmen boten die Reliefs und Texte aus Medinet Habu. Die Neigung, die reichlich vorhandenen Brandschichten am Ende der Spätbronze- und am Anfang der Eisenzeit monokausal zu erklären ${ }^{77}$, ja selbst Datierungen davon abhängig zu machen, führte zu einem relativ geschlossenen Bild. Dies wurde noch verstärkt durch die Anbindung der "Philisterkeramik" an einen ethnisch benennbaren Träger, wodurch die über vierzig Orte, die "Philisterkeramik" aufweisen ${ }^{78}$, in die historische Deutung mit hineingenommen wurden.

Nun bot die "Zwei-Zangen-Theorie" - eine Angriffswelle sei über Land von Kleinasien nach Syrien gekommen, eine andere über Wasser nach Ägypten, von wo sie mit Billigung der Pharaonen in Palästina angesiedelt wurden - gerade für die palästinische Küstenebene einen gewissen Spielraum. Brandschichten konnten auf direkt angreifende Gruppen zurückgeführt werden. Die Orte, wo diese Spuren fehlten, fielen unter die Kontinuität der ägyptischen Präsenz. ${ }^{79}$

Deutlich wird, wie entscheidend es war, in welchem Rahmen das vorliegende Material interpretiert wurde.

Wenn wir zuerst die Orte zusammenstellen, die in der fraglichen Region mit einer Brandschicht in der Spätbronzezeit aufwarten, ergibt sich folgendes Bild: Tell Ğemme (Jurșa?) ${ }^{80}$ : Die Brandschicht zwischen 184/185 kann nicht, wie noch von Petrie behauptet, an den Anfang der Eisenzeit datiert werden, sondern muß im 10.Jh. angesetzt werden ${ }^{81}$; Tell eš-Šería: Brandschicht Stratum IX; Asdod (Tell er-Rās bei Esdūd): Brandschicht Stratum XIV; Tell Murra: Brandschicht Stratum 7; Bet-Šemeš (Tell er-Rumële): Brandschicht Stratum IVB; Geser (Tell Ǧezer): Brandschicht Stratum XIV; Yaffa: teilweise Verwüstung Stratum IV; Tell el-Ǧeriše: Ende SB mit einer Brandschicht; Aphek-Antipatris (Tell Rās el-'Ën): Brandschicht X12; Tell el-Qassis: Ende SB mit einer Brandschicht; Tel Zerōr: Brandschicht Stratum XII; Tell Abū Huwām: Brandschicht Stratum Vc.; Tell Sukās: Brandschicht Stratum X. Von

\footnotetext{
77 Vgl. Strobel, Seevölkersturm, 23-100; Lehmann, Welt, $12 \mathrm{ff}$.

78 Vgl. T. Dothan, Philistines, Map 2, 26 und H. Weippert, Palästina, Abb.4.7, 378.

79 Eine gewisse Bestatigung erfuhr diese Sicht durch die Neudatierung der eisenzeitlichen Schichten in Tell el-Hơsn (Bet Šean). Hier reichte die agyptische Präsenz bis tief in die Eisenzeit, und eine "Überbrückung" durch eine Seevölkerpräsenz scheint nicht ausgeschlossen zu sein. James, Iron Age; Hankey, Late Mycenaean Pottery; ders., Mycenaean Pottery; Geva, Reassessment; Yadin / Geva, Investigations; H. Weippert, Palästina, 365.

80 Maisler, Yurza.

81 T. Dothan, Philistines, 34.
} 
den Ausgräbern um 1230 angesetzt, LH IIIC 1 Ware vorhanden; Alalah: Brandschicht IB/C; Meskene/Emar: umfassende Brandschicht, die literarisch auf das 2.Regierungsjahr des kassitischen Königs Melišipak 1185/1181 festgelegt werden $\mathrm{kann}^{82}$; Rās ibn Hāni: Brandschicht etwa gleichzeitig mit Ugarit. Nachfolgesiedlung mit Myk IIIC 1b Keramik; Ugarit: umfassende Brandschicht; Tarsus: Brandschicht IIA. In der Nachfolgeschicht IIB monochrome hethitische Keramik und SH IIIC; Beycesultan: Brandschicht in II. Myk IIIB Keramik (lokal) in II, primitive Nachfolgesiedlung; Karaoğlan: Starke Brandschicht. Die Datierung ist unsicher. Es gibt eine Siedlungslücke bis zum 9.Jh.; Firakdin: Datierung der Brandschicht ist möglich durch eine mykenische Bügelkanne SH IIIB. Danach eine Siedlungslücke; Mașat: Starke Brandschicht (SH IIIB), gefolgt von einer Siedlungslücke bis zum 9.Jh.; Alaça Hüyük: Brand in einem öffentlichen Gebäude, danach Siedlungslücke; Hattuša: Brand in den öffentlichen Gebäuden, danach Siedlungslücke.

Auf der Insel Zypern finden sich an den wichtigsten Fundorten: Enkomi, Sinda, Kition, Kouklia, Hala Sultan Tepe, Athienou, Pyla-(Kokkinokremos) und Maa-Palaeokastros in den meisten Fällen Brandschichten, die die LC II Periode beenden, verbunden mit der Myk IIIB Keramik. Die Myk IIIC 1b Ware beherrscht die Periode LC III A und hat Nachfolger in den späteren Schichten der Perioden LC III B und LC III C mit der Proto-White-Painted Ware (=Myk IIIC 1c). In LC III A findet sich noch aber noch immer Myk IIIB Keramik. Eine direkte Ableitung der Myk IIIC $1 \mathrm{~b}$ Ware von Myk IIIB gelingt nicht in jeder Hinsicht. Sowohl die Form der Myk IIIB Skyphoi und Kylikes in Kition, Hala Sultan Tekke und in Pyla sowie die Dekoration der Zickzackanordnungen und der Spiralen scheint hier umgekehrt von Myk IIIC 1b abgeleitet zu sein. In LC III A kommen Myk IIIB und Myk IIIC $1 \mathrm{~b}$ nebeneinander vor. ${ }^{83}$ Nach einer zweiten Brandschicht ist die Myk IIIC $1 \mathrm{~b}$ Ware noch nicht verschwunden, doch werden jetzt auch Derivate produziert. Für die ältere Forschung ergab sich aus diesen beiden Brandschichten eine doppelte Zäsur, denn LC III A hatte nicht nur einen anderen keramischen Schwerpunkt, sondern führte auch, so war die Meinung, die Quadersteinarchitektur ein. So wurde hier mit einer mykenischen Kolonisation gerechnet. Die zweite Brandschicht wäre dann den Seevölkern zuzuschreiben. Hauptzeuge war hier die Abbildung eines Kriegers mit Rundschild und Federkrone in Enkomi IIIB = LC III A-2. Wenn aber die beiden Keramikstile nebeneinander vorkommen und die Datierung der ersten Brandschicht heruntergesetzt werden muß, weil sie durch eine zu hoch angesetzte ägyptische Chronologie festgelegt wurde, und wenn außerdem das Argument der Exklusivität der Quadersteinarchitektur widerlegt wird, weil sie weit im Alten Orient verbreitet war und auch schon in

82 Arnaud, Les textes, 88f, 97f; Bierbrier, Destruction, $136 \mathrm{f}$.

83 KJing, Mycenaean IIIC:1b Pottery. 
LC IIC vorkam, dann bahnt sich die Möglichkeit an, daß auf Zypern mit nur einer Zerstörungsschicht zu rechnen ist. ${ }^{84}$

Eine solche Zusammenstellung führte wohl zum Heranziehen der Brandschichten, um die Theorie einer weitreichenden Seevölkerinvasion zu stützen. Trotzdem ist dieses Bild trügerisch.

Schauen wir nach Norden, nach Kleinasien, so wurde das Credo eines einheitlichen Zerstörungshorizontes beim Auseinanderbrechen des hethitischen Großreiches bis vor kurzem in fast allen Geschichtsdarstellungen präsentiert. ${ }^{85}$

Als Kronzeuge diente zuerst Hुattuša, die Hauptstadt des Hethiterreiches, wo die offiziellen Bauten gezielt durch Brand verwüstet wurden, wie auch in Alaça Hüyük, Mașat, Firakdin, Karaoğlan, Beycesultan und Tarsus. Geht es nur um eine ungefähre Gleichzeitigkeit, hat diese Liste eine gewisse Existenzberechtigung. Wird aber nach dem Zusammenhang von Vorgeschichte, Kontext und Folgezeit gefragt, gibt es erhebliche Differenzen. ${ }^{86}$ In 11 Orten mit einer hethitischen Besiedlung endet diese 8x mit einer Brandschicht, dreimal gibt es ein nicht gewaltsames Ende. Für eine nähere Bestimmung ist eine genaue Datierung sehr wichtig. Sie ist bei den genannten Orten möglich durch die Siegel des Suppilulijuma ${ }^{87}$ und das Vorhandensein von SH oder Myk IIIB Ware. Von den 8 Brandschichten können nur drei einigermaßen genau datiert werden, $5 x$ ist eine genauere Datierung nicht möglich. Verbinden wir das Kriterium der Brandschichten mit der Datierungsfrage, kann von einem einheitlichen Zerstörungshorizont nicht die Rede sein. Suchen wir nach Beweisen für eine bewußte, geplante Vernichtung, kommen nur Hattuša und Alaça Hüyük in Frage. Eine solche geplante Verwüstung kann ihre Ursache haben in äußerer Feindbedrohung oder inneren Unruhen. Den Untergang dieser beiden Orte ausgerechnet den Seevölkern zuschreiben zu wollen, ist eine kühne Hypothese. Denn wenn diese Seevölkerverbände von der Küste aus operierten, hätten sie, um Hattuša zu erobern, einen ganz gewaltigen Umweg in Kauf nehmen müssen.

Das gleiche Bild ergibt sich in Nordsyrien. Mit Ausnahme von Ugarit, Ras Ibn Hani und Meskene/Emar können die Brandschichten nicht genau datiert werden. Wohl ist auffällig, daß es relativ viele Orte auf einem recht kleinen

84 Muhly, Role.

85 Vgl. die Beispiele bei Bittel, Ende, $39 \mathrm{f}$ und in den Nachbardisziplinen bei Donner, Geschichte 1, 42 oder Soggin, History, 53: "They (Seapeoples) were the effective cause of the fall of the Hittite empire and of the Syrian city-states of Ugarit and Alalakh."

86 Es ist der Verdienst von K.Bittel, schon vor fünfzehn Jahren auf diese Relativierung hingewiesen zu haben: Bittel, Ende.

87 Siehe für die neuere Beurteilung des letzten hethitischen Großkonigs als Bauherr: Neve, AA 1989, 316-332; 1990, 279-286; 1991, 302-325. 
Gebiet gibt. Die Dichte erklärt sich wahrscheinlich damit, daß an den Grenzen des ehemaligen Hethiterreiches die Turbulenzen in der ausgehenden Spätbronzezeit am stärksten gewesen sind.

Die gleiche Differenzierung wie in Kleinasien ist auch notwendig für die Brandschichten in der Küstenebene in Palästina.

In Tell eš-Serĩa findet sich die "Philisterkeramik" vor und nach der Brandschicht, in Asdod zuerst Myk IIIC 1b, die aber bis XII weiterläuft, dann ab XIIIa "Philisterkeramik". Für Tell Murra ist weiter ägyptische Präsenz anzunehmen. Die Eroberung Gesers ist wahrscheinlich Mer-enptah zuzuschreiben, wonach es eine Siedlungslücke gibt. In Aphek wird die kanaanäische Stadtkultur weitergeführt. Tel Sippor, mitten im philistäischen Gebiet gelegen, zeigt überhaupt keine Verwüstungsspuren. Bei Bet-Šemeš ist es absolut unmöglich, einen möglichen Angreifer zu identifizieren. Soweit Datierungen möglich sind, liegen sie auch bei den Städten in Palästina erheblich auseinander.

Das Kriterium der Brandschichten kann für eine groß angelegte Völkerwanderungstheorie nur benutzt werden, wenn lediglich die Tatsache, daß Ort $\mathrm{X}$ durch einen Brand $\mathrm{Y}$ verwüstet wurde, verwendet wird. Fragt man nach möglichen Ursachen: äußerer Feindbedrohung, inneren Unruhen, Unfall, Erdbeben, nach exakter Datierung, nach Kontext und Nachgeschichte, dann wird das Bild unendlich differenzierter. Am einheitlichsten schneidet dabei noch Zypern ab.

\section{Seevölker und Pantheon}

Die vorausgegangenen Ausführungen versuchten zu zeigen, da $ß$ wir es nicht mit einer großen Völkerbewegung zu tun haben, sondern mit lokal und zeitlich begrenztem Auftreten unterschiedlicher Gruppen. Die Einheit dieser Bewegung ist erst von den Texten und Reliefs in Medinet Habu hineingebracht worden im Rahmen ihres eigenen Kerygmas. Die Keramik in ihrem synchronen und diachronen Kontext zeigte, daß wir mit einer längeren Vorgeschichte von Handelsbeziehungen und Ansiedlung sowie lokalen gewalttätigen Übergriffen zu rechnen haben.

Spiegelt sich nun dieses differenzierte Bild auch religiös wider? Oder gibt es so etwas wie ein eigenständiges Pantheon der Seevölker?

Über die im Alten Testament erwähnten Philistergötter kann man sich kurz fassen. Es handelt sich um Dagon/Dagan, Aštoreth, Baal Zebub/. Nach dem AT ist Dagon/Dagan der Hauptgott der Philister. Er wurde verehrt im Tempel in Asdod (1 Sam 5,2ff) sowie in Gaza (Ri 16,23). Schon in der Amarnakorrespondenz (317/318) gibt es einen Daganhaltigen Namen (Dagantakala) und zwei Orte, Jos 15,41 und 19,27 (Ašer), heißen Bet Dagon. Mag er also im 
Alten Testament fast exklusiv mit den Philistern und nicht mit den übrigen Kanaanitern in Verbindung gebracht werden, so ist er doch in der Küstenregion mit seinen Toponymen, auch ohne Seevölker, bodenständig.

Balu in Ugarit gilt als Sohn Dagans, der seit altakkadischer Zeit eine wichtige Rolle im nördlichen Mesopotamien spielte. Mit Dagon/Dagan liegt also keine Eigenständigkeit in Sachen Pantheon vor.

Die Astoret/Astæeræet (Aštoræet ist bošaet-Vokalisation, ${ }^{88}$ ) wird mit den Philistern in Verbindung gebracht mit dem Hinweis auf die Darbringung der Waffen Sauls in ihrem Tempel nach 1 Sam 31,10. Durch den Nachsatz von 10b wird dieser Tempel in Bet Šean gesucht: Die Waffen werden in den Tempel gebracht, Sauls Leiche an die Mauer von Bet Šean gehängt. Diese Verbindung stand so lange wie die anthropoiden Sarkophage als typisch philistäisch galten. Diese Verbindung muß aufgegeben werden; eine noch größere Schwierigkeit bereitet die notwendig gewordene Herunterdatierung der Schichten in Bet Šean. Die beste Lösung ist wohl, den vorangehenden V.9 in dem Sinne zu verstehen, daß Sauls Rüstung im ganzen Land herumgeschickt wird, um dann endlich in einem Astartetempel zu landen.

Auf jeden Fall ist klar, daß Astarte belegt ist in Ebla, Mari, Babylonien, Ugarit, Emar - um nur einige Orte zu nennen; demnach ist sie im Orient zu Hause und wird nicht von Seevölkergruppen mitgebracht worden sein.

Über Baal Zebub/1 schließlich berichtet 2 Kön 1,2-5. Er gilt als Heilgott. Bei ihm werden Gottesbescheide eingeholt. Weil auch er in Ugarit belegt ist, gehört er zum normalen westsemitischen Götterrepertoire.

Nachdem wir in der literarischen Überlieferung nicht von einer Eigenständigkeit reden können; - wie sieht es dann mit dem archäologischen Befund aus? ${ }^{89}$ In Enkomi auf Zypern wurde in den Seevölkerschichten ein Heiligtum mit dem sogenannten Barren-Gott gefunden. ${ }^{90}$ Es handelt sich um eine $35 \mathrm{~cm}$ hohe Gestalt mit Bart, konischer Kopfbedeckung und Hörnern. Er trägt Beinschienen, einen Rundschild und in dem erhobenen rechten Arm einen Speer. Was ihn an die Kupferindustrie bindet, ist die Tatsache, daß er auf einem Vierzungenbarren, einer Variante des sogenannten Rinderfellbarren, steht. Die Basisform dieser Göttergestalt ist bekannt. Es handelt sich um eine Rescheffigur; die ganze Haltung hat einen genuin syropalästinischen Hintergrund.

Wenn die Götterstatue in Verbindung gebracht werden darf mit den Seevölkergruppen, dann ist es verführerisch, hier an Šerden - Gruppen zu denken, die ja auch mit Hörnerhelm, Rundschild und Speer ausgerüstet sind und mit nacktem Oberkörper und Schürze dargestellt werden. Zugleich ist die Ver-

88 Müller, ThWAT VI, 459.

89 Zu den Figurinen aus Palasstina siehe demnächst die Dissertation von Rüdiger Schmitt, Hamburg.

90 Negbi, Gods, 38 und Buchholz, Metallhandel. 
bindung mit der Kupferindustrie Zyperns nicht zu leugnen. Diese Verbindung macht wiederum aufmerksam auf die zentrale Rolle Zyperns in der Metallindustrie (Kupfer) und dem Handel in der Spätbronzezeit. Nachdem schon die keramischen Fäden in Bezug auf die Seevölkerfrage in Zypern zusammeliefen, gilt das gleiche für die Metallindustrie und den Handel.

Die Ansiedlung von Seevölkergruppen in Palästina war anscheinend ein längerer Proze $B$ als die postulierte Zwangsansiedlung nach den Berichten des Ramses III es schildern sollen. $\mathrm{Da} B$ mykenische und ägäische Einflüsse auf teilweise friedlichen und handelstechnischen Wegen nach Pälastina gekommen sind und nicht im Laufe einer kurzen gewalttätigen Invasion, würde auch den keramischen Prozeß besser erklären. Wenn wir es bei dem Barrengott in seiner Šerdentracht mit einer Seevölkergottheit zu tun haben, wird dies damit bestätigt. Hier findet sich kein Hinweis auf eine rein zerstörerische Tätigkeit, sondern auf eine Präsenz im Rahmen der Kupferindustrie. Daß wir "Seevölker" in ihrem zypriotischen Kontext als Teilhaber an der Metallindustrie ansehen dürfen, kann mit dem Barrengott gezeigt werden. Zugleich aber ist der Typus der Gottheit wieder lokal von syropalästinischen Hintergründen geprägt.

Wahrscheinlich zu Floor III gehörend und noch in der Folgeschicht nach der Brandschicht benutzt - und somit der "Seevölker"schicht angehörend, fand sich gleichfalls in Enkomi die Statue des sogenannten "gehörnten Gottes". Die Höhe beträgt $55 \mathrm{~cm}$, das linke Bein steht etwas vor. Der Oberkörper ist nackt wie die Füße. Bekleidet ist die Gottheit mit einem Rock und mit einem schweren Band gegürtet. Die konische Kappe hat eine gewellte Oberfläche (nach Dikaios als Darstellung von Tierhaar). Der linke Arm liegt mit geballter Faust auf dem Magen, der rechte Arm ist ab dem Ellbogen horizontal, die Hand gestreckt, der Handpalm nach unten. Die Ohren stehen weit ab, die Augen sind nachdrücklich bearbeitet, um den Mund liegt ein leises Lächeln. Der Körper ist muskulös dargestellt.

Für die rechte Nase und das Lächeln sucht man nach Ursprüngen in der Ägäis. Profilansichten von Baal und El-Statuetten widerlegen dies. Hörnerkappe, Schürze, gestreckter Arm sind in der syrischen Tradition wohlbekannt; für den am Magen liegenden Arm hat man ägyptischen Einfluß ausgemacht, vermittelt über Syrien. Außergewöhnlich ist die Länge der Hörner. Ich kenne keine vergleichbare Darstellung, es sei denn, man wäre berechtigt, die Darstellung Els(?) auf der Schlangenstele aus Ugarit, wo er eine konische Kopfbedeckung trägt und worauf zwei massive Stierhörner angebracht sind, plastisch umzusetzen (Caquot, PI.VII).

Was die Identifizierung angeht, scheinen wir uns im Rahmen der Reschefdarstellungen zu befinden.

So steht die Gottheit für die Lage Zyperns in vollkommener Weise. Es handelt sich nicht um eine abhebbare Eigenheit; Einflüsse von Ost, West und Norden treffen sich hier. Wir stoßen auf das gleichen Phänomen wie wir es in 
der literarischen Tradition der Philistergötter hatten. Waren sie dort vollständig im Rahmen des westsemitischen Pantheons erklärbar, so hier im Lokalkolorit Zyperns.

Resümierend darf gesagt werden: Ein wohlumrissenes eigenes, eventuell selbst von Herkunftstraditionen getragenes Pantheon hat es bei den Seevölkern nicht gegeben.

Wo wir sie dingfest machen wollen, spiegeln die Göttergestalten die Internationalität der betreffenden Gegend wider.

Die Achsen dieser Einflüsse laufen von der mykenisch-ägäischen Welt nach Syrien und umgekehrt, von Kleinasien nach Pälastina vice versa. Sie kreuzen sich in Zypern, das eine Schlüsselstellung in diesen Beziehungen innehat.

Für unsere Fragestellung ist also nicht nur die direkte Verbindung Palästina - Kleinasien wichtig: Die Insel Zypern hat eine wichtige Position in der Verbindung zwischen den beiden Regionen. 
Bibliographie

Amiran, R, Ancient Pottery of the Holy Land, Jerusalem 1969, $266 \mathrm{f}$

Amaud, $D$., Les textes d'Emar et la chronologie de la fin du Bronze récent, Syria 52 (1975) 87. 105

Arnold, D., Wandrelief und Raumfunktion in ågyptischen Tempeln des Neuen Reiches (MÄSt 2), Berlin 1962

Bierbrier, M.L., The Date of the Destruction of Emar and Egyptian Chronology, JEA 64 (1978) $136 \mathrm{f}$

Bittel, K, Das Ende des Hethiterreiches aufgrund archăologischer Zeugnisse, JFIV 1976 (1977), $36-55$

Bleiberg, E., Historical Texts as Political Propaganda During the New Kingdom, BES 7 (1985/86) 5-13

Brug, J.F., A Literary and Archaeological Study of the Philistines (BAR International Series 265), Oxford 1985

Buchhol, H.G., Der Metalihandel des zweiten Jahrtausend im Mittelmeerraum (OLA 23), Leuven 1988, 187-228

Cifola, B., Ramses III and the Sea Peoples: A Structural Analysis of the Medinet Habu Inscriptions, Or NS 57 (1988) 275-306

Dietrich, M. / Loretz, O., Das Land Qt, UF 12 (1980) 390

Donner, H., Geschichte des Volkes Israel und seiner Nachbarn in Grundzügen, 2 Bde (GAT 4/12), Gottingen 1984.1986

Dotham, M., Ashdod at the End of the Late Bronze Age and the Beginning of the Iron Age, in: F.M. Cross, Symposia. Celebrating the Seventy-Fifth Anniversary of the Founding of the Amercican Schools of Oriental Research (1900-1975), Cambridge/MA 1979, 125-134

Dothan, T., The Philistines and Their Material Culture, Jerusalem 1982

- Some Aspects of the Appearance of the Sea Peoples and the Philistines in Canaan, in: $S$. Deger-Jalkotzky (Hg.), Griechenland, die Ägais und die Levante wahhrend der 'Dark Ages' vom 12. bis zum 9. Jh. v.Chr., Acta des Symposions von Stift Zwettl 11.-14.Okt. 1980 zu Ehren von F. Schachermeyer, Wien 1983, 99-117(120)

- The Philistines Reconsidered, in: Biblical Archaeology Today. Proceedings of the International Congress on Biblical Archaeology (Jerusalem, April 1984), Jerusalem 1985, 165-176

- $\rightarrow$ J. Gunneweg

Edel, E. Der Seevölkerbericht aus dem 8. Jahre Ramses' III, Mélanges G.E. Mokhtar, Le Caire 1985, 223-237

Edgerton, W.F. / Wilson, JA., Historical Records of Ramses III. The Texts in MEDINET HABU Volumes I and II. Translated with Explanatory Notes (SAOC 12), Chicago 1936

Franken, H.J., Excavations at Deir 'Allä I. A Stratigraphical and Analytical Study of the Early Iron Age Pottery, Leiden 1969

Fritz, V., Das Ende der spatbronzezeitlichen Stadı Hazor Stratum XIII und die biblische Überlieferung in Josua 11 und Richter 4, UF 5 (1973) 123-139 
Furumark, A., Mycenaean Pottery II. Chronology, Stockholm $1972=$ The Chronology of the Mycenaean Pottery 1941

Geva, Sh, A Reassessment of the Chronology of Beth Shean Strata V and IV, IEJ 29 (1979) 6-10

- $\rightarrow$ Yadin, $Y$.

Gittin, $S . \rightarrow J$. Gunneweg

Görg, M., "Bundesterminologie" im Seevolkertext Ramses' III, BN 42 (1988) 19-26 = M.Görg, Beitrăge zur Zeitgeschichte der Anfănge Israels. Dokumente - Materialien - Notizen (ÄAT 2), Wiesbaden 1989, 149-156

Guterbock, H.G., The Hittite Conquest of Cyprus reconsidered, JNES 26 (1967) 73-81

Gunneweg, J. / Dothan, T. / Perlman, I. / Gittin, S., On the Origin of Pottery from Tel Miqne Ekron, BASOR 264 (1986) 3-16

Hankey, V., Late Mycenaean Pottery at Beth Shan, AJA 70 (1966) 169171

- Mycenaean Pottery in the Middle East, BSA 62 (1967) 127-128

Helck, W., Geschichte des Alten Ägypten (HdO), Leiden 1968

- Die Seevolker in den agyptischen Quellen (Jahresbericht des Frankfurter Instituts für Vorgeschichte 1976), Frankfurt 1977, 7-21

- Nochmals zu Ramses' III. Seevolkerbericht, Studien zur Altagyptischen Kultur 14 (1987) 129-145

Hölbl, G., Die historischen Aussagen der ägyptischen Seevölkerinschriften, in: S. Deger-Jalkotzky (Hg.), Griechenland, die Ägăis und die Levante wăhrend der 'Dark Ages' vom 12. bis zum 9. Jh. v.Chr., Acta des Symposions von Stift Zwettl 11.-14.Okt. 1980 zu Ehren von Fr. Schachermeyer, Wien 1983, 121-138(-143)

Hoftijzer, J., Ugaritische brieven uit de tijd van de ondergang van de stad, in: Schrijvend verleden. Documenten uit het Oude Nabije Oosten vertaald en toegelicht, uitgegeven door $K . R$. Veenhof, Leiden 1983, 94-99

James, F.W., The Iron Age at Beth Shan: A Study of Levels VI-IV, Philadelphia/PA 1969 Janssen, J.M.A., Ramses III, Leiden 1948, 30ff

Kitchen, KA., Ramesside Inscriptions V/1-2, Oxford 1970/1972

Kling, B., Mycenaean IIIC:1b Pottery in Cyprus: Principal Characteristics and Historical Context, in: $V$. Karageorghis, J.D. Muhly (eds.), Cyprus at the Close of the Late Bronze Age, Nicosia 1984, 29-38

Lehmann, $G$ A., Die Šikalājü - Ein neues Zeugnis zu den 'Seevơlker'- Heerfahrten im spăten 13.Jh. v.Chr. (RS 34.129), UF 11 (1979) (= FS C.F.A. Schaeffer) 481-494

- Die mykenisch-frühgriechische Welt und der ostliche Mittelmeerraum in der Zeit der 'Seevölker'-Invasionen um 1200 v.Chr. (RheinischWestfâlische Akademie der Wissenschaften, Vorträge G 276), Opladen 1985

Liverani, M., Memorandum on the Approach to Historiographic Texts, Or NS 42 (1973) 178-194 Loretz, O. $\rightarrow$ Dietrich, $M$.

Maisler, B., Yurza: The Identification of Tell Jemmeh, PEQ (1952) 48-51 
Mazar, A., The Emergence of the Philistine Material Culture, IEJ 35 (1985) 95-107

- Some Aspects of the "Sea Peoples" Settlement, in: M. Heltzer / E. Lipiniski (Eds.), Society and Economy in the Eastern Mediterranean (c.1500-1000 B.C.). Proceedings of the International Symposium held at the University of Haifa from the 28th of April to the 2nd of May 1985 (OLA 23), Leuven 1988, 251-260

de Moor, J.C., The Rise of Yahwism. The Roots of Israelite Monotheism (BETL XCI), Leuven $1990,146 \mathrm{f}$

Müller, H.P., תרפע, ThWAT VI (1989) 453-463

Muhly, J.D., The Role of the Sea Peoples in Cyprus during the LC III Period, in: V. Karageorghis / J.D. Muhly (eds.), Cyprus at the Close of the Late Bronze Age, Nicosia 1984, 39-55

Negbi, O., Canaanite Gods in Metal, Tel Aviv 1976

Nelsom H.H. (Field Director of the Epigraphic Survey), Medinet Habu I. Earlier Historical Records of Ramses III (OIP 8), Plates 1-54, Chicago 1930

- Medinet Habu II. Later Historical Records of Ramses III (OIP 9), Plates 55-130, Chicago 1932

Neve, $P .$, AA $1989,316-332 ; 1990,279-286 ; 1991,302-325$

Noort, E., Transjordan in Joshua 13: Some Aspects, in: $A$. Hadidi (ed.), Studies in the Archaeology and History of Jordan, Vol.III, Amman / London 1987, 125-130

Noth, M., Geschichte Israels, Gottingen ${ }^{3} 1956 /{ }^{10} 1986$

Perlman, $I . \rightarrow$ Gunneweg, $J$.

Singer, I., The Beginning of Philistine Settlement in Canaan and the Northern Boundary of Philistia, Tel Aviv 12 (1985) 109-122

Soggin, J.A., A History of Israel. From the Beginnings to the Bar Kochba Revolt (AD 135), London 1984

Spalinger, A.J., Aspects of the Military Documents of the Ancient Egyptians, New Haven / London 1982

Stadelmann, R., Die Abwehr der Seevölker unter Ramses III, Saec. 19 (1968) 156-171

Strange, J., Caphtor/Keftiu. A new investigation (AThD XIV), Leiden 1980

Strobel, $A$., Der spătbronzezeitliche Seevölkersturm. Ein Forschungsüberblick mit Folgerungen zur biblischen Exodusthematik (BZAW 145), Berlin / New York 1976

Veenhof, KR., Geschiedenis van het Oude Nabije Oosten. Bijbels Handboek I, Kampen 1981

Weippert, H., Palästina in vorhellenistischer Zeit (HdA II/1), München 1988

Weippert, M., Ein ugaritischer Beleg für das Land "Qadi" der agyptischen Texte?, ZDPV 85 (1969) 35-50

Widmer, W., Zur Darstellung der Seevolker am Großen Tempel von Medinet Habu, ZÄS 102 (1975) 67-77

Wilson, JA. $\rightarrow$ Edgerton, W.F.

Wreszinski, W., Atlas zur altägyptischen Kulturgeschichte, Leipzig 1914-1935

Yadin, Y. / Sh. Geva, Investigations at Beth Shean, The Early Iron Age Strata (Qedem 23), Jerusalem 1986 



\section{Eckart Otto}

Körperverletzung im hethitischen und israelitischen Recht Rechts- und religionshistorische Aspekte

\section{Das Problemfeld}

Die Veröffentlichung der Hethitischen Gesetze durch Friedrich Hrozny im Jahre $1921^{1}$ und die im darauffolgenden Jahr erschienene erste Übersetzung in die deutsche Sprache durch Heinrich Zimmern unter Mitwirkung von Johannes Friedrich ${ }^{2}$ hat in der Alttestamentlichen Wissenschaft bei weitem nicht die Beachtung gefunden und wissenschaftliche Reaktionen ausgelöst wie knapp zwanzig Jahre zuvor die Veröffentlichung des Kodex Hammurapi. Die Argumentationsfiguren der Reaktionen aber wiederholten sich. Emanuel Ring verneinte in seiner 1926 veröffentlichten Arbeit "Israels Rechtsleben im Lichte der neuentdeckten assyrischen und hethitischen Gesetzesurkunden"3 jeden Zusammenhang zwischen hethitischem und israelitischem Recht, da das hethitische Strafrecht im Vergleich mit dem des Alten Testaments einen Zustand des Gemeinwesens verrate, "in dem unzweifelhaft eine mehr vorgeschrittene Rechtsentwicklung sich geltend zu machen angefangen hat ${ }^{\text {n4 }}$. Demgegenüber hat Erich-Paul Matter in einer Heidelberger Dissertation von $1933^{5}$ mit einem Einfluß des kulturhistorisch entwickelteren hethitischen Rechts auf das Recht Israels gerechnet, während Alfred Jepsen ${ }^{6}$ in seiner 1927 veröffentlichten Dissertation zum "Bundesbuch" aufgrund von Parallelen und Differenzen zwischen altbabylonischem, assyrischem, hethitischem und israelitischem Recht in Abwandlung der These eines "semitischen Urgesetzes" als eine Quelle dieser Rechte annahm ${ }^{8}$. Über diese Alternativen ist die Forschung bis heute kaum hinausgekommen. Im Gegenteil: Sie hat sich in den letzten fünfzig Jahren auf den Rechtsvergleich konzentriert und die Frage nach den Rechtsrezeptionen durch Formen des rechtsvergleichenden "patternism",

\footnotetext{
Keilschrifttexte.

Hethitische Gesetze.

$179 \mathrm{ff} .200 \mathrm{ff}$.

AaO, 183. Entsprechend haben sich San Nicolo (Rechtsquellen 77) und David (Codex 1-26) über das Verhalitnis des altbabylonischen zum israelitischen Recht geaußert.

Bedeutung, 23ff.40f.

Bundesbuch, 55ff, bes. 80; vgl. ders., Hebräer, 55-68.

Vgl. Müller, Gesetze, 210ff.

Vgl. auch für das Verhaltnis des israelitischen zum altbabylonischen Recht entsprechend Johns, Laws, 49ff; Ebel / (Thielmann), Rechtsgeschichte, 15.
} 
der Thesen einer einheitlichen altorientalischen Rechtskultur ${ }^{9}$ oder, jüngst von Raymond Westbrook ${ }^{10}$ vertreten, eines den gesamten Alten Orient einschließlich Israels und des frühen Rom ${ }^{11}$ umfassenden "common law" einer Schultradition $^{12}$ überholen wollen.

Ein besonderes Gewicht im Rechtsvergleich ist den Rechtssätzen zu Körperverletzungsfällen des altisraelitischen "Bundesbuches" und im hethitischen Recht zugefallen. F.C. Fensham ${ }^{13}$ hat aufgrund der zahlreichen Parallelen zwischen Heth.K. § 10 und Ex 21,18f răq Sibtô jitten Heth.K. § 10 entsprechend als Forderung nicht nur einer Geldzahlung, sondern auch der Stellung eines Ersatzarbeiters interpretiert. Shalom M. Paul ${ }^{14}$ hat diese Deutung bestritten und răq šbtô jitten die auf Geldforderung beschränkt. Ephraim Avigdor Spei$\operatorname{ser}^{15}$ hat wenatăn biplitim in Ex 21,22 als "payment to be based on reckoning" gedeutet und mit Heth.K. $\S 17$, der Differenzierung der Ersatzleistung nach dem Stadium der Schwangerschaft, in Verbindung gebracht. Doch ist die Verbindung mit akk. pälilum "Wächter" (AHw 816) wahrscheinlicher ${ }^{16}$. Schließlich kann man darauf verweisen, daß im Gegensatz zu $\mathrm{CH} \S 210^{17}$ das hethitische und israelitische Körperverletzungsrecht nur die Bestrafung des Täters, nicht aber von Familienmitgliedern kennen. Der Erlaß Telipinus [VS]II § 31.55-56 ${ }^{18}$ formuliert für das Königshaus ein Prinzip der Beschränkung der Strafe auf den Täter ${ }^{19}$. Doch wird man darin kaum einen direkten traditionshistorischen Zusammenhang von hethitischem und israelitischem Recht, sondern eher eine rechtshistorische Parallelentwicklung sehen. Die bisherige rechtsvergleichende Arbeit an den hethitischen und altisraelitischen Rechtssätzen des Körperverletzungsrechts hat zwar einige verwandte Motive, kaum

9 S. Alt, Ursprünge, 290; Boecker, Recht, 11ff; Locher, Ehre, 381, Anm.1 (Lit.) sowie der Sache nach Paul, Book of the Covenant, 102; Cardascia, Droits, 63-70; s. dazu differenzierend Yaron, Evolution, 78ff.

10 Law Codes, 247-264; ders., Studies, 1ff; vgl. auch ahnlich Malul, Studies, 99-152.

11 S. Westbrook, Twelve Tables, 74-121.

12 S. dazu Westbrook / Wilcke, Liability, 111-121; ders., Marriage Law, $2 \mathrm{ff}$.

13 Hittite Law, 333-335; so auch Hoffner, Hittitology, 38f; vgl. auch Cazelles, Code d'Alliance, 54.

14 Book of the Covenant, 69 Anm. 1; vgl. Schwienhorst-Schönberger, Bundesbuch, 57.

15 Stem PLL, 301-306; vgl. Stol, Zwangerschap, 15.

16 S. Otto, Korperverletzungen, $120 \mathrm{f}$.

17 Vgl. Ries, Kollektivhaftung, 184f.

$18 \mathrm{Zu}$ Text und Übersetzung s. Hoffmann, Erlaß Telipinus, 34f.; vgl. dazu Korošec, Kollektivhaftung, 187-209; Haase, Kollektivhaftung, 224f.

19 Vgl. auch Dtn 24,16; s. dazu Otto, Verantwortung, 296. 
aber eine Abhängigkeit des israelitischen vom hethitischen Recht aufweisen können.

Hinzu kommt, daß die von Albrecht $\mathrm{Alt}^{20}$ griffig zusammengefaßte These seines Schülers Alfred Jepsen ${ }^{21}$ vom Ursprung des kasuistischen Fallrechts, das er aufgrund der engen Parallelen mit dem altbabylonischen Recht auf die Rezeption von den vorisraelitischen Landesbewohnern zurückführte, zu revidieren ist. Es mag noch archäologische Kontingenz sein, daß bislang kein vorisraelitisches Fallrecht in Palästina im Gegensatz zu apodiktischen Rechtsformulierungen bekannt geworden ist. Durchschlagender ist der Nachweis von Gerhard Liedke $^{22}$, daß das kasuistische Recht des "Bundesbuches" kaum auf ein Stadtrecht zurückgeht, sondern als bäuerlich-dörfliches Recht in indigen israelitischen Rechtserzählungen wurzelt, wie es Paul Koschaker ${ }^{23}$ entsprechend für den Mittelassyrischen Kodex aufwies. Clemens Locher ${ }^{24}$ hat diesen Nachweis für Dtn 22,13-21 erneut erbracht. Wie sollte eine Vermittlung hethitischer Rechtsmotive in bäuerlich-israelitische Ortsgerichte auf dem mittelpalästinischen Gebirgsland vorstellbar sein, insbesondere, wenn, wie von Victor Korošec ${ }^{25}$ und Einar v. Schuler ${ }^{26}$ vertreten, der Geltungsbereich des Hethitischen Kodex auf die Kernländer Hattis eingeschränkt war?

Die Problemlage wird noch verwickelter, wenn wir die Motive mit einbeziehen, die das altisraelitische Körperverletzungsrecht des "Bundesbuches" mit dem altbabylonischen Recht gegen das hethitische Recht gemeinsam hat, so vor allem die Talion in Ex 21,24.(25) ${ }^{27}$, die Rechtssätze zur Körperverletzung einer Schwangeren in Ex 21,22f, die mit UM-55-21-71- \$§ 4; 5;

Ursprünge, 285-302; vgl. dazu den Forschungsbericht von Schottroff, Recht, 3-29.

Bundesbuch, 55ff.

Gestalt, 39ff.53ff.

23 Altassyrische Gesetze, 17ff.68.79f.83; zum altbabylonischen Recht s. zuletzt Zaccagnini, Formazione, 40ff. Zum hethitischen Recht s. Follet, Lois, 7f; Friedrich, Gesetze, 1: "Die hethitische Textgruppe, die die Forschung herkömmlich als 'Hethitische Gesetze' bezeichnet, ist keine offizielle Gesetzessammlung wie etwa der Codex Hammurabi, sondern besteht nach Ansicht des Verfassers aus Niederschriften einmal gefallter Rechtsentscheidungen für den Gebrauch der Juristen."

24 Ehre, 83ff.90ff (Lit.); ders., Prozeßprotokoll, 298-309.

's Stellung, 27f; ders., Hettitica, $45 f$.

16 Konigserlässe, 436; vgl. auch Collins, Laws, 136-141.

17 S. dazu Jüngling, Talionsformeln, 1-38; Kugelmass, Lex Talionis; Otto, Talion, 101-130; vgl. auch den Forschungsüberblick von Martin-Achard, Talion, 173-188; s. auch u. Anm. 103.

8 Text s. Civil, Law Fragments, 4ff; Szlechter, Lois sumériennes, 80f.124ff; vgl. zuletzt Otto, Korperverletzungen, 46-50. 
$212^{29}$ und mass. K.A $\S \S(21) ; 50^{30}$ gegen Heth. K. $\S 17 ; 18 ; \mathrm{XVI}$; XVII ${ }^{31}$ zwischen Körperverletzung mit und ohne Todesfolge differenzieren, sowie schließlich die Rechtssätze vom stößigen Ochsen in Ex 21,28-32. (35f), die Parallelen in CE $\S \S 53-55^{32}$ und $\mathrm{CH} \S \S 250-252^{33}$ haben. Gerade die Rechtssätze vom stößigen Ochsen und der Körperverletzung einer Schwangeren dienten Jacob J. Finkelstein ${ }^{34}$, einen traditionsgeschichtlichen Zusammenhang zwischen altbabylonischem sowie altisraelitischem Recht, und Raymond Westbrook $^{35}$, um ein einheitliches altorientalisches "common law" noch zu erweisen.

Pauschale Thesen eines einheitlichen Keilschriftrechts ${ }^{36}$, einer altorientalischen Rechtskultur ${ }^{37}$, einer gemeinorientalischen koiné des Rechts ${ }^{38}$, eines den gesamten Orient umfassenden "common law" oder allgemeinorientalischer "customary laws" im Gegensatz zu differenzierten "proper laws" ${ }^{139}$ verhelfen nicht zu rechtshistorischer Konkretion. Es soll im folgenden geprüft werden, ob nicht die Fixierung der Analyse auf den je einzelnen Rechtssatz und mit der überlieferungsgeschichtlichen und redaktionsgeschichtlichen Analyse der Rechtskorpora der "patternism" überwunden werden können.

Das altorientalische Körperverletzungsrecht des "Bundesbuches" enthält Motive, die Parallelen im altbabylonischen, nicht aber im hethitischen Recht, neben solchen, die Parallelen im hethitischen, nicht aber im altbabylonischen Recht haben. Ich frage daher in einem ersten Arbeitsschritt nach der Überlieferungsgeschichte des Körperverletzungsrechts innerhalb des hethitischen Rechts und von da ausgehend nach dem traditionsgeschichtlichen Verhältnis zum altbabylonischen und israelitischen Recht. In einem letzten Arbeitsschritt

29 Text s. Borger, $\mathrm{BAL}^{2}, 38 \mathrm{f}$.

30 Text s. Schroeder, KAV 1; vgl. auch zu Text und Übersetzung Saporetti, Leggi Medioassire. 85; Otto, Körperverletzungen, 81-90.

31 Text und Übersetzungen s. Friedrich, Gesetze, 42f.104; Otto, Körperverletzungen, 97-102.

32 Text s. Goetze, Laws of Eshnunna, 132ff; Yaron, Laws of Eshnunna, 76ff; Otto, Kode ESnunna, 110ff.

33 Text s. Borger, BAL ${ }^{2}$, 42; vgl. Otto, Körperverletzungen, 147-164.

34 Ox, 1-89; vgl. auch ders., Deodands, 169-290; ders., Apperceptions, 591-608.

35 Studies, 57ff.83ff.

36 Vgl. Koschaker, Keilschriftrecht, 1-39; vgl. dazu Cardascia, Droits cuneiformes, 15; Schottroff Recht, 10f.

37 S. o. Anm. 20.

38 Zaccagnini (Formazione, 45f) spricht mit Hinweis auf das Körperverletzungsrecht von eine koiné altorientalischen Rechts.

39 S. Yaron, Laws of Eshnunna, 291ff. Zum Forschungsstand s. auch Otto, Bedeutung, 139-145 
ma-a-na-as SIG $5-a t-[(t a)-r i(m a)]$ nu-ư̌-ši 6 GÍN KÙ.BABBAR pa-a-i LU A.ZU- úa ku-uš-ša-an apa-a-aš-pát $[(p a-a-i)]$

Ser. I B I 29-30: heth.K. \& 11

ták-ku LÚ.U ${ }_{19}$.LU-an EL-LUM QA-AS-SÚ na-aš-ma GİR-ŠU Ku-iš-ki tu-wa-a[r-n]i-iz-zi nu-ǔs-še 20 GÍN KÙ.BABBAR pa-a-i pár-na-aš-se-e-a šu-wa-a-i-iz-zi

Ser. I B I 31-32: heth.K. \& 12

ták-ku İR-na-an na-aš-ma GÉME-an QA-AS.SÚ na-aš-ma GÌR-ŠU ku-iš-ki tu-wa-ar-na-zi 10 GÍN KÙ.BABBAR pa-a-i pár-na-aš-še-e-a šu-wa-a-i-iz-zi

Ser. I B I 33-34: heth.K. $\S 13$

ták-ku LÚ.U ${ }_{19}$.LU-an EL-LAM KIR $14^{-\zeta e-i t ~} k u-i \zeta ̌-k i$ wa-a-ki 1 MA.NA KÙ.BABBAR pa-a-i párna-aš-se-e-a šu-wa-a-i-e-iz-zi

Ser. I B I 35-36: heth.K. \& 14

ták-ku IR-an na-aš-ma GÉME -an $\mathrm{KIR}_{14}$-še-it ku-iš-ki wa-a-ki 3 GÍN KÙ.BABBAR pa-a-i párna-aš-se-e-a suu-wa-a-i-iz-zi

Ser. I B I 37-38: heth.K. \& 15

ták-ku LÙ.U ${ }_{19}$.LU-as EL-LAM iš-ta-ma-na-aš-sa-an ku-iš-ki iš-kal-la-a-ri 12 GÍN KÙ.BABBAR pa-a-i pár-na-aš-še-e-a šu-wa-a-i-iz-zi

Ser. I B I 39: heth.K. \& 16

ták-ku İR-an na-aš-ma GÉME-an GEŠTUG-aš-ša-an ku-iš-ki iš-kal-la-ri 3 [GÍN)] KÙ.BABBAR $p a-a-i$

Ser. I B I 40-42: heth.K. § 17

[(ták-k)]u MUNUS-aš EL-LI sar-hu-wa-an-du-uš-šu-uš ku-ǐ̌-ki $p[(i-e)]$ - $-[(3 i-y a-)] z i \quad[t a ́ k-k u]$ ITU.10. ${ }^{\mathrm{KAM}} 10$ GIN KÙ.BABBAR pa-a-i tak-ku [[-ứ]] ITU.5. ${ }^{\mathrm{KAM}} 5$ GÍN K[Ü.BABBAR] pa-a$i[$ par-n]a-aš-s[e-e-a] šu-wa-a-i[-iz-z]i

Ser. I B I 43-44: heth.K. § 18

ták-ku GÉME-aš sar-ḩu-wa-an[du-u]š-su-uš ku-iš-ki pi-e[(s-si-y)]a-zi ták-ku ITU.10.KAM 5(?) GÍN KÙ.BABBAR pa-a-[i] 


\section{Übersetzung}

\section{Heth.K. \& 7}

Wenn jemand einen freien Menschen blendet oder seinen Zahn ausschlagt ${ }^{\mathbf{a}}$, gab er fruher 1 Mine Silber und jetzt gibt er 20 Schekel Silber; auch spaht er zu seinem Haus ${ }^{b}$.

\section{Heth.K. $\$ 8$}

Wenn jemand einen Unfreien oder eine Unfreie blendet oder seinen (ihren) Zahn ausschlagt, gibt er 10 Schekel Silber; auch spaht er zu seinem Haus.

\section{Heth.K. § 9}

Wenn jemand den Kopf $^{c}$ eines Menschen verletzt, gab er früher 6 Schekel Silber und der Verletzte nahm 3 Schekel Silber, der Palast nahm 3 Schekel Silber. Und jetzt hat der Konig die (Abgabe an den Palast) abgeschafft und nur der Verletzte nimmt 3 Schekel Silberd.

\section{Heth.K. § 10}

Wenn jemand einen Menschen verletzt und ihn krank macht, so pflegt er den Betreffenden. An seiner Stelle gibt er einen Menschen, und (der) arbeitet in seinem Hause, bis er gesund ist. Wenn er aber gesund ist, gibt er ihm 6 Schekel Silber. Auch für den Arzt gibt jener den Lohn.

\section{Heth.K. \& 11}

Wenn jemand Hand oder Fuß eines freien Menschen zerbricht, gibt er ihm 20 Schekel Silber; auch spaht er zu seinem Haus.

\section{Heth.K. \& 12}

Wenn jemand Hand oder Fuß eines Unfreien oder einer Unfreien zerbricht, gibt er 10 Schekel Silber; auch spaht er zu seinem Haus.

a Gegen die Übersetzung von lag- mit "schief schlagen" (so Friedrich, Gesetze, 126; ders., Worterbuch, 125) hat Haase (RLA VI, 179) geltend gemacht, daß die Parallelisierung mit dem Verlust eines Auges in Heth.K. $\S 7$ den Verlust eines Zahnes nahelegt. Dies wird durch die Entsprechung mit akk. nadu (s. CAD N/, 95) bestatigt. In $\mathrm{CH} \S 200$ und $\mathrm{CE} \S 42$ wird jeweils über den Verlust eines Zahnes gehandelt.

b Zur Vindikationsformel parnaššea šuwaizzi s. Oettinger, Stammbildung, 294-298 sowie zuletzt Otto, Korperverletzungen, 98f; ders., Vindikationsformel, 94-96.

c Riemschneider (Korperverletzungen, 177-182) hat mit Verweis auf Heth.K. §§ VII; LX (KBo VI 4) SAG.DU als Bezeichnung pars pro toto für die "Person" interpretiert und Heth.K. $\$ 9$ auf die leichte, Heth.K $\S 10$ auf die schwere Korperverletzung gedeutet. Dagegen spricht, daß, wie Haase (Leibesverletzung, 116) gezeigt hat, SAG.DU in KBo VI 4 eher Schreiberversehen sei, als daß es Anlaß sein könnte, SAG.DU in Heth.K. $\$ 9$ mit "Person" zu übersetzen. Die Verbindung LÚ.U ${ }_{19}$.LU SAG.DU-SÚ wăre bei einer Übersetzung mit "Person" eine auffallige Doppelung.

d Zur Partikel -za s. Souček, Bearbeitung, 460: Sie "soll hier hervorheben, daß der Verletzte die als Strafe geleistete Abgabe fiur sich nimmt; also soll damit der Gegensatz zu dem Stande vor der Reform hervorgehoben werden"; vgl. auch ders., Schlußformel, 27. 
Heth.K \& 13

Wenn jemand die Nase eines freien Menschen (ab)beißt, gibt er eine Mine Silber; auch spalht er zu seinem Haus.

Heth.K. \& 14

Wenn jemand die Nase eines Unfreien oder einer Unfreien abbeißt, gibt er 3 Schekel Silber; auch spăht er zu seinem Haus.

Heth.K § 15

Wenn jemand das Ohr eines freien Menschen zerschlitzt, gibt er 12 Schekel Silber; auch spăht er zu seinem Haus.

Heth.K. $§ 16$

Wenn jemand das Ohr eines Unfreien oder einer Unfreien zerschlitzt, gibt er 3 Schekel Silber.

Heth.K. $\S 17$

Wenn jemand die Leibesfrucht einer freien Frau abstoßt, [wenn] (es) der 10. Monat (ist), gibt er 10 Schekel Silber, wenn (es) der 5. Monat (ist), gibt er 5 Schekel [Silber]; auch spaht er zu seinem Haus.

Heth.K. \& 18

Wenn jemand die Leibes[frucht] einer Unfreien abstoßt, wenn (es) der 10. Monat (ist), gibt er 5 (?) Schekel Silber.

Die Rechtssätze in Heth.K. §§ 7-18 unterscheiden zwischen schweren und leichten Körperverletzungen. Unter den schweren Körperverletzungen wird zwischen solchen, die heilen, dem Knochenbruch von Hand und Fuß (Heth.K. $\S \S 11 ; 12)$, und solchen, die bleibenden Schaden zur Folge haben, so dem Verlust von Auge, Zahn, Nase oder Ohr (Heth.K. §§ 7; 8; 13-16), differenziert. Unter den leichten Körperverletzungen wird zwischen solchen, die einen Arbeitsausfall und Heilungskosten zur Folge haben (Heth.K. $\S 10$ ), und solchen, die keine derartigen Folgen haben (Heth.K. § 9), unterschieden. Die Zusammenstellung der Rechtssätze will analoge, in den Rechtsfolgen unterschiedlich zu handhabende Fälle abgrenzen. Dem dient auch die kunstvolle Anordnung der Rechtssätze ${ }^{45}$. Der Rechtssatz Heth.K. $\S 10$ hebt sich als lex generalis von den übrigen Rechtssätzen in Heth.K. $\$ \S 7-18^{46}$ ab, da im Gegensatz zu diesen keine Verletzung eines spezifischen Körperteils genannt, sondern nur allgemein von Verletzen (hünink-) und Krankmachen (ištarnink-) gesprochen wird. Auch Heth.K. $\$ 9$ hebt sich durch Allgemeinheit und geringe Geldzahlungsforderung von den übrigen, die Verletzungen des Kopfes betreffenden Rechtssätzen in Heth.K. $\S ~ 7 ; 8 ; 13-16$ ab. Die beiden Rechtssätze Heth.K. §§ 9; 10 verbindet, daß im Gegensatz zu den übrigen Rechtsfällen in Heth.K. §§

\footnotetext{
45

Vgl. Otto, Korperverletzungen, 103-110.

46 S. auch Grothus, Rechtsordnung, 57.
} 
7-18 nicht zwischen den Körperverletzungen der Freien und der Sklaven unterschieden wird und $E L-L U M$ in Verbindung mit LÚ.U $U_{19} . L U$ fehlt. Die Rechtssätze Heth.K. \$\$ 9-10 bilden einen Kern von zwei Grundsatzregelungen, von denen die übrigen Rechtssätze spezifische Fälle abgrenzen. Heth.K. \$§ 7-8; 13-16 grenzen von Heth.K. $\$ 9$ die Fälle der bleibenden Körperverletzung von Organen des Kopfes ab, Heth.K. §§ 11-12 von Heth.K. § 10 die Fälle der schweren heilenden Körperverletzung bei Bruch von Hand oder FuB ${ }^{47}$. Richard Haase ${ }^{48}$ hat aufgrund der Trennung der Verletzungsfälle des Kopfes in Heth.K. \$§ 7-9 von denen in Heth.K. \$§ 13-16 in Heth.K. §§ 7-9 einen überlieferungsgeschichtlichen Zusatz gesehen. Habe Victor Korošec ${ }^{49}$ für die Rechtssätze der Tafel I ein Redaktionsprinzip der Abfolge vom wertvollen zum weniger wertvollen Rechtsgut erkannt, so lasse sich dieses Prinzip auch in Heth.K. §§ 10-18 aufweisen. "Geht man nämlich bei der Betrachtung der Leibesverletzungen von $\S 10$ aus, so steht an der Spitze die Verletzung eines Menschen, welche Bettlägerigkeit zur Folge hat, also eine nicht ganz unbeträchtliche Störung der Gesundheit voraussetzt. Es folgen Verletzungen der Extremitäten, dann schwerwiegende Verstümmelungen des Kopfes und schließlich der Verlust der Leibesfrucht (II 17, 18) ${ }^{\mathrm{n} 50}$. Die Wertung der Schwere des Falles durch die hethitische Redaktion ist nur aus den Rechtsfolgebestimmungen abzulesen, die gerade eine umgekehrte Tendenz zeigen. Dann aber ist kein ausreichendes Argument ersichtlich, um Heth.K. $\$$ 7.9 als sekundär auszuscheiden. Vielmehr hat der Redaktor die Rechtssätze zur Körperverletzung des Kopfes in Heth.K. \$§ 7-9; 13-16, mit der in keilschriftlichen Rechtstexten weit verbreiteten Inklusionstechnik arbeitend ${ }^{51}$, als Rahmen für Heth.K. $\S \S 10 ; 11$; 12 genutzt. Durch die ebenfalls weit verbreitete Redaktionstechnik alternierender Anordnung von Rechtssätzen der Freien und Sklaven in einem A-B-Sche$\mathrm{ma}^{52}$ werden die Rechtssätze der Körperverletzung einer Schwangeren in den Zusammenhang der Körperverletzungsfälle eingebunden, so daß sich folgender Aufbau von Heth.K. \$§ 7-18 ergibt, der seine nächste Parallele im israelitischen Körperverletzungsrecht des "Bundesbuches" hat ${ }^{53}$ :

$47 \mathrm{Zu}$ den Heilungsproblemen und -risiken von Knochenbrüchen in der Antike s. Völkl, Körperverletzung, 7 ff (Lit.).

48 Leibesverletzung, 114.

49 Sistematika, 11; ders., Keilschriftrecht, 181 mit Anm. 3; ders., Gesetze, 289; ders., Struktur, 290.

$50 \mathrm{AaO} 114$.

51 Vgl. dazu Otto, Kodex Esnunna, 68ff.

52 Vgl. dazu Otto, Rechtssystematik, 187ff; ders., Kodex EŠnunna, 135ff.

53 S. Otto, Rechtsbegründungen, 24ff. Der Versuch von $K$ Peckeruhn (Handschrift, 152ff) in Heth.K. $\S \S 1-18$ einen Dekalog als Vorlage zu rekonstruieren, dürfte kaum überzeugen. 
A: § 7: Rechtssatz der freien Bürger

B: § 8: Sklavenrecht

§ 9: Grundsatzregelung

\$10: Grundsatzregelung

\} lex generalis

A: §11: Rechtssatz der freien Bürger

B: §12: Sklavenrecht

A: §13: Rechtssatz der freien Bürger

B: §14: Sklavenrecht

A: §15: Rechtssatz der freien Bürger

B: §16: Sklavenrecht

A: §17: Rechtssatz der freien Bürger

B: §18: Sklavenrecht

Die als Rahmen genutzten Rechtssätze Heth.K. §§ 7; 8; 9; 13-16 haben eine eigenständige Überlieferungsgeschichte. Eine ältere, vorreformerische Sammlung der Rechtssätze ist noch erkennbar. Sie listete die vier bleibenden Verletzungen des Verlustes von Auge, Zahn, Nase und Ohr auf, wobei die Zerstörung des Ohres weniger schwerwiegend als die übrigen drei Verletzungen bewertet wurde. Davon abgegrenzt sind die heilenden Verletzungen des Kopfes (Heth.K. $\S 9^{*}$ ). Schon für diese älteste Sammlung ist eine Inklusion von Heth.K. § 9* durch die Fälle der schweren Körperverletzung zu vermuten.

Mit der Reform kommen neue Aspekte in der Gestaltung der Rechtssätze hinzu. Die Ergänzung von Heth.K. § 9 durch den Zusatz "und jetzt hat der König die (Abgabe an den Palast) abgeschafft und nur der Verletzte nimmt 3 Schekel Silber" nennt das auch für die Reform in Heth.K. \& 7 anzunehmende Prinzip. In der Zahlungsforderung von 1 Mine Silber vor der Reform war ein Anteil des Palastes enthalten, der nunmehr fortfiel, so daß sich entsprechend die Forderung auf 20 Schekel Silber ermäßigte. Die Summe von 10 Schekeln in der entsprechenden sklavenrechtlichen Bestimmung in Heth.K. $\S 8$ ist auf das Duplum in dem Reformzusatz in Heth.K. $\S 7$ bezogen - ein Hinweis darauf, da $\beta$ die sklavenrechtlichen Bestimmungen, die auch keinen Reformzusatz erhalten, erst mit der Reformüberarbeitung eingeführt wurden. Auch in Heth.K. § 13; 15 fehlt der Reformzusatz. Bei der Alternative, ob der Tarif vor der Reform unverändert blieb oder implizit gesenkt wurde, hat die erste Möglichkeit die höhere Wahrscheinlichkeit für sich. Auffällig ist die im Vergleich zu Heth.K. §§ 7; 8 große Diskrepanz zwischen Sklavenrecht und Recht der Freien von 3 Schekel und 1 Mine Silber in Heth.K. $\$ \S 13 ; 14$. Die sklavenrechtliche Bestimmung interpretiert die hohe Zahlungsforderung von 1 Mine Silber bei Verlust der Nase eines Freien mit der Entstellung und also dem Ehrverlust. Für einen Sklaven gilt dieser Gesichtspunkt als irrelevant, so daß für ihn 
Verlust von Nase und Ohr auf eine Stufe gestellt werden können, während für den Freien Verlust der Nase mit dem Duplum des Verlustes eines Ohres bezahlt wird. In Heth.K. $\$ \$ 11 ; 12$ werden die Zahlungsforderungen von 20 und 10 Schekel Silber mit denen der Reformformulierungen in Heth.K. $\$$ 7; 8 parallelisiert, so daß die Einfügung dieser Rechtssätze mit Heth.K. § 10 auf den Redaktor des Reformtextes zurückzuführen ist.

Überlieferungsgeschichtlicher Kern der Rechtssätze in Heth.K. §§ 7-18 ist also eine Tarifliste der Verletzungen des Kopfes in Heth.K. $\$ \S 7^{*} ; 9^{*} ; 13 ; 15$, in die Reformzusätze in Heth.K. $\$ \S 7 ; 9$, die sklavenrechtlichen Sätze in Heth.K. §§ 8; 14; 16 sowie die Rechtssätze der übrigen Körperverletzungsfälle in Heth.K. \$§ 10-12 eingefügt, die Körperverletzung einer Schwangeren in Heth.K. $\S \S 17 ; 18$ als Anhang angefügt und durch die alternierende Anordnung von Rechtssätzen der Freien und Sklaven in den Zusammenhang von Heth.K. § 7-16 einbezogen wurden.

Die Rechtssätze Heth.K \$§ 7-18 lassen als Lücke die Regelung von bleibenden schweren Körperverletzungen der übrigen Körperteile. Der "Paralleltext" KBo VI 4 27-29 (Heth.K. \& X) schließt diese Lücke:

ták-ku LUU EL.LUM ŠU-SÚ na-aš-ma GIR-šU ku-ǐs-ki du-ua-ar-ni-iz-zi na-ă̌ ma-a-an karma-la-as-sa-i nu-uS-si 20 GíN KÜ.BABBAR pa-a-i ma-a-na-as U.UL-ma kar-ma-la-aš-sa-i nu-ưs-si 10 GIN KÙ.BABBAR pa-a-i

"Wenn jemand die Hand oder den Fuß eines freien Menschen zerbricht und (sie) steif bleiben $^{54}$, gibt er ihm 20 Šekel Silber; wenn sie aber nicht steif bleiben, gibt er ihm 10 Schekel Silber.

Davon abgesetzt wird die Regelung der schweren heilenden Körperverletzungen in KBo VI 4 22-26 (Heth.K. § IX), die aus der Verbindung von Heth.K. $\S 9$ und Heth.K. $\$ 10$ gebildet wurde:

"Wenn jemand den Kopf eines Mannes schwer verletzt ${ }^{55}$, pflegt er ihn. An seiner Stelle gibt er einen Menschen, und (der) arbeitet so lange $\mathrm{e}^{56}$ in seinem Haus, bis er gesund ist. Wenn er aber gesund ist, gibt er ihm 10 Šekel Silber. Auch gibt er als Lohn an den Arzt 3 Šekel Silber; wenn es aber ein Unfreier ist, gibt er 2 Šekel Silber."

Die Rechtssätze Heth.K. §§ 7-18 sind am Prinzip der Erfolgshaftung orientiert und differenzieren nicht zwischen vorsätzlicher und unvorsätzlicher Körperverletzung. Daß in Heth.K. §§ 17; 18 im Gegensatz zu Heth.K. § 77a nicht

\footnotetext{
54 Vgl. Friedrich, Worterbuch, 101.

$55 \mathrm{Vgl}$. Friedrich, aaO 54.

56 So wird mit Friedrich (Gesetze, 51 Anm. 14) das Iterativum ausgedrückt.
} 
das Schlagen (walh-) erwähnt wird; reicht nicht als Begründung der These, Heth.K. §§ 17; 18 regele die unvorsätzliche Körperverletzung einer Schwangeren $^{57}$. Entsprechend ist in diesen Rechtssätzen der Bußaspekt ausgeklammert $^{58}$. Eine die Zahlungsforderung am Alter des Fötus messende Rechtsfolge wäre unter dem Aspekt der Verschuldenshaftung wenig sinnvoll, wohl aber der Ersatzleistung in der Erfolgshaftung. Erst im "Paralleltext" KBo VI 4 14-15 (Heth.K. $\S \mathrm{V}$ ) wird nach dem Prinzip der Verschuldenshaftung zwischen vorsätzlicher und unvorsätzlicher Tat differenziert:

ták-ku LÚ-an EL.LUM šu-ul-la-an-na-za ku-ǐ̌-ki da-šu-ua-ah-hi 1 MA.NA KÚ. BABBAR pa-a-i ták-ka šU-aš ua-aš-ıa-i 20 GIN KU.BABBAR pa-a-i

"Wenn jemand einen freien Mann infolge eines Streites blendet, gibt er eine Mine Silber.

Wenn die Hand sündigt, gibt er 20 Šekel Silber."

Der formelhafte Ausdruck ŠU-aš uaštai "die Hand sündigt" hat in hethitischen Orakeltexten (KUB V 3 I 3.8; V 4 II 27) ${ }^{59}$ Parallelen zur Bezeichnung der Ursache göttlichen Zornes. In Heth.K. $\S \mathrm{V}$ ist diese Phrase wie ihre entferntere Parallele in Ex 21,13 wă ǎaer lo' sada' weha'aelohîm 'innā l'jadô ("wenn einer nicht nachgestellt hat, sondern Gott es zufällig seiner Hand geschehen lie $\beta^{\prime \prime 60}$ ) zur Bezeichnung der Unvorsätzlichkeit mit einer Milderung der Rechtsfolge verbunden. Das Prinzip der Erfolgshaftung wird zugunsten der Verschuldenshaftung dadurch überwunden, daß in einer Rechtsfiktion vom Täter als Verursacher abgelenkt und auf eine außerhalb seiner Verfügungsgewalt liegende Ursache das Erfolgshaftungsprinzip angewandt wird. Ähnliche Überwindungen der Erfolgshaftungen haben sich im altbabylonischen, israelitischen und römischen Recht im XII-Tafelgesetz VIII 24a (SI TELUM MANU FUGIT MAGIS QUAM IECIT' ${ }^{\text {o1 }}$ vollzogen.

III. Zur Frage der überlieferungsgeschichtlichen Abhängigkeit des hethitischen vom altbabylonischen Körperverletzungsrecht

Hinsichtlich der überlieferungsgeschichtlichen Abhängigkeit des hethitischen vom altbabylonischen Recht ist in der Forschung unterschiedlich geurteilt wor-

57 Gegen Haase, Vermögensrechte, 59f; ders., Korperverletzung, 181.

Gegen Haase, Wiedergutmachtung, $13 \mathrm{f}$.

59 Vgl. Friedrich, Gesetze, 90; Grothus, Rechtsordnung, 15.

60 S. dazu Otto, Rechtsbegründungen, 32f.

61 S. Diill, Zwölftafelgesetz, 54f; vgl. dazu Völkl, Körperverletzung, 83ff (Lit.). 
den. Während Ernst Neufeld ${ }^{62}$ den Einfluß für gering und nicht nachweisbar hält, ist für Victor Korošec ${ }^{63}$ ein Einfluß des altbabylonischen Rechts (CE §§ $42 ; 44 ; 45$ ) auch auf das hethitische Körperverletzungsrecht wahrscheinlich.

Wie in Heth.K. $\S \S 7^{*} ; 9^{*} ; 13 ; 15$ liegen den Rechtssatzsammlungen der Körperverletzungsfälle im Kodex Ešnunna und Kodex Hammurapi als älteste Überlieferungsschicht jeweils an der reinen Erfolgshaftung orientierte Tarifbestimmungen für Körperverletzungen zugrunde. Die Sammlung des Körperverletzungsrecht in $C E \$ \$ 42-48 ; 53-58$ hat ihren überlieferungsgeschichtlichen Kern in den Rechtssätzen CE $\$ \S 42 a ; 43-46^{64}$.

\section{Text}

$A$ iii 32-33; B iii 17-18: CE § 42a

summa awilum appe awilim ǐ̌suk-ma ittakis 1 mana kaspam išaqqal

$A$ iii 35-36; $B$ iii 21-22: CE $\S 43$

summa awilum ubān awilim ittakis $2 / 3$ mana kaspam išaqqal

A iii 36-37; B iii 23-24: CE § 44

šumma awïlum awillam ina süqim iskim-ma qüs-su išteber $1 / 2$ mana kaspam išaqqal

$A$ iii 38; B iii 25: CE $\S 45$

šumma šep-šu išteber 1/2 mana kaspam išaqqal

$A$ iii 39-40: $\mathrm{CE} \$ 46$

summa awilum awilam imhaṣ-ma ha<la>-š (Haddad 116 6': kirra-šu) išteber 1/3 mana kaspam išaqqal

62 Laws, 106.

63 Codification, 103; ders., Probleme, 294; vgl. auch ders., Wechselbeziehungen, 295-310.

64 S. Otto, Kodex ESnunna, 109ff. 


\section{Übersetzung ${ }^{65}$}

CE § 42a

Wenn ein awïlum die Nase eines awïlum abbeißt und abtrennt, zahlt er eine Mine Silber ${ }^{66}$.

CE \& 43

Wenn ein awilum den Finger eines awilum abtrennt, zahlt er 2/3 Mine Silber.

CE $\$ 44$

Wenn ein awilum einen awilum auf der Straße fortstoßt und seine Hand bricht, zahlt er eine 1/2 Mine Silber.

CE $\S 45$

Wenn er einen Fuß bricht, zahlt er 1/2 Mine Silber.

CE § 46

Wenn ein awilum einen awilum schlăgt und seinen Oberschenkel (Haddad 116 6': Schlüsselbein) bricht, zahlt er 1/3 Mine Silber.

Diese Sammlung von Tarifbestimmungen differenziert zwischen bleibenden Körperschäden des Verlustes von Auge und Finger und heilenden Körperverletzungen der Brüche von Hand, Fuß und Oberschenkel ${ }^{67}$. Die Redaktion ordnet diese Rechtssätze in einer absteigenden Linie beginnend mit dem Kopf und die Verletzung von Extremitäten in der Reihenfolge von außen nach innen voranschreitend an, so daß sich die Abfolge von Nase, Finger, Hand, Fuß, Oberschenkel ergibt. Für eine direkte Abhängigkeit der Tarifbestimmungen im Hethitischen Kodex von denen im Kodex Ešnunna gibt es angesichts der unterschiedlichen redaktionellen Strukturen keinen Anhaltspunkt. Doch stimmen die Tarifbestimmungen darin überein, daß sie an der Erfolgshaftung orientiert die Rechtsfolgen nach dem Gesichtspunkt der Schwere der Verletzung abstufen und dabei zwischen bleibenden und heilenden Körperschäden unterscheiden. Durch die Einfügung von inüm 1 mana šinnum 1/2 mana uznu 1/2 mana mehes lètim 10 siqil kaspam išaqqal ("für ein Auge zahlt er eine Mine, für einen Zahn 1/2 Mine, für ein Ohr 1/2 Mine, für einen Schlag auf die Wange 10 Schekel Silber") in CE § 42b werden Differenzierungen der Rechts-

65 Zur Kommentierung s. Otto, Kodex EXnnunna, 114ff; vgl. zu CE $\$ 46$ auch Roth, LE 46-47A, $70 \mathrm{f}$.

66 inum 1 mana šinnum 1/2 mana uznu 1/2 mana mehes lêtim 10 šiqil kaspam išaqqal ist die Apodosis verdoppelnde Anfügung an den ursprünglich CE \& 43 entsprechend formulierten Rechtssatz.

67 Auch Haddad 116 ist eine derartige Liste von Tarifbestimmungen, die aber im Falle der Korperverletzung mit Todesfolge bereits nach dem Verschuldensprinzip (ina risbatim) differenziert; vgl. dazu Al-Rawi, Assault, 117-120. 
folgen bleibender Verletzungen des Kopfes eingeführt, die den Verlust von Auge und Nase gleich, den Verlust von Zahn und Ohr geringer bewerten und mit der mehes lētim den Tatbestand der iniuria einführen. Der altbabylonische Kodex Ešnunna differenziert damit zwischen Verlust von Auge und Zahn, was hethitisch erst der "Paralleltext" KBo VI 4 in Heth.K. § VII nachvollzieht. Auch die Differenzierung nach dem Verschuldensprinzip, die im Kodex Ešnunna mit CE $§ 47$ (ina saltim) ${ }^{68}$ eingeführt wird" ${ }^{69}$, findet sich hethitisch erst im "Paralleltext". Den Tatbestand der iniuria hat das hethitische Recht gar nicht in das Körperverletzungsrecht aufgenommen ${ }^{70}$.

Die Überlieferungsgeschichte des Körperverletzungsrechts im Kodex Hammurapi ist verwickelter als die des Kodex Ešnunna. Kernüberlieferung sind die Rechtssätze CH §§ 196-201, die redaktionell mit den eine eigenständige Redaktionsstruktur aufweisenden Rechtssätzen zur iniuria in CH §§ 195; 202-205 verbunden wurden. Die so entstandene Reihe $\mathrm{CH}$ §§ 195-205 wurde vom Redaktor des Kodex Hammurapi mit den nach dem Verschuldensprinzip (ina risbatim) differenzierenden Rechtssätzen $\mathrm{CH} \$ \S$ 206-214 verbunden ${ }^{71}$.

\section{Text}

CH Kol. xvii [RS] 45-49: CH \& 196

summa awilum in mär awilim uhtappid in-šu uhappadū

CH Kol. xvii [RS] 50-53: $\mathrm{CH} \S 197$

šumma eșemti awilim ištebir eșemta-šu ǐ̌ebberū

CH Kol. xvii [RS] 54-59: $\mathrm{CH} \& 198$

šumma in muškēnim uhtappid ù lū eșemti muškēnim ištebir 1 mana kaspam išaqqal

CH Kol. xvii [RS] 60-65: CH § 199

summa in warad awilim uhtappid $\bar{u}$ lù eșemti warad awïlim ištebir mišil simi-šu išaqqal

CH Kol. xvii [RS] 66-70: $\mathrm{CH} \S 200$

summa awilum šinni awilim mehri-šu ittadi sinna-šu inaddû

68 Vgl. Landsberger, Jungfrăulichkeit, 101; vgl. auch Szlechter, Lois d'Ěnunna, 140; Otto, Kodex ESnunna, 116.

69 S. Otto, Korperverletzungen, 71-78.

70 S. zur Aufnahme der iniuria in das frühromische Korperverletzungsrecht XII-Tafelgesetz VIII 4: SI INIURLA ALTERI FAXSIT VIGINTI QUINQUE POENA SUNTO; s. Dull, ZwOlftafelgesetz, 48f; Völkl, Körperverletzung, $169 \mathrm{ff}$.

71 S. dazu Otto, Korperverletzungen, 56-70. 
CH Kol. xvii [RS] 71-74: $\mathrm{CH} \& 201$

summa Sinni muškēnim ittadi 1/3 mana kaspam ǐsaqqal

\section{Übersetzung $^{72}$}

\section{CH \& 196}

Wenn ein awilum das Auge eines mar awilim zerstơrt, zerstört man seine Augen.

\section{CH \& 197}

Wenn er einen Knochen eines awilum zerbricht, bricht man einen seiner Knochen.

\section{CH \& 198}

Wenn er ein Auge eines muskēnum zerstört oder einen Knochen eines muškēnum bricht, zahlt er eine Mine Silber.

\section{CH $§ 199$}

Wenn er das Auge eines Sklaven eines awilum zerstort oder einen Knochen des Sklaven eines awilum zerstort, zahlt er die Hălfte seines Kaufpreises.

\section{$\mathrm{CH} \S 200$}

Wenn ein awilum den Zahn eines ihm ebenbürtigen awilum ausschlagt, schlagt man seinen Zahn aus.

\section{CH § 201}

Wenn er den Zahn eines muškēnum ausschlägt, zahlt er 1/3 Mine Silber.

Die der altbabylonischen Gesellschaftsschichtung folgende Differenzierung in awilü und muškēnū ist überlieferungsgeschichtlicher Zuwachs dieser Sammlung ${ }^{73}$ und damit verbunden die Einführung des Schutzes der Klasse der awili durch die Prävention der talionischen Sanktionsandrohung ${ }^{74}$. Die ursprüngliche Tarifliste der Ersatzzahlungen hat die Zerstörung von Auge, Zahn sowie Knochenbruch von awilum und wardum ${ }^{75}$ umfaßt. Diese Tarifliste ist eng

72 S. Otto, aaO, 60-62.

73 Vgl. Yaron, Laws of Eshnunna, 145. Vgl. auch zum muškēnum-Problem Kraus, Mesopotamischer Mensch, 92-125; ders., Verfügungen, 329-331; anders Klíma, muskènum-Problematik, 267-274; vgl. auch den Diskussionsuberblick von Yaron, aaO, 132ff (Lit.).

74 Diese Tendenz prägt auch die Rechtssatze CH §§ 195; 202-205; vgl. Otto, Körperverletzungen, 67-69.74f; ders., Talion, 112-117.

75 Moglicherweise ist den Tarifbestimmungen in Heth.K. $\S \S 7-18$ entsprechend die Einführung des sklavenrechtlichen Satzes in CH $§ 199$ ebenfalls eine Erweiterung. Die $\mathrm{CH} \S 198$ (sek.) entsprechende, $\mathrm{CH} \S \S 196 ; 197$ zusammenfassende Formulierung könnte dafür sprechen; die ursprüngliche Tarifliste hat dann die Rechtssatze CH §§ 196*; 197*; 200* umfaßt: summa awilum in mär awilim uhtappid (... mana kaspam išaqqal) 
verwandt mit der in CE $\S \S 42 * .43-46$. Beide sind an der Erfolgshaftung orientiert und differenzieren zwischen Knochenbrüchen als heilende und bleibende Körperverletzungen. Mit der Konzentration auf die Verletzungen von Auge und Zahn steht diese Tarifliste im Kodex Hammurapi der im Hethitischen Kodex näher als die des Kodex Ešnunna.

Parallel zur Reformredaktion des Hethitischen Kodex wird auch in $\mathrm{CH} \S \S$ 196-201 zwischen Freien und Sklaven differenziert, findet $\mathrm{CH} \S 206$ zu einer Heth.K. § 10 ähnlichen Lösung und werden Heth.K. §§ 17; 18 entsprechende Rechtssätze der Körperverletzung einer Schwangeren (CH \$\$ 209-214) angefügt. Die hethitische Fassung dieses Falles in Heth.K $\$ \S 17 ; 18$ unterscheidet sich von den altbabylonischen Belegen in UM 55-21-71 $\S 4 ; 5^{76}$ und $\mathrm{CH} \S \S$ 209-214 dadurch, daß der Fall der Körperverletzung mit Todesfolge nicht aufgenommen wurde ${ }^{77}$. Diese Abweichung erklärt aber die Redaktionsstruktur des Hethitischen Kodex, der in Heth.K. $\S 1-4 ;(5 ; 6)$ die Tötungsdelikte zusammenfaßt und von den Körperverletzungen abgrenzt ${ }^{78}$. Die in $\mathrm{CH} \S \S$ 195; 202-205 breit entfaltete iniuria wurde nicht ins hethitische Körperverletzungsrecht aufgenommen. Die Differenzierung zwischen vorsätzlicher und unvorsätzlicher Körperverletzung, die die Redaktion des Kodex Hammurapi durch die Verbindung von $\mathrm{CH} \$ \S 206-208$ mit $\mathrm{CH}$ \$§ 209-214 vornimmt, wird hethitisch erst im "Paralleltext" KBo VI 4, also Jahrhunderte später, nachvollzogen. Die Differenzierung nach dem Verschuldensprinzip in Heth.K. $\$$ V geht andere Wege als die in CE $\$ \$ 42-47$ und $\mathrm{CH} \S \S 206-214$. Während das Motiv des Streits im altbabylonischen (ina risbatim [CH § 206], ina șaltim [CE § 47; Haddad 116'9]) und im israelitischen Recht ( $w^{e} k \hat{a} j^{e}$ ríbun "a našîm [Ex 21,18], w'kâ jinnașâ "našîm [Ex 21,22]) zur Bezeichnung der Unvorsätzlichkeit dient, wird im "Paralleltext" KBo VI 4 suullannaza ("infolge [Ablativ] eines Streites") als Gegensatz zu ŠU-aš uasštai ("die Hand sündigt") gerade Ausdruck der Vorsätzlichkeit.

Ein traditionsgeschichtlicher Zusammenhang zwischen altbabylonischem und hethitischem Recht ist für die Tarifbestimmungen als Kernüberlieferungen des Körperverletzungsrechts wahrscheinlich. Die altbabylonischen und hethitischen

šumma eșemti awilim ištebir (... mana kaspam išaqqal) šumma awilum šinni awilim ittadi (... mana kaspam išaqqal).

S. o. Anm. 28.

77 Darin weicht Heth.K. §§ 17;18 auch vom Mittelassyrischen Kodex §§ 21; 50-52 (zum Text s. Saporetti, Leggi Medioassire, 44f.85ff) ab und geht nur mit YOS I 28 [RS] §§ 1; 2 parallel; s. dazu Clay, Inscriptions, Nr. 28; Römer, Altmesopotamisches Recht, 326 Anm. 65 (Lit.); Otto, Korperverletzungen, 26-28.

18 S. Otto, Körperverletzungen, $109 \mathrm{f}$. 
Tarifbestimmungen stimmen in der Orientierung an der Erfolgshaftung und in der Differenzierung zwischen bleibenden und heilenden Verletzungen überein. Auswahl und Anordnung der Fälle sind variabel, doch sind die Differenzen zwischen dem hethitischen und dem altbabylonischen Recht nicht größer als die zwischen den Tafeln A/B und Haddad 116 des Kodex Ešnunna sowie zwischen dem Kodex Ešnunna und dem Kodex Hammurapi. Noch auf die Reformfassung der Rechtssätze Heth.K. \$§ 7-18 ist in der Einführung von Heth.K. \$§ 11 (par. CE $\S 44 ; 45$ ) und Heth.K. §§ 17; 18 (par. CH \$§ 209-214) ein altbabylonischer Einfluß möglich. Vor allem aber sind die alternierende Anordnung der Rechtssätze in einem A-B-Schema und die Redaktion in der Inklusionstechnik Redaktionstechniken, die ihren Ursprung in den rechtsgelehrten Redaktionen von Rechtsüberlieferungen des "Tafelhauses" (É.DUB.BA) haben ${ }^{79}$. Altbabylonische Rechtssätze und Rechtstechniken sind hethitisch rezipiert worden ${ }^{80}$.

Sollte sich dieses Ergebnis auf der Basis umfangreicherer Textanalysen bewähren, ist die in der Forschung weithin akzeptierte These, daß das Recht des Hethitischen Kodex vor der Reform Gewohnheitsrecht, das der Reform aber gesatztes Recht $\operatorname{se}^{81}$, zu revidieren. Der Hethitische Kodex geht auf die Rezeption altbabylonischer rechtlicher Schultradition des É.DUB.BA zurück, die Einfluß auf das hethitische Rechtswesen gewann und als solche auch dem Einfluß des hattischen Palastes unterlag. Die Redaktion der Rechtssätze und die Weiterentwicklung in dem "Paralleltext" KBo VI $4^{82}$ sind Ausdruck der Schulgelehrsamkeit. Der Hethitische Kodex ist also nicht direkt Reformtext, sondern spiegelt in gelehrter Tradition die Reform wider.

79 S. Otto, Kodex EXnunna, 68ff.135ff.177ff; ders., Rechtssystematik, 175-197. Altbabylonischet Einfluß ist auch in der Eroffnung der Protasen mit ták-ka (šumma) zu vermuten (Mitteilung von Herrn Kollegen Neu). $K$ Peckeruhn will auch in LÚ.U. ${ }_{19}$.LU EL-LUM Anpassung ar. altbabylonisch awilum sehen (Handschrift, 151).

Dieses Ergebnis laßt Zweifel an der Frühdatierung durch Archi (Formazione, 63f) aufkom men; vgl. Otto, Altorientalische Rechtsgeschichte, 9-11. Zu mittelhethitischen Zeugnissen de hethitischen Rezeption altbabylonischer Überlieferungen s. Röllig, Mondgott, 260-273; Wil. helm, Gilgames-Fragmente, 99-121; vgl. auch Tigay, Gilgamesh Epic, 111ff. Eine Vermittlun! durch die Hurriter (s. dazu Kammenhuber, Gilgames-Epos, 45-58; dies., Orakelpraxis, 64 Mascheroni, Scribi Hurriti, 151-173; Ünal, Narrative, 138ff) sollte nicht gegen eine unmittel bare Vermittlung durch die mesopotamische Schultradition (s. dazu Beckman, Mesopotamias Learning, 97-114) zu hoch veranschlagt werden.

81 S. Neufeld, Laws, 95ff; Guterbock, Authority, 21; Archi, Testo, 61ff; ders., Formazione, 63f.

82 Zu KBo VI 5 (C) s. Imparati, Leggi ittite, 17f; vgl. auch Follet, Lois Hittites, 7. 


\section{Hethitisches und israelitisches Körperverletzungsrecht}

Das israelitische Körperverletzungsrecht des "Bundesbuches" ist in Ex 21,1832 zusammengestellt ${ }^{83}$ und vom Kontext durch die Bildung der Protasen der Rechtssätze in Ex 21,18f.20f.22-25.26f.28-32 mit Verben des Schlagens und Stoßens ${ }^{84}$ abgegrenzt ${ }^{85}$. Ex 21,18f.22* sind die überlieferungsgeschichtlichen Kernsätze dieser Sammlung, die ursprünglich nur von der Körperverletzung ohne Todesfolge verbunden mit dem Spezialfall der Fehlgeburt aufgrund des Stoßens einer schwangeren Frau handelte. Diese Rechtssätze wurden um die sklavenrechtlichen Regelungen in Ex 21,20f.26f erweitert und mit Ex 21,23 und den Rechtssätzen vom stößigen Ochsen in Ex 21,29-32 um die Funktion der Abgrenzung der Körperverletzung ohne Todesfolge von denen mit Todesfolge erweitert. Diese Erweiterungsschicht der talionischen Formulierungen, der Schutzbestimmungen für die Sklaven und der Rechtssätze vom stößigen Ochsen hat keine auch nur entfernten Parallelen mit dem hethitischen Recht, während die Kernüberlieferung in Ex 21,18f.22* in Heth.K. \$§ 10; 17 Entsprechungen hat.

Ex 21,18f:

"Wenn Mănner miteinander streiten, und es schlägt ein Mann einen anderen mit einem Stein oder mit der Faust, so daß er nicht stirbt, aber bettlagerig wird, wenn er wieder aufsteht und draußen auf einem Stock umhergeht, bleibt der Schläger straffrei. Nur für sein Daheimsitzen muß er zahlen und für die Heilung auch."

83 S. Otto, Rechtsbegründungen, $24 \mathrm{ff}$.

84 Ex 21,18f: wehikkā; $\quad$ Ex 21,20: jăkkāē;

Ex 21,22: wenag̊pû; $\quad$ Ex 21,26: jăkkāē;

Ex 21,27: jăppil; $\quad$ Ex 21,28: jiggăh;

Ex 21,29: năggah; $\quad$ Ex 21,31: jiggăh.

Ex 21,32: jiggăh.

35 Osumi (Bundesbuch, 108ff) zieht dagegen Ex 21,12-23 zu einer "abgeschlossenen Struktur" zum Problem des Totschlags zusammen, wăhrend Schwienhorst-Schönberger (Bundesbuch, 213ff; ders., Rechtsvorschriften, 135ff) einen literarischen Zusammenhang zwischen Ex 21,12 und Ex 21,18ff herstellt, der durch Ex 21,13-17 aufgesprengt worden sei; s. dagegen Otto, Korperverletzungen, 138-146; ders., Gottesrecht, 425; Weimar, Bundesbuch, 351f. 
Ex 21,22:

"Wenn Mănner miteinander raufen und eine schwangere Frau stoßen, so daß ihr Kind abgeht, es aber kein tödlicher Unfall ${ }^{86}$ ist, $^{87}$ soll eine Geldbuße auferlegt werden in der Hohe, die der Ehemann ihm auferlegt, und er soll vor Zeugen ${ }^{88}$ bezahlen."

Ex 21,22 unterscheidet sich charakteristisch von Heth.K. \$§ 17; 18; XVI; XVII. Während in den hethitischen Rechtssätzen Tarife für die Fehlgeburt aufgrund der Körperverletzung einer Schwangeren differenziert nach der ersten und zweiten Hälfte der Schwangerschaft ${ }^{89}$ und nach Freien und Unfreien aufgelistet werden, regelt Ex 21,22 nur das Verfahren, nicht aber die Höhe der Haftung, die Verhandlungssache der Streitparteien ist. Die Funktion der Fixierung der Zahlungsforderungen in den Keilschriftrechten ist nur schwer zu bestimmen. Gerhard Ries ${ }^{90}$ weist darauf hin, daß die in der Urkunde UCBC $756^{91}$ verhängte Zahlungsforderung von $31 / 3$ Schekel Silber für eine Ohrfeige weit unter den Tarifen von $\mathrm{CE} \S 42$ und $\mathrm{CH} \S \S 203 ; 204$ bleibt. Er vermutet, $\mathrm{da} B$ es sich jeweils um Höchstsätze handle, den Gerichten also ein Freiraum in der Zumessung der Haftung innerhalb dieses Rahmens zufalle. Doch erklärt sich so nicht die komplexe Systematik der Abstufungen in den Tariflisten. Sie wird aber aus der Funktion dieser Rechtssätze als Rechtsparadigmen in der Ausbildung zum Rechtsentscheid im Analogieschluß verständlich ${ }^{92}$. Anhand der abgestuften Tarife in den Rechtsfolgebestimmungen, in Heth.K. \$§ 17; 18 sind es allein für die Körperverletzung der Schwangeren ohne Todesfolge drei, wird zur beurteilenden Abgrenzung der Fälle in den Protasen angeleitet. Ex 21,22 steht dem faktischen Rechtsfindungsprozeß näher und spiegelt ihn wider. Die Höhe der Entschädigungszahlung wird von den Betroffenen, Täter und

86 Schwienhorst-Schönberger (Bundesbuch, 92) interpretiert 'asôn als "jede Art von Unglück" wăhrend Jackson (Exodus 21:22-5, 96) 'asôn auf den Fơtus als "Frühgeburt" und Westbrook (Lex talionis, 57; vgl. ders., Studies, 691) sowie Stol (Oog, 38-44) 'asôn auf die anonyme Gewalttat deuten; s. dazu Otto, Korperverletzungen, $119 f$.

$87 w^{e} l o^{\prime} j i h^{e} j a ̈ \bar{e}$ 'asôn könnte zur abgrenzenden Verknüpfung von Ex 21,22 und Ex 21,23 bei de Anfügung von Ex 21,23 in den Kontext von V. 22 eingefügt worden sein.

$88 \mathrm{Zu} w^{e}$ natăn biplilîn s.o. Anm. 15.16.

89 Vgl. Otto, Körperverletzungen, 99f. Zur Zahlung der Schwangerschaftsmonate s. Haase, Zeit 343; anders Friedrich, Gesetze, 92; Imparati, Leggi ittite, 203. Die LXX differenziert ebenfall: nach Schwangerschaftsstadien in Ex 21,22f. Gegen Isser (Tradition, 30-45) ist MT nicht nact LXX zu korrigieren, um so einen Zusammenhang mit Heth.K. §§ 17; 18; XVI; XVII herzu stellen. Die LXX differenziert ebenfalls nach Schwangerschaftsstadien in Ex 21,22f.

90 Körperverletzung, 177.

91 S. Lutz, Verdict, 379-381.

92 S. Otto, Kodex EXnnunna, bes. 181ff; vgl. auch zum Analogieschluß Fikentscher, Analogie, 83 100. 
geschädigtem Ehemann ${ }^{93}$, im Ortsgericht ausgehandelt ${ }^{94}$ und vor Zeugen bezahlt ${ }^{95}$. Schließlich differenziert Ex 21,22 nicht zwischen der Körperverletzung der Sklaven und der Freien. Zeigt Ex 21,22 also darin einen ursprünglicheren Stand als Heth.K. §§ 17; 18; XVI; XVII ${ }^{96}$, so differenziert Ex 21,22 über diese Rechtssätze hinaus mit der Eröffnung des Rechtssatzes durch das Motiv w'kâ jinnașu 'anašim nach dem Verschuldensprinzip. Die entscheidende Differenz zur gesamten Tradition dieses Falles in den Keilschriftrechten liegt dann darin, daß mit der Anfügung von Ex 21,23 dieses Motiv auch auf den Fall der Körperverletzung mit Todesfolge ausgedehnt und die unvorsätzliche Tötung mit der Todessanktion naepaeš tăhăt naepaš belegt wird ${ }^{97}$. Noch im "Paralleltext" KBo VI 4 Heth.K. \& XVI verbleibt die Körperverletzung einer Schwangeren im Bereiche der Erfolgshaftung, während eine Differenzierung nach dem Prinzip der Verschuldenshaftung nur für Fälle schwerer Körperverletzung vorgenommen wird.

Auch Ex 21,18f unterscheidet mit der Eröffnung des Rechtssatzes mit $w^{e} k \hat{\imath}$ jerîbun 'anašim zwischen vorsätzlicher und unvorsätzlicher Körperverletzung und regelt die unvorsätzliche Körperverletzung. Über Ex 21,22 hinaus wird die Unvorsätzlichkeit $^{98}$ noch durch das Motiv des Schlags mit Faust oder Stein ( $w^{e} h i k k \bar{a}$ 'îs 'aet re'eha $b^{e '}$ aebaen 'ô be'aegrop) unterstrichen, das zum Ausdruck bringen soll, da $\beta$ es sich um eine spontane Tat handelt, die von der Absicht getragen war, dem Gegner Ehrverletzung und Schmerz zuzufügen, nicht aber ihn zu töten oder schwer zu verletzen ${ }^{99}$. Die Parallelität zwischen Heth.K. § 10 und Ex 21,18f reduziert sich auf das Motiv der Erstattung der Arztkosten. Schon in der Regelung der Versorgung des Kranken und des Arbeitsausfalles gehen die Rechtssätze getrennte Wege. Vor allem aber hat die komplexe Systematik der Falleingrenzung in Ex 21,18f keine Entsprechung in

S. dazu Niehr, Rechtsprechung, 47.

94 S. dazu Cazelles, Code d'Alliance, 55; Liedke, Gestalt, $44 \mathrm{f}$.

Vgl. auch Boecker, Redeformen, 14; Niehr, Rechtsprechung, $57 f$.

S. Otto, Körperverletzungen, 125-128.

7 Die Formel naepaeš tăhăt naepaeš bezeichnet nicht eine Ersatzzahlungsforderung, sondern ist Formulierung der Todessanktion; s. Kugelmass, Lex Talionis 65f.128ff.142ff.202ff; anders Lipin̈ski, nätan, 700 gefolgt von Schwienhorst-Schönberger, Bundesbuch, 101; s. dagegen Otto, Korperverletzungen, $122 \mathrm{f}$ Anm. 1.

Der Vorsatz wird wohl für den Verletzungserfolg, nicht aber für den Schlag ausgeschlossen; s. Ries, Korperverletzung, 176; anders Schenker, Versohnung, 41f; vgl. auch die Prozeßurkunde in Pfeiffer / Speiser, Nuzi Texts, Nr. 72.

9 Vgl. auch XII-Tafelgesetz VIII 3 MANU FUSTI(VE); s. Dïll, Zwölftafelgesetz, 48f; vgl. Völkl, Körperverletzung, 149ff. Für das griechische Recht vgl. Latte, Strafrecht, 286; anders MacDowel, Law, 124. 
Heth.K § 10. So wird der zu regelnde Fall von dem der Körperverletzung mit Todesfolge ( $w^{\ell} l o^{\prime}$ jamât) wie dem der leichten Körperverletzung oder iniuria ( $w^{e}$ napăl l'miškab) und der schweren bleibenden Körperverletzung durch die gleichzeitig die Ersatzleistungshöhe begrenzende Temporalbestimmung 'im jaqûm ${ }^{100}$ abgegrenzt. Geregelt wird also der Fall der unvorsätzlichen schweren aber heilenden Körperverletzung. Diese Distinktionen fehlen in Heth.K. $\S$ 10. Ein traditionsgeschichtlicher Zusammenhang zwischen den hethitischen Rechtssätzen Heth.K. \$§ 10; 17 und Ex 21,18f.22* ist also unwahrscheinlich. Ex 21,18f entstammt der Rechtsprechungspraxis israelitischer Ortsgerichte. Ein Traditionszusammenhang zwischen der dörflich-bäuerlichen Lebenswelt Israels und anatolisch-hethitischer gelehrter Rechtskultur hat auch wenig Plausibilität für sich ${ }^{101}$.

Dieses nicht spektakuläre Ergebnis erscheint in einem anderen Licht, wenn wir dagegen die Redaktionsstrukturen des hethitischen und israelitischen Körperverletzungsrechts vergleichen. In der Sammlung des Körperverletzungsrechts in Ex 21,18-32 werden die Rechtssätze des Sklavenrechts (Ex 21,20f.26f. 32) und der Rechte der freien Israeliten (Ex 21,18f.22-25.28-31) in einem A-BSchema alternierend angeordnet ${ }^{102}$. Mit der Einführung der Körperverletzungsfälle mit Todesfolge (Ex 21,20f.23.29ff) wurde auch die Talionsformel eingeführt, um ihre Gültigkeit für die Fälle der Körperverletzung mit Todesfolge zu bestätigen und in den Fällen der Körperverletzung ohne Todesfolge durch die um die Formel herum gruppierten Rechtssätze außer Kraft zu setzen $^{103}$. Die Redaktionsstruktur zeigt also, daß die Alternative, die Talions-

$100 \mathrm{Vgl.} \mathrm{Schwienhorst-Schönberger,} \mathrm{Bundesbuch,} \mathrm{53f.}$

101 S. Otto, Korperverletzungen, 165-187; ders., Town. Die von Ahlström (Diffusion, 92ff) beigebrachten Hinweise zeigen, daß es im Gegensatz zu den Küstenebenen im Bergland keinen großeren anatolischen Einfluß in der frühen Eisenzeit gab; vgl. zum Problem auch McMahon, Hittites, $71 \mathrm{ff}$ (Lit.). Zur kulturhistorischen Differenzierung von Stadt und Land im spattbronzezeitlichen und fruheisenzeitlichen Palästina s. Otto, Stadt, 225-241.

102 S. Otto, Rechtsbegründungen, 24ff.

103 S. Otto, Korperverletzungen, 122f. Ähnlich Dtn 19,21, s. Otto, Soziale Verantwortung, 294f; ders., Talion, 121-124; ders., Deuteronomium. Die Talionsformel hat in ihrer überlieferungsgeschichtlich ursprünglichen Gestalt der Aufzahlung der vier Köperteile Auge, Zahn, Hand und Fuß (s. Wagner, Rechtssătze, 3ff; Jüngling, Talionsformeln, 15ff) der Prävention von Korperverjetzungen gedient, die die Grenzen der lokalen Rechtsgemeinden uberschritten und nicht durch das kasuistische Konfliktregelungsrecht Ex 21,18f erfaßt wurden; s. Otto, Korperverletzungen, 134-137; ders., Gewaltvermeidung, 103-106. Ex 21,24 ist fest in die Redaktionsstruktur der Sammlung des Körperverletzungsrechts eingebunden. Darauf weist die Vernetzung mit Ex 21,20f.26f (tăhăt 'ênô / tăhăt šinnô [Ex 21,24.26]; w'kî jăkkāēe 'îs 'aet 'ăbdô 'ô 'aet "âmatô / w'kî jăkkāè 'î́s 'aet 'ên 'ăbdô 'ô 'aet 'ên 'a matô [Ex 21,20.26]). Zu Ex 21,25 s. Weinar, Bundesbuch, 352f. Ist eine literarische Aussonderung von Ex 21,24 ausge. schlossen, so ist eine Abgrenzung von Ex 21,25 moglich, aber nicht wahrscheinlich, da gerade 
formel wörtlich oder als Tarifkatalog für Kompensationszahlungen zu verstehen, zu einfach ist. Mit der Abgrenzung der Rechtssätze des Sklavenrechts von denen der freien Bürger und der Abgrenzung der Rechtssätze der Körperverletzung mit Todesfolge von denen ohne Todesfolge bezogen auf Ex 21,23b.24f als zentrierender Mitte der Struktur ergibt sich folgender Aufbau von $\mathrm{Ex}$ 21,18-32:
A: $\operatorname{Ex} 21,18 f$
B: Ex $21,20 \mathrm{f}$
Rechtssatz der freien Bürger
Sklavenrecht
A: $\operatorname{Ex} 21,22 \mathrm{f}$
Ex 21,23b-25
B: Ex 21,26f
Rechtssätze der freien Bürger
A: $\operatorname{Ex} 21,28-31$
B: Ex 21,32
Grundsatzregelung (lex generalis)
Sklavenrecht
Rechtssätze der freien Bürger
Sklavenrecht

Auch die Rechtssätze des hethitischen Körperverletzungsrechts in Heth.K. \$\$ 7-18 sind zur Abgrenzung von Sklavenrecht und Recht der Freien in einem A-B-Schema alternierend angeordnet und auf Heth.K. $\$ \$ 9 ; 10$ als Grundsatzregelung (lex generalis) zentriert, so daß sich folgender Aufbau ergibt:
A: $\$ 7 \quad$ Rechtssatz der freien Bürger
B: $\$ 8$ Sklavenrecht
$\$ \S 9 ; 10$ Grundsatzregelung (lex generalis)
A: $\S 11 \quad$ Rechtssatz der freien Bürger
B: $\$ 12$ Sklavenrecht
A: $\$ 13$ Rechtssatz der freien Bürger
B: $\$ 14$ Sklavenrecht
A: § 15 Rechtssatz der freien Bürger
B: $\$ 16 \quad$ Sklavenrecht
A: $\$ 17$ Rechtssatz der freien Bürger
B: $\S 18$ Sklavenrecht

Die hethitische Rechtssatzredaktion hat wie die israelitische Anteil an der Schultradition der Redaktionstechniken des mesopotamischen É.DUB.BA. Die alternierende Anordnung größerer Rechtssatzgruppen hat ihren Ursprung in

in den spăten Texten Dtn 19,21 und Lev 24,18-20 dieser Vers keine Parallele hat. So dürfte es sich um einen vorliterarischen Zuwachs zu Ex 21,24 handeln; zum Überblick über die Forschung s. auch die Anm. 27 genannte Literatur. 
dem Anordnungsschema von Fall und Gegenfall ${ }^{104}$. In der spätsumerisch abgefaßten altbabylonischen Tafel YOS I 28 \$\$ 1-5 ist dieser Zusammenhang noch nachvollziehbar. Die Inklusionstechnik als Ursprung zentrierender Anordnung stammt ebenfalls aus der Rechtssatzredaktion des É.DUB.BA ${ }^{105}$. Man wird also auch für die Redaktion des israelitischen Körperverletzungsrechts in Ex 21,18-32 nicht mit einem direkten hethitischen Einfluß, sondern mit einer Abhängigkeit beider Rechte vom mesopotamischen Schulcurriculum des É.DUB.BA rechnen. Die einzelnen Rechtssätze des israelitischen Körperverletzungsrechts in Ex 21,18f.22*, die sklavenrechtlichen Weiterentwicklungen in Ex 21,20f.26f, vor allem die todesrechtliche Sanktion der unvorsätzlichen Tötung einer Schwangeren (Ex. 21,23) sind indigen israelitischen Ursprungs in der Rechtspraxis der israelitischen Ortsgerichte. Ein Einfluß internationaler Rechtsgelehrsamkeit der Keilschriftrechte auf die dörflich-bäuerliche Lebenswelt dieser sich der staatlichen Aufsicht über lange Zeit entziehenden Ortsgerichtsbarkeit ${ }^{106}$ ist eher unwahrscheinlich. In der Schreibergelehrsamkeit ${ }^{107}$ der städtischen Verwaltungszentren Israels ${ }^{108}$ dagegen konnte das keilschriftliche Schulcurriculum, das vorisraelitisch in Palästina bezeugt ist ${ }^{109}$, nachwirkenden Einflu $\beta^{110}$ auf die Redaktion israelitischer Rechtskodizes als Ausdruck israelitischer Rechtsgelehrsamkeit gewinnen.

104 Zum Redaktionsprinzip der Anordnung von Fall und Gegenfall s. Petschow, Gesetzestechnik, 171 mit Anm. 148 (Lit.); ders., Systematik, 134 Anm. 3, 136, 142 Anm. 5; Locher, Ehre, 110ff; Eichler, Structure, 71-84; Otto, Kodex ESnunna, 135ff.177ff.

105 S. Otto, Kodex EXnunna, $68 \mathrm{ff}$.

106 S. dazu Macholz, Gerichtsverfassung, 157-182; ders., Justizorganisation, 314-340; vgl. auch Whitelam, Authority, 71ff; Niehr, Gerichtsorganisation, 206-227; ders., Rechtsprechung, 58ff.

107 Vgl. dazu Lipiński, State Scribes, 157-164. Ob die Schreibergelehrsamkeit in Israel an feste Schulinstitutionen gebunden war, mag dahingestellt bleiben; vgl. Puech, Écoles, 202; Schwienhorst-Schönberger, Bundesbuch, 260ff.

108 S. dazu Cazelles, Droit public, 105; vgl. Ahlström, Administration, 1ff; de Geus, Stad, 137ff; Otto, 'îr, $56 \mathrm{ff}$.

109 S. Goetze / Levy, Fragment, 121-128; vgl. dazu Tigay, Gilgamesh Epic, 123ff. Vgl. auch die Auflistung der palästinischen Keilschrifttexte in Galling, Textbuch, 13f; Weippert, Palästina, 266f; s. dazu Edzard, Archive, 248-259.

110 Vgl. auch Hess, Amarna Correspondence, 249-265. K. Peckeruhns These (Handschrift, 165) einer Vermittlung nomadischer Rechtstradition dürfte kaum überzeugen. Ähnlich ist der Befund für Ex 22,15f im Verhăltnis zum Mittelassyrischen Kodex §§ 55; 56; vgl. Otto, Besitzrechte. 


\section{Zur Rechtsbegründung im hethitischen und israelitischen Recht}

Hans Gustav Güterbock ${ }^{111}$ formulierte apodiktisch: "The Hittite Laws are civil, not religious". Dem hat Moshe Weinfeld ${ }^{12}$ unter Berufung auf Heth.K. $\S \S 166-170 ; 173 ; 187-196 ; 199-200$ entgegengehalten: "It should be said however that in contradiction to the Babylonian-Assyrian law which is pure of civil nature the Hittite law code contains also laws of the sacred sphere similar to Biblical law"113. Entscheidender aber als Rechtssätze, die die Sakralsphäre betreffen, sind für das Wesen von Recht die expliziten Rechtsbegründungen. Es ist zwischen Kodizes, die mit Prolog und Epilog versehen wurden, dem Kodex Urnammu, Lipit-ištar und Hammurapi, und solchen ohne Rahmung, dem Kodex Ešnunna, dem Mittelassyrischen Kodex und dem Hethitischen Kodex, zu unterscheiden. Das Korpus der Rechtssätze stammt jeweils aus dem Schulcurriculum des "Tafelhauses" und diente der Rechtsgelehrtenausbildung. Mit der Rahmung durch Prolog und Epilog änderte sich die Gattung. Aus rechtsgelehrter Literatur wurde eine königliche Rechtsdeklaration mit programmatischer Absicht. Die Korpora der Rechtssätze wurden Gliedgattung in einer Rahmengattung ${ }^{114}$ der Rechtsproklamation. Die mit einem Rahmen versehenen Kodizes sind also auf zwei Ebenen, als Texte der Schreibergelehrsamkeit und als Deklamationen königlicher Rechtsideologie unter Einbeziehung der Rahmungen zu interpretieren.

Der Rahmen des Kodex Hammurapi ${ }^{115}$ promulgiert den Anspruch des Königs, von Marduk beauftragt ${ }^{116}$ "rechte Bahn" (usum) unter den Menschen durchzusetzen. Damit ist dem König eine Funktion zugewiesen, die im Pantheon von Šamaš ausgeübt wird ${ }^{117}$. In CH I 40-42 (kima ${ }^{D}$ Šamaš ana șalmät qaqqadim wașêmma ["wie Šamaš den Menschen aufzugehen"]) und CH V 3-9

111 Authority, 21.

112 Apodictic Law, 66 Anm. 3. Haase (Jurisdiction .69) will aus KUB VI, 43, III, 15-17 auf einen gottlichen Ursprung des hethitischen Rechts schließen (s. auch Klengel u.a., Kulturgeschichte, 243). Doch sagt der Text nur etwas uber die Rechtsdurchsetzung durch den Sonnengott (s.u.) aus.

113 Ebenso strittig ist die Frage, ob das altbabylonische Recht des Kodex Hammurapi "completely secular" (so Driver / Miles, Babylonian Laws, 39) oder religios motiviert sei; so Koch, Gesetz, 41.

114 Zur Unterscheidung von Gliedgattung und Rahmengattung s. Koch, Formgeschichte, $29 \mathrm{ff}$.

115 S. dazu Ries, Prolog, 18ff; vgl. auch Klima, Nichtjuridische Bestandteile, 161-186; ders., Juristische Gegebenheiten, 146-169; Otto, Bedeutung, 153-157.

116 Vgl. dazu Sommerfeld, Marduk, 63ff.112ff.121ff; ders., Art. Marduk, 364; sowie Klíma, Politisches Profil, 209-224.

117 Vgl. dazu Janowski, Rettungsgewißheit, 84ff. 


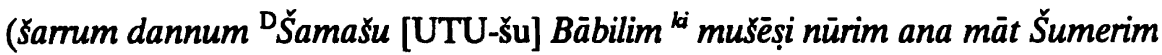
u Akkadîm ["der mächtige König, Sonnengott von Babylon, der das Licht aufgehen läßt über das Land Sumer und Akkad"]) werden Hammurapi und Šamaš parallelisiert. Das Flachrelief der Stele ${ }^{118}$, das den König in der Gebetshaltung vor Šamaš darstellt, sowie die Erwähnungen des Gottes Šamaš in CH XLVII 84 (ina qibit 'Šamaš), CH XLVIII 95-98 (Hammurapi šar mišarim sa Ď́amaš kinātim isrukušum), CH XLIX 11-15 (awilum šu kima iati šar mišarim ${ }^{D}$ Šamaš gis ḩaț̣ašu limik), CH L 14.19 ('Šamaš...bēlum tukulti) zeigen, $\mathrm{da} ß$ die Parallelisierung nicht als Vergöttlichung des Königs, sondern als Funktionsidentität verstanden wurde. Die Rechtssätze selbst wurden nicht auf göttliche Autorität, sondern als dināt mišarim ša Hammurapi šarrum le’um ukinnumu ("gerechte Rechtssprüche, die Hammurapi, der fähige König, festsetzt") auf die Autorität des Königs zurückgeführt ${ }^{119}$. Auch die hethitische Königsideologie kennt die Funktionsparallelisierung von König und Sonnengott im Hirtenamt über die Menschen als "gerechter Herr des Gerichts" (ha-an-daan za ha-an-ne-eš-na-aš iš-ha-a-aš; KUB XXXI 127 I 1) ${ }^{120}$, die sich auch in der Königsbezeichnung DUTU ${ }^{S I}$ (akk. samsi) "Meine Sonne" ${ }^{n 121}$ ausdrückt. Haben Sonnengott und König gleichermaßen die Funktion, "Gerechtigkeit" (handandatar = NIG.SI.SA [akk. mišarum] ${ }^{122}$ ) aufzurichten, so wird man davon ausgehen können, daß auch hethitisch die Rechtssätze nicht unmittelbar auf die göttliche Sphäre als Rechtsquelle, sondern nach altbabylonischem Vorbild auf den König zurückgeführt wurden.

Darin unterscheiden sich die keilschriftlichen Rechtsbegründungen grundsätzlich von den theologischen Rechtsbegründungen Israels. Die Sammlung des Körperverletzungsrechts in Ex 21,18-32 wurde Teil einer im Horizont Jerusalemer $J H W H$-Königstheologie redigierten Rechtssammlung in $\mathrm{Ex}(20,24-26), 21,2-$ $22,26^{123}$, deren theologisches Profil in Ex 22.20a $2.22 .24 a .25 .26^{124}$, dem vom Redaktor dieser Sammlung gestalteten Abschluß, deutlich wird:

"Den Fremdling sollst du nicht bedrücken. Wenn du inn tatsächlich bedrückst und er schreit zu mir, so werde ich sein Geschrei erhoren. Wenn du in meinem Volk dem Armen,

\footnotetext{
118 S. dazu Orthmann, Orient, Abb. 181; vgl. Janowski, aaO, 87f (Lit.).

119 Vgl. Renger, Stele, 228-235.

120 S. dazu Güterbock, Composition, 237.244; Goetze, Kleinasien, 137f; Fauth, Sonnengottheit, 247; zu KUB XXIV 3 I 34' s.u.

121 S. dazu Neu, Anitta-Text, 128f; Gonnet, Titulaire, 19f; Kellerman, Sun-God, 206f; Fauth, Sonnengottheit, 227ff.245ff.260; Janowski, Rettungsgewißheit, 101 Anm. 476; s. dazu das Kolophon des Gesetzesfragmentes KBo VI 6 (ša abi Šamši); vgl. Korošec, Codification, 103.

122 S. Güterbock, Authority, $23 \mathrm{f}$.

123 S. Otto, Rechtsbegründungen, 40ff; vgl. ders., Kultus, 161-179; ders., șijjôn, 1018.

124 Zur Aussonderung der literarisch sekundaren Zusătze in Ex 22,20-26 s. Halbe, Privilegrecht, 426ff; Otto, Rechtsbegründungen, 5; vgl. auch Lohfink, Bearbeitung, 91-113.
} 
der bei dir ist, Geld leihst, so sollst du ihm kein Wucherer sein. Wenn du den Mantel deines Nachsten als Pfand nimmst, so sollst du ihn bis Sonnenuntergang zurückgeben ${ }^{125}$. Denn es ist seine einzige Decke, eine Hulle fur seine Haut. Worin soll er sonst schlafen? Wenn er zu mir schreit, so werde ich ihn hören, denn barmherzig (hănnun) bin ich".

Das Motiv des barmherzigen Königsgottes in Ex 22,26b $\gamma$ kâ ḥ̆nnun 'anît26 berührt sich mit dem hethitischen Hymnus des Königs Muršili II. (KUB XXIV 3 I 29' - II 2') ${ }^{127}$. Die Sonnengöttin von Arinna ${ }^{128}$ setzt als oberste Reichsgöttin dargestellt Recht durch (I 34f' ha-an-ta-an-da-sa-az ha-an-ni-eš-na-as EN-aš zi-ik-pát ["du allein bist die Herrin des gerechten Gerichtes"]) und übt Barmherzigkeit:

$z i-i k-p a ́ t-z a{ }^{\mathrm{D}} \mathrm{UTU}{ }^{\mathrm{URU}}$ A-ri-in-na gi-in-zu-un-la-as DINGIR-LUM zi-ik [nu] gi-in-zu zi-ikpát da-ă̌-ki-ši

"Du allein Sonnengottin von Arinna, bist eine barmherzige Gottheit, [und] nur du ubst immer wieder Barmherzigkeit" (KUB XXIV 3 I 39f).

Über altorientalische Rechtsbegründung hinausführend wird in Israel JHWH selbst zur Quelle des Rechts ${ }^{129}$ und begründet im Recht ein für jedermann gültiges Ethos der Barmherzigkeit des in der Gesellschaft Starken mit dem Schwachen, das in der Forderung der Solidarität noch mit dem Feind (Ex 23,4f ${ }^{130}$ alle Möglichkeiten des Rechts hinter sich läßt.

125 Zum "geteilten Eigentum" s. Petschow, Pfandrecht, $132 \mathrm{ff}$.

126 S. auch die El-Reprassentanz hnnnil in KTU 1.65 6; vgl. de Tarragon, Culte, 160-162.

$127 \mathrm{Zu}$ Text und Übersetzung s. Lebrun, Hymnes, 55ff; Janowski, Rettungsgewißheit, 100. Zu Aspekten einer "Armentheologie" s. auch die hurritisch-hethitische Bilingue KBo XXXII (bes. 15 I/II); s. Neu, Sprache, 16f.

128 Vgl. dazu Goetze, Kleinasien, 136f; Fauth, Sonnengottheit, 238ff; Janowski, Rettungsgewißheit, 99f.

129 S. Lohfink, huqqîm, 1ff; ders., Gebot, 63ff; Otto, Ethik.. Zum Dekalog s. Otto, Dekalog, 59-68; vgl. auch Greenberg, Attitudes, 101-112; Welch, Reflections, 113-119; Greenberg, Reply, 120125.

130 S. dazu Huffmon, Exodus 23: 4-5, 271-278; Halbe, Gemeinschaft, 63ff; Otto, Ausdifferenzierung, 135-161; ders., Gewaltvermeidung; Barbiero, Nemico, 23ff; abweichend Cooper, Exodus 23:5, 1-22. 


\section{Bibliographie}

Ahlström, G.W., Royal Administration and National Religion in Ancient Palestine (SHANE 1), Leiden 1982

- Diffusion in Iron Age Palestine: Some Aspects, SJOT (1990/1) 82-105

Al-Rawi, F.N.H., Assault and Battery, Sumer 38 (1982) 117-120

$A l t, A$. , Die Ursprunge des israelitischen Rechts (1934), in: ders., Kleine Schriften, Bd. 1, München 1953, 278-332

Archi, A., Sulla formazione del testo delle leggi ittite, Studi Micenei ed Egeo-Anatolici 6 (1968) 54 89

- La formazione del diritto nell'Anatolia ittita, in: $A$. Theodorides u.a., La formazione del diritto nel Vicino Oriente Antico (Università di Roma "La Sapienza". Pubblicazioni dell'Istituto di Diritto Romano e dei Diritti dell'Oriente Mediterraneo 65), Rom / Neapel 1988, 61-75

Barbiero, G., L'asino del nemico. Non violenza e amore del nemico nella legislazione dell'Antico Testamento (Es 23,4-5; Dt 22,1-4; Lv 19,18), Diss. Frankfurt 1988

Beckman, G., Mesopotamians and Mesopotamian Learning at Hattußa, JCS 35 (1983) 97-114

Boecker, H.J., Redeformen des Rechtslebens im Alten Testament (WMANT 14), NeukirchenVluyn ${ }^{2} 1970$

- Recht und Gesetz im Alten Testament und im Alten Orient (NStB 10), Neukirchen-Vluyn 21984

Borger, $R$, Babylonisch-assyrische Lesestücke (AnOr 54), Rom ${ }^{2} 1979$ (= BAL)

Cardascia, G., Droits cunéiformes, in: J. Gilissen (Hg.), Introduction bibliographique à l'histoire du droit et à l'ethnologie juridique A/2, Brüssel 1966, 1-142

- Droit cunéiforme et droit biblique (PWCJS 6/1), Jerusalem 1977, 63-70

Cazelles, H., Etudes sur le Code d'Alliance, Paris 1946

- Droit public dans le Deutéronome, in: N. Lohfink (Hg.), Das Deuteronomium. Entstehung, Gestalt und Botschaft (BEThL 68), Leuven 1985, 99-106

Civil, M., New Sumerian Law Fragments, in: Studies in Honor of Benno Landsberger (AS 16), Chicago 1965, 1-12

Clay, A.T., Miscellaneous Inscriptions of the Yale Babylonian Collection, New Haven 1915

Collins, B.J., $\S 54$ of the Hittite Laws and the Old Kingdom Periphery, Or. 56 (1987) 136-141

Cooper, A., The Plain Sense of Exodus 23:5, HUCA 49 (1988) 1-22

David, M., De codex Hammourabi en zijn verhouding tot de wetsbepalingen in Exodus, TRG 17 (1939) 1-26

Driver, G.R. / Miles, J.C., The Babylonian Laws, Bd. 1, Legal Commentary, Oxford ${ }^{2} 1956$

Düll, $R$, Das Zwölftafelgesetz. Texte, Übersetzungen und Erlauterungen, München / Zürich ${ }^{6} 1989$

Ebel, F. / (Thielmann, G.), Rechtsgeschichte. Ein Lehrbuch, Bd. 1: Antike und Mittelalter, Heidelberg 1989

Edzard, D.O., Amarna und die Archive seiner Korrespondenten zwischen Ugarit und Gaza, in: $J$. Amitai (Hg.), Biblical Archaeology Today. Proceedings of the International Congress of Biblical Archaeology Jerusalem - April 1984, Jerusalem 1985, 248-259

Eichler, B.L., Literary Structure in the Laws of Eshnunna, in: F. Rochberg-Halton (Hg.), Language, Literature and History. FS E. Reiner (AOS 67), Chicago 1987, 71-84 
Fauth, W., Sonnengottheit $\left({ }^{\mathrm{D}} \mathrm{UTU}\right)$ und "Konnigliche Sonne" $\left({ }^{\mathrm{D}} \mathrm{UTU} \mathrm{U}^{\zeta \zeta}\right)$ bei den Hethitern, UF 11 (FS C.F.A. Schaeffer) (1979), 227-263

Fensham, F.C., Ex XXI: 18-19 in the Light of Hittite Law \& 10, VT 10 (1960) 333-335

Fikentscher, $W$., Die Verwendung von Analogie und allgemeinen Rechtsprinzipien in der Rechtsprechung, in: La sentenza in Europa. Metodo, tecnica e stile, Padua 1988, 83-100

Finkelstein, J.J., Some Historical Perspectives on Deodands, Forfeitures, Wrongful Death and the Western Notion of Sovereignty, Temple Law Quarterly 46 (1973) 169-290

- The West, the Bible and the Ancient East: Apperceptions and Categorisations, Man 9 (1974) 591-608

- The Ox that Gored, TAPhS 71 (1981) $1-89$

Follet, $R$, Les Lois Hittites, MUSJ 30 (1953) 3-19

Friedrich J., Hethitisches Worterbuch. Kurzgefaßte kritische Sammlung der Deutung hethitischer Worter, Heidelberg 1952 (mit 3 Erganzungsheften 1957-1966)

- Die hethitischen Gesetze, Transkription, Übersetzung, sprachliche Erlauterungen und vollstăndiges Wöterverzeichnis (DMOA 7), Leiden ${ }^{2} 1971$

Galling, $K$ u.a., Textbuch zur Geschichte Israels, Tübingen ${ }^{2} 1968$

de Geus, C.H.J., De Israelitische stad (Palaestina antiqua 3), Kampen 1984

Goetze, A., The Laws of Eshnunna (AASOR 31), New Haven 1956

- Kleinasien (HAW III. 1.3.3.1), München 1957

- / Levy, S., Fragment of the Gilgamesh Epic from Megiddo (Atiqot [Engl. Ser.] 2), 1959, 121 128

Greenberg, M., Biblical Attitudes toward Power: Ideal and Reality in Law and Prophets, in: E.B. Firmage / Weiss, B.G. / J.W. Welch (ed.), Religion and Law: Biblical-Judaic and Islamic Perspectives, Winona Lake 1990, 101-112

- Reply to the Comments of John Welch by Moshe Greenberg, in: E.B. Firmage / B.G. Weiss / J. W. Welch, Religion and Law: Biblical-Judaic and Islamic Perspectives, Winona Lake/IN 1990, 120-125

Grothus, J., Die Rechtsordnung der Hethiter, Wiesbaden 1973

Gutterbock, H.G., Authority and Law in the Hittite Kingdom, in: H.M. Hoenigswald (ed.), Authority and Law in the Ancient Orient (JAOS Suppl. 17), Baltimore 1954, 16-24

- The Composition of Hittite Prayers to the Sun, JAOS 78 (1958) 237-245

Haase, $R$, Der privatrechtliche Schutz der Person und der einzelnen Vermögensrechte in der hethitischen Rechtssammlung, Diss. iur. Tübingen 1961

- Regelt $\$ 9$ der hethitischen Rechtssammlung eine leichte Leibesverletzung?, BiOr 19 (1962) 114-116

- Die Wiedergutmachung des Schadens nach den hethitischen Rechtssammlungen, RIDA 3/19 (1972) 11-27

- Die Kollektivhaftung bei den Hethitern. Ein Überblick, in: Studi in Onore di Cesare Sanfilippo, Bd. 1, Mailand 1982, 221-230

- Art. Körperverletzung, B. Hethiter, RLA VI (1982) 178-181

- Die Zeit als juristische Tatsache in den hethitischen Gesetzen, in: Estudios en Homenaje al J. Iglesias, Madrid 1988, 343-346

- Some Problems of Hittite Law and Jurisdiction, in: M. Heltzer / E. Lipinski (Hg.), Society and Economy in the Eastern Mediterranean (c.1500-1000 B.C.). Proceedings of the International Symposium held at the University of Haifa from the $28^{\text {th }}$ of April to the $2^{\text {nd }}$ of May 1985 (Orientalia Lovaniensia Analecta 23), Leuven 1988, 69-77

Halbe, J., Das Privilegrecht Jahwes Ex 34,10-26. Gestalt und Wesen, Herkunft und Wirken in der vordeuteronomischen Zeit (FRLANT 114), Gottingen 1975 
- "Gemeinschaft, die Welt unterbricht". Grundfragen und -inhalte deuteronomischer Theologie und Überlieferungsbildung im Lichte der Ursprungsbedingungen alttestamentlichen Rechts, in: N. Lohfink (Hg.), Das Deuteronomium. Entstehung, Gestalt und Botschaft (BEThL 68), Leuven 1985, 55-75

Hess, $R . S$., Hebrew Psalms and Amarna Correspondence from Jerusalem. Some Comparisons and Implications, ZAW 101 (1989) 249-265

Hoffmann, I., Der Erlaß Telepinus (THeth 11), Heidelberg 1984

Hoffner, $H . A$., Some Contributions of Hittitology to Old Testament Study, TynB 13 (1969) 27-55

Hrozny, F., Keilschrifttexte aus Boghazkoi, VI. Heft (WVDOG 36/2), Leipzig 1921

Huffmon, H.B., Exodus 23: 4-5: A Comparative Study, in: H.N. Bream (Hg.), A Light unto my Path (FS J.M. Myers), Philadelphia 1974, 271-278

Imparati, $F$., Le Leggi ittite (Incunabula Graeca 7), Rom 1964

Isser, S., Two Traditions: The Law of Exodus 21:22-23 Revisited, CBQ 52 (1990) 30-45

Jackson, B.S., The Problem of Exodus 21: 22-5 (IUS TALIONIS), in: ders., Essays in Jewish and Comparative Legal History (SJLA 10), Leiden 1975, 75-107

Janowski, B., Rettungsgewißheit und Epiphanie des Heils. Das Motiv der Hilfe Gottes "am Morgen" im Alten Orient und im Alten Testament, Bd. 1, Alter Orient (WMANT 59), Neukirchen-Vluyn 1989

Jepsen, A., Untersuchungen zum Bundesbuch (BWANT 41), Stuttgart 1927

- Die "Hebräer" und ihr Recht, AfO 15 (1945-1951) 55-68

Johns, C.H.W., The Relation between the Laws of Babylonia and the Laws of the Hebrew Peoples, SchL 1912, London 1914

Jüngling, $H .-W$., "Auge für Auge, Zahn für Zahn". Bemerkungen zu Sinn und Geltung der alttestamentlichen Talionsformeln, ThPh 59 (1984) 1-38

Kammenhuber, $A$., Die hethitische und hurrische Überlieferung zum "Gilgames"-Epos, MSS 21 (1967) 45-58

- Keilschrifttexte aus Bogazkoy (KBO XIX), Or. 43 (1974) 114-124

- Orakelpraxis, Traume und Vorzeichenschau bei den Hethitern (THeth 7), Heidelberg 1976

- Das Ende des typisch alten Duktus im Hethitischen, in: J.N. Postgate u.a. (Hg.), Societies and Languages of the Ancient Near East. Studies in Honour of I.M. Diakonoff, Warminster 1982, 150-159

Klengel, $H$. u.a., Kulturgeschichte des alten Vorderasiens, Berlin 1989

Kellerman, G., The King and the Sun-God in the Old Hittite Period, Tel Aviv 5 (1978) 199-208

Klíma, J., Einige Bemerkungen zur Bedeutung der "nichtjuridischen" Bestandteile der altbabylonischen Gesetzeswerke, JJP 5 (1951) 161-186

- Die juristischen Gegebenheiten in den Prologen und Epilogen der mesopotamischen Gesetzeswerke, in: $H$. van Voss u.a. (ed.), Travels in the World of the Old Testament (FS M.A. Beek), Assen 1974, 146-169

- Im ewigen Banne der muškēnum-Problematik?, in: J. Harmatta / G. Komoróczy (Hg.), Wirtschaft und Gesellschaft im Alten Vorderasien, Budapest 1976, 267-274

- Das politische Profil der altmesopotamischen Herrscher im Lichte der Prologe und Epiloge ihrer Gesetze, in: B. Hruška / G. Komoróczy (Hg.), FS L. Matous, Bd. 1, Budapest 1978, 209. 224

Koch, $K$, Was ist Formgeschichte? Methoden der Bibelexegese, Neukirchen-Vluyn ${ }^{3} 1974$

- Art. Gesetz I. Altes Testament, TRE XIII (1984) 40-52

Korǒ̌ec, V., Sistematika prve hetitske pravne zbirke, Zbornik 1930 
- Die Kollektivhaftung im hethitischen Recht. Ein Beitrag zu ihrer Entwicklungsgeschichte, ArOr 18 (1950) 187-209

- Das hethitische Recht in seiner Stellung zwischen Osten und Westen, Sud-Ost-Forschungen 15 (1956) 22-40

- Keilschriftrecht (HO I/3), Leiden 1956, 49-219. 466-478

- Le problème de la codification dans le domaine du droit hittite, RIDA III/4 (1957) 93-105

- Hethitica (Slovenska akademija znanosti in umetnost Razprave Dissertationes IV/ 7), Ljubljajna 1958

- $\quad$ Art. Gesetze D. Hatti, RLA III (1971), 288-297

- Einige Probleme zur Struktur der hethitischen Gesetze, in: J. Harmatta / G. Komoróczy (Hg.), Wirtschaft und Gesellschaft im Alten Vorderasien, Budapest 1976, 287-298

- Die hethitischen Gesetze in ihren Wechselbeziehungen zu den Nachbarvolkern, in: H.-J. Nissen / J. Renger (Hg.), Mesopotamien und seine Nachbarn (BBVO 1) Berlin 1982, 295-310

Koschaker, $P$., Quellenkritische Untersuchungen zu den "altassyrischen Gesetzen" (MVÄG 26/3), Leipzig 1921

- Keilschriftrecht, ZDMG 89 (1935) 1-39

Kraus, F.R. Vom mesopotamischen Menschen der altbabylonischen Zeit und seiner Welt (MNAW.L [N.S.] 36/6), Amsterdam 1973

- Königliche Verfügungen in altbabylonischer Zeit (SDIO 11), Leiden 1984

Kugelmass, H.J., Lex Talionis in the Old Testament, Ph.D.Diss. University of Montreal, 1985

Landsberger, B., Jungfraulichkeit: Ein Beitrag zum Thema "Beilager und Eheschließung" - mit einem Anhang: Neue Lesungen und Deutungen im Gesetzbuch von ESnunna, in: $J . A$. Ankum u.a. (Hg.), Symbolae juridicae et historicae. (FS M. David, Bd. 2; Jura Orientis Antiqui), Leiden 1968, 41-105

Latte, $K$, Beitrage zum griechischen Strafrecht, in: E. Berneker (Hg.), Zur griechischen Rechtsgeschichte (WdF 45), Darmstadt 1968, 263-314

Lebrun, $R$, Hymnes et prières hittites (Homo Religiosus 4), Louvain-La-Neuve 1980

Levy, $S$. $\rightarrow$ Goetze, $A$.

Liedke, G., Gestalt und Bezeichnung alttestamentlicher Rechtssätze. Eine formgeschichtlichterminologische Studie (WMANT 39), Neukirchen-Vluyn 1971

Lipinsski, E., Art. nätan, ThWAT V (1986) 693-712

Locher, $C$., Deuteronomium 22, 13-21. Vom Prozeßprotokoll zum kasuistischen Gesetz, in: $N$. Lohfink (Hg.), Das Deuteronomium. Entstehung, Gestalt und Botschaft (BEThL 68), Leuven 1985, 298-309

- Die Ehre einer Frau in Israel. Exegetische und rechtsvergleichende Studien zu Deuteronomium 22,13-21 (OBO 70), Fribourg / Göttingen 1986

Lohfink, N., Die huqqîm ûmišpātîm im Buch Deuteronomium und ihre Neubegrenzung durch Dtn 12,1 , Bib. 70 (1989) 1-30

- Kennt das Alte Testament einen Unterschied von "Gebot" und "Gesetz"?, JBTh 4 (1989) 63. 89

- Gibt es eine deuteronomistische Bearbeitung im Bundesbuch?, in: C. Brekelmans / J. Lust (ed.), Pentateuchal and Deuteronomistic Studies (BEThL 94), Leuven 1990, 91-113

Lutz, H.F., The Verdict of a Trial Judge in a Case of Assault and Battery (UCP 9/VI), Berkeley/ CA 1930, 379-381. Pl. 4

MacDowell, D.M., The Law in Classical Athens, London 1978

Macholz, G.C., Die Stellung des Konigs in der israelitischen Gerichtsverfassung, ZAW 84 (1972) 157-182

- Zur Geschichte der Justizorganisation in Juda, ZAW 84 (1972) 314-340 
Malul, M., The Comparative Method in Ancient Near Eastern and Biblical Legal Studies (AOAT 227), Kevelaer / Neukirchen-Vluyn 1990

Martin-Achard, R, Récents travaux sur la loi du Talion selon l'Ancien Testament, RHPhR 69 (1989) 173-188

Mascheroni L.M., Scribi Hurriti a Boğazköy: Una verifica prosografica, Studi Micenei ed EgeoAnatolici 24, 1984, 151-173

Matter, E.-P., Die Bedeutung der Hethiter für das Alte Testament. Eine religions-, rechtsgeschichtliche und ethnologische Studie, Diss.theol. Heidelberg 1933

Müller, H.D., Die Gesetze Hammurabis und ihr Verhăltnis zur mosaischen Gesetzgebung sowie zu den XII Tafeln, Wien 1903

Neu, E., Der Anitta-Text (StBoT 18), Wiesbaden 1974

- Das Hurritische: Eine altorientalische Sprache in neuem Licht (AAWLM.G 1988/3), Mainz 1988

Neufeld, E., The Hittite Laws, London 1951

Niehr, H., Rechtsprechung in Israel. Untersuchungen zur Geschichte der Gerichtsorganisation im Alten Testament (SBS 130), Stuttgart 1987

- Grundzüge der Forschung zur Gerichtsorganisation Israels, BZ 31 (1987) 206-227

Oettinger, N., Die Stammbildung des hethitischen Verbums (EBSK 64), Heidelberg 1984

Orthmann, W., Der Alte Orient (PKG 14), Berlin 1975

Osumi, Y., Die Kompositionsgeschichte des Bundesbuches Ex 20,22b-23,33 (OBO 105), Fribourg / Göttingen 1991

Otto, E., Kultus und Ethos in Jerusalemer Theologie. Ein Beitrag zur theologischen Begründung der Ethik im Alten Testament, ZAW 98 (1986) 161-179

- Sozial- und rechtshistorische Aspekte in der Ausdifferenzierung eines altisraelitischen Ethos aus dem Recht (Osnabrücker Hochschulschriften. Schriftenreihe des Fachbereiches 3, Bd. 9), Osnabrück 1987, 135-161

- Rechtssystematik im altbabylonischen "Codex ESnunna" und im altisraelitischen "Bundesbuch". Eine redaktionsgeschichtliche und rechtsvergleichende Analyse von CE $\S \S 17 ; 18 ; 22-28$ und Ex 21,18-32; 22,6-14; 23,1-3.6-8, UF 19 (1987) 175-197

- Art. îr, ThWAT VI (1987) 175-197

- Wandel der Rechtsbegründungen in der Gesellschaftsgeschichte des antiken Israel. Eine Rechtsgeschichte des "Bundesbuches" Ex XX 22 - XXIII 13 (StudBibl 3), Leiden 1988

- Rechtsgeschichte der Redaktionen im Kodex EŠnunna und im "Bundesbuch". Eine redaktionsgeschichtliche und rechtsvergleichende Studie zu altbabylonischen und altisraelitischen Rechtsüberlieferungen (OBO 85), Fribourg / Göttingen 1989

- Art șijjon, ThWAT VI (1989) 994-1028

- Stadt und Land im spátbronzezeitlichen und früheisenzeitlichen Palastina. Zur Methodik der Korrelierung von Geographie und antiker Religionsgeschichte, in: K Rudolph / G. Rinschede (Hg.), Beitrăge zur Religion / Umwelt-Forschung (Geographia Religionum 6), Berlin 1989, 225-241.

- Die keilschriftlichen Parallelen der Vindikationsformel in Dtn 20,10, ZAW 102 (1990) 94-96

- Körperverletzungen in den Keilschriftrechten und im Alten Testament. Studien zum Rechtstransfer im Alten Orient (AOAT 226), Kevelaer / Neukirchen-Vluyn 1991

- Auf dem Wege zu einer altorientalischen Rechtsgeschichte, BiOr 48 (1991) 5-13

- Die Bedeutung der altorientalischen Rechtsgeschichte für das Verständnis des Alten Testaments, ZThK 88 (1991) 139-168

- Die Geschichte der Talion im Alten Orient und Israel, in: D.R. Daniels / U. Glessmer / M. Rösel, Ernten was man săt (FS K. Koch), Neukirchen-Vluyn 1991, 101-130 
- Vom Profanrecht zum Gottesrecht: das Bundesbuch, ThR 56 (1991) 421-427

- Soziale Verantwortung und Reinheit des Landes. Zur Redaktion der kasuistischen Rechtssatze in Deuteronomium 19-25, in: $R$. Liwak / S. Wagner (Hg.), Prophetie und geschichtliche Wirklichkeit im alten Israel (FS S. Herrmann), Stuttgart u.a. 1991, 290-306

- Der Dekalog als Brennspiegel israelitischer Rechtsgeschichte, in: J. Hausmann / H.J. Zobel (Hg.), Alttestamentlicher Glaube und Biblische Theologie (FS H.D. Preuß), Stuttgart u.a. 1992, 59-68

- Gewaltvermeidung und -uberwindung in Recht und Religion Israels, in: J. Niewiadomski / W. Palaver (Hg.), Dramatische Erlosungslehre, Innsbruck 1992, 97-117

- Town and Rural Countryside in the Ancient Israelite Law. Reception and Redaction in Cuneiform Law and Israelite Law, in: ders., Kontinuum und Proprium. Studien zur Sozialgeschichte und Rechtsgeschichte des Alten Orients und Israels (Orientalia Biblica et Christiana), Glückstadt 1992/93

- Vom Bundesbuch zum Deuteronomium. Die deuteronomistische Redaktion in Dtn 12-26 (erscheint als Festschriftbeitrag), Freiburg 1993

- Theologische Ethik im Alten Testament (ThW 3/2), Stuttgart u.a. 1993

- Korperverletzung oder Verletzung von Besitzrechten? Zur Redaktion von Ex 22,15f. und §§ 55; 56 des Mittelassyrischen Kodex der Tafel A, ZAW 105 (1993)

Paul, S.M., Studies in the Book of the Covenant in the Light of Cuneiform and Biblical Law (VT.S 18), Leiden, 1970

Peckeruhn, K, Die Handschrift A der Hethitischen Gesetze, Diss. phil. Würzburg 1988

Petschow, H., Neubabylonisches Pfandrecht (ASAW.Ph. 48/1), Leipzig 1956

- Zur Systematik und Gesetzestechnik im Codex Hammurapi, ZA 57 (1965) 146-172

- Zur "Systematik" in den Gesetzen von Eschnunna, in: JA. Ankum u.a. (Hg.), Symbolae juridicae et historicae. FS M. David, Bd. 2 (Jura Orientis Antiqui), Leiden 1968, 131-143

Pfeiffer, R.H. / Speiser, EA., One Hundred New Selected Nuzi Texts (AASOR 16), New Haven 1936

Puech, E., Les écoles dans l'Israel préexilique. Donneés épigraphiques (VT.S 40), Leiden 1988, 189-203

Renger, J., Hammurapis Stele "König der Gerechtigkeit". Zur Frage von Recht und Gesetz in der altbabylonischen Zeit, WO 8 (1976) 228-235

Riemschneider, K, Zu den Korperverletzungen im hethitischen Recht, ArOr 29 (1961) 177-182

Ries, G., Art. Korperverletzung. A. Mesopotamien, RLA VI (1982) 173-178

- $\quad$ Art. Kollektivhaftung, RLA VI (1982) 182-186

- Prolog und Epilog in Gesetzen des Altertums (MBPAR 76), München 1983

Ring, E., Israels Rechtsleben im Lichte der neuentdeckten assyrischen und hethitischen Gesetzesurkunden, Stockholm / Leipzig 1926

Röllig, W., Der Mondgott und die Kuh. Ein Lehrstück zur Problematik der Textüberlieferung im Alten Orient, Or. 54 (1985) 260-273

Römer, W.H.Ph, Einige Bemerkungen zum altmesopotamischen Recht, sonderlich nach Quellen in sumerischer Sprache, ZAW 95 (1983) 319-336 Roth, $M$., On LE \$§ 46-47 A, N.A.B.U. 3 (1990) $70 f$

San Nicolò, M., Beiträge zur Rechtsgeschichte im Bereiche der Keilschriftlichen Rechtsquellen, (Instituttet for Sammenlignende Kulturforskning Ser. A XIII), Oslo 1931

Saporetti, C., Le leggi medioassire (DSC 2), Malibu 1979

Schenker, A., Versobnnung und Widerstand. Bibeltheologische Untersuchung zum Strafen Gottes und der Menschen, besonders im Lichte von Exodus 21-22 (SBS 139), Stuttgart 1990 
Schottroff, W., Zum alttestamentlichen Recht, VF 22 (1977) 3-29

Schroeder, O., Keilschrifttexte aus Assur verschiedenen Inhalts, Leipzig 1920 (= KAV)

von Schuler, E., Hethitische Konigserlässe als Quellen der Rechtsfindung und ihr Verhaltnis zum kodifizierten Recht, in: $R$ von Kienle u.a. (Hg.), FS J. Friedrich, Heidelberg 1959, 435-472

Schwienhorst-Schönberger, $L$, "Dies sind die Rechtsvorschriften, die du ihnen vorlegen sollst". Zur Struktur und Entstehung des Bundesbuches, in: F.-L. Hossfeld (Hg.), Vom Sinai zum Horeb. Stationen alttestamentlicher Glaubensgeschichte (FS E. Zenger), Würzburg 1989, 119-143

- Das Bundesbuch. Studien zu seiner Entstehung und Theologie (BZAW 188), Berlin 1990

Sommerfeld, $W$., Der Aufstieg Marduks. Die Stellung Marduks in der babylonischen Religion des zweiten Jahrtausends v. Chr. (AOAT 213), Kevelaer / Neukirchen-Vluyn 1982

- Art. Marduk. A. Philologisch I. In Mesopotamien, RLA VII 5/6 (1989) 360-370

Soucek, $V$., Einige Bemerkungen zur kritischen Bearbeitung der hethitischen Gesetze, OLZ 56 (1961) 453-468

- Bemerkungen zur Schlußformel der hethitischen Gesetze (parnašsēa šuuăaizzi), ArOr 29 (1961) $1-29$

Speiser, EA., The Stem PLL in Hebrew, JBL 82 (1963) 301-306

Stol, M., Zwangerschap en geboorte bij de Babyloniěrs en in de Bijbel (MEOL 23), Leiden 1983

- Oog om oog, tand om tand: en barbaarse wet?, Phoenix 33 (1988) 38-44

Szlechter, E., Les lois d'ESnunna, RIDA 3/25 (1978) 109-219

- Les lois sumériennes: I - Le Code d’Ur-Nammu. II - Le Code de Lipit Istar (Pontificium Institutum Utr. Juris Stud. et Doc. 6), Rom 1983

de Tarragon, J.-M., Le culte à Ugarit d'après les textes de la pratique en cunéiformes alphabétiques (CRB 19), Paris 1980

Tigay, J.H., The Evolution of the Gilgamesh Epic, Philadelphia 1982

Unal, A., The Power of Narrative in the Hittite Literature, BA 52 (1989) 130-143

Völkl, A., Die Verfolgung der Korperverletzung im fruhen Romischen Recht. Studien zum Verhăltnis von Tötungsverbrechen und Injuriendelikt (Forschungen zum Römischen Recht 35), Wien / Köln 1984

Wagner, $V .$, Rechtssătze in gebundener Sprache und Rechtssatzreihen im israelitischen Recht. Ein Beitrag zur Gattungsforschung (BZAW 127), Berlin 1972

Weimar, P., Art. Bundesbuch, Neues Bibel-Lexikon I/3 (1990) 348-356

Weinfeld, M., The Origin of the Apodictic Law. An Overlooked Source, VT 23 (1973) 63-75

Weippert, H., Palästina in vorhellenistischer Zeit (HdA II/1), München 1988

Welch, J.W., Reflections on Postulates: Power and Ancient Laws - A Response to Moshe Greenberg, in: E.B. Firmage / B.G. Weiss / J.W. Welch (ed.), Religion and Law: Biblical-Judaic and Islamic Perspectives, Winona Lake, 1990, 113-119

Westbrook, R. / Wilcke, C., The Liability of an Innocent Purchaser of Stolen Goods in Early Mesopotamian Law, AfO 25 (1974-77) 111-121

- Biblical and Cuneiform Law Codes, RB 92 (1985) 247-264

- Lex talionis and Exodus 21,22-25, RB 93 (1986) 52-69

- Studies in Biblical and Cuneiform Law (CRB 26), Paris 1988

- The Nature and Origins of the Twelve Tables, ZSS (Rom. Abt.) 105 (1988) 74-121

- Old Babylonian Marriage Law (AfO Beih. 23), Horn 1988

Whitelam, K.A., The Just King. Monarchical Judicial Authority in Ancient Israel (JSOT.S 12), Sheffield 1979

Wilhelm, G., Neue akkadische Gilgames-Fragmente aus Hattusa, ZA 78 (1988) 99-121 
Yarom, $R$, The Laws of Eshnunna, Jerusalem / Leiden ${ }^{2} 1988$

- The Evolution of Biblical Law, in: $A$. Theodorides u.a., La formazione del diritto nel Vicino Oriente Antico (Universita di Roma "La Sapienza". Pubblicazioni dell'Istituto di Diritto Romano e dei Diritti dell'Oriente Mediterraneo 65), Rom / Neapel 1988, 77-108

Zaccagnini, $C$., $\mathrm{La}$ formazione del diritto in Mesopotamia. Codificazioni regie e consuetudine nel II Millennio a.C., in: $A$. Theodorides u.a., La formazione del diritto nel Vicino Oriente Antico (Università di Roma "La Sapienza". Pubblicazioni dell'Istituto di Diritto Romano e dei Diritti dell'Oriente Mediterraneo 65), Rom / Neapel 1988, 35-50

Zimmerm, H. / Friedrich, J., Hethitische Gesetze aus dem Staatsarchiv von Boghazkoi (um 1300 v. Chr.) (AO 23/2), Leipzig 1922 

Notzeit-Mythologem und Nichtigkeitsfluch*

\section{I}

Zeiten kollektiver Not und Bedrohung haben verschiedene Ursachen: Krieg, Mißernte, Unwetter, um nur einige zu nennen. Unter dem Stichwort Krisenritual wurden in der Vergangenheit diejenigen Mechanismen diskutiert, die zur Bewältigung kollektiver Notlagen eingesetzt werden. ${ }^{1}$ Im Alten Testament dient beispielsweise das kollektive Fastenritual zur Beseitigung oder Milderung solcher Notlagen; aus Ugarit ist ein Opferzeremoniell und Gebet für Baal bekannt; in Guzana und Emar sind über diese Zeremonien hinaus Reinigungsriten für die Stadt bezeugt. ${ }^{2}$

Ein komplexes Geschehen aus Ritual und Mythos-Rezitation ist aus dem kleinasiatischen Bereich bekannt. Es handelt sich um den Mythos vom verschwundenen (Wetter-) Gott, der in den Überlieferungen vom verschwundenen Telepinu die Einbindung in ein Evokationsritual erkennen läßt. Das Geschehen dient dazu, den Gott herbeizuzitieren, um dadurch die eingetretene und im Mythos erzählte Notlage zu lösen.

Die genannten Fälle haben gemeinsam, daß sie als Krisenrituale bereits manifeste Notsituationen einer Klärung zuführen sollen. Quasi potentiell vorhandene Notzeiten, die durch Fluch- oder Gerichtsworte angekündigt und angedroht werden, wurden nicht erfaßt. Vornehmlich in den Fluchabschnitten von Königsinschriften und/oder Staatsverträgen kann man zwischen individuellen und kollektiven Bedrohungen unterscheiden. ${ }^{3}$ Während der individuelle Fluch einer einzelnen Person Sanktionen für den Fall der Stipulationsübertretung oder Beschädigung des Inschriftenträgers androht, ist der kollektive

Herrn Professor Dr. Wolfgang Richter zum 65. Geburtstag. Der Beitrag ist eine ausgearbeitete Fassung einer vorgetragenen 'Mitteilung' auf dem Symposion. Für die Gelegenheit zur Publikation gebuhrt mein besonderer Dank den Herren Professoren Bernd Janowski, Klaus Koch, Gernot Wilhelm und Volkert Haas.

Vgl. Podella, Șôm-Fasten, 117.151.

2 Zum AT zusammenfassend vgl. Podella, Șôm-Fasten, 265ff; zu Ugarit vgl. RS 24.266 = KTU 1.119 = TRU I, 25ff; Saracino, Siege, 263-269; zu Guzana und Emar vgl. Janowski, Sühne, 56f mit Anm. 144ff; zu dem Beleg aus Emar Msk 74146 s. jetzt Arnaud, Emar VI/3, Nr. 452, 53.

3 Vgl. zu den Flüchen etwa: McCarthy, Treaty, 172ff, Hillers, Treaty-Curses, pass.; Schottroff, Fluchspruch, 159f; zu den nA adê-Verträgen vgl. Watanabe, adê-Vereidigung, 33ff; dies., Anrufung, 106ff; Parpola, Treaties, 161-189; Franke, Fluch, 177ff; Charpin, Inscriptions, zu den Fluchformeln $60 \mathrm{ff}$. 
Fluch meist genealogisch, geographisch oder kollektivierend bzw. singularisch abstrahierend gestaltet (vgl. Lev 26,14ff; Dtn 28,15ff).

Innerhalb dieser Fluchreihen begegnet eine Fluchform, die sich dadurch auszeichnet, daß entweder die im Vordersatz genannte Handlung in einem syndetisch angeschlossenen Nachsatz mit $l^{\prime}+$ Präformativkonjugation verneint oder mit einem anderen Verbum ihre Wirkungslosigkeit beschrieben wird. ${ }^{4}$

Lev 26,26 lautet:

Wenn ich euch zerbreche den Stab des Brotes, dann werden zehn Frauen in einem einzigen Ofen backen und euer Brot abgewogen herbeibringen.

Dann werdet ihr essen und werdet euch nicht sattigen.

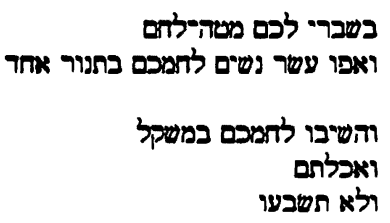

In singularischer Formulierung - aber kollektivem Sinn - in Dtn 28,30:

Du verlobst dich mit einer Frau, aber ein anderer Mann schlaft mit ihr. ${ }^{5}$

Du baust ein Haus, wirst aber nicht in inm wohnen. Du pflanzt einen Weinberg, wirst ihn aber nicht 'benutzen'.6

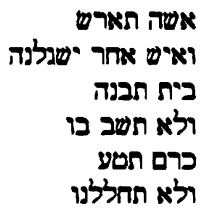

In der deutschsprachigen exegetischen Fachliteratur hat sich für diese Fluchform der Terminus antithetischer Fluch ${ }^{7}$, Nichtigkeitsfluch oder Wirkungslosigkeitsfluch $^{8}$ eingebürgert, in der englischen und französischen Literatur die Termini futility curse und malédiction futilite. Das gemeinsame Charakteristikum dieser Flüche besteht nach der formgeschichtlichen Beschreibung H.W. Wolffs darin, daß jeweils "im sg. Anredestil eine lebenswichtige Tätigkeit genannt" und

4 Es handelt sich hier um Lev 26,26 und Dtn 28,30-31.38-40; Hos 4,10; 5,6; Am 4,8; 5,11; 8,12; (Hag 1,6); Zeph 1,13; Mi 3,4a; 6,14-15.

s

אר "verloben" als Rechtsfolge der Zahlung des Brautpreises, vgl. Gesenius ${ }^{18}$, s.v. S. 103b; zu

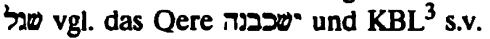

6 Wortlich: entweihen.

7 Vgl. Schottroff, Fluchspruch, 159; ebenso Plöger bei Jeremias, Kultprophetie, $169 f$.

8 Vgl. Wolff, Micha, 231f; Hillers, Treaty-Curses, 28ff; Lemaire / Durand, Sfire, 133. 
ihre "erhoffte Wirkung alsbald mit $w l^{\prime}$ negiert" werde ${ }^{9}$ bzw. daß sie "die Vergeblichkeit wichtiger menschlicher Aktionen" und damit "ein totales Frustrationserlebnis" ${ }^{\text {10 }}$ verursachen.

Wolff wie auch Hillers verweisen jeweils auf altorientalische Parallelen, ohne jedoch historische oder religionsgeschichtliche Schlüsse zu ziehen. Diskutiert werden im einzelnen:

1. der Text des Vertrages zwischen Mati' ilu v. Arpad mit Bar Ga'yah von KTK auf den Sfire-Stelen ${ }^{11}$,

2. die Fluchformeln in der assyrisch-aramäischen Bilingue vom Tell Fekherije $^{12}$ und

3. die Flüche gegen die Qedariter auf dem Rassamzylinder Assurbanipals.

Donner und Röllig verweisen über die genannten Texte hinaus auf die Fluchformeln in den Staatsverträgen zwischen Šamši-Adad V. und Mardukzäkir-šumi l. sowie zwischen Asarhaddon und Baal von Tyros ${ }^{13}$, die jedoch die uns an dieser Stelle interessierende Fluchform nicht enthalten. ${ }^{14}$

Bevor wir uns der Frage nach dem Wert der altorientalischen Parallelen zuwenden, seien die fraglichen alttestamentlichen Texte jeweils im Wortlaut wiedergegeben:

\section{Wolf, Micha, 162.}

10 Ebd.

11 Ausgewăhlte Literatur: Lemaire / Durand, a.a.O.; Krebernik, ZA 74 (1984) 156-160 Rez. dazu; Soden, KTK/KISKI, 133-141; Durand, Les Anciens de Talhayum, 112f zu TL'W; Rössler, TUAT I/2, 178-189 Übersetzung; Erstpublikation: Ronzevalle, Fragments, 237-260 pl. xxxix-xlv; Dupont-Sommer, Sfiré, 205-321 pl. i-xxviii I-II; Donner / Röllig, KAI 222-224, Tf. xv-xxiii I-III; Fitzmyer, Sefire, pass.; Lipinski, Studies, 24-57; Noth, Hintergrund, 118ff; McCarthy, Treaty, 98ff; Lipinski in: Beyerlin, Textbuch, 272-282 Úbersetzung; Sader, Les états, $127 \mathrm{ff}$.

Aus der Fülle der Literatur vgl. z.B. Abou-Assaf, Statue, 3ff; Abou-Assaf / Bordreuil / Millard, Tell Fekherye, pass.; Angerstorfer, Gedanken, 7-11; Dohmen, Gottebenbildlichkeit, 91-106; Fales, Bilinguisme, 233-250; Millard, Assyrians, 101-108 Abb. 1; ders., Etymology, 103-106; Pardee / Biggs, Review, 253-257; Puech, Inscriptions, 576-587, 578ff; Sader, Les états, $15 \mathrm{ff}$.

Donner / Röllig, KAI, 247 zu KAI Nr. 222 A 22-24, 247; zu den Texten vgl. Weidner, Staatsvertrag, 27ff; und Borger, TUAT I/2, 158ff; sowie jetzt Parpola / Watanabe, SAA II, 4ff, $8 \mathrm{ff}$.

Der Vertragstext zwischen Asarhaddon und Baal von Tyrus kündigt in IV 16ff an, daß Speisen, Kleid und Öl von den Gơttern verdorben werden sollen. Im zweiten Vertragstext zwischen Šamsi-Adad V. und Marduk-zäkir-sumi I., vgl. Weidner, Staatsvertrag, 27ff, ist Z.30 vom "Körper" die Rede, an dem oder mit dem etwas geschieht. Anfang und Ende der Zeile sind weggebrochen, so daß keine năhere Bestimmung moglich ist. 


\section{Die alttestamentlichen Belege}

\section{Gruppe 1:}

Lev 26, 26: s.o.

Mi 6,14.15: Du wirst essen, aber nicht satt werden.

Hos 4,10: Sie essen, werden aber nicht satt.

Sie treiben Hurerei, aber vermehren werden sie sich nicht, denn sie haben Jahwe verlassen, indem sie Hurerei trieben.

Gruppe 2:

Dtn 28,30: s.o.

31: Dein Ochse wird vor dir geschlachtet, aber du wirst nicht von inm essen.

Dein Esel wird von dir weggeraubt, aber er kehrt nicht zu dir zurück.

שורך טבוח לעיניך

ולא תאכל ממנו לורו

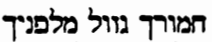
ולא •שוב לך מורד

Am 5,11: [5,10: Anklageformulierung; 5,11: Urteilseinleitung durch לכן] Quadersteinhauser habt ihr gebaut, aber wohnen werdet ihr nicht in ihnen. Prächtige Weingărten habt ihr gepflanzt, aber trinken werdet ihr ihren Wein nicht.

Zeph 1,13: [1,12: Anklageformulierung; 1,13: Urteilseinleitung durch וריה Hăuser haben sie gebaut, aber sie werden nicht <darin> wohnen. ובנו בתים ולא •שבו כתים Und Weinberge haben sie gepflanzt, aber deren Wein werden sie nicht trinken. 
Mi 3,4a: Dann werden sie zu Jahwe rufen, ${ }^{15}$ aber er wird ihnen nicht antworten.

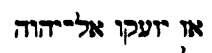
ולא יענה אות אליחם

Mi 6,15b: Du wirst Oliven keltern, aber dich mit Öl nicht waschen.

Und Most < keltern>, 16 aber Wein nicht trinken.

Dtn 28,41: Sơne und Töchter zeugst du, aber sie gehoren dir nicht, denn sie ziehen in die Gefangenschaft.
אתה תדרך זית

ולא תסוך סמר חמות

ותירוש תיאס

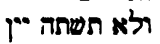

בנים ובנות תוליד

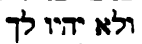

כי ילכו בשבי יוצי

\section{Gruppe 3:}

Dtn 28,39-40: Weinberge hast du gepflanzt

כרמים תטע

ועבדת כותם

und <sie> bearbeitet,

aber Wein wirst du weder trinken

noch wirst du <ihn> in Vorrat legen,

denn der Wurm frißt inn auf.

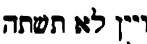

ולא תאגר ליח רכיור

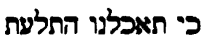

Ölbăume hast du in deinem ganzen Gebiet,

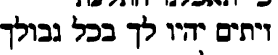

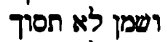

aber mit Öl wirst du dich nicht waschen,

כי יסל ויתר לחסר

denn deine Oliven fallen ab.

בצאנם ובבקרם •לכו

לבקש את יזוה וכבים ילני

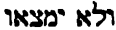

חלץ מהם ימוז

לנעו שתים שלש ערים אל עיר אחת

לישתות מים

ולא "שבעט מים

Am 4,8: Es wanken zwei, drei Stadte

zu einer anderen,

um Wasser zu trinken,

aber sie werden nicht satt.

\section{Che}

5 Die Partikel ix liegt hier mit zukünftiger Bedeutung vor.

16 Das in diesem elliptischen Satz fehlende Verb steht im ersten Satz und ist hier sinngemăß zu ergänzen. 
Am 8,12: Sie wanken von Meer zu Meer, und von Șapon her bis zum Osten streifen sie herum, 17

um das Wort Jahwes zu suchen, aber sie werden es nicht finden.

ומצפון עד מורח "שוטטו

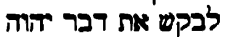

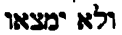

Diesen Beispieltexten ist nicht nur formal das Schema: "Vorsatz-wl'- Nachsatz" gemeinsam, sondern sie bilden auch deswegen eine einheitliche Gruppe, weil bei den genannten Handlungen jeweils die zweite semantisch die Negierung des zu erwartenden Effektes der ersten darstellt.

In vereinfachter Schreibweise ergeben sich die folgenden Schemata:

Form 1: (ohne lexematische Objekte)

Verb $_{1}+w+$ l' $^{\prime}+$ Verb $_{2}$ :

Lev 26,26; Mi 6,14.15; mit Erweiterung um einen kausalen ky-Satz in Hos 4,10.

Form 2: (mit lexematischem direkten bzw. präpositional gebildeten Objekten) $\mathrm{O}+\mathrm{Verb}_{1}+\mathrm{w}+\mathrm{l}^{\prime}+\mathrm{Verb}_{2}+\mathrm{O}_{<.}{ }^{18}$ :

Dtn 28,30.31; Am 5,11; Zeph 1,13; Mi 3,4a; 6,15b; mit Erweiterung um einen kausalen $k y$-Satz in Dtn 28,41.

Form 3: (singulär durch Parallelbildung [nur Dtn 28,39] und mit Objekt in erster Position vor dem Prohibitiv)

O Verb $1+w+\mathrm{O}_{<-}+\mathrm{w}+\mathrm{l}^{\prime}+\mathrm{Verb}_{2}+$ ky-Satz:

Dtn 28,39.40 [statt $O$ an erster Position steht hier das Subjekt].

Form 4: (Langform, dh. mit finaler Umstandsbestimmung im ersten Satz) Verb $_{1}+$ Inf.cstr. $++w+l^{\prime}+$ Verb $_{2}$ :

Hos 5,6; Am 4,8.12.

Wie aus dieser Zusammenstellung deutlich hervorgeht, lassen sich die belegten Formen prinzipiell in Kurzformen und Erweiterungsformen differenzieren. Die Erweiterungen betreffen die Ebenen der Syntax und Satzfügung. Während Form 1-3 um einen kausalen ky-Satz, z.B. in Dtn 28,41 "denn sie gehen in die Gefangenschaft", erweitert sein kann, der die negierte Handlung noch präziser begründet, indem konkrete Vorgänge aus Natur und Geschichte

17 Lies mit einigen Handschriften 'd; vgl. auch Wolff, Amos, $378 \mathrm{ff}$.

Zur Abkùrzungsweise: $\mathrm{O}=$ Objekt. Die Aufnahme bzw. der Rückbezug (abgekürzt: _..) beim Objekt wird entweder mittels Pronominalisierung hergestellt oder dadurch, da $\beta$ Verb ${ }_{2}$ die resultative Handlung zum vorausgehenden Satz angibt, z.B. bauen / wohnen; pflanzen / ernten; essen / satt werden. 
angeführt werden, beinhaltet Form 4 eine übergreifende Handlung mit einer konkreten Zweckbestimmung - auf letztere bezieht sich der Prohibitiv. ${ }^{19}$

Diesen Formen kann im prophetischen Gerichtswort eine Anklageformulierung vorangehen, wie z.B. Am 5,10+11: "Sie hassen im Tor den, der zurechtweist, und scheuen den, der vollständig aussagt, darum: weil ihr Pachtzins vom Hilflosen erpreßt und Kornsteuer von ihm nehmt, gilt: Quadersteinhäuser habt ihr gebaut, aber wohnen sollt ihr nicht in ihnen".

Als eigentliche Entwicklungen und Umprägungen müssen Form 3 und Form 4 angesehen werden, insofern hier das einfache zweigliedrige Schema durchbrochen wird, einerseits durch ein in sich verschachteltes 4-Satz-Schema, andererseits durch die Negation einer finalen Umstandsbestimmung.

Mit dieser Entwicklung oder besser Umprägung der Redeform, zu deren Beispielen schon Jeremias festgestellt hat, daß in den Fluchreihen von Dtn 28 und Lev 26 erheblich älteres Material verarbeitet ist und daß dieses "deutlich bäuerliche Verhältnisse Palästina-Syriens im Blick" hat, ${ }^{20}$ vollzieht sich aber auch eine Wanderung zwischen verschiedenen Textgattungen: Fluchabschnitte aus Gesetzbüchern und prophetische Gerichtsworte - die Frage nach dem Ermöglichungsgrund dieser Wanderschaft durch literarische Gattungen sei vorläufig noch zurückgestellt.

Neben der formalen Beziehung der Texte untereinander hat der Nichtigkeitsfluch die Funktion, auf literarischer Ebene eine Notzeit als Strafe für die Übertretung des göttlichen Willens oder einer Bundesverplichtung vorauszusagen - im Falle von Hag 1,6 eine Notzeit als Folge des in Trümmern liegenden Tempels als existent zu konstatieren. Dieser Interpretation korrespondiert, daß Tritojesaja dasselbe Schema in nun positiver Wendung benutzt, um die eschatologische Herrlichkeit Jerusalems und die neue Gesellschaft anzusagen:

Jes 62,9: "sondern die, die es [das Korn] sammeln, werden es essen, und sie werden Jahwe loben; und die, die ihn [den Wein] ernten, werden ihn trinken in meinen heiligen Vorhöfen" oder:

Jes 65,21: "Und sie werden Hauser bauen und bewohnen, und sie werden Weinberge pflanzen und deren Früchte essen".21

19 In etwas anderer Formulierung darf zu den Kurzformen noch Hag 1,6 gezăhlt werden. Statt $w l$ steht hier allerdings w'yn: "Essen, aber keine Săttigung // Trinken, aber kein Rausch // Kleidung, aber keine Warme für inn".

20 Kultprophetie, 169.

21 Zu Text und Sache vgl. Koenen, Ethik, 251, 255, 128-131, $176 \mathrm{f}$. 
Gerade das zuletzt genannte Beispiel verdeutlicht, wie der Prophet den Spruch aus Am 5,11 aufgreift und entsprechend seiner eigenen Intention positiv umformuliert. Das Beispiel zeigt aber auch, da $B$ der Nichtigkeitsfluch in der späteren Zeit keine Bedeutung mehr besaß, sondern verstärkt in den gut einhundert Jahren zwischen dem Auftreten der Propheten Amos, Hosea, Micha und Zephanja (ca. 750 - 630 v. Chr.) bezeugt ist.

Thematisch dominant sind Handlungen und Vorgänge im Bereich der Ernährung und Ernte. Daneben begegnen aber auch die Bereiche von Familie, Haus und Hof bis hin zur Vergeblichkeit kultischer Handlungen. Damit ist auch thematisch der Bereich des "Bäuerlichen" verlassen (Hos 5,6; Am 8,12).

\section{Die altorientalischen Parallelen}

Wie bereits angedeutet, werden besonders die Fluchreihen aus Lev 26 und Dtn 28 gern mit Flüchen aus aramäischen und neuassyrischen Texten in Beziehung gesetzt, wobei allerdings die Art und Weise des Aufeinanderbezogenseins nicht näher erfaßt wird. Damit ist unklar, ob historische oder religions- bzw. literaturgeschichtliche Relationen gemeint sind. Bevor diese Fragen näher erörtert werden, sollen die fraglichen Texte im Wortlaut wiedergegeben werden:

a) Staatsvertragstext zwischen Bar Ga'yah von KTK und Mati'ilu von Arpad (Mitte des 8. Jh.s v. Chr.) ${ }^{22}$, Z. 22-23:
(22) yhyngn 'lym
wšb' ssyh yhynqn "\%
$w^{\prime} l$ yšb'
wšb'] (23) swrh yhyngn ' $g l$
wsb' sn yhynqn 'imr
$w^{\prime l} y s\left[b^{*}\right.$
$w^{\prime} l y^{\prime} b^{\prime}$
$\left.w[l] y^{\zeta}\right](24) b^{\prime}$

ein Kind săugen, und es wird doch nicht satt;

und sieben Stuten sollen ein Fohlen săugen, und es wird doch nicht sa[tt werden; und sieben] Kühe sollen ein Kalb saugen, und es wird doch nicht satt werden;

und sieben Schafe sollen ein Lamm saugen, und [es wird doch nicht satt] werden.

22 Text hier nach KAI 222; s. auch Sader, Les états, 127ff; vgl. auch Parpola / Watanabe, SAA II, XXVIIf. 
b) $\mathrm{Rm} B$ IX $=$ ARAB II $\S 828=$ ANET $300^{23}$ : aus dem 7. Jh. v. Chr. heißt es entsprechend im Fluchwunsch:

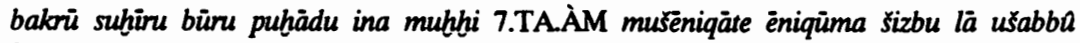 karassun}

the young camels, donkey foals, calves, lambs sucked seven times and more at the mothers who nursed them, yet could not satiate their stomachs with milk. ${ }^{24}$

c) Tell Fekherije ${ }^{25}$, aram. Z. 19.20-22:

wl zr' w'l yhạsd

wrih s'wn lhynqn 'mr w'l yrwh

wrih swr[n] lhyngn 'gl w'l yrwy

wr'h nšwn lhynqn 'lym w'l yrwy

wm'h nక̌wn Ipn btnwr lhm w'l ymInh ${ }^{26}$ und möge er auch săen, so soll er nicht ernten und hundert Mutterschafe sollen ein Lamm săugen, es soll nicht satt werden und hundert Kühe sollen ein Kalb săugen, es soll nicht satt werden, und hundert Frauen sollen einen Saugling stillen, er soll nicht satt werden, und hundert Frauen, die Brot im Ofen backen, sie sollen ihn nicht füllen ${ }^{27}$.

23 Zum Paralleltext (Tontafelinschrift VAT 5600 Kol. ii Z. 13-15) s. Streck, Asb. 78; 378; vgl. auch Parpola / Watanabe, SAA II, XXIIf.

24 Lesung und Übersetzung nach CAD B s.v. bakru, 35a. Zu den Flüchen, besonders zu dem literarischen Versatzstuck mit dem Thema "Kannibalismus" vgl. Eph'al, Arabs, 50f, 149f, 154 A. 531; Oeming, Kannibalismus, 90-106, bes. 100ff, oder liegen der Qedariter-Episode Überlieferungen eines Staatsvertrages zugrunde, vgl. Eph'al, aaO, 50 A. 152; Borger, TUAT I/2, 177.

25 Der folgende aramaische wie auch assyrische Text nach Greenfield / Shaffer, Notes, 112. Bearbeitungen auch bei Sader, Les états, $15 \mathrm{ff}, 19 \mathrm{ff}$. $\mathrm{Zu}$ den sprachlichen Besonderheiten der assyrischen wie aramaischen Version vgl. Fales, Bilinguisme, 239f; vgl. auch Greenfield / Shaffer, Curse formulae, $47 \mathrm{ff}$; zur Datierung vgl. Naveh, Date, $131 \mathrm{ff}$ (11. Jh. aus palăographischen Gründen), und Sader, Les états, 24ff (8. Jh.).

Zur Orthographie der Inschrift und Abweichungen gegenuber dem Aramaischen aus Sfire vgl. Andersen / Freedman, Orthography, 12ff. Ihyngn wird gemeinhin als 3. pl. fem. Jussiv mit proklitischem $/ l /$ Hafel einer Wurzel ynq aufgefaßt, vgl. Abou-Assaf, Statue, 50; Fales, Bilinguisme, 239.

27 Im Aramäischen bezeichnet ' $l$ + Kurzimperfekt Vetitiv und "den negierten Wunsch", vgl. Degen, Grammatik, 125. Dies wurde durch die Übersetzung mit "sollen" versuchsweise angedeutet. Vermutlich würden auch die hebraischen Beispiele durch eine stringentere Übersetzung den eigentlichen Charakter als Fluch besser zum Ausdruck bringen. 
Die assyrische Version ${ }^{28}$ lautet Z. 30-36:

30 ...li-riš lu-ú la

31 e-și-di...

32 ... $1 \mathrm{ME}$ lahrü( $\left.\mathrm{U}_{8}\right)$ la ú-sá-ba-a

33 huräpu(UDU.NIM) $1 \mathrm{ME}$ littu(GU ${ }_{4}$.ÁB) la ú-šá-ba-a mu-re

$341 \mathrm{ME}$ a-li-a-te la ú-sá-ba-a märu(DUMU)

$351 \mathrm{ME}$ a-pi-a-te la-a sam-la-a

36 tinüru(NININDU)...

Charakteristisch ist auch hier, da $B$ die positive Handlung des Vordersatzes hinsichtlich ihrer Wirkung im Nachsatz negiert wird. Die Ähnlichkeit zum atl. Nichtigkeitsfluch zeigt sich auch auf syntaktischer Ebene - jedoch mit der Einschränkung, daß statt Prohibitiv wie im Hebräischen in den aramäischen und neuassyrischen Beispielen jeweils Vetitiv (' $l+$ PK Kurzform, nA Prohibitiv: $l \bar{a}$ bzw. $l \bar{u} l \bar{a}+$ Präs. ${ }^{29}$ ) gebraucht wird.

Thematisch sind die Beispiele aus der Umwelt auf den Vorgang des Trinkens beim Stillen und Säugen und auf Aussaat und Ernte begrenzt, so daß hier sehr viel stärker als in den alttestamentlichen Belegen der Kontext von Fruchtbarkeit und Nachkommenschaft hervortritt. Weiterhin entsprechen auch die Textgattungen, nämlich Fluchformulare in den beiden Inschriften aus T.Fekherije und Sfire bzw. "purely literary elaborations" ${ }^{130}$ im Assurbanipal-Text, den atl. Kontexten von (literarischer) Schriftprophetie und Segen-und-FluchAbschnitten der Bundesurkunde. ${ }^{31}$

Eigens diskutiert werden muß an dieser Stelle aber das Verhaltnis zwischen Lev 26,26 und T. Fekherije Z. 33-36, da dieser Text nicht nur bis ins Vokabular mit Lev 26,26 verwandt ist, sondern eine Art missing link zwischen hebraischen, aramaischen und assyrischen Vorstellungen darstellt.

Lev 26,26 ist hinsichtlich seiner syntaktischen Anbindung an V. 25 nicht eindeutig. Nach Elliger gehört entgegen der Akzentsetzung die gesamte Infinitivkonstruktion am Anfang von V.26 syntaktisch wie inhaltlich zu V.25aß.b: "Und ihr euch dann in eure Stadt versammelt, dann sende ich die Pest unter euch; und ihr werdet in Feindeshand gegeben 26 wenn ich euch den Brotstab zerbreche". Diese Abgrenzung findet weiteren Anhalt in der Verknüpfung von Hunger und Pest mit dem Zerbrechen des מטת in Ez 5,16. ${ }^{32}$ Auf diese Weise ergibt sich eine inhaltlich noch exaktere Parallele zu T. Fekherije, assyrische

$28 \mathrm{Zu}$ den Besonderheiten der assyrischen Textform vgl. Fales, Bilinguisme, 239; Greenfield / Shaffer, Curse formulae, 55.

29 Zur Beteuerungsform lū, sowie zur Vertretung des Vetitiv durch Prohibitiv im Neuassyrischen vgl. voden, GAG §81f h.: im Sinne eines negierten Wunsches gebraucht.

30 Ephial, Arabs, 50.

31 So in der Terminologie Brauliks, Gesetz, 155.

32 Der "Brotstab" begegnet neben diesen beiden Stellen sonst nur noch in Ez 4,16; 14,13 und Ps 105,16 , vgl. Elliger, Leviticus, $368 \mathrm{f}$. 
Version, 36. Beide Texte verwenden das Bild von den brotbackenden Frauen (hebr. הפא, aram. 'ax, akk. epu), die den Ofen (hebr. u. aram. רנת, akk. tinünu) nicht zu fülen vermogen. Damit bestatigt sich die These von Jeremias ${ }^{33}$, daß in Lev 26,26 bedeutend alteres Material verarbeitet ist. Das leitet uber zu der Frage nach Herkunft und Vermittlung des an die Săttigungsthematik geknüpten Nichtigkeitsfluches.

Syntaktische Gestaltung, Thematik und Vokabular sind in den aramäischen Belegen in größerem Maße begrenzt als im Alten Testament, was aber an der Anzahl derzeit bekannter altaramäischer Texte liegen kann. Gleichzeitig zeigt diese Begrenzung zusammen mit dem Sachverhalt, daß die assyrische Version des Fluchabschnitts der T.-Fekherije-Inschrift wohl eine Übersetzung aus dem Aramäischen darstellt ${ }^{34}$, daß der Nichtigkeitsfluch in dieser Gestaltung keine assyrische Redeform darstellt, sondern besser als nur ein Beispiel der auch sonst bekannten Aramaisierung Assyriens ${ }^{35}$ verstanden wird.

Die aramäische Version des Nichtigkeitsfluches bildet damit nicht allein formal und inhaltlich die engste Parallele zu den alttestamentlichen Formen, sondern führt uns auch historisch und geographisch in die unmittelbare Nachbarschaft zu den Propheten Hosea, Amos und Micha und in das Gebiet des nördlichen Mesopotamiens.

Tell Fekherije ${ }^{36}$ (das antike Sikāni) liegt in Syrien, im Territorium des Aramäerstaates Bït Bahiäni am Oberlauf des Habur; Sfire liegt im Gebiet von Bït Agüsi, ca. $50 \mathrm{~km}$ südöstlich von Aleppo. ${ }^{37}$ In nördlicher bzw. nordöstlicher Nachbarschaft liegen die sog. neuhethitischen Kleinstaaten Karkemisch, Gurgum (Maras) und Milid (Arslantepe), die ebenso wie die Aramäerstaaten erst

33 S.o. S. 457. Auch Schottroff, Fluchspruch, 162, vermutet, daß Israel diese "Fluchwortformen ... erst auf dem Boden des Kulturlandes kennengelernt, übernommen und weitergebildet hat". Die seit langem notierten Übereinstimmungen der großen atl. Fluchreihen in Lev 26 und Dtn 28 mit Passagen der vassel-treaties Asarhaddons und Assurbanipals, vgl. Frankena, Vasseltreaties, 144ff und Watson, Rez. zu Watanabe, 154, wurden großtenteils in einem Abhăngigkeitsverhältnis von den neuassyrischen Texten gedeutet, s. z.B. Weinfeld, Deuteronomy, 122f, 125f, Frankena, ebd. Seit der Entdeckung der Inschrift von Tell Fekherije scheint sich hier ein Umdenken abzuzeichnen, vgl. den Hinweis bei Greenfield, Aramaic Studies, 113 A. 8, daß immerhin die Moglichkeit bestehe, daß die nA Fluchformulare auf einer alteren Vorlage fußten, die ihrerseits mit dem Aramaischen konform ging.

Vgl. Dohmen, Statue, 92 A. 6.

35 Weitere Beispiele bei Tadmor, Aramaization, 449ff; dort auch zur eventuellen Herkunft der adé-Vereidigung und der Hofprophetie aus dem aramaischen Kulturbereich; vgl. auch Garelli, Importance, 437ff. In diesen Zusammenhang gehoren ferner die zahlreichen Übereinstimmungen zwischen den prophetischen Orakeln des Alten Testaments, der aramalischen Inschrift Zakkurs von Hamath und den erst in neuassyrischer Zeit belegten Heilsorakeln in assyrischen Texten, vgl. eher zu vorsichtig in der Beurteilung Weippert, Prophetien, 104.

Vgl. Sader, Etats 22ff, 31; s.a. Wilhelm, Grundzüge, $37 f$.

37 Vgl. auch Sader, Etats, 149ff. 
gegen Ende des 8. Jh.s. endgültig dem nA Großreich einverleibt werden. Auch dies mag ein Hinweis auf den aramäisch-syrischen Vorrang der Textbelege gegenüber dem späten Beleg bei Assurbanipal sein.

Die formale und inhaltliche wie auch die historisch-geographische und kulturelle Nähe der atl. Prophetie des 8. und 7. Jh.s. v. Chr. zu den Aramäerstaaten Syriens läßt demnach vermuten, daß der Nichtigkeitsfluch nicht ursprünglich israelitisch ist, sondern von den nördlichen Nachbarn Israels übernommen wurde. Untrennbar mit diesem Problem verbunden ist die Frage, ob mit der aramäischen Vermittlung auch gleichzeitig die Herkunft der Fluchform festgestellt ist. ${ }^{38}$

Nach dem Untergang des hethitischen Großreichs, Ugarits und Emars im ausgehenden 13. oder am Anfang des 12. Jh.s. v. Chr. durch den massiven Druck neuer Völkerschaften, die auf dem Land- und Seeweg in ihre neuen Lebensräume vordrangen ${ }^{39}$, erscheinen in Syrien vornehmlich Aramäer, zu denen sich später die Israeliten zählen ${ }^{40}$, und Luwier, die ihre anatolische Heimat in Richtung (Süd-) Osten hatten verlassen müssen. ${ }^{41}$ In der neu entstehenden Vielfalt kleinerer aramäischer und neuhethitischer Staaten kommt

$38 \mathrm{Zu}$ Geschichte und Kulturkontakt in dem geographischen Dreieck Kilikien, Anatolien, Syrien vgl. Garelli / Nikiprowetzky, Le Proche Orient, 61f, 84ff; Hallo / Simpson, The Ancient Near East, 123ff; Sader, Les êtats, pass.; Winter, Art, 355ff u.a. zur Bauform des bit hiläni; Tadmor, Aramaization, 449ff; zur Spătbronzezeit vgl. etwa die Beitragge unter Sektion 4 in: Le Moyen Euphrate, 203ff; Margueron, Aux marches de l'empire hittite , 47ff; Beyer, Le sceau-cylindre de Shahurunuwa, 67ff; Tsukimoto, Tili-Šarnuma, 65-74; Sürenhagen, Konigssiegel, 183-190; Wilhelm, Grundzüge, 50ff zur Eroberung von Karkemisch durch Suppiluliuma und zur Installierung seines Sohnes Pijašili unter dem hurritischen Thronnamen Šarri-kưun. Wilhelm zufolge zeigen die hurritischen Namenselemente aller weiteren Herrscher in Karkemisch, daß mit einer dominant hurritischen Tradition hier wie uberhaupt in den sog. "vier hurritischen Konigreichen westlich des Euphrat" (Landsberger) zu rechnen ist.

39 Vgl. grundsătzlich Lehmann, Die ŠIKALĀJŪ, 481-494 mit reichhaltiger Literatur; Singer, Hittite Empire, 413-421, bes. 418 zu Karkemisch; einer grundlegenden Revision unterzieht $E$. Noort in seinem Beitrag in diesem Band die These, daß die Seevölkerinvasion archăologisch nachprufbar sei.

40 Vgl. Lemaire, Mari, la Bible et le monde nord-ouest sémitique, 558 mit Anm. 87.88. Er unterscheidet zwei Gruppen der Landnahme im 13. Jh. v. Chr.: "les Benê Israel venant d'Egypte et installés dans la montagne d'Ephraim, au sud-ouest de Sichem, et les Bene Jacob du pays araméen et installés dans le pays de Hépher au nord-ouest de Sichem"; vgl. auch Reinhold, Beziehungen, 39-67.

41 Vgl. Wilhelm, Grundzüge, $56 \mathrm{f}$. 
es schnell zu einer kulturellen Symbiose ${ }^{42}$ kleinasiatischer, hurritischer und aramäischer Elemente, die archäologisch ${ }^{43}$, kunstgeschichtlich und epigraphisch sichtbar wird. Für die eingangs gestellte Frage nach der Herkunft des Nichtigkeitsfluches erweist sich der Rekurs auf diesen auch religionshistorisch bedeutsamen Sachverhalt in mehrfacher Hinsicht als nützlich.

In seinem Artikel "Notzeit" hat E. von Schuler ${ }^{44}$ im Wörterbuch der Mythologie auf die hethitischen Mythen vom verschwundenen Gott, im besonderen auf die Überlieferungen um Telepinu hingewiesen. ${ }^{45}$ Die Notzeit, von der Menschen, Tiere und Götterwelt gleichermaßen betroffen sind, entsteht dadurch, daß ein Gott aus Zorn seinen Verantwortungsbereich verläßt und für die Menschen unerreichbar wird. Anzeichen der Not ist - wie im atl. Nichtigkeitsfluch - auch hier, daß vitale Lebensäußerungen ihre Wirkung verlieren: Essen und Trinken ${ }^{46}$ führen nicht zur Sättigung; der Fortpflanzungsakt bringt keine Nachkommen.

Notzeitschilderungen dieses Typs begegnen - der Terminologie H. Ottens folgend - im Telepinu-Mythos ${ }^{47}$, im Wettergott-Mythos ${ }^{48}$ und im Ašertu-Mythos. ${ }^{49}$ Gleichzeitig macht das rituelle Geschehen im Telepinu-Mythos deutlich, daß der Mythos im Zusammenhang konkreter Notbewältigung erzählt

42 Vgl. die bereits 0 . Anm. 38 genannte Literatur; als besonders tragfăhig für einen religionsgeschichtlichen Vergleich scheint sich uber die dort gegebenen Hinweise hinaus das zu eignen, was im weitesten Sinne unter Stein"kult" (auch Petrogenie u.a.?) zu verstehen ist, vgl. vorlâufig die Hinweise bei Arnaud, Le Moyen Euphrate, 254f; Durand, Le culte, 82ff; Arnaud, Emar VI/3 s.v. zukru-Fest; die Vermutung Durands, daß akk. sikannu eine Stele als Behausung/Repräsentation eines Numens meine, findet nicht nur durch den Ölritus am Stein der Hebat im Ritual Emar VI/3, 369, 34:45 eine glänzende Bestătigung, sondern jetzt auch durch Texte aus Munbãqa am oberen Euphratknie, vgl. Dietrich / Loretz / Mayer, Sikanum, 134ff.

Vgl. neuerdings Parayre, Carchemish, 319-360; Beyer, Le Sceau-Cylindre, 67-78; vgl. auch die Beiträge zu den neueren französischen Grabungen in Syrien in der Contribution francaise a l'archéologie syrienne, $53 \mathrm{ff}$.

44 Art. Verschwundene Gottheiten, 207-208; Art. Notzeit, 188-189.

Vgl. insgesamt Podella, Ṣర0m-Fasten, 50ff.

Gemeint ist nicht das kultische Essen und Trinken bzw. die Verehrung eines Gottes, indem man "ihm trinkt", vgl. Rosenkranz, Kultisches Trinken und Essen, 283-289.

KUB XVII 10; vgl. CTH 324; Transkription bei Laroche, RHA 77 (1966) 89-110; Ubersetzungen bei Goetze, Telepinu (ANET 126ff); Haas, Magie, 81ff; Kühne, in: Beyerlin, 182ff. CTH 325; Transkription bei Laroche, a.a.O., 111-134; Übersetzung Otten, Überlieferungen, 56f; Haas, Magie, 82ff.

49 CTH 342. Transkription bei Laroche, RHA 82 (1968) 25ff; Bearbeitung bei Otten, MIO 1, $125 \mathrm{ff}$; ders., MDOG 85, $27 \mathrm{ff}$; Hoffner, RHA 76, 5ff; ders., Hittite mythological texts, $141 \mathrm{f}$. 
wird. Der verschwundene Gott wird herbeizitiert und muß von seinem als Materie gedachten Zorn gereinigt werden. ${ }^{50}$

Fassung B des Telepinu-Mythos lautet:

2 [Rinder, Schafe und] Menschen [begatten sich nicht mehr],

3 [und selbst die tr]ăchtig [sind, konnen nicht gebaren.

$4 \mathrm{Im}$ [Lande entstand] eine Hungersnot. [Der große Sonnengott veranstaltete]

5 [ein Fest] und [lud] die großen [und die kleinen Göt]ter [ein; sie aßen,]

6 wurden [aber nicht satt,] sie tranken [und loschten nicht ihren Durst.]

7 Da sprach der [Wettergott] zu den Gottern: ["Telepinu ist nicht mehr hier (?).]

$8 \mathrm{Er}$ ist erzurnt und [hat alles Gute mit sich genommen (?).]

9 Nun ist im Lande eine [Hungersnot entstanden". Die großen]

10 und die kleinen Gotter [begannen] Telepinu [zu suchen und fanden] ihn nicht. ${ }^{51}$

Ebenso heißt es im Haupttext, nachdem Telepinu sich inmitten eines Moores(? $)^{52}$ versteckt und schlafen gelegt hat:

(19) The great Sun-god arranged for a feast and invited the thousand gods. They ate, (20)

but they did not satisfy their hunger; they drank, but they did not quench their thirst. 53

Im Wettergott-Mythos trifft das Unheil auch die Tiere. Dadurch, daß der Wettergott über Ašmunikkal erzürnt ist, entsteht eine Notzeit:

17...im Rinderstall [wurden] die Rinder 18 [bedrückt.] Sie fressen, [werden] aber nicht 19 [satt,] sie saufen [und] löschen nicht ihren Durst. ${ }^{54}$

Schließlich heißt es im deutlich kanaanäisch beeinflußten Ašertu-Mythos:

24 ...Asertu

25 hörte [diese] Krănkung, und es ergrimm[te] ihr der Sinn.

26 [ ]...stellte sie und [begann] sieben Jahre zu klagen.

27 [Die Gotter] schmausen, sie zechen,

28 [werden aber nicht satt, loschen nicht ihren Durst]. ${ }^{55}$

50 Terminus solcher Bitten um Reinigung von Zorn und Rückkehr ist mugai-, vgl. Kellermann, Telepinu Myth, 115-123, bes. 121 mit A. 21; s. ferner zur Semantik und den Belegen CHD 3, s.v. mugai- 319-322; s.v. mugawar 324a; s.v. muke/ǐšar 324b-326.

51 Text nach Otten, Überlieferungen, $16 \mathrm{f}$.

52 Vgl. Hoffner, Myths, 15; vgl. auch Pecchioli Daddi / Polvani, mitologia, 79 (palude [=Sumpf, Morast]).

53 Text nach Goetze, Telepinu, 126.

54 Nach Otten, Überlieferungen, $56 \mathrm{f}$.

55 Otten, MIO 1, 127. Rekonstruktion der letzten Zeile nach den Telepinu-Texten. 
Das in seiner Motivik (Verlust der sättigenden $\mathrm{Kraft}^{56}$ ) in der hethitischen Literatur gut bezeugte Notzeit-Mythologem zeigt seine thematische Verwandtschaft nicht allein mit den oben behandelten aramäischen und alttestamentlichen Beispielen, sondern erweist sich neben etlichen anderen Beispielen als ein offenbar aus luwischem Milieu stammendes Traditionselement im TelepinuMythos. Als solches begegnet es in einem ebenfalls dem luwischen Bereich zuzuordnenden Ritual gegen Augenkrankheiten im Kontext eines Festes, zu dem der Sonnengott die anderen Gottheiten einlädt. ${ }^{57}$

Innerhalb dieses Kontextes, der durch die Ankunft eines oder mehrerer Götter präzise bestimmt ist, findet sich das Motiv "Sättigung" in zwei ebenfalls dem (hurritisch-)luwischen ${ }^{58}$ Milieu verhafteten Evokationsritualen aus Kizzuwatna, KUB XV 34 mit Dupl. (CTH 483) und IBOT III 148 (CTH 485). ${ }^{59}$

Im ersten Text, einer evocatio an die männlichen Zederngötter, heißt es, KUB XV 34, I, Z. 48f:

"Die kraftvollen männlichen Zederngotter so[II]en die Wege ess[en] (und) trinken, sie sollen sich satt essen (und) satt trinken",

und an anderer Stelle desselben Rituals, Kol. III, Z. 41f:

"Die Götter, die zu den Flüssen (und) Quellen kommen, sollen dann wieder satt gegessen (und) satt getrunk[en] sein".60

56 Zum Text vgl. Otten, aaO, 15, Fassung B, Kol. I, Z.5f: is-p][-i-e-er...[ba-as--Si-ik-ki-ir]; 58, Fassung D, Kol. III, Z.7f is-pi-i-e-er...ba-ass-si-ik-ki[-ir]; RHA 77, 90 Z 20: is-pri-i-e-er...ba-aš-siik-ki-ir; Parallelpaar ist demnach hašsik- und išpai-, vgl. Friedrich, HWb, s.vv., 63, 89; s. auch Otten, MIO 1, 129. Neben diesen beiden Verben, die den Begriff der Sattigung umschreiben, verweist Ehelolf, Lexikon, 137-160, 139f noch auf das Verbum nink-, s. Friedrich, HWb, s.v. 151. - Ehelolfs Hinweis auf einen zu KUB XVII 10 I 6ff parallelen Fluch in der mesopotamischen Literatur (Reisner, SBH 131 Z. 56f) findet in der neuen Bearbeitung des Textes bei Cohen, The Canonical Lamentations, 152ff allerdings nur teilweise Bestattigung, s. unter AME AMAŠANA The Bull in his Fold unter Textzeuge H: VAT $246=$ SBH I, S. 155 Z. 31f "Lord of the nation, the ewe has abandoned (her) lamb. The goat has abandoned (her) kid. Oh, your city is faithful! The true bearing mother has abandoned her child. The wife of the warrior has abandoned the little child her (own) child...".

57 Vgl. KUB XVII 10 I 19-20 mit KBo XII 89 Rs. III 11-14, bei Haas / Wilhelm, Riten, 29.

Zur Differenzierung luwischer und hurritischer magischer Praktiken und Materie vgl. HaasWilhelm, Riten, 12-23. Entsprechend ihrer Analyse der Evokationsrituale wären die zwei Arten des Zitierens, das Herbeiziehen auf einer Stoffbahn und das auf Wegen, jeweils unterschiedlichem Milieu zuzuordnen.

Vgl. Haas / Wilhelm, Riten, 9.

60 Übersetzung bei Haas / Wilhelm, Riten, 187, 199. 
Der zweite Text beinhaltet eine Evokation an den Wettergott des hamriHeiligtums ${ }^{61}$ und ihm zugeordnete andere Gottheiten, IBoT III, 148, III, Z. 5f; 10ff:

"...Der Herr des Pflockes (und) der Herr des St[uhles] sollen gesattigt sein und s[ie sollen] den Pflock schützen!"

Es folgt die Gabe von Opfertieren und Speisen:

"und er spricht folgendermaßen: 'Herr (des) Stuhl(s), sei satt gegessen, sei satt getrunken und sei wieder besanftigt, sage d[u] aber einer Gottheit gegenuber nichts Böses!"'62

Die beiden Zitate zeigen in formaler Ähnlichkeit mit Tritojesaja ${ }^{63}$, daß dem Sättigungsverlust in der Notzeit die neuerlangte sättigende Kraft der Nahrung zum Zeitpunkt der Rückkehr oder Ankunft des Gottes entspricht. Dieser positive Sachverhalt, daß göttliche Epiphanie mit dem auch körperlichen Wohlbefinden der Gottheit engstens zusammenhängt, findet auffallende Parallelen in rein hurritischen Sprüchen einer Reihe untereinander verwandter Rituale des AZU-Priesters, die offenbar nicht für offizielle Amtsträger, sondern eher für Privatpersonen konzipiert waren und die das Wohlwollen der Götter herstellen sollten. ${ }^{64}$ Nur ein Beleg für den Spruch stammt aus der Serie itkahi, in deren Mittelpunkt Tašmišarri, vermutlich der spätere König Tuthaliya III, steht. $^{65}$

Das Prädikat des Spruches (eine Evokationsformel ?) ist die Form $k e l=o(=m)$, der die Verbalwurzel $k e l-$ "s. wohlbefinden, sättigen(?)" (dazu keldi vgl. akk. sulmu "Heil, Wohlbefinden") zugrundeliegt; in KBo 21, 33+; KBo 19,

61 Zu diesem Kultort vgl. Wilhelm, Grundzüge, 92; Haas / Wilhelm, Riten, 116f; sowie Menzel, Tempel, 261f zu Gotterprozessionen in nA Gartenanlagen, s. auch HSS 14, 218, Z. 2.

13 anš Weizen

2 (hat) Erwimatuni, wahrend die Gotter den Garten betreten,

3 und Tebiptilla (und) Erwiša (und) Tarmia

4 im Monat Attanašwe

5 als Palastration

6 genommen

7 (und) nach Arrapha

8 getragen

Zum ambašsi-(Brand-)Opfer vgl. Haas / Wilhelm, Riten, 87; Wegner, Gestalt und Kult, 139f; weitere Prozessionsbelege bei Mayer, Nuzi-Studien, 147f, zum Teil im Kontext der Ausgabe von Gewändern und Getreide.

62 Úbersetzung Haas / Wilhelm, Riten, 223; gemå den Hinweisen bei Ehelolf auf drei Verben der Săttigung findet sich in diesen Evokationsritualen das Wortpaar: išpai- // nink-.

63

Siehe oben S. 433.

64 Nach der Interpretation von Salvini / Wegner, ChS I/2, 1 .

65 Vgl. Haas, ChS I/1, 7f, 15. 
136 I 17'; KUB 25, 47 I 11'; KBo 21,28 Vs.? I 11'; 21, 29, 9'; KUB 45, 3 I 14 (// KBo 24, 58+ Vs. 4'); KBo 23, 12 Rs. (!), 21; KUB 32, 44 Vs. II, 2-3 und IBoT 2, 39 Rs. $14-17 .^{66}$

Die Anwendung dieses Rituals für "Opfer an den Thron der Hepat" (ChS I/2, Nr. 1-6), scheint sowohl in Kleinasien als auch in Syrien bezeugt zu sein, wenn die Textfunde in Boğazköy-Hattuša und - nun kaum überraschend - in Ugarit eine solche Interpretation erlauben. ${ }^{67}$ Die Sättigungsformel in den in hurritischer Sprache gehaltenen Sprüchen des Ritualfachmanns wird von Wilhelm ${ }^{68}$ übersetzt:

Nimm Platz(?), Hepat, du selbst, komm um Wasser und Weihrauch willen, befinde dich wohl <durch> mein Thronopfer, durch sein kelde- (und) ambassi-Opfer. ${ }^{69}$

Das durch die kleinasiatische Literatur verfolgte Motiv "Wohlergehen/Sättigung" kann an dieser Stelle zwei unterschiedlichen Bereichen zugeordnet werden. Es findet sich in negativer Ausformung bei der Notzeitschilderung in den

66 Für den freundlichen Hinweis auf diese Texte danke ich Prof. Volkert Haas und Prof. Gernot Wilhelm, letzterem auch für eine kritische Durchsicht dieses Abschnitts. Zusammenstellung der Belege bei Wilhelm, Ablativ-Instrumentalis, 96-113, 107ff. Die Texte liegen nun innerhalb des Corpus der hurritischen Sprachdenkmäler = ChS vor; Salvini / Wegner, Die Rituale des AZU-Priesters, ChS I/2; Haas, Die Serien itkahi und itkalzi des AZU-Priesters, Rituale für Tašmisarri und Tatuhepa sowie weitere Texte mit Bezug auf Tasmisarri, ChS I/1.

Konkordanz:

ChS I/1, Nr. 3, Rs. $17=$ IBoT $2,39=3$. Tafel des itkahi-Rituals

ChS I/2, Nr. 1, Vs. I 23-25.35.50-52.56-60; II 30-32.55-56; Rs. III 2-6; IV 17-18.20-22.36-37 $=\mathrm{KBO} 21,33+=$ Opfer an den Thron der Hepat

ChS I/2, Nr. 17,Vs. I, 20.30-32, II 38-39, III 22"-24" = KBo 21, 28; $21,29=7$. Tafel des Sarra-Opfers

ChS I/2, Nr. 26,Vs. I ?, 10'-11' = KUB 25, 47 = Parallele zu Nr. 17.

ChS I/2, Nr. 27,Vs. II, 13 = KUB 32, $44=$ Parallele zu Nr. 17.

ChS I/2, Nr. 31,Vs. I 4'.17'; Rs. IV 14'.27' = KBo 19, 136. = Parallele zu Nr. 17.

ChS I/2, Nr. 40,Vs. I, 13-14.28.30-31(?).37-38 = KUB 45,3 = 6.Tafel des allanuwassi-Opfers.

67 Zur Identifizierung der Texte RS 24.278 (=KTU 1.128); RS 24.285 (=KTU 1.131); CTA 168 (=KTU 1.44); CTA 169 (=KTU 1.54) vgl. Laroche, Ug. V, 512. Zu weiteren Berührungen zwischen der hurritischen Ritualliteratur und luwischen und nordsyrischen Traditionen vgl. Wilhelm, Grundzüge, 98ff. Der im Register zum hurritischen Vokabular in Ug. V sich findende Eintrag $\mathrm{klm}$ mit Verweis auf CTA 175,1 und CTA 166,2 (= KTU 1.42) ist nur für letzteren Beleg ergiebig, wenn klm.kldn die fragliche Formel "dir sei wohl durch ein keldiOpfer" wiedergibt; nicht berucksichtigt hat diese Frage Kowal, Untersuchungen, 129-138 mit neuer Umschrift auf S. 138.

A.a.O., 109; vgl. auch Salvini / Wegner, ChS I/2, 1f.

69 Vgl. ebenfalls in den Vorarbeiten zu ChS bei Salvini / Wegner, Die hethitisch-hurritischen Rituale des ${ }^{\text {LÚ }}$ AZU-Priesters, 87-95, bes. 89, sowie Salvini, Note sulle "sentenze" hurriche nei rituali ittiti di KBo XXI e XXII, zu kel- "soddisfare, beneficare", 229 u. 237. 
Überlieferungen vom verschwundenen Gott ${ }^{70}$. Der positive Aspekt der Sättigung jedoch wird einerseits mit der Rückkehr des verschwundenen Gottes verbunden und erscheint andererseits in verallgemeinerter Form im Zusammenhang der Zitierung von Gottheiten zu unterschiedlichen Zwecken und in unterschiedlichen Kontexten.

"Sättigung" und "Sattsein" annoncieren demnach das Ende der Notzeit. Dieses ist charakterisiert durch die wiedererlangte Gottespräsenz und die restituierte Leistungsfähigkeit des fraglichen Gottes. Das in den untersuchten Texten nur noch literarische Motiv "essen, ohne satt zu werden" reflektiert oder bewahrt die Erinnerung an eine Notsituation, die gerade dadurch gekennzeichnet war, daß alles Tun nutz- und erfolglos blieb.

Ob eine reale Nahrungsmittelverknappung, die durch Mißernte oder Getreidekrankheit ausgelöst wurde, hier verarbeitet wurde, bleibt hypothetisch. Die Not wurde theologisch gedeutet und auf das Verschwinden der Gottheit und ihren Zorn wegen einer Verletzung des göttlichen Rechtsbereichs übertragen und konnte so als Paradigma für alle künftigen Notzeiten zur Verfügung stehen. Beide Aspekte, der konkrete historische Haftpunkt wie auch die paradigmatische Funktion, scheinen strukturanalog in der alttestamentlichen Prophetie durch die begründenden $k y$-Sätze wieder eingefangen zu werden, insofern der verneinten Handlung eine Begründung beigegeben und diese einem zukünftigen (wegen des paradigmatischen Charakters) geschichtlichen Ereignis (etwa der Ankündigung des Exils) zugeordnet wird. ${ }^{71}$

Erscheint schon aus geographischen und chronologischen Gründen eine direkte Entlehnung des luwischen Notzeit-Mythologems ins Alte Testament als unwahrscheinlich, so bleibt doch der Umstand hervorzuheben, daß hethitische und luwische Traditionen in Syrien bis ins 8. Jahrhundert v. Chr. gepflegt wurden. ${ }^{72}$ Dies ist nicht nur an der Vielzahl der hieroglyphenluwischen ${ }^{73}$ Inschriften abzulesen, sondern auch daran, daß einige genealogische Linien durch den Zusammenbruch des hethitischen Großreichs nicht zu bestehen aufhören.

Aber auch in den Notzeitschilderungen des hurritischen Mythenzyklus um Kumarbi, s. dazu. Haas, Betrachtungen, 97ff; ders., Berggotter, 149ff, sowie Podella, ȘÖm-Fasten, 51ff.

71

72 Vgl. aus den 0.g. Beispielen Dtn 28,39.40.41.

Zum folgenden vgl. Hawkins, Maras, 352f; ders., Karkamis, 427-446, bes. $441 \mathrm{ff}$; ders., Assyrians and Hittites, 67-83, zu den atl. Bezügen im Blick auf das Jes 10,9; Am 6,2 erwahnte כלנו/ה im Bereich von Unqi, 81ff; ders., Kuzi-Tesub, 99-108; ders., Hatti, 152-159, bes. 154; ders., Hamath, 68f; Tsukimoto, Tili-Sarruma, 65-74; Röllig, Gurgum, 703f; Parayre, Carchemish, $330 \mathrm{ff}$.

Eine Gesamtpublikation durch J.D. Hawkins ist in Kürze vorgesehen, vgl. vorlaufig ders., The Negatives in Hieroglyphic Luwian, 119-156; ders. - Morpurgo Davies, The Late Hieroglyhic Luwian Corpus, 267-295; zum Keilschriftluwischen vgl. Starke, Die keilschrift-luwischen Texte in Umschrift, 1ff, A. 11. 
Somit ist es erlaubt, über das magische Datum 1200 v.Chr. hinaus ein Traditionskontinuum bis weit in die Eisenzeit hinein anzunehmen.

Ein erst vor wenigen Jahren in Lidar-Höyük gefundenes hethitisches Siegel $^{74}$ bezeugt für Karkemisch jetzt die folgende Abfolge von Regenten (Tabelle 1):

Šarri-kušuh, Šahurunuwa, Ini-Tešup, Talmi-Tešup und Kuzi-Tešup. Letzterer ist der Sohn des synchron zu Suppiluliuma II. und Ammurapi von Ugarit bezeugten Talmi-Tešup, also der letzten Herrscher vor dem Zusammenbruch der syrischen Staatenwelt um 1200 v. Chr. Diese Königstradition setzt sich vermutlich in zwei Linien weiter fort:

1. Kuzi-Tešup ist zugleich der Vater der mit PUGNUS-mili I. einsetzenden Königsfolge von Malatya/Milid. Ihm folgen weitere vier Generationen, so daß man von einem Datum der Regentschaft Kuzi-Tešups um 1200 v.Chr. oder etwas später ausgehend - bei einer durchschnittlichen Regierungszeit von 30 Jahren - in Malatya in die erste Hälfte des 11. Jh.s gelangt (vgl. Tabelle 1).

2. Die Gürün-Inschrift Runtiyas' nennt erstmals nach dem Zerfall des hethitischen Großreichs die alte Königstitulatur "großer König, Held" als Epitheton für den Großvater des Autors, Kuzi-Tešup: MAGNUS.REX ... HEROS. In der genealogisch isolierten Linie $\mathrm{x}$-pa-zitis bis Ura-Tarhunzas findet ebenfalls dieser Titel Verwendung. Ab der unter Suhis beginnenden Reihe begegnet er nicht mehr. $^{75}$

Für die letzten Jahre der Eigenstaatlichkeit von Karkemisch belegen die luwischen Inschriften zwischen den Regenten Piširi (Mitte 8. Jh.s synchron Tiglathpileser III.) und Sangara (9. Jh. synchron Assurnasirpal II. und Salamanassar III. 870-848 v. Chr.) drei weitere Könige. Für die Zeit der mit Suhis beginnenden Linie sind nochmals vier Regenten überliefert, so da $B$ insgesamt 11 Generationen (Tudhaliya ?) nach Kuzi-Tešup bekannt sind. Auch für Maraş/Gurgum ist eine neun Generationen zurückreichende Chronologie ab Halparuntiyas III. (ca. 805 v.Chr.) bezeugt, die ebenfalls bis ins 11 . Jahrhundert hinaufreicht (vgl. Tabelle 2).

Aus diesen mehr oder weniger geschätzten und auf mehreren Hypothesen basierenden Rekonstruktionen läßt sich eine Kontinuität hinsichtlich Besiedlung und kultureller Traditionen wahrscheinlich machen, die das Ende des

74 Vgl. Sürenhagen, Königssiegel, 183-190; zur Lesung und zur historischen Einordnung Hawkins, Kuzi Tesub, 99ff.

Vgl. Hawkins, Kuzi Tesub, 104ff; sowie zur hethitischen Konigstitulatur Gonnet, La titulature, bes. $18 \mathrm{f}$ und $25 \mathrm{zu}$ den Titeln LUGAL.GAL "großer König" und UR.SAG (qarradu) "Held"; s. auch Laroche, Les Hiéroglyphes Hittites, Nr. 18; 21; Kuzi-Tesup wird nur in der GürünInschrift mit diesem Titel versehen, vgl. Hawkins, ebd.; zum meistens parallel belegten Titel "kơnigliche Sonne" sowie zur Ähnlichkeit zwischen Sonnengott und Kơnig in der syrohethitischen Spatzeit vgl. Fauth, Sonnengottheit ( $\left.{ }^{\mathrm{D}} \mathrm{UTU}\right)$ und 'kơnigliche Sonne' $\left({ }^{\mathrm{D}} \mathrm{UTU}^{S I}\right), 235 \mathrm{ff}$. 
hethitischen Großreichs überdauerten und - zumindest in der ersten Phase - in Karkemisch lokalisiert werden können.

Die Herrschaftsausweitung auf das Gebiet von Malatya/Milid zeigt, daß sich die Könige von Karkemisch bis zur Formierung und Konsolidierung der aramäischen Staaten (vgl. Tabelle 3$)^{76}$ als legitime Nachfolger der hethitischen Großkönige ansahen.

Angesichts einer solchen Situation ist es äußerst wahrscheinlich, daß mitsamt der/den Königstradition(en) auch mythisches, literarisches und rituelles Wissen bzw. Erfahrungen und Erinnerungen daran in die neu entstandene Kleinstaatenwelt gelangte. In dieser engen Symbiose zwischen späthethitischen und aramäischen Staaten erscheint eine Tradierung des zum hethitischen Mytheninventar gehörenden Notzeit-Mythologems am wahrscheinlichsten. Israelitische Kontakte zu diesen Staaten wären gut im Vorfeld des sog. "syrisch-ephraemitischen Krieges" denkbar, als etwa Tiglathpileser III. die Könige von Kummuh, Aram, Que, Milid, Tabal, Karkemisch und Gurgum direkt neben Menachem von Samaria als Mitglieder der antiassyrischen Koalition aufführt. ${ }^{77}$

In einer solchen Konstellation könnte die ursprünglich luwische "Sättigungsthematik" in aramäische, neuassyrische und israelitische Kontexte vermittelt worden sein. Vermittlungshilfe war dabei wohl die Tatsache, daß - wie die aramäisch-assyrischen Beispiele lehren - der negative Aspekt der Notzeit (Gotteszorn - Gottesferne) sich sehr gut in die Fluchabschnitte von Vertragstexten und Steleninschriften integrieren ließ. Denn er war von Hause aus auf den Zorn einer Gottheit bezogen. Auch historisch paßt diese Konstellation gut zum Auftreten des Nichtigkeitsfluches in der Prophetie des 8. Jh.s v. Chr.

Dieser doppelte Aspekt, Gotteszorn und juridische Verwendung, wurde von den alttestamentlichen Autoren aufgenommen und konnte sowohl in die Gesetzesformulierungen als auch in die prophetischen Gerichtsworte und dann in das dtr Segen-und-Fluchschema entlehnt werden.

$\mathrm{Da} B$ die Redeform relativ ungebrochen im Alten Testament wiederbegegnet, erklärt sich durch ihre paradigmatische Funktion in den Beschreibungen der Folge göttlichen Zorns.

76 Nach Sader, Les états, 307. Daß sich heth.-luwische Traditionen vielleicht auch in den Aramäerstaaten halten konnten, konnte durch entsprechende Namenselemente in den phönizischen Inschriften von Sam'al, vgl. auch $189 \mathrm{f}$ zur Bevolkerung und Ausdehnung des Staates, bezeugt werden.

77 Vgl. Levine, Stelae, 18 Z. 1ff; Weippert, Menahem, pass.; Rost, Keilschrifttexte, 26, Z. 150ff Vielleicht darf sogar die Notiz in 1 Kon 10,28f als Hinweis auf direkte Handelsbeziehungen mit Que in Kilikien gewertet werden, vgl. Hawkins, The neo-hittite states, 382; Donner, Geschichte, 219, 304 und 298 mit Hinweis darauf, daß die aramäischen Staatsvertragstexte aus dem Vorfeld der antiassyrischen Koalition stammen. 
Tabelle 1: Belegte Synchronismen nach Tsukimoto und Hawkins

Karkemix̌

Šarri-kušuḩ

Šahurunuwa

Ini-Tešup

Talmi-Tešup

(

Kuzi-Tesup

L

x-pa-zitis

Ura-Tarḩunzas

Suhis I.

Astuwatamanzas

Suhis II.

Katuwas

Sangara

Astiruwas (ab 840 v.Chr.)

Yariris (Araras)

Kamanis

Piširi (ab 740 v.Chr.) synchron: $\quad$ Tiglathpileser III. (744-727 v.Chr.) Sargon II. (721-705 v.Chr.)
Ugarit:

Suppiluliuma I. Niqmadu II.

Muwatalli Niqmepa

Tudḩalija IV. Ibirānu

Suppiluliuma II. Amurapi

Malatya/Milid:

Arnuwantis I. PUGNUS-mili II.

Arnuwantis II. synchron: Assurnasirpal II. (883-859 v.Chr.)

Salmanassar III. (858-824 v. Chr.) 
Tabelle 2: Die Regenten in Gurgum/Maras

Astuwatamanzas (2. Hälfte 11. Jh: v.Chr.)

(Muwatalis ?) (1070-920 v. Chr. ??)

Laramas I. Palalam I. (1.Hălfte 10.Jh. v.Chr.)

Muwanzis

Halparuntiyas I.

Muwatalis Mutalli - 1. Jahr Sulmānuǎared (860 v.Chr.)

Halparuntiyas II. Qalparunda - ARAB I \& 610 (855 v.Chr.)

Laramas II. Palalam, König v. Gurgum

Halparuntiyas III. Qalparunda - Adadnērari III. (805 v.Chr.)

Tarhulara synchron: Sardur IIl. (743 v.Chr.) - Mati'ilu

Mutallu aus Bit Pa'allu (710 v.Chr.) 
Tabelle 3: Die Regenten der Aramäerstaaten

\begin{tabular}{|c|c|c|c|c|c|}
\hline Jh. Bit Bahiani & Bit Adini & Bit Agusi & Sam'al & Hamat & Damaskus \\
\hline 11. -- & -- & -- & -- & To'i & -- \\
\hline 10. Bahianu & Adini & -- & -- & $\begin{array}{l}\text { Joram/ } \\
\text { Hadoram }\end{array}$ & \\
\hline 9. Abisalamu & Ahuni & $\begin{array}{l}\text { Gūsi } \\
\text { Arame } \\
\text { Ataršumki }\end{array}$ & $\begin{array}{l}\text { Gabbar } \\
\text { Bmh } \\
\text { Hayānu } \\
\text { Ş’1 } \\
\text { Kilamuwa } \\
\text { Qrl }\end{array}$ & $\begin{array}{l}\text { Paratas } \\
\text { Urhilinas } \\
\text { Uratamis } \\
\text { Zakkur } \\
\text {-- }\end{array}$ & $\begin{array}{l}\text { Rezon } \\
\text { Hezion } \\
\text { Tabrimmon } \\
\text { Bar-Hadad I. } \\
\text { Adad-idri } \\
\text { Hazael } \\
\text { Mari' }\end{array}$ \\
\hline $\begin{array}{l}\text { 8. Šamaš-nūri } \\
\text { Hdys'y } \\
\text { Hadianu } \\
\text { Kapara } \\
\text {-- }\end{array}$ & $\begin{array}{l}-- \\
-- \\
-- \\
--\end{array}$ & Mati'ilu & $\begin{array}{l}\text { Panamuwa } \\
\text { Brșr } \\
\text { Usurpator } \\
\text { Panamuwa } \\
\text { Bar-rakib }\end{array}$ & $\begin{array}{l}\text { Eni-ilu } \\
\text { Yaubi'di } \\
\text {-- } \\
\text { II. }\end{array}$ & $\begin{array}{l}\text { Bar-Hadad II. } \\
\text { Rahianu }\end{array}$ \\
\hline
\end{tabular}


Bibliographie

Abou-Assaf, A., Die Statue des HDYS'Y, Konig von Guzana, MDOG 113 (1981) 3-22

- / Bordreuil, P. / Millard, A.R, La statue de Tell Fekherye, Paris 1982

Andersen, F. I. / Freedman, D. N., The Orthography of the Aramaic Portion of the Tell Fekherye Bilingual, in: Text and Context. Old Testament and Semitic Studies for F.C. Fensham, ed. by. W. Claassen (JSOT Suppl. Ser. 48), Sheffield 1981, 9-49

Angerstorfer, A., Gedanken zur Analyse der Inschrift(en) der Beterstatue vom Tel Fecherije, BN 24 (1984) 7-11

Arnaud, D., Recherches au pays d'Aštata Emar VI/3. Textes sumériens et accadiens, Paris 1986

- Recherches au pays d'Aštata Emar VI/4. Textes de la bibliotheque: transcriptions et traductions, Paris 1987

Beyer, $D$., Le sceau-cylindre de Shahurunuwa, roi de Karkémish, in: La Syrie, 67-78

Biggs, R.D. $\rightarrow$ Pardee, $D$.

Borger, $R$, Assyrische Staatsverträge, in: TUAT I/2, Gutersloh 1983, 155-177

Bordreuil, P. $\rightarrow$ Abou-Assaf, $A$.

Braulik, G., Gesetz als Evangelium, in: ders., Studien zur Theologie des Deuteronomiums (Stuttgarter Biblische Aufsatzbănde 2), Stuttgart 1988, 123-160

Charpin, D., Inscriptions votives d'epoque assyrienne, M.A.R.I. 3 (1984) 41-81

Cohen, M., The Canonical Lamentations of Ancient Mesopotamia, Ann Arbor 1988

Contribution française à l'archeologie syrienne, IFAPO, Damas 1989

Dalley, St., 'NIN.LIL = mul(I)is(s)u, the Treaty of Barga'yah, and Herodotus' Mylitta, RA 73 (1979) $177-178$

Degen, $R$, Altaramäische Grammatik der Inschriften des 10.-8. Jh. v. Chr. (Abh. f. d. Kunde d. Morgenlandes Bd. 38.3), Wiesbaden 1969

Dietrich, M. / Loretz, O. / Mayer, W., Sikanum "Betyle", UF 21 (1989) 134-139

Dohmen, Chr., Die Statue von Tell Fecherije und die Gottebenbildlichkeit des Menschen. Ein Beitrag zur Bildterminologie, BN 22 (1983) 91-106

Donner, H., Geschichte des Volkes Israel und seiner Nachbarn in Grundzügen, Göttingen 1987

- I Röllig, W., Kanaanäische und Aramăische Inschriften Bd. II, Wiesbaden 1964

Dupont-Sommer, A., Les inscriptions araméennes de Sfiré, Mémoires présentés par divers savants à l'Académie des Inscriptions et Belles Lettres [MAIBL], 15 (1958) 205-321 pl. i-xxviii I-II

Durand, J.M., Le culte des bétyles en Syrie, in: Miscellanea Babylonica. Mélanges offerts à Maurice Birot, ed. par J.-M. Durand et J.-R. Kupper, Paris 1985, 79-84

- Les Anciens de Talbayum, RA 82 (1988) 97-113

Ehelolf, $H$. , Zum hethitischen Lexikon, KIF 1 (1930) 137-160

Elliger, $K$, Leviticus (HAT I/4), Tubingen 1966

Ephial, I., The Ancient Arabs. Nomads on the Borders of the Fertile Crescent 9th-5th Centuries B.C., Leiden 1982

Fales, F.M., Le double bilinguisme de la statue de Tell Fekherye, Syria 60 (1983) 233-250

Fauth, W., Sonnengottheit ( ${ }^{\mathrm{U}} \mathrm{UTU}$ ) und 'kơnigliche Sonne' $\left({ }^{\mathrm{D}} \mathrm{UTU}^{S l}\right.$ ) bei den Hethitern, UF 11 (1979) 227-263

Fitzmyer, J.A., The Aramaic Inscriptions of Sefire (Biblica et Orientalia 19), Roma 1967 
Franke, S., Fluch und Morser. Gedanken zur Symbolkraft eines Inschriftentragers, in: DUMU-EDUB-BA-A. Studies in Honor of A.W. Sjobberg, ed. by H. Behrens, D. Loding M.T. Roth, Philadelphia 1989, 177-180

Frankena, $R$, The Vassel-Treaties of Esarhaddon and the Dating of Deuteronomy (OTS 14), Leiden 1965, 122-154

Freedman, D.N. $\rightarrow$ Andersen, F.I.

Friedrich, J., Hethitisches Wöterbuch, Heidelberg 1952

Garelli, $P$., Importance et rôle des Araméens dans l'administration de l'empire assyrien, in: Nissen / Renger (Hg.), Mesopotamien, 437-447

- I Nikiprowetzky, V., Le Proche-Orient Asiatique, Paris 1974

Goetze, A., The Telepinu-Myth, in: ANET, 126-128

Gonnet, $H$., La titulature royale hittite au II ${ }^{\mathrm{e}}$ millénaire avant J.-C., Heth 3 (1979) 3-108

Greenfield, J. C., Aramaic Studies and the Bible, VT.S 32 (1981) 100-130

- / Shaffer, A., Notes on the Akkadian-Aramaic Bilingual Statue from Tell Fekherye, Iraq 45 (1983) $109-116$

- I Shaffer, A., Notes on the Curse Formulae of the Tell Fekherye Inscription, RB 92 (1985) 47. 59

Haas, V., Magie und Mythen im Reich der Hethiter. I. Vegetationskulte und Pflanzenmagie, Hamburg 1977

- Betrachtungen zum ursprünglichen Schauplatz der Mythen vom Gott Kumarbi, SMEA 22 (1980) 97-105

- Hethitische Berggötter und hurritische Steindämonen. Riten, Kulte und Mythen, Mainz 1982

- Die Serien itkahi und itkalzi des AZU-Priesters, Rituale für Tašmisarri und Tatuhepa sowie weitere Texte mit Bezug auf Tašmišarri (ChS I/1), Roma 1984

- / Wilhelm, G., Hurritische und luwische Riten aus Kizzuwatna (AOATS 3), Kevelaer / Neukirchen-Vluyn 1974

Hallo, W. / Simpson, W.K, The Ancient Near East, New York 1971

Hawkins, J.D., Art. Hamath, RIA 4, 67-70

- Art. Hatti, RIA 4, 152-159

- Art. Karkamis, RIA 6, 427-446

- Art. Maras, RIA 7, 352f

- The Negatives in Hieroglyphic Luwian, AnSt 25 (1975) 119-156

- Assyrians and Hittites, Iraq 36 (1974) 67-83

- The Neo-Hittite States in Syria and Anatolia, The Cambridge Ancient History, 2nd Ed., Vol. III, Part 1, Cambridge 1982, 372-441

- Kuzi-TeSub and the "Great Kings" of Karkamiš, AnSt 38 (1988) 99-108

- /Morpurgo Davies, A., The Late Hieroglyhic Luwian Corpus: Some New Lexical Recognitions, Heth 8 (1987) 267-295

Hillers, D.R., Treaty-Curses and the Old Testament Prophets (BibOr 16), Rome 1964

Hoffner, Jr., HA., Hittite mythological texts: A Survey, in: Unity and Diversity, ed. by $H$. Goedicke and J.J.M. Roberts, Baltimore / London 1975, 136-145

- Hittite Myths (Society of Biblical Literature, Writings from the Ancient World 2), Atlanta/GA 1990

Janowski, B., Sühne als Heilsgeschehen. Studien zur Sühnetheologie der Priesterschrift und zur Wurzel KPR im Alten Orient und im Alten Testament (WMANT 55), Neukirchen-Vluyn 1982 
Jeremias, J., Kultprophetie und Gerichtsverkundigung in der spaten Konigszeit Israels (WMANT 35), Neukirchen-Vluyn 1970

Kellermann, G., The Telepinu Myth Reconsidered, in: KaniłXuwar, FS H.G. Guterbock, ed. by $H$. Hoffner and G.M. Beckman (AS 23), Chicago 1986, 115-123

Koenen, $K$, Ethik und Eschatologie im Tritojesajabuch. Eine literarkritische und redaktionsgeschichtliche Studie (WMANT 62), Neukirchen-Vluyn 1990

Kowal, B., Untersuchungen zum Text KTU 1.42 (= CTA 166), ArOr 51 (1983) 129-138

Krebernik, M., Rezension zu Lemaire-Durand, ZA 74 (1984) 156-160

Kilhne, $C$., Hethitische Texte, in: $W$. Beyerlin (Hg.), Religionsgeschichtliches Textbuch zum Alten Testament (GAT 1), Gôttingen ${ }^{2} 1985,169-204$

Levine, L.D., Two Neo-Assyrian Stelae from Iran, The Royal Ontario Museum 1972

Laroche, E., Les hieroglyphes hittite, Paris 1960

Lehmann, G.A., Die ŠIKALĀJO - ein neues Zeugnis zu den "Seevölker"-Heerfahrten im spatten 13.Jh.v.Chr. (RS 34.129), UF 11 (1979) 481-494

Lemaire, A., Mari, la Bible et le monde nord-ouest sémitique, M.A.R.I. 4 (1985) 549-558

- / Durand, J.M., Les Inscriptions araméennes de Sfiré et l'Assyrie de Shamshi-ilu, Genève-Paris 1984

Lipinski, E., Nordsemitische Texte, in: W. Beyerlin, Religionsgeschichtliches Textbuch zum Alten Testament, Gottingen 1975, 245-284

- Studies in Aramaic Inscriptions and Onomasties I., Orientalia Lovaniensia Analecta 1, Leuven 1975, 24-57

Loretz, O. $\rightarrow$ Dietrich, $M$.

Marguerom, J.Cl., Aux marches de l'empire hittite: une campagne de fouille à tell Faq'ous (Syrie), citadelle du pays d'Astata, in: La Syrie, 47ff

- (ed.), Le Moyen Euphrate. Zone de contacts et d'échanges, Strasbourg 1979

Mayer, W., Nuzi-Studien I. Die Archive des Palastes und die Prosopographie der Berufe (AOAT 205/1), Kevelaer / Neukirchen-Vluyn 1978

- $\rightarrow$ Dietrich, $M$.

McCarthy, D., Treaty and Covenant (AnBib 21a), Rome 1978

Menzel, B., Assyrische Tempel, Bd.1-2 (Studia Pohl Ser. Maj. 10), Rome 1981

Millard, A.R., Assyrians and Arameans, Iraq 45 (1983) 101-108 Abb. 1

- The Etymology of Eden, VT 34 (1984) 103-106

- $\rightarrow$ Abou-Assaf, $A$.

Naveh, J., The Date of the Tell Fekherye Inscription, Shnaton V-VI (1982-3), 131-141 (Hebr.) Nikiprowetzky, $V . \rightarrow$ Garelli, $P$.

Nissen, H.-J. / Renger, J., Mesopotamien und seine Nachbarn (Berliner Beiträge zum Vorderen Orient), 2 Teile, Berlin 1982

Noth, M., Der historische Hintergrund der Inschriften von Sefire, ZDPV 77 (1961) 118-172

Oeming, M., "Ich habe einen Greis gegessen". Kannibalismus und Autophagie als Topos der Kriegsnotschilderung in der Kilamuwa-Inschrift, Zeile 5-8, im Alten Orient und im Alten Testament, BN 47 (1989) 90-106

Otten, $H$., Die Überlieferungen des Telepinu-Mythus (MVAeG 46/1), Leipzig 1942

- Ein kanaanáitischer Mythus aus BogazkOy, MIO 1 (1953) 125-150 
Parayre, D., Carchemish entre Anatolie et Syrie a travers l'image du disque solaire aile (ca. 1800 717 avant J.C.), Heth 8 (1987) 319-360

Pardee, D. / Biggs, R.D., Review zu Abou-Assaf / Bordreuil / Millard, La statue, JNES 43 (1984) 253-257

Parpola, S., Neo Assyrian Treaties from the Royal Archives of Nineveh, JCS 39 (1987) 161-189

- I Watanabe, $K$ (Hg.), State Archives of Assyria, Vol. II. Neo-Assyrian Treaties and Loyalty Oaths (SAA II), Helsinki 1988

Pecchioli Daddi, F. / Polvani, A.M., La mitologia ittita, Brescia 1990

Podella, Th, Șom-Fasten. Kollektive Trauer um den verborgenen Gott im Alten Testament (AOAT 224), Kevelaer / Neukirchen-Vluyn 1989

Polvani, A.M. $\rightarrow$ Pecchioli Daddi, F.

Puech, E., Les inscriptions araménnes I et III de Sfire: Nouvelles lectures, RB 89 (1982) 576-587

Reinhold, G.G.G., Die Beziehungen Altisraels zu den aramäischen Staaten in der israelitischjudaischen Konigszeit (EHS.T 368), Frankfurt a.M. / Bern / New York / Paris 1989

Röllig, W., Art. Gurgum, RLA 4, 703f

- $\rightarrow$ Donner, $H$.

Rössler, O., Aramaische Staatsverträge, in: TUAT I/2, Gütersloh 1983, 178-189

Ronzevalle, S., Fragments d'inscriptions araméennes des environs d'Alep, MUSJ 15 (1930/31), 237-260 pl. xxxix-xlv

Rosenkranz, B., Kultisches Trinken und Essen bei den Hethitern, in: FS Heinrich Otten, hg. v. $E$. Neu und Chr. Ruister, Wiesbaden 1973, 283-289

Rost, P., Die Keilschrifttexte Tiglathpilesers III, Leipzig 1893

Sader, $H$., Les états araméens de Syrie depuis leur fondation jusqu'à leur transformation en provinces assyriennes, Diss. Tubingen 1984

Salvini, M., Note sulle "sentenze" hurriche nei rituali ittiti di KBo XXI e XXII, OrAnt 14 (1975) 227-241

- /Wegner, I., Die hethitisch-hurritischen Rituale des LÚAZU-Priesters, SMEA 22 (1980) 87-95

- / Wegner, I., Die Rituale des AZU-Priesters, Teil I: Die Texte (ChS I/2), Roma 1986

Saracino, F., A State of Siege: Mi 5,4-5 and an Ugaritic Prayer, ZAW 95 (1983) 263-269

Schottroff, $W$., Der altisraelitische Fluchspruch (WMANT 30), Neukirchen-Vluyn 1969

Schuler, E. von, Art. Notzeit, in: WdM 1, 188-189

- Art. Verschwundene Gottheiten, in: WdM 1, 207-208

Schwartz, G.M., The Origins of the Aramaeans in Syria and Northern Mesopotamia: Research Problems and Potential Strategies, in: To the Euphrates and beyond. Archaeological Studies in Honour of M.N. van Loon, ed. by O.R.C. Haex e.a., Rotterdam 1989, 275-291

Shaffer, A. $\rightarrow$ Greenfield, J.C.

Simpson, $W . K \rightarrow$ Hallo, $W$.

Singer, I., Dating the End of the Hittite Empire, Heth 8 (1987) 413-421

Soden, $W$. von, Das nordsyrische KTK/KISKI und der Turtan Šamsi-Ilu, SEL 2 (1985) 133-141

Starke, F., Die keilschrift-luwischen Texte in Umschrift (StBoT 30), Wiesbaden 1985

Streck, M., Assurbanipal und die letzten assyrischen Könige bis zum Untergange Niniveh's. II. Teil: Texte (VAB 7/2), Leipzig 1916

Sürenhagen, D., Ein Königssiegel aus Kargamis, MDOG 118 (1986) 183-190

La Syrie au bronze récent. Receuil publié à l'occasion du cinquantenaire de la découverte d'Ougarit - Ras Shamra (Extraits de la XXVII ${ }^{e}$ Rencontre Assyriologique Internationale, Paris, Juillet 1980), Paris 1982 
Tadmor, H., The Aramaization of Assyria, Aspects of Western Impact, in: Nissen / Renger (Hg.), 449-470

Tsukimoto, A., Eine neue Urkunde des Tili-Šarruma, Sohn des Königs von Karkamiš, ASJ 6 (1984) $65-74$

Watanabe, $K$, Die literarische Überlieferung eines babylonisch-assyrischen Fluchthemas mit Anrufung des Mondgottes Sîn, ASJ 6 (1984) 99-119

- Die adê-Vereidigung anlässlich der Thronfolgeregelung Asarhaddons (BagM Bh. 3), Berlin 1987

Watson, W.G.E., Rez. zu Watanabe, Vereidigung, Aula Orientalis 7 (1989) 153-154

Wegner, I., Gestalt und Kult der Ištar-Šawuska (AOAT 36), Kevelaer / Neukirchen-Vluyn 1981

- $\rightarrow$ Salvini, $M$.

Weidner, E., Der Staatsvertrag Ał̌urniraris VI von Assyrien mit Mati'ilu von Bît-Agusi, AfO 8 (1932-33) 17-34

Weinfeld, M., Deuteronomy and the Deuteronomic School, Oxford 1972

Weippert, M., Menahem von Israel und seine Zeitgenossen in einer Steleninschrift des assyrischen Konigs Tiglathpileser III. aus dem Iran, ZDPV 89 (1973) 26-53

- Assyrische Prophetien der Zeit Asarhaddons und Assurbanipals, in: Assyrian Royal Inscriptions: New Horizons in Literary, Ideological, and Historical Analysis. Papers of a Symposium Held in Cetona (Siena) June 26-28, 1980, ed. by F.M. Fales (Orientis Antiqui Collectio XVII), Roma 1981, 71-115

Wilhelm, G., Grundzuge der Geschichte und Kultur der Hurriter, Darmstadt 1982

- Der hurritische Ablativ-Instrumentalis /ne/, ZA 73 (1983) 96-113

- $\rightarrow$ Haas, $V$.

Winter, I., Art as Evidence for Interaction: Relations Between the Assyrian Empire and North Syria, in: Nissen / Renger (Hg.), 355-382

Wolff, H.W., Joel und Amos (BK XIV/2), Neukirchen-Vluyn ${ }^{2} 1975$

- Micha (BK XIV/4), Neukirchen-Vluyn 1982 
Traces of Hittite Cult in Shiloh, Bethel and in Jerusalem

B. Mazar has argued for years that the Hivites, the Hittites and the Jebusites began to settle in the hill country of Eretz Israel following the massive migration from Syria and Anatolia after the collapse of the Hittite empire, at the end of the thirteen century BCE. ${ }^{1}$ According to Jos $11: 3 b$ and Jud 3:3 the Hivites dwelled in the area of the Hermon and the Lebanon and the Beqa' as far as Lebo-Hamath (cf. also 2 Sam 24:7). Mazar suggested that from the north the Hivites spread to Shechem (Gen 34:2) and to Gibeon (Jos 9:7), while the Hittites settled mainly in Hebron (Gen 23) and the Jebusites in Jerusalem. The city of Bethel was also inhabited by Hittites as may be learned from its previous name Luz which, according to Mazar, is indentical with the name Lawazantiya or Luhuzantiya situated near Kizzuwatna in Anatolia. ${ }^{2}$ The man who fled from Bethel following the assault of the house Joseph (Judg 1:22-26) indeed settled in 'the land of Hittites' in the city called Luz. As I have tried to show elsewhere, the region of Kizzuwatna was a sacred area that was freed from political subjugation and was ruled by priests. ${ }^{3}$ Indeed a lot of cultic traditions originated in this sacred center which was comprised of Lawazantiya, Kummani and Kizzuwatna were preserved in Hittite-Hurrian ritual texts ${ }^{4}$ and from there they passed to Ugarit and Israel. It is not just by incident that Bethel appears in the Israelite priestly literature as an important holy place. According to the priestly passage in Gen 35:9-15 God reveals himself to Jacob and gives him the new name of Israel in Bethel and not in Penuel of Transjordan as the other source in Gen 32:25-33 has it. By the same token we find that Pinchas, the son of Elazar the priest, serves before the ark of the covenant at Bethel (Judg 20:28). The Israelites settled in the area where the Hittites, Hivites and Jebusites lived before and therefore it is no wonder that they adopted religious customs and ceremonies from their predecessors. This is reflected in Ezekiel's words about Jerusalem: 'Your father the Amorite and your mother the Hittite' $(16: 3,45)$. A bulk of laws and customs known from the Hittites are reflected in the Biblical laws and especially in the priestly code. ${ }^{5}$ Thus, for example, the quantity of festival offerings in the Bible equal the quantity of the offerings in the Hittite festival calendars:

\footnotetext{
Cf. his most recent article, Early Israelite Settlement, 35-48.

Cf. Wegner, La(hu)wazantija, 433f. The old form was Luhuzantiya.

Justice and Righteousness, 61, 138-139.

4 For the complete collection of Kizzuwatna rituals cf. Laroche, Textes Hittites, 471-500. See also Haas / Wilhelm, Hurritsche Riten.
}

5 Weinfeld, Social and Cultic Institiutions, 95-125. 
'one bull, seven lambs ... one goat ... meal offerings and libation' ${ }^{6}$ which is to be compared with the festival calendar in Num 29:2-6, 8-11, 13-16 etc: 'one bull, seven lambs ... one goat, their meal, offerings and libations'.

Great similarities are found in both cultures in respect ot the purification of a childbearing woman: there is a distinction between the birth of a male and the birth of female concerning the duration of the blood purification period. The offerings at the end of purification period are identical in both cultures: a lamb and a bird (Lev 12:6). ${ }^{7}$

The ceremonies of purification in the Hittite and Israelite milieu are very similar. The similarities are especially striking in connection with the purification of a house, in both cases two birds with cedar and crimson are taken for the ceremony. ${ }^{8}$ The scape-goat ritual in Lev 16 is very close to the substitution ritual among the Hittites. As in Israel (Lev 16:21) so in Heth hands are laid upon the animal (see below) before it is sent out to the plain, and the sins and the evil of the Israelites are carried away into the desert. It is true, in contrast to the Hittite rite, the scapegoat in ancient Israel is not an offering of appeasement nor is it a substitute to suffer Azazel's anger. ${ }^{9}$ Sending the goat to the wilderness is only to remove the impurity from the sanctuary and the children of Israel. However, one must admit that the basic elements of the ceremony and especially the figure of Azazel are of pre-Israelite origin, i.e. taken from local cults. ${ }^{10}$

Furthermore cultic customs concerning the scapegoat not mentioned in the Bible but attested in later sources of the second Temple period, can be traced back to Hittite ritual. Thus we read in Mishnah Yoma 4:2, 6:6 that a crimson colored strap was tied to the animals horns, a practice attested in the Hittite cult of the scapegoat. ${ }^{11}$ Similary we hear in Mishnah Yoma 6:4 that people used to pull the hair of the passing scapegoat and said 'take (sins) and go' (tll $\left.w s^{\prime}\right)$. This is actually mentioned in a hittite ritual of purification: ${ }^{12}$ 'as the goat goes by you and you pull off of it some hair ... in the same way pull off of this offerer's evil, impurity, sin divine anger ... and short life. ${ }^{13}$ By the same token the spitting on the scape mentioned in the epistle of Barnabas: "and do you all

6 Dinçol / Darga, Feste, 100: 4-10. See also recently publishes texts from Emar: Arnaud, Emar VI,3, 350-391 passim.

7 Cf. my article, Social and Cultic Institutions, 100-101.

8 Ibid, 101.

9 See Wright, Disposal, 49.

10 Cf. the article of Janowski / Wilhelm in this volume.

11 Cf. Gurney, Aspects, 47f.

12 Otten, Reinigungsritual, 70.

13 See Wright, Disposal, 35. 
spite on it and goad it"14 is also attested in the Hittite purification rituals: "the offerer spits out (the impurities) the curses, false oath and calumnies"15.

As in Israel so among the Hittites a distinction is made, as shown by Milgrom, ${ }^{16}$ between the priests who officiate inside the sanctuary and those who fulfill the minor functions - like watching - in the periphery of the sanctuary (= Levites).

Some other affinities to the Hittite tradition may be indicated:

1. The slaughtering of sacrificial animals in the Hittite documents and in ancient Israel is very similar. As in the Hittite ritual so in the Israelite one the slaughtering of the animal is done in the same manner: the cutting of the breathing tube (npš in Biblical Hebrew: auli- in Hittite) and the gullet as has been recently shown by Cord Kühne ${ }^{17}$. Most instructive is the fact that in both cultures the slaughterer gives away the blood to the priest for libation (cf. e.g. $2 \mathrm{Chr}$ 29:22). Special vessels were used for the collection of the blood and as in the Hittite case so in Israelite practice generally it is not the owner of the animal who slaughters it but the priest or the Levite (cf. Ezek 44:11; $2 \mathrm{Chr}$ 29:22; 30:15,17; 35:11) or a professional slaughterer (compare Targum Ps Jon. to Lev 1:5).

2. The gesture of Hand placement (semikha) in the Israelite tradition is congruent with the same gesture in the Hittite one. In both traditions the twohanded placement serves to invest other persons with authority (cf. Num 8:10; 27:18-23; Deut. 34:9), while the one-handed placement serves to attribute the offering material to the one who performes hand placement. ${ }^{18}$

3. The meticulous performance of the rites so characteristic of the priestly code in ancient Israel is clearly expressed in the confessions and prayers of the hittite kings. Thus, for example, we read in Muwatalli's prayer to the storm-god of Kummanni (KBo XI, 1):

Whatever I ... now find from hieroglyphic records, this I shall carry out and [what] I have [not] brought into correspondence with the ceremonial rites (saklai-) of the gods, you, 0 storm-god, my Lord, know it. And whenever I shall examine (punusk) a venerable old man, as they remember a (certain) rite and tell it, I shall also carry it out ... I shall follow the (covenantal) bond (ishiul) of the gods that I am rediscovering, and it shall be henceforth carried on. 19

14 Cf. Apostolic Fathers I, Loeb Classical Library Barnabas vii, 8, 366-367; see the dicussion of Alon, Studies I, 302-305.

15 Cf. Kammenhuber, Ketten, 78.

16 The Shared Custody, 86.

17 Kühne, Hethitische auli, 86.

18 Wright, Gesture, 433-446.

19 Houwink ten Cate, Muwatallis' Prayer, 106-107 lines 21-27. 
The written instructions of the gods which the king rediscovered are associated here with the ishiul which like Hebrew bryt represents the covenantal law imposed on the people and is characteristic of the Priestly Code where the law is called ברית (compare Lev 24:8 (bryt 'wlm) with v.9 (hq "wlm). ${ }^{20}$ Very instructive from the point of view of comparison with Hebrew traditions is the king's declaration that he will carry out whatever has been referred to him through the recollection of a venerable old man. This corresponds to the tradition preserved in Mishnah Eduyot concerning the collection of testimonies given by sages on legal matters not attested in the conventional written lore.

4. Very instructive for the affinities between the Hittite cultic customs and the Jerusalemite ones is the passage in 2 Sam 5:6-8 concerning the blind and the lame. To our opinion we have here an etiology for the non-admission of the crippled into the Temple (or the city, see below), a custom not attested in the genuine priestly rules of ancient Israel (i.e. from before the Davidic period).

Let us first clarify the text. In v.6 we read: 'David was told: "you will not enter here ( $=$ the royal chapel or Jerusalem or the city) unless you remove the blind and the lamen (read hasirka i.e. you remove, instead of hesirka i.e. they will remove you). In v.8 we read: 'and the soul of David hated (Qumran: $s n$ ' $h$ ) the blind and the lame that is why they say: "no blind or lame shall come into the house"' (of the Lord, cf. LXX and Targum). This custom is reflected in the Temple scroll from Qumran where the blind is not permitted to enter the holy city (45:12-14). In the other Qumran writings we find that the crippled shall not be admitted into the holy community ('dt qdS), (1QSa II:4-11) neither will he participate in the holy war (1QM VII:4-5). ${ }^{21}$

Now this custom is indeed attested in Hittite cultic texts. In KUB V 7:24ff which contains oracles given when investigating the anger of the gods we read: "we asked the temple officials and they said: "two mutilated people (kurjuriantes) came into the temple". Bird omina, unfavourable. We asked again and they said: "two invalids (iškalantes) walked about the temple". Bird omina unfavorable. Since crippled people walked about the temple the Hittite old woman will perform a rite for the god'. 2

It seems then that David adopted the Hittite custom and introduced it into Israel as an innovation, since in the Israelite priestly laws the mutilated were

20 Weinfeld, Origin, 64ff.

21 Schiffinan, Purity, 373-389.

22 Goetze KUB V,7; $\mathrm{ANET}^{2}$, 497. I am thankful to Dr. G. Kellerman for the clarification of the Hittite terms for mutilated and invalids. 
not allowed to officiate in the temple (Lev. 21:16-23) but were admitted to enter the temple. ${ }^{23}$

5. Another affinity to Hittite tradition is the resort of King Saul to three types of mantic procedure: 'dreams, casting the lot (= oracle) and prophets' (1 Sam 28:6). These are attested in the prayer of Mursili: 'let me see in a dream, an oracle or a declaration of a prophet' (ANET $\left.{ }^{2}, 396\right)$.

6. Another affinity to the Hittite tradition is the triple punishment: famine, plague, and war mentioned in 2 Sam 24:13 attested also in the prayer of Mursili in connection with the violation of the oath of God (ANET $\left.{ }^{2}, 396\right)$.

7. Another phenomenon common to the Hittites and ancient Israel is the concept of collective retribution, both vertical: punishment through coming generations, and horizontal: the whole family or society suffers because of the sin of an individual. The first type of retribution is expressed in the old dictum: 'I am ... an impassioned God, visiting the iniquities of the fathers upon the children, upon the third and fourth generation' (Exod 20:5; Deut 5:9; compare Exod 34:7; Num 14:18). This notion persisted for hundreds of years because we find it even in the mouth of the survivors of the catastrophy after the fall of Jerusalem. According to the book of Lamentation after the destruction of Jerusalem the people of Judah complained saying: 'our father sinned and are no more and we bear the burden of their guilt' (5:7).

The horizontal concept of collective retribution in ancient Israel is clearly expressed in the Korah's story in Num 16:32-33: 'and the earth opened its mouth and swallowed them up with their households and all Korah's people and all their possessions'.

Similarly we read in the Achan story in Jos 7:24-25: 'and Joshua took Achan ... and his sons and daughters ... his oxen and his asses and his sheep and all ... Israel stoned them'.

The concept of vertical and horizontal collective punishment is clearly expressed in the Hittite literature of the fourteenth and thirteenth cent. BCE. Thus we read in the Hittite instructions for priests and temple officials:

\footnotetext{
'The temper of the god's is strong: it does not quickly take hold but when it takes hold it will not let go'24 (KUB XIII:4, II:27), which reminds us Exod 34:6-7: 'YHWH slow to anger ('rk' 'pym) ... but does not remit punisment, visits the iniquity of the fathers ... upon the third and fourth generation'.
}

The notion of collective horizontal punishment occurs in the same Hittite texts in a most explicit manner and very similar to the Achan story:

\footnotetext{
23 It seems that the Chronicler (1 Chr 11:4-9) also was not content with the rigid attitude towards invalids, and therefore omitted altogether the episode of 'the lame and the blind' from his tradition of David's conquest of Jerusalem.
}

24 Hoffner, Hittites, 220. 
'If anyone arouses the anger of a god, does the god take revenge on him alone? Does he not take revenge on his wife, his children, his kin ... his slaves ... his cattle and sheep together with his crop and will utterly destroy him' (ANET $\left.{ }^{2}, 208\right)$.

The idea of collective vertical punishment appears in the plague prayer of Mursili, where the Hittite king complains that he suffers because of his father's sins:

'My father sinned and transgressed against the word of the Hattian God ... but I have not sinned in any respect. It is only too true, however, that the father's sin falls upon the son, so my father's sin has fallen upon me' $\left(\mathrm{ANET}^{2}, 395\right) .^{25}$

The idea of familial vertical punishment pervaded ancient Greek literature. Thus we find in the fragments of Solon's poems: 'because of them (the sinful parents) the children and those who come after them will bear punishment' (13,31, compare Theognis, 731-742). Similarly we read in Aeschylus: 'Swift is its retribution (of the transgression), yet unto the third generation it abides' (Seven against Thebes, 743-744) and in the fragments of Euripides' tragedies: 'the sins of the parents on the children the gods do visit'.

Cicero ascribes to Stoic philosophy the following:

\begin{abstract}
'the divine power is such that even if a person has escaped punishment by dying, the punishment is turned on his children and grandchildren and their descendants' to which he reacts:

what a remarkable instance of divine justice! Would any state tolerate a lawgiver who should enact that a son or grandson was to be sentenced for the transgressions of a father or grandfather?' (de Natura Deorum III, 38).
\end{abstract}

The notion of communal punishment in ancient Israel was so common that in the days before the destruction of Jerusalem a proverb was circulation in Jerusalem, 'Fathers ate unripe grapes and their sons' teeth are set on edge' (Jer 31:28; Ezek 18:2), and the prophets Jeremiah and Ezekiel fought against this view. Jeremiah foresees a time when this principle will be abandoned: 'everyone shall die for his sins; he who eats unripe grapes, his teeth shall be set on edge' (31:29). Similary Ezekiel states that this proverb shall not be used anymore in Israel: 'it is the person who sins that shall die' (18:2-3). By the same token the author of Deuteronomy who refers to the principle of solidarity in 7:9-10 reinterprets the principle of visiting the father's sins upon his descendants by stating: "he repays them that hate him to their face; he is never late with him who hates him; he requites him to his face" (for the phrase "to his face', meaning 'personally', cf. Job 21:19: 'Is God reserving his punisment for his sons? Let him pay back to him that he may feel it?'). 
This individualistic principle fits well the deuteronomic law in Deuteronomy 24:16, 'Fathers shall not be put to death for children, nor children be put to death for fathers; a person shall be put to death only for his own crime,' which nicely answers Cicero's questioning of the divine justice of familial solidarity (see above) 'would any state tolerate a son being sentenced for the transgressions of his father?'

The deuteronomic author (Deut 7:9-10) in fact revises the old principle of familial solidarity by altogether denying communal punishment. He quotes the old hymnic credo of Exodus 34:6-7 and Numbers 14:18 and retains the beneficial part of it, 'keeping kindness to the thousandth generation' but omits altogether the clause about visiting the father's sins upon their descendants and argues just the contrary: God repays the sinner personally (see above).

8) As I have shown elsewhere ${ }^{26}$ the covenant with Abraham and David are to be seen as unconditioned royal grants like the ones in the ancient Near East, where the suzerain bestows gifts on his servants who distinguished themselves by serving their masters loyally. Most instructive in this regard are the Hittite royal grants: The Hittite king says to his vassal: 'After you, your son and grandson will possess it, nobody will take it away from them; if one of your descendants sins, the king will prosecute him, ... but nobody will take away either his house or his land in order to give it to a descendant of somebody else' (KBo IV, 10 obv. 8-14). Compare 2 Sam 7:8-16 in connection with the promise of dynasty to David: 'I will establish his royal throne forever ... when he does wrong I will chastise him ... but I will never withdraw my favor from him'. ${ }^{27}$

A Hittite grant typologically similar to the grant of dynasty to David is to be found in the decree of Hattusili concerning Mittannamuwa, his chief scribe:

\begin{abstract}
Mittannamuwa was a man of grace (kannišanza UKU-as') to my father ... and my brother Muwatalli was kindly disposed to him ... I committed myself for (šer memiiahhat) the sons of Mittannamuwa ... and you will keep (pahhasadumat) ... and so shall the sons of my Sun and the grandsons of my Sun keep. And as my Sun, Hattusili, and Puduhepa, the great queen, were kindly disposed (kanesta) towards the sons of Mittannumuwa so shall be my sons and grandsons ... And they shall not abandon the grace (aššlan anda la daliianzi) of my son. The grace and their positions shall not be removed (ueh) ${ }^{28}$
\end{abstract}

Like Hebrew țwhh/hsd, Akkadian tāabtu/damiqtu and Aramaic țbt', Hittite ašsul and kannešuwar connote kindness and covenantal relationship. As in the case of David, so in the Hittite grant the promise is to be 'kept' (šmr) with the future generations of the devoted servant, i.e. 'the man of grace' (cf. in Ps

Covenant, 184-203.

27 Laroche, Ulmi-Teshub, compare Cavaignac, Daddassa-Dattasa, 65-76. For the connection with the Davidic covenant see de Vaux, 'Le roi d'Israel, 119-133.

Goetze, Hattusilis, KUB I, 1, 44ff (= MVAeG 1924, 3). 
89:19). The most striking parallel to the promise of David is the last sentence: 'The grace and their positons shall not be removed'. (anda) daliia equals Akkadian ezébu $=$ Hebrew $z b$ which is often employed in connection with hssd/'mt or hssd, while ueh - 'turn away' (remove) - equals Hebrew swr which appears in 2 Sam 7 in a phrase similar to that of Hittite grant: whsdy 1' yswr mmnw 'and my grace shall not turn away from him' (vs. 15).

9) As I have tried to show in my article in Vetus Testamentum 1973, 63f the apodictic style of the Israelite law is rooted in the so called "instructions" of the Hittite legal sphere. These instructions constitute legal ordinances promulgated by the Hittite King and imposed by an oath on his subjects. The instructions are named $i$ shiul which equals Hebrew bryt (= bond) and Akkadian riksu. Like the Hittite instructions Biblical law contains commandments formulated in the second person imposed by a bond and oath. Furthermore, some of the apodictic laws in the Bible are even identical in contents with Hittite instructions. Thus, for example, in a Hittite passage instructing the border commandments to judge honestly we read:

If anyone brings a suit ... the commander of the border guards shall judge it properly ... he should not decide in favor of a superior, a brother, his wife or his friend. Nobody should take bribes. He must not make a just case unjust, he must not make an unjust case just ... Do whatever is right. Whenever you arrive at a town call all the people of the town together ... judge and set them right. A foreigner who settles in the land provide him fully with seeds, cattle and sheep (E. von Schuler, Hethit. Dienstanweisungen, 47).

\title{
Compare Exod 23:1-9:
}

\begin{abstract}
"You shall neither side with the mighty to do wrong ... nor shall you favor a superior man in his cause. You shall not wrest the judgment of your poor in his cause. Keep far from a false case, do not execute the innocent and the righteous for I will not justify the wrongdoer (or with the LXX: you shall not justify the wrongdoer). Do not take bribes ... you shall not opress the stranger".
\end{abstract}

The similarity between the passages is expressed by the address to the officers in their capacity as judges to judge rightly, to avoid impartiality, not to take bribes and to support the foreigner.

It seems that both royal chapels: Jerusalem and Bethel inherited legal and ritual customs from the Hittites, the Hivites and the Jebusites and these are reflected in the Israelite priestly literature. In fact it is not only Bethel and Jerusalem which were influenced by Hittite-Hurrian customs for, as we shall see, Shiloh the center of the priesthood of Eli was also influenced by them.

In the present study we want to adduce evidence about some ceremonial customs common to the Hittite-Hurrian and Israelite traditions. These are related to the end of the period of Judges and the beginning of the monarchic period. 
Let us start our discussion with a description of the daily service in Hittite sanctuary of the city Nerik compared with the service at the Israelite sanctuary of Shiloh.

\section{The Priest and the Seer}

In the story about Shiloh and 1 Sam 3 we find that Samuel who is later called a seer (ro'eh, 1 Sam 9:9) serves the Lord under Eli, the priest, in Shiloh. Samuel was sleeping in the Temple of the Lord 'where the ark of God was'. 'When the lamp of God has not yet gone out' (1 Sam 3:3) while 'Eli was asleep in his usual place' (ibid v.2). We do not know in which place in the temple Samuel was sleeping. It is even possible that the phrase 'in the temple of the Lord where the ark of God was' does not refer to Samuel but to 'the lamp of God'. 29 We also do not know where was 'the place' of Eli. At any rate it seems that they slept close to each other since Samuel went three times during the night to Eli in connection with the divine call which reached him. In the continuation we are told that in the morning 'Samuel opened the gates of the house of the $\operatorname{Lord}^{30}$ (v.15) and it is not clear whether he opened them from inside or from outside.

Now, it is very interesting that a similar procedure is found in a Hittite text concering the temple of Nerik which may illuminate our description in the book of Samuel. There we read: ${ }^{31}$

This is a instruction (ishiul $=$ 'covenant') ${ }^{32}$...

The water of the daily offering bring constantly, the daily bread which the king offers to God, you, the priests, will arrange it like this: when the priests and the seer (LÚ hal = bära) come before the God they will remove the (old) bread ... and will arrange the (new) bread. When it becomes dark they will place ${ }^{33}$ the lamp and close the temple. The priest and the seer will sleep before the gate.

We find then here like in 1 Sam 3 a priest and a seer sleeping while the temple is closed and the lamp is burning inside, but here it is said explicitly that

29 See e.g. TB. Qiddushin 78b and Targ. Jon ad loc. LXX (B) omits YHWH after hykl and it seems that the Qumran version $\left(4 Q \mathrm{Sam}^{\mathrm{a}}\right)$ skips the words: 'YHWH 'šr šm 'rwn 'lwhym', cf. McCarter, I Samuel, ad loc., 95. This for apologetical reasons: to avoid the sleeping of Samuel in the Hechal (the nave of the Temple).

30 On the opening of the Temple gates in the morning, see Mishnah Tamid 1:1 and Sukkah 5:5.

31 KUB XXXI, 113; Haas, Kult, 131-133.

32 Cf. note 20.

33 Verbally to 'place', to 'put', Hittite dai is to be rendered here to 'put' (Akkadian: šakānu). 
both sleep before the gate whereas in 1 Sam 3 it is not clear where exactly they sleep. In the light of the analogy we might suggest that Eli and Samuel also sleep in front of the gate. In the Hittite text we find next to the instruction about the lamp in the temple the instruction about the divine bread. By the same token the Israelite priestly legislator juxtaposes the instruction about the lamp in the Tabernacle with the instruction about the shew bread (Lev. 24:1-9; cf. Exod 25:23-40; 40:22-25). In Lev 24:1-9 the lamp comes before the shew bread whereas in Exodus, like in the Hittite source, the shew bread comes before the lamp. The lamp in the Hittite text was kindled every evening and this corresponds to the injunction in Lev 24:3 that the lamp will be burned 'from evening to morning'.

The offering of water which appears at the beginning of the Hittite text illuminate the verses in Exod 25:29; $37: 16$ (comp. Num 4:7) which speak about libatory vessels (mnqyt: $\sqrt{n} n a q \hat{a}=$ to pour; $q$ swt hnsk) placed on the table of the shew bread. These vessels allude to a drink offering which was apparently eliminated in later time; for libation of water in the Israelite cult cf. 1 Sam 7:6 $6^{34}, 2$ Sam 23:16 (wysk 'tm 1YHWH) and mark the controversy between the Pharisees and the Sadduceans concerning the libation of water in the temple during the feast of Tabernacles (Mishnah Sukkah 4:9, TB Sukkah 48b).

The injunction in the Hittite text about the removal of the old bread and the arranging of the new bread every day correspond to the episode about David and Ahimelek, the priest, in 1 Sam 21:7. There we read about the holy bread which was 'removed from before YHWH to be replaced by fresh (hot) bread on the day it was taken away'. The plain meaning of this verse seems to be that the old bread was replaced by fresh bread every day ${ }^{35}$ like in the Hittite instruction and not once a week as found in the command of Lev 24:8. The latter may reflect a later development.

34 LXX adds '(and poured it) upon the earth' (Heb = 'rsh), that is not upon the altar which may reflect a Sadducean attitude towards 'water libation'. MT uses here the verb špk and not $n s k$, the cultic term for libation, which may indicate that it is a symbolical act of purification from sin and not an offering. (See Driver, Notes, 64). For the libation of water in the Assyrian cult, see Elat, Samuel the Judge, 11-12.

35 In the Babylonian cult they used to change the bread four times a day (ANET ${ }^{2}, 343$ ). 


\section{Cultic Processions}

It has been suggested by scholars ${ }^{36}$ that the narrative of the transfer of the ark from Qiryat-Yearim to Jerusalem is a reflection of a periodical cultic procession which was common during the Davidic-Solomonic period. This seems plausible and will be supported by the following Hittite analogy. It should be stressed that acceptance of this supposition does not necessitate the denial of the historical value of the narrative. To our opinion the scribe who depicted the historical event of the transfer of the ark borrowed motifs from the cultic processions as they were known to him from his observations. Some of the features of the procession as described by him, might be anachronistic. But the story on the whole seems to be authentic (cf. Ps 132).

We intend to adduce evidence from Hittite cultic texts for the existence of Hittite ceremonies similar to those described in 2 Sam 6 . These texts refer also to the accounts of the transferring of the ark and the holy vessels as found in the book of Numbers.

In the framework of this discussion I will deal with two Hittite texts published recently:

1) The study by I. Singer on the KI.LAM festival.

2) V. Haas / L. Jacob-Rost, Festritual. For a reverse of the order of the fragments concerning the third and fourth days of the festival, cf. P. Taracha, Festritual.

These two texts describe cultic ceremonies in which the king or the crown prince, priests and the assembly of the people take part. In the center of these ceremonies stands a procession of cultic objects such as the 'divine animals' carried on a cart in the KI.LAM ceremony and the ark with the god which is carried in a carriage in the ceremony of the festival of Telepinu. These ceremonies are accompanied by players and dancers along sacrifices to the gods.

We shall adduce here the details of those ceremonies which may enlighten the narrative about the transfer of the ark in 2 Sam 6 and the transporting of the Tabernacle in Numbers 4 as well as the account in Num 7 about the gifts of the chieftains at the dedication of the Tabernacle in Num 7.

1. Similar to the description in 2 Sam 6 which describes the two men (priests) who lead the ark which is accompanied by playing the harps, lyres, tamborines, etc. we read in the texts depiction the ceremony of the Telepinu festival:

36 About this cf. recently McCarter, II Samuel, 178-184. According to this theory, Pss 24, 132 reflect also a cultic procession, see e.g. Hillers, Ritual Procession, 48-55; Cross, Canaanite Myth, 91-111. 
They put the god (Telepinu) on the cart while one priest stands against the other and holds the god in its place. They play with the tamborine and cymbal before the god ... the contesters (LU.MES.GEŠPU) perform the contest before the god. ${ }^{37}$

As in 2 Sam 6:3 so here too two men take care of the secure move of the holy object (= the statue). If we accept the LXX reading in 6:3: we'ahiw instead of we ahyo ${ }^{38}$ the parallel is even closer: in the Biblical text Uza and his brother (colleague) hold the ark just like the priest and his colleague hold the statue or the ark with the statue (see below) in the Hittite text. Both processions are accompanied by playing musical instruments and dance (see below).

2. In the Hittite procession we find the ark (container $=$ GIŠ tuppi) where they put the statue of Telepinu (No. 14, Rs IV 32) ${ }^{39}$ and similar to the packing of the holy vessels in Num 4 we find in the Hittite text the packing of the holy vessels and their placing on the cart for the procession (no. 13 Rs III, 1'-5'; no. 12 Vs. $\left.8^{\prime}-12^{\prime}\right) .{ }^{40}$ Holy carts passing in the procession are found in the KI.LAM festival. ${ }^{41}$ The wandering of the Israelites in the desert is described in the Book of Numbers against the background of the dismantling of the Tabernacle before the journey and its erection during the encampments. It seems however that the basis for this schematic description is rooted in the recurrent festive processions which took place in ancient Israel as well as among the Hittites. Both the account of 2 Sam 6 and the account of Num 4 are in fact anchored in periodic ceremonies which were transformed into one time events that is bringing the Tabernacle to the promised land (Num 4 and 7) on the one hand and bringing the ark to Jerusalem (2 Sam 6 ) on the other.

3. The KI.LAM festival ${ }^{42}$ opens with the king washing in the bathroom (É. $\mathrm{DU}_{10}$ US.SA $=$ bit rimki) ${ }^{43}$ while a curtain is drawn up in front of him. Then he dresses a white shirt, a raw cloth (TUG warhui). This dressing of a 'raw cloth' reminds us of David being dressed for the ceremony in a 'linen ephod'. (2 Sam 6:14, comp 1 Sam 2:18). Indeed, at sacred ceremonies clothes made of linen and not of fine Egyptian byssus (క̌š/buș) were used in Egypt, Israel ${ }^{44}$ and, as we now see, among the Hittites too. On the day of atonement the high

\footnotetext{
37 Nr. 1, Rs III 18'-27', Nr. 8 Vs III, 11'-26'; Haas / Rost, 43ff, 46-64.

38 LXX read: we'ehaw 'and his brothers'.

39 Cf. Haas / Rost, ibid., 76, 78.

40 Ibid. 60, 62, 68, 70, 71; See discussion, 27.

41 See Singer, KI.LAM Festival, I 59.

42 Ibid. 58.

43 Ibid. 11.

44 See Haran, malbušey kehuna, EM 3 col. 1048.
} 
priest officiated in the holy of the holies dressed in linen $(b d)(\operatorname{Lev} 16: 4)^{45}$ and not as usual in golden garments. In the Rabbinic literature the linen clothes were called 'white clothes' (bgdy $1 b n,{ }^{46}$ Mishna Yoma 3:6 etc) as in the Hittite text quoted above.

The description of the Hittite king washing in the bathroom and dressing in white and 'raw cloth' is congruent with the description of the high priest's service on the day of atonement, as it appears in Mishnah Yoma 3:6:

They draw up a sheet of byssos between him and the people, he undressed, descended and immersed, ascended and dried himself, they brought to him the white clothes, he dressed.

At the end of the ceremony the high priest removes the linen clothes (Lev 16:23, compare Mishnah Yoma 3:6, 4:6) and the same is done by the Hittite king at the end of the ceremony (KBo XXVII 42, 12-23) ${ }^{47}$. One has to keep in mind that in ancient Israel like in the Hittite cult the kings officiated in the

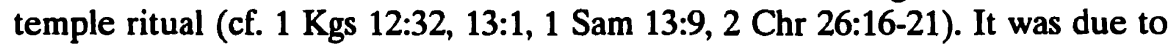
the anti-monarchic ideology that tradition eliminated the king from the temple rituals, putting instead of the king, the priest. ${ }^{48}$

4. In 2 Sam 6:5 we read that David and all Israel were playing before the Lord with all kinds of cypress wood ( $b^{\text {'sy }}$ brwsym), with lyres, harps, timbrels, sistrums and cymbals. In the parallel of $1 \mathrm{Chr} 13: 8$ we find instead of $b$ sy brwšym: $b k 1$ ' $z$ wbšyrym = 'with all might and with songs'. It seems that the reading: $b k 1 ' z$ in Chronicles was influenced by 2 Sam 6:14. In the Septuagint to 2 Sam 6:5: en organois hèrmosmenois en ischyi kai en ödais 'with tuned instruments, with might and with songs', which reflects a double reading " $k 1$ ' $z$ and $k l y$ ' $z$. The LXX to $1 \mathrm{Chr}$ 13:8 renders the MT: en pase dynamei kai en psaltódois 'in all might and with songs/psalms'. It seems that the Chronicler (1 Chr 13:8) as well as the Septuagint to 2 Sam 6:5 try to solve the difficulty of playing with cypress wood, reading $b k I$ ' $z$ wb5yrym, instead of 'sy brwšym but the truth is that we have to accept the reading of the MT and to understand 'sy brwšym as 'clappers of cypress wood juniper' as some understood it. ${ }^{49}$ Indeed such clappers were found in Egyptian paintings that describe 'playing before god'. ${ }^{50}$ Furthermore, the combination of wood with musical instruments

45 The officiating angels in heaven are also dressed with linen, see Ezek. 9:2-3, 11; 10:2; Dan $10: 5 ; 12: 6-7$.

46 About the use of (bgdy)lbn in the Rabbinic literature as against bd in the Bible see Hurvitz, Garment, 140-141.

47 Singer, ibid, 73.

48 Cf. my article (note 5), 122-123.

49 See Soggin, Wachholderholz, 374-377.

50 Cf. Keel, Die Weisheit, 35 no. 103. 
is found in a Hittite text that depicts the 'evocation', the call to the foreign gods to come the Heth (KUB XV, 34).

Let the effect of the cedar and the music of the lyres ...

be an inducement to the gods that they will get them called here. ${ }^{51}$

The situation here is similar to that of 2 Sam 6: the bringing of the gods from a foreign land.

5. The only place in the Bible where we find playing and dancing before the God is 2 Sam 6. The bringing up of the ark of the Lord with joy/festivity (bsmhh , v. 12) is depicted here in a very concrete manner: the kings and the people play music before God (v. 5); they dance and leap before Him (vv. 14, 16) and all this is accompanied by sacrifice and distributing gifts (vv. 18-19).

Such features are encountered in Egyptian iconography, ${ }^{52}$ but a full analogy to 2 Sam 6 is attested in the Hittite texts. Most important is the description of the KI.LAM festival ${ }^{53}$ which contains a procession similar to that found in 2 Sam 6. Here we find the dancers/comedians (LÚ.MEŠ ALAM.KA.X UD) ${ }^{54}$ dance the 'leopard dance', they clap hands and play music. The oxen are harnessed to the carts; the horns and the yokes are mounted in gold. Golden lunulae are affixed to their foreheads. ${ }^{55}$ Ten or more dancers, one of them naked, follow the cart. The 'administrators' of royal storehouses of various towns of the kingdom stand near a heap of produce brought from their respect 'house'. The herald introduces them to the king, ritual offerings are offered before the storm god.

At the end of the text we find instructions for the 'great assembly' (salli ašššar) which takes place in the tent. ${ }^{56}$ At the assembly drinking the gods ${ }^{57}$ is celebrated; presents are distributed to the race runners: silver, bread and garments. ${ }^{58}$

51 Goetze, $\mathrm{ANET}^{2}, 353$.

52 Keel, ibid.

53 Singer, KI.LAM Festival, $56 \mathrm{ff}$.

54 Translated by Singer. comedians, ibid. 95n. 22.

55 Compare Mishnah Bikkurim III, 2-3: 'Before them goes the bull ..., its horns overlaid with gold and a wreath of olive leaves on his head. The flute is played before them until they draw near to Jerusalem'. In light of the fact that such customs are found among the Hittites, there is no warrant for the alleged Greek influence in the ceremony as Lieberman tried to assume (Hellenism, 144). It seems that this was a custom spread in the East and also was practiced in ancient Israel, though it is not reflected in the Bible. Singer, ibid. 98-101. See also my article, 'Social and cultic Institutions', 103-104.

57 Cf. Güterbock, To drink a God, 26.

Singer, ibid. 75 and his discussion, 103-104. 
This ceremony finds its parallel in 2 Sam 6 . Here too people play before the god i.e. before the cart that carries the ark and the king himself participates in the dancing. Similar to the 'naked dancer' in the Hittite ceremony we find David exposing himself and because of this Michal, the daughter of Saul, mocks him (v. 20). Furthermore the Septuagint to 2 Sam 6:20-21 which preserved the authentic version $^{59}$ brings us even closer to the Hittite ceremony. As Orlinsky suggested, ${ }^{60}$ we have to accept the reading of the LXX in v. 20 that reads rqdym instead of ryqum in the Masoretic text (cf. $1 \mathrm{Chr}$. 15:29). Moreover in the following verse the Septuagint preserved several words which were omitted in the Masoretic text because of homoioteleuton (1pny YHWH) 'rqd. brwk $Y H W H\left({ }^{\prime} \xi r b h r\right){ }^{61}$ We should then read: 'Before YHWH I am dancing ... Blessed be YHWH who chose me'. It is then clear that like in the Hittite text in the ceremony of 2 Sam 6 there were dancers only that here David acted unconventionally and involved himself in naked dancing which does not suit a king. Indeed in the Hittite ceremony the king sits on his chair and does not mix himself with the dancers, he only watches them, whereas David participates in dancing and even exposes himself like the naked dancer mentioned in the Hittite ceremony. Michal's behavior should perhaps be explained as a protest against breaking the routine of the ceremony.

The ceremony in 2 Sam 6 concludes with the bringing of the ark in the tent and the offering of sacrifices (v.17). This may correspond to the 'great assembly' that takes place in the tent in the Hittite ceremony. At the end of the ceremony the distribution of presents to the people takes place. Everybody is given: a loaf of bread, an 'ešpar, and a cake (v.19). The word 'ešpar has not been explained until now and in the light of the Hittite parallel where a garment is given to the runners besides silver and bread, 'spr in 2 Sam 6:19 may be also seen as a dress, taking in account the fact that išparu in Akkadian and 'špr in Aramaic means weaver. The difference between the Hittite description and the Israelite one is that in the Hittite description the gifts are distribute to all the people participationg in the ceremony. It is possible that in the original Israelite tradition the gifts were designated to the players (mśhqym) only and that later when the old custom was forgotten the 'players' were identified with 'all Israel' (v.5) and it was understood that the gifts were given to all the people: 'the whole multitude of Israel, man and woman alike (v.19).

6. In Numbers 7 we find a depiction of the dedication ceremony of the Tabernacle where the chieftains (nśy'ym) play a central role. The chieftains bring six carts, every cart harnassed to two oxen and in addition every cheftain brings his

59 Cf. McCarter, II Samuel, $185 \mathrm{ff}$.

60 Orlinsky, haroqdim for hareqim, 25-35.

61 The eye of the scribe skipped from the first YHWH to the second, see McCarter, II Samuel, 185. 
offering : one silver bowl and one silver basin, both filled with choice flour with oil mixed in it; one gold ladel with incense, one bull, one ram and one lamb for burnt offering, one goat for sin offering; two oxen, five rams, five he goats and five lambs for well being offerings (Num 7:13). At the end of the chapter the offerings are summarized : twelve bowls, twelve basins ... sixty rams, sixty lambs, etc. As has been observed by scholars ${ }^{62}$ this account is rooted in the administrative lists of the temple that come to summarize the offerings brought to the temple for dedication ceremonies ${ }^{63}$ and not just to describe the acutal offerings of a day. That Num 7 is to be seen as a periodic celebration may be supported by the KI.LAM text which speaks about a recurring event, and there we find a special account about the 'administrators' of the royal storehouses of various towns of the kingdom bringing produce from their respective houses. ${ }^{64}$ It seems that the 'chieftains of the tribes' by bringing their tribute to the Tabernacle fulfill the same function that the Hittite administrators fulfill in the KI.LAM festival. The chapter about the chieftains in Num 7 was apparently composed in a period other than the United Monarchy, since during the Davidic period the ark was still transported on a cart (2 Sam 6:3) while according to Num 7:9 the ark could be carried only on the shoulders. In its general layout the chapter reflects a cultic ceremony which took place from time to time at the dedication of the altar of the Tabernacle or the sanctuary (cf. Ezek 43:26-27; 2 Chr 7:5). The same applies to the account of the transfer of the ark in 2 Sam 6.

In sum both the accounts in Numbers 4 and 7 and in 2 Sam 6 have a lot of affinities with the Hittite festival procession which apparently influenced the Israelite cult.

One must admit that some of these customs and regulations might have been prevalent not only among the Hittites and the Israelites but also among the Mesopotamians and the Egyptians. However, the fact that so many religious beliefs and cultic pehnomena are attested only among these two peoples which historically had physical contacts (why should Ezekiel invent a Hittite origin for Jerusalem) leads us to the supposition that the Israelite nomads must have adopted cultic customs from their predecessors when they settled on the land. It is also possible that the culture in Syro-Palestine was patterned after HittiteHurrian models even before the thirteenth century, but that it was undoubtedly

Cf. Levine, Tabernacle Texts, 312-313.

63 For the recurring dedication ( $\left.m / w^{\prime} y m\right)$ ceremonies cf. Lev. 8:34: 'everything done today, YHWH commanded to be done (in the future). 'This was understood as a command to repeat the ceremony annually (Targ. Ps. Jon.: 'after the days of dedication'). See the Temple scroll from Qumran 15:14, cf. Yadin, Temple Scoll, I 91, II, 64, See also Ezek 43:26.

64

Singer, ibid. 62-63. 
strengthened by the influx of Hittite elements after the collapse of the Hittite empire.

Bibliography

Alom G., Studies in Jewish History in the Times of the Second Temple and the Talmud, vol. I, Tel-Aviv 1971 (Hebrew)

Amaud, D., Recherches au Pays d'Aštata Emar VI,3: Textes sumériens et accadiens, Paris 1986

Cavaignac, E., Daddassa-Dattasa, RHA 10 (1933), 65-76

Cross, F. M., Canaanite Myth and Hebrew Epic, Cambridge/MA 1973

Dinçol, A. M. / Darga M., Die Feste von Karahna, Anatolica 3 (1969-1970) 99-118

Driver $S$. $R$, Notes on the Hebrew Text and the Topography of the Books of Samuel, Oxford 1913

Elat, M., Samuel the Judge in the light of 1 Sam 7, Shnaton 7-8 (1983/1984), 11-12 (Hebrew)

Goetze, A., Hattusilis, Keilschriftenurkunden aus Boghazkoi I, 1 (MVAeG 1924,3), Leipzig 1925

Güterbock, $H$., To drink a God, XXXIV RAI: Abstracts, 6-10/VII, Istanbul 1987, 26

Gurney, O.R, Some Aspects of Hittite Religion (The Schweich Lectures 1976), Oxford 1977

Haas, V., Der Kult von Nerik, Studia Pohl 4, Roma 1970

- IJakob-Rost, L, Das Festritual des Gottes Telipinu in Hanhana und in Kaska, Altorientalische Forschungen 11 (1984) 10-91

- / Wilhelm, G., Hurritische und luwische Riten aus Kizzuwatna (AOATS 3), Neukirchen-Vluyn 1974

Haran, M., malbusey Kehuna, Encyclopaedia Miqra'it 3, 1048

Hillers, D. R. Ritual Procession of the Ark and Ps. 132, CBQ 30 (1968) 48-55

Hoffner, H. A., The Hittites and the Hurrians, in: D. J. Wiseman (ed.), Peoples of the Old Testament Times, Oxford 1973, 197-229

Houwink ten Cate, P. H., Muwatallis' Prayer to the Storm God of Kummanni, RHA 25 (1967) 101-140

Hurvitz, A., The Garments of Aharon and his Sons according to IQ War VII, 9-10, in: Y. Avishur / J. Blau (eds.), Studies in Bible and the Ancient Near East (FS S.E. Loewenstamm), Jerusalem 1978, 139-145 (Heb.).198

Janowski, B. / Wilhelm G., Der Bock, der die Sünden hinaustrágt. Zur Religionsgeschichte des Azazel-Ritus Lev 16,10.21f [in diesem Band]

Kammenhuber, A., Ketten von Unheils - und Heilsbegriffen, Or. 54 (1985) 77-105

$K e e l, O$., Die Weisheit spielt vor Gott. Ein ikonographischer Beitrag zur Deutung des $\mathbf{m}^{\mathbf{e}}$ sahăgat in Sprüche 8,30, Freiburg (Schweiz) / Gottingen 1974

Kühne C., Hethitisch auli- und einige Aspekte altanatolischer Opferpraxis, ZA 76 (1986) 85-117

Laroche, E., Un point d'histoire: Ulmi-Teshub, RHA 48 (1948) 40-48

- Textes Hittites, numbers 471-500, Paris 1971

Levine, BA., The Descriptive Tabernacle Texts of the Pentaeuch, JAOS 85 (1965) 307-318 
Lieberman, S., Hellenism in Jewish Palestine, New York ${ }^{2} 1962$

Malamat, A., Doctrines of Causality in Hittite and Biblical Historiography, VT 5 (1955) 1-12

Mazar, B., The Early Israelite Settlement in the Hill country. The Early Biblical Period, Historical

Studies, S. Ahituv / B.A. Levine (eds.), Israel Exploration Society, Jerusalem 1986, 35-48

McCarter, P. K, I Samuel (The Anchor Bible), New York, 1984

Milgrom, J., The Shared Custody of the Tabernacle and Hittite Analogy, JAOS 90 (1970) 204-209

Orlinsky, H. M., haroqdim for hareqim in 2 Sam 6,20, JBL 65 (1946) 25-35

Otten, H., Ein Reinigungsritual im Hethitischen: Gis hatalkisina', AfO 16 (1952-53) 69-71

Schiffman L. H., Purity and Exclusion in Serekh Ha'edah, in: J. Amitai (ed.), Biblical Archaeology Today. Proceedings of the International Congress on Biblical Archaeology in Jerusalem, Jerusalem 1985, 373-389

Singer, I., The Hittite KI.LAM Festival I (SBoT 27), Wiesbaden 1983

Soggin, J. A., "Wachholderholz" 2 Sam VI 5a gleich "Schlaghölzer", "Klapper"?, VT 14 (1964) 373-377

Taracha, $P$., Zum Festritual des Gottes Telipinu in Hanhana und in Kasha, Altorientalische Forschungen 13 (1986) 180-183

de Vaux, $R$, Le roi d'Israêl, in: Mélanges Tisserant I, Rom 1964, 119-133

Wegner, I., La(hu)wazantija, RA 6 (1983) 119-133

Weinfeld, M., The Covenant of Grant in the Old Testament and the Ancient Near East, JAOS 90 (1970) 184-203

- The Origin of the Apodictic Law, VT 23 (1973) 63-75

- Social and Cultic Instititutions in the Priestly Source against their Ancient Near Eastern Background, Eighth World Congress of Jewish Studies, Panel Sessions, Bible Studies and Hebrew Language, Jerusalem 1983, 95-129

- Justice and Righteousness in Israel and the Nations, Jerusalem 1985 (Hebrew)

Wilhelm, G., Grundzüge der Geschichte und Kultur der Hurriter, Darmstadt 1982

$-\rightarrow$ Haas, $V$.

- $\rightarrow$ Janowski, $B$.

Wright, D. P., The Disposal of Impurity, Atlanta / GA 1987

- The Gesture of Hand Placement in the Hebrew Bible and Hittite Literature, JAOS 106 (1986) $433-446$

Yadin Y. (ed.), The Temple Scroll, 3 vols, Israel Exploration Society, Jerusalem 1983 


\section{Analogy in Biblical and Hittite Ritual ${ }^{1}$}

The study of similar phenomena from temporally and geographically proximate societies, such as from ancient Anatolia and ancient Israel, can have one of two basic purposes: (1) establishing genetic relationships between the phenomena specifically and the societies more generally or (2) elucidating the phenomena in one or both of the societies concerned without particular regard to genetic connections. ${ }^{2}$ The first use is historical in nature and is perhaps the most important and urgent since it is part of establishing a phenomenon's basic context upon which an extended understanding may be built; that is, historical considerations are arguably a prerequisite to interpretive considerations. But this approach is laden with difficulties and uncertainties. It is easy to find parallels but difficult to verify an actual hereditary relationship. Careful studies along this line are apt to - almost required to - end with a boldface question mark. Hence the second approach, which is more directly interpretive, might provide a way of using comparative data that is more immediately productive. To be sure this approach has its own traps and snares, but with caution interpretive comparison can be conducted safely and with substantial results in every case. And indeed, as it turns out, it can help prepare the way for more effective and valid conclusions about historical links since it can yield better comprehension of the phenomena studied.

Here I will treat analogy in biblical and Hittite ritual (to be defined anon) via the second, interpretive avenue. ${ }^{3}$ In the past I have used this general method of comparison in regard to other issues by observing contrasts between similar phenomena. ${ }^{4}$ Recognizing differences generated questions about the reasons for those differences, and subsequent solution of these queries through study of a phenomenon's own context clarified its meaning. Here the elucidative approach will operative in another fashion. In the first part of the paper I will examine a number of segments from biblical and Hittite ritual texts collec-

1 Work on this paper was carried out to a large extent in Israel in affiliation with the Hebrew University at Jerusalem on a Fulbright award from the United States-Israel Educational Foundation in 1989-90.

2 See my brief but more precise comments on the comparative method in my book, Disposal, 5-9.

3 For some past work comparing Hittite and Biblical ritual practices, see Moyer, "Cultic Practices"; Milgrom, Levitical Terminology, 49-59; Id., Cult, 27-55, 140-142; Wright, Disposal; Weinfeld, "Social and Cultic Institutions"; Segal, "More Parallels"; Barré, "Extrabiblical Literature".

4 See Wright, Disposal, 5-9 and passim. In contrast to the terminology in my book where the category of interpretive comparison is a limited and illegitimate category, I use "interpretive" here more broadly to describe any use of comparative material for explanation. Within this broader definition contrastive comparison may be included. 
tively to establish the widest possible range of phenomena and forms that can be comprehended under the rubric of ritual analogy. The worth of this part of the study will be in serving as a guide against which particular cases can be judged and defined and providing basic analytic perspectives and categories for examination of particular cases in future study.

In the second part of the paper I will continue the use of interpretive comparison but in a different and admittedly more speculative way. One of the pitfalls in interpretive comparison is the assumption that similar phenomena have the same rationale. This fallacy is most apt to occur when cultural elements - ideas, practices, and products - associated with a phenomenon in one society are assumed to apply to a similar phenomenon in another society. Cultural elements are variable, and similar phenomena in discrete cultures have distinctive contexts; hence, what is found in one case cannot be supposed to exist in the other. But if differences between societies obtain at a cultural level, it seems that at a more basic level of human be-ing - the physiological, the psychological, the linguistic, and the socio-psychological - there are some commonalities that transcend cultural differentiation. This introductory study of ritual analogy leads us to recognize and describe to some extent one of these commonalities. As we look through the examples used to describe the forms of analogy in the first part of this paper, we will see great differences of content, specific form, social structure, ideology, theology, etc. - all cultural differences between the Hittite and biblical examples. But at the same time we will see that a conceptual or cognitive similarity and common rationale seems to be shared by the two traditions. This commonality is the metaphorical way of thinking. Primary phenomena are described "in other words" and in other acts which portray and communicate feelings and thoughts in a lively and active way to ritual participants (or to readers or hearers in literary and narrative contexts). Analogy allows "reality" to be described and perceptions and moods to be formulated. This brief study of metaphorical thought will draw on anthropological, sociological, psychological, linguistic, rhetorical and literary-theoretical perspectives. 5

Some work on this type of ritual in the Near East that has been done includes Fohrer, "Gattung", "Prophetie", and id., Die symbolischen Handlungen; Goetze, Kleinasien, 155-158; Hillers, Treaty-Curses, 18-27; Schott, Vergleiche; and Schulz, "Fluchsymbolik". This work does not come close to treating the phenomenon in the breadth entered into here and the theoretical framework of much of it is not teneble. An interesting article on this type of ritual in some Greek sources is Faraone, "Hermes". (I here thank Chris Faraone for his steering me to some theoretical materials on the subject of ritual analogy.) 


\section{Analytic Considerations}

Our interest is in the broadest possible manifestation of ritual analogy so as to give us the largest framework in which to think about the phenomenon; hence, the broadest possible definitions of ritual and analogy are to be entertained. ${ }^{6}$ First, therefore, let us define what is meant here by ritual and its related terms and clarify differences between different types of ritual texts and verbal elements that appear in those texts.

The nouns "ritual" or "rite" refer, phenomenologically, to activities and actions - experiences in time - that portray social or psychological meaning beyond any simple practical value they may have. ${ }^{7}$ For example, changing a tire does not carry much meaning beyond repairing the breakdown so that one can get back on the road. But if one stops to change a tire of a stranded motorist to demonstrate to oneself or to others one's sense of propriety deriving from a religious or communal commitment - or to demonstrate one's physical strength out of a hope to get a date with a young female motorist (a mating ritual?), the act then conveys something more than a practical intent and is thus a ritual. ${ }^{8}$ For the sake of clear discussion, I use "ritual" to refer to the general phenomenon spoken of here or a particular whole instance of such a phenomenon. I use "rite" to refer to a particular complete ritual act within a larger ritual. 9

This definition of ritual as an act or experience should be differentiated from a text of prescriptions that may lie behind it. Those of us who deal with

6 I avoid using the term "magic" to describe all or part of the rites that I discuss here. The notion of magic largely grows out of an implicit polemic that attempts to distinguish between rites - identified as religious - in Judeo-Christian "orthodoxy," versus differing ritual practices identified as magic - in other traditions or cultures. Separation of ritual practices in this way does not seem analytically useful (note T. Gaster's unnecessary - but insightful - struggle to set Frazer right in Frazer, New Golden Bough, 171). Attempts at a "scientific" definition of magic show how much the realm of religion is really one with so-called magic (e.g., Goode, Religion, 37-55). The only place where the term "magic" is helpful is in translation of terms and discussion of conceptions from primary literature which have a polemic thrust in their own context (i.e., Hittite alwanzatar, used of the affliction a patient suffers because of a sorcerer may be translated "magic"). On some of these issues, see Penner, "Rationality"; Ricks, "Magician."

7

One can argue that no act is performed simply for practical purposes, since individuals or groups act in social contexts and all actions therefore reflect those contexts. For example meals, a seemingly practical affair, are not simply to acquire nutrition (cf. Douglas, "Meal"). Taking this understanding, one would have to distinguish between the different degrees of symbolism that acts have in different contexts.

8 Cf. Wuthnow, Meaning, 99; Douglas, "Social Control," 368, for situations not commonly thought of as ritual.

9 For example, I speak of the Tunnawiya ritual versus the rite of grasping a cow's horn contained in that ritual (to be treated in a moment). 
texts are accustomed to use the term "ritual" for the written formulation that prescribes or describes the actual ritual (e.g., the Day of Atonement ritual; the Samuha ritual). This overlapping of use is tolerable as long as the distinction between performance in time versus instruction in inscription is recognized. The distinction is exactly the same as that in music: we speak of music as what we hear (performance) as well as what is written on the conductor's score (text). As we will see later in dealing with some of the examples of analogy, it will be important to distinguish between a phenomenon as it appears in a ritual text vis-à-vis a phenomenon as it appears (or would appear based on the text) in a ritual performance.

There are three different kinds of ritual texts. Some texts have the main goal of prescribing or describing a ritual or ritual action from beginning to end, such as the Day of Atonement ritual in Leviticus 16. These types of texts represent themselves as ritual in nature. Texts like these can be called comprehensive ritual texts. Other texts which do not present themselves expressly as ritual prescriptions or descriptions are nonetheless employed in ritual contexts, e.g., psalms, certain mythological texts, and even prophetic oracles. ${ }^{10}$ These can be called contextual ritual texts. The third type are texts, such as narratives, whose goal is other than ritual, but which happen to describe a ritual usage. These texts are conscious of their ritual elements but subordinate them to other goals. These can be called incidental ritual texts. A distinction between these three types is necessary for judging the significance and dynamics of the individual ritual elements. We will be mostly concerned with comprehensive texts, but examples will be brought from contextual and incidental texts. An objection might be raised that using such a broad array of genres dilutes the results of this study and that the correlation of differences in genre and form must be considered. A study of differences will eventually need to be done, but for the present a broad, inclusive approach provides the best beginning. And rather than diluting the results, this study shows that diverse ritual texts have much in common and must be studied together. Certain lines delimiting one type of text from another are erased, but this does not lead to evidential blurring and anarchy. New demarcations and relationships of the evidence appear to take the place of older perceptions.

Another textual distinction following from the two foregoing observations needs to be made. In comprehensive, sometimes in incidental, ritual texts there are words that prescribe or describe a performance and there are words within this prescriptive and descriptive frame that are to be recited in the performance - an incantation, prayer, spell, readings from a holy text, and so forth. These two text elements may be labelled direction and recitation, respectively. The

10 Many of these texts are "recitations" that appear within a ritual performance, as I will describe below. 
two elements have a different relationship of signification in text and in performance. As text, the recitation relates meaningfully to the direction as a literary text; in performance the recitation gains its significance vis-à-vis the actions performed. A full analysis of a ritual text will treat both of these relationships of meaning.

Now, we are interested here in analogy as it appears in any of the ritual definitions, situations, and texts just described. What do we mean by analogy in this context? Analogy in ritual is any type of explicit or implicit comparison between a primary concern or phenomenon and a secondary concern or phenomenon that belongs to a conceptual field or "reality" that is to a greater or lesser degree separate from that of the primary concern or phenomenon, which comparison defines or signifies the sort of thing that is thought to have transpired, to be transpiring, or will transpire with regard to the primary concern or phenomenon. ${ }^{11}$

This cumbersome abstract definition needs to be supplied with an example or two to make it concrete. A comprehensive prescriptive Hittite ritual composed by the "old (or wise) woman" cult practitioner Tunnawiya ("The Ritual of Uncleanness and the Ritual of the River, by Tunnawiya the Old Woman"12) seeks to cure a woman of miscarriage or barrenness or a man of impotence. It contains a rite to be performed on behalf of a woman patient ${ }^{13}$ in which the old woman officiating in the ritual takes hold of the horn of a cow and says:

Sungod, my lord, just as this cow is fertile, and (is) in a fertile pen, and keeps filling the pen with bulls (and) cows, indeed, in the same way may the offerer be fertile! May she in the same way fill (her) house with sons, daughters, grandchildren, great-grandchildren, [ ] in successive generations!"14

11 This definition has an added constraint that is not strictly implicit in the terms "analogical" or "ritual" that I use to define my study. I am concerned here mainly with analogy in ritual that has to do with changes and permutations of circumstances, situations, states, and statuses, which, to be sure, are often the goal of ritual. If I wanted to be exact in the description of what is meant with regard to analogy in this study, I should use the a title and description such as "situation-, circumstance-, or status-changing analogy in biblical and Hittite ritual." Such a description, as is obvious, is too ponderous to use. Nevertheless, this limitation does not mean that the number of examples for study will be significantly less than the total number of cases of analogy in a given ritual text. Each case of analogy must be examined to see if it implicitly, if not explicitly, has to do with a situational or status change.

12 KUB 7.53 + (CTH 409; ed. and trans. by Goetze and Sturtevant, Tunnawi). This title is from the colophon, iv 43-44.

13 At first glance it is not clear if this rite could be performed for a male. Some data indicate that it could, but using a bull. Bovines are to provided for the ritual according to i 52, a cow for a female patient and a bull for a male. Nowhere else in the ritual are they used and so it seems that these are those that are to be used in the very rite under discussion. (Elsewhere in the text there is a correspondence of the sex of animals with that of the patients [i 11, 12-13].)

14 iv 8-13. 
This recitation explicitly displays the primary and secondary components of analogical comparison. The secondary element comes first with reference to a discrete phenomenon (i.e., "just as this cow is fertile" etc.). This is related to the primary condition of the patient's barrenness and expresses the hope that she become fertile (i.e., "may the offerer be fertile!" etc.). These members of the analogy may be described by the terms phoros and theme, respectively, which derive from the study of analogy in rhetoric. ${ }^{15}$ To keep track of the members of a given example, I will display analogical forms in this paper with the members marked, in the following way:

Phoros: Sungod, my lord, just as this cow is fertile, and (is) in a fertile pen, and keeps filling the pen with bulls (and) cows,

Theme: indeed, in the same way may the offerer be fertile! May she in the same way fill (her) house with sons, daughters, grandchildren, great-grandchildren, [ ] in successive generations. ${ }^{16}$

Another case exemplifying the basic two members of analogy comes from another ritual composed by Tunnawiya ("When the Old Woman takes the King or Queen from the Earth [=Underworld]"). ${ }^{17}$ At one point a clay door socket is held up to the head of the ritual patient. An incantation is then recited:

"O powerful door socket, b[reath] for this person greatly, breath for this person has been shut off greatly; he has become oppressed."

This is immediately followed by this analogy: ${ }^{18}$

Phoros: $\quad$ As a door tu[rns] on (its) socket,

Theme: $\quad(\mathrm{so})^{19}$ [may] evil day, short year, the anger of the gods, and the tongue of the many $t$ [urn] back from (its) course. ${ }^{20}$

15 The terms are proposed by Perelinan and Olbrechts-Tyteca, Rhetoric, 373.

See below for an analysis of the deeper formal complexity of this example.

$17 \mathrm{KBo} 21.1+$ (CTH $760 \mathrm{I} 1+{ }^{*} 448.1$; ed. and trans. by Hutter, Behexung). The title is from the colophon tablet $1, \mathrm{KBo} 21.1$ iv 5-6; cf. i 1-2. See Hutter's book, pp. 10, 55-57, for the argument that the Tunnawiyas of these two rituals are the same person. The two rituals contain some similar elements. The text for sexual dysfunction uses two door sockets (KUB 7.53+i 44; ii 2). This text does not say what is done with them, only that one (perhaps both) were lifted over the patient. Perhaps a rite similar to that in the ritual for the royal pair is performed with the sockets in the text for sexual dysfunction.

18 Tablet 4, KBo 21.6 vs. 4-5 (cf. the duplicate KBo 25.193 6-7; cf. Hutter, Behexung, 44-45, 52).

19 The adverb is implied.

20 Tablet 4, KBo 21.6 vs. 6-8 (duplicate: KBo 25.193 8-10; Hutter, Behexung, 44, 52f.). 
After another analogical rite with other materials, the old woman holds the clay socket up over the patient ${ }^{21}$, waves it back and forth over him and recites an incantation instructing the patient to spit several times, thus ejecting the divine anger.

These introductory examples represent only one type of analogical expression possible. Besides these where recitation and action are combined, there are other cases where analogical verbal expressions appear without complementary acts and where analogical acts appear without complementary verbal expressions. Moreover, analogical verbal elements in and of themselves have diverse forms and in some cases only a theme (or a phoros) may appear and thus require accompanying actions to supplement their expression to give them sense. We turn now to describe this variety of form and composition.

First, the verbal elements or recitations by themselves. We find three basic types: (1) full analogy, (2) simile, and (3) metaphor. I use these terms here to define specific syntactic forms. ${ }^{22}$ The incantation or spells in the Tunnawiya rites are examples of full analogy. These contain a phoros and theme which are each complete syntactically (i.e., with subjects and predicates). Simile and metaphor (to be defined in a moment) are, as rhetorical and literary study has recognized, essentially truncated forms of analogy. ${ }^{23}$ Though in actuality we can never expand a simile or metaphor into a definite underlying or conceptually original analogy, nor should we think that a psycholinguistic process has transformed a more complete deep structure analogy into an abbreviated surface metaphor or simile, for analytic purposes these truncated forms can be expanded to full analogical form.

A simile is a case where the theme has a verb (including a copula) and the phoros consists of a verbless phrase introduced by a word of comparison such as "like." ${ }^{\text {24 }}$ This form of analogy is ubiquitous, especially in the Psalms. For example, Ps 35:5a, with the members identified, reads:

Theme: May they [the psalmist's enemies] be

Phoros: like chaff before the wind!

21 Apparently a type of manipulation different from the first holding-up of the socket.

22 I use the term "metaphor" in this first part of this paper to refer specifically to a form of analogy. In the introduction to this paper and below in the second part I use the term (and its adjectives) to refer also to a way of thinking. It might have been better for the terminology of this paper to refer to the "analogical" rather than the metaphorical way of thinking. But anthropological and literary study has accustomed us to the term "metaphor(ic[al])" as a general way of construing and describing reality and so I use this term. The context of form versus thought will clue the reader to the usage intended.

23 See, for example, Perelinan and Olbrechts-Tyteca, Rhetoric, 398-405; Booth, Company, 306.

Here I take this rigid definition of simile for formal purposes. 
If we were to imagine this as a full analogy it would run something like:

Theme: $\quad$ May they come to no good

Phoros: just as chaff before the wind is scattered and lost.

Again, there is no definite way of expanding a simile (or a metaphor). Other predicates could be thought of in this case. I have expanded the simile here only for the purpose of showing that a full analogy is inherent in it. The difficulty in expanding a simile or metaphor reveals the ambiguity of these forms as opposed to full analogy and may indicate why in certain contexts (not necessarily ritual) these figures are more attractive versions of analogy.

An example of metaphor, also abundant in the Psalms, comes from Ps 140:12b:

Theme: $\quad$ Evil will HUNT DOWN the violent man. ${ }^{25}$

In metaphor, the theme appears alone and there is, as it were, the replacement of a literal element of a theme with the corresponding element of a hypothetical phoros. This "borrowed" element is capitalized in this example. ${ }^{26}$ This replacement can be called phoric transfer, though again we should not think of a psycho-linguistic operation where metaphor has actually derived from analogy. To see the analogical character of the metaphor, we could expand this example to something like

Phoros: Just as a person hunts down an animal,

Theme: $\quad$ so will evil befall the violent man.

Both full analogy and simile may display phoric transfer in the theme. From the Tunnawiya ritual for reproductive dysfunction we have the following verbal analogy addressed to hattalkišna-wood, which is particularly apt for purificatory purposes because of its natural properties:

Phoros: $\quad(\mathrm{As})^{27}$ a goat goes by you and you pull (huittiyaši) some hair off of it (and as) the bull goes by you (and) you pull (huittiyasi) some hair off of it,

Theme: in the same way PULL (huittiya) evil, impurity, magic, sin, divine anger, curse, the tongue of the masses (and) a short life OFF of this offerer! ${ }^{28}$

25 Taking 'is hamas ra' $y^{e}$ șadaenn $\hat{\imath}$ as a syntactic unit against the MT accentuation. The last word of the verse, $F$ madhepot, perhaps to be construed as "incessantly", "untiringly," has been left out here because of its obscurity.

Metaphorical elements will be capitalized in the themes of the following examples as well for clarity.

27 The comparative conjunction mahhan/GIM is missing (even in view of Otten's corrections, "Reinigungsritual," 70b), but is implied by the correlative adverb QATAMMA in iii 42.

28 KUB 7.53+ iii 35-42 (with the corrections of Otten, "Reinigungsritual," 70b). See my discussion, Disposal, 34-35. 
Here the verbal description used of hattalkišna-wood's natural property in being able to pull off hair is brought over into the theme to describe how the various evils will be affected, i.e., "pulled off." ${ }^{\text {"29 }}$ To clarify the metaphorical character of the verb in the theme, one only need imagine nonmetaphorical (or less metaphorical) ways the thematic idea could be expressed (e.g., "in the same way may you annul the evil...").

Phoric transfer in a simile is found in a curse in the Akkadian treaty between Suppiluliyuma and the Mitannian Mattiwaza, son of Tushrata:

Theme: $\quad$ May I, Mattiwaza, together with any second wife I take, and may we Hurrians, together with our possessions, GO UP TO THE SKY

Phoros: like smoke. ${ }^{30}$

The phrase "go up to the sky" is a phoric element that pertains to the situation of smoke and reflects a full analogy, something like

Theme: $\quad$ May I, Mattiwaza, together with any second wife I take, and may we Hurrians, together with our possessions, perish,

Phoros: just as smoke goes up to the sky.

In the preceding outline of the basic types of verbal expression we notice that the examples have one of two referential bases: ritual act or external phenomena. The former is where the phoric comparison exists within the ritual context and the latter is where comparison is made to something outside the ritual. Within the category of reference in ritual act there is a finer subdivision of deictic or demonstrative reference and procedural reference. Deictic or demonstrative reference is where an object or material on hand for the rite is referred to as an example of the phoric notion with no other significant action being performed with it. Procedural reference is where an act is performed that in some way represents part or all of the phoric idea.

Examples of external reference are in the similes and metaphors in the contextual ritual texts, i.e., the Psalms, and in the comprehensive text of the Mattiwaza treaty. The examples referred to situations outside the ritual contexts - chaff being blown, hunting, and smoke rising - for their expression. External reference, however, is not limited to cases of simile and metaphor as we will see from another example in just a moment. An example of deictic ritual reference is in the Tunnawiya cow rite. The old woman grasps the cow

This natural property may be made concrete in covering the gate with wool, iii 21-22.

KBo 1.3 (CTH 52) ii 31-32 (= Weidner, Politische Dokumente, p. 54, lines 48-49). Cf. CAD Q: $326 \mathrm{~b}$ for this passage and for other comparisons with smoke in ritual situations. See also Hillers, Treaty-Curses, 23 on the passage. 
horn and recites the incantation. ${ }^{31}$ The cow is not treated otherwise. ${ }^{32}$ Procedural ritual reference is found in the hattalkišna-wood analogy already cited. While there is a deictic element in referring to the qualities of the wood, the patient passes through a gate made of the wood - a procedure - to effect purification and healing. The door socket analogy is a mixed case. There is a ritual procedure with the clay model of the socket: holding it by the head of the patient and waving it over him. But the specific analogy refers externally to a door in general, not to an item in the ritual context.

An example from the ritual of "Alli, the Woman of Arzawa" ${ }^{\text {33 }}$ augments the foregoing short list of cases of external reference in comprehensive ritual texts. In a full analogy which may constitute the end of the series of thread and related analogies (to be discussed later), we read:

Afterwards she (the old woman) takes white wool and says:

Phoros: $\quad$ B[ehold(?) ...], just as a savage enemy makes peace [...]

Theme: in the same way may this white wool cleanse this magic (and) impurity. Whether someone treated him evilly b[efore the gods] or whether [someone] treated him evilly before human[s], now, may this white wool take (it) away from all his body parts. May it give it back to the magic-making person. May this person (the patient) be clean before (all). ${ }^{34}$

The text gives no evidence that an act of making peace, real or symbolic, is performed as part of the ritual. The peace-making appears to be a general external situation which is brought to bear on the cleansing process. This is an unusual case since the situation brought in the phoros does not parallel the situation of the theme syntactically or conceptually. It is difficult to imagine how there might be a replacement of elements of the theme by those from the phoros through phoric transfer as we have seen in some preceding cases. The disparity in the two members makes it an intriguing and engaging analogy from a literary point of view. More mental energy is expended in interpreting the relationship of the two members than in other cases we have seen.

A unique combination of a deictic and procedural reference is found in the two onion (or garlic? ${ }^{35}$ ) analogies in the "Ritual of (the city) Samuha"36,

31 As a deictic act, the grasping of the horn may be compared to the gesture of hand placement in the Bible and Hittite literature. See my article, "Hand Placement."

32 Except that it is taken back to its pen (iv 14).

33 KUB 24.9+ (CTH 402; ed. and trans. by Jakob-Rost, Malli). On the name of the ritual composer as Alli, and not Malli, see Otten, "Alli", 81.

34 ii 8-15.

35 See Hoffner, Alimenta, 108-109. If a garlic clove was used, then an action such as picking the clove apart would have to be substituted for the following description of peeling an onion. 
which in part seeks to purify the impurity of a temple. The two analogies appear in sequence. The first is a citation of what a sorcerer is to have been saying and doing to affect the temple. The second is the reversal of the sorcery by word and action. I cite the ritual set-up with the analogies:

They then give her/him an o[nion (suppiwashar)]. Thereupon he/she says the following: "If before the god someone [has been sa]ying the following:

Phoros 1: 'Just as this ${ }^{37}$ onion (suppiwašhar) is wrapped up (hulaliyanza) with layers, one [not] being able to sepa[rate] from the other,

Theme 1: let evils, oath, curse, and uncleanness be WRAPPED UP (hulaliyan) LIKE AN ONION (Suppiwashor) AROUND the temple, ${ }^{, 38}$

Phoros 2: $\quad$ now, behold, I have peeled away (Sippanun) this onion (šuppiwašhar) (and) [of it] have retained this one bare stalk.

Theme 2: In this way may evil word, oa[th, cu]rse, and uncleanness be PEELED AWAY (sippaidd ${ }^{39}$ ) from [befor]e the god! Let the god and offerer be clean from th[at ma]tter! ${ }^{40}$

36 KUB 29.7+ (CTH 480; ed. and trans. by Lebrun, Samuha, 117-143). The ritual is given this name in the colophon, rs. 74.

37 It is possible to read kas (here in line 37) as the interjection kasa "behold" (a "Verschreibung"; cf. Jakob-Rost, Malli, 65; for other examples, cf. Hutter, Behexung, 142). The beginning of this phoros would then read: "Behold, just as an onion ..." Taking kas as a demonstrative is at first appearances difficult because its gender is common and would be thus in disagreement with suppiwashar which by form is neuter (cf. $\mathrm{HE}^{1}$ 199). This is a repeated "error", however: in line 39 the common gender (accusative) demonstrative (kan) is used with suppiwašhar and in line 37 the common gender participle hulaliyanza modifies the noun (also in line 40 Lebrun, Samuha, 123, restores the common gender enclitic pronoun -an translated "[of it]" which refers to suppiwašhar). Thus a reading of $\mathrm{kas}^{\zeta}$ as a demonstrative is possible. This interpretation is adopted by Lebrun, Samuha, 131. Hoffner, Alimenta, 109, says the foregoing grammatical points are evidence enough to take suppiwašhar as a common gender word. - The point of this quibble is to determine what type of referential base exists in the analogy. If kas meant "behold", the onion would not be a specific onion on hand in the rite and would thus provide a case of external reference. On this see below.

This member is actually complex and could, in a more detailed analysis, be represented as

Theme 1: let evil, oath, curse, and uncleanness be WRAPPED UP

Phoros 1: (reiterated): like an onion

Theme 1: (continued): around the temple

Thus a "redundant" simile appears in the first theme.

39 The nominative hurtaix "curse" in the list of evils to be removed suggests the curses are the subject of Sippaidu, not the objects, and that this verb should be construed passively (so Lebrun's translation and Goetze, "Contributions," 320). Hoffner, Alimenta, 108, takes the offerer as the subject of the verb: "even so let him (the sacrificer) peel off evil word, oa[th, c]urse, ..." (cf. similarly Goetze, ANET, 346).

40 ii 36-41 (Lebrun's line numbering). I have capitalized elements transferred from the phoros in the translation. 
In the first analogy, a sorcerer is thought to have used an onion to cast evil upon the temple (and by the implication of the second theme, on the ritual patient and god). That this person would have used an actual onion, and would not have just referred externally to one in general is indicated by the demonstrative construction "this onion." ${ }^{41}$ The use of an onion in this first rite would be for deictic reference, much as the cow in the Tunnawiya rite was used for deictic reference. The second analogy, however, goes further. Presupposing the rite in the first analogy, it uses an onion procedurally by peeling it.

The examples of verbal expressions that we have seen thus far with ritual actions demonstrating or referring in someway to the phoric situation (the cow, door socket, hattalkišna-wood, and onion rites) have had full analogical verbal forms. Frequently a ritual action is accompanied by a verbal element that lacks a phoros, and in some of these cases the solitary verbal theme is incomplete, not having an adverb of comparison ("thus", "in the same way", etc.). This ellipsis hides to some degree the analogical relation of action to theme.

An example of analogical action with a verbal element containing only a theme, though having a correlative adverb, is in Jer 51:59-64a. Jeremiah was to have sent Seraiah, a quartermaster or tribute officer, to Babylon with a document delineating the calamity that was about to befall that city. Seraiah was to read the document with the following accompanying prayer (v. 62): "Yhwh, it is you who have spoken against this place, to cut it off so that there will no longer be any inhabitant there, man or beast, for it is to be a desolation forever." This last prayer summarizes the document's content and directs attention to the analogical act and statement which follow here (vv. 63-64a):

Phoros (ritual action): When you finish reading this document, you shall tie a stone to it (the document) and cast it into the middle of the Euphrates. You shall then say:

Theme: $\quad$ "In this way shall Babylon SINK AND NOT RISE because of the calamity I am bringing against it.

Here the phoros is expressed in ritual action and only the theme is verbalized. The analogical character of the act and expression is clear because of the connecting adverb "in this way" (kaka) . The analogical interplay and connection of the act and verbal expression are further reflected in a type of phoric transfer that has taken place. The capitalized phrase in the theme is a metaphorical description that derives from the action of the stone and document in the

41 See note 37. Hillers, Treaty-Curses, 19-21, discusses briefly the issue of how the presence of a demonstrative points to a ritual action that is performed rather than a simple figure of speech. 

This particular example constitutes an intersection of two roads of formal analysis already examined. One the one hand, it is a case of full analogy with only a theme expressed verbally, like that in Jeremiah 51 . If a comparative adverb such as kakä "so", "in the same way" were present in the theme in the present example, it would be exactly like the case in Jeremiah in form. On the other hand, the verbal theme is a case of metaphor, like that in Ps 140:12b described above (the capitalized words, again, indicate the metaphorical elements in the theme in 1 Kings 11:31). If the theme from 1 Kings existed by itself it would not be much different from the case of verbal metaphor in Ps 140:12b. Conversely, if Ps 140:12b were accompanied by a ritual act, a mimetic act of hunting for example, it would be no different formally from the example in 1 Kings. Thus the kingdom-transfer rite hovers between a type of full analogy and a type of metaphor. This type of analogy can be designated metaphor with phoric action.

A rite much the converse of the example from 1 Kings 11 is found in the ritual of "Huwarlu, the Augur" ${ }^{\text {"43 }}$. Instead of having a phoric ritual action with a thematic verbal element, this rite has a thematic ritual action with a phoric verbal element. ${ }^{44}$ The ritual seeks to remove from a king, queen, and their palace "magical word (or words)" (kallar uttar) connected with "terrifying birds $^{n 45}$. One of the rites involves waving ${ }^{46}$ a live dog inside the palace and reciting the following incantation:

Whatever [magical] word (is) in the king and queen, in his/her body, or (is) in the palace, behold, (his, i.e., the dog's) member (is) GREAT, his heart (is) GREAT. He, the ASS, is TAKING (IT) UP. He has CONQUERED it. Let him CARRY [AWAY] the evil ma[gical word]. Wherever the gods have designated it, there let him CARRY it. ${ }^{47}$

After this incantation the dog is taken away and perhaps dispatched alive or killed. ${ }^{48}$ In this example the rite performed with the dog is thematic relative to the incantation, which is phoric. ${ }^{49}$ That is, the dog-waving and dispatch

43 KBo 4.2 (CTH 398; ed. and trans. Kronasser, "KBo IV 2").

44 The action is thematic to the verbal element in a relative sense. One can analyze the action as phoric or analogical in certain respects relative to the basic cure that is sought. See the considerations on the notion of "distance", below.

45 kallar uttar/INIM (occasionally with idalu "evil" added): i [1], 15, 17-18, 26, 51, 60, 67, 70; ii 18-97, 「111, 18, 19-20, 23 (idalu uttar "evil word" in i 68); hatugaeš MUŠEN.HI.A/wataeš i 2 (only MUŠEN.HII.A is legible here), $r 161,18$; ii 32.

46 The dog thus acquires the evil and can bear it away. On this act see the Tunnawiya door socket rite, above, and my book, Disposal, 32-34.

47 ii 8-13.

48 See discussion of this issue in my book, Disposal, 59 .

49 Deeper analysis could describe the analogical character of the rite performed with the dog. 
seek to remove evils directly while the incantation metaphorically describes the dispatched animal and its operations (metaphorical elements are capitalized). In the incantation, it is an "ass," not a dog, that removes the evil. This animal has grand and powerful heart and genitalia. It "conquers" the evil. It "takes up" and "carries away" the evil, terms that perhaps develop an ass-as-beast-ofburden metaphor. The metaphorical character of these last verbs would be particularly evident in the case that the dog was to be killed and not dispatched alive. The implicit schematic full analogy behind the ritual action and incantation would be something like this:

Phoros: Just as an ass is powerful, effectively takes up a burden, and bears it away,
Theme:

In the last few cases of analogy the verbal element that accompanies a ritual act has appeared as a lone theme or phoros. Analogy can be present even in cases where no verbal element exists at all but only ritual action. These are cases of what might be called eclipsed or hidden analogy. Recognizing that analogy may exist in such cases is one of the key observations of this survey because it shows that analogy is a fundamental element in almost all (if not all) ritual situations. For an example let us take the perhaps most common ritual action, ablution. While this rite is usually considered in the systems in which it appears self-effective and thus not analogical to its users, it appears to obtain its significance ultimately from mundane bathing and washing by analogy. A full analogy might be constructed for it as follows:

Phoros: Just as a mundane bath removes dust and dirt from a person,

Theme: $\quad$ so a ritual bath removes evil from the patient.

Many ritual actions like this - e.g., anointing, shaving, clothing, combing - have similar echoes in common, mundane practice which appears to constitute the analogical basis and context for the rites. In addition, implied analogical significance may derive from natural characteristics of materials (as opposed to actions) or their ability to symbolize natural characteristics (cf. the case of hattalkišna-wood above). Such may be the case with the cedar wood, hyssop, and scarlet material used in the Red Cow ritual and the cleansing of a person or house recovered from șară ăt (so-called "leprosy"). ${ }^{50}$

Other types of hidden analogy are to be found. One is that involved in the use of terminology which has phonological similarities with other terms either used in the rite or existing in language outside the rite. For example, the Samuha onion analogies use the word suppiwašhar "onion" as well as in the second analogy the verb arha sippai- "to peel away". These terms, used for a

50 Num 19:6; Lev 14:4, 6, 49, 51, 52. 
central symbolic element and action, echo the stem šuppi- "pure, holy" and its verbal and nominal congeners, which are not used in the rite but are present in the Hittite lexical inventory. ${ }^{51}$ The onion analogy may have been chosen because of its terminological reflections and not just the physical character of the vegetable. ${ }^{52}$ Analogy in such cases lies in the likeness of one term to the other. By use of the one term or object identified by a particular term, the notions of the other are brought to bear on the ritual situation. Such analogies are latent and oblique and thus difficult to verbalize. The analogy behind this word play would be something like this:

Phoros: Just as Suppiwašbar and Šppai- which occur in the rite have phonological similarities to suppi-,

Theme: $\quad$ so may the rite have a šuppi-effect. ${ }^{n 3}$

The case of analogy in actions such as bathing brings up another analytic issue: the distance between the foci (objects or persons undergoing a status change or suffering a state) in the phoros and theme in a given analogy. In bathing, the act which has analogical significance is performed directly on the patient. In contrast, it is possible to imagine a case where a figurine representing the patient is washed to symbolize the cleansing of the human patient or where a piece of dirty linen is washed to symbolize this purification. When an element of the theme is directly treated by an element of the phoros, as in ablution, we have intersecting analogy; when the two members are kept separate, as in the cases just imagined, we have parallel analogy. ${ }^{54}$ The cow and two onion-peeling rites above are cases of parallel analogy: what happens to or is the case with objects that are not connected with the patient represents what happens to the patient. The hattalkišna-wood, cloak tearing, and door socket rites are cases of intersecting analogy: the patients are brought into contact

51 See Goetze, "Contributions," 318-320, for a possible connection of suppi- "pure" with suppiwashar "onion". Cf. Hoffner, Alimenta, 108-109, for cautions on this. There would seem to be no actual etymological connection between šippai- "peel" and šuppi- "pure" (cf. HW', 193). Whatever the actual etymologies, folk perceptions of word connections can still operate.

52 Those with a reader-response (here "performer-response"?) perspective would say that even if the ritual writer did not intend this connection, the performers may have perceived it.

On this type of analogy in Akkadian ritual, see Farber, "Associative Magic"; Id., Schlaf, Kindchen, Schlaf!, 35, 45, 169; outside the Near East, see Tambiah, "Form", 215-218; Feinman, "Temples", 76.

54 A finer analysis on the basis of tropological relationships (in terms of metonymy, synecdoche, and metaphor) between foci is possible. This tropological analysis can also be applied to the circumstances (the processes or states that the foci suffer) in a phoros and theme. 
someway with the analogical materials. ${ }^{55}$ In these distinctions in distance I am not seeking to perpetuate notions about contagion and homoeopathy connected with past study of so-called "magic". Rather, these are formal and expressive variations of analogical ritual on a par with the other analytical variations we have been studying here.

Two different modes are to be distinguished in analogy: transformative and stative. ${ }^{56}$ Transformative analogy seeks to change the state or status of a patient. Stative analogy describes an already existing state or status. The latter type is often used to describe a patient's condition which is then to be rectified by transformative ritual. Usually the tenses and moods of the verbs and the character of actions indicate which analogical mode is at hand. Imperative, jussive, or future tenses in a verbal analogy are signs of the transformative mode. ${ }^{57}$ Actions that indicate status change are transformative. Past tense verbs in verbal analogy are indicative of the stative mode. Stative analogy may also be hidden in transformative formulations, behind adjectives and relative clauses which suppose a preexisting condition. In actions, stative analogy is to be found in manipulations, gestures, or acts which characterize the state of the patient in preparation for a transformative act that undoes that state.

Before exemplifying the foregoing modes it is to be noted that analogy often appears in compounded form. There are (at least) four types: coordinated, subordinated, string, and mixed-dimensional compounding. Coordinated compounding is when a number of individual analogies on an equal plane with one another occur within a single analogy. Subordinated compounding is where an analogical element appears that is not on an equal plane with the main analogical element(s). This is often found in cases where a stative analogy describing a preexisting condition is embedded in a transformative analogy that seeks to change that preexisting condition. String compounding is the juxtaposition of a series of complete analogies. Mixed-dimensional compounding is where one or more hidden or implicit analogies appear inside an explicit analogical statement or act.

55 The cow rite could be made an intersecting type by having the patient hold the cow's horn. To speculate about how a rite could be made into the other type will throw light on the variations.

56 My category "transformative" overlaps somewhat with Tambiah's category "prospective" (versus "retrospective", his correlative category; see his "Magical Power", 189), but is essentially different. His is a category of response: prospective ritual prepares for matters that lie in the future and restrospective ritual responds to preceding events. My category of transformative analogy concerns only the change of status without reference to future (or past) circumstances. A finer distinction between types of transformative analogy could be made, such as between those which have a jussive or imperative color versus those that are predictive. 
A few examples will clarify the issues of modes and compound analogy. Coordinated compounding appears in the Tunnawiya cow rite. Close analysis shows that while there is a single analogy syntactically, there are actually two equal ranking analogies there:

Phoros 1: Sungod, my lord, just as this cow is fertile,

Phoros 2: and (is) in a fertile pen, ${ }^{58}$ and keeps filling the pen with bulls (and) cows,

Theme 1: indeed, in the same way may the offerer be fertile!

Theme 2: $\quad$ May she in the same way fill (her) house with sons, daughters, grandchildren, great-grandchildren, [ ] in successive generations.

Two types of compounding can be seen in the Samuha onion analogies brought above: (1) two complete analogies occur together in a chain and are hence string analogies, and (2) as we have noted, "inside" these two analogies is perhaps a hidden analogy based on the play between the words suppiwašhar, sippai- and suppi-, which provides a case of mixed-dimensional compounding. What is interesting about the complete analogies is the way the different modes appear in the string. Both are verbally formulated as transformative analogies, but in conceptual function they are not of the same type. The first analogy is a quotation of what is thought to have already happened. It describes a negative condition that has fallen upon the temple and the patients. Its rhetorical strategy is to set the stage for using the second transformative and purifying analogy. Therefore, though the first analogy is transformative, since it is a quotation of a past event, it functions statively - a virtual stative analogy.

A more complicated case is found in the imprecatory Psalm 109. We will spend a bit more time with this example to see how the various analytic distinctions described in this paper can elucidate our reading of ritual texts. How the parts of this composition are to be related to one another and how the MT is to be improved upon are disputed points. I operate on the assumption that vv. 6-19 are a formulation of the psalmist and are to be understood as a quotation of an attack that his enemies are making against him. In this case the singular enemy in vv. 6-19 (vis-à-vis the plural enemies in the other verses) is not the psalmist's enemy, but the psalmist himself as an enemy from the point of view of his enemies. I also take the MT at its word, not because this is necessarily the "original" text, but because it objectively lies before us, is intelligible, and offers some temporal nuances that will allow the honing of analytical tools.

We concentrate on vv. 6-19, especially $17-19$. The section opens with the enemies of the psalmist trying to concoct some legal proceedings against him by

58 This initial phrase of the second phoros might be taken as constituting a phoros separate from the phrase that follows, thus yielding a total of three phoroi. I have not subdivided the second phoros since this first phrase does not have a corresponding theme. One could say that the second phrase in the second phoros explains what a fertile pen is. Conceptually, then, it would form a unit with the second phrase. 
which he will be convicted. But this is not all, they are presented as pronouncing a curse of karet ("cutting-off") and domestic destruction on the psalmist (early death, loss of property, extinction of posterity, etc.). The rationale for the judicial proceedings and the utterance of this curse is given late in the quotation. They say that he is guilty of not having remembered kindness (haesaed) and has persecuted the poor (v. 16). Metaphor (capitalized) and simile (with phoric transfer, capitalized) are then used in vv. 17-18 to augment this deficient condition which was spoken of nonfiguratively in the previous verses:

\section{Metaphor:}

(17) He loved curse, so this HAS COME UPON him.

\section{Metaphor:}

He did not desire blessing, so that has BECOME DISTANT FROM him

Simile:

Theme: (18) He has PUT ON curse

Phoros: like a cloak,

\section{Simile:}

Theme: it (= curse) HAS ENTERED HIS BOWELS

Phoros: like water

Simile:

Phoros: and like oil

Theme: (it (= curse) HAS ENTERED) INTO HIS BONES.

In the MT these two verses, containing a string of five stative analogical statements (the last elliptical), describe the state of affairs that exists from the psalmist's view of the enemies' point of view. In v. 17 metaphors of distance have been used. ${ }^{59}$ As we first read this verse we do not know exactly how the closeness of curse and the distance of blessing might be interpreted in terms of a fuller analogy. That is, curse and blessing are near and distant like unto what? The similes in v. 18 have a more complete analogical form and make our perception more precise. By v. 18's first saying that he has put on curse like a cloak, the reader/reciter interprets the "coming upon" in v. 17a as having to do with the proximity of clothing. The distancing of blessing in $\mathrm{v} .17 \mathrm{~b}$ is not further defined, but it is informed contrastively by the detail given about curse. V. 18 continues with other proximity similes: it enters his insides like water, i.e., like water one drinks, and into his bones like oil, presumably referring to an alimentary situation. ${ }^{60}$ Thus, this particular string passes from general to more pre-

59 The second metaphor about blessing being distant alerts us to the metaphorical character of the first metaphor which, with the verb "has come upon", does not strike us at first as a strong metaphor.

60 These figures are not entirely clear. The water simile brings to mind the bitter cursing waters of the suspected adulteress (Num 5:11-31). While an echo in some way need not be denied, the simile is simply "like water" not "like ordeal or cursing water". 
cise analogical forms and images. This demonstrates how strings may function together to focus and intensify perceptions.

But this focussing does not end with v. 18. Vv. 17-18 contained stative analogical forms describing what had already occurred; v. 19 continues with a transformative simile whose phoros is a coordinated compound:

Theme: (Therefore,) let it (curse) be for him

Phoros 1: like a garment in which one covers oneself,

Phoros 2: $\quad$ and like a girdle which one regularly puts on.

This propels what has already been conceived of as happening into the future: it asks that the curse that has already befallen the "enemy" (i.e., the psalmist) continue. The analogical expression has become more intense: in v. 17 there were stative metaphors, then in v. 18 stative similes, now in v. 19 a transformative coordinated compound simile. The stative forms can be seen as not simply describing a situation but serving to underscore the transformative curse in $\mathbf{v}$. 19. They almost serve, collectively and conceptually, as a phoros against the entirety of v. 19: just as the psalmist has been affected with curse already, so may he continue to be affected.

Another example showing the compounding of analogy and its different modes is in the Alli ritual. This contains a string of nine similarly formulated rites. ${ }^{61}$ In each of the first seven rites, the old woman officiant places ${ }^{62}$ a different color thread representing the evil on a patient suffering, as these sections state, from "magic" (alwanzata[r]) ${ }^{63}$ In each case the old woman recites a descriptive incantation as she removes the thread and wraps it around

Likewise the oil simile may be an alimentary counterpart to the water simile, with no particular association with other ritual.

61 i $31-36,37-40,41-44,45-48,49-53,54-58,59-63,64-68,69-73$. The beginning of column ii may be the conclusion of the series. It has another wool rite (the "enemy-making-peace" analogy, referred to above), but its formulation is different.

62 The placement of a thread on the patient is only explicitly stated in the first rite. It seems implicit in the following six rites in the old woman's use of the phrase "I am taking from $\mathrm{him} / \mathrm{her}$ (i.e., the patient)" -si daskimi and in the subsequent winding of the threads around the figurines.

63 Elsewhere in the ritual "evil magic" idalu alwanzatar in ii 32; iii 38. The ritual lists other evils of which the patient is being cured or purified: "sickness" (inan; i 25), "evil" (HUL/idalu-, sg. and pl.; i 61; ii 12, 13, 36, 38, 42; iii [40?]; iv 16 [variant text H]), "impurity" (papratar, in apposition to alwanzata[r]; ii 10); "evil dreams" (idaluweš tešhuš, in apposition to alwanzata[r]; ii 23); "evil tongue" (idalu- EME; iii 37; clay and wax tongues representing this evil are used in the ritual; cf. i 3, 4; ii 61, 62; cf. ii 28); and "evil war (?)" (idalu hullanzatar; iii 38). In addition to this, the ritual acts seem to indicate that some sort of sorcery or witchcraft is to be considered the evil (perhaps the former since it appears to be considered a volitional act). To be added to this are the more metaphorical descriptions of evil such as we will treat in this section of this paper. On some of the evils, cf. Jakob-Rost, Malli, 56-57. 
a figurine representing the magician who caused the evil. In the eighth and ninth rites a black fleece and wine are used, respectively. How these items are manipulated is not clear, but the formulation of the incantations is similar to the foregoing thread rites and thus makes them part of that series. ${ }^{64}$

The green-thread rite displays how analogy works at a specific level and reflects the issues involved in the other individual cases in this series. The text reads:

Phoros (ritual action): (45) [After thi]s, she (i.e., the old woman) forms green wool into a thread in the same way (as before). She [says] the following:

Theme: (46) "[Whoever] did magic on [th] is person, whoever MADE (him/her) GREE[N],(47) [now] I am TAKING magic (and) GREENNESS FROM him/her. (48) I am GIVING IT BACK to its [master]."

Phoros (continued): She winds the thread around the figurines.

This rite consists of a ritual action with a verbal accompaniment. The recitation is not an explicit analogy, with its own phoros and theme, but a metaphorcontaining thematic statement whose phoros is the ritual action. The metaphors in the thematic statement are: "making green", "greenness" ${ }^{15}$, "taking from", and "giving back". These derive from the ritual action. One can imagine ways of expressing the theme without these specific terms that connect it to the ritual action. Fleshing out the full analogy that lies behind the ritual action and incantation with demetaphorization of the theme, we get with something like

Phoros: just as I take from the patient this green thread which has been placed on $\mathrm{him} / \mathrm{her}$, and place it on the figurines,

Theme: so the magic and affliction that was inflicted upon the patient will be terminated and affect the one who caused it.

The spoken element in the actual recitation matches only the thematic member in this reconstruction. The phoros appears in the performance only.

This reconstructed analogy helps to bring into view the compound elements and modes in the rite. The main analogy (fleshed-out, above) is a coordinate transformative analogy: (1) as I take this green thread ... so magic and affliction

64 The black fleece and wine are apparently held up to mark their ritual presence and point of reference, much like the grasping of the cow horn in the Tunnawiya rite, noted above (note the phrase "I hold the black wool," Alli i 65). The items at the end of the Alli series must have been used in contact with the patient or in his/her proximity since the verb "I am taking" daskimi appears with the fleece (i 67; i.e., taking away) and the functional equivalent "I am removing drunkenness" arha wiyaniškimi appears in the case of the wine. What was done with these materials after this is not known (but cf. ii 16).

The noun "greenness" ( SIG $_{7}$ SIG $_{7}$-ta) appears in apposition to "magic" (alwanzata), almost as if it the latter is an anticipatory gloss to define "greenness". Alternatively, "greenness" can be taken as an appositional modifier of "magic" yielding the sense "green magic". 
... will be terminated, and (2) just as I place it on the figurines ... so will it affect the one who caused it. A subordinate stative analogy lies behind this: the placement of green thread (see note 62) represents the preexisting condition that must be rectified. In the reconstructed analogy this is reflected in the relative clauses with past tenses: "green thread which has been placed on him/her" is like "magic and affliction that was inflicted upon the patient." This preexisting condition is reflected in the actual incantation by the preterite tenses alwanzahhit "did magic", hahlahhiskit "made green" (line 46). Note that in the actual incantation no reference is made to the placement of the thread. The placement is therefore a preparatory secondary act as opposed to the primary transformative act. Overlapping these coordinate and subordinate analogies is an implicit analogy in the matter of greenness constituting a case of mixed-dimensional compounding. The use of the color green has its meaning in connection with the other colored materials in this series of rites. The implicit analogy could run something like: "just as green and other colors are indicative of affliction, so magic is afflicting." There is another implicit analogy in the winding of the string around the figurines: "just as string is wound around and confines the figure, so magic will be wound around and confine the one who created the real magic." Though the thread is apparently not wound on the patient (cf. i 31-32), the winding on the figurines does tend to characterize the afflictive character of the patient's suffering. This combination of explicit and implicit, coordinate and subordinate and transformative and stative analogies gives the individual rite its effect and depth.

Now this particular "greenness" rite, as we have said, is part of a larger series of similar rites. Its meaning and effect derive not only from the specific features within it but from its relation to the other rites in the series. Hence a macroanalysis of the string of rites together in addition to the micro-analysis of the individual rites is necessary. I have already noted that the analogical significance of the color green is dependent on the entirety of colors used in the series. In this respect all the colors serve collectively in an implicit phoros against the magic that is suffered. But each rite also serves individually in an accumulative fashion, in the manner that we have seen in Psalm 109. One way of considering this interaction is in terms of the performed or experienced ritual. The performed ritual is like a musical composition which takes place over a period of time. In the series, there is an accumulative power in the analogies as one moves from the first to the last: (1) thread of an undefined color, (2) red wool thread, (3) black wool thread, (4) green wool thread, (5) blue wool thread, (6) white wool thread, (7) white linen thread, (8) a black fleece, and (9) wine. What is interesting here is that as we come to the end of the series, there is a movement away from threads toward other objects. Too, though the form of the incantations remains essentially the same, the incantations with the fleece and wine are a bit longer. In short, by the complementary 
piling up of all these rites, the ritual has the effect of characterizing the totality of the evil that the patient is suffering and, consequently, its total removal. And it does this in a climactic way, through variation of analogical materials and lengthening of recitations at the end of the series.

One last analytical point - one self-evident from the examples presented and from the comments about transformative and stative analogy - is that ritual analogy is concerned with describing or establishing two basic qualities or states: blessing or curse. The category of blessing includes any positive state such as healing, annulling of portended evil, purification, or sanctification. Curse includes any negative quality, such as sickness, magical affliction, or impurity. The cow, door socket, hattalkišna-wood, second onion, peace-making, and ablution analogies are examples of analogical blessing. Pss 35:5a, 140:12b, the Mattiwaza treaty, the first onion analogy, Jer 51:63-64, the Huwarlu dog rite, and Ps 109:17-19 are examples of analogical curse. Sometimes there is a mixture of qualities in one example: the cloak tearing rite in $1 \mathrm{Kings} 11$ curses Solomon and blesses Jeroboam; the Alli thread-fleece-wine analogies bless the patient and curse the sorcerer.

While other points of analysis can be listed and discovered, and while those given can be refined, this survey provides the basic perspectives for the analysis of the forms and content of analogical ritual. As we began to see with the last examples - though not fully because of space limitations - analysis along these lines lights up some dark corners of ritual formulation and practice. We begin to perceive the symbolic dynamics within rites and rituals and begin to understand something of the logic that inheres in them. What remains for us now is making a brief statement about the conceptual bases and general logic of this type of ritual.

\section{The Function and Effects of Ritual Analogy}

The ubiquity and concentration of analogy in biblical and Hittite ritual raises the difficult but fundamental question of why such forms were used. In days past one might have heard the response that these ritual constructs arise from a false science; i.e., primitives so-called have false conception of natural law and "reality" and hence wrongly associated causes and effects. ${ }^{66}$ One might have heard also that the "primitives" have a different logical mentality from ours: persons, objects, materials, and other phenomena are seen to participate together in a mystic way that to us is illogical or better, as it is argued, prelogi-

66 Frazer, Golden Bough: Magic Art, 1: 53. He says, for example, "magic is a spurious system of natural law as well as a fallacious guide of conduct; it is a false science as well as an abortive art." He qualifies himself immediately saying that it is not really a science, but an art, a "bastard art." 
cal. The relationship of items and persons meant that affecting or manipulating an item was perceived as a way to affect an item associated with it. ${ }^{67}$ In the last two generations, these views have been replaced with or largely modified to views which credit members of primitive - now better called traditional or preindustrial $^{68}$ - societies with conceptual aptitude and the ability to discern an "empirical reality" (basic causes and effects) despite whatever complementary "mystical reality" they may entertain. This is not to say that there is now a consensus regarding how the thought of traditional peoples is to be understood, but there is a growing tendency to see their way or ways of thinking - and the significance of this plural will be borne out below - as similar to ours, though with different cultural content, rather than to see it as an entirely distinctive mode of perception. ${ }^{69}$

In line with the spirit of recent study, together with hints from literary, rhetorical, and linguistic theory and study, it may be suggested that the generative matrix of analogical ritual is the linguistic and psychological necessity to represent the unknown with the known, what we can term metaphorical thought. This mode of thought in ritual is akin to our use of metaphor in language in general and in literary and rhetorical contexts more specifically, whose main effect and concern is pellucid, engaging, and persuasive expression and conceptualization. Metaphorical thinking contrasts with but exists in the same mind alongside empirical thinking, which itself may be founded in part on metaphorical perception, but which is based on everyday, replicated, and replicable experience and has a greater degree of object- or event-directed review, criticism, and skepticism than does metaphorical thinking. Empirical thinking of this latter sort is (or is thought to be) the hallmark of western science. ${ }^{70}$ Ritual analogy, being metaphorical, is thus not scientific, i.e., it does

Cf. Lévy-Bruhl, How Natives Think, esp. pp. 69-104.

"Preliterate" is used by some, but cannot be employed for the biblical and Hittite societies.

69 See, for example, the essays in Horton and Finnegan, Modes. See also Littleton, "Introduction".

70 This is not to say that metaphorical thinking does not play a part in scientific thought; see Tambiah, "Form", 209-211. Empirical and metaphorical thinking should not be thought of as modes that exist without each other. They are part of one mind. Indeed, to separate them as I have done here is certainly a false move, but one that for the moment is heuristically helpful. Though these forms of thought exist together, there are certain situations or conditions which favor one over the other. This favoring is at a specific level due to the type of problem that is being dealt with: empirical thought seems more prominent in mundane, practical, investigative matters while metaphorical thought is prominent in matters that are more difficult, unique, emotionally engaging, and require creativity. Favoring one type of thought is also due to broad historical, intellectual, sociological, political, religious, etc. developments: a society may become generally predisposed to one type of thought over another because of inherited tradition (cf. 
not derive from an attempt at empirically sorting out effective and ineffective procedures that could cause blessing or curse.

It is true that some cures or curses utilize materials with properties that can physiologically or medicinally produce described and desired effects and that analogical rites can have psychosomatic or placebo effects. But the rites with "active ingredients" are few and the psychosomatic effects ${ }^{71}$ cannot explain the use of analogy in the first place. Furthermore, adopting the explanation of metaphorical thinking in analogical ritual is not to deny that some expressions or procedures were thought of by their users as having a literal or direct result. $^{72}$ But this, again, does not explain the origin of analogy's use. It would seem that the notion of a metaphor's literality is a secondary or superimposed articulation of the metaphorical idea based on cultural and social concerns and factors rather than inherent in the linguistic and psychological matrix of metaphorical thinking. Hence, the facts that certain ritual practices may produce psychosomatic effects and that the practitioners sometimes interpret these practices as directly effective do not gainsay a metaphorical origin for these practices and their persisting latent metaphorical power. Let me emphasize and expand this last point: it would seem that the metaphorical character of analogy still functions to perpetuate the practice of an analogical rite even when performers claim that this rite is not to be understood metaphorically.

As with most psychologically oriented theories the foregoing assertions are difficult to prove because of inaccessibility to evidence, and here especially by one trained as a philologist. Nevertheless I will venture forth in what follows and discuss four points that relate to - illustrate, support, or follow from - the general thesis just proposed. They are a few of the many lines of investigation must be followed.

(1) All language is metaphorical (in the general sense of that term), i.e., it describes things in terms of something else. This metaphorical quality is evident in two ways: (a) in the arbitrary correspondence of a signifier to what is signified, and (b) in the extension of language from one sphere to another due to some perceived relationship between the two spheres. Metaphorization in these ways can allow what is normally described in many words to be summarized or

Lloyd, Magic, on the development of scientific thought in ancient Greece and the West in this regard).

We no doubt underestimate the psycho-physical effects of ritual. This it seems is largely because we students of foreign cultures are not at home in the social and cultural context that we study and thus cannot be moved as the native participants are or were moved.

72 Reasons for the development of this idea include the fear that a metaphoric perception would lead to ritual change, relaxation, abeyance, or termination. It may also derive, after the fact, from the type of form used. I will discuss below forms that tend to keep metaphoric perceptions alive. 
encapsulated in a single or a few words. It also can make what is nebulous welldefined and concrete. In the second sense, metaphorization also widens comprehension of objects and phenomena by bringing into descriptions of them external and ultimately unrelated characteristics that inform perceptions of the object or phenomenon. ${ }^{73}$ Thus metaphor has a rhetorical function in shaping the responses of those experiencing and using it.

Ritual analogy seems to arise out of and operate within this context of metaphorical summary, concretization, and advancement of perception. It puts positive and negative conditions and processes which are complex, intangible, diffuse, or have an uncontrollable "otherness" - those situations in the themes into simple, concrete, controllable, illustrative, and perception expanding terms - the situations in the phoroi. Making effective or treating the phoric situation is a symbolic way of making effective or treating the thematic situation. In the Samuha onion analogies, for example, the evil affecting the temple is impalpable and uncontrollable. The reference to what a sorcerer may have said to pollute the building is a way for the performers to make the evil concrete and then to be able to manipulate it by peeling an onion. In intersecting transformative analogy where a thematic element is being directly treated, the metaphorical element gives a particular definition to the thematic condition or situation so that it can be accordingly treated or activated. In the case of ritual bathing, for example, the thematic evil is treated directly (i.e., washed off) and thereby is given a certain type of concreteness: it is not any type of evil (like an onion that needs peeling) but is dirt-like, the kind of stain that everyday water removes. (One of the results, incidentally, of using one metaphor instead of another is that perceptions of the evil or blessing unique to the metaphor chosen will develop. In this way analogical ritual is to be considered one of the determinants in shaping the conception of evil and blessing as they systematically develop within a particular society. ${ }^{74}$ )

As ritual analogy concretizes perceptions about what is bad or good, it also, like metaphor in literary or rhetorical contexts, enlivens perceptions and responses, generates mental involvement, and shapes attitudes. Several types of responses, - e.g., joy, hope, anger, devotion, ecstasy, aesthetic appreciation - are triggered. Perhaps of particular import are responses with social consequence. The ritual experience can create commitment to the religious order of things which in its turn supports the entire social system. More directly, analogical ritual awakens responses such as sympathy for those suffering, hatred toward

3 Sometimes comprehension may be confused by metaphor.

74 Of course the reverse is true, metaphors are chosen that are more or less consistent with the view of evil and blessing within a society. Metaphors, however, often spin off unintended meanings and thus threaten to change established perceptions. Analogy in this way can be seen as a factor in ritual and cultural change. 
those causing the evil, and respect and gratitude for the officials and government acting on behalf of the suffering or sponsoring their cure. Analogical ritual such as that in the Mattiwaza treaty is used to extract a commitment from underlings to serve their master. Compare along this line one of the several analogies from the Hittite "Soldiers' Oath" text:
He places malt (and) wort ${ }^{75}$ in their (the soldiers') hands. They lick it. He speaks to them as follows: "Just as this wort is ground by the millstone, is mixed with water, is cooked, and is mashed - whoever breaks these oaths, perpetrates evil against the king, queen, the king's children, or against the land of Hatti, may these oaths seize him! May they grind his bones in the same way! May he be stewed(?)! May he be mashed! May he be brought to an evil death!" They (the soldiers) then say: "So be it. ${ }^{.76}$

This and accompanying analogies in the text illustrate the gravity of the soldiers' obligations to their lord and thus helps to shape their response. Similarly, analogical ritual and expressions can be used to stir and fortify a band of warriors so they might be successful in battle, such as when, as the story goes, Joshua summoned the Israelites to place their feet on the necks of the five captured Amorite kings which indicated: "thus shall Yhwh do to all your enemies that you are fighting. ${ }^{n 7}$ Notably, to the extent that analogical ritual can move participants in directions hoped for, there is a cause-effect relation between the ritual and a result. But this is not the technical type of causeeffect relation which was denied above: it is not putting the feet on the necks of enemy kings that directly secures the victory; rather, the gesture helps to structure emotions so that victory is achieved; the effect is an indirect outcome of the analogical act.

(2) For ritual analogy to have the foregoing effects, it requires a certain logical quality: the situation described by the phoros must be believable. ${ }^{78}$ Many phoroi refer to natural situations: a particular cow may be fertile, doors turn in their sockets, wind blows chaff away, haltakišna-wood pulls off animal hair, smokes goes up to the sky, onions have wrapped up layers, stones sink in rivers, asses carry burdens, water washes away dirt. Other phoroi refer to acts

75 Or "beerbread" (CHD L: 71; M: 126); "barm" (Puhvel, Dictionary, 362-363). Cf. Hoffner, Alimenta, 144.

76 KBo 6.34 ii $19-30$ (trans. Goetze, ANET, 353-354; ed. and trans., Oettinger, Die militărischen Eide).

77 Cf. Joshua 10:23-25. While the specific historicity of this event may be questioned, it shows a type of ritual that could have been performed by the ancient Israelites.

78 Cf. Tambiah's passing comment on the empiricism of the Mujiwu tree in Ndembu ritual, "Form", 217. Cf. the comment of Perelman and Olbrechts-Tyteca, Rhetoric, 373, that "in the ordinary course, the phoros is better known than the theme of which it should clarify the structure or establish the value, either its value as a whole or the respective value of its components." 
that are performable: animals can be hunted and killed, enemies can make peace, cloaks can be ripped to pieces and portions parcelled out, clothing can be put on, threads and strings (ritual lint?) can be removed. A phoros occasionally may have supernatural elements which may be incredible to members of another society or cultural tradition; but for those who would use the analogical form the phoros these must be as believable as the other listed here. ${ }^{79}$ Nevertheless, despite the appearance of some supernatural phoroi, there is a tendency to use natural or everyday phoroi - situations or acts that could be agreed upon cross-culturally. If a phoros were not believable to the performers, the analogy would be a case of irony: "Just as a dog flies when it jumps off a cliff, so may our king succeed in his battle" - certainly an incantation one would hope the enemy would recite!

The natural or performable situations in the phoroi and the logical character of an analogy in building on this foundation of credibleness reveals an element of empirical thinking on the part of the users of analogy. ${ }^{80}$ This suggests that in many cases the users of this sort of ritual perceived a causative disjuncture between phoros and theme and did not take the phoros to be the direct cause of the thematic action. To put it differently, the regularity and multiplicity of phenomena in nature and practical life on the side of the phoros vis-à-vis the less consistent results on the side of theme may have prevented many cases of analogical from collapsing into a simple perception of cause and effect. ${ }^{81}$

(3) Some of the forms of analogy indicate, furthermore, that the metaphoric gap between phoros and theme may have been felt. Parallel analogy, and particularly that where there is reference to external phenomena such as in the case of the peace-making enemy or door socket analogies as well as in the simile in the Mattiwaza treaty, places a gulf between the phoros and theme that would not allow for a notion of causality. That is, a general phenomenon would not be seen as leading to a specific cure or curse. These are more clearly illustrations or examples of what is expected to occur than mechanisms for their

79 Compare Isa 66:22

Phoros: For just as the new heavens and new earth which I am making endure before me, says Yhwh,

Theme: so will your seed and your name endure.

80 Halpern, First Historians, from a different vantage point has demonstrated the empirical thinking of a biblical writer, the Deuteronomistic historian.

81 There is another element of empiricism to be noted. As is implied in this discussion, some analogical ritual is perceived as being directly effective. This means there will be many chances for ritual failure. In most cases, however, instead of the failure being used as evidence against the legitimacy of the ritual, the cultural context that begat or sustains the rite provides logical justification for its failure (e.g., the words were not said exactly right). This justification reveals an empirical way of thinking. 
occurrence. ${ }^{82}$ These cases may indicate that other forms, such as intersecting analogy, where direct effectiveness might be supposed, were not necessarily perceived as directly effective. The Alli thread-placement rite also gives an indication that analogical actions, in addition to words, could be felt as being metaphorical. The rite is performed to remove evils caused through sorcery. Though the patient has already been bewitched, the rite itself requires the placement of a thread on him or her to concretize this evil-bound situation. This move to metaphorize the already present evil hints that for the performers the thread removal and its wrapping around images of the sorcerer were also perceived as metaphoric acts.

(4) Another hint that biblical and Hittite analogical ritual is to be explained by the process of metaphorization is the fact that we western, modern, "scientific" thinkers practice and even savor analogical ritual which we understand as something metaphorical. Two examples. The rhetorician Wayne Booth in a recent discussion of metaphor told of an experience that a lawyer friend had when the latter defended a large southern utility company against a smaller company. The defense was confident of victory until counsel for the smaller concern approached the jury with the following: "So now we see what it is. They got us where they want us. They're holdin' us up with one hand, their good sharp fishin' knife in the other, and they're sayin', 'you jes set still, little catfish, we're jes gonna gut ya." When this was finished the defense was routed. ${ }^{83}$

This example is not so remote from those seen in the Bible and Hittite literature. The courtroom scene is a quasi-ritual situation and the metaphor of the plaintiff's lawyer is thus a quasi-ritual speech. The speech operates in much the same way as outlined, above. It concretizes the attack made upon the smaller company. But more, its formulation is calculated to engage the energies and loyalties of the jury so that the members' jugdment would be swayed in favor of the smaller company. Social roles and alliances were thus defined. The

82 And here one can begin to think of the distinction between arguments from example, illustration, model, and analogy in rhetoric (see Perelman and Olbrechts-Tyteca, Rhetoric, 350-398) and how such distinctions can be brought into the analysis of different types of ritual analogy.

Booth, Company, 304. The form of this metaphor is worth noting. It includes a citation (or feigned citation) of what the enemy is saying, like the first onion analogy in the Samuha ritual or Ps 109:6-19. The analogy is expressed as a metaphor without a phoric phrase existing separately. The full analogy (abbreviated) would run something like: "Just as one holds up a catfish ... to gut it, so the small company is about to be (or is being) ruined." Since it is a quotation, it has a quasi-stative function. That is, the transformation that is sought is not the gutting of the fish, but rather the consequent neutralization of this threat. By the way, Wuthnow, Meaning, 100 , notes that a "jury trial ... is clearly one of the central rites [my italics] of the modern system of jurisprudence". 
large company became the sorcerer or the attacking demon; the small company became the innocent sufferer; and so society came to the rescue.

If this example seems too distant from ancient Near Eastern ritual, another might be more compelling. A British news report, which I heard on Israeli television (ITV), dealt with a protest against Prime Minister Margaret Thatcher's proposed poll tax in the late winter of $1990 .{ }^{84} \mathrm{~A}$ mass of protesters were trying to breach a police barricade to a public building but were unsuccessful. The report then noted that they set an effigy of Mrs. Thatcher on fire. The general analogy implicit in this act is clear: the protesters hope that as the dummy was deformed, mutilated, and suffered an inglorious end, so Mrs. Thatcher, or at least the proposal she was supporting, would fail. Of particular interest, however, is the rite's denouement and the reporter's summation. The film showed the dummy burning and falling to the ground, perhaps by accident. The reporter ended with an analogy, using words close to: "Protesters hope that as Margaret Thatcher fell, so she would come down from her poll tax." Here members of modern western society performed an analogical rite and the reporter, surely as skeptical and empirical as any journalist in Britain, threw in his own interpretive analogical spell. ${ }^{85}$ Analogical ritual is thus not foreign to us, but part of our way of thinking.

\section{Conclusion}

This study has attempted to define the major formal characteristics of ritual analogy in the Bible and Hittite literature. It has further essayed to explain in part the conceptual significance of this ritual and thus why analogy was used. What has been said here about form should aid in the analysis of any rite, even though the particular case may appear to be lacking analogy, since analogy permeates ritual through and through and may be hidden under the surface configuration. Searching out and describing the formal characteristics listed in this paper will also help give a precise understanding of the intersignification of individual elements in ritual. To name is to know and this study goes a long way in identifying and describing the relationship of meaning between the different elements of ritual analogy. The discussion about form has shown,

84

Seen and heard by the author March 9, 1990 (8:20 p.m.).

Other examples of analogical ritual in the modern western world can be found. In view of recent political debates in the U.S., one thinks about flag burning as analogical ritual. A common example is tossing darts at or otherwise mutilating a picture of an imagined unworthy. Sports (especially high school and collegiate) have their priesthoods (cheerleading squads, pep clubs, etc.) and recite incantations (cheers) and perform analogical rites (e.g., stealing or kidnapping the other team's or school's emblem or mascot or performing an act where the emblem or mascot is symbolically conquered at an athletic contest). 
moreover, that ritual texts or phenomena that are not generally considered together, for example, metaphor in the Psalms and ritual acts or recitations in comprehensive texts, are to be generically related. This kinship is suggested by the appearance of analogical forms in the diverse texts. This association, however, is also betokened by the occasional similarity of content in these texts. One can compare, for example, Ps 109:17-18 and especially v. 19, discussed above, with the following incantation from the Alli ritual:

(16) [I]f a [woman] has performed (a ritual) on him/her (the patient), you, Sun-god, know her. (17) May [i]t (the evil) be a kureššar-hat <for her>! May she set it up on her head! (18) May she take [th]em (the evils) back! May it be a girdle for her! (19) May she bind [them] (the evils represented by the girdle) on herself? May it be a shoe for her! May she put it on! $!^{86}$

In both the evil is compared to clothing that the malefactor is to wear.

Apart from form, what has been said in this paper about the rationale for the rites will broaden our perception and appreciation of the logic inherent in ritual activities. While the actual success or failure of a rite and whether or not performers believe in the direct efficacy of their rites can remain subjects of study, investigation of rhetorical, social, psychological, and linguistic motives and effects in analogy will be seen as more productive and interesting avenues

86 i 16-19. Jakob-Rost, Malli, 23, translates lines 17-19: "(17) [so soll e]s <ihr> eine Kopfbedeckung sein, und sie soll sie auf ihren Kopf drücken, (18) [und sie] soll sie zurücknehmen; und es soll ihr ein Gürtel sein, (19) [und] er soll [sie] einschnüren; es soll ihr ein Schuh sein, und er soll sie drücken." (The Hittite is: (17) [na-a]t<-si> TUG $k u$-ri-es-šar e-eš-du na-at-ša-an I-NA SAG.DU-ŠU ši-ya-an har-du (18) [n]e-za EGIR-pa da-a-ü iš-hu-zi-sa-at-si e-eš-du (19) [ne-]iz iš-hu-zi-id-du KUŚ E.SIR-ma-at-ši e-eš-du na-at-za šar-ku-ud-du.) Jakob-Rost's translation is questionable. It seems that the subject of the verbs referring to clothing placement have the sorceress as the subject, not the pieces of clothing. Except for Siyan hardu (line 17) regarding the headcovering, the other verbs (ishuziddu and sarkuddu) have the reflexive $-z(a)$ particle which suggests that the sorceress is doing the action to herself. The verb sarkuwai- (line 19), too, can mean simply to "put on (shoes)" (cf. StBoT 28, 1.a I 17; 2.a.1 I 8; KUB 34.118 ii 7 [cf. line 6 where la- "untie, unbind" is the opposite; cf. CHD L: 2a]; KUB 36.7a iii $40-41$ + KUB 17.7 iii 10-11 [cf. CHD L: 62a]; etc.). Lastly, in Jakob-Rost's translation, the apparently rightly restored $e$-pronoun in [ne]-iz of line 19 has to be taken as a nominative singular common gender (so Malli, 110: "N.Sg.!c.!," referring to the girdle). In the translation offered here it may remain an accusative plural neuter, like that in the previous line. (Admittedly, the $-a t[-]$ and $e$ - pronouns here are still difficult). - Note the placement of the clothing on three prominent and widely distributed body parts: head, waist, and feet. This reminds one of the placement of blood on the ears, thumbs, and big toes of Aaron and his sons when they are consecrated (Exod 29:19-20; Lev 8:22-24), the placement of blood and oil on the same body parts of a person recovered from șära'at (Lev 14:14, 17, 25, 28), and the placement of blood on the temple building doorposts, on the altar in the temple courtyard, and on the doorposts of the gate to the inner court of Ezekiel's temple complex (Ezek 45:19). The whole is affected by treating three prominent parts. 
since this sort of investigation generally offers a positive estimation of ritual activity and is a hermeneutical endeavor that is quite open-ended.

Finally, I have not sought to make conclusions about genetic connections between Israelite and Hittite practices at this point in my study. One might think that the broad similarity between biblical and Hittite analogical rites, and even the occasional specific similarity in content, such as that between Ps 109:19 and Alli i 16-19, just noted, are evidence of a hereditary relationship. While similarities cannot be quickly dismissed, it seems that those we have seen so far are fortuitous, especially now after looking at the psychological and rhetorical rationale of analogical ritual. Analogy is to be found in the ritual of every society, and common everyday situations, such as putting on clothing, serve as the raw materials for building metaphors to describe the indescribable. Only when form and content tightly overlap can we begin to think of historical connections. Perhaps the future will provide us with this evidence. 
Bibliography

Barré, M. L., "The Extrabiblical Literature", Journal of Religion and Culture 19 (1984) 53-72

Booth, W.C., The Company We Keep: An Ethics of Fiction, Berkeley 1988

Douglas, M., "Social Control of Cognition: Some Factors in Joke Perception", Man 3 (1968) 361-376

- "Deciphering a Meal", in: Implicit Meanings, London 1975, 249-275

Faraone, $C A$., "Hermes But No Marrow: Another Look at a Puzzling Magical Spell", ZPE 72 (1988) 279-286

Farber, W., "Associative Magic: Some Rituals, Word Plays, and Philology", JAOS 106 (1986) 447-449

- Schlaf, Kindchen, Schlaf! Mesopotamische Baby-Beschworungen und Rituale (Mesopotamian Civilizations Series), Winona Lake/IN 1989

Feinman, G.M., "Mesoamerican Temples", pp. 67-82 in Temple in Society, M.V. Fox (ed.), Winona Lake 1988

Finnegan, $R$. Hortom, $R$.

Fohrer, G., "Die Gattung der Berichte über symbolische Handlungen der Propheten", ZAW 64 (1952) 444-476

- $\quad$ "Prophetie und Magie", ZAW 78 (1966) 25-47

- Die symbolischen Handlungen der Propheten, Zurich ${ }^{2} 1968$

Frazer, J.G., The Golden Bough: A Study in Magic and Religion, Part I: The Magic Art and the Evolution of Kings, 2 vols., London ${ }^{3} 1911$

- The New Golden Bough, in: T.H. Gaster (ed.), New York 1959

Goetze, A., "Contributions to Hittite Lexicography", JCS 1 (1947) 307-320

- Kulturgeschichte Kleinasiens (2d ed. HAW III.1.3.3/1), München 1957

- / Sturtevant, E.H., The Hittite Ritual of Tunnawi (AOS 14), New Haven 1938

Goode, W.J., Religion Among the Primitives, Glencoe 1951

Halperm, B., The First Historians: The Hebrew Bible and History, San Francisco 1988

Hillers, D., Treaty-Curses and the Old Testament Prophets (BibOr 16), Roma 1964

Hoffner, $H A$ A., Alimenta Hethaeorum: Food Production in Hittite Asia Minor, New Haven, 1974 Horton, $R$ / Finnegan, $R$. (eds.), Modes of Thought: Essays on Thinking in Western and NonWestern Societies, London 1973

Hutter, M., Behexung, Entsühnung und Heilung: Das Ritual der Tunnawiya für ein Königspaar aus mittelhethitischer Zeit (KBo XXI 1 - KUB IX 34 - KBo XXI 6) (OBO 82), Freiburg (Schweiz) / Göttingen 1988

Jakob-Rost, L., Das Ritual der Malli aus Arzawa gegen Behexung (KUB XXIV 9+) (THeth 2), Heidelberg 1972

Kronasser, H., "Das hethitische Ritual KBo IV 2", Die Sprache 8 (1962) 89-107

Lebrum, $R$. Samuha: Foyer Religieux de l'Empire Hittite (Publications de l'Institut Orientaliste de Louvain 11), Louvain-la-Neuve 1976

Lévy-Bruhl, L., How Natives Think. Ed. with a new introduction, Princeton 1985 
Littleton, C.S., "Introduction: Lucien Lévy-Bruhl and the Concept of Cognitive Relativity", in: $L$. Lévy-Bruhl, How Natives Think, Princeton 1985, v-lviii

Lloyd, G.E.R., Magic, Reason, and Experience: Studies in the Origins and Development of Greek Science, Cambridge 1979

Milgrom, J., Studies in Levitical Terminology, I: The Encroacher and the Levite; the Term 'Abodah (University of California Publications: Near Eastern Studies), Berkeley, 1970

- Cult and Conscience: The Asham and the Priestly Doctrine of Repentance (SJLA 18), Leiden 1976

Moyer, J.C., "Hittite and Israelite Cultic Practices: A Selected Comparison", pp. 19-37 in Scripture in Context II: More Essays on the Comparative Method, W. Hallo, et al. (eds.), Winona Lake/IN 1983

Oettinger, N., Die militárischen Eide der Hethiter (StBoT 22), Wiesbaden, 1976

Olbrechts-Tyteca, $L \rightarrow$ Perelman, $C$.

Otten, $H$., "Ein Reinigungsritual im Hethitischen: GIS batalkišna-", AfO 16 (1952-53) 69-71

- "Das Ritual der Alī aus Arzawa", ZA 63 (1973) 76-82

Perelman, C. / Olbrechts-Tyteca, L., The New Rhetoric: A Treatise on Argumentation, Paris 1969 Penner, H., "Rationality, Ritual, and Science", in: J. Neusner, E.S. Frerichs, P.V.M. Flesher (eds.), Religion, Science, and Magic in Concert and in Conflict, New York/Oxford 1989, 11-24

Puhvel, J., Hittite Etymological Dictionary, Vols. 1 \& 2, Berlin 1984

Ricks, S.D., "The Magician as Outside in the Hebrew Bible". in: P. Flesher (ed.), New Perspectives on Ancient Judaism (vol. 5), Washington / Lanham, MD 1990, pp. 125-134

Schott, A., Die Vergleiche in den akkadischen Konigsinschriften (MVÄG 1925), Leipzig ${ }^{2} 1926$

Schulz, H., "Zur Fluchsymbolik in der altisraelitischen Gebetsbeschwörung", Symb. 8 (1986) 35-59

Segal, $P$., "More Parallels between the Priestly Literature and the Hittite Instructions for Temple Officials", Shnaton 7-8 (1984) 265-68

Sturtevant, E.H. $\rightarrow$ Goetze, A.

Tainbiah, S.J., "The Magical Power of Words", Man 3 (1968) 175-208

- "Form and Meaning of Magical Acts: A Point of View", in: R. Horton / R. Finnegan (eds.), Modes of Thought: Essays on Thinking in Western and Non-Western Societies, London 1973, 199-229

Weidner, E.F., Politische Dokumente aus Kleinasien: Die Staatsverträge in akkadischer Sprache aus dem Archiv von Boghazköi (BoSt 8), Leipzig 1923

Weinfeld, M., "Social and Cultic Institutions in the Priestly Source Against Their Ancient Near Eastern Background", in: Proceedings of the Eighth World Congress of Jewish Studies: Panel Sessions - Bible Studies and Hebrew Language, Jerusalem, 1983, 95-129

Wright, D.P., "The Gesture of Hand Placement in the Hebrew Bible and in Hittite Literature", JAOS 106 (1986) 433-46

- The Disposal of Impurity: Elimination Rites in the Bible and in Hittite and Mesopotamian Literature (Society of Biblical Literature Dissertation Series 101), Atlanta/GA 1987

Wuthnow, R., Meaning and Moral Otder: Explorations in Cultural Analysis, Berkeley 1987 
Diskussion zum Thema "Opfer- und Eingeweideschau" 

Opfer- und Leberschau in Israel

Philologische und historische Aspekte

Die Beschauung von Eingeweiden und Lebern geschlachteter Tiere (extispicium), besonders von Schafen (ovis aries), war bei den Semiten des Alten Orients weit verbreitet. ${ }^{1}$ Die Bekanntheit dieser Wissenschaft bei den im Westen siedelnden Etruskern bezeugt deren große Verbreitung im Mittelmeergebiet. ${ }^{2}$ Auch die Phöniker als unmittelbare Nachbarn der Israeliten dürften die Leberschau gekannt haben. ${ }^{3}$ Dagegen wird in der Bibelwissenschaft angenommen, da $ß$ die Israeliten vom Anfang ihrer Geschichte an das Extispizium wegen ihres Jahweglaubens abgelehnt hätten und darin u.a. auch die Unterscheidung Israels vom Götzendienst der Umwelt begründet sei.

Aufgrund der großen Ausbreitung dieser Orakelart im Alten Orient würde Israel unter historischen Gesichtspunkten eine unerklärbare Ausnahme bilden, falls tatsächlich nachgewiesen werden könnte, daß die Beschauung der Eingeweide von Opfertieren bei diesem Volk unbekannt war. ${ }^{4}$ Aus einigen biblischen Stellen scheint jedoch hervorzugehen, daß diese Art der Erkundung göttlichen Willens auch in Israel zu gewissen Zeiten praktiziert wurde. In Kontrast hierzu fehlt auf archäologischer Seite aus Israel und Juda nicht nur Material, das gleichfalls in diese Richtung zeigen würde, sondern einige Anhaltspunkte legen von dieser Seite sogar nahe, die Praxis einer divinatio in Gestalt von Eingeweide- und Leberschau für Israel in Frage zu stellen. Es wird so der Anschein eines unüberwindlichen Hiatus zwischen philologisch-historischen Argumenten und archäologischem Material erweckt.

Im folgenden sollen nochmals kurz die Belege philologischer und historischer Natur zusammengefaßt werden, die sowohl einerseits für das Bekanntsein der Leberschau in Israel sprechen und die andererseits auch zu erklären vermögen, warum über sie in der Bibel weithin Schweigen gebreitet wird. ${ }^{5}$ Denn es wird auch in diesem Streit zu berücksichtigen sein, daß wir in den Berichten der kanonischen biblischen Autoren mit einer Art Dogmengeschichte des nachexilischen Judentums konfrontiert sind, das von seiner monotheistischen Einstellung her jede Form von Opferschau zur Erkundung göttlichen

Siehe den folgenden Beitrag von J.-W. Meyer in diesem Band.

2 Ribichini, L'aruspicina, 308, zur Diskussion, ob die Phöniker als Vermittler dieser Orakelkunst an die Etrusker anzusehen sind.

Ribichini, L'aruspicina, 307-317, referiert umfassend über die Problemlage.

4 Im folgenden wird auf eine generelle Behandlung der sogenannten priesterlichen Orakelkunst, die von der spăteren Bibelredaktion akzeptiert wurde, verzichtet; siehe hierzu u.a. Huffmon, Priestly Divination, 355-359.

5 Siehe ausführlich Loretz, Leberschau, 9-34. 
Willens demonstrativ ablehnen mußte und sich in der Folge auch gezwungen sah, die Vergangenheit in der Perspektive des reinen Jahwismus darzustellen. $\mathrm{Da}$ aber Funde von Leber- und Lungenmodellen in Ugarit ${ }^{6}$ und an anderen Orten für die vorisraelitische Zeit bis nach Palästina (Hazor, Megiddo) die Bedeutung der in Mesopotamien entwickelten Opferschau auch für Altsyrien und Palästina aufweisen, stellt sich von selbst die Frage, ob Israel diese Tradition tatsächlich gekannt und wie es sich zu ihr gestellt hat.

Im folgenden sollen zuerst die philologischen und dann an zweiter Stelle die historischen Fragen behandelt werden, die für oder gegen eine Ausübung der Eingeweide- und Leberschau in Israel sprechen.

\section{Philologische Hinweise auf die Ausübung der Leberschau}

Für die Durchführung von Eingeweide- und Opferschau in Israel sind Texte anzuführen, die sowohl einen terminus technicus für den Opferschauer (br) als auch für die Tätigkeit der Beschauung (bqr), den Begriff 'wt "Zeichen, Vorzeichen" sowie gesetzliche Regelungen über die Benützung von Lebern geschlachteter Tiere enthalten.

6 Dietrich / Loretz, Mantik, 1-85. 
1. $b r=b a ̈ r a ~ " O p f e r s c h a u(p r i e s t) e r " 7$ - Jes 44,25-26a; Jer 50,36; Hos 11,6

\section{Die Aussage im Buche Deuterojesaja}

mpr 'twt bdjm 8

w qsmjm jhwll

mšjb hakmjm 'hwwr $w$ d'tm jskl

$m q j m d b r{ }^{\prime} b d w$

w șt $\mathrm{mr}$ 'kjw jsljm
Der die Vorzeichen der 'Opferschauer' zerbricht, die Wahrsager' macht er zum Gespott.

Der die Weisen umkehren laßt rückwărts, ihr Wissen macht er toricht.

Der das Wort seiner Knechte verwirklicht, den Plan seiner Boten laßt er erfullen.

(Jes 44,25-26a)

wird hinsichtlich der Verurteilung der Opferschauer und Wahrsager entweder auf fremde, im Dienst anderer Götter stehende Orakelpriester oder auf Männer bezogen, die zwar im Bereich der Jahwereligion wirken, sich dabei aber nichtisraelitischer mantischer Praktiken bedienen. ${ }^{10}$

7 AHw 109-110; CAD B 121-125: bära "diviner"; zur Frage, ob punisch br' von bärâ abzuleiten ist, siehe Ribichini, L'aruspicina, 307-308.

81 brjm; Ges. ${ }^{18}, 125$ : ${ }^{*} b d_{5}$, wird bd in Jes 44,25 und Jer 50,36 im Anschluß an Haupt, Elements, zu Recht als Verschreibung furr $b r$ angesehen; HAL 105: *bd V, wird auf amurritisch baddum "e. Funktionarr" (Māri) verwiesen und bd unter Berufung auf Driver und Noth in Jes 44,25; Jer 50,36 und Hos 11,6 mit "Orakelpriester" ubersetzt; HAL 147: "br V cj ? wird auf akkadisch bära für Jes 44,25; Jer 50,36; Hos 11,6 verwiesen. Da baddum auf keinen Fall einen Operschau(priest)er bezeichnet (AHw 95: baddum [bațum?] "ein Funktionarr"; CAD 27: baddu [a military rank], mit folgender Erlauterung zu dieser Bedeutungsangabe: "The baddu is in charge of an armed reconnaissance and therefore probably an officer of military rank, or an official concerned with military affairs."), beruht die Ubersetzung von hebraisch $b d$ mit "Orakelpriester" und die Kreation eines bd V (HAL 105) entgegen Driver, Notes, 19-20, auf vollig ungesicherter Grundlage. Noth, Ursprünge, 34-35, hat zum Vorschlag Drivers, baddum mit "Wahrsager(?)" zu ubersetzen, nur bemerkt: "Das Wort wăre dann wohl mit dem in spăteren aramäischen Dialekten vorkommenden Stamm $b d$ ' = 'ersinnen', 'erdenken' zusammenzubringen; vgl. aber auch das phơnikische bd = 'leeres Geschwătz"; Edzard, Mari, 144, stellt fest: "badd/ttrum (F.), Bedeutung und sprachliche Zuordnung unbekannt. Die von Driver erratene Bedeutung 'Wahrsager(?)' paßt nicht in den Zusammenhang von ARM 2,30,9."; Rabin, baddim, schließt eine Verbindung von baddum mit arabisch biddah "strength" nicht aus. - Die Parallelităt von MT bdjm mit qsmjm und die Unmoglichkeit, für ersteres philologisch eine Bedeutung zu erheben, die auf Orakelkunst hindeutet, sprechen für die Lesung brim.

9 HAL 1041: qsm qal 3a; Werner, Studien, 122.

10 Siehe zur Diskussion Werner, Studien, 121-125. 
Da die in Parallele zu den brjm "Opferschauern" getadelten qsmjm "Wahrsager" in Israel verbreitet waren (Jes 3,2; Jer 29,8; Mi 3,7; Sach 10,2), wird zu Recht angenommen, daß für die brjm "Opferschauer" dasselbe zutrifft." Die in dem redaktionell eingefügten Text Jes 44,25-26a erwähnten Personenkreise sind alle als gleichzeitig in Juda tätig zu denken und nicht auf babylonische Verhältnisse zu beziehen.

Die 'twt "Zeichen, Vorzeichen" (siehe 1.4) der brjm "Opferschauer" werden von Jahwe als nichtig erwiesen. Allein das Wort der Jahweknechte und -boten vermag kundzutun, was Jahwe zu tun gedenkt.

Im Spruch Jes 44,25-26a werden folglich Praktiken aus dem exilisch-nachexilischen Israel beschrieben, die kaum als neuerer babylonischer Import, sondern als alte israelitische Traditionen anzusehen sind. Diesem Zeugnis zufolge wurde die Leberschau auch noch in exilisch-nachexilischer Zeit unter den Juden von der alten Zunft der Fachleute durchgeführt und scheint jedenfalls soviel Zuspruch gefunden zu haben, daß sie von der jahwistischen Prophetie als Konkurrenz bekämpft wurde.

In Jer 50,36 ist vom Versagen der babylonischen bdjm (1. brjm $)^{12}$ die Rede.

Äußerst umstritten sind Lesung und Deutung von Hos $11,6 .^{13}$ Die konsequente Schreibung $b d$ für $b r$ legt den Gedanken an eine bewußte Änderung nahe: $b r$ "Opferschau(priest)er $>b d$ "Geschwätz"14.

Wollte man die Tätigkeit des $b r=b \bar{a} r \hat{~}$ in Israel leugnen, so müßte man wenigstens eingestehen, da $\beta$ den Juden die Leberschau durch ihre Berührung mit den Babyloniern bekannt war, wie aus der Nachricht über die Leberschau $\left(r^{\prime} h b k b d\right)$ des Königs Nebukadnezar von Babylon bei der militärisch wichtigen Entscheidung über den besten Weg nach Jerusalem in Ez 21,26 hervorgeht. ${ }^{15}$

11 Werner, Studien, 122.

12 Rudolph, Jeremia, 304, rechtfertigt bdjm "Orakelpriester" mit einem Hinweis auf Sellin, Geschichte, 134.

13 Siehe Kommentare zur Stelle; Werner, Studien, 121.122.

14 Ges. ${ }^{18}, 125: b d_{4}$.

15 Zimmerli, Ezechiel I, 489-490, schließt aus dem Nebeneinander von Pfeil-, Teraphim- und Leberorakel in $\mathrm{Ez} 21,26$, daß der biblische Autor Züge israelitischer und spezifisch babylonischer Gottesbefragung mische. Die Teraphim seien spater vom strengen Jahweglauben scharf verpont worden. Das Beschauen der Leber werde im AT sonst nicht erwăhnt. - Aus Ez 21,26 laßt sich ebenso gut unter Voraussetzung der Lesung br in Jes 44,25; Jer 50,36; Hos 11,6 auch folgern, daß der Autor Orakelarten erwahnt, die alle in Juda bekannt waren. Die Auslegungsgeschichte von Ez 21,26 zeigt besonders anschaulich, wie sehr Vorurteile die Exegese leiten. 
2. bqr "eine Opferschau durchführen", ein kanaanäisch-israelitischer terminus technicus

An zwei Stellen in den Psalmen (Ps 5,4; 27,4) und an einer in den historischen Berichten (2 Kön 16,15) erscheint entweder ein Nomen bqr oder das Verbum bqr. Diese Belege werden von den Interpreten ganz unterschiedlich und oftmals widersprüchlich übersetzt und gedeutet. ${ }^{16}$ Die Diskussion über bqr litt dabei vor allem an mangelndem Vergleichsmaterial aus der Umwelt Israels.

Durch die Erkenntnis, daß in den ugaritischen Texten bqr einmal als terminus technicus der Leberschau belegt ist, wird die Diskussion darüber, ob hebräisch bqr pi in 2 Kön 16,15; Ps 5,4 und 27,4 gleichfalls auf die Leberschau zu beziehen ist, auf eine neue Basis gestellt.

a) Ugaritisch bqr "untersuchen, (eine Leber) inspizieren" - KTU 1.78:5

Die Diskussion über ugaritisch $b q r$ hat seit 1964 durch die Erkenntnis von J. Gray, daß in KTU 1.78:5 das Verbum bqr auf die Leberschau zu beziehen ist $^{17}$, neuen Auftrieb und eine gegenüber früher gesicherte Basis erhalten. Denn aus der Formulierung von KTU 1.78 geht eindeutig hervor, daß bqr die anläßlich einer Sonnenfinsternis am fünften März 1223 v. Chr. durchgeführte Leberschau bezeichnet. Diese war zur Bestimmung des positiven oder negativen Charakters des außergewöhnlichen Naturgeschens notwendig geworden. ${ }^{18}$

Allein von KTU 1.78 her wird ersichtlich, daß in Ugarit der Opferschauer eine bedeutsame Rolle gespielt hat. Der Schreiber Ili-malku bringt sich z.B. stolz als Schüler eines Opferschauers $\left(\right.$ prln $\left.^{19}\right)$ und Sekretär des Königs von Ugarit in Erinnerung.

Vom Gebrauch von bqr in KTU 1.78:5 her kann folglich ausgeschlossen werden, daß hly "sehen - prüfend ansehen/nachschauen" an einigen Stellen im Aqhat-Epos auf die Leberschau bezogen werden könnte. ${ }^{20}$

16 Siehe hierzu im einzelnen die Auflistung der gebrăuchlichen Deutungen in Loretz, Leberschau, 13.18-19.20-24.68-71.

17 Dietrich / Loretz, Mantik, 43.

18 Siehe zu Deutung und Datierung von KTU 1.78 De Jong / Van Soldt, Redating, 65-77; Dietrich / Loretz, Mantik, 39-85.

19 Van Soldt, 'Atn prin, 365-368, zu KTU 1.6 VI 55-58.

20 Fuhs, Sehen, 53-54, übersetzt in diesem Kontext (KTU 1.19 III 4.[10].19.24.33.38) kbd "Inneres, Bauch" irrtümlich mit "Leber". Wenn er ferner von $b q^{*}$ "spalten" her argumentiert, $\mathrm{da} B$ das Aufschneiden bzw. das Aufreißen der Leber und Anschauen derselben gewiß nichts 
b) bqr "Schauopfer"? - Ps 5,4

S. Mowinckel betont nachdrücklich, daß in Ps 5,4 von der Opferschau die Rede sei. Er befürwortet für das Nomen bqr die Übersetzung "Schauopfer" und schlägt für V. 3b-4 folgende Übersetzung vor:

Denn ich flehe zu dir"21, Jahwe, erhore meine Stimme;

ein Schauopfer ${ }^{22}$ rüste ich dir zu und spahe <nach einem Zeichen>. ${ }^{23}$

Da V. 4 im Qinah-Metrum verfaßt ist ${ }^{24}$, verstößt der Vorschlag von S. Mowinckel gegen die kolometrische Struktur des Bikolons.

Für V. 3b-4 dürfte am ehesten folgende Kolometrie anzusetzen sein:

kj 'ljk 'tpll JHWH'25 [bqr]

ts'm qwlj

$b q r " r k l k \ldots$

w'sph $<l k>$
15 [18] Denn zu dir flehe ich, Jahwe [in der Fruhe] ${ }^{26}$,

8 du wirst meine Stimme horen.

$9+x$ In der Frühe rüste ich dir zu ...

$5<7>$ und spahe 'nach dir' aus.

(Ps 5,3b-4)

S. Mowinckel geht bei seiner Interpretation von Ps $5 \mathrm{zu}$ Recht von der Erkenntnis aus, daß ein Opfer mit nachfolgender Opferschau beschrieben wird. Er berücksichtigt jedoch zu wenig, daß bei einer Opferschau im Bereich des Alten Orients in erster Linie an eine Leberschau zu denken und folglich ein allgemeiner Verweis auf ein 'Schauopfer' zu wenig konkret ist.

An der Deutung von S. Mowinckel ist in erster Linie zu bemängeln, da $B$ allein aus kolometrischen Gründen bqr in Ps 5,3b-4 kein Opferterminus sein kann. Denn das erste bqr schießt kolometrisch über und ist wohl vom zweiten, das als eine klare Zeitangabe zu verstehen ist, bedingt.

An zweiter Stelle ist zu betonen, daß der Gegenstand der Opferschau nicht das Opfer selbst war, sondern nur dessen Eingeweide oder in erster Linie seine Leber bzw. seine Lunge. Ein terminus technicus 'Schauopfer' (bqr) ist deshalb sachlich kaum zu rechtfertigen. Ferner ist unwahrscheinlich, daß vom terminus

mit der Leberschau zu tun habe und auch hdy hier nicht mit derselben in Verbindung zu bringen ist, so ist ihm zuzustimmen.

21 Das erste bqr wird von S. Mowinckel getilgt.

22 Mowinckel, Psalmenstudien I, 54, "sacrifice for omens' (böqer)".

23 Mowinckel, Psalmenstudien I, 147; ders., Psalmenstudien II, 54.

24 Siehe z.B. Gunkel, Psalmen, 17.

25 Die Autoren sind sich uneinig, ob JHWH oder bqr als Zusatz anzusehen ist.

26 Die eckige Klammer besagt hier und im folgenden, daß es sich um Zusátze zum Text handelt. 
technicus des Inspizierens bqr pi her ein Opferbegriff bqr gebildet worden sein könnte.

Zusammenfassend ist deshalb festzuhalten, daß in Ps 5,4 zwar höchstwahrscheinlich einmal von einer Opferart die Rede war ${ }^{27}$, die auch mit Opferschau hätte verbunden sein können ${ }^{28}$, aber bqr allein aus kolometrischen Gründen keine Bezeichnung eines Opfers sein kann. Es besteht folglich kein Grund für die Erweiterung des hebräischen Lexikons durch ein Nomen bqr I "Schau-

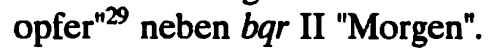

\section{c) bqr im Tempel - Ps 27,4}

H. Gunkel ordnet Ps $27,1-6^{30}$ den Vertrauensliedern zu. ${ }^{31}$ Er sieht in ihnen den Ausdruck individuellen Vertrauens zu Jahwe ${ }^{32}$. Von dieser Position aus fällt es ihm schwer, für diese "pathetischen Übertreibungen der glühenden israelitischen Geistesart ${ }^{\text {t33 }}$ eine Datierung über die allgemeine Feststellung hinaus vorzunehmen, daß diese Art Lied einer entwickelteren Stufe der Dichtung angehöre. S. Mowinckel zählt das Lied zu den "protective psalms" und sieht als dessen Beter. einen König an. ${ }^{34}$

$\alpha)$ Kolometrie und Übersetzung von Ps 27,1-6

27.1.1 $[l d w d]$

27.1.2 JHWH' 'wrj $w$ j jsj
13
Von David.

Jahwe ist mein Licht und mein Heil,

27 Zur Diskussion uber die Verbindung von Ps 5 mit einem Opfer siehe u.a. Kilchler, Orakel, 295-296; Gerstenberger, Psalms I, 60-61; Janowski, Rettungsgewißheit I, 188, lehnt eine Verbindung mit Opfer ab und denkt, daß in V. 4 von einem Rechtsentscheid die Rede ist. Kilchler, Orakel, 296.

29 So HAL 145; Ges. ${ }^{18}, 170$, wird zwar kein bqr "Schauopfer" eingeführt, aber unter bqr "Morgen" 1, vermerkt, daß Ps 5,4b strittig sei und von S. Mowinckel "Schauopfer" vorgeschlagen werde.

Zur Diskussion, ob der Psalm in die Teile V. 1-6 und 7-14 zu gliedern sei, siehe Gerstenberger, Psalms I, 124-127.

31 Zur Gliederung von Ps 27 in zwei Teile siehe die Kommentare. 
27.1.3 $m m^{\prime} \mathbf{j}^{\prime} j r^{\prime}$

27.1.4 JHWH miwz hij

27.1.5 m mj 'phd

11

7

12

27.2.1 b qrb 'lj mrjm

27.2.2 l' $k l\left[{ }^{\prime} t\right] b s j^{\prime}$

27.2.3 șrj w'jbj lj hmh

27.2.4 kslw $w$ nplw

27.3.1 'm thnh 'lj mhnh

27.3.2 $\quad r$ jjr' lbj

27.3.3 ' $m$ tqwm 'lj mlhmh

27.3.4 b z't 'nj bwth

27.4.1 'ht Slij m't JHWH

15

27.4.2 'wth 'bqs'

27.4.3 [sbtj b bjt JHWH

27.4.4 kl jmj hjj]

27.4.5 l hzwt b n'm JHWH

27.4.6 w l bqr b hjklw

27.5.1 kj jspnnj b skh

27.5.2 b jwm r'h

27.5.3 jstrnj b str ' $h l w$

27.5.4 b șwr jrwmmnj

12

27.6.1 w'th jnwm r'sj

27.6.2 $\urcorner$ 'jbj [sbjbwtj]

27.6.3 w'zbhh b 'hlw

27.6.4 zbhj tnw'h

11

9

27.6.5 ['Sjirh w'zmrh l JHWH] vor wem sollte ich mich fürchten?

Jahwe ist meines Lebens Schutzburg, vor wem sollte mir bangen?

Dringen Übeltatter auf mich ein, mein Fleisch zu fressen -

meine Gegner und Widersacher, sie müssen straucheln und fallen.

Lagert sich ein Heerlager gegen mich, mein Herz fürchtet sich nicht.

Erhebt sich auch Krieg gegen mich, trotzdem bleibe ich getrost.

Eines habe ich von Jahwe erbeten; das begehre ich;

[ $\mathrm{Zu}$ wohnen in Jahwes Haus alle Tage meines Lebens!] $\mathrm{Zu}$ schauen im "Angenehmen", $\mathrm{zu}$ inspizieren im Heiligtum!

Denn er verbirgt mich in 'seiner Hütte' am Tage des Unheils.

Er schirmt mich im Schutz seines Zeltes, auf einen Felsen hebt er mich hoch.

Und nun erhebt sich mein Haupt über meine Feinde [ringsum].

In seinem Zelt will ich opfern Opfer voller Jubel

[Ich will Jahwe singen und spielen!] 
ß) Kolometrische und philologische Einzelbemerkungen

27.2.2

't - . - Ein Zusatz, der das Kolon zerdehnt.

27.4.1 - 27.4.6

Die Einheit und Abfolge der Handlungen der Bikola 27.4.1 - 27.4.2 und 27.4.5 - 27.4.6 wird durch das Zitat 27.4.2 - 27.4.3 gestört.

$27.4 .2-27.4 .3$

Zitat nach Ps 23,6; zum Zitatcharakter dieses Bikolons siehe BHSa-a; Gunkel, Psalmen, 114-115; Podechard, Psautier, 129; Mowinckel, Tricola, 68.72; ders., Psalmenstudien I, 238; Kraus, Psalmen I, 363. Für die sekundäre Herkunft dieses Bikolons spricht auch, daß es die Strophenordnung des Liedes stört, siehe besonders Mowinckel, Tricola, 68.72.

27.4.4 - 27.4 .5

Siehe $\gamma$.

27.6.2

sbjbwtj - - Sekundäre Auffüllung.

$27.6 .3-27.6 .4$

Diese Einheit ist als überfüllt anzusehen, siehe Gunkel, Psalmen, 115; Mowinckel, Tricola, 25; ders., Psalmenstudien I, 238; die Art der Zusätze ist strittig.

$\gamma)$ Die Wortpaare $h z h \| b q r$ und $n^{\prime} m \| h j k l$ in Ps 27,4

Das Bikolon

l hawt b n'm JHWH 13

wl bqr b hjklw $\quad 11$ 
ist aus den Wortpaaren $h z h \| b q r$ und $n^{\prime} m \| h j k l$ aufgebaut, so daß die Frage besteht, ob aus diesen formalen Parallelitäten auch Schlüsse über deren inhaltliche Aussage zu ziehen sind. ${ }^{35}$

S. Mowinckel hat von der Formulierung hzh $b n^{\prime} m$ "die Schönheit zu schauen", die er als kultische Formulierung deutete, her abgeleitet, daß auch das parallele bqr $b$ hjkl ein technischer Ausdruck kultischer Art sei. ${ }^{36}$ Aus der Zusammenschau von bqr in Ps 27,4 und 2 Kön 16,15 folgerte er, daß bqr pi "genau untersuchen" an diesen Stellen kultisch zu verstehen sei: "Biqqër in kultischem Sinne muß wohl demnach die Opferschau zwecks Orakelgebung bezeichnen. $\mathrm{DaB}$ dieses Offenbarungsmittel in Israel nicht unbekannt war, zeigen Gen 4,4 f.; $15,10 \mathrm{f} .{ }^{\prime \prime 37}$

An dieser Argumentation ist nur zu bemängeln, daß zwar der Parallelismus $h z h \| b q r$, aber nicht der folgende $n^{\prime} m \| h j k l$ ernstgenommen wird. Denn S. Mowinckel deutete das hzh $b$ n $^{\prime} m$ in Übereinstimmung mit der Mehrzahl der Interpreten als Umschreibung für das Eintreten des Beters in den Tempel und das Erfahren der Gnade Gottes beim Besuch des Heiligtums.

Aus dem Wortpaar $n^{\prime} m \| h j k l$ geht jedoch zwingend hervor, daß auch $n^{\prime} m$ als Bezeichnung für den Tempel anzusehen ist. Dieser Parallelismus spiegelt wiederum das ugaritische Wortpaar $n^{\prime} m \| q d \zeta$ wieder. ${ }^{38}$ Dies ergibt sich aus folgender Botschaft Baals, die er seinen Boten für 'Anat übergibt:

$\begin{array}{lll}\text { atm } w \text { ank ibgyh } & 12 & \text { Komm, und ich werde es enthüllen } \\ b \text { tk gry } \text { il spn } & 11 & \text { inmitten meines Berges, des gottlichen Saphon, } \\ b \text { qds } b \text { gr nhly } & 12 & \text { im Heiligtum, auf meinem Erbberg, } \\ b n^{\prime} m b \text { g } b^{\prime} \text { tliyt } & 13 & \text { am lieblichen Ort, auf der Hơhe des Sieges! }\end{array}$

(KTU 1.3 III 28-31)

Baal umschreibt hier seinen Wohn- und Thronsitz auf dem Berg Saphon mit den Wortpaaren $q d s^{\prime}$ - gr nhlt $\| n^{\prime} m$ - $g b^{\prime}$ tliyt, so daß sich hieraus die Parallelpaare $q d \zeta \| n^{\prime} m$ und $g r n h l t \| g b^{c}$ tliyt ergeben.

Auf diesem Wege erkennen wir mit Hilfe von KTU 1.3 III 30-31, daß in Ps 27,4 n'm nicht auf das Schauen der Schönheit der Gottheit oder das Betrachten einer Gottesstatue im Tempel zu beziehen ist ${ }^{39}$, sondern eine Bezeichnung des Heiligtums (hjkl) vorliegt.

35 Es ist der Beachtung wert, daß weder Avishur, Studies, noch Dahood, Parallel Pairs, 153, Nr. 130, diese Parallelismen notieren. M. Dahood gelangt durch eine überdehnte Kolometrie in Ps 27,4 zum Wortpaar bt I hjkl.

Mowinckel, Psalmenstudien I, 146. 
J.C. Greenfield bietet von der Erkenntnis her, daß das ugaritische Wortpaar $n^{\prime} m \| q d \zeta$ in der hebräischem Dichtung mit $n^{\prime} m \| h j k l$ aufgenommen und reflektiert wird, für V. 4 folgende Übersetzung an:

One thing I ask of the Lord,

only that do I seek:

to live in the house of the Lord

all the days of my life,

to gaze upon the beauty of the Lord,

to frequent his temple. ${ }^{40}$

Der Psalmist, so führt er weiter aus, suche also nicht die Schönheit des Herrn anzuschauen, sondern an dessen lieblichem Ort sein Leben zu verbringen. Er wünsche sich sozusagen den Zustand einer ewig andauernden Pilgerreise. ${ }^{41}$ M.S. Smith wiederum deutet das hah $b n^{\text {im }}$ auf das "Sehen" der Gottheit, die Erfahrung ihrer Gegenwart im Tempel hin. ${ }^{42}$

Auf ähnliche Weise bezieht H.F. Fuhs das hzh in Ps 27,4 auf die Erfahrung von Gottes Handlungen in der Geschichte. ${ }^{43}$ Er führt als Parallelstelle hierzu Ps 63,3 an, wo er mit $\mathrm{BH}^{44}$ erwägt, vielleicht bqštj hzwtk "ich begehre, dich zu schauen" zu übersetzen. Hierin drücke sich dann das Verlangen, der Wunsch und die Erwartung aus, Gottes helfenden Beistand gegen die bösartigen Widersacher zu erfahren. ${ }^{45}$

Entgegen diesem Versuch einer Deutung von $b$ qd in Ps 63,3 dürfte festzuhalten sein, daß hier eine genaue Parallele zu $b n^{i} m \| b h j k l$ von Ps 27,4 gegeben ist und diese Stellen sich folglich aufs beste gegenseitig beleuchten.

Bei der Beurteilung der Tätigkeit des hzh "Sehens" im Heiligtum ist zu berücksichtigen, daß dieses vornehmlich als terminus technicus der Mantik gebraucht wird. ${ }^{46}$ Wir erhalten so mit $h z h$ einen Parallelbegriff zu bqr.

Wenn mit hyzh "sehen" sowohl in Ps 27,4 als auch in 63,3 der Empfang von Visionen im Heiligtum beschrieben wird, so wird diese Art von Orakel an erster Stelle noch zusätzlich durch Parallelisierung mit der Leberschau (bqr) unterstrichen.

Von KTU 1.3 III 28-31 und 1.78:5 her erschließt sich uns auf diese Weise nicht nur die poetische Struktur von Ps 27,4, sondern auch der Bezug von bqr

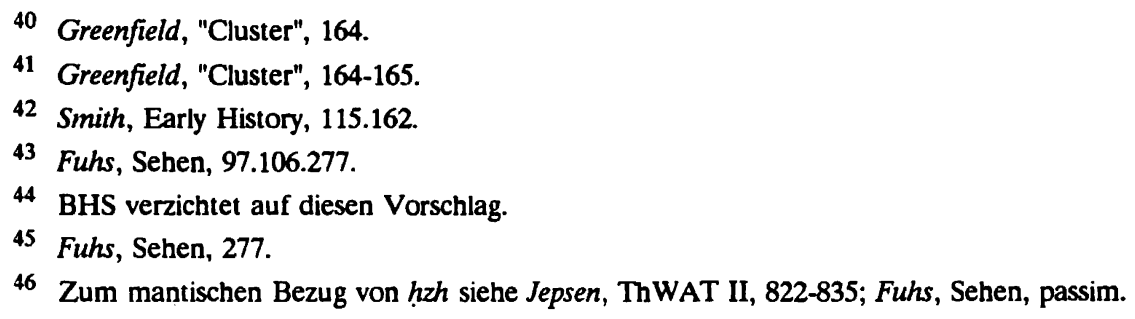


zur Leberschau. Zugleich wird es so auch möglich, den mantischen Aspekt von hrh besser zu erfassen. ${ }^{47}$

\section{反) Ergebnis}

Für die Annahme, daß in Ps 27,1-6 ein König spreche, bietet der Text in V. 4 einen guten Anhaltspunkt. Es ist kaum anzunehmen, da $B$ es jedem Israeliten offenstand, im Tempelareal durch Visionen der Propheten $(h z h)$ und durch Leberschau (bqr) die Zukunft durch Fachleute der Mantik erforschen zu lassen. Dies war vornehmlich ein zum Teil auch kostspieliges Privileg der Könige.

Aus der Ortsangabe $b n^{\prime} m \| b h j k l$ dürfte sich nur eine allgemeine Verbindung der mantischen Tätigkeiten mit dem Tempelgebiet entnehmen lassen. Es wird mit dieser Ausdrucksweise keineswegs zwingend gefordert, die mantischen Operationen der Seher und Opferschauer ins Innerste des Tempels zu verlegen.

\section{d) $b q r$ in 2 Kön 16,15}

Die Deutungen von bqr in 2 Kön 16,15, die in den Kommentaren vorgetragen werden, zeichnen sich größtenteils durch zahlreiche Widersprüchlichkeiten aus. Einige Gelehrte berufen sich z.B. auf B. Stade ${ }^{48}$ und betonen, daß es müBig sei, über die Bedeutung von bqr zu spekulieren, da das Wort entweder im Alten Testament Hapaxlegomenon sei, wahrscheinlich ein Nomen, das erst sekundär durch die Punktation der Masoreten zu einer Verbalform geworden $^{49}$ oder in Anlehnung an bqr in Ps 27,4 versuchsweise mit "to frequent" zu übersetzen sei und einen "privaten Gebrauch" anzeige, aber keine kultische Neueinführung wie z.B. eine Eingeweideschau. ${ }^{50}$

Die Interpreten dieser ablehnenden Richtung gehen jeweils von einer mit der jeweiligen Auslegung von 2 Kön 16,15b im vorhinein abgestimmten Deutung von Ps 27,4 aus.

E. Würthwein, der die herkömmliche Übersetzung von 2 Kön $16,15 \mathrm{~b}$ mit "Was mit dem ehernen Altar geschehen soll, will ich noch überlegen." ablehnt,

47 Van Soldt, 'Atn prln, 367, betont, daß bära von bara "sehen, inspizieren" und prln von p/wur"sehen" abzuleiten sind. Stade, Reden, 207.

49 Spieckermann, Juda, 367 mit Anm. 140, scheint einen Zusammenhang mit Ps 27,4 entgegen G. von Rad abzulehnen.

Cogan / Tadmor, II Kings, 185.189. 
übersetzt die Stelle folgendermaßen: "Und der eherne Altar soll mit dazu dienen, die Opferschau vorzunehmen." ${ }^{51}$ Er schließt sich damit der zuerst von S. Mowinckel vorgetragenen Deutung ${ }^{52}$ an und betont, daß für bqr pi "Opferschau vornehmen" nicht so sehr bqrh in Lev 19,20 spreche, wo man mit der Bedeutung "Untersuchung (eines Deliktes)" auskomme, wohl aber Ps 27,4, wo auch G. von Rad "an eine viel speziellere und zwar kultische Tätigkeit" denke und auf das nabatäische Wort mubaqqiru, vielleicht "Opferschauer", verweise. Der judäische König Achaz habe diesen Brauch von den Assyrern übernommen und damit eine mit der Vasallenschaft aufgezwungene Pflicht erfüllt. ${ }^{53}$

Gegen eine Verbindung der Leberschau in 2 Kön 16,15b mit der assyrischen Religionspolitik spricht nicht nur, da $B$ die Assyrer es abgelehnt haben, den unterworfenen Völker die eigenen religiösen Traditionen aufzuzwingen, sondern auch Ps 27,4. Denn letztere Stelle ist kaum durch assyrischen Einfluß zu erklären. Hätte der König die Leberschau zum erstenmal eingeführt, wäre auch die Übernahme der Fachleute hierfür $(b r)^{54}$ nötig gewesen. Die Deuteronomiker hätten dieses Novum sicher nicht ohne Kritik in ihren Berichten übergangen.

Eine offene Frage bleibt, wie weit der eherne Altar für die Opferschau auf der Seite des neuen Altars gegen Norden hin abgerückt war (2 Kön 16,14).

Zusammenfassend dürfte folglich festzuhalten sein, daß die Erwähnung der Opferschau in 2 Kön 16,15 auf alte israelitische Tradition, nicht aber auf assyrische Pression zurückzuführen ist. Hiermit stimmt auch überein, daß der für die Leberschau vorgesehene Altar nicht zu den Neuerungen aus Damaskus gehört.

\section{Der Leberlappen in der Gesetzgebung}

Der Leberlappen wird in der Gesetzgebung des Pentateuch elfmal behandelt (jtrt $h k b d$, Ex 29,22; Lev 8,16.25; 9,19; $h$ jtrt ' $h$ kbd, Ex 29,13; Lev 3,4.10.15; 4,9; 7,4; $h$ jtrt mn $h k b d$, Lev 9,10). Unter den Interpreten wird diskutiert, ob es sich um den Spigelschen Lappen (lobus caudatus) ${ }^{55}$ oder den Hauptlappen, das sogenannte Leberband handle. ${ }^{56}$ Die Anordnung, den Leberlappen beim

\footnotetext{
51 Würthwein, Konige, 386.390.

52 Mowinckel, Psalmenstudien I, 146.

53 Würthwein, Konige, 390-391; auf assyrische Pression und Religionspolitik gegenüber den Unterlegenen verweist auch Spieckermann, Juda, 367-368.

54 Siehe zu I.1.

55 Rost, Leberlappen, 37.39.

56 Elliger, Leviticus, 52.
} 
Mahlopfer zu verbrennen, wird als Abwehr babylonischer Praktiken gedeutet. Denn eine verstümmelte Leber sei für die Leberschau unbrauchbar gewesen. ${ }^{57}$

Auch bei der Beurteilung dieser sicher gegen die Leberschau gerichteten Gesetzgebung sind mehrere Lösungen möglich. Wenn man von einer Auseinandersetzung mit spätem babylonischem Einfluß ausgeht, sollte nicht vergessen werden, daß die Behandlung der Leber in Zusammenhang mit dem šlmjmOpfer keineswegs dagegen spricht, da $B$ in vorexilischer Zeit und später die Leber bei dieser Schlachtung beschaut wurde. ${ }^{58}$ Die Gesetzgebung kann sich so gleichzeitig sowohl gegen frühere israelitische als auch gegen babylonische Praxis richten. 59

Aus der Gesetzgebung dürfte jedenfalls abzuleiten sein, daß die Anordnung über den Leberlappen sich gegen Praktiken richtet, die in nachexilischer Zeit eine reale Gefahr darstellten. Sie bezeugt so indirekt wohl die Ausübung von Leberschau im exilisch-nachexilischen Judentum.

\section{4. 'wt "Zeichen" als terminus technicus der Leberschau}

In Jes 44,25 ist ausdrücklich von den 'twt "Vorzeichen" der "Opferschau(priest)er" die Rede. ${ }^{60}$ Da nach Ausweis von Jer 10,261, des Ugaritischen $^{62}$ und des Akkadischen ${ }^{63}$ dieses Wort auch in Zusammenhang mit an-

57 Siehe zu dieser Diskussion u.a. Yerkes, Sacrifice, 155-156; Rost, Leberlappen, 40-41.

58 Del Olmo Lete, Anatomia, 124, deutet ugaritisch J̌̌rt "Kette" im Opfertext KTU 1.119:21 von $h$ jtrt 'I h kbd (Lev 29,13) her; siehe auch Korpel, Rift, 415. Es ist jedoch kaum anzunehmen, daß క̌št von akkadisch క̌erše(r)ru I "(Ketten-)Ring"? (AHw 1218) her interpretiert werden kann.

59 Milgrom, Leviticus I, 208, bemerkt zum Gebot, den lobus caudatus oder processus pyramidalis zu zerstoren, folgendes: "Why the caudate lobe was reserved for the deity is unknown. Nevertheless, the reason for this decision could not have been in order to prevent its use in divination; if so, then the rest of the liver - employed just as much as the long lobe in divination (hepatoscopy) - would also have been consigned to the altar." Der Autor legt seiner Argumentation die These zu Grunde, daß auch eine verstümmelte Leber für eine divinatio brauchbar gewesen sei und es in Israel zu keiner Zeit Leberschau gegeben habe. Dagegen ist einzuwenden, daß für eine Leberschau nur eine ganze Leber mit dem wichtigen lobus caudatus in Frage kommen konnte. Sinn und Zweck der biblischen Anordnung sind folglich klar und konnen keinem Mißverstăndnis unterliegen.

60 Siehe I.1.

61 Rudolph, Jeremia, 73, ominose Zeichen am Himmel.

62 Siehe att șin "Vorzeichen vom Kleinvieh" (KTU 1.103 + 143:1) in Geburtsomina; Dietrich / Loretz, Mantik, 1990, 92-93.102.

63 AHw 406: ittu II "Zeichen"; CAD I-J 304-310: ittu A 
deren mantischen Praktiken als terminus technicus verwendet wird, ergibt sich die Frage, ob ' $(w) t$ auch noch an weiteren biblischen Stellen neben Jes 44,25 Vorzeichen, die aus der Leberschau gewonnen werden, bezeichnet.

Wenn der Psalmist klagt:

\begin{tabular}{|c|c|c|}
\hline $\begin{array}{l}\text { 'wttinw } l \text { rijnw } \\
\text { ['jn 'wd nbj'] } \\
w l^{\prime} \text { 'tnw jd" } d \text { mh }\end{array}$ & $\begin{array}{l}13 \\
{[10]} \\
14\end{array}$ & $\begin{array}{l}\text { Zeichen für uns sehen wir nicht, } \\
\text { [Es gibt keinen Propheten mehr!] } \\
\text { unter uns ist keiner, der wüßte bis wann! }\end{array}$ \\
\hline
\end{tabular}

(Ps 74,9),

spielt er höchst wahrscheinlich auf die Situation nach der Zerstörung des Tempels (586 v. Chr.) an, als es nicht mehr möglich war, im Tempelbereich Opferschauen durchzuführen. ${ }^{64}$

\section{5. "nh "antworten" und minh "Antwort" als termini technici der Orakelkunst}

Das Verbum "nh "antworten" wird in Zusammenhang mit der Orakelpraxis und Opfern gebraucht. ${ }^{65}$ So ergibt sich nicht nur die Frage, ob bei der Verbindung von " $\mathrm{hh}$ mit einem Opfer eine Leberschau vorliegt, sondern auch, ob eine solche bei bloßem Gebrauch von ' $n$ h (1 Sam 8,18; 14,37; 23,4; 28,6a.15; 2 Sam 22,36) anzusetzen ist. Vielleicht bezwecken die Hinweise auf die Träume, Propheten und Urim (1 Sam 28,6.15) eine Ablenkung von einer selbstverständlichen Beziehung dieser Stellen auf die Opferschau.

In Mi 3,7 wird beschrieben, daß Gott seine $m^{\text {inh }}$ "Antwort" den Sehern und Wahrsagern versagt, ohne daß in diesem Zusammenhang auch die Opferschauer erwähnt werden.

\section{Zusammenfassung}

Die bereits von F. Küchler (Orakel, 296) beklagte Lage, daß uns die alttestamentlichen Schriften über Haruspicien keine positive Kunde gäben, hat $S$. Mowinckel (Psalmenstudien I, 146) durch seine Erkenntnis, daß bqr pi als terminus technicus der Opferschau anzusehen ist, zum besseren gewendet. Er hat als Belege für die Praxis der Opferschau in Israel Gen 4,4-5; 15,10-11; 2 Kön 16,15; Ps 5,4 sowie 27,4 angesehen.

64 Zur Auslegung von Ps 74 siehe Loretz, Leberschau, 81-101.

65

Stendebach, ThWAT VI, 239-240. 
Diese Problemstellung kann jetzt mit Hilfe von ugaritisch bqr D in KTU 1.78:5 in einem neuen Licht gesehen und einer weiteren Klärung zugeführt werden. Dadurch ist es möglich geworden, die biblische Terminologie auf eine ältere Fachsprache der auch bei den Westsemiten ausgeübten Eingeweide- und Leberschau zurückzuführen.

Die traditionelle bibelwissenschaftliche These, daß Leberschau bei den Israeliten selbst unbekannt gewesen sei, erweist sich folglich als unkritische Weiterführung deuteronomistischer Darstellung der israelitisch-jüdischen Geschichte. Die Deuteronomisten suchten alles, was sie mit dem jahwistischen Monotheismus als unvereinbar ansahen, entweder auf den verderblichen Einfluß der Kanaanäer und Babylonier zurückzuführen oder aus der Geschichte Israels zu entfernen. $\mathrm{Daß}$ sie bei diesem Unternehmen der Leberschau ihre besondere Aufmerksamkeit widmeten, geben die Texte noch zur Genüge zu erkennen.

Es ist folglich kaum die These zu vermeiden, daß die moderne bibelwissenschaftliche Wiederholung der deuteronomistischen These über die Ablehnung der Leberschau in Israel letztlich auf einem Mißverständnis der theologischen Intentionen der biblischen Schriftsteller beruht.

Wenn wir von bqrh (Lev 19,20 ${ }^{66}$ und bwqr (Am 7,14) ${ }^{67}$ absehen, so dürfte nun mit Hilfe von KTU 1.78:5 festzuhalten sein, daß auch in 2 Kön 16,15 und Ps 27,4 bqr pi. als terminus technicus der Opfer- bzw. Leberschau anzusehen ist und wir Belege für die Durchführung derselben im vorexilischen Israel besitzen. Der Natur der Texte entsprechend informieren uns sowohl Ps 27,4 als auch 2 Kön 16,15 nur über Könige, für die die Leberschau vom br (bārû) durchgeführt wurde.

Diese Annahme wird durch Jes 44,25 insoweit bestätigt und ergänzt, als dort von der Tätigkeit von Fachleuten der Opfer- und Leberschau (br) ohne Erwähnung des Königs die Rede ist. Der $b r$ war folglich auch in Israel für all jene zugänglich, die sich finanziell diese Wahrsagekunst leisten konnten.

Aus dem Gebrauch des Wortes br "Opferschau(priest)er" ersehen wir einerseits, wie eng die biblische Tradition an die mesopotamische anschließt, und vom westlichen bqr $\mathrm{D}$ her erkennen wir andererseits, daß diese Wahrsagekunst im Westen auch sprachlich eingebürgert war.

Die enge Verbindung der Leberschau mit dem Tempel, die in 2 Kön 16,15 und Ps 27,4 bezeugt ist, dürfte an westliche Besonderheiten anknüpfen.

66 Loretz, Leberschau, 22-23.

67 Loretz, Leberschau, 23-24. 
II. Historische Argumente für und gegen die Ausübung der Leberschau in Israel

Die Diskussion über die Kenntnis und Ausübung der Leberschau in Israel wird bei den einzelnen Forschern notwendig von deren Vorurteilen über die Frühgeschichte Israels beeinflußt. Es sind hier vor allem zwei Denkmodelle zu unterscheiden. Während im ersten vorausgesetzt wird, da $B$ die Leberschau durch babylonischen oder assyrischen Einflu $B$ in Israel Eingang gefunden habe, wird im zweiten angenommen, da $B$ Israel sich aus dem kanaanäischen Milieu heraus entwickelt habe und die Leberschau deshalb nicht als mesopotamischer Fremdkörper, sondern als integraler Bestandteil seines kanaanäischen kulturellen und religiösen Erbes anzusehen sei.

Zugunsten eines assyrischen bzw. babylonischen Importes der Opfer- und Leberschau wird angeführt, da $B$ in der unmittelbaren Umwelt Israels bei den Phönikern und Aramäern die Opferschau unbekannt gewesen sei. Dies wird mit den Umwälzungen der Seevölkerzeit begründet, die zum Abbruch der alten Traditionen geführt habe.

In dieser Beweisführung wird nicht nur eine allzu radikale Störung der Traditionen durch die Seevölker postuliert, sondern auch zu voreilig angenommen, da $B$ die Phönikier keine Kenntnis der Leberschau besessen hätten. ${ }^{68}$ Auch die These, da $B$ den Aramäern dieser Brauch fremd geblieben sei, wird vorläufig mangels Material als ein argumentum e silentio zu bewerten sein.

Es dürfte auch wenig überzeugend sein, die Frage der Ausübung der Leberschau in Israel zu eng mit der Frage nach der Entstehung des jahwistischen Monotheismus zu verbinden und zu postulieren, daß die Leberschau seit der Zeit Mose mit dem Jahweglauben unvereinbar gewesen sei. Jes 44,25 zufolge war in exilisch-nachexilischer Zeit jedenfalls der Glaube wirksam, daß die Kunst der Opferschauer von Jahwe verabscheut wird. Nach 2 Kön 16,15 und Ps 27,4 war dies in vorexilischer Zeit offensichtlich noch nicht der Fall.

Aus der Geschichte der Leberschau in Israel und im Judentum werden so eher Rückschlüsse auf die Entstehung des jahwistischen Monotheismus möglich. Den biblischen Schriften zufolge war Leberschau zeitweilig noch durchaus mit der Jahweverehrung vereinbar. Erst in exilisch-nachexilischer Zeit wurde mit der Durchsetzung des jahwistischen Monotheismus klar, daß neben der Thora die Leberschau als Kundgabe göttlichen Willens nicht mehr zulässig sein konnte.

Zusammenfassend dürfte folgendes festzuhalten sein: Die Opfer- und Leberschau gehört in Ugarit und Israel zu einer Tradition, die aus dem Zweistromland stammt. In Israel bildet sie einen Teil des kanaanäischen Erbes. Sie 
scheint bis in die exilisch-nachexilische Zeit hinein keineswegs von allen Kreisen als Widerspruch zur Jahweverehrung angesehen worden zu sein.

\section{Eingeweide- und Leberschau in der biblischen und bibelwissenschaftlichen Geschichtsschreibung}

In den nachexilisch redigierten biblischen Schriften finden sich nur noch vereinzelt Hinweise auf die Eingeweide- und Leberschau. In sprachlicher Hinsicht erweisen sich die termini technici als besonders wichtig. Denn sowohl bqr $\mathrm{D}$ "inspizieren, untersuchen" als auch $b r=b a ̈ r \hat{~}=p r l n$ "Seher" schließen die hebräische Terminologie und Praxis an die mesopotamische und altsyrisch-kanaanäische Hepatoskopie an. Diese Spezialisten übten ihre Tätigkeit in Parallele zu den Kollegen aus, die das Sehen (hzh) mittels Eingebung, Exstase und Visionen betrieben haben.

Wenn in der Bibel emphatisch nur noch die prophetische, seherische Art des Empfangs göttlicher Mitteilung anerkannt und geduldet, die Eingeweideund Leberschau zusammen mit der Astrologie aber abgelehnt wird, so sind die Gründe für diesen Vorgang leicht ersichtlich. Denn vom jüdischen Gesetz her, das nur noch das Reden der Gottheit durch das Wort kennt, war es zwar noch möglich, die Propheten als Träger göttlicher Botschaft zu akzeptieren, aber es scheint kein Weg mehr für die Möglichkeit offen zu sein, Eingeweide und Leber als Ort der Manifestation göttlichen Willens zu dulden.

In diesem Zusammenhang war auch sicher von Bedeutung, daß die Leberund Opferschau den göttlichen Willen als Manifestation der göttlichen Gestirne auffaßte. Nachdem für den monotheistischen Jahwismus die Gestirne ihres göttlichen Charakters entkleidet waren und als Schöpfungswerke Jahwes gepriesen wurden (Gen 1,14-18), hatte auch die Hepatoskopie ihre herkömmliche theologische Rechtfertigung verloren und konnte von den jüdischen Gelehrten nur noch abgelehnt bzw. verteufelt werden. ${ }^{69}$

Wenn in der Bibel nur noch Prophetie, Epiphanie und Traumdeutung als Wege der Gottesoffenbarung zugelassen werden, so wird uns kaum noch ein volles Bild der Vergangenheit vermitelt. Historisch und theologisch gesehen erweisen sich diese Formen der Mantik nur als ein Teil der einmal im semitischen Alten Orient und in Israel ausgeübten Wissenschaft von der Zukunft. Die biblische Geschichtsschreibung der nachexilischen Zeit stellt dagegen die Bemühungen der Mantiker der früheren Zeiten um Einsicht in den göttlichen Willen mittels Eingeweide- und Leberschau vom Standpunkt des monotheisti-

69 Da Traumdeutung (Oneiromantik) keine direkte Verbindung mit den Gestirnen aufweist, konnte diese auch von den biblischen Autoren geduldet werden. 
schen Jahwismus aus entweder negativ dar oder arbeitet mit den weit wirksameren Mitteln der Zensur und des Verschweigens.

Der bibelwissenschaftlichen Historiographie und Dogmengeschichte ist es inzwischen an der Wegkreuzung zwischen biblischer und wissenschaftlicher Geschichtsschreibung verwehrt, zur Lösung der Probleme etwa mit Nebukadnezar auf eine der drei Orakelarten Pfeil, Teraphim oder Leber zurückzugreifen. Angesichts des zur Verfügung stehenden biblischen und außerbiblischen Materials genügt es auch nicht mehr, die Frage der Eingeweide- und Leberschau in Israel durch Verbindung mit der traditionellen biblischen und bibelwissenschaftlichen historiographischen These von einer Einwanderung Israels mit einem voll entwickelten monotheistischen Jahwismus und einem notwendig damit verbundenen Verbot der Leberschau zu lösen. Andererseits sollte auch nicht der Versuch unternommen werden, von der engen Bindung Israels an die altorientalische Mantik her allein eine Frühgeschichte Israels zu rekonstruieren. Für das Gesamtbild der israelitisch-jüdischen Geschichte stellt die Eingeweideund Leberschau nur einige Mosaiksteine bereit, die jedoch mit ihrer Farbigkeit besonders zur Verlebendigung der altisraelitisch-jüdischen Vergangenheit beitragen.

\section{Fortleben der altorientalischen Orakeldeutung in der jüdischen Exegese}

Für eine ehemals in Israel reich entwickelte und breit praktizierte Mantik dürfte auch sprechen, daß in der jüdischen halachischen und aggadischen Exegese Methoden der altorientalischen Orakelinterpretation weitergeführt werden. ${ }^{70}$ Es ist folglich in Betracht zu ziehen, daß auch auf diesem Gebiet Traditionen der israelitischen Hepatoskopie weiterwirken.

\section{Ergebnis}

Zusammenfassend dürfte festzuhalten sein, daß genügend Anhaltspunkte vorliegen, die zur Annahme berechtigen, daß auch in Israel die Hepatoskopie verbreitet war. Deren Bindung an ein astrales Weltbild und die damit verbundenen Vorstellungen über die Verbindung von anthropomorphen Göttern mit Gestirnen führte bei der in exilisch-nachexilischer Zeit vollbrachten endgülitgen Formulierung und Durchsetzung des bilderlosen jahwistischen Monotheismus von selbst zur Verurteilung der Leberschau als Mittel der Erforschung und Erfahrung göttlichen Willens.

70 Tigay, Early Technique, 172-181. 

Milgrom, J., Leviticus 1-16 (AB 3), Garden City/NY 1991

Mowinckel, S., Psalmenstudien I, Oslo 1921

- Real and Apparent Tricola in Hebrew Psalm Poetry, Oslo 1957

- The Psalms in Israel's Worship I-II, Oxford 1963

Noth, M., Die Ursprünge Israels im Lichte neuer Quellen, Opladen 1961

Podechard, E., Le Psautier I, Lyon 1949

Rabin, C., Hebrew baddim "Power", JSS 18 (1973) 57-58

Ribichini, S., L'aruspicina fenicio-punica e la divinazione a Pafo, UF 21 (1989) 307-317

Rost, L., Der Leberlappen, ZAW 79 (1967) 35-41

Rudolph, W., Jeremia (HAT 12), Tubingen ${ }^{3} 1968$

Sellin, E., Geschichte des israelitisch-jüdischen Volkes I, Leipzig 1924

Smith, M.S., The Early History of God, San Francisco 1990

Spieckermann, H., Juda unter Assur in der Sargonidenzeit (FRLANT 129), Göttingen 1982

Stade, B., Ausgewahlte akademische Reden und Abhandlungen, Gießen ${ }^{2} 1907$

Tadmor, H. $\rightarrow$ Cogan, M.

Tigay, J.H., An Early Technique of Aggadic Exegesis, in: H. Tadmor / M. Weinfeld (eds.), History, Historiography and Interpretation: Studies in Biblical and Cuneiform Literatures, Jerusalem 1983, 169-189

Van Soldt, W.H., 'Atn prln, "'Attā/ēnu the Diviner", UF 21 (1989) 365-368

- $\rightarrow$ de Jong, $J$.

Werner, W., Studien zur alttestamentlichen Vorstellung vom Plan Jahwes (BZAW 173), Berlin / New York 1988

Wiurthwein, E., Die Bücher der Könige 1. Kơn. 17 - 2. Kơn. 25 (ATD 11/2), Gơttingen 1984

Yerkes, R.K., Sacrifice in Greek and Roman Religions and Early Judaism, New York 1952; London 1953

Zimmerli, W., Ezechiel I (BK XIII/1), Neukirchen-Vluyn ${ }^{2} 1979$ 

Die Eingeweideschau im vor- und nachexilischen Israel, in Nordsyrien und Anatolien

Die als Zeugnisse für die Praxis der Eingeweideschau, speziell der Leberschau, angesehenen Belege in den Texten des Alten Testaments sind umstritten. Auf die unterschiedliche Interpretation der entsprechenden Abschnitte soll hier nicht eingegangen werden ${ }^{1}$. Zusammenfassend lassen sich die als Belege in Anspruch genommenen Textstellen in drei Gruppen unterteilen:

1. Textstellen, die durch die Verwendung des Begriffs boqär gekennzeichnet sind (Ps 5,4; 27,4; 2 Kön 16,15; Num 16,5; Ez 21,26);

2. Textstellen, in denen der Leberlappen oder Teile des Organs im Zusammenhang mit Opfern erwähnt werden (Ex 29,13.22; Lev 3,4. 10.15; 4,9; 7,4; 8,16.25; 9,10.19);

3. Textstellen, in denen der Begriff 'ot auftritt, der mit akk. ittu "Zeichen" gleichgesetzt wird und möglicherweise als göttliche Zeichen interpretiert werden kann (z.B. Ps.20,7-9; 21,9-13; 60,8-10; 74,4-9; 86,17)2.

Von diesen Textstellen kommen, selbst für die Forscher, die für den Gebrauch der Eingeweideschau in Israel eintreten, nur boqär in Ps 27,4 und 2 Kön 16,15 in der Bedeutung "eine Opferschau durchführen" sowie möglicherweise 'ot in Ps 74,4 tatsächlich als Beleg in Betracht ${ }^{3}$. Für die Übernahme wird auf deren Verwendung im syrisch-kanaanäischen Gebiet während des 2. Jts. v. Chr. verwiesen; in diesem Zusammenhang werden besonders die Funde von Tonmodellen verschiedener Organe (Leber, Lunge) sowie der Gebrauch von boqär in Verbindung mit der Leberschau in einem Text aus Ugarit (KTU 1.78,5) hervorgehoben. Im Folgenden sollen von archäologischer Seite die Argumente, die für oder gegen die Möglichkeit einer Übernahme dieser Form

1 Eine Diskussion der differierenden Standpunkte findet sich in der Arbeit von $O$. Loretz, Leberschau, sowie in einem weiteren Beitrag von O. Loretz in diesem Band.

2 Da akk. ittu alle "Zeichen" umfaßt, die von den Gottern gegeben werden - neben den Veranderungen auf den Eingeweiden z.B. auch durch Mißgeburten, Vogelflug usw. (vgl. A.L. Oppenheim, Ancient Mesopotamia, 221-222) -, soll auf die betreffenden Textstellen hier nicht năher eingegangen werden.

Auf ein weiteres, von $O$. Loretz in seinem Betrag zur Leberschau in Israel, S. 509ff, m. Anm. 4, angeführtes Argument, hebr. bd in Jes. 44,25, Jer. 50,36 und Hos. 11,6 als mögliche Verschreibung für hebr. br anzusehen und mit akk. barù (Opferschauer) gleichzusetzen, und als Hinweis für die Praxis der Leberschau bei den Israeliten zu werten, kann von archăologischer Seite keine Stellung bezogen werden; allerdings ist der baru im Alten Orient für verschiedene Formen der Opferschau, nicht nur die Eingeweideschau zustăndig, vgl. J. Renger, Untersuchungen, 207-208. 
der Divination durch die Israeliten sprechen, einander gegenübergestellt werden.

Die Eingeweide- und Leberschau als ein Mittel, den göttlichen Willen zu erfragen, ist in Mesopotamien bereits seit dem 3. Jt. v. Chr. bekannt ${ }^{4}$. Die ersten schriftlichen Erwähnungen von Wahrsagern finden sich in Texten der Frühdynastischen Zeit, doch reicht die Ausübung dieser Form der Divination vermutlich noch weiter zurück. Nach einer ersten Systematisierung der zu diesem Ritual gehörigen Texte durch die Akkader, läßt sich zu Beginn der altbabylonischen Zeit, in den ersten Jahrhunderten des 2. Jts. v. Chr., eine Differenzierung der Omentexte in Kompendien und Berichte feststellen. Unter Kompendien sind Listen zu verstehen, die entweder das Auftreten einer Anomalie in verschiedenen Bereichen der Eingeweide oder verschiedene Krankheitsbilder eines Teilbereiches beschreiben; die Berichte enthalten ausführliche Aufzeichnungen und Bewertungen tatsächlich durchgeführter Opferschaurituale. In den gleichen Zeitraum, den Beginn des 2. Jts. v. Chr., ist, nach der bisherigen Fundsituation zu urteilen, die Entstehung von Tonmodellen der untersuchten Eingeweide, vor allem der Leber und der Lunge, anzusetzen.

Auch für diese Modelle lassen sich, wie für die Texte, zwei Gruppen unterscheiden; die einen haben, entsprechend den Kompendien, zur Interpretation des ominösen Befundes und zur Ausbildung der angehenden Wahrsager gedient, die anderen sind als modellhafte Nachbildungen der Ergebnisse einer Opferschau anzusehen, und entsprechen daher den Berichten. Die ältesten, bisher bekannten Exemplare derartiger Modelle stammen aus dem Palast von Mari und sind in die Zeit der sakkanakku (ca. 19. Jh. v. Chr.) zu datieren. Während aus Mesopotamien selbst nur wenig vergleichbare Modelle bekannt sind, setzt bereits im Verlauf der Mittleren Bronzezeit, in der ersten Hälfte des 2. Jts. v. Chr., ihre Verbreitung, und damit die der zugehörigen Praxis, in Nordsyrien ein (Lebermodelle: Halawa, Ebla, Tell Bi'a; Lungenmodelle: Ebla; Milzmodell: Mari $\left.{ }^{5}\right)$. In der Späten Bronzezeit ist dann ein intensiver Gebrauch der Eingeweideschau für das syrische Gebiet (Texte u. Modelle: Ugarit, Emar; nur Modelle: Mumbaqat, Tell el-Hajj, Alalakh), für Palästina (Modelle: Hazor, Megiddo) und für Anatolien (Texte und Modelle: Boğazköy) belegt. In der Überlieferung zeichnen sich zwei voneinander unabhängige Wege ab: während

4 Dazu ausführlich J.-W. Meyer, Untersuchungen. Die folgende Darstellung (Abschnitt II) ist eine Zusammenfassung der Ergebnisse dieser Arbeit, der auch Literaturhinweise und Belege zu entnehmen sind.

5

Dazu demnăchst J.-W. Meyer, Milzmodell. 
eine ältere Tradition vollständig auf der babylonischen Praxis beruht und, vermutlich ausgehend von Mari, zu einer Verbreitung in alle oben genannten Gebiete führt, weisen ein Teil der Texte und Modelle aus Boğazköy und Emar auf eine Vermittlung und zugleich Modifizierung der Praxis durch die Hurriter hin.

Mit dem Einfall der sogenannten "Seevölker" um 1180 v. Chr. lassen sich in den davon betroffenen Gebieten Anatoliens und Syrien/Palästinas nicht nur die Herstellung derartiger Modelle, sondern vermutlich auch der Gebrauch dieser Form der Divination nicht mehr nachweisen. Es vollzieht sich offenbar ein Bruch mit der babylonischen Tradition, der sich u.a. darin äußert, daß bei den jetzt im Westen dominierenden Gruppen, den Phöniziern, Aramäern und Phrygern, die Praxis der Leberschau nicht mehr nachzuweisen ist ${ }^{6}$; somit wäre Israel das einzige Gebiet außerhalb Assyriens und Babyloniens sowie der davon unmittelbar beeinflußten Bereiche (2.B. Omentexte aus Sultantepe ${ }^{7}$ ), in dem diese Tradition auch weiterhin bestanden hat ${ }^{8}$. Für Babylonien und Assyrien dagegen läßt sich, trotz Überlieferungslücken, für die Verwendung der Eingeweide- und Leberschau als ein Mittel, den göttlichen Willen zu erfragen, ein Zeitraum vom 3. Jt. v. Chr. bis zur Seleukidenzeit überblicken, ein Zeitraum, in dem sich die Art und Weise der Durchführung kaum verändert hat.

Geändert hat sich aber der Personenkreis und der Anlaß, für den das Ritual durchgeführt wurde. Seit der Gutäerzeit gegen Ende des 3. Jts. v. Chr. sind Jahresdaten überliefert, aus denen hervorgeht, daß wichtige Entscheidungen im öffentlichen Leben von den Ergebnissen einer Leberschau abhängig waren. Noch weiter zurück, bis in die Akkad-Zeit, reicht die Erwähnung politischer Ereignisse in Omentexten, die allerdings nur in einer altbabylonischen Redaktion vorliegen und deren Zusammenhang mit tatsächlich durchgeführten Ritualen nicht gesichert ist. Dagegen geht aus diesen Texten ein enger Kontakt zwischen dem Palast und den Ausführenden der Leberschau hervor, der auch noch in altbabylonischer Zeit durch den Fundort und durch die gesellschaftliche Stellung der für die Rituale verantwortlichen Personen zum Ausdruck kommt: in Mari, Ebla und Tell Bi'a wurden die betreffenden Modelle (und Texte) im Palastbereich gefunden; aus zahlreichen Texten aus Mari geht

6 Zur möglichen Kenntnis und Verwendung der Leberschau bei den Aramäern und Phöniziern, vgl. den Beitrag von $O$. Loretz in diesem Band mit Hinweis auf einen Artikel von S. Ribichini, L'aruspicina. Nach mündl. Mitteilung von O. Loretz schließt S. Ribichini die Möglichkeit, daß die Phönizier die Praxis der Opferschau gekannt haben,zwar nicht aus, kann aber auch keine eindeutigen Belege dafür anführen.

O.R. Gurney, Sultantepe Tablets, 30. E. Reiner, Another Volume, 186.

8 Zur Praxis der Leberschau bei den Etruskern: J.A. Pfiffig, Religio Etrusca, 121-127; zur Herkunft der etruskischen Leberschau aus dem Vorderen Orient: J. Nougayrol, Les rapports, 509-519. Zur Moglichkeit einer Übernahme bereits gegen Ende des 2. Jts. v. Chr. aus dem syrisch-palästinensischen Gebiet durch Gruppen der "Seevolker": J.-W. Meyer, Herkunft. 
außerdem nicht nur die Bedeutung der Leberschau für politische Entscheidungen hervor, sondern auch die Durchführung der entsprechenden Rituale durch politische Beamte. Der Wahrsager (bara) ${ }^{9}$ gehört nicht zum Tempelpersonal, und die Rituale finden nicht im Tempel statt; die Eingeweideschau war, wie alle mantischen Praktiken, in Babylonien kein Element des im Tempel stattfindenden Kultes.

Seit der altbabylonischen Zeit läßt sich aus den Texten eine Öffnung des Rituals zum privaten Bereich entnehmen, da die Apodosis häufig auf das Leben des "einfachen Menschen" Bezug nimmt. Diese Öffnung kommt auch durch einen Teil der Fundkomplexe, aus denen die Modelle stammen, zum Ausdruck; die Tonleber aus Halawa wurde in einer Siedlung gefunden, in der keine öffentlichen Bauten bestanden haben und eines der Modelle aus Ebla stammt aus der Umgebung eines Tempels, der sich in der Unterstadt, nicht auf der Akropolis befunden hat. Bestätigt wird diese Ausdehnung auf den privaten Bereich durch Fundsituation derartiger Modelle in der zweiten Hälfte des 2. Jts. v. Chr.: Die beiden Fragmente aus Hazor wurden in dem Vorhof eines Tempels der Unterstadt gefunden; anhand der Installationen sowie der zahlreichen Tierknochen aus diesem Bereich ist zu vermuten, daß das Ritual der Eingeweideschau im Hof, der der Öffentlichkeit zugänglich gewesen sein dürfte, vollzogen wurde. Auch eines der Modelle aus Megiddo stammt nicht aus dem Tempel selbst, sondern aus einem der Zingelräume. Noch deutlicher wird diese räumliche Trennung von den palatialen Institutionen in den nordsyrischen Städten Ugarit, Emar und Mumbaqat. Zwar bezeugen die Texte auch weiterhin Anfragen der staatlichen Macht, doch finden sich weitaus mehr Anfragen von Privatleuten; zudem ist in den Wohnvierteln der drei Orte für die Durchführung des Rituals jeweils ein spezielles Gebäude - das "Haus eines Wahrsagers" -, nachgewiesen; eine vergleichbare Anlage findet sich auch im kassitischen Babylon. Aus diesen Befunden geht eindeutig hervor, daß keine direkte Verbindung zwischen dem Ort, an dem das Ritual vollzogen wurde und den staatlichen Institutionen - Tempel und Palast - mehr bestanden hat.

Dagegen läßt sich im hethitischen Boğazköy auch weiterhin diese enge Verbindung zwischen Palast, Tempel und der Durchführung der Leberschau nachweisen. Die Tonlebermodelle, wie auch die entsprechenden Texte, stammen entweder aus Gebäuden auf der Königsburg oder aus dem Bereich des Großen Tempels. Diese von der mesopotamischen Tradition abweichende Stellung der Divination bei den Hethitern ist auf die hurritisch geprägte Überlieferung sowie auf die Stellung derartiger Rituale und magischen Praktiken im täglichen Leben zurückzuführen, die sich unmittelbar auf die Person des Königs beziehen, der im Mittelpunkt des religiösen Denkens steht. Zwar

9 Zur Gleichsetzung von hebr. br mit akk. barû vgl. den Beitrag von $O$. Loretz in diesem Band m. Anm. 4-6. 
konnten auch Privatpersonen Omenanfragen stellen, jedoch nur in Verbindung mit der Institution des Tempels, da die Erstellung und Auswertung von Omina und Orakeln zu dem Tätigkeitsbereich der Priesterschaft gehörte. Der hethitische Priester ermittelt durch Orakelanfragen die Bedeutung eines Omens und macht es mit Hilfe der Magie unschädlich. In Mesopotamien stellt der Wahrsager (bara) die Bedeutung der einzelnen Omina mit Hilfe der Kompendien fest und faßt die Ergebnisse in einem Bericht zusammen. Im Falle eines ungünstigen Ausgangs der Wahrsagung kann entweder eine Wiederholung der Opferschau oder ein Ritual zur Abwehr des ungünstigen Einflusses, das namburbiRitual, vollzogen werden ${ }^{10}$; auch die Ausführenden dieser Abwehr-Rituale gehören, wie die bara (Wahrsager), zu einer eigenen Berufsgruppe, den LÚ ašipu. Wie die Befunde aus Ugarit zeigen, können beide Tätigkeiten von einer Person ausgeübt werden, die aber nicht zur Priesterschaft gehört, sondern immer eine entsprechend ausgebildete Privatperson ist.

\section{III}

Da mit der Anwesenheit israelitischer Gruppen in den Gebirgsgegenden Palästinas bereits zu Beginn der Späten Bronzezeit gerechnet werden mu $\beta^{11}$, wurde von verschiedenen Autoren die Möglichkeit einer direkten Übernahme der Eingeweideschau von den Kanaanitern erwogen ${ }^{12}$. Eine derartige Übernahme setzt aber nicht nur die Ausübung dieser Praxis in einem der Gebiete voraus, die sich während des 2 . Jts. v. Chr. auf dem Gebiet oder in unmittelbarer Nachbarschaft des späteren Staates Israel befunden haben, sondern auch das Weiterbestehen von älteren Traditionen nach der Gründung des Staates. Wenn dies der Fall sein sollte, stellt sich weiterhin die Frage, welchen kulturellen Traditionen die Israeliten folgen. Neben einer Überlieferung aus dem Gebiet der kanaanäischen Stadtstaaten, deren Nachfolge die Israeliten antreten, kommen dabei auch die nordsyrisch-anatolischen Zentren für eine derartige Übernahme in Betracht; schließlich muß auch die Möglichkeit einer direkten Übernahme von den Assyrern erwogen werden, die die Praxis der Leberschau noch im 1. Jts. v. Chr. ausgeübt haben, und die im Verlaufe ihrer militärischen Expansion mit den Israeliten in Kontakt gekommen sind.

Die als Belege für die Praxis der Eingeweideschau angeführten Textzeugnisse aus dem Alten Testament setzen eine enge Beziehung zwischen dem

\footnotetext{
10 Auch die Omentexte sowie die damit verbundenen Abwehrrituale aus Sultantepe (Anm. 3) stehen in dieser Tradition.

11 Dazu u.a. A. Malamat, Struggle, 80-87.

12 Dazu O. Loretz, Leberschau, 13-28 (s. Anm. 1).
} 
Königtum und dem Tempel voraus, da die Durchführung des Rituals durch den König im Tempel stattgefunden haben soll. Zwar war auch im nordsyrischen Raum (Mari, Tell Bi'a, Ebla) die Durchführung der Eingeweideschau mit dem Palast verbunden, jedoch nicht mit dem Tempel ${ }^{13}$. Außerdem wird das Ritual niemals vom König selbst vollzogen, sondern immer von einem spezialisierten Wahrsager (bar $\mathfrak{a}$ ), der sowohl Staatsbeamter (Mari) als auch eine entsprechend ausgebildete Privatperson sein konnte. Mit der Ausbreitung der Eingeweideschau im Verlaufe des 2. Jts. v. Chr. erfolgte die Durchführung nur noch in Bauten der jeweiligen Unterstadt, häufig sogar im "Haus eines Wahrsagers". Der Anlaß einer Inspektion war immer eine konkrete Anfrage von staatlicher oder privater Seite; die jeweiligen positiven oder negativen Ergebnisse wurden notiert und wie Staats- oder Privaturkunden archiviert. Bei der Leberschau in Nordsyrien-Mesopotamien handelt es sich somit nicht um ein Ritual im kultischen Sinne und sie wurde weder im Tempel noch durch Tempelpersonal vollzogen ${ }^{14}$. Anlaß und Durchführung unterscheiden sich damit erheblich von der Praxis, die aus den dafür in Anspruch genommenen Texten des Alten Testaments hervorgeht.

Zudem setzt eine Interpretation von boqär im Sinne von "eine Leberschau betreiben" in Ps 27,4 eine Verbindung von Jahwestatue und Leberschauritual voraus ${ }^{15}$; ohne an dieser Stelle auf die Diskussion einzugehen, ob es Götterstatuen in den Tempeln Israels gegeben hat, muß festgestellt werden, daß keine ausreichende inhaltliche Übereinstimmung mit den als Parallelen angeführten Texten aus Ugarit (KTU 1.90,1-2; RIH 77/10B + 22,1-2; 8-9) besteht, da sich diese Texte nur auf das "Schauen der Götterstatue" durch den König beziehen und keine Verbindung zur Leberschau aufweisen; das Vorkommen von boqär "eine Opferschau durchführen" in KTU 1.78,5 weist wiederum keinen Zusammenhang mit einer Götterstatue auf, so daß dieser Text nur als Beleg für die Eingeweideschau in Ugarit dienen kann. Auch andere Hinweise auf die Durchführung einer Eingeweideschau vor Götterbildern, d.h. in Zusammenhang mit der Kultreligion, sind $\mathrm{m}$. W. nicht vorhanden. Eine Interpretation von Ps

13 Die Lebermodelle aus Megiddo und Hazor stammen zwar jeweils aus dem Tempelbereich, die Fundumstände sprechen jedoch gegen die Durchfuhrung der Leberschau innerhalb des Tempels. Bei den Modellen aus Megiddo handelt es sich um die Deponierung eines Lebermodells, auf dem die Ergebnisse einer Leberschau eingetragen worden sind, die für die Errichtung des Tempels durchgeführt wurde; die Modelle aus Hazor wurden im offentlichen Vorhof des Tempels, außerhalb des eigentlichen Heiligtums gefunden; dazu, J.-W. Meyer, Untersuchungen, 24-32 (s. Anm. 4).

14 Etwas anders stellt sich allerdings die Situation in der von hurritischen Einflüßen geprägten Leberschau der Hethiter dar; dazu, A. Archi, Hethitische Mantik; J.-W. Meyer, Untersuchungen, 268-270.

15

O. Loretz, Leberschau, 58-80 mit weiterer Literatur, sowie der Beitrag in diesem Band. 
27,4 in Verbindung mit der Leberschau setzt eine grundsätzliche Veränderung des entsprechenden altorientalischen Rituals voraus, und es daher nicht ohne weiteres möglich, diesen Text als Beleg für die Praxis der Eingeweideschau in Israel heranzuziehen ${ }^{16}$.

Auch der zweite Text, 2 Kön 16,15, unabhängig davon, ob er tatsächlich als Zeugnis für die Eingeweideschau in Anspruch genommen werden $\operatorname{kann}^{17}$, bestätigt kaum die Übernahme älterer, syrisch-kanaanitischer Traditionen des 2 . Jts. v.Chr.. Aus dem Textzusammenhang geht hervor, daß Achas (742-726 v.Chr. König von Juda) nach dem Vorbild der Assyrer im Tempel von Jerusalem einen Altar errichten läßt ${ }^{18}$. Es ist denkbar, daß Achas, der die Assyrer gegen einen gemeinsamen Angriff der Herrscher von Damaskus und Israel (Pekah, 734-732 v. Chr.) zu Hilfe gerufen hat, an diesem Altar assyrische Kulte durchführen will (vgl. $2 \mathrm{Chr} 28,23$ ); doch das es sich dabei um die Leberschau gehandelt hat, bleibt weiterhin fraglich ${ }^{19}$.

Zwar wurde in dieser Zeit in Assyrien (und Babylonien) die Tradition der Eingeweideschau weitergeführt ${ }^{20}$, die dazugehörigen Rituale fanden aber wiederum nicht im Tempel statt, sondern, wie aus den Unterschriften auf den entsprechenden Tafeln hervorgeht, im Palast. Weiterhin läßt sich aus den Texten - vorwiegend. Leberschauberichte ${ }^{21}$ und "Anfragen an den Sonnengott" $^{\prime 22}$ - wiederum ein enger Zusammenhang mit dem Herrscher entneh$\operatorname{men}^{23}$, doch sind daneben auch private Anfragen belegt ${ }^{24}$. Anlaß für eine

$16 \mathrm{Zu}$ den wichtigsten Übersetzungen der umstrittenen Textpassage, die auch eine andere Deutung erlauben, vgl. $O$. Loretz, Leberschau, 68-69.

17 So $O$. Loretz, Leberschau, 20-22 mit ausfuhrlicher Literatur: vgl. seinen zweiten Beitrag in diesem Band.

18 Und zwar auf der Westseite des Tempels, d.h. in Kultrichtung, wăhrend der Altar Jahwes auf die Nordseite gerückt wird.

19

Auf eine Diskussion der weiteren Textstellen Ps 5,4, Num 16,5 und Ez 21,26 kann verzichtet werden, da sie als Beleg für die Praxis der Leberschau in Israel nicht in Anspruch genommen werden; vgl. $O$. Loretz, Leberschau, 13-20.26.

20 Auf die Moglichkeit eines "Imports" von Wahrsagern aus Babylonien durch die assyrischen Konige, und damit auf ein Fortbestehen der Tradition vor allem in Babylonien verweist J. Aro, Remarks. Einen vergleichbaren "Import" auch für Israel anzunehmen, ohne den die Technik der Durchführung und Interpretation der Zeichen nicht denkbar ist, kann ausgeschlossen werden, da die jüdischen Kritiker des Königs zweifellos darüber berichtet hătten; so auch $O$. Loretz, Leberschau, 21; zur Leberschau als Geheimwissenschaft, die nur einer kleinen, eigens dafür ausgebildeten Gruppe bekannt ist, $R$. Borger, nisirti baruti, vgl. J.W. Meyer, Untersuchungen, 270-271.

21 E.G. Klauber, Politisch-religiose Texte.

22 J.A. Knudtzon, Assyrische Gebete.

23 Z.B. K 102: E.G. Klauber, Politisch-religiose Texte, 106-109.

Z.B. K 3979: E.G. Klauber, Politisch-religiose Texte, 153-156. 
Opferschau war, wie im 2. Jt. v.Chr., eine konkrete Frage, die von der Gottheit (Samaš und Adad) beantwortet werden sollte, nicht die Durchführung eines Rituals im 'Angesicht der Gottheit' oder eine andere religiöse Zeremonie.

Eine Bestätigung für die räumliche Trennung und die unterschiedliche Handhabung von magischen und religiösen Praktiken ist Darstellungen auf assyrischen Reliefs zu entnehmen; zugleich geben diese Darstellungen einen direkten Hinweis auf die rituellen Einrichtungen, die Achas möglicherweise in Damaskus gesehen und nach Jerusalem gebracht hat (2 Kön 16,10-20).

Seit Salmanassar III. (858-824 v.Chr.) finden sich im Zusammenhang mit der Belagerung von feindlichen Städten Darstellungen von assyrischen Feldlagern $^{25}$. Diese Bilder vermitteln einen Eindruck von der Organisation des assyrischen Heeres; außen umgeben von einer Befestigungsmauer, innen gegliedert durch Wege, entsprechen die Lager kleinen, geplant angelegten Städten ${ }^{26}$. Es lassen sich zwei Arten von Unterkünften unterscheiden: feste, pavillonartige Bauten, die als Wohnung des Königs und seiner näheren Umgebung gedient haben ${ }^{27}$ sowie einfache Zelte zur Aufnahme des Trosses. In letzteren werden neben Tätigkeiten des täglichen Lebens, wie das Zubereiten von Mahlzeiten, das Mahlen von Mehl, die Herstellung von Getränken auch Handlungen durchgeführt, die zweifellos kultischen Charakter haben ${ }^{28} . \mathrm{Zu}$ diesen gehören ein Teil der Szenen, in denen die Schlachtung von Tieren wiedergegeben ist ${ }^{29}$. Das Opfertier, ein Schaf oder Widder, liegt mit dem Rücken auf einem einfachen Tisch; zwei Männer führen die Schlachtung durch.

25 Z.B. L.W. King, Bronze Reliefs, 1.6; II, 6; III, 1.6; IV, 1; V, 6; VII, 6; IX, 4.6 (Salmanassar); EA.W. Budge, Assyrian Sculptures, Taf. 23,1 (Salmanassar); 29 (Assurbanipal); A.H. Layard, Second Series, Taf. 24.36.50.63.77 (Sanherib); A. Paterson, Assyrian Sculptures, Taf. 94 (Sanherib).

26 Interessant ist der Wandel in der außeren Form derartiger Lager; wăhrend zur Zeit Salmanassar III. sowohl rechteckige (quadratische) als auch runde (ovale) Lager verwendet wurden, sind aus der spăteren Zeit nur noch Darstellungen runder (ovaler) Feldlager bekannt. Möglicherweise sind für diesen Wandel taktische Gründe verantwortlich, da ein rundes Lager leichter zu verteidigen ist, als ein eckiges. Die Wiedergabe der Befestigung dieser Lager mit zinnenbekronten Türmen und Mauern gleicht der der Stadtbefestigungen; dabei handelt es sich aber um eine "idealisierte" Darstellung, da, aus Gründen der Beweglickeit, derartige Feldlager vermutlich mit Palisaden errichtet wurden.

27 Deutlich erkennbar z.B. anhand der Darstellung eines derartigen Pavillons außerhalb eines Lagers wăhrend des Empfangs des Tribut von Lahis durch den Herrscher (Sanherib), A.H. Layard, Niniveh, Taf. 23 (Anm. 18); innerhalb eines Lagers (Sanherib), A.H. Layard, Niniveh, Taf. 77 (Anm. 18); dieses Lager wird in der Bibel (2 Kg. 18,14.17;19,8) erwahnt.

28 Vgl. dazu E. Bleibtreu, Kulthandlungen, 43-52, ohne allerdings einen Teil dieser Handlungen mit der Leberschau zu verbinden.

29 Z.B. E.A.W. Budge, Assyrian Sculptures, Taf. 23,1 (Anm. 25); C.J. Gadd, Stones, Abb. 29; A.H. Layard, Niniveh, Taf. 36. 
Ein bärtiger Mann, mit einem langen Gewand und häufig (unter Assurnasirpal) mit einer konischen Kappe bekleidet, steht meistens hinter dem Tier, dessen Läufe gefesselt sind. Der zweite, ebenfalls bärtige Mann trägt einen kurzen Rock und keine Kopfbedeckung; er hält, bei einem Teil der Darstellungen, die Vorderbeine des Opfertieres. Unter dem herabhängendem Kopf befindet sich häufig eine Fußschale zum Auffangen des Blutes (Abb. 1). Die Vermutung, diese Szenen als Darstellungen einer rituellen Schlachtung im Zusammenhang mit der Eingeweideschau und den Ausführenden als Wahrsager zu interpretieren, läßt sich nur anhand weniger ikonographischer Details bestätigen: Die Rückenlage des Tieres entspricht zwar der Position eines Opfertieres bei der Eingeweideschau, doch das profane Schlachten wird ebenfalls in dieser Weise durchgeführt und in den Reliefs dargestellt ${ }^{30}$. Allerdings liegt das Tier in diesen Fällen auf der Erde $^{31}$ oder es hängt mit den Hinterläufen an einer Zeltstange $\mathrm{e}^{32}$. Zudem tragen die Ausführenden in diesen Szenen entweder keine Kopfbedeckung oder sind durch Helme eindeutig als Soldaten gekennzeichnet. Gerade die Kopfbedeckung weist aber für die hier als Wahrsager angesehene Person auf einen Status als Beamter des Königshofes hin.

Diese Person ist von einer weiteren zu trennen, die ebenfalls Rituale vollzieht; auch sie trägt ein langes Gewand, doch durch die Kahlköpfigkeit und die Form der hohen Kappe unterscheidet sie sich deutlich von dem Wahrsager ${ }^{33}$. Bei dieser Person handelt es sich um einen Priester, der häufig im Rahmen von Zeremonien dargestellt ist, die vor einem Wagen mit Standarten (urigallû) durchgeführt werden (Abb. 2). Vergleichbare Standarten finden sich vor Tempelfassaden ${ }^{34}$ und in anderen Kulthandlungen, so daß sie als Götterstandarten anzusehen sind. Aus der Zeit Sanheribs stammt eine Kampfszene ${ }^{35}$, in der ein derartiger Wagen von den Truppen als eine Art beweglicher Altar mitgeführt wurde $^{36}$. J.E. Reade hat diesen Priester als kalu -Priester (Kultsänger) identifiziert $^{37}$, und sein Auftreten im Zusammenhang mit Musikanten bestätigt diese

Z.B. A.H. Layard, Niniveh, Taf. 24 (Anm. 25).

Z.B. A.H. Layard, Niniveh, Taf. 76.

Z.B. A.H. Layard, Niniveh, Taf. 76.

Z.B. C.J. Gadd, Stones, Abb. 29 (Anm. 29).

Z.B. R.D. Barnett / M. Falkner, Sculptures, Taf. 60.

Z.B. C.J. Gadd, Stones, Taf. 28.

E. Bleibtreu, Kulthandlungen, hat daraufhingewiesen, daß es sich bei dem Wagen um den des Reichsgottes handeln könte. Da aus den Reliefs keine Darstellung von Opfern vor einem Gotterbild bekannt ist (s.u.), ist es denkbar, daß dieser Wagen den Gott selbst bei der Opferhandlung vertritt.

37 J.E. Reade, Court, 96. 
Vermutung ${ }^{38}$. Auch die als Wahrsager bezeichnete Person kann zusammen mit Musikanten im Gefolge des Königs auftreten, jedoch nicht als Spieler, sondern in speziellen Zeremonien, die vermutlich seine Anwesenheit erforderlich machten, wie z.B. bei Riten an der Tigrisquelle bei der Aufstellung eines Standbildes ${ }^{39}$, jeweils durch Salmanassar III. ${ }^{40}$.

In keiner der Darstellungen findet die rituelle Schlachtung auf einem besonderen Altar statt und weder aus den Texten noch aus den archäologischen Befunden geht die Notwendigkeit eines Altars für die Opferschau hervor; im Gegensatz dazu ist für andere kultische Handlungen ein Altar notwendig ${ }^{41}$. Es ist daher anzunehmen, daß Achas, der sicher die unterschiedlichen Rituale in Damaskus gesehen hat, die Errichtung des Altars in Jerusalem zwar mit der Einführung assyrischer Kulte verbinden wollte, jedoch vermutlich nicht mit dem der Eingeweideschau.

\section{IV}

Eine Untersuchung der materiellen Kultur Israels während der Frühen Eisenzeit zeigt, daß von jüdischer Seite offenbar nur geringe Neigungen oder Möglichkeiten vorhanden waren, Traditionen der Völker, deren Nachfolge sie angetreten haben, zu übernehmen und fortzuführen. Sowohl in den verwendeten Bauformen und Baukonzepten ${ }^{42}$ als auch in der Keramikproduktion zeich-

38 Es besteht moglicherweise eine Verbindung zwischen dem Gesang des kala-Priesters und der (ekstatischen) Prophetie, eine Verbindung, die auch in der Bibel (z.B. 1 Sam 10,5; 2 Kön 3,1416; 1 Chron 25,1-3) zu belegen ist; dazu H.B. Huffmon, Prophecy, 112-114; vgl. G. Dossin, Prophétisme, 77-86, mit weiterer Literatur.

39 L.W. King, Bronze Reliefs, Taf. 19 (Anm. 25). Bei weiteren Darstellungen von Götterstatuen auf den Reliefs handelt es sich ausschließlich um Kriegsbeute (z.B. A.H. Layard, The Monuments of Niniveh I., London 1849, Taf. 65), vgl. E. Bleibtreu, Kulthandlungen, Anm. 13 (Anm. 28).

Auf eine vielleicht recht aufschluBreiche Beobachtung soll kurz hingewiesen werden; in den Szenen, in denen die als Wahrsager angesehene Person zusammen mit dem Kơnig oder Hofstaat auftritt und keine unmittelbaren Ritualhandlungen vornimmt, trägt sie einen Stab, vergleichbar dem Griffel der Schreiber. Eventuell kann hierin ein Symbol der Wahrsager gesehen werden; gleichzeitig besteht die Moglichkeit, daß der Beruf der Schreiber und Wahrsager von der gleichen Person ausgeübt werden konnte. In diesem Zusammenhang ist gerade auf die neuassyrischen Omentexten zu verweisen, in denen der Begriff "Zeichnungen" (uṣurtu) haufig für Leberteile und deren Verănderungen verwendet wird und die von "Zeichnungen, die die Gotter in die Leber geschrieben haben", sprechen.

41 Z.B. R.D. Barnett / M. Falkner, Sculptures, Taf. 60; A.H. Layard, Niniveh, Taf. 50 (Anm. 25). 
net sich bereits in vorexilischer Zeit, mit dem Beginn der israelitischen Vorherrschaft, ein Wandel von der kanaanäischen Kultur der Späten Bronzezeit und der der Philister der Frühen Eisenzeit ab; spätestens nach der Staatsbildung ist ein weitgehender Bruch mit der kannaanäischen Tradition und eine enge Verbindung zur nordsyrisch-aramäischen Kultur anzunehmen. Diese Annahme wird auch durch die Äußerungen der Israeliten über die in Palästina vor ihrer Ankunft ansässige Bevölkerung der Kanaaaniter (und Philister) bestätigt, die sich deutlich von der Beurteilung der Aramäer unterscheidet, mit denen sie sich offenbar verwandt fühlten, und die vermutlich Teile der gleichen Einwanderungswelle gewesen sind ${ }^{43}$. Diese gemeinsame Geschichte kann die während der Frühen Eisenzeit bestehenden Beziehungen zwischen Israel und den aramäisierten späthethitischen Staaten erklären.

Trotz der vielfältigen Verbindungen zwischen Israel und den Kulturen des übrigen Alten Orients findet, nach der bisherigen Fundlage zu urteilen, die Annahme, in Israel sei die Eingeweideschau praktiziert worden, von archäologischer Seite keine Unterstützung. Gerade auch in diesem Punkte geht Israel offensichtlich mit den anderen Staaten des eisenzeitlichen Syrien zusammen, in denen sich die dort in der Bronzezeit praktizierte Eingeweideschau nicht über den tiefen kulturellen Einschnitt der sog. "Seevölkerzeit" hat halten können. Mit Sicherheit hat es zwar im vorexilischen Israel sowohl die intuitive Form der Weissagung (divinatio naturalis), die Offenbarung des göttlichen Willens durch unmittelbare Eingebung (Prophezeiung, Träume, Ekstase), als auch die induktive Form (divinatio artificalis), die Beobachtung und Auswertung von Zeichen gegeben $^{44}$; doch läßt sich von der induktiven Form der Weissagung nur die provozierte Variante (Becher- und Loswahrsagung ${ }^{45}$ ) nachweisen, während die Auswertung unprovozierter Vorzeichen, zu denen auch die Eingeweideschau (und Vogelschau) gehört, nicht gesichert ist. Alle in Israel praktizierten Formen der Wahrsagung lassen sich somit nicht an mesopotamische, sondern

43 Dazu J.F. Healey, Culture, 31-37 mit weiterer Literatur.

$44 \mathrm{Zu}$ den verschiedenen in Israel praktizierten Formen der Wahrsagung, vgl. O. Eissfeldt, Wahrsagung, 141-146.

45 Für die Becherwahrsagung findet sich nur ein Beleg in der Bibel (Gen 44,5), der aber eindeutig auf außer-israelitische Praktiken hinweist (auf den agyptisierten Joseph). Dagegen hat das Losorakel, wenn die von $O$. Eissfeldt, Wahrsagung, 142-143 (Anm. 44) vorgeschlagene Deutung des Ephod mit den Urim und Tummim als Losorakel tatsächlich zutrifft, in vorexilischer Zeit große Bedeutung gehabt; Losorakel aber sind in Anatolien verbreitet (KINOrakel, dazu A. Kammenhuber, Orakelpraxis, 10) und nicht in Babylonien; zum Losorakel bei den Etruskern, vgl. A.J. Pfiffig, Religio Etrusca, 153. 
eher an westliche Traditionen anschließen ${ }^{46}$; in diesem Gebiet hat es aber im 1. Jts. v. Chr. keine Leberschau mehr gegeben ${ }^{47}$ und im 2. Jts. v. Chr. nur in einer Form, die nicht der aus der Bibel zu entnehmenden Praxis entspricht. Wenn es daher zutrifft, da $\beta$ im vorexilischen Israel die Eingeweideschau nicht ausgeübt wurde, dann bezieht sich auch das nachexilische Verbot der Leberbefragung und anderer mantischer Praktiken (Ez 21, 26; Dtn 18,9-12) nicht auf israelitische Rituale, sondern auf babylonische. Der von O. Loretz angesprochene Gegensatz zwischen den philologischen und den archäologischen Interpretationen der betreffenden Quellen zur Leberschau in Israel ${ }^{48}$ bleibt somit auch weiterhin bestehen.

46 Allgemein, A.L. Oppenheim, Ancient Mesopotamia, $208-227$ (Anm. 2); zu dem Unterschied zwischen der babylonischen und der westlichen Form der Prophezeiung, wie sie aus Mari, Emar und Ugarit bekannt ist, R.D. Biggs, "Prophecies", 117-132; H.B. Huffmon, 101-124; zu Traumen, A.L. Oppenheim, Interpretation; A. Kammenhuber, Orakelpraxis; V. Haas, Rez. zu A. Kammenhuber, 142-150; zu Becherorakel, J. Hunger, Becherwahrsagung.

Vgl. aber Anm. 5.

$48 \mathrm{Vgl}$. den Beitrag in diesem Band. 


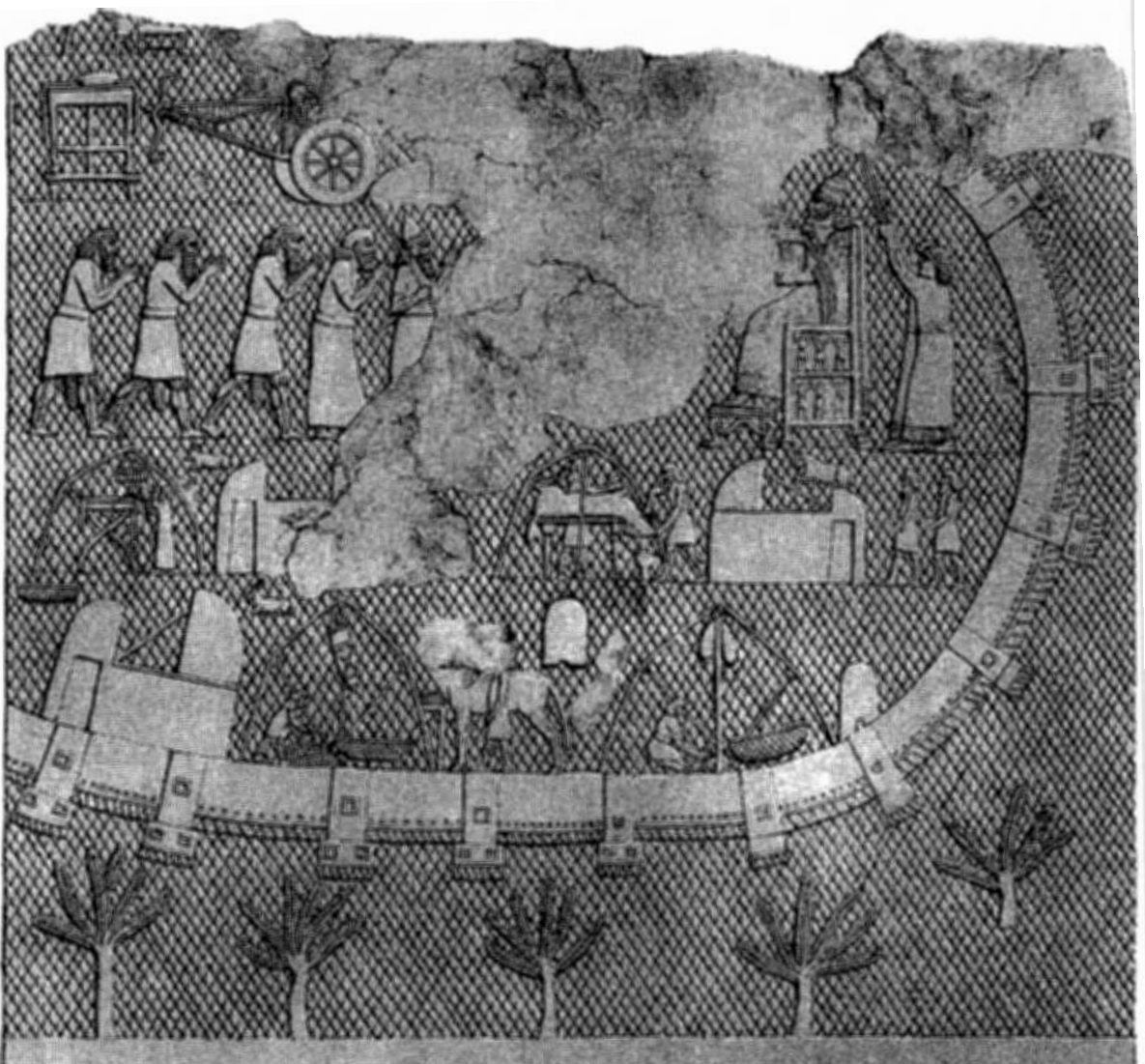

Abb. 1 Wandrelief aus dem Palast des Sanherib (n. Layard, Second Series, Taf. 36) 


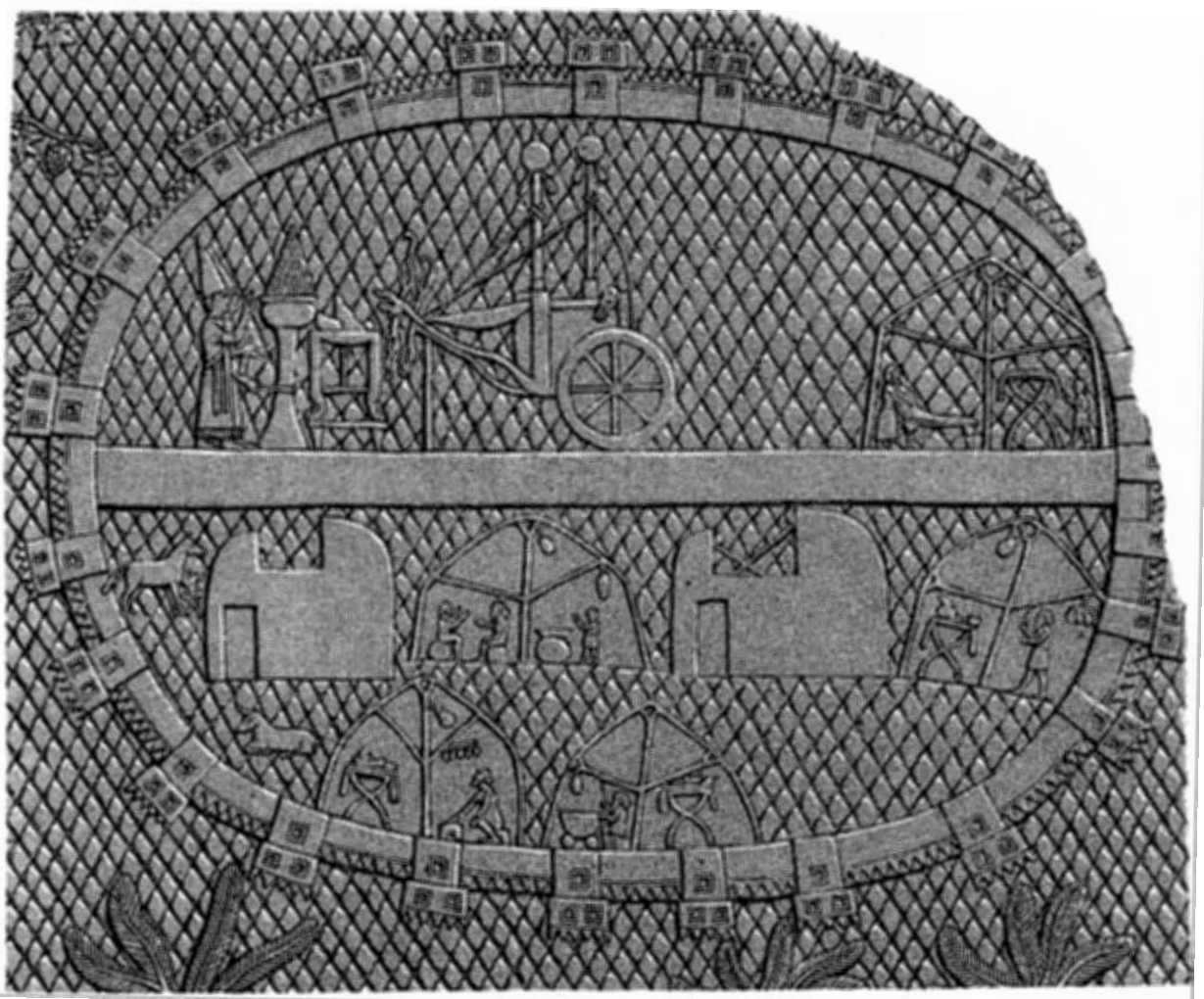

Abb.2 Wandrelief aus dem Palast des Sanherib (n. Layard, Second Series, Taf. 24) 


\section{Bibliographie}

Archi, A., Hethitische Mantik und ihre Beziehungen zur mesopotamischen Mantik, BBVO (1982) 279-293

Aro, J., Remarks on the Practise of Extispicy in the Time of Esarhaddon and Assurbanipal, CRRA 15 (1966) 109-117

Barnett, R.D. / Falkner, M., The Sculptures of Assur-nasir-apli II (883-859 B.C.) Tiglath-pileser III (745-727 B.C.) Esarhaddon (681-669 B.C.) from the Central and South-West Palaces at Nimrud, London 1962

Biggs, R.D., More Babylonian "Prophecies", Iraq 29 (1967) 117-132

Bleibtreu, E., Kulthandlungen im Zeltlager Sanheribs, in: I. Seybold, Meqor Hajim (FS G. Molin), Graz 1983

Borger, R, nisirti baruti, Geheimnis der Haruspizin, BiOr 14 (1957) 190-195

Budge, E.A.W., Assyrian Sculptures in the British Museum. Reign of Ashur-nasir-pal, 885-860, Oxford 1914

Dossin, G., Sur le Prophétisme à Mari, CRRA 14 (1966) 77-82

Eissfeldt, O., Wahrsagung im Alten Testament, CRRA 14 (1966) 141-146

Falkner, M. $\rightarrow$ Barnett, R.D.

Gadd, C.J., The Stones of Assyria. The surviving remains of Assyrian Sculpture, their recovery and their original positions, London 1936

Gurney, O.R., The Sultantepe Tablets, A Preliminary Note, Anat. Stud. 3 (1952) 25-35

Haas, V., Rez. zu A. Kammenhuber 1976, WZKM 69 (1977) 142-150

Healy, J.F., Ancient Culture and the Bible, ARAM 1 (1989) 31-37

Huffmon, H.B., Prophecy in the Mari Letters, BA 31 (1968) 101-124

Hunger, J., Becherwahrsagung bei den Babyloniern (LSS I/1), Leipzig 1903

Kammenhuber, A., Orakelpraxis, Traume und Vorzeichendeutung bei den Hethitern (THeth 7), Heidelberg 1976

King, L.W., Bronze Reliefs from the Gates of Shalmaneser King of Assyria B.C. 860-825, London 1915

Klauber, E.G., Politisch-religiöse Texte aus der Sargoniden-Zeit, Leipzig 1913

Knudtzon, J.A., Assyrische Gebete an den Sonnengott, Leipzig 1893

Layard, A.H., The Monuments of Niniveh. From Drawings made on the spot, vol. I, London 1849

- A Second Series of the Monuments of Niniveh; including bas-reliefs from the Palace of Sennacherib and Bronzes from the Ruins of Nimrud. From drawings made on the spot, during a second expedition to Assyria, London 1853

Loretz, O., Leberschau, Sündenbock, Asasel in Ugarit und Israel. Leberschau und Jahwestatue in Psalm 27, Leberschau in Psalm 74 (UBL 3), Altenberge 1985 
Malamat, A., Struggle Against the Philistines, in: H.H. Ben-Sasson, The History of the Jewish People, vol. 4, Tel Aviv 1976

Meyer, J.-W., Zur Herkunft der etruskischen Lebermodelle, Studia Phoenicia 3 (1985) 105-120

- Untersuchungen zu den Tonlebermodellen aus dem Aiten Orient (AOAT 39), NeukirchenVluyn 1987

- Ein Milzmodell aus Mari (AO 27906) (MARI 7, im Druck)

Nougayrol, J., Les rapports des haruspicines etrusques et assyro-babylonienne et le foie d'argile de Falerii Veteres (Villa Giulia 3786), CRAI (1955) 509-519

Oppenheim, A.L., The Interpretation of Dreams in the Ancient Near East, Philadelphia 1956

- Ancient Mesopotamia, Chicago 1964

Patersom, A., Assyrian Sculptures. Palace of Sinacherib, The Hague 1915

Pfiffig, JA., Religio Etrusca, Graz 1975

Reade, J.E., The Neo-Assyrian Court and Army: Evidence from the Sculptures, Iraq 34 (1972) 87 112

Reiner, E., Another Volume of Sultantepe Tablets, JNES 26 (1967) 177-221

Renger, J., Untersuchungen zum Priestertum der altbabylonischen Zeit. 2. Teil (Schluß), ZA 59 (NF 25) (1969) 104-230

Ribichini, S., L'aruspicina fenicio-punica e la divinazione a Pafo, UF 21 (1989) 307-317 


\section{Hinweise zu den Autoren}

Alfonso Archi, geb. 1940; Professor für Hethitologie an der Universităt Rom "La Sapienza". Hauptinteressen sind die verschiedenen Aspekte des religiösen Lebens im alten Kleinasien. Seit 1977 Grabungsphilologe der Italienischen Archłologischen Expedition in Tell Mardikh / Ebla (Syrien) und Koordinator der "Publications of the Archives from Ebla (3rd millennium B.C.)". Seine Forschungen zu den Ebla-Texten konzentrieren sich auf Themen der Wirtschaftsgeschichte. - Wichtige Publikationen: Hethitische Orakeltexte (Keilschrifturkunden aus BoghazkOi, Heft 49, 50, 52 [1973-1985]); Testi amministrativi: assegnazioni di tessuti (Archivi reali di Ebla - Testi I, 1985); Testi amministrativi. Registrazioni di metalli e tessuti (Archivi reali di Ebla - Testi 7, 1988).

Walter Burkert, geb. 1931; Studium der Klassischen Philologie, Geschichte und Philosophie in Erlangen und Munchen, 1955 Promotion, 1961 Habilitation (jeweils in Erlangen), 1966-1969 Professor an der TU Berlin; seitdem Professor der Klassischen Philologie an der Universitát Zürich; Gastprofessuren in Harvard (1968) und Berkeley (1977); Balzan-Preis 1990. Hauptarbeitsgebiet: Griechische Religion und Philosophie. - Wichtige Publikationen: Weisheit und Wissenschaft, Nürnberg 1962; Homo Necans, Berlin / New York 1972; Griechische Religion der archaischen und klassischen Epoche, Stuttgart u.a. 1977; Structure and History in Greek Mythology and Ritual, Berkeley u.a. 1979; Die orientalisierende Epoche in der griechischen Religion und Literatur, Heidelberg 1984; Antike Mysterien, München 1990.

Peter Frei, geb. 1925; Studium der Klassischen Philologie, Alten Geschichte und Indogermanistik an der Universităt Zürich; 1953 Promotion; 1953-1955 Stipendiat am Thesaurus Linguae Latinae in München; 1955-1968 Gymnasiallehrer an verschiedenen schweizerischen Gymnasien; 1967 Habilitation an der Universităt Zürich; 1970 Professur für Alte Geschichte mit besonderer Berücksichtigung des Vorderen Orients; ab 1976 topographische Feldforschungen in der Gegend von Eskişehir (Nordwesttürkei). Hauptarbeitsgebiete: Kleinasien (v.a. Lykien und Phrygien) im Altertum; Beruhrung zwischen Klassischer Antike und Orient; Antike Verwaltungsgeschichte; Großreiche im Altertum.

Volkert Haas, geb. 1936; Studium der Altorientalistik und der Vorderasiatischen Altertumskunde in Berlin und Marburg; 1968 Promotion und 1975 Habilitation in Berlin; 1981-1989 Professor für Geschichte und Kultur des Alten Orients in Konstanz; seit 1989 Professor für Altorientalische Philologie an der FU Berlin. - Wichtige Publikationen: Der Kult von Nerik. Ein Beitrag zur hethitischen Religionsgeschichte, Rom 1970; Magie und Mythen im Reich der Hethiter, Hamburg 1977; Hethitische Berggotter und hurritische Steindămonen, Mainz 1982; verschiedene Bănde des Corpus der hurritischen Sprachdenkmaler (Rom 1984ff); Vorzeitmythen und Götterberge in altorientalischer und griechischer Überlieferung, Konstanz 1983.

Manfred Hutter, geb. 1957; Assistenzprofessor am Institut für Religionswissenschaft, Universităt Graz. Forschungsschwerpunkte: Hethitische und nordsyrische Religionsgeschichte, Manichäismus und Zoroastrismus. -Wichtige Publikationen: Hiskija - König von Juda, Graz 1982; Altorientalische Vorstellungen von der Unterwelt, Freiburg (Schweiz) / Götingen 1985; Behexung, Entsühnung und Heilung. Das Ritual der Tunnawiya für ein Königspaar aus mittelhethitischer Zeit, Freiburg (Schweiz) / Gottingen 1988; Das manichäische Urdrama des Lichtes, Wien 1989; zus. mit K.M. Woschitz und K. Prenner: Manis kosmogonische Sabuhragantexte, Wiesbaden 1992.

Bernd Janowski, geb. 1943; 1967-1972 Studium der Ev. Theologie, Altorientalistik und Ägyptologie in Tübingen. 1980 Promotion, 1984 Habilitation. Nach Lehrtátigkeiten in Tübingen (1972-1985), Kiel (1985) und Hamburg (1986-1991) seit 1991 Professor für Alttestamentliche Theologie in Heidelberg. Hauptarbeitsgebiete: Religionsgeschichte Israels, Theologie des Alten Testaments und Biblische Theologie. - Wichtige Publikationen: Sühe als Heilsgeschehen (WMANT 55), Neukir- 
chen-Vluyn 1982/21994; Rettungsgewißheit und Epiphanie des Heils, Bd. 1 (WMANT 59), Neukirchen-Vluyn 1989; Gefahrten und Feinde des Lebens. Das Tier in der Lebenswelt des alten Israel, Neukirchen-Vluyn 1993 (zus. mit U. Neumann-Gorsolke und U. Gleßmer); Gottes Gegenwart in Israel. Beitrage zur Theologie des Alten Testaments, Neukirchen-Vluyn 1993. Zahlreiche Aufsatze zur Theologie des Alten Testaments und zur Religionsgeschichte Israels. Herausgeber: Forschungen zum Alten Testament, Tübingen 1991ff (zus. mit H. Spieckermann); Jahrbuch für Biblische Theologie, Neukirchen-Vluyn 1986ff (zus. mit I. Baldermann u.a.); Wissenschaftliche Monographien zum Alten und Neuen Testament, Neukirchen-Vluyn (zus. mit O.H. Steck, ab Bd. 65 [1991]), u.a.

Klaus Koch, geb. 1926; emerit. Professor für Altes Testament und altorientalische Religionsgeschichte an der Universitat Hamburg; 1951-1954 Assistent am Alttestamentlichen Seminar der Universitat Heidelberg. 1954-1956 Pfarrer in Jena-Prießnitz; 1956-1960 Privatdozent für AT in Erlangen und Hamburg; 1960-1962 Professor für AT an der Kirchlichen Hochschule Wuppertal; seit 1962 an der Universitat Hamburg. Forschungsschwerpunkte: Alttestamentliche Apokalyptik, insbesondere das Buch Daniel; Untersuchung maßgeblicher Tendenzen in der Geschichte der altorientalischen Religionen. - Wichtige Veroffentlichungen: Was ist Formgeschichte? Neue Wege der Bibelexegese, Neukirchen-Vluyn '51989; Ratlos vor der Apokalyptik, Gütersloh 1970; Die Profeten I/II (Urban Taschenbücher 280.281), Stuttgart u.a. 1978/1980; Das Buch Daniel (EdF 144), Darmstadt 1980; Studien zur alttestamentlichen und altorientalischen Religionsgeschichte, hg. v. E. Otto, 1988; Spuren des hebräischen Denkens, Gesammelte Aufsătze I, hg. v. B. Janowski / M. Krause, Neukirchen-Vluyn 1991. Zahlreiche Artikel in Zeitschriften und Sammelwerken.

Cord Kühne, geb. 1936; Privatdozent in Heidelberg und Saarbrücken. Forschungsschwerpunkte: Akkadisch (Mittelbabylonisch) als internationale Verkehrssprache im mittleren 2. Jts. v. Chr., Geschichte des westlichen Vorderasiens im 2. Jt., Hethitische Religionsgeschichte. - Wichtige Publikationen: Die Chronologie der internationalen Korrespondenz von El-Amarna (AOAT 17), Neukirchen-Vluyn 1973; zus. mit H. Otten, Der Šaušgamuwa-Vertrag (StBoT 16), Wiesbaden 1971; Politische Szenerie und internationale Beziehungen Vorderasiens im 2. Jt. v. Chr., zugleich ein Konzept der Kurzchronologie, BBVO 1/, 203-64; "Hethitische Texte" in: W. Beyerlin, RTAT, Gottingen ${ }^{2} 1985,169-204$. Demnachst erscheint der erste Band einer Bearbeitung der in hethitischer Sprache uberlieferten Huwašanna-Rituale.

Oswald Loretz, geb. 1928; Professor am Institut für Ugarit-Forschung an der Universităt Münster; Forschungsschwerpunkte: Altes Testament und Ugarit-Texte. - Wichtige Publikationen: Textausgaben (KTU), Herausgeber von UBL; Mitherausgeber von UF, AOAT und ALASP. Bibliographie in SEL 5 (1988) 1-12.

Jan-Waalke Meyer, geb. 1945; Studium der VorderasiatischenArchäologie, Altorientalischen Philologie und Klassischen Archäologie in Freiburg und Saarbrücken, 1985 Promotion; derzeit laufendes Habilitationsverfahren in Saarbrücken. Wissenschaftlicher Mitarbeiter in Saarbrücken und Berlin; Teilnahme an verschiedenen Ausgrabungen im Libanon (Kamid el-Loz) und in Syrien (Halawa, Tell Chuera, Tell Schech Hammad); Forschungsschwerpunkte: Syrien und Palastina (Bronze- und Eisenzeit). - Wichtige Publikationen: Zur Herkunft der etruskischen Lebermodelle, in: Studia Phoenicia III (1985) 105-120; Untersuchungen zu den Tonlebermodellen aus dem Alten Orient (AOAT 39), Kevelaer / Neukirchen-Vluyn 1987; Die Friedhofe von Shamseddin und Djerniye (SBVA 3), 1991; weitere Aufsătze in Zeitschriften und Sammelwerken.

Erich Neu, geb. 1936; Studium der Vergleichenden Sprachwissenschaft, Altorientalistik, Klassischen Philologie und Pádagogik an der Universităt Marburg; 1966 Promotion in Marburg; 1972 
Habilitation in Gottingen; 1976 Professor fur 'Allgemeine und Vergleichende Sprachwissenschaft; Hethitologie' an der Universitat Bochum. Arbeitsgebiet: Indogermanistik und Hethitologie. Wichtige Publikationen: Interpretation der hethitischen mediopassiven Verbformen, Wiesbaden 1968; Ein althethitisches Gewitterritual, Wiesbaden 1970; Der Anitta-Text, Wiesbaden 1974; Glossar zu den althethitischen Ritualtexten, Wiesbaden 1983; Das Hurritische: Eine altorientalische Sprache in neuem Licht, Mainz / Stuttgart 1988; Hethitisches Zeichenlexikon (zus. mit C. Ruster), Wiesbaden 1989.

Edward Noort, geb. 1944; Studium in Amsterdam, Kampen und Göttingen. 1975-1979 Wiss. Assistent in Gottingen, 1979-1989 Ordinarius für Altes Testament in Kampen; 1989-1993 Professor für Altes Testament und Biblische Archäologie an der Universităt Hamburg, ab 1993 an der Rijksuniversiteit Groningen (NL). Forschungsschwerpunkte: Fruhgeschichte Israels, Biblische Archăologie, Deuteronomistik, Buch Josua. - Wichtige Publikationen: Untersuchungen zum Gottesbescheid in Mari. Die Mariprophetie in der alttestamentlichen Forschung (AOAT 202), Neukirchen-Vluyn 1977; Biblisch-archăologische Hermeneutik und alttestamentliche Exegese, Kampen 1979; Israel en de westelijke Jordaanoever, Kampen 1983 (dtsch.: Israel und das westliche Jordanufer, Neukirchen-Vluyn 1987); Geweld in het Oude Testament, Deelft 1985; Een duister duel. Over de theologie van het bock Job, Kampen, 1986.

Eckart Otto, geb. 1944; 1979-1986 Professor für Altes Testament und Biblische Archăologie an der Universităt Hamburg, 1986-1991 an der Universităt Osnabrück, seit 1991 an der Universităt Mainz, 1979-1985 regelmaßige Lehrtatigkeit in Jerusalem. Forschungsschwerpunkte: Altorientalische und israelitische Rechtsgeschichte, Theologische Ethik des Alten Testaments, Exegese des Deuteronomiums und Biblische Archð̋ologie. - Wichtige Publikationen: Das Mazzotfest in Gilgal, Stuttgart u.a. 1975; Jakob in Sichem, Stuttgart u.a. 1979; Jerusalem. Die Geschichte der Heiligen Stadt, Stuttgart u.a. 1980; Wandel der Rechtsbegründungen in der Gesellschaftsgeschichte Israels, Leiden 1988; Rechtsgeschichte der Redaktionen im Kodex EXnnunna und im "Bundesbuch" (OBO 85), Freiburg (Schweiz) / Göttingen 1988; Korperverletzungen in den Keilschriftrechten und im Alten Testament (AOAT 226), Kevelaer / Neukirchen-Vluyn 1991; Theologische Ethik des Aiten Testaments, Stuttgart u.a. 1993.

Thomas Podella, geb. 1955; Studium der Ev. Theologie in Wuppertal und Tübingen; 1982-84 Wiss. Angestellter an der Ev.-Theol. Fakultat Tübingen; 1987 Promotion; 1986-1991 Wiss. Angestellter am DFG-Projekt "EDV-gestützte Analyse alttestamentlicher Texte", Tübingen; seit 1991 Wissenschaftlicher Assistent, Universităt Heidelberg. Arbeitsgebiete: Biblische Theologie, alttestamentliche und altorientalische Religionsgeschichte. - Wichtige Publikationen: ȘరOm-Fasten. Kollektive Trauer um den verborgenen Gott im Alten Testament (AOAT 224), Neukirchen-Vluyn 1989; L'Aldila nelle concezioni vetero-testamentarie: Sheol, in: P. Xella (ed.), Archeologia dell'Inferno, Verona 1987, 163-190; Thematischer Vergleich zwischen Gen 37, 34-35 und KTU 1.5 VI, 23-25, SEL 4 (1987) 67-78; Ein mediterraner Trauerritus, UF 18 (1986) 263-269; Grundzüge alttestamentlicher Jenseitsvorstellungen, BN 43 (1988) 70-89; Sich zeigen und gesehen werden, ZAH 2 (1989) 160-187; zus. mit P. Xella, The World, in: What the Bible Really Says, ed. by M. Smith, R. J. Hoffmann, Buffalo 1989, 229-237; Der "Chaoskampfmythos" im Alten Testament, in: FS K. Bergerhof (AOAT), Neukirchen-Vluyn 1993; Artikel in Lexika und Handbüchern.

Moshe Weinfeld, geb. 1925; Professor an der Hebrew University, Jerusalem. - Wichtige Publikationen: Deuteronomy and the Deuteronomistic School, Oxford 1972; Justice and Righteousness in Israel and in the Nations (hebr.), Jerusalem 1985; The Land of Israel in the ancient Israelite Literature, Jerusalem 1993; The Qumran Sects: its organization, liturgy and worship. The organi- 
zational Pattern and the Penal Code in the Qumran Sect (NTOA 2), Freiburg (Schweiz) / Gottingen 1986. Zahlreiche Artikel und Aufsatze in Lexika, Zeitschriften und Sammelwerken.

Gernot Wilhelm, geb. 1945; Studium der Altorientalistik (Assyriologie und Hethitologie) und der Vorderasiatischen Archäologie in Berlin und Münster. 1969 Promotion in Berlin, 1975 Habilitation in Saarbrucken. Nach Lehrtătigkeiten in Saarbrücken (1970-82), Heidelberg (1975-82), Hamburg (1981-88), seit 1988 Professor fur Orientalische Philologie in Würzburg. Forschungsschwerpunkte: Geschichte, Kultur, Wirtschaft und Gesellschaft der Spaten Bronzezeit in Vorderasien, RandAkkadisch (insbesondere Nuzi-Urkunden), Hurritisch-urartäische Sprachwissenschaft, Anatolistik mit besonderer Berücksichtigung der Rezeption akkadischer und hurritischer Traditionen, altorientalische Chronologie. - Wichtige Publikationen: Untersuchungen zum Hurro-Akkadischen von Nuzi (1970); mit V. Haas: Hurritische und luwische Riten aus Kizzuwatna (1974); Das Archiv des Šilwa-teß̌up 2 (1980), 3 (1985), 4 (1992); Grundzäge der Geschichte und Kultur der Hurriter (1982); engl.: The Hurrians (1989); Sumerische und akkadische literarische Texte (KBo 36) (1991); Medizinische Omina aus Hattusa (StBoT 36) (1993). Zahireiche Artikel und Aufsatze in Zeitschriften und Sammelwerken.

David P. Wright, geb. 1953; 1984-1989 Assistant Professor of Hebrew and Near Eastern Languages at Brigham Young University, Utah; 1989-1990 Junior Researcher, Fulbright Award at Hebrew University Jerusalem; 1990-1991 Visiting Assistant Professor of Religion at Middlebury College, Vermont; seit 1991 Assistant Professor of Bible and the Ancient Near East at Brandeis University. Hauptarbeitsgebiete: Biblical and Near Eastern Ritual, Pentateuchal Studies, Biblical Interpretation. - Wichtige Publikationen: The Disposal of Impurity. Elimination Rites in the Bible and in Hittite and Mesopotamian Literature, Atlanta/GA 1987. Artikel und Aufsatze in Lexika und Zeitschriften. 
Zum vorliegenden Buch

Der Band thematisiert die vielfältigen religiösen Beziehungen zwischen Anatolien, Nordsyrien und Palästina/Israel vom 3. bis zum 1. Jt. v.Chr. Am Beispiel der Götterwelt, der Mythenbildung, der Ritualistik, des Kults und des Rechts wird in den 18 Beiträgen von Alttestamentlern, Assyriologen, Hethitologen, Gräzisten und Archäologen der Frage des Religionskontaktes in diesem Kulturraum erstmals umfassend nachgegangen. Einen besonderen Schwerpunkt bilden die gemeinsamen/verwandten mythisch-epischen und kultischrituellen Überlieferungen. 